\title{
SOURCEBOOK ON THE PRODUCTION OF ELECTRICITY FROM GEOTHERMAL ENERGY
}

\author{
Joseph Kestin, editor-in-chief
}

\author{
Ronald DiPippo, editor \\ H. Ezzat Khalifa, editor \\ D. John Ryley, editor \\ Brown University \\ Providence, Rhode Island 02912
}

Published March 1980

Prepared under the sponsorship of the United States Department of Energy Assistant Secretary for Resource Applications

Division of Geothermal Energy

Washington, D.C. 20585

Under Contract No. EY-76-S-4051.A002

For sale by the Superintendent of Documents, U.S. Government Printing Offlce Washington, D.C. 20402 


\section{DISCLAIMER}

This report was prepared as an account of work sponsored by an agency of the United States Government. Neither the United States Government nor any agency Thereof, nor any of their employees, makes any warranty, express or implied, or assumes any legal liability or responsibility for the accuracy, completeness, or usefulness of any information, apparatus, product, or process disclosed, or represents that its use would not infringe privately owned rights. Reference herein to any specific commercial product, process, or service by trade name, trademark, manufacturer, or otherwise does not necessarily constitute or imply its endorsement, recommendation, or favoring by the United States Government or any agency thereof. The views and opinions of authors expressed herein do not necessarily state or reflect those of the United States Government or any agency thereof. 


\section{DISCLAIMER}

Portions of this document may be illegible in electronic image products. Images are produced from the best available original document. 


\section{NOTICE}

This report was prepared as an account of work sponsored by the United States Government. Neither the United States nor the United States Department of Energy, nor any of their employees, makes any warranty, express or implied, or assumes any legal liability or responsibility for the accuracy, completeness, or usefulness of any information, apparatus, product, or process disclosed, or represents that its use would not infringe privately owned rights. Reference herein to any specific commercial product, process, or service by trade name, mark, manufacturer, or othenwise, does not necessarily constitute or imply its endorsement, recommendation, or favoring by the United States Government or any agency thereof. The views and opinions of authors expressed herein do not necessarily state or reflect those of the United States Government or any agency thereof. 


\section{List of Contributors}

Angevine, Jack M., B.S.M.E., M.S. (Management). Staff Scientist-Mechanical Engineer, Lawrence Berkeley Laboratory, Berkeley, CA. Sect. 8.2.

Austin, Arthur L. (Roy), B.S.M.E., M.S.M.E., Dr. Eng. M.E. Senior Staff Member, Energy Resources and Planning, Lawrence Livermore Laboratory (Formerly Project Leader, Geothermal Energy Program), Livermore, CA. Sect. 4.4.

Bialy, Stanley C., B.S.M.E., M.S.M.E. Engineer, Utility and Industrial Product Design, Medium Steam Turbine Department, Genera! Electric Company, Lynn, MA. Sect. 4.1.3.

Boehm, Robert F., B.S.M.E., M.S.M.E., Ph.D. Professor of Mechanical Engineering, University of Utah, Salt Lake City, UT. Sect. 4.2.6.

Bloomster, Clarence H., B.S.Met.E., M.B.A. Manager, Advanced Energy Analysis, Pacific Northwest Laboratories operated by Battelle Memorial Institute, Richland, WA. Chap. 7.

Brunot, Albert W., B.S.M.E. Consulting Engineer, Scientific Application, Medium Steam Turbine Department, General Electric Company, Lynn, MA. Sect. 4.1.2.

Cameron, Joseph A., B.S.Met.E. Manager, Materials Engineering, Elliott Company, Jeannette, PA. Sect. 4.1.6.

Conover, Marshall F., B.A. Geothermal Program Manager, Radian Corporation, Austin, TX. Chap. 6.

Curzon, Anne M., B.S. Mechanical Engineer, Radian Corporation, Austin, TX. Chap. 6.

Dart, Robert H., B.S.M.E., M.S.M.E. Senior Engineer, Utilization Technology Branch, Geothermal Electric Division, EG\&G Idaho, Inc., Idaho Falls, ID. Sect. 4.2.5.

Diment, William H., A.B., M.A., Ph.D. Research Geophysicist, U.S. Geological Survey, Dept. of Interior, Reston, VA. Sect. 2.1.

DiPippo, Ronald, Sc.B., Sc.M., Ph.D. Professor of Mechanical Engineering, Southeastern Massachusetts University, N. Dartmouth, MA. Also Adjunct Professor of Engineering (Research), Brown University, Providence, RI. Chap. 1, Sect, 2.4, Chaps. 9 and 10, Editor.

Doyle, Padraic A., B.S.Envir.E., M.S.M.E. Staff Scientist-Mechanical Engineer, Lawrence Berkeley Laboratory, Berkeley, CA. Sect. 8.2. 
Dunn, Frederick D., B.S.M.E.: Vice President, Rogers Engineering Company, Inc., San Francisco, CA. Sect. 8.1.

Ellis, Peter F., II, B.S. Engineer/Scientist, Radian Corporation, Austin, TX. Chap. 6.

Eskesen, John H., B. Sc., Ph.D. Manager, Electro-Mechanical Engineering and Physics, Medium Steam Turbine Dept., General Electric Company, Lynn, MA. Sects. 4.1.1-4.1.5, 4.2.1, 4.2.3, 4.2.4.

Faust, Charles R., B.S., Ph.D. (Formerly Hydrologist, U.S. Geological Survey, Department of Interior, Reston, VA.), GeoTran, Inc., Reston, VA. Sect. 2.3.

Floyd, Acey L., B.S., M.S., Ph.D. Senior Staff Scientist, Lockheed-California Company, Burbank, CA. (Formerly Science Advisor to Public Service Dept., City of Burbank). Sects. 8.1, 8.3.

Fulton, Robert L., B.S. Eng. Staff Scientist-Mechanical Engineer, Lawrence Berkeley Laboratory, Berkeley, CA. Sect. 8.2.

Hartley, Robert P., B.S. Geol. Program Manager for Geothermal Energy Industrial Environmental Research Laboratory, U.S. Environmental Protection Agency, Cincinnati, OH. Chap. 9.

Iregui, Roberto, B.S.Ch.E., M.S.Ch.E. Process Engineer, Rogers Engineering Co., Inc., San Francisco, CA. Sect. 8.1.

Jacobs, Harold R., B.S.G.E., M.S.M.E., Ph.D. Professor of Mechanical Engineering, University of Utah, Salt Lake City, UT. Sect. 4.2.6.

Kelley, George F., B.S.M.E. Senior Engineer, Thermodynamics Evaluation and Improvement, Medium Steam Turbine Dept., General Electric Company, Lynn, MA. Sect. 4.1.4, 4.2.4.

Kestin, Joseph, Dipl. Ing., Ph.D., D.I.C., M.A., D.Sc. Professor of Engineering, Brown University, Providence, RI. Chaps. 1 and 3, Sect. 4.2.2., Editor and Project Manager.

Khalifa, H. Ezzat, B.Sc., M.Sc., Ph.D. Systems Engineer, United Technologies Research Center, E. Hartford, CT. (Formerly Assistant Professor of Engineering (Research), Division of Engineering, Brown University, Providence, RI.) Sects. 4.2.2, 4.3, 5.7., Editor.

Meader, Paul F., Dipl. Ing. (M.E.), Ph.D. Professor of Engineering, Brown University, Providence, RI. Chap. 7.

McFarland, Clifton B., B.S.M.E., M.S. Chief, Hydrothermal Technology Section, Division of Geothermal Energy, Dept. of Energy, Washington, D.C. Foreword.

Melilli, Albert S., B.S., M.S.Met. Manager, Materials and Processes Engineering, Medium Steam Turbine Dept., General Electric Co., Lynn, MA. Sect. 4.1.4.

Mercer, James W., B.S., M.S., Ph.D. (Formerly Hydrologist, U.S. Geological Survey, Dept. of Interior, Reston, VA.), GeoTran, Inc., Reston, VA. Sect. 2.3. 
Mizen, Lawrence R., B.S.M.E., M.S.M.E. Engineer, Control Systems Application, Medium Steam Turbine Dept., General Electric Co., Lynn, MA. Sect. 4.1.5.

Pines, Howard S., B.S. Eng. Sci., M.S.M.E. Staff Scientist-Mechanical Engineer, Lawrence Berkeley Laboratory, Berkeley, CA. Sect. 8.2.

Pope, William L., B.S.M.E. Staff Scientist-Mechanical Engineer, Lawrence Berkeley Laboratory, Berkeley, CA. Sect. 8.2.

Rendine, Anthony P., B.S.M.E. Manager, Turbine \& HRSG Product Design Engineering, Medium Steam Turbine Dept., General Electric Co., Lynn, MA. Sect. 4.1.4.

Robertson, Roy C., B.S.M.E., M.S.M.E. Engineering Staff, Energy Division, Oak Ridge National Laboratory, Oak Ridge, TN. Sects. 5.1-5.6.

Ryley, D. John, B.Sc., M.Sc., D.Sc., Ph.D. Professor, Department of Mechanical Engineering, University of Liverpool, England. Sects. 2.2, 2.4-2.6, 4.4, Editor.

Shepard, Clayton V. H., B.S.M.E. Manager, Control Systems Application Engineering, Medium Steam Turbine Dept., General Electric Company, Lynn, MA. Sect. 4.1.5.

Silvester, Lonard F., B.S.Ch. and Math. Ph.D. Staff Scientist-Physical Chemist, Lawrence Berkeley Laboratory, Berkeley, CA. Sect. 8.2.

Simay, Gregory L., B.S.A.Ph., M.S.E.E. Science Advisor, Public Service Department, City of Burbank, CA. Sects. 8.1, 8.3.

Whitbeck, Judson F., B.S.Marine Sci., B.S.M.E., M.S.M.E. Manager, Utilization Technology Branch, Geothermal Electric Division, EG\&G Idaho, Inc., Idaho Falls, ID. Sect. 4.2.5.

Whitehead, Alan, B.Sc. (Chemistry), Ph.D. Manager, Chemistry and Insulation Engineering, Medium Steam Turbine Dept., General Electric Company, Lynn, MA. Sect. 4.1.2. 
(

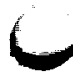




\section{Contents}

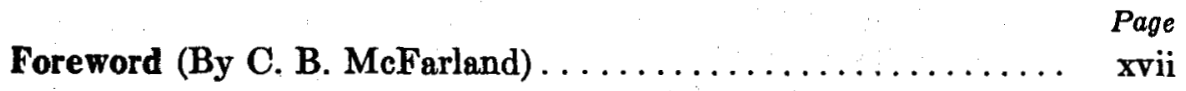

Chapter 1. Introduction (By J. Kestin, aided by R. DiPippo).... 1

Chapter 2. Resource Characteristics: Exploration, Evaluation and Derelopment

2.1 Geology and geophysics of geothermal areas (By W. H.

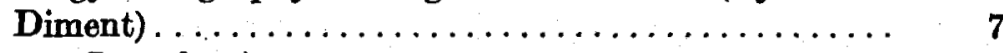

2.1.1 Introduction.................... 7

2.1.2 Exploration for geothermal systems......... 13

2.1.3 Examples of kinds of systems............ $\quad 56$

2.1.4 Acknowledgements.................... 77

2.1.5 Bibliography.................... 77

2.2 Heat and mass transfer in reservoirs (By D. J. Ryley)... 103

2.2.1. Transfer of heat by thermal convection......... 103

2.2.2 Mass and heat transfer within the geothermal reservoir.......................... 107

2.2.3 Drawdown and build-up in reservoirs........ 109

2.2.4 The heat content of igneous-related geothermal systems.......................... 113

2.2.5 The heat content of hydrothermal convection systems....................... 114

2.2.6 Mechanical properties of rocks........... 116

2.2.7 Rock fracture methods. . . . . . . . . . . . . 116

2.2.8 References......................... 119

2.3 The physics of fluid flow and heat transport in geotherma]

systems (By J. W. Mercer and C. R. Faust)........ 121

2.3.1 Introduction ........................ 121

2.3.2 Theoretical development................. 124

2.3.3 Geothermal systems under natural conditions..... 129

2.3.4 Geothermal systems under exploitation......... 130

2.3.5 Concluding remarks ..................... 133

2.3.6 References.......................... 133

2.4 Drilling for geothermal resources (By D. J. Ryley and R. DiPippo)........................ 136

2.4.1 The standard drilling rig. . . . . . . . . . 136 
Chapter 2. Resource Characteristics: Exploration-Continued

2.4 Drilling for geothermal resources-Continued Page

2.4.2 The geothermal well site............... 136

2.4.3 Drill bits and drilling fluids............... 137

2.4.4 Casing and cementing. . . . . . . . $140 \ldots \ldots \ldots \ldots, \ldots$

2.4.5 Stimulating well flow.................. 141

2.4.6 Drilling costs........................ 142

2.4.7 Advanced drilling methods............... 149

2.4.8 Acknowledgements.................... 153

2.4.9 References.......................... 153

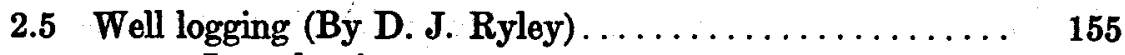

2.5.1 Introduction......................... 155

2.5.2 Geophysical measurements.............. 156

2.5.3 Geological observations.................. 166

2.5.4 Some limitations of logging methods......... 168

2.5.5 Example of a production well $\log \ldots \ldots \ldots \ldots \ldots \ldots \quad 168$

2.5.6 References........................ 170

2.6 Analysis of the flow in the reservoir-well system (By D. J.

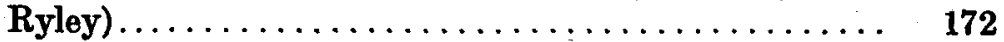

2.6.1 Flow in a well pipe.................. 172

2.6.2 Characteristics of the combined well-reservoir system...................... 183

2.6.3 Patterns of two-phase association in vertical twophase flow....................... 200

2.6.4 Thermodynamic availability in geothermal systems............................ 203

2.6.5 The surface transmission of geofluids......... 210

2.6.6 References......................... 224

Chapter 3. Available Work in Geothermal Energy (By J. Kestin)

3.1 Introduction.

3.2 The geothermal reservoir................... 228

3.3 Thermodynamic state at inlet and exit........... 230

3.4 Typical installations...................... $\quad 232$

3.5 The thermodynamic system . . . . . . . . . . . . . 237

3.6 The atmosphere........................ 237

3.7 The Second Law and entropy production........... 238

3.8 The governing equations $\ldots \ldots \ldots \ldots \ldots \ldots \ldots \ldots \ldots \ldots, \mathbf{2 3 9}$

3.8.1 First Law.......................... 239

3.8.2 Second Law....................... 241

3.9 Capacity to perform work. . . . . . . . . . . . 243

3.10 Energy dissipation and utilization factor........... 245

3.11 Rate of heat rejection to atmosphere . . . . . . . . 246

3.12 Numerical examples...................... 247 
Chapter 3. Available Work in Geothermal Energy-Continued

3.13 Fossil fuel. ...........................

3.14 Energy and cycle efficiency as a measure of capacity to perform work . . . . . . . . . . . . . . . . . 254

3.15 Historical digression. . . . . . . . . . . . . . . . . . 257

3.16 Graphical representation of available work......... 257

3.16.1 General T, s diagram.................. 258

3.16.2 $T$, s diagram for steam................. 259

3.16.3 Loss due to free exhaust................ 260

3.16.4 Change in exit temperature and in heat-rejection temperature....................... 262

3.16.5 The general Mollier diagram.............. 263

3.16.6 Mollier diagram for steam: adiabatic expansion.. 265

3.16.7 Adiabatic expansion in $\mathrm{T}$, s diagram......... 266

3.16.8 Exergy-entropy diagram................ 266

3.17 A note on thermophysical properties............ 268

3.17.1 Water substance..................... 268

3.17.2 Aqueous solutions..................... 269

3.17.3 Hydrocarbons: Isobutane............... 270

3.18 List of symbols. . . . . . . . . . . . . . . . . . . $\quad 272$

3.19 References........................... 273

\section{Chapter 4. Power Systems}

4.1 Flashed steam/steam turbine cycles............. 276

4.1.1 Introduction (By J. H. Eskesen) ............. 276

4.1.2 Cycle thermodynamics (By J. H. Eskesen, A.

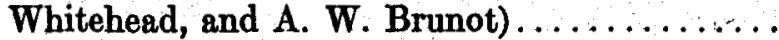

4.1.3 Special design features (By J. H. Eskesen and

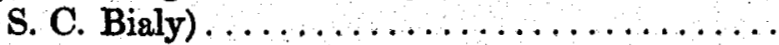

4.1.4 Steam turbine characteristics and design requirements (By J. H. Eskesen, G. F. Kelley, A. S.

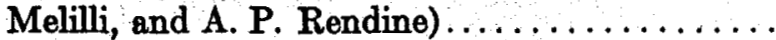

4.1.5 Geothermal steam turbine controls (By J. H. Eskesen, L. B. Mizen, and C. V. H. Shepard)...

281

4.1.6 Material selection for geothermal steam turbines (By J. A. Cameron) .................... 343

4.2 Binary cycles........................ 350

4.2.1 Introduction (By J. H. Eskesen) ........... 350

4.2.2 Thermophysical properties of working fluids (By J. Kestin and H. E. Khalifa) ............ 351

4.2.3 Cycle thermodynamics (By J. H. Eskesen) ...... 360

4.2.4 Axial flow organic fluid turbine (By J. $\mathrm{H}$. Eskesen and G. F. Kelley) . 


\section{Chapter 4. Power Systems-Continued}

4.2 Binary cycles-Continued

4.2.5 Brine heat exchangers (By R. H. Dart and J. F. Whitbeck) . . . . . . . . . . . . . . . .

4.2.6 Direct contact binary cycles (By H. R. Jacobs and R. F. Boehm).

4.3 Hybrid fossil-geothermal systems (By H. E. Khalifa) ...

4.3.1 Introductory remarks. . . . . . . . . . . . . .

4.3.2 Thermodynamics of hybrid energy conversion systems.

473

4.3.3 The geothermal-preheat system ............. 479

4.3.4 The fossil-superheat systems.............. $\mathbf{4 8 6}$

4.3.5 Design and economic criteria . . . . . . . . . 491

4.3.6 Conclusions. . . . . . . . . . . . . . . . . 500

4.3.7 References............................. 501

4.3.8 Nomenclature......................... 503

4.4 Status of the development of the total flow system for electric power production from geothermal energy (By A. L. Austin, edited by D. J. Ryley) ......... 504

4.4.1 Introduction......................... 504

4.4.2 Characteristics of wellhead fluids........... 505

4.4.3 Energy conversion concepts.............. 506

4.4.4 Brine chemistry effects ................ 535

4.4.5 A possible total flow system . . . . . . . . . . . 536

4.4.6 References.......................... 538

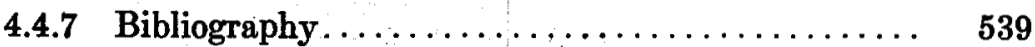

4.4.8 Nomenclature...................... 539

Chapter 5. Waste Heat Rejection from Geothermal Power Stations

5.1 General (By R. C. Robertson).............. 541

5.1 .1 Introduction....................... 541

5.1.2 Typical waste heat rejection systems and general design considerations.................. 544

5.1.3 Waste heat utilization. . . . . . . . . . . . . . 548

5.1.4 Water availability and the law........... 550

5.1.5 References...................... 552

5.2 Condensers (By R. C. Robertson) $\ldots \ldots \ldots \ldots \ldots \ldots \ldots \quad 552$

5.2 .1 General ......................... 552

5.2.2 Effect of condensing temperatures on geothermal station performance. . . . . . . . . . . . . 555

5.2.3 Direct-contact condensers. ................ 557

5.2.4 Surface condensers. . . . . . . . . . . . . . . . . . 562

5.2.5 References........................... 598 


\section{Chapter 5. Waste Heat Rejection-Continued}

5.3 Heat dissipation systems and equipment (By R. C Robertson) .......................... $\quad 600$

5.3.1 General.......................... $\quad 600$

5.3.2 Once-through cooling systems.............. 600

5.3.3 Cooling lakes and ponds . . . . . . . . . . . . . . 602

5.3.4 Spray ponds and canals................ 605

5.3.5 Cooling towers....................... 611

5.3.6 References......................... 641

5.4 Phased cooling (By R. C. Robertson) ........... 644

5.5 Variable, or "floating," power cooling concept (By R. C. Robertson).

5.6 Heat rejection equipment in $50-\mathrm{MW}(e)$ station: Conceptual designs at Heber and Niland, California (By R. C. Robertson) .

5.6.1 General ........................... 648

5.6.2 Heber. . . . . . . . . . . . . . . . . . . . . . 648

5.6.3 Niland ........................ 652

5.6.4 Heber with wet/dry cooling tower........... 654

5.6 .5 References....................... 655

5.7 Effect of fluctuations in ambient temperature (By H. E. Khalifa $) \ldots \ldots \ldots \ldots \ldots \ldots \ldots \ldots \ldots \ldots \ldots, 656$

5.7.1 Introduction........................ 656

$\mathbf{5 . 7 . 2}$ Ideal case........................ 656

5.7.3 Behavior of actual systems.............. 659

5.7.4 Choice of the design point $\ldots \ldots \ldots \ldots \ldots \ldots \ldots, 661$

5.7.5 References........................ 663

Chapter 6. Materials Selection Guidelines for Geothermal Power Systems (By M. F. Conover, P. F. Ellis II, and A. M. Curzon)

6.1 Introduction $\ldots \ldots \ldots \ldots \ldots \ldots \ldots \ldots \ldots \ldots \ldots \ldots, 664$

6.2 Geothermal power cycles.................... 664

6.3 Corrosion modes for metals in geothermal systems...... 666

6.4 Corrosive species in geothermal fluids.............. 667

6.5 Performance of metals in geothermal systems......... 668

6.5.1 Metals performance in wellhead and flashed liquid streams.......................... 668

6.5.2 Performance of metals in condensate streams..... 678

6.5.3 Performance of metals in contact with steam from liquid-dominated sources................ 678

6.6 Nonmetallic materials. . . . . . . . . . . . . . . . . $\quad 679$

6.7 References............................. $\quad 680$ 
Chapter 7. Economic Considerations (By C. H. Bloomster and P. F. Maeder)

7.1 Purposes of economic analysis................ 682

7.2 Basic concepts and terminology $\ldots \ldots \ldots \ldots \ldots \ldots \ldots \ldots, 683$

7.3 Cost accounting.......................... 688

7.4 Definitions...........................

7.5 The income statement. . . . . . . . . . . . . . 691

7.6 Analytical methods........................ $\quad 692$

7.6.1 Net present value method.............. 692

7.6.2 Unit cost determination................. 693

7.6.3 Internal rate of return. . . . . . . . . . . . . $69 . \ldots$

7.6.4 Differential analysis .................. 694

7.6.5 Payback period....................... 694

7.6.6 Fixed charge rate.................... 695

7.6.7 Analysis using the capital recovery factor ....... 697

7.6.8 Cost effectiveness, benefit-cost, and value analyses. 697

7.6.9 Sensitivity analysis.................... 699

7.7 Sensitivity of electrical production cost to technical and

financial factors. . . . . . . . . . . . . . . . . . . . . 699

7.7.1 Influence of wellhead temperature.......... 700

7.7.2 Flow rate ............................ 703

7.7.3 Well cost........................ 704

7.7.4 Power plant capacity................... 705

7.7.5 Conversion efficiency .................. 707

7.7.6 Load factor. . . . . . . . . . . . . . . . . . . . . 707

7.7.7 Power cycle....................... 708

$\mathbf{7 . 7 . 8}$ Financial factors.................... 709

7.8 Inflation. . . . . . . . . . . .

7.9 References............................. 712

7.10 Bibliography....................... 713

Chapter 8. Criteria for Selection and Conceptual Design Optimization

8.1 Criteria for selection (By A. L. Floyd, R. Iregui, F. D. Dunn, and G. Simay) ................... 714

8.1.1 Introduction.......................... 714

8.1.2 Market factors...................... 717

8.1.3 Operating factors................... 723

8.1.4 Financing and cash flow ............... 728

8.1.5 Summary of selection process............ 728

8.2 Conceptual design optimization (By W. L. Pope, P. A. Doyle, H. S. Pines, R. L. Fulton, L. F. Silvester, and J. M. Angevine)

$\mathbf{8 . 2 . 1}$ Introduction........................ $\mathbf{7 2 9}$ 
Chapter 8. Criteria for Selection and Conceptual Design Optimization-Continued

8.2 Conceptual design optimization-Continued Page

8.2.2 Features of state-of-the-art codes............ 732

8.2.3 Current software limitations.............. 733

8.2.4 Systems design selection criteria . . . . . . . . 734

8.2.5 Synthesis of plant/field alternatives.......... 735

8.2.6 Plant boundary assumptions-coupling to the reservoir.......................... $\mathbf{7 4 2}$

8.2.7 Influence of well design................ 746

8.2.8 Systems analysis-computerized design optimization......................... 748

8.2.9 Optimization using the LBL GEOTHM code.... 750

8.2.10 Thermodynamic optimization as a prelude to cost optimization......................... 755

8.2.11 GEOTHM example problems............. 757

8.2.12 Example problem results................ 761

8.2.13 Summary and conclusions............... $\mathbf{7 7 0}$

8.2.14 Notation......................... 772

8.2.15 References......................... 774

8.3 Location and procurement of components (by A. L. Floyd

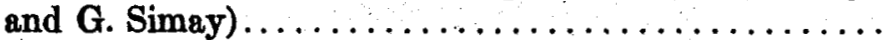

8.3.1 The designer's problem................... 778

8.3.2 Available equipment and components......... 780

8.3.3 Equipment and components to be modified or developed......................... 782

8.3.4 Management of procurement.............. 784

8.3.5 Applicable codes and standards ............ 785

Chapter 9. Environmental Considerations (By R. P. Hartley, edited by R. DiPippo)

9.1 Regulatory approach and applicable laws............

9.1.1 Overall perspective.

9.1.2 Geothermal energy pollution control regulatory 786

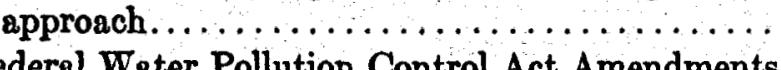

9.1.3 Federal Water Pollution Control Act Amendments (FWPCA) of 1972.

9.1.4 Clean Air Act as amended................. 790

9.1.5 Safe Drinking Water Act.................. 791

9.1.6 Resource Conservation and Recovery Act of 1976 . 791

9.1.7 Toxic Substances Control Act............... 792

9.1.8 Noise Control Act of $1972 \ldots \ldots \ldots \ldots \ldots \ldots \ldots .793$

9.1.9 Other Federal laws pertaining to geothermal pollution control..................... 


\section{Chapter 9. Environmental Considerations-Continued}

9.1 Regulatory approach and applicable laws-Continued 9.1.10 State and local pollution control laws and regulations ....................... 795

9.2 Pollution effects from geothermal energy operations.... . 796

9.2.1 Sources of pollution. . . . . . . . . . . . . . $\quad \mathbf{7 9 6}$

9.2.2 Pollutants derived from geothermal fluids....... 800

9.2.3 Noise derived from geothermal operations....... 803

9.2.4 Environmental effects of geothermal pollutants... 805

9.3 EPA suggested pollutant discharge limits........... 817

9.3.1 General........................... $8 \mathbf{8 1 7}$

9.3.2 Air pollutant limitations. . . . . . . . . . . . . 817

9.3.3 Water pollutant limitations................. 818

9.3.4 Land-disposed waste limitations............... 820

9.3.5 Noise limitations...................... $\quad 820$

9.4 Air pollution control technology $\ldots \ldots \ldots \ldots \ldots \ldots \ldots \ldots, \quad \mathbf{8 2 0}$

9.4.1 Stretford process..................... 821

9.4.2 Iron catalyst process . . . . . . . . . . . . . $\quad 823$

9.4.3 EIC process....................... 826

9.4.4 Dow oxygenation process. . . . . . . . . . . 831

9.4.5 Solid sorbent process . . . . . . . . . . . . . $\quad 831$

9.4.6 Claus process..................... $\quad 833$

9.4.7 Hydrogen peroxide process............... 834

$\mathbf{9 . 4 . 8}$ Ozone process. . . . . . . . . . . . . . . . $\quad 835$

9.4.9 Burner-scrubber process. . . . . . . . . . . . . 836

9.4.10 Catalyst-scrubber process. . . . . . . . . . . $\quad \mathbf{8 3 6}$

9.4.11 Deuterium process. . . . . . . . . . . . . . . . 836

9.5 Liquid, solid and noise pollution control technology... 836

9.5.1 Wastewater treatment technologies............ 836

9.5.2 Wastewater disposal technologies............ 843

9.5.3 Solid waste disposal . . . . . . . . . . . . . . 857

9.5.4 Noise control. . . . . . . . . . . . . . . . . . . 858

9.6 Environmental monitoring.................... 859

9.6.1 Air and water point-source monitoring....... 860

9.6.2 Ambient air monitoring................. $\mathbf{8 6 0}$

9.6.3 Ambient water monitoring. . . . . . . . . . . 861

9.6.4 Ground water monitoring............... 862

9.6.5 Land-disposed wastes.................. 863

9.6.6 Noise monitoring. .................... 863

9.6.7 Baseline air and water monitoring.......... 864

9.7 Future development of effluent and emissions standards. . 864

9.8 References........................... 866 
Chapter 10. Geothermal Power Plants Around the World (By R. DiPippo)

10.1 Introduction

10.1.1 Historical overview.

10.1.2 Energy conversion systems

10.1.3 Power plant performance factors

10.2 China

10.3 El Salvador

10.3.1 Overviow

10.3.2 Ahůchapán.

874

10.3.3 Other geothermal areas in El Salvador.

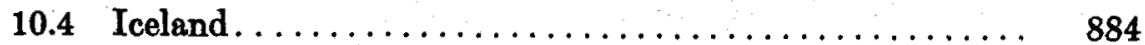

10.4.1 Geological features................... 884

10.4.2 Namafjall...................... 885

10.4.3 Krafla......................... 886

10.4.4 Svartsengi........................ 889

10.5 Italy . . . . . . . . . . . .

10.5.1 Overview...................... 889

10.5.2 Larderello (Boraciferous Region) ........... 890

10.5.3 Monte Amiata . . . . . . . . . . . . . . . . . . . 893

10.5.4 Travale.......................... 899

10.6 Japan............................. 900

10.6.1 Overview......................... 900

10.6.2 Matsukawa....................... 900

10.6.3 Otake ........................ 903

10.6.4 Onuma ......................... 903

10.6.5 Onikobe......................... 904

10.6.6 Hatchobaru ...................... 904

10.6.7 Kakkonda ....................... 906

10.6.8 Mori and Otake pilot binary plants.......... 906

10.6.9 Mori ........................... 908

10.6.10 Other promising areas in Japan........, ... 908

10.7 Mexico............................... 908

10.7.1 General remarks ..................... 908

10.7.2 Pathe........................... 910

10.7.3 Cerro Prieto.......................... 910

10.7.4 Future developments of geothermal power in Mexico.......................... 917

10.8 New Zealand . . . . . . . . . . . . . . . . . . . 918

10.8.1 Introduction..................... 918

10.8.2 Wairakei......................... 919

10.8.3 Kawerau........................... 924

10.8.4 Ohaki (Broadlands) ................... 926

10.8.5 Other geothermal areas in New Zealand....... 927 
Chapter 10. Geothermal Power Plants Around the World-Con.

10.9 Philippines. $\ldots \ldots \ldots \ldots \ldots \ldots \ldots \ldots \ldots \ldots \ldots \ldots \ldots, \quad 928$

10.9.1 Outlook......................... 928

10.9.2 Tiwi........................

10.9.3 Makiling Banahaw (Los Baños) ............. 929

10.9.4 Leyte (Tongonan) .................. 929

10.9.5 Other Philippine areas with geothermal potential. . 929

10.10 Turkey ............................ 931

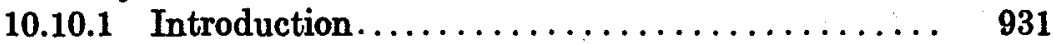

10.10.2 Kuzlddere......................... 932

10.10.3 Other areas being explored in Turkey......... 933

10.11 Union of Soviet Socialist Republics............. 934

10.11.1 Overview. . . . . . . . .

10.11.2 Pauzhetka.......................... 934

10.11.3 Paratunka....................... 937

10.11.4 Bolshoye-Bannoye.................. 941

10.11.5 Potential Soviet geothermal power stations...... 942

10.12 United States.......................... 942

10.12.1 Historical background . ............... 942

10.12.2 The Geysers - Sonoma and Lake counties, Calif . . 943

10.12.3 Magmamax dual binary plant-East Mesa, Calif ........................... 953

10.12.4 Republic Geothermal-East Mesa, Calif....... 954

10.12.5 Southern California Edison-Brawley, Calif..... 955

10.12.6 Planned geothermal plants in the Imperial Valley,

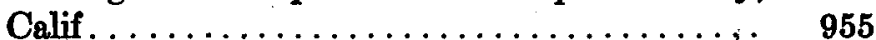

10.12.7 Double-boiling binary plant, Raft River, Idaho.. 957

10.12.8 Hawaii geothermal project-Puna, Hawaii...... 957

10.12.9 Valles Caldera demonstration plant-Valles Caldera, N. Mex.

959

10.12.10 Other potential geothermal plants in the United States.......................... 960

10.13 Countries planning geothermal power plants........ 960

10.13.1 Overall survey ..................... 960

10.13.2 Azores (Portugal) . . . . . . . . . . . . . . 962

10.13.3 Chile............................ 962

10.13.4 Costa Rica......................... 963

10.13.5 Guatemala........................ 963

10.13.6 Honduras........................... 964

10.13.7 Indonesia........................ 964

10.13.8 Kenya............................ 965

10.13.9 Nicaragua ....................... 965

10.13.10 Panama......................... 966

10.14 References............................. 966

Index..................................... 973 


\section{Foreword}

(By Chrrivon B. MuFaruand, Chief, Hydrothermal Technology Section, Division of Geothermal Energy, Department of Energy)

Although geothermal energy has long been recognized as an alternative energy source, its development to date has been minimal due to the abundance of other low-cost sources of energy. The downtrend in domestic oil production and the Arab oil embargo of 1973 set the stage for a national assessment of the potential of geothermal energy and prompted Congress to pass the Geothermal Steam Act of 1974 . A result of this act was the initiation of a vigorous Federal program to stimulate geothermal development, an effort which is reflected in part by this sourcebook on geothermal energy utilization. The efforts to produce the sourcebook have brought together representatives from industry, academia, and the government in an attempt to scrutinize large volumes of research results, operating powerplant performance data, and cost data in order to present the state of the art in geothermal energy utilization in a way useful for conceptual design or economic evaluation purposes. The contributors recognize that new technology or improved uses of existing technology will be necessary to economically exploit the moderate-temperature hot water geothermal resources (which constitute the greatest percentage of the resource base). Accordingly, the sourcebook also contains information on new technology which has yet to be reduced to practice. Every effort was made to be objective in the evaluation and presentation of information relating to new technologies. However, in a field evolving as rapidly as geothermal energy, some omissions will undoubtedly occur.

The geothermal utilization system design problem spans many specialized technical disciplines (i.e., geology, hydrology, geochemistry, materials, etc.). Experts in many of these areas have contributed to the sourcebook to give it the depth and credibility to make it a viable industry reference. The selection of material presented reflects the diversity of the subject and the importance of an integrated design approach. Environmental and economic considerations are given equal weight with the most detailed engineering considerations.

In spite of the numerous notable individual written contributions to the sourcebook, the value of the final product must be attributed to Brown University, especially Professors Kestin and DiPippo, who provided the guidance, motivation and toil resulting in a coherent and encompassing presentation of the subject of geothermal energy utilization. 


\title{
Chapter 1
}

\section{Introduction}

\author{
(By J. Kestin, aided by R. DiPippo)
}

The initiative to create this Sourcebook came from the Division of Geothermal Energy of the Department of Energy and was communicated to me by Mr. Clifton B. McFarland who was designated to act as the Program Manager. 'These were still the early days of the accelerated effort of research into all aspects of energy technology. In particular, although some knowledge concerning the conversion of geothermal energy into electricity existed, it was uncoordinated and diffuse.

The gist of the proposal was to assemble a small team at Brown University for the purpose of organizing the writing of this Sourcebook by carefully selected specialists. The engineers and scientists who agreed to take part in the venture had a deep understanding of some special aspect of energy conversion that had a bearing on geothermal power production but not of the whole. The first task undertaken by myself and my colleagues Ronald DiPippo and H. Ezzat Khalifa, was to organize a series of seminars. A total of nine such seminars called CATMECs * was convened. The participants were chosen from among prospective authors as well as experts who were willing to share their knowledge with the group even though other commitments prevented them from becoming more active participants. As time progressed a more and more clearly focussed and comprehensive collective understanding emerged. The Sourcebook attempts to impart such a comprehensive and properly focussed understanding of the peculiarities of geothermal energy to the reader. The editorial team hopes that the Sourcebook will be found useful by a wide circle of interested persons because it reflects the expertise of specialists drawn from many

\footnotetext{
- CATMEC stands for meetings of the Centers for the Analysis of Thermal/Mechanical Energy Conversion Concepts. These meetings were convened as follows: CATMEC-1 and 2 (informal)) in Washington, D.C., in early 1976; CATMEC-3 in Providence in November 1976; CATMEC-4 in Berkeley in January 1977; OATMEO-5 in Salt Lake Oity in April 1977; OATMEC-6 in Washington, D.O, in July 1977 ; OATMEO-7 in Providence in November 1977; CATMEC-8 in San Diego in February 1978; and CATMEC-9 in Providence in August 1978. Copies of the Minutes of CATMEC-3 through 9 are available from the National Technical Information Service (NTIS), U.S. Department of Commerce, Springfield, Va. 22161.
} 
fields and ranging from geology, through chemistry, chemical and mechanical engineering to economics and policy making. For example, a designer of turbines will be able to inform himself about the characteristics of aquifers, an economist will find indications on the importance of thermodynamic "available work" for the evaluation of a potential installation, or of the thrust of present-day regulatory codes and laws. In short, special attention has been paid to a unification of expert knowledge drawn from as many diverse fields as necessary in order to acquire an integrated view of geothermal energy. Thus, the Sourcebook should prove useful to geologists prospecting for geothermal energy, managers of geothermal reservoirs, mathematicians working on codes to model their behavior, mechanical and chemical engineers interested in the design of plants and their components, physicists working on thermodynamic properties, metallurgists, economists, environmentalists and planners, provided only that their sectional interest is connected with or bears upon geothermal energy.

Even though the emphasis in planning the contents of the Sourcebook was on integration of expertise, the fact remains that the text placed in the hands of a reader is not the product of a single pen. For this reason, it resembles an encyclopedia or a handbook more closely than a textbook or treatise. The thirty-nine authors, working singly or cooperating in groups, were given freedom and latitude to write spontaneously in their own style. Rather than impose on them a set of restraining rules, the editorial team made the judgement that complete integration was not required for the type of prospective reader whom they could imagine. For this reason, for example, each author was left free to arrange his references in the style of his own choosing. The references have not been collected in one place in all chapters, but footnotes have been included to make it easier to locate bibliographical listings throughout the book. However, all equations, tables and figures are numbered consecutively in a unified way within each chapter.

The Sourcebook consists of ten chapters not all of which have been written by a single author. The subdivision into chapters and sections was accomplished by the editors from sections submitted by the authors. The sections and subsections are numbered on a decimal pattern; the table of contents lists all subheadings up to three numerals and indicates the authors. The names of authors are listed at the highest level (chapter, section or subsection) for which each was responsible.

The selection of topics that the reader now finds between the covers of the Sourcebook is the result of planning as well as growth. Throughout the process of selection, elimination and modification, Mr. McFarland played a very active role. He initiated the original plan, was consulted when changes were made, and, most importantly, he identified the experts, persuaded them to contribute, and financed their participation.

Along with the Sourcebook, the Brown University team initiated the production of a companion volume entitled Geothermal Energy as a 
Source of Electricity-A Worldwide Survey of the Design and Operation of Geothernal Power Plants. This was written by a single author, Professor Ronald DiPippo. The companion volume is believed to represent, as accurately as possible, the state of development of geothermal power throughout the world as of July 1979.

A geothermal power station utilizes a natural resource- $a$ flow of more or less contaminated water at elevated pressure and temperature, which either flashes into steam or vaporizes an organic working fluid to drive a turbine. The system is capable of producing useful work in the form of an electric output (or just shaft work) because the "raw material," the brine, is found existing naturally in a state of nonequilibrium with the surroundings. The process of allowing this material to tend towards equilibrium with the atmosphere is responsible for the production of useful work (in the thermodynamic as well as in the social sense). Thus, the first condition is to discover an exploitable reservoir of this working fluid and to assess its individual characteristics. This is a lengthy process of exploration and development which must precede even the conceptual design of the power plant. Whether a particular field, properly delineated and characterized, is renewable or of limited life cannot be decided by presently available techniques. However, practice suggests that a lifetime of 30-50 years of profitable exploitation may be expected.

Bearing the above characterisites in mind we open the Sourcebook with a large chapter, chapter 2, entitled Resource Characteristics: Exploration, Evaluation, and Development. The individual sections were written by five contributors.*

The principal topics covered in chapter 2 include an introduction to the geology and geophysics of geothermal areas and a description of the essentials of geothermal exploration. The chapter continues with a study of reservoir mechanics and the principles of reservoir modeling. A good deal of attention is paid to drilling and well-logging and to a simplified analysis of fluid flow in reservoirs and wells. The chapter is comprehensive, but some readers may consider it insufficiently homogeneous; as already emphasized earlier, this was unavoidable on the one hand, and considered acceptable, on the other.

Chapter 3, Available Work in Geothermal Energy, gives a review of the principles of energy conversion based on thermodynamic considerations specifically adapted to geothermal installations. Emphasis is placed on the concept of available work in justified preference to an analysis in terms of ideal cycles which do not occur (other than only partially in binary installations).

The thermodynamic analysis of this chapter clearly brings into relief the importance of the heat-rejection system in a geothermal installation. The available specific work is sensitively affected by the rejection tem-

\footnotetext{
*An alphabetical listing of all authors together with their credentials and affiliations appears before the Foreword.
} 
perature which must be kept as close to that of the surroumdings as is practicable. Diumal and seasonal fluctuations reflect on the heat-rejection temperature and affect the design of the condenser and cooling tower, particularly in binary systems where fluid properties allow a greater range of design options than in a conventional power plant. Similarly, the ratio of heat rejected to useful work is large and greatly influences design. It can be said that this is due to the inherently low "equivalent Rankine efficiency" of operation, but this, by itself is of no consequence. The designer must strive to attain a high utilization factor and come as close to extracting the specific available work as economics permit. He must, however, realize that his condenser and associated equipment will be larger than he is accustomed to, and that this distributes the relative investment in turbine and heat-rejection equipment differently than in conventional fossil or nuclear power station.

Chapter 4 bears the title Poroer Systems and was produced by a comparatively large group of contributors involved in practical design and production supervision. Some readers will think that this is the pivotal chapter of the Sourcebook. The chapter can be thought of as consisting of two complementary parts. The first part deals with systems whose technology is established. This includes installations supplied with steam directly from wells or with steam extracted after one or more stages of flashing. It can be said that the technology for these is proven because such installations already exist (see chapter 10). The chapter also deals with binary-fluid installations whose practicality has yet to be demonstrated on a commercial scale. The crisp articles on materials selection and on sources of thermodynamic data complete this part.

The second part of chapter 4 describes two less conventional generic types of energy conversion systems. One of these is the so-called hybrid fossil-geothermal system which combines in a single plant features commonly found in separate fossil and geothermal installations. The advantages claimed for such systems are that significant economies of utilization of both energy resources are possible, resulting in a reduced cost of electricity. Although no plants of this type exist today, one such design is under serious consideration for a site in the western United States where fossil and geothermal energy resources exist in close proximity to one another.

The other advanced system is the impulse turbine version of the socalled total flow energy conversion system. This offers the prospect of a very high utilization factor but suffers from a number of practical disadvantages which the present state of engineering practice has not succeeded in removing.

Waste Heat Rejection is treated in chapter 5. The presentation is thorough and coherently presented. Strong emphasis is placed on the design of systems to meet the demands of geothermal power. Case studies of plants located in the Imperial Valley are included. A discussion of the 
effect of variations in ambient temperature on the waste heat and power output of geothermal plants concludes this chapter.

In chapter 6, Materials Selection Guidelines for Geothermal Power Systems, the reader will learn about the special requirements for materials in the light of the corrosive nature of the fluids encountered in geothermal plants. It is seen that the severity of the problem depends on whether the material under stress is exposed to geothermal steam, geothermal liquid before flashing, or condensate. The survey includes both metallic and non-metallic materials. An obvious lesson from this chapter is that the plant designer must have reliable data on hand characterizing the geofluid, in all phases, before he begins to specify materials for separators, flash tanks, piping, turbines, etc.

One of the more important considerations concerning the use of geothermal energy is the cost of the electricity it generates as compared with the calculated or projected cost for alternative or competing energy conversion systems. Debate continues, for example, over whether a flashsteam or a binary-fluid plant operating on a given resource would generate electricity more economically. Comparisons are often difficult to make because of wide discrepancies among economic models and methods favored by different authors. Chapter 7, Economic Considierations, attempts to lay the foundation for a systematic methodology that should allow the reader to make intercomparisons of alternative power systems. The effect of various technical and economic factors on cost is discussed including the impact of inflation.

Chapter 8, Criteria for Selection and Conceptual Design Optimization, is divided into three parts. The first presents the factors that influence the decision on whether or not to install a power plant and, if so, what type of plant is most appropriate for a given set of economic and market conditions. The second deals with the multiparameter optimization codes that are being developed to help designers to gain an understanding of the sensitivity of plant performance and system cost to each of the many variables entering into the problem. The GEOTHM code of the Lawrence Berkeley Laboratory is used as an example. The last part of the chapter offers a valuable aid to the potential designer. It describes services that are available to assist him in finding suppliers of standard components and companies that will design and manufacture special items of equipment.

One of the factors bearing importantly on the expansion of geothermal power is the concern for the environmental impact of geothermal development, particularly, but not exclusively, in the United States. Chapter 9 , Environmental Considerations, was written by the official of the U.S. Environmental Protection Agency who promulgated the EPA document, "Pollution Control Guidance for Geothermal Energy Development" in June 1978. In fact chapter 8 is an edited version of this EPA document. As such it constitutes a monograph on the subject; it is a comprehensive report dealing with the current regulatory statutes bearing on geothermal 
energy exploitation, the passible deleterious effects on the surroundings from all phases of geothermal power development, and describes in detail the technology that exists or is under development to cope with the pollution problems.

The Sourcebook concludes with chapter 10, Geothermal Power Plants Around the World, a compendium of information on plants that now exist, once existed, and are planned in the foreseeable future. This chapter is a condensation of the full volume by Professor DiPippo mentioned earlier, and contains a country-by-country survey in which each geothermal unit is described. The reader will find information about the reservoir, the wells and gathering system, the energy conversion plant including the waste heat rejection system, the efficiency and reliability, and the costs of the plant and of the electricity generated. One of the conclusions that can be drawn from the survey is that it is difficult to generalize; each particular geothermal field is unique. The reservoir must be thoroughly understood before a designer can properly specify the energy conversion equipment. Not all geothermal power projects can be viewed as totally successful; it is important that we learn as much as we can from such cases. By and large, however, geothermal power plants are very reliable, safe, and relatively inexpensive. The environmental impact is mild and localized.

It is important to understand, however, that there is an element of risk associated with geothermal energy utilization because of uncertainties about the productive lifetime of a newly discovered field. Research and development efforts now in progress are aimed at reducing these risks, while at the same time cutting geothermal power costs and improving overall system performance. We expect that geothermal energy will play a vital role in supplying the needs of many developing countries, as it already does in El Salvador, for example. The chapter concludes by pointing to several projects now in progress in the United States and to those in many countries that are on the verge of useful exploitation of geothermal energy for electrical power.

The editors and contributors hope that this Sourcebook will help to bring about the successful implementation of plans for the development of geothermal energy around the world. In conclusion we emphasize that none of us believes that geothermal energy by itself will rescue us from our energy plight, but we do believe that unless we begin to make sensible use of energy resources that exist and are ready to be exploited now, the problems will only get worse. 


\section{Chapter 2}

\section{Resource Characteristics: Exploration, Evaluation, and Development}

2.1 Geology and geophysics of geothermal areas (By William $\mathrm{H}$. Diment*)

\section{Q.1.1 Introduction}

Although temperature increases with depth in the Earth's crust, there are only a few localities where reservoirs of both sufficient temperature and sufficient permeability exist at depths economically accessible to the drill. A great range of combinations of these characteristics exists that may provide exploitable resources now, or with development of suitable technology, in the future. At one end of the spectrum might be hot molten rock (magma) in a shallow magma chamber or anomalously hot dry rock at a depth of a few kilometers. Both have little or no permeability, but some schemes for extracting the heat may be feasible. At the other end of the spectrum are thick aquifers of high permeability at moderate depths which may produce sufficient quantities of warm water for space heating even though they may be in regions of normal or near-normal heat flow.

2.1.1.1 Classification of geothermal systems. There is no generally accepted classification for geothermal systems, but the one used by Muffler $[1976$, p. 499] embraces most of the types likely to be encountered and provides a useful framework for discussion. His scheme is adopted here in a form modified to take account of the fact that the words resource and reserve have taken on rather specialized meanings in connection with the economic assessment of geothermal energy [White and Williams, 1975; Muffler and Christiansen, 1978; Muffler and Cataldi, 1979; Muffler and Guffanti, 1979].

1. Geothermal systems related to young igneous intrusions in the upper crust.

a. Magma

b. Hot dry rock

c. Convective hydrothermal systems

*United States Geological Survey, Reston, Va. 
2. Geothermal systems not related to young igneous intrusions in the upper crust.

a. Systems in low-porosity conductive environments

b. Systems in low-porosity conductive environments modified by circulation of meteoric water

c. Systems in high-porosity environments at hydrostatic pressure

d. Systems in high-porosity environments at pressures greatly in excess of hydrostatic (the "geopressured systems").

Some aspects of this classification will be considered in greater detail in later sections, but the terms "conductive environments" and "young igneous intrusions in the upper crust" require amplification as part of a framework for discussion.

2.1.1.2. Conductive environments. In most regions the internal heat of the earth escapes through the crust largely by conduction. In other regions heat transfer to the surface is dominated by. mass transport of heat by intrusion of molten rock (magma) into the crust or by circulation of ground water through permeable rocks of the crust. Although it is often quite impossible to separate the conductive and convective components of heat transfer, the distinction is useful for thinking about the temperature distribution within the crust.

One reason for supposing that the heat transport through the crust is by conduction (at least in some places and at shallow depth) is that careful measurements in drill holes indicate that heat flow $(q)$ does not vary with depth $(z)$; that is, the heat flow in any interval $\left(q_{i}=K_{i}\left(\Delta T_{i} / \Delta Z_{i}\right)\right)$ is the same as that in any other interval in the drill hole. $K_{1}$ is the thermal conductivity of the rocks in the depth interval $\left(\Delta Z_{i}\right)$, and $\Delta T_{i}$ is the temperature difference across the interval. Some qualifications are given later.

Maps showing the global distribution of heat flow measurements have been prepared by Lee and Uyeda [1965]* and most recently by Grim [1976]. Data for the United States were summarized by Sass and Lachenbruch [1979]; Lachenbruch and Sass [1977, 1978]; and in more detail by Sass et al. [1976]; Diment et al. [1975]; Blackwell [1971a]; Roy et al. [1968a]; and Sass and Munroe [1974]. The last is notable because it contains tabulations of the temperatures and thermal conductivities from which the heat flow measurements in the United States were derived. The reports on heat flow by Blackwell [1971b] and Diment [1975] in the last two U.S. National Reports to the International Union of Geodesy and Geophysics contain many additional references of direct or peripheral interest.

Observations of bottom-hole temperatures and thermal gradients derived from the bottom-hole temperature and average surface temperatures in more than 25,000 wells drilled largely in the petroleum producing prov-

\footnotetext{
*The references for this section appear on p.77.
} 
inces of North America (American Association of Petroleum Geologists and U.S. Geological Survey, [1976a,b]) are not inconsistent with conductive transport in mariy places, but provided no test of it because the mean conductivities of the rocks are poorly known.

Another reason for supposing that conduction dominates in places is that temperatures extrapolated to mantle depths on the basis of near-surface heat-flow measurements and assumptions regarding the variation of radioactive heat production with depth in the crust yield temperatures compatible with melting relations in the mantle (e.g., Lachenbruch and Sass [1977, 1978]; Wyllie [1971]).

The basis for the extrapolation of shallow temperatures to depth was discovered by Birch, Roy, and Decker [1968], who measured heat flow $(q)$ in holes drilled into plutonic rocks at various sites in northeastern United States. They also measured the radioactive heat generation $(A)$ at each site and found a linear relation between $q$ and $A$ :

$$
q=q^{*}+D A
$$

In a general way the term $D A$ is the component of heat flow due to the radioactive heat production in the upper crust, and the $q^{*}$ or "reduced heat flow" is the component that originates from the lower crust and mantle. Subsequent measurements in plutonic rocks of the Basin and Range [Roy et al., 1968b] and the Sierra Nevada [Lachenbruch, 1968; Roy et al., $1968 \mathrm{a}, \mathrm{b}]$ also showed a linear relation. The parameters for the three provinces, in which extensive $q-A$ studies have been made, are shown in the following table:

\begin{tabular}{|c|c|c|c|}
\hline Region & $\left(\mathrm{HFU}^{*}\right)$ & $\underset{(\mathrm{km})}{D}$ & $\begin{array}{l}D A_{\text {max }} \\
\text { (HFU) }\end{array}$ \\
\hline 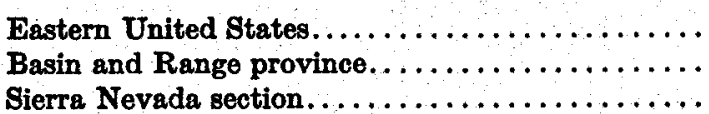 & $\begin{array}{l}0.8 \\
1.4 \\
0.4\end{array}$ & $\begin{array}{l}7.5 \\
10.0 \\
10.0\end{array}$ & $\begin{array}{l}\sim 1.5 \\
\sim 1.0 \\
\sim 1.0\end{array}$ \\
\hline
\end{tabular}

Note: 1 heat-flow unit (HFU) $=1 \times 10^{-6} \mathrm{cal} / \mathrm{cm}^{3} \mathrm{~s}$.

The slope $(D)$ varies little among the regions, but differences among the intercept values $\left(q^{*}\right)$ are large.

These observations lead to the notion that continents can be divided into heat-flow provinces, each typified mainly by its own $q^{*}$, and that the variation of heat flow within a province is a consequence of the variation of the heat generation of upper crustal rocks. Indeed, $q-A$ points from Australia [Jaeger, 1970; Sass et al., 1976a, b] and the Precambrian shield areas of the world [see summary by Rao and Jessop, 1975] seem to fall close to either the northeastern United States or the Basin and Range lines. Moreover, the regions of high $q^{*}$ are those of recent tectonism, and those of low $q^{*}$ are those of either ancient tectonism (northeastern United States and the Precambrian shields) or regions where a cold slab subducted into the 
mantle appears to give rise to anomalously low $q^{*}$, as in the Sierra Nevada [Lachenbruch, 1968; Roy et al., 1968b; 1972; Blackwell, 1971a, b].

These observations have also been taken to mean [Roy et al., 1968b, 1972; Blackwell, 1971b] that: (1) $q^{*}$ for the eastern United States may be typical of all stable continental regions older than a few hundred million years, and (2) $q^{*}$ for the Basin and Range province is close to the maximum that might be found over broad regions of the continental crust, the rationale being that the base of the crust in the Basin and Range is near melting and that further increase of temperature would lead to melting that would buffer additional heat input into the crust. Both of these generalizations are attractive. They form a framework from which to view the many anomalies that are now becoming apparent.

It is also evident from the preceding table that the second term $D A$ in the equation can be a large fraction of the observed heat flow. Consequently, a detailed map of heat flow (were the data available) within a heat-flow province would be both highly variable and highly intricate because of abrupt lateral variations in heat production. These lateral variations are best illustrated by the studies in New England [Birch et al., 1968; Roy et al., 1968 a,b; Roy et al., 1972], where a comparatively large number of heat-flow measurements have been made in a variety of basement rock types and a large amount of heat-production information is available both from measurements on cores and from surveys of gamma activity. They are also evident from the relatively detailed investigations in the Sierra Nevada [Lachenbruch, 1968].

The $q-A$ relation provides a basis for calculation of temperature $T$ at depth $z$, assuming that the variation with depth of heat production $A$ and thermal conductivity $K$ are reasonably well known. The two most commonly used models for the decrease in $A$ with depth are : (1) $A$ is constant to the depth $H$, and (2) $A$ decreases exponentially with depth $A=A_{0} \exp -(z / D)$ where $D$ is a constant and $A_{0}$ is the radioactive heat generation at the surface.

Assuming the conductivity is constant, the temperatures at depth for the two models are (for example, Jaeger, 1965; Lachenbruch, 1968) :

$$
\begin{aligned}
& T=T_{0}+\frac{A H^{2}}{2 K}\left[\frac{2 z}{\bar{H}}-\left(\frac{z}{\bar{H}}\right)^{2}\right]+\frac{q^{*} z}{K} \\
& T=T_{0}+\frac{A_{0} D^{2}}{K}\left(1-e^{-z / D}\right)+\frac{q^{*} z}{K},
\end{aligned}
$$

where $T_{0}$ is the mean surface temperature and hereafter is taken as zero because we are interested primarily in temperature above mean surface temperature.

If the two models are to yield equal heat flow at the surface, $D$ must equal $B$. If $D$ is about $10 \mathrm{~km}$ as suggested by the $q-A$ relation, $A$ will decrease to $A_{o} / e$ or $0.37 A_{0}$ at $10 \mathrm{~km}$ and to $0.05 A_{0}$ at $30 \mathrm{~km}$ (roughly the 
thickness of the crust). In a general way, then, the first model (constant $A$ ) represents the case where crustal radioactivity is concentrated near the surface, and the second model (exponential $A$ ) represents the case where it decreases with depth throughout the crust. Consequently, $q^{*}$ can be thought of as the heat coming from the lower crust and mantle in the first case and as the heat coming from the mantle in the second.

For the same $q^{*}$, the temperatures at depth for the exponential model are somewhat higher than for the constant $A$ model. However, at $3 \mathrm{~km}$, the difference is about $1^{\circ} \mathrm{C}$, and at $10 \mathrm{~km}$, it does not exceed a few tens of degrees even for the highest values of heat generation. For purposes of the present discussion, the difference between the models is unimportant.

Temperature-depth curves constructed from these equations for various values of $A, D$, and $q^{*}$ have been presented [Lachenbruch, 1970; Blackwell, 1971b; Roy et al., 1968; Diment et al., 1975]. The set reproduced in figure 2.1 [Lachenbruch and Sass, 1977, figure 22] is based on the exponen-

Temperature, ${ }^{\circ} \mathrm{C}$

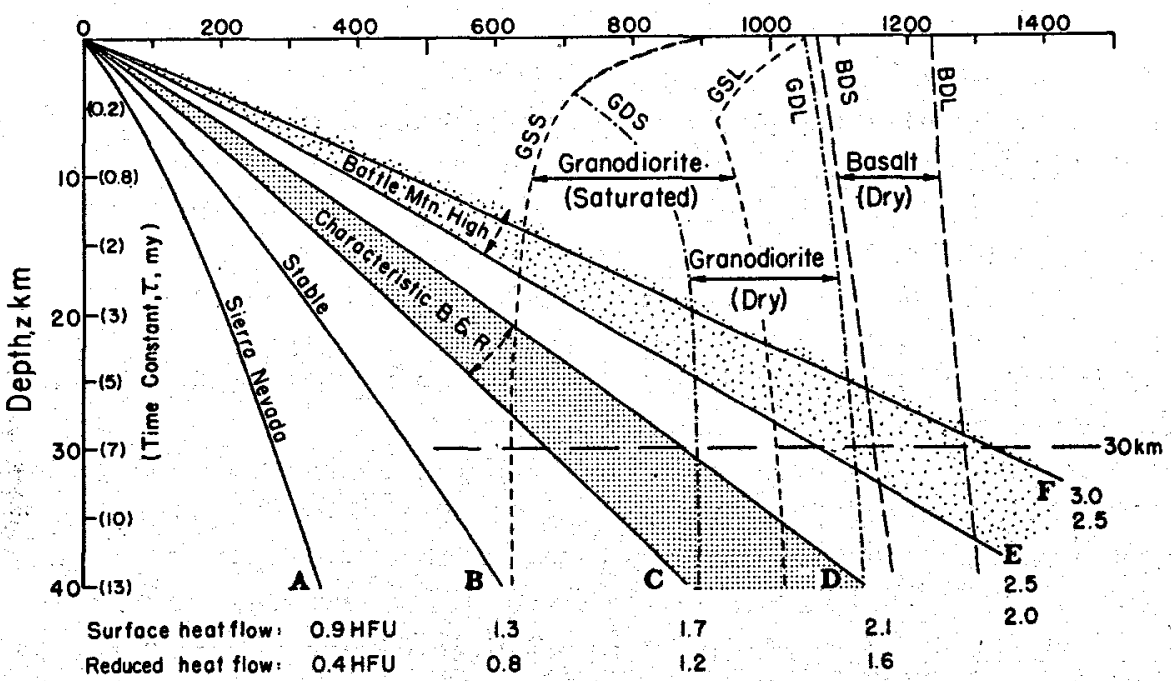

Fioune 2.1-Generalized conductive temperature profiles for the Sierra Nevada crust (A), a stable reference crust (B), the characteristic Basin and Range crust (C to $D$ ); and lower limiting (E) and typical (F) conditions in the crust of the Battle Mountaln High. All curves are drawn for a surface heat production (A) of $5 \mathrm{HGU}$ and thermal conductivity (K) of $6 \mathrm{mcal} / \mathrm{cm} \mathrm{s}{ }^{\circ} \mathrm{C}$. Corresponding surface heat flow and reduced or "mantle" heat flow are shown at the bottom of each curve. Melting relations [after Wyllie, 1971] are shown for intermediate crustal rock by curves GSS (granodiorite saturated solidus), GSL (granodiorite saturated liquidus), GDS (granodiorite dry solidus), and GDL (granodiorite dry liquidus); and for basalt by BDS (basalt dry solidus) and BDL (basalt dry liquidus). In parentheses on the depth axis is shown the time in million of years (my) required for the overburden to approach thermal equilibrium after intrusion by a sill maintained at constant temperature. Reproduced from Lachenbruch and Sass [1977, figure 22]. 
tial model and a heat production $(A)$ of $5 \mathrm{hgu}$, which is a commonly used average. $A$ could range between 0 and $20 \mathrm{hgu}$ (see section 2.1.2.5.d) and temperatures would vary accordingly. Figure 2.1 also shows various melting curves that will be considered later.

In the last few years, many additional observations have been made but have not been fully published or critically examined. They tend to confirm the $q-A$ relationships in the low heat flow provinces, although there is some evidence that there may be recognizable subprovinces in the eastern United States [Costain et al., 1978; Smith, Gregory, and Garvey, 1978). On the other hand, the new $q-A$ data for the Basin and Range province of western United States exhibit a wide scatter about the line originally proposed for this province [Lachenbruch and Sass, 1977, figure 13]. This scatter is not surprising. There is considerable evidence for recent melting in the crust [Christiansen and Lipman, 1972; Stewart and Carlson, 1978]. Moreover, the extensional regime and active faulting probably promote deep circulation of meteoric water.

\subsubsection{Distribution of young igneous intrusions. Molten or recently solid-} ified bodies of rock at shallow depths $(<10 \mathrm{~km})$ in the crust are attractive targets for geothermal development. The intrusion itself, or the rocks heated by it, may be utilizable given development of appropriate technology. Water heated by the intrusion may now provide an exploitable resource provided appropriate conduits and reservoirs exist.

Present igneous activity is largely near active plate margins, be they spreading ridges, subduction zones, or transform margins [e.g., White, 1973, figure 1; Muffler, 1976, figure 4]. Some activity seemingly remote from present margins has been attributed to hot spots (or melting anomalies as Shaw and Jackson [1973] call them) in the mantle. Various mechanisms have been proposed: plumes in the mantle [Wilson, 1963; Morgan, 1971, 1972], propagating fractures [Jackson and Wright, 1970; McDougall, 1971], rheological intrusions [Green, 1971], shear melting [Shaw, 1973], bumps on the asthenosphere [Menard, 1973] and thermal runaways [Anderson and Perkins, 1974]. It is not clear which mechanisms are dominant or whether various types of hot spots may result from different types of mechanisms. Broad extensional regimes such as the Basin and Range province of the western United States do not fit neatly into the simpler schemes of plate tectonics. A change from a continental margin of subduction to one of transform motion some 17 million years ago [Thompson and Burke, 1974] is involved [Atwater, 1970; Christiansen and Lipman, 1972].

Not all areas of recent volcanism have large shallow magma chambers. Indeed most probably do not. Smith and Shaw $[1973,1975]$ reasoned that in most environments, basaltic, andesitic and comparable magmas that originate in the mantle or lowermost crust rise to the surface where their 
heat is rapidly lost to the atmosphere. The conduits are small, the ascent is rapid and little heat is transferred to the upper levels of the crust. They excepted certain large oceanic systems [see also Muffer, 1976]. On the other hand, silicic magmas may be present in upper crust, and if they are young enough and large enough they present attractive targets. Thus, the distribution and age of silicic volcanic rocks that have reached the surface are important guides to exploration.

\subsubsection{Exploration for geothermal systems}

2.1.2.1 Introduction and general considerations. Practically every potentially applicable technique known to the geologist, geophysicist, and hydrologist appears to have been applied in the search for, and elucidation of, geothermal reservoirs. This is not to say that these techniques have been applied most effectively or in appropriate combination or sequence. A part of the apparent plethora of exploration techniques is a consequence of the number of things sought: the location of a deep source of heat and the regional context in which it exists are best studied from the point of view of regional volcanism and tectonism as refined by regional heat flow, gravity and magnetic surveys, deep electrical soundings, and active and passive seismic methods. Delineation of a geothermal reservoir requires rather different methods or at least much more detailed application of the above techniques. Evaluation of reservoir characteristics by study of the chemical and isotopic composition of waters issuing from hot springs or shallow holes is an additional realm of exploration as is the development of chronology of volcanic events by radiometric and paleomagnetic dating. The better explored regions (Larderello, Italy; The Geysers, California; Roosevelt Hot Springs, Utah; Long Valley, California; Cerro Prieto, Mexico; Valles Caldera, New Mexico; Raft River Valley, Idaho) are emerging as case histories, but many data remain proprietary and many data have not been fully integrated.

Some exploration strategies have been offered [e.g., Bodvarsson, 1970; Combs and Muffer, 1973; Duprat and Omnes, 1976; McNitt, 1976; Pálmason, 1976; Ward et al, 1978], and many are implicit in the emerging case histories. Critiques are beginning to appear [e.g., Meidav and Tonani, 1976]. Clearly, the exploration strategy for a recent volcanic caldera is different than that for a geopressured zone deep in a sedimentary basin. Even within a given class of targets, selections of techniques could vary considerably depending on terrain, climate, hydrologic conditions and accessibility.

Few geothermal wells produce fluids of high enough temperature to be of interest for electric power production at depths less than $1 \mathrm{~km}$. Thus, the real exploration target is at or below this depth. Many techniques reveal conditions only at shallower depths, and because ascending hot 
waters often follow devious paths, near-surface manifestations may be considerably displaced from a deep hydrothermal reservoir. Diagnostic techniques for locating deep reservoirs are poorly developed. A better knowledge of the anomalous properties of rocks in the reservoir region is required as well as improved means to detect them.

Some of the techniques employed are well developed and have been adequately described in recent texts. We do little more than enumerate them here except to note how they have been used in the search for geothermal energy. The Glossary of Geology [Gary et al., 1972] is a necessary tool for exploring the literature. The Encyclopedic Dictionary of Exploration Geophysics [Sheriff, 1973] is an especially useful source for sorting out terminology as well as getting a basic notion of the many geophysical techniques available. The Handbook of Physical Constants [Birch, 1942; Clark, 1966] contains much information on the physical properties of interest. The thermodynamic properties of minerals were tabulated recently by Robie et al. [1978].

A recent geologic time scale [e.g., Van Eysinga, 1975] that takes account of recent changes in the Cenozoic time scale is useful, as is a knowledge of the location of the physiographic provinces of the United States [e.g., U.S. Geological Survey, 1970].

\subsubsection{Remote sensing. Aerial photographs have long been an indispensa-} ble tool for geologists in mapping and interpretation of geologic conditions. The subject is well developed and many excellent sources exist: American Society of Photogrammetry [1960]; Ray [1960]. Remote sensing from satellites and development of sensors covering other parts of the electromagnetic spectrum have added new dimensions which can be appreciated by examination of several recent monographs and symposia proceedings: Reeves et al. [1975]; Williams and Carter [1976]; Environmental Research Institute of Michigan [1975].

In connection with geothermal programs, remote sensing techniques are likely to find application in several areas: (1) Probably the most important is in the analysis of near-surface geologic structure, the distribution of rock types and the definition of zones of hydrothermal alteration [e.g., Abrams et al., 1977; Rowan et al., 1974, 1977]. (2) The definition of hydrologic subtleties (as manifest by anomalies in vegetation) that may result from geothermal conditions at depth. (3) The direct determination of hot zones at the surface from thermal infrared (IR) imagery.

Watson [1975] reviewed the application of thermal infrared (3-5 or 8-14 $\mu \mathrm{m}$ ) imagery to geothermal problems and found a threshold sensitivity of $650 \mathrm{HFU}\left(1 \mathrm{HFU}=1 \times 10^{-6} \mathrm{cal} / \mathrm{cm}^{2} \mathrm{~s}\right)$ for one sample per diurnal cycle and 75 HFU for three.optimally timed samples per diurnal cycle. These heat flows are very large compared with average heat flow from the 
Earth ( 1.5 HFU) or compared with those associated with deeply buried thermal systems which rarely exceed ten or a fow tens of HFU. Consequently, the technique is useful only in determining temperature anomalies at or within a few decimeters of the surface such as hot springs, fumaroles, and steaming ground.

Thermal IR images nicely outline an area of near-surface hot-water discharge in the Narrows of the Raft River Valley of Idaho [Watson, 1975; England and Johnson, 1976].

Dickinson [1976], in analyzing the results of a thermal IR $(4.5-5.5 \mu \mathrm{m})$ survey of the Tauhara geothermal field, New Zealand, was able to: (1) divide surface temperatures into three ranges (ambient, 1 to $3^{\circ} \mathrm{C}$ above ambient, and $>3^{\circ} \mathrm{C}$ above ambient); (2) correlate anomalies with temperature measurements made in the soil; (3) determine the effects of vegetation; (4) establish a boundary between regions of conductive and convective heat flow.

England and Johnson [1976] examined the use of the microwave part of the spectrum and found that the radio brightness of soil is determined primarily by the amount of soil moisture and its state (water or ice) and not by the temperature. They found that the spectral variation of radio brightness is diagnostic of the depth to the frostline and suggest that radio brightness should reveal geothermally induced thinning or absence of frost. The findings call to mind White's [1969] use of snow-melt patterns to delineate tharmal anomalies.

\section{Q.12.3 Late Cenozoio silicic volcanic rocks}

2.1.2.3. Introduction and data sources. Although an intrusion older than a few million years would have long since cooled past the point of geothermal interest (section 2.1.2.3.c), there are reasons to look at the distribution and nature of volcanic rocks back to $10 \mathrm{My}$ or more: (1) Many volcanic systems have not been studied in sufficient detail to establish their range in age. (2) Many volcanic systems have long histories; $2 \mathrm{My}$ is not uncommon, longer if precursor and late activities are included (section 2.1.2.3.d). (3) At least some volcanic centers migrate slowly with time [e.g., Christiansen and Lipman, 1972; Walker et al., 1974; Christiansen and McKee, 1978; Luedke and Smith, 1978a] and knowledge of the spatial and temporal progression might help to locate the more promising geothermal targets.

Knowledge of young volcanic systems, particularly of their age, has accumulated rapidly in recent years. Luedke and Smith [1978a, 1978b] have prepared maps $(1: 1,000,000)$ showing the distribution, composition (silica content) and age of late Cenozoic $(<16 \mathrm{My})$ volcanic centers in Arizona and New Mexico [1978a] and in Colorado, Utah and southwestern Wyoming [1978b]. Many hundreds of references to original sources are included. Stowart and Carlson [1978] present more generalized maps 
(1: $5,000,000)$ showing the distribution, lithology and age of Cenozoic igneous rocks in western United States [see also Lachenbruch and Sass, 1977 , figure 8, who superimposed a heat flow map on the map showing the distribution of rocks erupted in the last $17 \mathrm{My}$ ]. Other regional compilations are available: Nevada [Stewart and Carlson, 1976]; the Northwest [Armstrong, 1978].

2.1.2.3.b Some regional considerations. The crust in much of the western United States has been torn apart and invaded by hot mafic magmas from below during the past 20 million years or so [e.g., Lachenbruch and Sass, 1978; Christiansen and McKee, 1978]. 'The loci of intrusion have migrated and now lie largely near the edges of the Great Basin, although relationships are uncertain in some regions.

Regional geology and geophysics give a notion of where these hot regions are and/or have been. The regions of massive mafic intrusion tend to be marked by low average elevation and consequently by high Bouguer gravity anomalies [e.g., Eaton et al., 1978], high heat flow [Lachenbruch and Sass, 1977, 1978; Blackwell, 1978], thin crust and low $P_{n}$ velocity (for compressional waves in the uppermost mantle) [e.g., D. P. Hill, 1978; Smith, 1978], high electrical conductivity at depth [e.g., Gough, 1974], and shallow Curie-point isotherm [Bhattacharyya and Leu, 1975; Byerly and Stolt, 1977; Mayhew, 1979]. Each of these subjects has a considerable literature, and some of it is referenced in various sections on individual methods. Two recent monographs are particularly important as starting points [Heacock, ed., 1977; and Smith and Eaton, eds., $1978]$.

2.1.2.3.c Conductive and convective cooling of intrusions. Many mathematical models have been constructed to describe the conductive cooling of intrusions [e.g., Lovering, 1935; Jaeger, 1964, 1965; Carslaw and. Jaeger, 1959; Simmons, 1967; Lachenbruch et al., 1976a ; Goguel, 1976]. With time the models have become more elaborate geometrically, and now with high speed computers it is possible to describe the temperature field about any shape as a function of time given appropriate initial conditions and knowledge of thermal properties of the intrusion and host rock.

To get a notion of the dimensions and properties involved in conductive cooling, let us examine a very simple case. The temperature $\left(T,{ }^{\circ} \mathrm{C}\right)$ on the midplane of a horizontal intrusion of infinite lateral extent and of thickness $(h, \mathrm{~cm})$ at times $(t, \mathrm{~s})$ relatively long after intrusion is [Jaeger, 1965, p. 13]:

$$
T=\frac{T_{\rho} h}{2}(\pi k t)^{-1 / 2}
$$

where $T_{0}$ is the initial excess of temperature, and $k$ is the thermal diffusivity (here taken to be $0.01 \mathrm{~cm}^{2} / \mathrm{s}$ ). The times for the center of the 
intrusion to cool to $T / T_{0}=1 / 2$ and $T / T_{0}=1 / 4$ for intrusion of various thicknesses are:

$$
\begin{aligned}
& T / T_{0}=1 / 2 \quad T / T_{0}=1 / 4 \\
& h=0.5 \mathrm{~km} \ldots \ldots \ldots \ldots \ldots \ldots 2.5 \times 10^{3} \mathrm{yr} \quad 1.0 \times 10^{4} \mathrm{yr} \\
& h=1 \mathrm{~km} \ldots \ldots \ldots \ldots \ldots \ldots 1.0 \times 10^{4} \mathrm{yr} \quad 4.0 \times 10^{4} \mathrm{yr} \\
& h=5 \mathrm{~km} \ldots \ldots \ldots \ldots \ldots \ldots 2.5 \times 10^{6} \mathrm{yr} \quad 1.0 \times 10^{6} \mathrm{yr} \\
& h=10 \mathrm{~km} \ldots \ldots \ldots \ldots \ldots \ldots 1.0 \times 10^{\circ} \mathrm{yr} \quad 4.0 \times 10^{6} \mathrm{yr}
\end{aligned}
$$

The initial temperature for a silicic intrusion might be about $850^{\circ} \mathrm{C}$ [Smith and Shaw, 1975, p. 60] and might be lower if magma were partially crystallized or if the volatile content were high (see figure 2.1). Thus, it appears than an intrusion would have to be rather young and quite thick to be of geothermal interest.

The effect of the latent heat of crystallization $(L)$ is not included in the calculation but can be approximated by replacing $T_{0}$ by $\left(T_{0}+L / c\right)$ where $c$ is the specific heat of the magma. Values of $L=65 \mathrm{cal} / \mathrm{g}$ and $\theta=0.3 \mathrm{cal} / \mathrm{g}$ $\mathrm{C}^{\circ}$ are commonly assumed [Smith and Shaw, 1975 ; Lachenbruch et al., 1976a], thus increasing the effective temperature of the magma by about $217^{\circ} \mathrm{C}$. The problem of assessing the role of latent heat is not this simple. Details have been addressed by Jaeger [1959, 1961, 1964], Carslaw and Jaeger [1959, chapter 11], and Lachenbruch et al. [1976a].

So far we have considered the conductive cooling of thin intrusions injected all at once. This may provide a satisfactory approximation for the cooling history of thin sills and dikes. However, the large intrusions of interest in connection with geothermal energy are not thin, they are, not intruded all at once, and they cool by both conductive and convective processes. Moreover, it is not entirely clear how these intrusive masses were generated or how far they moved. A good example of the uncertainties likely to be encountered and the limits to which they can be evaluated is given by Lachenbruch et al. [1976a] in their analysis of thermal conditions in the Long Valley caldera.

Although it has been appreciated for some time that circulation of meteoric water plays a role in the cooling of intrusions, it has not been until recently that attempts have been made to quantify the effect in a general way. Smith and Shaw $[1979$, p. 15] wrote in terms of "hydrothermal cooling efficiencies" for magmatic systems. This concept has been developed from widely different approaches to the effects of hydrothermal cooling [Norton and Knight, 1977; Peck et al., 1977; Shaw et al., 1977]. Zero efficiency refers to conductive cooling alone. A 50 percent efficiency is assigned to the cooling of a thin lava sheet quenched by rainfall [Shaw et al., 1977]. On the basis of hydrothermal convection models of Norton and Knight [1977], Smith and Shaw [1979,p. 16] stated :

Most hydrothermal systems above high-level silicic chambers would be considerably less efficient than the model of quenched lava; efficien- 
cies probably range from zero to 20 percent. For example, Yellowstone probably represents a system near 20 percent efficiency. All systems resembling water-quenched lava bodies would be grouped with efficiencies near 30 percent, depending on the recharge rate for vaporized water; efficiencies above 30 percent would be anticipated only in very wet climates such as Hawaii.

They also noted that the relation of the efficiency scale to cooling times requires additional modeling.

2.1.2.3.d Duration of volcanic systems. The intrusion of a silicic magma into the upper crust cannot be considered as a single event from a thermal point of view. Indeed it is now recognized that many systems have complex histories extending over periods of a few million years but that insufficient radiometric dates are available to describe adequately the histories of most systems [Smith and Shaw, 1975, 1979; R. L. Smith et al., 1978].

Intrusion of silicic magma is commonly preceded by extrusion of basic or intermediate volcanic rocks and is often followed by such activity. Moreover, associated volcanism in the form of basaltic "shadows," intermediate volcanic dome sequences and previous caldera cycles [Smith and Shaw, 1979, p. 17] attest to the resupply of heat over a long period of time. This resupply of heat can only be caused by repeated intrusion of material from below.

Some general models have been developed. For example, Christiansen and McKee [1978, p. 295] nicely summarized one view of the spatial and temporal progression of volcanic events in the eastern Snake River Plain:

Christiansen and Blank (1969), Christiansen and Lipman (1972), and Christiansen (in preparation) have emphasized a somewhat different view of this relationship; they have stressed that the fundamental character of the volcanism is basaltic, but that cycles of rhyolitic volcanism mark the eastward propagation of the system. A sequence is repeated in each new area that becomes the head of the volcanic zone as it propagates northeastward along the axis of the eastern Snake River Plain. This cyclic sequence begins with basaltic or contemporaneous basaltic and rhyolitic volcanism of small to moderate volume. This is followed by the evolution of a very large rhyolitic magma chamber that sustains the eruption of rhyolites. The sequence climaxes in voluminous ash-flow eruptions and associated caldera-collapse of the source area and culminates in postcollapse rhyolitic volcanism. The Yellowstone Plateau is now in this stage (Christiansen, 1974). One rhyolitic cycle in each successive area has a duration on the order of 1 to $2 \mathrm{My}$, during which time basaltic volcanism continues around the margins but not within the principal rhyolitic source area. A rhyolitic cycle ends with solidification and fracturing of the large rhyolitic magma chamber; this allows basalts to erupt through the former rhyolitic source area, accompanied only 
occasionally by small volumes of rhyolite or mixed basalt-rhyolite complexes. Island Park, just west of Yellowstone is now in this stage (Hamilton, 1965; Christiansen, 1975). Ultimately, as the head of the volcanic zone propagates eastward past an area, the activity in that area reverts to continued basaltic volcanism while the axis of the volcanic zone subsides, as on most of the Snake River Plain.

Events are sufficiently well known in some other volcanic areas that detailed histories can be constructed, for example: the Long Valley caldera of California [Bailey et al., 1976] and the Valles caldera of New Mexico [Smith et al., 1970; Doell et al., 1968; Smith and Bailey, 1968].

\subsubsection{Hot springs and geochemical thermometry. The classic source on} the distribution of thermal springs is that of Waring most recently revised by Blankenship and Bentall [Waring, 1965]. With the increased interest in geothermal energy, many additional compilations of geothermal systems and thermal isprings have been made [e.g., Renner et al., 1975; Brook et al., 1979 ; Sammel, 1979].

Clearly the temperature of the water issuing from a hot spring tells us little about the temperatures below, where the hot water originated. The boiling curve cannot be exceeded by much in near-surface condition without eruption. Moreover, the mixture of hot waters from depth with cold near-surface ground waters reduces the temperature of the effluent from depth to a degree that cannot be appreciated iwithout other evidence. The other evidence comes in the form of chemical and isotopic analysis of the surface or borehole effluent, which under favorable circumstances can yield an estimate of the temperature of a subsurface reservoir where the effluent had previously equilibrated.

There are several geochemical thermometers that have been used which, in the hands of trained geochemists, appear to yield consistent results.

Although many chemical geothermometers have been considered and are in various stages of development [e.g., Truesdell, 1976; Fllis and Mahon, 1977; McKenzie and Truesdell, 1977; Brook et al., 1979], the $\mathrm{SiO}_{2}$ [Fournier and Rowe, 1966] and Na-K-Ca [Fournier and Truesdell, 1073] geothermometers have been the most widely used. The most important basic assumptions [Fournier et al., 1974] as distilled by Renner et al. [1975, p. 51] are:

(1) temperature-dependent reactions exist between constituents in the water and the rocks of a reservoir; (2) all constituents involved in the reactions are sufficiently abundant so that supply is not a limiting factor; (3) chemical equilibrium is attained at the reservoir temperature; (4) little or no equilibration or change in composition occurs at lower temperatures as the water flows from the reservoir to the surface; and (5) the water from the reservoir does not mix with any other water at intermediate levels. Assumptions 1, 2, and 3 commonly seem to be valid for the $\mathrm{SiO}_{2}$ and $\mathrm{Na}-\mathrm{K}-\mathrm{Ca}$ geothermometers. 
Nearly all reservoir rocks contain quartz, and residence times of a fow days or weeks are sufficient to saturate the water in $\mathrm{SiO}_{2}$ with respect to quartz at temperatures much above $150^{\circ} \mathrm{C}$. Also, most waters seem to attain equilibrium in $\mathrm{Na}, \mathrm{K}$ and $\mathrm{Ca}$ with respect to the common clay minerals and feldspars. However, some indicated temperatures of our tabulated data are not reliable, at least in part because waters high in free $\mathrm{CO}_{2}$ may not have attained equilibrium with the rocks or because they attained equilibrium with mineral assemblages other than those assumed for the geothermometers. In order to gain internal consistency, the $\mathrm{SiO}_{2}$ temperatures reported in the tables are based on equilibrium with quartz rather than chalcedony or amorphous forms of silica. However, some reported systems, especially those of low temperature, may have equilibrated with one of these more soluble forms of silica: The predicted temperatures of such systems will be too high. Assumption 4, that water flows to the surface without chemical change, is probably never strictly true, but useful minimum temperatures can be predicted. Assumption 5, that no mixing occurs with cool shallow waters, may frequently be invalid. Mixing, formerly considered to be a major obstacle in predicting subsurface temperatures, has recently been utilized to advantage by Fournier and Truesdell (1974). In favorable circumstances, temperatures higher than those indicated by the $\mathrm{SiO}_{2}$ or Na-K-Ca geothermometers can be predicted at deeper levels in a stacked series of reservoirs (Truesdell and Fournier, 1975). These mixing models are still so new that they have been applied only to a few systems. Other chemical and isotopic methods of temperature prediction are also being developed by Truesdell and others.

\subsubsection{Subsurface temperatures and heat flow}

2.1.2.5.a Measurement of temperatures in drill holes. The temperature of the liquid in the drill hole is commonly measured with a thermistor lowered into the hole on the end of an insulated three or four conductor cable [Swartz, 1954; Roy et al., 1968b; Sass et al., 1971a; Simmons, 1965]. A bridge or digital multimeter is used to measure the resistance of the thermistor, which in turn is converted into a temperature through the use of appropriate relationships [Robertson et al., 1966; Sass et al., 1971]. A relative precision of $0.001^{\circ} \mathrm{C}$ is easily attained. An absolute accuracy of about $0.02^{\circ} \mathrm{C}$ is achievable through calibration against quartz thermometers or platinum resistance thermometers and a triple point cell. The effect of pressure on thermistors is small [Travernier and Prache, 1952; Misener and Thompson, 1952; Diment and Robertson, 1963].

Platinum resistance thermometers have also been used as downhole sensors [Costain and Wright, 1973]. 
Conventional insulation fails at about $150^{\circ} \mathrm{C}$. Teflon insulated cables of various kinds and performance characteristics may be good to over $200^{\circ} \mathrm{C}$ and have been used successfully to $170^{\circ} \mathrm{C}$ at depths of 2 $\mathrm{km}$ [Urban et al., 1978]. At higher temperatures, self-contained sensing and recording devices that can be lowered into the hole on a wire line are required. White et al. [1975] used maximum thermometers in shallow holes at Yellowstone National Park. More commonly, standard oilindustry clock driven mechanical thermometers are used [Mathias, 1976]. Veneruso and Stoller [1978] addressed the problem of geophysical instrumentation in high-temperature and corrosive environments.

2.1.2.5.b Correction of temperature data. The temperature measured is that of the liquid in the hole. (If the hole is filled with gas, the time constant of the sensor is much greater, and special precautions are required in the acquisition and interpretation of the data.) This temperature may be quite different from the surrounding rock prior to drilling: (1) If the temperature gradient in the liquid exceeds a critical value, the liquid will convect [Hales, 1937; Krige, 1939; Misener and Beck, 1960]. The size of the "convection cells" is on the order of a hole diameter [Diment, 1967; Gretener, 1967; Sammel, 1968.] Thus, the amplitude of the temperature oscillation is proportional to the temperature gradient and hole diameter. Temperature variations as large as $0.2^{\circ} \mathrm{C}$ at a gradient of $300^{\circ} \mathrm{C} / \mathrm{km}$ in a $20-\mathrm{cm}$ diameter hole over a period of a few tens of minutes have been observed [Urban et al., 1978]. Although this is a small quantity, the phenomenon places a limit on the use of temperature logs to examine details of stratigraphy or the influx or egress of small quantities of liquid or gas. (2) The drilling process, principally the circulation of the drilling fluid, distorts the natural thermal regime [Bullard, 1947; Jaeger, 1965], but reasonable corrections for the effects often can be made provided that several sets of temperature observations are available and that the drilling history is known [Lachenbruch and Brewer, 1959]. Large losses of drilling fluid to "thief zones" can produce large thermal disturbances. (3) Commonly the waters in aquifers are not in hydrostatic equilibrium, and exchange of waters among them may occur either along the open hole or in the annulus between hole and casing. The thermal effect of flowing wells has been studied [Birch, 1947], and the size of the effect has been abundantly illustrated [e.g., Roy et al., 1072]. Serious studies of heat flow begin with measurements in holes in which a casing has been installed and grouted into place. Unfortunately, this is commonly not the case and many (perhaps the majority of) heat flow measurements are suspect.

Another class of disturbances results from the variations of the temperature on the surface of the ground. Although the effects on subsurface temperatures and temperature gradients are often small, they can be significant or even dominant. The effects of diurnal temperature variations extend to depths of only a few centimeters, those of prolonged cold snaps 
to depths of a few meters and those of annual temperature variation to 10 meters or so [Carslaw and Jaeger, 1959; Ingersoll et al., 1948]. Longer term variations extend to greater depth. Disturbances due to heated buildings or cultivation or clearing of the land [Diment and Weaver, 1964; Roy et al., 1972] may extend tens or a few hundred meters depending on the time of onset of the disturbance. Past transgressions or regressions of the sea or the presence of lakes may have a considerable effect on the subsurface temperatures, as, Lachenbruch [1957] and Lachenbruch et al. [1962] have shown in connection with the distribution of permafrost and heat flow in the Arctic. The effects of Pleistocene glaciations extend to depths of several kilometers [Birch, 1948] and may be significant in assessing the lateral variation of heat flow where the measurements are made in rocks whose conductivities are greatly different [Diment et al., 1972]. Uplift and erosion tend to increase thermal gradients below while subsidence and deposition tend to decrease them [e.g., Jaeger, 1965]. Birch [1950] gave a complete treatment of uplift and erosion and summarizes the long history of the subject. In rough terrain, the topographic effect may be significant. Normally, calculation of a steady state correction (i.e., the present topography has persisted indefinitely) is sufficient to show whether the effect must be considered further.

Perhaps the most pervasive and subtle disturbance of temperature is due to the flow of ground water through permeable and not so permeable rocks. This is because conductive heat flow is so small a quantity; thus, a small downward flow can wipe out the normal gradient and a small upward flow can greatly magnify it [Bredehoft and Papadopulos, 1965]. Lachenbruch and Sass [1977] discussed the problem in some detail and give some useful rules of thumb for estimating the size of the effect.

There are entire regions where rocks of high permeability extend to depths of kilometers and where it is practically impossible to get a meaningful measure of conductive heat flow. The lava plains of the Columbia plateaus and the Snake River Plain [Brott and Blackwell, 1978] and the volcanic terrain of the Cascade Range are examples.

On a more local scale, there are many examples of temperature disturbances due to flow of ground water. Anomalously low temperature gradients are often taken as indicative of areas of local hydrologic recharge [e.g., Lachenbruch et al., 1976b, p. 765], cultural influences such as leakage from unlined canals [e.g., Diment et al., 1977] or ground-water withdrawal from subsurface aquifers [Diment et al., 1965]. Although such effects can often be appreciated qualitatively, rarely is enough hydrologic information available to correct for them quantitatively.

2.1.2.5.b Thermal properties of rocks. In problems of steady-state conduction, the thermal conductivity $\left(K, \mathrm{cal} / \mathrm{cm} \mathrm{s} C^{\circ}\right)$ is the quantity of 
interest. In transient problems the thermal diffusivity $\left(\delta=K / \mathrm{C}_{\rho}, \mathrm{cm}^{2} / \mathrm{s}\right)$, the specific heat $\left(C, \mathrm{cal} / \mathrm{g} \mathrm{C}^{\circ}\right)$, and density $\left(\rho, \mathrm{g} / \mathrm{cm}^{s}\right)$ enter the equations of heat transport. Among rocks, the variation in $K$ (an order of magnitude) is much larger than the variation in $\sigma_{\rho}$, so it is appropriate to cast the discussion in terms of $K$. Tabulations of density or molar volume and specific heats may be found elsewhere [Robie et al., 1966, 1978; Robie, 1966].

The conductivities of the principal rock-forming minerals and rocks are rather well known [Birch and Clark, 1941; Birch, 1942; Clark, 1966; Diment, 1964; Horai and Simmons, 1969]. A representative set is given in table 2.1. In addition there are several factors to note: (1) The conductivities of air and water are much lower than those of any of the principal rock-forming minerals. For water-saturated rocks, a reasonable approximation for the relation between conductivity (K) and porosity $(\phi)$ is the

TABLE 2.1-Typical values of the thermal conductivity (mcal/cm $8^{\circ} \mathrm{C}$ ) of the principal rock-forming substances at $30^{\circ} \mathrm{C}$

Silice minerals

a-Quartz

Opal

Silica glass.

Framework silicates

Feldspars.

Sodalite.

Nepheline. . . . . .

Epidote.

Olivines

Fosterite. . . . . . . . .

Fayalite................

Monticellite.

Pyroxenes

Jadite. ..............

Other pyroxenes.......... 9-12

Amphiboles

Tremolite.............

Actinolite.................

Hornblende. .............

Sheet silicates

Micas...................

Pyrophyllite. . . . . . . . . .

Talc...............

Chlorite. . . . . . . . . .

Serpentine...............

Aluminum silicates

Kyanite
Andalusite

16

Sillimanite.............. 26

3.3

3. 3

Garnets

Almandine-pyrope........ g

Grossularite............. 13

Spessartite............. 8

Oxides

Magnetite. ............. 13

Hematite. ............. 25

IImenite. ............... 6

Sulfides

Pyrite.............. $60+$

Pyrrhotite.............. 10

Chlorides and fluorides

Halite................ 15

Sylvite.............. 15

Fluorite............. 22

Carbonates

Calcite. ............. 8

Dolomite. . . . . 13

Aragonite............. 5

6- Sulfates

12 Anhydrite................ 14

$12 \ldots$ Gypsum ................ 3.1

12 Water....................... 1.4

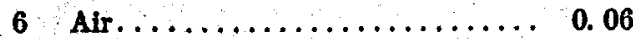

Data were compiled from various sources, principally Birch and Clark [1940]; Clark [1966]; Diment [1964 and unpublished data], and Horai and Simmons [1971]. Some minerals (e.g., micas) are highly anisotropic, and values selected usually represent those of randomly oriented aggregates. 
geometric mean conductivity [Woodside and Messmer, 1961; Horai and Simmons, 1969 ; Sass et al., 1971 a, b] :

$$
\hat{K}=K \boldsymbol{K} K_{\bullet}^{(1-\phi)}
$$

where the subscripts $l$ and 8 refer to the liquid and solid phases. (2) Many rock-forming minerals are anisotropic [Birch, 1942; Clark, 1966b] but the anisotropy has been measured only for large single crystals. The ratios of principal conductivities for quartz and mica are 1.7 and about 5, respectively. Many rocks are also anisotropic, and ratios between 1.2 and 1.5 are common [Diment and Werre, 1964, table 2]. (3) Thermal conductivity is a function of temperature (see Birch and Clark [1940]; Kittel, [1962]; Clark [1957] for development of ideas). At ordinary temperatures and up to roughly $1000^{\circ} \mathrm{C}$ heat is transferred through dielectric crystals largely by lattice vibrations (phonon conduction). In this temperature interval, conductivity of most crystals is proportional to the reciprocal of temperature.

Important exceptions are some of the feldspars and the glasses whose conductivity increases slightly as temperature increases. Above a certain temperature, heat transport by electromagnetic radiation may become the dominant mode of heat transfer [Clark, 1957; Schatz and Simmons, 1972; Mao and Bell, 1971, 1972; Shankland, Duba, and Woronow, 1974]. Transport by mobile charge carriers and excitons may also be significant [Clark, 1969].

2.1.2.5.d Radioactive heat generation. That heat generated by the decay of uranium, thorium, and potassium accounts for most of the heat generated in the earth and that these elements are strongly concentrated toward the surface have been known for some time [for reviews see Birch, 1951, 1954]. In recent years many more data have accumulated [Clark et al., 1966; Roy et al., 1968a; Lachenbruch and Sass, 1977; Swanberg, 1972; Swanberg et al., 1974;.D. L. Smith et al., 1978] and notions about the vertical variations have been refined [Lambert and Heier, 1967; Albarede, 1975 ; Lachenbruch, 1970, 1971].

A few generalizations on the heat production of rocks might be useful, although the reader is cautioned that the ranges for a given rock type are large and that considerable uncertainty exists in some of the typical values given. The unit is the heat generation unit $\left(1 \mathrm{hgu}=1 \times 10^{-18} \mathrm{cal} /\right.$ $\mathrm{cm}^{3} \mathrm{~s}$ ). The more felsic (silicic) igneous rocks are more radioactive than the mafic (basic) rocks. Ultramafic (ultrabasic) rocks are considerably less radioactive than either. Typical values might be: granite, $12 \mathrm{hgu}$; quartz monzonite, $5 \mathrm{hgu}$; basalt or gabbro, $2 \mathrm{hgu}$; ultramafic rock, $<0.5 \mathrm{hgu}$. Igneous rocks of alkaline affinities generally have higher radioactivities than their less alkaline equivalents. For example, average values for some 
felsic alkaline plutons in New England are as high as 22 hgu [Roy et al., 1968a]. Values for metamorphic rock vary widely. Typical granitic gneissess might range from 4 to $10 \mathrm{hgu}$. Anorthosites are impoverished in radioactivity and have $<1$ hgu [Roy et al., 1968a]. Sediments vary widely. Carbonate rocks have very low radioactives [Clark et al., 1966; Wollenberg and Smith, 1970]. Some thick bituminous shales have been regarded as marginal ore reserves for uranium.

\subsubsection{5.e Chemical heat generation. Many small heat sources and sinks} of short duration are significant in determining the fine structure of the thermal regime in certain localities; for example, the burning of underground coal seams, the subsurface injection of steam or fluids of anomalous temperature in connection with the secondary production of petroleum, and oxidation/reduction reactions in shallow ore bodies. Such disturbances are of no regional significance, and the volumes of rock affected are small.

On the other hand, broad classes of chemical reactions, and perhaps biochemical reactions, have not been adequately evaluated in terms of their influence on the thermal regime. Here, we mention only one.

Ellis [1967] notes that most hydration reactions of silicates are exothermic as is the devitrification of glasses. The heat of crystallization of silica glass to quartz is about $83 \mathrm{cal} / \mathrm{g}$ and that of albite glass to albite is about $43 \mathrm{cal} / \mathrm{g}$ [Cumberlidge and Saull, 1959; Kracek and Neuvonen, 1952]. The transformation of alkali feldspar to mica involves a heat output of $40 \mathrm{cal} / \mathrm{g}$ [Hemley, 1959]. For the pumice and ignimbrite typical of the Now Zealand Taupo volcanic zone, Ellis [1967, p. 500] reasoned that: (1) A reasonable heat of devitrification and hydration might be $75 \mathrm{cal} / \mathrm{g}$. (2) Assuming a specific heat of $0.2 \mathrm{cal} / \mathrm{g}$ and a water content of $0.1 \mathrm{~g} / \mathrm{cm}^{3}$, the adiabatic temperature rise would be $300^{\circ} \mathrm{C}$. (3) Each cubic kilometer of rock heated by this means would be capable of maintaining the production of a major geothermal system such as Wairakei (about $3 \times 10^{15} \mathrm{cal} / \mathrm{yr}$ ) for 100 years. (4) Inasmuch as hundreds of cubic kilometers of rock are involved, the mechanism could make a significant contribution to the lifetime of a geothermal area. (5) The mechanism would be particularly effective in the propagation of heat in the initial heating of a large aquifer volume.

Toulmin and Clark [1967] considered various processes that tend to heat or cool hydrothermal fiuids.

\subsubsection{5.f Extrapolation of temperatures to depth. The principles of ex-} trapolating near-surface temperatures to depth in a conductive regime are outlined in section 2.1.1.2, but a fow additional notes may bo useful : (1) Commonly, the thermal conductivity of porous near-surface rocks (as in an alluvial-filled valley or caldera) may be quite low ( $\leqslant 2 \mathrm{mcal} / \mathrm{cm} \mathrm{s}$ 
$\left.{ }^{\circ} \mathrm{C}\right)$, especially if they are only partially saturated or contain a high fraction of clay, zeolites, glass, or feldspar. The gradients would be correspondingly high as compared with those below in more indurated rock, perhaps by a factor of two or three. (2) Perturbations of the thermal gradient due to conditions near the surface, as previously discussed, are likely to be most severe near the surface. Rarely can these effects be estimated quantitatively, and it is necessary to drill to depths where they are small in order to obtain gradients suitable for extrapolation to depth. This depth of drilling may vary considerably from prospect to prospect and governs whether gradient or heat flow measurement is an economically viable part of an exploration program in a given area.

Gradients of much more than a $100^{\circ} \mathrm{C} / \mathrm{km}$ clearly cannot be extrapolated far without encountering some sort of anomalous condition. Indeed, it would appear that the larger the thermal gradient the shallower the depth to the anomalous condition. The boiling point curve [White, 1973, figure 3] cannot be exceeded by much, although White et al. [1973, 1975] noted that because of thermo-artesian pressure and self-sealing effects, near-surface pressure gradients may exceed hydrostatic pressure at Yellowstone Park, and temperatures may plot somewhat above the boiling point curve. The anomalous condition might also be an aquifer or fault conveying hot water or the top of a thick hydrothermal convection system.

\subsubsection{5.g Examples of temperature logs. Probably thousands of deep} temperature logs have been made in geothermal regions, many more if the geopressured regions are included. Few have been published and fewer still were taken under such conditions that the temperatures closely represent those of the rocks before drilling. A few logs are presented to illustrate specific points and to set the stage for illustrating different kinds of systems in later sections.

The Geysers. Figure 2.2 [after Urban et al., 1976] shows two temperature profiles. Both have been corrected for terrain effects. Both holes had attained thermal equilibrium. The shallower hole has a low gradient $\left(60^{\circ} \mathrm{C} / \mathrm{km}\right)$ and is far outside the boundaries of the known steam field. The deeper hole, which is in the steam field, has a much larger gradient $\left(150^{\circ} \mathrm{C} / \mathrm{km}\right)$, and it is notable that extrapolation of the temperature curve (the dashed line) is close to the temperature and depth of the first steam (the large dot). Logs in two other deep holes (not shown) into the steam zone (based on extrapolation to equilibrium temperatures) show the same notable linearity in the conductive region but a sharp decrease in gradient (to $\sim 20^{\circ} \mathrm{C} / \mathrm{km}$ ) at the top of the steam zone [Hite and Fehlberg, 1976]. Apparently gradient measurements in shallow $(\sim 100 \mathrm{~m})$ exploration holes as well as deeper production holes have been used widely in estimating depth to steam, although few data have been released. The 


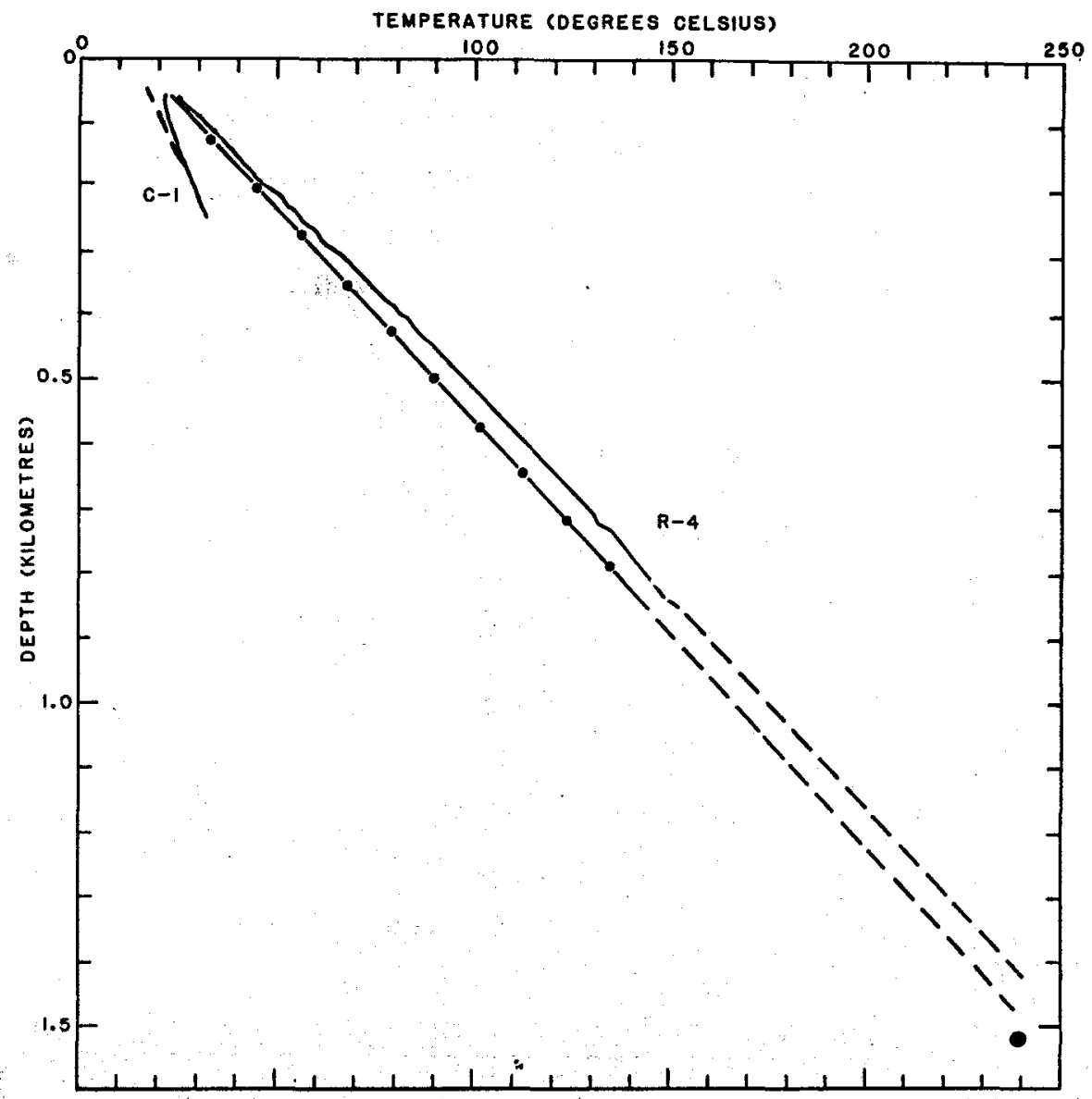

Frguke 2.2-Equilibrium temperature profiles near The Geysers [after Urban, et al., 1976, fgure 3]. $\mathrm{C}-1$ is at a locality well outside the known steam fleld. $\mathrm{R}-4$ is at a locality over the steam fleld. Solid lines are observed temperatures, dotdashed lines are those corrected for the effect of terrain; dashed lines are linear extrapolations. Large dot is depth and temperature of first steam as established from adjacent wells.

conductive cap over the steam zone is a notable feature and is discussed further in section 2.1.3.1.c.

Long Valley. The Long Valley caldera, California, at the eastern edge of the Sierra Nevada has been the subject of much geologic, geophysical, and hydrologic investigation (the proceedings of a symposium on these topics were published in the Journal of Geophysical Research, 1976, v. 85, pp. 721-860). Many shallow holes and one deep hole have been drilled. The deep hole (Republic Geothermal, Inc., No. 66-29 [Smith and Rex, 1977]) was drilled in the southeastern part of the caldera to a total depth of $2.1 \mathrm{~km}$, and several temperature logs (figure 2.3) were obtained in it up to several days after drilling when it was plugged at a depth of $290 \mathrm{~m}$. 


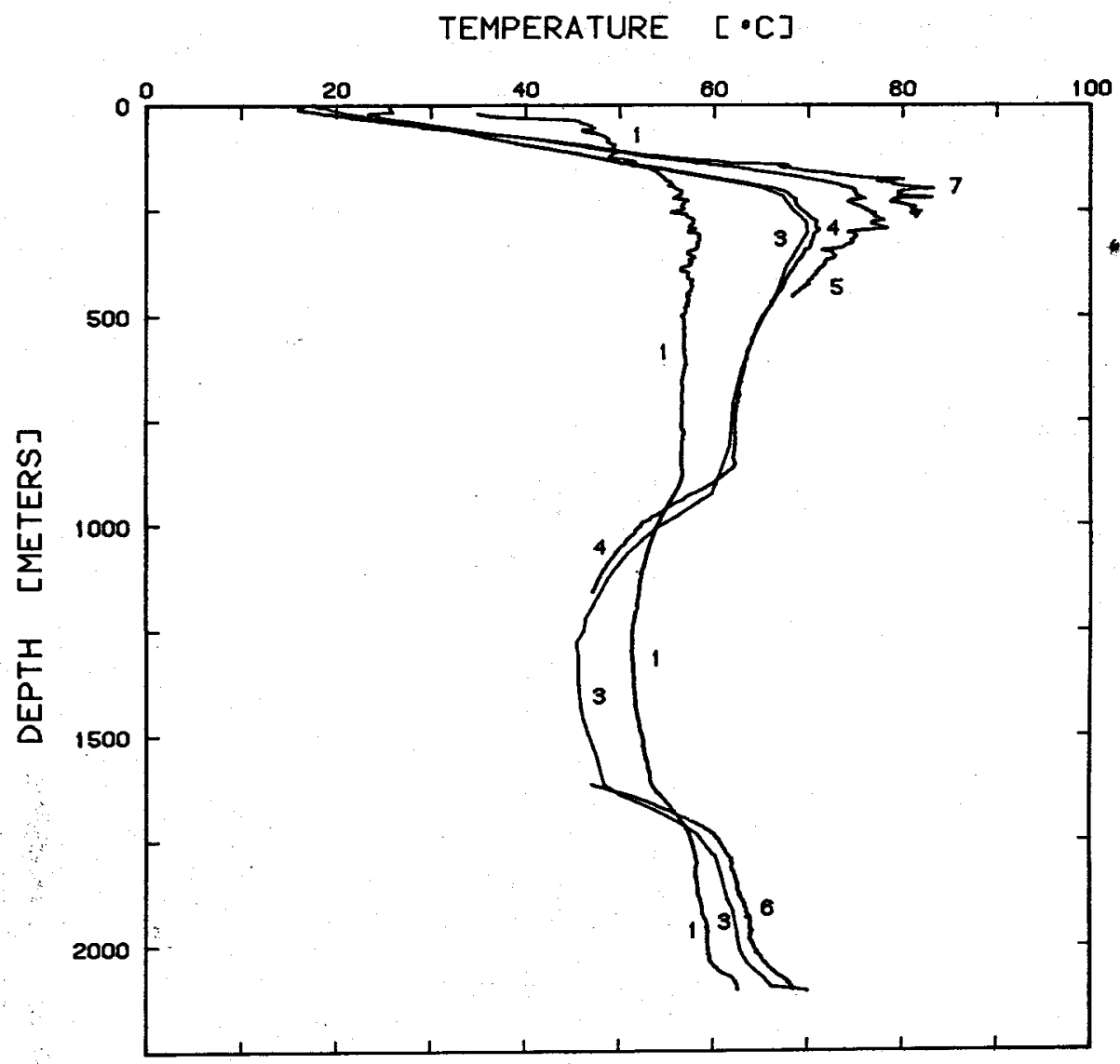

FTGURE 2.8-U.S. Geological Survey temperature logs In Republic Geothermal, Inc.,

Long Valley hole 66-29. Logs are numbered in sequence of time after drilling:

1) 6/10/76 (8.5 hrs after last circulation of drilling fluid) ; 2) 6/11/76 (42.5 hrs) by Schlumberger Well Service Corp. (not shown) ; 3) 6/13/76 (90 hrs) ; 4) 6/13/78 (95 hrs) upper $1200 \mathrm{~m}$ only; 5) 6/19/76 (144 hrs) upper $400 \mathrm{~m}$ only ; 6) 6/20/76 (168 hrs); hole washed to $1615 \mathrm{~m}$ with circulation time of 2 hours, temperatures shown for 1615-2100 m interval only; 7) 7/12/76 (528 hrs), not counting $2 \mathrm{hr}$ circulation on $6 / 20 / 76$, hole plugged at $267 \mathrm{~m}$. Log 3 by $\mathrm{S}$. W. Keys ; the remainder by T. C. Urban, W. H. Diment, and M. Nathenson.

Although penetrating the mud in the deep hole with light tools $(50-100 \mathrm{~kg})$ was difficult, once the mud began to congeal, sufficient data were obtained to illustrate the decay of the drilling disturbance with time and to obtain temperatures reasonably close to equilibrium. The upper levels of the hole are heating, the middle cooling, and bottom heating. The temperature curve in the upper levels $(\sim 300 \mathrm{~m})$ is not unlike some others in shallow holes in the caldera [Lachenbruch et al., 1976b; Smith and Rex, 1977] in that temperature gradients are very high near the surface and then drop sharply. It may be notable that the 
reduction in gradient occurs near the boiling point of water $\left(\sim 90^{\circ} \mathrm{C}\right)$ at these elevations $(\sim 2 \mathrm{~km})$. Evidently, the high near-surface temperatures result from the lateral spreading through porous rock of hot water from distant fractures. The unexpectedly low temperatures from middepth to the bottom of the hole have been attributed to invasion of cold meteoric water [Smith and Rex, 1977].

East Mesa. The East Mesa geothermal field in the Imperial Valley of southernmost California has been extensively studied and, because most of the work was done under the auspices of the U.S. Bureau of Reclamation, much information has been published. Five deep holes $(\sim 2 \mathrm{~km})$ have been drilled by the Bureau, and temperatures in them are reasonably well known [e.g., Mathias, 1976; Swanberg, 1976]. Moreover, about 100 shallow holes $(\sim 100 \mathrm{~m})$ have been drilled for temperature measurements [e.g., Combs, 1971; Swanberg, 1976].

The temperature and gradient plots in figure 2.4 [Urban et al., 1978] were obtained in hole USBR 31-1, which had not been disturbed for a year prior to logging. High gradients predominate in the conductive cap and are affected by hydrologic disturbances to at least $150 \mathrm{~m}$ and possibly to as great a depth as $400 \mathrm{~m}$ [Diment et al., 1977]. The base of the conductive cap $(\sim 840 \mathrm{~m})$ is marked by an abrupt decrease in gradient to $\sim 40^{\circ} \mathrm{C} / \mathrm{km}$. This low gradient persists throughout the remainder of the hole except near the perforated zones below $\sim 1650 \mathrm{~m}$. Gradients as low or lower are typical of the other four holes [e.g., Swanberg, 1976]. The lowgradient zone has often been taken as a zone of convection, although Urban et al. [1978] noted that the low gradients could be a consequence of conduc-

TEMPERATURE $[\cdot C]$ GRADIENT $[\cdot C / K M]$

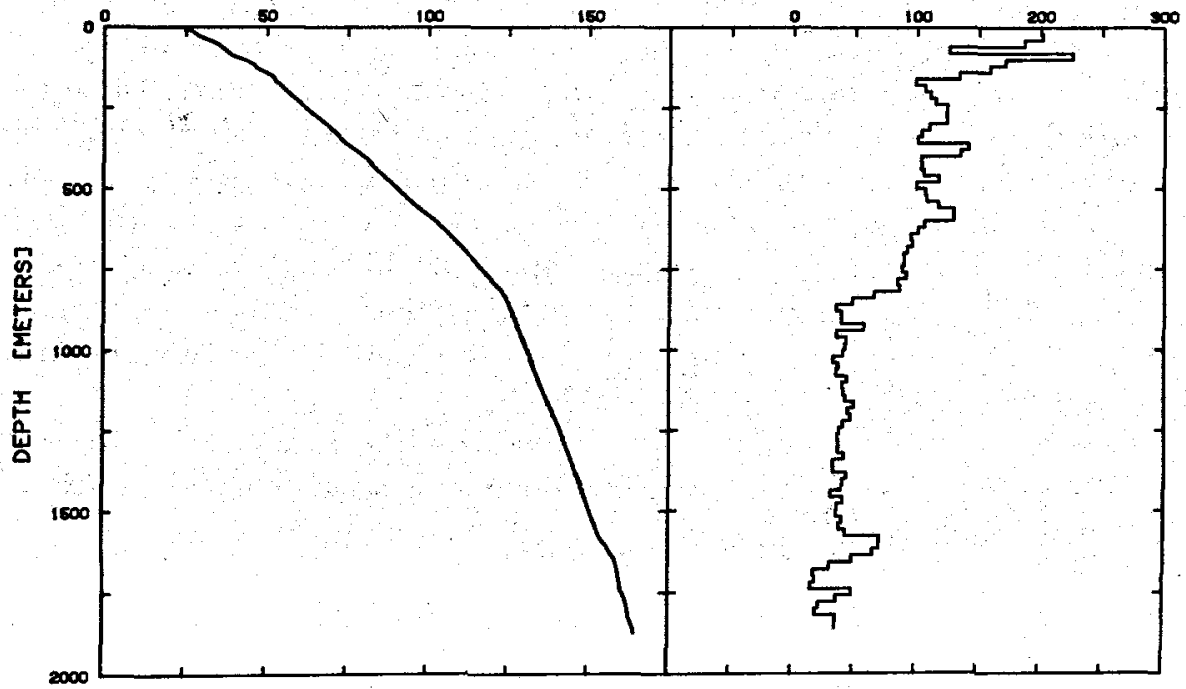

FTGURE 2.4-Equilibrium temperatures and temperature gradients in USBR hole 31-1, East Mesa, California. Reproduced from Urban et al. [1978]. 
tive heating from hot water flowing laterally beneath the cap from distant fractures.

2.1.2.6 Gravity methods. Lateral variations of the density of rocks in the subsurface can be detected by precise measurement of gravity. The technique is well described in most texts on geophysical prospecting [e.g., Nettleton, 1940, 1971; Grant and West, 1965; Dobrin, 1976]. Although measurements can be made from moving ships at sea and from aircraft, they are less precise (particularly the latter) than those that can be obtained with modern gravity meters on land. Such instruments have been used in the examination of regional and local geologic structure, and, because gravity varies with elevation, as an inexpensive way to monitor elevation change due to subsurface fluid withdrawal or active tectonism [Hunt, 1970a, 1970b, 1977; Isherwood, 1978; Lambert and Beaumont, 1977; Oliver et al., 1975; Rundle, 1978].

The property of interest is density, which is rather well known for most rocks and rock-forming minerals [e.g., Daly et al., 1966]. Precise determinations for pure phases can be obtained from Robie et al. $[1966 ; 1978]$ by dividing the formula weight by the molar volume as determined by $\mathbf{X}$-ray methods. The densities of a few common nonporous rocks are approximately : granites, 2.6-2.7; basalt, diabase, and gabbro, 2.9-3.0; dunite, 3.3; eclogite, 3.3-3.6; limestone, 2.7; dolomite, 2.8-2.9 ; quartzite, 2.6 ; rocksalt, $2.2 \mathrm{~g} / \mathrm{cm}^{3}$. The density of glasses prepared from rocks is 5 to 10 percent lower than their crystalline counterparts [Daly et al., 1966, table 4-3].

Inasmuch as the density of water is about one and that of air is negligible for present purposes, the porosity has considerable influence on the density of a rock. The density of a rock with air-filled pores is $\rho_{a}=\rho_{s}(1-\phi)$ and that for one with water-filled pores is $\rho_{w}=\rho_{s}(1-\phi)+\rho_{l} \phi$, where $\rho_{s}$ is the mean density of the solid fraction, $\rho$ is the density of water, and $\phi$ is the porosity expressed as a fraction. Many sediments, particularly those recently deposited and near the surface, have porosities exceeding $20 \%$ or even $50 \%$ and it is clear that the effect of porosity on density is significant. It is also evident that the difference in density between a rock with air-filled and water-filled pores is simply $\rho_{l} \phi$. Suppose the porosity of a steam reservoir is $10 \%$ and that the reservoir is $1 \mathrm{~km}$ thick; the gravity anomaly would be $4.2 \mathrm{mgal}$ (using the formula for the attraction of a laterally infinite slab), a quantity that is easily detectable.

The analysis of gravity data for exploration purposes in land areas is almost always done in terms of the Bouguer gravity anomaly $(B A$ in milligals; $1 \mathrm{mgal}=0.001 \mathrm{~cm} / \mathrm{sec}^{2}$ ),

$$
B A=g_{0}-\left[\delta_{o}-0.3086 h+2 \pi G_{\rho} h-T\right],
$$

where $g_{0}$ is the gravity observed at a particular point; $\delta_{o}$ is the theoretical gravity (that which one would expect) at sea level and at the latitude of 
the point; $0.3086 h$ is the variation of gravity with elevation in meters above sea level (the so-called free-air correction); $2 \pi G_{\rho} h$ is the Bouguer correction that is the attraction of a slab of density $\rho\left(\mathrm{g} / \mathrm{cm}^{2}\right)$ of infinite lateral extent and thickness $h$; $G$ is the universal gravitational constant; and $T$ is the terrain correction (usually small) which takes account of the departure of the actual terrain from that of the slab approximation. The attraction of the slab is $0.04185 \rho h \mathrm{mgal} / \mathrm{m}$ or $0.11174 \mathrm{mgal} / \mathrm{m}$ for a density of $2.67 \mathrm{gm} / \mathrm{cm}^{3}$ which, being close to the average density of crustal rock, is commonly used for computation. With this density, the combined freeair and Bouguer correction is $0.1969 \mathrm{mgal} / \mathrm{m}$ and the reduction expression becomes:

$$
B A=g_{0}-\left[\delta_{0}-0.1969 h-T\right] \text {. }
$$

With regards to utilization of the technique, there are several things to note: (1) $g_{0}$ can be measured in the field with a relative precision of about 0.01 mgal provided appropriate techniques and instruments are used. (2) $\delta_{0}$ varies nonlinearly with latitude and is about $0.800 \mathrm{mgal} / \mathrm{km}$ at latitude $40^{\circ}$ [Nettleton, 1940, p. 52]. Positioning adequate for most purposes can be obtained from modern topographic maps. (3) The sensitivity to elevation is evidently considerable, and results accurate to tenths of milligals require the measurement of elevation. If so, this is the principal cost of a gravity survey. (4) A density of $2.67 \mathrm{~g} / \mathrm{cm}^{3}$ is commonly used in the Bouguer reduction. This can lead to significant error in areas where the rocks are of low density (e.g., light porous volcanic rocks or alluvium) and where topographic relief is significant. For an example, if the reduction density is in error by $0.4 \mathrm{~g} / \mathrm{cm}^{8}$ and the topographic relief is $400 \mathrm{~m}$, the error is $6.7 \mathrm{mgal}$, a quantity that would be of significance in the analysis of most local geologic problems. (5) The terrain correction rarely exceeds a few tenths of a milligal in flat to hilly terrains, but in mountainous regions it can amount to several, or even several tens of milligals. The calculation of the terrain correction requires the average elevation of topography at various distances from the gravity observation; thus, reasonably accurate topographic maps (especially of areas near the station) are required. The averaging of elevations for the required "compartments" is a tedious process if the terrain has not been digitized previously, and can add significantly to the total cost of gravity surveys.

Clearly, gravity measurements are useful in estimating thickness and configuration of low-density sedimentary fill in fault-bounded valleys such as the Raft River Valley of Idaho [Mabey et al., 1978a] or in calderas filled with low-density volcanic rocks as in Long Valley, California [Kane et al., 1976]. A gravity low in the vicinity of The Geysers geothermal area suggests the presence of a felsic, perhaps partially molten, pluton beneath the area [Chapman, 1975; Isherwood, 1976]. 
On a much finer scale, gravity surveys may aid in the detection of small igenous plutons or thermally metamorphosed zones [Biehler, 1971; Combs and Muffer, 1973; Goldstein and Paulsson, 1977].

Interpretations of gravity data are not unique in the sense that many configurations of anomalous mass could produce the same gravity anomaly. The data do, however, constrain the range of possibilities. Further constraints, imposed by geologic mapping, drilling, and other geophysical techniques permit more information to be drawn from the gravity data. The technique, like magnetic surveys, is best used in reconnaissance, and later in more detail along with other techniques.

Woollard and Joesting [1964] produced a gravity map of the conterminous United States (scale 1: 2,500,000, contour interval $10 \mathrm{mgal}$ ). Eaton et al. [1978] presented a new map at the same scale for the region west of longitude $109^{\circ} \mathrm{W}$. A new national map and a map of North America are scheduled for 1981 [Lyons, 1978]. Maps for many areas and states are too numerous to list, but much of the information is available in digital format on magnetic tape from the Defense Mapping Agency of the U.S. Department of Defense.

\subsubsection{Magnetic methods. The main part of the Earth's magnetic field} owes its origin to convective motions in the Earth's core. Once this component is removed, we are left with anomalies due to variations in magnetization of rocks in the outer few tens of kilometers of the Earth, the exact depth depending on temperature. Above the Curie temperature, rocks cease to be strongly magnetic. The Curie temperature for magnetite $\left(\mathrm{Fe}_{3} \mathrm{O}_{4}\right)$, which is a principal mineral causing rocks to be magnetic, is $580^{\circ} \mathrm{C}$.

The intensity of magnetization of rocks is of particular interest. With the exception of the titanomagnetites and a few rare minerals, the principal rock-forming minerals are very weakly magnetic [e.g., Nagata, 1961; Grant and West, 1965; Lindsley et al., 1966]. Thus, it is the "magnetite" content of a rock that determines its magnetic properties. Plots of magnetic susceptibility versus magnetite content show a roughly linear relationship between the two, but with very large scatter about the mean. The satter reflects the details of the chemistry of the Fe-Ti-O system, the degree of exsolution of the various phases, and the size of the crystal (monodomain sized or more usually multidomain sized).

Another way of looking at the magnetic properties of rocks is to ask the question: Where is the iron? If it is in "magnetite" it will contribute to the magnetization of the rocks. If it is in chlorite, some hydrated iron oxide, or in pyrite $\left(\mathrm{FeS}_{2}\right)$, it will not. (Caution : Some forms of the $\mathrm{FeS}_{1+3}$ system are magnetic.) The question is of some interest in geothermal exploration because alkeration of magnetite to nonmagnetic minerals by hot solutions would cause a reduction in magnetic intensity that could bo detected by magnetic surveys. 
Additional complications arise from the fact that the intensity of magnetization is the sum of two vector quantities: the induced magnetization (usually the larger) and the remanent magnetization that was "frozen in" when the "magnetite" cooled through the Curie temperature. The induced component is, of course, parallel to the Earth's magnetic field whose inclination varies from 0 to $90^{\circ}$, from magnetic equator to pole, respectively. This variation must be taken into account in the interpretation of aeromagnetic surveys because the apparent correlation between anomalies and geology may be quite different at high latitudes than at low latitudes.

The "frozen in" (thermoremanent) component of magnetization is not always small in relation to the induced component. Indeed, its ratio with the induced component $Q$ sometimes exceeds one. Thus, the thermoremanent component of magnetization could be dominant. If the magnetic field of the Earth at the time the rock cooled through the Curie point was reversed (as it does from time to time), a magnetic low could be observed over a body of high "magnetite" concentration.

There is a tendency sometimes to view magnetic and gravity maps as yielding the same kinds of information in the sense that mafic igneous rocks are denser and often more magnetic than felsic rocks; that gravity and magnetic trends should be roughly colinear, etc. In detail, the rough analogy often breaks down completely for two reasons: (1) Density and magnetic polarization are two different properties. Moreover, the latter is likely to exhibit much wider variations that depend not only on the details of bulk chemistry but also on subtleties due to the distribution of iron and titanium among the mineral phases, grain size, and cooling history. Furthermore, the magnetization of a rock is a vector quantity whose direction depends on the intensity of magnetization induced by the present field but also on the component that has been frozen in. (2) The gravitational and magnetic fields due to a body of the same shape differ. According to Poisson's relation [0.g., Nettleton, 1940; Grant and West, 1965] the magnetic potential $(W)$ due to a given body of uniform density $(\rho)$ and uniform magnetization $(I)$ can be calculated from the gravitational potential $(U)$ :

$$
W=-\frac{I}{a_{p}}\left(\frac{\partial U}{\partial i}\right)
$$

where $G$ is the gravitational constant and $i$ is the direction of magnetization. Thus the magnetic force $(F)$ in any direction $(S)$ is

$$
F=-\frac{\partial W}{\partial S}=\frac{I}{G_{\rho}} \frac{\partial}{\partial S}\left(\frac{\partial U}{\partial i}\right)
$$

or in the special case (high latitudes) where both $S$ and $i$ are vertically downward $(Z)$

$$
F_{z}=\frac{I}{G_{\rho}} \frac{\partial^{2} U}{\partial Z^{2}}=\frac{I}{G_{\rho}}\left(\frac{\partial g_{Z}}{\partial Z}\right)
$$


The term $g_{z}$ represents the vertical component of the gravitational field. The point is that the magnetic anomaly is a derivative of the gravity anomaly and a rather complicated one where $i$ and $s$ are not coincident. Magnetic anomalies tend to mark the edges of anomalous bodies, especially if they are broad, whereas gravity anomalies tend to mark their centers.

In recent years pseudogravity maps have been calculated from magnetic data [Baranov, 1957; Grant and West, 1965; Smith et al., 1974]; these maps tend to bring the magnetic anomalies in closer spatial conformance with the bodies that cause them. However, to make these maps it should be recalled that it is necessary to assume that the direction of magnetization is closely coincident with the present magnetic field, and to assume a value for the proportionality constant in Poisson's relation.

Most magnetic surveys are conducted from aircraft, which permits rapid acquisition of highly precise data. Typically lines are spaced at intervals ranging from a few tenths to several kilometers depending on objective. Detailed surveys on the ground have played a role in some exploration programs. Techniques for the acquisition and interpretation of magnetic data are rather fully explored in the texts cited in the previous section.

Magnetic data are useful in several ways. In a regional context, maps of the depth to the Curie isothermal surface would clearly be of interest. Vacquier and Affleck [1941] found an average depth of about $20 \mathrm{~km}$ from a worldwide selection of anomalies. Blackwell [1971b] found an average depth of $22 \mathrm{~km}$ for the Basin and Range province. More precise measurements have been made in the vicinity of Yellowstone National Park [Bhattacharyya and Leu, 1975] where depths less than $10 \mathrm{~km}$ were found, and in central and northern Arizona [Byerly and Stolt, 1977] where depths between 4 and $30 \mathrm{~km}$ were reported. The technique holds promise but has not been fully exploited.

Satellite magnetometry is beginning to yield information on regional contrasts in magnetization. Mayhew [1979, p. 94] in analyzing data for the western states noted that apparent magnetization contrast may result mainly from undulations of the Curie isotherm; secondary effects may be caused by variations of magnetization among crustal blocks.

Inasmuch as most sedimentary rocks are essentially nonmagnetic (excepting volcanic rocks), aeromagnetic anomalies mainly reflect contrast in magnetization among the igneous and metamorphic rocks comprising the basement. The amplitude and sharpness of the anomalies depend strongly on the depth to basement, and, indeed, can be used to calculate the depth to it. Structural relief on the basement may produce observable magnetic anomalies, but these are usually much smaller than those produced by contrasts in magnetization within the basement.

Although magnetic coverage is currently available for 75 percent of the contiguous United States [Hinze, 1978], the data sets were acquired over a period of time, in different formats, at different elevations, and different 
line spacings. A regional compilation (scale 1:2,500,000, contour interval 100 gammas) covering most of the Basin and Range area and some adjacent region was recently published by Mabey et al. [1978]. A photomosaic map of the various surveys at a scale of $1: 2,500,000$ is in preparation [Hinze, 1978]. Many of the maps that now exist are publications of the U.S. Geological Survey or states.

2.1.2.8 Electrical methods. It may be appropriate to make a few general remarks at the outset about the applicability and promise of electrical methods in geothermal exploration, a problem that has been addressed by several [e.g., Keller, 1970; Ward et al., 1978j. The reason to do so is that the number of methods is so large and the manner of interpretation so varied that they cannot be individually assessed in an article of this brevity.

Electrical and electromagnetic methods have a long but checkered history in geophysical exploration. Successful application has been found in the search for ores and in the delineation of ground water supplies [see standard tests such as Heiland, 1946; Jakosky, 1950; Parasnis, 1962 ; Grant and West, 1965; Keller and Frischknecht, 1966; Telford et al., 1976]. These methods have been shunned largely, but not entirely, in the exploration for petroleum in this country, in part, because the targets are moderately deep where the resolution of seismic reflection methods is much greater, and in part because the electrical methods are best used in reconnaissance.

The great variety of techniques results from the fact that there are numerous ways that electromagnetic fields are induced in the Earth either naturally or artificially. The configuration of arrays, the part of the electromagnetic spectrum employed, the instrumentation, and the techniques of analysis are also many.

Results of electrical techniques are far more difficult to interpret than those of some other geophysical techniques. Tracing the source of error is far more difficult. Interpretations are truly three-dimensional spatial problems, which are difficult to reduce to easily visualized two- or one-dimensional configurations. Only recently with the availability of high-speed computers has it been possible to address many of the problems.

A part of the allure of electrical methods in geophysical prospecting is that the principal property measured (deduced) is the electrical resistivity (reciprocal or conductivity) of rocks, which is strongly dependent on temperature and degree of "thermal alteration" of rocks. The fact that resistivity is also strongly dependent on the salinity of the fluids in the pores of rocks adds a complication that negates the interpretation of resistivity anomalies in terms of temperature alone (see section 2.1.2.8.a).

Unlike many other geophysical techniques that have been honed to near perfection, electrical and electromagnetic methods are emerging, perhaps 
just beginning to emerge. Recent advances in instrumentation are significant.

2.1.2.8.a Properties measured. The behavior of electromagnetic waves in a medium is determined by three properties: electrical resistivity, dielectric constant, and magnetic permeability. In the present context, the resistivity (or its reciprocal, conductivity) is by far the most important. With the exception of the native metals and a few minerals that act as semiconductors, the resistivities of the principal rock-forming minerals are high [e.g., Keller, 1966; Keller and Frischknecht, 1966] at ordinary temperatures. At elevated temperatures, resistivities of the common rockforming minerals drop as atoms thermally excited from the crystal lattice contribute more to the transport of electricity. In the upper part of the crust, conduction is dominated not by the transport through the solid fraction but by electrolytic transport through solutions of electrolytes contained within the pores and microfractures within the rock.

Thus, the general distribution of resistivity in the crust is [e.g., Keller, 1971; Keller and Fergerson, 1977] : (1) a low resistivity upper crust due to the presence of conductive fluids within the rocks; (2) a high resistivity middle crust where microfractures are closed; (3) a low resistivity lower crust where high temperatures promote greater transport due to ion excitation.

Effect of composition (solid fraction). In the upper crust effects of composition are masked. In the lower crust where microcracks have been closed and temperatures are higher, compositional effects may be important. Keller [1971, p. 107] noted:

The electrical conductivity of a dry rock is appreciably affected by the chemical and mineralogical composition of the rock. At high temperatures, conductivity is contributed by ions thermally excited from the crystal lattice. Rocks that contain a large number of small ions, such as magnesium, iron, aluminum, hydrogen, and hydroxyl will be more conductive than rocks with a low content of such ions. As a result, light colored or felsic rock tend to be more highly resistive. Dark-colored or mafic rocks are more conductive by one or two orders of magnitude, and the most conductive rocks are those that are rich in hydrated minerals and that contain the hydrogen and hydroxyl ions in their crystal structure.

Effect of composition (fluid phase). Pure water is a poor conductor [Dorsey, 1968]. However, addition of electrolytes increases its conductivity markedly. At fairly low concentrations the increase in conductivity $(C$ in $\mathrm{mho} / \mathrm{m})$ with concentration of strong electrolytes $(S$ in $\mathrm{g} / \mathrm{l})$ is nearly linear; thus, if salinity increases an order of magnitude, resistivity decreases an order of magnitude. At $25^{\circ} \mathrm{C}$ the relation is approximately $S=(8 \pm 2) C$. Useful tables and graphs have been presented by Pirson 
[1963] and Keller and Frischknecht [1966]. The range of salinity of natural waters is large: rain, $10^{-2}$; freshwater lakes, $10^{-1}$; oceans, 35; brines, $10^{2} \mathrm{~g} / \mathrm{l}$.

Effect of composition (whole rock). In the upper crust the resistivity is largely determined by the arrangement of pores and cracks in a rock, and the nature of the fluids that fill them. An empirical relation [Archie, 1942] between rock resistivity $(\rho)$ and other parameters widely used [e.g., Grant and West, 1965; Keller and Frischknecht, 1966]. For fully saturated rocks,

$$
\rho=a_{\rho_{w} \phi^{-m}}
$$

where $\rho_{w}$ is the resistivity of the water contained in the rock, $\phi$ is the fractional pore volume, and $a$ and $m$ are arbitrary parameters whose values are chosen to fit a given set of measurements. The expression is used to define the formation factor $(F)$

$$
F=\frac{\rho}{p_{w 0}}=a \phi^{-m}
$$

Although there is significant variation in $a$ and $m$ [Keller, 1966, table $26-5], a$ is close to one and $m$ is close to two; thus, to a first approximation the formation factor is the inverse of the square of porosity. In determinations of rock resistivity, the estimation of $\rho_{w}$ presents the major uncertainty. Even if the resistivity of water extracted from the rock is known, the problem is not simple, for the resistivity of water in the rock is usually decreased by ionization of clay minerals and surface conductance along the surface of mineral grains. Keller and Frischknecht [1966] discussed the mechanisms in considerable detail and noted (p. 25) that in fine-grained rock, apparent resistivities are much lower than would be expected from the chemistry of water extracted from the rock. If the conductivity of the extracted water is high the added contributions may not be important. On the other hand, if the resistivity of the extracted water is high it may be impossible to predict the resistivity of the water in the pores unless the cation exchange capacity is known.

Incomplete saturation of pore space with electrolytes poses an additional problem which is sometimes addressed by multiplying Archie's relation by an additional factor $S^{-n}$ where $S$ is the fraction of the pore space filled with electrolyte and $n$ is an experimentally determined parameter. Keller and Frischknecht $[1966$, p. 28] recognized two cases. As long as a continuous film of electrolyte covers all surfaces of the rock, $n$ is about 2 . If the rock is desaturated to the point where the films are no longer continuous, the resistivity increases sharply to values of 4 or 5 . The conditions under which this critical saturation is achieved depends on the rock fabric, e.g., fine grained rocks retain more water by virtue of the greater influence of capillary forces. 
Effect of temperature (solid fraction). At elevated temperatures such as would be expected near the base of the crust or near intrusions, lower resistivities would be expected. Keller $(1971$, p. 107) noted:

The electrical conductivity of water-free crystalline rocks is profoundly affected by temperature. At temperatures of a few hundred degrees Kelvin, the conductivity of a dry rock is $10^{-8} \mathrm{mho} / \mathrm{m}$, with a range of \pm 2 orders of magnitude. Near the melting point, the conductivity is $10^{-3} \mathrm{mho} / \mathrm{m}$, with a range of \pm 2 orders of magnitude. At upper mantle temperatures, a change in temperature of 100 degrees may change the conductivity of a dry rock by an order of magnitude.

Effect of temperature (liquid fraction). The electrical conductivity $(C)$ of a solution of electrolytes is commonly expressed as:

$$
C=C_{25}(1+B(T-25))
$$

where $C_{25}$ is the conductivity of the solution at $25^{\circ} \mathrm{C}$ (any reference temperature could be used), $T$ is temperature, and $B$ is a parameter whose value is usually between 0.022 and 0.025 for salts and 0.016 to 0.019 for acids [e.g., Prutton and Maron, 1944]. Thus, conductivity increases by a little over $2 \%$ per degree. The increase in conductivity with temperature is roughly linear nearly to the critical point of water where it lessens and reverses sign at a temperature depending upon salinity and pressure [Quist and Marshall, 1968]. (See also Brace [1971] who reproduced their curves and gives many additional references.) Rocks should exhibit a similar decrease in resistivity with temperature, at least over a narrow range, at relatively low temperatures. There are, of course, many complexities [e.g., Brace and Orange, 1968; Brace, 1971].

Effect of pressure. Aside from the critical effect of pressure in reducing porosity of various types [Brace, 1971], pressure plays a small role in determining the resistivity of a rock. Below the critical point, the conductivities of electrolytic solutions are rather insensitive to variation in pressure [e.g., Quist and Marshall, 1968].

Anisotropy. Many rocks are electrically anisotropic both on a microscale, where prefered orientation of conduction paths imparts an anisotropy, and on a macroscale, where layered beds of different resistivity make the bulk medium anisotropic. The resistivity is generally highest in the direction perpendicular to bedding and lowest in the direction along it. The square root of the ratio of these two resistivities is taken as a measure of the anisotropy. Commonly, the anisotropy is less than two but it may reach four or more [Keller, 1966; Keller and Frischknecht, 1966]. Risk [1976] gave a good example of how resistivity anisotropy measurements can be used in the detection of buried zones of fissured rock.

2.1.2.8.b Galvanic resistivity methods. Most galvanic resistivity methods involve a current introduced directly into the ground through metal 
electrodes driven into the ground at points $A$ and $B$, and the measurement of a potential between electrodes emplaced at points $C$ and $D$. The frequency of the current is kept low so that displacement currents are insignificant, but pure direct current is rarely used so as to avoid electrolytic polarization at the electrodes. Commonly a square wave is used.

The number of techniques in this class reflects the number of arrangements of the current and potential electrodes that have been found useful for various purposes. Certain configurations are useful for the determination of the variation of resistivity with depth while others are useful for rapid reconnaissance of near-surface lateral variations in resistivity. The economy of the variants depends on how much insulated wire has to be laid out and how often it must be rearranged to achieve a given objective.

Keller and Frischknecht [1966, p. 90] grouped the arrangements as follows: (1) those in which $C$ and $D$ are widely spaced so as to give a measure of potential difference; (2) those in which $C$ and $D$ are closely spaced so as to yield a measure of the potential gradient; (3) those in which the distances between $A$ and $B$ and between $C$ and $D$ are both short so as to yield a measure of the curvature of the potential function.

The quantity derived from any of these measurements is an apparent resistivity $\left(\rho_{a}\right)$ that can be expressed simply as:

$$
\rho_{a}=K \frac{\Delta U}{I}
$$

where $\Delta U$ is the potential measured between $\mathrm{C}$ and $\mathrm{D}, I$ is the current driven into the ground, and $K$ is a geometrical factor that depends on the arrangement of the electrodes.

Schlumberger array. A commonly used array in geothermal exploration is the Schlumberger array:

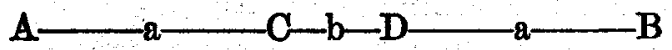

where the capital letters refer to electrodes as before and the small letters indicate distances. The distance $b$ is small so that potential difference measured approximates the potential gradient. The geometrical factor for this array is [Keller and Frischknecht, 1966, p. 95] :

$$
K=x\left(\frac{a^{2}}{b}-\frac{b}{4}\right)
$$

It should be noted that according to the theorem of reciprocity the current and potential electrodes can be interchanged without change in the measured voltage; thus, where it is advantageous to keep the separation of the current electrodes short, $\mathrm{C}$ and $\mathrm{D}$ can be used as current electrodes [e.g., Keller and Frischknecht, 1966, p. 100]. 
The apparent resistivity as a function of electrode separation can be calculated for a sequence of horizontal layers of different resistivities. Interpretation consists of curve matching and/or inversion by computer techniques.

Stanley et al. [1976] used Schlumberger soundings along with other electrical methods to examine the distribution of resistivity with depth in the Long Valley caldera. Their experiment involved maximum electrode spacings $(2 a+b)$ ranging from 1.22 to $3.66 \mathrm{~km}$ at 49 locations. Field data were corrected for potential electrode spacing changes [Kunetz, 1966] and were smoothed to remove small cusps introduced by near-surface lateral inhomogeneities [Zohdy, 1975]. The curves of apparent resistivity versus electrode spacing where then digitized and processed by an automatic inversion program [Zohdy, 1974c, 1975]. According to Stanley et al. $[1976$, p. 812$]$ :

The automatic program typically provides an interpretative solution of the field data consisting of seven to ten lnyers. Dar Zarrouk curves [Zohdy, 1974a] when then used to produce geoelectrically equivalent solutions that contained fewer layers and were correlated with nearby soundings. The final layering interpretations were checked by generating theoretical sounding curves [Zohdy, 1974b] for comparison with the field data.

The geological interpretation is discussed in section 2.1.3.1.c.

Schlumberger soundings have been used to delineate the shallow resistivity structure in many areas: e.g., Yellowstone National Park, Wyoming [Zohdy et al., 1973]; Raft River, Idaho [Williams et al., 1976; Mabey et al., 1978a]; Broadlands, New Zealand [Risk et al., 1970]; Kawerau, New Zealand [Macdonald and Muffler, 1972].

Bipole-dipole methods. This technique has been used recently as a rapid reconnaissance method to outline gross resistivity features of geothermal areas. It is sometimes called the total-field resistivity method [Zohdy, 1973]. A current bipole of a kilometer or more in length is used. The "dipole" where the potential difference is measured actually consists of three electrodes so as to record the components of the potential gradient.

In the Long Valley caldera, California, Stanley et al. [1976] used four different current bipoles of lengths ranging between about 2.2 and $3 \mathrm{~km}$ and mapped the potential field about each. The results, expressed in terms of apparent resistivity, show considerable similarities in the areas where coverage overlaps, but also notable differences especially where the current bipoles were in widely different parts of the caldera. In general, the results outline areas of anomalous resistivity, but no attempt was made to interpret the results in terms of the resistivity structure with depth because lateral variations of resistivity in this complex environment are very large especially when viewed in connection with the dimensions of the arrays. 
The regions of anomalous resistivity, thus revealed, were investigated by techniques more appropriate to the determination of resistivity with depth. A similar sequence of experiments was conducted in the Raft River Valley, Idaho, but in less detail [Williams et al., 1976].

2.1.2.8.c Magnetotelluric methods. Variations of the Earth's magnetic field with time induce currents within the Earth. The periods of the fluctuations range from milliseconds to many years. The longer period variations owe their origin to interaction of solar radiation with the magnetosphere and ionosphere whereas those with periods shorter than one second are almost entirely due to distant lightning strokes or cultural activity [e.g., Keller and Frischknecht, 1966]. In practice the periods of interest for resistivity determination range from milliseconds to a day.

Although something can be learned about the distribution of resistivity in the Earth by analysis of either the electrical or magnetic variations, in recent years it has become common to record the two simultaneously which has the advantage of providing a more definitive determination of the spatial distribution of resistivity.

The basic theory of the magnetotelluric method is due to Cagniard [1953]. It has been applied, using various parts of the spectrum, to: (1) the elucidation of the deep electrical structure of the crust and upper mantle [e.g., Bostick and Smith, 1962; Plouff, 1966; Vozoff and Ellis, 1966; Madden and Swift, 1969; Chaipayungpun and Landisman, 1977]; (2) the study of sedimentary basins [e.g., Vozoff and Swift, 1968; Vozoff, 1972]; and (3) the exploration for mineral deposits [e.g., Strangway et al., 1973] and the delineation of shallow geothermal systems [e.g., Hoover and Long, 1976; Hoover et al., 1978]. In the last case, waves in the audio part of the spectrum (about 10 to $20,000 \mathrm{~Hz}$ ) are commonly used; thus, the name audiomagnetotelluric method.

Regardless of the part of the spectrum used, or of the purpose, two simple relationships are useful in illustrating some aspects and limitations of the method. When a plane wave of frequency $f$, in $\mathrm{Hz}$, is incident upon a horizontally stratified earth, simultaneous measurement of the gradient of the electric field $E_{x}$, in $\mathrm{mv} / \mathrm{km}$, and as measured by electrodes spaced ten or inore meters apart, in a horizontal direction $x$ and measurement of the horizontal component of the magnetic field $H_{y}$, in gammas, in an orthogonal direction $y$ yield an expression for the apparent resistivity ( $\rho_{a}$ in ohm-m) of the medium

$$
\rho_{a}=\frac{1}{5 f}\left(\frac{E_{x}}{H_{y}}\right)^{2}
$$

If the earth were uniform and isotropic the apparent resistivity $\left(\rho_{a}\right)$ would equal the true resistivity $(\rho)$ and would not vary with frequency. However, in a layered earth where $\rho$ varies with depth, $\rho_{a}$ is a function of 
frequency and is related to variation of true resistivity in a complex way that depends on the spatial distribution of resistivity.

The second relation is that between "skin depth" $(\delta$, in $\mathrm{m}$, resistivity $\rho$, in ohm-m, and frequency $f$, in $\mathbf{H z}$.

$$
\delta=503\left(\frac{\rho}{f}\right)^{1 / 2} .
$$

The skin depth is the depth in a uniform medium at which the current density drops to $1 / e$ (or 0.368 ) of that at the surface and is a rough measure of the depth to which resistivity contrast can be sensed. Hoover et al. [1978] suggested that 0.75 would be a better measure of this.

In a study of some 30 localities in the Basin and Range province, Hoover et al. [1978, p. 1510] found a histogram of apparent resistivities to peak in the internal 10-26 ohm-m at the lowest frequency used $(7.5 \mathrm{~Hz})$. This resistivity range corresponds to a range in skin depths of 581 to $937 \mathrm{~m}$ at this frequency. Evidently, the region explored is not very deep.

The apparent resistivity as a function of frequency can be calculated for any combination of horizontal layers; interpretation of observations is accomplished by curve matching [e.g., Yungul, 1961] or by computer techniques.

Once significant lateral variations in resistivity are admitted, the density and kind of data required and the sophistication of interpretation increase considerably. The induced fields depend on the attitude of geologic formations. In order to sort out the complexities it may be necessary to record five components $\left(H_{x}, H_{y}, H_{z}, E_{x}\right.$, and $\left.E_{v}\right)$ rather than the two [e.g., Vozoff, 1972]. The method, like many electrical methods, is quite sensitive to lateral variations in resistivity and caution must be exercised not to confuse them with variations of resistivity with depth.

Complexities of interpretation of magnetotelluric data in the complex three-dimensional environment near Roosevelt Hot Springs, Utah, illustrate the kind and magnitudes of the uncertainties involved. Ward et al. [1978] stated:

The apparent resistivities from 85 magnetotelluric and audiomagnetotelluric (MT/AMT) soundings have been inverted to $1-\mathrm{D}$ model earths at each sounding site. We believe that the resulting models are totally unrealistic representations of a subsurface distribution of true resistivities [Wannamaker et al., 1978]. The interpreted resistivities of less than $0.1 \Omega-\mathrm{m}$ at depths of 2 to $5 \mathrm{~km}$ are virtually impossible to obtain unless graphitic horizons or massive sulfides are present, given that our earlier discussion indicated that clay alteration should be absent at these depths. Insofar as our current geologic evidence precludes graphite or sulfides, we are inclined to believe that the resistivities in the 2 to $5 \mathrm{~km}$ range interpreted from the MT/AMT data are 
artifacts of the interpretation technique and could readily arise in conductive materials in the top $0.5 \mathrm{~km}$. That the conventional means of identifying TE and TM modes is inapplicable in this 3-D resistivity environment also arises as a problem with the MT/AMT method. Three-dimensional earth modeling, now in progress, may resolve these problems. If not, then the MT/AMT method may decline in application in geothermal exploration.

2.1.2.8.d Tellurio methods. The technique is a special case of the magnetotelluric method in which only components of the electric field are measured. It is noted separately because: (1) historically its development preceded that of the magnetotelluric method which requires special magnetometers that only recently became available; (2) there is an extensive history of the utilization of the technique in exploration; and (3) it is only possible to study ratios of resistivities by simultaneously recording the electric field components at several locations.

The technique and its history are well described by Keller and Frischknecht [1966].

2.1.2.8. Induction (electromagnetic) methods. We deal here with controlled time-varying magnetic fields usually in the frequency range 100 to $5000 \mathrm{~Hz}$; these frequencies are generally higher than those of the natural field used in the magnetotelluric methods and lower than those used in radio-wave studies. The magnetic field is generated by oscillating currents either in a loop above the ground or in a long wire grounded at both ends. The oscillating magnetic field induces eddy currents in a conducting earth which, in turn, produce their own magnetic fields. The resultant field is usually detected with a second loop. By analysis of the resultant field with respect to the forcing field, variation in the resistivity of the earth can be determined. As in the case of the galvanic resistivity methods, there are many arrangements of source and receiver depending on objective.

The theory and/or application of the techniques are well described by Keller and Frischknecht [1966]; Ward [1967 a, b], Ward et al. [1974]; and Telford et al. [1976].

Tripp et al. [1978] used a two-loop system utilizing 14 frequencies between 10.5 Hz and $86 \mathrm{kHz}$ at Roosevelt Hot Springs, Utah. A transmitting coil $10 \mathrm{~m}$ in diameter was vertically suspended from an aluminum mast. The receiving coils consisted of two orthogonally aligned, tunable, ferrite-cored coils. The results were used to investigate the resistivity structure to depths of $100 \mathrm{~m}$. They found that joint inversion of the electromagnetic and Schlumberger sounding data resulted in statistically better conductivity models than those obtained from the Schlumberger data alone. 
A quite different technique was employed by Stanley et al. [1976] in a reconnaissance mode in Long Valley, California. Here the transmitting antenna was the current bipole used in the bipole-dipole experiments described in section 2.1.2.8.b; but the technique otherwise differs. In the time-domain eleetromagnetic sounding method (TMS) [Vanyan, 1966], the transient magnetic field generated by the square wave input to the bipole gives rise to distant variations in the magnetic field which when recorded as a function of time yield information on the variation of resistivity with depth provided that horizontal layers can be assumed. This was done, and by comparison of the observed results with those generated by computer [Anderson, 1973] the distribution of resistivity with depth was inferred to a depth of about a kilometer.

2.1.2.8.f Self-potential methods. When two suitable nonpolarizing electrodes are emplaced in the ground some tens of meters apart, a steady electrical potential may be observed between them. With appropriate care, particularly with regard to the placement of electrodes and due consideration of nonsteady sources, fairly reproducible results can be obtained. By moving one electrode about a fixed one or by leapfrogging the electrodes, a sizable area can be surveyed quickly.

Large self-potential (SP) anomalies of intriguing patterns have been found in many geothermal areas. Corwin and Hoover [1979] reviewed much of the recent information and gave an account of the various mechanisms, natural as well as cultural, that could give rise to SP anomalies [see also Telford et al., 1976].

A principal problem is the abundance of mechanisms. To separate those anomalies of geothermal interest from others is a formidable task especially because the mechanisms themselves are not fully understood. Corwin and Hoover [1979, p. 235] noted:

Reproducible data of course, are not necessarily meaningful in terms of geothermal activity. The possibility that the measurements have been affected by nonthermal subsurface water flow, conductive mineral deposits, stray currents (and other cultural effects such as plowed fields, cultivation, irrigation, or agricultural chemicals), or soil moisture and chemistry variations must be carefully considered. These effects may be minimized by judicious selection of survey lines and electrode sites, and careful observation and recording of soil type and condition, local geology, vegetation, topography, and cultural manifestations.

In summary, it would seem that SP surveys may be worthwhile especially in environments where experience has shown that they yield information of interest [e.g., Zablocki, 1976]. SP surveys are inexpensive, particularly when conducted along with other geophysical surveys, and may yield anomalies that require further examination. 
2.1.2.8.g Induced polarization methods. Induced polarization (IP) overvoltage methods have widely applied in the search for shallow metallic deposits [e.g., Wait, 1959; Keller and Frisehknecht, 1966; Madden and Cantwell, 1967].

The basis of the method is that when a current is applied to a porous rock containing disseminated electronic conductors, such as metallic sulfides or graphite, the current is "blocked" by creation of an electrochemical barrier resulting from the surface polarization of metallic minerals. This barrier must be overcome before current can flow through the interfaces between the metallic minerals and the solution in the pore spaces. According to Madden and Cantwell [1967, p. 374]:

The forces which oppose the flow are said to polarize the interface; and the added voltage necessary to drive the current across this barrier is sometimes known as the overvoltage. When the inducing current is turned off, the over voltages that were set up decay in time. Observations of these decaying voltages represent one method of detecting the polarization effects within the rock, and the term overvoltage method is used by some groups to describe such techniques. Since it also takes a finite time to build up these overvoltages, one finds that the impedance of these zones decreases with increasing frequency, so that measurements may also be made in the frequency domain.

The techniques for measuring the induced polarization response in the field are similar to those employed in the galvanic resistivity methods [e.g., Keller and Frischknecht, 1966, p. 473] and, as with the latter, there are many.

In a reconnaissance of a part of Yellowstone caldera, Zohdy et al. [1978], using measurements in the frequency domain with maximum electrode spacing of about $600 \mathrm{~m}$, detected IP anomalies attributable to disseminated pyrite deposited by sulfur-rich thermal waters at locations where these waters mix with shallow ground water.

\subsubsection{Seismie methods}

2.1.2.9 Propertie mesured. The velocity and attenuation of elastic waves are the properties of interest. Two groups of waves exist: the body waves, which propagate through a substance, and the surface waves, which involve a surface in their mode of propagation. Although surface waves have been of considerable use in elucidating large-scale, structures of the earth, they have found little use in local explorations and will not be considered further here.

The body waves are of two kinds: dilatational and shear. Dilatational waves (alse called compressional waves, $P$-waves or primary waves) involve particle motion in the direetion of propagation. Shear waves (also called S-waves, transverse, or secondary waves) involve particle motion 
transverse to the direction of propagation. Their velocities $\left(\nabla_{p}, \nabla_{s}\right.$ respectively) are:

$$
V_{p}=\sqrt{\frac{k+\frac{4 \mu}{3}}{\rho}}=\sqrt{\frac{E}{\rho}\left(1+\frac{2 \sigma^{2}}{1-\sigma-2 \sigma^{2}}\right)}
$$

and

$$
V,=\sqrt{\frac{\mu}{\rho}}=\sqrt{\frac{E}{\rho 2(1+\sigma)}},
$$

where $k$ is the bulk modulus (the reciprocal of the compressibility), $\mu$ is the rigidity modulus, $\rho$ is the density, $E$ is Young's modulus, and $\sigma$ is Poisson's ratio. Derivations of these expressions can be found in most modern seismology or exploration texts [e.g., Dobrin, 1976 ; Grant and West, 1965; Dix, 1852].

The ratio of the velocities is:

$$
\frac{V_{p}}{V}=\sqrt{\frac{k}{\mu}+\frac{4}{3}}=\sqrt{\frac{1-\sigma}{1+\sigma}}
$$

and it is evident that $\nabla_{p}$ must always exceed $V_{\text {a }}$ because in the first expression both $k$ and $\mu$ are always positive and in the second $\sigma$ cannot exceed $1 / 2$ in an ideal solid. For most consolidated rock materials $V_{p} / V$, is between 1.5 and 2.0 [Dobrin, 1976, p. 37]. It is also notable that the modulus of rigidity ( $\mu$, which is the ratio of shear stress to shear strain, vanishes for a fluid. Consequently, S-waves do not propagate through fluids, and velocity reduction and attenuation can be expected in partially molten material.

So far we have thought in terms of wave propagation in a uniform isotropic medium. Rocks and their consitutents are usually neither uniform nor isotropic. Moreover, their properties vary with temperature, porosity, total pressure, and fluid pressure. The subject is quite complex and is far too broad to be covered in detail here. Observations are limited to a few generalizations that may be useful in geothermal prospecting.

Effect of pressure. Velocities increase rapidly with pressure up to a kilobar or so whereupon they take on intrinsic values and rise more slowly with further increase in pressure. For low-porosity igneous and metamorphic rocks, the increase in velocity from a few bars to a kilobar is due to the closing of intercrystalline microcracks. The size of the effect is not entirely predictable, although it typically amounts to about ten percent. For this reason it is quite difficult to make sense out of the correlation of rock type and velocity unless this effect has been eliminated. Although the pressure effect is most easily studied on small samples in the laboratory, the laboratory results are consistent with seismic-refraction studies in the field. Birch [1960, 1961] has reviewed the foregoing subjects in considerable detail. Recently, the influence of microcracks on other properties and the relation of these properties with seismic velocities has received 
much attention: compressibility [Birch and Bancroft, 1938; Brace, 1965; Simmons et al., 1974], the velocity of both compressional and shear waves [Hughes and Cross, 1951: Simmons, 1964a, b; Nur and Simmons, 1969a, b; Feues et al., 1977], electrical resistivity [Brace and Orange, 1968], and thermal conductivity [Walsh and Decker, 1966]. The microcracks have been characterized microscopically [Simmons and Richter, 1976; and Richter and Simmons, 1977]. Theoretical aspects of the relation of cracks to various properties have been discussed by several [Walsh, 1965, 1973; Walsh and Brace, 1966; Walsh and Decker, 1966; Budiansky and O'Connell, 1976; O'Connell and Budiansky, 1974; Warren and Nashner, 1976].

Anisotropy. The intrinsic anisotropy (i.e., that due to the orientation and arrangement of anisotropic minerals) for most igneous and metamorphic rocks is not large [Birch, 1961]. Notable exceptions are the dunites and pyroxinites whose anisotropies may reach $10 \%$ and $5 \%$, respectively, even at a pressure of 10 kilobars [Birch, 1961, p. 2203]. Similarly N. I. Christensen [1966, 1971], Peselnick et al. [1974, 1977], and Peselnick and Nicolas [1978] found a high degree of anisotropy in samples of dunite and peridotite. The anisotropy is notable not only on a sample scale but also for much larger volumes of rock where mineral orientations are governed by flow processes in the mantle or attending the intrusion of ultramafic rocks. The azimuthal dependence of $P$-wave velocities traversing the upper mantle has been explained in this way [Hess, 1964; Raitt et al., 1969; Morris et al., 1969; Keen and Barrett, 1971; Cann 1968; Francis, 1969; Avé Lallemant and Carter, 1970; Carter et al., 1972]. Although this effect is not particularly important in the context of geothermal exploration, it may have to be considered in connection with the delineation of hot spots by analysis of teleseismic $P$-wave delays, especially where the delays are so large as to require anomalous material extending to deep within the mantle [Tyer, 1974].

Anisotropy caused by regionally oriented cracks in the upper crust have been tentatively invoked to explain part of the teleseismic P-wave delays at The Geysers [Iyer et al., 1978] but this has not been established independently by other means.

Effect of composition. It has been known for some time that nonporous rocks composed of the denser mineral assemblages (the mafic and ultramafic rock as compared with the felsic rocks) exhibit higher velocities. Several empirical curves have been presented relating velocity and density [Nafe and Drake according to Press, 1966; Woollard, 1959]; but the scatter about the mean is large. Birch [1961] found that the scatter could be reduced considerably by regarding the velocity as function of not only density but also of mean atomic weight ( $m$, formula weight divided by number of particles). In other words, for rocks of mean atomic weight 20 , velocity is linearly related to density and for those of mean atomic weight 22 , velocity is similarly related to density, and so on. The slopes of the lines are about the same $\left(3 \mathrm{~km} / \mathrm{s}\right.$ per $\left.\mathrm{g} / \mathrm{cm}^{3}\right)$ but the intercept on the $\rho$-axis in- 
creases with mean atomic weight. For most igneous and metamorphic rocks, $\mathrm{m}$ falls between 20 and 22 . Departures on the high side represent iron-rich rocks.

Typical values for the velocities of some rocks and other substance of interest are give in table 2.2. These values give only an approximate notion of those that might be encountered in a given application.

TABLE 2.2-Typical values of the velocities of compressional waves through some rocks and other materials of interest

\begin{tabular}{|c|c|c|c|c|}
\hline Material & $(\mathrm{km} / \mathrm{sec})$ & $\begin{array}{l}\text { Density } \\
\left(\mathrm{g} / \mathrm{cm}^{2}\right)\end{array}$ & $\begin{array}{r}\text { Pressure } \\
\text { (bars) }\end{array}$ & References and notes \\
\hline \multicolumn{5}{|c|}{ Igneous and metamorphic rocks } \\
\hline Granite............ & $\begin{array}{l}5.1 \\
6.06\end{array}$ & 2.655 & $\begin{array}{r}10 \\
1000\end{array}$ & Barre, Vt. (1) \\
\hline Granodiorite........ & $\begin{array}{l}\text { 4. } 4 \\
6.27\end{array}$ & 2. 705 & $\begin{array}{r}10 \\
1000\end{array}$ & Butte, Mont. (1) \\
\hline Gabbro........... & $\begin{array}{l}5.8 \\
6.93\end{array}$ & 3. 054 & $\begin{array}{r}10 \\
1000\end{array}$ & French Creek, Pa. (1) \\
\hline Dunite....... & $\begin{array}{l}7.7 \\
8.19\end{array}$ & 3. 312 & $\begin{array}{r}10 \\
1000\end{array}$ & $\begin{array}{l}\text { Twin Sisters Peaks, } \\
\text { Wash. (1) }\end{array}$ \\
\hline Eclogite...$\ldots \ldots \ldots$ & $\begin{array}{l}7.31 \\
7.69\end{array}$ & 3. 441 & $\begin{array}{r}10 \\
1000\end{array}$ & Healdsburg, Calif. (1) \\
\hline Serpentinite... & $\begin{array}{l}5.8 \\
6.02\end{array}$ & 2. 710 & $\begin{array}{r}10 \\
1000\end{array}$ & California (1) \\
\hline Anorthosite......... & $\begin{array}{l}6.73 \\
6.86\end{array}$ & 2. 768 & $\begin{array}{r}10 \\
1000\end{array}$ & Tahswus, N.Y. (1) \\
\hline Slate............. & $\begin{array}{l}\text { 5. } 49 \\
5.79\end{array}$ & 2. 734 & $\begin{array}{r}10 \\
1000\end{array}$ & Medford, Mass. (1) \\
\hline Mica schist. . ....... & $\begin{array}{l}5.7 \\
6.43\end{array}$ & 2. 797 & $\begin{array}{r}10 \\
1000\end{array}$ & Woodville, Vt. (1) \\
\hline Chlorite schist: . . . . . & $\begin{array}{l}4.8 \\
6.75\end{array}$ & 2.841 & $\begin{array}{r}10 \\
1000\end{array}$ & Chester, Vt. (1) \\
\hline Marble.... & $\begin{array}{l}\text { 5. } 1 \\
6.61\end{array}$ & 2. 704 & $\begin{array}{r}10 \\
1000\end{array}$ & Danby, Vt. (1) \\
\hline Dolomitic marble...... & $\begin{array}{l}5.6 \\
6.98\end{array}$ & 2. 844 & $\begin{array}{r}10 \\
1000\end{array}$ & Rutland, Vt. (1) \\
\hline Quartzite........... & $\begin{array}{l}5.6 \\
6.11\end{array}$ & 2. 647 & $\begin{array}{r}10 \\
1000\end{array}$ & Mont. (1) \\
\hline
\end{tabular}

Sedimentary rocks of low porosity

Limestone:

\begin{tabular}{|c|c|c|c|c|}
\hline Lithographic. . . . . . . & 5. 5 & 2. 543 & 10 & (1) \\
\hline & 5. 59 & & 1000 & \\
\hline Solenhoffen . . . . . . . & 5. 97 & & & (2) \\
\hline Argillaceous......... & 6. 03 & & & (2) \\
\hline Anhydrite. . . . . . . . . & $\begin{array}{l}4.8 \\
6.0\end{array}$ & 2. 928 & $\begin{array}{r}10 \\
1000\end{array}$ & (1) \\
\hline Sandstone & $\begin{array}{l}\text { 3. } 9 \\
\text { 5. } 0\end{array}$ & 2. 659 & $\begin{array}{r}10 \\
1000\end{array}$ & Catskill, N.Y. (1) \\
\hline $\begin{array}{l}\text { Rock salt... } \\
\text { Greywacke. }\end{array}$ & $\begin{array}{l}4.7 \\
5.4 \\
5.63\end{array}$ & $\begin{array}{l}2.2 \\
2.679\end{array}$ & $\begin{array}{r}10 \\
1000\end{array}$ & $\begin{array}{l}\text { (3) } \\
\text { New Zealand (1) }\end{array}$ \\
\hline
\end{tabular}


TABL1 2.2-Typical values of the velocities of compressional waves through some rocks and other materials of interest-Continued

\begin{tabular}{llrl}
\hline Material & $(\mathrm{km} / \mathrm{sec})$ & $\begin{array}{l}V_{\mathrm{p}}^{\mathrm{Density}} \\
\left(\mathrm{g} / \mathrm{cm}^{8}\right)\end{array}$ & $\begin{array}{c}\text { Pressure } \\
\text { (bars) }\end{array}$ \\
\hline
\end{tabular}

Sedimentary rocks of moderate to high porosity.

\begin{tabular}{|c|c|c|c|c|}
\hline \multirow[t]{7}{*}{ All types............ } & 1.5 & 1.4 & & $\begin{array}{l}\text { Curve of Nafe and } \\
\text { Drake }(2,4)\end{array}$ \\
\hline & 1.5 & 1. 6 & & \\
\hline & 1. 7 & 1. 8 & & \\
\hline & 2.2 & 2. 0 & . & \\
\hline & 2.9 & 2. 2 & & \\
\hline & 4.2 & 2.4 & & \\
\hline & 5. 5 & 2. 6 & & \\
\hline \multirow[t]{5}{*}{ Mean of several types.. } & 1.7 & 2. 0 & & $V=0.109 \rho^{4}(3)$ \\
\hline & 2. 6 & 2. 2 & & \\
\hline & 3. 6 & 2.4 & & \\
\hline & 5. 0 & 2.6 & & \\
\hline & & lcanic ro & & \\
\hline Obsidian........... & $\begin{array}{l}5.80 \\
5.62\end{array}$ & 2. 376 & $\begin{array}{r}10 \\
10,000\end{array}$ & Modoc., Cal. (1) \\
\hline Diabase glass. & 6. 30 & 2. 750 & 10 & (1) \\
\hline \multicolumn{2}{|c|}{ Rhyolite tuff........4 0-4.4 } & $\mathbf{R}$ & $\sim 400$ & $\begin{array}{l}\text { Long Valley, Calif. } \\
\text { Densely welded (5) }\end{array}$ \\
\hline Tuff............ & 2. 2 & $\mathbf{R}$ & & New Zealand (2) \\
\hline Friable tuff. . . . . . . & -2.4 & $\mathbf{A}$ & $\sim 60$ & Nevada Test Site (6) \\
\hline $\begin{array}{l}\text { Bedded tuff } \ldots \ldots \ldots \ldots \\
\text { Basalts. } \ldots \ldots \ldots \ldots \ldots\end{array}$ & -3.7 & $\mathbf{A}$ & $\sim 100$ & Nevada Test Site (6) \\
\hline
\end{tabular}

Other materials

Air, $0^{\circ} \mathrm{C} \ldots \ldots \ldots \ldots \quad 0.3315$

$1 \quad V_{,}=0.3315+0.000607$ $\mathbf{T}\left({ }^{\circ} \mathrm{C}\right)$.

Water, $0^{\circ} \mathrm{C}, \mathrm{S}=0 \ldots \ldots \quad 1.449$

Ice, intrinsic . ........ 4.0

1 See note b. (7)

Glacial ice, firn to $\quad 1.0-40$

blue ice.

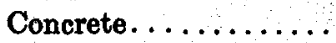

3. 6

5. 9-6.3

$\mathrm{SiO}_{2}$ glass. . . . .

5. 53

2. 213

10 (1)

10,000

\footnotetext{
Notes-

$a-$ where velocities are given for two different pressures, the measurements were made on the same sample or group of samples if averages were used.

$R$-indicates a velocity determined by refraction measurement in the field.

$A$-indicates a measurement in a drill hole.

$b$-velocity through sea water: $V_{\mathrm{b}}(\mathrm{m} / \mathrm{sec})=1449+4.6 \mathrm{~T}-0.055 \mathrm{~T}^{2}+0.0003 \mathrm{~T}^{\mathrm{a}}+(1.39$

$-0.012 \mathrm{~T})(\mathrm{S}-35)+0.017 \mathrm{Z} ; \mathrm{T}\left({ }^{\circ} \mathrm{C}\right), \mathrm{S}(\mathrm{g} / \mathrm{l}), \mathrm{Z}(\mathrm{depth}, \mathrm{m})(7)$.

References: (1) Birch [1960]; (2) Press [1966]; (3) Gardner et al. [1974]; (4) Dobrin [1976]; (5) Hill [1976]; (6) Keller [1960]; (7) Sheriff [1973].
} 
Effect of porosity and fuid content. The propagation of elastic waves through porous media has received much attention: first in connection with mapping of the potential petroleum or gas bearing structures, second in connection with attempts to estimate the fraction of water, oil, or gas in the pores of rocks from velocities or acoustic impedances measured from the surface or in drill holes, and third in connection with a more basic understanding of crustal properties and processes (e.g., the dilatancydiffusion theory of earthquake prediction [Nur, 1972; Scholtz et al., 1973]).

Recently Toksoz et al. [1976] cast the problem in a rather general sense and discussed [p. 639] :

(1) The calculation of seismic velocities in rock models with a spectrum of pore shapes and the influence of pore shapes on the velocities; (2) the relative effects of saturating fluids (oil, gas, brine, or their mixture) on the velocities; (3) the elastic effects of overburden and pore fluid pressures on pore shapes and seismic velocities; $(4)$ the interpretation of laboratory data on velocities with different saturants to determine the spectra of pore shapes in rock; and (5) prediction of in-situ seismic velocities and reflection coefficients for rocks fully or partially saturated with gas, oil, or brine.

Their many conclusions are too lengthy to present here but it may be especially significant for geothermal exploration that compressional wave velocities are generally lower for dry or gas-saturated rocks than they are for water-saturated rocks [see also Nur and Simmons, 1969b], whereas shear wave velocities are either about the same or higher (especially for highly porous rocks) for gas-saturated rocks. This means that $\nabla_{p} / \nabla_{q}$ or o are quite different for gas-saturated and water-saturated rocks. Moreover, small quantities of immiscible gas bubbles inside water or brine lower the fluid bulk modulus [see also Domenico, 1974]. With about 5 percent gas in brine compressional velocities are as low or lower than the pure gassaturated rock. If both shear and compressional velocities could be accurately measured through the same rock volume $V_{p} / V_{s}$ or $\sigma$ could be important parameters in identifying gas-saturated formations.

Majer and McEvilly [1979] and Combs and Rotstein [1976] reported anomalously low $V_{p} / V_{s}$ and $\sigma$ for The Geysers and Coso geothermal areas, respectively. Both groups suggest that the anomalies may be a consequence of vapor-filled cracks. However, the chemistry of water from the Coso system indicates that it is a hot-water system [Fournier et al., 1978].

Effect of temperature. The velocity of seismic waves through rocks decreases with increasing temperature [e.g., Birch, 1958; Hughes and Maurette, 1957; Stewart and Peselnick, 1978]. Although the effect is rather small $\left(\sim 10^{-3} \mathrm{~km} / \mathrm{s} \mathrm{C}^{\circ}\right)$ under ordinary conditions, it is large enough to offset the increase in velocity with pressure (depth) in areas where the thermal gradient in the crust is on the high side of normal. In the laboratory the measurement is difficult to make because of damage to samples 
heated at low pressures. Significant results are largely limited to those obtained at pressures high enough to effectively close microcracks (over two kilobars in the Stewart and Peselnick [1978] experiments). Consequently, little is known directly about the temperature dependence of the velocity of seismic waves in rocks at low pressures and shallow depths.

The velocities of seismic waves through molten rocks are considerably less than those through their crystalline counterparts [Murase and McBirney, 1973]. Partial melting of a small fraction of rock is thought to be the principal reason for low velocities and high attenuation in the asthenosphere of the upper mantle [e.g., Walsh, 1968]. Where melting exists in the crust, equally anomalous conditions might bo expected.

Attenuation. As seismic waves pass through the Earth, they are attenuated by geometrical spreading and by an elastic conversion of motion to heat. The specific attenuation factor $1 / Q$ for homogeneous solid materials is essentially independent of frequency, whereas that for liquids varies linearly with frequency [e.g., the reviews of Knopoff, 1964; Anderson and Archambeau, 1964; Anderson and Hart, 1978].

At The Geysers, California, Majer and McEvilly [1979] sought evidence for the production zone affecting the amplitude and wave form of P-waves using a technique developed by Teng [1968]. They found that $Q$ appears high in the steam field with respect to regional values at shallow depths $(<1 \mathrm{~km})$ and that it decreases with depth.

In the East Mesa geothermal area of the Imperial Valley, California, Combs and Jarzabek [1978] found anomalously high attenuation of the higher frequency components of $P$-waves traversing the reservoir area and suggested that this phenomenon reflects properties of the geothermal reservoir at depth. They cautioned that the observed anomalies may be due to local subsurface complexities at depth. We observe [Diment et al., 1977], however, that the two stations exhibiting anomalous attenuation of high frequencies are located where the water table is relatively deep $(\sim 10 \mathrm{~m})$, whereas the two stations that do not exhibit the anomalous attenuation are located where the water table is several meters deep. This taken with the observation that surface waves are very slow in this area [McEvilly and Schecter, 1977, p. 119] of highly dessicated sands suggests that groundamplification and velocity studies may be required to determine the causes of these anomalies, much as Iyer and Hitchcock [1976b] have suggested in connection with the analyses of seismic noise (section 2.1.2.9.f).

2.1.2.9.b Reflection surveys. Reflection seismology is the most useful and carefully honed geophysical technique of the petroleum explorer. It is also the most expensive (several thousand dollars per line mile on land).

In principle the technique is deceptively simple. Elastic waves are generated at the surface by an explosion in a shallow drill hole, by the impact of heavy weight, or by a mechanical vibrator. Waves refiected from subsurface strata are recorded and analyzed in terms of geologic structure 
and in terms of the properties of the rocks traversed. In practice both technique and interpretation have become increasingly more sophisticated [e.g., Claerbout, 1976; Dorbin, 1976; Telford et al., 1976; Waters, 1978; Sheriff, 1978].

Outside of the petroleum provinces there are few examples of the application of the technique partly because : it is costly, it is difficult to apply in rough terrain, the stratigraphy and structure may be sufficiently complex so that application of the technique does not appear promising, or, if the data are good, they usually remain proprietary or are sold on a restricted basis.

Two reflection profiles were obtained in the Leach Hot Springs area of Grass Valley, Nevada, using modern field and processing techniques [Majer, 1978]. They nicely illustrate the fine structure of the bounding and intrabasin faults.

The Consortium for Continental Reflection Profiling (COCORP) has run several reflection profiles with field and processing procedures designed to enhance deep reflections in the Rio Grande rift of New Mexico [Oliver, 1978]. The profiles not only show how the sediments are broken into horst and graben structures in the shallow part of the section but also show, a strong reflector at about 7 seconds $(18-20 \mathrm{~km}$ ) which corresponds to the top of a magma chamber postulated by Sanford et al. [1977] on the basis of other evidence.

2.1.2.9.c Refraction surveys. Refraction surveys differ from reflection surveys in that the lateral distance between source and receivers is much greater for refraction surveys. In other words, the ray paths for reflection surveys are nearly vertical whereas those for refraction surveys are largely horizontal. Refraction surveys lack the resolution of reflection surveys but often give a better resolution of velocity structure especially at great depth.

Refraction surveys have been successfully used to determine the depth to basement in valleys filled with volcanic rocks and alluvium [e.g., Ackermann, 1979] as well as to study the velocity structure within the relatively unconsolidated rocks. Hill [1976] successfully predicted the thickness of the volcanic debris in the Long Valley caldera of California.

Other applications have been discussed in section 2.1.2.9.a.

2.1.2.9.d Teleseismic P-voave delays. Over the years seismologists have progressively refined travel-time curves or tables that show the average arrival time of various waves as a function of distance from earthquakes. Herrin [1968] gave a recent set for P-wave arrival times. Some waves arrive significantly early or late with respect to the average. These traveltime anomalies are usually attributed to an anomalous velocity structure either near the source or near the receiver, the rationale being that the earth becomes more homogeneous with depth where the waves from distant earthquakes spend most of their time in transit from focus to receiver. By 
selection of appropriate earthquakes, consideration of azimuthal effects [e.g., Bolt and Nuttli, 1966; Nuttli and Bolt, 1969], and the use of reference stations [e.g., Steeples and Iyer, 1976a,b], effects of anomalous conditions near the source can be minimized.

In a regional sense, it has been found that $P$-waves are delayed about one second in western United States as compared with eastern United States [e.g., Hales and Herrin, 1972], that the region of $P$-wave delays correlate with the region of low $P_{n}$ velocity [Herrin and Taggart, 1962] and high heat flow [e.g., Blackwell, 1971b, 1978; Roy et al., 1972]. Inasmuch as the velocity of seismic waves decreases with temperature and degree of partial melting, the P-wave delays are taken to mean elevated temperatures in the mantle in a large part of the western United States.

Large local P-wave delays have been found in detailed studies of the caldera in Yellowstone National Park [Iyer, 1975a], the Long Valley caldera of California [Steeples and Iyer, 1976b], and the Geysers-Clear Lake area of California [Iyer et al., 1978]. In each case the delays are attributed primarily to hot, perhaps partially molten, intrusive masses occupying a significant fraction of the crust and perhaps a part of the mantle.

Significant P-wave anomalies have been observed in fairly detailed studies in nonvolcanic areas: at the Large Aperture Seismic Array in eastern Montana [Iyer and Healy, 1972]; in certain areas of eastern North America [Fletcher et al., 1978]; and in the New Madrid region of Missouri [Mitchell et al., 1977]. Although these anomalies may not be quite so large or abrupt as those apparently associated with recent intrusions, they serve as a reminder that a range of conditions may have to be considered in the analysis.

2.1.2.9.e Microearthquakes. Although there is no precise definition of the term microearthquakes, they are generally regarded as small earthquakes in the Richter [1958] magnitude range 4 to -2 [e.g., Ward, 1972]. Above this range earthquakes are instrumentally detectable on a worldwide basis. The lower limit is simply the detectability of an earthquake at a distance of a few kilometers and depends upon ambient noise conditions. Experience [e.g., Richter, 1958, p. 359] suggests that there are roughly ten times as many earthquakes in each successively lower magnitude interval (e.g., 10 magnitude-3 shocks for each magnitude-4 shock) but it is not entirely clear that the extrapolation to the magnitude -2 range would be valid [e.g., Scholtz, 1968].

Conceptually there is good reason to suppose that microseismicity might be anomalously high in the vicinity of geothermal reservoirs related to intrusion of magma. By nature they are dynamic, non-steady-state systems. Small earthquakes might be expected from stress changes attending natural or induced fluid loss, cooling of the heat source, thermal alteration [Ward and Bjornsson, 1971] and active metamorphism as in the sedi- 
ments of the Imperial Valley of California [e.g., Muffler and White, 1969]. Moreover, it is known that increase in fluid pressure along faults by deep well injection can induce seismicity [Evans, 1966; Healy et al., 1968; Raleigh et al., 1976], and it might be supposed that microseismicity could outline faults that may channel geothermal fluids [Facca and Tonani, 1964; Ward, 1972].

In reality, seismic networks capable of accurately locating microearthquakes over a fairly broad area and over a significant period of time are expensive. Rarely has it been possible to relate microearthquakes to specific structures, although a few examples from geothermal areas suggest this can be done [Ward, 1972, figure 3; Combs and Hadley, 1977] but in some cases the relation is equivocal [Hamilton and Muffler, 1972].

Although Ward [1972] found that microearthquakes occur in most major geothermal areas, there are areas where they do not. The only microearthquakes recorded in a one month period in the Long Valley caldera were restricted to a single locality near the edge of the caldera, although seismicity outside the caldera was high [Steeples and Pitt, 1976]. The microseismicity near the Roosevelt Hot Springs area, Utah [Ward et al., 1978 ] is not especially anomalous particularly when viewed in comparison with some adjacent areas. The swarm-like occurrence of some microearthquakes as noted by some of the previously cited authors [see also Hill, 1977] may be the reason for the apparent dichotomy. For example, Combs and Hadley [1977] reported considerable microseismicity, some of it swarm-like, in the East Mesa area in California over a five week period. Yet none had been found for a one month interval in 1972 [R. M. Hamilton, personal communication, 1978]. Subsequently, McEvilly and Schechter [1977] found none for a one month period in the same area.

The miscroseismicity of The Geysers-Clear Lake area of California has been studied in more detail than that of most geothermal areas, although no studies were made prior to the first significant production of steam. A continuous recording net has been in operation since 1975 [Bufe et al., 1976, 1978] and for short periods earlier [Lange and Westphal, 1969; Hamilton and Muffler, 1972; Majer and McEvilly, 1979]. Tentative generalizations are beginning to emerge: (1) Microseismicity in the area as a whole is anomalously high and appears to be getting higher, perhaps in response to increased production of steam. (2) The spatial distribution of microearthquakes is diffuse and does not show any well-defined throughgoing faults. (3) Foci are shallow $(<5 \mathrm{~km})$ which could be taken to mean elevated temperatures beneath the reservoir [Majer and McEvilly, 1979, p. 266]. (4) Microearthquakes are generally absent within the known geothermal reservoir, although they tend to outline it [Majer and McEvilly, 1979].

A different use of microearthquakes in geothermal areas is as energy sources to delineate velocity structure and attenuation properties much as 
would be done with standard techniques of refraction seismology. It should be recalled, however, that both the time of origin and location of a microearthquake are derived quantities whose precision depends on the density of stations and some knowledge of velocity structure. Consequently, microearthquake studies alone rarely yield the same precision as refraction surveys. The accuracy achieved by a network can be considerably improved by a few well placed explosions of known origin times.

2.1.2.9.f Seismic noise. In addition to microearthquakes, there is some reason to suppose that the level of ambient ground motion might be anomalously high in geothermal areas: (1) There is a level below which microearthquakes can no longer be identified as discrete events but the higher amplitude phases would contribute to the ground motion and could produce a noise anomaly provided they were sufficiently frequent. (2) Phase changes, such as subsurface boiling, might produce significant noise.

Clacy [1968] and Whiteford [1970, 1976] found large noise anomalies in the vicinity of known geothermal anomalies in New Zealand. Iyer and Hitchcock [1974] found high levels of noise in and around all the major geyser basins in Yellowstone National Park and postulated that higher frequency components were the result of geyser eruptions, fumaroles, and bubbling hot springs, whereas the lower frequency components might result from deeper convection of hot water associated with each system.

Douze and Sorrells [1972] and Goforth et al. [1972] found high noise levels over the East Mesa geothermal area in California but Iyer [1975b] and Iyer and Hitchcock [1976a] obtained conflicting results in the same area and attributed most of the noise to cultural activity of various sorts.

In an extensive study of seismic noise in Long Valley, California, Iyer and Hitchcock [1976a] found a noise anomaly over the eastern part of the caldera. They concluded that a part of this was the result of groundmotion amplification due to the presence of soft sedimentary material and that part of the higher frequency noise could be generated by cultural sources or cattle.

In their concluding remarks summarizing experience in several areas, Iyer and Hitchcock [1976b, p. 1082] stated:

Our experience has shown that contouring seismic noise anomalies, though useful, does not in itself provide conclusive indications for exploratory drilling of a geothermal prospect. Ground-amplification studies and velocity studies have to be carried out simultaneously with noise-amplitude studies. There is scope for development of sophisticated array techniques to study velocity and azimuth of travel of seismic noise waves. Case histories of noise measurements in a variety of geothermal environments and nongeothermal areas, using all of the above techniques, are required to make a realistic evaluation of seismic noise as a geothermal exploration tool. 


\section{Q.1.3 Examples of kinds of systems}

In the United States many hundreds of localities have been examined to one degree or another in an attempt to assess their geothermal potential [e.g., White and Williams, eds., 1975; Muffler, ed. 1979].

Much is known about some systems, little about others. None is completely understood, and each has at least some unique characteristics. Information on some of the most promising systems is just beginning to become available, but most of it remains proprietary. Consequently, the choice of which systems to illustrate is rather arbitrary and is dictated by personal experience, availability of literature, and limits of time and space.

\subsubsection{Systems related to young intrusions in the upper crust}

2.1.3.1.a Magma. Methods for precisely locating a magma chamber at a depth of several kilometers remain to be developed, although experience being gained from intensive investigations at many localities already mentioned may sharpen tools appropriate for the purpose. The technology to drill a deep hole close to, much less into, a magma chamber does not exist [Shoemaker, 1975]. Moreover, means of extracting energy from it have not been proven. Nonetheless, the subject has received considerable attention because energy stored in shallow magma chambers is large [Peck, 1975; Smith and Shaw, 1975]. Even the energy stored in the small Kilauea Iki lava lake is considerable [Kennedy and Griggs, 1960].

The problems of locating and extracting energy directly from a buried circulating magma are being explored [Colp, 1974; Colp and Brandvold, 1976; Stoller and Colp, 1978]. The Kilauea Iki lava lake has been used as a field laboratory [Colv and Okamura, 1978; Hermance et al., 1978].

2.1.3.1.b Hot $d r y$ rock. Considered here are environments that are: (1) relatively hot by virtue of their proximity to young igneous intrusions or perhaps other conditions, and (2) relatively dry in that intrinsic and fracture porosity are low. Such conditions are also considered in section 2.1.3.2.a.

Such conditions are widespread, of course, especially if depths of $3 \mathrm{~km}$ or more are considered. The amount of heat stored is enormous [e.g., Smith and Shaw, 1975, Diment et al., 1975]. The trick is to get the heat out by an economically viable process.

The general notion is that fractures could be created by one of several techniques, a fluid circulated through the fracture system and recovered, whereupon the heat acquired during transit could be removed. Various schemes for fracturing have been considered [e.g., Harlow and Pracht, 1972; Burnham and Stewart, 1973; Ramey et al., 1973; Smith et al., 1973; Austin and Leonard, 1973]. 
The Los Alamos Scientific Laboratory (LASL) has conducted the only large-scale experiment [e.g., Smith et al., 1973, 1976; J. H. Hill, 1978] and results, although incomplete, are being watched with considerable interest. A verticle hole was drilled to $\sim 3 \mathrm{~km}$; a near-vertical fracture was created by hydrofracturing; and a second hole was drilled to intersect the fracture near its bottom so that water circulated through the fracture could be recovered and its heat extracted.

The experiment was conducted in the Jemez Plateau of New Mexico some $13 \mathrm{~km}$ west of the center of the Valles caldera which was formed about 1 million years ago [Smith et al., 1970; Doell et al., 1968; Smith and Bailey, 1968] and which is itself the site of known geothermal resources [Dondanville, 1978]. Rocks penetrated at the LASL site include $\sim 700 \mathrm{~m}$ of sediments and volcanics and a variety of igneous and metamorphic rocks [J. H. Hill, 1978]. The temperature at the bottom of extraction hole $(3064 \mathrm{~m})$ was $205.5^{\circ} \mathrm{C}$ [ J. H. Hill, 1978, p. 276].

In a recent summary $J$. H. Hill [1978] indicated that the experiment was successful in that circulation was obtained through the loop and that an average of $>5 \mathrm{MW}$ power was extracted during a run from January 26 to April 1, 1978. Many questions remain that can only be answered by prolonged operation of the system: Will the cracks remain open? How leaky is the system? How important are chemical reactions in determining crack properties? Will significant secondary fracture permenbility develop as the system cools in response to prolonged circulation?

In a broader context other questions remain: What is the frequency of occurrence of appropriate environments? What is the total volume of rock that might be tapped [Muffler, 1979]?

2.1.3.1.c Convective hydrothermal systems.-The Geysers-Clear Lake geothermal region. The region is about $110 \mathrm{~km}$ northwest of San Francisco, California. The installed electrical generating capacity of the steam field exceeds $600 \mathrm{MW}$, is growing [Brook et al., 1979, p. 45], and should reach $908 \mathrm{MW}$ by 1980 [L. J. P. Muffler, personal communication].

In addition to the steam field there are adjacent areas to the northeast where hot water $\left(\sim 200^{\circ} \mathrm{C}\right)$ may be abundant [e.g., Goff et al. 1977; Goff and Donnelly, 1978; White et al., 1973], although no attempt has been made yet to produce it from the geothermal wells drilled there.

The region falls within a broad zone of transform faulting between the Pacific and North American plates, but it is not far from the triple junction of these plates and the small Gorda Plate to the north [e.g., Atwater, 1970 ], and the situation is locally complex. Indeed, Heard [1978] recognized a new small intracontinental plate (the Humbolt Plate) east of Cape Mendocino, the eastern boundary of which trends north-northwesterly approximately through the Geysers-Clear Lake region. He further suggested that the many echelon faults forming the eastern boundary of 
this plate are so young that there has been insufficient time to integrate the fault zone into single surficial break.

The heat flow in a broad zone all along the San Andreas fault system is known to be high ( 2 HFU) [Lachenbruch and Sass, 1973] but the Geysers-Clear Lake region may be even more anomalous. One drill hole at Cloverdale some $15 \mathrm{~km}$ west of the steam field yielded a heat flow of 3-4 HFU [Urban et al., 1976].

Volcanism, some of it silicic, in the Clear Lake volcanic field, which ranges in age from 2,000 to 10,000 years [Hearn et al., 1976; Goff et al., 1977], attests to recent melting in upper mantle and crust. The volcanic rocks are but a thin veneer over the Mesozoic basement rocks [McLaughlin and Stanley, 1976], and no large caldera collapse structures are evident. However, the region may be one of incipient caldera formation [Smith and Shaw, 1973; Hearn et al., 1976].

A large negative Bouguer gravity anomaly ( $\sim 25$ mgal) exists in the central part of the area [Chapman, 1975; Isherwood, 1976]. The anomaly may represent a cooling pluton below $(\sim 10 \mathrm{~km})$ but it is not entirely clear whether a significant part of the anomaly results from other causes. An electrical resistivity low corresponds with the gravity low [McLaughlin and Stanley, 1976; Goff et al., 1977]. Iyer et al. [1978] found large Pwave delays $(\sim 1 \mathrm{~s})$ in the area of the gravity and resistivity lows but noted [p. 313]:

Such delays in excess of 1 sec over small spatial extent become difficult to explain in terms of large velocity contrasts associated with partial melt. Anisotropic crack structure in the top $5 \mathrm{~km}$ may be responsible for these variations.

In summary, considerable geophysical evidence indicates the existence of a hot intrusion deep in the crust but interpretations are clouded by shallow conditions that may have been produced by the intrusion.

Although the boundaries of the steam reservoir are not particularly well defined, it appears that the reservoir falls between two northwesterly trending fault zones separated by some $10 \mathrm{~km}$ : The Collayami fault zone on the northeast and the Mercuryville fault zone on the southwest [McLaughlin and Stanley, 1976; Goff et al., 1977]. The block is composed of a variety of highly contorted rocks of the Franciscan sequence (Upper Jurassic and Oretaceous) and an Upper Jurassic ophiolite sequence according to McLaughlin and Stanley [1976], who concluded [p. 484] :

Geothermal resources in The Geysers area tend to be concentrated within imbricated north-northeast to southeast-dipping slabs of Franciscan graywacke. Critical parameters for economic concentrations of steam in the region appear to be: (1) the presence of channelways that allow percolation of meteoric water to some depth, providing an adequate but not excessive recharge of water to the system; (2) the presence of favorable local structural traps for steam accumulation 
in fault and fracture zones (such as in The Geysers Resort Area) or in the crests of structural highs (such as in the Castle Rock Springs area); and (3) a potent heat source.

The deep steam zone (as compared with the shallow steam zone $<1$ km depth near the Geysers Resort) that is currently being exploited generally lies between 2 and $3 \mathrm{~km}$ in depth [Dondanville as cited by Majer and McEvilly, 1979, p. 254]. The steam is near the temperature $\left(236^{\circ} \mathrm{C}\right)$ and pressure $(32 \mathrm{bar})$ of maximum enthalpy $(670 \mathrm{cal} / \mathrm{g})$ of steam [White et al., 1971]. This also appears to be true of the initial steam production at Larderello, Italy [James, 1968], Kawah Kamojang, Indonesia [Weres et al., 1977], and Matsukawa, Japan [Nakamura et al., 1970 ; White, 1973]. It is notable that the pressure of the steam zone is far below hydrostatic pressure, and, were it not for an efficient self-sealing mechanism the steam zone would be quickly drowned by near-surface ground water.

White et al. [1971] and White [1973] reviowed the reasons why the conditions in the steam zone arise. Boiling from a deep vapor-liquid interface is a part of their preferred model.

As previously noted (section 2.1.2.5.g) the temperature profile above the steam zone is remarkably linear and extrapolates to the temperature and depth of known steam. The linearity of the profile indicates that heat transport is by conduction alone (at least in this locality) and attests to the efficacy of the self-sealing mechanisms in the rocks capping the steam zone. This is even more remarkable in view of the active tectonism of the region. Also in regard to the linearity of the temperature profile, Urban et al. [1976, p. 1241] stated:

Comparison of the observed profiles with models calculated on the basis of conductive heat flow, a flat-topped reservoir of infinite lateral extent, and steam temperature constant over time suggest that the reservoir is at least several thousand years old and quite possibly ten or more thousands of years old. Beyond about 10,000 yrs., temperatures are so close to steady state that no information as to age can be derived. Although the rate of conductive heat loss above the steam zones is about two orders of magnitude less than the present rate of extraction by producing steam wells, the total loss of heat by conduction over several thousands of years may have exceeded the annual extraction of heat from steam wells by more than a factor of ten.

Roosevelt Hot Springs geothermal area. The Roosevelt Hot Springs geothermal area is $20 \mathrm{~km}$ northeast of Milford, Utah, and is one of several near the eastern edge of the Basin and Range Province [see maps of Grim, 1977; Muffler, 1979, map 1]. Ward et al. [1978] provides a useful summary from which most of the following information is drawn.

Deep drilling $(\sim 2 \mathrm{~km})$ for commercial power production began in 1875 (apparently on the basis of shallow heat flow measurements and high 
geochemical temperatures) and seven of eleven deep wells appear productive. Flow tests indicate potential production of water and steam of about $4.5 \times 10^{5} \mathrm{~kg} / \mathrm{hr}$ per well at shut-in bottom-hole temperatures near $260^{\circ} \mathrm{C}$ [Ward et al., 1978, p. 1516].

Although the recent silicic volcanism suggests melting in the upper crust, no "magma chamber" is yet evident [Ward et al., 1978]. P-waves generated by small earthquakes some $30 \mathrm{~km}$ to the northeast and recorded on the west flank of the Mineral Mountains are delayed as much as $0.2 \mathrm{sec}$. S-wave attenuations appear high. Some unexplained gravity lows exist, but these could equally well be due to other density contrasts in the upper crust. The location of the region is anomalous in the sense that it is near the intersection of northerly trending late Cenozoic horst and graben structures of the western Great Basin and the easterly trending PiocheBeaver-Tushar mineral trend [Stokes, 1968] which falls along an easterly trending crustal discontinuity [Stewart et al., 1977; Best and Hamblin, 1978; Mabey et al., 1978]. Both trends are seismically active [Smith and Sbar, 1974; Eaton et al., 1978; Smith, 1978] and Ward et al. [1978, p. 1526] suggested that the seismicity may reflect a highly fractured crust that could facilitate magma migration into the upper crust and thus enhance the geothermal potential.

A comprehensive study of the geology, geochemistry, and geophysics of the area was begun in 1975 largely by researchers from the University of Utah. A summary of their preliminary findings [Ward et al., 1978] is notable in that it contains elements of strategy, technique evaluation, and interpretation uncommon to reports of this kind.

The area of interest is located in a highly faulted region between the Mineral Mountains on the east and the Milford Valley on the west. The Mineral Mountains are largely composed of Tertiary granite and granodiorite, schists and gneisses of unknown age, and Cretaceous and Paleozoic sedimentary rocks. The granitic rocks are no older than $35 \mathrm{My}$ and several $\mathrm{K}$-Ar dates are close to $10 \mathrm{My}$. Tertiary and quaternary basalts and rhyolite mantle the Mineral Mountains in places. Milford Valley is a graben containing some $1.4 \mathrm{~km}$ of alluvium overlying a basement presumably composed of the rock types exposed in the Mineral Mountains.

The Mineral Mountains region has experienced repeated volcanism : ages of about $20,10,8$, and $2 \mathrm{My}$ have been reported. The most recent episode began about $0.8 \mathrm{My}$ ago with eruption of rhyolite flows from vents about 4 $\mathrm{km}$ east of the zone of near-surface thermal activity as defined by a zone of hydrothermal alteration and hot springs (mainly extinct). Subsequent activity $(0.6-0.5 \mathrm{My})$ produced rhyolite flows and small domes along the crest and western flank of the Mineral Mountains. Pre-eruption magma temperatures were estimated to range from a low of $650^{\circ} \mathrm{C}$ for the domes to a high of $785^{\circ} \mathrm{C}$ for the flows based on both the iron-titanium oxide and the two-feldspar thermometers. 
Hot-spring deposits (siliceous sinter) and near-surface hydrothermal alteration are evident along the NNW-trending Opal Mound fault, which bounds the deep production zone on the west. Both alluvium and underlying granitic rocks have been altered to varying degrees by the acid sulfate waters. Hydrothermal alteration is closely associated with fractures to a depth of $2 \mathrm{~km}$ in one deep well.

Because of the hydrothermal alteration of feldspars to electrically more conductive brine-soaked clays, various electrical methods (dipole-dipole resistivity with various spacings, Schlumberger resistivity, and electromagnetic methods) used singly or in combination yielded much information about the distribution of faulting in the upper 500 meters of the section [see also Tripp et al., 1978]. Information derived from 700 terraincorrected gravity measurements and from aeromagnetic ( $1 / 4$ mile line spacing) surveys extend and supplement this information as well as giving a notion of conditions at greater depth (e.g., thickness of the alluvium in the Milford Valley).

Heat-flow measurements in 40 shallow (40 to $200 \mathrm{~m}$ ) drill holes range between 0.7 and $214 \mathrm{HFU}$. Inasmuch as heat flow rarely exceeds $3 \mathrm{HFU}$ in the Basin and Range except where hydrothermal convection is involved and averages a little over $2 \mathrm{HFU}$, the lowest values are taken to represent areas of ground-water recharge. The very high values $(>20 \mathrm{HFU})$ are found in a $2 \mathrm{~km}$ wide band parallel to and including the Opal Mound fault. They represent leakage from the fault and illustrate the strong structural control on the system.

With regard to the deep reservoir, the Opal Mound fault is the western boundary of a fracture zone estimated to be at least $0.5 \mathrm{~km}$ wide near the surface. However, production from fractures has been obtained from deep wells as much as $1.5 \mathrm{~km}$ east of the fault. Neither the dip nor the true width of the fracture zone is known.

The reservoir is of the hot-water type as defined by White et al. [1971]. The deep waters are relatively dilute sodium chloride brines (ionic strength $0.1-0.2$ ), and have sulfate concentrations ranging between 48 and $128 \mathrm{mg} / \mathrm{l}$, and total dissolved solids of about $7000 \mathrm{mg} / \mathrm{l}$.

In an epilogue to their summary, Ward et al. [1978, p. 1541] gave the following assessment of the state of the exploration art in this region:

We have yet to find useful applications of the earth noise, microearthquake, $P$-wave delay, magnetotelluric, and self-potential methods in this complex geologic setting. Nevertheless, we are continuing to study these methods. Thirty years ago, mining geophysical exploration was in the same state of uncertainty but has matured substantially since then. Whither thou, geothermal geophysical exploration? After four years of intensive study of the Roosevelt Hot Springs thermal area, we have learned of the general locations of the fracture systems which allow cold meteoric fluid flow to depth and of hot thermal fluid flow to surface. The data reported here have helped industry in locat- 
ing wells but have not prevented drilling of four nonproductive wells. Data currently being analyzed are expected to provide significant improvement in our model of the subsurface. However, many problems will remain.

Specific problems requiring pure and applied research include (a) means for detecting and delineating fault systems in which thermal fluids percolate; (b) means for evaluating the size, productivity, and longevity of a fracture-dominated geothermal reservoir; (c) means for identifying the fluid-rock interactions which lead to heat flow to surface; and (d) means for identifying the source of heat. These are difficult problems to solve.

Long Valley caldera. The Long Valley caldera, Mono County, California, is chosen as an example because exploitable resources are likely to be found in this and similar environments, and because it has been the site of extensive geological, geochemical, and geophysical investigations, which are largely summarized in a series of papers in the Journal of Geophysical Research [1976, v. 81, pp. 721-860]. Moreover, a deep (2.1 km) hole was subsequently drilled in the eastern part of caldera and it is interesting to compare conditions inferred from shallow measurements with those revealed by the drill [Smith and Rex, 1977].

Surface manifestations of a high-temperature hot-water system at depth are many. Numerous hot springs are present in parts of the caldera and the geochemical temperature of water from them, as well as those from shallow $(<300 \mathrm{~m})$ shut-in wells at Casa Diablo indicate that reservoir temperatures are in excess of $200^{\circ} \mathrm{C}$ according to Mariner and Willey [1976], and Fournier et al. [1976] who also noted that temperatures as high as $177^{\circ} \mathrm{C}$ have been observed in the shut-in wells. The thermal waters are sodium bicarbonate-chloride waters containing $1000-1420 \mathrm{mg} / \mathrm{l}$ of dissolved solids. The salinity and high concentrations of arsenic (up to 2.2 $\mathrm{mg} / \mathrm{l}$ ) and boron (up to $15 \mathrm{mg} / \mathrm{l}$ ) will make it necessary in any development program to isolate the effluent of the wells from the fresh water system [Mariner and Willey, 1976, p: 792].

Recent volcanic features (craters and rhyolite domes) in the western part of the caldera and extending north are less than a thousand years old [Bailey et al., 1976], thus suggesting the presence of a shallow silicic magma chamber or a remanent thereof. For these reasons and others [Muffler and Williams, 1976], the caldera was selected for extensive investigation.

With regard to regional setting, the Long Valley caldera lies on the extreme western edge of the Great Basin at the foot of the Sierra Nevada. This physiographic boundary also marks a heat flow province boundary [Lachenbruch et a]., 1976] between a thick cold crust/lithosphere to the west and a thin hot crust/lithosphere to the east.

Regional seismicity is high along parts of this boundary, particularly to the south of Long Valley [e.g., D. P. Hill, 1978; Smith, 1978], although 
recent seismicity in the caldera itself is low [Steeples and Pitt, 1976], which might be taken as an indication of elevated temperature. A]though there is impressive geologic evidence for normal faulting along the east flank of the Sierra Nevada beginning about $2 \mathrm{My}$ ago and continuing through recent time [Christensen, 1966], strike-slip components predominate in focal plane solutions [Pitt and Steeples, 1975; D. P. Hill, 1978]. Moreover, surface displacements of the great Owens Valley earthquake of 1872 were predominantly strike-slip [D. P. Hill, 1978]. Conditions are rather different than at the eastern edge of Great Basin where dip-slip prevails [e.g., Smith, 1978; Smith and Lindh, 1978].

In an experiment designed to investigate the deep velocity structure beneath the caldera, Steeples and Iyer [1976a, b] recorded P-wave delay times from distant earthquakes utilizing a temporary seismograph net. They concluded [p. 849]:

Relative $P$-wave delays of $0.3 \mathrm{~s}$ persist at stations in the west central part of the Long Valley caldera after regional and near-surface effects have been removed. Ray tracing indicates that low-velocity material exists beneath the caldera at depths greater than $7 \mathrm{~km}$ and less than $40 \mathrm{~km}$, probably less than $25 \mathrm{~km}$. The velocity contrast with normal crust must be at least 5\% to satisfy the data and is probably in the range 10-15\%. We believe that the low velocity indicates anomalously hot rock at depth and that relative teleseismic P-residuals may be useful for investigations of sources of geothermal energy.

The volcanic history of the caldera and its environs was neatly summarized by Bailey et al. [1976]. After a considerable period of preheating as manifested by a prolonged period $(\sim 1 \mathrm{My})$ of intermittent volcanism, a magma chamber filled with silicic magma most of which was massively erupted $0.7 \mathrm{My}$ ago. As it was erupted the caldera floor $(17 \times 32 \mathrm{~km})$ collapsed and was filled with a great thickmess of densely (mostly) welded Bishop Tuff. Volcanic activity continued in various forms. Shortly after the caldera collapsed, the "early rhyolites," consisting of rhyolite tuffs, domes, and flows, were accumulated on the floor of the caldera to a thickness of at least $500 \mathrm{~m}$.

Contemporaneously with the eruption of the early rhyolites, a resurgent dome was formed in the western part of the caldera. This structure and associated faulting are the principal internal structures of the western part of the caldera. The early rhyolites are exposed in the dome. After formation of the resurgent dome, highly pumiceous rhyolites continued to accumulate in the moat surrounding the dome. Subsequent volcanism in cluded rhyodacites erupted near the rim of the caldera, late basalts and the Holocene rhyolites previously noted.

After caldera formation the depression was filled by a lake (now drained) that covered all the valley floor with the exception of the resurgent dome. Lacustrine sediments blanket the valley floor at least to a depth of $300 \mathrm{~m}$. 
In a very general way the sedimentary/volcanic sequence is: marsh deposits, lake sediments, porous tuffs and flows, densely welded Bishop tuff, precaldera volcanic rocks, and a basement of Sierran-type igneous and/or metamorphic rocks.

The large gravity low over the caldera has long been interpreted as due to a thick accumulation of low-density volcanic rocks and sediments [Pakiser, 1961; Pakiser et al., 1964; Kane et al., 1976]. Given the additional constraints of the seismic-refraction measurements [Hill, 1976], a reasonably accurate picture of the thickness of the volcanic materials and sediments in the caldera has been obtained [see also Muffler and Williams, 1976].

Hill [1976], using two refraction profiles across the caldera, was able to develop the following seismic stratigraphy: metamorphic basement rock, $6.0 \pm 0.4 \mathrm{~km} / \mathrm{sec}$; Bishop Tuff and Glass Mountain Rhyolite, $4.0-4.4 \mathrm{~km} /$ sec; postcollapse rhyolites, rhyodacites, and basalts, $2.6-3.4 \mathrm{~km} / \mathrm{sec}$; nearsurface materials including highly jointed volcanic rocks, alluvium, and glacial, lake, and marsh deposits, $1.5-1.9 \mathrm{~km} / \mathrm{sec}$. Although the refraction line is several kilometers north of the deep hole in the southeastrn part of the caldera, the refraction results are reasonably consistent with those found in the deep hole [Smith and Rex, 1977, figures.11 and 12], especially when the northerly dip [Muffler and Williams, 1976, figure 3] in this region is taken into account. The top of the early postcaldera tuffs in the hole is $330 \mathrm{~m}$, whereas Hill [1976, figure 7] got about $500 \mathrm{~m}$ for the top of a $2.8 \mathrm{~km} / \mathrm{sec}$ layer. The top of the densely welded part of the Bishop Tuff in the hole is about $930 \mathrm{~m}$, whereas the top of Hill's $4.4 \mathrm{~km} / \mathrm{sec}$ layer is about $1100 \mathrm{~m}$. The hole bottomed at $2109 \mathrm{~m}$ in a nonwelded unit (top about $2075 \mathrm{~m}$ ) after penetrating a massive (460 m thick) welded unit. Hill showed a depth to basement of about $2700 \mathrm{~m}$.

Electrical prospecting in the caldera was of several kinds and has been noted in section 2.1.2.8. The total field resistivity maps obtained from bipole-dipole resistivity surveys [Stanley et al., 1976] mainly reflect the resistivity distribution at rather shallow depths. The results from the audiomagnetotelluric soundings [Hoover et al., 1976] show an apparent resistivity low in the vicinity of the deep well, but the resistivities are so low that the skin depths (a measure of the depth of effective penetration) are less than $1 \mathrm{~km}$ in the vicinity of the deep hole. A fence diagram of the electrical-resistivity structure of the caldera constructed by one-dimensional inversion of Schlumberger and time domain electromagnetic soundings [Stanley et al., 1976, figure 9] reveals much shallow resistivity structure. However, the depth to which boundaries can be resolved in this region of rapid lateral changes in resistivity is difficult to ascertain (section 2.1.2.8). Stanley et al. [1976, figure 9] showed no unquestioned boundaries below about $1500 \mathrm{~m}$ and most are less. One might be inclined to think that the resistivity structure was not effectively explored below a depth of a kilometer. Certainly there is nothing in their results or those of Hoover 
et al. [1976] to suggest what was found in the deep well, namely resistivities of more than a thousand ohm-meters associated with the densely welded part of the Bishop Tuff beginning at about $930 \mathrm{~m}$ and extending with minor interruption to the total depth of $2109 \mathrm{~m}$ [Smith and Rex, 1977 , figure 11].

Tho temperature profiles for the deep hole (figure 2.3) are close enough to equilibrium that they reflect approximate temperatures in the surrounding rocks. The high gradients in the uppermost part of the hole as well as the reversal at $300 \mathrm{~m}$ were anticipated, for they are typical of a class of temperature distributions measured in shallow $(<400 \mathrm{~m})$ holes previously drilled in the caldera [Lachenbruch et al., 1976]. Indeed the shallow holes drilled close to the deep hole had similar temperature profiles [Smith and Rex, 1977]. The question was then not whether the temperature would reverse, but rather at what depth it would begin to rise again and at what depth would the temperatures reach those of economic interest. The results were totally unexpected from any inferences that could be drawn from any data gathered from the near surface. The temperature continued to decrease to a depth of about $1300 \mathrm{~m}$, and then it feebly increase to $72^{\circ} \mathrm{C}$ at the total depth of $2109 \mathrm{~m}$.

The fine structure of the temperature profile tells us something about what is going on but leaves many questions unresolved. The shallow temperature maximum near $300 \mathrm{~m}$ most probably respresents hot water flowing laterally that came up along faults not more than a few kilometers away. It is also noteworthy that the temperatures, although decreasing with depth, remain relatively high to a depth of about $900 \mathrm{~m}$ where they again abruptly decrease with depth. This depth of change is at the top of the densely welded (resistivity $1000 \mathrm{ohm}-\mathrm{m}$ ) part of the Bishop Tuff [Smith and Rex, 1977, figure 11].

Smith and Rex [1977] attributed the low temperatures in the lower part of the hole to deep circulation of cold meteoric water, but other interpretations are possible.

It is possible, perhaps even probable, that no laterally extensive hightemporature $\left(>200^{\circ} \mathrm{C}\right)$ reservoirs exist in Long Valley. Perhaps the hot water is confined to fracture systems related either to the resurgent dome or to regional Sierran faulting [e.g., Stanley et al., 1976]. Such appears to be the case in the Valles caldera of New Mexico where production is from fractures associated with a graben structure in the resurgent dome [Dondanville, 1978].

The experience gained in Long Valley illustrates the difficulty of assessing the lateral extent of geothermal systems at depth. Hot water rises along fractures, spreads outward at relatively shallow depths, and leaves evidence of hydrothermal activity over a broad region in the form of hot springs and hydrothermally altered rock. Under reasonably favorable conditions, the distribution can be mapped by electrical methods but only to relatively modest depths. 
East Mesa geothermal area. The East Mesa geothermal area, Imperial County, California, is one of several in the Salton Trough of southern California and northern Mexico. From north to south they are [see map 1 of Muffler, 1979]: Salton Sea [Helgeson, 1968; Muffler and White, 1969 ; Robinson and Elders, 1976 ; Kasameyer and Younker, 1978]; Brawley; Glamis; East Mesa ; Dunes [Bird and Elders, 1976; Combs and Wilt, 1976]; Heber [Brown and Elders, 1976; Olson, 1976]; and Cerro Prieto, Mexico [Mercado, 1970; Koenig, 1973; Reed, 1976; Elders et al., 1978; Olson and Elders, 1978; Hoagland and Elders, 1978].

All these areas are in the Salton Trough, which is the landward extension of the Gulf of California. The region is one of active rifting. Baja California and adjacent parts of California are moving northwestward and a little seaward, thus creating the gulf and the trough.

The rifting is produced by a series of short spreading centers connected by long transform faults [e.g., Larson et al., 1968; Atwater, 1970; Elders et al., 1972; Moore, 1973; Elders and Biehler, 1975]. The details of the rift system are complex and some would prefer to think in terms of "leaky" transform faults [Elders and Biehler, 1975]. In the gulf the spreading centers appear to be manifest by deep basins [Henyey and Bischoff, 1973; Moore, 1973] and high heat flow [Von Herzen, 1963; Lawver, 1975]. The magnetic anomaly patterns so typical of ocenn spreading centers are absent except near the mouth of the gulf [Larson, 1972; Larson et al., 1972].

Quite possibly rifting extends into the Salton Trough, although it is harder to demonstrate because the trough is filled with as much as $6 \mathrm{~km}$ of sediment [Kovach et al., 1962; Biehler et al., 1964] derived primarily from the Colorado River [Merriam and Bandy, 1965; Muffler and Doe, 1968].

Some Quaternary igneous activity in the trough is evident: (1) The rhyolite domes near the southeast end of the Salton Sea [Kelley and Soske, 1936; Griscom and Muffer, 1971] are approximately 16,000 years old [Muffler and White, 1969] and steam still issues from cracks in some of them [Robinson and Elders, 1976]; (2) silicic and mafic rocks were encountered in several holes drilled in the Salton Sea area [Robinson et al., 1976]; (3) a dacite-basalt volcano exists near Cerro Prieto [Koenig, 1973]; (4) pleistocene diabase was penetrated in a drill hole at the Heber geothermal area [Brown and Elders, 1976; Olson, 1976].

The volcanism of the Salton Sea area appears to be characterized by a bimodal basalt-rhyolite assemblage typical of many extensional environments. The composition of the basalt suggests that it represents magma formed in the upper mantle beneath an active spreading center [Elders et al., 1972; Robinson and Elders, 1976]. The petrogenesis of the rhyolites is not as well understood [Robinson and Elders, 1976].

Heat flow as determined in shallow drill holes in parts of the Salton Trough is high [Rex, 1966; Combs, 1971, 1972; Combs and Rex, 1971; Combs and Muffler, 1973; Swanberg, 1976; Iee and Cohen, 1979]. To a 
degree, these shallow measurements are indicative of the thermal regime at depth [e.g., Swanberg, 1976], but in places, the shallow temperature gradients are subject to severe hydrologic perturbations [Diment et al., 1977] resulting from canal leakage and regional ground-water flow [Loeltz et al., 1975].

The sediments of Salton Trough are being actively metamorphosed to rocks of the greenschist facies by hot ascending brines [Muffler and White, 1969]. Moreover, decarbonization reactions lead to the release of $\mathrm{CO}_{2}$ as evidenced by the abundant production of the Imperial Carbon Dioxide Gas Field [Muffer and White, 1968]. The metamorphism leads to a reduction of intrinsic porosity; thus, the hotter regions store less water [Dutcher et al., 1972], although fracture porosity and permeability may be significant.

Subsurface conditions in the East Mesa area are better known to the public than those in most areas of the Salton Trough because: (1) A part of the area has been set aside for a U.S. Bureau of Reclamation (USBR). desalting experiment and later, in cooperation with the Department of Energy (DOE) and the Lawrence Berkeley Laboratory (LBL), as a geothermal test facility [USBR, 1974, 1977]; (2) considerable deep drilling and testing has been done, the results of which have been published or otherwise made available; (3) an unusually broad spectrum of investigations has been undertaken which will utimately yield one of the better case histories of the exploration for and development of geothermal resources in the Salton Trough.

A few details of the five deep holes drilled by USBR in the East Mesa area are given in table 2.3 [reproduced from USBR, 1977, table 1] and yield a notion of some characteristics of the reservoir: (1) The temperatures are not so high as those at the Salton Sea or Cerro Prieto localities; (2) the salinity of the water, particularly above $2000 \mathrm{~m}$, is modest compared with nearly saturated brines extracted from the Salton Sea or Cerro Prieto fields; (3) there is a considerable increase in salinity between $2 \mathrm{~km}$ and $2.4 \mathrm{~km}$ (hole 6-1) which may reflect penetration into a different system; (4) substantial production can be achieved through the perforated and slotted intervals of casing.

A temperature profile (figure 2.4) in hole 31-1 obtained under nearequilibrium conditions [Urban et al., 1978] illustrates additional aspects of the reservoir and its cap: (1) The sharp break in gradient at about $840 \mathrm{~m}$ is common to all five holes [e.g., Swanberg, 1976], although there are minor variations in depth to the break among the holes; (2) the region above the break is generally referred to as the "conductive cap" of the system which, because of high clay content and resulting low permeability, arrests the upward flow of hot ascending waters; (3) the zone below the cap that exhibits much lower temperature gradients is usually referred to as the "convective reservoir" where transpoif of heat is thought to be largely by 
TABLE 2.3-USBR geothermal well characteristics, geothermal resource investigations, Imperial Valley, California

(Reproduced from U.S. Bureau of Reclamation, 1977, table 1)

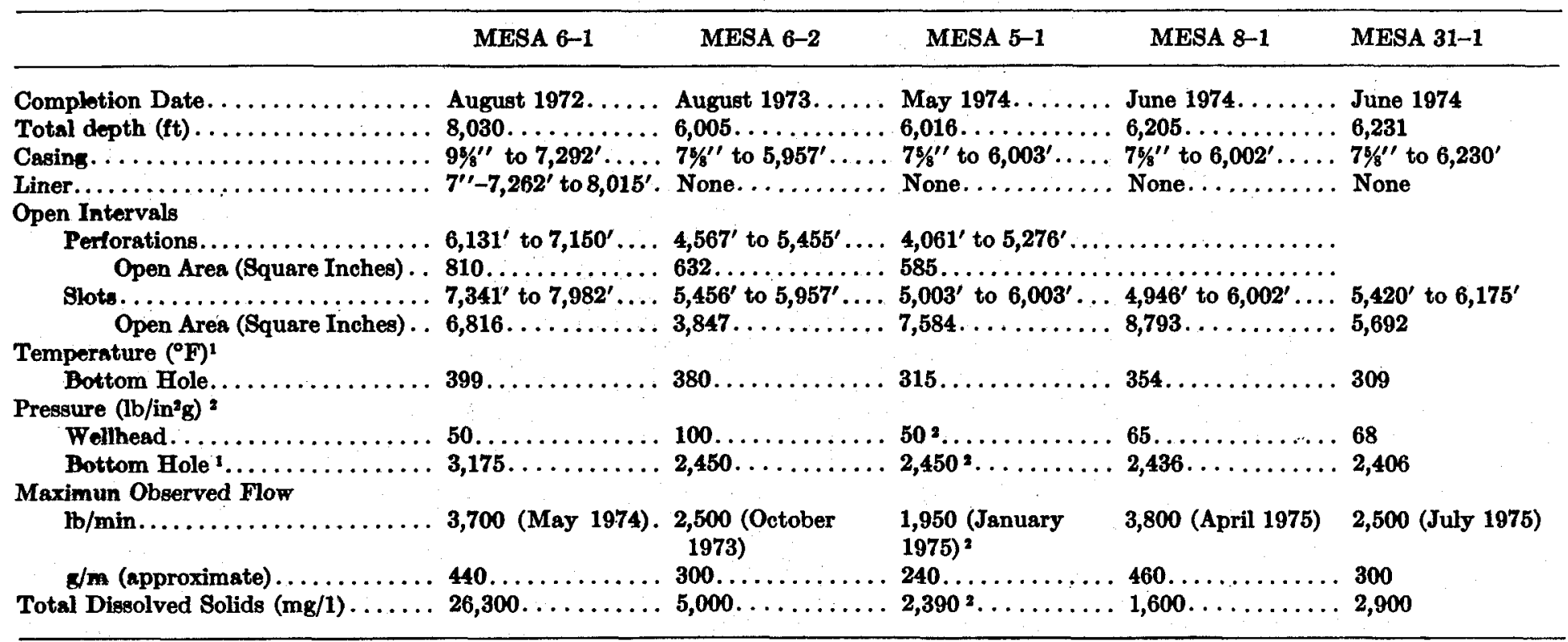

1 Well shut-in.

Before injection. 
convection, although other explanations for the low gradients are possible (section 2.1.2.5.f).

The gradients in the uppermost $200 \mathrm{~m}$ are anomalously high as they are in many of the shallow $(\sim 100 \mathrm{~m})$ holes [Combs, 1971; Swanberg, 1976] that were used initially to outline the boundaries of the geothermal area. Recently, it has become apparent that the near-surface thermal regime is greatly complicated by leakage from the three major water-distribution canals (unlined) that roughly bound the East Mesa geothermal area [Diment et al., 1977]. The water table has risen as much as $20 \mathrm{~m}$ in response to this leakage [Loeltz et al., 1975]. Although quantitative correction for the effect is difficult, an empirical correction has been used by TRW Systems Group [USBR, 1977, p. 11]. Perhaps the numerical modeling technique such as Miller [1977] employed to model the shallow regime over the area and environs would be useful if sufficient hydrologic information were available and if it could be applied in sufficient detail. Additional hydrologic disturbances may also exert a significant influence on the shallow thermal regime: the regional flow of ground water to the northwest [Loeltz et al., 1975]; oscillations in the level of ancient Lake Cahuilla whose last major shoreline traverses the western part of the geothermal area [Loeltz et al., 1975]. These details are of little general significance except that they illustrate the kinds of uncertainties that often attend the interpretaion of shallow temperature data.

The deltaic sands and clays that comprise the main part of the sedimentary sequence at East Mesa interfinger with lacustrine (lake) and aeolian (wind blown) deposits especially in the shallow part of the section [Loeltz et al., 1975]. The sedimentary sequence extends at least to the bottom of two deep petroleum tests adjacent to the area (American Petrofina, $3.1 \mathrm{~km}$; Texaco Ingebretsen $3.5 \mathrm{~km}$ [USBR, 1977]. Seismic-refraction measurements [Biehler et al., 1964] $10 \mathrm{~km}$ to the west of the area suggest a total depth of 5-6 km. Randall [1971] examined sand/shale ratios for the part of the section known from drill holes and found them to increase with depth and to the east. From geophysical logs, Swanberg [1976] found that the rocks of the "conductive cap" are more clay rich than those of the reservoir below.

Porosity in the USBR holes and adjacent wells is high $(\sim 35 \%)$ near the surface, decreases modestly to $2 \mathrm{~km}$, and then usually drops to $\sim 20 \%$ or below at greater depth [USBR, 1977, figure 3-5]. USBR [1977, p. 8] also concluded :

Note that lower porosity and permeability are characteristic of holes in the thermal area where abandoned holes off the thermal area appear more porous and permeable. This effect may be due to the deposition of water transported dissolved material as related to the anomalous heat area. 
The structure beneath the East Mesa geothermal area and environs is not well known and may never be known in much detail because the stratigraphy is complex. USBR [1977, p. 11] suggested (on the basis of interwell correlation of geophysical logs, dipmeter data, reflection seismograph lines across the area, and well pressure tests) that: "The field lies in a southwest plunging nose traversed by a northwest-southeast trending fault."

\subsubsection{Systems not related to young igneous intrusions in the upper crust}

2.1.3.2.a Systems in low porosity conductive environments. Considered here are those hot dry rock environments that are not directly related to young igneous intrusions in the upper crust (see section 2.1.3.1.b). They occur in conduction-dominated regimes and are, therefore, likely to be rather deep. The depth depends, of course, on the temperature sought and the size of the conductive gradient in a particular region. The extremes of gradient likely to be encountered on a regional basis are illustrated in figure 2.1.

Little is presently known about such hot dry rock environments or how to define these properties by near surface measurements. Muffler [1979, p. 160] noted:

At our present state of knowledge, extensive deep drilling is an essential step in exploration for hot dry rock. Geologic, geophysical, and geochemical techniques used alone are simply inadequate.

We would hasten to add, however, that the knowledge gained in the past decade about the properties of rocks in the hot dry rock temperaturepressure range is impressive; and that this knowledge coupled with sophisticated measurements in deep drill holes, could provide the basis for the better definition of such regimes by geophysical means. This is a research frontier.

Clearly, the interest in such regimes stems from the enormous amount of energy contained within them. Muffler [1979, pp. 160-162] grappled with the problem of how much thermal energy might someday be extracted from hot dry rock systems.

2.1.3.2.b Systems in low porosity conductive environments modified by circulation of meteoric water. Many systems in the Basin and Range Province and some adjacent regions of the western United States at least partially fall within this category. It is not really known whether some of them are related to young igneous intrusions as used in a previous context, or whether they owe their heat to the anomalously hot crust of the region. As previously noted (sections 2.1.1.2 and 2.1.2.3), the "mantle" or reduced heat flow $\left(q^{*}\right)$ is so high as to imply partial melting in lowermost crust and upper mantle. Moreover, this province is one of considerable crustal extention [e.g., Gilluly, 1972, figure 6; Thompson and Burke, 
1974; Lachenbruch and Sass, 1978] which most probably permits anomalously deep penetration of meteoric water.

The intrinsic porosity in the hotter and deeper part of these systems is probably low, although considerable fracture porosity probably exists. In the shallow and colder parts of some systems, considerable intrinsic porosity and permeability exists where hot waters ascending from below have entered deep alluvium-filled valleys, but even here the porosity and permeability may have been reduced by deposition or alteration.

Raft River geothermal area. The Raft River geothermal area of southern Idaho is the site of a Department of Energy project to utilize $150^{\circ} \mathrm{C}$ water for various purposes including a planned pilot power plant using a dual-boiling binary cycle with isobutane as the working fluid [Kunze et al., 1976; Muffler, ed., 1979, map 1]. Seven deep (1-2 km) wells have been drilled [Blake, 1978] and production obtained from the lowermost sediments filling this fault-bounded depression and/or from fractures in the igneous and metamorphic rocks below [Miller et al., 1978].

Surface manifestations of hydrothermal activity are few. The area was classified as a geothermal area on the basis of two shallow wells that flow boiling water [Goodwin et al., 1971] and yield silica and $\mathrm{Na}-\mathrm{K}-\mathrm{Ca}$ temperatures [Young and Mitchell, 1973] close to the maximum temperature $\left(147^{\circ} \mathrm{C}\right)$ observed in the first deep geothermal well [Williams et al., 1976]. Thermal IR imagery (section 2.1.2.2) outlines an area of near-surface hot water discharge in The Narrows about $8 \mathrm{~km}$ southwest of the deep wells. Samples from shallow and intermediate depth $(\sim 300$ $\mathrm{m})$ holes indicate pervasive hydrothermal alteration in some localities.

Silicic volcanism (rhyolite flows and domes) in the area is no younger than about $7 \mathrm{My}$ [Williams et al., 1976]. The age of the youngest surface faulting in the area is estimated to be about 0.1 My [Williams et al., 1976].

From a regional point of view, the Raft.River Valley would at first appear to be a fault-bounded valley typical of the eastern margin of the Great Basin. However, its tectonic environment is rather unusual in several respects: (1) The eastern Snake River Plains bounds it on the north some $50 \mathrm{~km}$ north of the deep wells. The Snake River Plain has been the site of vast outpourings of upper Cenozoic volcanic rocks [e.g., Christiansen and McKee, 1978], and there is reason to suppose that heat flow and crustal temperatures would be high [e.g., Brott and Blackwell, 1978]; (2) on the south, the Raft River Valley is terminated by the Raft River Mountains, one of the few east-trending ranges in the Basin and Range Province; (3) a northeast-trending structure (The Narrows structure), possibly of regional significance [Mabey et al., 1978], traverses the valley and separates regions of widely different structura] style in Pliocene and Miocene Salt Lake Formation [Williams et al., 1976]. The deep production wells are near the intersection of The Narrows 
structure and the north-trending faults bounding the western part of the valley.

A geophysical program of some detail [Williams et al., 1976; Mabey et al., 1978; Ackermann, 1979] successfully predicted the depth to basement (gravity, seismic refraction and Schlumberger electrical soundings), outlined the distribution of volcanic rocks (aeromagnetic surveys), and delineated several faults (a combination of the aforementioned techniques plus bipole-dipole total resistivity surveys). Unusual lateral variations in seismic velocities encountered in the refraction surveys are attributed by Ackermann [1979] to pervasive hydrothermal alteration of sediments in parts of the area. The complexities caused by these variations and the complexities of the structure of the area are such that interpretations of the details of the structure are somewhat controversial [e.g., contrast Mabey et al., 1978, and Ackermann, 1979].

Audiomagnetotelluric soundings, telluric current surveys, and selfpotential surveys were also made in this complex environment. The results, although interesting, are not easily interpreted in terms of the distribution of resistivity (AMT) or in terms of thermo-kinetic source locations (SP). A single deep magnetotelluric sounding was undertaken several kilometers northwest of the deep wells as part of a regional study of southern Idaho [Stanley et al., 1977]. A one dimensional inversion of the data suggests a deep conductor $(0.9 \mathrm{ohm}-\mathrm{m})$ starting at a depth of 6.3 $\mathrm{km}$, the significance of which is unknown according to Mabey et al. [1978].

Heat-flow measurements in the Raft River Valley and the regional environs were tabulated by Urban and Diment [1975]. With the exception of the area of hydrothermal convection where heat flows as high as 8 HFU were observed, heat flow (2.5 to 3 HFU) is only slightly high by Basin and Range standards. Temperature gradients measured in two abandoned petroleum tests also support this notion.

Williams et al. [1976] concluded that circulation of meteoric water to depths of 3 to $5 \mathrm{~km}$ could account for the hot water encountered in the deep wells.

2.1.3.2 Systems in high-porosity conduotive environments. Rocks of significant porosity and permeability extend to considerable depth in many sedimentary basins, as witnessed by the explorationists' search for oil and gas to depths approaching $10 \mathrm{~km}$. Porosity and permeability both tend to decrease with depth. Clays are compacted to shales; but overburden pressure alone does not reduce the porosity of sand much. This takes deposition in the pore spaces, a complex process which generally increases with age of the rocks. On the other hand, secondary porosity and permeability may develop as a consequence of processes such as fracturing, dolomitization, and leaching. In short, rocks of significant porosity and permeability might be expected locally to depths of several kilometers 
or more, but the chances of encountering them decrease with depth. This might also be said of igneous and metamorphic terranes, where fracture permeability can be very large locally even at considerable depth, but is not easily predictable short of drilling.

The geothermal gradients in many sedimentary basins are not particularly attractive for geothermal development, especially for the production of electric power which requires temperatures over $150^{\circ} \mathrm{C}$; temperatures this high can be reached only at depths of $\sim 4 \mathrm{~km}$ or more [e.g., American Association of Petroleum Geologists and U.S. Geological Survey, 1975]. On the other hand gradients in sedimentary basins tend to be higher than those in igneous and metamorphic terranes of the same heat flow because the thermal conductivity of porous sedimentary rocks is considerably lower than that of their metamorphosed equivalents. The effect of such a low conductivity blanket may be significant especially if it is thick [e.g., Diment et al., 1975, table 9].

In some cases aquifers at shallow depths $(<2000 \mathrm{~m})$ are sufficiently productive that even modest temperatures $\left(\sim 50^{\circ} \mathrm{C}\right)$ may make development attractive for space heating or certain industrial or agricultural processes [e.g., Einarsson, 1970].

The practicality of such development has been demonstrated at several localities near Paris, France. Here waters of temperatures between 57 and $75^{\circ} \mathrm{C}$ are extracted from a sandstone aquifer $1500-2000 \mathrm{~m}$ deep, circulated through a distribution system and reinjected into the same formation through injection wells on the order of $1 \mathrm{~km}$ from the production wells [Clot, 1977; Garnish, 1978; Varet, 1979]. The area exhibits rather normal geothermal gradients, although the regional heat flow is higher than the world average [Hentinger and Jolivet, 1970; Varet, 1979].

Another project to extract warm water from a relatively shallow depth $(\sim 2 \mathrm{~km})$ in a region of normal heat flow is underway in the Atlantic Coastal Plain of the eastern United States [Paddison, 1978; Tillman, 1978). Here the Coastal Plain sediments of low thermal conductivity blanket a metamorphosed and plutonized basement to a depth of $2 \mathrm{~km}$ or more near the coast. An additional bonus in temperature is being sought by selecting sites over granitic plutons of high radioactive heat production [Costain and Sinha, 1978]. The project is being conducted under the auspices of the U.S. Department of Energy. Although considerable geological and geophysical exploration has been conducted, including the completion of many $300 \mathrm{~m}$ holes for heat-flow measurements, the nature of the resource remains to be evaluated by deep drilling and testing.

In regions of anomalously high heat flow correspondingly higher temperatures would be expected. For example, in the Hungarian Basin, Boldizar [1970], and Boldizar and Korim [1976] reported up to $3 \mathrm{~km}$ of porous Cenozoic sediments in a region characterized by temperature 
gradients of 50 to $70^{\circ} \mathrm{C} / \mathrm{km}$ and heat flows of 2.0 to $3.4 \mu \mathrm{cal} / \mathrm{cm}^{2} \mathrm{~s}$. Boldizar and Korim [1976, p. 297] stated :

The main hot water reservoir is in the Upper Pliocene (Pannonian) sandstone formation. Hot water is produced by wells from blanket or sheet-like sand and sandstone intercalated frequently by siltstone. Along the 100 to $300 \mathrm{~m}$ length three to eight permeable strata are perforated resulting in $1-3 \mathrm{~m}^{8} / \mathrm{m}$ in hot water at 80 to $99^{\circ} \mathrm{C}$ temperature. The reservoir pressure at every depth corresponds to the density of the respective brine column of geothermal temperature and hydrostatic pressure distribution. Wells are overflowing with a shut-down pressure of 3-5 atm; 70,000 km of Pannonian sediment store $2800 \mathrm{~km}^{3}$ of hot water of which 10 percent is economically recoverable, amounting to $10^{16} \mathrm{kcal}$ of utilizable heat.

\subsubsection{Systems in high-porosity environments at pressures greatly in} excess of hydrostatic (the "geopressured systems"). Deep within certain sedimentary basins, zones exist where pore pressures considerably exceed hydrostatic pressure and even approach lithostatic pressure. The waters are hot enough to be of geothermal interest. Moreover, they contain considerable amounts of dissolved methane. Thus, three forms of energy might be extracted from wells drilled into such regimes: (1) The kinetic energy that could be developed from overpressure at the wellhead (generally regarded as small [e.g., Papadopulos et al., 1975; Hawkins, 1977; Wallace et al.; 1979]), (2) the heat energy of the extracted fluid, and (3) the combustion energy of the dissolved methane.

Geopressured zones are usually considered to be those that have vertical pressure gradients exceeding $10.5 \mathrm{kPa} / \mathrm{m}=0.105 \mathrm{bar} / \mathrm{m}=0.465 \mathrm{psi} / \mathrm{ft}$ [Wallace et al., 1979]. The pressure gradient in a fluid column of density $1.0 \mathrm{~g} / \mathrm{cm}^{3}$ is $9.8 \mathrm{kPa} / \mathrm{m}$ assuming that gravity is $980 \mathrm{~cm} / \mathrm{sec}^{2}$. Thus, 10.5 $\mathrm{kPa} / \mathrm{m}$ is close to hydrostatic pressure when the salinity of the pore water is considered. Potter and Brown [1977] gave the density of water to $500^{\circ} \mathrm{C}$, $200 \mathrm{MPa}$, and 25 percent by weight of $\mathrm{NaCl}$. Pressure gradients as measured over long intervals of depth in geopressured zones are often close to or exceed the lithostatic pressure gradient taken as $22.6 \mathrm{kPa} / \mathrm{m}$ by Wallace et al. [1979] after Norwood and Holland [1974]. Over short intervals, especially near the top of geopressured zones, pressure gradients may be much higher, of course.

Wallace et al. [1979, p. 148] identified eleven geopressured basins in the conterminous United States:

(1) Northern Gulf of Mexico basin: Texas and Louisiana, onshore-offshore. (2) Mississippi salt basin : Mississippi, southwest Alabama (?). (3) Appalachian basin: New York, Pennsylvania, West Virginia, western Virginia. (4) Anadarko-Ardmore basin : northwest Texas, west central Oklahoma. (5) North Louisiana salt basin : north central Louisiana and south central Arkansas (\%). (6) Delaware basin : 
southeastern New Mexico and west Texas. (7) Uinta basin: northeastern Utah and western Colorado. (8) Greater Green River basin including over-thrust belt, Wind River, Powder River and associated basins: Wyoming, eastern Idaho, northern Utah and northern Colorado. (9) Williston basin; North Dakota. (10) Great Valley miogeosyncline Franciscan eugeosyncline, Santa Barbara Channel, Los Angeles, Ventura and Tanner Banks basins : California onshore-offshore. (11) Grays Harbor to Hoh Head basin area: offshore Oregon and Washington Coos Bay to Vancouver Island.

They tabulated the geologic ages of the geopressured formations, their approximate depth ranges, the approximate ranges of pressure gradients. the approximate temperature ranges, and the probable geopressuring mechanisms which may vary from basin to basin. The mechanisms cited are: vertical compression (static load), resistance to fluid expulsion, diagenesis (particularly of the clays), uplift, horizontal compression (dynamic loading), and internal forces.

The northern Gulf of Mexico basin is by far the best known of the geopressured basins. Indeed Wallace et al. [1979], in a recent resource assessment, used data from over 3500 wells. Much of the geologic information relevant to the geopressured resources of the Gulf Coast has been repeatedly and enthusiastically summarized by Jones [e.g., 1970, 1976a, $1976 \mathrm{~b}]$, and much of the following was drawn from his accounts and from Wallace et al. [1979].

The basin has been filling with concomitant subsidence for the past 40 million years or so and there are now in excess of $15 \mathrm{~km}$ of sediments in the deepest part of the basin. The locus of sedimentation has shifted slowly seaward as successively younger beds covered and loaded those below. The sediments are largely sands, siltstones, and shales whose vagaries of distribution reflects a combination of fluvial, deltaic, and marine deposition. For deposits of the same age the sands are closest to the shore and the clays are farthest toward the sea.

The whole sequence of sediments is shot through with growth faults and faults caused by the massive intrusion of Jurassic salt from below; the salt intrusion continues to this day. As the explorationist for petroleum well knows, these faults compartmentalize reservoirs into zones that are not easily defined.

Now let us address the question why the geopressured zones exist and why they occur below a certain depth range. First consider the distribution of pressure with depth. The pressure is largely hydrostatic to a depth of $4 \mathrm{~km}$ (nominal). Then it abruptly increases, and at greater depths it may even approach lithostatic pressure. Temperatures appear to follow a somewhat similar pattern: low or rather normal geothermal gradients in the upper region, or the hydropressure zone as Jones [1976a] would call it; an abrupt increase in gradient going into the geopressure zone, and a sustained high temperature gradient below. 
In a conceptual sense, the phenomenon appears reasonably clear. Over time the sedimentary column has been increasingly loaded from above; thus, the known compaction must yield water to horizons above and ultimately to the surface. The process is locally and regionally impeded by the presence of impermeable clays. Therefore, it is not surprising that pressure anomalies would develop.

The fact that the transition from hydropressure to geopressure zones occur over a relatively narrow interval of temperature and depth has led some to the hypothesis that the discontinuity is the consequence of the diagenesis of the clay minerals. Montmorillonite dehydrates at temperatures of 80 to $120^{\circ} \mathrm{C}$ and the waters are expelled to adjacent sand reservoirs; thus, the pressures in the sand reservoirs are increased, the porosities are increased, and the salinities are decreased [Jones, 1976a]. However, the importance of clay transformations in generating high pressures has been questioned [Kharaka et al., 1978]. Moreover, Kharaka et al. [1978, p. 371] attributed the large differences in salinity of water in the geopressured zones from different fields mainly to interaction of water with salt beds.

The location of and depth to geopressured zones are in part determined by rock type. Wallace et al. [1979, p. 134] stated :

Fluid pressures higher than normal are most commonly associated with the alternating sandstone and shale facies and the massive shale facies. These fluid pressures usually increase with increasing depth and shale volume from the alternating sandstone and shale facies into the massive shale facies [Norwood and Holland, 1974, pp. 184-186]. Fluid pressures in these facies are high because expulsion of pore fluids is restricted. In addition, thermal expansion of water and addition of water from dehydration of clay tend to increase the volume of pore water. As a result, geopressures have probably existed in these sediments since burial to depths of $2000 \mathrm{ft}(610 \mathrm{~m})$ or less [Chapman, 1972, p. 790]. The fluids in geopressured zones must support a large part of the weight of the overburden.

Fluid pressures in the massive sandstone facies most commonly are normal because pore waters have been free to drain, allowing the sand to compact in response to increasing sedimentary load and thereby permitting the dissipation of pressure [Dickinson, 1953, p. 415]. In some cases, however, facies boundaries, growth faults, salt tectonics, or post-depositional alteration have effectively isolated sandstone bodies and prevented compaction and fluid expulsion; thus geopressures can exist locally in the massive sandstone facies.

The intrusion of hundreds of salt domes into the sedimentary pile has had important effects on the structural and thermal regimes. The intrusion produces faulting. Rim synclines surrounding the salt masses may have a structural relief of $3 \mathrm{~km}$ or so. The salt was probably intruded at fairly high temperatures and thus transported considerable heat upward. More- 
over, the thermal conductivity of salt is relatively high [Clark, 1966b] as compared with that of the sediments; and the salt masses funnel heat upward.

The resource potential of the geopressured zones is enormous [Papadopulos et al., 1975; Wallace et al., 1979]. But, many questions remain : e.g., Are the geopressured waters saturated with methane? What is saturation over the temperature, pressure, and salinity range of interest, a part of which is covered only by extrapolation [Haas, 1978]? Is there additional methane present in the form of immobile gas as suggested by Randolph [1977]? Are individual production zones of sufficient lateral extent to support sustained production? What are the characteristics of the brines [Hankins et al., 1978; Karkalits and Hankins, 1978] and to what depths must they be reinjected?

\section{Q.1.4 Acknowledgements}

L. J. P. Muffler read two drafts of the paper and contributed substantial information and guidance. I also appreciate the thoughtful reviews of the entire manuscript by E. C. Robertson and T. C. Urban. H. M. Iyer and J. S. Pomeroy provided useful input to parts of it. S. E. Brock contributed significantly to the bibliographic work and engineered the production of the manuscript in a short time.

\subsubsection{Bibliography}

Abrams, M. J., Ashley, R. P., Rowan, L. C., Goetz, A. F. H., and Kahle, A. B., 1977. Mapping of hydrothermal alteration in the Cuprite mining district, Nevada, using aircraft scanner images for the spectral region 0.46 to $2.36 \mu \mathrm{m}$ : Geology, vol. 5, pp. 713-718.

Ackermann, H. D., 1979. Seismic refraction study of the Raft River geothermal area, Idaho: Geophysics, vol. 44, pp. 216-225.

Albarede, F., 1975. The heat flow/heat generation relationship - an interaction model of fluids with cooling intrusions: Earth and Planetary Science Letters, vol. 27, pp. 73-78.

American Association of Petroleum Geologists and U.S. Geological Survey, 1976a. Geothermal gradient map of North America: Reston, Va., U.S. Geological Survey, 2 sheets, scale 1:5,000,000.

American Association of Petroleum Geologists and U.S. Geological Survey, 1976b. Subsurface temperature map of North America: Reston, Va., US. Geological Survey, 2 sheets, scale 1:5,000,000.

American Society of Photogrammetry, 1960. Manual of photographic interpretation: Falls Church, Virginia.

Anderson, D. L., and Archambeau, C. B., 1964. The anelasticity of the Earth: Journal of Geophysical Research, vol. 69, No. 10, pp. 2071-2084.

Anderson, D. L., and Hart, R. S.; 1978. Q of the Earth: Journal of Geophysical Research, vol. 83, pp. 5869-5882.

Anderson, O. L., and Perkins, P. C., 1974. Runaway temperatures in the asthenosphere resulting from viscous heating: Journal of Geophysical Research, vol. 79, pp. 21362138. 
Anderson, W. L., 1973. FORTRAN 4 programs for the determination of the transient tangential electric field and vertical magnetic field about a vertical magnetic dipole for an M-layer stratified earth by numerical integration and digital linear filtering: Springfield, Virginia, U.S. Department of Commerce, National Technical Information Service, PB2-21240.

Archie, G. E., 1942. The electrical resistivity log as an aid in determining some reservoir characteristics: American Institute of Mining and Metallurgical Engineers Transactions, vol. 146, pp. 54-62.

Armstrong, R. L., 1978. Cenozoic igneous history of the U.S. Cordillera from lat $42^{\circ}$ to $49^{\circ} \mathrm{N}$, in Smith, R. B., and Eaton, G. P., eds., Cenozoic tectonics and regional geophysics of the western Cordillera: Geological Society of America Memoir 152, pp. 265-282.

Atwater, T., 1970. Implications of plate tectonics for the Cenozoic tectonic evolution of western North America: Geological Society of America Bulletin, vol. 81, pp. 3513-3536.

Austin, C. F., and Leonard, G. W., 1973. Chemical explosive stimulation of geothermal wells, in Kruger, P., and Otte, C., eds., Geothermal energy: Stanford, California, Stanford University Press, pp. 269-292.

Avè Lallemant, H. G., and Carter, N. L., 1970. Syntectonic recrystallization of olivine and modes of flow in the upper mantle: Geological Society of America Bulletin, vol. 81, pp. 2203-2220.

Bailey, R. A., Dalrymple, G. B., and Lamphere, M. A., 1976. Volcanism, structure, and geochronology of Long Valley caldera, Mono County, California: Journal of Geophysical Research, vol. 81, pp. 725-744.

Baranov, V., 1957. A new method for interpretation of aeromagnetic maps; pseudogravimetric maps: Geophysics, vol. 22, pp.359-383.

Barnes, H. L., ed., 1967. Geochemistry of hydrothermal ore deposits : New York, Holt, Rinehart and Winston.

Best, M. G., and Hamblin, W. K., 1978. Origin of the northern Basin and Range province; Implications from the geology of its eastern boundary, in Smith, R. B., and Eaton, G. P., eds., Cenozoic tectonics and regional geophysics of the western Cordillera: Geological Society of America Memoir 15\%, pp. 313-300.

Bhattacharyya, B. K., and Leu, Lei-Kuang, 1975. Analysis of magnetic anomalies over Yellowstone National Park; Mapping of Curie point isothermal surface for geothermal reconnaissance: Journal of Geophysical Research, vol. 80, pp. 4461-4465.

Biehler, S., 1971. Gravity studies in the Imperial Valley, in Cooperative geologicalgeophysical-geochemical investigations of geothermal resources in the Imperial Valley area of California: Riverside, California, University of California, pp. 29-41.

Biehler, S., Kovach, R. L., and Allen, C. R., 1964. Geophysical framework of northern end of Gulf of California structural province, in Van Andel, T. H., and Shore, G. G., Jr., eds., Marine geology of the Gulf of California: American Association of Petroleum Geologists Memoir 3, pp. 126-143.

Birch, F., ed., 1942. Handbook of physical constants: Geological Society of America Special Paper $\$ 6$.

Birch, F., 1947. Temperatures and heat flow in a well near Colorado Springs: American Journal of Science, vol. 245, pp. 733-753.

Birch, F., 1948. The effects of Pleistocene climatic variations upon geothermal gradients: American Journal of Science, vol. 246, pp. 729-760.

Birch, F., 1950. Flow of beat in the Front Range, Colorado: Geological Society of America Bulletin, vol. 61, pp. 567-630.

Birch, F., 1951. Recent work on the radioactivity of potassium and some related geophysical problems: Journal of Geophysical Research, vol. 56, pp. 107-126.

Birch, F., 1954. Heat from radioactivity, in Faul, H., ed., Nuclear geology: New York, John Wiley and Sons, pp. 148-174. 
Birch, F., 1958. Interpretation of the seismic structure of the crust in the light of experimental studies of wave velocities in rocks, in Contributions in geophysics in honor of Beno Gutenberg: New York, Pergamon Press, pp. 158-170.

Birch, F., 1960. The velocity of compressional waves in rocks to 10 kilobars, pt. 1: Journal of Geophysical Research, vol. 65, pp. 1083-1102.

Birch, F., 1961. The velocity of compressional waves in rocks to 10 kilobars, pt. 2: Journal of Geophysical Research, vol. 66, pp. 2199-2224.

Birch, F., and Bancroft, D., 1938. The effect of pressure on the rigidity of rocks, II: Journal of Geology, vol. 46, pp. 113-141.

Birch, F., and Clark H., 1940. The thermal conductivity of rocks and its dependence upon temperature and composition, pts. I and II: American Journal of Science, vol. 238 , pp. 529-558, 613-635.

Birch, F., Roy, R. F., and Decker, E. R., 1968. Heat flows and thermal history in New England and New York, in Zen, E-an, White, W. S., Hadley, J. B., and Thompson, J. B., Jr., eds., Studies of Appalachian geology; Northern and maritime: New York, Interscience, pp. 437-451.

Bird, D. K., and Elders, W. A., 1976. Hydrothermal alteration and mass transfer in the discharge portion of the Dunes geothermal system, Imperial Valley of California, Proceedings of Second United Nations Symposium on the Development and Use of Geothermal Resources, San Francisco, California, 20-29 May 1975, vol. 1: Washington, D.C., Government Printing Office, pp. 285-295.

Blackwell, D. D., 1971a. The thermal structure of the continental crust, in Heacock, J. G., ed., The structure and physical properties of the Earth's Crust: American Geophysical Union Geophysical Monograph 14, pp. 169-184.

Blackwell, D. D., 1971b, Heat flow, in US. National report to the International Union of Geodesy and Geophysics: American Geophysical Union Transactions, vol. 52, No. 5, pp. 135-139.

Blackwell, D. D., 1978. Heat flow and energy loss in the Western United States, in Smith, R. B., and Eaton, G. P., eds., Cenozoic tectonics and regional geophysics of the western Cordillera: Geological Society of America Memoir 152, pp. 175-208.

Blackwell, D. D., and Morgan, P., 1976. Geological and geophysical exploration of the Marysville geothermal area, Montana, U.S.A., in Proceedings of Second United Nations Symposium on the Development and Use of Geothermal Resources, San Francisco, California, 20-29 May 1975, vol. 2: Washington, D.C., US. Government Printing Office, pp. 895-902.

Blake, G. L., ed., 1978. Semi-annual progress report for the Idaho geothermal program, October 1, 1977, to March 31, 1978: Idaho Falls, Idaho, EG and G Idaho, Inc., Report No. TREE 1278. (Prepared for the U.S. Department of Energy.)

Bodvarsson, G., 1970. Evaluation of geothermal prospects and the objectives of geothermal exploration: Geoexploration, vol. 8, pp. 7-17.

Boldizar, T, 1970. Geothermal energy production from porous sediments in Hungary: Geothermics, Special Issue 2, vol. 2, pt. 1, pp. 99-109.

Boldizar, T., and Korim, K., 1976. Hydrogeology of the Pannonian geothermal basin, Proceedings of Second United Nations Symposium on the Development and Use of Geothermal Resources, 20-29 May, 1975, San Francisco, California: Washington, D.C., US. Government Printing Office, vol. 1, pp. 297-303.

Bolt, B. A., and Nuttli, O. W., 1966. P-wave residuals as a function of azimuth, Journal of Geophysical Research, vol. 71, pp. 5977-5985.

Bostick, F. X., Jr., and Smith, H. W., 1962. Investigation of large-scale inhomogeneity in the Earth by the magnetotelluric method: Institute of Radio Engineers Proceedinigs, vol. 40, pp. 2339-2346.

Brace, W. F., 1965. Some new measurements on the linear compressibility of rocks: Journal of Geophysical Research, vol. 70, pp. 391-398. 
Brace, W. F., 1971. Resistivity of saturated crustal rocks to $40 \mathrm{~km}$ based on laboratory studies, in Heacock, J. G., ed., The structure and physical properties of the Earth's crust: American Geophysical Union Geophysical Monograph 14, pp. 243256.

Brace, W. F., and Orange, A. S., 1968. Electrical resistivity changes in saturated rocks during fracture and frictional sliding: Journal of Geophysical Research, vol. 73, pp. 1433-1445.

Bredehoft, J. D., and Papadopulos, I. S., 1965. Rates of vertical groundwater movement estimated from the Earth's thermal profile: Water Resources Research, vol. 1, pp. 325-328.

Brook, C. A., Mariner, R. H., Mabey, D. R., Swanson, J. R., Guffanti, Marianne, and Muffier, L. J. P., 1979. Hydrothermal convection systems with reservoir temperatures $\geqslant 90^{\circ} \mathrm{C}$, in Muffler, L. J. P., ed., Assessment of geothermal resources of the United States-1978: US. Geological Survey Circular 790, pp. 18-85.

Brott, C. A., and Blackwell, D. D., 1978. Tectonic implicatioins of the heat flow of the western Snake River plain, Idaho: Geological Society of America Bulletin, vol. 89 , pp. 1697-1707.

Brown, P. R. L., and Elders, W. A., 1976. Hydrothermal alteration of diabase, Heber geothermal field, Imperial Valley, California [äbs.]: Geological Society of America Abstracts with Programs, vol. 8, No. 6, pp. 793.

Budiansky, B., and O'Connell, R. J., 1976. Elastic moduli of a cracked solid: International Journal of Solid Structure, vol. 12, pp. 81-97.

Bufe, C. G., Marks, S. M., Lester, F. W., Louie, K., and Briscoe, S., 1978. Seismicity of The Geysers/Clear Lake geothermal area, California [abs.]: Earthquake Notes, vol. 49, No. 1, pp. 32-33.

Bufe, C. G., Phluke, J. H., Lester, F. W., and Marks, S. M., 1976. Map showing preliminary hypocenters of earthquakes in the Healdsburg $(1: 100,000)$ quadrangle, Lake Berryessa to Clear Lake, California January 1969-June 1976; U.S. Geological Survey Open File Map 76-80\%.

Bullard, E. C., 1947. The time necessary for a bore hole to attain temperature equilibrium: Royal Astronomical Society Monthly Notices Geophysical Supplement, vol. 5, pp. 127-130.

Burnham, J. B., and Stewart, D. E.; 1973. Recovery of geothermal energy from hot, dry rock with nuclear explosives, in Kruger, $\mathbf{P}$, and Otte, C., eds., Geothermal energy: Stanford, California, Stanford University Press, pp. 223-230.

Burst, J. F., 1969. Diagenesis of Gulf Coast clayey sediments and its possible relation to petroleum migration: American Association of Petroleum Geologists Bulletin, vol. 50, pp. 2472-2478.

Byerly, P. E., and Stolt, R. H., 1977. An attempt to define the Curie point isotherm in northern and central Arizona: Geophysics, vol. 47, pp. 1394-1400.

Cagniard, L., 1953. Basic theory of the magneto-telluric method of geophysical prospecting: Geophysics, vol. 18, pp. 605-635.

Cann, J. R., 1968. Geological processes at mid-ocean ridge crests: Royal Astronomical Society Geophysical Journal, vol. 15, pp. 331-341.

Carslaw, H. S., and Jaeger, J. C., 1959. Conduction of heat in solids (2d ed.): London, Oxford University Press.

Carter, N. L., Baker, D. W., and George, R. P., 1972. Seismic anisotropy, flow, and constitution of the upper mantle, in Heard, H. C., Borg, I. Y., Carter, N. L., and Raleigh, C. B., eds., Flow and fracture of rocks: American Geophysical Union Geophysical Monograph 16, pp. 167-190.

Chaipayungpun, W., and Landisman, M., 1977. Crust and upper mantle near the western edge of the Great Plains, in Heacock, J. G., ed., The Earth's crust: American Geophysical Union Geophysical Monograph 20, pp. 553-575. 
Chapman, R. E., 1972. Clays with abnormal interstitial fluid pressures: American Association of Petroleum Geologists Bulletin, vol. 56, No. 4, pp. 790-795.

Chapman, R. H., 1975. Geophysical study of the Clear Lake region, California: California Division of Mines and Geology Special Report 116.

Christensen, M. N., 1966. Late Cenozoic crustal movements in the Sierra Nevada of California: Geological Society of America Bulletin, vol. 77, pp. 168-182.

Christensen, N. I., 1966. Elasticity of ultrabasic rocks: Journal of Geophysical Research, vol. 71, pp. 5921-5931.

Christensen, N. I., 1971. Fabric, seismic anisotropy and tectonic history of the Twin Sisters dunite, Washington: Geological Society of America Bulletin, vol. 82, pp. 1681-1694.

Christiansen, R. L., 1974. Quaternary volcanism of the Yellowstone rhyolite plateau region, Wyoming-Idaho-Montana [abs.]: EOS (American Geophysical Union Transactions), vol. 56, p. 1189.

Christiansen, R. L., 1975. Origin and geothermal potential of Island Park, eastern Idaho: Geological Society of America Abstracts with Programs, vol. 7, pp. 595-596.

Christiansen, R. L., and Blank, H. R., Jr., 1969. Volcanic evolution of the Yellowstone rhyolite plateau and eastern Snake River plain, U. S. A. [abs.], in Symposium on volcanoes and their roots, volume of abstracts: Oxford, England, International Association of Volcanology and Chemistry of the Earth's Interior, pp. 220-221.

Christiansen, R. L., and Lipman, P. W., 1972. Cenozoic volcanism and plate tectonic evolution of the western United States: Royal Society of London Philosophical Transactions, Series A, vol. 271, pp. 249-284.

Christiansen, R. L., and McKee, E. H., 1978. Late Cenozoic volcanic and tectonic evolution of the Great Basin and Columbia Intermontane regions, in Smith, R. B., and Eaton, G. P., eds., Cenozoic tectonics and regional geophysics of the western Cordillera: Geological Society of America Memoir 152, pp. 283-311.

Clacy, G. R. T., 1968. Geothermal ground noise amplitude and frequency spectra in the New Zealand volcanic region. Journal of Geophysical Research, vol. 73, pp. 5377.

Claerbout, J. F., 1976. Fundamentals of geophysical data processing with application to petroleum prospecting: New York, McGraw-Hill.

Clark, S. P., Jr., 1957. Radiative transfer in the Earth's mantle: American Geophysical Union Transactions, vol. 38, pp. 931-938.

Clark, S. P., Jr., 1966. Thermal conductivity, in Clark, S. P., Jr., ed., Handbook of physical constants: Geological Society of America Memoir 97, pp. 459-482.

Clark, S. P., Jr., 1969. Heat conductivity in the mantle, in Hart, P. J., ed., The Earth's crust and upper mantle: Americal Geophysical Union Geophysical Monograph 18, pp. 622-626.

Clark, S. P., Jr., Peterman, Z. E., and Heier, K. S., 1966. Abundances of uranium, thorium, and potassium, in Clark, S. P., Jr., ed., Handbook of physical constants: Geological Society of America Memoir 97, pp. 521-542.

Clot, A., 1977. La geothermie "basse energy": La recherche, vol. 8, pp. 213-223.

Colp, J. L., 1974. Magma Tap-the ultimate geothermal energy program: CircumPacific Energy and Mineral Resources Conference at Honolulu, Hawaii, August 28, 1974.

Colp, J. L., and Brandvold, G. E., 1976. The Sandia magma energy research project: Proceedings Second United Nations Symposium on the Development and Use of Geothermal Resources, San Francisco, California, 20-29 May 1975 vol. 3: Washington, D.C., U.S. Government Printing Office, pp. 1599-1607.

Colp, J. L., and Okamura, R. T., 1978. Drilling into molten rock at Kilauea Iki: Geothermal Resources Council Transactions, vol. 2, pp. 105-108.

Combs, J., 1971. Heat flow and geothermal resource estimates for the Imperial Valley, in Rex, R. W., et al., Cooperative geological-geophysical-geochemical investiga- 
tions of geothermal resources in the Imperial Valley area of California: Riverside, University of California, pp. 5-27.

Combs, J., 1972. Preliminary heat flow values and temperature distributions associated with the Mesa and Dunes geothermal anomalies, Imperial Valley, southern California [abs.]: EOS (American Geophysical Union Transactions), vol. 53, No. 4, pp. 515-516.

Combs, J., and Hadley, D., 1977. Microearthquake investigation of the Mesa geothermal anomaly, Imperial Valley, California: Geophysics, vol. 42, pp. 17-33.

Combs, J., and Jarzabek, D., 1978. Seismic wave attenuation anomalies in the East Mesa geothermal field, Imperial Valley, California; Preliminary results: Geothermal Resources Council Transactions, vol. 2, pp. 109-112.

Combs, J., and Muffler, L. J. P., 1973. Exploration for geothermal resources, in Kruger, P., and Otte, C., eds., Geothermal energy: Stanford, California, Stanford University Press, pp. 95-128.

Combs, J., and Rex, R. W., 1971. Geothermal investigations in the Imperial Valley of California [abs.]: Geological Society of America Abstracts with Programs, vol. 3, No. 2, pp. 101-102.

Combs, J., and Rotstein, Y., 1976. Microearthquake studies at the Coso geothermal area, China Lake, California, in Proceedings Second United Nations Symposium on the Development and Use of Geothermal Resources, San Francisco, California, 20-29 May, 1975, vol. 2: Washington, D.C., U.S. Government Printing Office, pp. 909-916.

Combs, J., and Wilt, M., 1976. Telluric mapping, telluric profiling, and self-potential surveys of the Dunes geothermal anomaly, Imperial Valley, California, in Proceedings Second United Nations Symposium on the Development and Use of Geothermal Resources, San Francisco, California, 20-29 May 1975, vol. 2: Washington, D.C., U.S. Government Printing Office, pp. 917-928.

Corwin, R. F., and Hoover, D. B., 1979. The self-potential method in geothermal exploration: Geophysics, vol. 44, pp. 226-245.

Costain, J. K., and Sinha, A. K., 1978. Relationship between heat flow and heat generation in the southeastern United States: Geological Society of America Abstracts wili, Programs, vol. 10, No. 4, p. 166.

Costain, J. K., and Wright, P. M., 1973. Heat flow at Spor Mountain, Jordan Valley, Bingham, and La Sal, Utah: Journal of Geophysical Research, vol. 78, pp. 86878698.

Cumberlidge, J. T., and Saull, V. A., 1959. Some experiments on surface and strain energy in minerals [abs.]: Geological Society of America Bulletin, vol. 70, No. 12 , pt. 2, p. 1584 .

Daly, R. A., Manger, G. E., and Clark, S. P., Jr., 1966. Density of rocks, in Clark, S. P., Jr., Handbook of physical constants: Geological Society America Memoir 97, pp. 19-26.

Dickinson, D. J., 1976. An airborne infrared survey of the Tauhara geothermal field, New Zealand, Proceedings Second United Nations Symposium on the Development and Use of Geothermal Resources, San Francisco, California, 20-29 May 1975, vol. 2: Washington, D.C., U.S. Government Printing Office, pp. 955-961.

Dickinson, G., 1953. Geological aspects of abnormal reservoir pressures in Gulf Coast Louisiana: American Association of Petroleum Geologists Bulletin, vol. 37, No. 3, pp. $410-432$.

Diment, W. H., 1964. Thermal conductivity of serpentinites from Mayaguez, Puerto Rico, and from some other localities, in Burk, C. A., ed., A study of serpentinite-the AMSOC core hole near Mayaguez, Puerto Rico: National Academy of SciencesNational Research Council Publication 1188, pp. 92-106. 
Diment, W. H., 1967. Thermal regime of a large diameter bore hole-instability of the water column and comparison of air and water-filled conditions: Geophysics, vol. 32 , pp. 720-726.

Diment, W. H., 1975. Heat flow and shallow thermal regime, in Bell, P. M., ed., U.S. National Report 1971-1975: Reviews of Geophysics and Space Physics, vol. 13, pp. 340-344 and 372-379.

Diment, W. H., Marine, I. W., Neiheisel, J., and Siple, G. E., 1965. Subsurface temperatures, thermal conductivity, and heat flow near Aiken, South Carolina: Journal of Geophysical Research, vol. 70, pp. 5635-5644.

Diment, W. H., and Robertson, E. C., 1963. Temperature, thermal conductivity, and heat flow in a drilled hole near Oak Ridge, Tennessee: Journal of Geophysical Research, vol. 68, pp. 5035-5047.

Diment, W. H., Urban, T. C., and Revetta, F. A., 1972. Some geophysical anomalies in the Eastern United States, in Robertson, E. C., ed., The Nature of the Solid Earth: New York, McGraw-Hill, pp. 544-572.

Diment, W. H., Urban, T. C., Sass, J. H., Marshall, B. W., Munroe, R. J., and Lachenbruch, A. H., 1975. Temperatures and heat contents based on conductive transport of heat, in White, D. E., and Williams, D. L., eds., Assessment of geothermal resources of the United States-1975: US. Geological Survey Circular 726, pp. 84-103.

Diment, W. H., Urban, T. C., Natheson, Manual, and Mathias. K. E., 1977. East Mesa geothermal anomaly, Imperial County, California: Effects of canal leakage on shallow thermal regime [abs.] : EOS (American Geophysical Union, Transactions), vol. 58, p. 1241.

Diment, W. H., and Weaver, J. D., 1964. Subsurface temperatures and heat flow in the AMSOC core hole near Mayaguez, Puerto Rico, in Burk, C. A., ed., A study of serpentinite: The AMSOC core hole near Mayaguez, Puerto Rico: National Acudemy of Sciences-National Research Council Publication 1188, pp. 75-91.

Diment, W. H., and Werre, R. W., 1964. Terrestrial heat flow near Washington, D.C.: Journal of Geophysical Research, vol. 69, pp. 2143-2149.

Dix, C. H., 1952. Seismic prospecting for oil: New York, Harper and Brothers.

Dobrin, M. B., 1976. Introduction to geophysical prospecting: New York, McGrawHill.

Doell, R. R., Dalrymple, G. B., Smith, R. L., and Bailey, R. A., 1968. Paleomagnetism, potassium-argon ages, and geology of the rhyolites and-associated rocks of the Valles Caldera, New Mexico, in Studies in Volcanology, Geological Society of America Memoir 116, pp. 211-248.

Domenico, S. N., 1974. Effect of water saturation on seismic reflectivity of sand reservoirs encased in shale: Geophysics, vol. 39, pp. 759-769.

Dondanville, R. F., 1978. Geologic characteristics of the Valles Caldera geothermal system, New Mexico: Geothermul Resources Council Transactions, vol. 2, pp. 157160.

Dorsey, N. E, 1968. Properties of ordinary water-substance: New York, Hafner.

Douze, E. J., and Sorrells, G. G., 1972. Geothermal ground-noise surveys: Geophysics, vol. 37, pp. $813-824$.

Duprat, A., and Omnes, G., 1976. The costs of geophysical programs in geothermal exploration: Proceedings Second United Nations Symposium on the Development and Use of Geothermal Resources, San Francisco, California, 20-29 May 1975, vol. 2: Washington, D.C., U.S. Government Printing Office, pp. 963-970.

Dutcher, L. C., Hardt, W. F., and Moyle, W. R., Jr., 1972. Preliminary appraisal of groundwater in storage with reference to geothermal resources in the Imperial Valley area, California: U.S. Geological Survey Circular 649.

Eaton, G. P., Wahl, R. R., Prostka, H. J., Mabey, D. R., and Kleinkopf, M. D., 1978. Regional gravity and tectonic patterns-Their relation to late Cenozoic epirogeny 
and lateral spreading in the western Cordillera, in Smith, R. B., and Eaton, G. P., eds., Cenozoic tectonics and regional geophysics of the western Cordillera: Geological Society of America Memoir 152, pp. 51-91.

Einarsson, S. S., 1970. Utilization of low enthalpy water for space heating, industrial, agricultural, and other uses: Geothermics, Special Issue 2, vol. 1, pp. 112-121.

Elders, W. A., and Biehler, S., 1975. Gulf of California rift system and its implications for the tectonics of western North America: Geology, vol. 3, pp. 85-87.

Elders, W. A., Hoagland, J. R., and Olson, E. R., 1978. Hydrothermal mineralogy and isotopic geochemistry in the Cerro Prieto geothermal field, Mexico. III. Practical applications: Geothermal Resources Council Transactons, vol. 2, pp. 177-180.

Elders, W. A., Rex, R. W., Meidav, T., Robinson, P. T., and Biehler, S., 1972. Crustal spreading in southern California: Science, vol. 178, No. 4056, pp. 15-24.

Ellis, A. J., 1967. The chemistry of some explored geothermal systems, in Barnes, H. L., ed., Geochemistry of hydrothermal ore deposits: New York, Holt, Rinehart and Winston, pp. 465-514.

Ellis, A. J., and Mahon, W. A. J., 1977. Chemistry and geothermal systems: New York, Academic Press.

England, A. W., and Johnson, G. R., 1976. Thermal microwave detection of near surface thermal anomalies: Proceedings Second United Nations Symposium on the Development and Use of Geothermal Resources, San Francisco, California, 20-29 May 1975, vol. 2: Washington, D.C., U.S. Government Printing Office, pp. 971-977.

Environmental Research Institute of Michigan, 1975. Proceedings of the Tenth International Symposium on Remote Sensing of the Environment, 6-10 October 1975: Ann Arbor, Michigan, Center for Remote Sensing Information and Analysis, Environmental Research Institute of Michigan, vol. 2.

Evans, D. M., 1966. The Denver area earthquakes and the Rocky Mountain Arsenal disposal well: The Mountain Geologist, vol. 3, pp. 23-26.

Facca, G., and Tonani, F., 1964. Theory and technology of a geothermal field: Bulletin Volcanologique, vol. 27, pp. 143-189.

Feues, M., Simmons, G., and Siegfried, R. W., 1977. Microcracks in crustal igneous rocks - physical properties, in Heacock, J. G., ed., The Earth's crust: American Geophysical Union Geophysical Monograph 20, pp. 95-117.

Fletcher, J. B., Sbar, M. L., and Sykes, L. R., 1978. Seismic trends and travel time residuals in eastern North America and their tectonic implications: Geological Society of American Bulletin, vol. 89, pp. 1656-1676.

Fournier, R. O., and Rowe, J.J., 1966. Estimation of underground temperatures from the silica content of water from hot springs and wet steam wells: American Journal of Science, vol. 264, pp. 685-697.

Fournier, R. O., Sorey, M. L., Mariner, R. H., and Truesdell, A. H., 1976. Geochemical prediction of aquifer temperatures in the geothermal system at Long Valley, California: U.S. Geological Survey Open-File Report 76-469.

Fournier, R. O., Thompson, J. M., and Austin, C. F., 1978. Chemical analyses and preliminary interpretation of waters collected from CGEH No. 1 geothermal well at Coso, California: US. Geological Survey Open-File Report 78-494.

Fournier, R. O., and Truesdell, A. H., 1973. An empirical Na-K-Ca geothermometer for natural waters: Geochimica et Cosmochimica, vol. 37, pp. 1255-1275.

Fournier, R. O., and Truesdell, A. H., 1974. Estimating subsurface temperatures where warm springs result from mixing hot and cold waters [abs.]: International Symposium on Water-Rock Interaction, Czechoslovakia, Abstract volume, p. 59.

Fournier, R. O., White, D. E., and Truesdell, A. H., 1974. Geochemical indicators of subsurface temperatures, part 1, Basic assumptions: U.S. Geological Survey Journal of Research, vol. 2, No. 3, pp. 259-262. 
Francis, T. J. G., 1969. Generation of seismic anisotropy in the upper mantle along mid-ocenn ridges: Nature, vol. 221, pp. 162-165.

Gardner, G. H. F., Gardner, I. W., and Gregory, A. R., 1974. Formation velocity and density-the diagnostic basics for stratigraphic traps: Geophysics, vol. 39, pp. 770780.

Garnish, J. D., 1978. Progress in geothermal energy: Endeavor, New Series, vol. 2, pp. 66-71.

Gary, Margaret, McAfee, Robert Jr,, and Wolf, C. L., eds., 1972. Glossary of geology: Washington, D.C., American Geological Institute.

Gilluly, J., 1972. Tectonics involved in the evolution of mountain ranges, in Robertson, E. C., ed., The nature of the solid earth: Now York, McGraw-Hill, pp. 406-439.

Goff, F. E., and Donnelly, J. M., 1978. The influence of $P_{\text {cos, salinity and bedrock type }}$ on the $\mathrm{Na}-\mathrm{K}-\mathrm{Ca}$ geothermometer as applied in the Clear Lake geothermal region, California: Geothermal Resources Council Transactions, vol, 2, pp. 211-213.

Goff, F. E., Donnelly, J. M., Thompson, J. M., and Hern, B. C., Jr., 1977. Geothermal prospecting in The Geysers-Clear Lake area, California: Geology, vol. 5, pp. 509511.

Goff, F. W., and McLaughlin, R. M., 1976, Geology of the Cobb Mountain-Ford Flat Geothermal area, Lake County, California: US. Geological Survey Open File Map 76-221, scale 1: 24,000 .

Goforth, T. T., Douze, E. J., and Sorrells, G. G., 1972. Seismic noise measurements in a geothermal area: Geophysical Prospecting, vol. 20, p. 76.

Goguel, J.., 1976. Geothermics (English edition): New York, McGraw-Hill.

Goldstein, N. E., and Paulsson, B., 1977 Northern Nevada investigations-gravity studies, in Earth Sciences Division Annual Report, Lawrence Berkeley Laboratory, University of California: Springfield, Virginia, National Technical Information Service, U.S. Department of Commerce, p. 137.

Goodwin, L. H., Haiger, L. B., Rioux, R. L., White, D. E., Muffler, L. J. P., and Wayland, R. G., 1971. Classification of public lands valuable for geothermal steam and associated geothermal resources: US. Geological Survey Circular 647.

Gough, D. I., 1974. Electrical conductivity under western North America in relation to heat flow, seismology, and structure: Journal of Geomagnetism and Geoelectricity, vol. 26, pp. 105-123.

Grant, F.S., and West, G. F., 1965. Interpretation theory in applied geophysics: New York, McGraw-Hill.

Green, D. H., 1971. Composition of basaltic magmas as indicators of conditions of origin-application to the oceanic volcanism: Philosophical Transactions Royal Society of London, Series A, vol. 268, pp. 707-725.

Gretener, P., 1967. On the thermal stability of large diameter wells-An observational report: Geophysics, vol. 32, pp. 727-738.

Grim, P. J., 1976. Terrestrial heat flow data [Map] : Boulder, Colorado, Word Data Center A, National Geophysical and Solar-Terrestrial Data Center, National Oceanic and Atmospheric Administration.

Grim, P. J., 1977. Geothermal energy resources of the western United States [Map]: Boulder, Colorado, National Geophysical and Solar-Terrestrial Data Center, National Oceanic and Atmospheric Administration, scale 1:2,500,000.

Grim, P. J., Nichols, C. R., Wright, P. M., Berry, G. W., and Swanson, 1978. State maps of low-temperature geothermal resources: Geothermal Resources Council Transactions, vol. 2, pp. 233-234.

Griscom, A., and Muffer, L.J.P., 1971. Aeromagnetic map and interpretation of the Salton Sea geothermal area; California: US. Geological Survey Geophysical Investigations Map GP-754, scale 1:62,500. 
Haas, J. L., Jr., 1978. An empirical equation with tables of smoothed solubilities of methane in water and aqueous sodium chloride solutions up to 25 weight percent, $360^{\circ} \mathrm{C}$, and $138 \mathrm{MPa}$ : U.S. Geological Survey Open-File Report 78-1004.

Hahman, W. R., Stone, C., and Witcher, J. C., 1978. Geothermal energy resources of Arizona, Geothermal map No. 1: Tucson, Arizona, Arizona Bureau of Geology and Mineral Technology, scale 1:1,000,000.

Hales, A. L., 1937. Convection currents in geysers: Royal Astronomical Society Monthly Notices, Geophysical Supplement, vol. 4, pp. 122-131.

Hales, A. L., and Herrin, E., 1972. Travel times of seismic waves, in Robertson, E. C., ed., The nature of the solid Earth: New York, McGraw-Hill, pp. 172-215.

Hamilton, R. M., 1965. Temperature variation at constant pressure of the electrical conductivity of periclase and olivine: Journal of Geophysical Research, vol. 70, pp. 5679-5692.

Hamilton, R. M., and Muffler, L. J. P., 1972. Microearthquakes at The Geysers geothermal area, California: Journal of Geophysical Research, vol. 77, pp. 2081-2086.

Hamilton, W., 1961. Origin of the Gulf of California: Geological Society of America Bulletin, vol. 72, pp. 1307-1318.

Hamilton, W., 1965. Geology and petrogenesis of the Island Park caldera of thyolite and basalt, eastern Idaho: U.S. Geological Survey Professional Paper 504-C.

Hankins, B. E., Chavanne, R. E., Ham, R. A., Karkalits, O. C., and Palermo, J. I., 1978. Chemical analysis of water from the world's first geopressured geothermal well: Geothermal Resources Council Transactions, vol. 2, pp. 253-256.

Harlow, F. H., and Pracht, W. E., 1972. A theoretical study of geothermal energy extraction: Journal of Geophysical Research, val. 77, pp. 7038-7048.

Harthill, N., 1978. A quadripole resistivity survey of the Imperial Valley, California: Geophysics, vol. 43, pp. 1485-1500.

Hawkins, M. F., Jr., 1977. Investigations on the geopressure energy resource of southern Louisiana: Baton Rouge, Louisiana, Louisiana State University, Petroleum Engineering Department, Final report, ORO-4889-14-ERDA Contract EY-76-S-05-4889.

Heacock, J. G., editor, 1977. The Earth's crust: American Geophysical Union Geophysical Monograph 20.

Healy, J. H., Rubey, W. W., Griggs, D. T, and Raleigh, C. B., 1968. The Denver earthquakes: Science, vol. 161, pp. 1301-1310.

Heard, D. G., 1978. Intracontinental plate boundary east of Cape Mendocino, California: Geology, vol. 6, pp. 721-725.

Hearn, B. C., Jr., Donnelly, J. M., and Goff, F. E., 1976. Preliminary map and cross. section of the Clear Lake volcanic field, Lake County, California: US. Geological Survey Open-File Map 76-751, scale 1:24,000.

Heiland, C. A., 1946, Geophysical exploration: New York, Prentice-Hall.

Helgeson, H. C., 1968. Geologic and thermodynamic characteristics of the Salton Sea geothermal system: American Journal of Science, vol. 266, pp. 129-166.

Hemley, J. J., 1959. Some mineralogical equilibria in the system $\mathrm{K}_{2} \mathrm{O}-\mathrm{Al}_{2} \mathrm{O}_{2}-\mathrm{SiO}_{2}-\mathrm{H}_{2} \mathrm{O}$ : American Journal of Science, vol. 257, pp. 241-270.

Hentinger, R., and Jolivet, J., 1970. Nouvelles determinations du flux geothermique en France: Tectonophysics, vol. 10, pp. 127-146.

Henyey, T. L., and Bischof, J. L., 1973. Tectonic elements of the northern part of the Gulf of California: Geological Society of America Bulletin, vol. 84, pp. 315329.

Hermance, J. F., Forsyth, D. W., and Colp, J. L., 1978. A critical assessment of geophysical sensing experiments on Kilauea Iki lava lake: Albuquerque, New Mexico, Sandia Laboratories, SAND 77-0828.

Herrin, E., 1968. Seismological tables for P-phases: Seismological Society of America Bulletin, vol. 58, pp. 1193-1239. 
Herrin, E., and Taggart, J., 1962. Regional variations in $P_{n}$ velocity and their effect on location of epicenters: Seismological Society of America Bulletin, vol. 52, pp. 1037-1046.

Hess, H. H., 1964. Seismic anisotropy of the uppermost mantle under the oceans: Nature, vol. 203, pp. 629-631.

Hill, D. P., 1976. Structure of Long Valley caldera, California, from a seismic refraction experiment: Journal of Geophysical Research, vol. 81, No. 5, pp. 745-753.

Hill, D. P., 1977. A model for earthquake swarms: Journal of Geophysical Research, vol. 82 , pp. $1347-1352$.

Hill, D. P., 1978. Seismic evidence for the structure and Cenozoic tectonics of the Pacific coast states, in Smith, R. B., and Eaton, G. P., eds., Cenozoic tectonics and regional geophysics of the western Cordillera: Geological Society of America Memoir 162, pp. 145-174.

Hill, J. H., 1978. The LASL hot dry rock geothermal energy development project: Geothermal Resources Council Transactions, vol. 2, pp. 275-277.

Hinze, W. J., 1978. National magnetic anomaly map committee: Geophysics, vol. 43, pp. 1620-1621.

Hite, J. R., and Fehlberg, E. L., 1976. Steam zone temperature gradients at The Geysers, in Kruger, P., and Ramey, H. J., Jr., eds., Second Workshop on Thermal Reservoir Engineering: Stanford, California, Stanford University, pp. 16-20.

Hoagland, J. R., and Elders, W. A., 1978. Hydrothermal mineralogy and isotopic geochemistry in the Cerro Prieto geothermal field, Mexico. I. Hydrothermal mineral zonation: Geothermal Resources Council Transactions, vol. 2, pp. 283-286.

Hoover, D. B., Frischknecht, F. C., and Tippens, C. L., 1976. Audiomagnetotelluric sounding as a reconnaissance exploration technique in Long Valley, California: Journal of Geophysical Research, vol. 81, pp. 801-809.

Hoover, D. B., and Long, C. L., 1976. Audio-magnetotelluric methods in reconnaissance geothermal exploration: Proceedings Second United Nations Symposium on the Development and Use of Geothermal Resources, San Francisco, California, 20-29 May 1975, vol. 2: Washington, D.C., U.S. Government Printing Office, pp. 1059-1064.

Hoover, D. B., Long, C. L., and Senterfit, R. M., 1978. Audiomagnetotelluric investigations in geothermal areas: Geophysics, vol. 43, pp 1501-1514.

Horai, K., and Simmons; M. G., 1969. Thermal conductivity of rock forming minerals: Earth and Planetary Science Letters, vol. 6, pp. 359-368.

Hughes, D. S., and Cross, J. H,, 1951. Elastic wave velocities in rock at high pressures and temperatures: Geophysics, vol. 16, pp. 577-593.

Hughes, D. S., and Maurette, C., 1957. Variation of elastic wave velocities in basic igneous rocks with pressure and temperature: Geophysics, vol. 22, pp. 23-31.

Hunt, T. M.; 1970a. Gravity changes at Wairakei geothermal field, New Zealand: Geological Society of America Bulletin, vol. 81, pp. 529-536.

Hunt, T. M., 1970b. Net mass loss from Wairakei geothermal field, New Zealand: Geothermics, special issue \&, vol. 2, pt. 1, pp. 487-491.

Hunt, T. M., 1977. Recharge of water in Wairakei geothermal field determined from repeated gravity measurements: New Zealand Journal of Geophysics, vol. 20, No. 2, pp. 303-317.

Ingersoll, L. R., Zobel, O. J., and Ingersoll, A. C., 1948. Heat conduction: New York, McGraw-Hill.

Isherwood, W. F., 1976. Gravity and magnetic studies of the Geysers-Clear Lake geothermal region, California, Proceedings Second United Nations Symposium on the Development and Use of Geothermal Resources, San Francisco, California, 20-29 May 1975, vol. 2: Washington, D.C., U.S. Government Printing Office, pp. 1065-1073. 
Isherwood, W. F., 1978. Geothermal reservoir interpretation from change in gravity: Proceedings of the Third Workshop on Geothermal Reservoir Engineering, Stanford, California, 14-16 December 1977, pp. 18-23.

Iyer, H. M., 1974. Search for geothermal seismic noise in the East Mesa area, Imperial Valley, California: Geophysics, vol. 40, No. 6, pp. 1066-1072.

Iyer, H. M., 1975a. Anomalous delays of teleseismic P-waves in Yellowstone National Park: Nature, vol. 253, pp. 425-427.

Iyer, H. M., 1975b. Search for geothermal seismic noise in the East Mesa area, Imperial Valley, California: Geophysics, vol. 40, pp. 1066-1072.

Iyer, H. M., and Healy, J. H., 1972. Teleseismic residuals at the LASA-U.S. Geological Survey extended array and their interpretation in terms of crust and upper mantle structure: Journal of Geophysical Research, vol. 77, pp. 1503.

Iyer, H. M., and Hitchcock, Tim, 1974. Seismic noise measurements in Yellowstone National Park: Geophysics, vol. 39, pp. 389-400.

Iyer, H. M., and. Hitchcock, Tim, 1976a. Seismic noise in Long Valley, California: Journal of Geophysical Research, vol. 81, No. 5, pp. 821-840.

Iyer, H. M., and Hitchcock, Tim, 1976b. Seismic noise as a geothermal exploration tool: Techniques and results: Proceedings Second United Nations Symposium on the Development and Use of Geothermal Resources, 20-29 May 1975, San Francisco, California, vol. 2: Washington, D.C., U.S. Government Printing Office pp. 1075-1083.

Iyer, H. M., Oppenheimer, D. H., and Hitchcock, T., 1978. Teleseismic P-delays of The Geysers-Clear Lake, California, geothermal region: Geothermal Resources Council Transactions, vol. 2, pp. 317-319.

Jachens, R. C., 1979. Temporal gravity changes as applied to studies of crustal deformation, in Proceedings Conference VII, stress and strain measurements related to earthquake prediction: US. Geological Survey Open-File Report 79-370, pp. 222-243.

Jackson, E. D., and Wright, T. L., 1970. Xenoliths in the Honolulu volcanic series: Journal of Petrology, vol. 11, pp. 405-430.

Jaeger, J. C., 1959. Temperatures outside a cooling intrusive sheet: American Journal of Science, vol. 257, pp. 44-54:

Jaeger, J. C., 1961. The cooling of irregularly shaped igneous bodies: American Journal of Science, vol. 259, pp. 721-734.

Jaeger, J. C., 1964. Thermal effects of intrusions: Reviews of Geophysics, vol. 2, pp. 443-466.

Jaeger, J. C., 1965. Application of the theory of heat conduction to geothermal measurements, in Lee, W. H. K., ed., Terrestrial heat flow: American Geophysical Union Geophysical Monograph 8, pp. 7-23.

Jaeger, J. C., 1970. Heat flow and radioactivity in Australia: Earth and Planetary Science Letters, vol. 81, pp. 285-292.

Jakosky, J. J., 1950. Exploration geophysics: Los Angeles, Trija.

James, R., 1968. Wairakei and Larderello, geothermal power systems compared: New Zealand Journal of Science and Technology, vol. 11, pp. 706-719.

Jones, P. H., 1970. Geothermal resources of the northern Gulf of Mexico basin: Geothermics, special issue, vol. 2, pt. 1, pp. 14-26.

Jones, P. H., 1976a. Geothermal and hydrodynamic regimes in the northern Gulf of Mexico basin: Proceedings Second United Nations Symposium on the Development and Use of Geothermal Resources, San Francisco, California, 20-29 May 1975, v. 1: Washington, D.C., U.S. Government Printing Office, pp. 429-440.

Jones, P. H., 1976b. Natural gas resources of the geopressured zones in the northern Gulf of Mexico basin. in Natural gas from unconventionel geologic sources: Washington, D.C., National Research Council, Board of Mineral Resources, Commission on Natural Resources, National Academy of Sciences, pp. 17-33. 
Kane, M. F., Mabey, D. R., and Brace, R., 1976. A gravity and magnetic investigation of the Jong Valley caldera, Mono County, California: Journal of Geaphysical Research, vol. 81, No. 5, pp. 754-762.

Karkalits, O. C., and.Hankins, B. E., 1978. Chemical analysis of dissolved natural gas in water from the world's first geopressured geothermal well: Geothermal Resources Council Transactions, vol. 2, pp. 351-354.

Kasameyer, P. W., and Younker, L. W., 1978. Natural fluid-flow patterns in the Salton Sea geothermal field: Geothermal Resources Council Transactions, vol. 2, pp. 359-361.

Keen, C. E., and Barrett, D. L., 1971. A measurement of seismic anisotropy in the northeast Pacific: Canadian Journal of Earth Sciences, vol. 8, pp. 1056-1064.

Keller, G. V., 1960. Physical properties of tuffs of the Oak Spring Formation, Nevada: $U$ S. Geological Survey Professional Paper 400-B, pp. B396-B400.

Keller, G. V., 1966. Electrical properties of rocks and minerals, in Clark, S. P., Jr., ed., Handbook of physical constants, Geological Society of America Memoir 97, pp. 546-577.

Keller, G. V., 1970. Inductive methods in prospecting for hot water: Geothermics, special issue 2, pp. 318-332.

Keller, G. V., 1971. Electrical studies of the crust and upper mantle, in Heacock, J.G., ed., The structure and physical properties of the Earth's crust: American Geophysical Union Geophysical Monograph 14, pp. 107-125.

Keller, G. V., and Fergerson, R. B., 1977. Determining the resistivity of a resistant layer in the crust, in Heacock, J. G., ed., The Earth's crust: American Geophysical Union Geophysica Monograph 20, pp. 440-469.

Keller, G. V., and Frischknecht, F. C., 1966. Electrical methods in geophysical prospecting: Oxford, Pergamon Press.

Kelley, V. C., and Soske. J. I., 1936. Origin of the Salton volcanic domes, Salton Sea, California: Journal of Geology, vol. 44, pp. 496-509.

Kennedy, G. C., and Griggs, D. T., 1960. Power recovery from the Kilauea Iki lava pool: Research Memorandum, RM-2696-AEC, The RAND Corporation.

Kharaka, Y. K., Brown, P. M., and Carothers, W. W., 1978. Chemistry of the waters in the geopressured zone from coastal Louisiana-implications for the geothermal development: Geothermal Resources Council Transactions, vol. 2, pp. 371-374.

Kittel, C, 1962. Introduction to solid state physics: New York, Wiley.

Knopoff, L., 1964. Q: Reviews of Geophysics, vol. 2, pp. 625-660.

Koenig, J. B., 1973. Worldwide status of geothermal development, in Kruger, P., and Otte, C., eds., Geothermal energy, Stanford, California, Stanford University Press, pp. 15-58.

Kovach, R. I., Allen, C. R., and Press F., 1962. Geophysical investigations in the Colorado Delta region: Journal of Geophysical Research, vol. 67, pp. 2845-2871.

Kracek, F. C., and Neuvonen, K. J., 1952. Thermochemistry of plagioclase and alkali feldspars: American Journal of Science, Bowen volume, pp. 293-318.

Krige, L. J., 1939. Borehole temperatures in the Transvaal, Orange Free State: Royal Society of London Proceedings, series A, vol. 173, pp. 450-474.

Kunetz, G., 1966, DC resistivity methods: Geoexploration Monographs, The Hague, Netherlands.

Kunze, J. F., Miller, L. G., and Whitbeck, J. F., 1976. Moderate temperature utilization project in the Raft River Valley: Proceedings Second.United Nations Symposium on the Development and Use of Geothermal Resources, San Francisco, California, 20-29 May 1975, vol. 3: Washington D.C., U.S. Government Printing Office, pp. 2021-2030.

Lachenbruch, A. H., 1957. Three-dimensional heat conduction in permafrost beneath heated buildings: US. Geological Survey Bulletin 1052-B. 
Lachenbruch, A. H., 1968. Preliminary geothermal model for the Sierra Nevada: Journal of Geophysical Research, vol. 73, pp. 6977-6989.

Lachenbruch, A. H., 1970. Crustal temperature and heat production-implications of the linear heat flow relation: Journal of Geophysical Research, vol. 75, pp. 32913300.

Lachenbruch, A. H., 1971. Vertical gradients of heat production in the continental crust, 1. Theoretical detectability from near-surface measurements: Journal of Geophysical Research, vol. 76, pp. 3842-3851.

Lachenbruch, A. H., and Brewer, M. C., 1959. Dissipation of the temperature effect of drilling a well in Arctic Alaska: US. Geological Survey Bulletin 1089-C, pp. 73-109.

Lachenbruch, A. H., Brewer, M. C., Greene, G. W., and Marshall, B. V., 1962. Temperatures in permafrost, in Temperature, its measurement and control in science and industry: New York, Reinhold, pp. 791-804.

Lachenbruch, A. H., and Bunker, C. M., 1971. Vertical gradients of heat production in the continental crust, 2. Some estimates from borehole data: Journal of Geophysical Research, vol. 76, pp. 3852-3860.

Lachenbruch, A. H., and Sass, J. H., 1973. Thermo-mechanical aspects of the San Andreas fault system, in Kovach, R. L., and Nur, A., eds., Tectonic problems of the San Andreas fault system: Stanford University Publications, Geological Sciences, vol. 13, pp. 192-205.

Lachenbruch, A. H., and Sass, J. H., 1977. Heat flow in the United States and the thermal regime of the crust, in Heacock, J. G., ed. The Earth's Crust: American Geophysical Union Geophysical Monograph, vol. 20, pp. 626-675.

Lachenbruch, A. H., and Sass, J. H., 1978. Models of an extending lithosphere and heat flow in the Basin and Range province, in Smith, R. B., and Eaton, G. P., eds. Cenozoic tectonics and regional geophysics of the western Cordillera: Geological Society of America Memoir 152, pp. 209-250.

Lachenbruch, A. H., Sass, J. H., Munroe, R. J., and Moses, T. H., Jr., 1976a. Geothermal setting and simple heat conduction models for the Long Valley caldera: Journal of Geophysical Research vol. 81, pp. 769-784.

Lachenbruch, A. H., Sorey, M. L. Lewis, R. E., and Sass, J. H., 1976b. The near-surface hydrothermal regime of Long Valley caldera: Journal of Geophysical Research, vol. 81, No. 5, pp. 763-768.

Lambert, A., and Beaumont, C., 1977. Nano variations in gravity due to seasonal ground water movements-Implications for gravitational detection of tectonic movements: Journal of Geophysical Research, vol. 82, pp. 297-304.

Lambert, I. B., and Heier, K. S., 1967. The vertical distribution of uranium, thorium, and potassium in the continental crust: Geochimica et Cosmochimica Acta, vol: 31, pp. 377-390.

Lange, A. L., and Westphal, W. H., 1969. Microearthquakes near The Geysers, Sonoma County, California: Journal of Geophysical Research, vol. 74, pp. 43774382.

Larson, R. L., 1972. Bathymetry, magnetic anomalies, and plate tectonic history of the mouth of the Gulf of California: Geological Society of America Bulletin, vol. 83, pp. 1343-1353.

Larson, R. L., Menard, H. W., and Smith, S. M., 1968. Gulf of California; A result of ocean-floor spreading and transform faulting: Science, vol. 161, pp. 781-784.

Iarson, P. A., Mudie, J. D., and Larson, R. L., 1972. Magnetic anomalies and fracture zone trends in the Gulf of California: Geological Society of America Bulletin, vol. 83, pp. 3361-3368.

Lawver, L. A., 1975. Heat flow in the Gulf of California [abs.7: Proceedings Second United Nations Symposium on the Development and Use of Geothermal Resources, 
San Francisco, California, 20-29 May 19\%5, vol. 1, Washington, D.C., U.S. Government Printing Office, pp. 53-54.

Lee, T. C., and Cohen, L. H., 1979. Onshore and offshore measurements of temperature gradients in the Salton Sea geothermal area, California: Geophysics, vol. 44, pp. 206-215.

Lee, W. H. K., and Uyeda, S., 1965. Review of heat flow data, in Lee, W. H. K., ed., Terrestrial heat flow: American Geophysical Union Geophysical Monograph 8, pp. $87-190$.

Lindsley, D. H., Andreasen, G. E., and Balsley, J. R., 1966. Magnetic properties of rocks and minerals. in Clark, S. P., Jr., ed. Handbook of physical constants: Geological Society of America Memoir 97, pp. 543-552.

Loeltz, O. J., Ireland, B., Robinson, J. H., and Olmstead, F. H., 1975. Geohydrologic reconnaissance of the Imperial Valley, California: U.S. Geological Survey Professional Paper 486-K.

Lovering, T. S., 1935. Theory of heat conduction applied to geological problems: Geological Society of America Bulletin, vol. 46, pp. 69-94.

Luedke, R. G., and Smith, R. L., 1978a. Map showing distribution, composition, and age of late Cenozoic volcanic centers in Arizona and New Mexico, US. Geological Survey Map I-1091-A, scale 1:1,000,000.

Luedke, R. G., and Smith, R. L., 1978b. Map showing distribution, composition, and age of late Cenozoic volcanic centers in Colorado, Utah, and southwestern Wyoming, US. Geological Survey Map I-1091-B, scale 1:1,000,000.

Iyyons, P. L., 1978. Gravity anomaly map committee-ad hoc: Geophysics, vol. 43, pp. 1614-1615.

Mabey, D. R., 1978. Gravity and aeromagnetic anomalies in the Rexburg area of eastern Idaho: U.S. Geological Survey Open-file Report 78-982.

Mabey, D. R., Hoover, D. B., O'Donnell, J. E., and Wilson, C. W., 1978a. Reconnaissance geophysical studies of the geothermal system in southern Raft River Valley, Idaho: Geophysics, vol. 43, pp. 1470-1484.

Mabey, D. R., Zietz, I., Eaton, G. P., and Kleinkopf, M. D., 1978b. Regional magnetic patterns in part of the Cordillera in the Western United States, in Smith, R. B., and Eaton, G. P., eds., Cenozoic tectonics and regional geophysics of the western Cordillera: Geological Society of America Memoir 152, pp. 93-106.

Macdonald, W. J. P., and Muffler, L. J. P., 1972. Recent geophysical exploration of the Kawerau geothermal field, North Island, New Zealand: New Zealand Journal of Geology and Geophysics, vol. 15, pp. 303-317.

Madden, T. R., and Cantwell, T., 1967. Induced polarization, a review in Mining Geophysics, Tulsa, Oklahoma, Society of Exploration Geophysicists, vol. 2, pp. 373400.

Madden, T. R., and Swift, C. M., Jr., 1969. Magnetotelluric studies of the electrical conductivity structure of the crust and upper mantle, in Hart, P. J., ed., The Earth's crust and upper mantle: American Geophysical Union Geophysical Monograph 18, pp. 469-479.

Majer, E. L., 1978. Seismological investigations in geothermal regions: Berkeley, California, University of California Ph.D. thesis, also available as LBL-7054.

Majer, E. L., and McEvilly, T. V., 1979. Seismological investigations at The Geysers geothermal field: Geophysics, vol. 44, pp. 246-269.

Mankinen, E. A., Donnelly, J. M., and Gromme, C. S., 1978. Geomagnetic polarity event recorded at 1.1 m.y.B.P. on Cobb Mountain, Clear Lake volcanic field, California: Geology, vol. 6, pp. 653-656.

Mao, H. K., and Bell, P. M., 1971. Crystal-field spectra: Carnegie Institution of Washington Yearbook, vol. 70, pp. 207-215. 
Mao, H. K., and Bell, P. M., 1972. Interpretation of the pressure effect on the optical absorption hands of natural fayalite to $20 \mathrm{~Kb}$ : Carnegie Institution of Washington Year Book, vol. 71, pp. 524-527.

Mariner, R. H., and Willey, L. M., 1976. Geochemistry of thermal waters in Long Valley, Mono County, California: Journal of Geophysical Research, vol. 81, pp. 792-800.

Mathias, K. E., 1976. The Mesa geothermal field-a preliminary evaluation of five geothermal wells, in Proceedings of Second United Nations Symposium on the Development and Use of Geothermal Resources, San Francisco, California, 20-29 May 1975, v. 3: Washington, D.C., U.S. Government Printing Office, pp. 1741-1747.

Mayhew, M. A., 1979. Regional crustal marnetization variation in the western United States: EOS (American Geophysical Union Transactions), vol. 60, No. 7, p. 94. McDougall, I., 1971. Volcanic island chains and seafloor spreading: Nature, vol. 231, pp. 141-144.

McEvilly, T. V., and Schechter, B., 1977. East Mesa seismic study, in Earth Sciences Division Annual Report, Lawrence Berkeley Laboratory, University of California: Springeld, Va., National Technical Information Service, U.S. Department of Commerce, p. 119.

McKenzie, W. F.. and Truesdell, A. H., 1977. Geothermal reservoir temperatures estimated from the oxygen isotope composition of dissolved sulfate and water from hot springs and shallow drill holes: Geothermics, vol. 5, pp. 51-61.

McLaughlin, R. J., and Stanley, W. D., 1976. Pre-Tertiary geology and structural control of geothermal resources. The Geysers steam field California, in Proceedings Second United Nations Symposium on the Development and Use of Geothermal Resources, San Francisco, California, 20-29 May 1975, vol. 1: Washington, D.C., U.S. Government Printing Office, pp. 475-486.

McNitt, J. R., 1976. Summary of United Nations geothermal exploration experience, 1965 to 1975, in Proceedings Second United Nations Symposium on the Development and Use of Geothermal Resources, San Francisco, California, 20-29 May 1975, vol. 2: Washington, D.C., U.S. Government Printing Office, pp. 1127-1134.

Meidav, T., and Tonani, F., 1976. A critique of geothermal exploration techniques: Proceedings Second United Nations Symposium on the Development and Use of Geothermal Resources, San Francisco, California, 20-29 May 1975, vol. 2: Washington, D.C., U.S. Government Printing Office, pp. 1143-1154.

Menard, H. W., 1973. Gravity anomalies and vertical tectonics as indicators of plate motions: EOS (American Geophysical Union Transactions), vol. 54, p. 239.

Mercado, S., 1970. High activity hydrothermal zones detected by $\mathrm{Na} / \mathrm{K}$, Cerro Prieto, Mexico: Geothermics, special issue 2, vol. 2, pt. 2, pp. 1367-1376.

Merriam, R., and Bandy, O. L., 1965. Source of upper Cenozoic sediments in Colorado delta region: Journal of Sedimentary Petrology, vol. 35, No. 4, pp. 911-916.

Miller, L. G., Prestwich, S. M., and Gould, R. W., 1978. Drilling and directional drilling a moderate-temperature geothermal resource: Geothermal Resources Council Transactions, vol. 2, pp. 455-456.

Miller, R. E., 1977. A Galerkin, finite-element analysis of steady-state flow and heat transport in the shallow hydrothermal system in the East Mesa area, Imperial Valley, California: U.S. Geological Survey Journal of Research, vol. 5, pp. 497-508.

Misener, A. D., and Beck, A. E., 1960. The measurement of heat flow over land, in Runcorn, S. K., ed., Methods and techniques in geophysics, vol. 1: New York, Interscience, pp. 10-61.

Misener, A. D., and Thompson. L. G. D., 1952. The pressure coefficient of resistance thermometers: Canadian Journal of Technology, vol. 30, pp. 89-94.

Mitchell, B. J., Cheng, C. C., and Stauder, W., 1977. A three-dimensional velocity model of the lithosphere beneath the New Madrid seismic zone: Seismological Society of America Bulletin, vol. 67, pp. 1061-1074. 
Moore, D. G., 1973. Plate edge deformation and crustal growth, Gulf of California structural province: Geological Society of America Bulletin, vol. 84, pp. 1883-1906.

Morgan, W. J., 1971. Convection plumes in the lower mantle: Nature, vol. 230, pp. $42-43$.

Morgan, W. J., 1972. Deep mantle convection plumes and plate motions: American Association of Petroleum Geologists Bulletin, vol. 56, pp. 203-213.

Morris, G. B., Raitt, R. W., and Shor, G. G., 1969. Velocity anisotropy and delay time maps of the mantle near Hawaii: Journal of Geophysical Research, vol. 74, pp. 4300-4316.

Muffler, L. J. P., 1976. Tectonic and hydrologic control of the nature and distribution of geothermal resources: Proceedings Second United Nations Symposium on the Development and Use of Geothermal Resources, 20-29 May 1975, San Francisco, California, vol. 1: Washington, D.C., U.S. Government Printing Office, pp. 499-507.

Muffler, L. J. P., ed., 1979. Assessment of geothermal resources of the United States1978: U.S. Geological Survey Circular 790.

Muffler, L. J. P., and Cataldi, R., 1979. Methods for regional assessment of geothermal resources: Geothermics, vol. 7 (in press).

Muffler, L. J. P., and Christiansen, R. L., 1978. Geothermal resource assessment of the United States: Pure and Applied Geophysics, vol. 117, pp. 160-171.

Muffler, L. J. P., and Doe, B. R., 1968. Composition and mean age of detritus of the Colorado River delta in the Salton Trough, southeastern California: Journal of Sedimentary Petrology, vol. 38, pp. 384-399.

Muffler, L. J. P., and Guffanti, M., 1979. Introduction, in Muffler, L. J. P., ed., Assessment of geothermal resources of the United States-1978: U.S. Geological Survey Circular 790, pp. 1-11.

Muffler, L. J. P., and White, D. E., 1968. Origin of $\mathrm{CO}_{2}$ in the Salton Sea geothermal system, southeastern California, U.S.A., in Genesis of mineral and thermal waters: International Geological Congress, 23rd, Prague, 1968, Proceedings, vol. 17, pp. 185-194.

Muffler, L. J. P., and White, D. E., 1969. Active metamorphosis of upper Cenozoic sediments in the Salton Sea geothermal field and the Salton Trough, southeastern California: Geological Society of America Bulletin, vol. 80, pp.157-182.

Muffler, L. J. P., and Williams, D. L., 1976. Geothermal investigations of the U.S. Geological Survey in Long Valley, California, 1972-1973: Journal of Geophysical Research, vol. 81, pp. 721-724.

Murase, T., and McBirney, A. R., 1973. Properties of some common igneous rocks and their melts at high temperature: Geological Society of America Bulletin, vol. 84, pp. 3563-3592.

Nagata, T., 1961. Rock magnetism: Tokyo, Maruzen.

Nakamura, H., Sumi, K., Katagiri, K., and Iwata, T., 1970. The geological environment of Matsukawa geothermal area, Japan: Geothermics, special issue 2, vol. 2 pt. 1, pp. 221-231.

Nettleton, L. L., 1940. Geophysical prospecting for oil: New York, McGraw-Hill.

Nettleton, L. L., 1971. Elementary gravity and magnetics for geologists and seismologists: Society of Exploration Geophysicists Monograph 1.

Norton, D., and Knight, J., 1977. Transport phenomena in hydrothermal systemscooling plutons: American Journal of Science, vol. 277, pp. 937-981.

Norwood, E. J., Jr., and Holland, D. S., 1974. Lithofacies mapping, a descriptive tool for ancient delta systems of the Louisiana Outer Continental Shelf: Gulf Coast Association of Geological Societies Transactions, vol. 24, pp. 175-188.

Nur, A., 1972. Dilatancy, pore fluids, and premonitory variations of $t_{n} / t_{\mathrm{p}}$ travel times: Seismological Society of America Bulletin, vol. 62, pp. 1217-1222. 
Nur, A., and Simmons, G., 1969a. Stress-induced velocity anisotropy in rock: Journal of Geophysical Research, vol. 74, pp. 6667-6674.

Nur, A., and Simmons, G., 1969b. The effect of saturation on velocity in low porosity rocks: Earth and Planetary Science Letters, vol. 7 pp. 183-193.

Nuttli, O. W., and Bolt, B. A., 1969. P-wave residuals as a function of azimuth, 2, undulations of the mantle low-velocity layer as an explanation: Journal of Geophsical Research, vol. 74, pp. 6594-6602.

O'Connell, R. J., and Budiansky, B., 1974. Seismic velocities in dry and saturated cracked solids: Journal of Geophysical Research, vol. 79, pp. 5412-5426.

Oliver, H. W., Robins, S. L., Grannell, R. B., Alewine, R. W., and Biehler, S., 1975. Surface and subsurface movements determined by remeasuring gravity, in Oakshott, G. B., ed., San Fernando earthquake of February 9, 1971: California Division of Mines and Geology Bulletin 196, pp. 195-211.

Oliver, J., 1978. Exploration of the continental basement by seismic reflection profiling: Nature, vol. 275 , pp. $485-488$.

Olson, E. R., 1976. Oxygen isotope study of diabase, Heber geothermal field, Imperial Valley, California [abs.] Geological Society of America Abstracts with Programs, vol. 8, No. 6, pp. 1036.

Olson, E. R., and Elders, W. A., 1978. Hydrothermal mineralogy and isotopic geochemistry in the Cerro Prieto geothermal field, Mexico II. Isotopic geochemistry: Geothermal Resources Council Transactions, vol. 2, pp. 513-516.

Paddison, F. C., 1978. Geothermal energy and the eastern United States: Geo-Heat Utilization Center Quarterly Bulletin, vol. 3, No. 3, pp. 1-4.

Pakiser, L. C., 1961. Gravity, volcanism, and crustal deformation in Long Valley, California: US'. Geological Survey Professional Paper 4R4-B, pp. B250-B253.

Pakiser, L. C., Kane, M. F., and Jackson, W. H., 1964. Structural geology and volcanism of Owens Valley region, California-A geophysical study: $U S$. Geological Survey Professional Paper 498.

Pálmason, G., 1976. Geophysical methods in geothermal exploration: Proceedings Second United Nations Symposium on the Development and Use of Geothermal Resources, San Francisco, 20-29 May 1975, vol. 2, Washington, D.C., U.S. Government Printing Office, pp. 1175-1184.

Papadopulos, S. S., Wallace, R. H., Jr., Wesselman, J. B., and Taylor, R. E., 1975. Assessment of onshore geopressured geothermal resources in the northern Gulf of Mexico basin, in White, D. E., and Williams, D. L., eds., Assessment of geothermal resources of the United States-1975: US. Geological Survey Circular 726, pp. 125-146.

Parasnis, D. C., 1962. Principles of applied geophysics: London, Methuen.

Peck, D. L., 1975. Recoverability of geothermal energy directly from molten igneous systems, in White, D. E., and Williams, D. L., eds., Assessment of geothermal resources of the United States-1975: US. Geological Survey Circular 726, pp. 122124.

Peck, D. L., Hamilton, M. S., and Shaw, H. R., 1977. Numerical analysis of lava lake cooling models; Part II, Application to Alae lava lake, Hawaii: American Journal of Science, vol. 277, pp. 415-437.

Peselnick, L., Lockwood, J. P., and Stewart, R. M., 1977, Anisotropic elastic velocities of some upper mantle xenoliths underlying the Sierra Nevada batholith: Journal of Geophysical Research, vol. 82, pp. 2005-2010.

Peselnick, L., Nicolas, A., and Stevenson, P. R., 1974. Velocity anisotropy in a mantle peridotite from the Ivrea zone-Application to upper mantle anisotropy: Journal of Geophysical Research, vol.79, pp. 1175-1182.

Peselnick, L., and Nicolas, A., 1978. Seismic anisotropy in an ophiolite peridotiteapplication to oceanic upper mantle: Journal of Geophysical Research, v. 83, p. 1227-1235. 
Pirson, S. J., 1963. Handbook of well log analysis: Englewood Cliffs, N. J., PrenticeHall.

Pitt, A. M., and Steeples, D. W:, 1975. Microearthquakes in the Mono Lake-northern Owens Valley region from September 28 to October 18, 1970: Seismological Society of America Bulletin, vol. 65, pp. 835-844.

Hlouff, D., 1966. Magnetotelluric soundings in southwestern United States: Geophysics, vol. 31, pp. 1145-1152.

Potter, K. W., II, and Brown, D. L., 1977. The volumetric properties of aqueous sodium chloride solutions from $0^{\circ} \mathrm{C}$ to $500^{\circ} \mathrm{C}$ at pressures up to 2,000 bars based on a regression of available data in the literature: US. Geological Survey Bulletin $1421-C$.

Press, F., 1966. Seismic Velocities, in Clark, S. P., Jr., ed., Handbook of physical constants. Geological Society of America Memoir 97, pp. 195-218.

Prutton, C. F., and Maron, S. H., 1944. Fundamental principles of physical chemistry: New York, Macmillan.

Quist, A. S., and Marshall, W. L., 1968. Electrical conductances of aqueous sodium chloride solutions from 0 to $800^{\circ}$ and at pressures to 4000 bars: Journal of Physical Chemistry, vol. 72, p. 684.

Raitt, R. W., Shor, G. G., Francis, T. J. G., and Morris, G. B., 1969. Anisotropy of the Pacific upper mantle: Journal of Geophysical Research, vol. 74, pp. 3095-3109.

Raleigh, C. B., Healy, J. H., and Bredehoeft, J. D., 1976. An experiment in earthquake control at Rangely, Colorado: Science, vol. 191, pp. 1230-1237.

Ramey, H. J., Jr., Kruger, P., and Raghavan, R., 1973. Explosive stimulation of hydrothermal reservoirs, in Kruger, $P_{\text {., }}$ and Otte, C., ed., Geothermal energy: Stanford, California, Stanford University Press, pp. 231-250.

Randall, W., 1971. Percent volume of sand bodies in the Imperial Valley (preliminary report), in Cooperative geological-geophysical-geochemical investigations of geothermal resources in the Imperial Valley area of California: University of California, Riverside, pp. 119-128.

Randolph, P. L., 1977. Natural gas content of geopressured aquifers: GeopressuredGeothermal Energy Conference, 3d, November 16-18, 197\%, University of Southwestern Louisiana, Lafayette, Proceedings, vol. 1, pp. ES23-46.

Rao, R. U. M., and Jessop, A. M., 1975. A comparison of the thermal characters of shields: Canadian Journal of Earth Sciences, vol. 12, pp. 347-360.. .

Ray, R. G., 1960. Aerial photographs in geologic interpretation and mapping: $U S$. Geological Survey Professional Paper 373.

Reed, M. J., 1976. Geology and hydrothermal metamorphism in the Cerro Prieto geothermal field, Mexico: Proceedings Second United Nations Symposium on the Development and Use of Geothermal Energy, San Francisco, Califormia, 20-29 May 1978 , vol. 1: Washington, D.C., U.S. Government Printing Office, pp. 539-547.

Reeves, R. G., Arson, A., and Landen, D., 1975. Manual of remote sensing: Falls Church, Virginia, American Society of Photogrammetry.

Renner, J. L., White, D. E., and Williams, D. L., 1975. Hydrothermal convection systems, in White, D. E., and Williams, D. L., eds., Assessment of geothermal resources of the United States-1975: U.S. Geophysical Survey Circular 726, pp. 5-57.

Rex, R. W., 1966. Heat flow in the Imperial Valley of California [abs.]: American Geophysical Union Transactions, vol. 47, No. 1, p. 181.

Richter, C. F., 1958. Elementary seismology: San Francisco, Freeman.

Richter, D., and Simmons, G., 1977. Microcracks in crustal igneous rocks-microscopy, in Heacock, J. G., ed., The Earth's crust: American Geophysical Union Geophysical Monograph 20, pp. 149-180.

Risk, G. F., 1976. Detection of buried zones of fissured rock in geothermal fields using resistivity anisotropy measurements, in Proceedings Second United Nations Symposium on the Development and Use of Geothermal Resources, San Francisco, Cali- 
fornia, 20-29 May 1975, vol. 2: Washington, D.C., U.S. Goverument Printing Office, pp. 1191-1198.

Risk, G. F., Macdonald, W. J. P., and Dawson, G. B., 1970. DC resistivity surveys of the Broadlands geothermal region: Geothermics, special issue 2, vol. 2, pt. 1, pp. 287-294.

Robertson, E. C., 1979. Thermal conductivity of rocks: U.S. Geological Survey OpenFile Report 79-356.

Robertson. E. C., Fournier, R. O., and Strong, C. P., 1976. Hydrothermal activity in southwestern Montana: Proceedings Second United Nations Symposium on the Development and Use of Geothermal Resources, San Francisco, California, 20-29 May 1975, vol. 1: Washington, D.C., U.S. Government Printing Office, pp. 553-561.

Robertson, E. C., Raspet, R., Swartz, J. H., and Lillard, M. E., 1966. Properties of thermistors used in geothermal investigations: U.S. Geological Survey Bulletin $1203-B$.

Robie, R. A., 1966. Thermodynamic properties of minerals, in Clark, S. P., Jr., nd., Handbook of physical constants: Geological Society of America Memoir 97, pp. 437-458.

Robie, R. A., Bethke, P. M., Toulmin, P. S., and Edwards, J. L., 1966. X-ray crystallographic data, densities, and molar volumes of minerals in Clark, S. P., Jr., ed., Handbook of physical constants: Geological Society of America Memoir 97, pp. 27-74.

Robie, R. A., Hemingway, B. S., and Fisher, J. R., 1978. Thermodynamic properties of minerals and related substances at $298.15 \mathrm{~K}$ and 1 bar (10 Pascals) pressure and at higher temperatures: US. Geological Survey Bulletin 1452.

Robinson, P. T., and Elders, W. A., 1976. Quaternary volcanism in the Salton Sea, geothermal field, Imperial Valley, California: Geological Society of America Bulletin, vol. 87, pp. 347-360.

Rowan, L. C., Goetz, A. H. F., and Ashley, R. P., 1977. Discrimination of hydrothermally altered and unaltered rocks in visible and near infrared multi-spectral images: Geophysics, vol. 42, pp. 522-535.

Rowan, L. C., Wetlaufer, P. H., Goetz, A. F. H., Billingsley, F. C., and Stewart, J. H., 1974. Discrimination of rock types and detection of hydrothermally altered areas in south-central Nevada by the use of computer-enhanced ERTS images: US. Geological Survey Professional Paper 885.

Roy, R. F., Blackwell, D. D., and Birch, F., 1968a. Heat generation of plutonic rocks and continental heat-flow provinces: Earth and Planetary Science Letters, vol. 5, pp. 1-12.

Roy, R. F., Blackwell, D. D., and Decker, E. R., 1972. Continental heat flow, in Robertson, E. C., ed., The nature of the solid Earth: New York, McGraw-Hill, pp. 506-544.

Roy, R. F., Decker, E. R., Blackwell, D. D., and Birch, F., 1968b. Heat flow in the United States: Journal of Geophysical Research, vol. 72, pp. 5207-5221.

Rundle, J. B., 1978. Gravity changes and the Palmdale uplift: Geophysical Research Letters, vol. 5, pp. 41-44.

Sammel, E. A., 1968. Convective flow and its effect on temperature logging in smalldiameter wells: Geophysics, vol. 33, pp. 1004-1012.

Sammel, E. A., 1979. Occurrence of low temperature geothermal waters in the United States, in Muffler, L. J. P., ed., Assessment of geothermal resources in the United States-1978: U.S. Geological Survey Circular 790, pp. 86-131.

Sanford, A. R., Mott, R. P., Shuleski, P. J., Reinhart, E. J., Caravella, F. J., Ward, R. M., and Wallace, T. C., 1977. Geophysical evidence for a magma body in the crust in the vicinity of Socorro, New Mexico, in Heacock, J. G., ed., The Earth's crust: American Geophysical Union Geophysical Monograph 20, pp. 385-404. 
Sass, J. H., Diment, W. H., Lachenbruch, A. H., Marshall, B. V., Munroe, R. J., Moses, T. H., Jr, and Urban, T. C., 1976a. A new heat-flow contour map of the conterminous United States: US. Geological Survey Open-File Report \%6-756.

Sass, J. H., Jaeger, J. C., and Munroe, R. J., 1976b. Heat flow and near-surface radioactivity of the Australian continental crust: US. Geological Survey Open-file Report 76-250.

Sass, J. H., and Lachenbruch, A. H., 1979. Heat flow and conduction-dominated thermal regimes, in Muffler, L. J. P., ed., Assessment of geothermal resources of the United States-1978: U.S. Geological Survey Circular 790, pp. 8-11.

Sass, J. H., Lachenbruch, A. H., and Munroe, R. J., 1971b. Thermal conductivity of rocks from measurements on fragments and its application to heat-flow determinations: Journal of Geophysical Research, vol. 76, pp. 3391-3401.

Sass, J. H., Lachenbruch, A. H., Munroe, R. J., Greene, G. W., and Moses, T. H., 1971a. Heat flow in the Western United States: Journal of Geophysical Research, vol. 76, pp. 6376-6413.

Sass, J. H., and Munroe, R. J., compilers, 1974. Basic heat-flow data for the United States: U.S. Geological Survey Open-file Report $74-9$.

Schatz, J. F., and Simmons, G., 1972. Thermal conductivity of Earth materials at high temperature: Journal of Geophysical Research, vol. 77, pp. 6966-6983.

Scholtz, C. H., 1968. The frequency-magnitude relation of microfracturing in rock and its relation to earthquakes: Seismological Society of America Bulletin, vol. 58, pp. $399-415$.

Scholtz, C. H., Sykes, L. R., and Aggarwal, Y. P., 1973. Earthquake prediction; A physical basis. Science, vol. 181, pp. 803-810.

Shankland, T. J., Duba, A. G., and Woronow, A., 1974. Pressure shifts of optical absorption bands in iron-bearing garnet, spinel, olivine, pyroxene, and periclase: Journal of Geophysical Research, vol. 79, pp. 3273-3282.

Shaw, H. R., 1973. Mantle convection and volcanic periodicity in the Pacific-evidence from Hawaii: Geological Society of America Bulletin, vol. 84, pp. 1505-1526.

Shaw, H. R., Hamilton, M. S., and Peck, D. L., 1977, Numerical analysis of lava lake cooling models; Part I, Description of the method: American Journal of Science, vol. 277, pp. 384-414.

Shaw, H. R., and Jackson, E. D., 1973. Linear island chains in the Pacific-result of thermal plumes or gravitational anchors? Journal of Geophysical Research, vol. 78, pp. 8634-8652.

Sheriff; R. E., 1973. Encyclopedic dictionary of exploration geophysics: Tulsa, Oklahoma, Society of Exploration Geophysicists.

Sheriff, R. E., 1978. A first course in geophysical exploration and interpretation: Boston, Massachusetts, International Human Resources Development Corp.

Shoemaker. E. M.. ed., 1975. Continental drilling: Washington, D.C., Carnegie Institution of Washington.

Simmons, G., 1964a. Velocity of compressional waves in various minerals at pressures to 10 kilobars: Journal of Geophysical Research, vol. 69, pp. 1117-1121.

Simmons, G., 1964b. Velocity of shear waves in rocks to 10 kilobars, 1: Journal of Geophysical Research, vol. 69, pp. 1123-1130.

Simmons, G., 1965. Continuous temperature-logging equipment: Journal of Geophysical Research, vol. 70, pp. 1349-1352.

Simmons, G., 1967. Interpretation of heat flow anomalies, 2, flux due to initial temperature of intrusives: Reviews of Geophysics and Space Physics, vol. 5, pp. 109-120.

Simmons, G., and Richter, D., 1976. Microcracks in rocks, in Strens, R. G. J., ed., The physics and chemistry of minerals and rocks: New York, John Wiley, pp. 105-107. 
Simmons, G., Siegfried, R. W., and Feves, 1974. Differential strain analysis-a new method for examining cracks in rocks: Journal of Geophysical Research, vol. 79, pp. $4383-4385$.

Smith, D. L., Gregory, R. G., and Garvey, M. J., 1978. A thermal reconnaissance of Georgia-heat flow and radioactive heat generation: Georgia Geological Survey Bulletin, vol. 93, pp. 93-104.

Smith, J. L., and Rex. R. W., 1977. Drilling results from the eastern Long Valley Caldera: American Nuclear Society Meeting on Energy and Mineral Recovery Research, Golden, Colorado, 12 April 197\%, pp. 529-540.

Smith, M. C., Aamodt, R. L., Potter, R. M., and Brown, D. W., 1976. Man-made geothermal reservoirs: Proceedings Second United Nations Symposium on the Development and Use of Geothermal Resources, San Francisco, California, 20-29 May 1975, vol. 3: Washington, D. C., U.S. Government Printing Office, pp. 17811787.

Smith, M. C., Potter, R. M., Brown, D. W., and Aamodt, R. L., 1973. Induction and growth of fractures in hot rock. in Kruger. P., and Otte, C.. eds. Geothermal energy: Stanford, California, Stanford University Press, pp. 251-268.

Smith, R. B., 1978. Seismicity, crustal structure, and intraplate tectonics of the interior of the western cordillera, in Smith, R. B., and Eaton, G. P., eds., Cenozoic tectonics and regional geophysics of the western Cordillera: Geological Society of America Memoir 152, pp. 111-144.

Smith, R. B., and Eaton, G. P., eds., 1978. Cenozoic tectonies and regional geophysics of the western Cordillera: Geological Society of America Memoir $15 \%$.

Smith, R. B., and Lindh, A. G., 1978. Fault-plane solutions of the western United States-A compilation, in Smith, R. B., and Eaton, G. P., eds., Cenozoic tectonics and regional geophysics of the Western Cordillera: Geological Society of America Memoir 15\%, pp. 107-109.

Smith, R. B., and Sbar, M., 1974. Contemporary tectonics and seismicity of the western states with emphasis on the Intermountain Seismic Belt: Geological Society of America Bulletin, vol. 85, pp. 1205-1218.

Smith, R. B., Shuey, R. T., Freidline, R. M., Otis, R. M., Alley I. B., 1974. Yellowstone hot spot; New magnetic and seismic evidence: Geology, vol. 2, pp. 451-455.

Smith, :R. L.. and Bailey, R. A.. 1968. Resurgent cauldrons: Geological Society of America Memoir 116, pp. 613-662.

Smith, R. L., Bailey, R. A., and Ross. C. S., 1970. Geologic map of the Jemez Mountains, New Mexico: U.S. Geological Survey Map I-571, scale 1: 250,000.

Smith, R. L., and Shaw, H. R., 1973. Volcanic rocks as geologic guides to geothermal exploration and evaluation [abs.]: EOS (American Geophysical Union Transactions), vol. 54, No. 11, p. 1213.

Smith, R. L., and Shaw, H. R., 1975. Igneous-related geothermal systems, in White, D. E., and Williams. D. L., eds., Assessment of geothermal resources of the United States-1975; US, Geological Survey Circular 726, pp. 58-83.

Smith, R. L., and Shaw, H. R., 1979. Igneous related geothermal svstems, in Muffler, L. J. P., ed., Assessment of geothermal resources of the United States-1978: $U S$. Geological Survey Circular 790, pp. 12-17.

Smith, R. L., Shaw, H. R., Luedke, R. G., and Russell, S. L., 1978. Comprehensive tables giving physical data and thermal energy estimates for young igneous systems of the United States: US. Geological Survey Open-File Report 78-925.

Sorey, M. L., and Lewis, R. E., 1976. Convective heat flow from hot springs in the Long Valley caldera, Mono County, California: Journal of Geophysical Research, vol. 81, pp. 785-791.

Stanley, W. D., Boehl, J. E., Bostick, F. X., and Smith, H. W., 1977. Geothermal significance of magnetotelluric sounding in the eastern Snake River Plain-Yellowstone region: Journal of Geophysical Research, vol. 82, pp. 2501-2514. 
Stanley, W. D., Jackson, D. B., and Zohdy, A. A. R., 1976. Deep electrical investigation in the Long Valley geothermal area, California: Journal of Geophysical Research, vol. 81, pp. 810-820.

Steeples, D. W., and Iyer, H. M., 1976. Teleseismic P-wave delays in geothermal exploration, Proceedings Second United Nations Symposium on the Development and Use of Geothermal Resources, San Francisco, California, 20-29 May 1975, vol. 2; Washington, D.C., U.S. Government Printing Office, pp. 1199-1206.

Steeples, D. W., and Tyer, H. M., 1976b. Low-velocity zone under Long Valley as determined from teleseismic events: Journal of Geophysical Research, vol. 81, pp. $849-860$.

Steeples, D. W., and Pitt, A. M., 1976. Microearthquakes in and near Long Valley: Journal of Geophysical Research, vol. 81, pp. 841-847.

Stewart, J. H., 1978. Basin-Range structure in western North America-A review. in Smith, R. B., and Eaton, G. P., eds., Cenozoic tectonics and regional geophysics of the western Cordillera: Geological Society of America Memoirs 152, pp. 1-31.

Stewart, J. H., and Carlson, J. E., 1976. Cenozoic rocks of Nevada-Four maps and a brief description of distribution, lithology, age and centers of volcanism: Nevada Bureau of Mines and Geology Map 62, scale 1:1,000,000.

Stewart, J. H., and Carlson, J. E., 1978. Generalized maps showing distribution, lithology and age of Cenozoic igneous rocks in the western United States, in Smith, R. B., and Eaton, G. P., eds., Cenozoic tectonics and regional geophysics of the western Cordillera: Geological Society of America Memoir 152, pp. 263-264.

Stewart, J. H., Moore, W. J., and Zietz, I., 1977. East-west patterns of Cenozoic igneous rocks, aeromagnetic anomalies, and mineral deposits, Nevada and Utah: Geological Society of America Bulletin, vol. 88, pp. 67-77.

Stewart, R. M., and Peselnick, L., 1978. Systematic behavior of compressional velocity in Franciscan rocks at high pressure and temperature: Journal of Geophysical Research, vol. 83, pp. 831-839.

Stokes, W. L., 1968. Relation of fault trends and mineralization, eastern Great Basin Utah: Economic Geology, vol.63, pp. 751-759.

Stoller, H. M., and Colp, J. L., 1978. Magma as a geothermal resource-a summary: Geothermal Resources Council Transactions, vol. 2, pp. 613-615.

Strangway, D. W., Swift, C. M., and Homer, R. C., 1973. The application of audiofrequency magnetotellurics (AMT) to mineral exploration: Geophysics, vol. 38, pp. $1159-1175$.

Suppe, J., Powell, C., and Berry, R., 1975. Regional topography, seismicity, Quaternary volcanism and the present-day tectonics of the western United States: American Journal of Science, vol. 275-A, pp. 397-436.

Swanberg, C. A., 1972. Vertical distribution of heat generation in the Idaho batholith: Journal of Geophysical Research, yol. 77, pp. 2508-2513.

Swanberg; C. A., 1976. The Mesa geothermal anomaly, Imperial Valley, California-A comparison and evaluation of results obtained from surface geophysics and deep drilling: Proceedings Second United Nations Symposium on the Development and Use of Geothermal Resources, San Francisco, 20-29 May 1975, vol. 2: Washington, D.C., U.S. Government Printing Office, pp. 1217-1229.

Swanberg, C. A., Chessman, M. D., Simmons, G., Smithson, S. B., Gronlie, G., and Heier, K. S., 1974. Heat-flow, heat-generation studies in Norway: Tectonophysics, vol. 23, pp. $31-48$.

Swartz, J.H., 1954. A geothermal measuring circuit: Science, vol. 120, pp. 573-574.

Telford, W. M., Geldart, L. P., Sheriff, R. E., and Keys, D. A., 1976. Applied geophysics : Cambridge, Cambridge University Press.

Teng, T. L., 1968. Attenuation of body waves and the Q structure of the mantle: Journal of Geophysical Research, vol. 73, pp. 2105-2216. 
Thompson, G. A., and Burke, D. B., 1974. Regional geophysics of the Basin and Range Province: Annual Review of Earth and Planetary Sciences, vol. 2, pp. 213-238.

Tillman, J. E., 1978. Geothermal resources in the eastern United States: Geo-heat Utilization Center, Quarterly Bulletin, vol. 4, No. 1, pp. 4-6.

Toksoz, M. F.. Cheng, C. H., and Timur, A., 1976. Velocities of seismic waves in porous rocks: Geophysics, vol. 41, pp. 621-645.

Toulmin, P., III, and Clark, S. P., Jr., 1967. Thermal aspects of ore formation, in Barnes, H. L., ed., Geochemistry of hydrothermal ore deposits: New York, Holt, Rinehart and Winston, pp. 437-464.

Travernier, P., and Prache, P., 1952. Influence de la pression sur la résistivité d'une thermistance: Journal de Physique et le Radium, vol. 13, pp. 423-426.

Tripp, A. C., Ward, S. H., Sill, W. R. Swift, C. M., Jr., and Petrik, W. R., 1978. Electromagnetic and Schlumberger resistivity sounding in the Roosevelt Hot Springs KGRA: Geophysics, vol. 43, pp. 1450-1469.

Truesdell, A. H., 1975. Summary of section III geochemical techniques in exploration: Proceedings Second United Nations Symposium on the Development and Use of Geothermal Resources, San Francisco, California, 20-29 May 1975, vol. 1: Washington, D.C., U.S. Government Printing Office, pp. liii-lxxix.

Truesdell, A. H., and Fournier, R. O., 1975, Calculations of deep temperatures in geothermal systems from the chemistry of boiling spring waters of mixed origin: Proceedings Second United Nations Symposium on the Development and Use of Geothermal Resources, San Francisco, California, 20-29 May 1975, vol. 1, pp. 837-844.

Urban, T. C., and Diment, W. H., 1975. Heat flow on the south flank of the Snake River Rift: Geological Society of America Abstracts with Programs, vol. 7, No. 5, p. 648.

Urban, T. C., Diment, W. H., and Nathenson, M., 1978. East Mesa geothermal anomaly, Imperial County, California-significance of temperatures in a deep drill hole near thermal equilibrium: Geothermal Resources Council Transactions, vol. 2, pp. 667-670.

Urban, T. C., Diment, W. H., Sass, J. H., and Jamieson, I. M., 1976. Heat flow at The Geysers, California, U.S.A.: Proceedings Second United Nations Symposium on the Development and Use of Geothermal Resources, San Francisco, California, 20-29 May 1975, vol. 2: Washington. D.C., U.S. Government Printing Office, pp. 1241-1245.

U.S. Bureau of Reclamation, 1974. Geothermal resource investigations, East Mesa Test Site, Imperial Valley, California-status report, November, 1974: Boulder City, Nevada.

U.S. Bureau of Reclamation, 1977. Geothermal resource investigations, East Mesa Test Site, Imperial Valley, California-status report, April 1977: Boulder City, Nevada.

U.S. Geological Survey, 1970. The national atlas of the United States: Washington, D.C.

Vacquier, V, and Affleck, J., 1941. Computation of the depth to the bottom of the Earth's magnetic crust: American Geophysical Union Transactions, pp. 446-450.

Van Eysinga, F. W. B., 1975. Geologic timetable, 3d edition, Amsterdam, Elsevier.

Vanyan, L. L., 1966. Electromagnetic depth soundings, translated by G. V. Keller: New York, Consultants Bureau.

Veneruso, A. F., and Stoller, H. M., 1978. High temperature instrumentation for geothermal applications: Geothermal Resources Council, Transactions, vol. 2, pp. $679-682$.

Varet, J., 1979. Low enthalpy geothermal fields, with reference to geothermal energy in France: Journal of Japan Geothermal Energy Association, vol. 15, pp. 3-16.

Von Herzen, R. P., 1963. Geothermal heat flow in the gulfs of California and Aden: Science, vol. 140, pp. 1207-1208. 
Vozoff, K., 1972. The magnetotelluric method in the exploration of sedimentary basins: Geophysics, v. 37, p. 98-141.

Vozoff, K., and Ellis, R. M., 1966. Magnetotelluric measurements in southern Alberta: Geophysics, vol. 31, pp. 1153-1157.

Vozoff, K., and Swift, C. M., Jr., 1968. Magnetotelluric measurements in the North German Basin: Geophysical Prospecting, vol. 16, pp. 454-473.

Wait, J. R., ed., 1959. Overvoltage research: New York, Pergamon.

Walker, G. W., Macleod, N. S., and McKee, E. H., 1974. Transgressive age of late Cenozoic silicic volcanic rocks across southeastern Oregon: Implications for geothermal potential: Geological Society of America Abstracts with Programs, vol. 6, No. 3, p. 272.

Wallace, R. H., Jr., Kraemer, T. F., Taylor, R. E., and Wesselman, J. B., 1979. Assessment of geopressured-geothermal resources in the northern Gulf of Mexico basin, in Muffler, L. J. P., ed., Assessment of the geothermal resources of the United States-1978: U.S. Geological Survey Circular 790, pp. 132-155.

Walsh, J. B., 1965. The effect of cracks on the compressibility of rock: Journal of Geophysical Research, vol. 70, pp. 381-389.

Walsh, J. B., 1968. Attenuation in partially melted material: Journal of Geophysical Research, vol. 73, pp. 2209-2216.

Walsh, J. B., 1973. Theoretical bounds for thermal expansion, specific heat, and strain energy due to internal stress: Journal of Geophysical Research, vol. 78, pp. 7637-7646.

Walsh, J. B., and Brace, W. F., 1966. Elasticity of rock-A review of some recent theoretical studies: Rock Mechanics and Engineering Geology, vol. 4, pp. 283-297.

Walsh, J. B., and Decker, E. R., 1966. Effect of pressure and saturating fluid on the thermal conductivity of compact rock: Journal of Geophysical Research, vol. 71, pp. 3053-3061.

Wannamaker, P. E., Sill, W. R.; and Ward, S. H., 1978. Magnetotelluric observations at the Roosevelt Hot Springs KGRA and Mineral Mts., Utah: Geothermal Resources Council Transactions, vol. 2, No. 2, pp. 697-700.

Ward, P. L., 1972. Microearthquake-prospecting tool and possible hazard in the development of geothermal resources: Geothermics, vol. 1, pp. 3-12.

Ward, P. L., and Bjornsson, S., 1971. Microearthquakes, swarms, and the geothermal areas of Iceland: Journal of Geophysical Research, vol. 76, pp. 3953-3982.

W.Ward, S. H.; 1967a. Electromagnetic theory for geophysical applications, in Mining geophysics: Tulsa, Oklahoma, Society of Exploration Geophysicists, vol. 2, pp. 10-196.

Ward, S. H., 1967b. The electromagnetic method, in Mining Geophysics: Tulsa, Oklahoma, Society of Exploration Geophysicists. vol. 2, pp. 224-372.

Ward, S. H., Pridmore, D. F., Rijo, L., and Glenn, W. E., 1974. Multispectral electromagnetic exploration for sulfides: Geophysics, vol. 39, pp. 666-682.

Ward, S. H., Parry, W. T., Nash, W. P., Sill, W. R., Cook, K. L., Smith, R. B., Chapman, D. S., Brown, F. H., Whelan, J. A., and Bowman, J. R., 1978. A summary of the geology, geochemistry and geophysics of the Roosevelt Hot Springs thermal area, Utah: Geophysics, vol. 43, pp. 1515-1542.

Waring, G. A.. as revised by Blankenship, R. L., and Bentall, R., 1965. Thermal Springs of the United States and other countries of the world-a summary: $U . S$. Geological Survey Professional Paper 492.

Warren, N., and Nashner, R., 1976. Theoretical calculation of compliances of a porous medium, in Strens. R. G. J., ed., The physics and chemistry of minerals and rocks: New York, John Wiley, pp. 197-216.

Waters, K. H., 1978. Reflection seismology : New York, Wiley.

Watson, K., 1975. Geothermal reconnaissance from quantitative analysis of thermal infrared images: Proceedings of Institute of Electrical and Electronics Engineers, pp. 128-137. 
Weaver, C. S., and Pitt, A. M., 1978. Traveltime curves and apparent velocities across the Yellowstone caldera: Earthquake Notes, vol. 49, No. 1, p. 70.

Weres, .0., Tsao, K., and Wood, B., 1977. Resource technology and environment at The Geysers: University of California, Lawrence Berkeley Laboratory, LBL-5231.

White, D. E. 1969. Rapid heat-flow. surveying of geothermal areas utilizing individual snowfalls or calorimeters: Journal of Geophysical Research, vol. 75, pp. 5191-5201.

White, D. E., 1973. Characteristics of geothermal resources, in Kruger, P., and Otte, C., eds., Geothermal energy: Stanford, Stanford University Press, pp. 69-94.

White, D. E., Barnes, Ivan. and O'Neill, J. R., 1973. Thermal and mineral water of non-meteoric origin, California Coast Ranges: Geological Society of America Bulletin, vol. 84, pp. 547-560.

White, D. E., Fournier, R. O., Muffler, L. J. P., and Truesdell, A. H., 1975. Physical results from research drilling in thermal areas of Yellowstone National Park, Wyoming: US. Geological Survey Professional Paper 892.

White, D. E., Muffler, L. J. P., and Truesdell, A. H., 1971. Vapor-dominated hydrothermal systems compared with hot-water systems: Economic Geology, vol. 66, pp. 75-97.

White, D. E., and Williams, D. L., 1975. Summary and conclusions, in White, D. E., and Williams, D. L., eds.. Assessment of geothermal resources of the United States-1975: USS. Geological Survey Circular 726, pp. 147-155.

Whiteford, P. C., 1970. Ground movements in the Waiotapu geothermal region, New Zealand: Geothermics, special issue 2, pt. 2, pp. 478-486.

Whiteford, P. C., 1976. Studies of the propagaton and source location of geothermal seismic noise: Proceedings Second United Nations Symposium on the Development and Use of Geothermal Resources, San Francisco, California, 20-29 May 1975, vol. 2: Washington, D.C., U.S. Government Printing Office, pp. 1263-1271.

Williams, D. L., Berkman, F., Mankinen, E. A., 1977. Implications of a magnetic model of the Long Valley caldera, California: Journal of Geophysical Research, vol. 82, pp. 3030-3038.

Williams, P. L., Mabey. D. R., Zohdy. A. A. R., Ackermann. H. D., Hoover, D. E., Pierce, K. L., and Oriel, S S., 1976. Geology and geophysics of the southern Raft River Valley geothermal area, Idaho, U.S.A.: Proceedings Second United Nations Symposium on the Development and Use of Geothermal Resources, San Francisco, California, 20-89 May 1975, vol. 2: Washington, D.C., U.S. Government Printing Office, pp. 1273-1282.

Williams, R. S., Jr., and Carter, W. D., eds., 1976. ERTS-1; A new window on our planet: U.S. Geological Survey Professional Paper 929.

Wilson, J. T., 1963. A possible origin of the Hawaiian Islands: Canadian Journal of Physics, vol. 41, pp. 863-870.

Wollenberg, H. A., and Smith, A. R., 1970. Radiogenic heat production in prebatholithic rocks of the central Sierra Nevada: Journal of Geophysic Research, vol. 75, pp. 431-438.

Woodside, W., and Messmer, J. H., 1961. Thermal conductivity of porous media: Journal of Applied Physics, vol. 32, p. 1688.

Woollard, G. P., 1959. Crustal structure from gravity and seismic measurements: Journal of Geophysical Research, vol. 64, pp. 1521-1544.

Woollard, G. P., and Joesting, H. R., 1964. Bouguer gravity anomaly map of the United States: Washington, D.C., U.S. Geological Survey, scale, 1:2,500,000.

Wyllie, P. J., 1971. Experimental limits for melting in the Earth's crust and upper mantle, in Heacock, J. G., ed., The structure and physical properties of the Earth's crust: American Geophysical Union Geophysical Monograph 14, pp. 279-301.

Wyss, M., and Brune, J. N., 1968. Seismic movement, stress, and source dimensions of earthquakes in the California-Nevada region: Journal of Geophysical Research, vol. 73, pp. 4681-4694. 
Young, H. W., and Mitchell, J. C., 1973. Geothermal investigations in Idaho-Part 1 , Geochemistry and geologic setting of selected geothermal waters: Idaho Department of Water Administration Information Bulletin 30.

Yungul, S. H., 1961. Magnetotelluric sounding three-layer interpretation curves: Geophysics, vol. 26, pp. 465-473.

Zablocki, C. J., 1976. Mapping thermal anomalies on an active volcano by the selfpotential method, Kilauea, Hawaii, Proceedings Second United Nations Symposium on the Development and Use of Geothermal Resources, San Francisco, California, 20-29 May 1975, vol. 2: Washington, D.C., U.S. Government Printing Office, pp. 1299-1309.

Zohdy, A. A. R., 1973. Total field resistivity mapping [abs.]: Geophysics, vol. 38, No. 6, p. 1231.

Zohdy, A. A. R., 1974a. The use of Dar Zarrouk curves in the interpretation of VES data: US. Geological Survey Bulletin 1818-D.

Zohdy, A. A. R., 1974b. A computer program for the automatic interpretation of Schlumberger sounding curves over horizontal stratified media: Springfield, Virginia, US. Department of Commerce, National Technical Information Service, PB232703.

Zohdy, A. A. R., 1974c. A computer program for the calculation of Schlumberger sounding curves by convolution: Springfield, Virginia, U.S. Department of Commerce, National Technical Information Service, PB-232056.

Zohdy, A. A. R., 1975. Automatic interpretation of Schlumberger curves using modified Dar Zarrouk function: US. Geological Survey Bulletin 1313-E.

Zohdy, A. A. R., Anderson, L. A.. and Muffler, L. J, P., 1973. Resistivity, self potential, and induced polarization survey of a vapor-dominated geothermal system: Geophysics, vol. 38, pp. 1130-1144.

\subsection{Heat and mass transfer in reservoirs (By D. J. Ryley*)}

\subsubsection{Transfer of heat by thermal convection}

The convective transfer of heat occurs within the earth at two distinct levels and in different contexts. Thus heat is brought to the base of the crust from deeper levels within the earth's asthenosphere by magmatic circulation within a convection cell. The heat may then be transferred upwards by conduction through igneous intrusions into the upper crust. If a hydrothermal flow within water-saturated rock is associated with the upper reaches of the intrusion, a convection cell may be set up within the rock. Heat would then be transferred still nearer to the surface and the water flow might be accessible by drilling. The former type of convection cell is most readily understood, and the open cell will now be described in more detail.

Figure 2.5 shows a vertical cross section through a space WXYZ between two impermeable layers WX and YZ containing only a Newtonian fluid. Attention is focussed on the volume of liquid having the cross-section ABCD. The effective height of this cell is $H$, and a temperature difference $\Delta T=T_{2}-T_{1}$ exists between the upper and lower constraining boundaries.

-Division of Engineering, Brown University, Providence, Rhode Island 02912 ; permanent address, Department of Mechanical Engineering, University of Liverpool, Liverpool, England. 

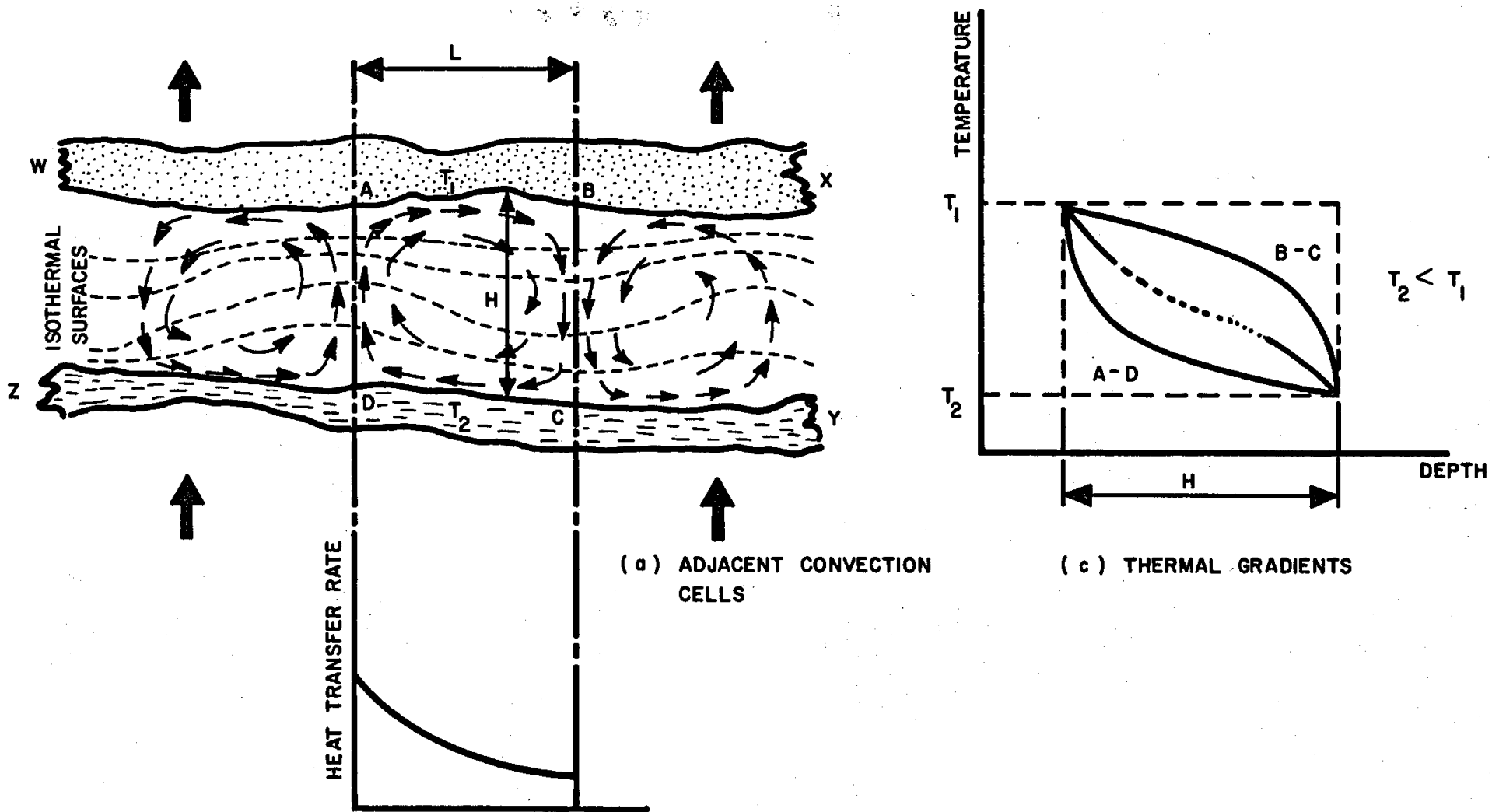

(b) HEAT TRANSFER

Froure 2.5-Convection cells.

(c) THERMAL GRADIENTS 
The fluid density $\rho$ at the bottom will decrease upon heating, and buoyancy effects may cause the heated fluid to rise. In such an event colder fluid would move in to take its place, and continuous circulation in the vertical plane would be promoted. When this type of steady circulation occurs, there is a continuous transport of heat from the lower to the upper surface, and the unit is referred to as a "convection cell." If the cell described is considered in conjunction with its neighbors, it is evident that there is a hot plume of ascending fluid at DA and a cold plume of descending fluid at BC. As a consequence of these fluid movements, there is a distortion of the isothermal temperature surfaces in the manner shown by the broken lines.

The conditions for the onset of convection were first derived by Rayleigh [1916]. The physical quantities assumed constant influencing the motion may be identified as the fluid kinematic viscosity $v$, the volume coefficient of thermal expansion $\alpha$, the thermal interval $\Delta T$, the cell vertical depth $H$, the thermal conductivity $\kappa$, the specific heat of the fluid $c$, and the acceleration of gravity $g$. These quantities may be used to compute the Rayleigh number $R a$ :

$$
R a=\frac{\alpha \Delta T}{H} \cdot g \frac{H^{4}}{\kappa \nu}=\frac{\alpha \Delta T g H^{3} \rho^{2} c}{\alpha \mu},
$$

where $\mu$ is the absolute viscosity $\left(=_{v} / p\right)$. The Rayleigh number may be subdivided:

$$
R a=\left(\frac{\alpha \Delta T g H^{3} \rho^{2}}{\mu^{2}}\right)\left(\frac{\mu c}{\kappa}\right)=(G r)(P r),
$$

where $G r$ is the Grashof number characterizing the ratio of buoyancy to viscosity, and $\mathrm{Pr}$ is the Prandtl number of the liquid characterizing the ratio of its momentum diffusivity to its thermal diffusivity. It is evident that viscosity $\mu$ has a significant influence on the rate of circulation in a cell. Thus a mantle cell with magma at a temperature not much exceeding the melting point of the rock may be expected to show very slow circulation. Arguments from the rate of continental drift suggest rates of up to $60 \mathrm{~mm} / \mathrm{yr}$.

To initiate convection it is necessary that $R a>R a_{\text {crtitcal, }}$ where

$$
R a_{\text {oritooal }}>\frac{27 \pi^{2}}{4} \fallingdotseq 67
$$

The above theory is applicable to an open cell but the principle may be modified to cover the case where the fluid is contained in permeable rock, the fluid normally being crustal water. For modelling, the rock is assumed uniform in texture having a permeability $K$ and a thermal conductivity $\kappa_{\mu}$. The thermal conductivity of the fluid is $\kappa_{k}$. The equation 2.2 is now modified to the form

$$
R a=\left(\frac{K \alpha \Delta T g H \rho^{2}}{\mu^{2}\left(\kappa_{M} / \kappa_{F}\right)}\right)\left(\frac{\mu c}{\kappa_{F}}\right)=(G r)(P r)
$$


The classical value [Lapwood, 1948] for $R a_{\text {crtitioa }}$ is now $4 \pi^{2}=39.5$ for a cell of square aspect ratio having an impermeable floor and ceiling. It has, however, been demonstrated [Kassay and Zebib, 1975] that the critical value of $R a$ is substantially reduced when the classic theory is refined by recognizing viscosity variation in the convecting fluid. The effect of variable permeability has been studied by Ribando and Torrance [1976].

In steady-state operation for both types of cell the circulating fluid is seen to act as an agent for heat transfer, accepting heat at a deep hightemperature location and rejecting it at a shallower location of lower temperature. In studies of geothermal reservoirs we are principally interested in the upper crustal cell with hydrothermal circulation, not the deep magmatic cell. For both types of cell the heat transfer may be expressed in the familiar form

$$
N u=f(R a),
$$

where $N u=h H / \times$ where $h$ is the heat transfer coefficient.

The Nusselt number, $N u$, may be regarded as the ratio of the total heat transmitted to that transmitted by conduction alone and is therefore an index of the magnitude of the convective heat transfer. The relation between $N u$ and $R a$ has been given differently by different workers [Elder, 1965; Witherspoon, 1977; Takahashi and Chen, 1975]. It is unlikely that predictions based, as is frequent, upon simplified laboratory models will give results which closely simulate the performance of actual cells with their vastly greater complexity. Some curves of $N u$ versus $R a$ are given in figure 2.6.

To convey some idea of the magnitudes of natural cells, it is believed [Witherspoon, 1977] that at Wairakei, New Zealand, there are about

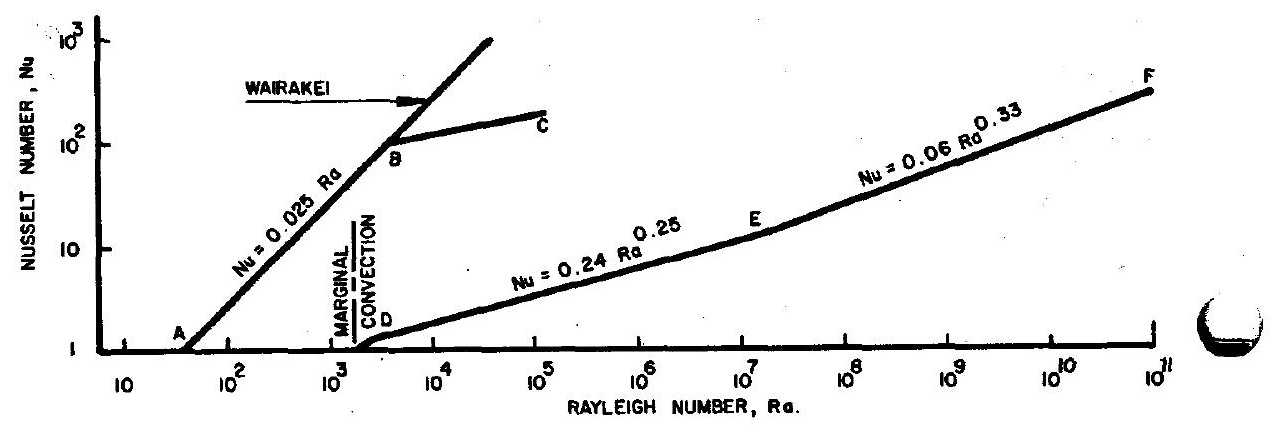

ABC (AFTER ELDER, 1965). AB MODEL CELLS EMPLONING WATER AND OL, USWG GLASS SPHERES AS TRACERS

BC LARGER MODEL CELL EMPLOYING WATER, USING EXPANDED PLASTIC BALLS AS TRACERS.

DE (AFTER SILVESTON, 19S8)

EF (AFTER MALKUS, 1954)

FrgURE 2.6-Nusselt number as a function of Rayleigh number for free convection in a viscous fluid. 
twelve contiguous convection cells in line of roughly square aspect ratio, i.e., $L=H$, of approximately $5 \mathrm{~km}$. The temperatures are approximately (figure 2.5) $T_{8}=400^{\circ} \mathrm{C}, T_{1}=20^{\circ} \mathrm{C}$. Values of $R a$ are believed to range in magnitude up to 5000 .

\subsubsection{Mass and heat transfer within the geothermal reservoir}

In all geothermal wells to date the object has been to drill into the underground hot water or steam/water flow and to extract it for use employing a downhole pump or exploiting artesian action. If a well is to yield a steady supply of hot fluid, two conditions must be fulfilled :

(1) There must be an adequate supply of water at depth. This implies that the underground water course (aquifer) must provide a flow area sufficient for the continuous replacement of extracted liquid.

(2) The aggregate area of swept rock must be adequate to provide the necessary transfer of heat from rock to liquid, and the geometry of the rock itself must be adequate to recover this heat by conduction from the rock reservoir heat.

2.2.2.1 The flow of geofuids. The motion of water through a packed particulate medium was first investigated by $H$. Darcy in 1856. His name is now associated with the unit of permeability $K$, and the one-dimensional volume flowrate $Q v$ of liquid through a permeable solid is given by

$$
Q_{r}=\frac{K A}{\mu} \frac{\partial P}{\partial x}
$$

where $A$ is the area perpendicular to the flow, $P$ is the pressure and $\mu$ is the viscosity. A permeable medium has a permeability of one darcy if a single-phase fluid of viscosity $1 \mathrm{cP}$ that completely fills the void space of the medium will flow through it at the rate of $1 \mathrm{ml} / \mathrm{s} \mathrm{cm}^{2}$ of cross-section under a pressure gradient of 1 atmosphere $/ \mathrm{cm}$.

The permability of a specimen may be found in the laboratory using a permeameter [Bear, 1972] in which the mass fiowrate through the specimen is measured under a controlled hydrostatic head. The same principle may be employed for strata in situ on the surface of a borehole [Smith et al., 1975]. There is evidence [Ramey et al., 1975] that the permeability of rock tends to fall with increase in temperature and confining pressure. Permeability may also be correlated with acoustic velocity [Trice and Warren, 1977].

Associated with rock permeability is its porosity, and care must be taken to distinguish between these properties. A rock may be porous but impermeable whereas the converse is not true. A rock will be permeable in proportion to the number and area of the effective flow passages through it and these passages contribute to its porosity. Porosity is usually defined 
as the ratio of aggregate void volume to the bulk volume. It is dimensionless and is expressed as a fraction or percentage. It may be calculated for a rock specimen from the expression :

$$
\text { total porosity, } \phi=100\left(1-\frac{\rho_{d}}{\rho_{g}}\right)
$$

where $\rho_{d}$ is the dry bulk density after oven drying and $\rho_{g}$ is the grain density, both readily measurable. The effective porosity may be determined by finding the volume of a fluid needed to saturate the accessible pores of a specimen [Dropek et al., 1975]. This value will normally be less than the total porosity as a consequence of occluded pores and voids. Porosity and permeability are related to electrical conductivity in fluid-saturated porous media.

There is no necessary functional relation between porosity and permeability. In some cases, as in loosely-packed particles the void may be regarded as the "continuous" component and the rock as the "dispersed" component. In other cases, as in some pyroclastic rocks of low permeability, the voids may be the "dispersed" component. In the former case, if the particles conform to a general geometric shape (e.g., plates, spheres) the void fraction and permeability may be found approximately by mathematical modelling.

Void fraction and permeability are both affected by compaction, consolidation, particle fracture, cementation, and aquifer erosion [Krumbein and Sloss, 1951].

2.2.2.2 Heat transfer to the hydrothermal flow. The hydrothermal flow during its passage through hot rock accepts heat from the swept surfaces. This transfer is influenced by the extent and nature of the rock porosity and permeability, of its subdivision by fracture and faulting, and by the size and packing of the individual grains, pebbles, boulders, etc. Only for simple geometries is it possible to model the heat transfer process. The extent to which fracture and other subdividing agencies have promoted fragmenation is defined by the specific surface of the rock sampl:

$$
\text { Specific surface, } S=\frac{\text { Total surface of fragments }}{\text { Mass of fragments }}
$$

The value of $S$ is easily found for geometric shapes and is then proportional to the specific number, $N$, where

$$
N=\frac{\text { Total population of geometrically identical fragments }}{\text { Total mass of fragments }}
$$

Heat transfer tends to be efficient in sediments where the water flows between small grains thus promoting a high value of $S$. Highly permeable 
clastic sediments are ideal [Bodvarsson, 1969]. The transfer efficiency can be relatively poor in igneous rock deficient in permeable fractures.

Few attempts have been made to construct mathematical models for analysis but Bodvarsson [1974] considers the case of a single-fracture flow, intergranular flow and intergranular vaporizing flow.

The fluid flowing through the rock may be single or two-phase. In "liquid-dominated" reservoirs the hydrostatic pressure on the water is normally sufficient to prevent vaporization. If, at any part of the flow, the pressure declines below the saturation value corresponding to the temperature, flashing will occur. If this condition is widespread and vapor abundant, the reservoir is said to be "vapor-dominated" (see sections 2.2.5 and 2.2.5.2). Depending upon the temperature, pressure and heat transfer at a given locality phase change in either direction may take place, and the fluid finally drawn off at the well base reflects the integrated effect of all these local actions. Variation of demand at the wellhead promotes a variation of pressure at the well base which may modify the phase change regime in the reservoir. If the reservoir possesses a high thermal and/or hydrological inertia, the ensuing transient may have a long duration.

\section{Q.2.3 Drawdown and buildup in reservoirs}

When closed a well will exhibit a range of constant values of internal pressure according to the depth at which measurement is taken. If the well is opened, there is a decline in pressure at all levels due to the aggregate friction in all flow passages and the conversion of pressure energy to kinetic energy. If the pressure at any location is observed, it will be found to decline over a relatively long period of time as the hydraulic system slowly regains a new equilibrium. This effect is referred to as "drawdown" and the pressure-time relation refiects the physical conditions in the reservoir : storage capacity, permeability, and compressibility. Drawdown is also related to the geofluid viscosity and the well dimensions, and may reflect the existence of any structural anomaly such as a barrier or a fault.

If now the well is reclosed, the internal pressure begins to recover, the rate of recovery depending upon the reservoir conditions already mentioned. This recovery is referred to as "buildup," and terminates when the original equilibrium is regained.

Both drawdown and buildup are hydrological phenomena, and no account is taken, in the analysis, of temperature variations and phase change both of which are assumed to be absent. It should be remembered, however, that viscosity is temperature-dependent as is interfacial surface tension which could be significant in capillary liquid passages.

Pressure-time measurements during the drawdown and buildup processes may be analyzed to provide data characterizing the reservoir. 
An outline of the method follows, and the subject is explored further in section 2.6.

The analytical model used is that of a transient potential distribution around a continuous line sink in an infinite, homogeneous, horizontal slab of finite thickness $B$ [Ferris et al., 1962]. The aim of the analysis is to determine reservoir transmissivity $K H$ and storativity $\phi c H$, where $K$ is the permeability, $\phi$ is the porosity, and $c$ the reservoir compressibility, and also to draw inferences concerning possible barriers and leaks. The transient pressure change around a line sink in an initially static system was given by Theis [1935] as:

$$
\Delta P=\frac{Q_{\nu} \mu P_{D}}{(v) K H}
$$

where $Q_{v}$ is the constant volumetric flow rate, $\mu$ is fluid viscosity, $P_{D}$ is dimensionless pressure, and $v$ is a constant depending on the units used. $\boldsymbol{P}_{D}$ is expressed as an integral of the dimensionless time, $t_{D}$ :

$$
P_{D}=1 / 2 \int_{u}^{\infty} \frac{e^{-u}}{u} d u,
$$

where $u=t_{D} / 4$. The dimensionless time $t_{D}$ is given by

$$
t_{D}=\frac{K t}{\phi \mu c r^{2}}
$$

in which $t$ is the time, and $r$ is the radius to the point of observation. To evaluate $K H$ and $\phi c H$ using the preceding equations, a technique of curve matching is conventionally used by plotting the pressure drawdown data on logarithmic scales. For $t_{D} \gg 1$ an asymptotic approximation may be used in which drawdown is plotted as a function of logarithmic time. In addition to obtaining $K H$ and $\phi c H$, the departure of the plotted data from the type-curve in the logarithmic plot or the occurrence of discontinuities in the slopes of the linear segments of the semi-logarithmic plot give indications of the probable presence of a barrier or of a leaky boundary in the system. Figure 2.7 shows the results of a short-term production test at Well RRGE 2 at the Raft River Geothermal Project, Idaho [Narasimhan and Witherspoon, 1977]. The flowrate $Q v$ was nearly constant at $0.85 \mathrm{~m}^{3} / \mathrm{min}$ (225 gal/min) for the test duration of $15 \mathrm{hr}$. After shutdown, pressure buildup was observed for a further $21 / 4 \mathrm{hr}$. The maximum drawdown was approximately $258.6 \mathrm{kPa}\left(37.5 \mathrm{lb} / \mathrm{in}^{2}\right)$, and the total pressure recovery during buildup was approximately $167.2 \mathrm{kPa}\left(24.3 \mathrm{lb} / \mathrm{in}^{2}\right)$. Figure $2.7 \mathrm{a}$ shows that between 15 and $600 \mathrm{~s}$ at the start of production, the drawdown curve closely matches the Theis type-curve. Computations based thereon indicate the following parameters for the reservoir in the vicinity of RRGE 2: $K H=14,234 \mathrm{md} \mathrm{m}(46,700 \mathrm{md} \mathrm{ft}) ; \phi c H=1.29 \times 10^{-3} \mathrm{~m} / \mathrm{kPa}$ 


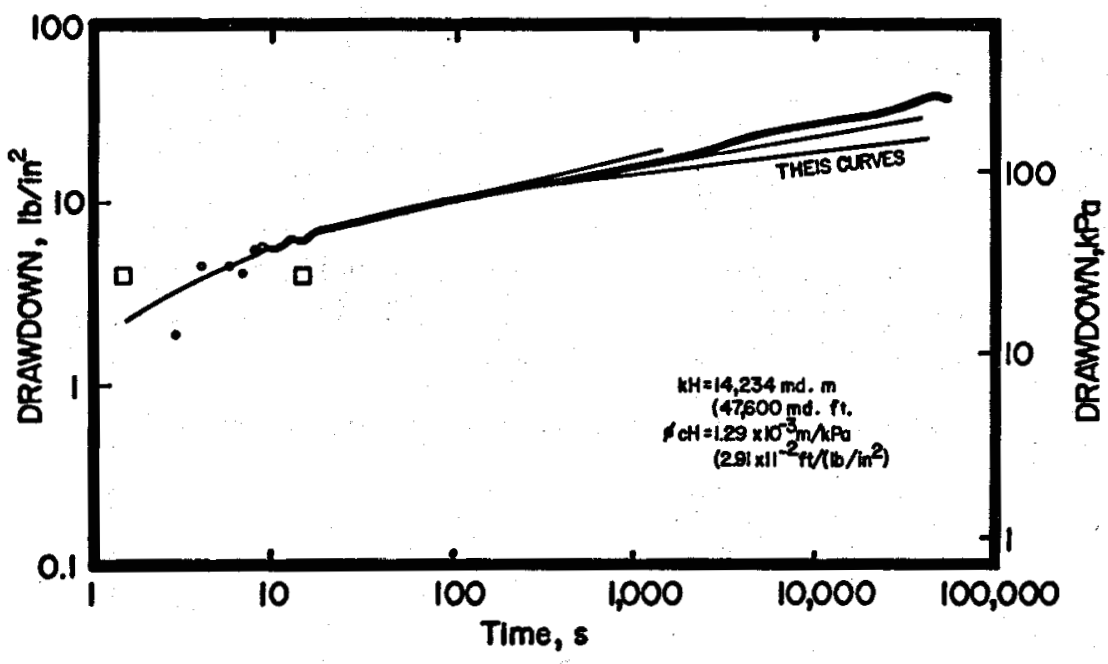

a. Log-log Plot

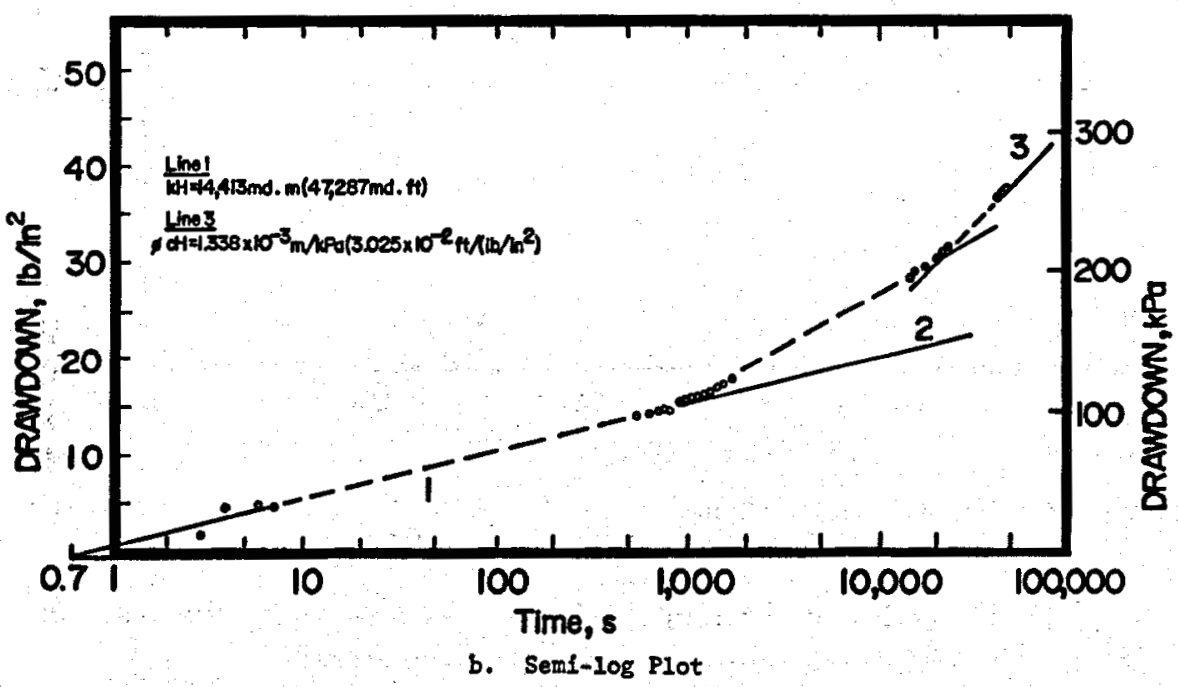

FravRe 2.7-Short-term production test, well RRGE 2. Drawdown versus time. (The Individual experimental points closely follow the trend curve and are omitted for clarity.) [After Narasimham and Witherspoon, 1977.]

$\left(2.91 \times 10^{-2} \mathrm{ft} / \mathrm{lb} / \mathrm{in}^{2}\right)$, assuming an effective well radius of $0.3048 \mathrm{~m}(1 \mathrm{ft})$. Because the production thickness $H$ of the reservoir was not accurately known, $K$ and $c$ could not be computed.

The data on figure $2.7 \mathrm{a}$ are redrawn on figure $2.7 \mathrm{~b}$ on logarithmic-linear axes. Values of $K H$ and $\phi c H$ calculated therefrom confirm acceptably those quoted above, and the plot reveals that from $800 \mathrm{~s}$ the drawdown data plot on three distinct line segments. The existence of a second and third 
segment suggests the probable presence of more than one barrier boundary near well RRGE 2.

A logarithmic plot of the buildup data is shown in figure 2.8. It is known from petroleum engineering literature that when pressure buildup is plotted logarithmically the presence of unit slope in the early drawdown data is indicative of well-bore storage effects, while the existence of a halfslope indicates the presence of large highly permeable fractures close to the bore. Neither case is applicable in figure 2.8 which suggests that the reservoir can be treated as a porous medium.

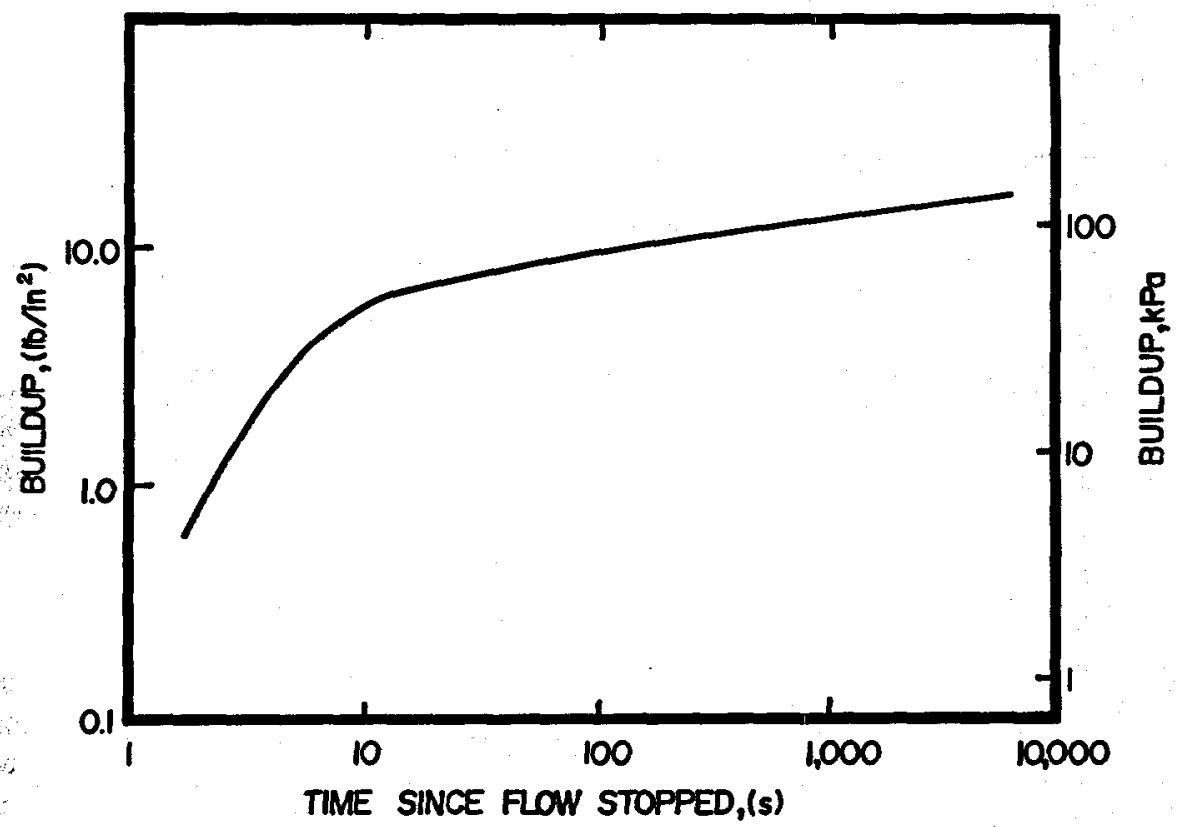

FraURe 2.8-Short-term production test, well RRGE 2. Buildup versus time. [After Narasimham and Witherspoon, 1977.]

The subject of drawdown and the inferences concerning the reservoir that it provides has been studied empirically by James [1975].

An instructive analytical paper on pressure transient analysis in geothermal wells has been presented by Ramey [1975].

2.2.3.1 Interference between adjacent wells. A geothermal reservoir may have an area of several square kilometers, and it cannot be adequately exploited by the flow through a single borehole which may be limited in diameter to about $0.3048 \mathrm{~m}$ (12 in). Several bores must be employed, and the question of their relative locations immediately arises. If they are placed too far apart, the reservoir will be under-utilized. If they are too close, they will collectively exceed the reservoir capacity. The influence of a well upon its neighbor is referred to as "interference." 
During the test program described above [Narasimhan and Witherspoon, 1977], tests were also conducted to explore the interference by well RRGE 2 on the closed "adjacent" well RRGE 1 located $1220 \mathrm{~m}(4000 \mathrm{ft})$ away which acted as the "observation" well. Water pressures were monitored with a downhole gage located at $3.965 \mathrm{MPa}\left(570 \mathrm{lb} / \mathrm{in}^{2}\right)$ and also at the surface where the pressure was $1.034 \mathrm{MPa}\left(150 \mathrm{lb} / \mathrm{in}^{2}\right)$. The maximum drawdown was $24.8 \mathrm{kPa}\left(3.6 \mathrm{lb} / \mathrm{in}^{2}\right)$. The subsequent buildup was also monitored. Both tests were analyzed using the methods described in section 2.2.8.

Similar tests were conducted at East Mesa, California, to explore the geometry and hydrological characteristics of the local geothermal reservoir [Narasimhan, McEdwards, and Witherspoon, 1977].

\subsubsection{The heat content of igneous-related geothermal systems}

On account of the geometric complexity of these systems and the uncertainties associated with any attempt to estimate their volumes and geological ages, it is only possible to offer a rough assessment of the stored energy. In their contribution to the Assessment of Geothermal Resources of the U.S., Smith and Shaw [1975] adopted the following procedure. They determined the radiometric age of the youngest volcanism which caused the emplacement of the magma chamber, as well as the extent of the superficial area by reference to the caldera, the vent distribution, the seismic shadow, fractures and uplift, in addition to the usual geophysical anomalies. The volume was calculated by assuming that the thickness of the magma chamber ranged from 2.5 to $10 \mathrm{~km}$ and using the available geological and geophysical data to obtain the thickness value which defined the most probable volume. In calculating the stored energy two major assumptions were made: (1) heat transfer in rocks surrounding the magma chamber is by solid state conduction, (2) effects of magmatic pre-heating and gains of magma subsequent to the original emplacement are ignored.

Silicic magma solidifies when its temperature declines below about $650^{\circ} \mathrm{C}$ $\left(1202^{\circ} \mathrm{F}\right)$ and is fully liquid at about $850^{\circ} \mathrm{C}\left(1562^{\circ} \mathrm{F}\right)$. The latent heat of crystallization is $272 \mathrm{~kJ} / \mathrm{kg}(65 \mathrm{cal} / \mathrm{g})$, the specific heat is $1.26 \mathrm{~kJ} / \mathrm{kg}^{\circ} \mathrm{C}$ $\left(0.3 \mathrm{cal} / \mathrm{g}^{\circ} \mathrm{C}\right)$, and the mean density of magma is $2500 \mathrm{~kg} / \mathrm{m}^{3}\left(2.5 \mathrm{~g} / \mathrm{cm}^{3}\right)$. The original energy content is calculated by adding together the liberated liquid heat and the released latent heat of crystallization, and the total between $850^{\circ} \mathrm{C}\left(1562^{\circ} \mathrm{F}\right)$ and $650^{\circ} \mathrm{C}\left(1202^{\circ} \mathrm{F}\right)$ is $523 \mathrm{~kJ} / \mathrm{kg}(125 \mathrm{cal} / \mathrm{g})$. If cooling continues down to $300^{\circ} \mathrm{C}\left(572^{\circ} \mathrm{F}\right)$ and the specific heat remains unaltered, the total energy liberated is $963 \mathrm{~kJ} / \mathrm{kg}$ (230 cal $/ \mathrm{g}$ ). On the assumption that $300^{\circ} \mathrm{C}\left(572^{\circ} \mathrm{F}\right)$ was the pre-existing temperature within the depth zone occupied by the magma, $963 \mathrm{~kJ} / \mathrm{kg}$ represents the access of specific stored energy resulting from the intrusion.

As a consequence of the emplacement of a magma chamber, the original gradient at the earth's surface will be modified. The time required for it 
to change to a new steady state is given approximately by relations discussed by Jaeger [1964]. For an assumed depth of cover of $4 \mathrm{~km}(2.5$ miles) and a thermal diffusivity of $0.7 \mathrm{~mm}^{2} / \mathrm{s}$, this time is about 360,000 years. If, therefore, the time lapse since the last eruption is much less than, say, 300,000 years, very little of the original heat has been lost at the earth's surface as a result of conduction. Heat has, however, been conducted from the magma into the adjacent lithosphere, particularly into the cap rock, and the amount can be calculated from conduction theory [Carslaw and Jaeger, 1959; Shaw, 1974] and shown to be given by:

$$
Q=51.6 A t^{0.5} \mathrm{cal},
$$

where $A$ is the contact area in $\mathrm{cm}^{2}$ and $t$ the elapsed time in seconds since the volcanic event. The equivalent expression when $A$ is in $\mathrm{m}^{2}$ and $Q$ in $\mathrm{kJ}$ is

$$
Q=2160 A t^{0.8} \mathrm{~kJ} \text {. }
$$

A comprehensive table is presented by Smith and Shaw [1975] of the magnitudes and energy contents of identified volcanic systems in the USA. A single example from their table illustrates the above. Thus the system at South Sister, Oregon, has a geological age of 2000 years, a chamber area of $35 \mathrm{~km}^{2}\left(13.5 \mathrm{miles}^{2}\right)$, and a chamber volume of $100 \mathrm{~km}^{3}\left(24 \mathrm{miles}^{3}\right)$. The total stored energy was originally $0.24 \times 10^{18} \mathrm{~kJ}\left(2.27 \times 10^{17} \mathrm{Btu}\right)$ of which $0.02 \times 10^{18} \mathrm{~kJ}\left(1.9 \times 10^{18} \mathrm{Btu}\right)$ has transfered to the cap rock.

The continued loss of energy from an igneous intrusion will lead in course of time to a situation in which there will be a temperature gradient within the intrusion itself. If the size and geometry of the intrusion are known, together with the temperature gradient and the specific heat of the rock, an assessment of the stored energy above an arbitrary temperature datum may readily be made by the summation of suitable volume elements [Garnish; 1976; Diment et al., 1975].

\subsubsection{The heat content of hydrothermal convection systems}

In hydrothermal convection systems most of the heat is transferred by the convective circulation of hot water or steam rather than by thermal conduction through solid rocks. Such circulation implies a high permeability, and most systems contain liquid water as the dominant pressurecontrolling fluid in fractures and pores. These systems are said to be "water-dominated." Wells drilled into such systems deliver at the wellhead a water/steam mixture which normally falls in the 10 to $30 \%$ dryness fraction range. In a few systems such as Larderello, Italy, and The Geysers, California, wells produce saturated or superheated vapor, and such sys- 
tems are said to be "vapor-dominated." It is convenient to consider each type separately.

2.2.5.1 Hot water-dominated systems. These systems range widely in temperature from values slightly above ambient to about $360^{\circ} \mathrm{C}\left(680^{\circ} \mathrm{F}\right)$ in the Salton Sea system and the nearby Cerro Prieto system of Mexico. They also range in salinity from very low values to brines of extreme salinity. The energy stored is strongly dependent on the temperature and weakly dependent upon the salinity. In their contribution to the Assessment of Geothermal Resources of the United States, Renner et al. [1975] list some 63 systems having indicated temperatures above $150^{\circ} \mathrm{C}\left(302^{\circ} \mathrm{F}\right)$ and a further 224 having indicated temperatures between $90^{\circ} \mathrm{C}\left(194^{\circ} \mathrm{F}\right)$ and $150^{\circ} \mathrm{C}\left(302^{\circ} \mathrm{F}\right)$.

Much uncertainty exists concerning the extent of many of these systems. The methods enumerated in the previous section were employed where possible, but if no better data were available an areal extent of $1.5 \mathrm{~km}^{2}$ ( 0.6 miles $\left.^{2}\right)$ was assumed. In default of data to the contrary the top of the system was assumed to lie at a depth of $1.5 \mathrm{~km}(0.93 \mathrm{mile})$. The bottom of the system was arbitrarily assumed to lie at $3 \mathrm{~km}(1.86 \mathrm{~m})$, the then current (1975) depth of economic geothermal drilling. Temperatures at depth were based on geochemical methods. The value chosen for volumetric specific heat was a composite value for water-soaked rock, assuming approximately $25 \%$ of the volume to be occupied by water, and taken to be $2.52 \mathrm{~kJ} / \mathrm{kg}^{\circ} \mathrm{C}\left(0.6 \mathrm{cal} / \mathrm{g}^{\circ} \mathrm{C}\right)$. The stored energy was then assessed as the product of mass, volumetric specific heat, and temperature interval above a datum of $15^{\circ} \mathrm{C}\left(59^{\circ} \mathrm{F}\right)$.

2.2.5.2 Vapor-dominated systems. Vapor-dominated systems differ in their production characteristics from hot water-dominated systems for reasons not fully understood. Production of steam from a reservoir results in a decline in pressure which promotes boiling in the pores, the latent enthalpy of the ensuing steam being supplied by the reservoir rocks. It has been suggested that probably $85 \%$ or more of the stored energy in vapor-dominated systems resides in the reservoir rocks [Truesdell and White, 1973]. To assess the extent of the stored energy, however, it is necessary to postulate a realistic model of the reservoir. Renner et al. [1975] describe a circulatory system in which a vapor-dominated reservoir is located above a deep water table. Withdrawal of vapor promotes a boiling/condensation regime within this system, and mass balance necessitates the discharge of water/vapor through surface vents. This model accounts for the observed behavior of vapor-dominated systems.

Notwithstanding the differing physical structure of this system, the stored energy is calculated using the same method as for the hot waterdominated system described above. 
[Note added in proof: An up-to-date catalog of geothermal reservoirs of the United States can be found in Circular 790 of the U.S. Geological Survey, edited by L. J. P. Muffler and published in 1979.]

\subsubsection{Mechanical properties of rocks}

The only mechanical property of interest in the following sections has been the density, which is involved in magma cell convection theory and in connection with the storage of energy. Porosity and permeability are not strictly physical properties; they are associated with the rock history and structure. Nevertheless, porosity and particularly permeability have a vital influence on the exploitation capability of a potential geothermal resource insofar as they govern the extent of the possible flowrate of a geofluid. Thus a hot but impervious rock can only be utilized if it can be made pervious by artificial means, i.e., by some method or rock fracturing. This requires the initiation and propagation of a matrix of cracks.

A crack is propagated when certain physical conditions exist at its leading edge and these conditions are described and analyzed mainly in terms of orthodox concepts in the mechanics of materials, viz., stress, strain, the elastic constants and their functional interrelations [Liebowitz, 1968; Jaeger and Cook, 1969]. Because the material is deep underground and subject to a triaxial compressive system arising from the overburden and from lateral tectonic compression, the bulk modulus and the volumetric strain assume enhanced importance. The elastic properties are found using apparatus and experimental techniques developed from classical testing machines [Pratt et al., 1975].

A mechanical property developed from classical studies of crack propagation in metals, the so-called fracture-toughness, has been applied to the prediction of crack advance in rocks. This property, which is measured experimentally [e.g., Clifton et al., 1976] is the plane strain critical stress intensity factor, $I_{I c}$. A tensile crack, such as produced in hydraulic fracturing, is understood to extend when the pressure on the crack face increases the strength of the elastic stress field singularity at the crack tip to the critical value $K_{I 0}$.

\subsubsection{Rock fracture methods}

The principal methods available for fracturing rock are [Diadkin and Pariisky, 1975] :

(1) By the use of garland charges of common explosives in the lower levels of wells with multiple faces,

(2) By multiple explosions of liquid explosives at the zone of fracturing,

(3) By hydraulic fracture of a rock massif,

(4) By burning petroleum products to create a "thermoblast." 
An additional method [American Oil Shale Corporation, 1971] involves the use of

(5) Nuclear explosives.

The common aim of all these methods is to create new fractures and cracks and to promote the extension of those already existing.

Chemical explosives, (1) and (2) above, can be used to enlarge ("spring") a drill hole in order to create a localized cavity at a selected horizon, e:g., on a productive zone. The nature of the fracture will depend upon the local geology and faulting and the extent to which faults have become plugged during drilling or previously [Austin and Leonard, 1973]. The use of chemical explosives in aquifer systems has been treated by Aladiev et al. [1975].

Chemical explosives rely for their action upon a transient, rapid, and largely uncontrolled rise in pressure. A slower, controlled pressure rise of controlled duration may be secured by hydraulic means, item (3) above. This consists essentially of pumping water under pressure into the formation. One such operation is described in detail by Smith et al. [1975]. The well behavior suggested that a pre-existing natural fracture began to open at a downhole pressure of $34 \mathrm{MPa}\left(4930 \mathrm{lb} / \mathrm{in}^{2}\right)$ at a depth of

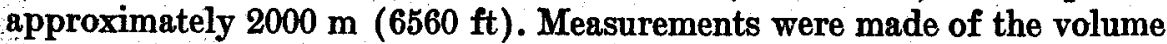
of water injected during opening of the formation and the recovery of water during subsequent venting, both before and after proppants were introduced. By injecting water at a constant rate of $132 \mathrm{l} / \mathrm{min}\left(4.7 \mathrm{ft}^{3} /\right.$ min) and observing the rate of pressure rise, an assumed flow area permitted the calculation of permeability, which was about $6 \mu \mathrm{d}$ for the local formation.

4. It may not be sufficient to initiate a fracture system of fixed extent and to rely thereafter for energy transfer upon the steady state conduction of heat to the rock/liquid interfaces (see section 2.2.2). Harlow and Pracht [1972] solved numerically the combined equations describing the coupled processes of fluid flow, heat transport, and rock fracture. Their results showed that continuing well production had a strong dependence upon the extent to which the underground fracture pressure can be maintained and the fracture zone continuously extended.

Nuclear explosions are, in principle, equivalent to chemical explosions, but of much greater magnitude. A nuclear explosion in rock proceeds in the following way : the energy released by the reaction creates a plasma of very high pressure and temperature. The heat produces a shock wave that successively vaporizes, melts, and fractures the surrounding rock before decaying to a seismic wave at relatively large distances from the original fission center. The sphere of vaporized rock created by the shock wave expands until its pressure is balanced by the weight of the overlying rock and by the strength of the surrounding rock. The result is a large spherical cavity surrounded by melted and fractured rock. After the explosion 
the fractured rock above the cavity will generally collapse, eliminating the cavity whose volume is then distributed above the explosion point. For alluvial material the porosity induced by collapse is small, and collapse can continue until the surface is reached and a subsidence crater forms. In hard rock, however, the induced porosity is significant, and collapse continues only to a height at which the cavity volume is consumed or a stable arch forms. The complete structure is called a chimney. For a summary of the use of nuclear explosives the reader is referred to Berman [1975]. A theoretical study of thermally-induced cracks in brittle solids has been made by Keer et al. [1976].

Notation for section $8 . \&$

\begin{tabular}{|c|c|}
\hline $\begin{array}{c}\cdots \\
\cdots \\
\cdots \\
\cdots \\
\cdots \\
\cdots \\
\cdots \\
\cdots\end{array}$ & 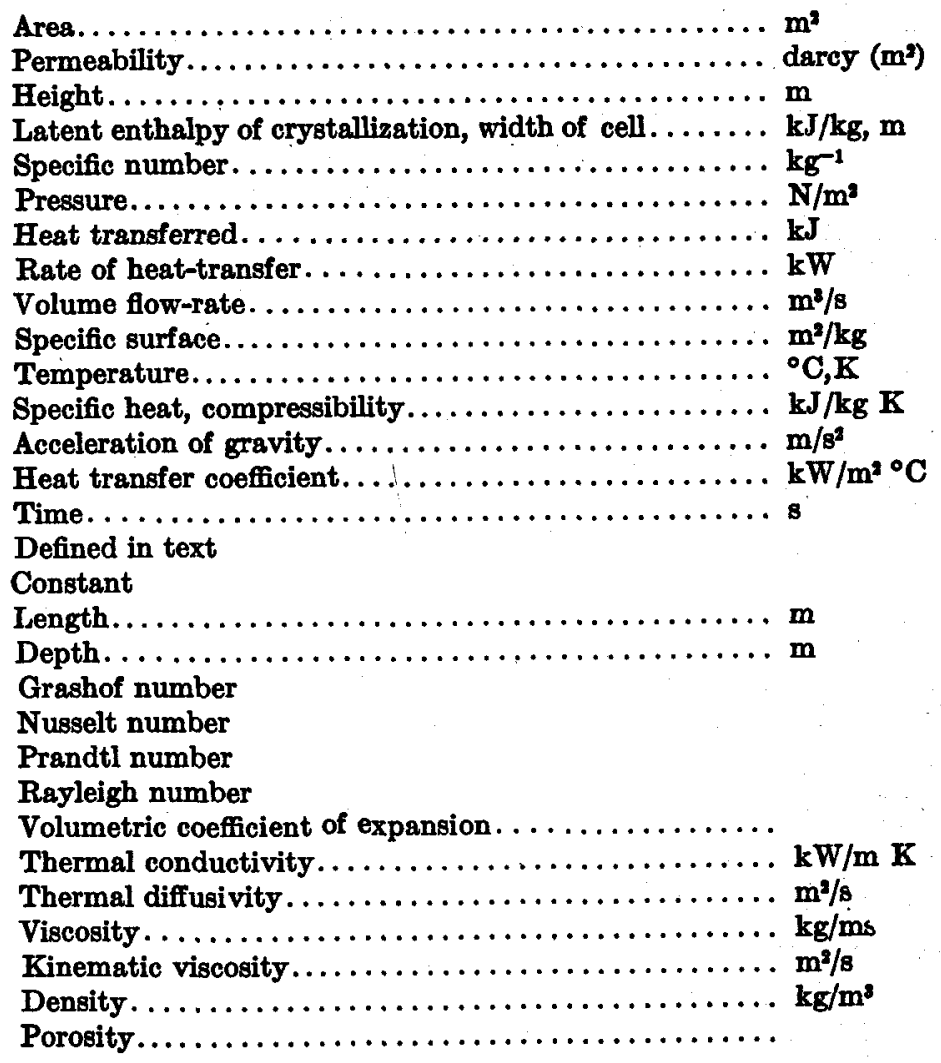 \\
\hline
\end{tabular}

BUBSCRIPTS

D....... Dimensionless

d........ Dry bulk

F.......... Geofluid

g........ Rock grain

$M$........ Rock 


\subsubsection{References for section 2.2}

Aladiev, I. T., Trusov, V. P., Peredary, A. D., Strigin, E. M., Saperov, E. V., and Fardzinov, V. K., 1975. "Heat and mass transfer processes in aquifer systems with artificially increased fracturing," Proc. Second UN. Symposium on the Development and Use of Geothermal Resources. San Francisco, Calif., May 1975, pp. 17151723.

American Oil Shale Corporation-U.S. Atomic Energy Commission, 1971. A feasibility study of a geothermal power plant. PNE-1550.

Austin, C. F., and Leonard, G. W., 1973. "Chemical explosive stimulation of geothermal wells," Chapter 15 of Geothermal Energy, Kruger, P., and Otte, C., (eds.). Stanford University Press, Stanford, Calif., 1973.

Bear, J., 1972. Dynamics of Fluids in Porous Media. American Elsevier Publishing Co., p. 649.

Berman, E. R., 1975. Geothermal Energy. Noyes Data Corporation, Park Ridge, N.J., 1975.

Bodvarsson, G., 1969. "On the temperature of water flowing through fractures," $J l$. Geophys. Res., 74, 8, pp. 1987-1992.

Bodvarsson, G., 1974. "Geothermal Resource Energetics," Geothermics, 3, 3, pp. 8392.

Carslaw, H. S., and Jaeger, J. C., 1959. Conduction of Heat in Solids, Oxford, Clerendon Press, p. 510.

Clifton, R. J., Simonson, E. R., Jones, A. H., and Green, S. J., 1976. "Determination of the initial-stress-intensity factor $K_{I C}$ from internally pressurized thick-walled vessels," Experimental Mechanics, 16, pp. 233-238

Darcy, H., 1856. Les Fontaines Publiques de la Ville de Dijon. Dalmont, Paris.

Diadkin, Y. D. and Pariisky, Y. H., 1975. "Theoretical and experimental grounds for utilization of dry rock geothermal resources in the mining industry," Proc. Second U.N. Symposium on the Development and Use of Geothermal Resources, San Francisco, Calif., May 1975, pp. 1609-1618.

Diment, W. H., Urban, T. C., Sass, J. H., Marshall, B. V., Munroe, R. J., and Lachenbruch, A. H., 1975. "Temperature and heat contents based on conductive transport of heat," Assessment of Geothermal Resources of the United States-1975 Geological Survey 726, pp. 84-103.

Dropek, R. K., Butters, S. W., and Jones, A. H., 1975. "Methods for determination of physical properties of rock materials," Report TR. 75-18, Terra Tek Inc., Salt Lake City, Utah, October, 1975.

Elder, J. W., 1965. "Physical processes in geothermal areas," Terrestrial Heat Flow, Geophysical Monograph Series, No. 8, American Geophysical Union Publn. No. 1288, pp. 211-239.

Ferris, J. G., Knowles, D. B., Brown, R. H., and Stallman, R. W., 1962. "Theory of aquifer tests," Water Supply Paper 15\$6-E, U.S. Geological Survey.

Garnish, J. D., 1976. "Geothermal Energy, the case for research in the United Kingdom," Energy Technology Support Unit, Harwell, Energy Paper No. 3, HMSO., London, England.

Harlow, F. H., and Pracht, W. E., 1972. "A theoretical study of geothermal energy extraction," Jl. Geophys. Res., 77, 35, pp. 7088-7048.

Jaeger, J. C., 1964. "Thermal effects of intrusions," Rev. Geophysics, vol. 2, pp. 443466 .

Jaeger, J. C., and Cook; N. G. W., 1969. Fundamentals of rock mechanics. Methuen, London, U.K.

James, Russell, 1975. "Drawdown test results differentiate between crack flow and porous bed permeability," Proc. Second UN. Symposium on the Development and Use of Geothermal Resources. Sän Francisco, Calif., May 1975, pp. 1715-1723. 
Kassay, D. R., and Zebib, A., 1976. "Variable viscosity effects on the onset of convection in porous media," Phys. of Fluids, 18, 12, pp. 1649-51.

Keer, L. M., Nemat-Nasser, S., and Parihar, K. S., 1976. "Growth and stability of thermally-induced cracks in brittle solids, "Northwestern University, Evanston, Ill., 60201. NSF Contract AER75-00187.

Krumbein, W. C., and Sloss. L. L., 1951. Stratigraphy and Sedimentation. First edition, W. H. Freeman, San Francisco, Calif., 1951.

Lapwood, E. R., 1948. "Convection of a fluid in a porous medium," Proc. Cambridge Phil. Soc., 44, pp. 508-521.

Liebowitz, H., 1968. A treatise on fracture. Academic Press, New York.

Muffier, L. J. P., ed., 1979. “Assessment of geothermal resources of the United States1978," Geological Survey Circular 790. Free on application to Branch of Distribution, U.S. Geological Survey, Arlington, Va., 22202.

Narasimhan, T. N., McEdwards, D. G., and Witherspoon, P. A., 1977. "Results of Reservoir Evaluation Tests, 1976 East Mesa Geothermal Field, CA.," Report LBL6369, Lawrence Berkeley Laboratory, University of California, Berkeley, Calif.

Narasimhan, T. N., and Witherspoon, P. A., 1977. "Reservoir evaluation tests on RRGE 1 and RRGE 2, Raft River Geothermal Project, Idaho," Report LBL-5958, Lawrence Berkeley Laboratory, University of California, Berkeley, Calif.

Pratt, H. R., Green, S. J., Jones, A. H., and Brace, W. F., 1975. "Physical and mechanical properties of selected geologic materials: a compendium," Report $\operatorname{Tr} 75-8$. Terra Tek, Inc. Salt Lake City, Utah.

Ramey, H. J., 1975. "Pressure transient analysis for geothermal wells." Proc. Second $U$. N. Symposium on the Development and Use of Geothermal Resources. San Francisco, Calif. May 1975, pp. 1749-1757.

Ramey, H. J., Jr., Kruger, P., London, A. L., and Brigham, A. L., 1975. "Geothermal reservoir engineering research at Stanford University," Proc. Second U.N. Symposium on the Development and Use of Geothermal Resources, San Francisco, Calif. May 1975, pp. 1763-1771.

Rayleigh, Lord, 1916. "On convection currents in a horizontal layer of fluid when the higher temperature is on the under side," Phil. Mag. Ser. 6, 32, pp. 529-546.

Renner, J. L., White, D. E., and Williams, D. L., 1975. "Hydrothermal convection systems," Assessment of Geothermal Resources of the United States-1975. Geological Survey Circular 726, pp. 5-57.

Ribando, R. J., and Torrence, K. E., 1975. "Natural convection in a porous medium: effects of confinement, variable permeability and thermal boundary conditions." ASME Paper 75-WA/HT-7S.

Shaw, H. R., 1974. "Diffusion of $\mathrm{H}_{2} \mathrm{O}$ Granitic Liquids: Part I Experimental Data; Part II Mass Transfer in Magma Chambers," in Geochemical Transport and Kinetics, A. W. Hoffman, B. J. Giletti, H. S. Yoder, and R. A. Yund, eds., Carnegie Inst. Wash. Pub. 634, pp. 139-170.

Smith, M. C., 1974. "The Los Alamos dry geothermal source demonstration project." Proc. Geothermal Power Development Conf. Univ. of California.

Smith, M. C., Aamodt, R. L., Potter, R. M., and Brown, D. W., 1975. "Man-made geothermal reservoirs." Proc. Second U.N. Symposium on the Development and Use of Geothermal Resources, San Francisco, Calif., May 1975, pp. 1781-1787.

Smith, R. L. and Shaw, H. R., 1975. "Igneous-Related Geothermal Systems," in Assessment of Geothermal Resources of the United States-1975, D. E. White and D. L. Williams, eds., USGS Circ. 726, U.S. Dept. of the Interior.

Takahashi, P., and Chen, B., 1975. The Hawaii Geothermal Project; Summary Report for Phase 1, May 1975, pp. 108-109. Univ. of Hawaii, Honolulu. 
Theis, C. V., 1935: "Relation between the lowering of the piezometric surface and the rate and duration of discharge of a well using groundwater storage," Amer. Geophys. Union Trans. 2, pp. 519-524 (duplicated as U.S. Geol. Survey Ground Water Note $5,1952)$.

Trice, R., and Warren, N., 1977. "Preliminary study on the correlation of acoustic velocity and permeability in two granodiorites from the LASL Fenton Hill deep borehole, GT-2, near the Valles Caldera, N.M." LASL Report LA-6851-MS.

Truesdell, A. H., and White, D. E., 1973. "Production of superheated steam from vapor-dominated reservoirs," Geothermics, 2, pp. 145-164.

Witherspoons, P. A., 1977. "Geothermal reservoir engineering," Report CATMEC/S, Division of Engineering, Brown University, Providence, R.I., Feb. 1977.

\subsection{The physics of fluid flow and heat transport in geothermal systems} (By James W. Mercer* and Charles R. Faust*)

\subsubsection{Introduction}

An understanding of the physics of fluid flow and heat transport in geothermal systems is important for the classification of and exploration for geothermal resources. This understanding is perhaps even more important in terms of aiding, in determining if the resource can be developed economically. Obviously, geothermal systems are very complex with many processes occurring in them. Some of these physical processes include: (1) Convective and conductive transport of heat in the fluid and rock matrix, (2) the transport of water and (or) steam in porous and fractured media, (3) solute transport including chemica] reactions that affect the flow characteristics of the medium, and (4) consolidation and land subsidence effects associated with fluid withdrawal. For many field problems, some of these processes have negligible effects and may be omitted, leading to a somewhat simpler description. Even with the simplifications, some rational framework is required in order to keep track of the important processes and how these processes interact.

One approach to attempt this "bookkeeping" of the physical behavior of geothermal systems is to use a mathematical model. Such a model consists of a set of equations that describe the transport processes active within the system and the solution to these equations subject to conditions that prevail at a particular site. This set of equations is general and may be used to consider two major subdivisions of geothermal modeling: (1) Modeling the geothermal systems under natural conditions in an effort to better understand how it forms and persists within the earth's crust, and (2) modeling the geothermal system during exploitation in order to predict its behavior subject to man-made stresses.

The formation of geothermal systems is thought to be associated with recent volcanism or significant tectonic movements. As a result of these activities, magmatic intrusions may occur at shallow depths in the earth's crust. Meteoric water is recharged to depth where it is heated directly or

\footnotetext{
*United States Geological Survey, Reston, Virginia 22092.
} 
indirectly by the intruded magma. Density differences caused by the heating drive the fluid buoyantly upward where it can be exploited for power production. To be economically significant, a geothermal resource must have high temperatures and be located at shallow depths within the earth's crust.

Since current technology does not permit economical extraction of heat directly from dry rock, geothermal resources must also contain a fluid (either steam or water) to transfer heat from the geothermal reservoir to the surface. In addition, the reservoir must have sufficient volume, porosity, and permeability to yield adequate flow rates to wells.

One simulates a geothermal system to understand its behavior as well as to estimate the quantity of recoverable energy and the rate at which mass and energy may be extracted. To achieve these objectives, known geological information obtained from both surface techniques and drilling is utilized to determine equation parameters and boundary and initial conditions. During the earlier stages of field development, this information is limited, and the simulation model will undoubtedly be crude. Through the simulation of a variety of producing schemes, however, the energy available and its rate of extraction may be roughly estimated. Reservoir characteristics can be varied to determine what parameters are most critical to reservoir production, and what additional data are required to improve the simulation. If the decision is made to develop the field further, the reservoir model may be used to help answer such engineering questions as optimal well location and spacing, or whether or not to reinject condensate. As more geological information becomes available through continued drilling, the simulation model may be updated to give a more accurate analysis of the geothermal reservoir.

In this discussion, we restrict our attention to hydrothermal systems, that is, geothermal systems containing water. In particular, hydrothermalconvection systems are considered where most of the heat is transferred by circulating fluids rather than by heat conduction. These systems can be further subdivided as either liquid dominated or vapor dominated [White et al., 19717. In the liquid-dominated type, water is the continuous phase throughout the system that provides the pressure control. Continuity of the liquid phase is evident from reservoir pressures that are near hydrostatic and the presence of soluble salts that are not found in significant quantities in low-pressure steam. In the vapor-dominated type, steam is the continuous, pressure-controlling phase, although water is also present.

As stated, hydrothermal systems are geothermal systems that contain fluid. Although geothermal fluids contain impurities, many reservoirs are often approximated as pure-water systems. Consider figure 2.9 , a pressure-temperature diagram of the liquid-vapor region for pure water [Whiting and Ramey, 1969]. The points $A, B$, and $C$ represent possible conditions for a hydrothermal system : compressed-liquid, saturated liquid- 
Figure 2.9-Generalized pressure-temperature diagram for pure water showing points $A, B$, and $C$ located in the compressed-liquid, saturated liquid-steam, and superheated steam regions, respectively [after Whiting and Ramey, 1869].

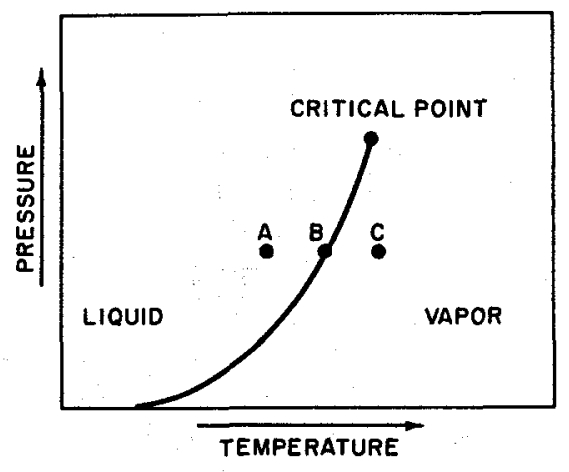

steam, and superheated steam, respectively. These points are also shown in figure 2.10, which is a pressure-enthalpy diagram for pure water [Whit-

FraUke 2.10-Generalized pressure-enthalpy diagram for pure water showing points $A, B$, and $O$ located in the compressed-liguid, saturated liquid-steam, and superheated steam reglons, respectively [after Whiting and Ramey, 1069]. Bold lines are isotherms and the dashed lines are lines of equal steam quality.

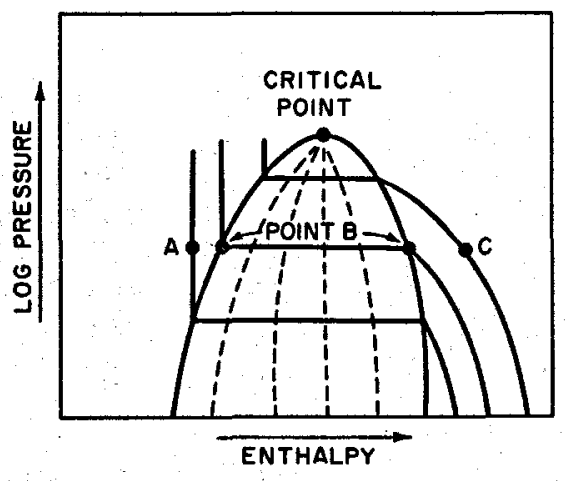

ing and Ramey, 1969]. The compressed-liquid region is the.condition existing in liquid-dominated hydrothermal systems. The vapor-dominated system described by White et al. [1971] is believed to exist mainly in the saturated liquid-steam region. In vapor-dominated systems, it is also probable, especially when influenced by exploitation, that parts of the system contain superheated steam.

At point A (see figure 2.9) in the compressed-liquid region, the system has one component, water, and one phase, liquid. According to Gibbs's phase rule, two independent intensive properties (for example, temperature and pressure) must be specified to determine the thermodynamic state of the system. Once these properties are specified, point $A$ can be located on any other thermodynamic diagram (for example, the pressureenthalpy diagram). Liquid-dominated reservoirs with these initial conditions yield water to wells. A decrease in pressure in the wellbore, however, causes steam to form providing a mixture of steam and water at the wellhead. Field data [Grindley, 1965] indicate that production of a geothermal reservoir initially at point $A$ will tend to cause an isothermal depletion, with reservoir pressures decreasing until the vapor-pressure curve is reached. 
At the vapor-pressure curve, point $B$ (see figure 2.9), one intensive property determines the thermodynamic state. Although the thermodynamic condition is specified as liquid and vapor in equilibrium, the relative amounts can not be determined unless two independent properties such as pressure and mixture enthalpy are known. Note from figure 2.10 that temperature and pressure do not determine the relative amounts since temperature and pressure are not independent in the two-phase region.

Once vapor forms in the reservoir, temperatures drop slightly as a result of the heat of vaporization used to form steam. Because the water saturation is high, the relative permeability for the liquid phase dominates, and water continues to be produced from the reservoir. Pressure decreases only slightly in the two-phase region because pressure is maintained by the formation of steam. As production continues, however, water saturations decrease, temperatures decrease, and consequently, pressures also decrease, with more steam being produced from the reservoir.

Point $\mathrm{C}$ lies entirely in the vapor (superheated steam) region. This condition probably rarely occurs naturally in a reservoir. As in the compressed-liquid region, two independent intensive properties are required to define the thermodynamic state. In this case, the reservoir would also tend to deplete isothermally.

This description of reservoir behavior has been based on the assumption that the reservoir fluid is pure water and (or) steam. Geothermal fluids, however, contain dissolved solids and noncondensable gases. For example, the total dissolved solids for the Wairakei, New Zealand, field are less than $3 \%$ by weight, whereas some geothermal fluids in Imperial Valley, California, contain as much as $30 \%$ dissolved solids by weight. Therefore, the vapor pressure of the fluid in a geothermal reservoir may not necessarily be that represented in the steam tables. For a fixed pressure, the boiling temperature of water will be elevated by the presence of impurities. General field behavior, however, should be qualitatively similar to that outlined for pure water.

\subsubsection{Theoretical development}

The physical properties of the fluid and reservoir vary spatially and temporally, and effects of gravity segregation of steam and water require vertical as well as horizontal treatment. Consequently, a general model must be a distributed parameter model with the capability of threedimensional simulation. To answer important engineering questions, a general model must not only accommodate the transient flow of compressed liquid, steam-water mixtures, and superheated steam, but must also allow for phase changes. In this discussion, we neglect solute transport and chemical reactions that may occur in the geothermal system. Furthermore, we assume that the reservoir can be treated as a porous medium. 
The general governing equations consist of mass, momentum, and thermal energy balances for each phase present in a geothermal system. Using a set of constitutive relationships, these balance equations may be reduced to two or three nonlinear partial differential equations.

Mass balance. The mass balances for steam, $s$, and water, $w$, may be written as:

and

$$
-\frac{\partial}{\partial x_{t}}\left(\bar{v}_{s} \rho_{s}\right)+q_{s}+d_{0}=\frac{\partial\left(\phi S_{s} \rho_{s}\right)}{\partial t}
$$

where

$$
-\frac{\partial}{\partial x_{i}}\left(\bar{v}_{w} \rho_{w}\right)+q_{w}-d_{v}=\frac{\partial\left(\phi S_{w} \rho_{w}\right)}{\partial t}
$$

$\bar{v}=$ phase average velocity, $\left[L t^{-1}\right]$

$\rho=$ average density, $\left[M L^{-3}\right]$

$q=$ source term, $\left[M L^{-3} t^{-1}\right]$

$d_{v}=$ rate of vaporization, $\left[M L^{-3} t^{-1}\right]$

$\phi=$ porosity, dimensionless

$S=$ saturation, dimensionless, where $S_{v}+S_{s}=1$

Momentum balance. For velocity, we assume that Darcy's equation for multiphase flow may be used

and

$$
\bar{v}_{s}=-\frac{\bar{k} k_{r s}}{\mu_{s}}\left(\frac{\partial p_{s}}{\partial x_{i}}-\rho_{s} \bar{g}\right)
$$

where

$$
\bar{v}_{w}=-\frac{\bar{k} k_{r w}}{\mu_{w}}\left(\frac{\partial p_{w}}{\partial x_{j}}-\rho_{w} \bar{g}\right)
$$

$\bar{k}=$ local intrinsic permeability tensor, $\left[L^{2}\right]$

$k_{r}=$ relative permeability, dimensionless

$\mu=$ dynamic viscosity, $\left[M L^{-1} t^{-1}\right]$

$p=$ pressure, $\left[M L^{-1} t^{-2}\right]$

$\bar{g}=$ gravitational acceleration, $\left[L t^{-2}\right]$

Energy balance. The thermal energy equations, neglecting viscous dissipation, for steam, water, and rock $(r)$ are:

$$
\begin{gathered}
\frac{\partial\left(\phi S_{s} \rho_{s} U_{s}\right)}{\partial t}+\frac{\partial}{\partial x_{i}}\left(\rho_{s} U_{s} \bar{v}_{s}\right)+\frac{\partial \bar{\lambda}_{s}}{\partial x_{i}}+p_{s} \frac{\partial \bar{v}_{s}}{\partial x_{i}}+q_{s} h_{s}+Q_{w s}+Q_{r t}=0 \\
\frac{\partial\left(\phi S_{w} \rho_{w o} U_{w}\right)}{\partial t}+\frac{\partial}{\partial x_{i}}\left(\rho_{w} U_{w} \bar{v}_{w}\right)+\frac{\partial \bar{\lambda}_{w}}{\partial x_{i}}+p_{w} \frac{\partial \bar{v}_{w}}{\partial x_{t}}+q_{w} h_{w}+Q_{s w}+Q_{r w}=0 \\
\frac{\partial\left[(1-\phi) \rho_{r} U_{r}\right]}{\partial t}+\frac{\partial \bar{\lambda}_{r}}{\partial x_{i}}+Q_{s r}+Q_{w r}=0
\end{gathered}
$$

in which

$U=$ internal energy per unit mass, $\left[L^{2} t^{-2}\right]$

$h=$ enthalpy per unit mass, $\left[L^{2} t^{-2}\right]$

$Q=$ interphase heat transfer term, $\left[M L^{-1} t^{-3}\right]$

$\bar{\lambda}=$ combined conduction-dispersion vector, $\left[\mathrm{Mt}^{-3}\right]$. 
The first subscript of the $Q$ term refers to the phase from which the energy is obtained, whereas the second subscript refers to the phase receiving the energy.

Constitutive relationships and simplifying assumptions. The equations presented in the previous sections have 23 dependent variables, e.g., densities, relative permeabilities, and viscosities. Many of these can be related to particular thermodynamic variables and thus, additional equations are needed expressing them as functions of these variables. To obtain equations 2.10-2.12, it was necessary to make the following simplifying assumptions: (1) Solute transport, chemical reactions, kinetic energy, viscous dissipation, and potential energy can be neglected; and (2) the geothermal reservoir behaves as a porous medium. In order to simplify the equations further and reduce the number of dependent variables constitutive relationships (i.e., expressions relating dependent variables) are used. In general, constitutive relationships are determined in the field and used to obtain the most simplified subset of the general equations that describe a particular geothermal reservoir application. For example, if a reservoir is liquid-dominated, with no chance for steam formation, it would be unnecessary to include the steam balance equations. For some applications, such as well-test analysis, isothermal conditions often exist over the period of analysis so that energy balance equations can be neglected.

For general two-phase reservoir applications, the constitutive relationships concern thermodynamics, capillary pressure, relative permeability, viscosity, reservoir consolidation, thermal exchange between phases, and thermal dispersion-conduction.

The thermodynamics of single-component water provide relationships between $S_{s}, S_{v}, \rho_{s}, \rho_{v}, U_{s}, U_{w}, h_{s}, h_{v o}, p_{s}, p_{v o}, \rho$ (mixture density of steam and water), $h$ (mixture enthalpy of steam and water), and $T$ (temperature). The final governing equations are usually reduced to two or three that are posed in terms of two or three thermodynamic variables. Models based on pressure-mixtuire enthalpy, pressure-mixture internal energy, mixture density-mixture internal energy, and pressure-temperature-saturation have been suggested by various authors.

Capillary pressure is the difference between steam pressure and water pressure, defined as

$$
p_{c}=p_{s}-p_{10}
$$

It is a property of the porous medium, but is, in general, also dependent upon the volume saturation of liquid and the temperature. Capillary pressure has the effect of apparently lowering the vapor pressure of water. Ramey et al. [1973] point out that the reason for this lowering is that vapor-pressure data found in steam tables [Meyer et al., 1968; Keenan et al., 1969] are based on flat steam-water interfaces, whereas the interface in porous media is curved. The amount the vapor-pressure curve is lowered 
in a geothermal reservoir is not completely understood. The work of Calhoun et al. [1949] on consolidated rock does show a lowering with decreased fluid saturation. Cady [1969] and Bilhartz [1971], however, indicate no significant vapor pressure lowering in experiments using unconsolidated sands. An important difference in these results is that the experiments of Calhoun et al. were made at a temperature of $36^{\circ} \mathrm{C}$, while those of Cady and Bilhartz were done over a temperature range from $121^{\circ} \mathrm{C}$ to $240^{\circ} \mathrm{C}$. Further work on the importance of capillary pressure in geothermal reservoirs is required. For many applications capillary pressure is assumed to be negligible.

Relative permeability is a property of the porous medium, and is also dependent on the volume saturation of liquid. It can be thought of as the ratio of the phase permeability to the total permeability and ranges in values from 0.0 to 1.0. Relative permeability is commonly treated as a function of saturation alone, and relationships similar to those in Brooks and Corey [1964] are used. Ramey et al. [1974] point out that relative permeability can also be a function of temperature. Using unconsolidated sand and working with oil and water, Poston et al. [1970] observed that for increased temperatures, the relative permeability curves shift to the left on the saturation axis.

Viscosity is dependent on both the pressure and temperature, but the pressure dependence is small and generally neglected.

Coupled equations for consolidation, fluid flow, and heat transport in geothermal reservoirs may be derived and solved, but consolidation is not the process of concern in many studies. A simple approximation of consolidation that incorporates its main effect on fluid flow may be used. This approximation relates the porosity to pressure by

$$
\varphi=\varphi_{1}+\beta\left(p-p_{i}\right)
$$

where $\varphi_{1}$ and $p_{t}$ are the initial porosity and pressure, respectively, and $\beta$ is the intergranular, vertical compressibility coefficient.

The movement of steam and water through porous media is sufficiently slow, and the surface areas of all phases are sufficiently large, that it is reasonable to assume that local thermal equilibrium among phases is achieved instantaneously. This common assumption permits the energy equations for rock, steam, and water to be combined and the medium conduction-dispersion term to be expressed as a function of a single temperature. In most developments the lumped conduction-dispersion term is defined by a Fourier-type equation,

$$
\bar{\lambda}_{s}+\bar{\lambda}_{w}+\bar{\lambda}_{r}=-\overline{\bar{K}}_{m} \nabla T,
$$

where $T$ is temperature and, in general, the medium conduction-dispersion $K_{m}$ is a tensor quantity. Regarding the thermal dispersion tensor it 
should be noted that Mercer [1973] separates the medium thermal dispersion tensor into three parts : conduction in the solid phase, diffusion in the liquid phase, and a velocity-dependent dispersion in the liquid phase. This last part is an attempt to take into account the heat transport related to the mixing of different temperature waters as they flow through the pore spaces. Furthermore, Somerton et al. [1974], point out that the thermal conductivity of the medium is a function of temperature, porosity, and water saturation.

Initial and boundary conditions. In order to obtain a solution to the governing equations for geothermal reservoirs, hydrodynamic and thermal boundary and initial conditions must be specified. These conditions can be deduced from a thorough examination of hydrologic and geologic data. There are generally three types of hydrodynamic boundary conditions in geothermal reservoirs: (1) Constant pressure boundary conditions, (2) no-flow boundary conditions along impermeable surfaces, and (3) specified flux. The corresponding thermal boundary conditions are: (1) Constant temperature, (2) no heat flow-insulated boundary, and (3) specified heat flux. When production or injection wells exist in the reservoir, additional boundary conditions specifying either the pressures or the mass flow rates for the sources or sinks are required.

Initial conditions, specifying thermodynamic variables throughout the reservoir at the beginning of the simulation, determine whether the reservoir is liquid- or vapor-dominated. In addition, the boundary conditions determine the flow conditions. Depending on the hydrodynamic and thermal boundary conditions, both free (or natural) and forced convection may occur in geothermal systems. Free convection generally dominates flow conditions in geothermal reservoirs before exploitation, while forced convection dominates during exploitation when externally imposed pressure gradients are generated due to production ánd/or reinjection of fluids.

$\boldsymbol{E}^{\prime}$ quation parameters. In addition to boundary and initial conditions, many of the equation parameters, which are also field parameters (for example, permeability), need to be determined. Some of these are determined by performing laboratory tests on core samples. Thermal conductivities and porosities may be obtained in this fashion. Permeabilities, however, are generally determined in the field using in situ techniques, such as well testing. This involves analyzing pressure data using simplified subsets of the general governing equations. This is often referred to as an inverse problem, since permeabilities are "backed out" from pressure build-up or drawdown data.

Such analyses have been preformed on several liquid-dominated reservoirs [Narasimhan, 1977] with limited success. These tests have established that well-testing, based on techniques developed in the fields of petroleum engineering and hydrogeology, is a valuable tool in estimating in situ parameters and in deciphering the geometry of geothermal reservoirs. 
The application of transient pressure analysis methods to vapordominated reservoirs has generally been done using methods developed for noncondensable gas reservoirs. Moench and Atkinson [1977] examine this problem and conclude that the presence of a vaporizing liquid will not complicate evaluation of the reservoir permeability-thickness product from drawdown data when the usual methods of gas reservoir engineering are applied. Simulated pressure buildup data, on the other hand, show characteristics that are markedly different from that expected for noncondensable gas.

\subsubsection{Geothermal systems under natural conditions}

A complete review of free convection models is included in Witherspoon et al. [1975]; only a brief discussion is presented here. In general, these models consist of convective heat transfer in a homogeneous porous layer heated from below. Natural geothermal systems have been investigated by many researchers. The main thrust of these studies has been to attempt to understand how geothermal systems can form and prevail under the various geological constraints known to exist in the earth's crust. Mathematical modeling of the natural conditions of heat and fluid flow in a geothermal region can be used to describe certain basic phenomena such as fluid convection induced by density differences and the associated convective heat transfer.

Numerous studies have considered the increased rate of vertical heat transfer through a freely convecting horizontal porous layer. Analytical results related to geothermal studies have been obtained by Wooding [1957, 1963] and Donaldson [1962, 1968, 1970]; numerical and experimental results are presented by Holst and Aziz [1972a, b], Combarnous and Bories [1973], and Horne and O'Sullivan [1974]. Combarnous and Bories [1973] have also considered the problem of an inclined porous layer bounded by isothermal surfaces. They show that since the temperature gradient and gravity are no longer colinear, the fluid is constantly moving regardless of the temperature gradient. For the most part, investigations of the natural convection problem treat one-layer systems with uniform boundary conditions and constant parameters.

Another model used in hydrothermal field simulation is the pipe system, in which fluid is assumed to be channeled through zones of higher permeability in rocks. Einarsson [1942] and Bodvarsson [1961] discuss the nature of thermal areas in Iceland in terms of pipe models involving circulation of water to depths of 2 to $3 \mathrm{~km}$ and discharge in hot spring areas. Elder [1966] analyzed hydrothermal areas in Iceland and New Zealand using zero dimensional (lumped parameter), one-dimensional (pipe system), and multidimensional (homogeneous porous media) models to quantify the general features of heat and mass transfer. White [1957, 1961] used pipe models to explain the chemical composition of waters associated with 
hydrothermal areas. A useful convective model analyzed by Donaldson $[1968,1970]$ consists of a permeable channel or reservoir at the base connecting recharge and discharge columns at the sides. Geometrical and physical parameters of the model, including the heat available at depth, can be adjusted to simulate the gross features of several types of hot water systems. Sorey [1975] analyzed this model numerically to evaluate effects of conducting side walls on circulatory convection in the discharge channel.

\subsubsection{Geothermal systems under exploitation}

There are several approaches to modeling geothermal systems. In this discussion, only deterministic mathematical models are considered. For this approach, a conceptual model of the system is formulated based on physical laws and experience. This concept is translated into mathematical expressions. Often the mathematical expressions are complex and it is necessary to make simplifying approximations. Solution normally requires the application of numerical methods and the use of the digital computer.

Justification for developing geothermal models arises from their use in better understanding specific geothermal fields and from their predictive capabilities. A model may be used to combine and verify various complex hypotheses on field behavior. These hypotheses can be refined and hopefully used to improve the understanding of a field. A well-conceived model can be used to estimate the quantity of recoverable energy and the optimum rates at which mass and energy can be extracted from a given geothermal reservoir. To make such predictions, equation parameters, boundary conditions, and initial conditions are required. These are determined from available data based upon geological, geophysical, geochemical, and hydrological studies of the geothermal reservoir. These are used in simulation runs, from which crude initial estimates of recoverable energy may be calculated. As development of the reservoir continues, new data provided by additional drilling and production records can be used to refine the accuracy of the model, yielding more dependable predictions, as well as a better reproduction of observed reservoir behavior. Additionally, the model may serve as a management tool to optimize engineering decisions such as producing schemes and well locations. Geothermal reservoir models may be subdivided into two general types: lumped parameter and distributed parameter.

Lumped-parameter models. A lumped-parameter model offers the simplest means of describing the behavior of a geothermal reservoir during exploitation. In this type of model, the entire system is considered a perfect mixing cell for both mass and energy. Instead of considering the internal distribution of mass and energy attention is restricted to the total amounts within the system and that crossing the boundaries. Because time is the only independent variable, the system can be characterized mathematically 
by a set of ordinary differential equations or an equivalent set of algebraic expressions representing total mass and energy [Witherspoon et al., 1975].

The first reservoir model applied to a geothermal field problem was a lumped-parameter model developed by Whiting and Ramey [1969]. Their model allowed fluid influx from an adjacent aquifer and was used to simulate the two-phase, steam-water behavior of the Wairakei hydrothermal field. This approach was also used by Cady [1969] to simulate a laboratory experiment. Brigham and Morrow [1974] applied a lumpedparameter model to vapor-dominated systems by considering three different liquid distributions. Martin [1975] used a lumped-parameter model to examine two-phase flow in a geothermal reservoir where the liquid and gas phases were uniformly distributed throughout the reservoir. Brigham and Morrow, and Martin considered the reservoir to be completely closed. Finally, Seki, Chen and Takahashi [1977] applied the Whiting-Ramey model to several fields and used a least-squares technique to match model outputs to historical data.

Distributed-parameter models. A model in which the properties of the rock and fluid are allowed to vary in space is referred to as a distributed-parameter model. In general, these models are complex and cannot be solved analytically. Analytical solutions do exist if one neglects energy transport and assumes isothermal flow. If this assumption is made, many of the solutions developed for well test analysis in aquifers and petroleum reservoirs may be used directly. An alternative approach to solving the equations analytically is to replace the governing partial differential equations by an equivalent set of algebraic equations and solve the problem numerically.

Harlow and Pracht [1972] considered the problem of extracting heat from dry rock using a distributed-parameter model, which simulated rock fracture and single-phase (compressed-liquid) flow. The first application of a distributed-parameter model to a geothermal field problem was made by Mercer et al. [1975]. Using a Galerkin finite-element method and solving for temperature and pressure, their areal model was restricted to liquiddominated reservoirs. The model was able to reproduce historical data at Wairakei until 1962, when large quantities of steam had formed in the reservoir. Toronyi and Farouq Ali [1975] developed a two-phase, twodimensional reservoir model that was coupled with a wellbore model. Their work was restricted to the saturated vapor-pressure curve; they solved for pressure and saturation and used a finite-difference technique that incorporated Newton-Raphson iteration (a method for evaluating nonlinear equations).

In 1975 at the Second United Nations Symposium on the Development and Use of Geothermal Resources held in San Francisco, three independent groups presented distributed parameter models capable of simulating both liquid- and vapor-dominated hydrothermal reservoirs [Faust and Mercer, 
1975 ; Garg et al., 1975a ; and Lasseter et al., 1975]. Faust and Mercer [1975] and later Mercer and Faust [1975] and Faust [1976] applied both Galerkin finite-element and finite-difference techniques to approximate a pressure-enthalpy formulation of the multiphase flow equations in two horizontal dimensions. Garg et al. [1975a] and Lasseter et al. [1975] both formulated their multiphase equations in terms of internal energy and density. The former used finite-difference techniques to approximate their equations, whereas the latter used an integrated, finite-difference technique. Both of these models were capable of treating three-dimensional problems.

Thomas and Pierson [1976] have also developed a model for simulating geothermal reservoirs containing water in either vapor or liquid states. The model is three-dimensional and solves for pressure, temperature, and saturation. Finite-difference techniques are used in conjunction with an implicit-pressure-explicit-saturation formation. Coats [1977] has proposed a model based on a pressure-temperature-saturation formulation that includes flow in well bores and discrete fractures. Finite-difference approximations are used along with fully-implicit Newton-Raphson iteration.

To account for subsidence at a geothermal field, Garg et al. [1975] coupled a multiphase reservoir model with a multidimensional finite-element deformation model designed to make use of a variety of elastic and (or) plastic constitutive relationships. Lippmann et al. [1976] also coupled a reservoir model with a consolidation model. The resulting geothermal subsidence model uses an integrated finite-difference scheme to solve for single-phase heat transport in three dimensions, and uses Terzaghi's onedimensional consolidation theory for stress-strain relationships.

Computer programs have been developed for simulating the movement of liquid water-methane mixtures as found in geopressured geothermal reservoirs [Garg et al., 1978]. The model is three-dimensional and coupled to a wellbore model. Pritchett et al. [1976] have also attempted to approximate the precipitation of salt in their geothermal reservoir model. The model approximates changes in porosity and permeability; however, they assume that the thermodynamic properties of the multiphase fluid are insensitive to salt concentration.

Finally, three additional field applications of distributed-parameter models for single-phase, liquid reservoirs have been published. Sorey et al. [1977] applied a cross-sectional, integrated finite-difference model to simulate steady-state conditions in the Long Valley hydrothermal system in California. Another California field, located in the East Mesa area, Imperial Valley, was simulated by Intercomp [1976]. Their model solved for pressure and temperature, and used finite-difference techniques. Kettenacker [1977] used a horizontal reservoir (pressure only) model and a vertical, one-dimensional heat transfer model for each well to examine the Raft River, Idaho, geothermal field. 


\subsubsection{Concluding remarks}

From these reports, it seems obvious that our mathematical tools, both analytical and numerical, are sufficiently powerful to solve the most difficult problems. Unfortunately, the conceptual basis of these mathematical models appears to need reinforcement. The geologic materials in which heat transport processes occur are not easily idealized. Constitutive relationships for thermal dispersion and relative permeability, and the description of flow and transport in fractured rock are areas that need further study. Finally, additional field verification of the complicated mathematical models are needed.

\subsubsection{References for section 2.3}

Bilhartz, H. L., Jr., 1971. "Fluid production from geothermal steam reservoirs": M. S. Report, Stanford University, Stanford, Calif.

Bodvarsson, G., 1961. "Physical characteristics of natural heat resources in Iceland," in paper G.6, U.N. Conf. on New Sources of Energy, Rome, Aug. 21-31.

Brigham, W. E., and Morrow, W. B., 1974. "P/Z behavior for geothermal steam reservoirs," Paper SPE 4899, presented at 44th Annual Calif. Reg. Meeting of the Soc. Pet. Engrgs., AIME, San Francisco.

Brooks, R. H., and Corey, A. T., 1964. "Hydraulic properties of porous media," Hydrology, paper No. 3, Colorado State University, Fort Collins, Colo.

Cady, G. V., 1969. Model studies of geothermal fluid production: $\mathrm{Ph}$. D. Thesis, Stanford University, Stanford, Calif.

Calhoun, J. C., Lewis, M., Jr., and Newman, R. C., 1949. "Experiments on the capillary properties of porous solids," Trans AIME, vol. 186, pp. 189-196.

Coats, K. H., 1977. "Geothermal reservoir modelling," in paper SPE 6892, presented at the 62nd Annual Fall Meeting of the Soc. Pet. Eng. AIME, Denver, Colo.

. Combarnous, M., and Bories, S., 1974. "Modelisation de la convection naturelle au sein d'une couche poreuse horisontal a l'aide d'un coefficient de transfert solidefluide," Int. Jour. Heat Mass Transfer, vol. 17, pp. 505-515.

Donaldson, I. G., 1962. "Temperature gradients in the upper layers of the earth's crust due to convective water flow," Jour. Geophys. Res., vol. 67, No. 9, pp. 3449-3459.

Donaldson, I. G., 1968a. "The flow of steam water mixtures through permeable beds, A simple simulation of a natural undisturbed hydrothermal region": New Zealand Jour. Sci., vol. 11, pp. 3-23.

Donaldson, I. G., 1968b. "A possible model for hydrothermal systems and methods of studying such a model," in paper 2580, 3rd Australian Conf. on Hydraulics and Fluid Mechanics, Nov.25-29.

Donaldson, I. G., 1970. "The simulation of geothermal systems with a simple convective model," in Geothermics, Special Issue 2, vol. 2, pt. 1, pp. 649-654.

Einarsson, T., 1942. "Ueber das Wesen der heissen Quellen Islands," Rit. Visind. Isl., vol. 26.

Elder, J. W., 1966. "Heat and mass transfer in the earth: Hydrothermal systems," New Zealand D.S.I.R. Bull. 169.

Faust, C. R., 1976. Numerical simulation of fluid flow and energy transport in liquidand vapor-dominated hydrothermal systems: $\mathrm{Ph}$. D. Thesis, Pennsylvania State University, University Park, $\mathrm{Pa}$. 
Faust, C. R., and Mercer, J. W., 1975. "Mathematical modeling of geothermal systems," in Proc. 2d United Nations Symposium on the Development and Use of Geothermal Resources, San Francisco, Calif., vol. 3, pp. 1633-1642.

Garg. S. K., Blake, T. T., Brownell, D. H., Jr., Nayfe, A. H., and Pritchett, J. W., 1975b. "Simulation of fluid-rock interactions in a geothermal basin," in Systems, Science and Software, Inc., Report No. SS-R-76-2734, La Jolla, Calif.

Garg, S. K., Pritchett, J. W., and Brownell, D. H., Jr., 1975a. "Transport of mass and energy in porous media," Proc. 2d United Nations Symposium on the Development and Use of Geothermal Resources, San Francisco, Calif., vol. 3, pp. 1651-1656.

Garg, S. K., Pritchett, J. W., Brownell, D. H., Jr., and Rinery, T. D., 1978. "Geopressured geothermal reservoir and wellbore simulation" in Systems, Science and Software, Inc., Report No. SS-R-78-8639, La Jolla, Calif.

Grindley, G. W., 1965. "The geology, structure and exploitation of the Wairakei field, Taupo, New Zealand," N. Z. Geological Survey, Bull.75.

Harlow, F. H., and Pracht, W. E., 1972. "A theoretical study of geothermal energy extraction," J. Geophs. Res., vol. 77, No. 35, pp. 7033-7048.

Holst, P. H., and Aziz, K., 1972a. "A theoretical and experimental study of natural convection in a confined porous medium," Canadian Jour. Chem. Engr., vol. 50, pp. 232-241.

Holst, P. H., and Aziz, K. 1972b. "Transient three-dimensional natural convection in confined porous media," Jour. Heat and Mass Transfer, vol. 15, pp. 73-90.

Horne, R. N., and O'Sullivan, M. J., 1974. "Oscillatory convection in a porous medium heated from below," in Jour. Fluid Mech., vol. 66, p. 2, pp. 339-352.

Intercomp, 1976. "Study of the geothermal reservoir underlying the East Mesa area, Imperial Valley, Calif." Report No. 28859-6001-RU-00, prepared for US. Dept. Interior, Bureau of Reclamation.

Keenan, J. H., Keyes, F. G., Hill, P. G., and Moore, I. G., 1969. Steam Tables: John Wiley and Sons, Inc., London.

Kettenacker, W. C., 1977. "Two-dimensional simulation of the Raft River geothermal reservoir and wells," Idaho National Engineering Lab. Report No. TREE-1085, Idaho Falls, Idaho.

Lasseter, T. J., Witherspoon, P. A., and Lippmann, M. J., 1975. "The numerical simulation of heat mass transfer in multidimensional two-phase geothermal reservoirs," in Proc. 2d United Nations Symposium on the Development and Use of Geothermal Resources, San Francisco, Calif., vol. 3, pp. 1715-1725.

Lippmann, M. J., Narasimhan, T. N., and Witherspoon, P. A., 1976. "Numerical simulation of reservoir compaction in liquid-dominated geothermal systems," submitted to the International Symposium on Land Subsidence, Anaheim, Calif.

Martin, J. C., 1975. "Analysis of internal steam drive in geothermal reservoirs," paper SPE 5382, presented at 45th Annual Calif. Reg. Meeting of the Soc. Pet. Engrgs., AIME, Ventura.

Mercer, J. W., Jr., 1973. Finite element approach to the modeling of hydrothermal systems: $\mathrm{Ph}$. D. Thesis, University of Illinois, Urbana-Champaign, III.

Mercer, J. W., and Fauist, C. R., 1975. "Simulation of water- and vapor-dominated hydrothermal reservoirs," in paper SPE 5620 presented at the 50th Annual Fall Meeting of the Soc. Pet. Eng. AIME, Dallas, Tex.

Mercer, J. W., Pinder, G. F., and Donaldson, I. G., 1975. "A Galerkin-finite element analysis of the hydrothermal system at Wairakei, New Zealand," J. Geophys. Res., vol. 80 , No. 17 , pp. $2608-2621$.

Meyer, C. A., McClintock, R. B., Silvestri, G. J., and Spencer, R. C., 1968. ASME Steam Tables, 2d ed., Am. Soc. Mech., Engrs., New York, N.Y. 
Moench, A. F., and Atkinson, P.G., 1977. "Transient pressure analysis in geothermal steam reservoirs with an immobile vaporizing liquid phase-summary report, Third Workshop," Geothermal Reservoir Engineering, Stanford University, Stanford, Calif., pp. 64-69.

Narasimhan, T. N., 1977. "Application of well testing to liquid dominated geothermal systems," in Proceedings: Invitational Well-Testing Symposium, Berkeley, Calif. pp. 63-71.

Poston, S. W., Ysrael, S., Hossain, A. K. M. S., Montgomery, E. F., IV, and Ramey, H. J., Jr., 1970. "The effect of temperature on irreducible water saturation, and relative permeability of unconsolidated sands," Soc. Pet. Engr. Jour., pp. 171-180.

Pritchett, J. W., Garg, S. K., Brownell, D. H., Jr., Rice, L. F., Rice, M.H., Riney, T. D., and Hendrickson, R. R., 1976 "Geohydrological environmental effects of geothermal power production phase IIA," Systems, Science and Software, Inc.

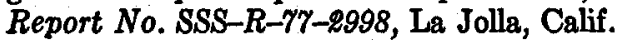

Ramey, H. J., Jr., Brigham, W. E., Chen, H. K., Atkinson, P. G., and Arihara, N., April, 1974. "Thermodynamic and hydrodynamic properties of hydrothermal systems," Interna. Report, Stanford University, Stanford, Calif.

Ramey, H. H., Jr., Kruger, P., and Raghavan, 1973. "Explosive stimulation of hydrothermal reservoirs," in Geothermal Energy, Stanford University Press, pp. 231-249.

Seki, A. S., Chen, B. H., and Takahashi, P. K., 1977. "Computer performance matching and prediction of geothermal reservoirs," Tech. Rep. No. 22, Univ. of Hawaii, Honolulu.

Somerton, W.H., Keese, J. A., and Chu, S. L., 1974. "Thermal behavior of unconsolidated oil sands," Soc. Pet. Eng. Jour, pp. 513-521.

Sorey, M. L., 1975. Numerical modeling of liquid geothermal systems, $\mathrm{Ph}$. D. Thesis, University of California, Berkeley, Calif.

Sorey, M. L., Lewis, R. E., and Olmsted, F. H., 1977. "The hydrothermal system of Long Valley Caldera, Calif.," US. Geological Survey Open-file Rept. 77-847.

Thomas, C. K., and Pierson, R., 1976. "Three-dimensional geothermal reservoir simulation," paper SPE 6104, presented at the 51st Annual Fall Meeting of the Soc. Pet. Eng. AIME, New Orleans, La.

Toronyi, R. M., and Farouq Ali, S. M., 1975. "Two-phase, two-dimensional simulation, of geothermal reservoir and the wellbore system," paper $S P E$ 5521, presented at the 50th Annual Fall Meeting of the Soc. Pet. Eng. AIME, Dallas, Tex.

White, D. E., 1957. "Thermal water of volcanic origin," in Bulletin Geol. Soc. Am., vol. 68 , pp. 1637-1658.

White, D. E., 1961. Preliminary evaluation of geothermal areas," paper G.L, UN. Conf. on New Sources of Energy, Rome, August 21-31.

White, D. E., Muffler, L. J. P., and Truesdell, A. H., 1971; "Vapor-dominated hydrothermal systems compared with hot-water systems," Econ. Geol., vol. 66, pp. 75-97.

Whiting, R. L., and Ramey, H. J., Jr., 1969. "Application of material and energy balances to geothermal steam production," Jour. Pet. Tech., vol. 21, No. 7, pp. 893-900.

Witherspoon, P. A., Neuman, S. P., Sorey, J. L., and Lippmann, M. J., 1975. "Modeling geothermal systems," paper presented at the International Meeting on Geothermal Phenomena and its Applications, Accademia Nationale dei Lincei, Rome, Italy.

Wooding, R. A., 1957. "Steady state free thermal convection of liquid in a saturated permeable medium, J. Fluid Mech., vol. 2, p. 273.

Wooding, R. A., 1963. "Convection in a saturated porous medium at large Rayleigh number or Peclet number," J. Fluid Mech., vol. 15, pt. 4, pp. 527-544. 


\section{Drilling for geothermal resources (By D. J. Ryley* and R. DiPippo**)}

Rotary drilling of deep holes is a mature industry with an extensive technology and experience base. Substantial drilling for steam and hot water, however, is a recent development. This drilling for geothermal resources uses standard oil-well equipment and methods, and relies primarily on experience gained in the petroleum industry. The unique problems of geothermal drilling have to do with the elevated temperatures and corrosive fluids and with the hard, abrasive rock and fractured formations typical of geothermal reservoirs. This section will present a brief outline of geothermal drilling, and will be concerned mainly with the special problems that are encountered.

\section{Q.4.1 Rotary dritling}

The oil-field drill rig is portable and adaptable to be moved from site to site and erected for use. The hole is drilled by turning a bit which is attached to the drill pipe. The drill pipe, which consists typically of thirty-foot lengths of thick walled pipe threaded together, is rotated by a power drive at the surface. The drill-pipe assembly is supported through a swivel hung from the drill rig, and weight on the bit is provided by drill collars, very thick walled pipe, just above the bit. Drilling fluid is pumped through the swivel at the top of the drill-pipe string and flows down the drill pipe and returns up the annular space. The drilling fluid carries the cuttings to the surface. When mud or brine (as opposed to air) is used as the drilling fluid, a pressure balance is maintained which prevents the reservoir fluid from blowing out the drilled hole.

At the surface, a diesel engine generates the power for the drilling and mud circulating. The drill pipe rotates through a rotary seal, designed to contain the circulating fluid return pressure, and through blowout prevention valves which can be shut off to help prevent a reservoir fluid blowout. When there is no drill-pipe in the hole, the surface valves seal off the drill hole. The drilling mud is screened at the surface to remove entrained chips and other material and recirculated down the hole.

\subsubsection{The geothermal well site}

Geothermal reservoirs may be vapor-dominated hydrothermal systems, liquid-dominated hydrothermal systems, geopressured formations, or hot

*Division of Engineering, Brown University, Providence, R.I. 02912 ; permanent address: Dept. of Mechanical Engineering, University of Liverpool, Liverpool, Fngland.

**Division of Engineering, Brown University, Providence, R.I. 02912 ; permanent address: Mechanical Engineering Department, Southeastern Massachusetts University, N. Dartmouth, Mass. 02747. 
dry rock formations. The formations range from unconsolidated sediments and friable sandstones to hard abrasive granites and metamorphosed sandstones frequently highly fractured. Known geothermal resources have temperatures as high as $370^{\circ} \mathrm{C}\left(700^{\circ} \mathrm{F}\right)$ in the hottest part of the reservoir. Hydrothermal reservoirs have depths that range from less than a hundred meters (essentially surface spring flow) to geopressured formations of $4600 \mathrm{~m}(15,000 \mathrm{ft})$ or more. Significant geothermal drilling has been done into reservoirs to depths of $0.75-3.3 \mathrm{~km}$ (2500 to $10,000 \mathrm{ft}$ ). Reservoir fluids include brines of extremely high salt concentrations with suspended solids and dissolved gases such as hydrogen sulfide and carbon dioxide.

Drilling into the softer sediments is generally very similar to oil and gas well drilling, except for the higher temperatures. Drilling into the hard, fractured formations poses severe problems of low drilling penetration rates, short bit life, frequent drill-pipe failure, and lost circulation problems. Furthermore, because many geothermal resources are located in volcanic and mountainous areas, the drilling site presents problems. Those at The Geysers, as described by Cromling [1973], are on rugged mountainous terrain accessible only up steep slopes.

\subsubsection{Drill bits and drilling fruids}

Short drill-bit life is a major problem in drilling geothermal wells. Bearing failure of roller drill-bits and excessive gage-row wear on the roller cones are the primary modes of failure. The bearing wear and gage-row wear are directly related, with one wear mechanism contributing to the other. Geothermal drilling is frequently made worse by the requirement of low bit weights in order to increase bearing life, and this low bit weight then leads to low penetration rates. A typical tri-cone roller bit is shown in figure 2.11.

Matsuo [1970] states, for example, that in Japanese fields drilling for steam is slower than drilling for oil or gas at depths ranging from 500$1300 \mathrm{~m}(1640-4265 \mathrm{ft})$ and working at downhole temperatures of about $97^{\circ} \mathrm{C}$ to $237^{\circ} \mathrm{C}\left(207-459^{\circ} \mathrm{F}\right)$.

Figure 2.12 shows data through 1974 for well depths and corresponding penetration rates for two geothermal resource sites in California. One site is a relatively easy drilling sedimentary formation when drilling is done primarily with brine as a drilling fluid, and the other site is a hard, fractured formation air drilled. The penetration rates are low in both formations; however, the hard, fractured formations drill somewhat faster because of the air drilling. Bit life is very short for air drilling, $\sim 20$ hours, since the air does not cool the drill hole and bit, and as a result, unlubricated mining type bits must be used. Air drilling also leads to severe drillpipe erosion problems caused by the high velocity of the cuttings being air lifted to the surface. 


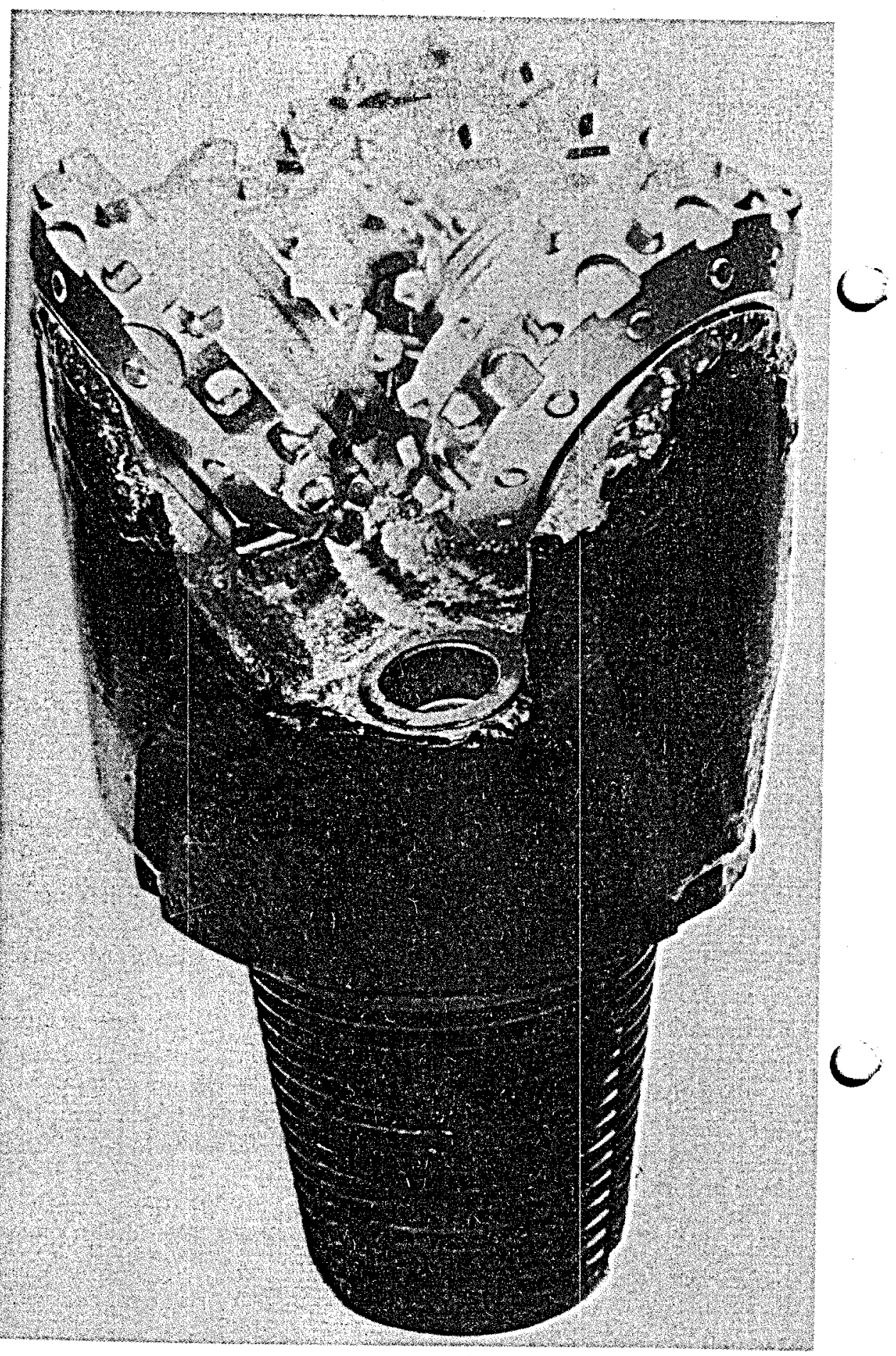

Fraure 2.11-Typical tri-cone roller bit. 

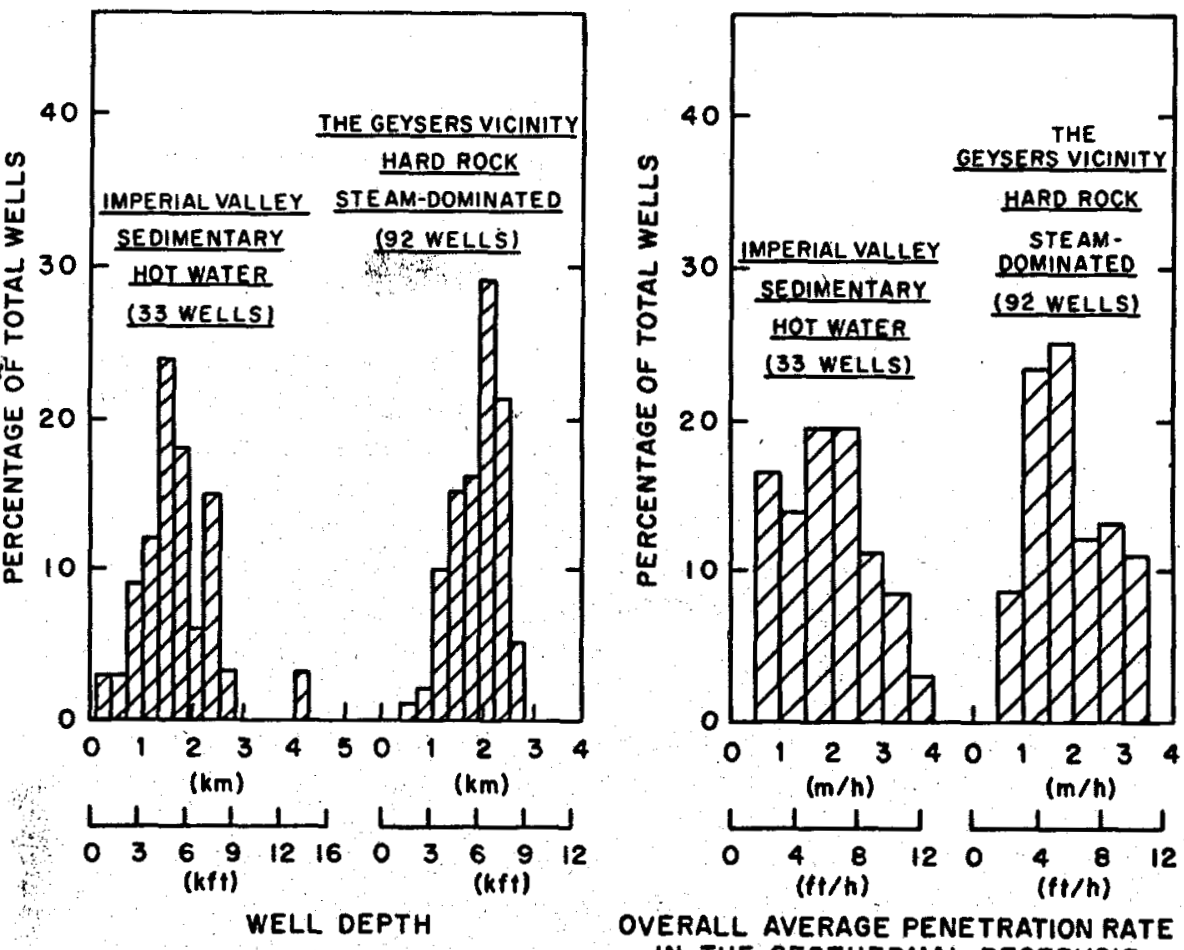

OVERALL AVERAGE PENETRATION RATE IN THE GEOTHERMAL RESERVOIR

Frgure 2.12-Histograms of depth and penetration rates for geothermal wells in the Imperial Valley and The Geysers [Altseimer, 1975].

The lack of adequate high-temperature drilling fluids is also a major problem. The upper temperature working limit for drilling muds is about $150-175^{\circ} \mathrm{C}\left(300-350^{\circ} \mathrm{F}\right)$. Brines are frequently used, and foam drilling is gaining attention, although environmental cleanup problems are a serious consideration with foams, particularly at high temperatures. Additionally, foams will not cool the drill hole and drill bit as much as brine or muds. Without adequate high-temperature drilling fluids, well-control, drillpipe sticking problems, bore-hole stability, and drilling operations will be difficult. Finally, lost circulation of the fluid return, and hence movement of cuttings into the formations, will continue to be a very major geothermal drilling problem.

Blowout prevention problems are enhanced in steam wells. The preventers commonly employ as seals elastomers that have a temperature limitation of about $123^{\circ} \mathrm{C}\left(253^{\circ} \mathrm{F}\right)$ [Maurer, 1975] which is insufficient for safe containment. These same elastomers are used for packers in drillstem testing.

In some geothermal reservoirs it is necessary to perforate the casing to gain access to the hydrothermal flow. This may be done utilizing bullets or shaped charges to create holes through the casing into the rock forma- 
tion. Thi perforating guns require improvement to enable their use with temperatures up to $370^{\circ} \mathrm{C}\left(700^{\circ} \mathrm{F}\right)$.

An instructive summary of geothermal drilling problems as they affect both sedimentary hot-water wells and igneous vapour-dominated wells is given by Altseimer [1975].

\subsubsection{Casing and cementing}

A well bore is stabilized and prepared for use by casing and cementing, a process that is carried out in stages during and at the conclusion of drilling. Before the advent of geothermal drilling an immense amount of technological knowledge and experience had become available for the casing and cementing of oil wells. New problems arose, however, because of the elevated temperatures and possibly corrosive nature of geothermal fluids. Dench [1970] reviewed the problems of casing design in New Zealand geothermal fields, especially as regards the fracturing of casing steels in the presence of cold damp hydrogen sulfide.

Thermal expansion and contraction effects can promote stresses leading to failure at casing joints. Cigni et al. [1975] quote stress rates of about $25 \mathrm{~kg} / \mathrm{cm}^{2}{ }^{\circ} \mathrm{C}\left(2.45 \mathrm{MPa} /{ }^{\circ} \mathrm{C}\right)$ on the stressed sections. Casing wear oceurred at The Geysers because rubber drill pipe protectors used to center the drill pipe in the well failed due to temperature and allowed the drill pipe to rub against the casing. Geopressured wells operating under high pressure require superior materials or very heavy casing walls.

It was found [Nakajima, 1970] that common cement was unsuitable for use at high temperatures as it became permeable and admitted cold water into the well. Failure of cementing is also treated by Dench [1970] and Matsuo [1970]. Cigni et al. [1975] emphasize the need to fill the wellcasing annulus uniformly and to secure good cement-casing and cementformation bonding to ensure that the casing/cement forms a single stressresistant unit, firmly anchored to the surrounding formation. They also describe the development and constituents of a slurry especially suitable for geothermal work. Using the casings for mechanical support of the borehole walls is very likely to promote well failure [Dominguez and Vital, 1975]. Work in the United States is presently being directed, for example, at the development of high temperature polymer concrete. This material shows promise for geothermal applications involving dry steam, hot water and flashing steam.

It is not possible to generalize about the dimensions and construction of casings for geothermal wells: In some cases it has been possible to employ a single diameter casing bore for the whole well depth, i.e., an "unstepped" well. Stepped wells are more common, however, and promote greater mass flowrate (section 2.6) to avoid flow limitation due to choking. They also facilitate construction. The depth to which a well is cased depends upon the mechanical stability of the reservoir formation and the locations of 
fluid influx. The number and depth of penetration of concentric casings varies considerably from site to site according to local needs and past experience, and even within the confines of a single site depending on the details of the reservoir [Dominguez and Vital, 1975].

In summary, the main problem encountered today deals with poor cementing jobs. To begin to solve this problem, one needs better hightemperature cements with controlled viscosity and set-up times. As much as possible should be learned from the mistakes of the past by the systematic determination of casing failure modes. It will be necessary to develop casing supports and formation sealing materials that will tolerate thermal stresses. For the long-term, casing coatings may be needed to combat the problem of casing corrosion.

\subsubsection{Stimulating well flow}

When a well bore has been drilled to the desired depth and the well casing is completed, a number of operations may remain to be undertaken before the well can be put into production. Normally, upon completion of drilling, steam or brine formations have been penetrated and the well will discharge spontaneously. During the early period after opening, fragments of rock and other detritus will be expelled. Sometimes, however, a well will fail to discharge spontaneously and requires stimulation. There are several methods of stimulation; they are diverse in type and vary widely from well to well.

The following techniques are frequently employed [Cigni et al., 1970]: swabbing. This operation is performed with a piston plunger of diameter a little less than that of the wellbore. The plunger is inserted to a depth of 200-300 m (656-984 ft) lower than the level of the free water or mud table. A one-way valve in the plunger permits the underlying fluid to pass through as the plunger is lowered. Raising the plunger lifts the overlying liquid out of the well. After a sufficient number of strokes, a liquid column has been removed sufficient to reduce the hydrostatic pressure to a value at which the well begins to discharge spontaneously.

Liquid nitrogen. The removal of liquid from the top of the column can be prompted by the injection of liquid nitrogen in the vicinity of the bottom of the liquid column to be expelled. Cigni et al. [1970] describe the application of this method to wells in the geothermal fields in Italy.

Compressed air. Compressed air can be employed instead of nitrogen and is preferred on safety grounds to swabbing. Standard air compressors are employed together with normal drill pipes. The annular space is pressurized with air and the column liquid is expelled through the interior of the drill pipe.

Foaming agents. Foaming agents may be employed to hasten selfaction in wells that would in any case begin to operate without aid after 
some lapse of time. Foaming agents help blowout by emulsifying the water column within the well.

Decompression. This is a device to "trigger" self-flowing in a well that is already on the point of self-action. It consists essentially of using a fluctuation in the level of near-saturated well water containing dissolved gas to promote a sudden pressure reduction over the water surface. The intent is to promote vigorous flashing which then becomes selfperpetuating.

Other operations. A variety of operations may be needed before a well is in full production. It may, for example, be found that the mass flow rate is deficient and that the well requires deepening. This is not a straightforward operation and involves several risks. Fortunately there are a number of professional methods to which the driller can resort [Cigni et al., 1970].

At the Cerro Prieto liquid-dominated, high-temperature field, it is claimed that the future mechanical condition of a well depends strongly on a careful start to production, and five operational stages are identified:

(1) The observation period.

(2) The stimulation period (if required).

(3) The heating period.

(4) The development period.

(5) Energy capacity evaluation.

The work program for each of these stages is described by Dominguez and Bermejo de la Mora [1975]. It is important to recognize, however, that it is not possible to generalize procedures from one country to another. What may be routine and standard in Mexico, for instance, may be unacceptable in the United States.

\subsubsection{Dritling costs}

There are four components to the cost of a well. These are: (1) The rotating cost (cost while drilling is underway); (2) cost while drilling is held up during repairs, logging, etc.; (3) cost of completion; and (4) miscellaneous costs associated with road construction, transportation of materials and equipment to the site, etc. The first of these, the rotating cost, has been modeled and analyzed by Newsom et al. [1976] and Dodd [1976], and reported by Friedman and El-Sawy [1977]. The rotating cost $F$ (in $\$ /$ length drilled) is given by :

$$
F=\left\{C\left[L+\nu\left(D+\frac{2}{2}\right)\right]+B\right\} / R L .
$$

The terms in equation (2.12) are defined as follows:

$C=$ hourly operating rate for the rig ("rig rate"), $\$ / \mathrm{h}$

$L=$ lifetime of the bit, $h$

$\nu=$ average tripping rate, $\mathrm{h} / \mathrm{m}$ or $\mathrm{h} / \mathrm{ft}$ 
$D=$ starting depth for drilling below ground level, $\mathrm{m}$ or $\mathrm{ft}$

$Z=$ total depth drilled, $m$ or $\mathrm{ft}$

$B=$ cost of the bit, $\$$

$R=$ average instantaneous penetration rate, $\mathrm{m} / \mathrm{h}$ or $\mathrm{ft} / \mathrm{h}$.

Parametric sensitivity studies have been performed [Dodd, 1976] on equation 2.13 in order to determine the effect of improvements in the various factors on the rotating well cost. The relative impact on $F$ is expressed in terms of a number of influence coefficients as follows:

$$
\frac{d F}{F}=k_{R}\left(\frac{d R}{R}\right)+k_{L}\left(\frac{d L}{L}\right)+k_{C}\left(\frac{d C}{C}\right)+k_{D}\left(\frac{d D}{D}\right)+k_{z}\left(\frac{d Z}{Z}\right)+k_{B}\left(\frac{d B}{B}\right)
$$

where

$$
\begin{aligned}
& k_{R}=\left(\frac{R}{\bar{F}}\right) \frac{\partial F}{\partial R} \\
& =-1 \text {, } \\
& k_{L}=\left(\frac{L}{F}\right) \frac{\partial F}{\partial L} \\
& =-\left\{1+\frac{L}{\nu\left(D+\frac{Z}{2}\right)+\frac{B}{C}}\right\}^{-1} \\
& k_{C}=\left(\frac{C}{F}\right) \frac{\partial F}{\partial C} \\
& =\left\{1+\frac{B}{C\left[L+v\left(D+\frac{Z}{2}\right)\right]}\right\}^{-1}, \\
& k_{D}=\left(\frac{D}{F}\right) \frac{\partial F}{\partial D} \\
& =\left\{1+\frac{2 C L+\nu C Z+2 B}{2 \nu C D}\right\}^{-1}, \\
& k_{z}=\left(\frac{Z}{F}\right) \frac{\partial F}{\partial Z} \\
& =\left\{1+\frac{2 C(L+\nu D)+2 B}{\nu C Z}\right\}^{-1}, \\
& k_{B}=\left(\frac{B}{F}\right) \frac{\partial F}{\partial B} \\
& =\{1+(C / B)[L+\nu(D+Z) / 2]\}^{-1} \text {. }
\end{aligned}
$$


These expressions were derived by writing

$$
F=F(R, L, C, D, Z, B),
$$

taking a first-order expansion,

$$
d F=\left(\frac{\partial F}{\partial R}\right) d R+\left(\frac{\partial F}{\partial L}\right) d L+\ldots
$$

and following straightforward mathematical techniques.

The most important influence coefficient is $k_{R}$, having an absolute value of unity; all the others are less than unity and depend on the values of $B, C, D, L$, and $Z$. Extensive tables showing the results of the sensitivity analyses may be found in Friedman and El-Sawy [1977].

The relationship between any two of the factors $B, C, \ldots$, for a constant rotating cost may be found from equation (2.13). For example, the penetration rate $R$ is related to the bit lifetime $L$ as follows:

$$
R=\left\{C\left[L+\nu\left(D+\frac{Z}{2}\right)\right]+B\right\} / F L
$$

where $C, v, D, Z$, and $B$ may be assigned specific numerical values. Then $R$ may be plotted as a function of $L$ for various fixed values of rotating cost. Such isocost curves may be used to determine trade-offs between bit life and penetration rate.

A typical curve is shown in figure 2.13 where it was assumed that the rotating cost was $\$ 35 / \mathrm{ft}$ and the starting depth was ground level $(D=0)$. It may be seen that when penetration rates are increased beyond about $6 \mathrm{~m} / \mathrm{h}(20 \mathrm{ft} / \mathrm{h})$, bit life may be drastically shortened while still maintaining the same rotating footage cost.

The improvements that would be required in bit life and penetration rate to bring about specific reductions in rotating cost can be obtained from a normalized isocost graph, such as figure 2.14. Here the normalized penetration rate (relative to the state-of-the-art nominal value of $3 \mathrm{~m} / \mathrm{h}$ or $10 \mathrm{ft} / \mathrm{h}$ ) is plotted as a function of normalized bit life (relative to the state-of-the-art nominal value of $12 \mathrm{~h}$ ) for percentage reductions in rotating cost ranging from $0 \%$ (nominal current value) to $85 \%$. The example shown in figure 2.14 pertains to the specific values of the other parameters, $Z, C$, etc., shown in the figure. It follows that, for this example, the rotating costs might be reduced by only about $60 \%$ from its current value if the penetration rate could be tripled with the same bit life. On the other hand, tripling the bit life for the current penetration rate would result in only a $25 \%$ decrease in rotating cost. Simultaneously increasing both bit life and penetration rate by factors of three would yield a $75 \%$ reduction in rotating cost. 


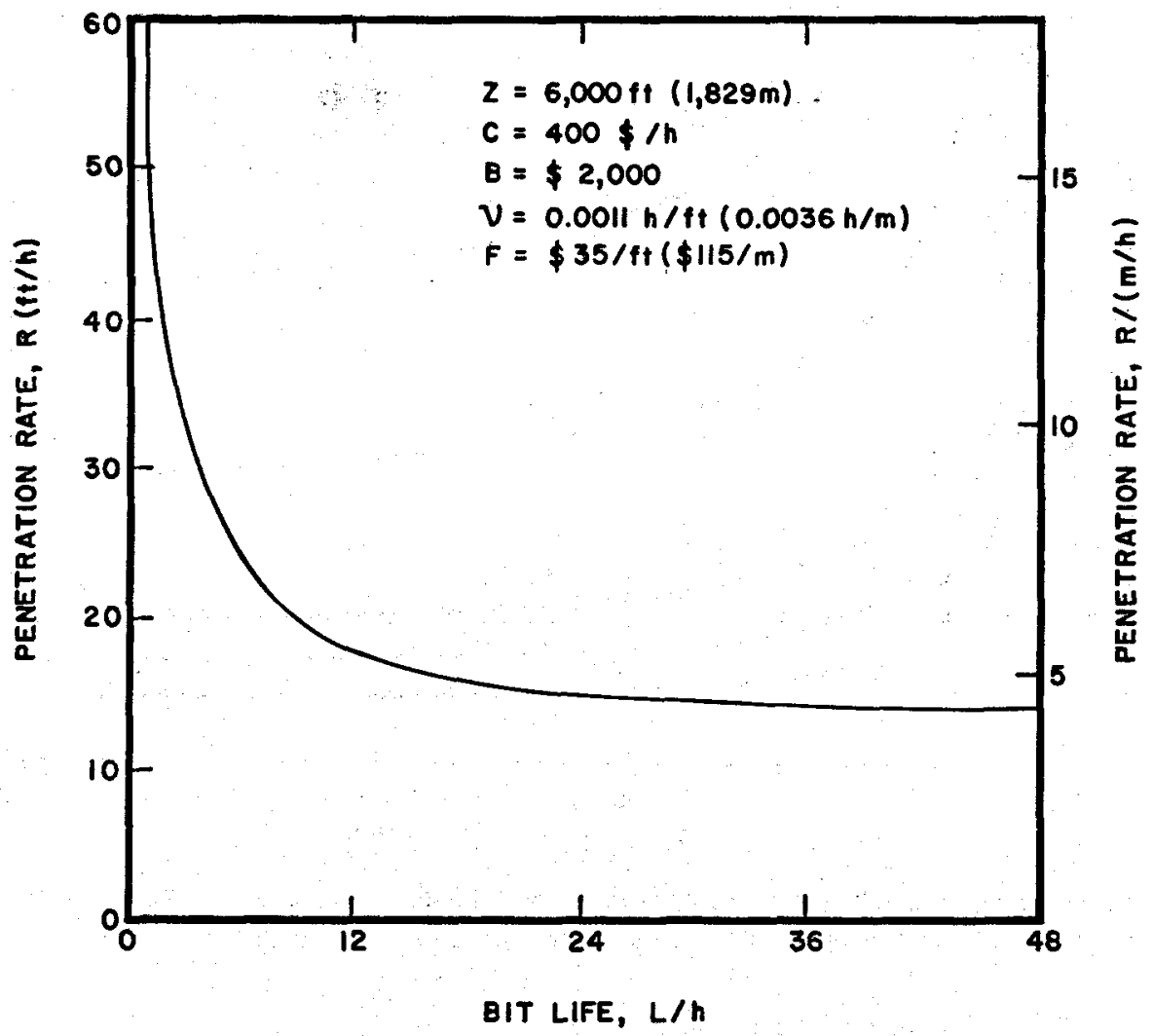

FIGURe 2.13-Isocost curve showing relationship between penetration rate and bit life [Friedman and kH-Sawy, 1977].

Rotating costs amount to about $30 \%$ of the total well costs in areas where the formation is hard to drill, and to less than $30 \%$ in easier areas [Polito and Varnado, 1978]. This percentage must be factored in when assessing the impact of the foregoing conclusions on total well costs.

Several surveys have been conducted of actual, total well costs, comparing geothermal wells to those in the oil and gas industry. Table 2.4 lists the costs of several geothermal wells at selected sites in the United States as of 1977. A detailed breakdown of the costs (1977) for a typical steam well at The Geysers is shown in table 2.5. The same well could have been drilled in 1972 for $\$ 400,000$, indicating an annual escalation of about $20 \%$ [Glass, 1977]. The trend in footage costs for land wells is one of rapid escalation and exceeds the general rate of inflation for the United States. Figure 2.15 illustrates this trend. In 1973 it was estimated [Grieder, 1973] that geothermal wells were costing $\$ 30-\$ 75 / \mathrm{ft}$, or roughly 2-4 times as much as oil and gas wells drilled on land. Recent figures indicate that this range is still valid. Geothermal wells in hard-drilling regions are about triple the cost (per unit depth) of petroleum wells; 


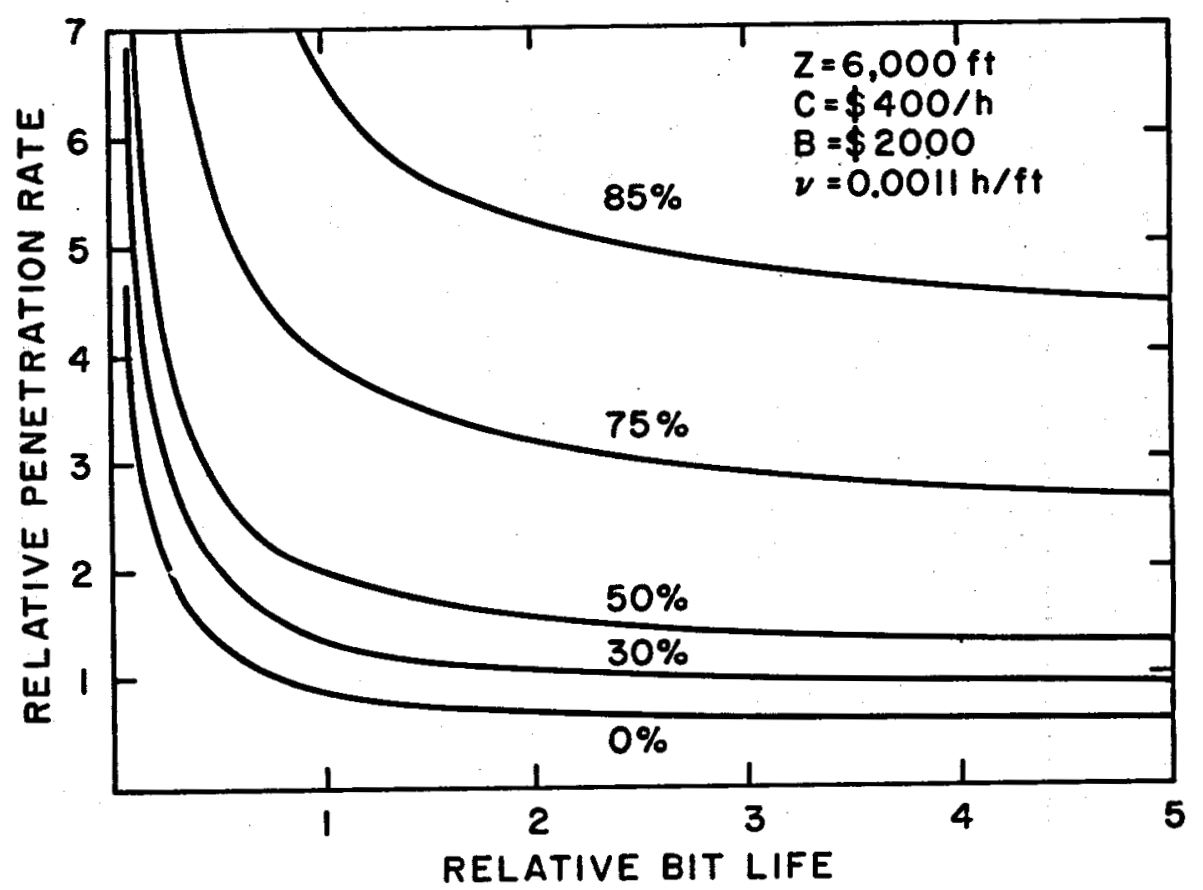

Fiadra 2.14-Normalized 1socost curves. Reference penetration rate=10 ft/h; reference bit life $=12 \mathrm{~h}$ [Friedman and El-Sawy, 1977].

TABLE 2.4-Well costs at selected U.S. geothermal sites (Frie'man and El-Sawy, 1977)

\begin{tabular}{|c|c|c|c|c|}
\hline Geothermal prospect & $\begin{array}{l}\text { Reservoir } \\
\text { classification }\end{array}$ & $\begin{array}{r}\text { Depth to } \\
\text { reservoir, } \\
\text { km }\end{array}$ & $\begin{array}{c}\text { Reservoir } \\
\text { tempera- } \\
\text { ture, }{ }^{\circ} \mathbf{C}\end{array}$ & $\begin{array}{l}\text { Well } \\
\text { cost, } \\
10^{3} \$\end{array}$ \\
\hline Alvord, Oregon. & Hard . . . . . . . . & 1.5 & 200 & 2437 \\
\hline Beowawe, Nevada. . & Hard. . . . . . . . . & 1. 0 & 240 & 984 \\
\hline Brady, Nevada. . & Hard... & 0.5 & 214 & 656 \\
\hline Brawley, Calif. & Soft. . . & 1. 5 & 260 & 400 \\
\hline Coso, Calif.... & Medium-hard..... & 1. 0 & 220 & 615 \\
\hline East Mesa, Calif... & Soft. . . . . . . . & 1.0 & 180 & 600 \\
\hline The Geysers, Calif.. & Medium.......... & 2.0 & 240 & 1003 \\
\hline Heber, Calif. . . . . & Soft. . . . . . . . & 1. 0 & 190 & 600 \\
\hline Lassen, Calif. . & Medium-hard..... & 1. 0 & 240 & 615 \\
\hline Puna, Hawaii.......... & Hard. . . . . . . . & 2. 0 & 275 & 2281 \\
\hline Raft River, Idaho... & Soft. . . . . . & 1.5 & 140 & 910 \\
\hline Safford, Arizona.... & Medium-hard. .... & 2.0 & 200 & 2138 \\
\hline Vale, Oregon....... & Soft............ & 1.0 & 160 & 591 \\
\hline
\end{tabular}


TABLE 2.5-Drilling and completion costs at a typical steam well at The Geysers (Glass, 1977)

Build road, location, and cellar........................

Move rig in and out.

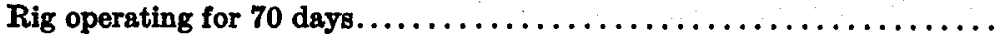

Air compressor rental.

40,000

Fuel for rig and air compressors. . . . . . . . . . . . . . . . . . . .

34,000

Excessive drill pipe wear. . . . . . . . . . . . . . . . . . . . . . .

25,000

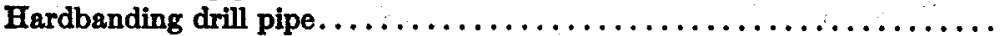

3,000

6,000

Drill pipe and drill collar inspection........................

15,000

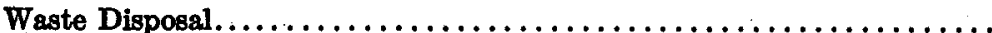

20,000

4,500

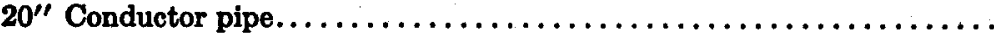

52,500

67,500

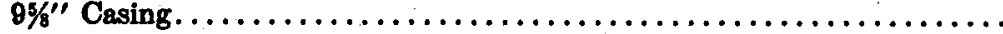

50,000

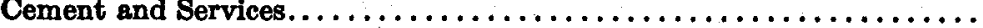

10,000

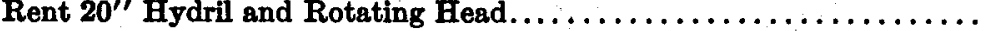

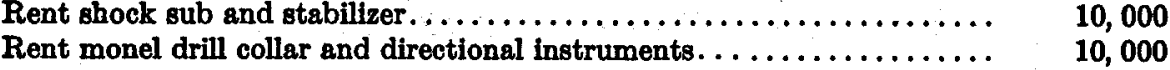

Drilling mud................................... $\mathbf{3 0}, \mathbf{0 0 0}$

Well head and muffier and flow line....................... 20,000

Miscellaneous transportation.......................... 10, 000

Logging. ..................................... $\quad \mathbf{8 , 0 0 0}$

Mud well logging..............................

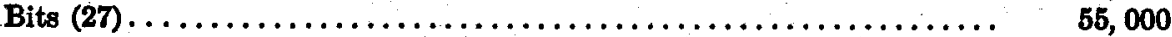

Miscellaneous................................... 50, 000

Direct supervision and overhead....................... 28, 000

Total. .............................. $\$ 1,008,500$

those in softer, sedimentary regions are about twice as expensive as petroleum wells.

Garnish [1976] has correlated the cost of drilling geothermal wells against the depth, $Z$, of the well, for both hard (granite) and soft (sedimentary) formations. He used data from Matsui [1973] and Patterson et al. [1973], ${ }^{*}$ and formulated the following expressions for the time, $t$, to drill deep holes.

$$
\begin{aligned}
& t / \text { years }=0.20 \exp (0.384 \mathrm{Z} / \mathrm{km}), \text { granite } \\
& t / \text { years }=0.07 \exp (0.384 \mathrm{Z} / \mathrm{km}), \text { sediments. }
\end{aligned}
$$

He then used plausible assumptions about the cost of bits, casing, rigs, crew charges, etc., to derive the following total cost equations:

$$
\begin{aligned}
& \text { Cost } / £=2.3 \times 10^{5} \exp (0.32 Z / \mathrm{km}), \text { granite } \\
& \text { Cost } / £=8.0 \times 10^{4} \exp (0.32 Z / \mathrm{km}) \text {, sediments. }
\end{aligned}
$$

*These references are cited in Garnish [1976]. 


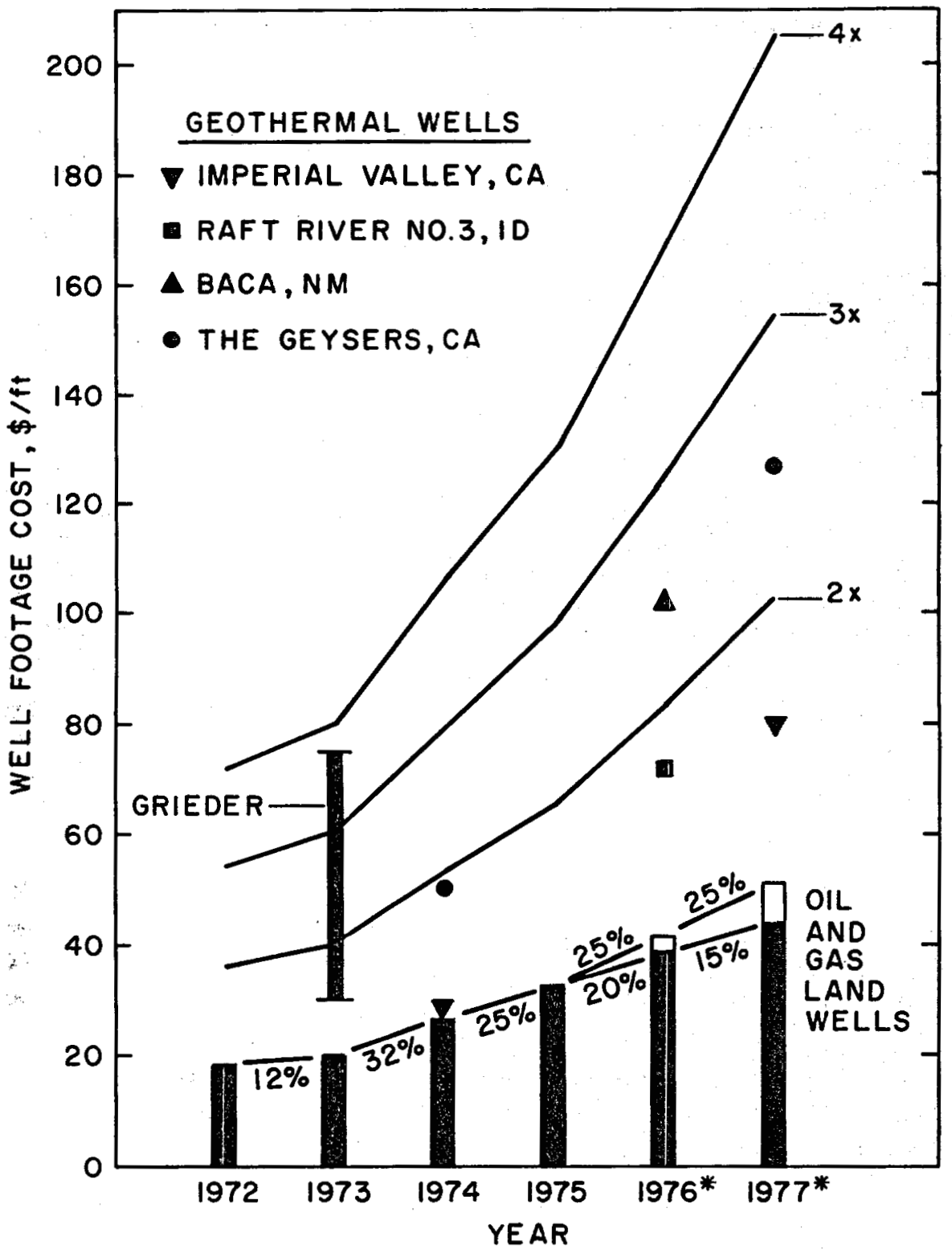

FradRe 2.15-Trends in well footage costs in the United States [after Polito and Varnado, 1978].

The costs in equations 2.19-2.20 are in 1976 British Pounds Sterling and are based on plant and wage rates prevailing at that time. Although it is not exactly valid to make a direct conversion to U.S. prices, one may obtain a rough equivalent of present costs (1979) by assuming a $10 \%$ annual 
inflation rate in British currency together with an average exchange rate of $\$ 1.80=£ 1$. Thus, the equivalent cost equations become:

$$
\begin{aligned}
& \text { Cost } / \$=5.5 \times 10^{5} \exp (0.32 Z / \mathrm{km}), \text { granite } \\
& \text { Cost } / \$=1.9 \times 10^{5} \exp (0.32 Z / \mathrm{km}), \text { sediments. }
\end{aligned}
$$

In light of the wide variability in well costs from one site to another (see table 2.4), equations 2.21-2.22 must be viewed as rough estimates.

The exponential nature of well cost as a function of depth is illustrated in figure 2.16 [Green, 1977 and updated by personal communications, 1978]. The relationship between cost and depth for several specific cases is plotted in log-log coordinates in figure 2.17. In each case the curve extends over that range of validity claimed by its author. In all cases, except for the dotted one, a single straight line represents the data. Thus, the cost-depth curve conforms to the law

$$
\text { Cost }=(\text { Constant }) \times(\text { Depth })^{n}
$$

where $n$ is a constant exponent. The values for $n$ are shown on the lines in figure 2.17. The dotted line (Imperial Valley and the Geysers) must be viewed as approximate. Equation 2.23 has also been applied to geothermal wells in the Soviet Union [Kremnjov et al., 1970], and a value $n=1.4$ seems to fit the published data.

Summing up, geothermal wells may be expected to cost 2-4 times as much as oil and gas wells, and to escalate at a rate greater than the general rate of inflation, perhaps as much as $25 \%$ annually. Efforts aimed at the development of better bits, drilling fluids, cements and equipment should be able to reduce the overall well cost by about $20 \%$ for the near term. Cost reductions substantially greater than $20 \%$ will be attainable through advanced technological development that will go beyond present-day rotary drilling technology [Polito and Varnado, 1978].

\subsection{Advanced drilling methods}

A number of advanced drilling methods are being considered for geothermal wells in order to eliminate some of the problems associated with this critical phase in the exploitation of geothermal energy. For example, the problem of lost circulation may occur when penetrating a formation that is extensively fractured or has a low ground-fluid pressure [Budd, 1973]. This problem may be solved by changing the coolant from mud to air, but at the risk of abrasion and/or corrosion (section 2.4.3). Besides, air may fail to prevent ingress of liquid in water-bearing strata. 
WELL DEPTH

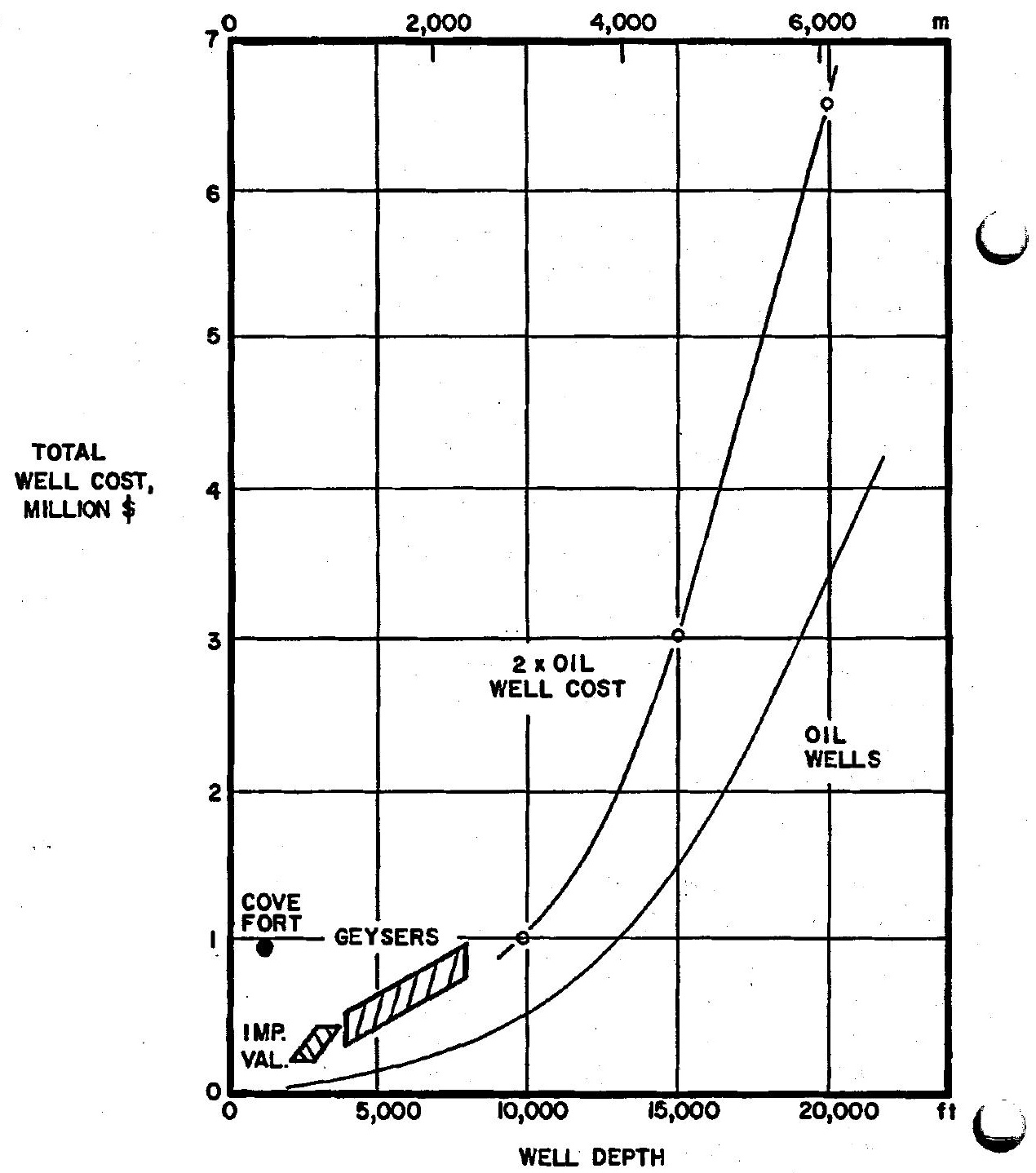

Froure 2.16-Well cost as a function of depth for oil and selected geothermal wells.

Improved drilling (and completion) methods would lessen the probability of a catastrophic failure or "blowout," which occurs when liquid or vapor under pressure forces a flow-path to the surface other than through the well bore, often between the casing and surrounding formations. This usually results in the loss of the well since restoration of control is impeded 
FINISHED DEPTH OF WELL, $Z / m$

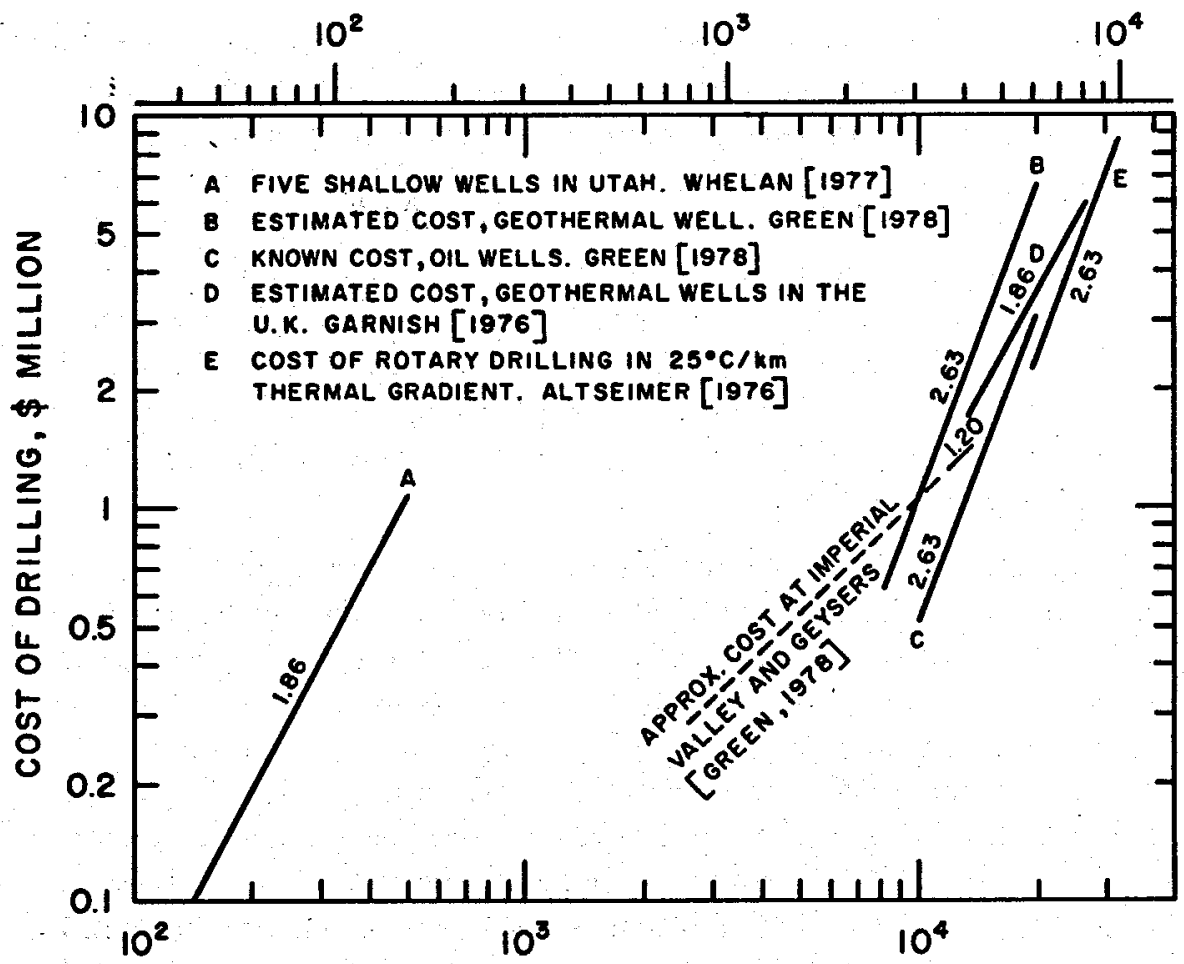

FINISHED DEPTH OF WELL, $Z / f t$.

Frgore 2.17-Correlations of well cost versus depth for selected geothermal wells in comparison to oil wells.

by the high temperature and exit velocity of the effluent, and the consequent rapid enlargement of the leak flow path [Smith, 1961; Dominguez and Vital, 1975].

Furthermore, it is hoped that the research and development into alternate drilling methods will cut down considerably the lengthy period (typically $500 \mathrm{~h} / \mathrm{km}$ or $805 \mathrm{~h} / \mathrm{mi}$ actual cutting time) required to drill a well by the conventional cutting tools. A particularly comprehensive assessment of the problems associated with geothermal drilling is given by Varnado [1979] in which he reports the findings of a panel of experts in the field. The report identified a variety of new drilling and completion systems that have the potential to reduce significantly the cost of geothermal wells.

One such program has been directed towards developing rock-melting penetrators ("subterrenes") [Altseimer, 1975]. Rocks and soils melt at relatively high temperatures. Thus common igneous rock melts at about $1230^{\circ} \mathrm{C}\left(2246^{\circ} \mathrm{F}\right)$, a value near that of steel $\left(1230-1530^{\circ} \mathrm{C}\right.$ or 2246 - 
$\left.2786^{\circ} \mathrm{F}\right)$. Melting penetrators would therefore have to use refractory metals such as molybdenum and tungsten. Two types of devices are possible:

(1) Devices which would melt the rock during their passage and divert the plastic material to the walls of the ensuing hole where it would solidify to form a glass lining. The need to remove debris from the hole would thus be avoided and the lining would possibly add structural stability to the hole.

(2) Devices which would pass the melted rock upward through a central extruding hole or a core. Rapid chilling of the rock would freeze it into fragments which could be transported up the stem by the coolant. A variant of this design would permit cores to be extruded which could then be retrieved by conventional means for geological study.

The penetrators described above were developed to the prototype stage and employed electrically heated elements, but other heating methods are possible. This program, however, is not being pursued at the present time.

Other melting and vaporization drills have been tested which employ lasers [Maurer, 1968], electron beams [Maurer, 1968; Schumacher, 1969], plasmas [Bouche, 1964], and rocket-exhaust [Shapir, 1963]. The jet piercing drill which burns fuel oil and oxygen to produce a flame temperature of $2370^{\circ} \mathrm{C}\left(4300^{\circ} \mathrm{F}\right)$ has found widespread application [Rubow, 1956].

A group of novel drills have been studied which remove the rock by mechanically induced stresses. These include turbines, explosives, pellet impact, implosion, ultrasonic, spark, downhole replaceable bit, continuous chain drill, terra drill, and erosion. These are described by Maurer [1975]. Difficulties with these exotic methods involve their application at depth in the well bore. Advanced theoretical and engineering development is needed to explore these and other methods in order to provide a revolutionary improvement over present technology.

Perhaps the three novel rock drilling techniques with the best chances for commercialization during the next 10-20 years are: downhole muddrilling motors that rotate the drill bit and accordingly new, improved drill bits to be used with such high-speed motors; augumented high-pressure water jet rotary-assisted techniques; and percussive, vibration-augmented systems to assist rotary, mechanical drill bits [Varnado, 1979].

In general, additional effort on a fundamental level is required to define and develop the next generation of rock drilling methods. Central to this issue is the need to better our understanding of the basic mechanics and energetics of in situ rock. Additional geophysical measurements in the field are needed to improve the knowledge of rock characteristics as they vary with depth. A complement to these endeavors is the development of improved models of rocks to bridge the gap between microscopic and 
macroscopic theories of fracture, and which include the effects of porosity, contained fluids and ductility. An essential feature of such activities is the establishment or utilization of high-pressure geophysical laboratory facilities that can contain large samples. This will allow grain size distribution effects to be evaluated and transport properties to be measured at conditions simulating those in situ. These laboratory data are needed to validate model predictions which can then be used in the interpretation of field measurements [Polito and Varnado, 1978].

Finally, innovations are possible in rig designs and well completion techniques. For example, there is a need for highly mobile rigs that can be quickly set up and broken down into standard size units for easy transportation [World Oil, 1976]. Split-level rigs with hydraulic hoists instead of conventional drawworks would substantially reduce trip times [OGJ, 1977]. Penetration rates may be increased ten-fold during the initial phase of drilling through the use of "push-down" rigs [Moore, 1977] when normal bit loads are small. Novel completion methods which substitute lightweight materials for steel casing would complement flexible tube designs by eliminating the need for expensive, heavy duty rigs [Polito and Varnado, 1978].

All novel techniques must be given consideration. Those which appear most promising must be thoroughly investigated if technological breakthroughs are to be achieved that could lead to significant reductions in the cost of geothermal drilling.

\subsubsection{Acknowledgements}

The authors thanks Drs. Sidney J. Green, Terra Tek, Salt Lake City, and Samuel G. Varnado, Sandia Laboratories, Albuquerque, for their valuable assistance and guidance in assembling the information for this section and for reviewing a draft of it. However, the authors assume responsibility for any errors or inaccuracies that may yet remain.

\subsubsection{References for section 2.4}

Altseimer, J. H., 1975. "Geothermal Well Technology and Potential Applications of Subterrene Devices-A Status Review," Proc. Second U.N. Symp. on the Devel. and Use of Geothermal Resources, San Francisco, Calif. vol., 2, pp. 1453-1470.

Altseimer, J. H., 1976. "Technical and Cost Analysis of Rock Melting Systems for Producing Geothermal Wells," Los Alamos Scientific Laboratory Rep. LA 6555-MS, Los Alamos, N. Mex.

Bouche, R. E., 1964. "Drilling Rocks with Plasma Jets" [MS Thesis T-992]: Colorado School of Mines, Golden, Colo.

Budd, C. F., Jr., 1973. "Steam Production at the Geysers Geothermal Field," in Geothermal Energy-Resources, Production, Simulation, P. Kruger and C. Otte, eds., Stanford Univ. Press, pp. 129-144.

Cigni, U., Fabri, F., and Giovannoni A., 1975. "Advancement in Cementation Techniques in the Italian Geothermal Wells," Proc. Second U.N. Symp. on the Devel, and Use of. Geothermal Resources, San Francisco, Calif. vol. 2, pp. 1471-1481. 
Cigni, U., Giovannoni, A., Luschi, E., and Vidali, M., 1970. "Completion of Producing Geothermal Wells," Proc. of the U.N. Symposium on the Devel. and Use of Geothermal Resources, Pisa, Italy, vol. 2.1, pp.757-763.

Cromling, T., 1973. "Geothermal Drilling in California," Paper SPE 4177 Presented at the 43d Annual California Regional Meeting of the Society of Petroleum Engineers of AIME, Bakersfield, Calif. Jour. Petroleum Tech., Sept.

Dench, N. D., 1970. "Casing String Design for Geothermal Wells," U.N. Symp. on the Devel. and Utilization of Geothermal Resources, Pisa, Italy, vol. 2.2, pp. 1485-1496.

Dodd, H. M., 1976. "An Economic Analysis of Downhole Replaceable Drill Bit Systems," Sandia Rep. SAND 76-0301, Sandia Laboratories, Albuquerque, N. Mex.

Dominguez A., B. and Bermejo de la Mora, F. J., 1975. "Present Methods of Opening and Starting Production in Wells at Cerro Prieto Geothermal Field, Baja California, Mexico," Proc. Second U.N. Symp. on the Devel. and Use of Geothermal Resources, San Francisco, Calif., vol. 3, pp. 1619-1633.

Dominguez A., B. and Vital B., F., 1975. "Repair and Control of Geothermal Wells at Cerro Prieto, Baja California, Mexico," Proc. Second U.N. Symp. on the Devel. and Use of Geothermal Resources, San Francisco, Calif., vol. 2, pp. 1483-1499.

Friedman, E. J. and El-Sawy, A., 1977. "Prospects for Improvements in Geothermal Well Technology and Their Expected Benefits," DGE/4014-4 MTR-7613; Metrek Division, The Metre Corp., McLean, Va.

Garnish, J. D., .1976. "Geothermal Energy, the Case for Research in the United Kingdom," Energy Tech. Supp. Unit, Harwell, Energy Paper No. 3, HMSO, London.

Glass, W. A., 1977. "1977 Drilling Methods and Costs at The Geysers," Geothermal Resources Council Trans., vol. 1, pp. 103-105.

Green, S. J.. 1977. "The Technology of Drilling Geothermal Wells," Minutes of the Fifth CATMEC Meeting, R. DiPippo, ed., Brown Univ. Rep. No. CATMEC/4, DOE No. COO/4051-5, Brown University, Providence, R.I.

Grieder, R., 1973. "Economic Considerations for Geothermal Exploration in the Western United States," presented at the Symposium, Colorado Department of Natural Resources, Denver, Colo. (December 6. 1973).

Kremnjov, O. A., Zhuravlenko, V. J., and Shurtzkov, A. V., 1970. "Technical-Economic Estimation of Geothermal Resources," Proc. of the U.N. Symp. on the Devel. and Use of Geothermal Resources, Pisa, Italy, vol. 2.2, pp: 1688-1696.

Matsuo, K.. 1970. "Present State of Drilling and Repairing of Geothermal Wells in Japan," Proc. of the U.N. Symposium on the Development and Use of Geothermal Resources, Pisa, Italy, vol. 2.2, pp. 1467-1479.

Maurer, W. C., 1968. Novel Drilling Techniques, Pergamon Press, Oxford.

Maurer, W. C., 1975. "Geothermal Drilling Technology." Proc. Second UN. Symp. on Devel. and Use of Geothermal Resources, San Francisco, Calif., vol. 2, pp. 1509-1521.

Moore, W. D., III, 1977. "Top-rotary 'Push-down' Rig Succeeds in Shallow Drilling," The Oil and Gas Journal, vol. 75, Sept. 19, p. 134.

Nakajima, Y., 1970. "Geothermal Drilling in the Matsukawa Area," Proc. of the U.N. Symposium on the Development and Use of Geothermal Resources, Pisa, Italy, vol. 2.2, pp. 1480-1484.

Newsom, M. M., St. Clair, J. A.. Ashmore. R. F., and Dodd. H. M., Jr., 1976. "The Down-hole Replaceable Drill Bit-Progress Report and Program Plan," Sandia Rep. SAND 76-0227, Sandia Laboratories, Albuquerque, N. Mex.

OGJ, 1977. "Hydraulic-lift Rig Finishes Break-in," The Oil and Gas Journal, vol. 75, No. 39 , Sept. 19 , pp. 125-126. 
Polito, J. and Varnado, S. G., 1978. "A Program in Geothermal Well Technology Directed Toward Achieving DOE/DGE Power-on-Line Goals," Sandia Rep. SAND 78-0766, Sandia Laboratories, Albuquerque, N. Mex.

Rubow, I. H., 1956. "Jet Piercing in Takonite": Mines Magazine, March.

Schumacher, B. W., 1969. "Electron Beams Apply an Old Principle to Rock-Breaking," Eng. and Mining Journal, June.

Shapir, Y. I., 1963. "Research on Forced Flame Drilling in the Altyn-Topkan Krivorzh Quarries," All-Union Research Inst. for Drilling Tech. USSR Proc., No. 10.

Smith, J. H., 1961. "Casing Failures in Geothermal Bores at Wairakei," Proc. UN. Conference on New Sources of Energy, Rome, vol. 3, pp. 254-263.

Varnado, S. G., ed., 1979. "Report of the Workshop on Advanced Geothermal Drilling and Completion Systems," Sandia Rep. SAND 79-1195, Sandia Laboratories; Albuquerque, N, Mex.

Whelan, J. A., 1977. "Thermal Gradient and Heat Flow Drilling," vol. 5 of Report on NSF Contract GI-43741, Univ. of Utah, Salt Lake City.

World Oil, 1976. "Helicopter Rig Can Drill to 20,000 Feet," May, p. 89.

\subsection{Well logging (By D. J. Ryley*)}

\subsubsection{Introduction}

The term "well logging" refers to the measurement, observation, and recording of all items of interest associated with the drilling, completion, and testing of a well. The term may be extended to include also all future observations made during the well's productive lifetime.

The log will record the mechanics of the drilling procedure, the bit life, the loss of circulation of drilling fluid, the rate of penetration, the total drilling time, the collapse of a local section of the bore wall, and any other occurrence which is noteworthy.

Any well, other than the most shallow, will penetrate $a$ number of geological horizons. It is customary, therefore, to recover continuously the chippings from the cutting surface for geological analysis. The chippings will be entrained in the drilling fluid and may be removed at the surface by screening. If two or more wells are located fairly close together, it is usually possible to obtain stratigraphic information such as the dip of the strata and the local variation in thickness of a given formation. It may also be possible to obtain information on structure : faults, joints, bedding planes, block displacement, folding, unconformities, and so on.

It is possible to make a number of geophysical measurements within the bore, by methods which will be discussed later. These measurements are of value in a number of ways which will be explored, not least because they may confirm predictions earlier made by surface-based geophysical meth. ods. These may thus be a valuable cross-fertilization between prediction and discovery.

*Division of Engineering, Brown University, Pxovidence, R.I., 02912; Dept. of Mechanical Engineering, University of Liverpool, Liverpool, England. 
It is usual to keep some performance records for established wells to monitor any change in their behavior with use. In the course of time most wells show a decline in flowrate, possibly in closed-in pressure and drawdown characteristics and the deptl of the water table. It is convenient to consider geophysical and geological data separately.

\subsection{Geophysical measurements}

2.5.2.1 Temperature. Temperature is the most significant property in the context of geothermal wells. Reliable measurements were made as long ago as 1830 using overflow thermometers. More recently a downhole geothermograph has been based on a bimetal strip. This strip actuates a scriber which makes a record on a smoked glass reception surface, the position of which could be indexed at will by wellhead control [Banwell, 1955]. Maximum thermometers have been widely used in the past [Mossop, 1950], either single or in dispersed groups. They have a slow response, are only moderately accurate, but are very reliable. Thermocouples may be employed, but require a very stable cold junction and a sensitive galvanometer to give accurate values of absolute (i.e., not relative) temperature.

It has become common practice to employ electrical methods, and the most popular temperature-sensing element is the thermistor, a small rugged resistive element having a high negative temperature coefficient of resistance $(\partial R / \partial T) / R)$. It is used in-conjunction with a Wheatstone Bridge, or equivalent device, located at the wellhead. Thermistors have a tendency to drift and require frequent calibration. Misener and Beek [1960] have discussed their use in detail.

An accurate and inexpensive thermometer (the "geothermometer") using a platinum wire resistor as a sensing probe has recently been developed by Ushijima et al. [1975]. It has proved satisfactory up to a temperature of $213^{\circ} \mathrm{C}\left(415^{\circ} \mathrm{F}\right)$ and a pressure of $9 \mathrm{MPa}\left(1305 \mathrm{lb} / \mathrm{in}^{2}\right)$.

It is convenient to point out here that there are several geochemical methods which may be used to indicate temperature. The most useful is to measure the concentration in a water sample of $\mathrm{SiO}_{2}$ [Bodvarsson and Palmason, 1964], since it has been found that the parts per million (PPM) of silica in thermal waters correlates closely with the temperature. This subject has been studied by Fournier et al. [1974].

2.5.2.2 Pressure. Pressure is more easily measured than temperature in geothermal bores, as in most other situations, and is therefore not widely discussed in the literature.

Downhole pressures may be measured by using standard oil field-type clock-driven recording instruments. Wellhead pressures may be taken with a standard bourdon-type pressure gauge calibrated with a deadweight tester [Mathias, 1975]. 
An approximate method of calculating downhole pressures for a well which is not discharging is to take a sounding of the depth and evaluate the hydrostatic pressure, correcting for density variation with temperature [Smith, 1975]. Gas or steam entrained within the water may impair the accuracy of this method.

At any location in a flowing well where both vapor and liquid phases are present, the pressure may be taken to be the saturation value appropriate to the temperature. This assumes a negligible temperature recovery due to interrupting the flow, and that equilibrium exists between the phases. It is also assumed that the saturation vapor pressure curve is known for the geofluid.

2.5.2.3 Elastic wave propagation. Elastic waves were first used to investigate boreholes in 1948, and it was soon found that acoustic velocity in rocks is related to their porosity. It was pointed out in section 2.2.11.1 that porosity is related to the electrical resistivity of formation water, and not unexpectedly acoustic velocity has been found also to correlate with the in-situ resistivity of rock. It has long been known that the acoustic velocity in an elastic medium is related to the elastic constants (see section 2.3.3.3).

The physical basis of this method of logging is as follows. The logging device may be up to four meters long and consist of a transmitter and one or more receivers. An acoustic wave series is transmitted into the bore side wall formation adjacent to the device and reviewed at known displacements from the transmitter after traversing the formation. The line interval (transit time) can be accurately measured from which the acoustic velocity can be found. The attenuation of the signal may also be measured; hence deductions concerning permeability may be made. Because acoustic waves encountering an interface between strata of different densities are in varying degrees transmitted, refracted, and reflected, it is frequently possible to interpret secondary signals returning after reflection. The time lapse and attenuation may provide information about the nature and structure of the rocks in the vicinity of the bore and also, after completion of the well, information on the status of the bonding between the cement and the formation [Pirson, 1963]. A short section of a sonic log is shown in figure 2.18 and includes the spontaneous potential (see section 2.5.2.4).

For an isotropic elastic solid the sonic velocity $\nabla_{a}$ is given by the standard expression:

$$
V_{a}=\sqrt{\frac{E+4 G / 3}{\rho}}
$$

where $E$ and $G$ are respectively Young's modulus and the shear modulus and $\rho$ is the density. Formations are, in general, far from isotropic and show great diversity both in composition and structure. It is necessary, 


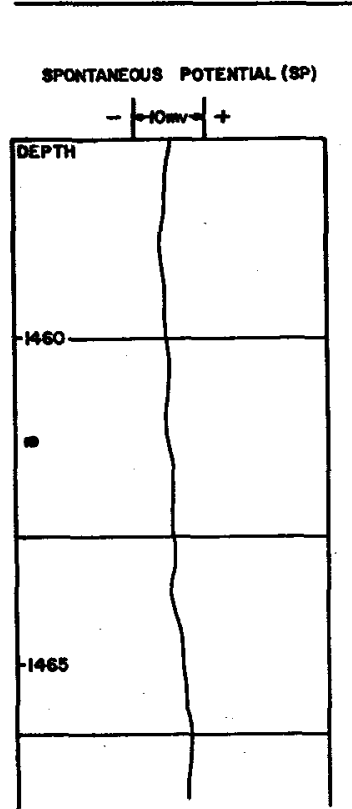

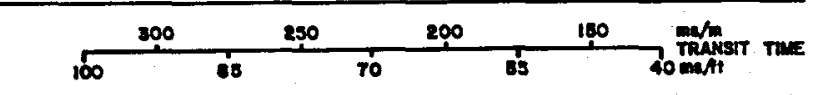

FTaURE 2.18-Acoustic instrument spacing one foot; two receivers porosfty scale is based on a matrix velocity $7010 \mathrm{~m} / \mathrm{s}(23,000 \mathrm{ft} / \mathrm{s})$ [after Pirson, 1963 ].

therefore, to find some velocities from in-situ and laboratory tests. Attempts have been made to relate empirically velocity with lithology [Faust, 1953], and also to model the lithologic structure [Grossman, 1951].

It has been shown [Wyllie et al., 1958] that porosity $\phi$ and acoustic velocity, $V$, are related by the so-called time-average formula:

$$
\frac{1}{V_{F}}=\frac{\phi}{V_{L}}+\frac{1-\phi}{V_{M}}
$$

where the subscripts $F, L$, and $M$ refer respectively to the formation, the saturating liquid, and the rock matrix. Liquid may be interpreted as water, oil, or gas, and $V_{L}$ is established by laboratory tests for various pressures. If $V_{F}$ is measured, $\phi$ may be obtained from a chart similar to figure 2.19. Corrections exist for consolidated and compacted sand formations that do not comply well with equation 2.25 [Pirson, 1963; Pickett, 1960]. Methods are also available to diagnose the presence of pore fluids and to identify them.

2.5.2.4 Electrical resistivity. Electrical well-logging was developed in the late 1920's as an extension of the resistivity method of surface prospecting. Resistivity values obtained with electrodes bearing against the uncased bore sidewall enabled the change of strata with depth to be recorded. The discovery that the resistivity was related to the local porosity, permeability 

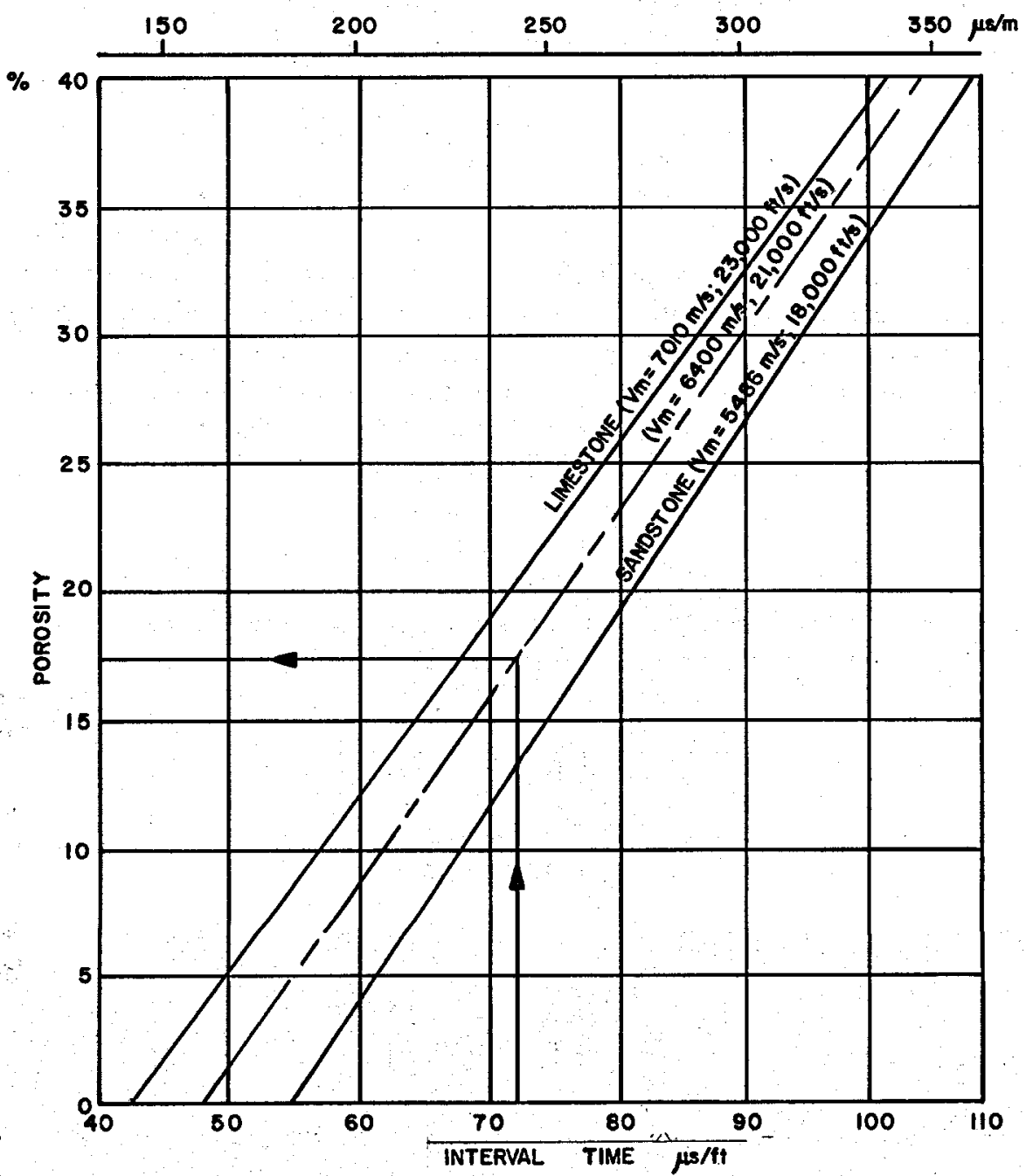

Figone 2.19-Relationship between porosity and acoustlc velocity for limestone and sandstone.

and geochemistry made possible the ready acquisition of a wealth of downhole data and has made the resistivity log one of the most valuable of the available logs.

The apparent resistivity arises not only from the formation and the geofluid saturating it, but also from the drilling fluid. Field work led to the discovery that if the potential of the borehole fluid with respect to the earth (known as the spontaneous potential, SP) was plotted against the depth deviations, a uniform value occurred opposite porous and permeable beds. This led to the establishment by Doll [1948] of a relatiouship between 
SP and the resistivity of the formation water, from which has arisen a variety of logging tools. These tools differ principally in respect to the disposition and nature of the devices used to promote a potential difference across sections of the bore sidewall. The common methods for measurement of formation resistivity are now described.

Conventional devices. Conventional resistivity logs are obtained by measuring the potential set up between two electrodes due to current fiowing between two other electrodes. The device is a network of four electrodes of which one is usually at the surface of the ground. Considering figure 2.20 , if current $I$ is emitted from the electrode $A$ surrounded by a homogeneous medium of resistivity $\rho$ ohm-meters, the resulting equipotential surfaces are spheres concentric with the electrode. The potential of a spherical surface at a distance $r$ from $A$ is

$$
\nabla=I_{\rho} / 4 \pi r
$$

For the electrode configuration of figure 2.21, the potential of $M$ due to current $I$ flowing between $A$ and $B$ is given by

$$
\begin{aligned}
V_{m} & =I \rho\left[\frac{1}{4 \pi A M}-\frac{1}{4 \pi B M}\right] \\
& =\frac{I \rho}{4 \pi}\left[\frac{B M-A M}{A M \times B M}\right]
\end{aligned}
$$

Similarly, for electrode $N$,

$$
V_{n}=\frac{I \rho}{4 \pi}\left[\frac{B N-A N}{A N \times \overline{B N}}\right],
$$

Hence

$$
V_{m}-V_{n}=\frac{I \rho}{4 \pi}\left[\frac{1}{A M}-\frac{1}{B M}-\frac{1}{A N}-\frac{1}{B N}\right]
$$

If $A M$ and $A N \ll A B$, then $\frac{1}{B M}$ and $\frac{1}{B N}$ are negligible and

$$
V_{m}-V_{n}=\frac{I \rho}{4 \pi}\left[\frac{A N-A M}{A M \times A N}\right]
$$

For the conventional survey $V_{m}$ and $V_{m}-V_{n}$ are employed. With equation 2.26 either electrode $B$ or $N$ is at the surface and the spacing $A M$ is small compared with the overall depth of the downhole electrodes. This is often known as the "normal" device and frequently two experimental curves are taken having a shorter and a longer AM spacing and desig- 


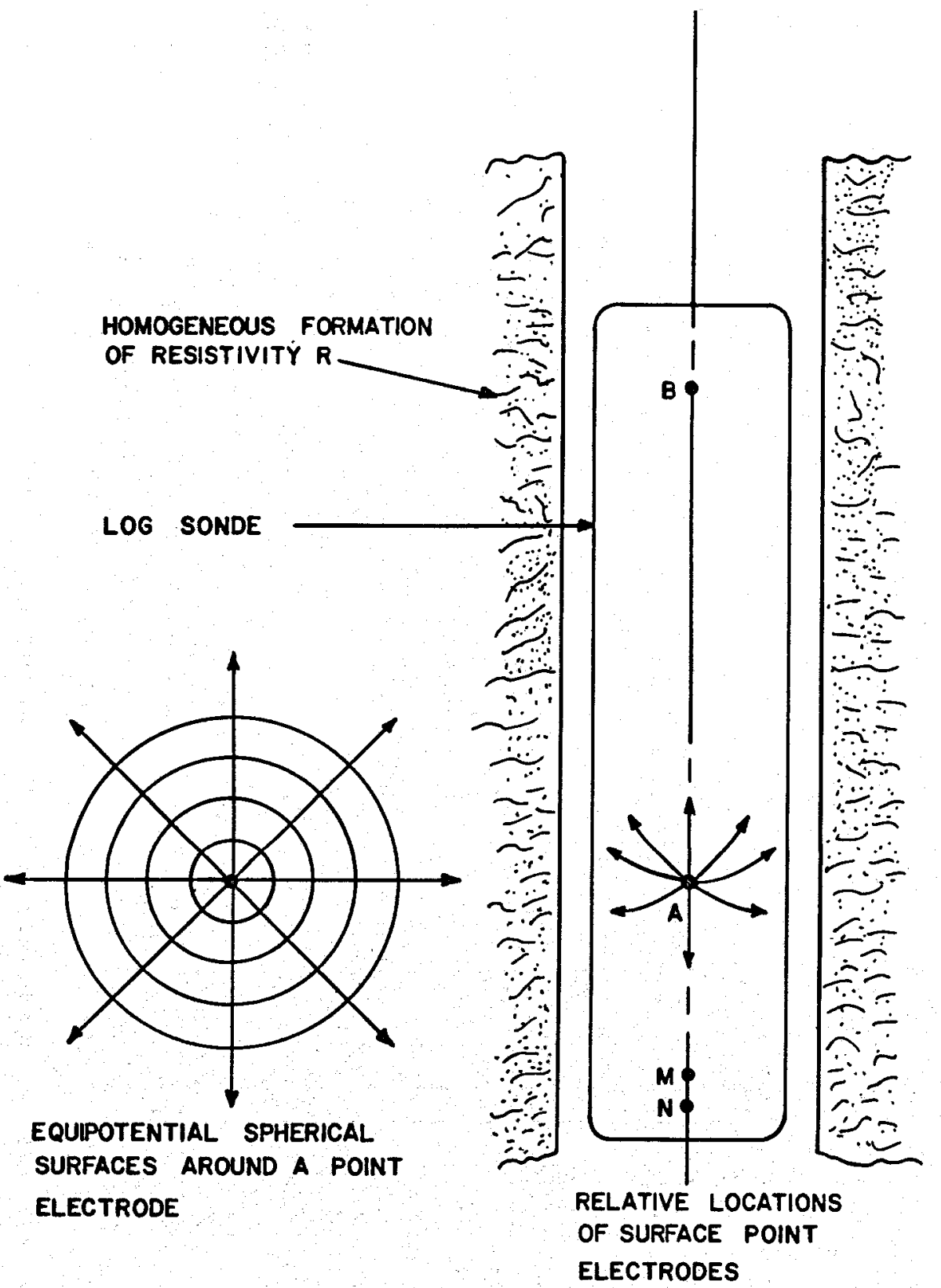

FIGURE 2.20-The four-electrode resistivity logging principle.

nated the short and the long normal [Gaskell and Threadgold, 1960]. If the electrode $B$ is at the surface and the length $M N$ is small compared with AM, the arrangement is known as the "lateral" device. 


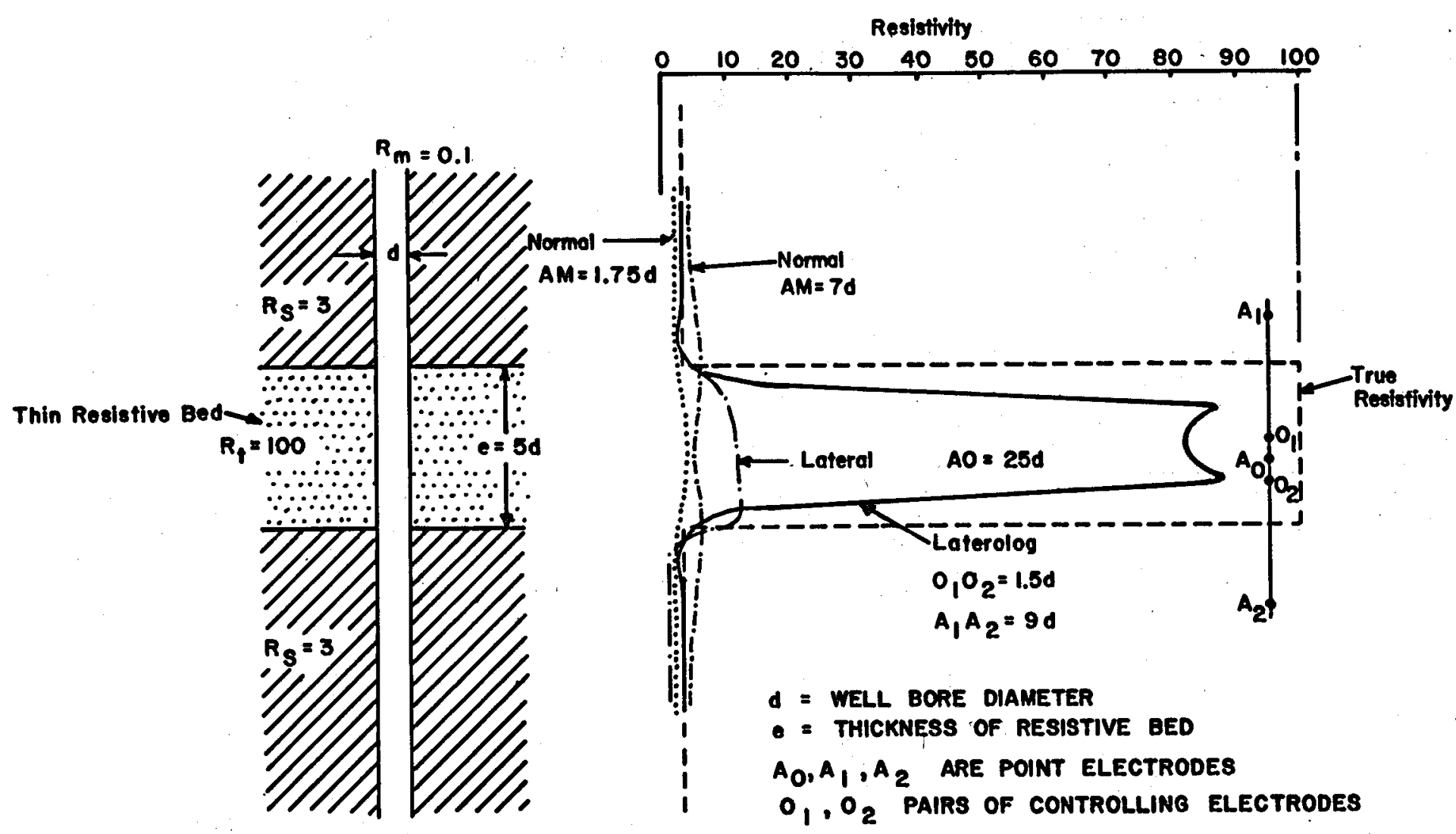

FiaURe 2.21-Comparison of electrical resistivity logging devices [after Pirson, 1963]. 
The arrangements of electrodes described above give inadequate discrimination in certain circumstances. The conventional log is not well adapted to deal with the radial variations of depth to which a filtrate from the drilling mud has penetrated, nor to deal with a thin bed which may be straddled by widely-spaced electrodes [Haun and LeRoy, 1958]. These limitations have led to the development of focussed-current devices, the laterolog, and the induction log.

The laterolog. The laterolog is a resistivity measuring method where in the current is constrained to flow radially through the formations as a sheet of predetermined thickness by means of an appropriate electrode arrangement and automatic control system. The laterolog 7 employs seven point electrodes; the laterolog 3 consists of a single center-point electrode with symmetrically-placed elongated electrodes above and below to achieve focussing. These instruments when compared with the conventional $\log$ show a sharper discrimination between different beds and a more accurate definition of their boundaries. They also give a close approximation to the true resistivity of thin beds, particularly in formations drilled with high salinity mud. These effects are illustrated in figure 2.21.

The induction log. The two advantages just stated with respect to the laterolog may also be secured by the use of an induction log, the principle of which is shown in figure 2.22. Alternating current of constant amplitude and frequency is supplied to the transmitter coil. This induces an alternating magnetic field in the rock surrounding the instrument of which rock the toroidal loop shown is an arbitrary element. An induced current is set up in this loop, the strength of which is proportional to the formation conductivity. This current promotes a secondary magnetic field which causes an electromotive force in the receiver coil.

The microlog. The microlog is a resistivity $\log$ recorded from three electrodes mounted vertically in line $2.54 \mathrm{~cm}$ (1 in) apart on a rubber pad. Spring pressure keeps the pad in contact with the bore sidewall preventing the mud from acting as a short-circuiting conductor and permitting resistivity measurements of a small volume of material at the wall face.

The microlaterolog. This device comprises one very small central electrode and three concentric circular ring electrodes and is a currentfocussing device. It is designed for use in low-porosity strata where the formation resistivity is high compared with the resistivity of the mud cake, resulting in a high current density in the latter and inaccurate resistivity indication for the former. The focussing system of the microlaterolog reduces to an acceptable level the error in measurement arising from the mud cake, and gives good results for low-resistivity formations.

Interpretation of resistivity logs. All resistivity logs are presented as a continuous, undulating trace curve drawn on a basis of depth. The trace form is related to the number and dispositions of the electrodes or the 


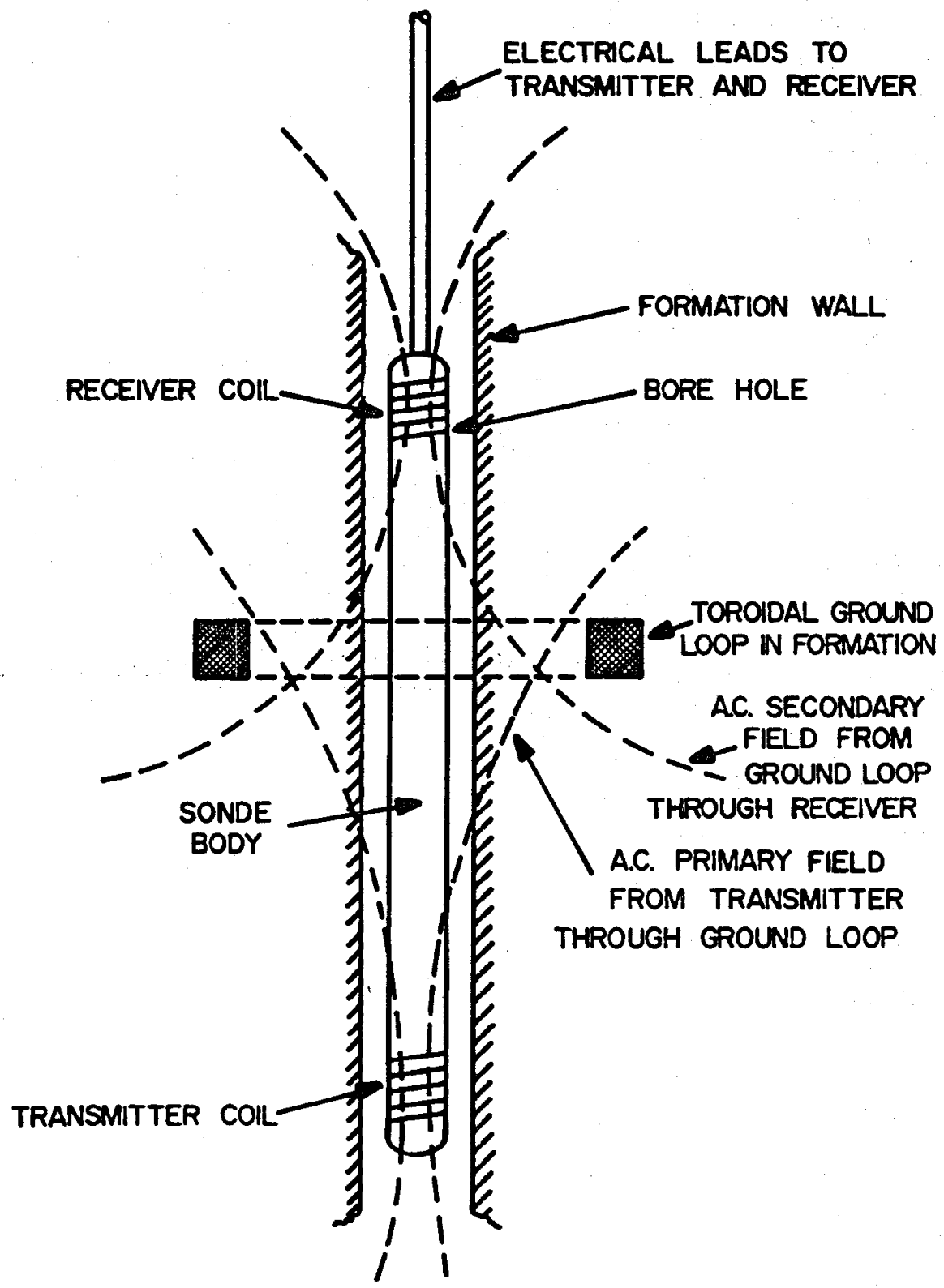

Fratre 2.22-Princlple of the induction log.

configuration of the focussing device, to the resistivity of the formation and of the drilling mud and to the invasion of the formation by the mud. Figure 2.21 shows comparative responses by a number of different logs to the same external stimuli, in this case arising from a thin, uninvaded, resistive bed with salt-mud in the well. It is evident that the responses are 
very different. A great deal of ingenuity has been devoted to the analysis, both qualitative and quantitative, of the trace-form of the log, and a large literature is available [e.g., Pirson, 1963] based mainly on oil and gas well drilling. A survey of the more recent papers concerned with logging geothermal boreholes suggests that only the SP log is of interest, presumably because it gives adequate qualitative information on the location of liquidbearing formations.

\subsubsection{Radioactivity well logging. Radioactivity well logging makes use} of naturally-occurring and induced nuclear radiations to obtain useful information about the formations penetrated by the borehole. The most useful logs are the gamma-ray and neutron curves and the density-measuring $\log$.

With few exceptions rocks contain small but measurable amounts of radioactive material mainly of the uranium, thorium, and potassium series. The gamma-ray log is a detector (based on any of the principles commonly. used in nuclear physics) which is passed at a uniform rate up the well. The detector accepts radiation, some having an energy level near the original value and a considerable amount at lower energy levels due to scattering losses in the surrounding material. If $I_{0}$ is the initial intensity of gamma radiation and $I$ the emergent intensity after traveling a distance $l$ in any material, then:

$$
I / I_{0}=e^{-\mu l}
$$

where $\mu$ is the gamma-ray absorption coefficient of the material and is given per unit length by

$$
\mu=\ln I_{0}-\ln I \text {. }
$$

The absorption coefficient $\mu$ is approximately proportional to the density $p$ of the absorbing material for a given energy of radiation. $I_{0}$ varies from about $1 \mathrm{MeV}$ average to $1.5 \mathrm{MeV}$ for potassium and $\mu / \rho$ is approximately 0.66 for an incident energy of $1.3 \mathrm{MeV}$. The value of $\mu$ for earth formations is generally in the range $\left(6-15 \mathrm{~m}^{-1}\right)$.

The introduction of the gamma-ray log enabled studies to be made of the lithology surrounding cased wells, and it became passible to survey older completed wells. This useful facility led to the development of neutron logging. In this case a curve is obtained by moving an active neutron source along the well which irradiates the formations and in its wake a radiation detector. The latter may be a device which responds to gamma radiation, in which case the method may be described as a neutron-gamma method, or a device which is sensitive to neutrons in which case it is designated a neutron-neutron method. Frequently both curves are obtained simultaneously during a single traverse of the well.

The density log was developed to meet the need for a device capable of measuring the density of subsurface rocks. It was found that the radioac- 
tivity log was well adapted for porosity measurement, and it so happens that most of the common types of rock have the same grain density. Thus porosity measurements are effectively measurements of density.

2.5.2.6 The caliper log. As its name suggests, this is a device for measuring the diameter of a well bore. It consists of four collapsible arms mounted $90^{\circ}$ apart on a steel hub. The tool is lowered to the base of the well where the arms are released. It is then raised to the surface at about $30.5 \mathrm{~m} / \mathrm{min}(100 \mathrm{ft} / \mathrm{min})$. As it traverses an individual spring keeps each arm in contact with the side of the hole, and the deviations from a standard diameter (e.g., the bit diameter) are automatically plotted as a function of depth.

2.5.2.7 The spinner. The spinner consists of a metal guard cage housing a small plastic impellor blade whose velocity of rotation can be recorded electrically on the surface. The spinner is lowered into the hole and maintained in position. If there is any bulk flow of liquid from any cause, the impellor rotates. Allowing for errors in the bore size, it is possible to monitor water movements at any location.

2.5.2.8 Miscellaneous logs. A number of records other than the above may be kept. Some examples are

(1) Depth of a bit penetration per day.

(2) Volume of mud lost on each occasion of lost circulation.

(3) Type of bit.

(4) Extent and direction of dip in strata.

(5) Penetration rate through a defined geological formation.

(6) Magnetic susceptibility [Hochstein and Hunt, 1970].

\subsubsection{Geological observations}

2.5.3.1 Sequence of geological formations. During the process of drilling, the hole usually penetrates a considerable number of different geological formations. Chippings from a given formation are borne to the surface entrained in the drilling mud. Here they are screened, washed, and prepared for geological examination by the usual methods. Cores may also be recovered, analyzed, and recorded as required. The methods for assessing the subsurface geology are described in standard texts, e.g., Haun and LeRoy [1958].

The acoustic log measures the velocity of compression waves which is a function of the rock elasticity $(E)$ and the rock density $(\rho)$. These properties vary within wide limits for various formations but remain laterally constant for a given lithology. Seismic wave logs are therefore useful as tools for geological correlation. The lithology log is exhibited (figure 
2.23) in the form of a column showing the variation with depth of the geological horizon penetrated along with other quantities of interest.

2.5.3.2 Structure of geological formations. It has already been pointed out in section 2.5.2.3 that seismic logging provides indications of rock structure. This may be interpreted both on a large and on a small scale

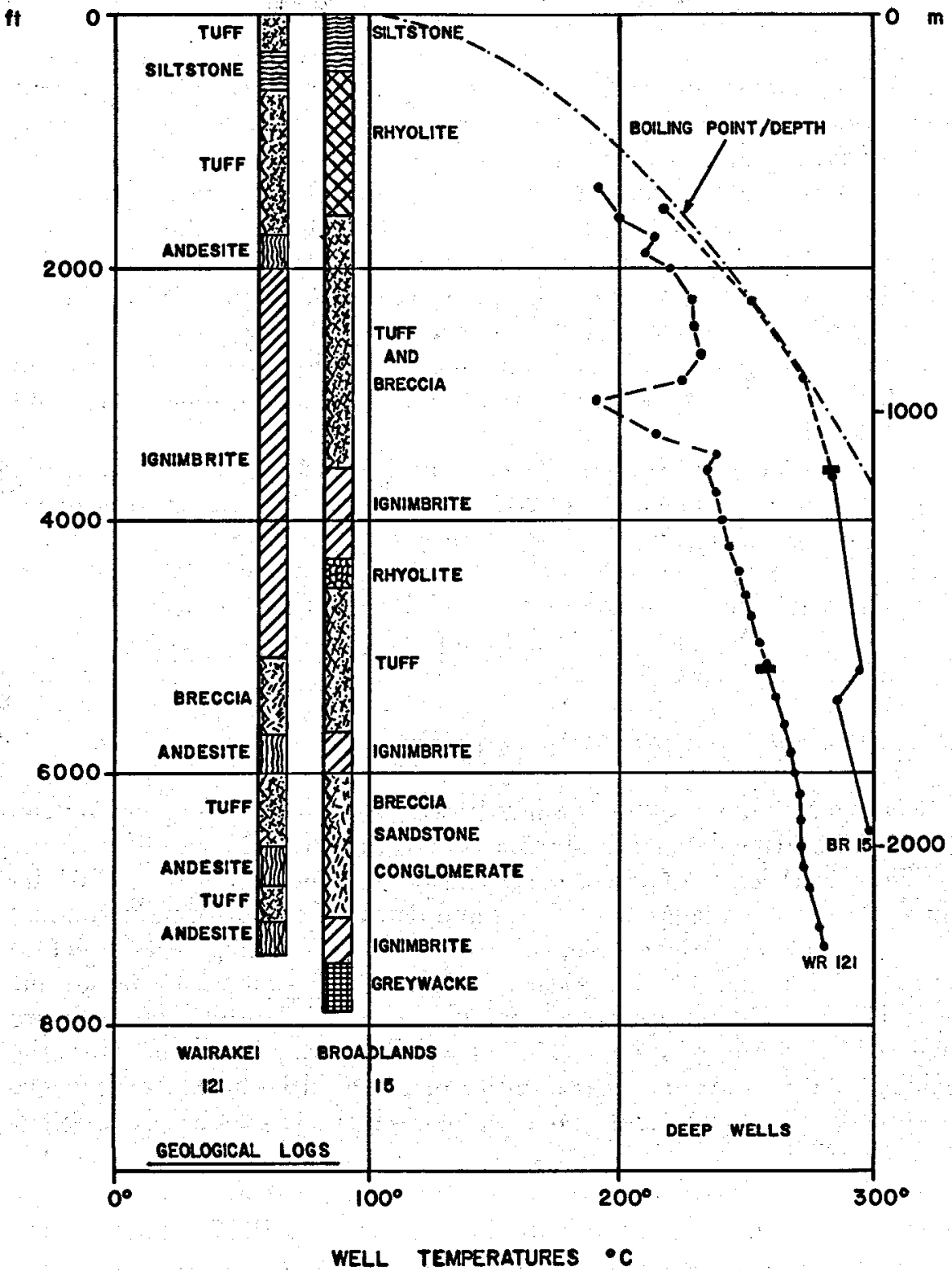

Fraore 2.23-Lthology of two wells in New Zealand [after Smith, 1970]. 
and may provide information on texture, joints, cracks, and bedding planes which in turn may yield information on geological age. Seismic velocities tend to increase as the degree of compaction and the geologic age increase [Faust, 1953].

\subsubsection{Some limitations of logging methods}

Well logging is an established technology for oil and gas wells, and the limitations of tools and techniques are identified and generally understood. The extension of this technology to geothermal wells is very recent and many established methods have been found inadequate in this context.

Thus far elevated temperatures have proved troublesome. Smith et al. [1975] state that commercial logging equipment has given trouble as downhole temperatures approached $150^{\circ} \mathrm{C}\left(302^{\circ} \mathrm{F}\right)$, and most of it has been unreliable at temperatures approaching $200^{\circ} \mathrm{C}\left(392^{\circ} \mathrm{F}\right)$. A test facility for well-logging cables has, however, been set up [SSS, 1977] to investigate the behavior of these cables at elevated temperatures.

Studies have also been commenced on the adaption, for temperatures up to $320^{\circ} \mathrm{C}\left(608^{\circ} \mathrm{F}\right)$, of electronic circuits for well-logging tools [Raymond et al., 1977.]

Another study is concerned with creating design standards for wells and also with the development of a precision temperature/pressure measuring probe [Ross, 1976]. Nevertheless, at the time of writing (March, 1978) there is strong dissatisfaction with the current status of geothermal logging. Technological shortcomings have been identified in some detail in the report describing the GREMP Plan [LBL, 1977], and it is evident that action is urgently needed.

\subsubsection{Example of a production well log}

Figures 2.24 and 2.25 have been redrawn from logs published by Matsuo [1970] presenting data on the Japanese well Ohnuma R-1.

Figure 2.24 is the drilling chart. The well profile is shown on the lefthand side and displays the diameter and depth of each section of conductor pipe together with the diameter over the cement casing at its interface with the formation. The temperature of the drilling mud was recorded, and it will be seen that at approximately $630 \mathrm{~m}(2067 \mathrm{ft})$ depth the temperature had risen to more than $80^{\circ} \mathrm{C}\left(176^{\circ} \mathrm{F}\right)$, and it became necessary to use the cooling tower to avoid any possibility of the fluid boiling. The sequence of temperature surveys and recovery of cores is shown on a basis of elapsed working days. The placing and setting of cement is likewise recorded. On the righthand side of the chart the geological log is displayed and alongside it the drill penetration rate. Replacement of the drill bit is not recorded on the chart. The geological log is marked with arrows to show the locations at which drilling circulation was lost. 


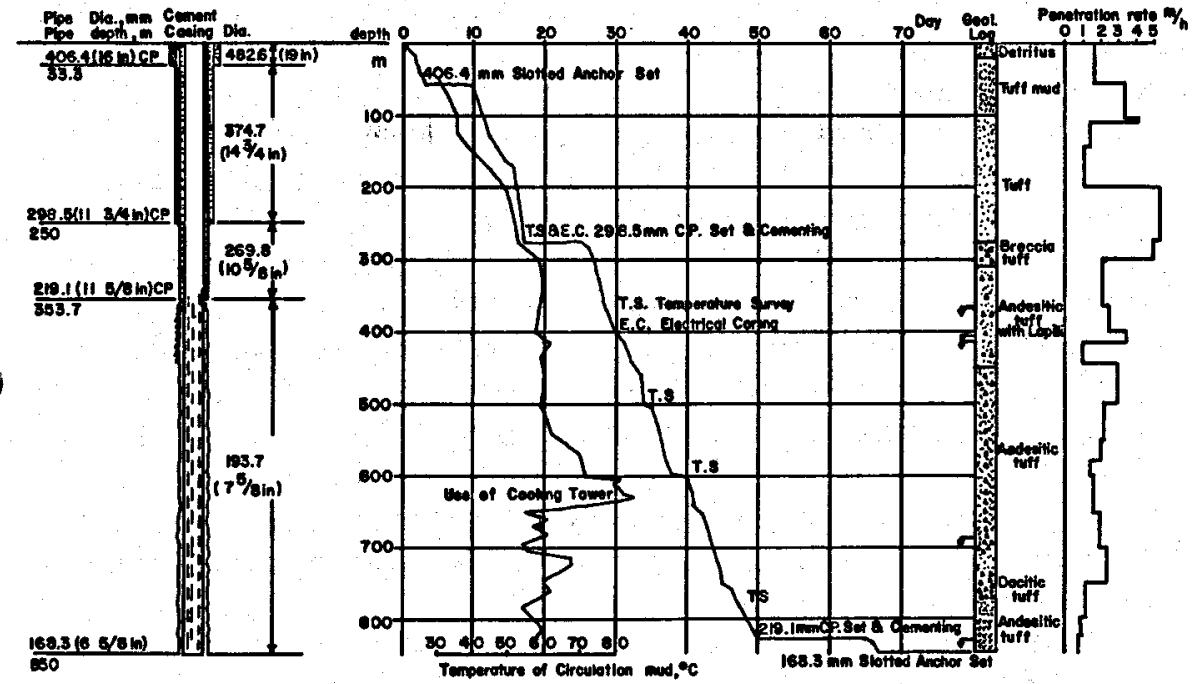

FraURa 2.24-Iogs for Japanese well Onuma R-1 [after Matsuo, 1970].

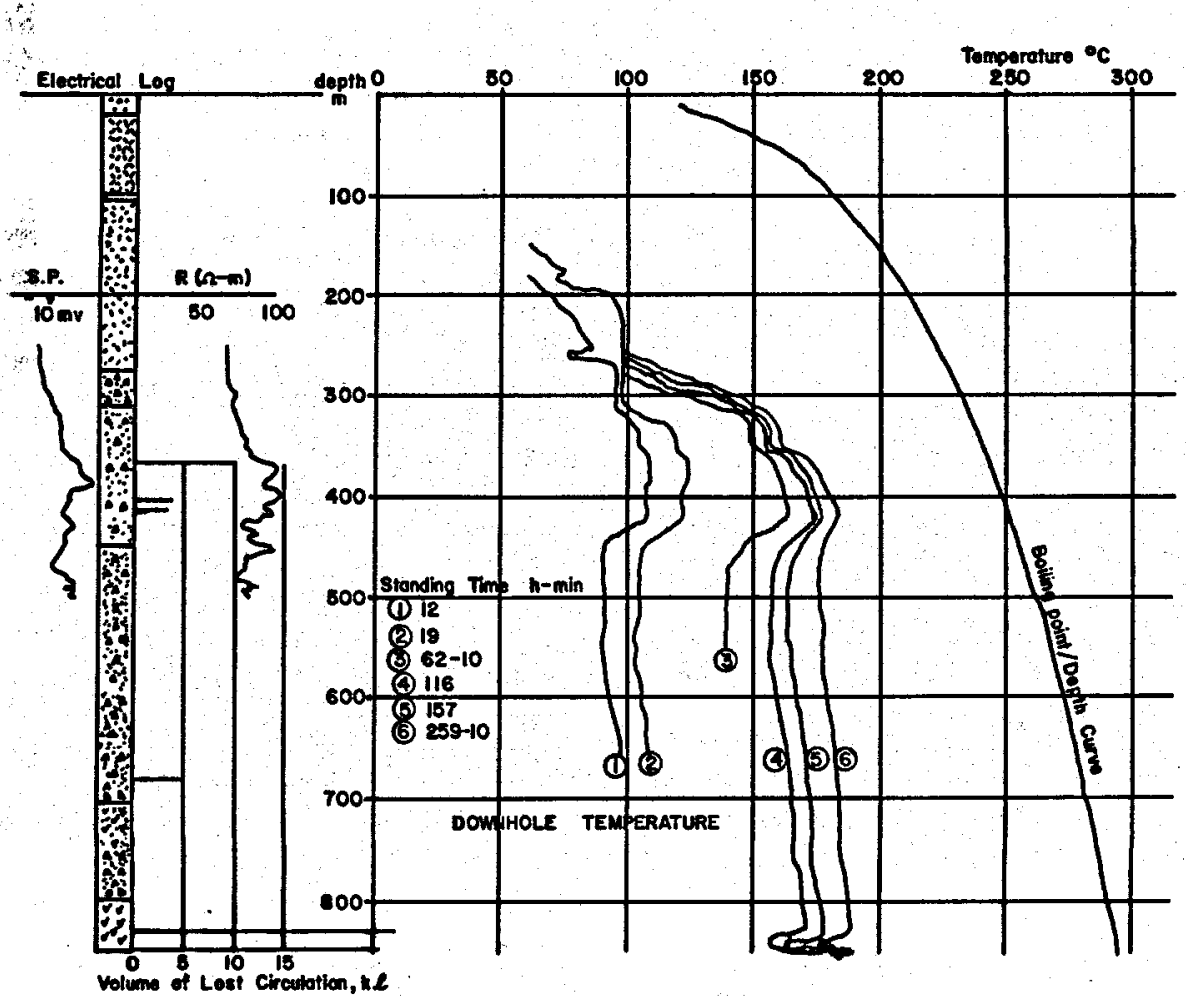

FiguRe 2.25-Logs for Japanese well Onuma R-1 [after Matsuo, 1970]. 
Figure 2.25 is the electrical log and temperature survey chart, and this chart complements the previous one. It displays the geological log for reference and alongside the spontaneous potential (SP) $\log$ in millivolts and corresponding values of electrical resistivity $R$ in ohm-meters. The electrical $\log$ was only employed over a limited section of depth. The locations of lost circulation are again displayed against the geological log, and the estimated volume of mud lost within the formation is shown as a bar chart. The downhole temperatures were taken either by thermometer or thermistor. There are six sets of readings taken at various times from $1 / 2$ day to 11 days after cessation of drilling. The temperature recovery with time of the downhole formations is readily observed, and the relative placing of curves 4,5 , and 6 suggests that at the time of taking temperature survey 6 the temperature was not rapidly approaching the equilibrium value at any location within the hole. The boiling point depth curve (see section 2.6.1.5) is added for comparison.

\subsubsection{References for section $\$ .5$}

Altseimer, J. H., 1976. "The subterrene rock-melting concept applied to the production of deep geothermal wells," Proc. Eleventh Intersociety Energy Conversion Engineering Conference, State Line, Nev., Sept. 12-17, pp. 717-723.

Banwell, C. J., 1955. "Phvsical investigations in geothermal steam for power in New Zealand," New Zealand Dept. Sci. Ind. Res. Bull 117 (I. I. Grange, Ed.), pp. 45-74.

Barber, L. H., Green, S. J., and Jones, A. H., 1976. "Geothermal environment effects on drill bit life," Proc. Eleventh Intersociety Energy Conversion Engineering Conference, State Line, Nev., vol. 1, pp. 711-716.

Bodvarsson, G., and Palmason, G., 1964. "Exploration of subsurface temperature in Iceland," Proc. U.N. Conf. New Sources of Energy, Rome, 1961, vol. 2, p. 91.

Cigni, U., Giovannoni, A., Luschi, E., and Vidali, M., 1970. "Completion of producing geothermal wells," Proc. U.N. Symp. on Devel. and Use of Geothermal Resources, Pisa, Italy, vol. 2.1, p.757.

Doll, H. G., 1948. "The S. P. log-theoretical analysis and principles of interpretation," Petrol. Tech., $N Y, 11, \mathrm{TP}-2463$.

Dominguez, B., and Mora, F. J. B. de la, 1975. "Present methods of opening and starting production wells at Cerro Prieto geothermal field, Baja California, Mexico," Proc. Second U.N. Symposium on Devel. and Use of Geothermal Resources, San Francisco, Calif., vol. 3, pp. 1619-1628.

Eshbach, O. W., ed., 1955. Handbook of Engineering Fundamentals, Edition 2, J. Wiley and Sons, Inc., London.

Faust, L. Y., 1953. "A velocity function including lithologic variations," Geophys., vol. 18, pp. 271-287.

Fournier, R. O. and Truesdell, A. H., 1970. "Chemical indicators of sub-surface temperature applied to hot spring waters of Yellowstone National Park, Wyoming, U.S.A.," Geothermics, special issue 2; 2, 1, pp. 529-535.

Fournier, R. O., White, D. E., and Truesdell, A. H., 1974. "Geochemical indicators of subsurface temperature, part 1: Basic Assumptions," US. Geol. Survey J. Res., vol. 2, p. 3.

Friedman, E. J., and El-Sawy, 1977. "Prospects for improvement in geothermal well technology and their expected benefits," MITRE Technical Report, MTR-7613, Dec. 1977. 
Garnish, J. D., 1976. "Geothermal energy: the case for research in the United Kingdom," Energy Paper No. 9, Department of Energy, HMSO, London.

Gaskell, T. F. and Threadgold, P., 1960. "Borehole Surveying," in Methods and Techniques in Geophysics, S. K. Runcorn, ed., vol. 1, pp. 62-103, Interscience Publishers, Inc., New York.

Green, S. J., 1977. "The Technology of Drilling Geothermal Wells," Minutes of the Fifth CATMEC Meeting, R. DiPippo, ed., COO-4051-5, Brown University, Providence, R.I.

Grossman, F., 1951. "Elastic waves through a packing of spheres," Geophys., vol. 17, pp. 673-685.

Haun, J. D., and LeRoy, L. W., eds., 1958. Subsurface Geology in Petroleum Exploration, Colorado School of Mines, Golden, Colo.

Hochstein, M. P. and Hunt, T. M., 1970. "Seismic, gravity and magnetic studies, Broadlands geothermal field, New Zealand," U.N. Symp. on the Devel and Use of Geothermal Resources, Pisa, Geothermics, special issue 2; 2, 1, pp. 333-346.

Kremnjov, O. A., Zhuravlenko, V. J., and Shurtzkov, A. V., 1970. "TechnicalEconomic Estimation of Geothermal Resources," Proc. of the UN. Symposium on the Development and Use of Geothermal Resources, Pisa, Italy, vol. 2.2, p. 1688.

LBL, 1977, Geothermal Reservoir Engineering Management Program Plan (GREMP Plan), Lawrence Berkeley Laboratory Rep. LBL-7000, UC-66a, TID-4500-R66, U. of California, Berkeley.

Mathias, K. E., 1975. "The Mesa geothermal field: a preliminary evaluation of five geothermal wells," Proc. Second U.N. Symp. on Devel. and Use of Geothermal Resourcess, San Francisco, Calif., vol. 3, pp. 1741-1747.

Matsuo, K., 1970. "Present State of drilling and repairing of geothermal production wells in Japan," Proc. U.N. Symp. on Devel. and Use of Geothermal Resources, Pisa, Italy, vol. 2.2, pp. 1467-1479.

Matsuo, K., 1973. "Drilling for geothermal steam and hot water," Geothermal Energy UNESCO, H. C. H. Armstead, ed., Paris, pp. 73-84.

Maurer, W. C., 1977. Near-Term Needs in Drilling Technology, Paper presented to the U.S. House of Representatives Fossil and Nuclear Energy Research, Development and Demonstration Subcommittee on Science and Technology, March 1.

Misener, A. D. and Beck, A. E., 1960. "The measurement of heat flow over land," Methods and Techniques in Geophysics, S. K. Runcorn, ed., vol. 1, pp. 10-61, Interscience Publishers, Inc., New York.

Mossop, S. C., 1950. "A multi-thermometer method for temperature measurement in boreholes,"J. Chem. Met. Min. Soc. South Africa, vol. 51, pp. 120-122.

Newsom, M., 1976. The Downhole Replaceable Drill Bit-Progress Report and Program Plan, Sandia Laboratory, Albuquerque, N. Mex.

Pickett, G. R., 1960. "The use of acoustic log in the evaluation of sandstone reservoirs," Geophys., vol. 25, p. 1, p. 250.

Pirson, S. J., 1963. Handbook of Well Log Analysis, Prentice-Hall, Inc., Englewood Cliffs, NJ.

Raymond, L. S., Hamilton, D. J., and Kerwin, W. J., 1977. Development of Passive Electronic Components for Instrumentation of Improved Geothermal Logging Tools and Components, Solid State Engineering Laboratory, University of Arizona, Tucson, Report No. COD-4081-2 for DOE (DGE).

Ross, L. W., 1976. "Two-phase flow in geothermal energy sources," Annual Report 1976, Denver Research Institute, The University of Denver, Colo., 80210.

Sensor Application Survey, Technical Report, Task 1, Report No. TID-27941 Westinghouse Electric Corp., Pittsburgh, Pa., for the U.S. Department of Energy (DGE).

Smith, J. H., 1975, "Geothermal development in New Zealand," Geothermics, special issue 2 ; vol. 2, pt. 1, pp. 232-247. 
SSS, 1977. "Test facility for well logging cables," Topical Report SAN/1208-1, Systems, iscience and Software, La Jolla, Calif.

Tan, E., 1975. "Geothermal drilling and testing, Afyon, Turkey;' Proc. Second U.N. Symp. on Devel. and Use of Geothermal Resources, SFn Trancisco, Calif., 1975 , vol. 2, pp. 1523-1526.

Ushijima, K., Nishikawa, K., Ito, T., Matsumoto, K., and ivoguchi, T., 1975. "A thermometer for geothermal thermometry in geotherual wells," Proc. Second U.N. Symp. on the Devel. and Use of Geothermal Resources, San Francisco, Calif., vol. 3, pp. 1829-1834.

Whelan, J. A., 1977. "Thermal gradient and heat flow drilling," Report on NSF Contract GI-43741, vol. 5, Univ. of Utah, Salt Lake City, Utah.

Wyllie, M. R., Gregory, A. R., and Gardner, G. H. F., 1958. "An experimental investigation of factors affecting elastic wave velocities in porous media," Geophys., vol. 23, pt. 3, pp. 459-493.

Yashell, T. F. and Threadgold, P., 1960. "Borehole Surveying," Methods and Techniques in Geophysics, S. K. Runcorn, ed., vol. 1, pp. 62-103, Interscience Publishers, Inc., New York.

\subsection{Analysis of the Flow in the Reservoir-Well System (By D. J. Ryley*)}

\subsubsection{Flow in a well pipe}

In order to analyze the upward flow of fluid in a well we consider a thermodynamic system the side boundaries of which are coincident with the boundaries swept by the fluid. The boundaries across which occur the liquid inflow and outflow may be defined as required. We may choose to include the reservoir and/or the power plant within the system, but for the present we are concerned only with the liquid column within the well pipe. It is convenient therefore to terminate the system flow boundaries at the well pipe entrance and exit.

Whatever may be the nature and extent of the energy transfers across the system boundary or within it, there will always exist continuity of mass flow, of energy and of momentum provided all conditions are established and steady, i.e., no transients occur. This applies equally for single- or twophase flow and is independent, in the latter case, of the existence or absence of "slip" between the phases.

2.6.1.1 The continuity equations for vertical flow in a pipe. Inasmuch as the great majority of geothermal well bores are vertical or very nearly so, the vertical well will be treated here. For a well with an inclined section it is a simple matter to insert an angle of inclination into the potential energy term [Gould, 1974].

An element of the flow, $A B C D$, is shown in figure 2.26. The symbols have their usual meanings. In the most general case there are elements of

\footnotetext{
-Division of Engineering, Brown University, Providence, R.I. 02912 ; permanent address: Dept. of Mechanical Engineering, University of Liverpool, Liverpool, England.
} 
heat and work transfer, respectively having rates of $d \dot{Q}$ and $d \dot{W}$. The flow will be taken to be two-phase and homogeneous. An element having phase slip can readily be analyzed [Ryley 1965; Fukuda et al., 1975] but introduces complications.

For mass continuity,

$$
\dot{m}=\rho T P
$$

For energy continuity,

$$
d \dot{Q}-d \dot{W}=\dot{m}\left[d h+d\left(\frac{V^{2}}{2}\right)+g d z\right]
$$

For momentum continuity it is necessary to recognize the friction force arising on the swept boundary which is denoted by $d F$ for the element as a whole. The momentum equation then becomes

$$
-d P=\rho_{T P} V d V+\frac{d F}{A}+\rho_{T P} g d z
$$

Integrating equation 2.31 over the whole height of the pipe,

$$
\begin{aligned}
\int_{z_{1}}^{z_{2}} d \dot{Q}-\int_{z}^{z_{3}} d \dot{W} & =\dot{m}\left[\int_{h_{1}}^{h_{3}} d h+\int_{V_{1}}^{V_{2}} d\left(\frac{V^{2}}{2}\right)+g \int_{z_{1}}^{z_{3}} d z\right] \\
& =\dot{m}\left[\left(h_{2}-h_{1}\right)+\frac{1}{2}\left(V_{2}^{2}-V_{1}^{2}\right)+g\left(z_{2}-z_{1}\right)\right] \\
& =\dot{m}\left[h_{02}-h_{01}+g\left(z_{2}-z_{1}\right)\right]
\end{aligned}
$$

The terms in $\dot{Q}$ and $\dot{W}$ cannot be integrated without a knowledge of the functions $\dot{Q}=\dot{Q}(z)$ and $\dot{W}=\dot{W}(z)$. However, in the practical well $\dot{W}$ will only occur if a downhole pump, wherever located, accepts an energy input from outside the well. The term in $\dot{Q}$ is frequently taken to be zero either because heat gains and losses balance or more usually because $Q$ is small compared with $\dot{m} h_{1}$, i.e., the well operation is substantially adiabatic. The non-adiabatic case will be considered in section 2.6.1.4.

With these simplifications, equation 2.33 a reduces to

$$
h_{1}+\frac{V_{1}^{2}}{2}=h_{2}+\frac{V_{2}^{2}}{2}+g\left(z_{2}-z_{1}\right)
$$

In a two-phase mixture with slip, these quantities must be interpreted thus: $h$ is the sum of the enthalpies of the saturated liquid and the saturated vapor respectively which together comprise unit mass crossing a flow section at $z_{1}$ or $z_{2} \cdot V^{2} / 2$ is likewise the combined kinetic energy.

The kinetic energy terms are usually small in comparison with the remaining terms, or $\nabla_{1} \simeq V_{2}$ and equation 2.34 may assume the frequently-used approximate form

$$
h_{1}=h_{2}+g\left(z_{2}-z_{1}\right)
$$


Even for a deep low-temperature well the potential energy term $g\left(z_{2}-z_{1}\right)$ never exceeds about 5\% of the enthalpy $h$ and hence for rough work equation 2.35 is sometimes abbreviated to

$$
h_{1}=h_{2}
$$

Considering now the momentum equation 2.32 and integrating we obtain

$$
-\int_{P_{1}}^{P_{1}} d P=\int_{V_{1}}^{V_{2}} \rho_{T P} V d V+\frac{1}{A} \int_{z_{1}}^{z_{2}} d F+g \int_{z_{1}}^{z_{2}} \rho_{T P} d z
$$

The density $\rho_{T P}^{*}$ and the velocity $\nabla$ are both functions of $z$. If $\tau$ is the shear stress at the boundary and $f_{T P}{ }^{*}$ the two-phase coefficient of friction,

$$
d F=\tau \pi D d z=f_{t P} \frac{\rho_{T P}}{2} \pi D V^{2} d z
$$

Equation 2.37 may now be written

$$
P_{1}-P_{2}=\int_{V_{1}}^{V_{2}} \rho_{T P} V d V+\frac{2}{D} \int_{z_{1}}^{z_{1}} f_{r P \rho_{T P}} V^{2} d z+g \int_{z_{1}}^{z_{2}} \rho_{T P} d z
$$

If only the liquid phase is present at all levels in the well and its mean density is $\rho_{w}$, the velocity $\nabla$ is substantially constant if the bore diameter $D$ does not change. Equation 2.39 may then be adjusted to give

$$
\frac{P_{1}-P_{2}}{\bar{\rho}_{W}}=\frac{2}{D} f_{W} V^{2}\left(z_{2}-z_{1}\right)+g\left(z_{2}-z_{1}\right)
$$

where $f_{W}$ is the friction factor for liquid alone assumed constant. Equation 2.40 is the Bernoulli equation for an incompressible flow with friction.

2.6.1.2 Artesian flow in wells. A well may or may not be self-flowing depending upon whether the bottom hole pressure exceeds or is less than the accompanying hydrostatic pressure due to the overlying fluid column in the pipe. The excess pressure to promote self-flow will arise as a consequence of one or both of two factors which may act singly or together: (1) The height of the external water table, and (2) the mean density of the geofluid lying between the water table and the well base. Thus considering figure 2.26 let the height of the well column be $z_{W}=z_{2}-z_{1}$ and let the column mean density be $\bar{\rho}$ irrespective of how this density is attained by variations in a single- or two-phase mixture. Let the elevation of the water table be $z_{T}$ (shown conventionally with $z_{T}>z_{W}$ ) and let the mean external

"The two-phase density prp and the two phase friction factor $f_{T r}$ will be discussed later. It is here sufficient to notice that each quantity is quality- (i.e., dryness fractlon-) dependent, and its magnitude may be written in terms of the quality so as to embrace the complete quality range from saturated liquid to saturated vapor. 


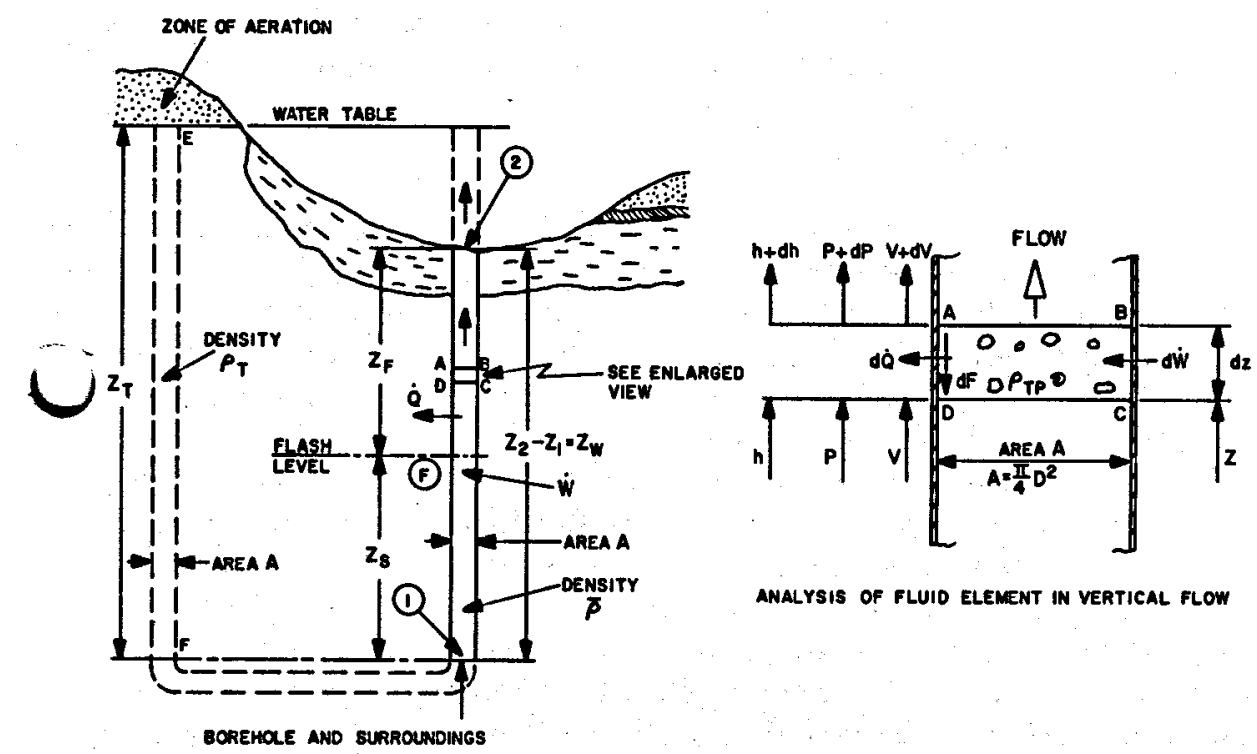

Figure 2.26-Analysis of vertical flow in a geothermal well.

liquid density be pr. An imaginary column EF of liquid of cross-sectional area $A$ equal to that of the well may be assumed connected to the well inlet as shown. Considering the well inlet, Section 1, the upward pressure due to the external column EF is

$$
P_{1}=\rho_{T} g z_{T}
$$

The closed-in pressure at the wellhead, section 2 , is less than $P_{1}$ by that generated by the well column, i.e.,

$$
\begin{aligned}
P_{2} & =\rho_{T} g z_{T}-\bar{p} g z_{W} \\
& =g\left(\rho_{T} z_{T}-\bar{p} z_{W}\right)
\end{aligned}
$$

The artesian action is governed by the quantity $\left(\rho_{T} z_{T}-\overline{\rho z}_{W}\right)$. If $\left(\rho_{T} z_{T}-\overline{\rho z}_{W}\right)>0$ the well will flow spontaneously. It is not necessary for the water table to be above the well exit for artesian action; it may be caused by density inequality. If $\left(\rho_{T} z_{T}-\bar{\rho}_{W}\right)>0$, then the well will flow upon opening the wellhead valve, the pressure $P_{2}$ will fall to compensate for the pressure losses associated with pipe friction and the generation of fluid kinetic energy in accordance with equation 2.39. The base pressure $P_{1}$ will also fall by an increment governed by the characteristics of the reservoir. In many wells the pressure $P_{1}$ is substantially equal to the hydrostatic pressure of the well column, i.e.,

$$
P_{1}=\bar{\rho} g z_{W}=\rho_{T} g z_{T}
$$

hence the well fills but does not flow. 
In the above treatment it was sufficient to define the height and mean density of the column EF. Both of these may depend upon a variety of external physical structures and conditions [Nathenson, 1974; Yuhara, 1970; Yuhara and Tomosada, 1965].

2.6.1.3 Phase change within the well. A hot liquid with a free surface will vaporize when the vapor pressure at the interface falls below the saturation value corresponding to the liquid temperature. However, when hot liquid is rising in a well no free surface is available when saturation conditions are reached, and a temporary metastable state ensues with the liquid becoming superheated. The duration of metastability is usually brief and is substantially terminated by the onset of vapor nucleation within the body of the liquid and at its boundaries. Thereafter thermal equilibrium will be continuously approached but never fully reached. No satisfactory criteria exist for calculating phase change rates in this context, and as the residual thermal disequilibrium is always likely to be small, it is conventional (and acceptable) to assume thermal equilibrium at all levels within the well including the two-phase vapor/liquid region. Thus above the flashing level, vaporization will continue with the mass flow dryness fraction increasing continuously until the wellhead is reached.

In the event that the flow is adiabatic $(\dot{Q}=0)$ and quasi-static and the entry temperature $T_{1}$ is known, the depth $z_{2}$ at which fiashing will occur can be calculated because $T_{1}$ defines the flashing pressure $P_{s 1}$. Provided therefore, that $d V \simeq 0$ and no pump is placed after section 1 (i.e., $d \dot{W}=0$ ) the momentum continuity equation between section 1 and the flash level reduces to

$$
P_{s 1}=P_{1}-\bar{p} w^{\prime} g\left(z_{W}-z_{F}\right)
$$

where $\bar{\rho}^{\prime}{ }^{\prime}$ is the mean liquid density for the part column below the flash level.

Equation 2.44 may be rearranged, with substitution from equation 2.43 to give

$$
z_{F}=z_{W}-\left(\frac{\rho_{T} z_{T}}{\bar{\rho}_{W}^{\prime}}-\frac{P_{S 1}}{\bar{\rho}_{W} g}\right)
$$

In the event that $z_{T}=z_{W}$ equation 2.45 reduces to

$$
z_{F}=\frac{P_{S 1}}{\bar{\rho}_{w^{\prime} g}}-z_{W}\left(\frac{\rho_{T}}{\bar{\rho}_{W}}-1\right)
$$

Some interesting implications of this expression are explored by Elliott [1977]. The subject of flash level is considered further in section 2.6.2.7.

2.6.1.4. The non-adiabatic roell. As stated above it is usual to assume that for the entire vertical bore

$$
\int_{21}^{22} d \dot{Q}=0
$$


but it is readily seen that conditions could arise in which this was not the case. Thus the ascending hot geofluid might traverse an aquifer of significant depth conveying a colder fluid, or a dry local intrusion at a temperature exceeding that of the lower formation reservoir being exploited.

In this event it may become necessary to resort to a finite interval solution, for which the equations 2.31 and 2.39 would take, for unit mass flowrate, the forms

and

$$
\Delta \dot{Q}-\Delta \dot{W}=\Delta h+\Delta\left(\frac{V^{2}}{2}\right)+g \Delta z
$$

$$
-\Delta P=\rho V \Delta V+\frac{2}{D} f_{\rho} V^{2} \Delta z+g_{\rho} \Delta z
$$

where $\Delta z$ is a finite dupth interval of arbitrary magnitude, and the friction coefficient $f$ and density $\rho$ are assigned appropriate values.

Mass continuity remains as

$$
\dot{m}=A_{\rho} \nabla
$$

To solve the coupled equations 2.47 through 2.49 , it is usual to start calculations from the well inlet. It is necessary to know $P_{1}, T_{1}, V_{1}$ and $A$; $h_{1}=h_{1}\left(T_{1}\right)$ and $\rho_{1}=\rho_{1}\left(P_{1}, T_{1}\right)$. It is thereafter necessary to know, for each depth increment $\Delta z$, the values of $\Delta \dot{Q}, \Delta \dot{W}$ and $f_{\text {Tp. }}$. The work transfer term $\Delta W$ will be zero except only at the location of a pump, if any. A given calculation sequence may be specific to the value of $\dot{m}$, because mass flowrate is functionally related to the drawdown and hence to $\boldsymbol{P}_{\mathbf{1}}$.

The calculation cannot proceed into the two-phase flow region unless values can be assigned to $f$. This raises the question of the flow pattern sequence and the locations within the well at which transitions of pattern occur.

The above procedure may be varied in detail, and computer solutions are usually sought [Nathenson, 1974; Austin, 1977; Elliot, 1975; Gould, 1974].

The object of a stepwise solution may be to establish certain inlet or other conditions which will promote a defined valuo of a property elsewhere (e.g., defined temperature at the wellhead). In such an event a guessed property may be used as input and the final result obtained by using iteration for progressive refinement.

2.6.1.5 The boiling point/depth curve. It is instructive to consider a nonflowing well in which the liquid is at boiling temperature throughout the column height. In this case if a diametral plane at a given depth in the liquid is considered there will be a single value of hydrostatic pressure due to the overlaying column and a corresponding value of boiling point temperature. The variation of boiling temperature with depth for a column of pure water saturated at all depths is shown in figure 2.27 together with 
PRESSURE

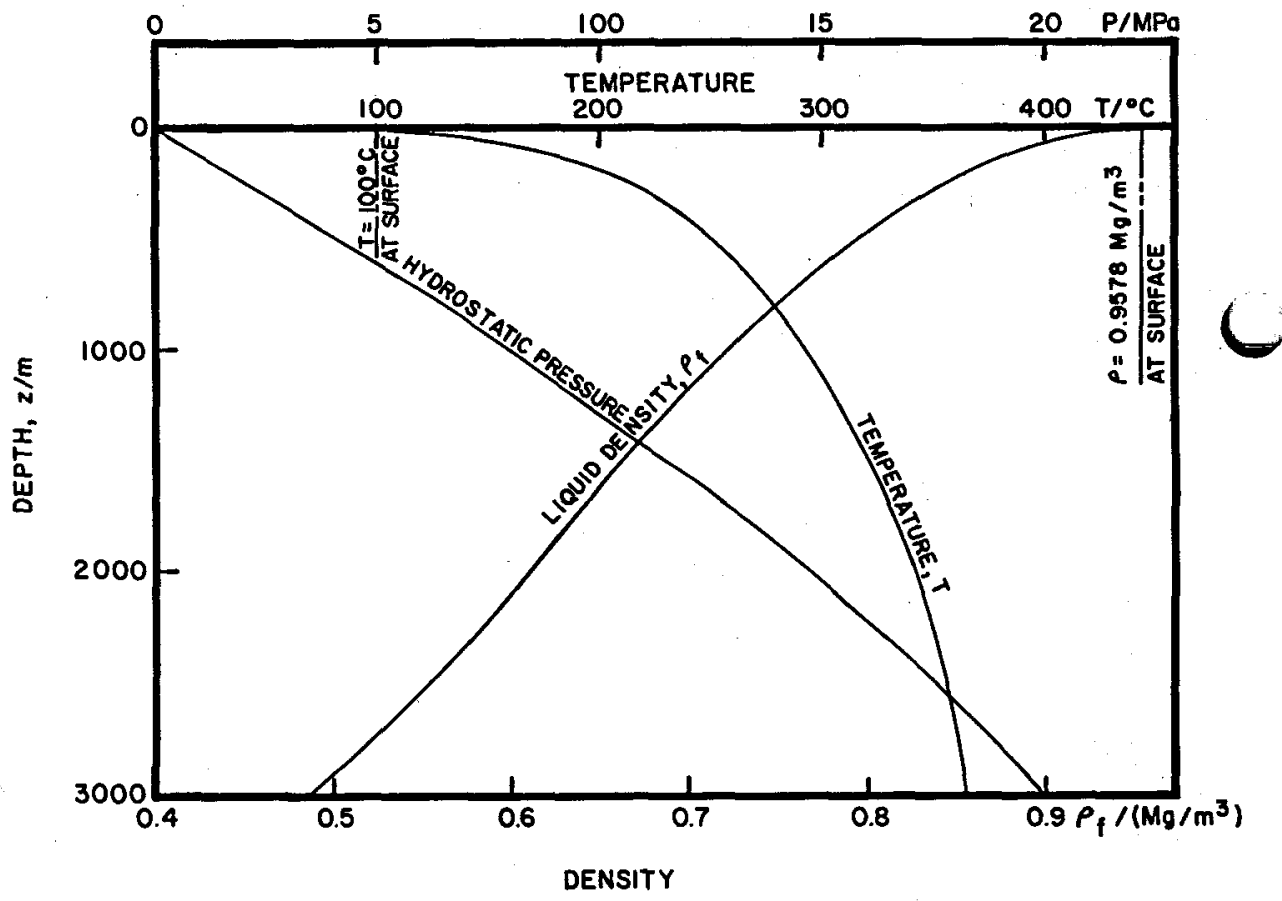

FIgURe 2.27-Temperature, hydrostatic pressure and liquid density for a pure water column saturated at all levels.

the pressure and density. It is seen that the temperature gradient is high it shallow levels but declines at deeper levels; also that the density decreases continuously towards the wellbottom. Any column of this type is thus in convective disequilibrium as is any column in which fluid of high density overlies fluid of lower density; hence most non-flowing columns have internal convection currents generated by the earth's temperature gradient (see section 2.2.2). Owing to the convective overturn and the low temperature/depth gradient at great depths there is virtually a constant temperature in this locality, frequently referred to as the "base temperature."

The boiling point/depth curve is modified for a liquid column containing dissolved salts. Figure 2.28 shows a family of such curves for water with various sodium chloride concentrations.

The boiling point/depth curve for pure water was calculated for a standard atmospheric pressure over the free surface, using finite depth intervals and tabulated thermodynamic properties. Down to a depth $z$ of $2 \mathrm{~km}$ the temperature/depth relation is given to within $\pm 1^{\circ} \mathrm{C}$ by the relation

$$
T=a z^{4}+b z^{3}+c z^{2}+d z+e
$$


TEMPERATURE

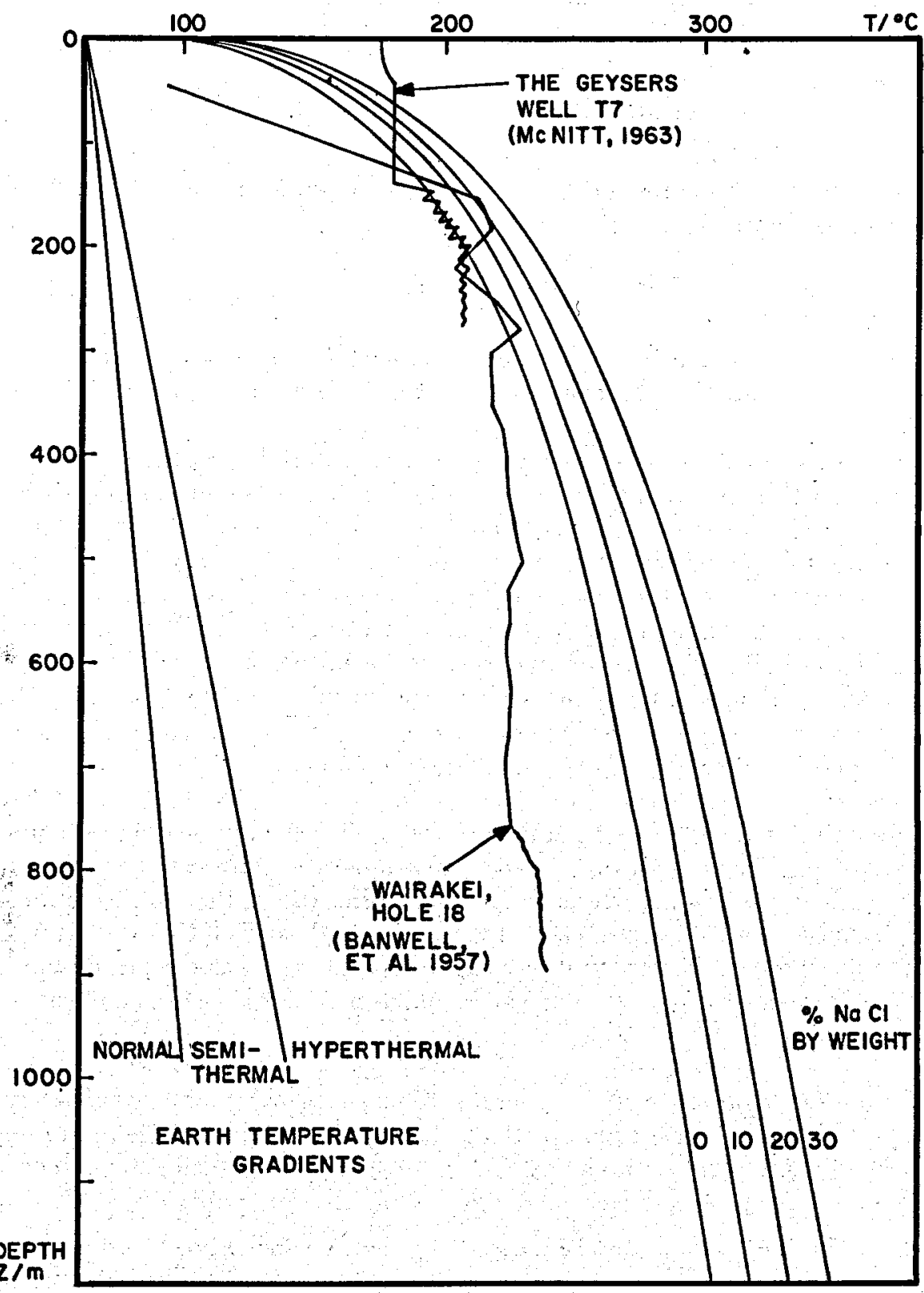

Frgore 2.28-Temperature v8. depth: Miscellaneous curves in earth and in brine. 
Where $T$ is in ${ }^{\circ} \mathrm{C}$ and $z$ is in meters, and the coefficients are

$$
\begin{aligned}
& a=-6.26862 \times 10^{-9}{ }^{\circ} \mathrm{C} / \mathrm{m}^{4} \\
& b=1.97471 \times 10^{-5}{ }^{\circ} \mathrm{C} / \mathrm{m}^{3} \\
& c=-1.54359 \times 10^{-2}{ }^{\circ} \mathrm{C} / \mathrm{m}^{2} \\
& d=2.15416{ }^{\circ} \mathrm{C} / \mathrm{m} \\
& e=100.0^{\circ} \mathrm{C}
\end{aligned}
$$

An alternative expression has been given by James [1970]. After conversion for depths in meters it reads

$$
T=69.56 z^{0.2085}
$$

where $T$ is ${ }^{\circ} \mathrm{C}$ and $z$ is in meters. The water surface temperature is assumed to be $100^{\circ} \mathrm{C}$ and the equation applies over the depth range $z=30 \mathrm{~m}$ to $3,050 \mathrm{~m}$.

Temperature/depth curves may be taken in a well during the process of drilling, when the completed well is filled with water and has remained static for a longer or shorter period, or while the well is flowing. Temperatures taken during drilling may be misleading and have been discussed in section 2.2.2. Most measurements are made on static closed-in wells [e.g., J. H. Smith, 1970], and the temperature/depth profile tends to lie within the boiling point/depth curve. Some explanations of the shapes assumed by temperature/depth curves are given by Vakin et al. [1970].

Figure 2.28 displays two anomalous temperature/depth curves taken with closed wells. That taken at Wairakei Hole 18 was taken after an elapsed time of 101 days in geofluid having dissolved solids of $0.38 \%$ by weight, and it reflects the general characteristics of temperature gradients in this area. There is a rapid increase in temperature down to the base of the confining sandstone where the temperature exceeds the boiling point/ depth value. The other curve was taken at well T7 at The Geysers after a lapse of 60 days. The constant value of temperature from a depth of 40 to $130 \mathrm{~m}$ indicates the existence of vapor which pressure measurements show to be saturated.

2.6.1.6 The pumped well. For reasons discussed below it may be necessary to provide a well with a pump. It has been pointed out that there are no thermedynamic criteria involved in choosing the pump location, but several other factors that must be considered include the following:

(1) The pump must be located at a depth sufficient to avoid cavitation at all loads. It will be shown in section 2.6.2.7 that as the mass flow from a well increases the depth to the flash level falls, and the pump location must ensure freedom from cavitation on full load.

(2) Whatever type of pump is employed it will have service connections with the surface, and the cost of these will increase with pump depth. 
(3) The cost and time of pump removal for servicing will increase as the pump depth increases.

A well may be pumped for one or more of the following reasons:

(a) To promote a flow in the absence of artesian action.

(b) To increase the flowrate in order to augment the well capacity. In this case it is also necessary to take account of the liquid supply to the wellbottom to ensure its adequacy. The drawdown characteristics of the reservoir must be examined lest the pump defeat its own purpose. This subject will be considered further in section 2.6.2.

(c) To suppress flashing within the wellbore. Boiling may cause the precipitation of solids which adhere to the bore and cause a progressive restriction on the mass flow. Suppression of flashing may also prevent limitation of the mass flowrate arising from vapor or vaporliquid choking at $a$ later stage in the flow.

It is convenient to consider these cases separately.

(1) Suppose the well is at rest and that the external conditions of water table level and ground water density are such that the well level is in equilibrium at a depth $z_{E}$ below the surface. Then for a frictionless flow without acceleration the minimum impellor work $W_{p}$ needed to pump the liquid to the surface is, for a mass flowrate $\dot{m}$

$$
\dot{W}_{p}=\dot{m} g z_{E}
$$

(2) If the impellor work exceeds $\dot{W}_{p}$ and the pump suction pressure were to remain unchanged, then the flowrate $\dot{m}$ would rise. In general $\dot{m}$ will rise and the suction pressure decline as $\dot{W}_{p}$ increases until the well reaches the maximum flowrate it can sustain.

(3) If flashing is to be prevented it is necessary to ensure that the fluid pressure exceeds the saturation value for the associated temperature until the location is reached where flashing is required or is acceptable. If flashing is to be suppressed until the exit from the wellbore, then the minimum excess pressure the pump must generate is that equivalent to the hydrostatic pressure increment above the flash level. If the liquid density above the flash level has then a mean value of $\bar{\rho}_{a}$ this minimum excess pressure will be

$$
\Delta P=\bar{\rho}_{s} g z_{F}
$$

which will have to be increased in practice to cover flow losses.

For the pumped well a step-rise occurs in the pressure as the liquid traverses the pump. Equation 2.40 can no longer be applied. Two Bernoulli equations are now required, one for the well section below the pump and the other for the well section above the pump. Denoting the suction and delivery pressures by $P_{i}$ and $P_{e}$ and the mean densities of the lower and 
upper columns by $\bar{\rho}_{L}$ and $\bar{\rho}_{H}$, the respective Bernoulli equations now become

and

$$
\frac{P_{1}-P_{t}}{\bar{\rho}_{L}}=\frac{2 \bar{f}_{L} z_{s} V^{2}}{\bar{D}}+g z_{s}
$$

$$
\frac{P_{e}-P_{2}}{\bar{\rho}_{H}}=\frac{2 \bar{f}_{H} z_{F} V^{2}}{D}+g z_{F},
$$

where $\bar{f}_{L}$ and $\bar{f}_{H}$ are the respective mean values of friction coefficient.

Wells may be pumped by means other than rotodynamic downhole pumps. The principle of one such method is shown in figure 2.29. Nitrogen or other inert gas is forced down the well to displace the liquid trapped above a check valve. When the liquid has been removed the containment volume is vented and the check valve opens to recharge it. A variant of this

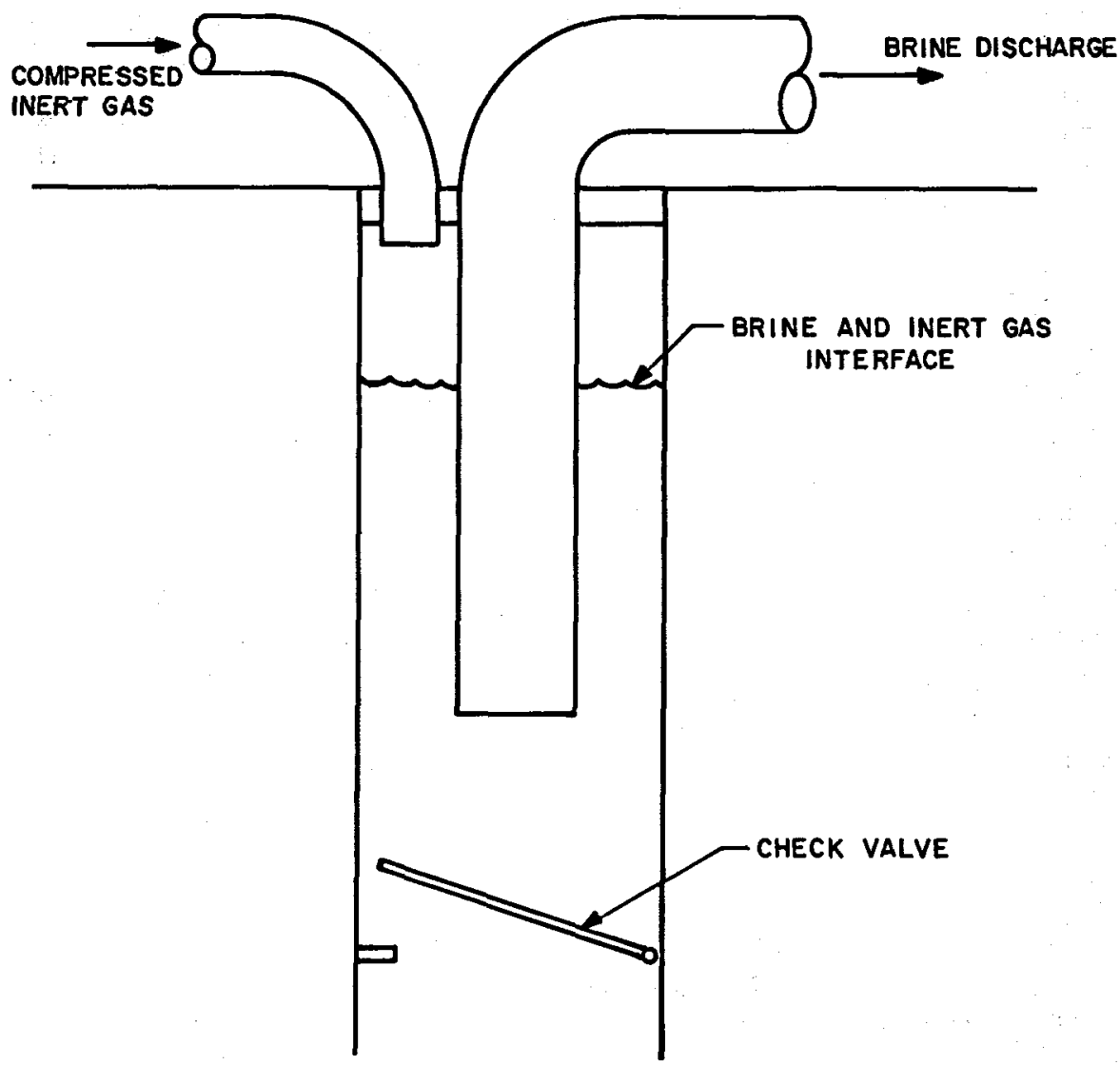

Figure 2.29-Well pumping by compressed gas. 
method is to inject the gas continuously at the wellbottom to provide buoyancy throughout the full column height [Elliott, 1977].

\subsubsection{Oharacteristics of the combined well-reservoir system}

The subject of drawdown was treated in section 2.2.5, and plots were presented showing the rate at which the drawdown pressure difference $\left(P_{s}-P_{1}\right.$, for this present section) for a particular well responded to time under a demand for a modified but thereafter constant mass flowrate. For this well the period of the transient, i.e., the elapsed time before the well-reservoir system regained stability was many hours. The recovery time is clearly related to the permeability of the formation, the geofluid viscosity and hence the base temperature, the closed-in pressure, and other features of the system. Every well has its own drawdown characteristics.

In the treatment to follow it is assumed that the drawdown is constant, i.e., the well is not operating within the period of the transient.

2.6.2.1 Single-phase (liquid) self-flowing system. In the foregoing sections analysis has been confined to the vertical pipe, and no cognizance has been taken of the aquifer from which it draws its supply. It is clear; however, that aquifer and pipe are not independent. Thus if the flow within the pipe increases, the pressure at the pipe inlet will fall and the extent of the pressure reduction will depend upon the freedom of flow of the geofluid through the formation, i.e., upon the height and permeability of the reservoir. Consider figure 2.30 which shows a cylindrical reservoir with a radius $R$ and a depth $L$. Applying Darcy's Law (section 2.2.4.1) to an elemental sleeve of thickness $d x$ across which the fluid pressure increment is $d P$, the mass flow is

or

$$
\dot{m}=\frac{-K 2 \pi R L \rho_{3}}{\mu} \frac{d P}{d x}
$$

$$
-\frac{d P}{\dot{m}}=\frac{\mu}{2 \pi K L \rho_{3}} \frac{d x}{x}
$$

For the conditions shown this integrates to give

$$
\dot{m}=\frac{2 \pi K L_{\rho_{3}}}{\mu} \frac{\left(P_{3}-P_{1}\right)}{\ln \frac{R}{r}}
$$

From a practical standpoint equation 2.56 is difficult to use. The radius $R$ of the reservoir is indeterminate, and indeed the reservoir will probably not be cylindrical. The quantities $K$ and $\mu$ may not be accurately known. However, the increase in $P_{3}-P_{1}$ consequent upon an increase in 


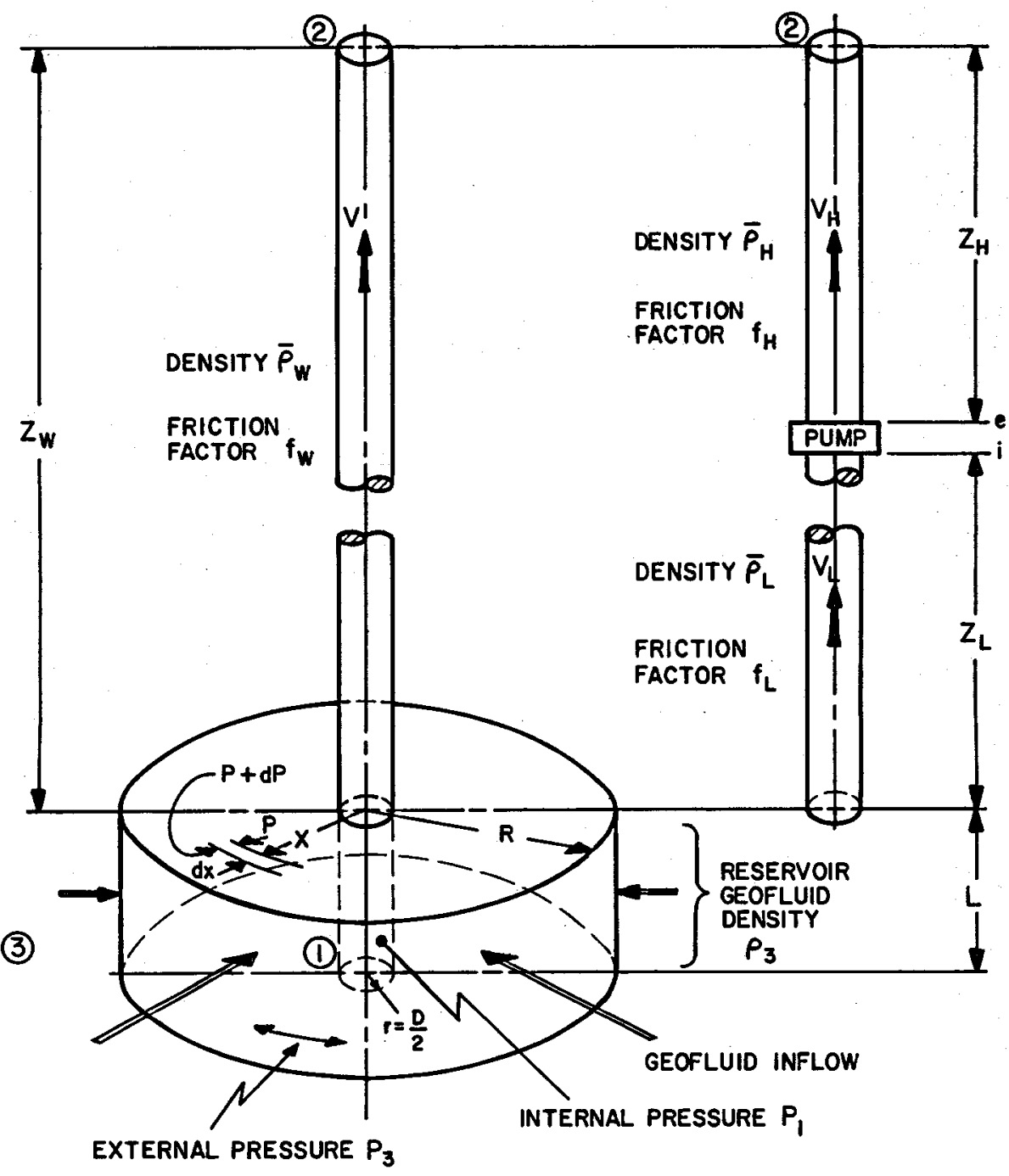

(a)

(b)

FIGURE 2.30-The well and associated reservoir: (a) No pump; (b) well pumped.

the flowrate $\dot{m}$ is readily found from wellhead observations, and equation 2.56 can be transposed thus:

$$
\frac{P_{3}-P_{1}}{\dot{m}}=\frac{\mu \ln \frac{R}{r}}{2 \pi K L_{\rho_{3}}}
$$

The quantity $\left(P_{3}-P_{1}\right) / \dot{m}$ is the reduction in wellbottom pressure below reservoir pressure per unit flowrate and is known as the drawdown pres- 
sure coefficient. The subject of drawdown transient was treated in section 2.2.5 and mentioned again briefly in section 2.6.2. The following analysis assumes that the drawdown coefficient $\left(P_{3}-P_{1}\right) / \dot{m}$ has attained its stable value and is no longer time-dependent.

We may now consider the self-flowing well-reservoir system shown in figure $2.30 \mathrm{a}$ and we will assume for the present that no phase change takes place. Applying equation 2.40 for the well pipe we have

$$
P_{2}=P_{1}-\frac{2 \bar{\rho}_{W} f_{W} V^{2} z_{W}}{D}-\bar{\rho}_{W} g z_{W}
$$

For the reservoir, the Darcy equation 2.57 gives, for the steady flow case,

$$
\dot{m}=\frac{2 \pi K L_{\rho_{3}}}{\mu} \frac{\left(P_{3}-P_{1}\right)}{\ln \frac{R}{r}}
$$

which may be transposed to give

$$
P_{1}=P_{3}-\frac{\mu \dot{m} \ln (R / r)}{2 \pi K L p_{8}}
$$

Combining equations 2.58 and 2.59 and observing from mass continuity that

$$
\begin{gathered}
V=4 \dot{m} / \pi D^{2} \bar{\rho}_{W} \\
P_{2}=P_{3}-\dot{m}\left(\frac{\mu}{\rho_{3}}\right)\left(\frac{1}{K L}\right) \frac{\ln (R / r)}{2 \pi}-\dot{m}^{2}\left(\frac{1}{\bar{\rho}_{W}}\right)\left(\frac{f_{W} z_{W}}{D^{5}}\right) \frac{32}{\pi^{2}}-\bar{\rho}_{W} g z_{W}
\end{gathered}
$$

Inspection shows that $P_{2}$ is a quadratic in $\dot{m}$. The quantities

are geofluid properties,

$$
\left(\frac{\mu}{\rho_{3}}\right) \text { and }\left(\frac{1}{\bar{\rho}_{W}}\right)
$$

$$
\left(\frac{1}{K L}\right)
$$

is an aquifier property, and

$$
\left(f_{w} z_{w} / D^{8}\right)
$$

is a wellpipe property. The terms on the right-hand side of the equation are pressure drop increments due, in order, to drawdown, pipe flow friction, and hydrostatic head.

2.6.2.2 Wellhead pressure-flow rate characteristic for a self-flonoing liquid well. Consider a well for which $z_{w}=1500 \mathrm{~m}(4921 \mathrm{ft}), L=300 \mathrm{~m}$ 
(984 ft), $D=0.254 \mathrm{~m}$ (10 in. pipe), $R / r$ is taken to be 500 , and the temperature at the well bottom is $220^{\circ} \mathrm{C}\left(428^{\circ} \mathrm{F}\right)$, chosen to avoid flashing within the pipe. We require the flow characteristics of this well for formation permeabilities 5 and 50 md and friction factors $f_{W}=0.004,0.008$, and 0.015 . The closed-in pressure is assumed to be $2.5 \mathrm{MPa}\left(363 \mathrm{lb} / \mathrm{in}^{2}\right)$, and the geofluid is taken to be pure water.

Stated in SI units, equation 2.60 yields

$$
P_{2}=25 \times 10^{5}-\dot{m}\left[\frac{4.8 \times 10^{5}}{K}\right]-5474.4 f_{W} \dot{m}^{2}
$$

Curves calculated from equation 2.61 are plotted in figure 2.31. The mass flow is observed to be very sensitive to the permeability of the aquifer formation and much less sensitive to the friction factor, especially at the lower permeability. A plot of viscosity $\mu$ with temperature for saturated water is shown in figure 2.32 over the full range of normal exploitable aquifer temperatures, and a high base temperature will be seen to provide some compensation for a low permeability. The range of permeability in rocks and soils is very large and ranges from $10^{8}$ md for clean gravel to $10^{-5} \mathrm{md}$ for certain types of granite. Drawdown pressure difference, $P_{3}-P_{1}$, is also shown in figure 2.31.

2.6.2.3 Single-phase (liquid) pumped system. Equation 2.60 may readily be extended to include the introduction of a downhole pump, as shown in the part diagram figure $2.30(\mathrm{~b})$. The main effect of the pump is to introduce a step change in the pressure, $\Delta P=P_{e}-P_{i}$, and to increase the velocity through the pipe. Treating, for the moment, the upper and lower sections separately, equations 2.58 and 2.59 may now be adjusted to read

$$
\begin{aligned}
P_{2}=P_{3}-\dot{m}\left(\frac{\mu}{\rho_{3}}\right)\left(\frac{1}{K L}\right) \frac{\ln (R / r)}{2 \pi}-\frac{2}{D}\left(\bar{\rho}_{L} \bar{f}_{L} V_{L}^{2} z_{L}+\bar{\rho}_{H} \bar{f}_{H} V_{H}^{2} z_{H}\right) \\
\\
-g\left(\bar{\rho}_{L} z_{L}+\bar{\rho}_{H} z_{H}\right)+\Delta P
\end{aligned}
$$

The change in density across the pump is small and so therefore is the change in velocity. The friction factor is dependent on the Reynolds number and both remain approximately constant. Equation 2.62 therefore reduces to equation 2.60 modified by the pump pressure increment term, i.e.,

$$
P_{2}=P_{3}-\dot{m}\left(\frac{\mu}{\rho_{3}}\right)\left(\frac{1}{K L}\right) \frac{\ln (R / r)}{2 \pi}-\dot{m}^{2}\left(\frac{1}{\bar{\rho}_{W}}\right)\left(\frac{f_{W} z_{W}}{D^{5}}\right) \frac{32}{\pi^{2}}+\Delta P-\bar{\rho}_{W} g z_{W}
$$

The sum of the constant terms in equation 2.63 now exceeds those in equation 2.60 with the effect of lifting the parabolic curve for $P_{2}$ and enhancing the mass flow $\dot{m}$. The pump load-head characteristic can be included by incorporating $\dot{m}=\dot{m}(\Delta P)$ in equation 2.63. The increased veloc- 


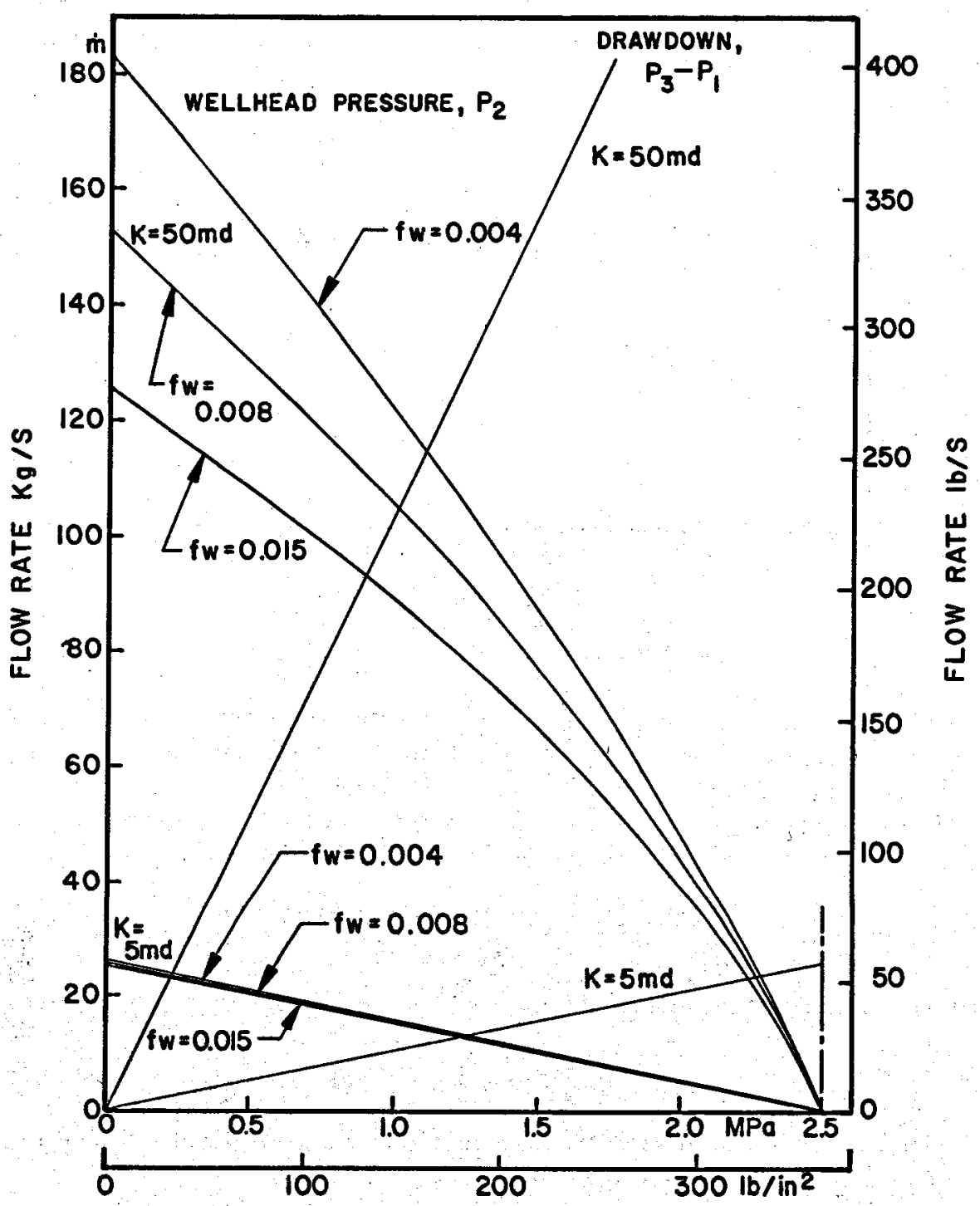

Fiauke 2.81-Flow rate, wellhead pressure and drawdown for self-flowing well.

ity will concurrently increase $f_{w}$ with a consequent fall in $P_{1}$ and an increase in drawdown to match the increased mass flow. As pointed out in section 2.6.1.6, $P_{i}$ must remain sufficiently high to avoid cavitation.

2.6.2.4 The two-phase self-flowing well. We now consider the case of the self-flowing well in which flashing occurs at some point within the pipe. It is assumed that hot water is delivered from the reservoir into the bottom of the pipe and that the upward flow is every where in thermal equilibrium 


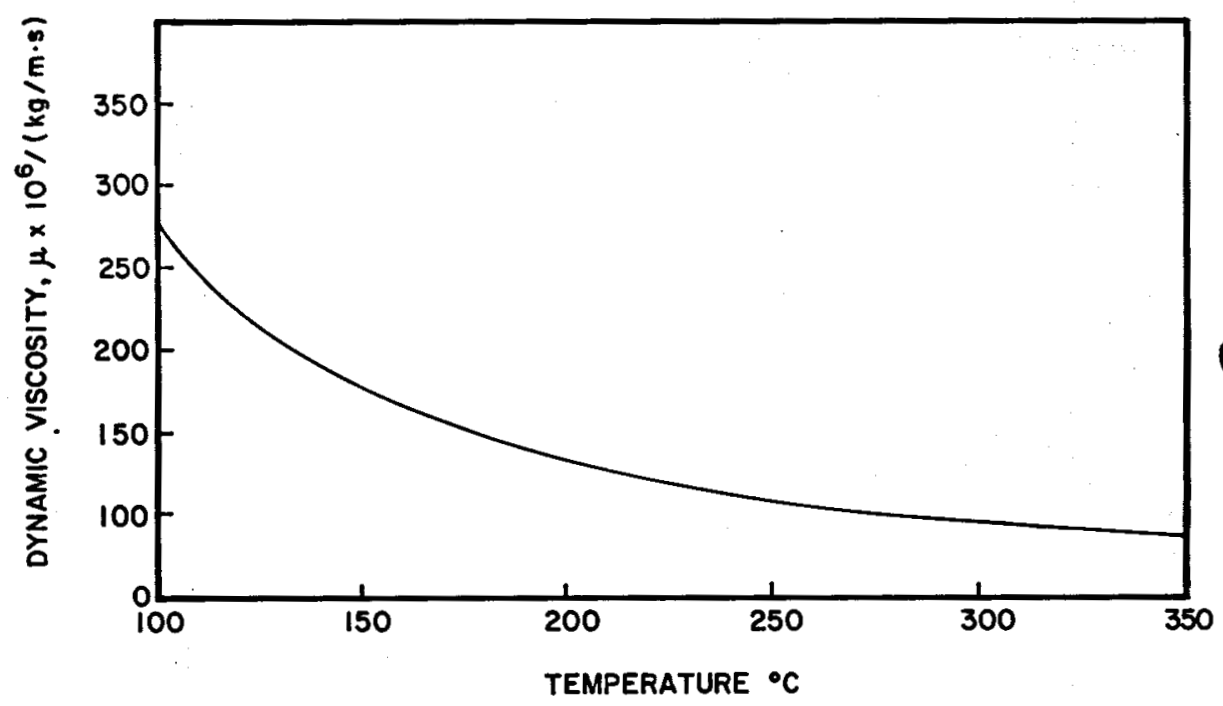

FraUre 2.32-Viscosity of pure saturated water.

so that flashing commences at the level at which the liquid becomes saturated. The sections of pipe above and below the flash level may be considered separately .

Referring to figure 2.33 (a) and denoting the single-phase properties by the subcript $S P$, we obtain from equation 2.33 for momentum continuity

$$
P_{1}-P_{F}=\int_{V_{1}}^{V_{r}} \rho_{S P} V d V+\frac{2}{D} \int_{z_{1}}^{z_{F}} f_{S P} \rho_{S P} V^{2} d z+g \int_{z}^{2 r} \rho_{S P} d z
$$

Since $\rho_{S P}$ is substantially constant over the height $z_{F}-z_{1}=z_{B}$, this gives

$$
\mathbb{P}_{1}-P_{F}=\frac{2}{D} f_{S P} \rho_{S P} V_{1}^{2} z_{S}+g \rho_{S P} z_{S}
$$

For the section above the flash level the acceleration term must be included and the corresponding equation is

$$
\begin{aligned}
P_{F}-P_{2} & =\int_{V r}^{V_{2}} \rho_{T P} V d V+\frac{2}{D} \int_{z p}^{z_{2}} f_{T P} \rho_{T P} V^{2} d z+g \int_{z_{P}}^{z_{2}} \rho_{T P} d z \\
& =\bar{\rho}_{T P} \frac{\left(V_{2}^{2}-V_{1}^{2}\right)}{2}+\frac{2}{D} \bar{f}_{T P} \bar{\rho}_{T P} \bar{V}^{2} z_{F}+g \bar{\rho}_{T P} z_{F}
\end{aligned}
$$

where the bar denotes the effective mean value of quantities that vary along $z_{F}$. Adding equation 2.64 and 2.65:

$P_{1}-P_{2}=\bar{\rho}_{T P} \frac{\left(V_{2}^{2}-V_{1}^{2}\right)}{2}+\frac{2}{D}\left(f_{S P} \rho_{S P} V_{1}^{2} z_{S}+\bar{f}_{T P} \bar{\rho}_{T P} \bar{V}^{2} z_{F}\right)+g\left(\rho_{S P} z_{S}+\bar{\rho}_{T P} z_{F}\right)$ 

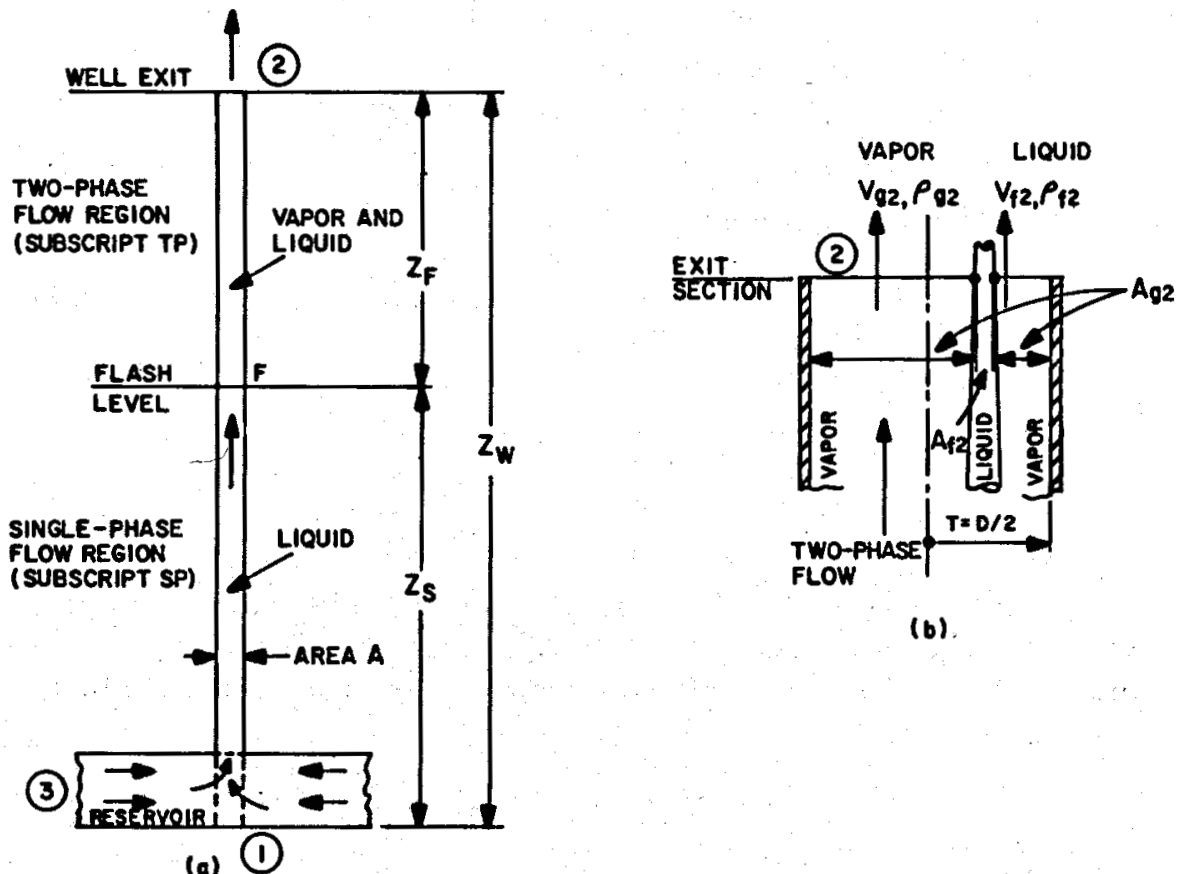

(b)

FraUk 2.33-The self-flowing flashing well : (a) Diagram showing general notation;

(b) notation at the wellhead where the equivalent flaments cross the well exit.

For energy continuity the full expression is given in equation $2.33 \mathrm{a}$; but to make the present analysis manageable the well will be assumed to be adiabatic and the approximate equation 2.36 will be employed, leading to

$$
x_{2}=\frac{h_{f 3}-h_{f 2}}{h_{f 2^{2}}}
$$

If the well exit, section 2 , is now considered we may concentrate, for the purpose of modeling, the vapor fraction $x_{2}$ and the liquid fraction $\left(1-x_{2}\right)$ into two discrete filaments (figure 2.33b) which have velocities and flow areas given respectively by $V_{22}, A_{92}$ and $V_{f 2}, A_{f 2}$. The dryness fraction is by definition*

$$
x_{2}=A_{g 2} V_{g 2} \rho_{g 2} /\left(A_{g 2} V_{g 2} \rho_{g 2}+A_{f_{2}} V_{\left.s_{2} \rho_{f 2}\right)}\right. \text {, }
$$

where $\rho_{g 2}$ and $\rho_{f_{2}}$ are respectively the saturation values of density for vapor and liquid at the exit pressure $\boldsymbol{P}_{\mathbf{2}}$.

The flow area is

$$
A=\pi D^{2} / 4 \text {, }
$$

and the area occupied only by the liquid filament is

$$
A_{f_{2}}=A-A_{82} \text {. }
$$

*This is the mass flow dryness fraction. 
The vapor velocity $V_{g 2}$ will normally exceed the liquid velocity $\nabla_{f 2}$, and the ratio $k_{2}$ is defined as the slip ratio

$$
k_{2}=V_{82} / V_{s 2}
$$

Equation 2.68 may be written in the form

$$
x_{2}=1 /\left(1+\left[A-A_{g 2}\right] \rho_{\rho 2} / A_{g 2} k_{2} \rho_{g 2}\right) .
$$

Mass continuity yields

$$
\dot{m}=\frac{\pi}{4} D^{2} \rho_{S P} V_{1}=A_{82} V_{g 2} \rho_{g 2}+\left(A-A_{g^{2}}\right) V_{g 2} \rho_{s 2} / k_{2} .
$$

Inspecting equation 2.66 it is necessary to consider more closely the quantities $\nabla_{2}, \bar{\rho}_{T P}, \bar{f}_{T P}$, and $\bar{V}$ all of which refer to the two-phase regime, Thus $V_{2}$ is a notational exit velocity for a homogeneous flow $\left(k_{2}=1\right)$ which would transport the same total exit kinetic energy that is conveyed by the phases; hence

$$
V_{2}^{2} / 2 g=x_{2} V_{g 2}^{2} / 2 g+\left(1-x_{2}\right) V_{f 2}^{2} / 2 g,
$$

which from equation 2.71 gives

$$
V_{2}=V_{g 2}\left(x_{2}+\left[1-x_{2}\right] / k_{2}^{2}\right)^{1 / 2} .
$$

The remaining quantities present grave difficulties which will be explored later (section 2.6.3) in more detail. For the present purpose we may acceptably define the mean two-phase density assuming that $x_{2}$ increases linearly with $z$ over the length $z_{F}$; thus:

$$
\bar{\rho}_{T P}=\frac{1}{2}\left(\rho_{S P}+x_{2} \rho_{g 2}+\left[1-x_{2}\right] \rho_{\rho 2}\right) .
$$

The effective friction factor $\bar{f}_{T P}$ will exceed $f_{S P}$ as a consequence of the enhanced velocity in the section $z_{p}$, and its value will depend upon the variation of $x$ between stations $F$ and 2. It is also dependent upon the prevailing pattern of association between the phases and cannot be stated in terms of the quantities already defined. For the same reason the effective velocity $\bar{\nabla}$ for defining the two-phase friction loss is obscure.

Combining equations 2.66 through 2.75 and including the drawdown term, the momentum equation analogous to equation 2.60 becomes

$$
\begin{aligned}
P_{2}=P_{3} & -\left\{\frac{\dot{m} \mu \ln (R / r)}{2 \pi L K \rho_{w 3}}\right\}-\left\{\frac{\bar{\rho}_{T P}}{2}\left[\left(x_{2}+\left[1-x_{2}\right] / k_{2}{ }^{2}\right) C_{1}^{2} \dot{m}^{2}-C_{2}{ }^{2} \dot{m}^{2}\right]\right\} \\
& -\frac{2}{D}\left\{f_{S P} \rho_{S P} z_{S} C_{2}{ }^{2} \dot{m}^{2}+\bar{f}_{T P} \bar{\rho}_{T P} z_{F} \bar{V}^{2}\right\}-g\left\{\rho_{S P} z_{S}+\bar{\rho}_{T P} z_{T}\right\}
\end{aligned}
$$


in which

where

$$
V_{82}=C_{1} \dot{n}
$$

$$
\begin{gathered}
C_{1}=\left(\rho_{\rho_{2}}+k_{2} \rho_{\varepsilon^{2}}\left[\frac{1}{x_{2}}-1\right]\right) x_{2} / A \rho_{\rho 2 \rho_{g^{2}},} \\
C_{2}=4 / \pi D^{2} \rho_{S P}, \quad \bar{\rho}_{T P}=\frac{1}{2}\left(\rho_{S P}+x_{2} \rho_{g^{2}}+\left[1-x_{2}\right] \rho_{\rho_{2}}\right)
\end{gathered}
$$

For a given well, depth $z_{W}=z_{F}+z_{s}$, diameter $=D=2 r$, reservoir pressure $=P_{3}$ and drawdown $=P_{3}-P_{1}$, if the bottomhole temperature is known, $h_{f_{3}}$ is defined. If, also, an arbitrary value of $P_{2}$ is assumed, then $\rho_{/ 2}$ and $\rho_{g 2}$ are defined, $x_{2}$ can be found from equation 2.67 , and $\bar{\rho}_{T P}$ from equation 2.75 . For the given well, equation 2.76 now reduces to the form

$$
P_{z}=A-B \dot{m}-\phi\left(k_{2}, \vec{f}_{T P}, f_{B P}\right) \dot{m}^{2}
$$

where $A$ and $B$ are constants and $\phi$ denotes a function of the remaining variables $k_{2}, \bar{f}_{T P}, f_{B P}$. If suitable values can be assigned to these quantities, equation 2.77 becomes, as for the single-phase well, a quadratic equation in $\dot{m}$. This can be solved and will be found to give a single valid value for the flowrate $\dot{m}$. The equation may also be used to explore the effects of changes in the magnitudes of $\bar{f}_{T P}, f_{B P}$, and $k_{2}$ on the flowrate. Following solution for $\dot{m}$, resubstitution yields the corresponding values of $V_{q 2}, V_{t 2}$, $V_{2}, A_{g_{2}}$ and $A_{f_{2}}$.

It is not necessary to base the analysis exclusively on the exit section 2 in the manner described above. The equivalent filament method may be employed for any arbitrary flow section within the two-phase region. This permits the use of a finite interval method for the two-phase sector of the flow and a step-by-step adjustment of $k_{2}, \vec{f}_{r P}$ and $f_{\mathrm{sp}}$.

It will be observed that it is not necessary to assume any particular two-phase flow pattern in the above analysis because the arguments arising out of equation 2.68 are not applicable only to grossly separated flow. If, of course, the flow patterns are known and empirical data available for $\bar{f}_{T P}$, then the predictive value of the theory is enhanced.

Further discussion of friction factors in two-phase flow will be found in section 2.6.4.5.

2.6.2.5 Wellhead characteristics for a self-flowing flashing well. The following data are based upon an actual well, but the flow is assumed to be pure water.

Reservoir temperature, $T_{3}=275^{\circ} \mathrm{C}\left(527^{\circ} \mathrm{F}\right)$; depth $z_{W}=1520 \mathrm{~m}(4987$ ft.); diameter $D=0.178 \mathrm{~m} \mathrm{(7} \mathrm{in);} \mathrm{drawdown} \mathrm{factor} 22.8 \mathrm{kPa} / \mathrm{kg} \mathrm{s}^{-1}$ $\left(1.5 \mathrm{lb} \mathrm{in}^{-2} / \mathrm{lb} \mathrm{s}^{-1}\right)$; closed-in pressure $3.4 \mathrm{MPa}\left(493 \mathrm{lb} / \mathrm{in}^{2}\right)$. 
The calculation procedure was as follows. An arbitrary value of wellhead pressure $P_{2}$ was chosen enabling $x_{2}$ to be calculated from equation 2.67 and defining $\rho_{f_{2}}$ and $\rho_{g_{2}} . \nabla_{2}$ is then expressed in terms of $x_{2}, k_{2}$ from equation 2.71, and $\overline{\rho_{T P}}$ from equation 2.75. Employing equations 2.69 through 2.74 enables $V_{2}$ to be expressed as a function of $\dot{m}, k_{2}, x_{2}, A_{2}$, and fluid properties, but since the latter three are already defined, $V_{2}$ becomes a function only of variables $\dot{m}$ and $k_{2} . V_{1}$ is immediately related to $\dot{m}$ by mass continuity, and $\bar{V}$ is obtained with sufficient accuracy by

$$
\bar{V}=\frac{\dot{m}}{2 A}\left(\frac{1}{\bar{\rho}_{T P}}+\frac{1}{\rho_{S P}}\right)
$$

The flash depth $z_{p}$ was determined from equation 2.46 , taking $\rho_{T}=\bar{\rho}_{W}=\rho_{S P P}$, and it was assumed constant with $P_{2}$. It will be shown in section 2.6.2.7 that this is not the case; the flash level moves down somewhat as $\dot{m}$ increases.

It is now possible to construct equation 2.76 in which $k_{2}, f_{S P}, \bar{f}_{T p}$, and $\dot{m}$ remain as unknowns. The value of 0.008 was assigned to $f_{S P}$ and $\bar{f}_{T P}$ for the purpose of this example, and used for all values of $P_{2}$. The variation of $k_{2}$ was explored and within its likely range of values was not found to be very significant. An arbitrary value was therefore chosen as displayed on figure 2.34. A quadratic equation in $\dot{m}$ now results which yields a unique positive value for $\dot{m}$. The remaining quantities of interest can be calculated by resubstitution as required.

The above procedure was repeated through a series of arbitrary values of $P_{2}$ and gave the results shown in figure 2.34 which may now be appraised.

As the wellhead valve is opened, the flowrate $\dot{m}$ rises rapidly with the fall in $P_{2}$ to high values of $P_{2}$, but the slope $d \dot{m} / d P_{2}$ declines as the value of $\dot{m}$ attains a constant value at about $0.75 \mathrm{MPa}$. At lower values of $P_{2}$ the $\dot{m}$ curve would pursue the dotted path but for the intervention of choking. Any further fall in pressure $P_{2}$ below about $0.75 \mathrm{MPa}$ does not influence the flowrate. Comparison of this curve with that experimentally obtained from the real well shows good agreement both for shape and location.

The value of $V_{92}$ is seen to rise to about $200 \mathrm{~m} / \mathrm{s}(656 \mathrm{ft} / \mathrm{s})$ at which velocity choking supervenes. It must be remembered that the vapor is moving in association with, but overtaking, the liquid and that momentum exchange between the fluids occurs actively. If the vapor had been alone, i.e., in single-phase flow, it would have choked at the normal acoustic velocity $\nabla_{a}=V(\gamma R T)$, which is approximately $500 \mathrm{~m} / \mathrm{s}(1640$ $\mathrm{ft} / \mathrm{s}$ ) for saturated steam at $0.75 \mathrm{MPa}$ pressure. The liquid velocity at exit, $\nabla_{t 2}$, is much less than $V_{92}$, and is governed by the slip which for this model was chosen arbitrarily, but having regard to the limited experimental data available [Ryley, 1964; Elliot, 1978]. The velocity $V_{2}$ 


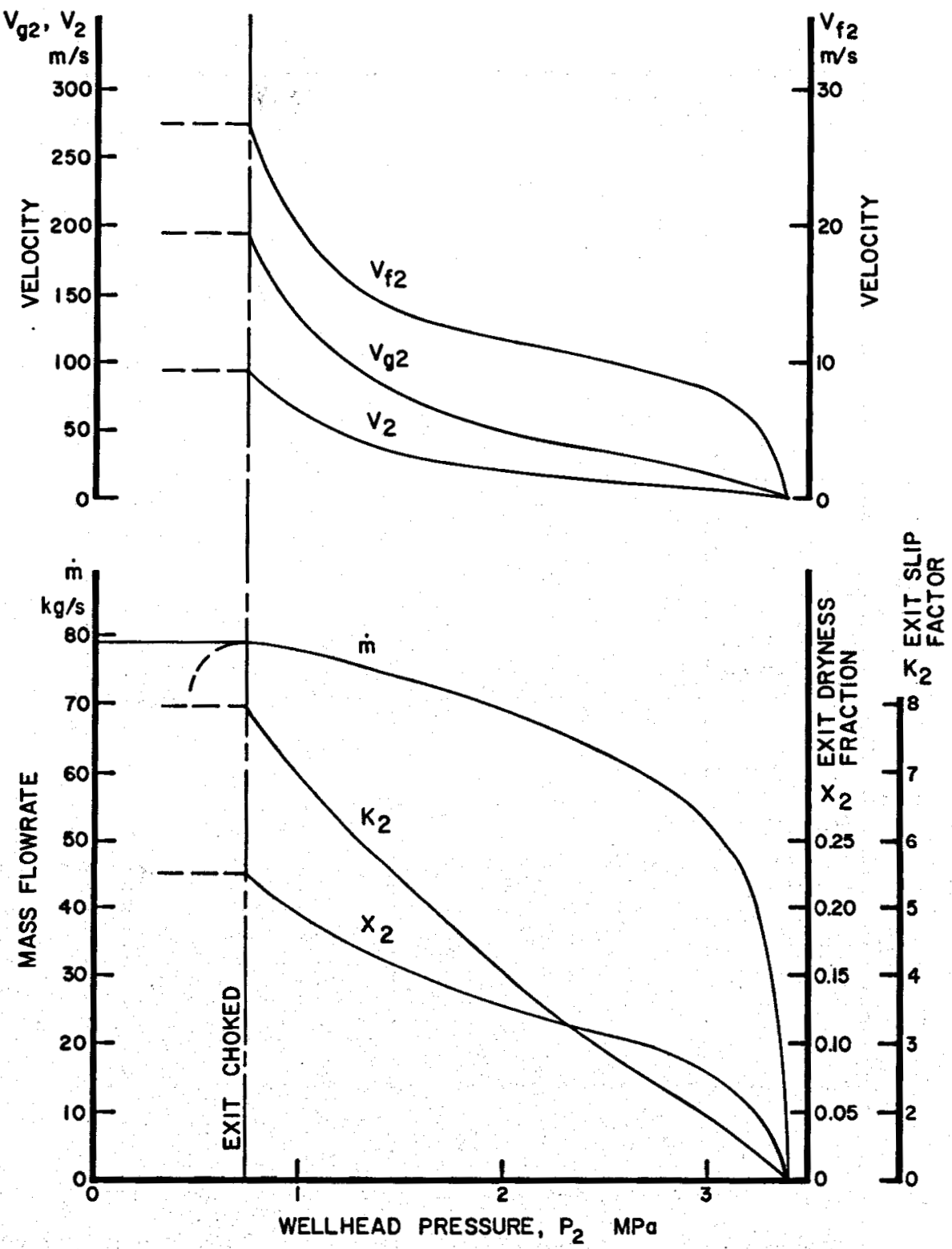

Fraure 2.84-The self-flowing flashing well : Miscellaneous curves.

rises only to about $100 \mathrm{~m} / \mathrm{s}(328 \mathrm{ft} / \mathrm{s})$ at the choked condition. This is the velocity which with homogeneous flow would discharge the same aggregate exit kinetic energy as does the combined two-phase flow. The subject of choking is considered in section 2.6.2.8.

Figure 2.35 shows the distribution of effective area as between the two phases. It will be observed that notwithstanding the very low values of $\propto_{2}$ 


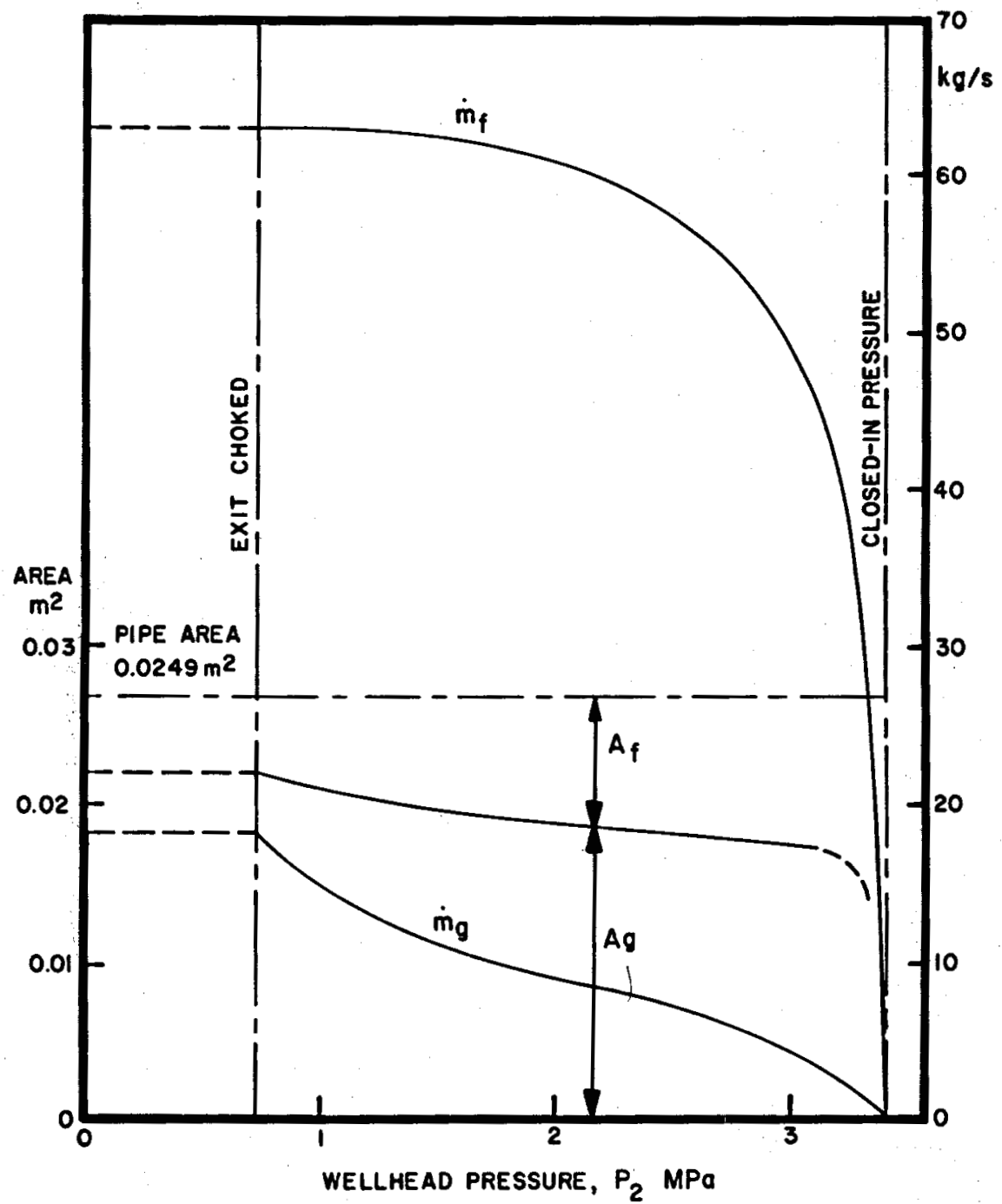

Frouke 2.35-The self-flowing flashing well : Miscellaneous curves.

the saturated vapor occupies more than half the pipe area over the whole significant range of wellhead pressure $P_{2}$. This occurs because $\rho_{g 2}<<p_{12}$ which also reflects the fact that most of the mass flow is contained in the saturated liquid discharge.

2.6.2.6 The stepped-diameter well. In the example presented in section 2.6.2.5, it was evident that the maximum flow was limited to about $80 \mathrm{~kg} / \mathrm{s}$ $(176 \mathrm{lb} / \mathrm{s})$ by the comparatively low values of the velocities at the pipe exit when choking occurred. Within the defined conditions there is no way in which these velocities can be increased, but the mass flow may be increased by an increase in the pipe diameter. There is no need to increase 
the diameter over the whole depth. In the example the water velocity through the pipe below the flash level was only $0.053 \mathrm{~m} / \mathrm{s}(0.174 \mathrm{ft} / \mathrm{s})$ and this could be substantially increased without significant extra frictional losses. The pipe diameter could therefore be increased from the vicinity of the flash level where the high specific volume of the vapor aided by the rising value of $x$ begins to influence adversely the mass flow.

The theory presented in section 2.6.2.4 can readily be modified to take account of an increase in pipe diameter. The step will normally occur below the flash level. Single phase friction losses must now be allocated to both the narrow bore pipe and the large bore pipe below the flash point. There will also be a pressure loss at the enlargement given by the standard expression

$$
\Delta P=C_{\rho S P} \nabla_{1}^{2} / 2
$$

where $\mathbf{C}$ is the standard loss coefficient for the ratio: original pipe area/ enlarged pipe area. The continuity equations for the exit must now, of course, be based on the enlarged area.

Curves illustrating the respective performance charucteristics of constant diameter and of stepped-diameter wells have been presented by Elliott [1975] ; James [1970] also refers to the subject.

2.6.2.7. Variation in depth to flash level in self-flowing well. The depth to the flash level, equation 2.46 , is based on the pressures arising from static liquid columns exterior to and within the well and does not include the pressure losses due to flow friction and drawdown. This subject is now reviewed in greater detail. It was shown in section 2.6.2.1 that for a singlephase self-flowing liquid well the wellhead pressure is given by equation 2.60.

$$
P_{2}=P_{3}-\dot{m}\left(\frac{\mu}{\rho_{3}}\right)\left(\frac{1}{\dot{K} L}\right) \frac{\ln (R / r)}{2 \pi}-\dot{m}^{2}\left(\frac{1}{\bar{\rho}_{W}}\right)\left(\frac{f_{W} z_{W}}{D^{5}}\right) \frac{32}{\pi^{2}}-\bar{\rho}_{W} g z_{W},
$$

where the terms on the right-hand side of the equation represent successive pressure drop increments due, in order, to drawdown, to pipe flow friction, and to hydrostatic head. Clearly, equation 2.60 is also valid for any pressure between $P_{1}$ and $P_{2}$ at whatever value of $z$ it may be located. Specifcally, if we wish to locate $z_{F}$, we may write

$$
P_{S}=P_{8}-\dot{m}\left(\frac{\mu}{\rho_{3}}\right)\left(\frac{1}{K L}\right) \frac{\ln (R / r)}{2 \pi}-\dot{m}^{2}\left(\frac{1}{\bar{\rho}_{W}}\right)\left(\frac{f_{W} z_{F}}{D^{5}}\right) \frac{32}{x^{2}}-\bar{\rho}_{W} g z_{F}
$$

Setting the saturation pressure $P_{B}$ at the appropriate value for the reservoir temperature and selecting the required value of $\dot{m}$, the fiash depth $z_{p}$ may be found for the full range of $m$ values.

Using the example devised for section 2.6.2.5, the variation of $z_{p}$ with $\dot{m}$ has been plotted (see figure $2.36(\mathrm{~b})$ ).

It is instructive to consider this topic from a graphic standpoint and the same example has been used. 


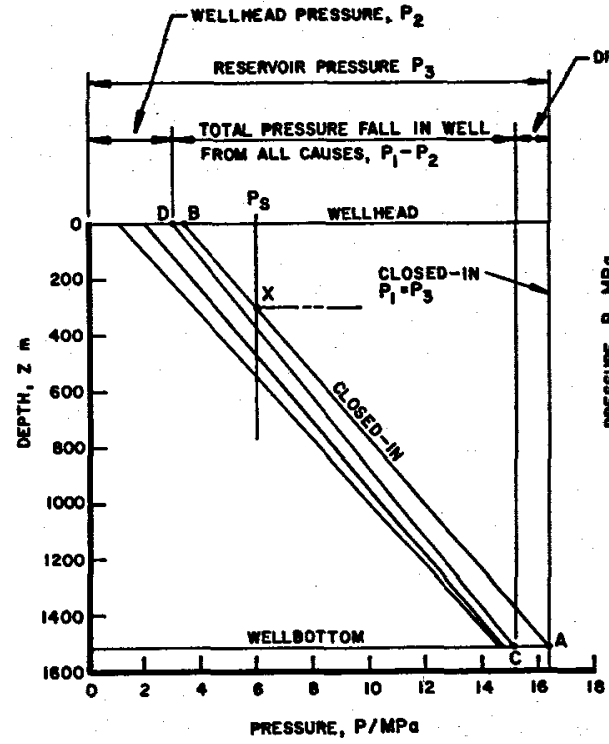

(a)

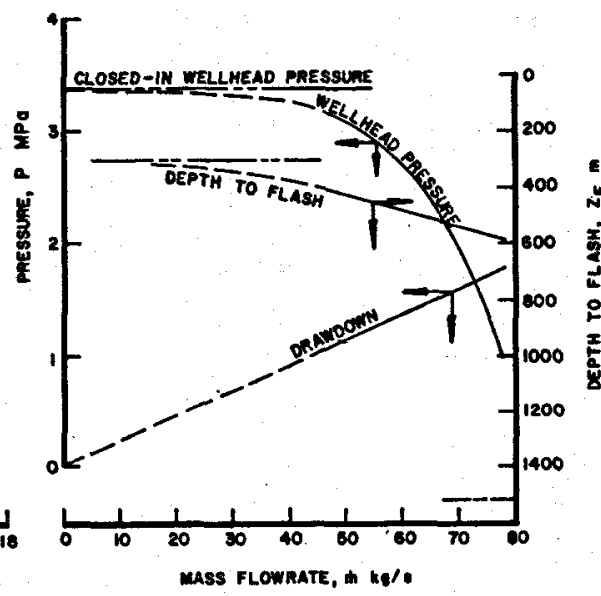

(b)

Frgubs 2.36-Depth to flash level in self-flowing well: (a) Pressure-depth curves; (b) miscellaneous curves.

The static pressure distribution in the well/reservoir combination is shown approximately in figure 2.36(a). Pressure fall increments; drawdown, well pipe and wellhead are shown horizontally as a function of depth. Consider first the closed-in condition. There will be no drawdown, $P_{1}$ will equal $P_{3}$ and point $A$ locates this condition at the wellbottom. The pressure drop up the pipe will be due only to the decline in hydrostatic pressure and will reach the closed-in value of wellhead pressure at $B$. Suppose now that the wellhead valve is partially opened. Flow now commences, a wellbottom drawdown pressure drop occurs and the wellbottom pressure assumes the position $C$. The pressure loss up the pipe is now a combination of that due to hydrostatic pressure, acceleration, and flow friction. The new wellhead pressure $P_{2}$ is now located at $D$. Increased opening of the wellhead valve moves the pressure distribution line further to the left as shown.

The base temperature in the reservoir defines a saturation pressure at which flashing will commence. This is shown as $P_{s}$ on diagram a, and the points of intersection of $P_{\&}$ with $\mathrm{AB}, \mathrm{CD}$, etc., shows the depths at which flashing commences for successive increments of wellhead valve opening. It will be seen that as the wellhead pressure $P_{2}$ falls and the mass flowrate $\dot{m}$ increases the flash level moves down the well. The closed-in case is of special interest in this connection. The line AB intersects pressure $P_{B}$ at point $X$. When the well is closed-in there is no flow and can be no flash level. If, however, the wellhead valve is "cracked" open and a small flow commences, the flash point establishes itself forthwith at the level $\mathbf{X}$.

It should be noted that the pressure lines $A B, C D$, etc., have been shown 
for convenience as linear. This is very nearly accurate for the whole closedin line AB. It is also substantially correct for the remaining lines $\mathrm{CD}$, etc., below the flash level. Above the flash level the flow is accelerated, the friction increases and the pressure declines more rapidly, causing the lines to curve slightly towards the pressure origin.

It should also be noted that the values of mass flowrate were calculated on the assumption of a constant depth of flashing and are only approximately correct. They would require iterative recalculation to establish their precise values.

Considering the curves in figure 2.36(b) the drawdown $P_{3}-P_{1}$ is seen to be linear as required by the Darcy equation (2.56) and the depth $z_{F}$ to the flash level is also nearly linear with $\dot{m}$ at the higher values of $\dot{m}$.

It should be borne in mind that the curves presented in figure 2.36 are appropriate only to the example chosen and serve to illustrate principles. Variations in reservoir permeability, base temperature, well depth, well bore, salinity, etc., would yield different characteristics but preserve the general pattern.

2.6.2.8 Choked flow. In section 2.6.2.5 it was shown in the numerical example that the mass flowrate $\dot{m}$ rose with a decline in wellhead pressure $P_{2}$ until a maximum flowrate was reached after which further reduction in $P_{2}$ had no influence on the discharge. This condition, referred to as "choking," is usually encountered though it may be absent in wells with very small values of closed-in pressure.

Choking in single-phase gas or vapor flow occurs at a nozzle throat or a pipe exit when the velocity at that section becomes equal to the local sonic velocity, thus preventing the upstream propagation of the pressure pulse arising from a further reduction of downstream pressure. The subject is well understood and for an ideal gas the sonic velocity is given by

$$
\nabla_{a}=(\gamma R T)^{1 / 2}
$$

where $T$ is the local value of absolute temperature. For any flow having a velocity $V$ at this temperature the Mach number is defined as

$$
M=\nabla / V_{a}
$$

If we now consider the two-phase flow, we might have a condition at a pipe exit in which the flow is annular (see section 2.6.3.1). In such an event the central vapor core is unimpeded, and its velocity would rise to the sonic velocity appropriate to the conditions. The surrounding annular sleeve of liquid would flow more slowly. Complete phase separation across a cylindrical interface is not possible, but sonic models so based have been employed and are known as vapor-choking models [Ryley, 1965].

If, as is usually the case, no such gross separation occurs between the phases, the conditions for choking are complex and much ingenuity has 
been expended in attempting to devise acceptable models. No finality has been renched, and the following brief summary of the history leading to the contemporary state of the art must suffice.

Early attempts to understand two-phase flow choking were not related to geothermal steam wells, and experiments were conducted with small diameter nozzles and pipes generally in the context of process engineering or nuclear reactor cooling channels. Two approaches to the study of modeling two-phase flow choking were distinguished by Hewitt and HallTaylor [1970]: (1) Models which employed similar ideas to those used in single-phase flow, and (2) models in which detailed analyses were made within the region leading to the point where the flow becomes critical. Most models fall into category 1 and are discussed below.

For unit mass of a flowing fluid with negligible friction losses in which no potential energy or work terms are involved, the energy balance on an element at the critical condition is

$$
-v d P=d\left(\frac{V_{c}^{2}}{2}\right)
$$

where $V_{c}$ is the critical velocity. Denoting the critical mass flux by $G_{c}$ where

$$
G_{c}=\frac{\dot{m}}{A}=\frac{V_{c}}{v}
$$

equation 2.83 may be rewritten as

$$
G_{c}^{2}=-\left(\frac{\partial P}{\partial v}\right)_{s}
$$

where the derivative is taken at constant entropy consistent with the assumption of thermodynamic reversibility. The same result can be derived from considerations of frictionless momentum transfer.

Different models arise from equation 2.85 according to the interpretation of the mean specific volume $v$. This will take account of the proportions of each phase present and may be based on (a) a homogeneous mixture, (b) a flow area, (c) a momentum flux, or (d) an energy flux. Investigators employing this general approach include Ryley [1952], Isbin et al. [1957], Fauske [1961], Cruver and Moulton [1967].

An attempt was made by Bodvarsson and Ryley [1966] to relate the findings of three of the above-named to critical discharge in geothermal wells. They calculated the flow for a given Icelandic well using the methods of Isbin et al. [1957], Fauske [1962] and Cruver [1963]. Cruver's theory, modified by him to take account of supersaturated flow in the exit, gave the best agreement with the results obtained from flow separation at the wellhead. 
So far as the writer knows no further attempts have been made to analyse geothermal well critical flow although the subject of two-phase critical flow in general has been vigorously pursued [e.g., DeJong and Firey, 1968; Katto, 1968; and Henry and Fauske, 1971].

2.6.2.9 Estimation of the mass flowrate from wells. For the satisfactory exploitation of geothermal wells it is necessary to know with some precision the mass of water and steam discharged. The total mass discharged from a fully open well is large, possibly exceeding $100 \mathrm{~kg} / \mathrm{s}(220 \mathrm{lb} / \mathrm{s})$, and it is generally impracticable to condense it for weighing or volume measurement. The following methods have been employed:

(1) Separation and weighing of the phases. This method was employed in Iceland. Crude separation was effected in a U-bend followed by further separation within a cyclone. The separated vapor was metered using two orifice plates $0.265 \mathrm{~m}(0.87 \mathrm{ft})$ diameter each mounted in a pipe $0.406 \mathrm{~m}(1.33 \mathrm{ft})$ bore. The separated liquid fractions were flashed. The resulting vapor was metered using a $0.145 \mathrm{~m}$ $(0.476 \mathrm{ft})$ orifice, and the surviving water was passed/over measuring weirs. A diagram of the equipment, which was portable, is shown by Bodvarsson and Ryley (1966). The equipment was of necessity very bulky and heavy. Mathias [1975] used somewhat similar equipment. Although simple in principle the method can lead to errors as, for example, when steam escapes in small quantities into a separated hot water pipe conveying the water to a measuring orifice [James, 1975].

(2) Sampling across the flow. This method was employed by Banwell [1957] who employed a sampling tube which could be moved diametrally across the flow of a vertical discharge. The mixture collected was condensed in a small calorimeter. By assuming the flow patterns were axisymmetric, the integrated flowrate could be found.

(3) Absorption of beta rays. This method was employed by Belin and Knox [1955] and Belin and Bainbridge [1957]. They measured the density of the mixture by the absorption of beta rays along a vertical throat diameter of a nozzle discharging steam and water horizontally. They found that a relation existed between the density and the dryness fraction. The mass discharge could then be calculated from an empirical relation containing the variables; upstream pressure and density.

(4) Sharp-edged orifices. Sharp-edged orifices may be used to measure two-phase flow throughout the entire dryness fraction range. This subject is very well documented, and readers may refer to the long series of researches conducted at the National Engineering Laboratory, Scotland [e.g., Chisholm and Watson, 1966], or to the reference list following Smith and Leang [1975].

(5) All the above methods when used with care are capable of fair accuracy, but as in the cases of numbers (1) and (3) especially they 
may be inconvenient to use on the geothermal well site. A simple empirical method due to James [1962] is widely used because of its great convenience. James showed that by means of a lip pressure tapping at the end of a pipe discharging geothermal fluid critically to the atmosphere, a fairly accurate estimate can be made if the stagnation enthalpy of the fluid is known. He used pipe sizes of $76.2 \mathrm{~mm}$ ( $3 \mathrm{in}), 152.4 \mathrm{~mm}(6 \mathrm{in})$, and $203.2 \mathrm{~mm}$ (8 in) diameter, a critical pressure range of 0.097 to $0.44 \mathrm{MPa}\left(14\right.$ to $64 \mathrm{lb} / \mathrm{in}^{2} \mathrm{abs}$.) and a stagnation enthalpy range of 535 to $2791 \mathrm{~kJ} / \mathrm{kg}(230$ to $1200 \mathrm{Btu} / \mathrm{lb})$. He claimed that the following empirical equation covers the data with an accuracy of $\pm 3 \%$ :

$$
\frac{G h^{1.102}}{P^{0.86}}=11400
$$

where the quantities are in traditional units, i.e., $G$, the mass velocity is in $\mathrm{lb} / \mathrm{s} \cdot \mathrm{ft}^{2} ; h$, the stagnation enthalpy is in $\mathrm{Btu} / \mathrm{lb}$, and $P$ the critical discharge pressure is in $\mathrm{lb} / \mathrm{in}^{2}$ abs. The corresponding expression in SI units is

$$
\frac{G h^{1.102}}{P^{0.26}}=16.757 \times 10^{8}
$$

where $h$ is in $\mathrm{kJ} / \mathrm{kg}, P$ in $\mathrm{MPa}$, and $G$ in $\mathrm{kg} / \mathrm{m}^{2} \cdot \mathrm{s}$.

\subsubsection{Patterns of two-phase association in vertical two-phase flow}

When hot water rises up a well pipe, its pressure falls as the overlying fluid mass decreases. There may be a concurrent fall in temperature or, in rare cases, an increase. Usually, the temperature falls but heat is not normally transported away from the flow sufficiently fast for a rapid temperature decline to take place. In the geothermal well it frequently happens that during the long upward path the pressure of the hot geofluid declines to the saturation value and vapor begins to form.

No direct observations of the subsequent behavior is possible in the geothermal well, but the subject has been studied extensively in other contexts over a period of several years. Frequently a two-component, two-phase mixture (e.g., air-water) has been employed because this permits the use of transparent pipes and channels and makes direct visual observation possible, but at the expense of excluding change of phase. Many experiments exist in which a single-component two-phase mixture, such as steam-water, has been used, but the elevated temperatures may raise problems with transparent containment.

The geometry of association of the phases is complex and varies with the height and many other experimental conditions, and many patterns 
of association ("flow patterns") have been postulated.* General agreement has now been reached on the identities of the significant, frequentlyrecurring patterns for co-current flow.

The type of flow pattern at any location within the flow might appear to be irrelevant. It is, however, of consequence in two connections:

(1) If the channel is conveying a coolant subject to evaporation, it is vital to know at what location adequate heat transfer from the inner walls to the coolant fails and damage to the channel ("burnout") takes place. This issue does not arise with geothermal wells.

(2) The pressure drop is functionally related to type of flow pattern, because the pattern is determined by the void fraction, slip ratio, pressure, velocity, passage geometry, interfacial surface tension, and possibly other factors which collectively influence the mean friction factor.

2.6.3.1 Flow pattern in vertical flow. There is general agreement that four generic types of flow pattern are found in vertical flow, and although these cannot be directly observed in the geothermal well, it is likely that they occur. They are shown in figure 2.37, and they occur in sequence downstream from the flash level in the following order:

Bubble flow. The onset of flashing promotes the formation of vapor bubbles at selected nucleation sites within the liquid and at the liquid boundary. These bubbles have substantially the same size at nucleation, but grow at different rates as a consequence of coalesence and/or continuing vaporization arising from continuing pressure reduction. The vapor is the dispersed phase and the liquid is the continuous phase.

Shug flow. Further growth and coalescence of bubbles promotes a succession of large bubbles which have nearly the same cross-section as the pipe. They are bullet-shaped and advance at approximately regular intervals separated by lengths occupied mainly by liquid which may or may not contain a dispersion of smaller vapor bubbles.

Churn flow. As the flow proceeds the further generation of vapor occurs and mass continuity necessitates an increasing average fluid velocity as the mean density falls. The slug structure becomes unstable and collapses with consequential "churning" or oscillatory motion. The size, disposition, and movements of the dispersed vapor elements are much less regular than with bubble or slug flow.

Annular flow. With additional generation of vapor it is to be expected that the growing dispersed vapor elements of the three previous cases will eventually coalesce to form a continuous vapor passage within the flow. In annular flow there is a thin liquid film on the channel walls presenting a

\footnotetext{
* Sets of flow patterns have also been postulated for horizontal two-phase flow, some patterns differing from those observed in vertical fow, and this subject will concern us when considering surface distribution of geofluids. For geothermal well studies we are not concerned with horizontal flow.
} 


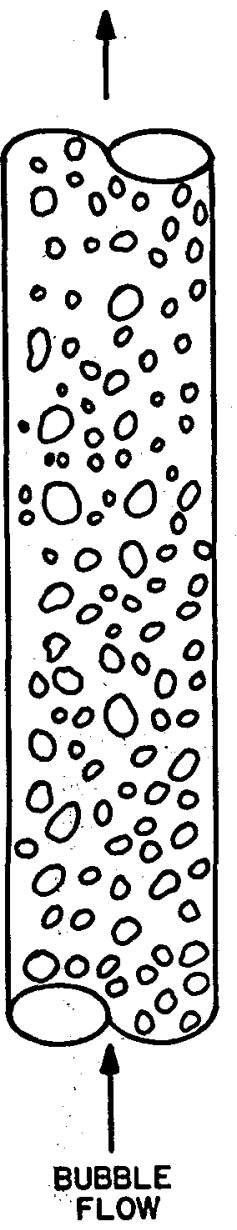

(a)
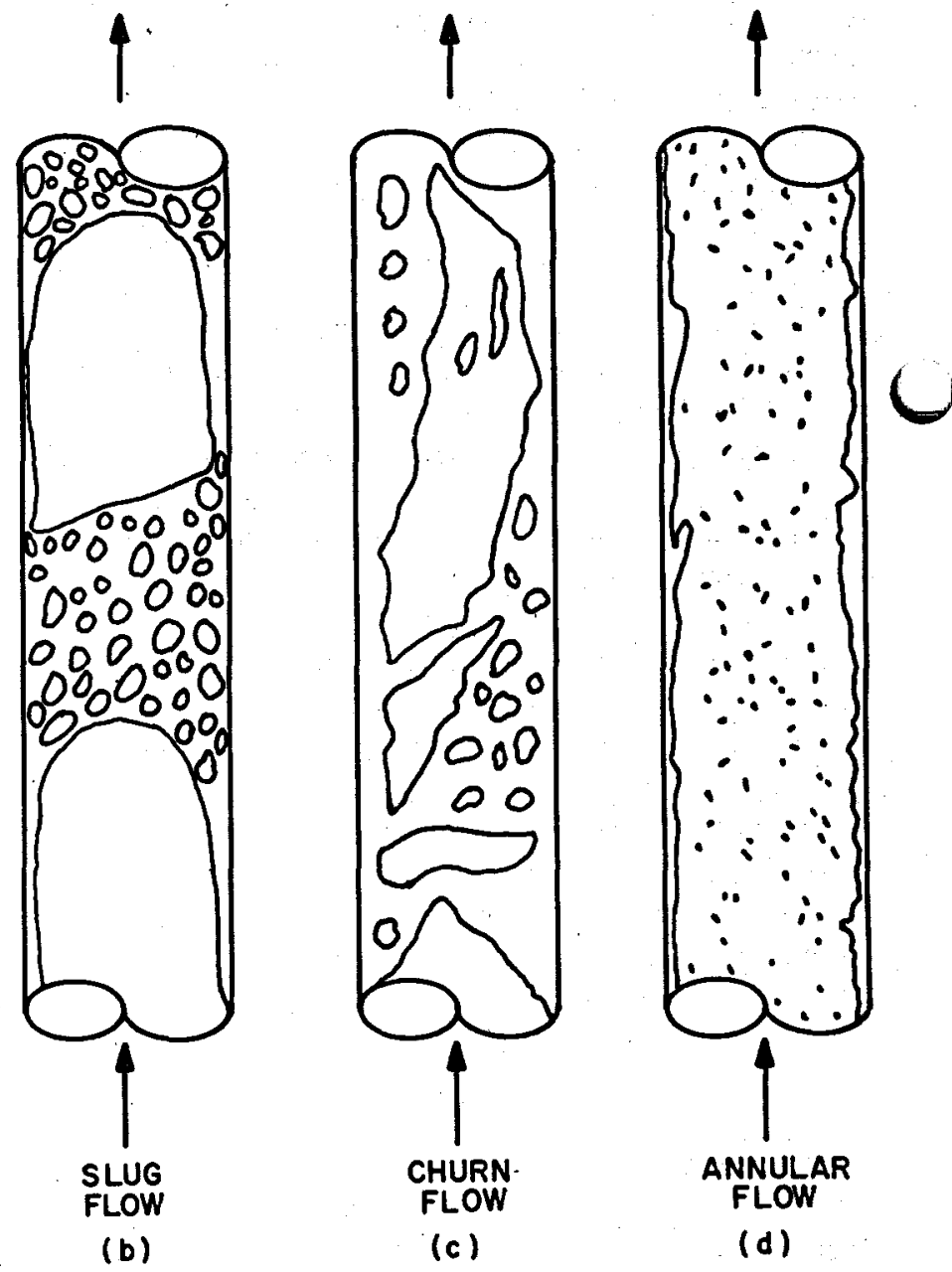

Fradre 2.37-Principal flow patterns in vertical two-phase flow.

more or less continuous interface to the vapor core. The liquid film may or may not contain residual vapor bubbles, and there may or may not be. dispersed liquid within the vapor core. The interface will be geometrically unstable, subject to oscillations and liquid and/or vapor may be transported across it in either direction.

The locations of flow regimes within the wellbore cannot be determined readily using instruments, and very few experimental data are available. The flashpoint location is revealed after some months of operation in a well with an adequate reservoir on constant load, because of the occurrence of deposited precipitate ("calciting"). The restriction so formed may be bored out, and the depth thereof is then known. Direct observation of the steam plume from a well discharging into the atmosphere frequently sug- 
gests a sheath of liquid leaving the inside wall of the pipe lip [Ryley, 1962; Belin and Bainbridge, 1957; Soda et al., 1975]. Traversing the efflux with a sampler supports this view [Banwell, 1957].

2.6.3.2 Transition of flow pattern. The factors which determine transition from one flow pattern to the sequential one have attracted much study for about two decades. It is now possible to give satisfactory qualitative explanations of the operation of these factors but difficult to devise acceptable models for predictive analysis. In any case, models can only be based on and tested by physical observations and all such data derives from pipes and channels providing a flow area at least an order of magnitude smaller than that provided by the bore of a geothermal well. The relevance of existing knowledge to the case of the well is therefore in grave doubt. The current position has been authoritatively summarized by Dukler [1977].

Observations on flow patterns have led to the construction of flow pattern diagrams which purport to display the boundaries dividing the different patterns plotted against rectangular axes based on those property groups believed to be significant variables. Many such diagrams exist and many have been surveyed by Vohr [1960] and Scott [1963]. Since 1963 a number of new diagrams have become available. No finality, however, has been reached. It is easy to show the locus of conditions representing flow in a tested well on many of these diagrams [Ryley, 1966; Bodvarsson and Ryley, 1966], and the curves obtained may appear plausible inasmuch as the flow traverses the expected regions and may become annular at exit. Such exercises must, however, be viewed with great caution as the flow pattern boundaries may have been based on experimental work performed in apparatus and with conditions very different from the geothermal well.

\subsubsection{Thermodynamic availability in geothermal systems}

The subject of thermodynamic availability will be treated formally later (chapter 3), and the reader should consult this section for an introduction to this concept. The specific thermodynamic availability is defined as

$$
b=h-T_{0} 8
$$

where $h, T$ and 8 have their usual meanings and the subscript 0 refers to the "dead state." This concept will be applied first to the well pipe alone and then to the system comprising the well pipe, the downhole pump (if any) and the power plant.

2.6.4.1 Availability analysis of the well pipe. Consider a well pipe, figure 2.38, and let subscripts 1 and 2 respectively denote the entry and exit sections. The following refers to unit mass of geofluid 


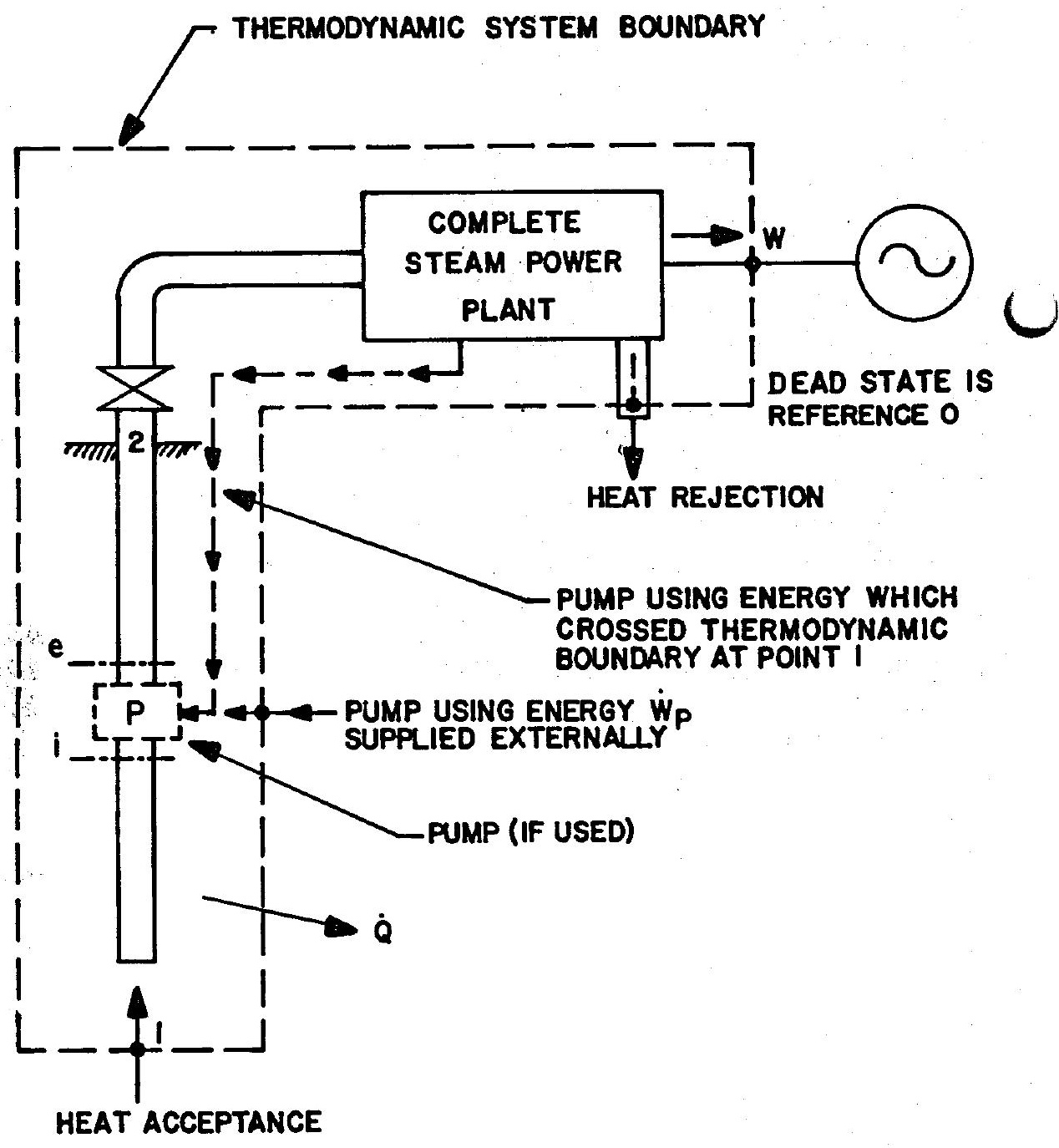

Froure 2.38-Diagram for illustrating the concept of availability.

Availability at wellbottom,

$$
b_{1}=h_{1}-T_{08_{1}}
$$

Availability at wellhead,

$$
b_{2}=h_{2}-T_{0} 8_{2}
$$

Loss in availability $\Delta b$ during the ascent of the geofluid

$$
\Delta b=b_{1}-b_{2}=h_{1}-h_{2}-T_{0}\left(8_{2}-s_{1}\right)
$$


For a well with no pump the steady flow energy equation gives

or

$$
\dot{Q}=\left(h_{2}+\frac{V_{2}^{2}}{2}+g z_{2}\right)-\left(h_{1}+\frac{V_{1}^{2}}{2}+g z_{1}\right)
$$

$$
h_{1}-h_{2}=\frac{1}{2}\left(V_{2}^{2}-V_{1}^{2}\right)+g\left(z_{2}-z_{1}\right)-\dot{Q} \text {. }
$$

By substituting the right-hand side of equation 2.92 for $h_{1}-h_{2}$ in equation 2.91

$$
\Delta b=\frac{1}{2}\left(V_{2}^{2}-V_{1}^{2}\right)+g\left(z_{2}-z_{1}\right)-\dot{Q}-T_{0}\left(s_{1}-s_{2}\right) .
$$

If there is a loss of heat from the well, $\dot{Q}$ is - ve and $\Delta b$ increases; if heat is gained $\dot{Q}$ is $+v e$ and $\Delta b$ diminishes. For the adiabatic well $\dot{Q}=0$ and

$$
\Delta b=\frac{1}{2}\left(V_{2}^{2}-V_{1}^{2}\right)+g\left(z_{2}-z_{1}\right)-T_{0}\left(s_{1}-s_{2}\right) .
$$

It is seen that the loss of availability of the fluid is increased if the geofluid gains kinetic energy in transit. Since flashing will normally occur within the well, the mean density of the fluid will fall and $V_{2}$ will exceed $V_{1}$. If, however, subcooled water is delivered at the exit, then $V_{2}=V_{1}$ and

$$
\Delta b=g\left(z_{2}-z_{1}\right)-T_{0}\left(8_{1}-8_{2}\right)
$$

If the flow is wholly free from friction losses, i.e., is isentropic, then $s_{1}=s_{2}$, whence

$$
\Delta b=g\left(z_{2}-z_{1}\right)
$$

This loss of availabiliity is uavoidable in the self-flowing well, because the geofluid cannot be exploited unless it is raised to the surface; and its potential energy gain can only be offset by an equivalent availability loss.

The effect of friction in the flow is to diminish $V_{2}$ and increase $\delta_{2}$ in equation 2.94. Friction is related to the other flow parameters through equation 2.39, and there is no simple way in which the coefficient of friction $f$ can be introduced into equation 2.94. It is evident, however, that if no wall or fluid friction occurred, i.e., the expanding flow was isentropic, then the loss of availability would equal the gain in exit fluid kinetic energy. Since the latter might be in part recoverable in the plant, the loss may be partly retrievable. On the other hand frictional reheating of any kind will generate entropy and promote an increase in $8_{2}$. The availability loss component $T_{0}\left(s_{1}-s_{2}\right)$ represents energy lost beyond recovery.

When assessing the possible output for a power plant, it is more realistic to relate it to the availability of the geofluid than its enthalpy inasmuch as only part of the enthalpy can be converted to mechanical work. Because 
the ultimate energy source is the downhole fluid, it can be argued that the downhole availability should be taken as the datum value. This is tantamount to regarding the wellpipe as part of the energy conversion plant. Conversely it can be plausibly argued that the availability loss due to potential energy gain must necessarily be incurred, that well construction gives little scope for the reduction of flow losses, and hence that it is realistic to take the wellhead availability as the datum. Unfortunately the downhole and wellhead availability cannot readily be related and the one predicated from the other because, as was shown in section 2.6.2.4, the twophase flow is too complex for rigorous analysis.

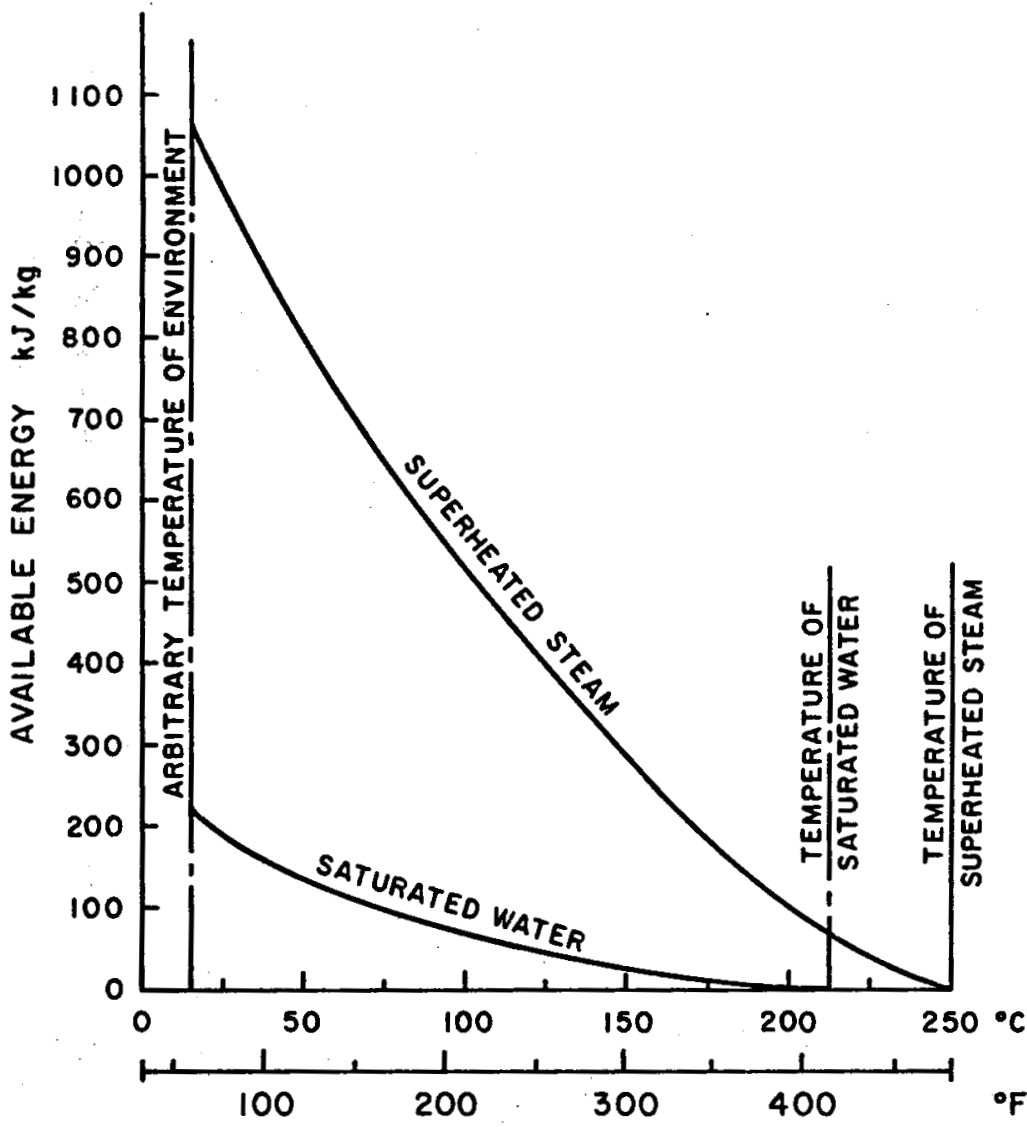

HEAT REJECTION TEMPERATURE FROM ENERGY CONVERSION DEVICE

CONDITIONS AT WELLHEAD

STEAM $2 \mathrm{MPO}, 250^{\circ} \mathrm{C}\left(290 \mathrm{lb} / \mathrm{in}^{2}\right.$ obs, $\left.482^{\circ} \mathrm{F}\right)$

WATER, SATURATED, $2 \mathrm{MPO}\left(290 \mathrm{lb} / \mathrm{in}^{2} \mathrm{abs}\right)$

Froura 2.39-Variation of available energy with heat rejection temperature from energy sources at given initial conditions. 
Availability curves are shown in figure 2.39 for slightly superheated steam and for saturated water both at a pressure of $2 \mathrm{MPa}\left(290 \mathrm{lb} / \mathrm{in}^{2} \mathrm{abs}\right)$ and a steam temperature of $250^{\circ} \mathrm{C}\left(482^{\circ} \mathrm{F}\right)$ at the wellhead. The rejection temperature from the conversion device is $15^{\circ} \mathrm{C}$, an arbitrary value for the environment.

If one assumes that these conditions are associated with a well of depth $2000 \mathrm{~m}(6562 \mathrm{ft})$ the additional potential energy, were it available, would add only $9.81 \times 2000 / 1000=19.62 \mathrm{~kJ} / \mathrm{kg}(8.4 \mathrm{Btu} / \mathrm{lb})$ to the availability. If for the same reservoir conditions the efflux velocity had been $200 \mathrm{~m} / \mathrm{s}$ $(656 \mathrm{ft} / \mathrm{s})$, the wellhead availability would have been diminished by 20 $\mathrm{kJ} / \mathrm{kg}(8.6 \mathrm{Btu} / \mathrm{lb})$. Because of their small relative magnitudes potential energy and kinetic energy terms are often disregarded in availability calculations.

Some tabulated values of the availability ("exergy") of geothermal water (pure) have been published by Bodvarsson and Eggers [1972].

2.6.4.2 Availabity analysis of the well pipe-power plant system. Consider now the geothermal well and associated power plant shown in figure 2.38. In the arguments to follow, no restrictions are placed on the nature of the well or of the power plant. A thermodynamic system boundary is drawn as shown around the complete plant. Reference positions are designated $1, e, i, 2$ as indicated, and the thermodynamic "dead" state has reference 0 . The thermodynamic availability is given by :

At the well entrance, section 1,

$$
b_{1}=h_{1}-T_{0} s_{1}
$$

At the dead state,

$$
b_{0}=h_{0}-T_{0} \delta_{0}
$$

The maximum available work from the plant is

$$
W^{0}=b_{1}-b_{0}=\left(h_{1}-h_{0}\right)-T_{0}\left(s_{1}-s_{0}\right) \text {. }
$$

Suppose the well is pumped by a pump driven by energy which was originally transferred across section 1 as part of the steady energy flux; then since the reference state is unaltered, the maximum available work $W^{0}$ from the plant remains the same. This does not mean that the output $W$ from the plant is unaltered; $W$ is, of course, diminished. This is evident by recognizing that the energy required to drive the pump remains within the system, and the overall effect of thus driving the pump is to dissipate energy internally and hence generate entropy. The operation is equivalent thermodynamically to introducing frictional irreversibilities within the system.

Consider now the case where the pump is externally driven and energy is supplied at the rate of $\dot{W}$ py a source outside the system boundary. The 
effect of the pump may be analyzed by considering a short section of the well flow embracing the pump. The fluid enters this section at level $i$ and leaves at level $e$. If the flow is adiabatic between these levels, the steady flow energy equation reads

$$
\dot{W}_{p}=\left(h_{b}+\frac{V_{\theta}^{2}}{2}+g z_{b}\right)-\left(h_{s}+\frac{V_{i}^{2}}{2}+g z_{t}\right) .
$$

The availability at the pump entry is

and at the pump exit is

$$
b_{i}=\left(h_{i}-T_{08 i}\right)
$$

$$
b_{e}=\left(h_{e}-T_{0} s_{e}\right) \text {. }
$$

The change in availability across the pump is therefore

$$
\Delta b_{p}=b_{e}-b_{i}=\left(h_{e}-h_{i}\right)-T_{0}\left(s_{e}-s_{i}\right) .
$$

The enthalpies are related through equation 2.99 whence

$$
\Delta b_{p}=\dot{W}_{p}-\left(\frac{V_{e}^{2}-V_{t}^{2}}{2}\right)-g\left(z_{e}-z_{t}\right)-T_{0}\left(s_{e}-s_{\imath}\right) .
$$

If the velocity change across the pump is zero and the small potential energy difference $g\left(z_{e}-z_{i}\right)$ is neglected, then

$$
\Delta b_{p}=\dot{W}_{p}-T_{0}\left(s_{s}-s_{i}\right) .
$$

If, finally, the pump operation is isentropic, $s_{e}=s_{i}$, then

$$
\Delta b_{p}=\dot{W}_{p} .
$$

In the ideal case for a perfect external pump, the availability is therefore increased by the amount of the pump work. This conclusion is thermodynamically independent of the pump location within the well, and of the nature of the phase or phases pumped. Practical considerations, however, influence the pump location (see section 2.6.1.6).

2.6.4.3 Utitization factor. If the shaft work output from a power plant is $\dot{W}$, the ratio of work output to availability defines the plant utilization factor, i.e.,

Utilization factor,

Also

$$
\eta_{u}=\frac{\dot{W}}{\dot{W}^{0}}
$$

$$
\dot{W}^{\circ}=\dot{W}+T_{0} \dot{\theta}
$$

where $\dot{\theta}$ is the aggregate specific entropy production rate within the plant. 
Any complete plant or subdivision thereof may be defined as a thermodynamic system, and every thermodynamic system is subject to its own individual availability loss which arises from its individual irreversibilities. Because of the great number of possible arrangements of components in power plants, each assembly yields its own value of $\dot{\theta}$ which can only be found by detailed analysis. This subject is treated in detail in chapter 3.

2.6.4.4 The dead 8tate. It is usual when defining the dead state to take as temperature datum that of the ambient air surrounding the plant. With geothermal plants, however, environmental considerations favor the reinjection of the hot spent fluid. A fairer basis for defining $\eta_{u}$ is to take $T_{0}$ to be the reinjection fluid temperature. At the time of writing (1978) the technology of reinjection is not well developed, and it is difficult to predict a meaningful magnitude for $T_{\text {。 }}$.

2.6.4.5 Friction factors in two-phase flow. When fluids are conveyed through channels, friction losses are always present and are incurred within the fluid and at the fluid boundary. Friction reveals itself as a flowwise fall in total pressure, and engineers have long been concerned to understand and minimize its effect. Friction in single-phase flow is well understood, and ample information is available for the accurate assessment of losses in all contexts of interest. Friction in two-phase flow has proved very intractable. It has been intensively studied over the last two or three decades, but no definitive theory has been formulated. Published material, while very extensive, remains largely empirical.

It is against this background that flow in geothermal wells must be appraised with the added disadvantage that almost all two-phase flow studies whether single- or two-component have been undertaken in small channels and usually in the laboratory.

The traditional approach to friction in homogenous single-phase flows is via the correlation between friction factor and flow Reynolds number:

$$
f=\phi(R e)
$$

The same outlook has been adopted for two-phase flows, whence by analogy,

$$
f_{T P}=\phi\left(R e_{T P}\right)=\phi\left(\frac{4 G A}{\mu_{T P}}\right)
$$

This incurs the difficulty of obtaining a satisfactory definition for twophase viscosity, and it is usual to devise an expression which recognizes the mass proportions of both saturated liquid and saturated vapor [Isbin et al., 1957 ; Cicchitti et al., 1960 ; and Dukler et al., 1962].

The most commonly used method of calculating two-phase pressure drops was devised by Martinelli and co-workers [Lockhart and Martinelli, 
1949; Martinelli and Nelson, 1948]. The theoretical justification for their approach is obscure, and the method may be regarded as empirical. They defined parameters as follows

$$
\begin{aligned}
\phi_{g \text { or } f}^{2} & =\frac{\left(d P_{F} / d z\right)}{\left(d P_{F} / d z\right)_{g} \text { or } f} \\
X^{2} & =\frac{\left(d P_{F} / d z\right)_{f}}{\left(d P_{F} / d z\right)_{g}}
\end{aligned}
$$

where $\left(d P_{F} / d z\right)_{0}$ and $\left(d P_{F} / d z\right)_{f}$ are the pressure gradients for the vapor and liquid phases respectively flowing alone in single-phase flow within the channel. Plots are presented to the parameters $\phi_{g}$ or $\phi_{f}$ against the parameter $X$, different lines being defined depending on whether the flows of the single-phase fluids are by definition laminar or turbulent.

The Lockhart-Martinelli model failed to give good correlations for steam-water mixtures at high pressure. This led to the modified model by Martinelli and Nelson [1948] and to several other models, one of the more successful being proposed by Baroczy [1965].

Dukler et al. [1964] studied frictional pressure drop in two-phase flow by developing correlations between the pressure drop and the other variables contributing thereto using the principle of similarity. They analyzed a very wide range of data. In discussing the best means of assessing the magnitude of friction factors for various flow patterns, Dukler [1977] recommends the similarity method for bubbly flow and for annular flows. For slug flow he advocates using the value based on the equivalent singlephase liquid flow.

The current (1978) position regarding experimental data from operating geothermal wells is very unsatisfactory. It is imperative to secure for analysis much more data from as wide a variety of wells as possible. Most needed are depthwise pressure and temperature traverses for wells operating at various discharge rates.

\subsubsection{The surface transmission of geofuids}

After a geofluid has arrived at the wellhead of an operating well it is necessary to transport it to the power station. Only in small applications where a single well provides power for a portable or semi-portable unit is the wellhead in close proximity to the prime mover [Rogers Engineering Co., 1976]. Normally, several wells will be operating and their combined output will be needed to maintain the power demand on the power plant, and they will be sited at some distance from it.

Certain constraints have to be met for the siting of both wells and power stations. Thus the location of a well is determined by a combination of factors; geological, geophysical, geochemical and to a limited extent, topographical, which collectively define the site most likely to be productive. It 
may be necessary to drill as many as 30 productive wells, ${ }^{*}$ no one of which must be so close to its nearest neighbor as to promote nutual interference (see section 2.2.5.1). During the economic life of the project some wells may become exhausted and new ones needed. The power station must be built upon a firm site, possibly adjacent to a river or lake, and readily accessible to wheeled transport. To meet all these constraints the total system will frequently be dispersed over a considerable area and many wells may be remote from the power station. At Wairakei, for example, the outlying wells are up to 2 miles, approximately, from the power station.

It is necessary, therefore, to construct a surface transmission system to deliver the output of every well to the station. This will comprise the main and subsidiary steam (or steam-water or water) pipes together with the associated civil engineering work, fittings and components. The design of the distribution system involves decisions under four main headings:

(1) The thermofluid-mechanics of the flow channels.

(2) The mechanical design of foundations, fixings and supports to enable the pipeline to fulfill its function.

(3) The material to be used for swept surfaces to minimize corrosion and erosion.

(4) The provision of safety and control devices.

This section is concerned with exploring items under heading (1), and headings (2) thru (4) will now be dealt with only briefly.

The pipework is only partly self-supporting. If a loop is made to go over a roadway it will require a light supporting steel structure. At a horizontal bend an anchor to the ground may be needed. It is necessary to calculate cumulative thermal expansion or inertia loads and ensure relief or reaction to the stresses thus caused. Long pipes must be supported at intervals on rollers. Stresses arising from ground subsidence must be considered [Stillwell et al., 1975]. A very comprehensive treatment of the applied mechanics of pipework systems has been given by Pollastri [1970].

Many geothermal fluids are highly corrosive and metals chosen for swept surfaces must be as resistant to attack as possible. Again, fluids may contain a large burden of dissolved solids which may be precipitated upon swept surfaces leading to plugging of the passages and means must be found to deal with this.

Safety devices cater to such contingencies as the overfilling of a water tank or the need to bypass automatically a pipe, vessel, etc., which has plugged or failed. Back-up valves may be needed to afford protection against failure to close by a master valve, or other valve in a critical location. Pressure release valves may be required to protect a vessel or pipeline against bursting, and automatic steam traps to prevent the accumulation of water in steam lines.

-Some unproductive bores will be drilled and abandoned. 
Control devices are highly varied, and only two examples are given. Thus a pump may be set in operation automatically to discharge a filled vessel, or to maintain a constant head in it. It may prove necessary to provide for closure of a valve in the transmission system by remote action in the control room. Control and safety have been treated by Armstead and Shaw [1970].

2.6.5.1. Pipeline transportation of geofluids. A pipeline may be required to convey dry steam, water, or a two-phase mixture, and the geofluid transmission system will depend upon the nature of the well output and the type of power cycle employed. The majority of wells deliver a two-phase mixture, and the early practice was to separate the phases at the wellhead [e.g., Haldane and Armstead, 1962]. The liquid phase was then rejected, and the saturated vapor was piped to the turbine. It was subsequently recognized that the liquid could be flashed to provide vapor which, upon expansion, would yield additional power, and a separate liquid line was provided [e.g., Haldane and Armstead, 1962]. The existence of two pipelines in close proximity, each conveying its own phase, provoked the question of the possibility of two-phase fluid transmission, and experiments were undertaken to test its feasibility [Takahashi et al., 1970]. The decision attending the adoption of two-phase fluid transmission arose from experience with the transmission of slightly wet steam. It was well known that entrained liquid slugs could attain high velocities and upon encountering a valve or pipe bend would be deposited by inertia causing excessive noise and pipe vibration [James, 1970]. The possibility of water hammer was also a threat, as were scale deposition and excessive pressure losses during flow.

The advantages attending the flashing of surface geofluid and the recovery of work from the vapor thus generated began to be appreciated, and preliminary tests were conducted in New Zealand [James et al., 1970; Wigley, 1970].

Test's which firmly established the feasibility of mixed-phase transmission were reported by Aikawa and Soda [1975]. The alternative types of transmission systems and associated cycles are shown in figure 2.40. The separated steam ("single flash") system can only be constructed in the manner shown, but three possible arrangements exist for the separated steam/single flash system. Consideration of cases (a) and (b) reveals the following disadvantages:

(i) The separator must be located at the wellhead.

(ii) Two pipes in parallel connect the wellhead and the power station. In case (a) the pipe for flashed steam must be of large bore because of the reduced pressure. Conversely, (b), if it is desired to flash the separated water at the station, thus reducing the pipe size, a hot water pump must be provided at the wellhead. Also, the pipe 
SEPARATED STEAM

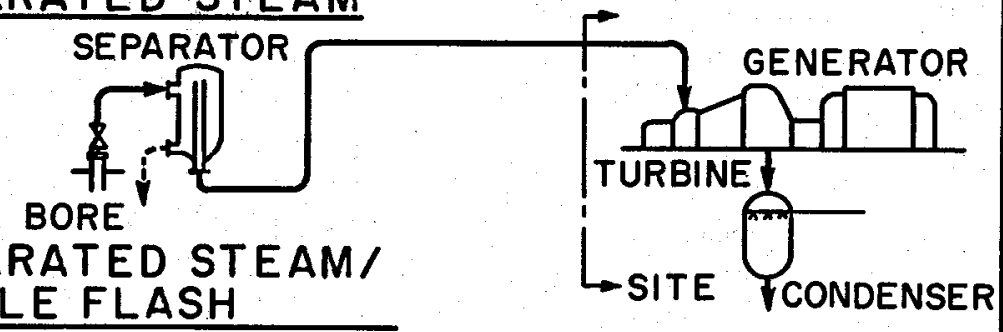

SEPARATED STEAM/ SINGLE FLASH

(a) STEAM SEPARATE TRANSMISSION SYSTEM

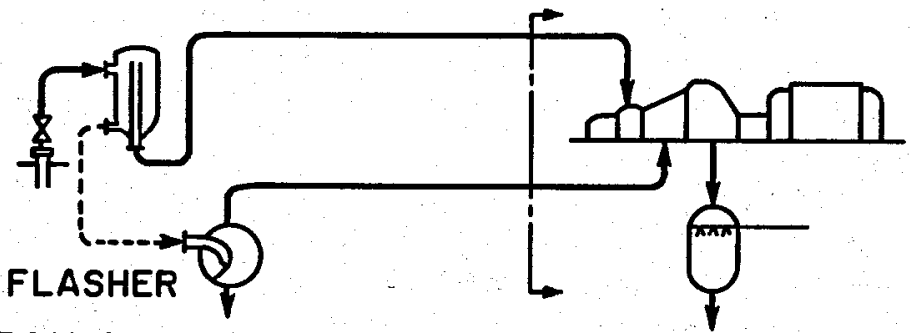

(b) STEAM AND WATER SEPARATE TRANSMISSION SYSTEM

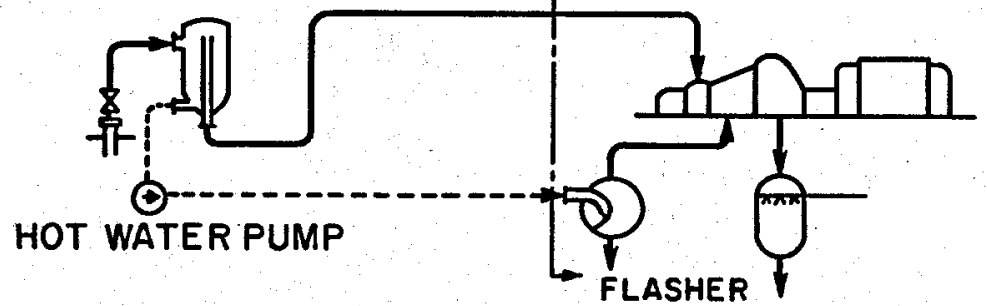

(C) STEAM - WATER MIXTURE TRANSMISSION SYSTEM

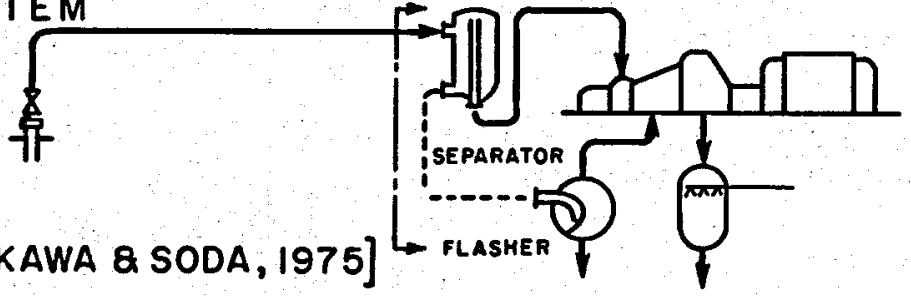

Frauke 2.40-Hot water type geothermal power plants and transmission systems.

may be subject to scaling, unless the water conveyed is maintained at a pressure high enough to suppress flashing.

(iii) Waste water must be piped from each wellhead to the disposal site.

The adoption of a single mixed-phase transmission line as in (c) substantially eliminates all these problems. There is, however, a small penalty in 
power output as shown in figure 2.41, which relates to the Hatchobaru plant [Aikawa and Soda, 1975]. These investigators also reported a test with a transmission system having a full-sized model pipeline $200 \mathrm{~m}(656 \mathrm{ft})$ long and $300 \mathrm{~mm}$ (11.8 in) diameter laid with a $7^{\circ}$ inclination angle passing a steam-water mixture of $160 \mathrm{Mg} / \mathrm{h}(160 \mathrm{t} / \mathrm{h})$ in order to study flow stability and water hammer. Typically for a pressure of $549 \mathrm{kPa}(79.6 \mathrm{lb}$ / in $^{2}$ ), dryness fraction 0.26 , and fluid velocity $58 \mathrm{~m} / \mathrm{s}(190 \mathrm{ft} / \mathrm{s})$, a rapid closure of the stop valve promoted a pressure rise of $117 \mathrm{kPa}\left(17 \mathrm{lb} / \mathrm{in}^{2}\right)$. This agreed closely with the value calculated from the momentum change of the mixture. The transient had faded in about $0.5 \mathrm{~s}$. It was concluded that mixed-phase transmission was feasible and advantageous in the case they studied, but they advised that, in general, before adopting this choice, the designer should consider all the circumstances; pressures, well locations, topography, etc.

The transient phenomena referred to above were also studied in detail by Soda et al. [1975], who also measured the velocities of pressure propagation in mixed-phase flows of dryness fraction 0.2 . The measured values showed poor agreement* with values calculated from the standard expression

$$
V_{a}=\sqrt{\left(\frac{\partial P}{\partial \rho}\right)}
$$

where the density $\rho$ is based on homogeneous flow.

Froure 2.41-Comparison of outputs between various cycles.

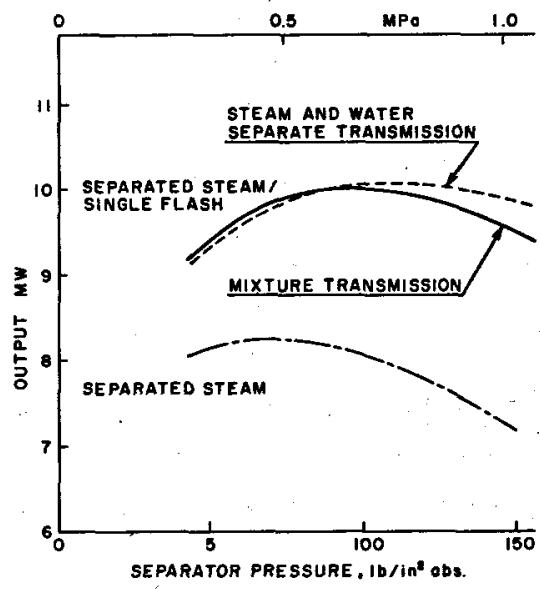

[AFTER AIKAWA SODA, 1975]

*Equation 2.112 is not directly applicable to this case. For mist or annular-mist liquid-vapor mixtures, the sonic velocity is known to be related to the dryness fraction, the size and space dispersion of the dispersed phase (liquid), and the frequency of the pressure pulse, if cyclic. The functional relation remains uncertain. 
2.6.5.2 Nature of the flow within the pipeline. In section 2.6 .3 above the subject of patterns of phase association for two-phase vertical flow was discussed and the recognized patterns were illustrated in figure 2.37. When the two-phase flow is horizontal the flow patterns are more complex because gravity causes an asymmetric distribution of the phases but the principal characteristics of the patterns are similar. The accepted categories are shown in figure 2.42 and may be compared with those for vertical flow shown in figure 2.37. Hewitt and Hall-Taylor [1970] comment on these patterns in the following terms:

(a) Bubble flow. This regime is essentially as described for vertical flow in section 2.6.3.1 (a), but the bubbles tend to flow in the upper part of the channel.

(b) Plug flow. This is similar to slug flow in the vertical case, but the liquid layer separating the vapor bubble from the wall tends to be thicker at the bottom of the channel than at the top. Also the bubble nose is asymmetric.

(c) Stratified flow. In this case the separation of the vapor and the liquid is complete, and a single interface separates the vapor in the top of the pipe from liquid at the bottom.

(d) Wavy flow. As the vapor velocity is increased in stratified flow, large surface waves begin to arise on the liquid layer.

(e) Slug flow. As the gas velocity is further increased in the wavy flow region, the wave amplitude increases until the top of the channel is reached. There, waves travel at high velocity, wetting the whole inner surface and leaving a liquid film on it.

(f) Annular flow. A further increase in vapor velocity causes the vapor to pierce the wall of the slugs, and the flow becomes essentially annular with a thicker film at the bottom than at the top.

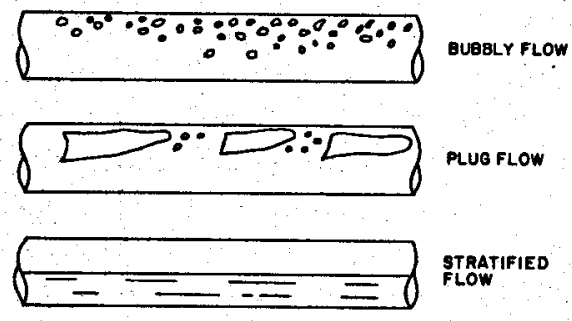

Froure 2.42-Two-phase patterns in horizontal flow.
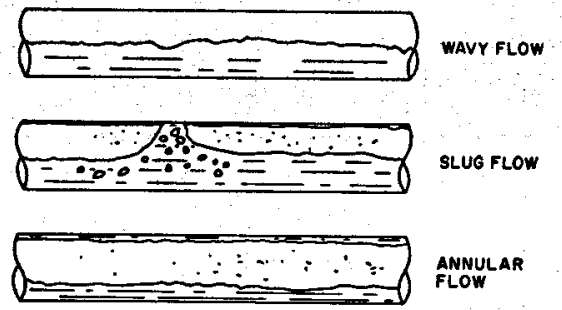

[AF TER HEWITT O HALL-TAYLOR, 1970] 
In geothermal plants the wellbore is always substantially vertical, but the surface steam mains may not be horizontal. According to the relation of the wells to each other and to the power station, the mains may be inclined at a variety of angles. At any given site the collecting pipe networks must conform broadly to the prevailing topography. Individual pipes will also have expansion loops where necessary. The flow pattern in a given inclined pipe may not be the same for both directions of flow. Flow patterns in inclined pipes are discussed by Brigham et al. [1957] and by Kosterin [1949].

The interest in flow patterns by investigators arises from the fact that the friction in a two-phase flow and probably also pipe vibration is related to them. Friction in two-phase flow exceeds that in vapor-only flow or liquid-only flow. The reader is referred to section 2.6.4.5 for a discussion of friction factors in two-phase flow within the wellbore. Much of what is written there is also applicable to the surface pipe except that the analysis of flow therein may be much more difficult. Work on vertical pipes in the laboratory shows that the effects upon the flow disturbance associated with the liquid entry persist for a long way before dying out. The wellbore, however, presents very long lengths of pipe after the entry or after a pipe diameter increase, and the flow patterns far downstream from such events are unlikely to be influenced by the past history of the flow. In the surface pipes there are few long lengths of uninterrupted horizontal flow; much of the transmission system is composed of branches, junctions, expansion bends, valves, etc., in addition to changes in direction, in inclination, and in altitude. It is likely therefore that most surface pipe flow is in confused and flow-transient patterns. Subject to this proviso we may consider now the location of experimental points on the diagram which have been devised to predict flow patterns and their transition.

2.6.5.3 Flow patterns and diagrams. A large number of flow pattern diagrams have been devised over the last twenty years, but only three appear to have been employed by authors describing the surface transport of geofluids in pipes, viz., those respectively associated with the names of Baker [1954], Hughes [1953], and Alves [1959]. The Baker diagram is the most widely known. It has been used by James et al. [1970], Wigley [1970], Takahashi et al. [1970], Soda et al. [1975], and Ryley [1966]. Takahashi et al. [1970], in addition to exhibiting results on the Baker diagram, also showed the same results on an Alves [1959] diagram, and on a Hughes [1953] diagram, and these are exhibited on figures 2.43, 2.44 and 2.45. In all cases a range of steam-water conditions was employed.

James et al. [1970] used a range of pressures from approximately 0.52 to $0.83 \mathrm{MPa}\left(75-120 \mathrm{lb} / \mathrm{in}^{2}\right.$ abs.). He employed a pipe of diameter $0.305 \mathrm{~m}$ (1 ft). Values of enthalpy, mass flow, and velocity are quoted, but dryness fraction is not given explicity. Nearly all his tests were with annular or dispersed flow. Wigley [1970] also employed a pipe of diameter $0.305 \mathrm{~m}$ 


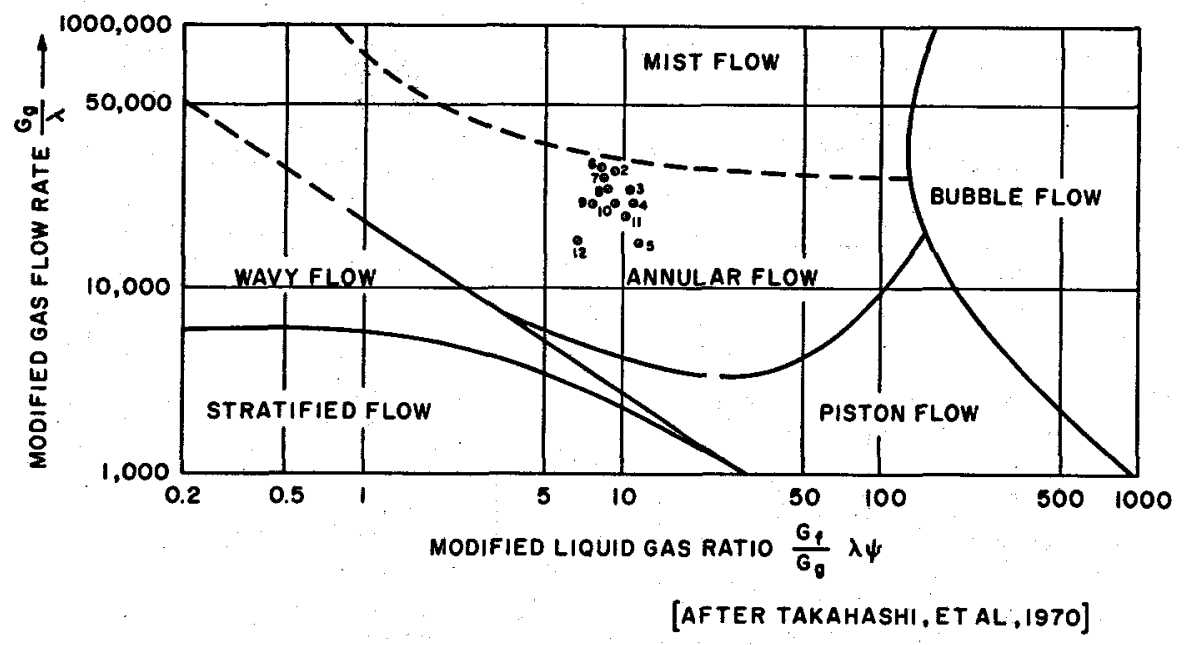

FiguRe 2.43--Experimental points shown on Baker flow regime diagram.

(1 ft). He maintained a constant pressure of $0.76 \mathrm{MPa}\left(110 \mathrm{lb} / \mathrm{in}^{2}\right.$ abs.) but varied the mixture flowrate from $4.54-342.9 \mathrm{Mg} / \mathrm{h}(10-756 \mathrm{klb} / \mathrm{h})$. When using production flowrates (i.e., the upper part of the range) his operating condition was annular or dispersed flow.

The apparatus used by Takahashi et al. [1970] was specially constructed to study flow and losses in straight pipe and selected types of bends. The pipe used had a diameter of $0.201 \mathrm{~m}(8 \mathrm{in}, 0.67 \mathrm{ft})$ and provided a straight horizontal section of length $23.85 \mathrm{~m}(78.2 \mathrm{ft})$ and a straight section inclined at $7^{\circ} 25^{\prime}$ of length $23.95 \mathrm{~m}(78.6 \mathrm{ft})$. Pressures were approximately the same for both sections and ranged from 0.21 to $0.25 \mathrm{MPa}(30.0-36.7 \mathrm{lb} /$ $\mathrm{in}^{2}$ abs.). The total flow was also common to both sections and ranged from $5.3-15.7 \mathrm{~kg} / \mathrm{s}(11.7-34.6 \mathrm{lb} / \mathrm{s})$. The flow patterns for all tests are shown in figures 2.43-2.45, and for each of the three diagrams, Alves, Hughes, and Baker, annular flow is predicted in virtually every case.

In a communication on a paper by James [1966], Ryley analyzed certain of the results for presentation on a Baker diagram. The pipe diameter employed was $0.20 \mathrm{~m}$ ( $8 \mathrm{in}, 0.67 \mathrm{ft}$ ), the pressure range was $0.52-1.9 \mathrm{MPa}$ and the dryness fraction range was $0.01-0.56$. These results defined points lying mainly in the annular-mist transition region with some more deeply within the mist region.

The results presented by Soda et al. [1975], which were sequential to those of Takahashi et al. [1970] were conducted on a $0.30 \mathrm{~m}$ (12 in, $1 \mathrm{ft}$ ) straight pipe of length $200 \mathrm{~m}(656 \mathrm{ft})$ having an inclination of $7^{\circ}$ to the horizontal. Pressures ranged from $0.28-0.59 \mathrm{MPa}$, dryness fractions from 0.04-0.26, and water mass flowrates from $13.3-33.3 \mathrm{~kg} / \mathrm{s}$. Results plotted on a Baker diagram for the velocity in the range $4-55 \mathrm{~m} / \mathrm{s}(13-80 \mathrm{ft} / \mathrm{s})$ are placed roughly in a line stretching from the annular-slug transition to well 


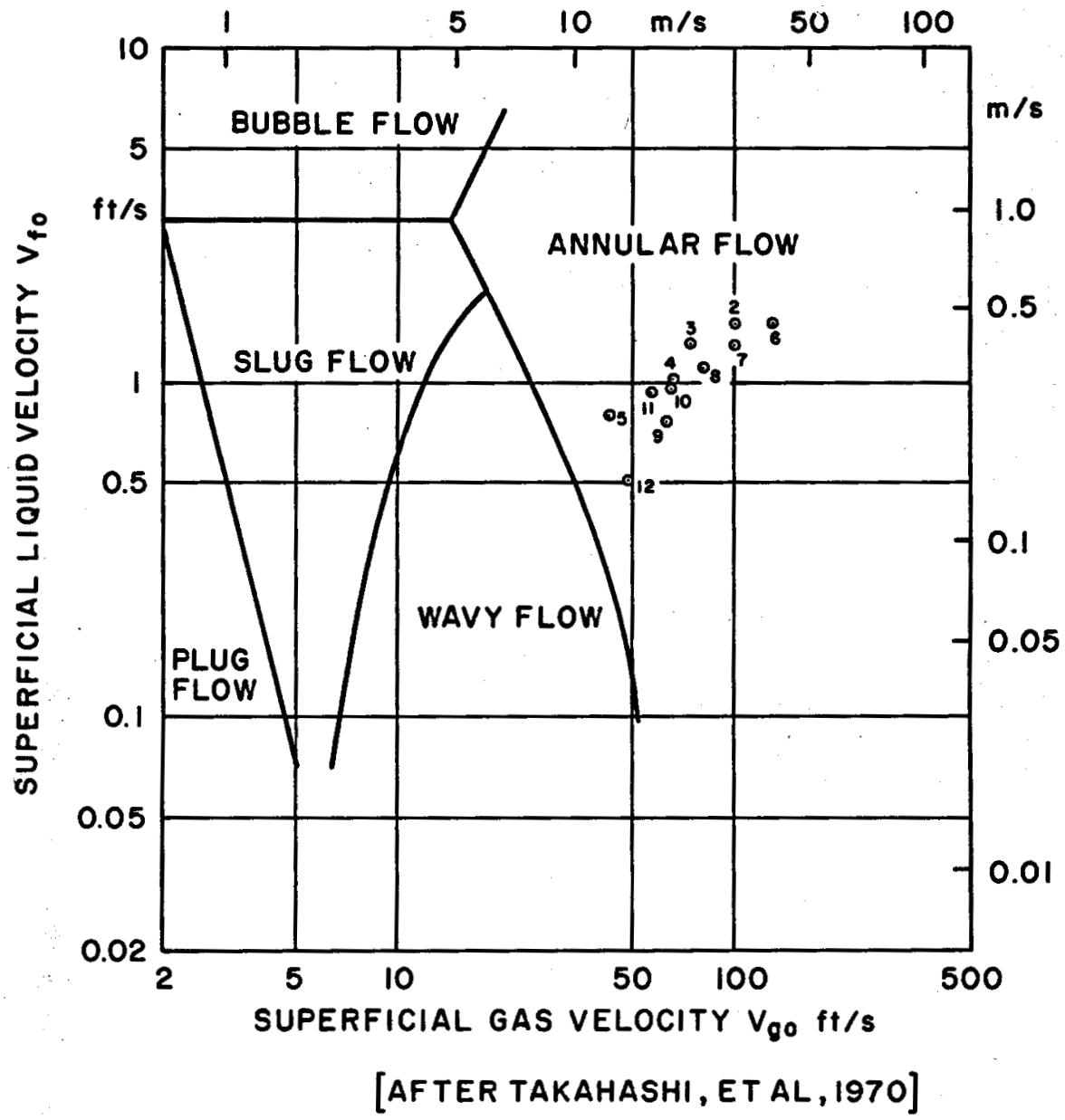

FraUre 2.44-Experimental points shown on Alves flow regime diagram.

within the region of mist flow. The apparatus also provided for visual observation to enable the existing flow patterns to be compared with those predicted, and minor disparities were found.

Experiments were conducted in the laboratory by Calder [1976] on transparent 1- and 2-in (25.4 and $50.8 \mathrm{~mm}$ ) diameter, horizontal pipes. A range of values of flowrate, pressure, quality, and velocity were employed, and the steam-water mixture was photographed. The Baker chart was found to give a reasonable prediction of the flow regime for each condition tested.

Summarizing the above, it may be said that the flow pattern to be expected in a steam-water transmission line from a wellhead will be either annular or annular mist. This is confirmed broadly by the few direct observations that exist, although the transition from annular to mist flow is 


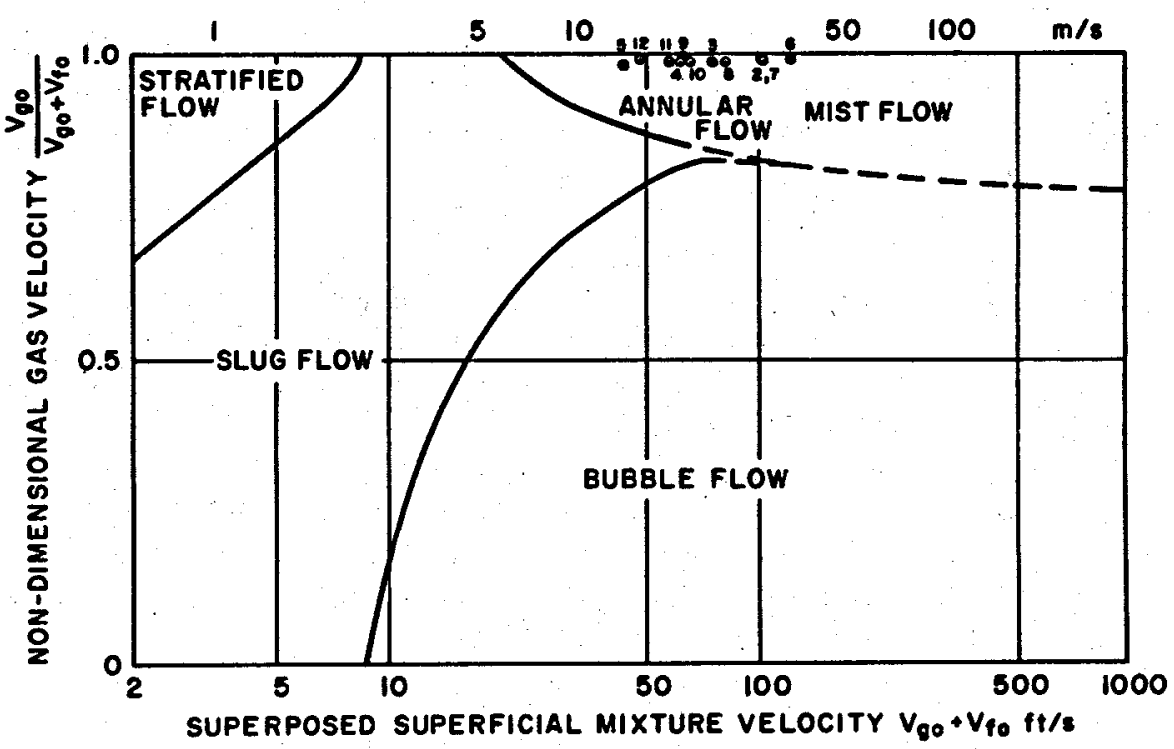

[AFTER TAKAHASHI, ET AL, 1970]

FIGURE 2.45-:Experimental points shown on Hughes flow regime diagram.

not well defined, and one would not expect it to be so. This apparently satisfactory agreement between prediction and observation should, however, be accepted with caution. When discussing the vertical well, section 2.6.3.2, it was pointed out that flow pattern diagrams have been devised empirically by fitting transition boundaries to experimental observations made with systems very different from the geothermal well. This reservation is also true for the surface transmission system. A new model has now become available for which the transitions are based wholly on physical concepts [Taitel and Dukler, 1976], and this should be fully predictive for horizontal and near-horizontal flow.

2.6.5.4 Friction in two-phase fiow. The nature of the two-phase flow is principally of interest in respect of the friction losses incurred. However, it is not necessary to know the flow patterns in a given pipe to obtain the friction loss. This can be found most expeditiously in a steady flow by the direct measurement of pressure gradient, and some of the investigators mentioned in section 2.6.5.4 also took pressure gradient measurements.

Losses in special pipe configurations have not been overlooked. Thus James et al. [1970], investigated the pressure loss in an expansion loop of $0.305 \mathrm{~m}$ (1 ft) diameter having axial lengths 9.4-8.1-9.4 m (30.8-26.6$30.8 \mathrm{ft}$ ) for pressures $0.52 \mathrm{MPa}\left(75 \mathrm{lb} / \mathrm{in}^{2}\right.$ abs.) in both the horizontal and upright positions. Takahashi et al. [1970] studied the losses in pipe bends. They used pressures in the range $0.21-0.25 \mathrm{MPa}\left(30.0-36.7 \mathrm{lb} / \mathrm{in}^{2}\right.$ abs.). Losses in straight pipes, bends of various kinds, and $\mathrm{T}$-junctions for steam- 
water flow in a $0.1 \mathrm{~m}(0.328 \mathrm{ft})$ horizontal pipe have been presented by Freeston [1978]. He employed pressures in the range 0.65-1.1 MPa (94.3$\left.159.5 \mathrm{lb} / \mathrm{in}^{2}\right)$ and values of dryness fraction in the range $0.05-0.33$.

2.6.5.5 The thermodynamics of geofluid transmission in pipes. This subject is analyzed by the application of the steady flow energy equation to a thermodynamic system defining the flow passage or passages under review. The analysis is in principle identical with that given for the wellbore in section 2.6.1.1, but is reproduced here in order to emphasize certain aspects and to confer greater generality.

We begin by considering a single pipe, which may be straight or curved in any manner, have any inclination and diameter or diameters, and support any valve or fitting. There is, however, no gain or loss of geofluid. Consider the steady flow energy equation for an element of the pipe of the length $d l$ as shown in figure 2.46 (a). Then

$$
d \dot{Q}=\dot{m}\left[d h+d\left(\frac{V^{2}}{2}\right)+g d z\right]
$$

where the mass flow $\dot{m}$ is given by

$$
\dot{m}=\rho_{I T P} V_{1} A_{1}=\rho_{2 T P} V_{2} A_{2}=\rho_{T P} V A
$$

for constant diameter pipe.

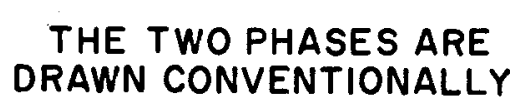
DRAWN CONVENTIONALLY

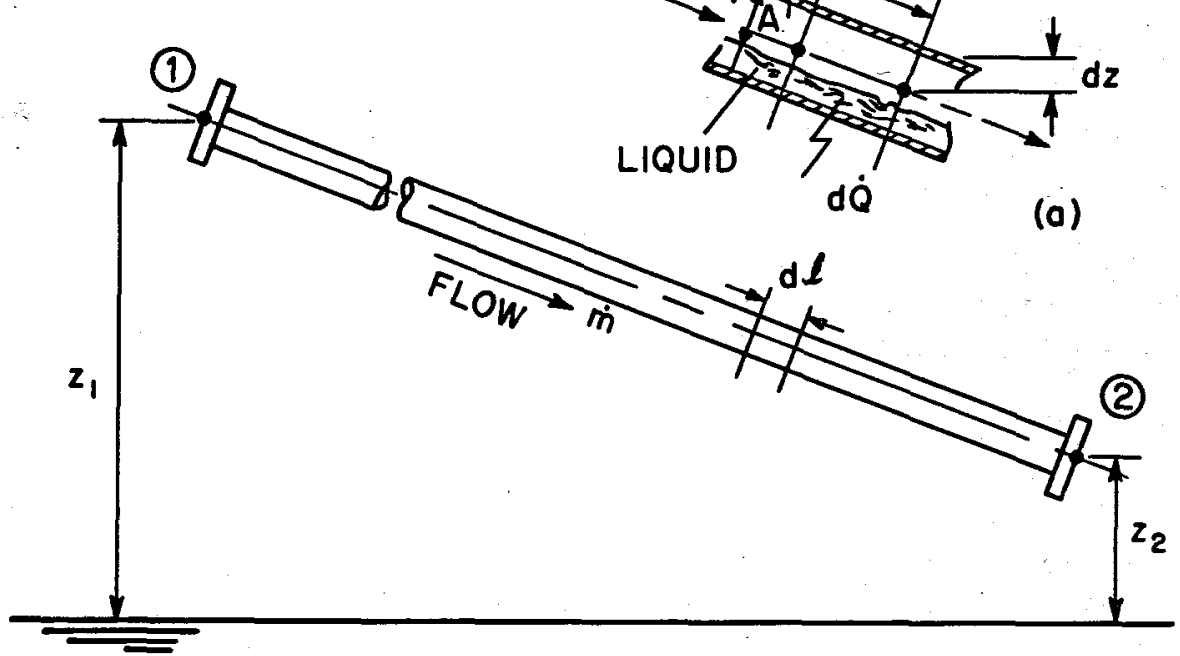

(b)

Fraure 2.46-(a) Element of pipe conveying two-phase fluid. (b) Inclined pipe conveying two-phase fluid. 
Here $\rho_{T P}$ is taken as the homogeneous density, and homogeneous (nonslip) flow is envisioned for the definitions of $h, V$ and $z$. For the complete pipe, figure 2.46b, of length $l$ with the fluid entry at 1 and exit at 2,

$$
\begin{aligned}
\int_{1}^{2} d \dot{Q} & =\dot{m}\left[\int_{h_{1}}^{h_{2}} d h+\int_{V_{1}}^{V_{2}} d\left(\frac{V^{2}}{2}\right)+g \int_{z_{1}}^{z_{2}} d z\right] \\
& =\dot{m}\left[\left(h_{2}-h_{1}\right)+\frac{1}{2}\left(V_{2}^{2}-V_{1}^{2}\right)+g\left(z_{2}-z_{1}\right)\right]
\end{aligned}
$$

The integral

$$
\int_{1}^{2} d \dot{Q}
$$

embraces the aggregate heat transfer between the locations 1 and 2 and cannot be integrated as a function. More correctly,

$$
\int_{1}^{2} d \dot{Q}=\sum_{1}^{2} \Delta \dot{Q}
$$

the constituent parts of which can be identified and treated. Thus this term covers all the heat losses (there will be no gain) from the pipe. These will include heat lost through the thermal insulation, and heat lost by pipe wall conduction at the locations 1 and 2 together with conductive losses into any structures supporting the pipe. In general, the potential energy term $g\left(z_{2}-z_{1}\right)$ will not be significant. Likewise $\nabla_{2}$ may not differ much from $\nabla_{1}$ and thus render insignificant the kinetic energy term $1 / 2\left(\nabla_{2}^{2}-V_{1}^{2}\right)$. Equation 2.115b will, for most purposes, be expressed with sufficient accuracy as

$$
\sum_{1}^{2} \Delta \dot{Q}=\dot{m}\left[h_{2}-h_{1}\right]
$$

Suppose now we consider a branched system of any configuration. Let the inlet quantities be identified by subscripts $1 a, 1 b, 1 c, \ldots, 1 n$ and the exit quantities by $2 a, 2 b, 2 c, \ldots, 2 q$. There are no restrictions on the number of inlets and exits, and $n$ and $q$ are arbitrary symbols denoting respectively the number of entries and exits.

For this case mass continuity requires

$$
\sum_{1=1 a}^{1 n} \dot{m}_{1}=\sum_{1=2 a}^{2 q} \dot{m}_{2}=\sum_{1=1 a}^{1 n} A_{1} V_{1} \rho_{1 T P}=\sum_{1=2 a}^{2 q} A_{2} V_{2 \rho_{2 T P}}
$$

and energy continuity requires

$$
\sum^{\text {grgtem }} \Delta \dot{Q}=\sum_{1=2 a}^{2 a} \dot{m}_{2}\left(h_{2}+\frac{V_{2}^{2}}{2}+g z_{2}\right)-\sum_{1=1 a}^{1 n} \dot{m}_{1}\left(h_{1}+\frac{V_{1}^{2}}{2}+g z_{1}\right)
$$

or, in the abbreviated form corresponding to equation (2.117),

$$
\sum^{\text {System }} \Delta \dot{Q}=\sum_{1=2 \alpha}^{2 q} \dot{m}_{2} h_{2}-\sum_{1=1 \alpha}^{1 n} \dot{m}_{1} h_{1} \text {. }
$$


It may be remarked in passing that all the quantities in equations 2.113 through 2.119 are experimentally measurable. This is not the case for the momentum equations where, for example, the resultant body forces on curved pipes conveying two-phase fluids cannot in practice be determined other than approximately. Momentum considerations involve friction losses in addition to body forces, but none of these categories is relevant to the thermodynamics of two-phase fluid transmission inasmuch as friction losses do not alter the fluid temperature; they merely increase slightly the delivery (exit) dryness fraction. Hence no increase occurs in any $\Delta \dot{Q}$.

The most significant quantity in the above is the aggregate heat loss $\Delta \dot{Q}$. The conducted loss at the boundaries of the pipe or system is small. Where the pipe is supported it is usually possible to avoid conduction paths. Where the pipe is secured or anchored this may prove more difficult. This leaves the heat transfer by convection from the heated surface as the principal mode of loss. This loss is minimized by thermal insulation, though heat loss is not the only criterion in deciding the thickness of the insulating layer. This question has been treated by Pollastri [1970] who has studied the trade-off between the conserved heat, the cost of the insulating layer, and the annual depreciation of the plant.

Notation

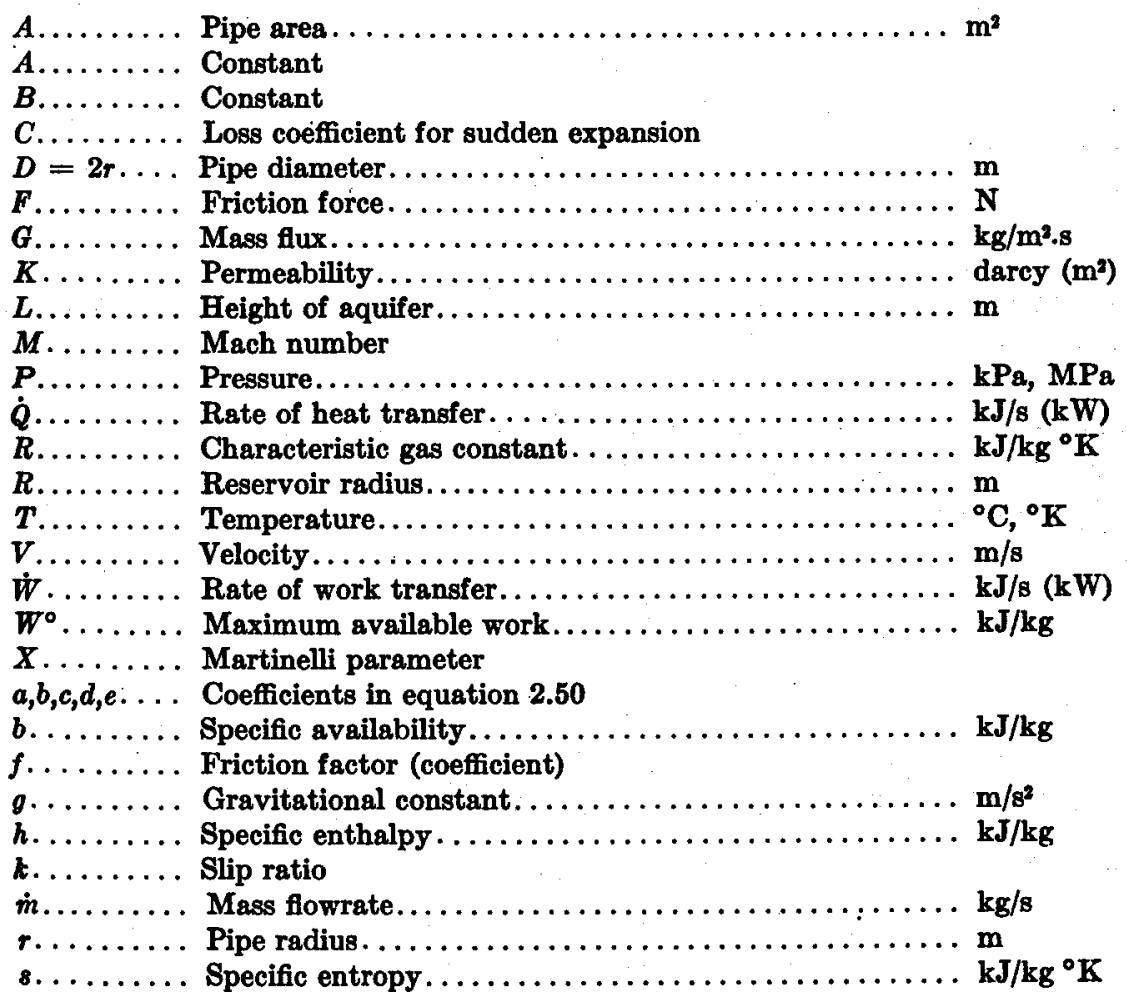


Notation-Continued

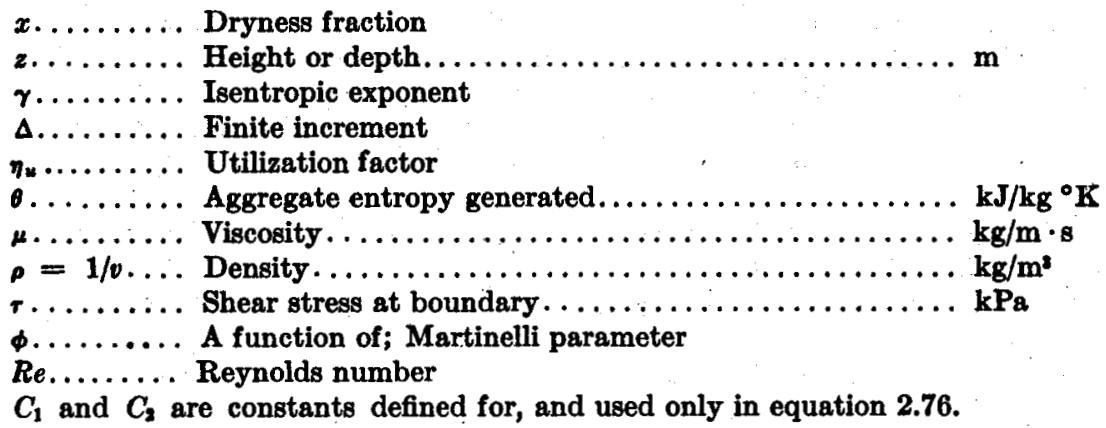

\section{Subscripts}

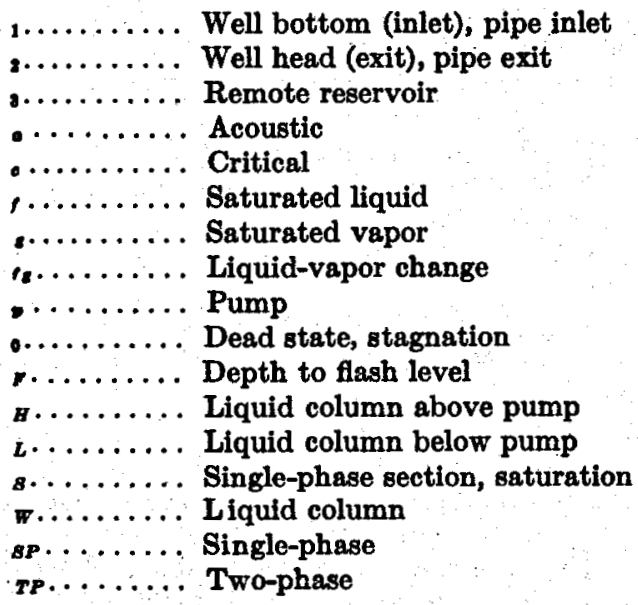

A bar ( $)$ above a symbol denotes a mean value.

$A$ dot ( $)$ above a symbol denotes a time rate.

\section{Additional notation}

$\sigma$ Surface tension dyn/cm

$\lambda$ Baker parameter $\left[\left(\frac{\rho_{g}}{0.075}\right)\left(\frac{\rho_{f}}{62.3}\right)^{0.5}\right\} \begin{aligned} & \mu_{l} \text { in centipoise } \\ & \rho \text { in } 1 \mathrm{bm} / \mathrm{ft}^{3}\end{aligned}$
$\psi$ Baker parameter $\left(\frac{73}{\sigma_{f}}\right)\left[\mu_{l}\left(\frac{62.3}{\rho_{f}}\right)^{2}\right]^{0.5}$
$\sigma$ in dyn/cm

Subscripts

- Superficial value 


\subsubsection{References for section 2.6}

The following two publications are referred to by the abbreviations given:

Pisa-Proceedings of the United Nations Symposium on the Development and Utilization of Geothermal Resources, Pisa, 22 Sept.-1 Oct., 1970.

SF-Proceedings of the Second United Nations Symposium on the Development and Use of Geothermal Resources, San Francisco, Calif., 20-29 May 1975.

Aikawa, K., and Soda, M., 1975. "Advanced design in Hatchobaru geothermal power station," SF 3, pp. 1881-1888.

Alves, G. E., 1959. "Concurrent liquid gas flow in a pipeline contractor," Chem. Engng. Progr., 50, p. 449.

Armstead, H. C. H., and Shaw, J. R., 1970. "Control and safety in geothermal installations," Pisa, 2, 1, pp. 848-864.

Austin, A. L., 1977. "Status of the development of the total flow system for electric power production from geothermal energy," CATMEC Report No. 4, Appendix C, May 1977, Division of Engineering, Brown University, Providence, R.I.

Baker, O., 1954. "Simultaneous flow of oil and gas," Oil Gas J., 53, p. 185.

Banwell, C. J., 1957. "Flow sampling and discharge measurement in geothermal bores," ASME Trans., 79, pp. 269-278.

Banwell, C. J., Cooper, E. R., Thompson, G. E. K., and McCree, K. J., 1957. "Physics of the New Zealand thermal area," N. Z. Dept. Sci. Ind. Res. Bull. 123, 109 pp.

Baroczy, C. J., 1965. "A systematic correlation for two-phase pressure drop," A.I.Ch.E.J. Preprint No. 37. Eighth National Heat Transfer Conference, Los Angeles, Calif.

Belin, R. E., and Knox, F. B., 1955. "The estimation of the distribution and quantity of water in two-phase steam-water systems," New Zealand J. of Sci. and Technology, 37, 3, pp. 385-395.

Belin, R. E., and Bainbridge, A. E.. 1957. "Estimation of dryness fraction and mass discharge of geothermal bores," Proc. Instn. Mech. Engnrs., 171, 36, pp. 967-982.

Bodvarsson, G., and Eggers, D. E., 1972. "The exergy of thermal water," Geothermics, 1, 3, pp. 93-95.

Bodvarsson, G., and Ryley, D. J., 1966. "The measurement of the weight discharge from geothermal steam wells," Jökull, III, 16 ar Reykjavik, pp. 184-198.

Brigham, W. E., Holstein, E. D., and Huntington, R. L., 1957. "Two-phase concurrent flow of liquids and air through inclined pipe," Oil Gas J., Nov. 11, 1957, p. 145.

Calder, C. A., 1976. "Flow-regime characterization for horizontal two-phase flow," LLL Report UCRL-52186, Oct. 5.

Chisholm, D., and Watson, G. C., 1966. "The flow of steam-water mixtures through sharp-edged orifices," National Engineering Laboratory, East Kilbride, Scotland. Report No. 213, Jan. 1966.

Cicchitti, A., Lombardi, C., Silvestri, M., Soldaini, G., and Zavattarelli, R., 1960. "Two-phase cooling experiments-pressure drop, heat transfer and burnout measurements," Energia Nucleare, 7, 6, pp. 407-25.

Cruver, J. E., and Moulton, R. W., 1967. "Critical flow of liquid-vapor mixtures," A.I.Ch.E.J., 13, pp. 52-60.

Cruver, J. E., 1963. "Metastable critical flow of steam-water mixtures," Thesis, University of Washington, 1963.

DeJong, V. J., and Firey, J. C., 1968. "Effect of slip and phase change on sound velocity in steam-water mixtures and the relation to critical flow," Proc. Des. and Eng. IEC, 7, p. 454.

Dukler, A. E., Wicks, M., and Cleveland, R., 1962. "Pressure drop and hold-up in two-phase flow: Part A, A comparison of existing correlations; Part B, An approach through similarity analysis," A.I.ChE. Journal, 10, 1, pp. 38-51. 
Dukler, A. E., 1977. "Modeling void fractions: A new method for predicting flow regimes in geothermal wells," CATMEC Report No. 6, Dec., Division of Engineering, Brown University, Providence, R.I.

Elliott, D. G., 1975. "Comparison of brine production methods and conversion processes for geothermal electric power generation," $E Q L$ Report No. 10, July 1975, California Institute of Technology, Pasadena, Calif.

Elliott, D. G., 1977. "Production well flow," CATMEC Report No. 3, Feb. 1977, Division of Engineering, Brown University, Providence, R.I.

Elliott, D. G., 1978. "Analysis of EM16-29 well flow data," CATMEC Report No. 10, Mar., Division of Engineering, Brown University, Providence, R.I.

Fauske, H. D., 1961. "Critical two-phase steam-water flows," Proc. 1961 Heat Transfer and Fluid Mechanics Institute, Stanford University Press, Stanford, Calif., p. 79.

Fauske, H. K., 1962. "Contribution to the theory of two-phase, one-component critical flow," Thesis, University of Chicago.

Freeston, D. H., 1978. "Duct losses in a geothermal steam-water flow," Conference on Momentum, Heat and Mass Transfer in Two-phase Energy and Chemical Systems, Sept. 4-9, Int. Centre for Heat and Mass Transfer, Dubrovnik, Yugoslavia (in press).

Fukuda, M., Aosaki, K., and Sekoguchi, K., 1975. "Some considerations on well characteristics at Otaki and Hatchobaru geothermal areas, Japan," SF, 3, pp. 1643-1649.

Gould, T. L., 1974. "Vertical two-phase steam-water flow in geothermal wells," $J l$. Petrol. Technology, 26, Aug., pp. 833-842.

Haldane, T. G. N., and Armstead, H. C. H., 1962. "The geothermal power development at Wairakei, New Zealand," Proc. Inst. Mech. Engrs., 176, 23, pp. 603-634.

Henry, R. E., and Fauske, H. K., 1971. "The two-phase critical flow of one-component mixtures in nozzles, orifices and short tubes," J. Heat Transfer, 93, 2, pp. 179-187.

Hewitt, G. F., and Hall-Taylor, N. S., 1970. Annular two-phase flow, Pergamon Press.

Hughes, R. R., 1953. "Flash vaporization," Chem. Engng. Progr., 49, p. 78.

Isbin, H. S., Moy, J. E., and daCruz, A. J. R., 1957. "Two-phase steam-water critical flow," A.I.Ch.E. Journal, 3, pp. 361-365.

James, R., 1962. "Steam-water critical flow through pipes," Proc. Instn. Mech. Engrs., 176, 26, pp. 741-748.

James, R., 1970. "Factors controlling borehole performance," Pisa, 2, 2, pp. 1502-1515.

James, R., 1970. "Power station strategy," Pisa, 2, 2, pp. 1676-1687.

James, R., 1975. "Possible serious effect of the presence of steam on hot water fiow" measurements utilizing an orifice meter," $S F, 3, \mathrm{pp}, 1703-1706$.

James, R., McDowell, G. D., and Allen, M. D., 1970. "Flow of steam-water mixtures through a 12-inch diameter pipeline," Pisa, 2, 2, pp. 1581-1587.

Katto, Y., 1968. "Dynamics of compressible saturated two-phase flow (critical flow)" $J S M E, 11,48$, pp. 1135-1144.

Kosterin, S. I., 1949. "An investigation of the influence of the diameter and inclination of a tube in the hydraulic resistance and flow structure of a gas-liquid mixture," Izv. Ak. Nauk SSSR, Otdel, Tekh. Nauk, No. 12, p. 1824.

Lockhart, R. W., and Martinelli, R. C., 1949. "Proposed correlation of data for isothermal two-phase, two-component flow in a pipe," Chem. Eng. Prog., 45, p. 39.

McNitt, J. R., 1963. "Exploration and development of geothermal power in California," Calif. Div. Mines Geol.Spec. Rept.75.

McNitt, J. R., 1965. "Review of geothermal resources," Terrestrial Heat Flow, Amer. Geophys. Union (Nat. Acad. Sciences) Publication No. 1288, W. H. K. Lee, ed., pp. 240-266.

Martinelli, R. C., and Nelson, D. B., 1948. "Prediction of pressure drop during forced circulation boiling of water," ASME Trans., 70, pp. 695-702.

Mathias, K. E., 1975. "The Mesa geothermal field-a preliminary evaluation of five geothermal wells," $S F, 3$, pp. 1741-1747. 
Nathenson, M., 1974. "Flashing flow in hot-water geothermal wells," $J$. Research U.S. Geol. Survey, 2, 6, pp. 743-751.

Pollastri, G., 1970. "Design and construction of steam pipelines," Pisa, 2, 1, pp. $780-811$.

Rogers Engineering Co., Inc., 1976. "Modular SMW geothermal power plant design considerations and guidelines," DOE (late ERDA), DGE Report UCRL-13684.

Ryley, D. J., 1952. "The flow of wet steam," The Engineer, 193, 338 (I), 363 (II), March 7-14.

Ryley, D. J., 1964a. "Property definition in equilibrium wet steam," Int. J. Mech. Sci., 6 , pp. $445-454$.

Ryley, D. J., 1964b. "Two-phase critical flow in geothermal steam wells," Int.J. Mech. Sci., pp. 273-285.

Ryley, D. J., 1965. "Two-phase critical mist flow," Symposium on Two-Phase Flow, Dept. of Chem. Engrg., Univ. of Exeter, England, Paper G301.

Ryley, D. J., 1966. Contribution to R. James; "Metering of steam-water two-phase flow by sharp-edged orifices," Proc. Instn. Mech. Engrs., 180 (I), 23, pp. 549-572, $1965-6$.

Scott, D. S., 1963. "Properties of co-current liquid-gas flow," Advances in Chem. Engrg., 4, Academic Press, New York.

Smith, R. V., and Leang, J. T., 1975. "Evaluation of correlations for two-phase flowmeters, three current-one new," J. Eng. for Power, pp. 589-595.

Smith, J. H., 1970. "Geothermal development in New Zealand," Pisa, 2, 1, pp. 232-247.

Soda, M., Takahashi, Y., Aikawa, K., Kubota, K. and Ejima, Y., 1975. "Experimental study on transient phenomena in steam-water mixtures flowing through a large pipeline for geothermal power stations," $S F, 3$, pp. 1789-1795.

Stillwell, W. B., Hall, W. K., and Tawhai, J., 1975. "Ground movement in New Zealand geothermal fields," $S F, 2, \mathrm{pp}$. 1427-1434.

Taitel, Y., and Dukler, A. E., 1976. "A model for predicting flow regime transitions in horizontal and near-horizontal gas-liquid flow," A.I.Ch.E.Jl., 22, pp. 47-55.

Takahashi, Y., Hayashida, T., Soezima, S., Aramaki, S., and Soda, M., 1970. "An experiment on pipeline transportation of steam-water mixtures at Otake geothermal field," Pisa, 2, 2, pp. 882-891.

Tolivia, E., 1972. "Flow in geothermal wells (an analytical study)," Geothermics, 1, 4, p. 141-145.

Vakin, E. A., Polak, B. G., Sugrobov, V. M., Erlikh, E. N., Belousov, V. I., and Pilipenko, G. F., 1970. "Recent hydrothermal systems of Kamchatka," Pisa, 2, 2, pp. 1116-1133.

Vohr, J. H., 1960. "Flow patterns of two-phase flow-a literature survey," TID-11514 (Quoted in Hewitt and Hall-Taylor [1970]).

Wigley, D. M., 1970. "Recovery of flash steam from hot bore water," Pisa, 2, 2, pp. 1588-1591.

Yuhara, K., 1970. "Estimation of hydrothermal system by means of wellhead observations," Pisa, 2, 2, pp. 1458-1462.

Yuhara, K., and Tomosada, A., 1965. "Thermodynamical properties of natural steam and hydrothermal structure of Beppu geothermal area." Spec. Contr. Geophys., Inst. Kyoto Univ. 5, 33. 


\title{
Chapter 3
}

\section{Available Work in Geothermal Energy}

\author{
(By J. Kestin)
}

\subsection{Introduction}

The purpose of this chapter is to assemble and to present to the reader the most important thermodynamic considerations which are needed for a clear understanding of the operation of geothermal installations used for the production of electricity. The need for this chapter arises from the fact that the commonly used method of thermodynamic cycle analysis (socalled First-Law analysis) is less suitable for our purpose than the method of available work (so-called Second-Law approach) favored here. It will be pointed out later that in the case of heat engines operating on fossil fuels, the two methods are nearly equally useful though even in this case the method of available work leads to a superior level of understanding. In our case it also lends itself to a more purposeful classification of geothermal wells from the point of view of their thermodynamic potential for the production of work. It is particularly apt in cases when the chemical constitution of the working fluid changes as it traverses the installation.

It is recognized that a designer working for a potential investor must ultimately justify his recommendations on the basis of a realistic calculation of the expected cost of production per kilowatt-hour of electricity at the terminal. It is further recognized that the economic optimum in given circumstances is not coincident with the thermodynamic optimum that we seek to establish in this chapter. However, past experience shows that the latter contains valuable indications for the former and constitutes an indispensable first step. Furthermore, the thermodynamic optimum depends on objective circumstances and the laws of nature, whereas the economic optimum takes into account political, fiscal and legal aspects which govern investment, as well as one's perception of the future course of inflation. These factors are in a continuous flux. For this reason the process of discovering the economic optimum is never definitive. By contrast, the establishment of the thermodynamic optimum can be made into a clear-cut, well-defined scientific problem.

We begin our discussion with a brief description of the nature of a geothermal reservoir and proceed to describe the characteristics of the most 
practical systems for the conversion of geothermal energy into work. This enables us to recognize the essential features of a convenient open system on which to construct the analysis. We then derive the appropriate specialized forms of the First and Second Laws of thermodynamics and introduce the related concepts of optimum available work, $w_{\circ}^{\circ}$, available work, $w^{\circ}$, entropy production, $\theta$, dissipated energy, $w_{d}$, and utilization factor, $\eta_{u}$. To persuade the reader of the utility of these concepts, we discuss the shortcomings of the method of cycle analysis when applied to geothermal plants.

Special attention is devoted to a detailed discussion of the most important general indicators that follow for the designer from a thermodynamic analysis. These include the recognition of the important role of the condenser temperature as it affects work and its sensitivity to changes in the condenser temperature, as well as to the diurnal and annual fluctuations in the temperature of the natural heat sink. Similarly, the overall influence of dissolved salts and evolving inert gases is analyzed.

Section 3.16 describes in detail various methods of graphically interpreting the concept of available work, and section 3.17 discusses the importance of easily accessible, reliable formulations of the thermophysical properties of the pure substances, solutions, and mixtures that the designer needs for success. Existing data are incomplete and contain in them inconsistencies that may present the designer with a seriously confused picture.

\subsection{The geothermal reservoir}

. The term geothermal energy used in the title of this chapter relates to the production of electricity, that is, of work in the thermodynamic sense, from hot fluids under pressure naturally found at a reasonable depth $(1-2 \mathrm{~km})$.in the earth's crust. Disregarding the complex geological details of the formation of such natural reesrvoirs of hot fluids, it is possible to schematize them in the manner shown in figures 3.1 and 3.2. The high tem-

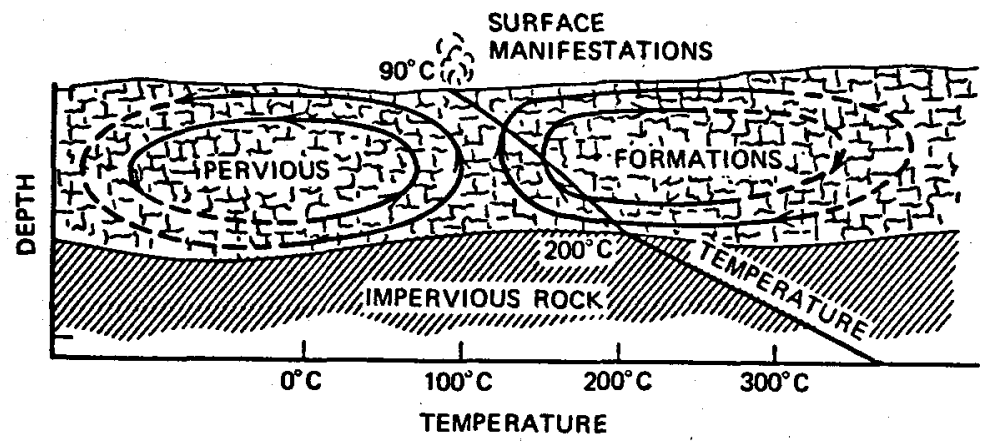

FroURE 3.1-Schematic diagram of the convective cells in a geothermal reserroir showing the temperature distribution, after Facca [1973]. 

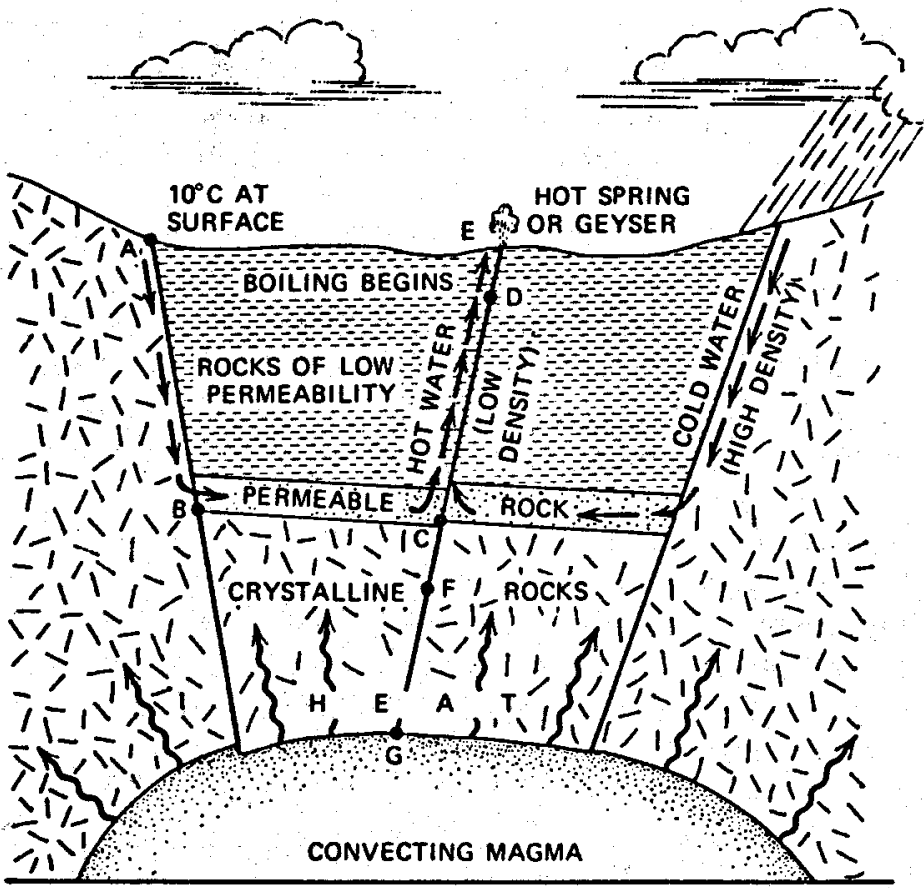

FIGURE 3.2- Schematic diagram of a characteristic geothermal reservoir in a permeable rock showing possible heat transfer and fluid circulation, after White [1973].

perature of the fluid of order $250-300^{\circ} \mathrm{C}$ maximum is caused by the natural convection of high-pressure water through a matrix of permeable rock. The convective cell transfers heat from a hot magmatic intrusion to a more accessible layer whence it may be extracted through an artificially drilled well, with or without the aid of a "downhole" pump. These convective cells operate on a large spatial scale and may extend over as much as $30 \mathrm{~km}$ horizontally. Similarly, the characteristic time of the transfer of heat from the magma is geological in order of magnitude $\left(10^{5}-10^{6} \mathrm{yr}\right)$. At the present time it is not possible to determine the lifetime of a geothermal reservoir, to assess whether the existing natural circulation can make up for the loss of hot fluid for exploitation, or whether by reinjection of the spent fluid it might be possible to establish continuous recirculation thus rendering the resource "renewable." Accumulated experience, however, shows that individual geothermal wells (as distinct from geothermal reservoirs) lose their usefulness after something like $10 \mathrm{yr}$ and must be treated as exhaustible.

As the liquid circulates through the permeable strata it dissolves smaller or larger quantities of minerals, such as sodium chloride $(\mathrm{NaCl})$, potassium chloride $(\mathrm{KCl})$, calcium chloride $\left(\mathrm{CaCl}_{2}\right)$, or silica $\left(\mathrm{SiO}_{2}\right)$, etc., and often also gases, most frequently carbon dioxide $\left(\mathrm{CO}_{2}\right)$ and nitrogen $\left(\mathrm{N}_{2}\right)$. 
In the geopressured reservoirs of the Gulf of Mexico it is common to encounter dissolved, combustible methane $\left(\mathrm{CH}_{4}\right)$. Typical compositions of naturally existing geothermal brines together with their thermodynamic characteristics can be found in Williams et al. [1977] and R. DiPippo $[1978 \mathrm{a}, \mathrm{b}, \mathrm{c}, \mathrm{d}, \mathrm{e}]$.

The type of geothermal resource considered here is described by the term hydrothermal. The possibility of creating an artificially maintained forced circulation through fissures in hot dry rocks is not discussed because it is still in an early stage of development. We also refrain from discussing geopressured resources, resources that rely on radiogenic heating or the methods of exploiting normal gradients and the tapping of heat in the magma.

The geothermal resource, then, is most probably an exhaustible reservoir of a high-pressure, high-temperature aqueous solution of salts and gases in varying proportions. As this substance is made to flow through the well upwards into the regions of lower static pressure, it may flash into steam if at some point the static pressure falls below the saturation pressure for the prevailing temperature. The latter is close to, but not exactly equal to, the vapor pressure of pure water due to the influence of the dissolved substances on the boiling point. Accordingly, the designer may have at his disposal wells which supply him with

(a) wet steam ("vapor-dominated");

(b) slightly superheated or saturated steam ("vapor-dominated");

(c) a liquid solution whose pressure is higher than that at saturation for the given temperature ("liquid-dominated");

(d) a low-quality, liquid-vapor mixture ("liquid-dominated").

It is clear that the first requirement placed on the design is to adapt the elements of the plant to the physical nature of the available fluid.

\subsection{Thermodynamic state at inlet and exit}

The fluid available at the wellhead is utilized, directly or indirectly, to drive a turbine. Proposals to employ alternative types of expanders, particularly in the form of a total-flow machine, have not reached the stage of economic exploitation. When steam is available ("vapor-dominated" reservoir), it is used directly with or without prior separation of its moisture, depending on conditions, Liquid brine ("liquid-dominated" reservoir) can be used to produce superheated or supercritical vapor of a suitable working fluid (freon, isobutane, etc.) which operates a specially designed turbine, the transfer of heat occurring, in most proposals, in a surface heat exchanger. This is the binary type of plant. Alternatively, the brine can be subjected to a single-stage or multiple-stage process of throttling as a result of which a fraction of it flashes into steam or into steam mixed with an inert gas. This is then used to drive a steam turbine. 
All such systems share the common characteristic that the brine, brought to the surface at a pressure and temperature exceeding in magnitude the pressure, $P_{0}$, of the surrounding atmosphere and its temperature, $T_{0}$, is expanded and cooled, supply work at the same time. Thus, the fundamental process of extracting work from the resource does not rely on a cycle, but on the transformation of the working fluid from its initial state 1 $\left(P_{1}, T_{1}\right)$ to some final state $2\left(P_{2}, T_{2}\right)$. The final state 2 is related to the pressure and temperature in the surrounding atmosphere and to the degree of perfection with which we can design the elements of the plant. The basic question that we seek to answer is how to secure the largest work rate attainable per unit mass rate of flow of a given brine.

In our quest for the thermodynamic optimum we shall assume that the initial state 1 is that prevailing at the wellhead. The change in thermodynamic state which occurs between the reservoir and wellhead, and which involves a loss in specific work, cannot be ignored by the designer; it must be taken into account when the design and operation of the well itself is fitted into the general scheme.

We recognize here that the designer of a geothermal plant is in a different situation from that of the designer of a fossil-fuel plant or, even, a nuclear plant in that his freedom to choose the inlet conditions of the working substances or to optimize with respect to them is much more limited. Nevertheless, he can exert some influence on the state at the wellhead under some conditions by his decision to employ or to omit a downhole pump. For example, if conditions are suitable, flashing in the well can be prevented by a downhole pump. Whether the use of such a pump is or is not justified in a particular field is not discussed in this report.

The pressure $P_{0}$ and temperature $T_{0}$ of the surrounding atmosphere are also beyond the designer's control. The pressure $P_{0}$ changes little but the temperature $T_{0}$ is subject to quasiperiodic fluctuations on two widely differing time-scales: diumal and annual. These quasiperiodic fluctuations exert a profound effect on the design of a geothermal plant. In order to understand this influence it is convenient first to analyze the thermodynamic processes that occur here on the assumption of a constant value of $T_{\text {a }}$ (as well as $P_{0}$ ). The effect of varying $T_{0}$ must be studied separately, and the variation of $P_{0}$ constitutes no more than a trivial perturbation of the main analysis. The rate of variation of $T_{0}$ is always slow enough to permit us to regard the time-dependent regime as quasisteady.

The final state 2 is one that the design analysis will determine. The most desirable, and, as must be expected, unattainable optimum will correspond to the highest value, $w_{0}^{\circ}$, of work per unit mass of fluid flowing through the installation. Here, the principles of thermodynamics supply a clear general rule: the largest amount of work will become available under the hypothetical conditions when the process of expansion from state 1 to state 2 and the process of discharge into the surrounding atmosphere occur without entropy production, that is, reversibly. In other 
words, the non-zero change in the entropy of the brine from state 1 to state 2 must be compensated by an equal and opposite change in the entropy of the surrounding atmosphere. For each departure from ideal conditions, a different final state 2 results.

\subsection{Typical installations}

Before we proceed to define the systems in terms of which the thermodynamic analysis is best conducted, it is useful to become familiar with several of the most practical arrangements currently employed or contemplated in the geothermal industry. Schematics of these are contained in figures 3.3-3.8.

Figure 3.3 represents the system used to exploit a direct, dry-steam resource. Steam at state $1\left(P_{1}, T_{1}\right)$ and rate $\dot{m}$ from the production well operates a condensing steam turbine which drives the generator and supplies work at a rate $\dot{W}$ to the surroundings. The condensed liquid, after transferring heat at a rate $\dot{Q}_{0}$ to the surroundings, is returned to the reinjection wells at state $2_{2}\left(P_{2}, T_{2}\right)$. In general, the chemical composition of the working fluid will also change between states 1 and 2 . For the sake of simplicity, it is assumed here that the steam contains no noncondensible gases. The thermodynamic system inside the control surface shown in broken lines is an open one; it communicates with the well at 1 , and with the atmosphere around the remainder of its boundary. The

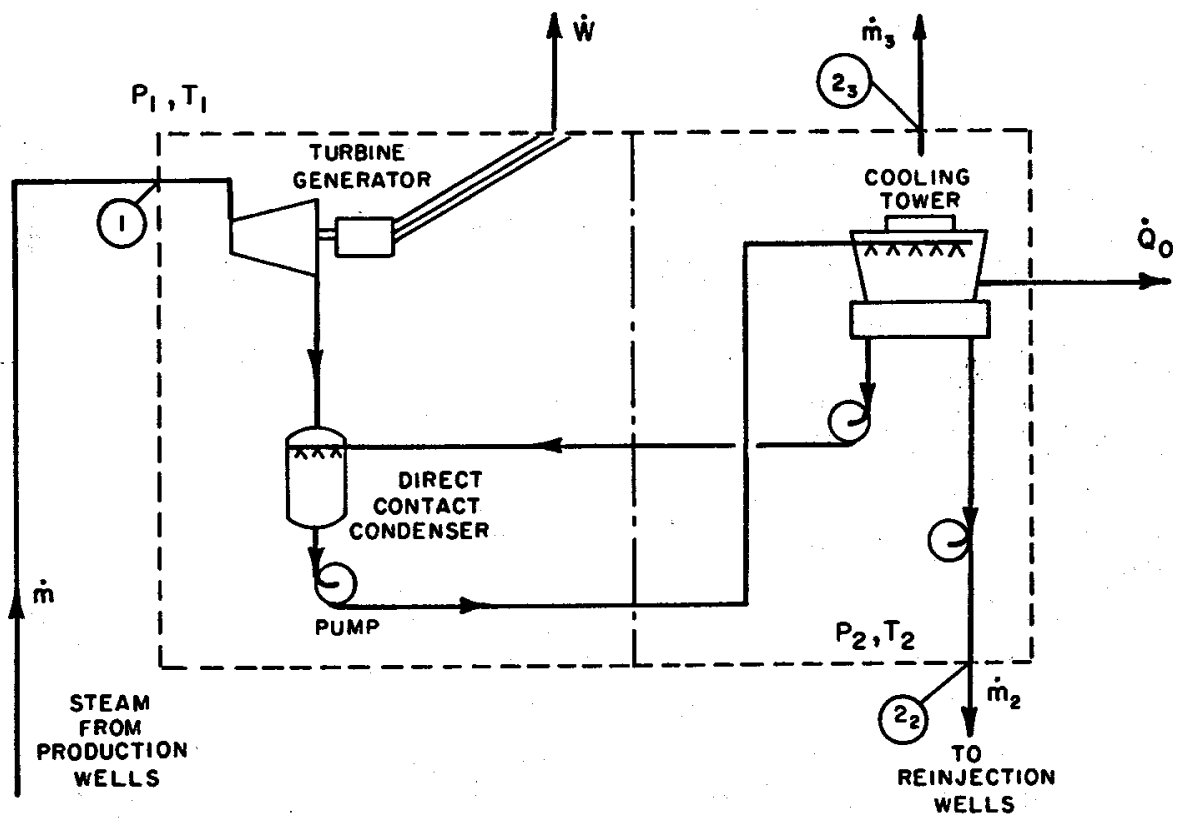

Figure 3.3-Schematic diagram of a direct dry-steam plant. 
work rate $\dot{W}$ is the net quantity measured at the bus bar, with that required to drive the pumps, fans, and other auxiliaries subtracted.

The cooling tower shown in the sketch discharges large quantities of vapor into the atmosphere. This is symbolized by a discharge of fluids at a rate $\dot{m}_{3}$ and at state $2_{3}$. The condensed fluid at state $2_{2}$ and rate $\dot{m}_{2}$ is discharged through the injection wells. By continuity we must have

$$
\dot{m}=\dot{m}_{2}+\dot{m}_{3} .
$$

Since up to $80 \%$ of the flow passing through the turbine may be lost through evaporation, a careful water budget must be established for each plant. In an alternative analysis, the operation of the cooling tower may be accounted for separately, and the control surface may be drawn through the supply and discharge line of the condenser. It should be noted that in normal operation a cooling tower must be supplied with make-up water. This stream has not been marked in figure 3.3 and subsequent diagrams to simplify the presentation. The equations remain essentially unchanged and the inclusion of an additional steam presents no difficulty.

Figure 3.4 contains a schematic diagram of a hydrothermal-steam turbine unit in which the two-phase mixture at 1 is first separated into a stream of vapor and liquid. The thermodynamic open system defined by the broken lines is the same in its essentials as that shown in figure 3.3,

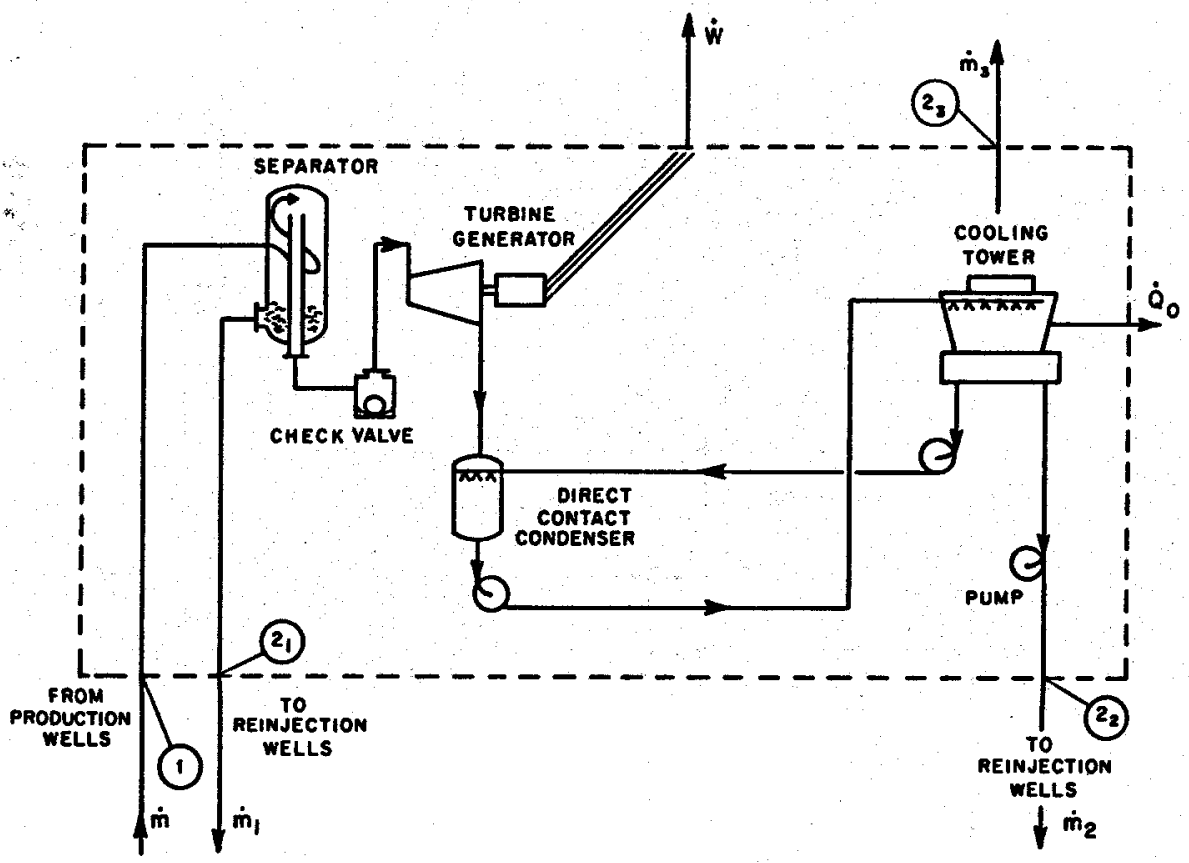

Fioure 3.4-Schematic diagram of a plant which utilizes a two-phase mixture. 
except that now the installation rejects liquid water through two channels : the separated condensate at state $2_{1}$ and rate $\dot{m}_{1}$ and the spent condensate at state $2_{2}$ and rate $\dot{m}_{2}$, with

$$
\dot{m}=\dot{m}_{1}+\dot{m}_{2}+\dot{m}_{3} \text {. }
$$

The schematic diagram in figure 3.5 illustrates the operation of a singleflash system which admits a high-pressure, high-temperature liquid aqueous solution of state $1\left(P_{1}, T_{1}\right)$ from the wells, throttles it in the flasher to produce a stream of liquid rejected at a rate $\dot{m}_{1}$ and a stream of steam which it directs to the turbogenerator. Ultimately, this is rejected as condensate at state $2_{2}$ and rate $\dot{m}_{2}$ after passing through the condenser and cooling tower. The latter loses fluid at rate $\dot{m}_{3}$ and state $2_{3}$ as before.

The diagram in figure 3.6 depicts a so-called double-flash system which operates with a two-phase fluid issuing from the wellhead. The brine is usually found in liquid form in the reservoir but flashes at a relatively high pressure into a mixture in the well. Steam is separated from the mixture in the separator, and the remaining high-pressure liquid is throttled once more in the flasher. In this manner the turbine is presented with two streams of steam, each dry but at a different pressure, and must be designed either as a two-cylinder unit or as a single-cylinder unit with two inlet points.

It would seem advantageous from a thermodynamic point of view to increase the number of flashes in such an installation because an increase

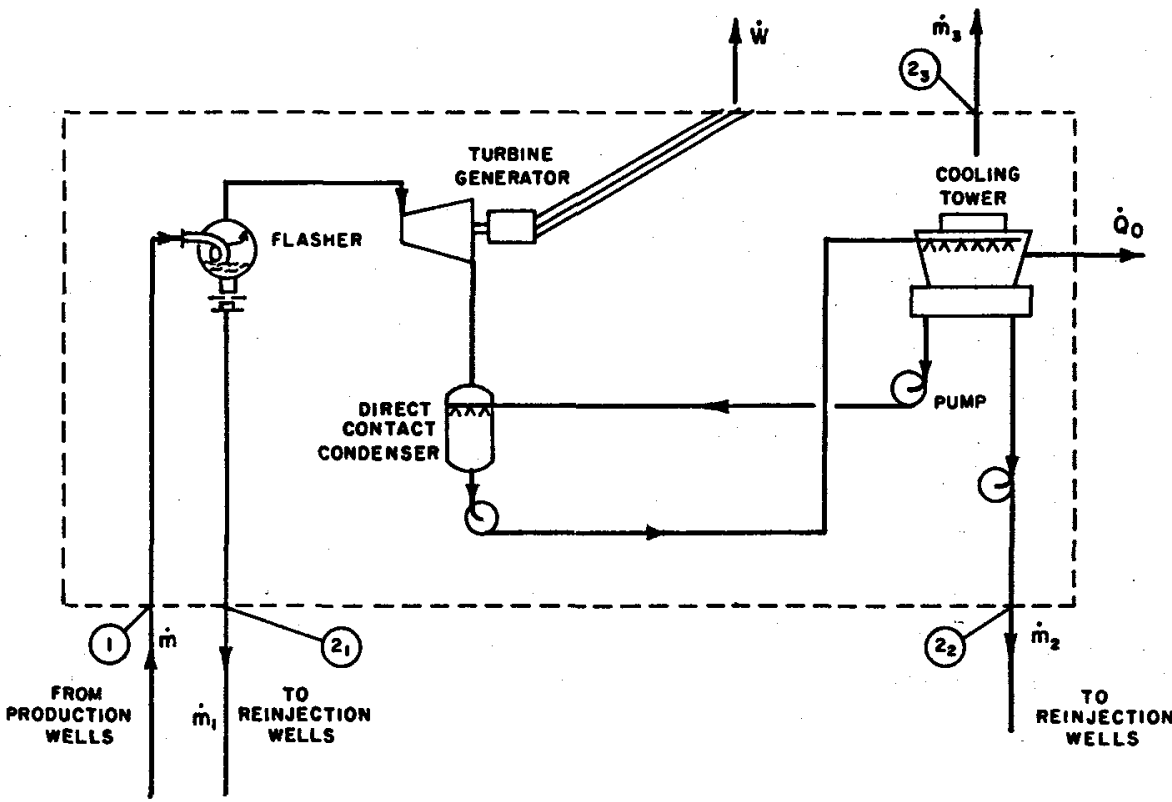

FraUde 3.5-Schematic diagram of a single-flash system. 


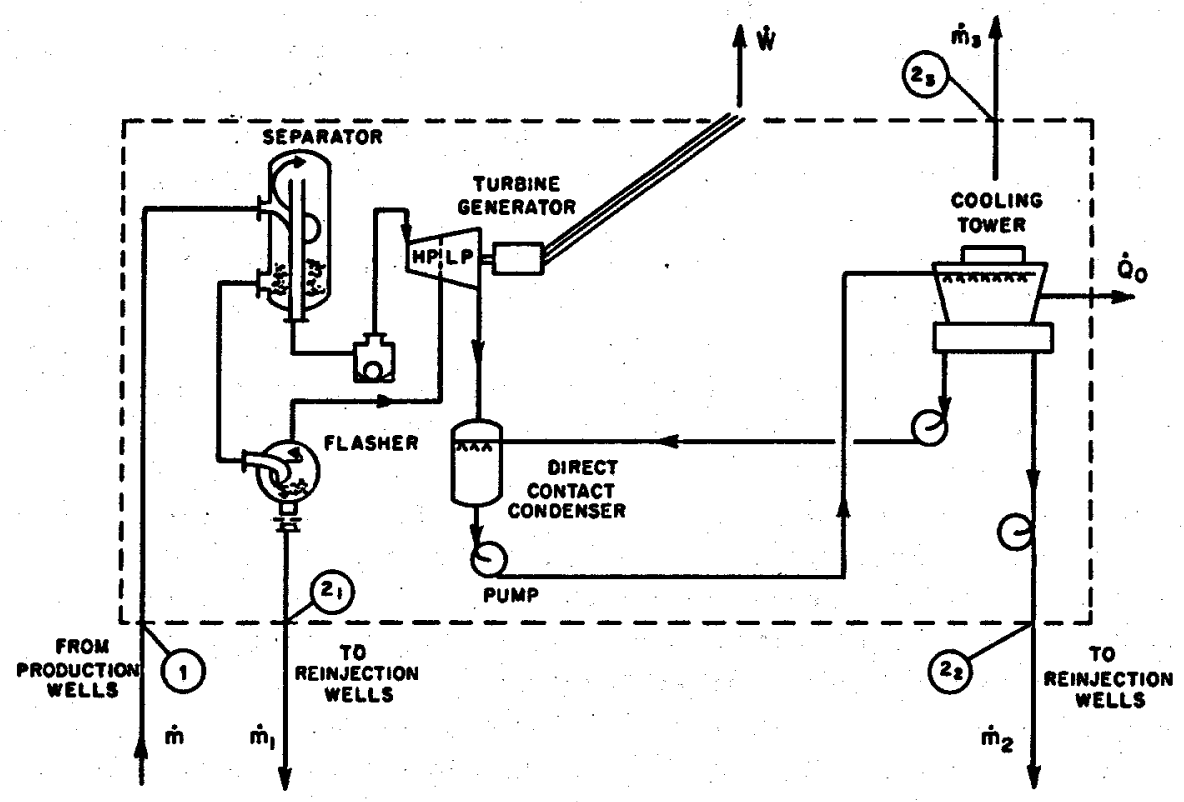

Frgure 3.6-Schematic diagram of double-flash system.

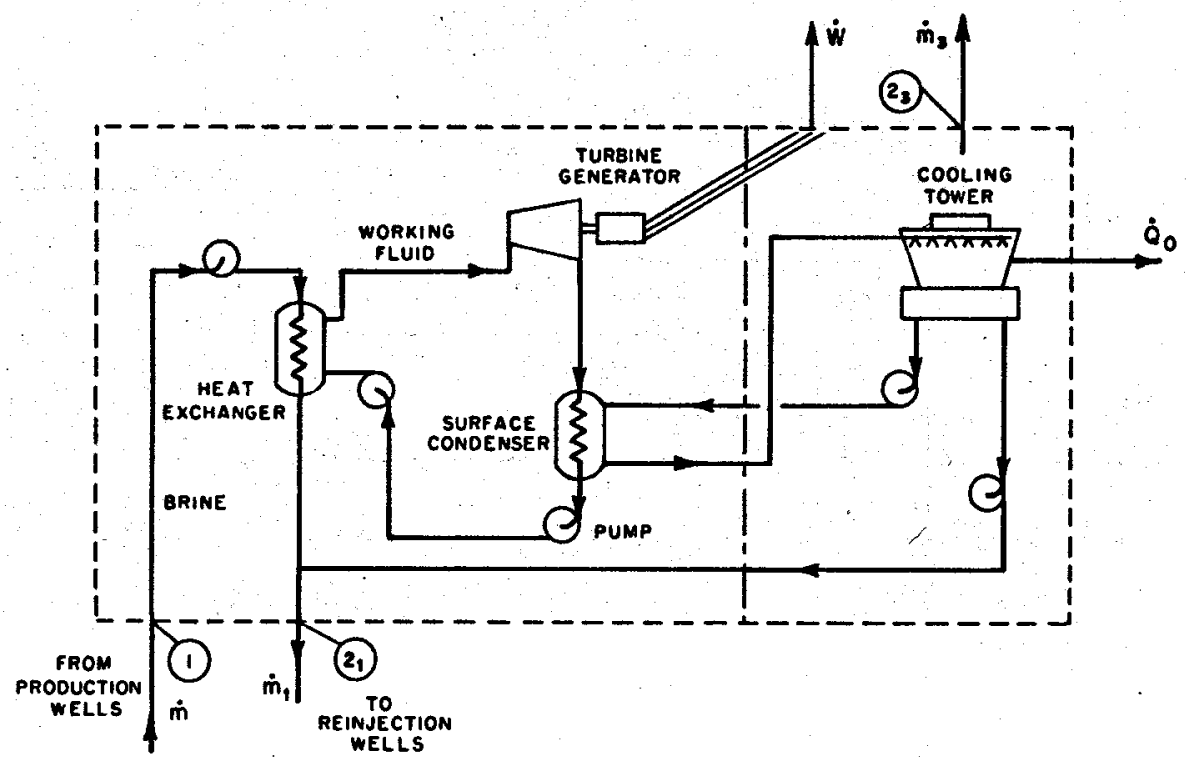

FraURe 3.7-Schematic diagram of binary unit. 
in the number of throttling stages improves the utilization factor, but the increased complexity of the plant reduces the attractiveness of such an arrangement.

The schematic of figure 3.7 represents a binary energy conversion system. Here the hot brine yields its energy in a counterflow heat exchanger to a suitably chosen working fluid characterized by a low boiling point. This may be a fluorocarbon, a hydrocarbon, such as isobutane or pentane, or a mixture of similar substances. The brine transforms its state from 1 to 2 without much change in composition and it should be noted that it does not transfer its heat at a constant temperature but over a range of temperatures from $T_{1}$ to $T_{2}$. The installation is equivalent to an open system which produces net work at a rate $\dot{W}$, rejects heat at a rate $\dot{Q}_{0}$, admits brine at a rate $\dot{m}$ at state 1 and rejects it at states $2_{1}$ and $2_{3}$ at the same total rate. The system contains an intermal loop consisting of the working-fluid side of the heat exchanger, of the turbine and the condenser. The working fluid circulating through this internal loop performs a closed Rankine cycle.

In the final example represented by figure 3.8 it is assumed that the entering brine at state 1 contains in it a dissolved inert gas, such as $\mathrm{CO}_{2}$ or $\mathrm{N}_{2}$. Since the solubility of a gas at the inlet conditions is relatively high, the inlet flow will occur, in most cases, in a single phase. Similarly, as shown here, the mixture of steam and inert gas is homogeneous. This mixture is made to flow through a turbine in which the shaft work is now produced by the joint expansion of vapor and inert gas. Along the path

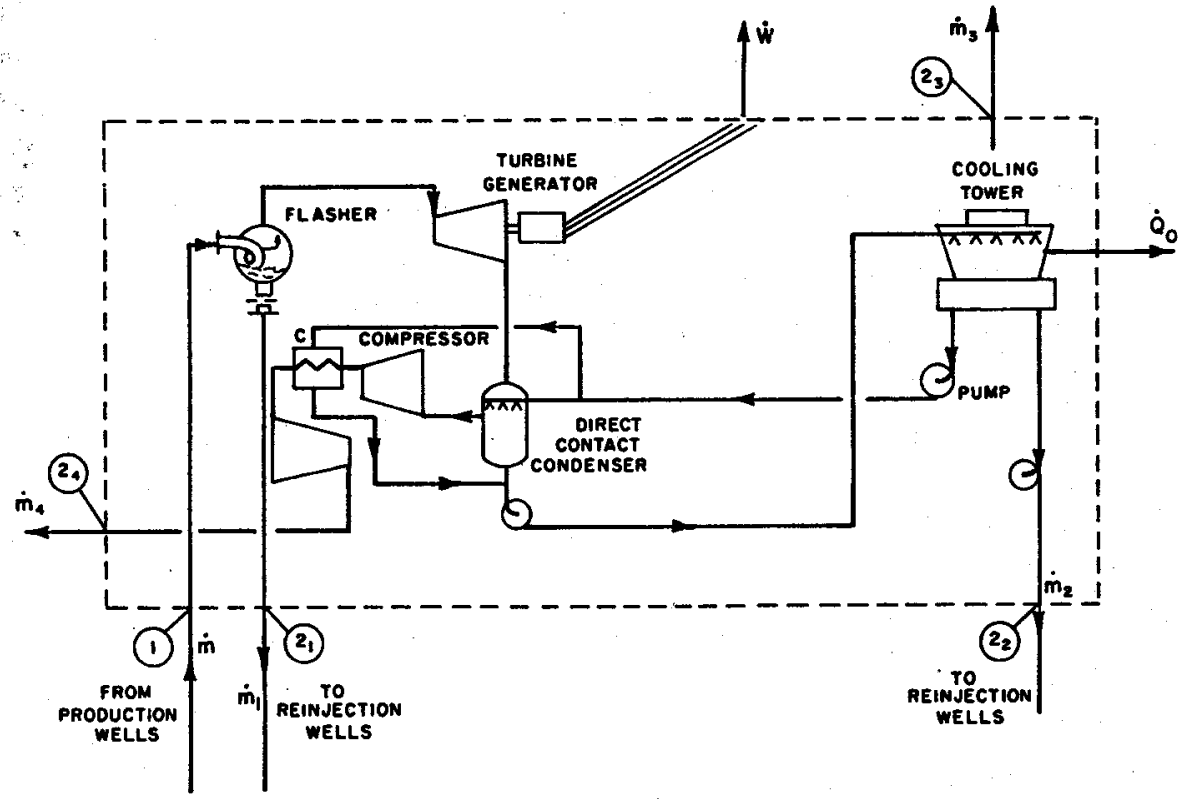

FraURE 3.8-Schematic diagram of a single-flash plant in which the fluid carries a substantial proportion of an inert gas. 
of expansion the steam will partly condense, and the condenser will evolve two phases: the liquid phase in which the dissolved gas constitutes a negligible quantity, and an equilibrium mixture of water vapor and gas. This gas, after initial compression and partial cooling in coil $c$, accompanied by further condénsation, must be compressed again before it can be rejected to the atmosphere. Compression can occur by means of an ejector, which is intrinsically inefficient, or through a rotary compressor. In any case a substantial amount of work must be expended, and this reduces the net work rate $\dot{W}$ compared with an installation with no inert gas. The difference in operation, compared with the previous examples, can be reduced to the observation that the open system has now acquired a channel through which gas at a rate $\dot{m}_{4}$ is rejected to the atmosphere at state $2_{4}$. The control volume shown in the sketch is so drawn as to place the compressor inside it.

\subsection{The thermodynamic system}

The examples of different installations presented in Section 3.4 convince us that we can choose for the analysis of geothermal installations the general open system depicted in figure 3.9. The system receives a steady stream at mass-fiow rate $\dot{m}$ of a fluid at state 1 . The state of the entering fluid is described by its temperature $T_{1}$, its pressure $P_{1}$ (or its quality $x_{1}$ ), the set of mol or mass fractions, $\xi_{1}$, of the noncondensible gases dissolved in it and of the mol or mass fractions, $\zeta_{1}$, of the dissolved solids. The system rejects, against a pressure $P_{o}, n$ streams at respective rates $\dot{m}_{1}, \ldots$, $\dot{m}_{i}, \ldots, \dot{m}_{n}$, each state being described by a similar set of parameters: $P_{2 i}, T_{2 i}\left(\right.$ or $\left.x_{2 i}\right), \xi_{2 i}$ and $\zeta_{2 i}$. If the exit pressures are higher than $P_{o}$, it is possible to gain extra work by allowing each stream to expand from $P_{2 i}$ to $\boldsymbol{P}_{0 .}$. In the opposite case, compressors are needed. The system is assumed to communicate with an ideal heat reservoir of constant temperature $T_{0}$ with which it exchanges heat at a rate $Q_{0}$ (positive if into the system, and negative if out of the system). Once started, the system is assumed to operate "spontaneously" producing net work at a rate $\dot{W}$.

We conduct the analysis in terms of open systems operating in steady state. This is justified for two reasons. First, geothermal installations are intrinsically intended for base-load operation involving very long periods of functioning under fixed conditions. Secondly, as already mentioned in connection with temperature variations, the effect of variable conditions is best studied as a quasisteady perturbation of the steady state.

\subsection{The atmosphere}

In the preceding choice of system, the atmosphere has been idealized into a work reservoir of constant back-pressure $P_{a}$ and a heat reservoir of constant temperature $T_{0}$. In accordance with the accepted methodology of 
thermodynamics we assume that the atmosphere, as distinct from the system, is always in equilibrium which is equivalent to saying that it can perform only reversible processes. Thus the work performed by the atmosphere when it is displaced at a volumetric rate $\dot{V}$ is

its energy changes at a rate

$$
\dot{W}_{a}=P_{o} \dot{V},
$$

$$
\dot{U}_{a}=-\dot{Q}_{o}
$$

and its entropy changes at a rate

$$
\dot{S}_{a}=-\dot{Q}_{o} / T_{\circ}
$$

Even though the system performs work against the atmosphere or has work performed on it at the rate $\dot{W}_{a}$, the assumption of "infinite size" for the work reservoir allows us to neglect this term in the computation of $\dot{U}_{a}$, but not in the energy balance of the system proper.

It should be emphasized at this point that the preceding framework for the analysis has been built around the two entities which exist naturally: the brine and the atmosphere. In particular, it recognizes the fact that the atmosphere consitutes the single heat sink which need not be sustained artificially.

\subsection{The Second Law and entropy production}

The so-called second part of the Second Law of thermodynamics [Kestin 1966, 1968, Kestin and Dorfman 1971] is usually formulated as the assertion that the entropy of an isolated system at the end of an irreversible process exceeds that at its begining The restriction to an isolated system is not really necessary, it being sufficient to consider an adiabatic system. Thus we can assert that the entropy of an adiabatic system which exchanges only work with the surroundings must increase from its value $S_{\alpha}^{\text {ad }}$ at the initial equilibrium state to its value $S_{\beta}^{\text {ad }}$ at the final equilibrium state, having performed an irreversible process $\alpha \rightarrow \beta$. It is now convenient to introduce a concept which has proved very fruitful in the study of irreversible processes in continuous systems-that of entropy production $\theta$. In the present application, the difference

$$
S_{\beta}^{\alpha d}-S_{\alpha}^{\text {add }}=\theta, \quad \theta>0,
$$

is defined as the entropy produced by the irreversible process $\alpha \rightarrow \beta$. Taking into account eq. 3.5 we can state the second part of the Second Law by simply asserting that the entropy production must be positive. We may, if we wish, add that in the unattainable case of reversible operation the entropy production vanishes $(\theta=0)$. 


\subsection{The governing equations}

\subsubsection{First Law}

In order to write down the two laws of thermodynamics for the open system shown in Fig. 3.9 it is convenient to create a closed adiabatic sys-

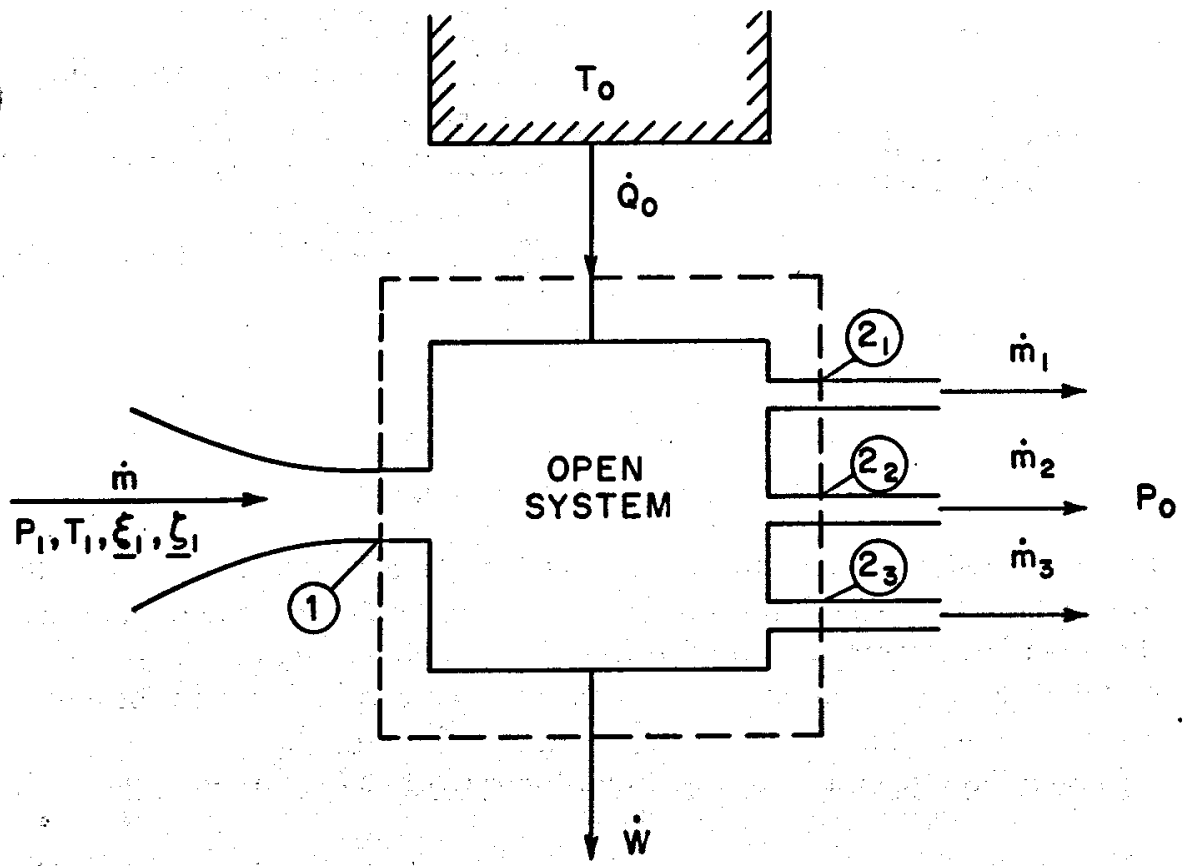

Fiaure 3.9-Open system chosen for the analysis.

tem by observing the installation during an interval of time $d t$ and by including in it

the geothermal plant-the open system of Fig. 3.9

the atmosphere

$\dot{m} d t$ units of brine about to enter the plant (this part "vanishes" from the adiabatic system after time $d t$ )

and by excluding

$n$ elements of volume $\dot{m}_{i} v_{z i} d t$ about to be filled by the effluents (these parts "appear" in the adiabatic system after time $d t$ ).

The adiabatic system is shown sketched in Fig. 3.10 which emphasizes that work must now be performed at the rates 


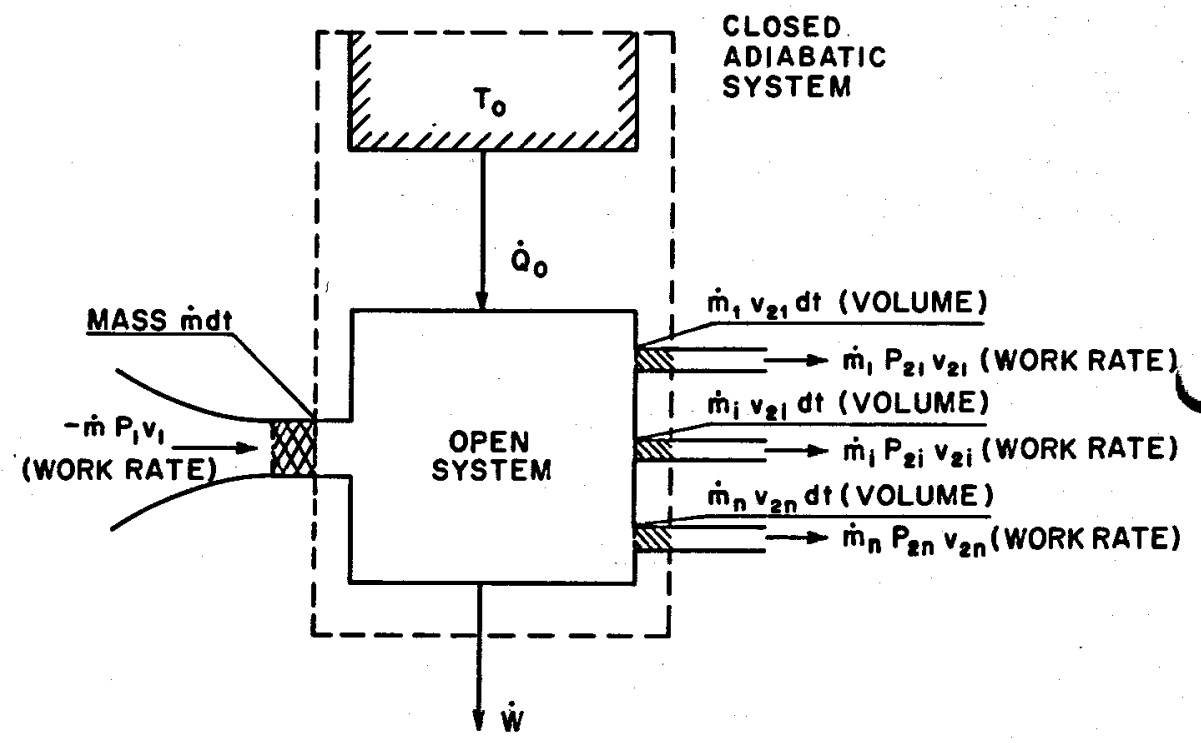

FraURe 3.10-Adiabatic system.

on its boundary in addition to the rate $W$. Here $v$ denotes the specific volume, and the generic term $\dot{m} P v$ represents the rate at which an atmosphere performs work on a fluid being displaced by or against its pressure, as stated in eq. 3.2. The energy of the heat reservoir, included in the closed system, changes at a rate $\dot{U}_{a}=-\dot{Q}_{a}$, as indicated in eq. 3.3.

In an adiabatic system of this kind, the rate of change of energy

$$
\dot{U}_{a}-\dot{m} u_{1}+\sum^{n} \dot{m}_{i} u_{2 i}=-\dot{Q}_{0}-\dot{m} u_{1}+\sum^{n} \dot{m}_{i} u_{2 i},
$$

must be balanced by the rate at which work is done by the system

$$
\dot{W}-\dot{m} P_{1} v_{1}+\sum^{n} \dot{m}_{i} P_{2} \imath v_{2 i}
$$

Collecting all terms, and introducing the enthalpy $h=u+P v$, we obtain the following, simple rate equation:

$$
\dot{Q}_{o}-\dot{W}=\sum^{n} \dot{m}_{i} h_{2 i}-\dot{m} h_{1},
$$

with

$$
\sum^{n} \dot{m}_{t}=\dot{m}
$$

In cases where the specific potential energy, $\mathrm{g} L$, with $L$ denoting vertical location with respect to an arbitrary level, and the specific kinetic energy 
of the entering and leaving streams, $1 / 2 \mathscr{V}^{2}$, with $\mathscr{V}$ denoting the velocity, are significant, the energy $u$ must be replaced by

$$
u+g L+\frac{1}{2} \mathscr{V}^{2},
$$

and eq. 3.7 acquires the more general form

$$
\dot{Q}_{0}-\dot{W}=\sum^{n} \dot{m}_{i}\left(h_{2 i}+g L_{2 i}+\frac{1}{2} \mathscr{V}_{2 i^{2}}\right)-\dot{m}\left(h_{1}+g L_{1}+\frac{1}{2} \mathscr{V}_{1^{2}}\right)
$$

In what follows, we shall make use of the form of eq. 3.7 for simplicity, relying on the fact that the user can add the kinetic and potential energy terms to the enthalpy when circumstances justify it.

\subsubsection{Second Law}

In an analogous way, we can write the entropy balance equation 3.5 for the closed system. First, we transform equation 3.5 into the very simple rate equation

$$
\dot{S}^{\text {ad }}=\dot{\theta}
$$

and note that the rate $S^{\text {ad }}$ must include that for the open system as well as for the heat reservoir in acordance with equation 3.4. The former is

$$
-\dot{m} s_{1}+\sum^{n} \dot{m}_{i} s_{2 i}
$$

and we obtain.

$$
-\dot{Q}_{o} / T_{0}-\dot{m} s_{1}+\sum \dot{m}_{t} s_{2 t}=\dot{\theta}
$$

By the elimination of the heat rate $\dot{Q}_{o}$ between equations 3.7 and 3.11 , we obtain the following expression which relates the work rate $\dot{W}$ to the change in state between inlet and outlets and the rate of entropy production caused by the intrinsically irreversible character of real processes:

$$
\dot{W}=\left\{\dot{m} h_{1}-\sum^{n} \dot{m}_{i} \dot{h}_{2 i}\right\}-T_{0}\left\{\dot{m} s_{1}-\sum^{n} \dot{m}_{i} s_{2 t}\right\}-T_{0} \dot{\theta} .
$$

It is useful to introduce the concept of specific work

$$
w=\dot{W} / \dot{m}
$$

per unit mass of brine into equation 3.12. The entropy production per unit mass of brine is denoted by $\theta$, so that

$$
\theta=\dot{\theta} / \dot{m}
$$


We then obtain the equivalent form

where

$$
w=\left\{h_{1}-\sum^{n} \mu_{i} h_{2 i}\right\}-T_{0}\left\{s_{i}-\sum^{n} \mu_{i} s_{2 i}\right\}-T_{0} \theta,
$$

$$
\mu_{i}=\dot{m}_{i} / \dot{m} .
$$

This, and the equivalent equation 3.12, are the most important expressions in this analysis. In the next section we shall proceed to interpret these equations and to adapt them to different circumstances.

As already stated, the two equivalent equations 3.12 and 3.14 relate the specific work (or the work rate) to the change in state described by the properties $h$ and $s$ (plus $L$ and $\mathscr{V}$ if necessary) which has occurred between inlet and outlet. Hence, implicitly at this stage, it is supposed that state 1 as well as all states $2_{i}$ are known. The entropy production, $\theta$, which is a measure of irreversibility, cannot be calculated other than by following all internal processes in detail. The only assumption of importance made during the derivation is that the open, steady-state system exchanges heat with a single thermal reservoir of constant temperature $T_{0}$.

The importance of equations 3.12 and 3.14 stems from the fact that they are valid for any working fluid without restriction, that they include in one formula the effects of the pressure and temperature of the working fluid, the temperature and pressure of the surroundings, the change in composition and phase of the working fluid and, if necessary, the change in elevation and flow velocity.

The quantity of work

$$
w^{\circ}=\left\{h_{1}-\sum^{n} \mu_{i} h_{2 i}\right\}-T_{0}\left\{\delta_{1}-\sum^{n} \mu_{i} s_{2 i}\right\},
$$

obtainable during reversible operation (i.e., at $\theta=0$ ) occupies an important place in our considerations. There is no general agreement as to the terminology for it. Terms such as maximum work, available work or exergy have been advocated. In the next section we shall discover the need for two new terms. For this reason we shall adopt the designation available work for the quantity $w^{\circ}$ from equation 3.16 which represents the work that a system is capable of furnishing during an arbitrary reversible process between a prescribed initial state 1 and a prescribed final state 2 . In the present study state 2 consists of $n$ state specifications for the effluents. The largest possible value, $w_{0}^{\circ}$, of $w^{\circ}$ for given inlet conditions will be defined as the exergy of state 1.

*The quantity $w^{\circ}$ is not really a maximum of $w$ with respect to $\theta$, because the derivative of $w$ does not vanish at $\theta=0$; it is a so-called supremum (largest value over an interval). 
Some authors also introduce the availability function

$$
b=\dot{h}-T_{o} s
$$

in terms of which equation 3.16 can be written

$$
w^{\circ}=b_{1}-\sum_{\mu_{1}}^{n} b_{2 i}
$$

We shall not use the availability function in this report.

It is worth adding here parenthetically that for $w^{\circ}<0$ we have

$$
\left|w^{\circ}\right|=\left\{\sum^{n} \mu_{i} h_{2 i}-h_{1}\right\}-T_{0}\left\{\sum^{n} \mu_{i} s_{2 i}-s_{1}\right\},
$$

which constitutes the smallest* absolute value of work done on the system.

\subsection{Capacity to perform work}

We now proceed to use the form of equation 3.14 to deduce an expression for the largest amount of work that can be derived from a unit mass of brine in its thermodynamic state at the wellhead, state 1 , given a set of conditions in the atmosphere.** We regard this best value, $w_{0}^{\circ}$ of $w$, as the brine's "capacity to perform work." In a conventional exposition which favors the cycle method, this role is ascribed to the "heat content," that is to the difference between the energy or enthalpy of the brine at state 1 and the effluents at the temperature $T_{0}$. We shall motivate our preference in section 3.14.

Since the entropy production, $\theta$, in equation 3.14 must always be positive, the vanishing of $\theta$ is a necessary condition for $w$ to be largest. This, however, is not sufficient, because the process of discharge, as well as all processes external to the adiabatic system of figure 3.10 must be reversible. To achieve reversibility outside the boundaries of the open system, it is further necessary to ensure that all effluents reach pressure $P_{o}$ and temperature $T_{o}$, otherwise the mixing of fluids in the atmosphere at different temperatures or pressures would cause further entropy production. Following J. H. Keenan $[1932,1941]$, we shall describe states $2_{i}$ characterized by $P_{o}, T_{o}$ as the dead state. However, even this is not sufficient, because the chemical nature of the effluents is different from that of the atmosphere, and entropy production due to the mixing of different fuids at constant pressure and temperature will occur. In order to avoid the latter it would be necessary to exhaust the effluents through semipermeable membranes or at a state in which the chemical potential of each species is equal to that which it

*In modern mathematical terminology this is described as an infimum (smallest value over an interval).

* If our goal were to assess the potential represented by a geothermal reservoir, we would choose state 1 in the reservoir itself at shut-off conditions. 
possesses in the atmospheric air. Such an additional process would increase the amount of work performed. A moment's reflection convinces us that this last possibility is unrealistic and that its adoption would be misleading because it would set for the designer a goal that he could not hope to approach by a sizeable, finite margin. For this reason, we adopt as our measure of the brine's capacity to perform work that quantity which results when operation incurs no internal entropy production

$$
\theta=0 \text {, }
$$

and when brine at state 1 is transformed into $n$ effuent streams, each discharge occurring at $P_{0}, T_{0}$ but at a composition $\xi_{2}, \zeta_{2}$ dictated by the operation of the actual plant. For example, in figure 3.8 we assume that the condensate leaving the plant is pure water or an aqueous salt solution, and that the inert gas leaves it at $P_{0}, T_{o}$ (with a very small addition of water vapor) rather than at a state of reduced chemical potential to match that prevailing in the atmosphere.

Bearing in mind the preceding limitations, we now distinguish between two expressions for available work: (a) The available work $w^{\circ}$ which can be obtained by reversible operation for the actual states $2_{i}$ prevailing at the exit, and (b) the available work $w_{o}^{\circ}$ which characterizes fictitious reversible operation to the dead state. We choose the latter as a measure of the brine's capacity to perform work. Thus, we record the following equations:

(a) Actual conditions:

$$
\begin{gathered}
w=\left\{h_{1}-\sum^{n} \mu_{i} h_{2 i}\right\}-T_{0}\left\{s_{1}-\sum^{n} \mu_{i} s_{2 i}\right\}-T_{0} \theta ; \\
w^{\circ}=\left\{h_{1}-\sum^{n} \mu_{i} h_{2 i}\right\}-T_{0}\left\{s_{1}-\sum^{n} \mu_{i} s_{2 i}\right\} ;
\end{gathered}
$$

state at exit: $P_{2 i}, T_{2 i}, \xi_{2 i}, \zeta_{2 i}$.

(b) Dead state reached at exit:

$$
w_{o}^{\circ}=\left\{h_{1}-\sum^{n} \mu_{i} h_{o i}\right\}-T_{0}\left\{s_{1}-\sum^{n} \mu_{i} s_{o i}\right\} ;
$$

state at exit: $P_{o i}, T_{o i}, \xi_{o i}, \zeta_{o i}$.

In order to distinguish between the available work, $w^{\circ}$, which characterizes two arbitrary states 1 and 2 , and its highest value, $w_{0}^{\circ}$ for a given state 1 with respect to a prescribed atmosphere of pressure $P_{o}$ and temperature $T_{o}$, we shall introduce the term exergy and the symbol $e$ for the latter.*

*Exergy, $e$, and availability, $b$, become identical if the enthalpy and entropy of the dead state are both normalized to zero, $h_{0}=\delta_{0}=0$. 
Hence equation 3.22 is equivalent to

$$
e_{1} \equiv w_{o}^{0}=\left\{h_{1}-\sum^{n} \mu_{i} h_{o i}\right\}-T_{0}\left\{s_{1}-\sum^{n} \mu_{i} s_{o i}\right\} .
$$

The exergy, $e_{1}$, of state 1 acquires the character of a thermodynamic potential as soon as $P_{o}$ and $T_{o}$ are laid down, as well as $\xi_{o i}$ and $\zeta_{o i}$. It is easy to see that

with

$$
w^{\circ}=e_{1}-e_{2}
$$

and

$$
e_{2}=\sum_{\mu_{1}}^{n}\left\{h_{2 i}-h_{0 i}-T_{0}\left(8_{2 i}-s_{o i}\right)\right\}
$$

$$
w=e_{1}-e_{2}-T_{0} \theta \text {. }
$$

\subsection{Energy dissipation and utilization factor}

The difference between the available work $w^{\circ}$ and the actual work delivered, $w$, for identical inlet and exhaust conditions is a measure of the shortcomings of the geothermal installation; it represents the work (or what is now fashionably, but inconsistently, called energy) dissipated or lost,

The difference

$$
w_{d}=w^{0}-w=T_{0} \theta
$$

$$
w_{d 0}=w_{0}^{\circ}-w=\left(w_{0}^{\circ}-w^{\circ}\right)+\left(w^{\circ}-w\right)
$$

is a measure of two effects : of the dissipation

$$
w_{d}^{a}=w_{0}^{\circ}-w^{\circ}=T_{0} \theta^{a}=w_{d 0}-w_{d}=e_{2}
$$

resulting from our inability to reach the dead state at exit, and the dissipation

$$
w_{d}=w^{\circ}-w=T_{0} \theta
$$

which generates entropy $\theta$ in the plant and is transferred to the atmosphere.

The entropy production $\theta$, or the real work $w$, can be calculated for an existing installation by carefully assessing all imperfections in the design. This is done by analyzing the thermodynamic processes undergone by the working fluid and by identifying all sources of irreversible behavior in the plant. Such a calculation will also lead us to the determination of all states $2_{i}$, and hence of $w_{d}{ }^{a}$ and $w_{d o}$. In a preliminary design analysis it is customary to introduce an empirical factor $\eta_{u}$, called the utilization factor, whose value is taken from earlier experience with similar installations or simply guessed. The utilization factor for the whole plant is defined as

$$
\eta_{u}=w / w_{0}^{\circ}=1-T_{0}\left(\theta^{a}+\theta\right) w_{0}^{\circ}
$$


that is as the ratio of the work actually delivered to the maximum possible with the given thermodynamic state at the inlet and the characteristics of the atmosphere. Typical values of $\eta_{u}$ for a variety of completed installations and based on the exergy $e_{1}=w^{\circ}$. of the fluid at the wellhead can be found in R. DiPippo [1978b].

The quantities $\theta^{a}+\theta, w_{d o}$ and $\eta_{u}$ are related to each other through the equations

$$
w_{d o}=\frac{1-\eta_{u}}{\eta_{u}} w=w_{o}^{\circ}\left(1-\eta_{u}\right)
$$

and

$$
\theta^{a}+\theta=\frac{1-\eta_{u}}{\eta_{u}} \frac{w}{T_{0}}=\frac{w_{0}^{\circ}\left(1-\eta_{u}\right)}{T_{0}} .
$$

The concept of a utilization factor can also be applied to a work-producing component of the plant, such as, for example, the turbine itself. In this case the utilization factor $\eta_{u}^{\prime}$ of the component is defined as

$$
\ddot{\eta}_{u}^{\prime}=w / w^{\circ}=1-T_{0} \theta / w^{\circ} .
$$

The relations corresponding to equations 3.32 and 3.33 are

$$
w_{a}=\frac{1-\eta_{u}^{\prime}}{\eta_{u}^{\prime}} w=w^{\circ}\left(1-\eta_{u}^{\prime}\right)
$$

and

$$
\theta=\frac{1-\eta_{u}^{\prime}}{\eta_{u}^{\prime}} \frac{w}{T_{o}}=\frac{w^{\circ}\left(1-\eta_{u}^{\prime}\right)}{T_{o}}
$$

\subsection{Rate of heat rejection to atmosphere}

Equation 3.7 combined with equation 3.12 allows us to calculate the rate at which heat is rejected to the atmosphere. Calculating

$$
q_{o}=\dot{Q}_{o} / \dot{m},
$$

that is the rate of heat rejection per unit mass of brine, we obtain

$$
-q_{0}=T_{0}\left\{s_{1}-\sum^{n} \mu_{1} s_{2 i}+\theta\right\} \text {. }
$$

This equation shows that the actual amount of heat rejected exceeds that which would be rejected under ideal operating conditions by the product of the absolute temperature of the atmosphere and the entropy generated by irreversible operation, that is by the dissipated work. By the use of equation 3.31 , it is possible to replace the latter by a combination of a work term and utilization factor. 
The ratio

$$
r=\left(-q_{0}\right) / w=\left(-q_{0}^{\circ}+T_{0} \theta\right) /\left(w^{\circ}-T_{0} \theta\right)
$$

of the heat rejection to the work, and its ideal value

$$
r_{0}^{\circ}=\left(-q_{0}^{\circ}\right) / w_{0}^{\circ},
$$

is a measure which gives an initial idea of the size of the heat rejection system.

We revert to this point in section 3.12 .

\subsection{Numerical examples}

In order to benefit from the equations of sections 3.9-3.11 to the full extent it is necessary to have access to reliable tables of thermodynamic properties of brines of prescribed compositions and of solutions of inert gases in them. These are quite scarce at present, and the matter will be discussed again in section 3.17. For this reason most contemporary calculations rely on the use of simplified models for the properties of brines. Clearly the simplest model is afforded by pure water substance whose thermodynamic properties have been carefully tabulated and sanctioned by a series of international agreements [C. A. Meyer et al., 1967]. However, the effect of dissolved solids must not be underestimated. The diagram in figure 3.11 depicts graphically the variation of the available work,

Fraure 3.11-Available work, $w_{0}^{\circ}$ of pure water at a pressure $P_{1}=8.59 \mathrm{MPa}$ (saturation pressure for $300^{\circ} \mathrm{C}$ ) as a function of temperature $T_{1}$ for $T_{0}=25^{\circ} \mathrm{C}$ and for various solutions of common salt at corresponding saturation pressures.

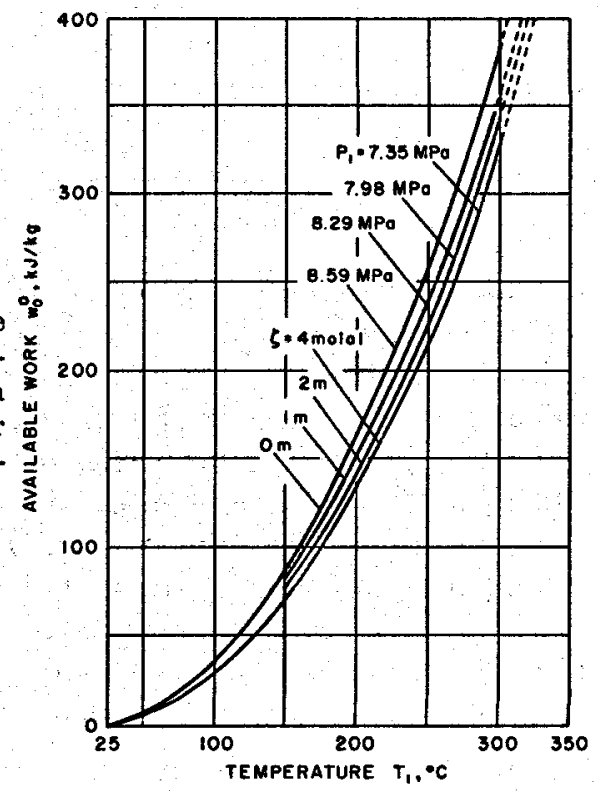

$w_{0}^{\circ}=e_{1}$, of pure water at a pressure of $P_{1}=8.59 \mathrm{MPa}$ (saturation pressure for $300^{\circ} \mathrm{C}$ ) as a function of temperature for $T_{o}=25^{\circ} \mathrm{C}$. The diagram 
also contains curves for solutions of sodium chloride under the same condition and for varying mass fractions $\xi$. At $\xi=1$ molal $^{*}$ (corresponding roughly to $5.5 \%$ of $\mathrm{NaCl}$ by weight), the loss in available work due to the presence of the solute ranges from $6.6 \%$ at $150^{\circ} \mathrm{C}$ to $7.0 \%$ at $300^{\circ} \mathrm{C}$. The properties of the salt solution were taken from Silvester and Pitzer (1976).

Similarly important is the admixture of an inert gas. The diagram in figure 3.12 represents the variation of the exergy for a vapor-dominated

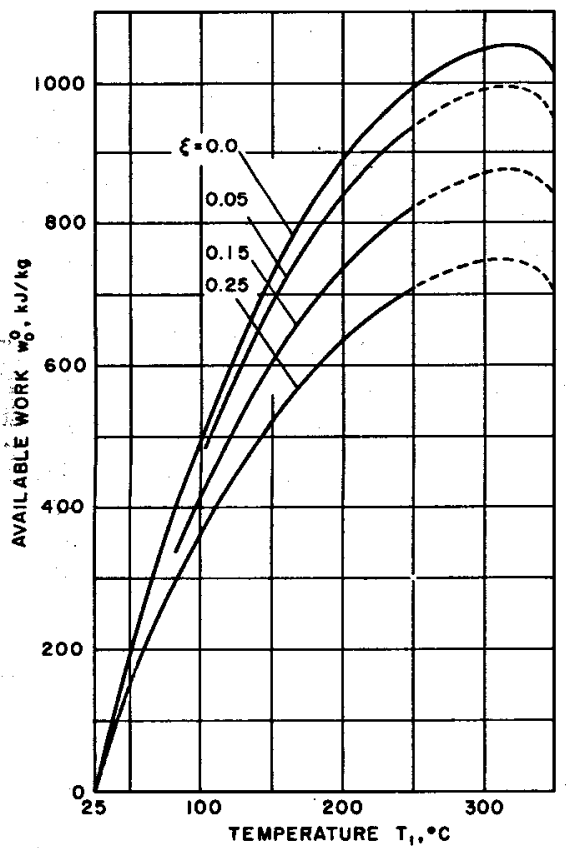

FIGURE 3.12-Available work, $w_{0}^{\circ}$ for a vapor-dominated well as a function of temperature $T_{1}$ and mass fraction of carbon dioxide, $\zeta=\dot{m}_{\text {total }}$. The case $\zeta_{1}=0.15$ roughly corresponds to the conditions encountered at Larderello in Italy.

well as a function of temperature with the mass fraction, $\xi-\dot{m}_{002} /, \dot{m}_{\text {total }}$, of carbon dioxide as a parameter. The case $\xi_{1}=0.15$ roughly corresponds to the conditions encountered in some wells at Larderello in Italy. The calculations have been performed on the assumption that the heat of mixing is negligible. The properties of steam were taken from Keenan et al. [1969] and those of carbon dioxide from Din [1956]. The atmospheric temperature has been assumed to be $T_{o}=25^{\circ} \mathrm{C}$.

The preceding two diagrams confirm the utility of employing available work to rank geothermal wells. Identical quantities of water and brine at the same temperature possess different capacities to perform work. For example, at $T_{1}=150^{\circ} \mathrm{C}, w_{0}^{\circ}=88.0 \mathrm{~kJ} / \mathrm{kg}$ for $\zeta_{i}=0$ and $w_{0}^{\circ}=71.6 \mathrm{~kJ} / \mathrm{kg}$ for $\zeta_{1}=4$ molal. Similarly, the same value $w_{0}^{\circ}=200 \mathrm{~kJ} / \mathrm{kg}$ occurs at

*The molality of a solution is defined as the number of moles of solute for each kilogram of solvent. 
$T_{1}=220^{\circ} \mathrm{C}$ for $\zeta_{1}=0$, and at $T_{1}=242^{\circ} \mathrm{C}$ for $\zeta_{1}=4$ molal. Analogous remarks apply to the mixture of saturated steam and carbon dioxide. One kilogram of mixture with $\xi=0.15$ has a lower capacity to perform work than pure saturated steam (by approximately $17 \%$ at $T_{1}=250^{\circ} \mathrm{C}$ ), both mixtures being at the same temperature but at different pressures, even though in the case of the mixture the partial pressure of steam is equal to its saturation pressure, the addition of carbon dioxide serving to increase the total pressure.

It is interesting to note that the available work of vapor-dominated wells, with or without an inert gas dissolved in the steam, passes through a maximum at a temperature slightly higher than $300^{\circ} \mathrm{C}$.*

Figure 3.13-The ideal available work, $w_{0}^{*}$, and the corresponding rejected heat, $-q_{0}^{\circ}$, for vapor-dominated wells with $T_{\mathrm{o}}=25^{\circ} \mathrm{C}$. The thick line corresponds to the practical range encountered in nuclear power plants.

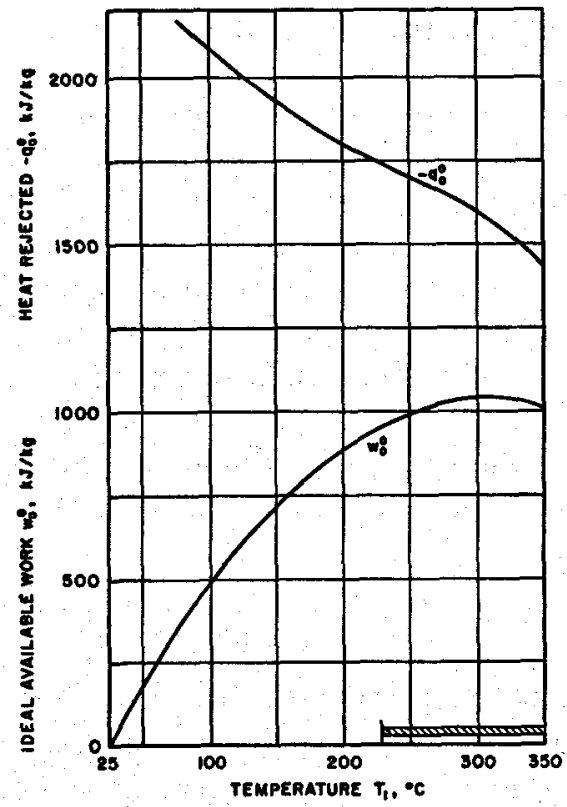

The diagram in figure 3.13 plots in one graph the ideal available work $w_{0}^{\circ}$ as well as the ideal rejected heat, $-q_{0}^{\circ}$, for a vapor-dominated well for pure steam when $\theta=0$. The quantities are given as functions of the inlet temperature $T_{1}$ with $T_{0}=25^{\circ} \mathrm{C}$. The diagram of figure 3.14 contains a cross-plot and represents the ideal ratio

$$
r_{0}^{\circ}=\left(-q_{0}^{0}\right) / w_{0}^{\circ}
$$

This ratio decreases from the very large value $r_{0}^{\circ}=4.3$ at $T_{1}=100^{\circ} \mathrm{C}$ to $r_{0}^{\circ}=1.6$ at $T_{1}=300^{\circ} \mathrm{C}$. The diagram illustrates clearly the fact that the heat rejection rate per unit power produced tends to be very large in geo-

\footnotetext{
*The broken lines in figure 3.12 indicate that the properties of the working fluid have been computed assuming ideal mixing.
} 


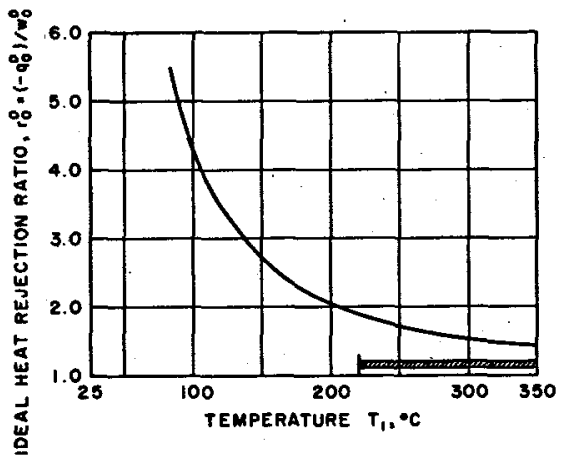

Fradre 3.14-Cross-plot from figure 3.13 showing the ideal heat-rejection ratio $r_{0}^{\circ}=\left(-q_{0}^{\circ}\right) / w_{0}^{\circ}$. The thick line corresponds to the practical range encountered in nuclear power plants.

thermal turbines and equation 3.36 shows that irreversible operation increases the quantity quite considerably by increasing the numerator and decreasing the denominator by the dissipated work $w_{d}=T_{0} \theta$.

For purposes of comparison we have plotted in figure 3.15 the ratio $r_{0}^{\circ}$ for near-critical and supercritical steam turbines operating at $T_{1}=540^{\circ} \mathrm{C}$ and different pressures. In nuclear installations which employ a boilingwater reactor, the steam is dry saturated at turbine inlet. The practical range of temperature $230-350^{\circ} \mathrm{C}$ is marked in figure 3.13 and 3.14. The three diagrams underline the fact that the relative heat rejection rate for a geothermal turbine tends to be higher than for its competitors, necessitating a larger (and more expensive) condenser per unit output. It must, however, be realized that the heat-rejection rate

$$
-\dot{Q}_{0}=-q_{0} \dot{m}
$$

is not identical with the rating of the condenser, because the latter handles only the fraction $\mu_{\mathrm{B}_{2} \mathrm{O}}$ of condensed water which leaves the installation through it. For example, the separated liquid in a flash-type plant bypasses the condenser, but the heat rejected by it to the atmosphere is included in $\left(-q_{0}^{\circ}\right)$. A detailed assessment of the proper condenser load presents no difficulty in individual cases.

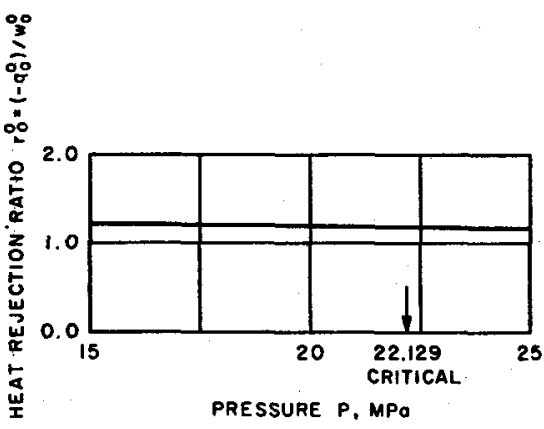

Figure 3.15-The ideal heat-rejection ratio $r_{0}^{\circ}$ for fossil turbines operating at $T_{1}=540^{\circ} \mathrm{C}$ and different pressures. 
It should not be automatically assumed that $q_{0}$ or $q_{0}^{\circ}$ are necessarily negative, even if they turn out to be so in geothermal energy conversion. We shall show in section 3.13 that for combustion processes $-q_{i}^{\bullet}$ is negative $\left(q_{0}^{\circ}>0\right)$ signifying that the process, like a heat pump, extracts heat from the surroundings. In such cases the available work may become larger than the total change in enthalpy

$$
h_{1}-\sum^{n} \mu_{i} h_{2 i}
$$

per unit mass of working fluid. The only quantity with a definite sign is that of entropy production, $\theta$, which must always be positive.

The very high head rejection ratio which occurs at lower temperatures $T_{1}$, illustrated in figure 3.14, suggests that the operation of a geothermal plant must be sensitive to the heat rejection temperature of the working fluid. Here it is necessary to distinguish two effects: (a) an increase in the brine rejection temperature $T_{2} ;(\mathrm{b})$ an increase in the temperature of the environment, $T_{0}$. For pure water, in the former case

$$
w^{\circ}=h_{1}-h_{2}-T_{0}\left(8_{1}-8_{2}\right) \text { and }-q^{\circ}=T_{0}\left(8_{1}-8_{2}\right)
$$

are analyzed as functions of $T_{2}$ with $T_{0}=$ const. In the second case, the expressions

$$
w_{0}^{\circ}=h_{1}-h_{0}-T_{0}\left(s_{1}-s_{0}\right) \text { and }-q_{0}^{\circ}=T_{0}\left(s_{1}-s_{0}\right)
$$

are analyzed as functions of $T_{0}$ on the supposition that $T_{2}=T_{0}$.

FradRe 8.16-The effect of the exit temperature $T_{3}$ on the available work $20^{\circ}$. Brine modelled as pure water. Atmosphere at $T_{0}=25^{\circ} \mathrm{O}$.

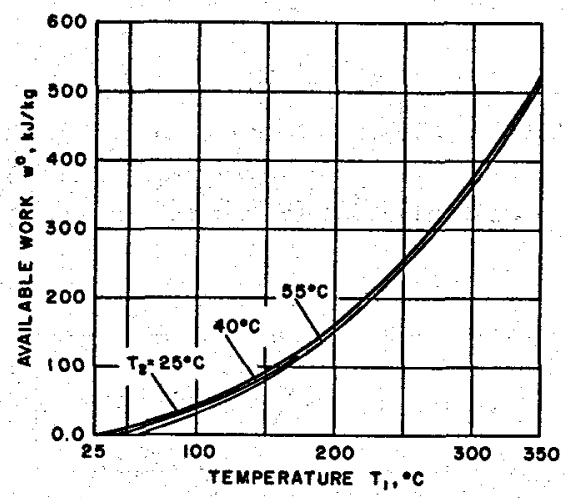

Case (a) implies that the brine is cooled to temperature $T_{2}>T_{0}$, but that heat is rejected in the condenser at the ideal temperature $T_{0}$. This case is illustrated in figures 3.16 and 3.17 which plot the available work $w^{\circ}=e_{1}-e_{2}$ and the heat rejection ratio $r^{\circ}=\left(-q^{\circ}\right) / w^{\circ}$ for pure water operating in an environment of $T_{0}=25^{\circ} \mathrm{C}$ with $T_{2}=25,40$ and $55^{\circ} \mathrm{C}$. The sensitivity to 


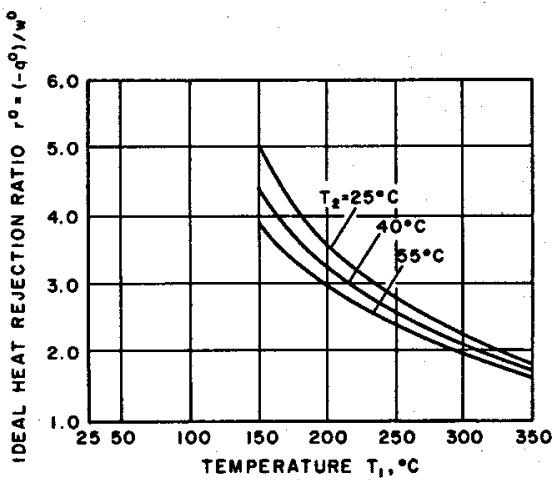

FToure 3.17-Effect of the exit temperature $T_{2}$ on the heat-rejection ratio $r^{\circ}=$ $\left(-q^{\circ}\right) / w^{\circ}$. Atmosphere at $T_{0}=25^{\circ} \mathrm{C}$. Brine inodelled as pure water.

changes in $T_{2}$ is of a few percent (approximately $2 \%$ on changing $T_{2}$ from $25^{\circ} \mathrm{C}$ to $55^{\circ} \mathrm{C}$ to $250^{\circ} \mathrm{C}$ ).

Case (b) implies that the brine is always cooled to $T_{\text {o }}$ equal to the rejection temperature which, itself, is made to assume the values $T_{0}=25,40$ and

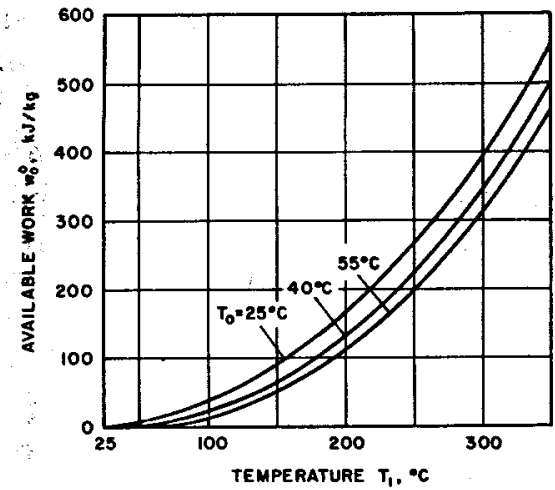

Figure 3.18-Effect of heat-rejection temperature, $T_{\circ}$, on the ideal available work, $w_{\circ}^{\circ}$. Brine modelled as pure water.

$55^{\circ} \mathrm{C}$. This case is illustrated in figures 3.18 and 3.19 and, as expected, the effect turns out to be considerably larger than previously, reaching a drop of $43 \%$ in $w_{0}^{\circ}$ on changing $T_{0}$ from $25^{\circ} \mathrm{C}$ to $55^{\circ} \mathrm{C}$ with $T_{1}=150^{\circ} \mathrm{C}$ as well as an increase of $42 \%$ in $r_{0}^{\circ}$ under the same conditions.

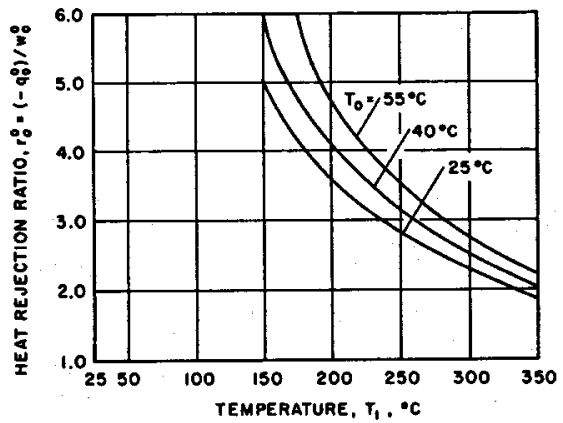

Froure 3.19-Effect of heat-rejection temperature $T_{0}$, on the ideal heat-rejection ratio $r_{0}^{\circ}=\left(-q_{0}^{\circ}\right) / w_{0}^{\circ}$. Brine modelled as pure water. 
It is seen from the preceding equations that a change in $T_{\mathrm{o}}$ in case (b) to $T^{\prime}{ }_{0}=T_{2}$ of case (a) reduces the available work by

$$
\left(T^{\prime \prime}-T_{0}\right)\left(8_{1}-8_{2}\right)
$$

The graphs show that the operation of a geothermal plant is very sensitive to the heat-rejection temperature, particularly, as might be expected, at the lower end of the inlet-temperature range. Comparison with figure 3.18 shows that at $w_{0}^{\circ}=200 \mathrm{~kJ} / \mathrm{kg}$ an increase of $15^{\circ} \mathrm{C}$ or $30^{\circ} \mathrm{C}$ in the heatrejection temperature $T_{2}=T_{\text {o }}$ is equivalent to a loss of $19^{\circ} \mathrm{C}$ and $34^{\circ} \mathrm{C}$, respectively, in the brine inlet temperature.

Similar diagrams could be prepared for operation with saturated steam, but we shall not present them here for the sake of brevity. The matter will be illustrated graphically with the aid of $T, 8$ diagrams in section 3.16.

\subsection{Fossil fuel}

The ideal available work $w_{0}^{\circ}$ in a fossil fuel is governed by the same general expression as that valid for geothermal energy, equation $3.23 \mathrm{~b}$ in section 3.12. The fossil fuel is usually fed to the burner at atmospheric pressure and temperature, and the optimum end condition for the combustion gases is the dead state. Furthermore, the air used for combustion is also aspirated at the dead state. Consequently, it is easy to see that the enthalpy and entropy differences in the above equation can be interpreted as the enthalpy of combustion, $\Delta H^{\circ}$, and the entropy of combustion, $\Delta S^{\circ}$, both taken at the standard state $P_{0}, T_{0}$. In actual fact the negative of these quantities must be taken because the usual convention in chemical tables is to use the symbol $\Delta$ in $\Delta H^{\circ}$ and $\Delta S^{\circ}$ to mean the difference between products (state 2) and reactants (state 1). Consequently,

$$
w_{0}^{\circ}=-\left\{\Delta H^{\circ}-T_{0} \Delta S^{\circ}\right\}=-\Delta G^{\circ},
$$

where $\Delta G^{\circ}$ denotes the Gibbs free energy of the reaction taken at standard conditions.

For example, from standard tables [Kestin, 1968] we can find for the complete combustion of carbon, $\Delta H^{\circ}=-32805 \mathrm{~kJ} / \mathrm{kg}$ and $\Delta G^{\circ}=-32877$ $\mathrm{kJ} / \mathrm{kg}$ so that heat $T_{0} \Delta S^{\circ}=72 \mathrm{~kJ} / \mathrm{kg}$ could be added to a reversible reactor. Similarly, for the complete combustion of methane, $\Delta H^{\circ}=-50181$ $\mathrm{kJ} / \mathrm{kg} ; \Delta G^{\circ}=-50084 \mathrm{~kJ} / \mathrm{kg} ; T_{\circ} \Delta S^{\circ}=-97 \mathrm{~kJ} / \mathrm{kg}$. These two examples demonstrate that the exergy of a fossil fuel differs very little from the enthalpy which can be derived from it upon complete combustion and cooling down to ambient temperature. The circumstance that $T_{\circ} \Delta S>0$ for carbon, indicating that $q_{0}^{\circ}$ is positive, that is, that heat is absorbed from the atmosphere when such a reaction is performed reversibly, as implied by the equation, is secondary for our purposes. We merely add parenthetically 
that the ideal work of a reversible fuel cell would exceed the enthapy made available by the same amount of fuel burned irreversibly.

\subsection{Energy and cycle efficiency as a measure of capacity to per- form work}

The conventional method of ranking thermal power plants and of crudely assessing their economy is to indicate their thermal efficiency. The simplest Carnot cycle assumes the existence of an energy reservoir which is capable of transferring heat at a rate $\dot{Q}=-\dot{U}$ without changing its temperature to an engine operating cyclically.* The adiabatic system which can be used to analyze the performance of such an engine is shown in figure 3.20. The First Law gives

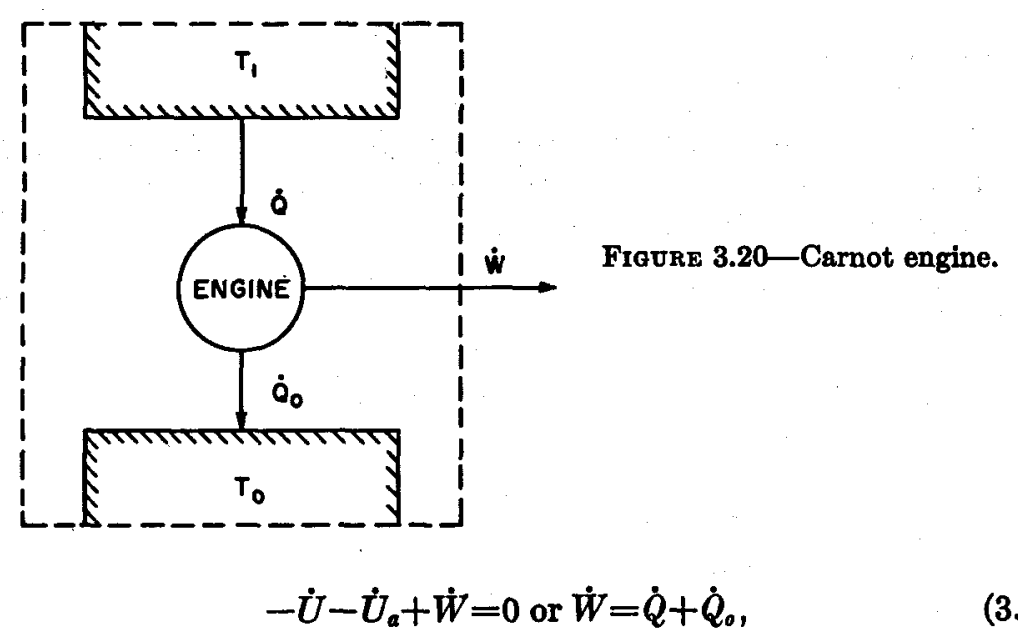

where $\dot{Q}$ and $\dot{Q}_{0}$ are reckoned positive when transferred to the Carnot engine. To conform with accepted conventions, we assign a positive value $Q_{0}$ when it is rejected to the atmosphere at $T_{o}$ and obtain the well-known expression

$$
\dot{W}=\dot{Q}-\dot{Q}_{0}
$$

With the same convention, the Second Law equation becomes

$$
-\dot{Q} / T_{1}+\dot{Q}_{o} / T_{0}=\dot{\theta}
$$

-In this section we refer to any cyclic engine which operates between twoo reservoirs of constant temperatures as a Carnot engine and make an explicit distinction between a reversible and an irreversible Carnot engine, as distinct from a reversible Carnot oucle. 
Referring to a unit mass of working fluid circulating at rate $\dot{m}$ through the Carnot engine, we can easily derive that

and

$$
w=q\left(1-T_{0} / T_{1}\right)-T_{0} \theta
$$

$$
w^{\circ}=q\left(1-T_{d} / T_{1}\right) \text {. }
$$

The preceding argument shows that the standard formula implied in the Carnot efficiency

$$
\eta^{\circ}=\frac{w^{\circ}}{q}=1-T_{0} / T_{1}
$$

is contained as a special case in the method of available work. The plant efficiency, taking into account the production of entropy, is

$$
\eta=\frac{w}{q}=1-\frac{T_{0}}{T_{1}}-\frac{T_{0} \theta}{q}
$$

It is normally argued that an engine operating with two heat reservoirs is superior if the entropy production, $\theta$, is reduced to a minimum, and if $T_{1}$ is as large as possible. This implies that the reference quantity, the heat per unit mass supplied, $q$, can serve as an acceptable measure of the operating cost. In a fossil-fuel plant the heat supplied, $q$, is usually set equal to the negative of the standard enthalpy of combustion $-\Delta H^{\circ}$, so that

$$
\eta=\frac{w}{\left(-\Delta H^{\circ}\right)}=1-\frac{T_{0}}{T_{1}}-\frac{T_{0} \theta}{\left(-\Delta H^{\circ}\right)}
$$

can be accepted as a first measure of economy. It was shown in section 3.13 that the energy of a fossil fuel is nearly equal to its standard heat of reaction and it follows that the utilization factor

$$
\eta_{u}=\frac{w}{w_{a}^{\circ}}
$$

is practically identical with the plant efficiency, equation 3.46 in this circumstances. Hence either $\eta$ or its equivalent, $\eta_{u}$, can be adopted as a crude economic measure, because $\Delta H^{\circ}$ or $w_{0}^{\circ}$ is proportional to the economic value of the fuel. A fossil fuel can be burned in a furnace at a temperature far exceeding the maximum admissible for existing turbine-blade materials, and $T_{1}$ can, therefore, be interpreted as the contemporary metallurgical Timit.

In the geothermal application the circumstances are different. First, the maximum temperature of a brine is far below the metallurgical limit. Consequently, the process of cooling the brine from $T_{1}$ to $T_{0}$ cannot be modelled 
by a heat reservoir of constant temperature $T_{1}$. Instead, the work per unit mass of brine is now

$$
w=h_{1}-h_{2}-T_{0}\left(s_{1}-s_{2}\right)-T_{0} \theta,
$$

if we simply assume (as in a binary system) that the brine is used to heat a working fluid which performs a Rankine cycle. In a plant of this kind

$$
\begin{aligned}
\eta_{u} & =\frac{w}{w^{\circ}}=\frac{h_{1}-h_{2}-T_{0}\left(s_{1}-s_{2}\right)-T_{0} \theta}{h_{1}-h_{2}-T_{0}\left(s_{1}-s_{2}\right)} \\
& =1-\frac{T_{0} \theta}{h_{1}-h_{2}-T_{0}\left(s_{1}-s_{2}\right)},
\end{aligned}
$$

whereas the thermal efficiency would become

$$
\eta=\frac{w}{h_{1}-h_{2}}=1-\frac{T_{0}\left(8_{1}-s_{2}\right)}{h_{1}-h_{2}}-\frac{T_{0} \theta}{h_{1}-h_{2}} .
$$

Now, the utilization factor and the thermal efficiency are not, even approximately, equal, because $T_{0}\left(8_{1}-8_{2}\right)$ and $h_{1}-h_{2}$ are of comparable orders of magnitude.

The diagram in figure 3.18 represents the available work $w_{0}^{\circ}$ for pure water at saturation pressure as a function of temperature $T_{1}$ for three rejection temperatures $T_{\circ}=25^{\circ} \mathrm{C}, 40^{\circ} \mathrm{C}$ and $55^{\circ} \mathrm{C}$. The corresponding ideal cycle efficiency is seen plotted in figure 3.21. If we wanted to judge the percentage improvement achieved by a well operating at $T_{1}=300^{\circ} \mathrm{C}$ compared with one at $T_{1}=150^{\circ} \mathrm{C}$ with heat rejection at $40^{\circ} \mathrm{C}$, we would compare $w_{0}^{\circ}=338 \mathrm{~kJ} / \mathrm{kg}$ with $w_{n}^{\circ}=67 \mathrm{~kJ} / \mathrm{kg}$ from figure 3.18 and conclude that the improvement is one by a factor of 5 . Indeed, the first installation would, other things being equal, deliver more than five times as much power as the second one. On the basis of plant thermal efficiency we would compare $\eta=0.285$ with $\eta=0.145$ and conclude that the improvement was merely by a factor of 2. The difference stems from the fact that comparison on the basis of two different enthalpy differences, $h_{1}-h_{2}=465 \mathrm{~kJ} / \mathrm{kg}$ in the second case and $h_{1}-h_{2}=1177 \mathrm{~kJ} / \mathrm{kg}$ in the first case, though consistent with the method of cycles, does not provide us here with an appropriate criterion.

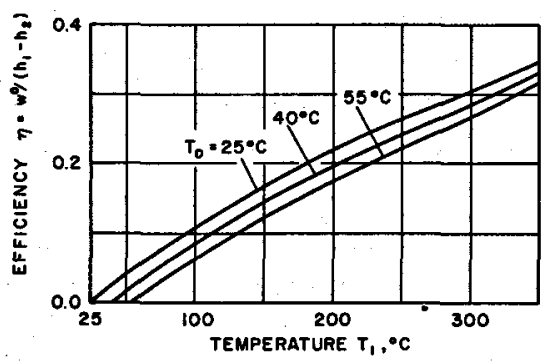

Fraure 3.21-Ideal thermal cycle efficiency $\eta$ from equation (3.51) with $\theta=0$ as a function of temperature $T_{1}$ for three values of $T_{0}$. 
Taking into account the preceding argument, we can motivate our preference for the use of the ideal available work, $w_{0}^{\circ}$ or $w^{\circ}$, as a first measure of a reservoir's "capacity to perform work" because it more nearly represents a thermodynamically defined objective function subject to optimization than does the "heat content" or the efficiency. It is the former quantity rather than the latter two (or the temperature $T_{1}$ ) which truly ranks brines from the point of view of their utility for the production of electricity.

The utility of this concept is enhanced by the fact that it embraces in one short formula the influence of the pressure, temperature, composition, and depth of location of the brine and the effect of the pressure and temperature of the surroundings as already mentioned in section 3.8.2. Furthermore, it applies to all types of geothermal resources, including geopressured, as well as to competing plants: fossil and nuclear. Finally, it provides us with a statement of the thermodynamic ideal for every element of the plant which the designer will attempt to approach more and more closely knowing that he will never reach it. Thus it can serve as a very useful framework for a detailed pre-design analysis.

\subsection{Historical digression}

The concept of available work, $w^{\circ}$, with respect to an idealized atmosphere which has proved so useful as a basis for an initial thermodynamic analysis of geothermal resources is far from being new. Even though there is no universal agreement as to its utility, it seems to belong to the category of concepts which are discovered and rediscovered quite independently from time to time, and many have claimed, or been assigned, priority of discovery. The concept occurs quite explicitly in J. W. Gibbs's famous treatise [1928 or 1961] written in 1878 and in a paper written by M. Gouy in 1889. Its characteristics for chemical reactions seem to have been known to M. E. Jouguet [1917], and the famous author of the first standard treatise on steam and gas turbine design, A. Stodola [1927], makes good use of it; the first, German edition of his work appeared before the First World War! The idea is also mentioned in M. Roy's once popular French treatise on continuum mechanics [1947], and its use has been advocated by Z. Rant $[1953,1956]$ in Germany and introduced into academic teaching by F. Bosnjakovic [1935] and H. D. Baehr [1966]. In this country, J. H. Keenan advocated its use as early as 1932 [see also Kennan et al. 1973], quoting G. Darrieus [1930] as his predecessor. A recent Russian textbook [available in an English translation of 1976] by V. A. Kirilin, V. V. Sychev and A. E. Scheindlin devotes much space to it. Last, we may mention J. Kestin's [1966] general treatise which introduces the concepts of lost and maximum work to the reader.

\subsection{Graphical representation of available work}

When the working fluid is a pure substance or when it passes through the installation without change in its chemical composition, the available 
work can be represented geometrically by areas or distances on the thermodynamic diagrams. These diagrams are also useful when, as a first approximation, the geothermal fluid is modelled by pure water substance. Graphical methods and illustrations can be extended to include mixtures. However, the details of these developments have not been worked out so far.

\section{\$.16.1 General T, s diagram}

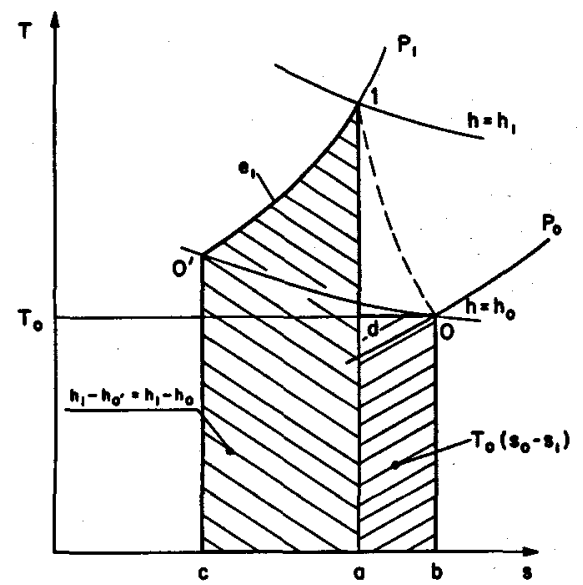

Figdre 3.22a-Representation of exergy as an area on a $T, 8$ diagram $\left(s_{1}-s_{0}\right)<0$.

The diagrams in figures $3.22 \mathrm{a}, \mathrm{b}$ contain a geometrical interpretation of the available work with respect to the dead state, or exergy, in a general $T, s$ diagram. In figure $3.22 \mathrm{a}\left(8_{1}-s_{0}\right)<0$, whereas in figure $3.22 \mathrm{~b}\left(8_{1}-8_{0}\right)>$ 0 . To understand the diagram it should be remembered that the area under an isobar between two points on it is equal to the enthalpy difference. For the process $1 \rightarrow 0$ under consideration, with 0 denoting the dead state, the enthalpy difference is equal to area $10^{\prime} \mathrm{ca}$, point $0^{\prime}$ being the projection on

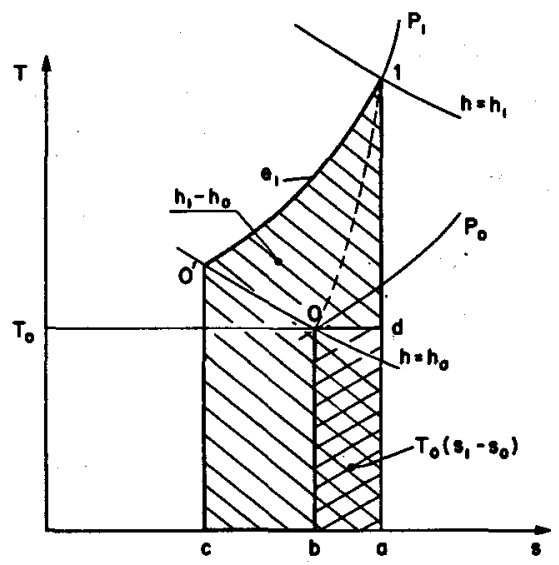

Figure 3.22b-Representation of exergy as an area on a $T$, s diagram $\left(s_{1}-s_{0}\right)>0$. 
isobar $P_{1}$ of point 0 along the curve $h=h_{0}$. The rectangle dOba represents the quantity $-T_{0}\left(s_{1}-s_{0}\right)$. The exergy $e_{1}$ is equal to the area $10^{\prime} \mathrm{cb} 0 \mathrm{~d}$ enclosed by the heavy line. (The reader will observe that the preceding description applies to both versions of the diagram.)

\subsubsection{T, s diagram for steam}

In the case of water and steam, the dead state with $P_{0} \sim 1$ atm and $T_{0} \sim 25^{\circ} \mathrm{C}$ lies very close to the vapor-pressure curve. Moreover, the isobars for liquid water for pressures considerably below the critical merge with the vapor-pressure line for all practical purposes. These details may sometimes cause difficulties of interpretation. The diagram in figure 3.23 gives

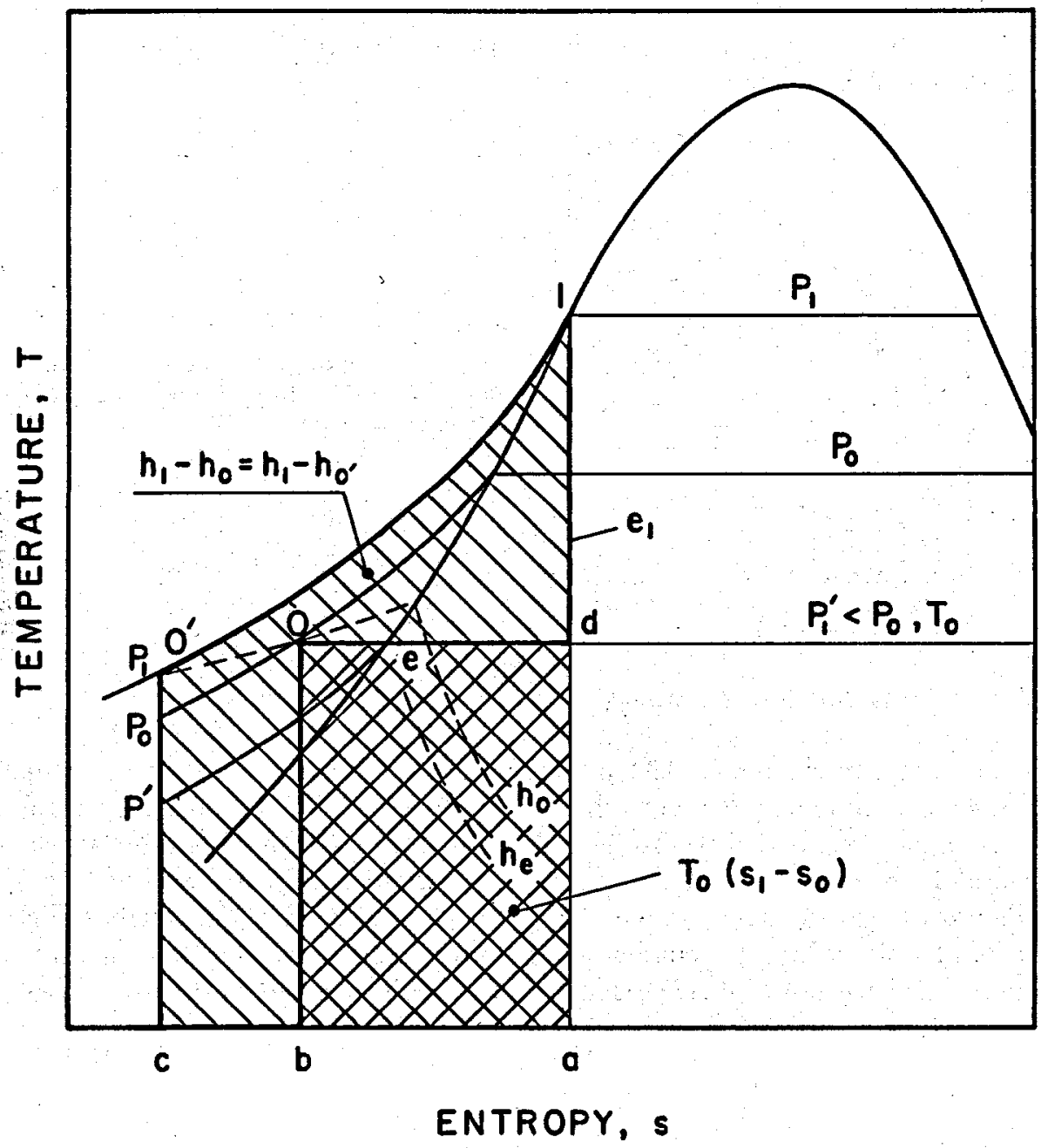

FradRe 3.23-Exergy for pure water (distance of dead state $O$ from vapor-pressure line exaggerated). 
a representation of exergy for saturated liquid water substance, point 1 , modelling a brine being cooled to the dead state 0 . The distances between the vapor-pressure curve and the lines of constant pressure in the liquid region have been exaggerated for emphasis. The accompanying diagram of figure 3.24 is the more familiar version in which the distinction between the vapor-pressure curve and the isobars has been suppressed. The enthalpy difference $h_{1}-h_{0}$ is represented by an area $10^{\prime} \mathrm{ca}$, and the term $T_{0}\left(8_{1}-s_{0}\right)$, area $0 \mathrm{dab}$, is subtracted from it. The condenser pressure $P^{\prime}$ has the saturation value for $T_{0}$ and is lower than the atmospheric pressure $P_{0}$. State $e$ corresponds to the exit from the condenser, and the pumping work, equal to $h_{0}-h_{e}$, has been automatically subtracted from the area which represents the exergy. In many calculations this work is neglected, because it is quite small, as seen from the coalescence of state e and 0 in figure 3.24. The available work, $w_{0}^{\circ}=e_{1}$, is the work that would be recovered in an ideal total-flow machine.

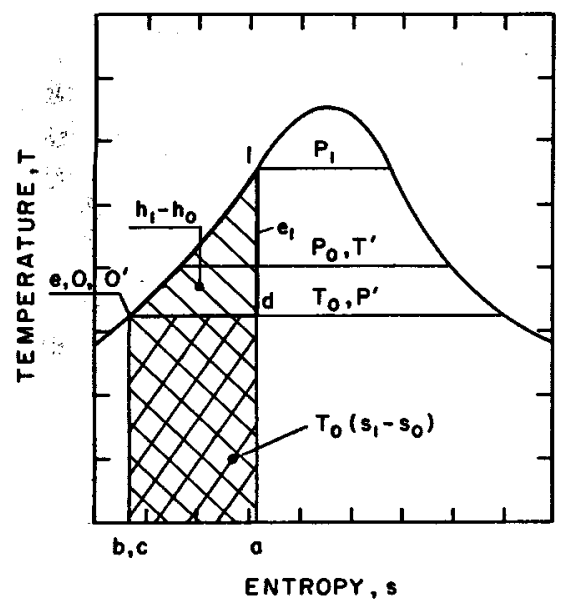

Fraure 3.24-Exergy for pure water (distance of dead state $O$ from vapor pressure line to scale).

\subsubsection{Loss due to free exhaust}

The diagram in figure 3.25 interprets the ideal work, $w_{0}^{\circ}=e_{1}$, of saturated steam upon expansion to the dead state, area 1 def. If the same steam were expanded to the atmospheric back-pressure $P_{0}$, the available work would be reduced to area $1 d^{\prime} e^{\prime} f$, and the diagram illustrates the large amount of additional available work, $e_{2}$, equal to area $e^{\prime} d$ 'de, attributable to the employment of a condenser. The available work, $w^{\circ}$, of a turbine operating with atmospheric exhaust, area $1 d^{\prime} e^{\prime} r$, is equal to the difference

$$
w^{\circ}=e_{1}-e_{2}
$$

of the exergy $e_{1}$ at sate 1 and the exergy $e_{2}$ at state $d^{\prime}$.

To obtain a clearer understanding of the importance of investing in a condenser, we have prepared the diagram of figure 3.26 , which plots the 
Froure 8.25-Gain in avallable work due to the use of a condenser.

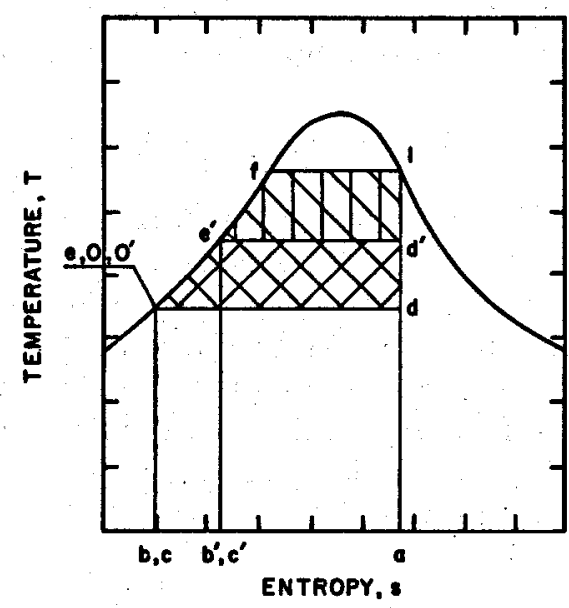

available work carried by saturated steam ranging in tenuperature from $150^{\circ} \mathrm{C}$ to $350^{\circ} \mathrm{C}$ (pressure from $0.48 \mathrm{MPa}$ to $16.5 \mathrm{MPa}$ ) and working against a condenser at $25^{\circ} \mathrm{C}(3.2 \mathrm{kPa})$. The reduction in work in operation with free exhaust is quite large ranging from $66 \%$ at $T_{1}=150^{\circ} \mathrm{C}$ to $37 \%$ at $300^{\circ} \mathrm{C}$. The reader will recognize that the present diagram constitutes an analog of figure 3.18 drawn for saturated steam and corresponds to $T_{0}=100^{\circ} \mathrm{C}$ (atmospheric back-pressure).

It should be clear that the available work in the last example is identical with the ideal work in a reversible Rankine cycle. This is due to the fact

Fiauke 3.26-Loss of a vailable work with atmospheric exhaust.

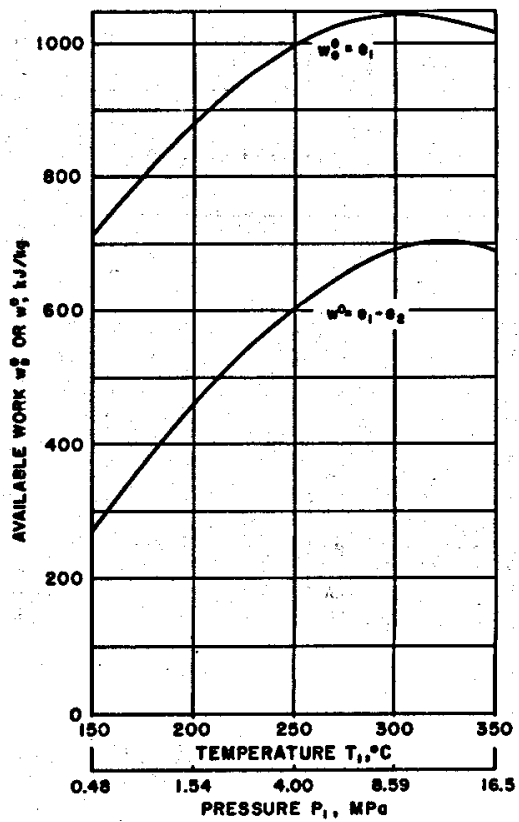


that in such circumstances the process of heating in the boiler from state 0 to state 1 is simply the reverse of isobaric cooling from 1 to 0 .

\subsubsection{Change in exit temperature and in heat-rejection temperature}

To conclude our study of $T, 8$ diagrams, we return to section 3.12 and illustrate the difference between allowing the brine to leave at a temperature $T_{2}>T_{0}$ and changing $T_{0}$ itself. This is done in figures $3.27 \mathrm{a}$ and $\mathrm{b}$. Recalling the diagram of figure 3.24, we see that the loss due to cooling the brine to $T_{2}>T_{0}$ is represented by area 2 edf which is equal to $e_{1}-e_{2}$. In figure $3.27 \mathrm{~b}$, the dead state shifts to $0^{\prime}$ and coincides with previous state 2 . Now the loss is equal to area $00^{\prime} \mathrm{ed}$ which is larger than the earlier loss by the rectangle $\left(T_{0}^{\prime}{ }_{0}-T_{o}\right)\left(s_{1}-8_{2}\right)$, represented by area 2edf, as stated in section 3.1.

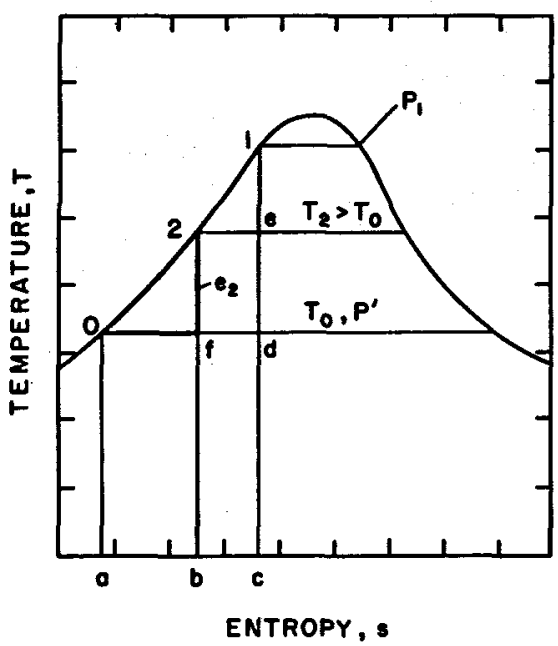

Fiadre 3.27a-Effect of leaving temperature on avallable work; changing $T_{2}$.

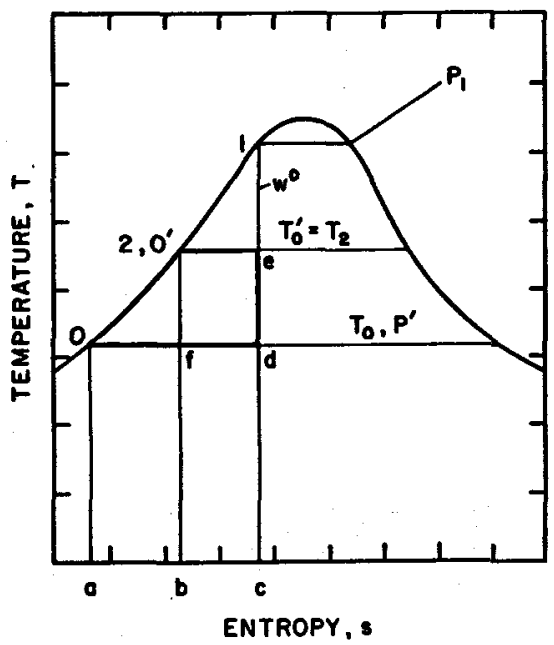

FrouRe 3.27b-Effect of leaving temperature on arailable work; changing $\boldsymbol{T}_{\text {o }}$. 


\subsubsection{The general Mollier diagram}

The available work can be represented by a length instead of an area if a Mollier $(h, s)$ diagram is employed. The sketch in figure 3.28 contains such a diagram for a substance for which the dead state 0 lies far away from the two-phase region. The projection $0^{\prime}$ of the dead state 0 on the vertical through state 1 marks the difference $h_{1}-h_{0}$. Recalling that

$$
(\partial h / \partial s)_{P}=T
$$

we conclude that the tangent $00^{\prime \prime}$ to $P_{o}$ at 0 has a slope equal to $T_{o}$, so that line $00^{\prime \prime}$ forms an angle

$$
\alpha=\tan ^{-1} T_{0}
$$

with the axis of abscissae. This line is called the line of the surroundings;

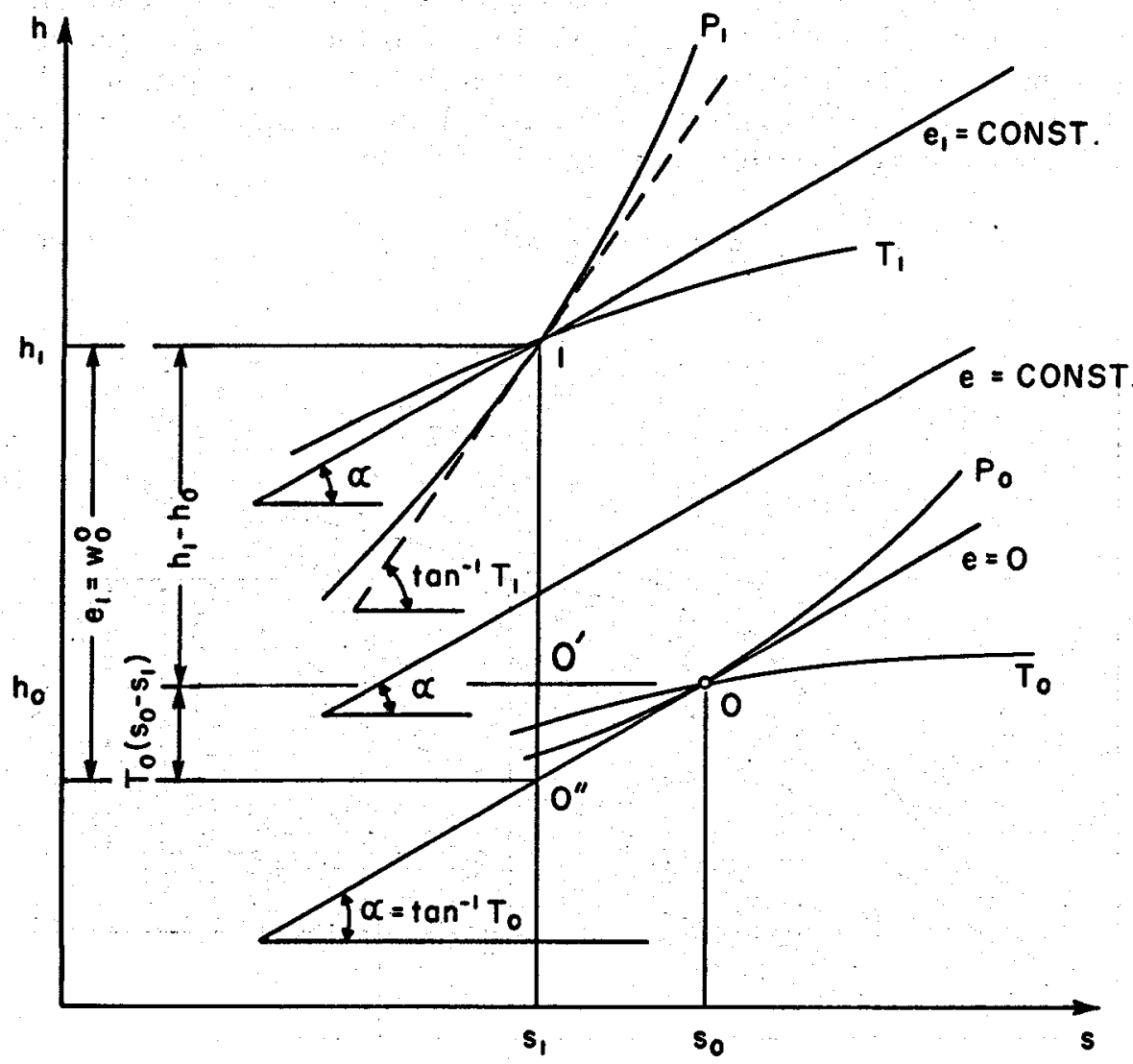

Figure 3.28-Mollier diagram for substance whose dead state $O$ is far removed from the two-phase region $\left(\alpha=\tan ^{-1} T_{0}\right)$. 
it intersects line $10^{\prime}$ at $0^{\prime \prime}$ and marks a distance $0^{\prime} 0^{\prime \prime}$ whose measure is

$$
T_{0}\left(8_{0}-s_{1}\right) \text {. }
$$

It follows that the distance $10^{\prime \prime}$ represents

$$
w_{0}^{\circ}=e_{1}=h_{1}-h_{0}-T_{0}\left(s_{1}-s_{0}\right) \text {. }
$$

We note for future reference that the line of the surroundings drawn through the dead state intersects the line $s_{1}=$ const at a point whose distance from point 1 to the exergy $e_{1}$.

We verify that the equation of the straight line $00^{\prime \prime}$ is

$$
\frac{h-h_{0}}{s-s_{0}}=T_{0} \text { or } h=h_{0}+T_{0}\left(s-s_{0}\right) \text {. }
$$

This line is the locus of all points for which $e=0$. Similarly, any line drawn at an angle $\alpha$ is a line of constant exergy, as shown. In particular, the line through point 1 drawn parallel to $e=0$ is the locus of all points $e_{1}=$ const; this line is different from the tangent to $P_{1}$ at 1 , shown dotted, whose slope is $T_{1}$. For completeness we record that the equation of a line of constant exergy $e$ in a Mollier diagram is

$$
h=h_{0}+T_{0}\left(s-s_{0}\right)+e .
$$

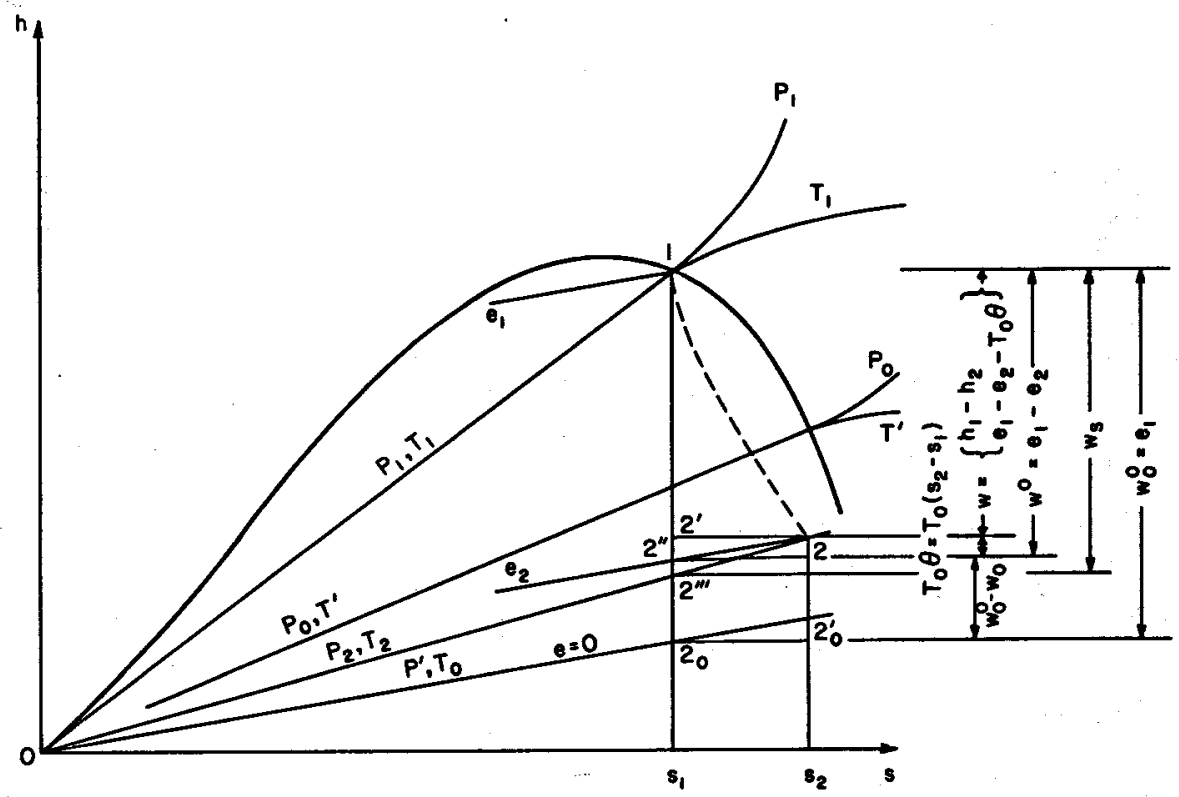

Figure 3.29-Adiabatic expansion in turbine. 


\subsubsection{Mollier diagram for steam: Adiabatic expansion}

Circumstances are somewhat more complex for water substance because the region of the Mollier diagram near the dead state is characterized by lines intersecting at inconvenient acute angles and is usually omitted from the chart. The geometric relationships can be illustrated with the aid of figure 3.29 which analyzes the adiabatic but non-isentropic expansion $1 \rightarrow 2$ of saturated steam in a turbine, assuming expansion to a condenser in which the saturation pressure $\boldsymbol{P}_{\mathbf{2}}<\boldsymbol{P}_{0}$ prevails, the corresponding temperature $T_{2}$ exceeding $T_{0}$. The line of the surroundings $e=0$ is the line $\mathrm{P}^{\prime}$ whose slope $T_{0}$ is less than either $T_{1}$ or $T_{2}$.

The work of the adiabatically operating turbine must satisfy eqs. 3.24 and 3.28 from which it follows that

and

$$
w=h_{1}-h_{2}
$$

The available work

$$
g=\left(8_{2}-s_{1}\right) \cdot T_{0} \text {. }
$$

$$
w^{\circ}=e_{1}-e_{2}=h_{1}-h_{2}+T_{0}\left(8_{2}-8_{1}\right)>v 0
$$

could be obtained if the process $1 \rightarrow 2$ were conducted fully reversibly, but exchanging heat with the surroundings at the single temperature $T_{0}$. Evidently, such a process would not be adiabatic or isentropic.

The real work, 20 , is represented by segment $12^{\prime}$, whereas the available work, $w^{\circ}$, corresponds to segment $12^{\prime \prime}$, the distance $2^{\prime} 2^{\prime \prime}$ being equal to the work

$$
w_{d}=w^{0}-w=T_{o}\left(s_{2}-s_{1}\right)
$$

dissipated in the turbine. The distance $2^{\prime \prime} 2_{0}$ is the work dissipated in the atmosphere, equation 3.29 , or

$$
w_{d}^{a}=w_{0}^{\circ}-w^{\circ}=T_{0} \theta^{a} .
$$

The diagram of figure 3.29 can be used to illustrate the difference between the conventional definition of turbine efficiency, $\eta_{t}$ and the component utilization factor, $\eta^{\prime} u$. In the former, the real work $w$ is compared with that of a fictitious process $1 \rightarrow 2^{\prime \prime \prime}$ which continues to be adiabatic, is reversible, and occurs against the prescribed condenser pressure $P_{2}$. At the end of this fictitious process the steam leaves the turbine at the fictitious state $2^{\prime \prime \prime}$ and produces work

$$
w_{s}=h_{1}-h_{2} \cdots
$$

The (isentropic) turbine efficiency is

$$
\eta_{t}=\frac{w}{w_{z}}=\frac{h_{1}-h_{2}}{h_{1}-h_{2}^{\prime \prime}}
$$


The method of available work avoids the introduction of the fictitious state $\cdot 2$ " 1 and compares the work of the turbine with that which would be obtained reversibly between the same end states, that is, with $20^{\circ}$. Hence the component utilization factor is defined as the ratio

Evidently

$$
\eta_{u}^{\prime}=\frac{w}{w^{\circ}}=\frac{h_{1}-h_{2}}{e_{1}-e_{2}}=\frac{h_{1}-h_{2}}{h_{1}-h_{2}^{\prime \prime}}
$$

because

$$
\begin{aligned}
& \eta_{u}^{\prime}>\eta_{i}, \\
& w^{\circ}<w_{s} .
\end{aligned}
$$

The advantage of applying the method of available work becomes clear in cases when the turbine is considered as a part of a larger installation, or if process $1 \rightarrow 2$ in figure 3.29 is interpreted as that which occurs in a single stage. This is a consequence of the fact that state 2 and not state $2^{\prime \prime \prime}$ prevails at the inlet of the next stage or element of the installation.

In cases when the state 2 at stage or turbine exit lies in the wet region of the diagram, it is possible to derive a simple relation between the efficiency, $\eta_{t}$, and the component utilization factor, $\eta_{u}^{\prime}$. This is done by noting that

$$
w_{s}=h_{1}-h_{2}-T_{2}\left(s_{1}-s_{2}\right) \text {, }
$$

because segment $2^{\prime} 2^{\prime \prime \prime}$ in figure 3.29 equals $T_{2}\left(\delta_{2}-s_{1}\right)$. Since

$$
\eta_{t}=\frac{h_{1}-h_{2}}{h_{1}-h_{2}+T_{2}\left(s_{2}-s_{1}\right)} \text { and } \eta_{u}^{\prime}=\frac{h_{1}-h_{2}}{h_{1}-h_{2}+T_{0}\left(s_{2}-s_{1}\right)},
$$

we conclude that

$$
\frac{\left(1 / \eta_{t}\right)-1}{\left(1 / \eta_{u}^{\prime}\right)-1}=\frac{T_{2}}{T_{0}}
$$

\subsubsection{Adibatio expansion in $T$, s diagram}

The process $1 \rightarrow 2$ of irreversible adiabatic expansion from figure 3.29 has been cross-plotted in the $T, 8$ diagram of figure 3.30 . In this diagram

$w_{0}^{\circ}=e_{1}$ is represented by area $0 \delta 12_{0}$

$e_{2}$ is represented by area $0 \alpha 22_{0}^{\prime}$, or area $0 \beta 2^{\prime \prime} 2_{\text {o }}$

$w^{\circ}$ is equal to area $\beta \delta 12^{\prime \prime}$ or area $\alpha \delta 12^{\prime \prime \prime}$ minus area $2^{\prime \prime \prime} 22_{0}^{\prime} 2_{0}$ $\left[=\left(T_{2}-T_{0}\right)\left(s_{2}-s_{1}\right)\right]$

$w_{a}=T_{0} \theta$ is equal to area $2_{0} 2_{0}^{\prime}$ ed

$w_{s}$ is equal to area $\alpha \delta 12^{\prime \prime \prime}$.

\subsubsection{Exergy-entropy diagram}

To conclude this section, we reproduce an $(e, 8)$ exergy-entropy diagram for steam after Z. Rant [1960], figure 3.31. The struture of the diagram should now be completely clear to the reader. 


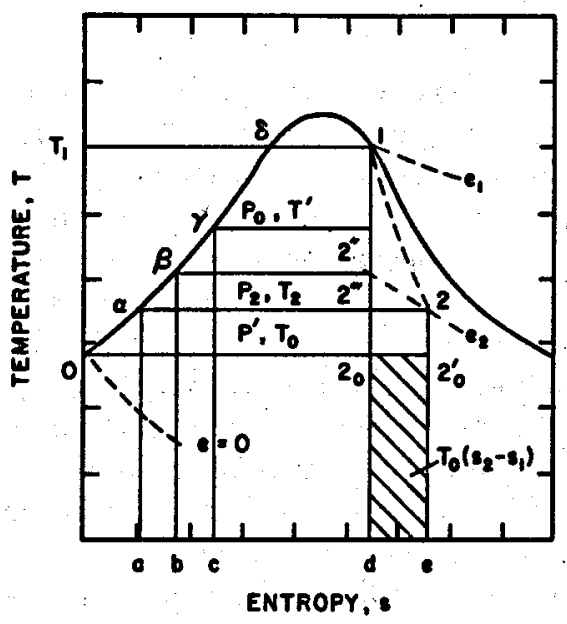

Frodne 8.80-Adiabatle turbine expansion in $T, 8$ diagram.

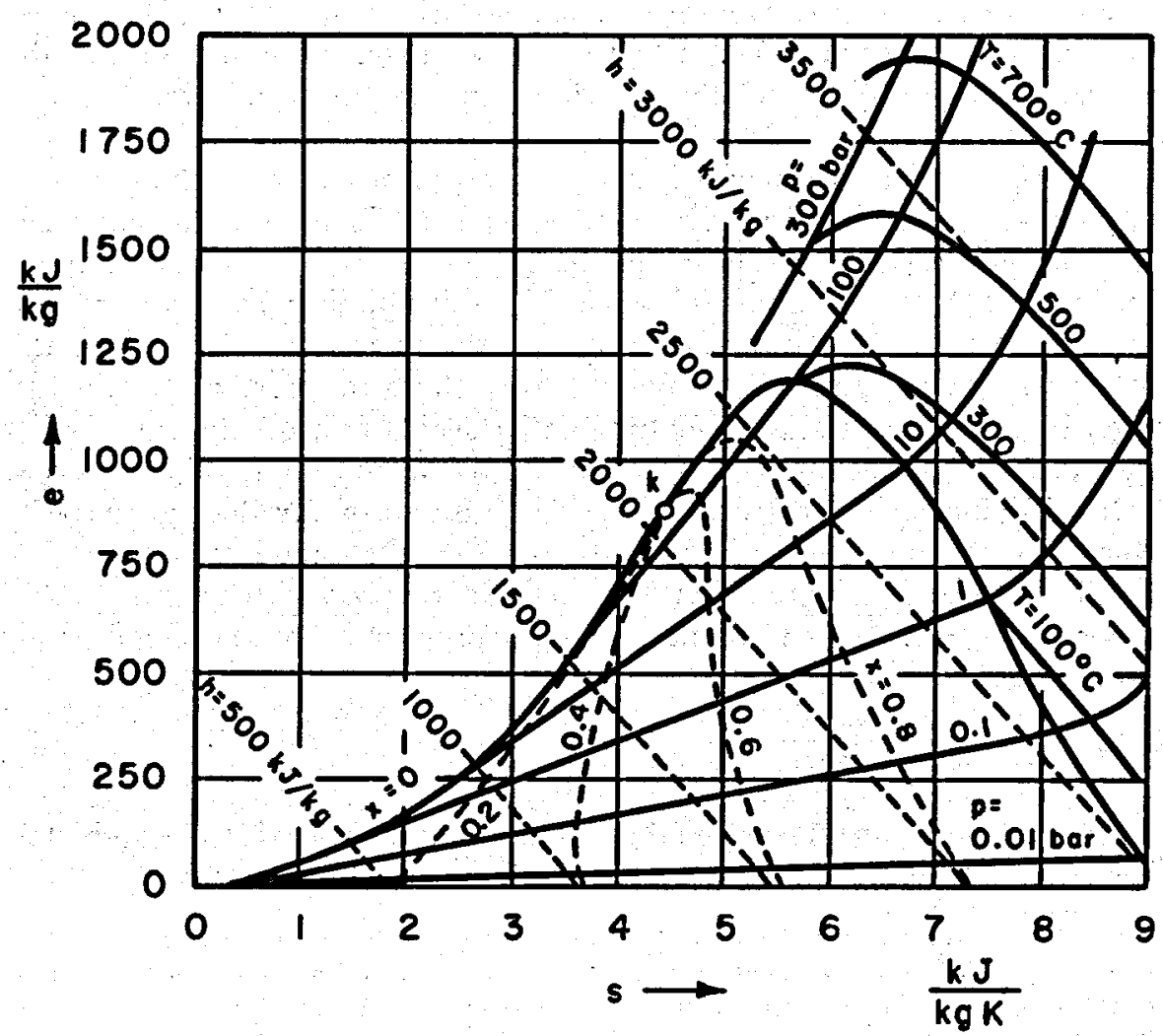

FiquRE 8.31-Exergy-entropy diagram after Rant (1060). 


\subsection{A note on thermophysical properties}

The considerations of the preceding sections demonstrate that even in the initial stages of a design study, particularly when extensive calculations are to be made with a view to optimizing variously selected objective functions, it is necessary to be in possession of an extensive collection of data on the thermophysical properties of a number of substances. In order to calculate available work we must know the thermodynamic properties of substances. For the calculation of entropy production (or, equivalently, work dissipated), it is also necessary to know such transport properties as viscosity, thermal conductivity, and diffusion coefficients which determine the Reynolds, Prandtl, and Schmidt numbers. In contemporary practice, the thermodynamic properties are usually embodied in a computer code based on an analytic formulation of a fundamental equation.*

In the case of a pure substance, the sufficient minimum information consists of a formulation of the $P, v, T$ equations augmented by the spectroscopic data of the ideal-gas state. A peculiar difficulty is presented by the near-critical region which should, rigorously speaking, be described by the use of so-called scaling laws (Sengers and Levelt Sengers, 1978).

The list of substances is large: it includes brines, i.e., aqueous solutions of a wide variety of salts with or without gases dissolved in them and about a dozen potentially useful fluorocarbons and hydrocarbons for binarysystem applications.

In assessing the situation it is necessary to emphasize that the presentday state of affairs still leaves much to be desired. The most important need is to develop verified correlation methods for the handling of the thermophysical properties of mixtures when the corresponding properties of the pure components are known. Fortunately, the thermodynamic properties of brines are not radically different from those of pure water. Consequently, in general studies, modelling with the aid of pure water reveals the essential trends and influence functions in sensitivity studies. However, a fully reliable and scientifically justified procedure for design analysis would require more extensive formulations for brines and mixtures.

Without attempting to exhaust the subject we proceed to impart to the reader the most essential items of information on thermophysical properties.

\section{1\%.1 Water substance}

After 50 years of international cooperation, the properties of water substance have been measured, correlated, and approved internationally over a

* A fundamental equation is one from which all equilibrium properties of a substance can be obtained without having recourse to integration. Thus a fundamental equation contains in it complete information regarding the equilibrium propertles. The functions $u=u(8, v, \xi, \zeta, h=h(8, P, \xi, \zeta)$, the Helmholtz free energy $f=$ $f(T, v, \xi, \zeta)$, etc. are examples of suitable forms. 
wide range of pressures and temperatures and to an extent which makes it the best documented substance in existence. As far as geothermal applications are concerned, it is possible to regard this information as complete.

The fundamental equation for water substance exists in four versions:

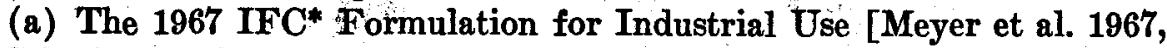
Schmidt 1969]; (b) The 1968 IFC Formulation for Scientific and General Use [Rivkin et al. 1978]; (c) The set of steam tables published by J. H. Keenan, F. G. Keyes et al. [1969]; (d) The fundamental equation formulated by Pollak [1976]. As far as geothermal applications are concerned, all these forms are equivalent. There exists a series of national steam tables published in a number of countries [Schmidt 1969, Rivkin et al. 1978, etc.] which derive from (a) or (b). Evidently, these should also be considered equivalent. In view of the degree of perfection achieved through the international effort, all earlier formulations, and all proposals which are not expressly compatible with the above, should be ignored.** The rigorous, and thermodynamically compatible formulation of the properties in the near-critical region is described in Sengers et al. [1978].

All tabulations of viscosity and thermal conductivity based on the 1964 international agreement are now obsolete, even though they form integral parts of most sets of valid tables. The new, internationally agreed, and much more reliable values are covered by two recent Releases disseminated by the International Association for the Properties of Steam [Anon. 1976, Kestin 1978].

\subsubsection{Aqueous solutions}

The International Association for the Properties of Steam has embarked on a program of correlation paralleling that for pure water, but so far no agreements in this field have been reached. Solutions of sodium chloride have been reasonably well explored and are sometimes used for the modelling of geothermal brines when pure-water models are thought to be inadequate. There exist two comprehensive tabulations [Haas 1976, Silvester and Pitzer 1976], and it is interesting to test them for mutual consistency. This has been done by computing the available work, $w_{0}^{\circ}$ of saturated liquid as a function of temperature for different values of $\zeta_{1}(=2,4,6$ molal $)$ against a dead state of $P_{0}=0.1 \mathrm{MPa}$ and $T_{0}=25^{\circ} \mathrm{C}$. The resulting graphs are shown in figure 3.32 which is an elaboration of figure 3.11. Here the full lines were obtained with the aid of Silvester and Pitzer's data [1976] and the dashed line with reference to Haas's data [1976]. The diagrams demonstrate an absence of mutual consistency in that the two results differ by as much as $9.8 \%$ at $\zeta_{1}=6$ molal and

\footnotetext{
* International Formulating Committee of the International Association for the Properties of Steam.

**With the possible exception of very accurate data Intended for calibration and similar purposes.
} 


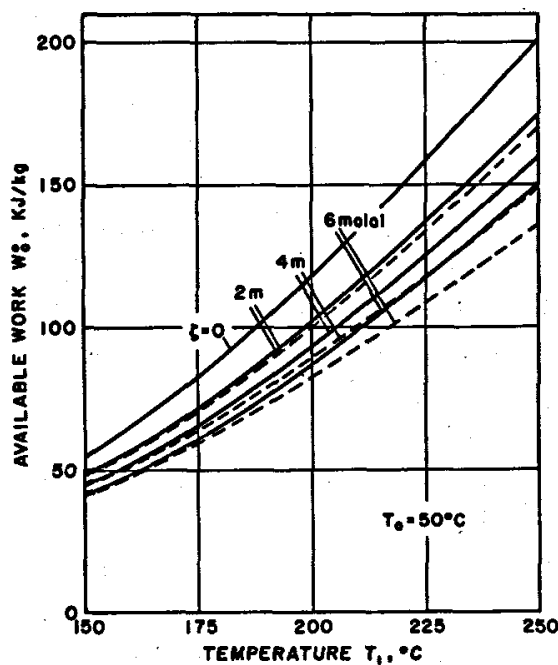

Frgure 3.32-The ideal available work $w_{0}^{*}$ $=e_{1}$, for saturated solutions of sodium chloride $(\mathrm{NaCl})$ against a dead state of $P_{0}=0.1 \mathrm{MPa}$ and $T_{0}=50^{\circ} \mathrm{C}$, for $\xi_{1}=0,2,4,6$ molal. See also figure 3.11 . (- data from [Silvester and Pitzer]; - - data from [Haas].)

$T_{1}=250^{\circ} \mathrm{C}$. The lower value $\zeta_{1}=4$ molal is typical of the KGRA at Niland in California, but even in this case the percentage discrepancy ranges from $1.8 \%$ at $150^{\circ} \mathrm{C}$ to $6.5 \%$ at $T_{1}=250^{\circ} \mathrm{C}$.

A comprehensive representation of the viscosity of sodium chloride solutions (up to $150^{\circ} \mathrm{C}$ ) is contained in a set of tables prepared by J. Kestin et al. [1977]. No data on thermal conductivity seem to exist.

\subsubsection{Hydrocarbons: 18obutane}

A complete survey of the thermophysical data of hydrocarbons (as well as fluorocarbons) is beyond the scope of this report. It is, however, worth mentioning that for isobutane, which seems to possess optimum thermodynamic properties for binary installations-there exist four different formulations of the fundamental equation:

(1) Starling, equation 1 [1973];

(2) Starling, equation 2 [Kumar et al., 1977];

(3) Eubank [Das et al., 1973];

(4) Milora and Combs [1977]; see also Milora and Tester [1976]

A direct comparison between the four formulations is tedious (and is reserved for an other detailed report) because the nature of the discrepancies very much depends on the domain of pressure and temperature considered. For this reason it is more interesting to follow through the results of a simple design analysis. We have chosen for this purpose a counterflow heat exchanger operating between pure water and supercritical isobutane.

In all cases, the inlet temperature of the water is $T_{1}=200^{\circ} \mathrm{C}$ and the exit temperature is $T_{0}^{\prime}=50^{\circ} \mathrm{C}$, the environment being at $T_{0}=35^{\circ} \mathrm{C}$. For this set of conditions we prescribe an identical inlet temperature $T_{1}^{\prime}=35^{\circ} \mathrm{C}$ 
for the isobutane, and a pinch-point temperature difference $\Delta \eta_{p}^{\prime}=5^{\circ} \mathrm{C}$. The following design data have been calculated:

(1) The exit temperature, $T_{1}^{\prime \prime}$, of the isobutane;

(2) The mass-flow ratio of isobutane to water, $\dot{m}_{i b} / \dot{m}_{w}$;

(3) The specific heating surface $A / \dot{m}_{\text {to }}$ per unit mass of water flowing;

(4)The specific heating surface $A / \dot{m}_{i b}$ per unit mass of isobutane flowing;

(5) The ideal available work (exergy, $w_{0}^{\circ}=e_{1}^{\prime \prime}$ ), in the isobutane at turbine entry;

(6) The ideal available work in the isobutane at turbine entry, $\dot{m}_{i b} w_{0}^{\circ} / \dot{m}_{w o}$ per unit mass of brine flowing.

The numerical results are seen summarized in table 3.1. They clearly bring into relief the absence of mutual consistency in the data and the wide discrepancies in design recommendations which hinge merely on the choice of the correlating fundamental equation. For example, the maximum difference in the heating surface (and hence cost) of the heat exchanger per unit mass flow of water reaches $18 \%$ and $25 \%$ per unit mass flow of isobutane, items (3) and (4). The largest difference in the available work in a unit mass of isobutane at turbine inlet reaches $75 \%$, item (5). Finally, the ratio $\dot{m}_{i b} w_{0}^{\circ} / \dot{m}_{v o}$ in column (6), which is a measure of the ideal work obtainable at the expense of a unit mass of brine reaches $31 \%$.

The situation with regard to some fluorocarbons is somewhat better, but that concerning some others, or the less popular hydrocarbons, is worse.

TABLE 3.1-Characteristic design parameters for a simple water-isobutane heat exchanger

Environment at $T_{0}=35^{\circ} \mathrm{C}$; water temperature at inlet $T_{1}=200^{\circ} \mathrm{C}$; at exit $T_{0}^{\prime}=50^{\circ} \mathrm{C}$; isobutane inlet temperature $\boldsymbol{T}_{1}^{\prime}=35^{\circ} \mathrm{C}$; pinch-point temperature $\Delta \boldsymbol{T}_{\boldsymbol{p}}=5^{\circ} \mathrm{C}$.

\begin{tabular}{lrrrrrr}
\hline Formulation & {$[1]$} & {$[2]$} & {$[3]$} & {$[4]$} & {$[5]$} & {$[6]$} \\
\hline$(1) \ldots \ldots \ldots \ldots \ldots$ & 153 & 1.30 & 539 & 415 & 90 & 117 \\
$(2) \ldots \ldots \ldots \ldots \ldots$ & 153 & 1.30 & 500 & 385 & 90 & 117 \\
$(3) \ldots \ldots \ldots \ldots \ldots$ & 140 & 1.56 & 540 & 473 & 100 & 115 \\
$(4) \ldots \ldots \ldots \ldots \ldots$ & 162 & 1.14 & 588 & 377 & 57 & 89
\end{tabular}

Data calculated with the aid of four different formulations of the properties of isobutane: (1) Starling (1973); (2) Starling [Kumar et al., (1977)]; (3) Eubank [Das et al., (1973)]; (4) Milora and Combs (1977).

[1] Isobutane exit temperature, $T_{1}^{\prime \prime} ;{ }^{\circ} \mathrm{C}$

[2] Ratio of flow rates $\mu=h_{i b} / h_{w}$ of isobitane to water

[3] Specific heating surface $A / \dot{m}_{w}$ per unit flow of water, $\mathrm{m}^{2} \mathrm{~s} / \mathrm{kg}$

[4] Specific heating surface $A / \dot{m}_{\text {ib }}$ per unit flow of isobutane, $\mathrm{m}^{2} \mathrm{~g} / \mathrm{kg}$

[5] Ideal available work (exergy) in isobutane at turbine entry, $w_{0}^{\circ}, \mathrm{kJ} / \mathrm{kg}$

[6] Ideal available work (exergy) in isobutane at turbine entry, $\dot{m}_{i b} 20_{0}^{\circ} / \dot{m}_{w}$, per unit mass of brine, $\mathrm{kJ} / \mathrm{kg}$. 


\subsection{List of symbols}

\section{LATIN}

$b$

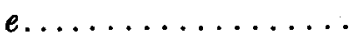

availability function

exergy

$e_{1} \ldots \ldots \ldots \ldots \ldots \ldots$

exergy recoverable upon expansion to dead state

$e_{2}$ exergy of fluid coming out of turbine at atmos-

pheric exhaust

$F$. . . . . . . . Helmholtz free energy

$g \ldots \ldots \ldots \ldots \ldots \ldots$ gravitational acceleration

H............. enthalpy

$L \ldots \ldots \ldots \ldots \ldots \ldots$ elevation

$\dot{m} \ldots \ldots \ldots \ldots \ldots$ mass flow rate

$\dot{m}_{1}, \dot{m}_{2}, \dot{m}_{3} \ldots \ldots \ldots$ mass flow rates of various streams in a geothermal plant

$P \ldots \ldots \ldots \ldots \ldots$ pressure

$\dot{Q} \ldots \ldots \ldots \ldots \ldots$ rate of heat flow

r................ heat rejection ratio

S............ entropy

T............. temperature

U.............. internal energy

$V \ldots \ldots \ldots \ldots \ldots$ volume

$\mathscr{V} \ldots \ldots \ldots \ldots \ldots$ velocity

$W \ldots \ldots \ldots \ldots$ work

The corresponding lower case letters of the extensive properties refer to the specific property, i.e., the property per unit mass.

\section{GREEK}

a.............. angle

$\Delta$ (operator)........ difference between products and reactants in a chemical reaction

$\zeta \ldots \ldots \ldots \ldots \ldots$ set of mass or mole fractions of solids

$\zeta \ldots \ldots \ldots \ldots \ldots \ldots$ mass or mole fraction of $i$ th component

$\eta \ldots \ldots \ldots \ldots \ldots$ efficiency

$\eta_{u} \ldots \ldots \ldots \ldots \ldots \ldots$ utilization factor

$\eta_{\imath} \ldots \ldots \ldots \ldots \ldots \ldots$ turbine efficiency

$\theta \ldots \ldots \ldots \ldots \ldots$ entropy production

$\mu_{3} \ldots \ldots \ldots \ldots \ldots$ mass fraction of $i$ th steam

$\xi \ldots \ldots \ldots \ldots$ set of mass or mole fractions of inert gas

$\xi_{1} \ldots \ldots \ldots \ldots \ldots$ mass or mole fraction of $i$ th inert gas

\section{SUPERSCRIPTS}

○

refers to operation at zero entropy production

................ denotes time rate

ad............. refers to adiabatic process 


\section{SUBSCRIPTS}

o............ refers to ambient conditions

$i \ldots \ldots \ldots \ldots \ldots \ldots$ refers to properties of the $i$ th stream of the geothermal fluid

$n \ldots \ldots \ldots \ldots \ldots$ refers to the $n$ streams of geothermal fluid

a............ refers to the atmosphere

$8 \ldots \ldots \ldots \ldots \ldots$ refers to isentropic

$d \ldots \ldots \ldots \ldots \ldots$ denotes dissipated

$\alpha, \beta \ldots \ldots \ldots \ldots$ refers to states $\alpha$ and $\beta$

$1 \ldots \ldots \ldots$ refers to initial state

$2 \ldots \ldots \ldots \ldots$ refers to final state.

\subsection{References}

Anonymous, 1976. "New values for the viscosity of water substance," Mechanical Engineering, July, p. 79.

Baehr, H. D., 1966. Thermodynamik, Springer-Verlag, Berlin.

Bosnjakovic, F., 1935. Technische Thermodynamik, vol. 1, Steinkopf, pp. 64-67. Translated by P. L. Blackshear, Jr., Holt, Rinehart and Winston, New York.

Darrieus, G., 1930. "The rational definition of steam turbine efficiencies," Engineering, September, pp. 283-285.

Das, T. R., Reed, C. O., and Eubank, P. H., 1973. "PVT surface and thermodynamic properties of Isobutane," J. Chem. Eng. Data, 18 (2), pp. 253-262.

Din, F., 1956. Thermodynamic functions of gases, volume 1, Ammonia, Carbon Dioxide, Carbon Monoxide, Butterworths, Scientific Publications, London.

DiPippo, R., 1978 (a). "A summary of the technical specifications of the geothermal power plants in the world," Brown Univ. Rep. No. CATMEC/8, D.O.E. No. COO/4051-14, Providence, R.I.

DiPippo, R., 1978 (b). "Geothermal power plants of Japan: A technical survey of existing and planned installations," Brown Univ. Rep. No. CATMEC/9, D.O.E. No. COO/4051-16, Providence, R.I.

DiPippo, R., 1978 (c). "Geothermal power plants of the United States: A technical survey of existing and planned installations," Brown Univ. Rep. No. CATMEC/14, D.0.E. No. CO0/4051-20, Providence, R.I.

DiPippo, R, 1978 (d). "Geothermal power plants of New Zealand, Philippines and Indonesia: A technical survey of existing and planned installations," Brown Univ. Rep. No. CATMEC/17, D.O.E. No. COO/4051-23, Providence, R.I.

DiPippo, R., 1978 (e). "Geothermal power plants of Mexico and Central America: A technical survey of existnig and planned installations," Brown Univ. Rep. No. CATMEC/20, D.0.E. No. COO/4051-26, Providence, R.I.

Facca, G., 1973. "The structural and behavior of geothermal fields," Geothermal Energy, ed. by H. C. H. Armstead, UNESCO, Paris.

Gibbs, J. W., 1928. The collected works of J.W. Gibbs, Longmans, Green and Co., New York, vol. I; Dover reprint 1961. Thermodynamics, pp. 33, 36, 37, 40, 90 and 360.

Gouy, M., 1889. "Sur 1' energie utilisable," Journal de Physique, vol. 8, pp. 501-518. Haas, J. L., Jr., 1976. "Thermodynamic properties of the coexisting phases and thermodynamic properties of the $\mathrm{NaCl}$ component in boiling $\mathrm{NaCl}$ solutions," Geological Survey Bulletin 1421-B, U.S. Government Printing Office, Washington. Jouguet, M. E., 1917. "Problems of energy conversion," Revue de Mecanique, March. Keenan, J. H., 1941. Thermodynamics, M.I.T. Press, Cambridge, Mass., pp. 289-313. 
Keenan, J. H., 1932. "A steam chart for second law analysis. A study of thermodynamic availability in the steam power plant," Mechanical Engineering, 54, pp. 195-204.

Keenan, J. H., Gyftopoulos, E. P., and Hatsopoulos, G. N., 1973. "The fuel shortage and thermodynamics. The entropy crisis," Proceedings of a conference held at the MIT, February 12-14.

Keenan, F. G., Keyes, F. G., Hill, P. G., and Moore, J. G., 1969. Steam Tables (International edition-metric units), Wiley, New York.

Kestin, J., 1966, 1968, A course in themodynamics, Blaisdell, Waltham, Massachusetts, vol. I, vol. II.

Kestin, J., 1978. "Thermal conductivity of water and steam," Mechanical Engineering, August, vol. 100, p. 46.

Kestin, J. and Dorfman, J. R., 1971. A course in statistical thermodynamics, Academic Press, New York, pp. 13-14 and 208-210.

Kestin, J., Khalifa, H. E., Ro, S. T., and Wakeham, W. A., 1977. "Preliminary data on the pressure effect on the viscosity of sodium chloride solutions in the temperature range $10-40^{\circ} \mathrm{C}, " J$. Chem. Eng. Data, vol. 22, p. 207.

Kestin, J., Khalifa, H. E., Abe, Y., Grimes, C. F., Sookiazian, H., and Wakeham, W. A., 1978. "The effect of Pressure on the Viscosity of Aqueous $\mathrm{NaCl}$ Solutions in the Temperature Range $20-150^{\circ} \mathrm{C}$," J. Chem. Eng. Data, vol. 23, p. 328.

Kirilin, V. A., Sychev, V. V., and Scheindlin, A. E., 1976. Engineering Thermodynamics, Mir Publishers, Moscow.

Kumar, K. H., Goin, K. M., and Starling, K. E., 1977. "Thermodynamic properties of isobutane using a modified BWR equation of state," School of Chemical Engineering \& Material Science, University of Oklahoma, Norman, Okla. Private communication.

Meyer, C. A., McClintock, R. B., Silvestri, K. G., and Spencer, R. C., Jr., 1967. 1967 ASME Steam Tables, published by ASME, New York.

Milora, S. L. and Combs, S. K., 1977. "Thermodynamic representation of Ammonia and Isobutane," Report prepared by Oak Ridge National Lab, Oak Ridge, Tenn., May, pp. 1-7, 23, 70-97.

Milora, S. L. and Tester, J. W., 1976. Geothermal energy as a source of electric power, The MIT Press, Cambridge, Mass.

Polak, R., 1976. "The thermodynamic properties of water to $1200 \mathrm{~K}$ and $300 \mathrm{bar}$ " (translated from German). Report PC-T CEGB $4 \mathrm{~T}$ (orig. Dr. Eng. Thesis Ruhr Univ. Bochum).

Rant, Z., 1956. "Exergie ein neues Wort für 'technische Arbeitfähigkeit,'" Forch. Ing. Wes., vol. 22, p. 36.

Rant, Z., 1960, Brennst-Wärme-Kraft 12, pp. 297-301.

Ray, M., 1947, "Thermodynamique des systèmes propulsifs à réaction et de la turbine à gaz," Dunod, Paris.

Rivkin, S. L., Aleksandrov, A. A., and Kremenuskaya, E. A., 1978. Thermodynamic derivatives for water and steam, translated and introduced by J. Kestin, Wiley, New York.

Schmidt, E., 1969. Properties of water and steam in SI units, Springer-Verlag.

Sengers, J. V. and Levelt Sengers, J. M. H., 1978. "Critical phenomena in classical fluids," Progress in Liquid Physics, p. 103.

Silvester, L. F. and Pitzer, K. S., 1976. "Thermodynamics or geothermal brines. 1. Thermodynamic properties of vapour saturated $\mathrm{NaCl}$ (aq.) solutions from 0 $300^{\circ} \mathrm{C}$," LBL 4456 . Available from National Technical Information Service, U.S. Department of Commerce.

Starling, K. E., 1973. Fluid thermodynamic properties for light petroleum systems, Gulf Publishing Co., Houston, pp. 194-205. 
Stodola, A., 1927. Steam and gas turbines, vol. II, translated by Loewenstein, L. C., McGraw-Hill.

Wahl, E. F., 1977. Geothermal energy utilization, J. Wiley \& Sons, New York.

White, D. E., 1973. "Characteristics of geothermal resources," in Geothermal Energy, ed. by P. Kruger and C. Otte, Stanford University Press.

Williams, F., Cohen, A., Pfundstein, R., and Pond, S., 1977. "Site-specific analysis of geothermal development-data files of prospective sites," prepared for E.R.D.A., Division of Geothermal Energy, The Mitre Corporation, Metrek division, McLean, Va. 


\section{Chapter 4}

\section{Power Systems}

\subsection{Flashed steam/steam turbine cycles}

\subsubsection{Introduction (By J. H. Eskesen*)}

Geothermal power plants using steam flashed from hot brine have been in operation for many years. The largest installation of this type is located in Wairakei, New Zealand, which was commissioned in 1959 and which now has an installed capacity of $190 \mathrm{MW}$. Similar plants are in operation in Japan, Iceland, El Salvador, and Mexico.

An aerial view of the geothermal power station in El Salvador (at Ahuachapán) is shown in figure 4.1. Total generating capacity of this installation is currently 60 megawatts, although construction is underway to increase output to 95 megawatts. Clearly visible in the photograph are the steam transmission lines linking the producing field in the right background, to the power house on the lower left. As is the case with all geothermal power plant installations, the cooling towers tend to dominate the rest of the plant equipment because of relatively low operating temperatures and, hence, low cycle efficiencies.

In all the systems which utilize steam flashed from hot brine, the twophase wellhead mixture is piped to a separator drum in which steam and brine are separated. Figure 4.2 shows a simple Weber-type cyclone separator installed at the Ahuachapan field. Steam and brine enter the drum tangentially to create swirl. Steam exits the separator through a pipe extending to the top of the drum and passes through a ball check valve before entering the transmission line to the turbine.

Residual brine can either be discarded or it can be flashed at a lower pressure to produce steam for a separate turbine or for a secondary admission point in the same machine. Although dual admission (mixed pressure) units are most attractive from an economic viewpoint, difficulties experienced in obtaining low intrusion loss at the lower pressure secondary admission frequently dictate the use of separate units.

Depending on the temperature of the geothermal brine, the dual flash cycle will produce between $20 \%$ and $30 \%$ more power than a single flash

*Medium Steam Turbine Dept.. General Electric Co., L,ynn, Mass. 


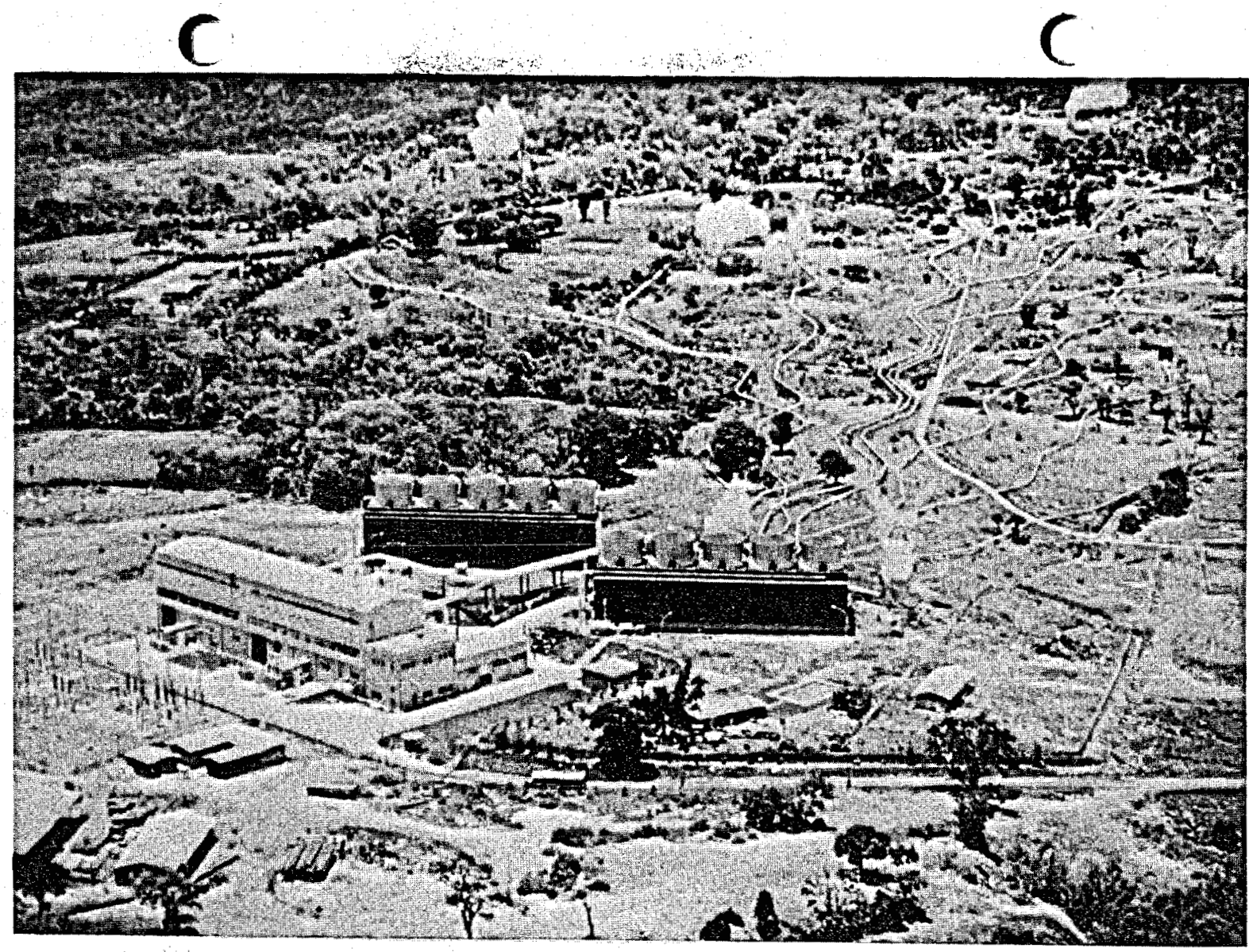

FxGURE 4.1-The Ahuachapan $60 \mathrm{MW}$ geothermal power plant and bore field. [Photo br C.E.L., El Salvador.] 


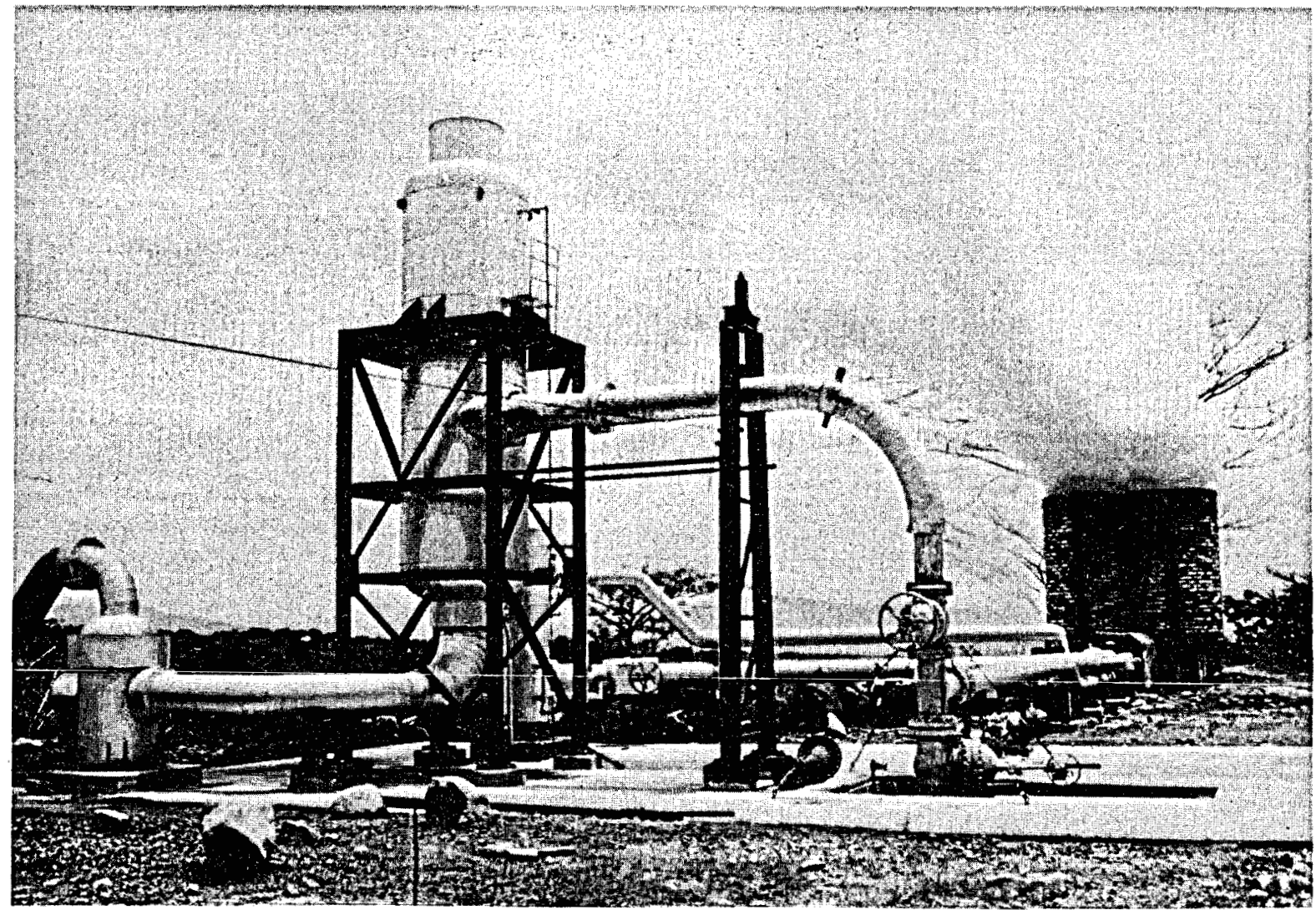

Frguke 4.2-Wellhead equipment for well AH-20 at Ahuachapan. [Photo by R. DiPippo.]

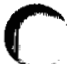

$C$ 
system with the same brine rate. However, the increase in performance must be weighed against the additional cost of supplying the secondary steam to the turbine. Usually, several secondary steam lines are required on a single unit to accommodate the large specific volume flow of low-pressure secondary steam. Moreover, it is common practice to supply a set of control valves with each steam line. The cost of this equipment is not insignificant and can, if the resource temperature is fairly low, more than exceed any economic advantage derived from the improved turbine performance.

Selecting the "proper size" of a geothermal power plant will depend principally on the productivity of wells and on the estimated power potential of the resource. If there are reasonable assurances that productivity and capacity will support a power plant development program, then plant construction in 40-50 MW modules is fairly typical when well production rates are the order of 4-5 MW per well.

Most commercial plants in operation today use condensing turbines since they produce approximately twice the output of units with an atmospheric exhaust. The condensate provides a source of makeup water for the wet cooling system and also permits the use of simple and relatively inexpensive barometric condensers. Figure 4.3 shows the relative size of the two barometric condensers employed at the Mexican power station at Cerro Prieto. Each unit operates at a pressure of 3.5 inches $\mathrm{Hg}$ and accommodates a steam flow of $630,000 \mathrm{lbs} . / \mathrm{hr}$.

The type and cost of the condensing system is, however, also governed by the concentration and type of non-condensible gases present in the liquid resource. Where hydrogen sulphide abatement is required, for example, more expensive surface condensers would have to be installed to accommodate the sulphur removal process. This type of condenser also adds about $4^{\circ} \mathrm{F}$ to the temperature approach to the wet bulb, and system performance would be reduced accordingly.

A more serious performance penalty is imposed by the concentration of gas itself since power must be consumed to eject (or pump) it from the main condenser. Carbon dioxide is of particular concern because not only is it frequently present in very large concentrations, but it also is essentially all released during the initial reduction in pressure at the primary steam flash. A $3 \%$ weight concentration of $\mathrm{CO}_{2}$ in the brine would, for example, translate to a $30 \%$ concentration in the primary steam flow given a $10 \%$ primary steam yield. In many cases where the level of non-condensibles is high, the cost of gas removal from the condensers may warrant the use of non-condensing units.

Fortunately, many geothermal systems which have exhibited high concentrations of $\mathrm{CO}_{2}$ initially have experienced a significant decline in $\mathrm{CO}_{2}$ release with continued reservoir production, and in these cases it was possible to add condensers (with some modification to the turbine) at a later date. In cases where the $\mathrm{CO}_{2}$ yield remains excessively high, a utility would 


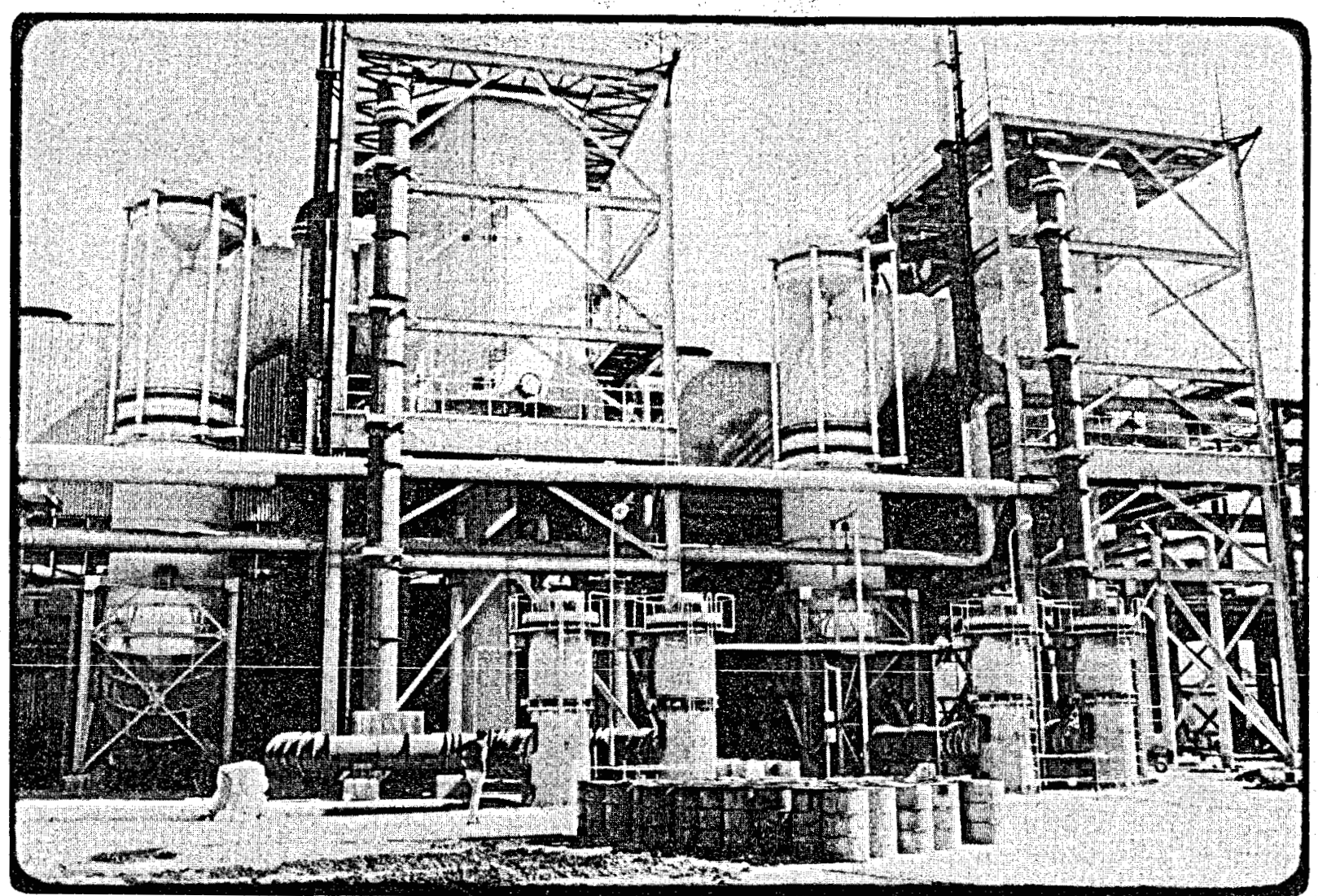

Fiaure 4.3-Barometric condensers for units 1 and 2 at Cerro Prieto. [Photo by R. DiPippo.]

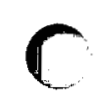


perhaps be wise to consider an alternative cycle rather than continue to operate an inefficient non condensing unit.

It is also important to note that since carbon dioxide gas release is usually accompanied by calcite precipitation, the operator of a $\mathrm{CO}_{2}$ contaminated field with self-flowing wells, is faced with the prospect of either injecting scale inhibitors or periodically reaming wells to remove scale.

Because $\mathrm{CO}_{2}$ contaminated liquid resources are fairly common, and because the thermodynamic analysis of the conventional steam turbine cycle is almost trivial, section 4.1.2 is devoted almost exclusively to analyzing the effect of $\mathrm{CO}_{2}$ on steam turbine performance. The effect of $\mathrm{CO}_{2}$ on the overall performance of the conventional steam cycle is analyzed, along with several cycles in which the contaminated steam is prevented from the turbine flow path and main condenser.

Section 4.1.3 outlines some of the specific design features of geothermal steam turbines, while section 4.1.4 describes turbine characteristics and outlines the primary design requirements; section 4.1.5 describes typical control systems and includes several examples of component design.

\subsubsection{Cycle thermodynamics (By J.H. Eskesen, A. Whitehead, and A. W. Brunot*)}

With the exception of a small $680 \mathrm{~kW}$ Freon 12 unit installed in Paratunka in the Soviet Union in 1967, which is now dismantled, the conversion of geothermal energy to electrical power has thus far been accomplished exclusively with steam turbines. There are two major reasons for this. First, steam turbine technology is well established, and second, hydrothermal systems so far exploited have been of sufficiently high grade for steam turbines to be applied efficiently and economically.

However, for many of the hydrothermal systems known today, the application of conventional condensing steam turbine technology is considered inappropriate. Where temperatures are very low, for example, the large inlet piping and control valves required to accommodate the large volume flows of flashed steam make the cost of this equipment prohibitive. The presence of noncondensible gas is, of course, also a deterrent since the extraction pump work required to effect its removal from the condenser can in some instances be prohibitively high, and if condensers are poorly designed can even exceed the extra power derived from the turbine's subatmospheric exhaust.

This section examines the effect of a noncondensible gas on the performance of the conventional steam turbine cycle. Also examined are several cycles in which, through the use of different modifications, the gas is prevented from entering the turbine flow path. Since $\mathrm{CO}_{2}$ forms the major constituent where noncondensibles are a problem, the discussion here is restricted to this gas.

* Medium Steam Turbine Dept., General Electric Co., Lynn, Mass. 
In each cycle, specific output (in terms of well flow) is calculated for a wide range of flash pressures. No attempt is made to relate these pressures to well productivity since well production rates depend upon the specific location and, therefore, are not easily defined for general analysis. In a particular application, however, well production rates cannot be isolated since the advantages of increased plant output and lower field development costs resulting from higher well flow rates must be weighed against the higher cost of surface piping and power plant equipment due to the lower wellhead pressures required to support the higher flows.

4.1.2.1 Carbon dioxide in geothermal brines. Carbon dioxide occurs in geothermal brines either as dissolved gas or as other related carbonate species, particularly the carbonates and bicarbonates of sodium and calcium. The behavior and distribution of carbon dioxide is of major concern for two reasons. First, as mentioned above, it contributes to turbine back pressure and must be removed by steam-jet ejectors or vacuum pumps which contribute a significant loss to the cycle performance. Second, ebullition of carbon dioxide and the related changes in fluid pH and chemistry are the controlling factors in the formation of calcium carbonate scale which can occur in production and reinjection wells. Clearly, if the engineer is to design a reliable power plant and specify generation equipment and steam production, he must be able to accurately predict the behavior of carbon dioxide in the system.

Carbon dioxide is present in geothermal brines as dissolved $\mathrm{CO}_{2}$, carbonic acid, $\mathrm{H}_{2} \mathrm{CO}_{3}$, and chemically combined as bicarbonates $\mathrm{NaHCO}_{3}$, $\mathrm{Ca}\left(\mathrm{HCO}_{3}\right)_{2}$ and carbonates $\mathrm{Na}_{2} \mathrm{CO}_{3}, \mathrm{CaCO}_{3}$.

The calculation methods described below involve consideration of dissolved $\mathrm{CO}_{2}$ and $\mathrm{H}_{2} \mathrm{CO}_{3}$ only and other chemical reactions which provide sources of $\mathrm{CO}_{2}$ for evolution have been ignored, e.g.:

$$
2 \mathrm{NaHCO}_{3}=\mathrm{Na}_{2} \mathrm{CO}_{3}+\mathrm{H}_{2} \mathrm{O}+\mathrm{CO}_{2}
$$

However, it should be pointed out that since chemical analyses are carried out on geothermal brine samples collected at the surface rather than at downhole locations, much of the $\mathrm{CO}_{2}$, which is chemically combined in the strata, is probably reported as $\mathrm{CO}_{2}$ in the analyses.

Downhole equilibrium $\mathrm{CO}_{2}$ concentration. In order to maintain dissolved $\left(\mathrm{CO}_{2}+\mathrm{H}_{2} \mathrm{CO}_{3}\right)$ in geothermal solutions, there must be a gas phase concentration of $\mathrm{CO}_{2}$ in equilibrium with the fluid in the reservoir. If it is assumed that such systems obey Henry's Law $K_{H}=P_{\mathrm{CO}_{2}} / X_{\mathrm{CO}_{2}}$, where $K_{H}$ is the Henry's Law constant and $P_{\mathrm{CO}_{2}}$ and $X_{\mathrm{CO}_{2}}$ are the partial pressures of $\mathrm{CO}_{2}$ in the gas phase and the mol fraction of $\mathrm{CO}_{2}$ in the liquid phase, respectively, then $P_{\mathrm{CO}_{2}}$ can be determined if $K_{H}$ is known. Values of $K_{H}$ 
TABLE 4.1-Values of $K_{B}$ for different temperatures and salinities

\begin{tabular}{|c|c|c|c|c|c|c|c|}
\hline \multirow[b]{2}{*}{ Solvent } & \multirow[b]{2}{*}{$\%$} & \multicolumn{6}{|c|}{$\mathbf{T}{ }^{\circ} \mathbf{F}\left({ }^{\circ} \mathrm{C}\right)$} \\
\hline & & $\begin{array}{c}212 \\
(100)\end{array}$ & $\begin{array}{c}302 \\
(150)\end{array}$ & $\begin{array}{c}392 \\
(200)\end{array}$ & $\begin{array}{c}482 \\
(250)\end{array}$ & $\begin{array}{c}572 \\
(300)\end{array}$ & $\begin{array}{c}662 \\
(350)\end{array}$ \\
\hline \multicolumn{2}{|c|}{ 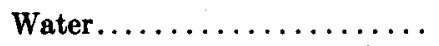 } & 5200 & 6000 & 6400 & 5300 & 3900 & 2100 \\
\hline \multicolumn{2}{|c|}{$0.5 \mathrm{M} \mathrm{NaCl} . \ldots \ldots \ldots \ldots \ldots$} & 5600 & 7150 & 7100 & 6000 & 4800 & 3300 \\
\hline \multicolumn{2}{|c|}{$1.0 \mathrm{M} \mathrm{NaCl} . \ldots \ldots \ldots \ldots \ldots$} & 6150 & 7800 & 7800 & 7000 & 5850 & 4400 \\
\hline \multicolumn{2}{|c|}{$2.0 \mathrm{M} \mathrm{NaCl} \ldots \ldots \ldots \ldots \ldots$} & 7450 & 9200 & 9400 & 8700 & 7800 & 6500 \\
\hline
\end{tabular}

Frgurs $4.4-K_{\mathrm{H}}$ vs. temperature for different salinities.

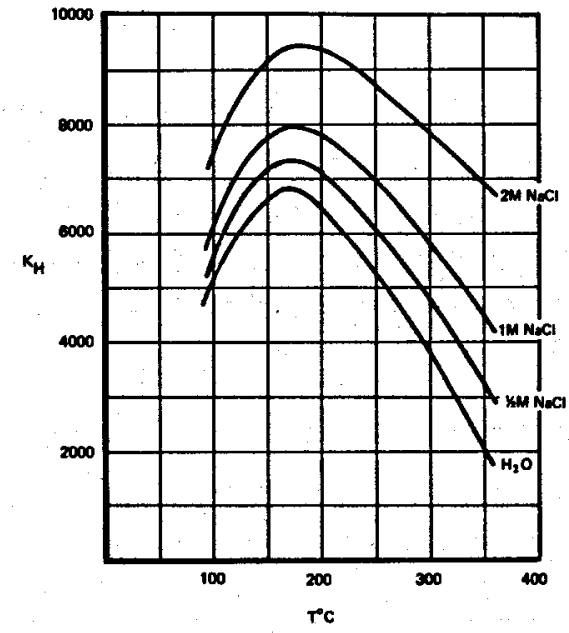

Frgure $4.5-K_{\mathrm{H}}$ v8, salinity for different temperatures.

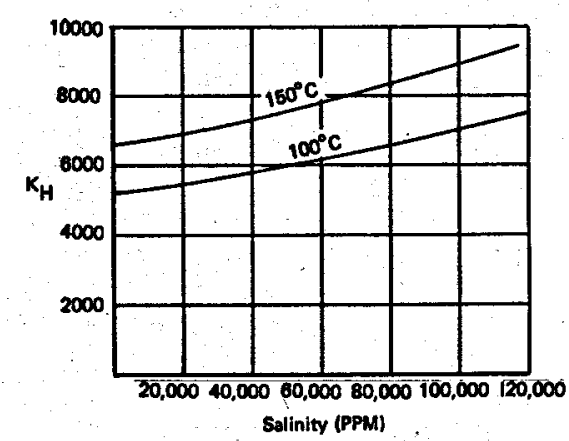

have been determined by Ellis and Golding $(1)^{*}$ and are shown tabulated in table 4.1 and plotted in figures 4.4 and 4.5 as a function of temperature and salinity. The method of calculating the equilibrium partial pressure of $\mathrm{CO}_{2}$ in the gas phase is shown in the following example.

* Numbers in parentheses denote references for sections 4.1 and 4.2 which may be found at the end of section 4.2. (See p. 466.) 
Example: Consider 100 grams of a $2 \mathrm{M} \mathrm{NaCl}$ brine solution at $200^{\circ} \mathrm{C}$ containing $2 \% \mathrm{w} / \mathrm{w}$ of $\mathrm{CO}_{2}$.

$2 \mathrm{gCO}_{2}=4.545 \times 10^{-2}$ moles

$11.7 \mathrm{gNaCl}=0.2$ moles

86.3. $\mathrm{gH}_{2} \mathrm{O}=4.7944$ moles

Total moles $=5.03985$

$X_{\mathrm{CO}_{2}}=4.545 \times 10^{-2} / 5.03985=9.018 \times 10^{-8}$

Now $\mathrm{P}_{\mathrm{CO}_{2}}$ (ata) $=K_{H} X_{\mathrm{CO}_{2}}$

For $2 \mathrm{M} \mathrm{NaCl}$ at $200^{\circ} \mathrm{C} K_{H}=9400$

$$
\begin{aligned}
P_{\text {CO }_{2}} & =9400 \times 9.018 \times 10^{-3} \\
& =84.77 \text { ata } \\
& =1246 \text { psia }
\end{aligned}
$$

Thus for a geothermal brine containing $117,000 \mathrm{ppm} \mathrm{NaCl}$ solids and $2 \%$ w/w dissolved carbon dioxide as $\mathrm{CO}_{2}$ and $\mathrm{H}_{2} \mathrm{CO}_{3}$, the down-hole pressure of carbon dioxide with gas phase will be 1246 psia. This treatment ignores the effect of hydrostatic pressure on $\mathrm{CO}_{2}$ solubility. The equilibrium partial pressures of $\mathrm{CO}_{2}$ for a variety of brine conditions are shown in table 4.2. The variation of $P_{\mathrm{CO} 2}$ with dissolved $\mathrm{CO}_{2}$ content is shown in

\begin{tabular}{|c|c|c|c|c|c|c|}
\hline \multirow[t]{2}{*}{ 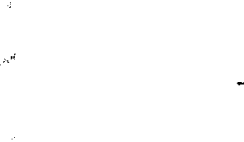 } & $\mathbf{T}^{\circ} \mathbf{C}$ & $\begin{array}{l}100 \\
212\end{array}$ & $\begin{array}{l}150 \\
302\end{array}$ & $\begin{array}{l}200 \\
392\end{array}$ & $\begin{array}{l}250 \\
482\end{array}$ & $\begin{array}{l}300 \\
572\end{array}$ \\
\hline & \multicolumn{3}{|l|}{$\% \mathrm{w} / \mathrm{w} \mathrm{CO}_{2}$} & \multicolumn{2}{|l|}{$\mathrm{PCO}_{2}$} & \\
\hline \multirow{5}{*}{ Water......... } & 0.05 & 15. 6 & 19.9 & 19. 3 & 15. 9 & 11.7 \\
\hline & 0. 10 & 31. 3 & 39.7 & 38. 5 & 31. 9 & 23. 5 \\
\hline & 1.00 & 315. 8 & 400.7 & 388. 5 & 321.8 & 236.8 \\
\hline & 2.00 & 632.8 & 803. 5 & 778. 9 & 645.0 & 474. 7 \\
\hline & 3. 00 & 955. 1 & 1212.0 & 1175.0 & 973.4 & 716. 3 \\
\hline \multirow[t]{5}{*}{$0.5 \mathrm{M} \mathrm{NaCl} \ldots}$. & 0.05 & 17. 2 & 21. 9 & 21.8 & 18.4 & 14. 7 \\
\hline & 0.10 & 34. 4 & 43. 9 & 43. 6 & 36.8 & 29. 5 \\
\hline & 1.00 & 345. 7 & 441. 4 & 438. 4 & 370.4 & 296. 4 \\
\hline & 2. 00 & 695. 8 & 888. 3 & 882. 1 & 745.4 & 596. 4 \\
\hline & 3. 00 & 1050.0 & 1341.0 & 1331. 0 & 1125.0 & 900.1 \\
\hline \multirow[t]{5}{*}{$1.0 \mathrm{M} \mathrm{NaCl} \ldots .}$. & 0.05 & 19. 3 & 24. 4 & 24. 4 & 21. 9 & 18. 3 \\
\hline & 0.10 & 38. 6 & 48. 9 & 48. 9 & 43. 9 & 36. 7 \\
\hline & 1.00 & 387.8 & 491.7 & 491. 7 & 441. 3 & 368. 8 \\
\hline & 2.00 & 780.4 & 989.7 & 989.8 & 888. 3 & 742. 3 \\
\hline & 3. 00 & 1178.0 & 1494.0 & 1494. 0 & 1341.0 & 1121.0 \\
\hline \multirow[t]{5}{*}{$2.0 \mathrm{M} \mathrm{NaCl} \ldots}$. & 0.05 & 24. 4 & 30.1 & 30.8 & 28. 5 & 25. 5 \\
\hline & 0. 10 & 48. 8 & 60.2 & 61.5 & 56.9 & 51. 1 \\
\hline & 1. 00 & 490.5 & 605.8 & 618. 9 & 572.8 & 513. 6 \\
\hline & 2. 00 & 987.5 & 1220.0 & 1246.0 & 1153.0 & 1034. 0 \\
\hline & 3. 00 & 1491.0 & 1841.0 & 1882.0 & 1741.0 & 1561. 0 \\
\hline
\end{tabular}
figure 4.6.

TABLE 4.2-Equilibrium partial pressures of $\mathrm{CO}$, 


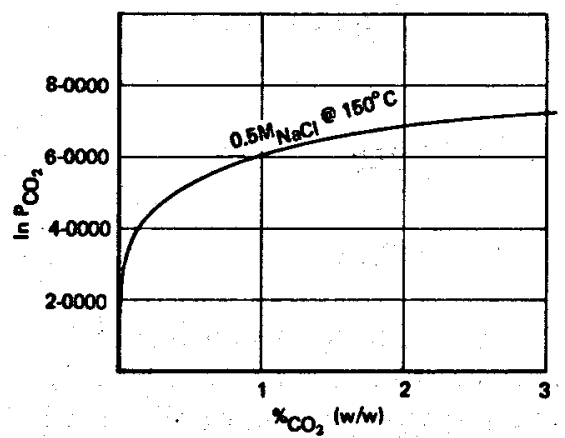

Figure 4.6-- $\mathrm{PCO}_{2}$ vs. percent weight $\mathrm{CO}_{2}$ in solution.

Flashing steam- $\mathrm{CO}_{2}$ mixtures. When geothermal fluid is expanded, the vapor phase of the resultant mixture will contain both steam and carbon dioxide. The amount of carbon dioxide in the flashed steam can be calculated in the manner described below.

Where $\mathrm{CO}_{2}$ and $\mathrm{H}_{2} \mathrm{O}$ exist in equilibrium in systems containing both liquid and gaseous phases, the concentrations in each phase can be defined by Ostwald's coefficient $\lambda$, or by coefficient $A$ where:

and

$$
\lambda=\frac{\text { grams } \mathrm{CO}_{2} / \mathrm{ml} \text { (liquid phase) }}{\text { grams CO} 2 / \mathrm{ml} \text { (vapor phase) }}
$$

$$
A=\left(n_{\mathrm{H}_{2} \mathrm{O}}^{i} n_{\mathrm{CO}_{2}}^{l}\right) /\left(n_{\mathrm{H}_{2} \mathrm{O}}^{l} n_{\mathrm{CO}_{2}}^{i}\right)
$$

where $n^{*}=$ number of moles in gas phase

$n^{l}=$ number of moles in liquid phase

Calculations using literature values of $\lambda$ or $A$ give essentially the same results.

Ellis and Golding (1) have determined $\lambda$ and $A$ for water and for different sodium chloride solutions. Their estimates of $A$ are listed in table 4.3.

\begin{tabular}{|c|c|c|c|c|}
\hline \multirow[b]{2}{*}{$\mathrm{T}^{\circ} \mathrm{C}$} & \multicolumn{4}{|c|}{ Molarity of $\mathrm{NaCl}$ solution } \\
\hline & Water & $0.5 \mathrm{M}$ & $1.0 \mathrm{M}$ & $2.0 \mathrm{M}$ \\
\hline $150 \ldots \ldots \ldots \ldots \ldots$ & 1349 & 1479 & 1660 & 1995 \\
\hline $160 \ldots \ldots$ & 1047 & 1122 & 1318 & 1585 \\
\hline $170 \ldots$ & 813 & 871 & 1023 & 1230 \\
\hline $180 \ldots$ & 631 & 676 & 794 & 955 \\
\hline $190 \ldots$ & 490 & 525 & 617 & 759 \\
\hline $200, \ldots \ldots \ldots \ldots$ & 380 & 427 & 479 & 588 \\
\hline
\end{tabular}

TABLE 4.3-Values of $1 / A$ for water and different salt solutions

For a given level of steam flashing both $n_{\mathrm{H}_{3} \mathrm{O}}$ and $n_{\mathrm{H}_{2} \mathrm{O}}$ are known. Thus by rearranging equation 4.3 , the ratio of carbon dioxide in the fluid and steam after flash can be computed, e.g. :

$$
n_{\mathrm{CO}_{2}}^{\imath} / n_{\mathrm{CO}_{2}}^{l}=n_{\mathrm{H}_{2} \mathrm{O}}^{v} / A n_{\mathrm{H}_{8} \mathrm{O}}^{l}
$$


As an example, consider water at $200^{\circ} \mathrm{C}$ which undergoes a $10 \%$ steam flash. From table 4.3, 1/ $A=380$.

After flash,

$$
n_{\mathrm{H}, \mathrm{O}}^{l}=0.90 / 18, n_{\mathrm{B}, \mathrm{O}}^{\mathfrak{O}}=0.10 / 18
$$

Hence,

$$
n_{\mathrm{CO}_{2}}^{\natural} / n_{\mathrm{CO}_{2}}^{l}=0.10 \times 380 / 0.90=42.22
$$

The percentage of the $\mathrm{CO}_{2}$ present in the fluid before flash which remains in the liquid phase after flash is, therefore: $1 /(1+42.22)=2.31 \%$.

If the separation factor, $S F_{\mathrm{CO}_{2}}$ is defined as the fraction of the original $\mathrm{CO}_{2}$ which is present in the vapor phase after flashing and $F F$ is the fraction of the original fluid flashed to steam, then

$$
S F_{\mathrm{CO}_{2}}=\frac{1 / A}{(1 / F F-1)+1 / A}=\frac{380}{(1 / 0.1-1)+380}=0.9769
$$

The variation of coefficient $A$ with temperature and salinity is shown in figures 4.7 and 4.8 .

The use of these calculation procedures ignores kinetic effects and assumes that a geothermal brine of say $20,000 \mathrm{ppm}$ total dissolved solids, of which the preponderance is sodium chloride, will behave essentially the
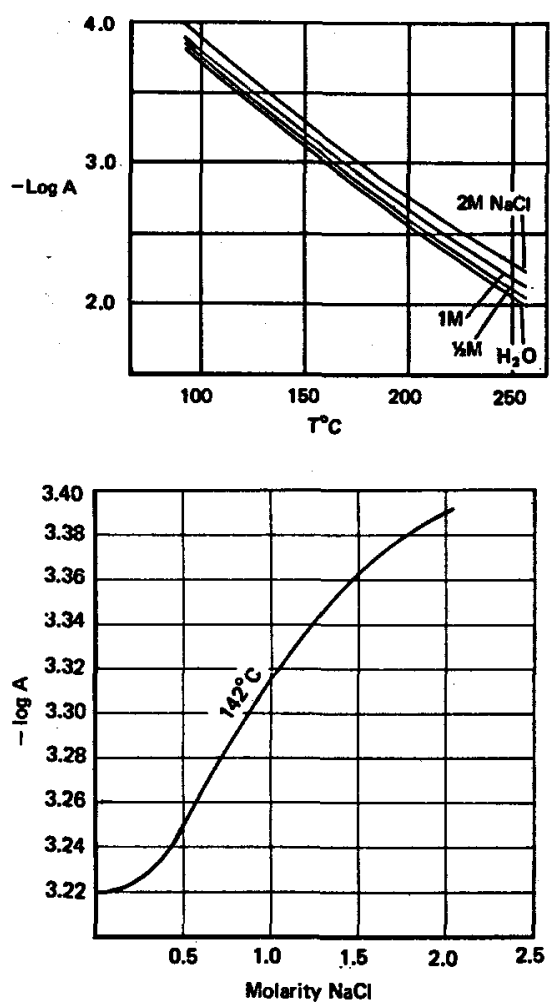

Fradre 4.7-Coefficient $A$ vs. temperature for different salinities.
Figure 4.8-Variation of coefficient $A$ with salinity. 
same as a pure sodium chloride solution. Accordingly, the calculations are approximations, which should be checked by experiments on actual fluids, but which should afford reasonably accurate estimates of $\mathrm{CO}_{2}$ behavior.

4.1.2.2 Steam turbine cycles. A total of four cycles are analyzed in this section: the conventional condensing steam turbine cycle and three modified cycles. Their overall performance is estimated and compared to that of selected flash binary cycles.

Throughout the analysis, the resource temperature, solids, and $\mathbf{C O}_{2}$ concentration were assumed to be $450^{\circ} \mathrm{F}, 2.5 \%$ and $3 \%$ by weight, respectively. The total enthalpy of the fluid before initial flash was assumed to be the saturated liquid enthalpy at the resource temperature, with negligible heat loss through the gathering lines between the wellheads and the powerhouse. Enthalpy values of liquid brine were obtained from reference (2). To facilitate calculations, the internal efficiency of the turbine, including inlet piping and valve throttling loss, was assumed to be constant, and exhaust loss was included on the basis of constant last-stage annulus velocity. In reality, internal efficiencies should vary somewhat with inlet pressure, but that would not significantly affect the comparative results presented herein.

No account is taken in the analysis of pressure drop in gathering lines since the purpose here is to compare cycles rather than calculate absolute performance. Such refinements can be included later. Furthermore, no account is taken of possible restrictions imposed by chemistry (i.e., calcite precipitation) on reservoir productivity -only thermodynamic arguments have been considered.

Condensing steam turbine cycle. The conventional steam cycle currently in use on geothermal systems, utilizes steam delivered directly from the reservoir or from flashing liquid systems where it is separated from the two-phase mixture before delivery to the turbine. The residual brine following the initial flash is either discarded or flashed at a lower pressure to provide more steam either for separate lower pressure turbines or for additional admission points downstream of the primary inlet in the same turbine. In practical systems where economic considerations generally outweigh thermodynamic reasoning, the number of flash stages will be limited to two.

The selection of flash temperatures is, of course, a function of several factors which include well productivity, turbine specific output per unit of well flow and different economic considerations. Conditions which produce optimum productivity in terms of available energy and flow rate are not necessarily those which produce maximum turbine output. Since the performance of self-flowing wells is site specific, well productivity cannot be well defined for analysis. The thermodynamic optimum, however, is readily established as shown by the following simple analysis. 
Consider the multiflash system shown in figure 4.9 in which a separate steam turbine is used for each stage of flash. The total system output can be expressed as:

$$
W=\sum_{k=1}^{n} M_{s, k} H_{i s, k} \eta_{k}
$$

where $M_{s, k}$ is the mass yield of steam from the $k$ th flash stage, $H_{i s, k}$ is the isentropic enthalpy drop between flash conditions and condenser and $\eta_{k}$ is the expansion efficiency. If a constant specific heat is assumed, during the expansion process, the specific output can be approximated as follows:

$$
\eta_{k} H_{i s, k}=C_{p}\left(T_{k}-T_{0}\right)
$$

The quantity of steam liberated from the $k$ th flash is obtained from the expression:

$$
M_{s, k}=\left(h_{k-1}-h_{k}\right) / H_{f s, k} \approx\left(T_{k-1}-T_{k}\right) \cdot C_{p} / H_{f s, k}
$$

where $h$ and $H_{f g}$ refer to the saturated liquid enthalpy and the heat of vaporization, respectively. Since $H_{f,}$ remains essentially constant over the temperature range of interest, $M_{s, k}$ can be assumed to be a function only of $h$ and the expression for turbine output becomes simply:

$$
W=C \sum_{k=2}^{n}\left(T_{k-1}-T_{k}\right)\left(T_{k}-T_{0}\right)
$$

where $C$ is a constant. For the output to be a maximum, the partial derivatives of output with respect to each fiash temperature must each be zero. This stipulation leads to the following equation set.

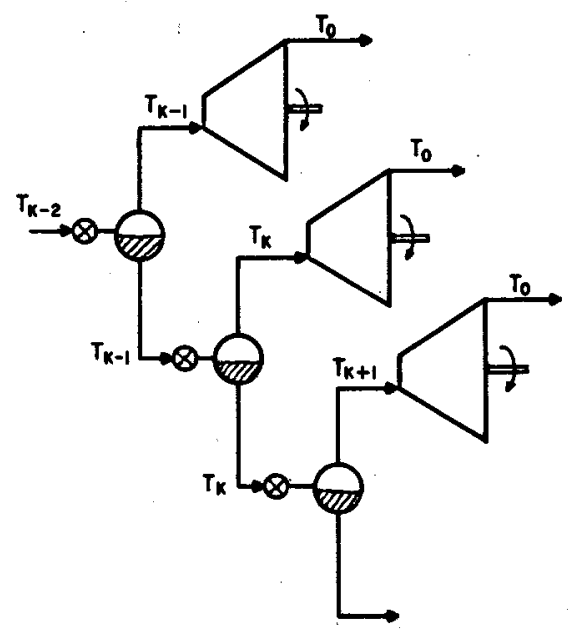

Fraure 4.9-Multiflash steam turbine cycle. 


$$
\left[\begin{array}{rrrrrr}
1 & -2 & 1 & & \\
& 1 & -2 & 1 & \\
& & 1 & -2 & 1 \\
& & & & & \\
& & & & & \\
& & & & & \\
& & & & & \\
& & & & &
\end{array}\right.
$$$$
\left.\begin{array}{rrrr}
1-2 & 1 & & \\
1 & -2 & 1 & \\
1 & -2 & 1
\end{array}\right]\left[\begin{array}{l}
T_{R} \\
T_{1} \\
T_{2} \\
\\
T_{n-1} \\
T_{n} \\
T_{0}
\end{array}\right]=\left[\begin{array}{l}
0 \\
0 \\
0 \\
0 \\
0 \\
0
\end{array}\right]
$$

where $T_{R}$ and $T_{0}$ refer to the initial brine or resource bottom hole temperature and the condensing temperature, respectively. By combining adjacent equations, one obtains the final result.

$$
T_{R}-T_{1}=T_{1}-T_{2}=T_{2}-T_{3}=\ldots=T_{n-1}-T_{n}=T_{n}-T_{0}
$$

i.e., that for maximum turbine output per unit of brine flow, the temperature intervals between successive flash stages are equal.

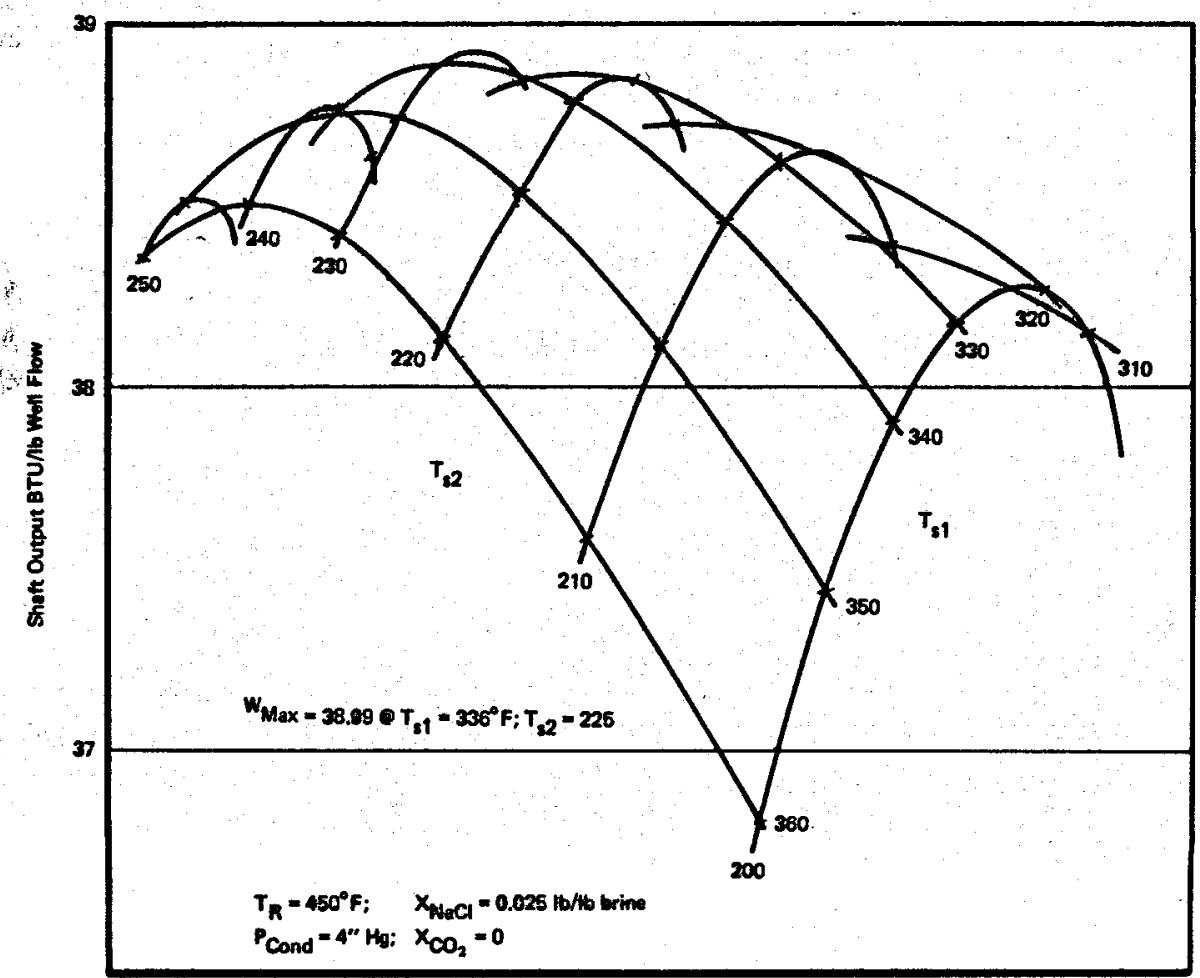

Frgure 4.10-Performance characteristics of dual flash/dual admission steam turbine cycle. 
This result is confirmed by the performance plot of figure 4.10 , which shows the variation in turbine output as a function of primary and secondary flash temperatures for a dual flash system operating on a liquid resource in which there is no $\mathrm{CO}_{2}$.

Maximum output of $38.94 \mathrm{BTU} / \mathrm{lb}$. brine is obtained from the dual flash cycle when the primary and secondary flash temperatures are $336^{\circ} \mathrm{F}$ and $225^{\circ} \mathrm{F}$, respectively. While these numbers do not quite agree with the theoretical values predicted, the small discrepancy can be readily accounted for in the simplifying assumptions used in the analysis. It is worth noting from the performance plot that a fairly wide variation in both flash temperatures can be tolerated without an appreciable loss of output.

The influence of the number of flash stages on turbine output in summarized in figure 4.11. Clearly incremental gains become smaller with increased stages and, therefore, cannot usually be justified economically.

If the $450^{\circ} \mathrm{F}$ resource were to contain $\mathrm{CO}_{2}$, essentially all of it would be liberated during the initial pressure reduction. Thus, if separate high and low pressure turbines are used for each stage of flash, only the high pressure unit would require $\mathrm{CO}_{2}$ removal from its condenser. The power consumed in doing this depends, of course, on the amount of $\mathrm{CO}_{2}$ present and also on the amount of vapor extracted with the gas. Although it is impossible to condense all the steam with a noncondensible present, the quantity of vapor processed by the pump can be reduced to a minimum by cooling the mixture to the lowest possible temperature below the value at the turbine exhaust. In condensers specifically designed to handle large quantities of gas, the final temperature reduction in the gas/vapor mixture is normally achieved in separate coolers installed in the pump extraction line.

The performance of this cycle depends on the back pressure that can be maintained at the turbine exhaust. The back pressure is the sum of the

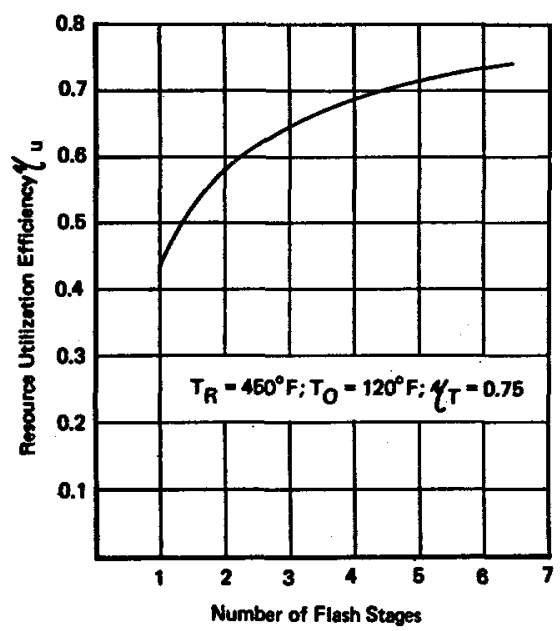

Froure 4.11-Resource utilization efficiency vs. number of flash stages. 
partial pressures of steam and $\mathrm{CO}_{2}$. The steam partial pressure is simply the saturation pressure corresponding to the temperature. The partial pressure of $\mathrm{CO}_{2}$ depends on its mass fraction. If the above resource contains $3 \% \mathrm{CO}_{2}$, the gas to steam ratio in the primary flow flashed at say $336^{\circ} \mathrm{F}$ will be 0.2290 . If the turbine exhaust can be maintained at $125^{\circ} \mathrm{F}$, the partial pressure of steam and $\mathrm{CO}_{2}$ will be 1.9420 psia and 0.2021 psia, respectively, assuming a dryness fraction in the exhaust of 0.9 . As steam condenses, the mass fraction of $\mathrm{CO}_{2}$ increases and its partial pressure also increases to maintain the total pressure in the condenser constant. If the final temperature in the pump extraction line can be reduced to within $5^{\circ}$ of the minimum cooling water temperature, which in this example we will assume is $90^{\circ} \mathrm{F}$, and the pressure drop in the condenser is $10 \%$, the gas to steam ratio will have increased to 3.34 , i.e., the pump will remove 0.299 pounds of steam with every pound of $\mathrm{CO}_{2}$ (negligible air infiltration is assumed). Assuming a pump internal efficiency of 0.80 and driver efficiency of 0.91 , the electrical power required for two stages of compression with intercooling to $95^{\circ} \mathrm{F}$ is $4.2 \mathrm{BTU} / \mathrm{lb}$. brine. If the pump inlet temperature were to increase, the quantity of steam rejected would also increase, and so too would the extraction pump work. The power requirements for two stage compression are shown as a function of inlet temperature in figure 4.12. Two stage compression, instead of a single stage, is easily justified in terms of cost and power saved.

The gas will, of course, contribute work as it expands through the turbine. The total pressure at the turbine inlet will increase in roughly the same proportion as at the exhaust, and hence the pressure ratio across the turbine will remain essentially constant. (In reality, there is a reduction in pressure ratio, since the quality of steam decreases during the expansion

Fraure 4.12-Condenser extraction work vs. compressor inlet temperature

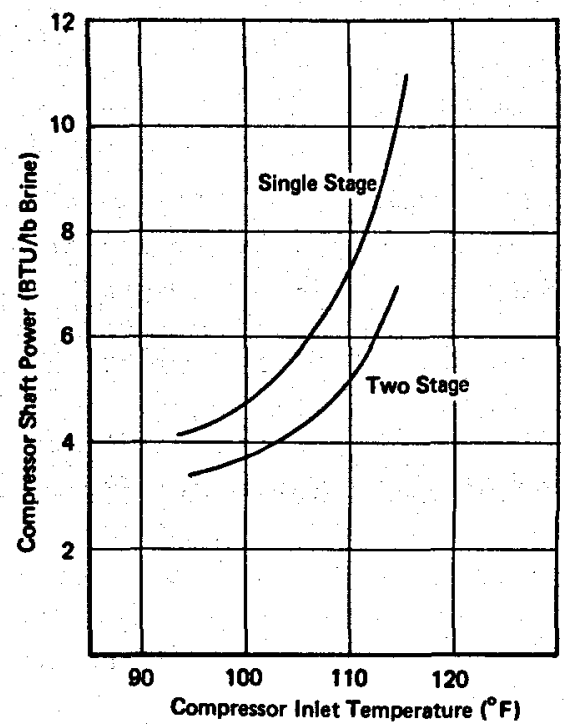


and the increase in total pressure at the exhaust is, therefore, proportionately slightly higher than at the inlet. However, the reduction is small and in the example cited above, it is less than 1\%.) Since the available energy in $\mathrm{CO}_{2}$ is less than in steam, the turbine specific output will decrease with increasing $\mathrm{CO}_{2}$ concentration in the steam. However, this reduction is more than offset by an increase in total yield when both steam and $\mathrm{CO}_{2}$ are flashed from brine as shown in the following analysis.

Consider a gas contaminated liquid resource. Its total enthalpy can be expressed as:

$$
h_{R}=\left(1-m_{g}\right) h_{f}+m_{g} h_{g}
$$

where $h_{f}$ and $h_{g}$ are the specific enthalpies of the liquid and gas, respectively, and $m_{g}$ is the mass fraction of gas. If we assume that all gas is liberated in the primary steam flash, the steam yield will be:

$$
m_{s}^{\prime}=\left\{\left(1-m_{g}\right)\left(h_{f}-h_{f}^{\prime}\right)+m_{\theta} C p_{g}\left(T_{R}-T^{\prime}\right)\right\} / H_{f g}^{\prime}
$$

where $T^{\prime}, h_{f}^{\prime}$ and $H_{f g}^{\prime}$ are the temperature, sensible liquid enthalpy and latent heat at flash conditions and $C_{p o}$ is the specific heat of the gas.

The ratio of this steam flow to that from an uncontaminated resource is therefore:

$$
\begin{gathered}
m_{s}^{\prime} / m_{s}=1-m_{g}\left[1-C_{p g}\left(T_{R}-T^{\prime}\right) /\left(h_{f}-h_{f}^{\prime}\right)\right] \\
\approx 1-m_{g}\left(1-C_{p g} / C_{p f}\right.
\end{gathered}
$$

If $f_{e}$ is defined as the ratio of the available energy of the mixture to that of pure steam for the same temperature conditions at entry and exit of the turbine, then the ratio of the work outputs from a mixture and from pure steam will be:

$$
\begin{aligned}
W^{\prime} / W & =E_{s} f_{e}\left(m^{\prime}{ }_{s}+m_{g}\right) / E_{s} m_{s} \\
& =m_{s}^{\prime} f_{e}\left(1+m_{g} / m_{s}^{\prime}\right) / m_{s}
\end{aligned}
$$

The variation of $f_{e}$ with $m_{g} / m^{\prime} s$ is shown in figure 4.13.

For the example considered, $m_{g} / m^{\prime} s=0.2290$ and hence $f_{e}=0.887$. Also, $m^{\prime}{ }_{s} / m_{s}=0.976$ and the above work ratio therefore becomes:

$$
W^{\prime} / W=0.976 \cdot 0.887 \cdot(1+0.2290)=1.0639
$$

Thus the gross output will actually increase with $\mathrm{CO}_{2}$ present. However, the net output will decrease since proportionately more extraction work is required. For the example cited, the turbine shaft input to the generator is estimated to be $40.23 \mathrm{BTU} / \mathrm{lb}$. brine; hence, the net generator output, after extraction pump work is subtracted, will be 35.72 BTU/lb. assuming a turbine-generator mechanical and electrical efficiency of 0.98 . 
Froure 4.13-Isentropic energy for steam $/ \mathrm{CO}_{2}$ mixtures.

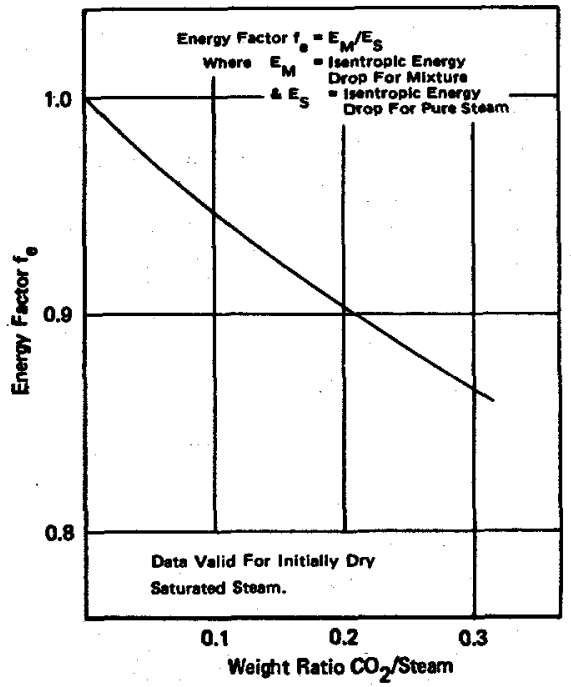

Steam vent cycle. It is evident from section 4.1.2.1 that if flash conditions can be controlled, the release of a small quantity of steam from the brine will be accompanied by the release of a very large quantity of carbon dioxide gas. The relationship between primary flash temperature and $\mathrm{CO}_{2}$ release from a $450^{\circ} \mathrm{F}$ resource is shown in table 4.4 Clearly, a steam flash of between 1 and $2 \%$ of the brine flow will remove $90 \%$ of the $\mathrm{CO}_{2}$. The gas can be vented to atmosphere and the steam may be condensed either by direct contact in a spray chamber or indirectly in a surface heat exchanger, and returned to the cycle for further heat recovery. Since the steam flashed from the residual brine in subsequent stages is essentially gas-free, it can be utilized directly in a condensing steam cycle.

The Steam Vent Cycle with a direct contact vent condenser is shown schematically in figure 4.14. The performance of this cycle is shown in figure 4.15 for a primary flash temperature of $440^{\circ} \mathrm{F}$ which corresponds to a primary steam yield of $1 \%$ of the brine flow and would, according to the calculation procedure outlined earlier, release about $85 \%$ of the

TABLE 4.4-Steam and $\mathrm{CO}_{2}$, yield vs. primary flash temperature $\left(T_{R}=450^{\circ}\right)$

\begin{tabular}{ccc}
\hline & $\begin{array}{c}\%(w t) \\
T_{B}-T_{B 1}\left({ }^{\circ} F\right)\end{array}$ & $\begin{array}{c}\%(w t) \\
\text { Steam yield }\end{array}$ \\
\hline 0 & 0 & 0 \\
\hline 10 & 1.4 & 85.0 \\
20 & 2.8 & 92.0 \\
30 & 4.1 & 94.5 \\
40 & 5.4 & 95.8 \\
50 & 6.7 & 96.6 \\
\hline
\end{tabular}




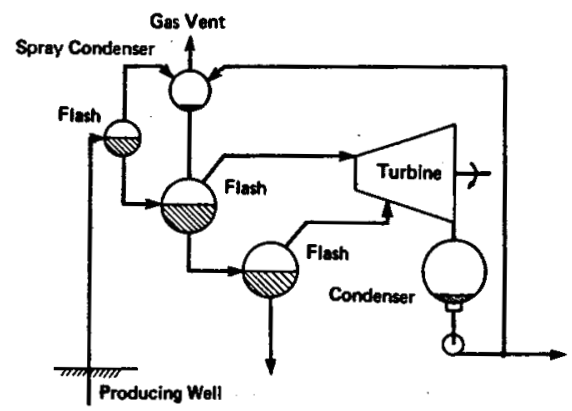

FIGURE 4.14-Schematic of steam vent cycle.

$\mathrm{CO}_{2}$ from the brine. The remaining gas would be released during the secondary flash, but no account was taken of this in calculating turbine performance.

The maximum output is $35.77 \mathrm{BTU} / \mathrm{lb}$. brine when the primary and secondary temperatures are $329^{\circ} \mathrm{F}$ and $224^{\circ} \mathrm{F}$, respectively. For brine containing $3 \% \mathrm{CO}_{2}$, this output increases by about $2.5 \%$ if a surface condenser replaces the direct contact condenser as shown in figure 4.16. However, this advantage all but disappears as the $\mathrm{CO}_{2}$ content in the brine approaches $0 \%$.

If residual brine at $329^{\circ} \mathrm{F}$ is used for spray water in the direct contact vent condenser instead of cold condensate at $125^{\circ} \mathrm{F}$, as indicated in figure

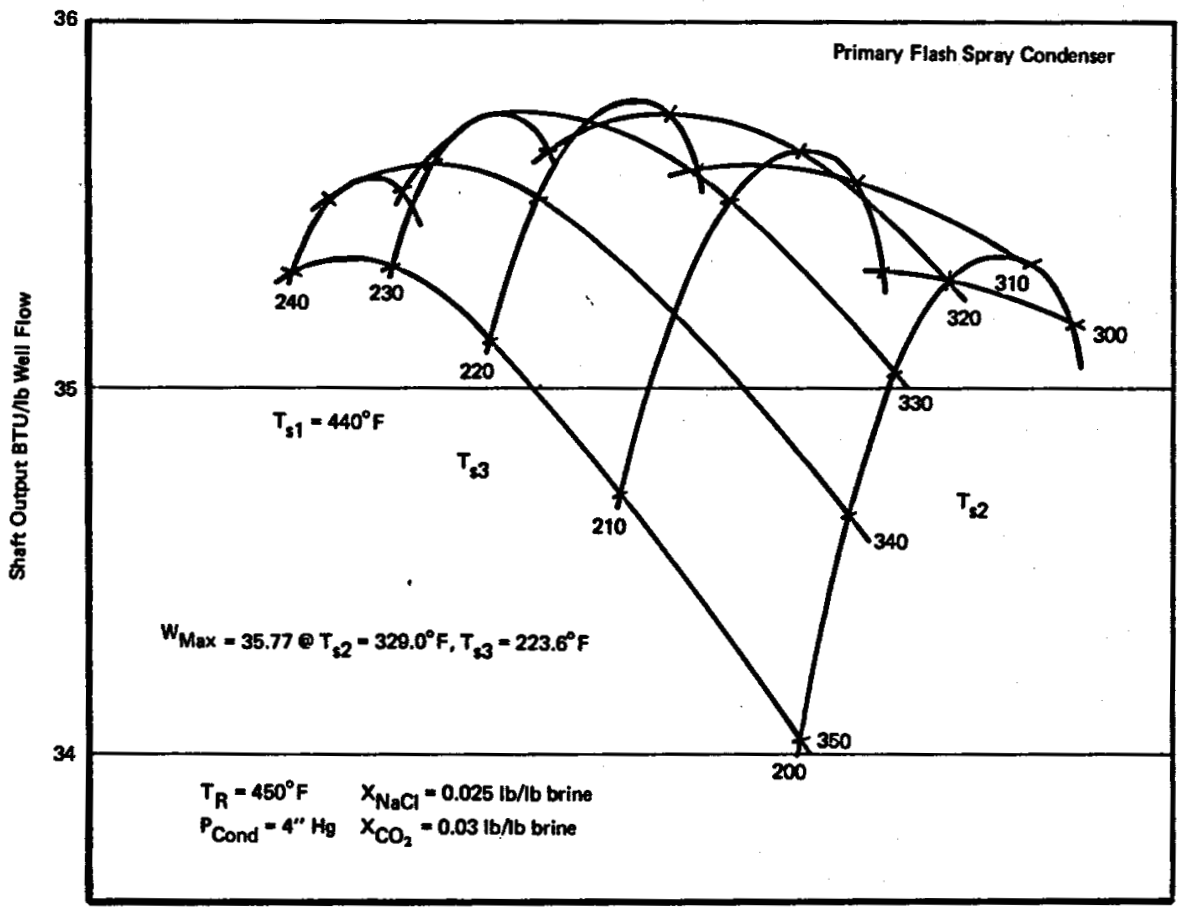

FIGURE 4.15-Performance characteristics of steam vent cycle. 


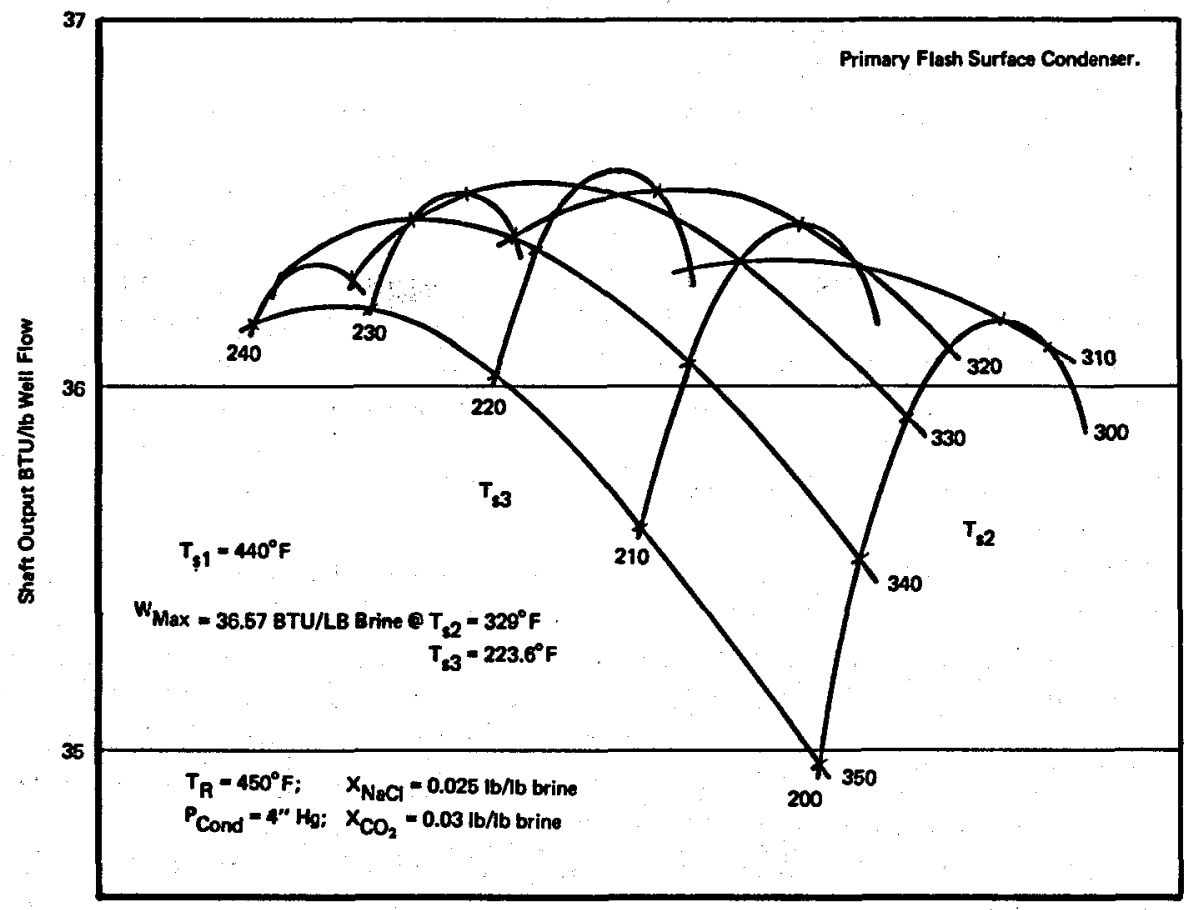

Frgure 4.16-Performance characteristics of steam vent cycle.

4.14, a gain of about $2.3 \%$ results. However, this is at the penalty of about a five-fold increase in coolant flow.

The outputs quoted purposely exclude any allowance for the well pumping necessary to provide reasonable flow rates when the brine is maintained in liquid form prior to the first flash. Pumping power requirements are site specific since they are determined not only by flow rate and pipe diameter, but also by reservoir permeability, resource temperature and well depth. The permeability determines the drawdown pressure, i.e., the pressure difference which exists between the reservoir and the well bottom. The pressure continues to fall as the liquid moves up the well due to the reduction in hydrostatic pressure and to a much lesser extent frictional effects. If the resource is devoid of gas, a point is eventually reached when the pressure equals the saturation pressure. If flashing is to be controlled, the pump must be located sufficiently below this flash point to prevent cavitation on the pump impellers. The manometric head on the pump is equal to the submerged depth plus the relatively small frictional pressure drop. Any tendency for the well to self flow, due to an artesian effect created by the density differential between the hot brine and surrounding colder water, is offset by the drawdown pressure, frictional pressure drop and increased density due to dissolved solids. 
The situation is compounded when the brine contains $\mathrm{CO}_{2}$, since the pump location is determined by the release of gas as well as steam. If the reservoir model described earlier is realistic, i.e., there is a gas phase concentration of $\mathrm{CO}_{2}$ in equilibrium with the fluid in the reservoir, then $\mathrm{CO}_{2}$ will flash as soon as the pressure is reduced, and this can be avoided only if the pump is located below the upper surface of the reservoir. If the pressure of the gas in the reservoir is less than the equilibrium partial pressure, then flashing will be delayed until the pressure is reduced sufficiently in the well. Since any space occupied by gas will also be occupied by steam at the corresponding saturation pressure, the manometric head on the pump must be greater than the sum of the partial pressures of gas and steam plus an allowance for the frictional pressure drop in the well and surface piping.

If a well pump with an efficiency of $75 \%$ were installed to prevent flashing at say $5,000 \mathrm{ft}$., it would consume approximately $8.5 \mathrm{BTU} / \mathrm{lb}$. brine in shaft power ignoring all frictional effects, and net output of the cycle would be reduced accordingly. If calcite precipitation is not a factor, the Steam Vent Cycle is capable of functioning with unpumped wells, although a significant reduction in efficiency will be induced by the much greater mass of steam flashed into the vent condenser.

Indirect steam cycle. Like the conventional cycle, the Indirect Cycle is designed to function without well pumping. Contaminated steam is separated from the two-phase mixture at the wellhead and used to generate gas-free steam from turbine condensate as shown in figure 4.17. Since the residual brine from the primary flash is again essentially gas-free, any subsequent steam flash will be uncontaminated and can be used directly in the turbine. A summary of the performance of this cycle is shown as a function of primary and secondary flash temperatures in figure 4.18. $T_{a 1}$, $T_{s 2}$ and $T_{s 3}$ are the temperatures at the primary flash, turbine inlet and secondary flash, respectively. Maximum output of $31.20 \mathrm{BTU} / \mathrm{lb}$. brine, which occurs at primary and secondary flash temperatures of $385^{\circ} \mathrm{F}$ and $251^{\circ} \mathrm{F}$, is almost $14 \%$ less than from the conventional cycle. The reduced output is in fact the result of available energy being lost due to the tem-

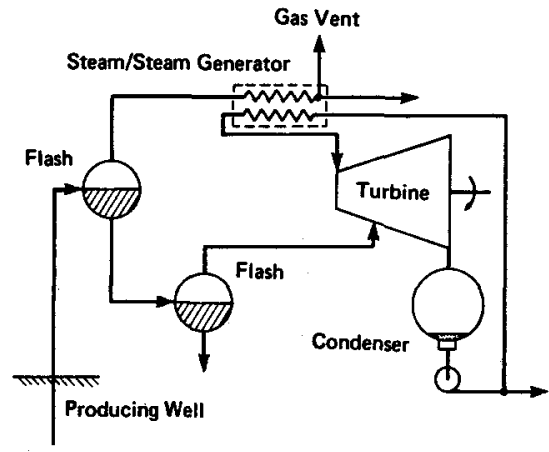

FIavre 4.17-Schematic of dual admission indirect steam cycle. 


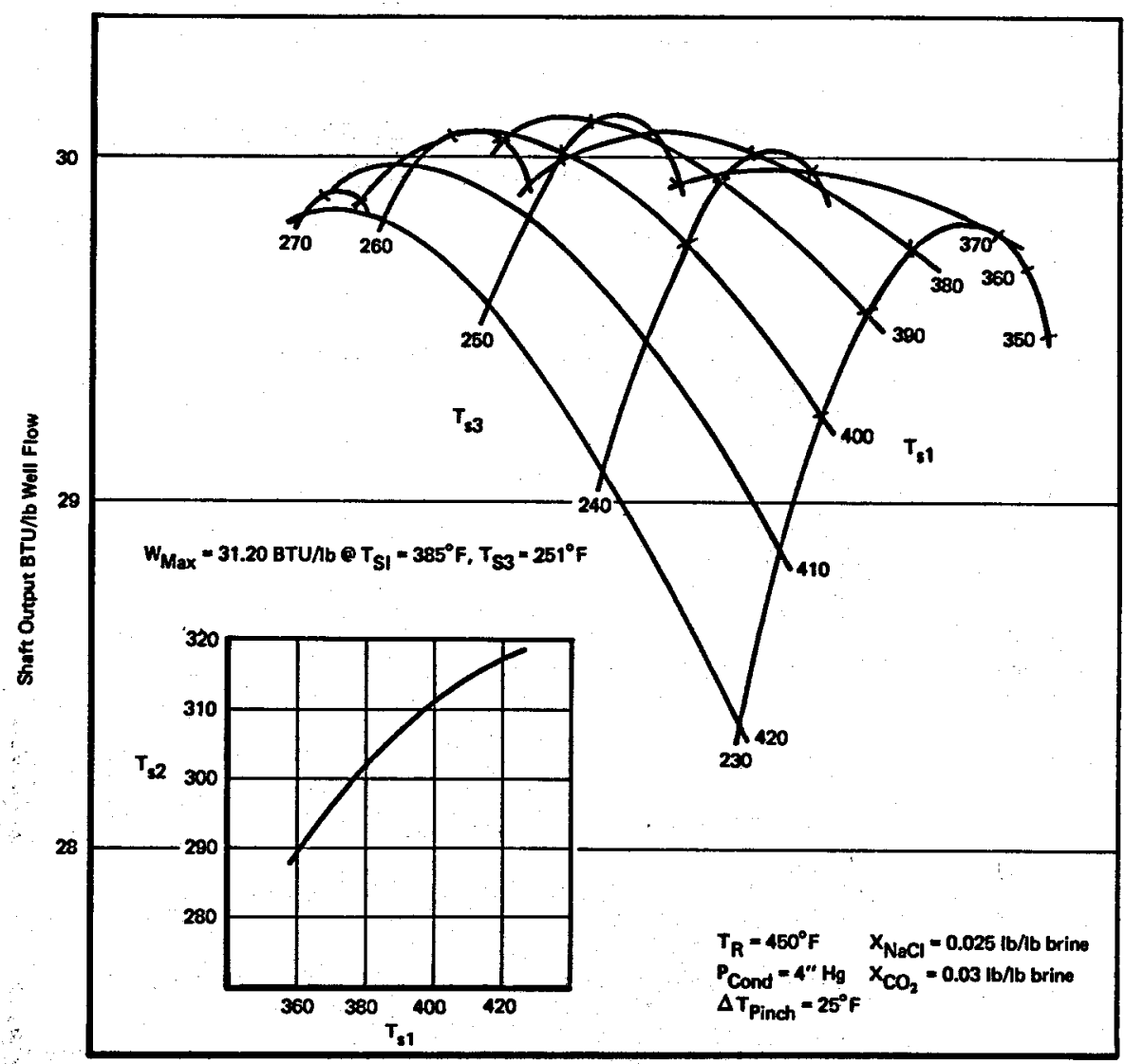

FIaURE 4.18-Performance characteristics of dual admission indirect steam cycle.

perature difference maintained in the steam generator and to the presence of non-condensible gas. Since the total pressure of the gas/steam mixture will remain essentially constant during the heat exchange process, any condensation of steam will cause the vapor pressure to fall, and hence the condensing temperature will also fall. The condensation process, will therefore, tend to follow the curved path depicted on the temperature/ enthalpy diagram of figure 4.19 , with the curvature decreasing with increasing gas concentration. The temperature difference $T_{B_{1}}-T_{B_{1}}^{\prime}$ represents the initial superheat in the primary steam due to the higher saturation temperature of the liquid brine. (Typically, steam flashed at $400^{\circ} \mathrm{F}$ from hypersaline brine containing $30 \%$ salt will be superheated by about $25^{\circ} \mathrm{F}$.) Since the generated steam evaporates at constant temperature, a pinch temperature difference will occur at the point where boiling begins. The magnitude of this temperature difference and its location relative to the condensation curve determines the temperature of the generated steam. 


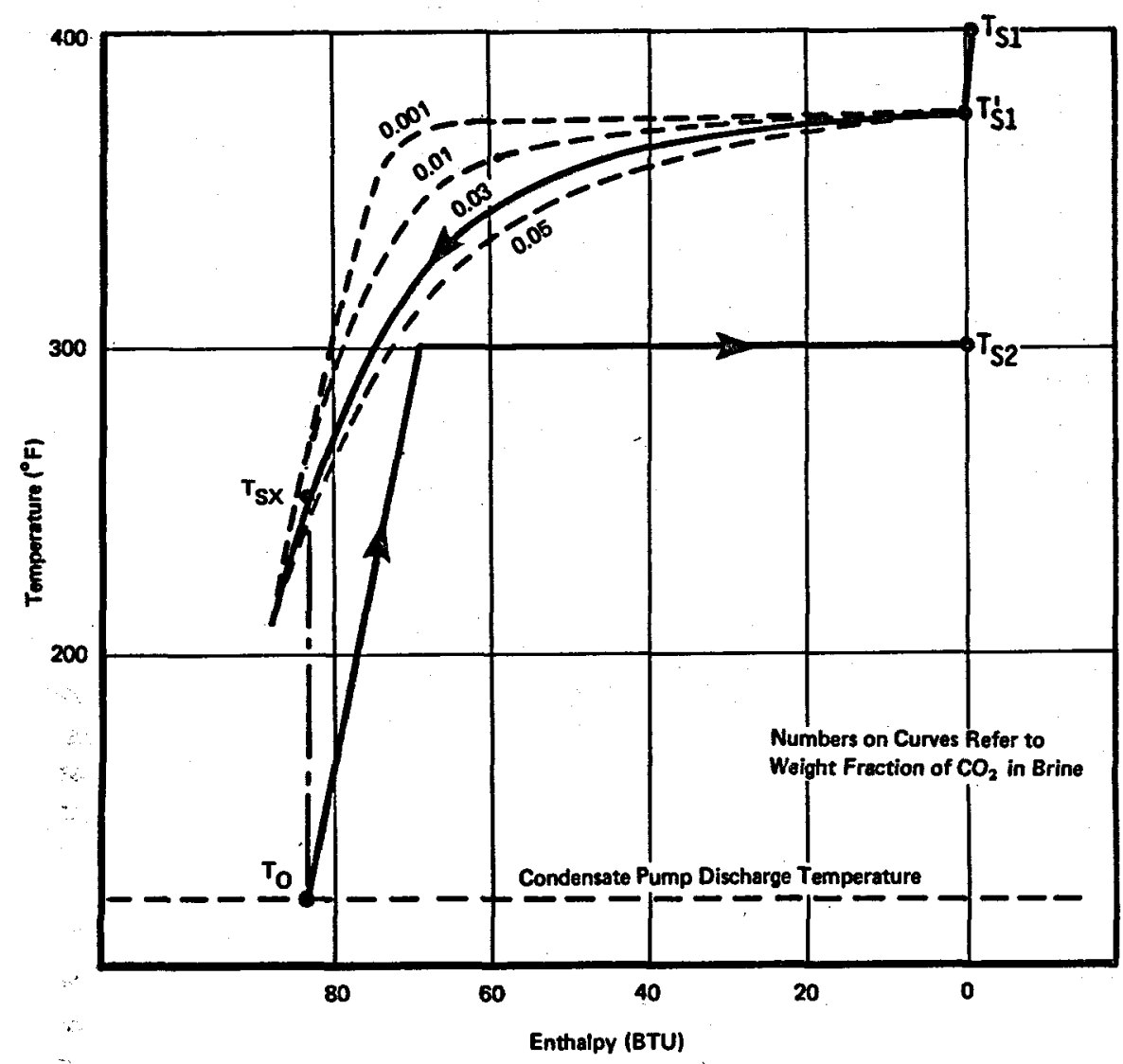

Froure 4.19-Temperature/enthalpy diagram for primary steam/steam generator.

The higher the gas concentration, the further this temperature is depressed below the primary flash temperature.

Since the available energy of the generated steam decreases with temperature, output will decrease with increasing $\mathrm{CO}_{2}$. The effect of $\mathrm{CO}_{2}$ concentration on the performance of the indirect cycle is shown in figure 4.20. As the primary flash temperature is increased and less primary steam is available to generate clean steam, the less pronounced the effect on output. When the primary flash operates at $360^{\circ} \mathrm{F}$, which is not an unreasonable temperature under self-flowing conditions with reasonable production rates for this particular resource, cycle output decreases by approximately $2 \%$ for each percent of $\mathrm{CO}_{2}$ in the brine.

In constructing the performance plot of figure 4.18, values of $T_{s 1}$ and $T_{83}$ were first established and $T_{82}$ was then adjusted until output was at a local maximum. This optimum value of $T_{82}$ was found to be independent of $T_{s 3}$ and a function only of $T_{81}$. Its relationship with $T_{31}$ is shown in the insert graph of figure 4.18. For the resourse conditions considered here, 
Frgure 4.20-Performance of indirect steam cycle rs. $\mathrm{CO}_{2}$.

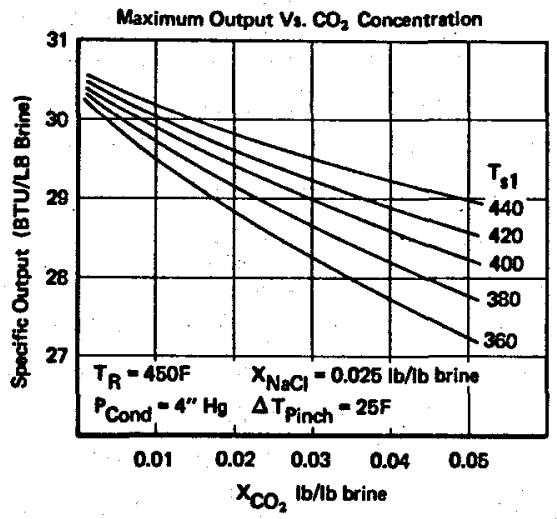

the temperature difference between the primary flash and the turbine inlet varies between $70^{\circ} \mathrm{F}$ and $95^{\circ} \mathrm{F}$ which reduces significantly the temperature difference between the turbine primary inlet and the secondary admission. In fact, at conditions which produce maximum output, this temperature difference is only about $50^{\circ} \mathrm{F}$.

Obviously, the cycle would be considerably simplified and costs greatly reduced if the temperature of the generated steam were reduced to the level of the secondary flash. The two flows could then be combined and introduced into the high pressure inlet of a single admission turbine. The performance of this simplified cycle is shown as a function of primary and secondary flash temperatures in figure 4.21. For a given primary flash temperature, there again exists a unique turbine inlet temperature at which output is a maximum. As the primary flash temperature increases and less primary steam is liberated, output also increases. In the limiting case where the primary flash temperature equals the bottom hole temperature, the cycle is reduced to a single flash/single admission system and output in-

Froure 4.21-Performance characteristics of dual flash/single admission indirect steam cycle.

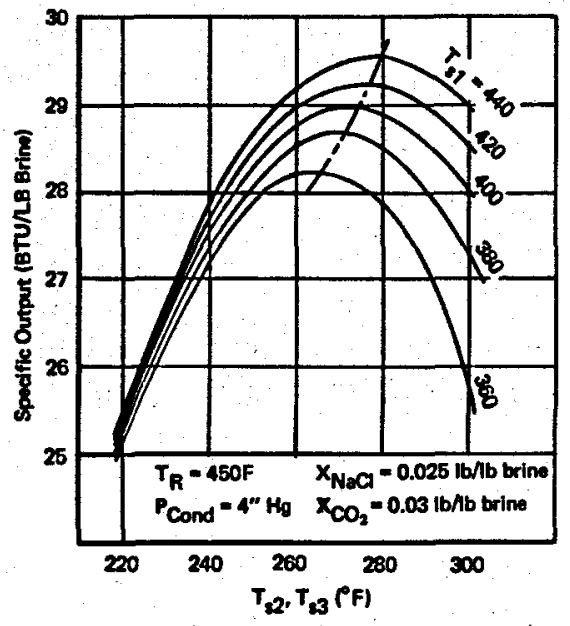


creases to $29.9 \mathrm{BTU} / \mathrm{lb}$. brine. Clearly such a situation is inadmissible since the primary objective of removing $\mathrm{CO}_{2}$ from the system would not be accomplished. The gas would remain in the brine and would be released at the secondary flash to enter the turbine. Moreover, to achieve the higher flash temperatures with reasonable flow rates, wells would require pumping. This offers no particular advantage for the indirect cycle since its overall performance would be considerably poorer than that of the steam vent cycle. Clearly, the performance of the indirect cycle without well pumping is insensitive to variations in the primary flash temperature. When the latter is reduced to $360^{\circ} \mathrm{F}$, the difference between the output of the single and dual admission indirect cycles is less than $6 \%$.

Bechtel steam oycle. The third modified steam cycle analyzed in this section is shown schematically in figure 4.22 . It was conceived originally

Brine

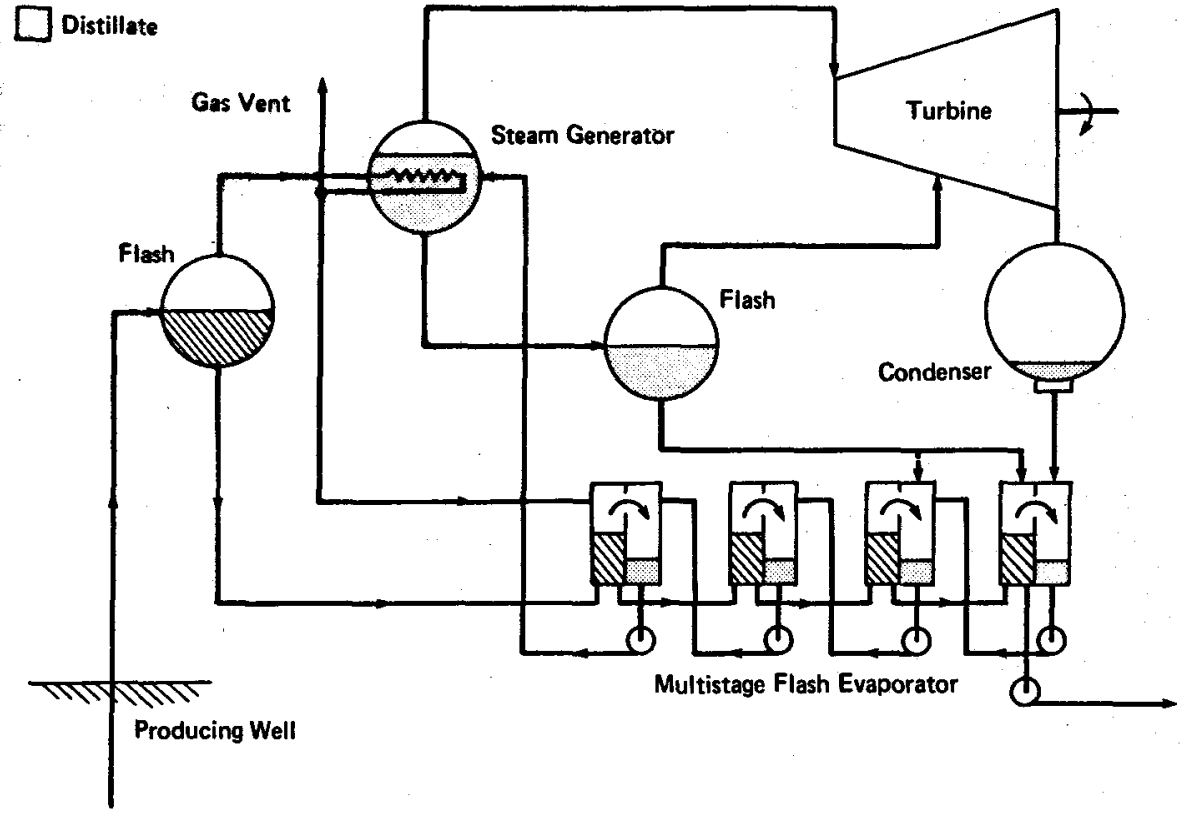

FIaUre 4.22-Schematic of Bechtel steam cycle.

by L. Awerbuck and C. T. Draney of the Bechtel Corporation and is referred to here simply as the "Bechtel Steam Cycle." The primary flash configuration is essentially indential to the indirect system. Contaminated steam is separated after primary flash and is used to generate gas-free steam from condensate. However, rather than utilizing the residual brine from the primary flash to generate gas-free secondary steam for the turbine, it is supplied instead to a multistage flash evaporator where it supple- 
ments and heats the flow of turbine condensate. The secondary steam is obtained by flashing saturated condensate from the steam generator.

The multistage evaporator consists of a long cylindrical shell divided axially by several partitions. Each stage is itself divided, although communication exists between the two compartments of each stage. Saturated liquid brine leaving the primary flash tank enters the left compartment of the first stage where it experiences a small reduction in pressure. The steam produced is condensed in the right compartment using a spray of condensate delivered from the next stage. Residual brine from the first stage is delivered to the second stage and the process is repeated. In this way, the supply of turbine condensate is supplemented and heated to near saturated conditions before delivery to the steam generator. Both the condensate from the primary and secondary flash processes are utilized in this heating process as shown in the diagram. The stages at which the two flows are admitted are determined by the condensate temperature. This should be approximately equal to and slightly above the saturation temperature of the vapor in the stage.

The performance of the Bechtel Cycle can be calculated by assuming values for the temperature at the primary flash, steam generator and secondary flash, and also for the amount of fresh water fed to the steam generator. The performance of the cycle will vary with the number of evaporator stages and the selection of the stage at which fresh water is added.

Consider the single evaporator stage shown in figure 4.23. $M$ is mass flow rate, $H$ specific enthalpy and $C$ is salinity. The subscripts $B, C, P C$ and $S C$ refer to brine, condensate, primary flash condensate (after gas and uncondensed vapor are vented) and secondary flash condensate, respectively. The pressure in the stage is equal to the saturation pressure of condensate at temperature $T_{c 2}$. In the first stage (highest pressure stage) of the evaporator, this temperature and the flow rate $M_{g z}$ have assumed values. In any other stage, $M_{C_{2}}$ and $H_{\sigma_{2}}$ are equal to $M_{\sigma_{1}}$ and $H_{C_{1}}$ of the adjacent higher pressure stage with some adjustment in enthalpy to account for the

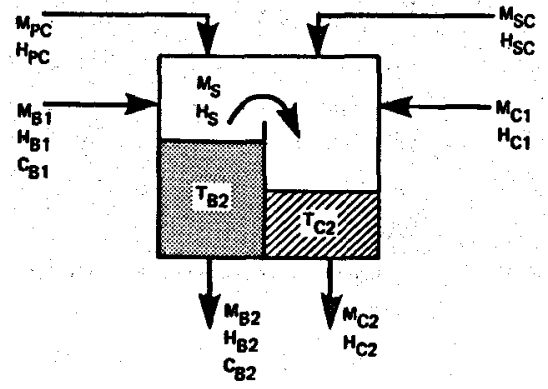

$M$ is mass flow rate, $H$ is specific enthalpy and $C$ is salinity. The subscripts B, C, S, PC and SC refer to brine, condensate, vepor, primary flash condensate and secondary flash condensate respectively.
Fraure 4.23-Single evaporator stage of Bechtel steam cycle. 
pump work added between stages. The brine conditions are known at entry to the first stage, and for subsequent stages are the same as the discharge conditions of the previous stage.

For steady state operation, there must be a heat balance, a flow balance and a concentration balance at each stage in the evaporator. This requirement results in the following set of simultaneous equations:

$$
\begin{gathered}
M_{B 1}+M_{P C}=M_{B 2}+M_{S} \\
M_{O 1}+M_{B C}+M_{B}=M_{C 2} \\
M_{B 1} H_{B 1}+M_{P C} H_{P C}=M_{B 2} H_{B 2}+M_{S} H_{S} \\
M_{O 1} H_{C 1}+M_{B O} H_{B C}+M_{B} H_{B}=M_{O 2} H_{C 2} \\
M_{B 1} C_{B 1}=M_{B 2} C_{B 2}
\end{gathered}
$$

The number of unknowns $M_{\mathrm{B} 2}, H_{\mathrm{B} 2}, C_{\mathrm{B}}, M_{\mathrm{B}}, M_{C_{1}}$ and $H_{C_{1}}$ exceeds by one the number of equations. However, $T_{B 2}$ is a function of the stage pressure and $C_{B 2}$, and $H_{B 2}$ is a function of $T_{B 2}$ and $C_{B 2}$ so that by iterating on $C_{B 2}$, the unknowns can be found for each heater section in turn.

In a similar manner, the overall heat, mass and concentration balances must be satisfied such that:

$$
\begin{gathered}
M_{B 1} \text { (first heater) }+\Sigma M_{P O}-\Sigma M_{B}=M_{B 2} \text { (last heater) } \\
M_{O 1} \text { (last heater) }+\Sigma M_{S C}+\Sigma M_{B}=M_{O 2} \text { (first heater) } \\
H_{C 1}=H \text { (Condensate) } \\
M_{C 1}=M \text { (Primary) }+M \text { (Secondary) }
\end{gathered}
$$

Equations 4.24 through 4.27 are solved iteratively to find $H_{c 2}$ in the first section. This establishes the steady state conditions for the cycle, together with a value for turbine output.

The output will vary with assumed initial conditions and also with the number of heater stages and stages at which the primary and secondary condensate flows are added. In general, output increases with the number of stages, although since a pump must be added with each stage, eventually a point of diminishing return is reached. For optimum system performance, the primary condensate should be added to the first stage at which $H_{P C}$ is just greater than $H_{B 1}$. Similarly. the secondary condensate should be added to the stage where $H_{s \sigma}$ is just greater than $\dot{H}_{\sigma 1}$.

The overall performance of the Bechtel Steam Cycle is shown in figure 4.24 as a function of the number of evaporator stages. A temperature of $440^{\circ} \mathrm{F}$ was selected for the primary flash and a pinch temperature difference of $25^{\circ} \mathrm{F}$ was assumed for the steam generator.

The gross output of the cycle with four evaporator stages is comparable to that of the Indirect Cycle. As more stages are included, output in- 


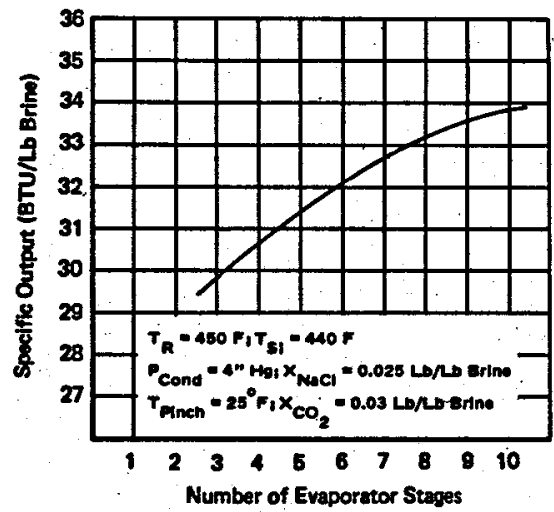

FraURe 4.24-Performance of Bechtel steam cycle vs. number of evaporator stages.

creases. However, with a very large number of stages, the additiona] pumping power required for condensate will tend to overcome the decreasing incremental gain in heat recovery from the brine and net output will decrease. The need for circulating pumps between evaporator stages presents a serious disadvantage for this cycle since not only do the pumps consume power and degrade performance; but they also handle condensate flows which are almost twice as great as the flow of liquid brine. Details of system flow rates and specific enthalpies are summarized in the flow diagram of figure 4.25 .

Av Brine

Distillate

$1176.6,0.1247$

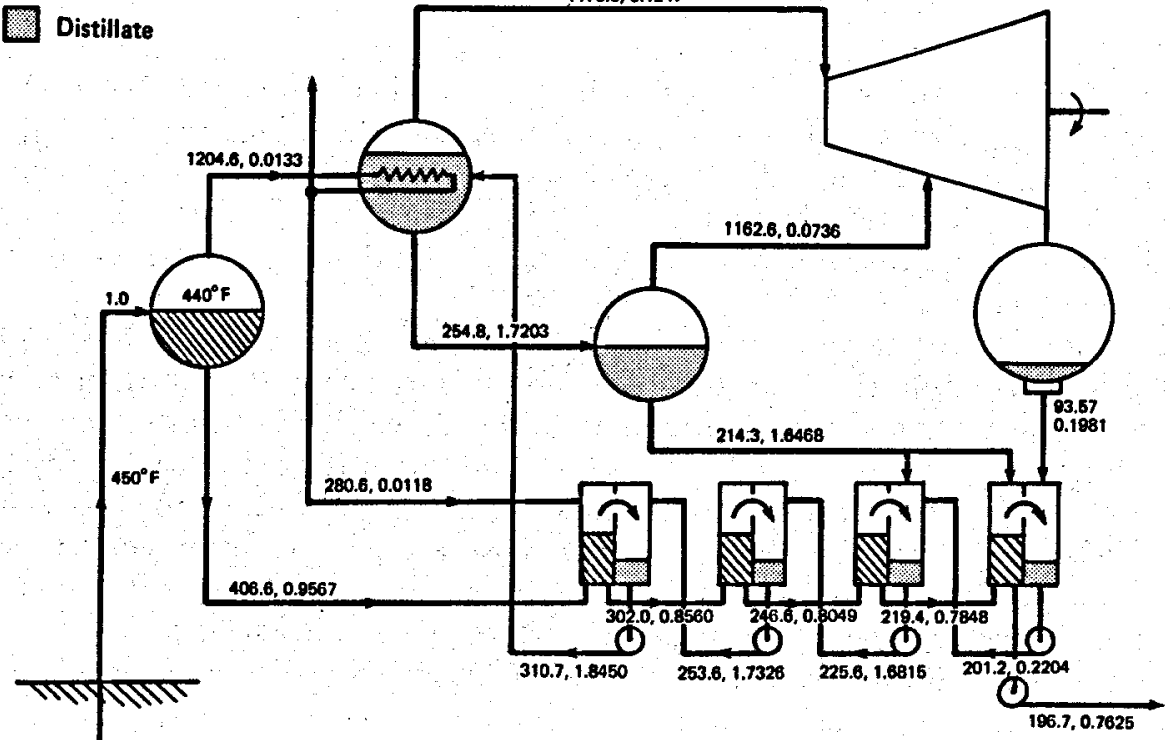

Fraure 4.25-Typical tlow diagram for Bechtel steam cycle. Numbers refer to specific enthalpy in $\mathrm{Btu} / \mathrm{lb}$ and flow rate in $\mathrm{lb} / \mathrm{lb}$ brine respectively. 


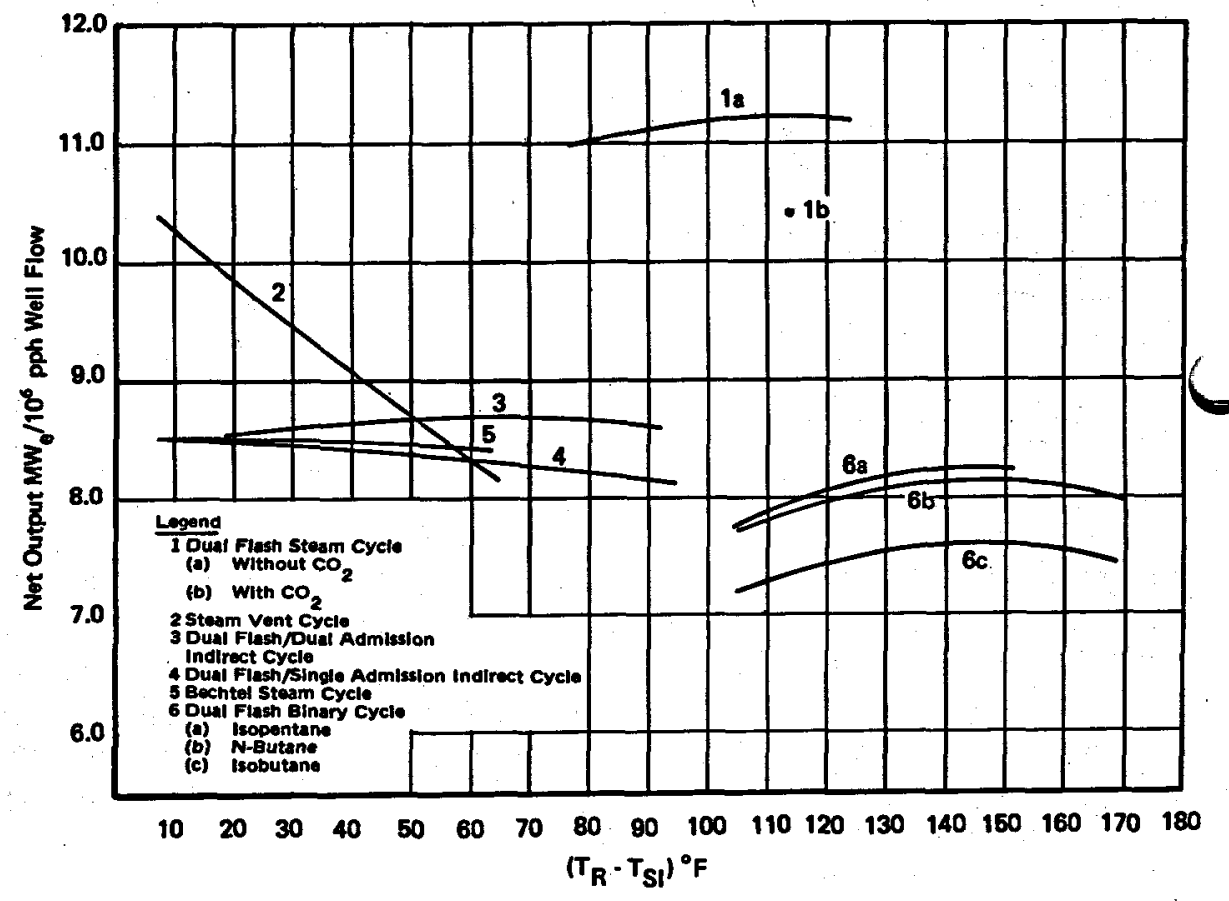

Figure 4.26-Summary of performance characteristics of steam cycles and selected flash binary cycles.

4.1.2.3 Comparison of cycles and general discussion. A summary of the performance of each cycle is shown as a function of primary flash temperature in figure 4.26. The output, given as electrical megawatts, assumes a generator efficiency of 0.985 . The performance of a dual flash binary cycle operating from the same resource conditions and using isobutane, normal butane and isopentane as the working fluid is included in the figure as a basis for comparison.

Highest output is obtained from the conventional cycle in which $\mathrm{CO}_{2}$ is removed from the main condenser and is only about $8 \%$ less than from the same cycle operating without influence from $\mathrm{CO}_{2}$. However, the cost of the compressors and gas coolers associated with removing $\mathrm{CO}_{2}$ is fairly high, and seems certain to raise the overall cost above that for the Vent Cycle. Costs will be even higher if surface, rather than spray condensers are used, since the deleterious effect of a non-condensible on heat transfer effectiveness will tend to increase the surface area requirement.

As expected, the gross output of the Vent Cycle approaches that of the conventional cycle as less steam is liberated at the higher primary flash temperature. Depending on site conditions, the fraction of the gross output required for the well pumps may be substantially more, or even less than the compressor work charged to the conventional cycle. The well pump work, however, should not be viewed as a direct loss since the pumps 
substantially increase the flow rate of each well and will result in reducing the number of wells required, probably compensating for most of the capital invested in well pumps and the cost of maintaining them. The merits of the Vent Cycle must, therefore, be evaluated for each specific site.

The Bechtel Cycle using a 4-stage flash evaporatur and the Indirect Cyclo have roughly the same performana, about $80 \%$ of the net output from the conventional steam cycle. The output of the Bechtel Cycle can be increased $10 \%$ or more by increasing the number of stages in the flash evaporator, but this also increases the cost and complexity. For a given plant net power rating, there will be a saving in the turbine-generator cost since there is no need to develop extra power for well pumps or large compressors. However, the steam generating heat exchangers for the Bechtel and Indirect Cycles are large and expensive and probably raise the overall costs above the cost of the conventional cycle.

The optimum temperature for the Vent Cycle primary flash will, of course, depend on the initial concentration of $\mathrm{CO}_{2}$ in the brine and on the amount of $\mathrm{CO}_{2}$ which can be tolerated in the system after initial flash. For high initial $\mathrm{CO}_{2}$ levels, temperature reductions of between $20^{\circ}$ and $30^{\circ} \mathrm{F}$ may be necessary to reduce gas concentration in the condenser to acceptable levels (see table 4.4). Clearly, a tradeoff must be made between the cost of extraction pump work at the condenser and lost work due to reducing the temperature of the primary flash.

White the Vent Cycle may have some obvious economic advantages over the conventional cycle, its application will ultimately depend on the reliability of well pumping and, where $\mathrm{CO}_{2}$ release occurs near the bottom of the well, the technical and practical feasibility of locating pumps at great depth. Application of the conventional cycle on self-flowing wells will be governed more by chemical constraints since the control of calcite precipitation, due to $\mathrm{CO}_{2}$ release, will depend on the development of inexpensive scale inhibitors and on reliable techniques for introducing them. Of course, if reliable well pumping and universal scale control can be demonstrated simultaneously, the conventional steam cycle and vent cycle would immediately lose some appeal since both would have poorer performance and would probably have a higher cost than a brine/binary cycle.

\subsubsection{Special design features (By J. H. Eskesen and S. C. Bialy*)}

The configuration of geothermal steam turbines depends primarily on the type of application and generating capacity. Generally, single flow units are employed at ratings below 25-30 MW. Double flow units may be used up to 60-70 MW, while four flow units are required for higher ratings.

Details of a double-flow turbine designed to operate on a single pressure level steam source are shown in figure 4.27. Steam enters at the centerline

* Medium Steam Turbine Dept., General Electric Co., Lynn, Mass. 


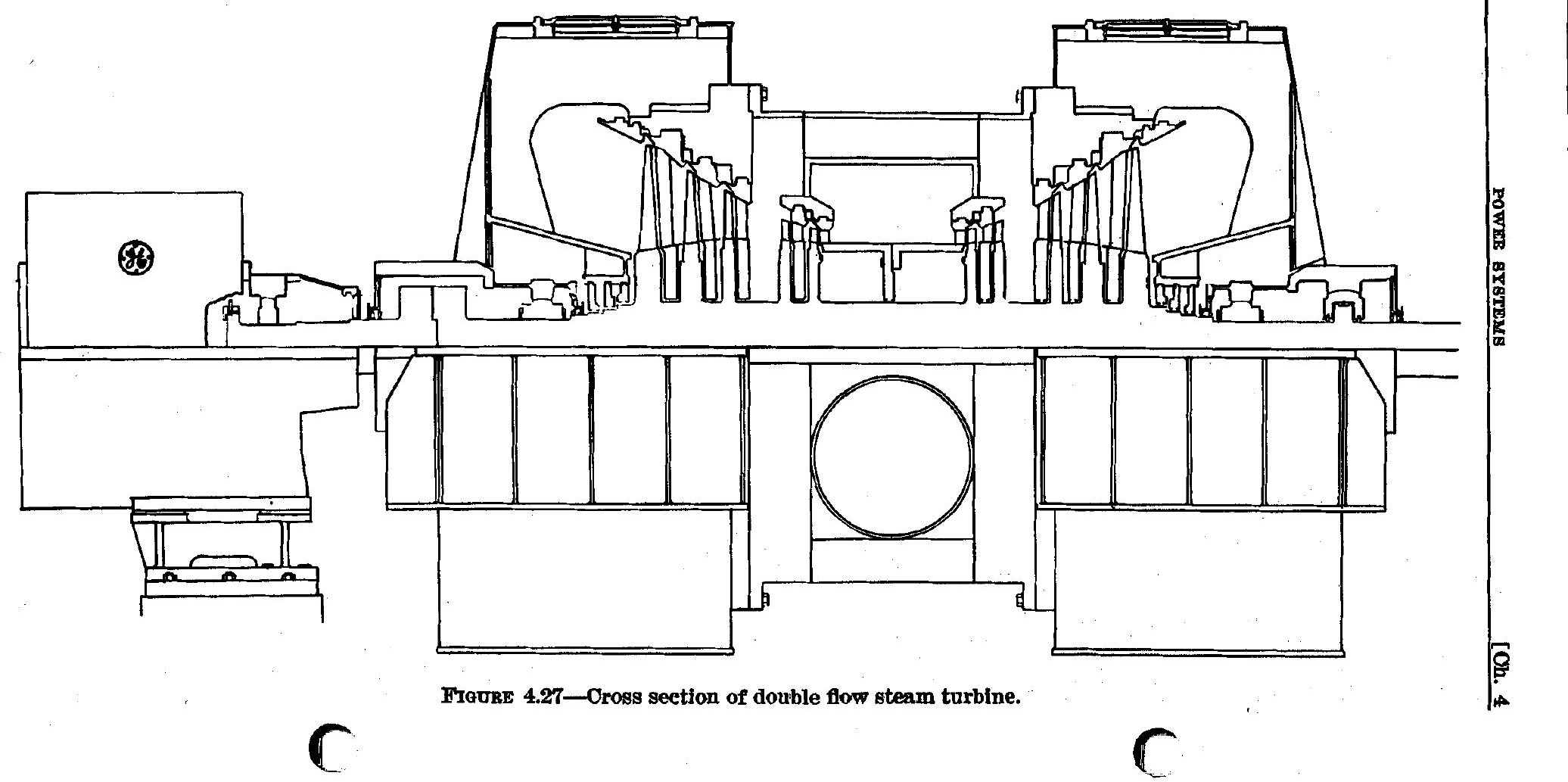


of the unit, expands axially along each flow path, which in this case contain six axial stages, and exhausts to the condenser. Note the existence of the pressure relief diaphragm in each exhaust hood. In dual pressure level systems, the low pressure flow would either be introduced at a secondary admission point downstream of the primary inlet, or it would be supplied to a separate turbine in tandem with the first. Both arrangements are shown schematically in figure 4.28.

The current generation of General Electric's double-flow geothermal units are of essentially the same design as the steam turbines currently employed in GE's combined cycle (STAG) plants. As is evident from figure 4.27, casings comprise two modular single flow units joined together by a single inlet section. A packaged unit with side exhausts is shown in figure 4.29. This modular type of construction contrasts with earlier designs used on Geyser units 13 and 15 in which the two exhaust manifolds were joined together to form a continuous outer shell which encased a double-flow inner barrel. The Geyser units are shown in various stages of construction in figures 4.30 through 4.33 .

Figure 4.30 shows the double-flow inner barrel assembly of Unit 15. The grooves machined in the barrel locate the nozzle diaphragms. Steam enters the turbine flow path through the rectangular section plenum on the machine centerline. The baffle plates shown welded to the exhaust section,
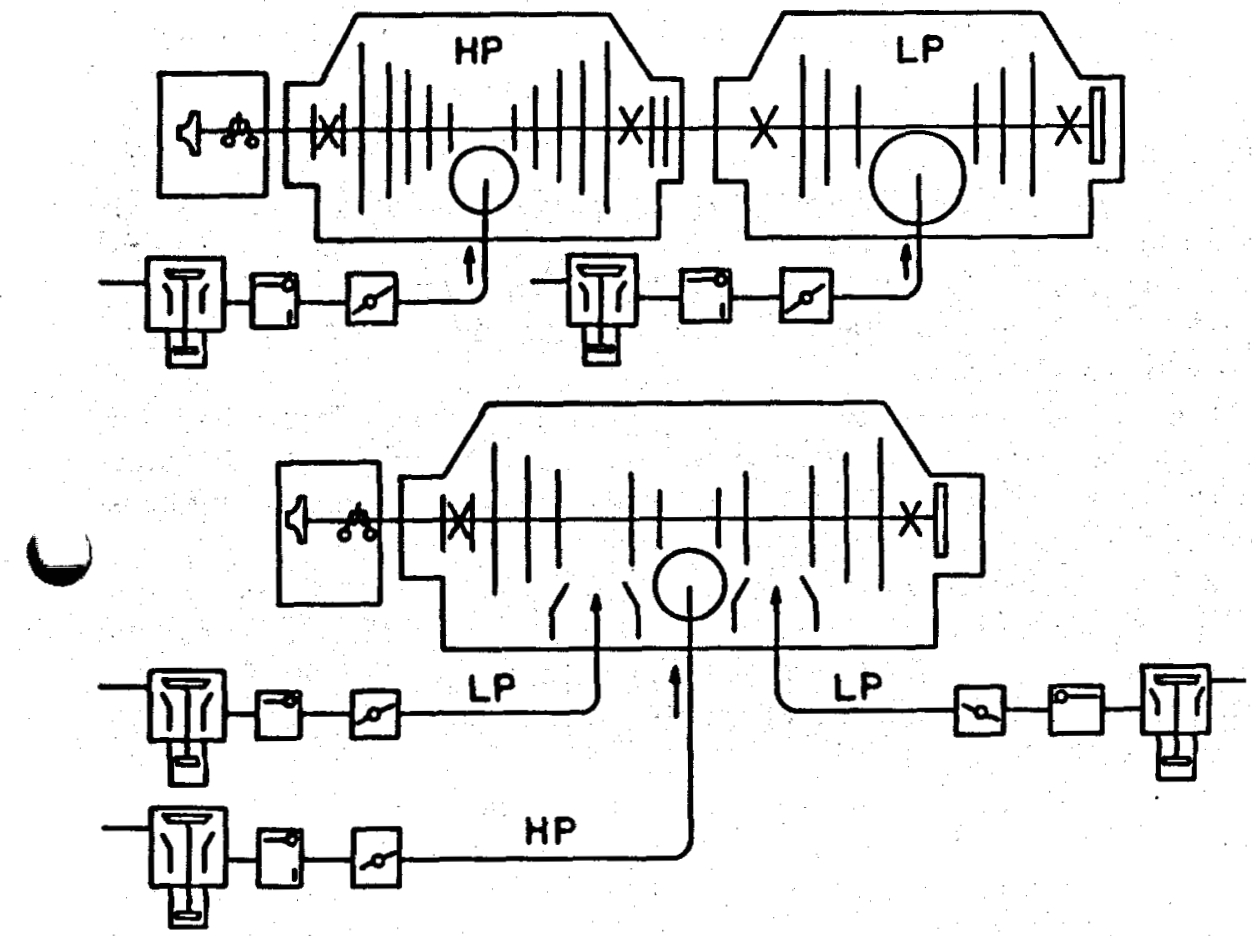

Figure 4.28-Alternative turbine configurations for dual flash systems. 


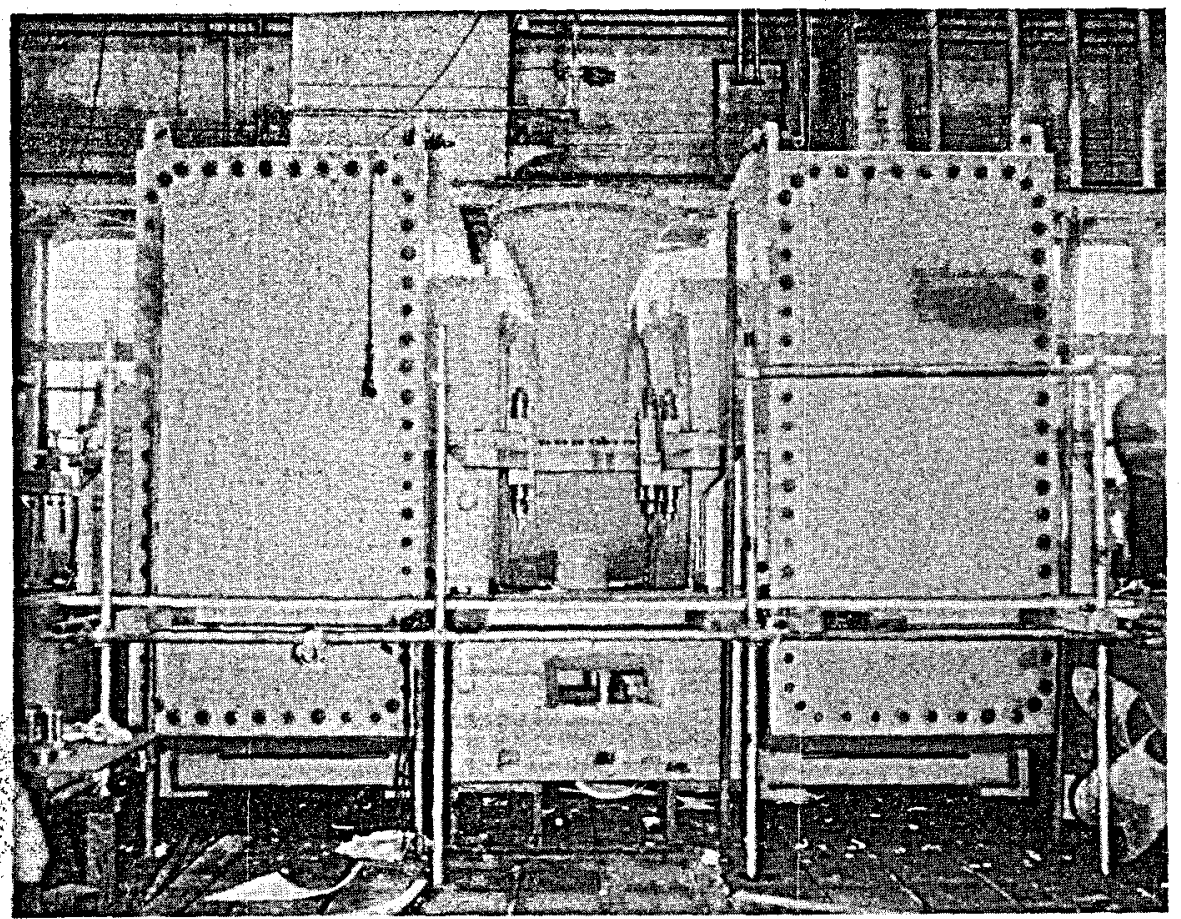

FIGURE 4.29-Packaged unit with side exhausts. [Photo by General Electric.]

are designed to help distribute the exhaust flow and reduce the exhaust, pressure drop.

Figures 4.31 and 4.32 show Unit 15 with nozzle diaphragms and turbine rotor installed. Each flow path contains five stages and each stage is banded to reduce bucket tip leakage and improve performance. One bucket must be omitted from each stage to facilitate entry into the circumferential dovetail of the wheel.

Figure 4.33 shows Unit 15 with the top half of the casing installed. The 36-inch diameter steam connection from the outer casing to the inner barrel is clearly evident, as is the turning gear on top of the bearing housing which "idles" the rotor during shutdown periods.

All nozzle diaphragms are fabricated from $12 \%$ Cr steel and are supported at the horizontal center line of the unit to minimize distortion and. misalignment caused by differential expansion. During startup, the casings are free to expand radially and axially while the diaphragms remain concentric with the shaft.

Stainless steel inserts shown in figures 4.34 and 4.35 in both the casing and diaphragm outer wall provide the steam joint at the outer diameter of the diaphragm. Pressure is applied to the joint by the static pressure differential across the nozzle. The stainless/stainless interface is designed to reduce the wire-drawing effect of wet steam should a leak develop across 


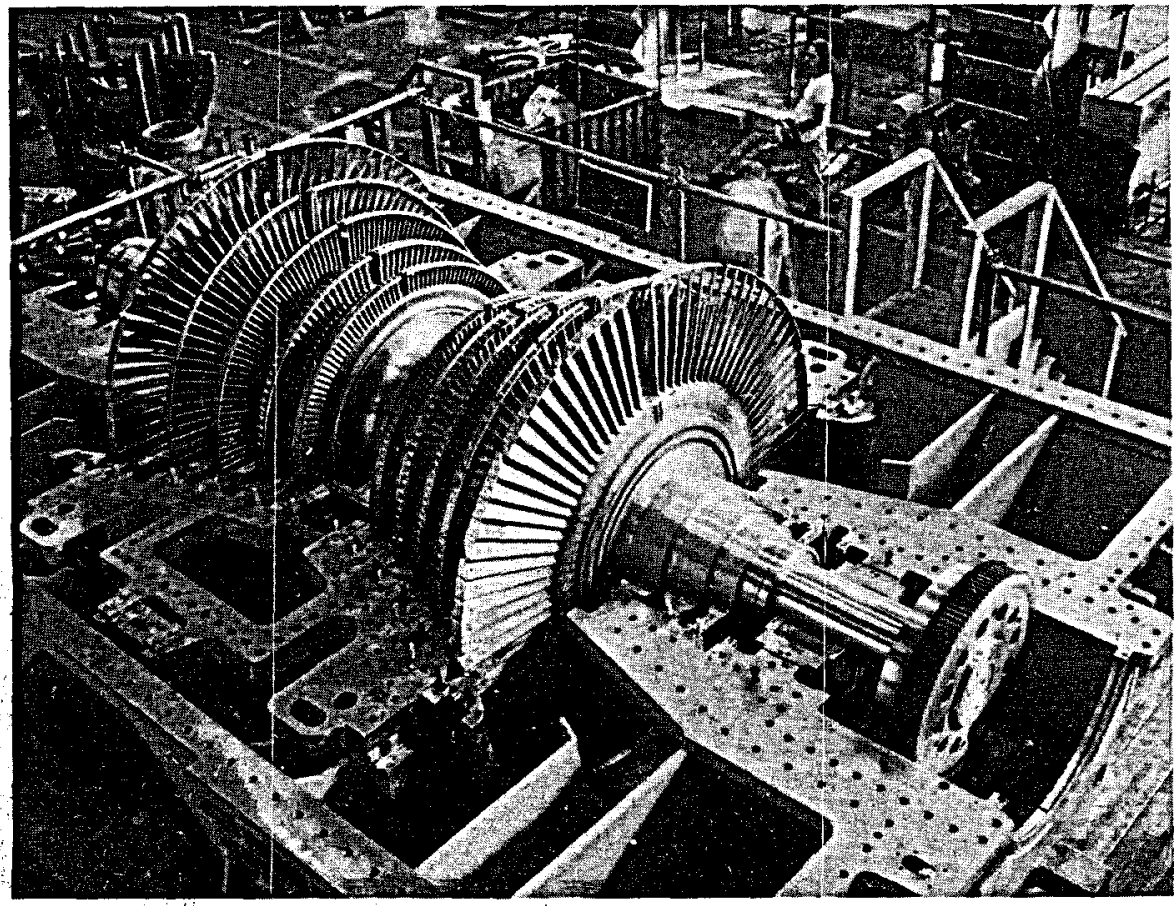

Fraune 4.31-Turbine rotor-Geyser unit 15. [Photo by General Electric.]

edge and collected in the cavity shown between adjacent diaphragm outer sidewalls in figures 4.34 and 4.35. The collection efficiency is a function of the blade height since the exposure time of shed droplets to crossflow increases towards the blade root and water shed from this region tends to be swept away.

Some of the water which collects on the nozzles is also recovered. The liquid film on the airfoil surface is induced by the turning steam flow to move downstream and radially outward. This radial component is important since it allows some of the water shed in the tip region of the trailing edge to be collected in the small groove connecting the large cavity in the stator.

\subsubsection{Steam turbine characteristics and design requirements (by J. $\mathrm{H}$.} Eskesen, G. F. Kelley, A. S. Melilli, and A. P. Rendine*

Because of the nature of geothermal resources, geothermal steam turbines differ in several respects from their conventional power plant counterparts. The large mass flow rates of low density, low enthalpy geothermal steam required to generate moderate quantities of power require large inlet pipes, simplified control valves and relatively few turbine stages. In addition,

- All from Medium Steam Turbine Dept., General Electric Co., Lynn, Mass. 


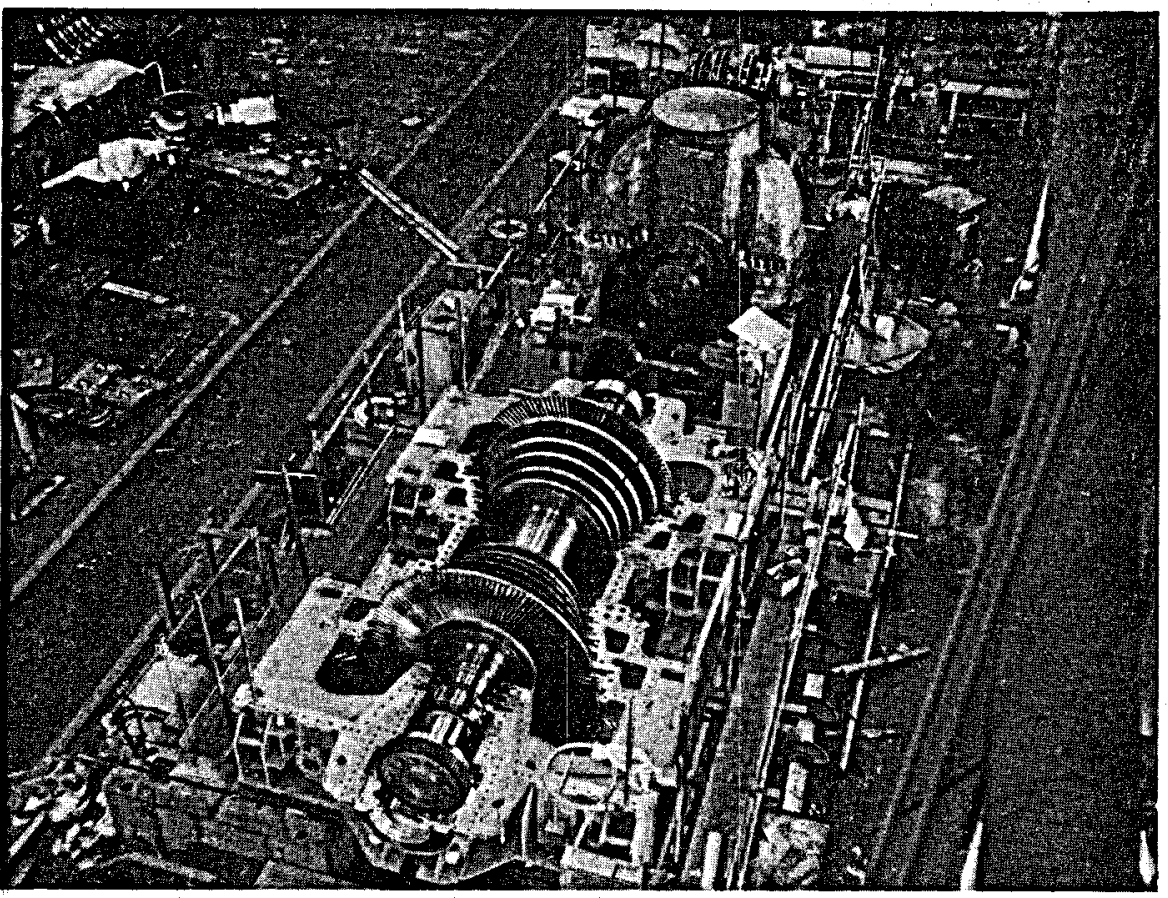

Froure 4.82-Turbine rotor/casing assembly-Geyser unit 15 .

[Photo by General Electric.]

since geothermal steam is frequently contaminated with corrosive gas, special design features must often be included to extend service life which usually results in some loss in efficiency.

In most other respects, however, the geothermal steam turbine is fairly conventional and is designed and constructed using components which have a history of reliability or which fall in the range of design experience where reliability is expected. The steam path design details are consistent with the economic value of the power produced, and the control system is designed to control load, flow or initial pressure and, of course, to prevent catastrophic failure in the event load is suddenly lost.

No attempt is made in this section to provide a fundamental theoretical account of axial flow turbine design. For this the reader is referred to reference (3). Rather, it was felt it would be more appropriate here to assume the reader is familiar with fundamentals and address instead some of the more practical aspects of geothermal steam turbine design.

4.1.4.1 Turbine characteristics. The turbine characteristics discussed in this section include both pressure and performance characteristics and the turbine internal efficiency.

Pressure characteristics. The geothermal steam turbine converts the thermal energy in geothermal steam into mechanical power. The efficiency 


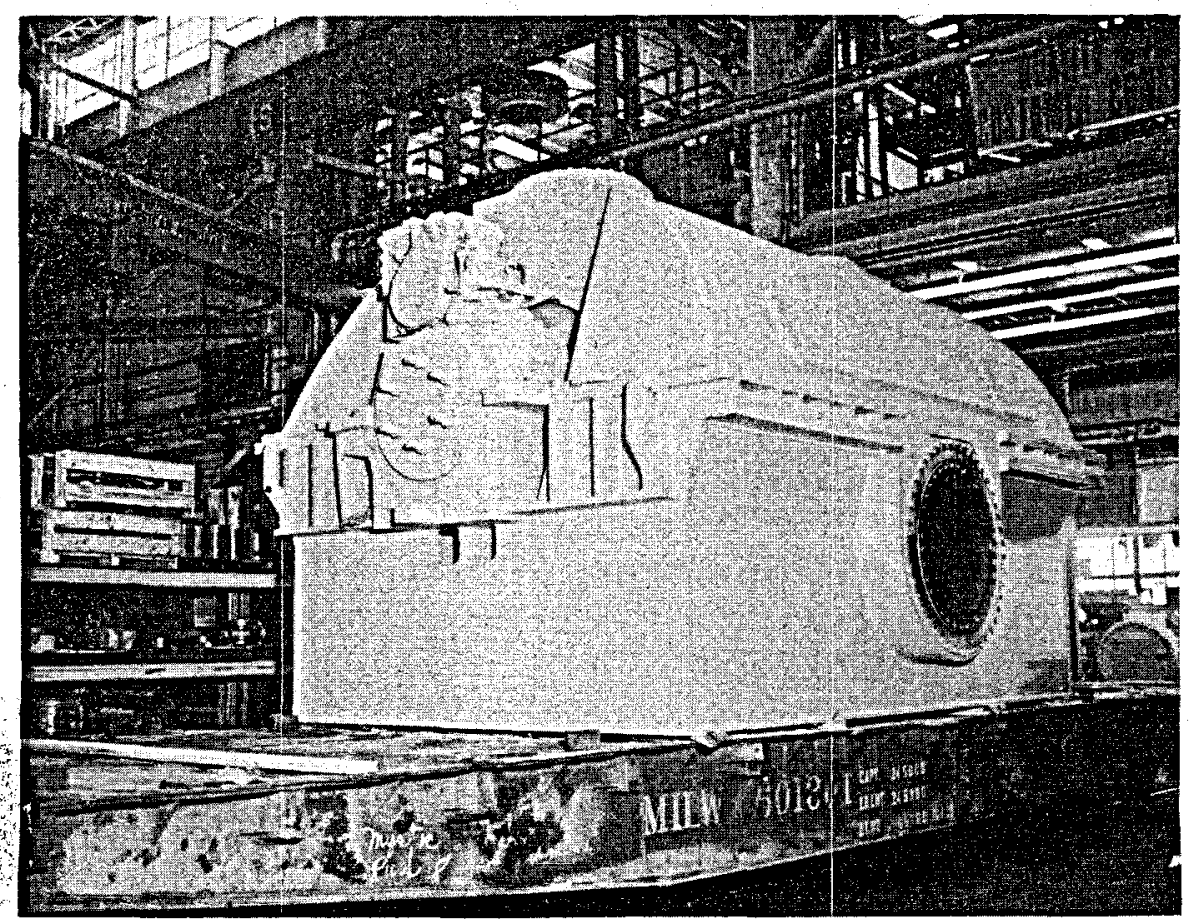

Figure 4.33-Packaged unit-Geyser unit 15. [Photo by General Electric.]

or steam rate will remain relatively constant over a fairly wide flow range. The steam pressure at the turbine inlet may be allowed to vary or may be held constant depending on the type of resource and control system employed. More will be said about the control system later. The pressure level at the turbine inlet will depend on stage pressure ratios and inlet design. The stage pressure ratio is a function of several variables and represents the combined pressure drop across the nozzle row and blade row.

The inlet pressure to the nozzle row can be expressed in terms of the following modified flow equation:

$$
Q=p_{1} A_{t} C f_{1} f_{2}(\mathrm{lb} / \mathrm{hr})
$$

which is derived from the perfect gas and continuity relationships. $p_{1}$ is the initial pressure in psia, $A_{t}$ is the throat area in square inches, and $C$ is a flow coefficient.

The function $f_{1}$ describes critical flow and is shown platted in figure 4.37 against initial enthalpy for a number of different inlet pressures. It was derived empirically to accurately predict the flow rates of wet steam. The flow function $f_{2}$ is the ratio of the flow rate at a given pressure ratio to the critical flow rate and is shown plotted against stage pressure ratio in figure 4.38. $A_{t}$ and $C$ are functions of geometry and, therefore, can be considered constant. From figure 4.37 it is clear that for wide variations 


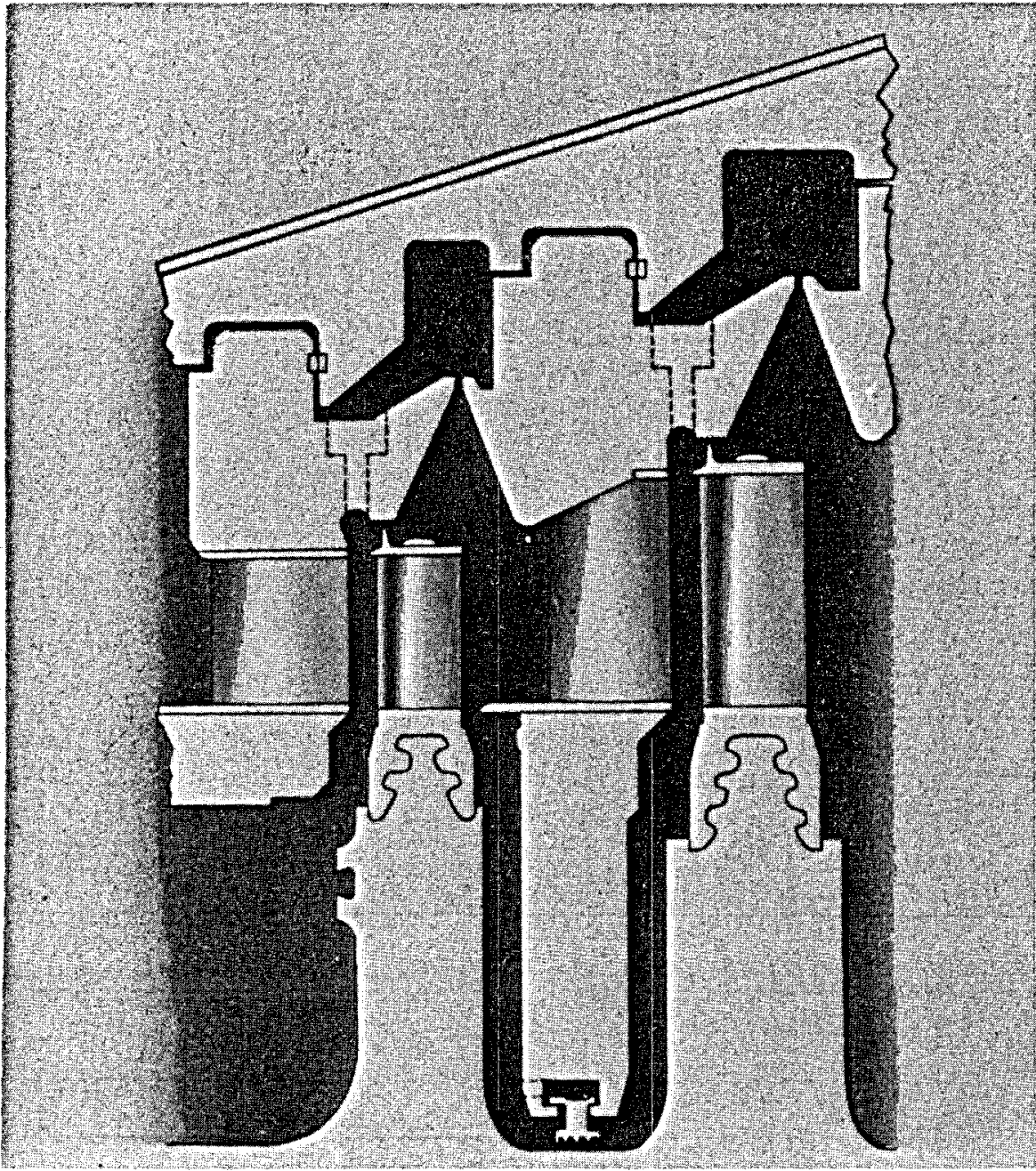

Frguke 4.34-Details of stainless steel insert in nozzle diaphragm outer sidewall.

in inlet conditions, the function $f_{1}$ changes very little. For example, a change in the inlet specific enthalpy of between 40 and $50 \mathrm{BTU} / \mathrm{lb}$, coupled with a ten-fold increase in specific volume results in a change in $f_{1}$ of less than $8 \%$. Similarly since nozzle rows in geathermal machines tend to operate at pressure ratios of 1.7 or higher and large changes in pressure ratio are not expected, the function $f_{2}$ will also change very little over the flow ranges anticipated. For practical purposes, therefore, $p_{1}$ can be assumed to be directly proportional to flow. This relationship has been used in figure 4.39 to predict the change in inlet pressure of the first and third stages of a dual admission steam turbine where secondary admission follows the second stage. Occasionally, pressure plots will be found 


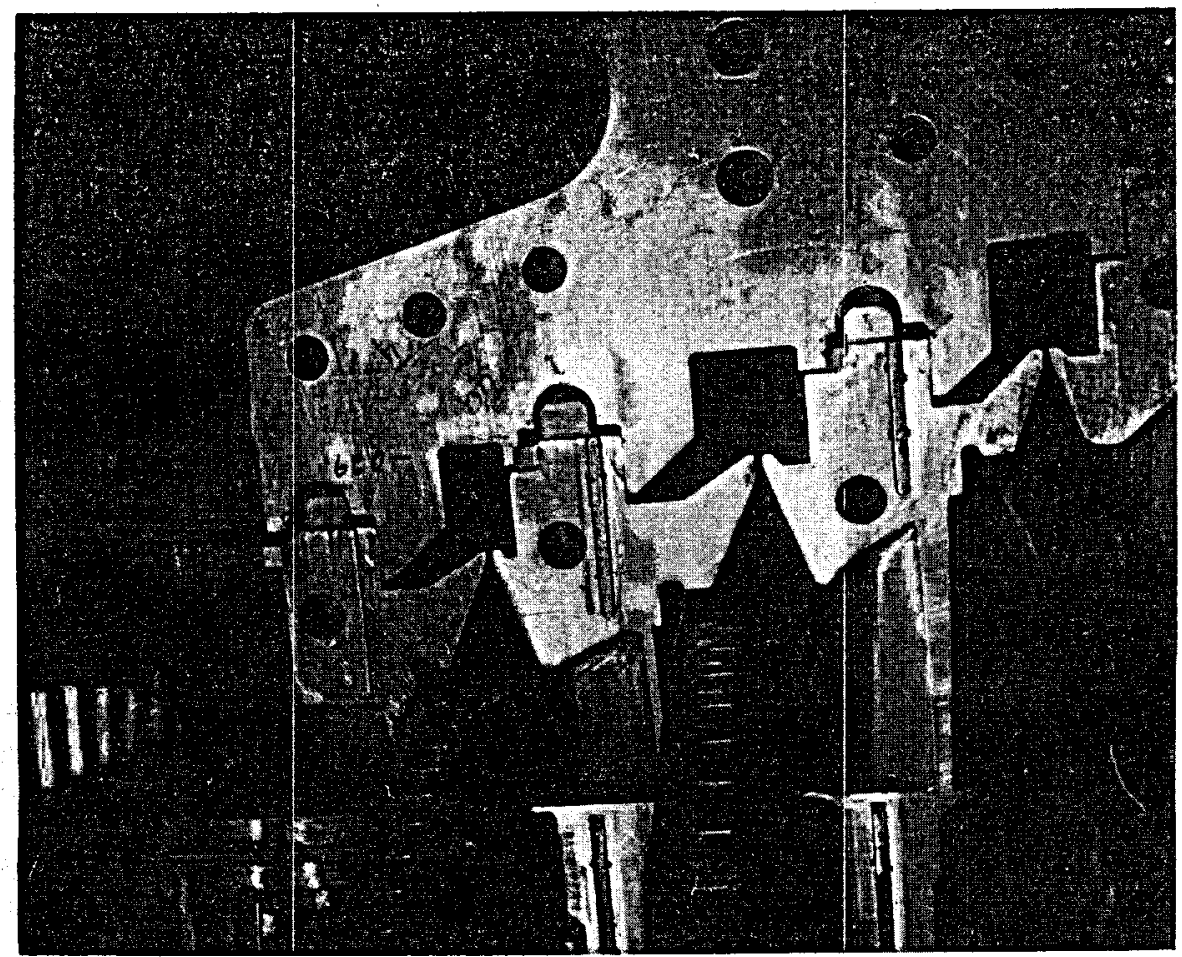

Frgure 4.35-Nozzle diaphragm outer sidewall assembly. [Photo by General Electric.]

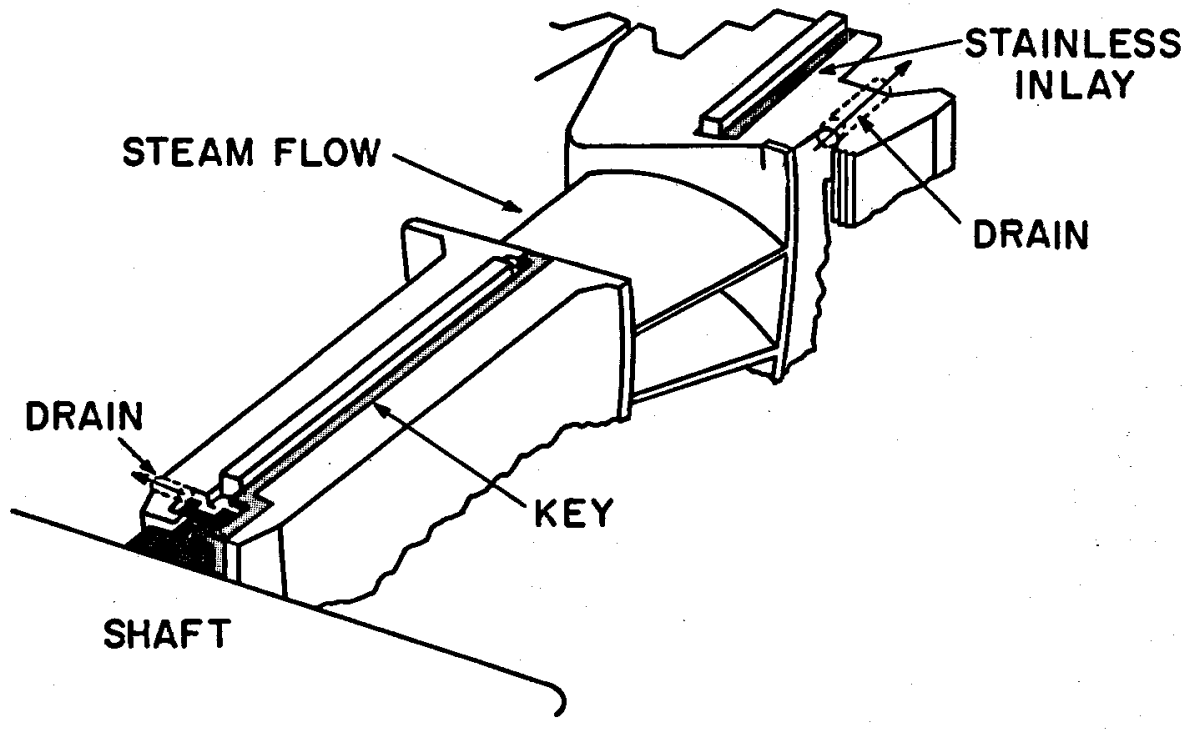

Frgure 4.36-Details of stainless inlay on diaphragm joint. 
Flauke 4.37-Flow function $f_{1}$ vs. initial enthalpy.

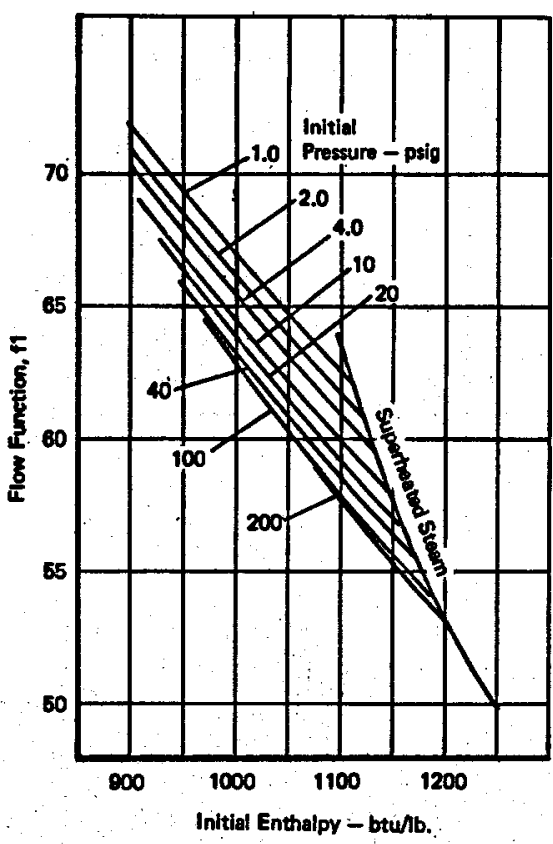

Frauke 4.38-Flow function $f_{2}$ vs pressure ratio.

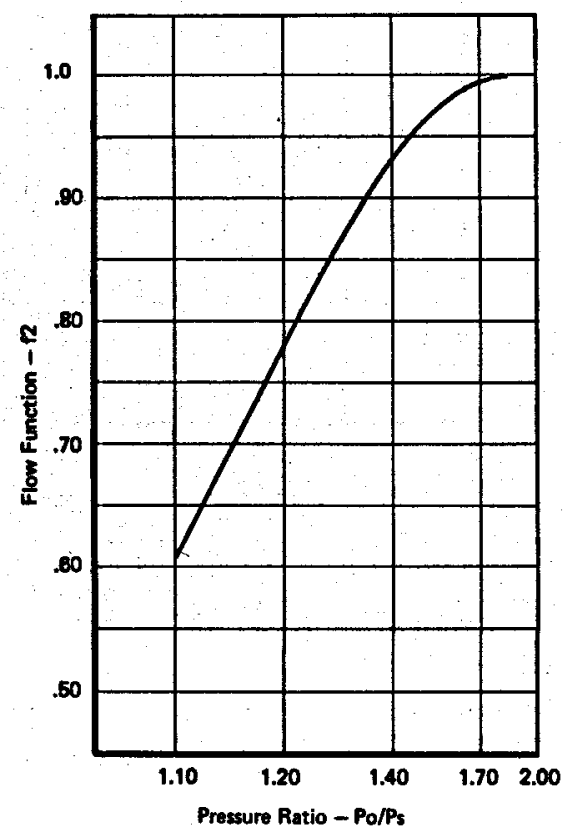




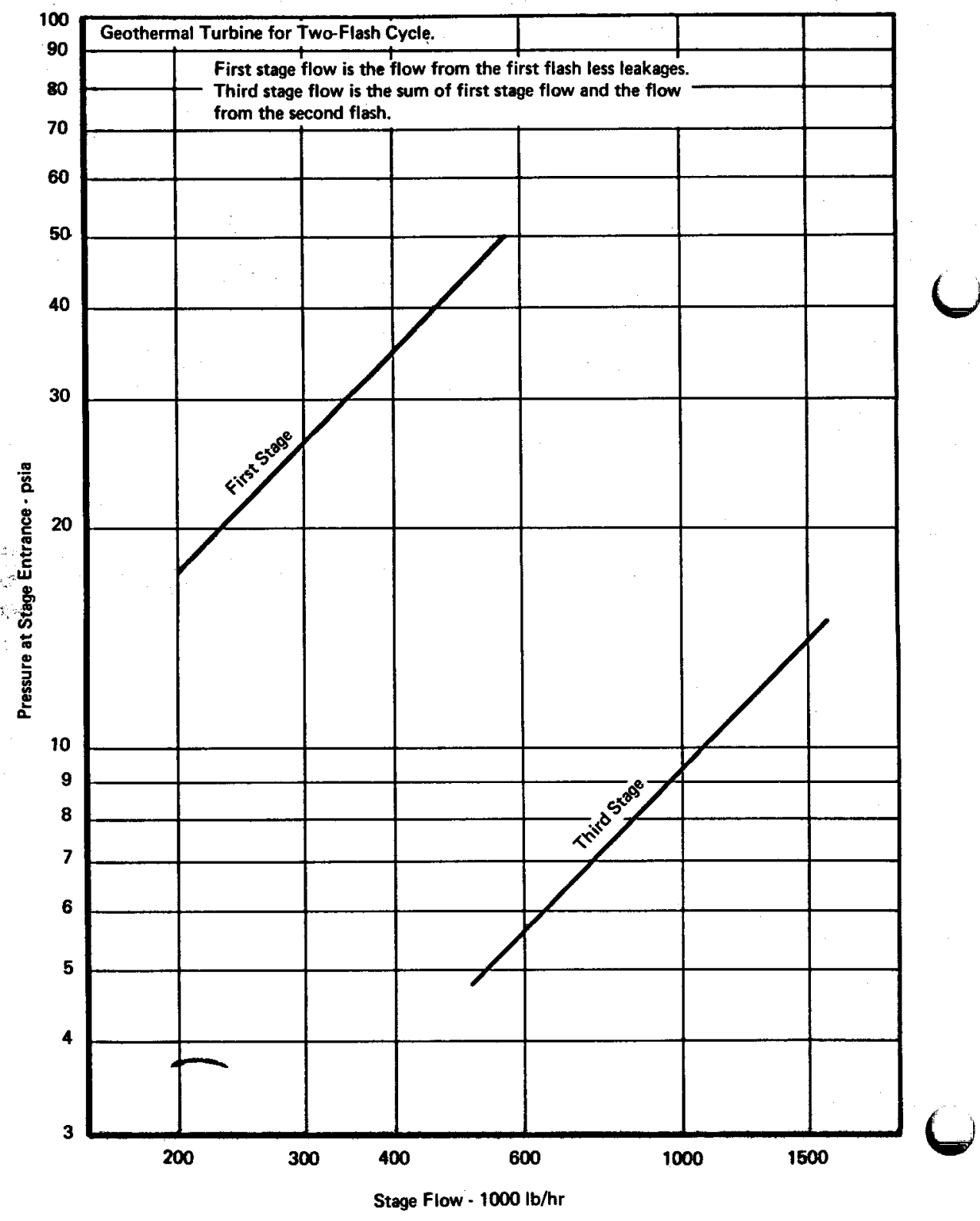

Frgure 4.39-Stage inlet pressure vs. flow rate.

where the slope of the lines has been modified to account for the small change in $f_{1}$ over the load range. Another often-used definition of the pressure-flow relationship is the equation:

$$
Q=c\left(p_{1} v_{1}\right)^{1 / 2}(\mathrm{lb} / \mathrm{hr})
$$


This expression is derived from the general flow energy equation with $f_{2}$ assumed constant and $f_{1}$ expressed as :

$$
f_{1}=k /\left(p_{1} v_{1}\right)^{1 / 2}
$$

where $v_{1}$ is the initial specific volume and $k$ is a constant.

Since the turbine inlet is defined as the point where plant piping connects turbine piping, the relationship between turbine inlet pressure and first stage inlet pressure will depend on the length and size of piping, the type of control valves used and geometry of the turbine's internal passageways leading to the first stage. For constant valve opening(s), the total inlet pressure loss will be very nearly a constant fraction of pressure. With the control valves wide open, these so-called throttling losses are usually between 5 and $7 \%$ of the inlet pressure.

As discussed earlier, the characteristics of the turbine control system will be the determining factor in the actual pressure characteristics at the inlet. If the control valves normally operate wide open, the inlet pressure will follow the stage pressure at a level 5-7\% higher. If, on the other hand, the inlet pressure is to be held constant, the turbine would be designed to operate with the first stage pressure 5-7\% less than the designed initial pressure at maximum flow and the control valves would throttle at reduced flows.

Performance characteristics. The performance of a geothermal turbine is usually measured in terms of a steam rate, i.e., the total mass of steam required to produce one kilowatt hour of output or

$$
S R=Q_{0} / E_{k w}
$$

The turbine electrical output $E_{k w}$ can be experienced as follows:

$$
E_{k i o}=\left(Q_{0}-Q_{L}\right)\left(\Delta H_{i, \eta_{i}}-L_{\varepsilon}\right) / 3412-L_{\text {rem }}(\mathrm{kW})
$$

where

$\Delta H_{t s}=$ isentropic enthalpy drop between the entrance to the first stage and the exhaust flange (BTU/lb).

$\eta_{t}=$ turbine internal efficiency.

$L_{e}=$ exhaust loss (BTU/lb).

$Q_{L}=$ leakage flow and steam seal requirements taken at the inlet $(\mathrm{lb} / \mathrm{hr}$ ).

$L_{\text {rem }}=$ aggregate of radiation, electrical and mechanical losses $(\mathrm{kW})$.

Each of these factors which contribute to turbine performance is discussed in the following section. Since both $\Delta \boldsymbol{H}_{i s}$ and $\eta_{i}$ describe the expansion process from the point of entry to the first-stage, the throttling loss described above is not included in this equation and must be accounted for separately. 
Turbine internal efficiency. The internal efficiency is defined as the expansion line efficiency for the entire group of stages. It includes losses in each stage due to moisture, leakage, windage and imperfections in the flow paths. It also includes performance gains due to reheat since losses in; a given stage appear as increased heat which can be utilized by the following stage. The internal efficiency of a well-designed turbine can be estimated from the following relationship:

where

$$
\eta_{i}=0.87\left(1-1300 N / Q_{1} v_{1}\right) f_{3}
$$

$N$ is the number of parallel flows in the turbine. (For a double-flow unit $N=2$ ).

$Q_{1}$ is the mass flow rate entering the first stage $(\mathrm{lb} / \mathrm{hr})$.

$v_{1}$ is the specific volume at entry to the first stage $\left(\mathrm{ft}^{3} / \mathrm{lb}\right)$.

$f_{3}$ is obtained from figure 4.40 at the condition entering the first stage.

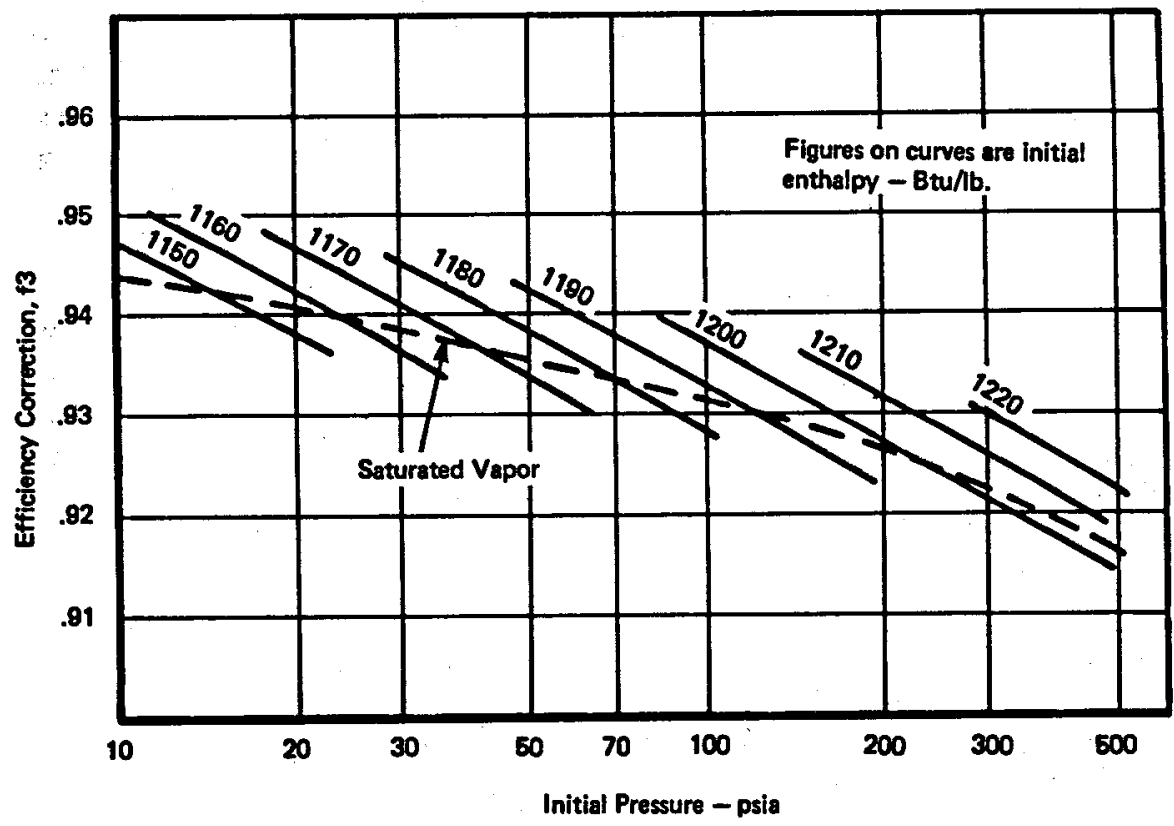

Figure 4.40-Efficiency correction factor vs. initial pressure.

Once the internal efficiency has been established, the turbine expansion line can be drawn on a Mollier chart. The upper end of the line will represent the condition at entrance to the first stage. The lower end, usually referred to as the expansion line end point and designated $E L E P$ is obtained from the expression:

$$
E L E P=H_{1}-\Delta H_{i 8} \eta
$$


where $H_{1}$ is the specific enthalpy entering the first stage. ELEP will appear on the chart at the exhaust flange pressure. The expansion line can be drawn using a Keuffel and Esser \#1864-41 curve with its bottom end projecting about 3.5 inches below the 4.0 psia line on the chart. The expansion line thus drawn represents the approximate state of the steam as it flows through the turbine. The final enthalpy of the steam will be greater, than that at point ELEP by an amount called the exhaust loss.

\subsubsection{Losses. Losses can be grouped in the following categories.}

Leakage and seal losses. Leakage and seal losses represent the leakage from valves and fittings in the inlet piping and also the steam required to operate the labyrinth seals used to prevent air and steam leaks. The total steam loss can be approximated using the simple expression:

$$
Q_{L}=1800 N
$$

where $N$ is the number of parallel steam flows in the turbine.

Exhaust loss. The exhaust loss is the loss in turbine energy due to kinetic energy leaving the last stage, to static pressure loss in the exhaust hood and to off-design performance of the last stage and preceding stages at low steam flows.

The static pressure loss in the exhaust hood is determined from test data. The energy in the residual velocity leaving the last stage is usually called the leaving loss and is calculated from the velocity diagram at the bucket exit. For subsonic flow, the leaving velocity of the steam $\left(V_{\mathrm{g}}\right)$ relative to the bucket, shown in the velocity diagram of figure 4.41 , is calculated from the continuity equation:

$$
V_{\mathbf{3}}=Q v_{B} / A_{B}
$$

where $Q$ is the steam flow rate, $v_{B}$ the specific volume of steam at the bucket throat and $A_{B}$ the bucket throat area.

For supersonic flow, the calculation of $V_{3}$ assumes that sonic flow exists at the throat of the blade passage. In this case, the axial component of the

Fraure 4.41-Turbine bucket velocity diagram.

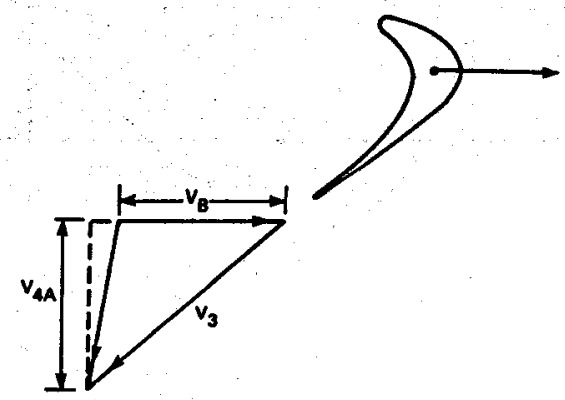


relative leaving velocity is calculated using the bucket annulus area $A_{A}$ and the specific volume at the annulus $\left(v_{A}\right)$, viz.

$$
\nabla_{4 A}=Q v_{A} / A_{A}
$$

The leaving loss $\left(L_{l}\right)$ is then calculated from the velocity components $V_{\mathrm{a}}$ and $\nabla_{4 A}$ and the tangential velocity of the buckets, i.e.,

$$
L_{l}=\nabla_{4}^{2} / 2=\left\{\nabla_{4 A}^{2}+\left(\left(\nabla_{3}-\nabla_{4 A}\right)^{1 / 2}-\nabla_{B}\right)^{2}\right\} / 2
$$

As the annulus velocity $V_{4 A}$ reaches the speed of sound (approximately $1400 \mathrm{fps}$ at 4 inches $\mathrm{Hg}$ ) the last stage cannot further utilize energy available to it. For this reason exhaust loss curves of the type shown in figure 4.42 are generally drawn for velocities up to $1400 \mathrm{fps}$ only. For applications where the annulus velocity is supersonic at the exhaust flange pressure, the overall turbine performance is calculated using an artificial exhaust pressure which results in an annulus velocity of about $1400 \mathrm{fps}$.

The loss at low mass flows in the stages preceding the last stage is usually referred to as "turn-up-loss" and is estimated from empirical data.

Each of the losses described above represents a loss in adiabatic energy. They are converted to a loss in used energy by multiplying by the appropriate last stage internal efficiency.

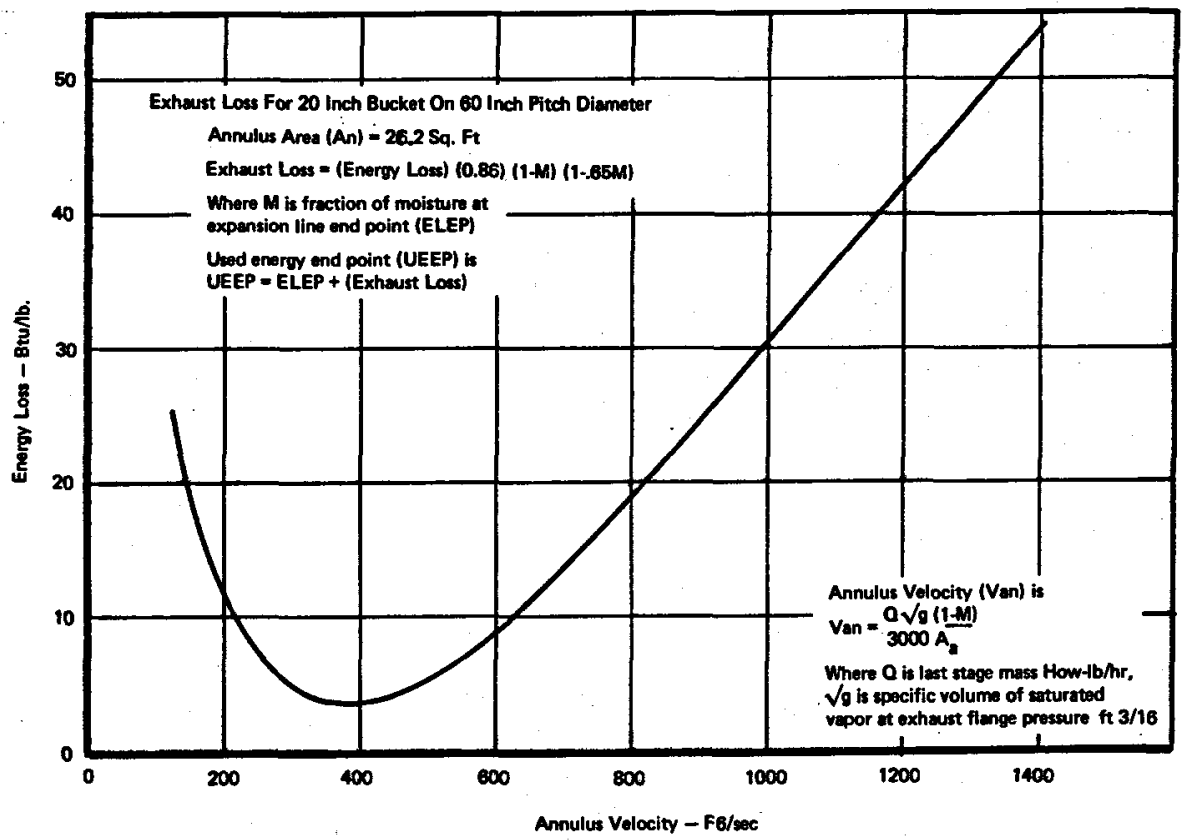

FIGURE 4.42-Exhaust loss vs. annulus velocity. 
An exhaust loss curve of the type shown in figure 4.42 is usually published for a specific turbine design by the manufacturer. It is a composite of the three types of loss, and can be used to establish approximate values of exhaust loss for different annulus velocities for a given annulus area.

Radiation, electrical and mechanical loss $\left(L_{\mathrm{rem}}\right)$. The major portion of this loss occurs in the generator in the form of excitation power, hysteresis and eddy-current loss in the steel, heat loss in the armature windings and windage. The generator losses will vary with megavolt-ampere rating, actual MVA output, voltage and power factor ratings, method of cooling and several other design parameters. Approximate values of generator losses are shown in figures 4.43 and 4.44 as a function of rated output and actual output. Rated MVA output can be calculated by dividing the maximum expected megavolt output by the minimum expected power factor at that output. Similarly, actual MVA output is calculated by dividing the actual megavolt output by the power factor rating at that output.

Radiation and mechanical losses represent the combination of heat losses, bearing losses, control system power requirements and other losses outside of the steam path and generator. The aggregate of these losses is usually relatively small and essentially constant over the load range. It is, there-

Froure 4.43-Iross factor $K_{1}$ vs. generator rating.

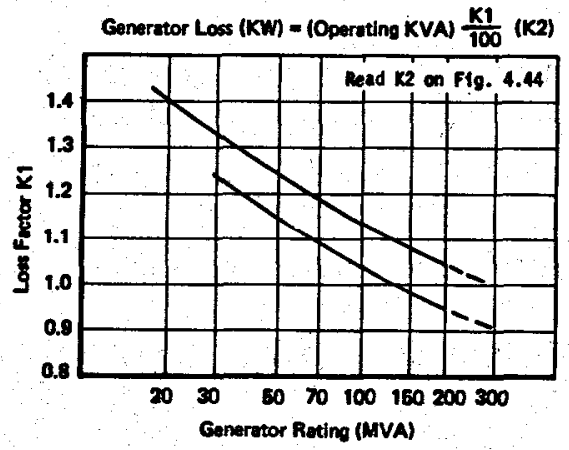

Frauke 4.41-Loss factor $K_{2}$ vs. percent of rated KVA.

Cenerator Loss (KW) = (Operating KVA) $\frac{K 1}{100}$ (K2)

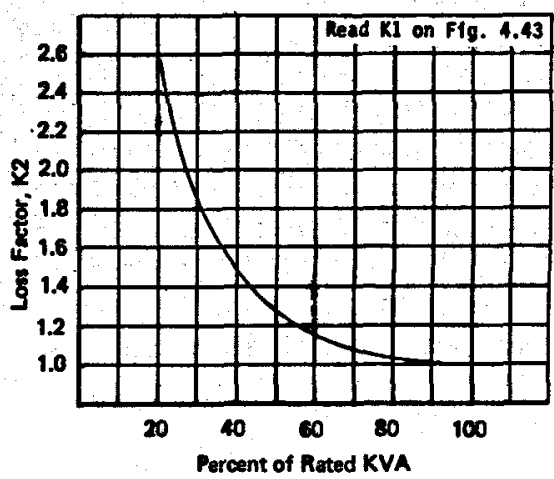


fore, often stated as a single number referred to as "fixed loss" or mechanical loss" $\left(I_{r_{m}}\right)$ and estimated as:

$$
L_{m}=175+2.5 \times 10^{-0} \times E_{k w o}(\mathrm{~kW})
$$

The total REM loss is the sum of the generator loss and fixed loss.

4.1.4.3 The performance of multiple inlet turbines. When multiple flash stages are used to extract more power from the brine, a separate turbine may be used for each stage of flash or a single turbine can be used with inlets provided at different stages where the pressure is proper to support the flash pressure. Individual turbines may be totally separate or mounted in tandem to drive a single generator. When separate, the performance of each unit is described approximately by equation 4.32 . When units are in tandem, $L_{\text {rem }}$ losses are applied to a single generator.

In multiple inlet machines, the stages must be designed for the increased steam flow after each admission and the performance calculation must account for the contribution of each flow increment. The performance analysis here addresses only a dual flash cycle, since this will undoubtedly be the most common application. The reader will be able to deduce the added terms required in the equations derived when more than two flash stages are used.

A relatively simple way to calculate the performance of a dual admission machine is to superimpose the expansions of the two flows. The adiabatic energy and turbine internal efficiency for each flow are defined as in equation 4.32, essentially as though each flow were in a separate turbine, although the exhaust loss is based on the combined flow. The total output, therefore, will be expressed as follows:

$$
\begin{aligned}
E_{k 2 b}=\left\{Q_{1}-Q_{L}\right)_{\eta_{i, 1} \Delta H_{i s, 1}}+Q_{2 \eta_{i, 2} \Delta H_{i s, 2}} & \left.-\left(Q_{1}-Q_{L}+Q_{2}\right) L_{e}\right\} / 3412-L_{\text {rem }}
\end{aligned}
$$

where subscripts 1 and 2 refer to the high and low pressure inlets, respectively. The minor differences between this equation and equation 4.32 are as follows:

(a) Some loss in internal efficiency is encountered when the low pressure steam is introduced into the machine. In the approximate internal efficiency statements used here, the loss is partially compensated for by using the high pressure fiow $Q_{1}-Q_{2}$ instead of the total flow and the low pressure inlet specific volume in calculating $\eta_{i, 2}$ from equation 4.33 . The exhaust loss is based on the total flow to each turbine. Since the exhaust loss is given in figure 4.42 as a function of steam quality at the expansion line end point, (ELEP) a weighted average ELEP is determined from the ELEP's calculated for each of the inlet flows using equation 4.32, i.e.,

$$
\begin{array}{r}
E L E P=\left\{\left(Q_{1}-Q_{L}\right)\left(H_{1}-\eta_{i, 1} \Delta H_{i,, 1}\right)+Q_{2}\left(H_{2}-\eta_{i, 2} \Delta H_{i,, 2}\right)\right\} / \\
\left(Q_{1}-Q_{L}+Q_{2}\right)
\end{array}
$$


(b) The calculation of stage pressures and enthalpies in the dual admission turbine is not quite as straightforward as in the case of the single admission unit, since the pressure entering each stage depends on the total mass flow. To determine the enthalpy entering a stage, the expansion line should be drawn for the two inlet flows as though each had been introduced into a separate turbine. Above the low pressure inlet, the enthalpy is read from the expansion line for the high pressure inlet flow at the given pressure. At the low pressure inlet point and below, the enthalpy is read from both expansion lines and an average weighted for mass flow is calculated.

4.1.4.4 Turbine size and general configuration. Not only do geothermal steam turbines tend to be large, but they also generally require a multiplicity of large diameter inlet pipes and control valves. Some machines may be single-flow designs, although since large volume flows must normally be accommodated, double and four flow units are more common. Since steam must ultimately leave the turbine with a reasonable leaving loss, both the size and configuration (i.e., single vs. multiple flow) are determined primarily at the last stage.

The dimensions of the last stage annulus are estimated from turbine output, mass flow rate and exhaust loss. In this case, it is convenient to express exhaust loss as a fraction of turbine output; i.e.,

$$
f_{E L}=\frac{Q_{e} L_{s}}{3412 E_{k w}}
$$

where

$$
\begin{aligned}
& Q_{e}=\text { the total last stage mass flow rate }(\mathrm{lb} / \mathrm{h}) \\
& L_{e}=\text { the exhaust loss (BTU/lb) } \\
& E_{k w}=\text { turbine output }(\mathrm{kW})
\end{aligned}
$$

As explained previously, exhaust loss is a complex function involving many variables. At the upper end of the flow range, however, its principal component is kinetic energy and it can, therefore, be approximated as:

$$
L_{e}=\eta \nabla_{a n}^{2} / 2 g
$$

where $\nabla_{a n}$ is the annulus velocity:

$$
\nabla_{a n}=Q . v / 3600 A_{e}
$$

$v$ is the specific volume at the expansion line end point (ELEP) in $\mathrm{ft}^{3} / \mathrm{lb}$, $A_{e}$ is the annulus area of the last stage in $\mathrm{ft}^{2}$ and $\eta$ is the internal efficiency of the last stage. Combining these equations gives the following expression for the annulus area :

$$
A_{a n}=\frac{Q_{e} v}{3600}\left(\frac{Q_{\imath} \eta}{6824 g J E_{k w} f_{E z}}\right)^{1 / 2}
$$


In estimating the total annulus area and the number of parallel flows required, the following design parameters and limitations of the last stage are considered.

The energy expansion capacity of a stage is determined at the bucket root. Since low pressure stages are usually designed with near zero reaction at the root, the optimum velocity ratio there is close to 0.5 and the stage expansion energy will, therefore, be about four times the energy equivalent of the bucket root tangential velocity. While low pressure stages are normally designed to extract as much energy as is practically possible, the designer generally avoids using supersonic stages in favor of less complex subsonic designs and for smaller ratings, tends to reduce the diameter in the interest of reducing overall machine size.

For $3600 \mathrm{rpm}$ machines, bucket root diameters range between 35 and 42 inches. Bucket height limits are usually expressed either in terms of the pitch diameter, i.e., the diameter at the bucket mid height, or as the ratio of tip and root diameters usually called the "radius ratio." Blade height to pitch diameter ratios $\left(H_{B} / D_{P}\right)$ of 0.25 can normally be obtained without extensive development work. Values as high as 0.34 have been achieved by some manufacturers using special designs to accommodate three dimensional flow effects.

The selection of inlet piping is usually dictated by material cost and performance penalties due to pressure loss. The pressure loss in the piping and valves is normally limited to between five and seven velocity heads for steam velocities in the range 150 to $200 \mathrm{fps}$. As a guide to evaluating the effect of pressure loss, a $1 \%$ throttling loss at inlet to a turbine operating on dry steam at 100 psia and a condenser pressure of $1.5 \mathrm{psia}$ will decrease the output by about $0.2 \%$.

4.1.4.5 Material strength considerations. The geometry of steam turbine buckets is, of course, not only a function of the aerodynamic considerations described previously ; it is also affected by the structural requirements necessary to provide long-term service and reliability. In the optimization process required to develop a reliable bucket design, consideration must be given to steam loading and to centrifugal stress and also to the resulting vibratory characteristios of the bucket/wheel assembly. Initially, the steam loads are established and bucket root widths are selected to meet performance and rane root bending stress requirements. This is usually a "first pass" approach which is often modified later following several iteration cycles as mechanical and thermal performance factors are evaluated. The vane root bending stress determines the load-carrying capacity of the buckets, and is estimated by treating the bucket as a cantilevered beam with a distributed load produced by the tangential steam forces. The maximum bending stress is usually located at the bucket root and is kept within accepable limits. 
Last stage bucket designs. The longer buckets such as those at the last stage of a condensing unit are the most complex in design and require fairly long design cycles. Bucket widths above the root section are highly variable because of shape considerations and stiffness requirements. Also, centrifugal loading is an important factor. Centrifugal stresses produced in the buckets and wheel are evaluated at key points and, where necessary, adjustments are made to the bucket section, dovetail size, etc., until strength requirements are satisfied. The design is, however, incomplete until the vibratory characteristics of the bucket/wheel assembly are determined. Since resonances amplify the bucket loading forces, considerable effort goes into "tuning" buckets to avoid having natural frequencies of vibration coincide with known excitation forces. For buckets eight or more inches long, which includes most last stage buckets, the natural frequencies of vibration are harmonics of shaft speed. An example of a typical frequency pattern for a "long" bucket is shown in the so-called Campbell Diagram of figure 4.45. The fundamental and lower frequency modes are plotted in the tangential, axial and torsional directions. Harmonics of shaft speed are shown as heavy dark lines. Their intersection with the natural frequency lines represent points of potential excitation where large vibratory stresses can be produced. It should be noted that natural frequencies tend to rise with speed due to the stiffening effect of centrifugal force.

Figure 4.45-Typical Campbell diagramfrequency variation with centrifugal load.

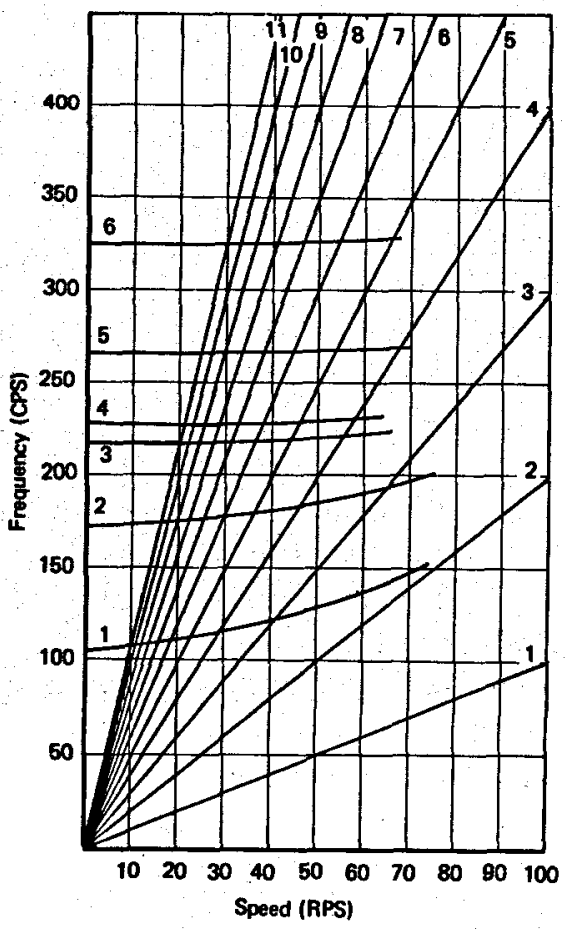


In general, the final design of a long turbine bucket requires a succession of iteration cycles in which steam loading, centrifugal stress and frequency response are balanced to optimize thermal and mechanical performance. Usually the development effort involved is much greater for the long buckets than for intermediate height blades discussed in the following section. Since the blade length of a long bucket need exceed only 8 in., in some machines several stages may belong to this class.

Design of intermediate height buckets. The majority of stages preceding the exhaust stage of a turbine normally contain shorter or intermediate height buckets. They are designed in a similar manner to the long bucket class, although the design parameters receive somewhat different emphasis.

The initial bucket sizing is again predicted from the steam loading forces, and widths are selected to comply with steam bending stress requirements. The centrifugal loads developed are, of course, less than those in longer blades due to the reduced height and generally similar pitch diameters. Centrifugal loading in shorter blades is normally only of concern when operating at high temperatures, and in relatively low temperature geothermal applications, therefore, it is not a limiting factor.

As with long blade designs, primary consideration is again given to frequency control to avoid vibratory resonances during operation. Normally, in the stage immediately preceding the last stage, buckets are relatively tall and the problem of avoiding resonance with harmonics of running speed is similar to that in the last stage. In stages further upstream, buckets are shorter and natural frequencies are correspondingly higher, and the predominant source of excitation shifts from harmonics of shaft speed to one associated with the stationary nozzles. This excitation source is due to variations in both steam pressure and wake flows in the nozzle exit plane, and the excitation frequency is the product of the number of nozzle partitions and rotational speed. This "nozzle passing frequency" if allowed to coincide with bucket natural frequencies may create large amplitudes of vibration within the bucket structure, and the resulting vibratory stress developed could eventually lead to fatigue failure.

To avoid resonance, the large number of bucket natural frequencies which exist in the tangential, axial and torsional directions must be predicted. Where groups of buckets are tied together at the tips, the effect of bucket interaction through the shroud band must be accounted for. Nozzle spacing is then selected such that excitation frequencies do not coincide with the most important vibration modes. However, because a large number of natural frequencies exist in the bucket structure, it is generally not possible to avoid all resonant conditions, and nozzle spacing will correspond to the lowest response level where trouble-free operation can be expected. The margins of safety established for vibratory stress are consistent with the precision of the calculation procedure and the machining and assembly tolerances. 
4.1.4.6 Guidelines for turbine materials selection. The specification of materials for use in geothermal steam turbines depends on the type of design, the operating environment and economic considerations. Design requirements are related to important material properties such as strength, toughness, and fatigue strength. Erosion and corrosion constitute the major environmental effects, while economic factors involve cost, availability and overall component producibility.

Unfortunately, it is seldom possible to select materials which have all properties optimised for a particular application since operating conditions vary widely between inlet and exhaust even on geothermal units. Moreover, since impurities in the steam may cause chemical attack, the turbine designer is usually faced with having to make a compromise with material properties and economic factors in the final specification.

As with all utility units, the geothermal steam turbine is required to function efficiently for long periods of time with a minimnm of maintenance. To ensure that this will in fact be the case, it is usual to subject candidate materials to extensive testing in the laboratory to evaluate properties such as tensile and yield strength, high and low cycle fatigue and fracture toughness.

Also included, where appropriate, are exposure tests to determine the erosion and corrosion characteristics of different alloys. The experiments are usually conducted over relatively short time periods at high and low temperatures, and the results are extrapolated to predict long-term behavior.

In some cases, exploratory environmental test programs are undertaken at field locations to supplement laboratory data. These programs usually involve experiments with special specimens in test chambers installed either on new wells or on extraction lines on existing steam turbines. While conditions within the test chamber are not truly representative of those in an actual turbine, they nevertheless provide an early screening process in the selection of turbine alloys.

The most valuable source of information relating to materials performance, however, is that reported from actual turbine service experience. Where available, the results of long experience under actual service conditions are applied directly in the definition of current and future turbine specifications. Where direct experience with a given environmental condition does not exist, the results of service in similar environments are augmented by laboratory data and engineering judgment. This latter approach is fairly common since considerable experience has been gained in both the industrial and geothermal field with a number of different hostile steam environments.

As noted previously, the actual mechanics of turbine design and different material requirements result in a compromise to balance high and low temperature qualities. In the superheated high temperature zones of high pressure industrial and conventional utility units, relaxation behavior, creep, 
fatigue strength, and the stability of material structure over long time periods are key properties which must be considered for establishing steady-state factors of safety. In the lower temperature zones, however, ductility and the short time, elevated temperature (above room temperature) properties such as tensile strength and yield strength are most important. From a practical viewpoint, the low temperature materials are preferred since they generally exhibit higher ductility, better fracture toughness, better machinability and weldability and are less difficult to maintain than the high temperature alloys. In the temperature range encountered in geothermal units, low temperature materials are considered adequate for providing long-term reliability.

Material toughness as measured by an impact test, together with the ductile to brittle transition temperature are two additional characteristics considered important by the designer. Components should operate at temperatures above the transition point, where the material behaves in a ductile manner with improved resistance to rapid crack propagation. In the low temperature regions of a condensing turbine, where the wheel bucket loads may be significant, materials with the lowest possible transition temperature (in addition to other required strength qualities) are selected.

In the wet regions of the turbine, both erosion and corrosion resistance are emphasized. Chemical attack caused by impurities in the steam may result in pitting or stress corrosion cracking ; in addition the corrosive geothermal steam environment may result in preferential paths of corrosion attack in some materials. Corrosion pitting attack will adversely affect fatigue behavior of turbine alloys and may result in failure of critical components. Most of the more common turbine alloys are susceptible to this type of atack, and in cases where it is expected to be a problem, the designer usually minimizes vibratory stresses by stiffening the blades, thereby ensuring reliable service and performance.

Erosion is a problem in the wet region of the turbine where high relative velocities exist between water droplets and a given target. Relative velocities are very high for example, where slow moving droplets which have condensed and are shed from the trailing edge of nozzles, impact the leading edge of fast moving blades. Bucket protection is normally provided either by flame hardening or by cobalt containing alloy inserts brazed to the leading edge. Stainless steel inserts and weld overlays offer protection to other areas where erosion may be encountered.

Although there are many factors which must be considered in the selection of suitable turbine materials, the component materials can be grouped in relatively few categories. The turbine steam path is constructed basically of $12 \% \mathrm{Cr}$ stainless steel. Rotors and wheels are manufactured from vacuum treated alloy steel forgings. Carbon and alloy steel castings or welded fabrications are used for the turbine shells and castings. A summary of materials used for major turbine components is given in table 4.5 . 
TABLE 4.5-Typical steam turbine materials

Component

Piping .

H.P. Casings

L.P. Casings

Fasteners.

Rotors.

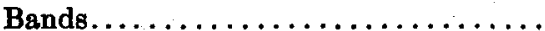

Nozzle Blades.
Material

ASTM A106, Gr B, ASTM A335, Gr P11 or P22

ASTM A356, Gr 1, 6, 9 or 10

ASTM A285 or A515

ASTM A216 or A217

ASTM A193 and A194

ASTM A470

AISI 403

AISI 403

AISI 405

Since geothermal steam turbines operate on steam at saturated conditions, material specification for these units has generally followed the practices used for the low temperature regions of conventional units, although in some cases more extensive use of stainless steel inserts and weld overlays is necessary for additional erosion resistance.

While reliable service of geothermal steam units is achieved primarily through the use of proper materials, precautions are nevertheless taken, where possible, to improve steam quality in the delivery lines. In flash systems, for example, the carryover of corrosive compounds can be essentially eliminated by the use of efficient steam separators.

Because of the high risk to equipment, the continued need for steam quality assessment and the use of successful steam supply treatment practices and/or other techniques to improve steam quality are considered necessary precautions to ensure successful performance and maintainability for geothermal service.

\subsubsection{Geothermal steam turbine controls (By J. H. Eskesen, L. B. Mizen,} C. V. H. Shepard*)

4.1.5.1 Introduction. The control system is an integral part of the steam turbine generator package providing control during startup, speed control under loaded operation and protection in case of emergency. The basic elements comprise a system of valves, valve controls and turbine monitoring. and protective systems. Generator controls are not included in this discussion since they are generally of conventional design and are described in detail elsewhere.

The system of valves includes stop valves, steam throttling control valves and check valves. They are of particular concern to the design engineer since they are unusually large to accommodate the large volumetric flows of low energy geothermal steam. Saturated geothermal steam at $300^{\circ} \mathrm{F}$ has

*All from Medium Steam Turbine Dept., General Electric Co., Lynn, Mass. 
approximately 15 times the specific volume and $1 / 5$ the available energy of steam in a conventional power plant operating at $1800 \mathrm{psia}$ and $1000^{\circ} \mathrm{F}$ and it, therefore, requires 75 times the steam flow to produce the same amount of power.

Also of concern to the design engineer is the quality of geothermal steam. Steam contaminants may be sufficiently corrosive to limit valve life and extreme care is taken to select proper materials. Other contaminants can form deposits and restrict operation of internal mechanisms. All these factors must be considered when designing a control mechanism which operates in the steam path.

The complexity of the valve controls will depend to a large extent on the plant operating routines. Continuous and long-term base loading is probably the preferred operating mode of most geothermal turbines due to the fairly constant availability of the energy source. Plant startups are infrequent and for most of the time the turbine-generator will be operating at or near rated output with all valves in the wide open position. Thus, automatic startup sequencing equipment would not be required, and some form of manual or semiautomatic startup sequencing equipment would normally be recommended.

The turbine-generator monitoring system is designed to provide fast corrective response to abnormal operating conditions. Condenser vacuum and turbine load are monitored and if preset limits are exceeded, appropriate corrective action is initiated. For personnel and equipment safety, duplicate overspeed protection is mandatory. The turbine overspeed trip designs are identical to those in all modern turbine-generator installations. Protection is also provided against the possibility of water ingestion into the turbine in the form of pressure sensing elements which override other controls to close the control valves.

The number and size of the control valves is established primarily by the power rating and resource type. Normally the valve and, hence, hydraulic actuator size increases with rating. Smaller machines use mechanical-hydraulic controls which operate on the lubricating oil system at normal pressures; pressure boost pumps are added for medium size units. Turbines rated at $50 \mathrm{MW}$ and higher generally have separate hydraulic systems for the controls which operate with fire-resistant fluids at pressures up to 2000 psi.

For many geothermal applications involving single flash or direct steam systems, mechanical-hydraulic control will be adequate. Where there are large numbers of control functions as in most dual flash systems, and especially those operating at low pressure, electro-hydraulic control with separate high pressure hydraulic systems will be used. Both control systems are discussed in this section following the description of inlet valve arrangements. 
4.1.5.2 Turbine valves. Inlet steam strainers. As its name implies, the function of the steam struiner is to remove foreign particles from the steam before it enters the valves and turbine. Several different designs exist. One design, called a Y-type strainer, which is used on Geyser units 13 and 15, is shown in the schematic of figure 4.46 and in figure 4.47.

The strainer body contains the steam inlet and outlet openings, guides for a removable basket and a cover. The cover contains two ports; the larger is a cleanout port and the smaller is a drain.

The cover may be removed for a complete inspection or the strainer basket may be removed without disturbing the strainer body assembly.

The basket consists of a permanent screen for final running with a finer, temporary screen within it. The running screen is stainless steel approximately $1 / 4$ inch thick, perforated with $7 / 64$ inch diameter holes. The temporary screen is carbon steel perforated with $1 / 32$ inch diameter holes and must be removed after the first 24 hours of operation at full load flow.

Main stop valve. The main stop valve is part of the emergency trip system. It is the first valve in the line after the steam strainer and its primary function is to shut off, as quickly as possible, the supply of steam to the turbine in case of an abnormal operating condition.

One type of stop valve design provides a controlled admission feature which makes it possible to control (throttle) the flow of inlet steam to the turbine during starting and up to 10 percent initial loading. Bypass valves inside the main valve disk will pass approximately 10 percent of full throttle flow with the turbine control valves wide open and with full

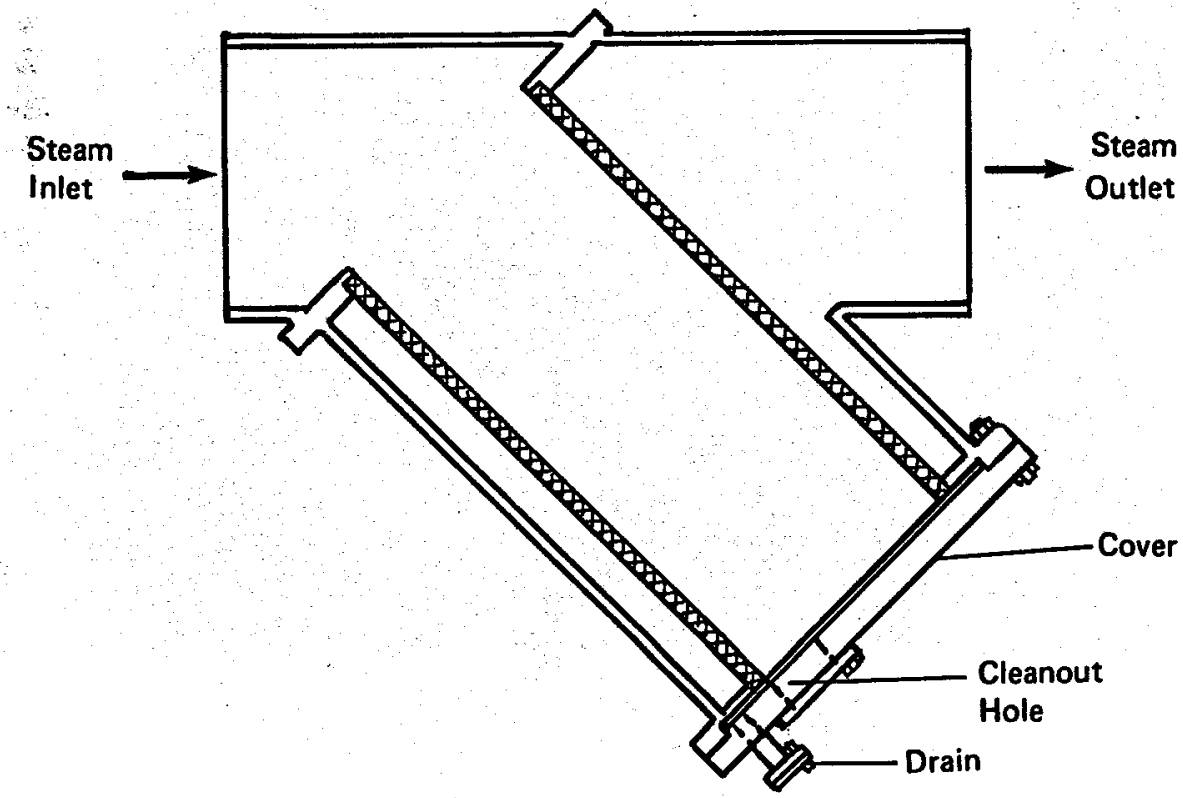

Froure 4.46-Schematic of steam strainer. 

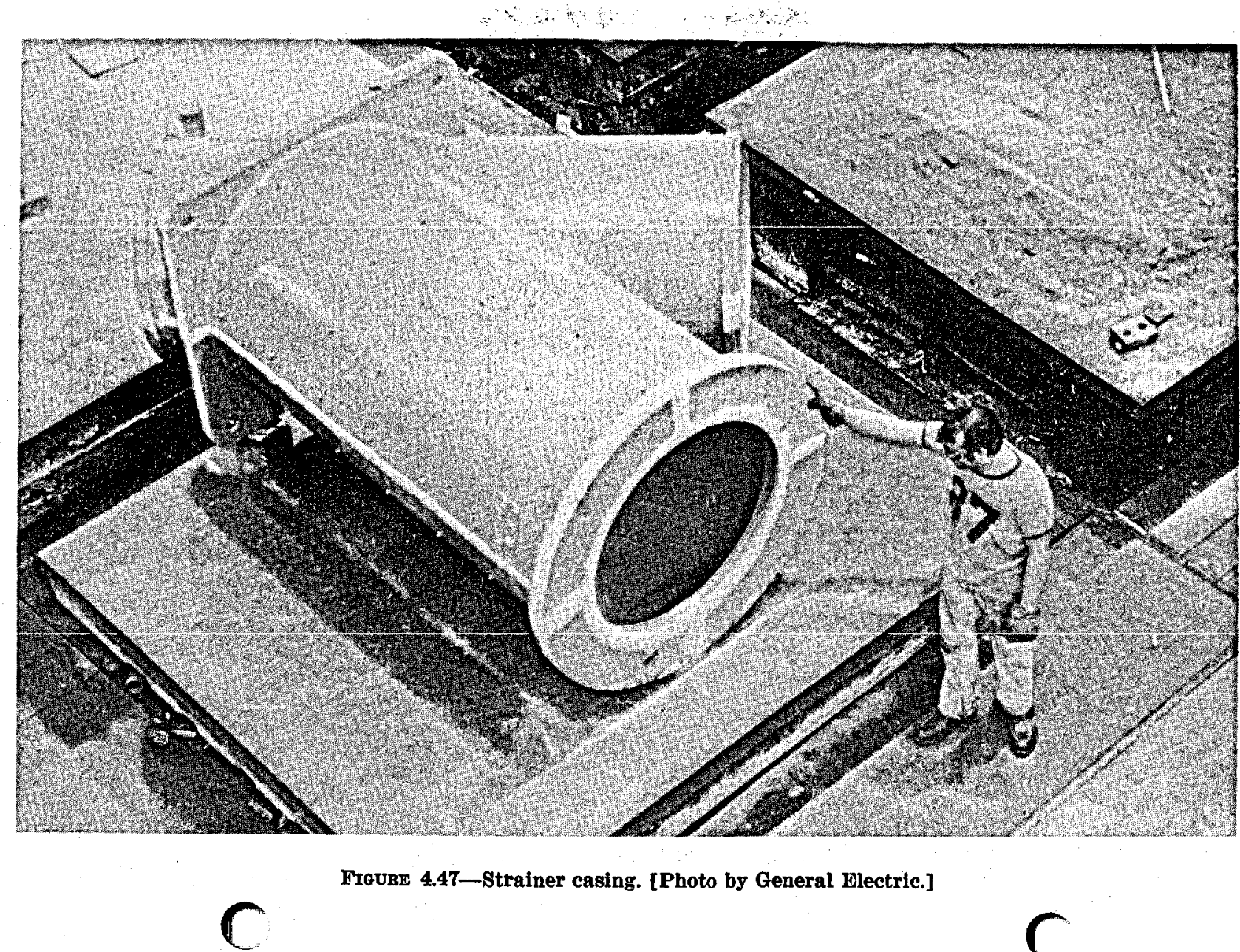

FIGURE 4.47-Strainer casing. [Photo by General Electric.] 
inlet pressure to stop valve. This is called a "Full-Arc" start. Valve designs without the controlled admission feature are available for applications where Full-Arc starting is not required. This is the type illustrated in the schematic of figure 4.48 and in figure 4.49 .

The valve body contains the steam inlet and outlet openings, above and below seat drains, the valve seat for the main valve disk, a valve stem leakoff and the valve stem bushing assembly.

The stop valve assembly, consisting of the main valve disk and upper disk, houses three smaller bypass valves. Both of the valve assemblies are mounted on a single valve stem.

Located in the base of the valve body below the valve seat is the pressure seal head assembly. It guides and restricts steam leakage along the valve stem during operation. The pressure seal head seats on a spiral wound gasket to seal at the base of the valve body and is pulled tightly against the gasket by a pulldown ring and jacking bolt arrangement. The force of the inlet steam at the top of the head assembly during turbine operation also tends to seat it against the gasket.

A vertical baffle is located diametrically opposite the steam inlet connection in the upper chamber of the valve. This minimizes the effect of steam eddy flow or swirls which creates turbulence and increases pressure drop.

The hydraulic operating cylinder is bolted to the bottom of the connector. It contains a piston rod coupled to the valve stem. Both are actuated by a piston which is spring-loaded in the closing direction.

Design features of the operating cylinder include a coaxial dump valve, a dashpot, a connection box, a test solenoid valve, position switches, and pressure taps for measuring pressures in the main and dump valve cylinders.

The dump valve and its cylinder are mounted directly below the main piston. Oil from the emergency trip system is piped through the connection box to this cylinder. When the emergency system is reset, trip oil pressure forces the dump valve upward against a spring, seating it against the bottom of the dishpot cavity. An orifice drilled through the dump valve allows the cylinder to be filled at a controlled rate. If trip oil pressure is lost, the spring forces the dump valve downward, guided by four fingers. Oil leaves the main cylinder rapidly through the throat of the dashpot cavity past the guide fingers and into the drain cavity surrounding the dump valve. This allows rapid closure of the stop valve disk.

In some geothermal applications, a butterfly valve having tight shutoff characteristics is used as a stop valve. This is particularly true of applications having the lowest pressures and highest volumetric flow requirements, and where scaling and deposit problems are particularly severe, since the butterfly design is less susceptible to sticking in hostile environments. The actuators used on butterfly valves are similar to those used on the conventional valves described earlier. 


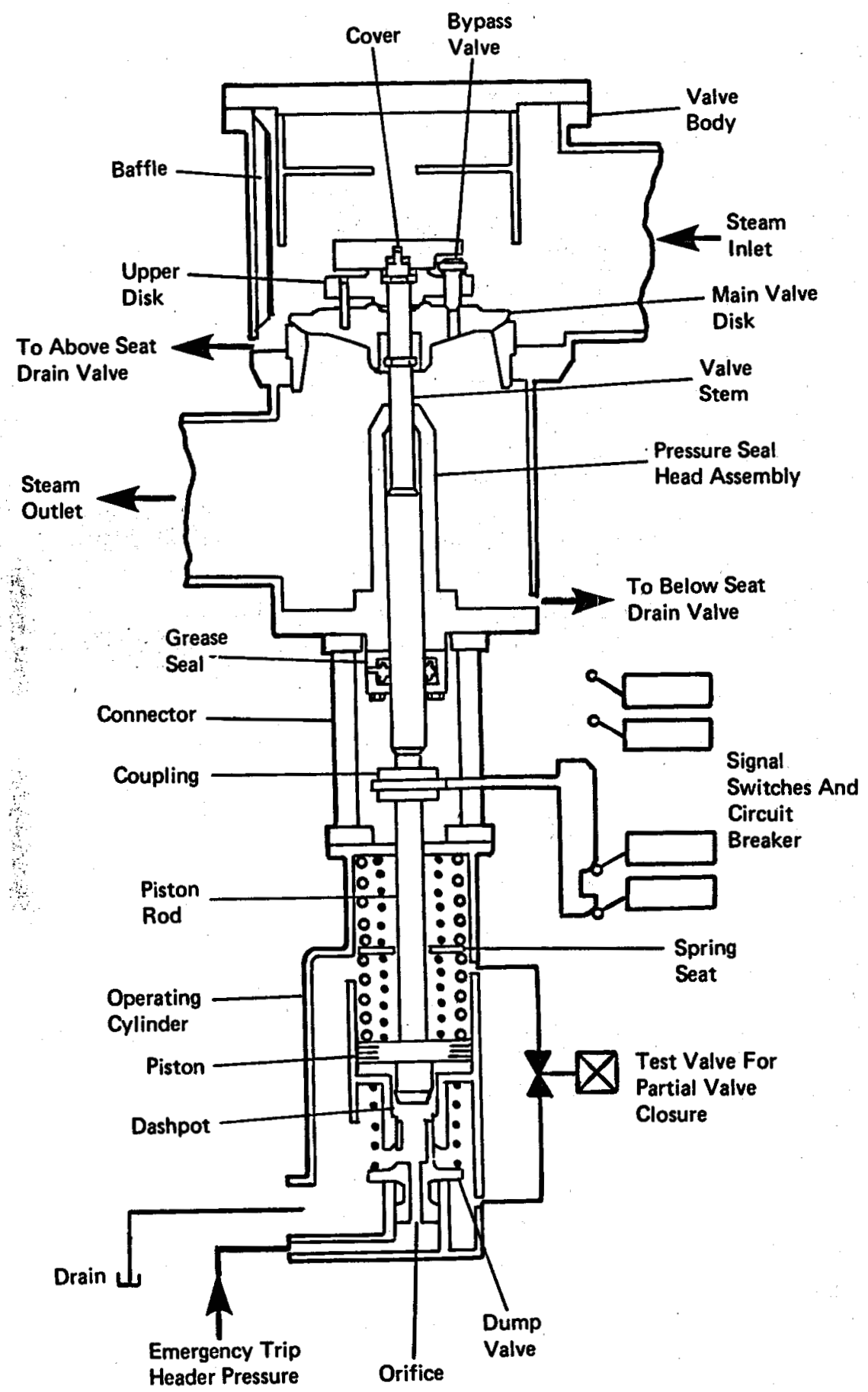

FIgUR: 4.48-Schematic of main stop valve. 


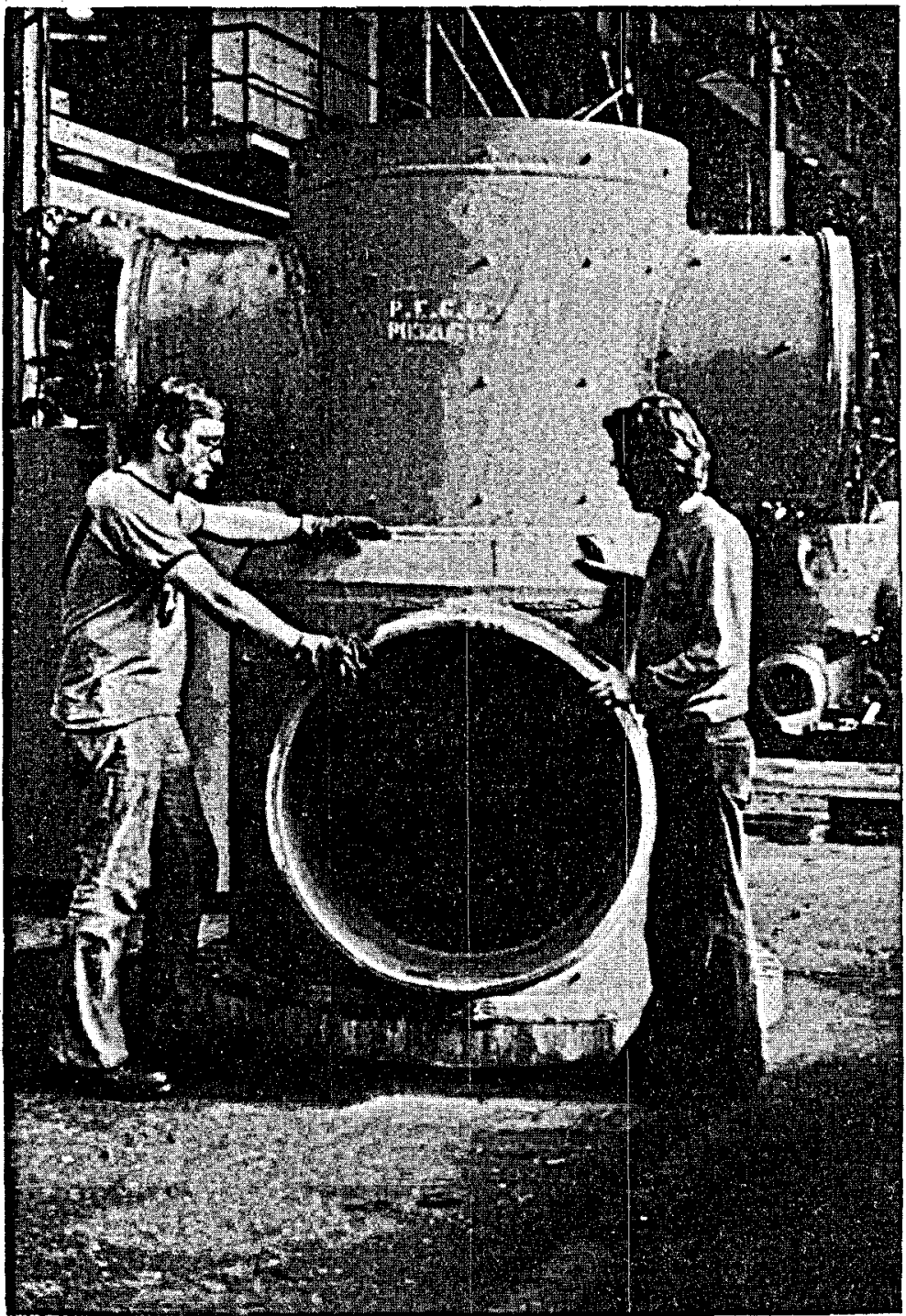

Fraure 4.49-Stop vaive casing. [Photo by General Electric.]

Check valves. Since the steam strainer cannot remove the smaller size particles from the steam, some deposits will form at various locations in the steam path. Although the stop valves are designed to prevent deposits from forming in areas that will cause them to freeze in position, a power assisted check valve is sometimes provided as an additional means of protection during emergency situations. This is located immediately downstream of the main stop valve and is designed as a $100 \%$ unbalanced type, i.e., it cannot be opened against rated steam pressure. To open the valve the pres- 
sure must be nearly equal on each side of the disk. This is accomplished during the standard plant startup procedure.

A typical check valve body is shown in figure 4.50. It contains the steam inlet and outlet openings, a drain at the bottom, a bolted-in valve seat and a bushing on either side for the valve disk shaft. The operating cylinder is mounted on the side of the valve body. A spring loaded plunger located in the cover prevents the disk from rattling when the valve is open.

The check valve assembly consists of a shaft, gimbal arm and check disk which contains two pressure balance holes. At the end of the shaft is a pinion gear which mates with a rack. The hydraulic operating cylinder is mounted on the side of the valve body. A piston rod in the operating cylinder is coupled directly to a rack which mates with a pinion gear on the valve shaft. The piston rod is spring-loaded in the closing direction.

A spring-loaded dump valve is an integral part of the operating cylinder. The dump valve cylinder is connected to the hydraulic emergency trip header and ports in the dump valve housing direct fluid under pressure to the bottom of the operating cylinder piston. If the trip header pressure is lost, the dump valve opens, allowing the check valve to close

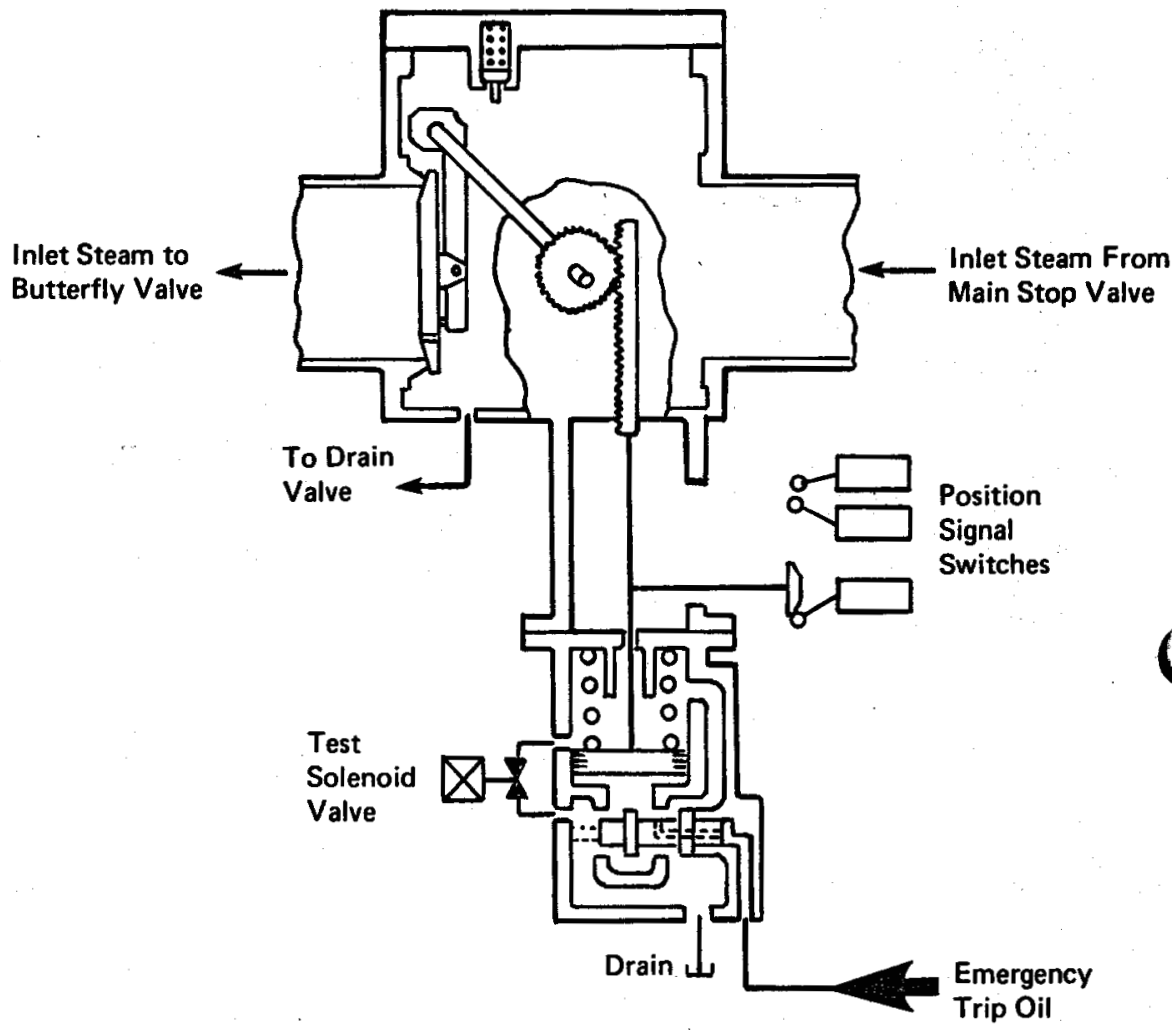

FTaURE 4.50-Schematic of check valve. 
instantly under the spring and steam forces. A test valve is used to check the freedom of the check valve shaft. When energized, it permits the piston to move a fixed distance in the closing direction which, in turn, allows the check valve shaft to rotate a fixed amount in the closing direction.

Steam throttling control valves. The control valves are located immediately downstream of the check valves. Several different designs exist each based on the spool or butterfly concept because of the large volume flows required. Spool valves are often used in low pressure applications to control large volume steam flows. The valve body has two seating surfaces arranged to provide the force-balanced design shown in figure 4.51. This basic design is generally applied as a four to eight valve assembly to obtain the best compromise between thermodynamic efficiency and accurate control of steam flow.

Since only one valve out of the series is actually controlling steam flow, the throttling losses are minimal, and if several valves are used in parallel rather than a single valve, a near linear flow-travel curve is obtained. Typical operating characteristics of the spool valve are shown in Figure 4.52.

For mechanical hydraulic control applications, a total of eight valves with four lifting arrangements are used. Each lifting arrangement opens pairs of valves in sequence. The lift is controlled by machining the spacer pieces for the inner two sets of valves, and by machining the length of the spool valve itself on the outer two sets.

Cam-type valve gear is used to compensate for the nonlinear flow-lift characteristics of the spool valves. This improves the flow-travel curve linearity and, therefore, improves the ability to accurately control steam

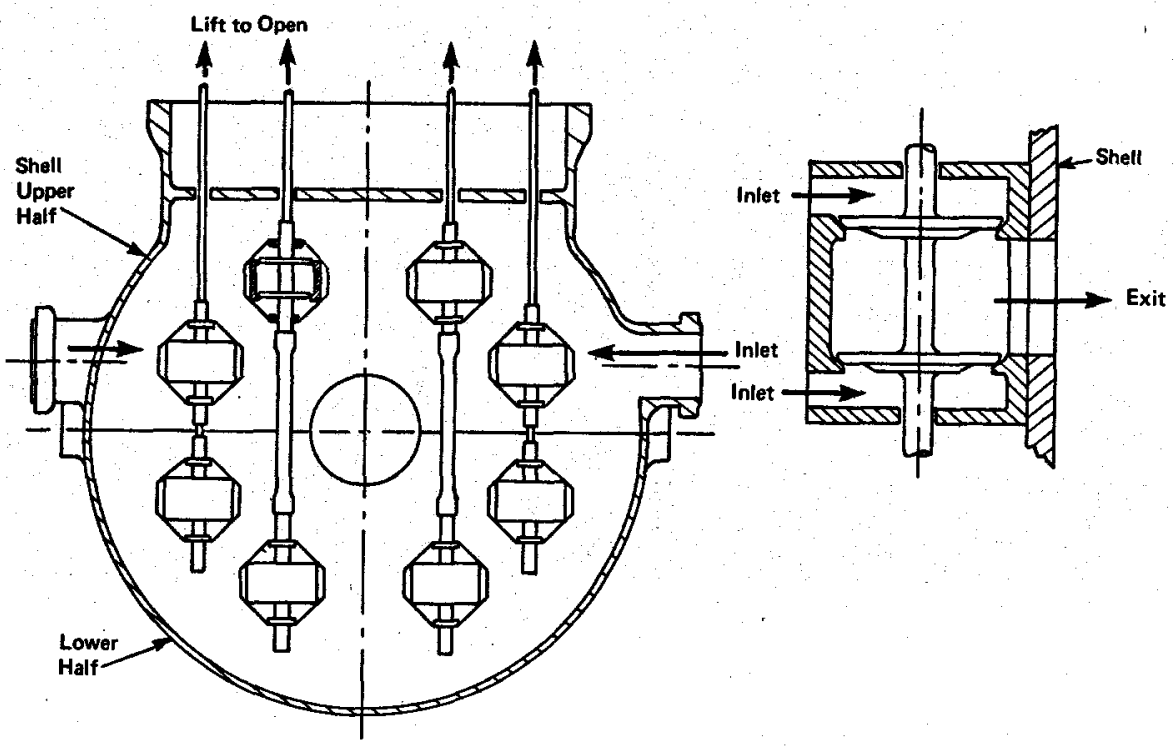

FraURE 4.51-Schematic of spool valve. 

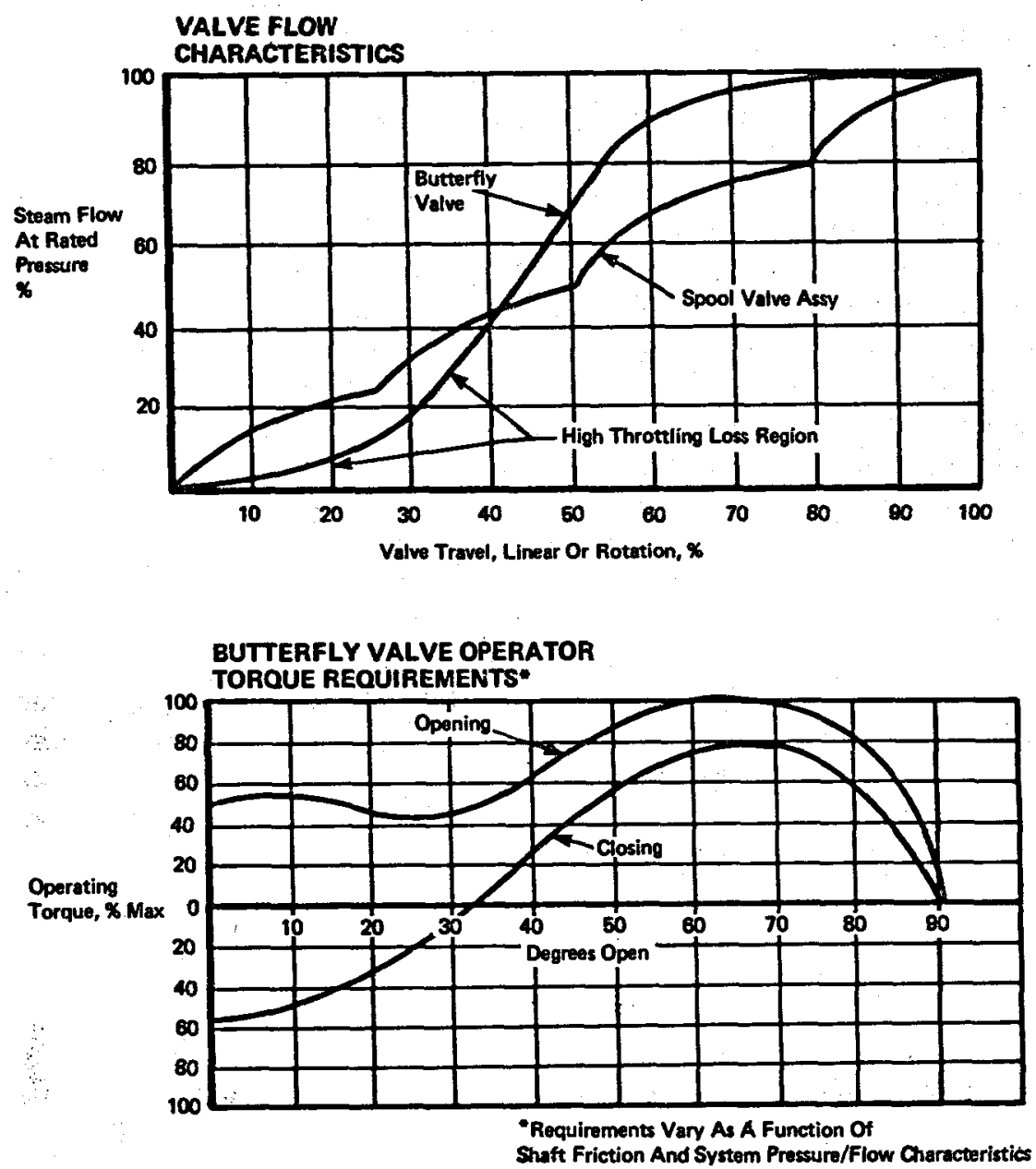

FGoURE 4.52-Operating characteristics of spool and butterfy valves.

flow. Due to balanced construction, the net operating force of the valve gear is fairly small and a single-acting operating cylinder with a spring closure can be used.

Access holes are provided in the side of the turbine casing so that the valve stems can be disconnected from the spool valve-lifting mechanism. The upper four spool valve bodies will remain with the lower half casing when the turbine casing is opened.

For other applications, a total of four valves, each operated by a separate actuator, is used. The actuators are positioned by low-pressure servovalves. The non-linear flow-lift characteristics of the spool valves are compensated for electronically.

Butterfly valves offer an alternative to the spool valve where accurate control of the steam flow is not required. They are compact and gen- 
erally operate nearly wide open so that generated power is a function of the available steam supply. Butterfly valves are also recommended where scaling is a potential problem since the rotating shaft is less likely to stick in position than the linear stem of the spool valve. The butterfly valve shown in figure 4.53 is installed in the 30 in. diameter inlet steam line to PG\&E's Geyser unit 15. Typical operating characteristics are shown in figure 4.52 and require the valve to be operated by a double-acting cyclinder.

\subsubsection{Valve controls. Electro-hydraulic control system. The electro-} hydraulic control system consists of the electro-hydraulic control center, hydraulic power unit, power actuator assemblies, permanent magnet generator and pressure transducers. The positioning of the control valves is in response to signals from the electro-hydraulic control center, and the power to operate the valves is supplied by the hydraulic power unit. A simple block diagram of an electro-hydraulic control system for direct steam application is shown in figure 4.54.

The electronic portion of the electro-hydraulic control system is contained in a separate control cabinet which includes the operating controls, computer power supplies, circuit monitoring elements and all the circuits for the control system. The cabinet is energized from 60-cycle, $115 \mathrm{vac}$ station power whenever turbine speed is below $3300 \mathrm{rpm}$. At speeds above $3300 \mathrm{rpm}$, a permanent magnet generator produces a $420-\mathrm{Hz}$ signal as

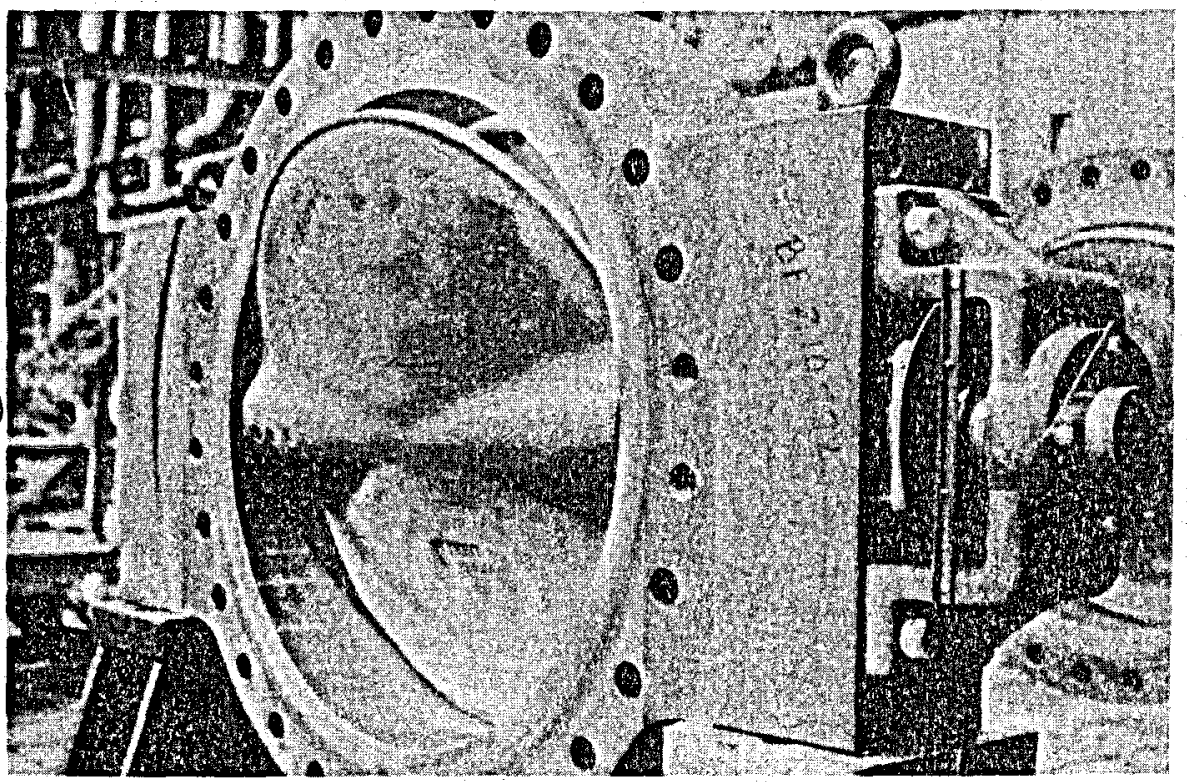

FraURe 4.53-Butterily control valve. [Photo by General Electric.] 


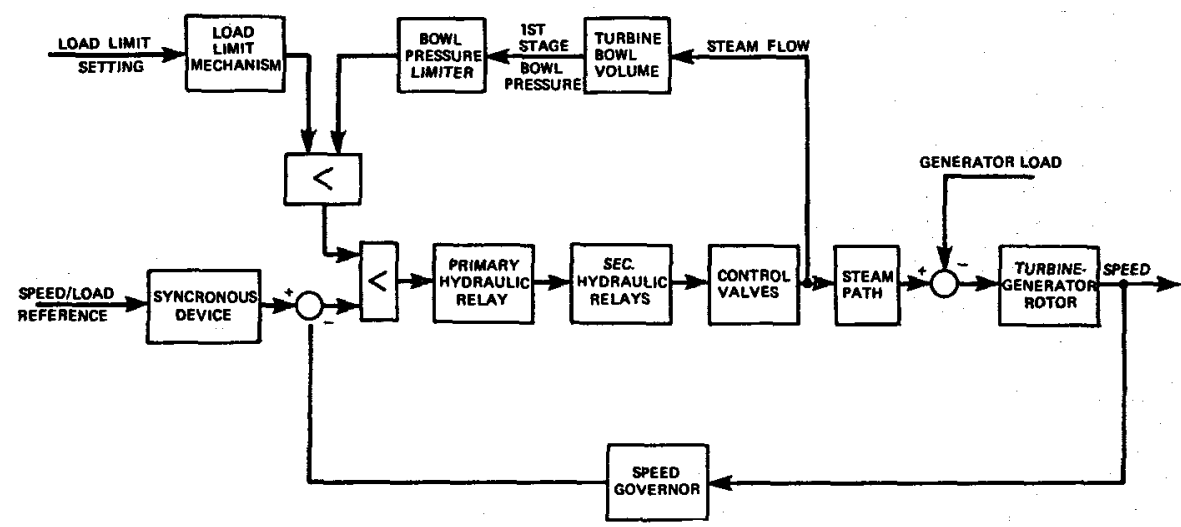

FraURE $4.54-$ Simplified block diagram of geothermal turbine control system.

well as arc power for the control cabinet. The control center provides the intelligence data and the command signals used to control turbine operation.

Inside the control cabinet a speed/load control subsystem compares actual turbine speed, sensed by the permanent magnet generator on the turbine rotor, with a speed reference and provides one command signal to the flow control subsystem. Some units have isochronous control elements or a speed corrector as an optional feature. This permits units to operate at constant speed regardless of load variations.

A ram servo subsystem positions the steam valves. It consists of a servo amplifier in the control center and a power actuator on the turbine. A separate subsystem is required for each separately-controlled valve. The servo amplifier provides the corrective current to the servo-valve when the control valve position does not correspond to the input command signal.

The power actuator consists of a hydraulic ram, manifold, servovalve and position feedback transducer. Upon a control command, the servovalve ports high-pressure hydraulic fluid through the manifold to the hydraulic ram. The ram piston rod mechanically positions the control valves and the position feedback transducer. Motion of the piston rod continues until the feedback voltage, which is proportional to distance, is equal to the command signal voltage. If the feedback lead from the transducer is disconnected or broken during turbine operation, the control valves will close.

The permanent magnet generator, driven by the turbine rotor, converts turbine speed to an $\mathbf{A C}$ voltage signal. The $\mathrm{AC}$ voltage is proportional to the speed of the turbine rotor and its frequency is $420-\mathrm{Hz}$ at $3600 \mathrm{rpm}$. Coil terminals are connected to the speed/load control subsystem and to the speed indicator. This generator also provides the power required for the electro-hydraulic control center. The turbine control center is, therefore, independent of the external power source except during startup. 
The self-contained high-pressure hydraulic system has two parallel pumping systems, a fluid reservoir, fluid cooler, heater, and an auxiliary filtering system. Either pumping system can be used as the on-line pump while the other remains on standby. Hydraulic fluid is supplied directly from the hydraulic unit to the power actuator assemblies which operate the control valves.

Mechanical-hydraulic control system. The mechanical-hydraulic control system is located at the turbine front standard and uses oil from the lubricating system as the hydraulic working fluid. Shaft mounted or motor driven pumps provide the required system pressure and flow. Speed/load control is accomplished using a mechanical governor connected through linkages to a hydraulic relay and valve actuator system. An independent overspeed governor is also incorporated in the basic control system to provide the backup overspeed protection.

Other operating variables such as extraction pressure and exhaust pressure can be simultaneously controlled with pressure transducers, linkages and hydraulic relays.

In this control system, the key element is the hydraulic relay. This is essentially a force amplifier with feedback in which a small precise input force signal is taken from the speed or pressure governor and amplified to provide the force necessary to position the steam control valves. Details of the hydraulic relay are shown in the schematic of figure 4.55. To understand its operation, suppose the free end of the lever is moved downward a small amount. The pilot valve will also move downward, closing the supply and opening the drain to the chamber above the piston. While simultaneously opening the supply and closing the drain to the chamber below the piston, oil flows into the lower chamber and discharges from the upper chamber and the piston moved upward. This closes the butterfly control valve and simultaneously moves the pilot valve upward. This action continues until the pilot valve is restored to its original position. The spring shown assists the hydraulic pressure in moving the control valve to its closed position. Clearly, if the free end of the lever is raised, the relay will operate in the reverse direction.

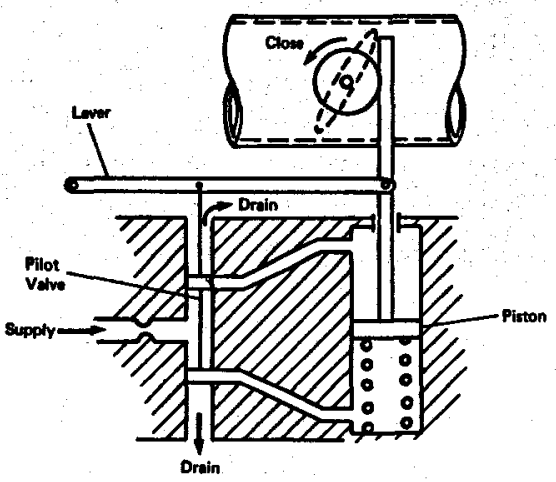

FraURe 4.55-Hydraulic relay. 


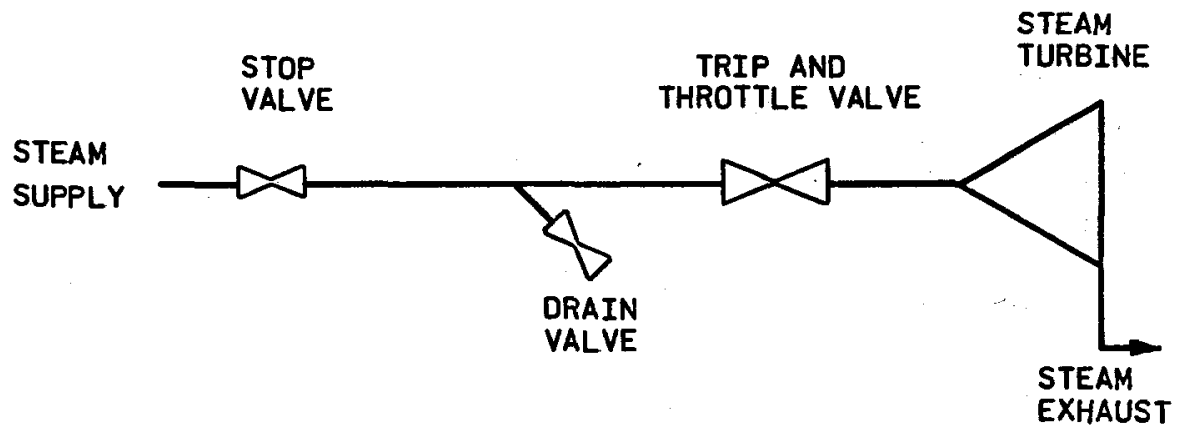

FraUre 4.56-Example of piping arrangement used to avoid standby corrosion in steam turbines.

4.1.5.4 Protective and auxiliary controls. Turbine-generator protective controls fall into several different categories such as supervisory, overspeed, special limits or trips and electrical. The auxiliary controls include all of the devices which monitor and control the turbine-generator auxiliary equipment such as the lube oil, hydraulic and generator cooling systems. Some form of each of these controls is supplied in all conventional power plant installations and their complexity is primarily a function of the equipment size and rating.

Turbine-generator supervisory equipment monitors journal bearing vibration, turbine shell/rotor differential thermal expansion, bearing, turbine shell and exhaust hood temperatures, steam valve position and rotational speed.

Each journal bearing is fitted with a single, noncontacting probe which measures the peak-to-peak radial displacement of the rotor with respect to the bearing at speeds above $500 \mathrm{rpm}$. This measurement provides a continuous measure of the mechanical condition of the turbine-generator.

Another noncontacting position probe is used to measure the differential expansion between the rotor and shell. This is of particular concern during startup when the rotor grows more rapidly than the stator and axial clearances change appreciably. Control of the relative motion between rotating and stationary assemblies is one of the factors which establishes maximum permissible startup and loading rates.

The first level of overspeed protection is speed control which acts to close the control valves before the speed reaches approximately $105 \%$ of rated value. This proportional type control effectively prevents a turbine trip in many overspeed situations. Where there are multiple inlet control valves, as in a dual flash system, a substantial amount of control logic is devoted to provide the proper corrective action to all the separate valve operators and to minimize the effect of reduced flow on the steam supply system.

An overspeed governor is included as a backup system and provides the last line of defense against destructive overspeeding. If the turbine reaches 
$110-112.5 \%$ rated speed, the overspeed governor will actuate the emergency trip system.

The standard device is rotor mounted and consists of an unbalanced bolt .which is actuated by centrifugal force against the force of a spring when the turbine overspeeds. This action strikes a trip finger which causes the trip valve to travel to its dump position, closing off the hydraulic oil supply and dumping pressure from the various relay cylinders, which closes all the stop valves. The emergency system is provided with a testing arrangement which permits the overspeed governor to be oil-tripped and reset while the unit is carrying load without interfering with the normal system operation.

Special protective controls such as a load limiter, condenser vacuum trip, loss of lube oil trip and manual trip may also be incorporated.

Load limiters are installed in situations where it is possible for the inlet steam pressure to rise substantially above the rated level. These controls proportionately close the steam valves to hold a preset upper load limit.

Loss of condenser vacuum can cause turbine wheel heating, high bucket stress and an extremely dangerous situation in the exhaust hood and condenser shells due to possible bursting pressure. Turbine trips actuated by high exhaust pressure are normally included, sometimes with a proportional loop for closing valves at the rate of vacuum loss.

Other turbine trip functions would be provided for thrust bearing failure, loss of lubricating oil, loss of hydraulic oil pressure, loss of generator load, and flash tank malfunctions such as high water level.

Generator protectives and auxiliary controls are similar to those found on standard power plant equipment of the same rating. Typically, these include relays for synchronizing, voltage matching, stator over temperature, negative phase sequence, loss of excitation, reverse power, differential current, and voltage balance.

Auxiliary controls are those associated with the lubricating oil, hydraulic pump and generator cooling systems. Various temperature and pressure parameters are measured and automatic controls are provided in vital areas, such as backup pump motor startup, in order to keep the turbine-generator operational under normal and emergency conditions.

\subsubsection{Materials selection for geothermal steam turbines (By Joseph A. Cameron*)}

Selection of materials for steam turbines using geothermal steam is fundamentally similar to the selection of materials for turbines operating on steam from fossil fuel fired boilers with some modification due to certain properties and characteristics of geothermal resources. For example, geothermal steam turbines do not operate in the range where long time high temperature properties of materials need to be considered. Conversely,

*Materials Engineering, Elliott Company, Jeanette, Pa. 
resistance to sulfide stress cracking and stress corrosion cracking may be more important in the case of geothermal steam than with more conventional boiler generated steam.

In the evaluation and selection of materials for geothermal steam turbines, it is necessary to consider the following properties and characteristies:

- Tensile properties

- Modulus of elasticity

- Corrosion resistance

- Erosion resistance

- Fatigue strength

- Coefficient of thermal expansion

- Susceptibility to brittle fracture (toughness)

- Material damping

- Specific heat

- Thermal conductivity

- Hardenability

- Weldability

4.1.6.1 Tensile properties. Tensile properties, especially the yield strength, must be known to select materials having adequate strength to withstand the stresses that will be imposed in service. Generally the operating stress is higher for rotating parts than for stationary components.

4.1.6.2 Modulus of elasticity. The modulus of elasticity must be known in order to compute operating stresses and to determine the deflection that will be encountered when a given stress is applied.

4.1.6.3 Corrosion resistance. Corrosion resistance, including resistance to sulfide stress cracking and stress corrosion cracking, is very important in the case of geothermal steam turbines. These problems are considered carefully in conventional steam turbines, but need to be emphasized even further in the case of geothermal steam. While geothermal steams do not often contain caustic soda, they can be high in hydrogen sulfide, chloride, and other corrosive agents which might give rise to premature and unexpected failures. These same contaminants can cause corrosion in the wet regions of a turbine or during the time the turbine is on stand-by operation if it is not blocked in such a way that steam cannot enter.

4.1.6.4 Erosion resistance. Erosion resistance is a factor in the selection of materials and protection systems in the wet regions of steam turbines. Since virtually the entire turbine is wet in geothermal steam turbines, it is important to use materials of adequate resistance to erosion. Erosion of turbine parts may also be accelerated in geothermal steam due to the presence of contaminants which make the moisture more aggressive. 
4.1.6.5 Fatigue strength. Fatigue problems due to resonance are less likely in turbines driving constant speed generators than in mechanical drive turbines which may be called upon to operate over a wide range of speed. Nevertheless, in geothermal steam where pitting corrosion is more likely to be encountered than in steam from fossil fuel fired boilers, fatigue is quite important.

4.1.6.6 Coefficient of thermal expansion. The coefficient of expansion determines the dimensional change which increases from ambient to operating temperature. The changes are less for geothermal steam turbines than for other turbines operating at higher temperatures, but this effect must still be taken into account.

4.1.6.7 Susceptibility to brittle fracture (toughness). Susceptibility to brittle failure (toughness) does not usually present a problem in geothermal steam turbines. It should, however, be examined, especially for new materials to avoid possible problems.

4.1.6.8 Material damping. Damping is considered in stress calculations, 6articularly with regard to vibration which may take place in turbine buckets. Conventional turbine bucket materials are good in this respect.

4.1.6.9 Specific heat and thermal conductivity. Specific heat and thermal conductivity like the coefficient of thermal expansion are used in the computation of dimensional changes and thermal stresses.

4.1.6.10 Hardenability. Hardenability is important to the turbine manufacturer in selecting materials that will respond to heat treatment in the section thicknesses involved. This property is not ordinarily of interest to the turbine user.

4.1.6.11 Weldability. Weldability is considered in selecting materials for parts which may be fabricated by welding or where repair welding may be performed as a field operation.

Turbines to be used with geothermal steam which have been built to date have been made from the same materials as would be used in turbines using steam from fossil fuel fired boilers. The compositions of the materials referred to in the following paragraphs are listed in table 4.6.

1. Rotating buckets have been made from $12 \%$ chromium steel, AISI Type 403 or 410 . The standard analysis is frequently modified slightly to minimize the occurrence of ferrite in the microstructure. The buckets of stages operating where there are substantial amounts of moisture are sometimes fitted with Stellite strips on the back side of the leading edge to minimize erosion by the moisture. 
TABLE 4.6-Composition of materials used in turbines

\begin{tabular}{|c|c|c|c|c|c|c|c|}
\hline Material & C & $\mathbf{M n}$ & $\mathrm{Ni}$ & $\mathrm{Cr}$ & Mo & $\mathbf{V}$ & Others \\
\hline AISI Type 403/410. & 0. 10 & 0.6 & 0.2 & 12.0 & 0.1 & - & - \\
\hline AISI Type $405 \ldots \ldots$ & 0.06 & 0.6 & 0.2 & 12.0 & 0.1 & - & $0.2 \mathrm{Al}$ \\
\hline AISI Type 4140.. & 0.40 & 0.8 & - & 1. 0 & 0.2 & - & - \\
\hline AISI Type $4340 \ldots$ & 0.40 & 0.8 & 1.8 & 0.8 & 0.25 & 一 & - \\
\hline ASTM A470 Cl. $4 \ldots$ & 0.24 & 0.4 & 2.8 & 0.6 & 0.3 & 0.04 & - \\
\hline ASTM A470 Cl. $6 \ldots$ & 0.24 & 0.4 & 3. 5 & 1. 5 & 0.4 & 0.08 & - \\
\hline ASTM A470 Cl.8. . & 0.30 & 0.8 & 0.5 & 1.2 & 1. 3 & 0.25 & - \\
\hline ASTM A517 Type B.. & 0. 18 & 0.8 & - & 0.5 & 0.2 & 0. 05 & $0.02 \mathrm{Ti}, 0.002 \mathrm{~B}$ \\
\hline ASTM A517 Type F... & 0.15 & 0.8 & 0.8 & 0.5 & 0.5 & 0.05 & $0.3 \mathrm{Cu}, 0.002 \mathrm{~B}$ \\
\hline D2C Ni Resist....... & 2.6 & 1.8 & 22.5 & - & - & - & - \\
\hline AISI Type $304 \ldots \ldots \ldots$ & 0.05 & 1.2 & 9. 0 & 19.0 & - & - & - \\
\hline Carbon Steel.......... & 0.25 & 0.7 & 一 & - & - & - & - \\
\hline
\end{tabular}

2. Diaphragm blades have been made from a $12 \%$ chromium steel, AISI Type 405 . Usually this nonhardening grade of $12 \%$ chromium steel is used to improve weldability of fabricated diaphragms or castability where the diaphragm centers and outer rings are made from cast iron.

3. Turbine rotors and disks have been made from carbon steel and low alloy steel, such as AISI 4340, ASTM A517 Type B or F, and ASTM A470 Class 4, 6, or 8 .

4. Sleeves on the shaft between disks have been made from either a medium carbon steel or a medium carbon alloy steel such as AISI 4140 or 4340 .

5. Shaft seals have been made in at least two ways. One method involves the use of thin strips $\left(0.012^{\prime \prime}\right.$ thick) of $12 \%$ chromium steel (AISI Type 410). The other method utilizes austenitic nickel alloy cast iron (D2C Ni Resist) seals.

6. Casings operate at low temperatures and low pressures. Cast or fabricated carbon steel has been used. In some cases AISI Type 304 stainless steel liner strips have been used in the casing to protect from erosion due to moisture being thrown off the rotating buckets.

Even in the case of fossil fuel fired boilers there may be a considerable difference in the quality of steam from one plant to another. Steam quality varies with such things as composition of the raw water, feed water treatment employed, percentage of make-up required, mode of operation, etc. In the case of geothermal steam, the variations are much greater. Variations in geothermal wells occur with time and from one location to another. To illustrate the substantial differences, table 4.7 shows the range of impurity concentrations in domestic geothermal waters. The acidity of these geothermal waters can be very high with $\mathrm{pH}$ as low as 1.8.

Variations in separated geothermal steam are much less extreme than those in geothermal waters; because the solids in solution in the water which cause the greatest variations should not be present in the steam. 
TABLE 4.7-Variations in U.S. domestic geothermal waters

\begin{tabular}{|c|c|}
\hline Contaminant & $\begin{array}{c}\text { Range of } \\
\text { concen- } \\
\text { tration } \\
(\mathrm{ppm})\end{array}$ \\
\hline 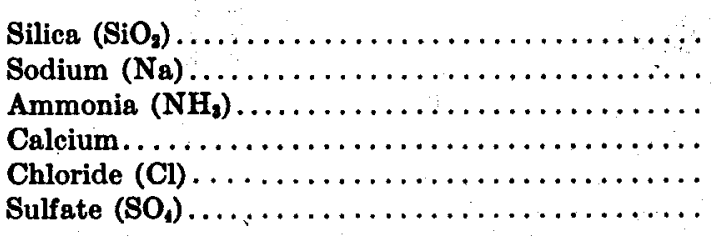 & $\begin{array}{l}16-96 \\
9-6500 \\
1-1400 \\
2-9200 \\
1-124000 \\
3-5700\end{array}$ \\
\hline
\end{tabular}

Efficiency of separation has a substantial influence on steam quality. Noncondensable gases may raise or lower (more usual) the $\mathrm{pH}$. The greatest variations will occur in the first condensate to form where the concentrations of dissolved gases will be greater than where more of the steam has condensed.

As pointed out previously, corrosion and erosion resistance are important properties of steam turbine bucket materials. It is usual in conventional turbines to provide erosion shields on turbine buckets operating over about 1000 feet per second and with moisture contents above 6-8\%. It may be necessary in aggressive geothermal service to adopt more conservative criteria and use moisture catchers. It has also been suggested that erosion may be reduced by the use of lashing wires rather than shrouds. Where it effective, could limit performance and increase the cost of turbines.

S Because of the aggressive nature of the geothermal steam and water, general or pitting corrosion may occur on turbine buckets under conditions of temperature and pressure where these problems would not ordinarily be encountered.

A phenomenon usually called stand-by corrosion occurs in turbines when steam is allowed to leak into a machine which is not in service. The steam then condenses and pitting corrosion results. This problem will undoubtedly be more acute with geothermal turbines because of the contaminants which will make the condensate more aggressive than is generally the case with steam from conventional fossil fuel fired boilers. These contaminants, for example hydrogen sulfide, are even more aggressive in the presence of oxygen. Geothermal steams usually do not contain oxygen. It is possible, however, that air containing oxygen may leak into a turbine during periods of standby. If there is condensate from a hydrogen sulfide bearing geothermal steam in a turbine and this leakage of air occurs corrosion will be accelerated. This problem may be avoided by arranging the piping (see figure 4.56) to prevent the leakage of steam into the turbine when it is not in operation and by purging the turbine when it is shut down with a nonreactive gas such as nitrogen. 
Fatigue failures of rotating buckets in geothermal steam turbines have occurred due to fatigue cracks propagating from corrosion pits. Pits on one such bucket are shown in figure 4.57. With the exception of stand-by corrosion, pitting corrosion rarely occurs in conventional turbines. This problem, like that of moisture erosion, could be alleviated by limiting the tip speed, but it would be preferable to find other solutions.

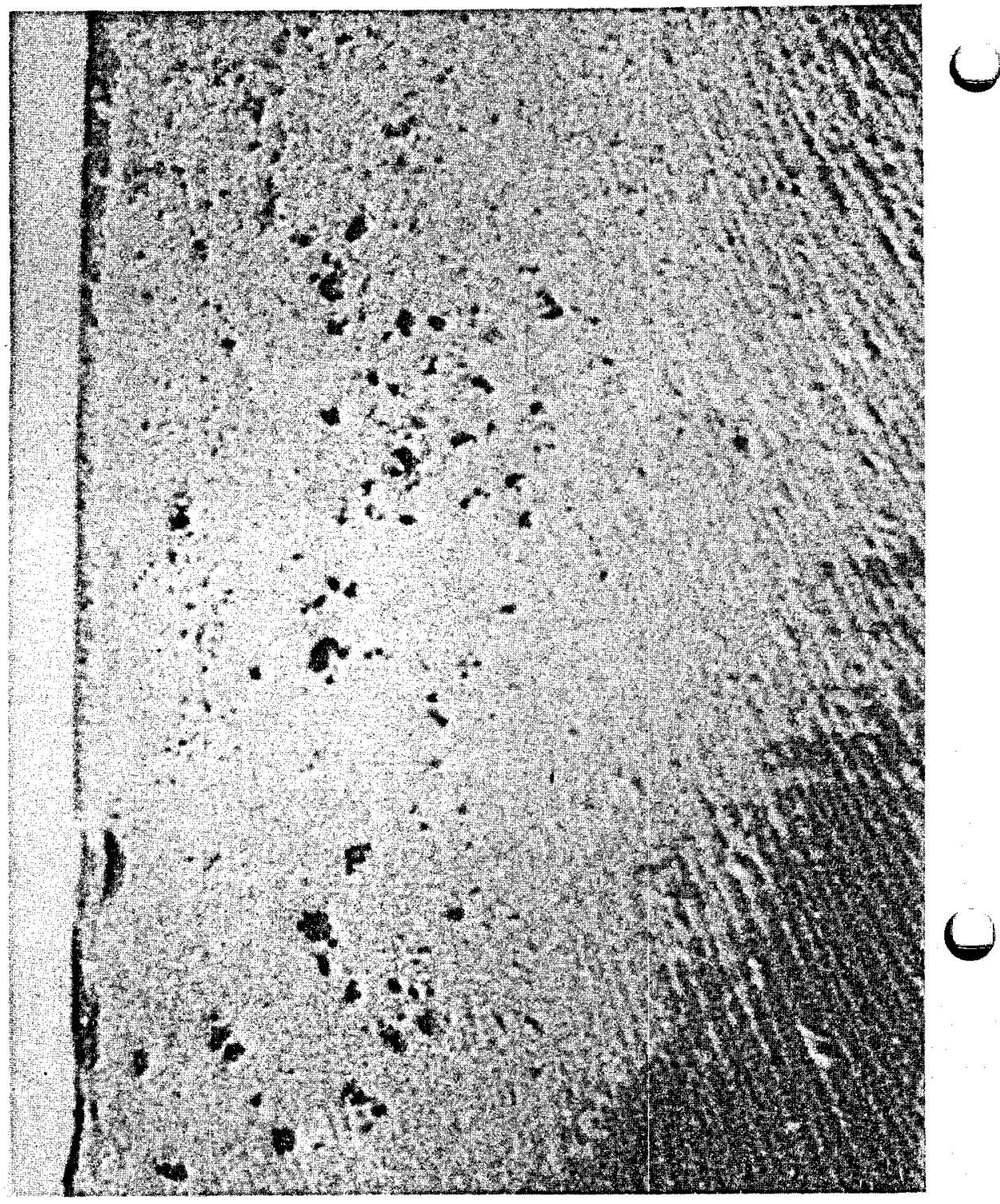

FraURE 4.57-Corrosion pits in bucket from turbine operating on geothermal steam. In service 2-3 years. Also shows mechanical damage on leading edge (on left). 
Fouling due to deposit of solids can occur in nozzles with loss of performance. Fouling, which causes an accumulation of solids under the shroud of steam turbine buckets, can also cause imbalance. This problem may be reduced by the use of lashing wires rather than shrouds. Where it is possible to design around the use of these damping devices their elimination will further reduce the fouling problems.

It has been reported that there have been failures in geothermal steam turbine buckets protected with Stellite strips due to the poor resistance to corrosion of the silver brazing alloy used to attach the strip. This material would have poor resistance to corrosion in geothermal steam in bulk, but the access of the steam to the brazing alloy is very limited, and there may be an alternative explanation.

Attaching the Stellite strip by brazing requires heating the material locally to about $1400^{\circ}$ F. This is enough to cause some degree of hardening in the material immediately underlying the strip. Many thousands of buckets have been protected in this manner without difficulty when operating with conventional steam. In the case of many geothermal steams, however, the steam is contaminated with hydrogen sulfide, and conditions at the location of the attachment of the Stellite strip to the turbine bucket may favor sulfide stress cracking. This problem may be avoided by using a post brazing heat treatment at $1100-1150^{\circ} \mathrm{F}$. to reduce the hardness of the heat affected zone.

In order to avoid sulfide stress cracking due to hydrogen sulfide, it is frequently recommended that materials be used having a maximum yield strength of 90,000 psi and/or a maximum hardness of Rockwell C22. Both buckets and disks, especially the latter, with yield strengths well above these figures have been used successfully in geothermal steam turbines. The yield strengths of some of the disks have been about 120,000 psi. It is apparent that the conditions of operation in these turbines have been less severe than in applications such as casings in sour crude oil wells where the more restrictive limits may be needed. For further details, consult the bibliography in section 4.1.6.12.

\subsubsection{Bibliography for section 4.1 .6}

Toney, S., Cohen, M., and Cron, C. J., 1977. "Metallurgical Evaluation of Materials for Geothermal Power Plant Applications," Geothermal Energy, September, pp. 8-38.

Marshall, T., and Hugill, A. J., 1957. "Corrosion by Low Pressure Geothermal Steam," Corrosion, vol. 19, pp. 329-365.

Yoshida, H., 1970. "Corrosion Control in Geothermal Steam Turbines," Tokyo Shibaura Electric Company (Toshiba) publications.

Dodd, F. J., Johnson, A. E., and Ham, W. C., 1975. "Material and Corrosion Testing at The Geysers Geothermal Power Plant," Second U.N. Symposium on the Development and Use of Geothermal Resources, San Francisco, Calif., May 20-30. 
Dodd, J. F., and Ham, W. C., 1975. "Corrosion Studies on The Geysers Geothermal Steam Power Plant," Golden Gate Materials Conference, San Francisco, Calif. January 22.

Tolivia, E. M., Hoashi, J. M., and Miyazaki, M., 1975. "Corrosion of Turbine Materials in Geothermal Steam in Cerro Prieto, Mexico," Second U.N. Symposium on Development and Use of Geothermal Resources, San Francisco, Calif., May 20-30.

Tokyo Shibaura Electric Co., 1969. "Toshiba Geothermal Power Plant," September.

Curran, R. M., Seguin, B. R., Quinlan, J. F., and Toney, S., 1969. "Stress Corrosion Cracking of Steam Turbine Materials," Southeastern Electric Exchange Conference, April 21-22.

McCord, T. G., Bussert, B. W., Curran, R. M., and Gould, G. C., 1975. "Stress Cracking of Steam Turbine Materials," NACE Paper No. 107.

Greer, J. B., 1973. "Factors Affecting the Sulfide Stress Cracking Performance of High Strength Steel," NACE Paper No. 55.

Keller, H. F., and Cameron, J. A., 1974. "Laboratory Evaluation of Susceptibility to Sulfide Cracking," NACE Paper No. 99.

Warren, D., and Beckman, G. W., 1957. "Sulfide Corrosion Cracking of High Strength Bolting Material," Corrosion, 13, pp. 631t-641t, October.

Splittgerber, A., 1949. "An Interesting Case of Corrosion of Steam Turbines," Von Wasser, vol. 17, pp. 146-149, Brutcher Translation 2925.

Highley, L., and Schmarrenberger, W. R., 1952. "Prevention of Standby Corrosion in Power Plants," Corrosion, vol. 8, No. 5, pp. 171-177.

\subsection{Binary cycles}

\subsubsection{Introduction (By J. H. Eskesen*)}

Organic Rankine cycles have received considerable attention over the past fow years for their ability to exploit low-grade energy sources, both geothermal and waste heat from conventional power plants, with fairly compact turbomachinery and, hence, relatively low equipment cost. The organic cycles proposed for geothermal applications are referred to as binary cycles despite the fact the word binary is normally used to describe cycles in which work is extracted from two different working fluids simultaneously, as in say a combined gas turbine/steam turbine plant. The geothermal binary cycle, in contrast, extracts work from a single working fluid whose heat supply is derived from liquid brine. Heat can either be transferred to the cycle working fluid from the brine directly or it can be derived from steam flashed from the brine. These two alternatives are referred to here as the Brine/Binary Cycle and the Flash/Binary Cycle, respectively.

Although the Brine/Binary Cycle is conceptually fairly simple and exhibits perhaps the highest resource utilization efficiency of all the nonhybrid geothermal power cycles proposed, the inability to prevent scale formation in surface type heat exchangers has thus far limited its proposed application in the United States to areas where the concentration of scale producing compounds is fairly low. Some work is in progress to demon-

*Medium Steam Turbine Dept., General Electric Co., Lynn, Mass. 
strate the feasibility of scale control via scale inhibitors and direct contact and fluidized bed heat exchangers, but this research is still in the preliminary stage, and is unlikely to produce conclusive results for several years. The fact that well pumping is required to maintain the brine in liquid form throughout the heat exchange process has also hindered development of the Brine/Binary Cycle since downhole pumping is not a mature technology and, therefore, cannot yet be implemented with any guarantee of success.

The potential difficulties associated with the Brine/Binary Cycle are not a factor with the Flash/Binary Cycle since brine can be allowed to flash in the well bore, thereby eliminating the need for downhole pumps, while efficient separators cah be utilized to reduce the carryover of dissolved solids to the point where problems of scaling are also eliminated.

The following analysis deals only with simple cycles. Regenerative cycles, which are attractive in conventional power plants because of their improved cycle efficiency, have no advantage in the geothermal arena since waste turbine energy would simply replace available cycle input energy and the specific output in terms of well flow would remain unaltered.

\section{4.\%. T'hermophysical properties of working fluids, (By J. Kestin* and} H. E. Khalifa $\dagger$ )

The designer of a binary geothermal plant must have available to him the thermodynamic and the transport properties of the secondary working fluid. Such fluids must have low boiling points, and the most practical candidates are hydrocarbons or fluorocarbons. Both pure fluids and mixtures can be used. The combination of thermodynamic properties of a particular fluid or mixture of fluids exerts an influence on attainable efficiency and utilization factors, but this influence cannot be obtained other than by a computer analysis of concrete cases.

The following sections contain a brief summary of what is available today, special emphasis being placed on the properties of the most promising working fluids. Since pilot binary plants in the U.S. and Japan $(4,5)^{* *}$ use isobutane as a working fluid, the availability of data and correlations for its thermophysical properties will be emphasized.

4.2.2.1 Pure fuids. The equilibrium thermodynamic properties of a pure fluid are completely determined by its fundamental equation $(6,7)$; (see also chapter 3). This can take one of several equivalent forms, such as

$$
u=u(s, v) ; h=h(8, P) ; f=f(T, v) \text { or } g=g(T, P) .
$$

- Brown University, Providence. R.I.

† United Technologies Research Center, East Hartford, CT.

* Numbers in parentheses denote references for this section which may be found at the end of section 4.2. (See p. 466.) 
Here $u$ denotes internal energy, $h$-enthalpy, $f$-the Helmholtz, and $g-$ the Gibbs free energy. The equation which forms the basis of the very well known Steam Tables $(8)$ is based on an equation of type 4.46c.

The use of a compact fundamental equation is very convenient for inclusion in the data bank organized in conjunction with an extensive computer code for design analysis.

An alternative and equivalent form of a fundamental equation utilizes the thermal equation of state, for example

$$
P=P(\rho, T) \text {. }
$$

augmented by a formulation of, say, the enthalpy in the ideal gas state

$$
h^{\circ}=h^{\circ}(T)
$$

The latter is nowadays computed by the methods of statistical thermodynamics (9) from spectroscopic data.

The thermal equation of state 4.47 is analytic in the whole domain of its validity except for the critical point. Modern research (10) shows that the fundamental equation, and hence also equation 4.47 is nonanalytic at the critical point. The need to take this circumstance into account complicates the formation, except for the fact that the affected domain represents only a small region around the critical point itself. For this reason all practical formulations, including ( 8 ), employ analytic forms.

The use of the pair of equations 4.47 and 4.48 has the added advantage that all departures from the ideal gas state calculated along isotherms are governed exclusively by equation 4.47, (see 7, pp. 251-3). Thus the formulation can be split into one representing ideal-gas behavior calculated from statistical mechanics and one representing the departure.

An extensive tabulation of ideal gas properties of many fluids of interest is contained in API research project 44 (11) and in the work of Zwolinski and collaborators (22-25). Table 4.8 contains a listing of the sources of ideal gas properties for a number of working fluids.

The thermal equation of state 4.47 is usually given an empiricallyinspired closed form. Among the many proposed, for our purposes it is sufficient to mention: (a) the Benedict-Webb-Rubin, or BWR equation $(20,21)$; and (b) the Martin-Hou equation $(1 \%, 22)$; they are discussed below.

The vapor-pressure of the substance is determined from the condition of phase equilibrium

$$
g^{l}(T, P)=g^{v}(T, P) \quad \text { along the saturation curve }
$$

for the specific Gibbs free energy of the liquid and vapor. This is equivalent to equating fugacities (21). 
TABLE 4.8-Ideal gas property reference key

\begin{tabular}{|c|c|}
\hline Fluid & Source \\
\hline 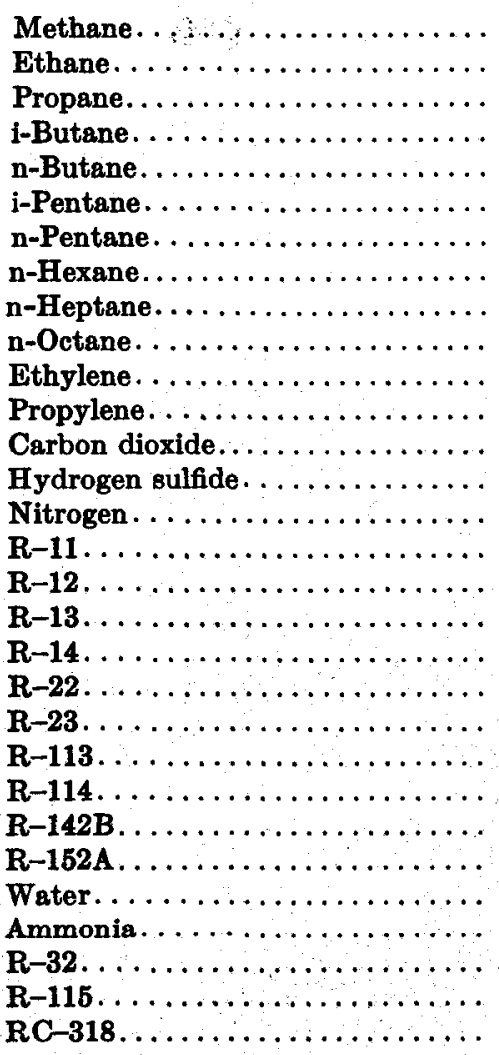 & $\begin{array}{l}{[16,11]} \\
{[16,11,12]} \\
{[16,11,17,18,12]} \\
{[16,11,17,18,14]} \\
{[16,11,14]} \\
{[16,11]} \\
{[16,11]} \\
{[16,11]} \\
{[16,11]} \\
{[16,11]} \\
{[16,11,13]} \\
{[16,11,13]} \\
{[16,11,17]} \\
{[16]} \\
{[16,11]} \\
{[19,17,16]} \\
{[19,16]} \\
{[19,16]} \\
{[19]} \\
{[19,17,16]} \\
{[19]} \\
{[19]} \\
{[19,17]} \\
{[19]} \\
{[19]} \\
{[16,17]} \\
{[16,17]} \\
{[17,16]} \\
{[17]} \\
{[17]}\end{array}$ \\
\hline
\end{tabular}

Numbers in brackets designate the literature references listed at the end of section 4.2 .

The Benedict-Webb-Rubin equation. The BWR equation, as modified by Starling et al., (16, 23) MBWR, has the form

$$
\begin{aligned}
=\rho R T+\left(B_{0} R 1-A_{0}-\right. & \left.\frac{C_{0}}{T^{2}}+\frac{D_{0}}{T^{3}}-\frac{E_{0}}{T^{4}}\right) \rho^{2}+\left(b R T-a-\frac{d}{T}\right) \rho^{3} \\
& +\alpha\left(a+\frac{d}{T}\right) \rho^{6}+\frac{c \rho^{3}}{T^{2}}\left(1+\gamma \rho^{2}\right) \exp \left(-\gamma \rho^{2}\right),
\end{aligned}
$$

which contains eleven individual numerical constants.* Table 4.9 lists the values of these constants for 27 compounds (16). The same reference contains recommended values of the ideal gas properties.

*The original BWR equation contains eight adjustable constants. 
TABLE 4.9.-Modified BWh equation of state parameters for twenty-ieven pure components

(Presure in psia, temperature in ${ }^{\circ} \mathbf{R}$, deneity in $\mathrm{lb}-\mathrm{mole} / \mathrm{ft}^{3}$ )

\begin{tabular}{|c|c|c|c|c|c|c|}
\hline & $\boldsymbol{B}_{\text {。 }}$ & $\boldsymbol{A}_{\mathbf{n}}$ & $C_{0} \times 10^{-8}$ & $\boldsymbol{\gamma}$ & $\boldsymbol{b}$ & $\boldsymbol{a}$ \\
\hline Methane................ & 0.723251 & 7520.29 & 2. 71092 & 1. 48640 & 0.925404 & 2574. 89 \\
\hline Ethane.............. & 0.826059 & 13439.3 & 29. 5195 & $2 . .99656$ & 3. 11206 & 22404.5 \\
\hline Propane............. & 0.964762 & 18634. 7 & 79. 6178 & 4. 56182 & 5. 46248 & 40066. 4 \\
\hline $\mathrm{i}-$ Butane $\ldots \ldots \ldots \ldots \ldots$ & 2. 02615 & 38980.2 & 106. 581 & 9. 21378 & 6. 70763 & 38864. 4 \\
\hline n-Butane $\ldots \ldots \ldots \ldots \ldots$ & 1. 56588 & 32544. 7 & 137. 436 & 7. 54122 & 9. 14066 & 71181.8 \\
\hline i-Pentane . . . . . . . . . . & 1. 27752 & 35742.0 & 228. 430 & 11. 7384 & 19. 8384 & 204344. 0 \\
\hline n-Pentane.............. & 2. 44417 & 51108.2 & 223. 931 & 11. 8593 & 16. 6070 & 162185.0 \\
\hline$\overline{\mathbf{n}}$-Hexane. . . . . . . . . . & 2. 66233 & 45333. 1 & 526. 067 & 14. 8720 & 29. 4983 & 434517.0 \\
\hline n-Heptane . . . . . . . . . . . & 3. 60493 & 77826. 9 & 615. 662 & 24. 7604 & 27. 4415 & 359087.0 \\
\hline 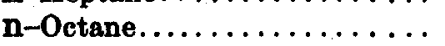 & 4. 86965 & 81690.6 & 996.546 & 21. 9888 & 10. 5907 & 131646.0 \\
\hline Ethylene. . . . . . . . . . . & 0.747945 & 12133. 9 & 16. 3203 & 2. 27971 & 2. 62914 & 15988. 1 \\
\hline Propylene.............. & 0.114457 & 6051. 36 & 97. 4762 & 4. 07919 & 7. 64114 & 81880.4 \\
\hline Carbon dioxide. .......... & 0.394117 & 6592.03 & 29. 5902 & 1. 64916 & 0.971443 & 5632.85 \\
\hline Hydrogen sulfide $\ldots \ldots \ldots \ldots$ & 0.297508 & 10586. 3 & 21. 1496 & 1. 20447 & 2. 53315 & 20511.0 \\
\hline Nitrogen ............... & 0.677022 & 4185. 05 & 1. 37936 & 1. 10011 & 0.833470 & 1404. 59 \\
\hline $\mathbf{R}-11 \ldots \ldots \ldots \ldots \ldots \ldots$ & 2. 075010 & 40744. 70 & 175. 5198 & 7. 483052 & 8. 898936 & 92892. 19 \\
\hline $\mathbf{R}-12 \ldots \ldots \ldots \ldots \ldots$ & 1. 598333 & 28858. 68 & 81.95445 & 5. 975451 & 7. 112878 & 55769.99 \\
\hline $\mathbf{R}-13 \ldots \ldots \ldots \ldots \ldots \ldots$ & 1. 218645 & 17443. 34 & 31. 98527 & 3. 815694 & 5. 437993 & 36049. 57 \\
\hline $\mathbf{R}-14 \ldots \ldots \ldots \ldots \ldots \ldots$ & 0. 5944908 & 11740.10 & 7. 041541 & 3. 419115 & 3. 492386 & 7863. 879 \\
\hline $\mathbf{R}-22 \ldots \ldots \ldots \ldots \ldots \ldots$ & 1. 217710 & 20137. 78 & 61. 69690 & 3. $\mathbf{3 1 1 5 8 4}$ & 4. 363955 & 36450.57 \\
\hline $\mathbf{R}-23 \ldots \ldots \ldots \ldots \ldots \ldots \ldots$ & 0. 3793391 & 12621. 08 & 24. 01073 & 2. 656389 & 3. 647122 & 16273. 04 \\
\hline $\mathbf{R}-113 \ldots \ldots \ldots \ldots \ldots \ldots$ & 2. 504935 & 72597.88 & 160. 1631 & 34. 20486 & 18. 81586 & 64737. 47 \\
\hline $\mathrm{R}-114 \ldots \ldots \ldots \ldots \ldots$ & 2. 332235 & 47189. 66 & 129. 6248 & 12. 33499 & 12. 35784 & 84157. 50 \\
\hline R-142B $\ldots \ldots \ldots \ldots \ldots \ldots$ & 2. 364154 & 30185.41 & 139. 2919 & 5. 034503 & 6. 364923 & 75356. 19 \\
\hline $\mathrm{R}-152 \mathrm{~A} \ldots \ldots \ldots \ldots \ldots \ldots$ & 2. 231568 & 30219. 47 & 91.15738 & 3. 834157 & 4. 401977 & 42785. 45 \\
\hline 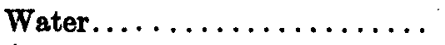 & 0.4552756 & 12432.87 & 122. 7536 & 0. 2215509 & 0. 2088909 & 514. 5405 \\
\hline Ammonia . . . . . . . . . & 0.7172304 & 10063. 212 & 47. 78621 & 0.5369631 & 0.542222 & 7368. 62 \\
\hline \multirow{2}{*}{ Units. . . . . . . . . . . } & $\mathrm{ft}^{\mathbf{2}}$ & psia fto & psia $\mathrm{ft}^{\circ} \mathrm{R}^{2}$ & $\mathrm{ft}^{\mathbf{6}}$ & $\mathrm{ft}^{6}$ & psia ft: \\
\hline & lb-mol & $(\mathrm{lb}-\mathrm{mol})^{2}$ & $(\mathrm{lb}-\mathrm{mol})^{2}$ & $\left(\overline{(\mathrm{b}-\mathrm{mol})^{2}}\right.$ & $(\mathrm{lb}-\mathrm{mol})^{2}$ & $(\mathrm{lb}-\mathrm{mol})^{3}$ \\
\hline
\end{tabular}




\begin{tabular}{|c|c|c|c|c|c|}
\hline & & & & & \\
\hline & $\alpha$ & $c \times 10^{-8}$ & $D_{0} \times 10^{-10}$ & $d \times 10^{-4}$ & $E_{0} \times 10^{-10}$ \\
\hline Methane. & 0.468828 & 4. 37222 & 1. 07737 & 4. 74891 & 3. 01122 \\
\hline Ethane......... & 0. 909681 & 68.1826 & 25. 7477 & 70. 2189 & 1468. 19 \\
\hline Propane........ & 2. 01402 & 274. 461 & 45. 3708 & 1505. 20 & 2560. 53 \\
\hline i-Butane ....... & 6. 87727 & 328. 220 & 147.046 & 618. 303 & 8981. 52 \\
\hline n-Butane ....... & 4. 00985 & 700. 044 & 33. 3159 & 3642. 38 & 230. 902 \\
\hline 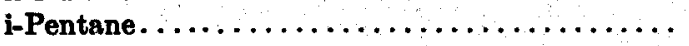 & 6. 16154 & 1290. 83 . & 142. 115 & 3792.20 & 2413. 26 \\
\hline n-Pentane $\ldots \ldots \ldots \ldots \ldots \ldots \ldots \ldots \ldots \ldots$ & 7. 06702 & 1352. 86 & 101. 769 & 3885. 21 & 3908. 60 \\
\hline n-Hexane....... & 9. 70230 & 3184. 12 & 552. 158 & 3274.60 & 62643.3 \\
\hline n-Heptan. & 21. 8782 & 3748.76 & 777. 123 & 835. 115 & 636. 251 \\
\hline n-Octane... & 34. 5124 & 6420.53 & 790. 575 & 18590.6 & 3464,19 \\
\hline Ethylene. . & 0. 589158 & 40. 9725 & 5. 17563 & 90.3550 & 1. 61706 \\
\hline Propylene..... . & 1.36532 & 294. 141 & 70. 5921 & 541.935 & 3412. 50 \\
\hline Carbon dioxide. & 0.395525 & 27. 4668 & 40. 9151 & 5. 99297 & 1. 02898 \\
\hline Hydrogen sulfide $\ldots \ldots \ldots \ldots \ldots \ldots \ldots \ldots \ldots$ & 0. 165961 & 43. 6132 & 4. 86518 & 1. 99731 & 3. 93226 \\
\hline Nitrogen................ & 0.302696 & 0.844317 & 1. 95183 & 3. 11894 & 121. 648 \\
\hline R-11. & 3. 874479 & 736. 7655 & 141. 2435 & 1386. 647 & 7275.933 \\
\hline $\mathbf{R}-12 \ldots$ & 2. 635286 & 318. 5777 & 52. 66135 & 912. 3462 & 2769. 722 \\
\hline $\mathbf{R}-\mathbf{1 3}$. & 1. 359589 & 104. 2572 & 11. 27538 & 372. 3436 & 284. 3204 \\
\hline $\mathrm{R}-14 \ldots$ & 0.7608927 & 14. 19856 & 5. 07972 & 131. 9613 & 67.75317 \\
\hline$R-22 \ldots \ldots$ & 1. 095192 & 174. 2752 & 31. 90431 & 370. 1302 & 0.0 \\
\hline R-23..... & 0.5314757 & 47. 69722 & 23. 83591 & 169. 9933 & 929. 0587 \\
\hline R-113... & 8. 910174 & 390. 5316 & 741. 6812 & 1451: 649 & 126549. 6 \\
\hline$R-114 \ldots$ & 7. 658150 & 516. 620 & 152. 9365 & 785. 8706 & 5601.881 \\
\hline R-142B $\ldots$ & 2. 557422 & 530. 2078 & 57. 40686 & 1347. 710 & 161. 2859 \\
\hline R-152A. . & 1. 521588 & 270. 5770 & 79. 04121 & 221. 5356 & 3806.589 \\
\hline Water.... & 0. 03580983 & 94. 10372 & 68. 22462 & 394.753 & 2258. 151 \\
\hline Ammonia. . & 0.0910937 & 65. 226392 & 0. 2420266 & 99. 273209 & 0.0012865 \\
\hline Units........ & psia $\mathrm{ft}^{\circ}$ & psia $\mathrm{ft}^{\circ}{ }^{\circ} \mathrm{R}^{2}$ & psia $\mathrm{ft}^{\circ}{ }^{\circ} \mathbf{R}^{*}$ & psia $\mathrm{ft}^{\circ}{ }^{\circ} \mathrm{R}$ & psia $\mathrm{ft}^{\circ}{ }^{\circ} \mathrm{R}^{4}$ \\
\hline & $(\mathrm{lb}-\mathrm{mol})^{8}$ & $(\mathrm{lb}-\mathrm{mol})^{8}$ & $(\mathrm{lb}-\mathrm{mol})^{2}$ & $(\mathrm{lb}-\mathrm{mrol})^{2}$ & $(\mathrm{lb}-\mathrm{mol})^{2}$ \\
\hline
\end{tabular}


Starling $(16,23)$ prepared extensive correlations for hydrocarbons and fluorocarbons according to this scheme and makes them available as a computer code, a set of tables and a set of Mollier $h, P$ charts.

Another modified version of the BWR equation was used by Eubank et al. $(24,25)$ to correlate the thermodynamic properties of normal and isobutane. The modification consists in dividing the domain into two subregions each of which is represented with the aid of eight different constants. The correlation imposes continuity conditions at the subregion boundary and optimizes a total of sixteen numerical constants. The result is known as "the differential regional BWR equation."

All correlations are based on what are essentially scant and incomplete experimental data.

A detailed analysis of the uncertainties contained in the various formulations is not available; it is even doubtful whether it would be profitable, given the lack of reliable experimental material.

As far as isobutane is concerned, it is possible to state that the formulations due to Starling $(16,23)$ and Das et al. (25) show similar uncertainties, even though their distribution over the $T, \rho$ domain is different in each case. The latter formulation is not quite thermodynamically consistent because the vapor-pressure curve was not determined with the aid of condition 4.49 but was correlated independently and directly from experiment. All these circumstances make the formulation due to Das et al. (25) somewhat cumbersome for repetitive calculations.

The Martin-Hou equation. The Martin-Hou equation uses dimensionless ratios, and has the form

$$
P, Z_{r}=\left[\sum_{i=0}^{4} f_{i}\left(T_{r}\right) /\left(v_{r}-b\right)^{i+1}\right]+f_{5}\left(T_{r}\right) e^{-a v_{r}}+f_{6}\left(T_{r}\right) e^{-2 a v_{r}}
$$

in which $f_{o}\left(T_{r}\right)=T_{r}$ and

$$
f_{i}\left(T_{r}\right)=A_{i}+B_{i} T_{r}+C_{i} \exp \left(-K T_{r}\right), i=1, \ldots, 6 .
$$

The equation includes 21 individual numerical constants. The latter are seen listed in table 4.10 for thirteen working fluids. A tabulation of the ideal gas data for these fluids can be found in Milora and Tester (17).

It is claimed that the Martin-Hou equation gives a superior fit to experimental data in the supercritical region compared with the BWR or MBWR equations. On the other hand, it is reported that the Martin-Hou equation is seriously in error in the compressed-liquid region (26). Moreover, according to Milora and Tester (1\%), the Martin-Hou equation must be supplemented by a separate formulation of experimental vapor-pressure data. This may adversely affect the thermodynamic consistency in the region near saturation.

$A$ comment on accuracy. The optimum values of the constants in any of the empirical equations of states are determined through a careful 
TABLE 4.10-Martin-Hou equation of state parameters*

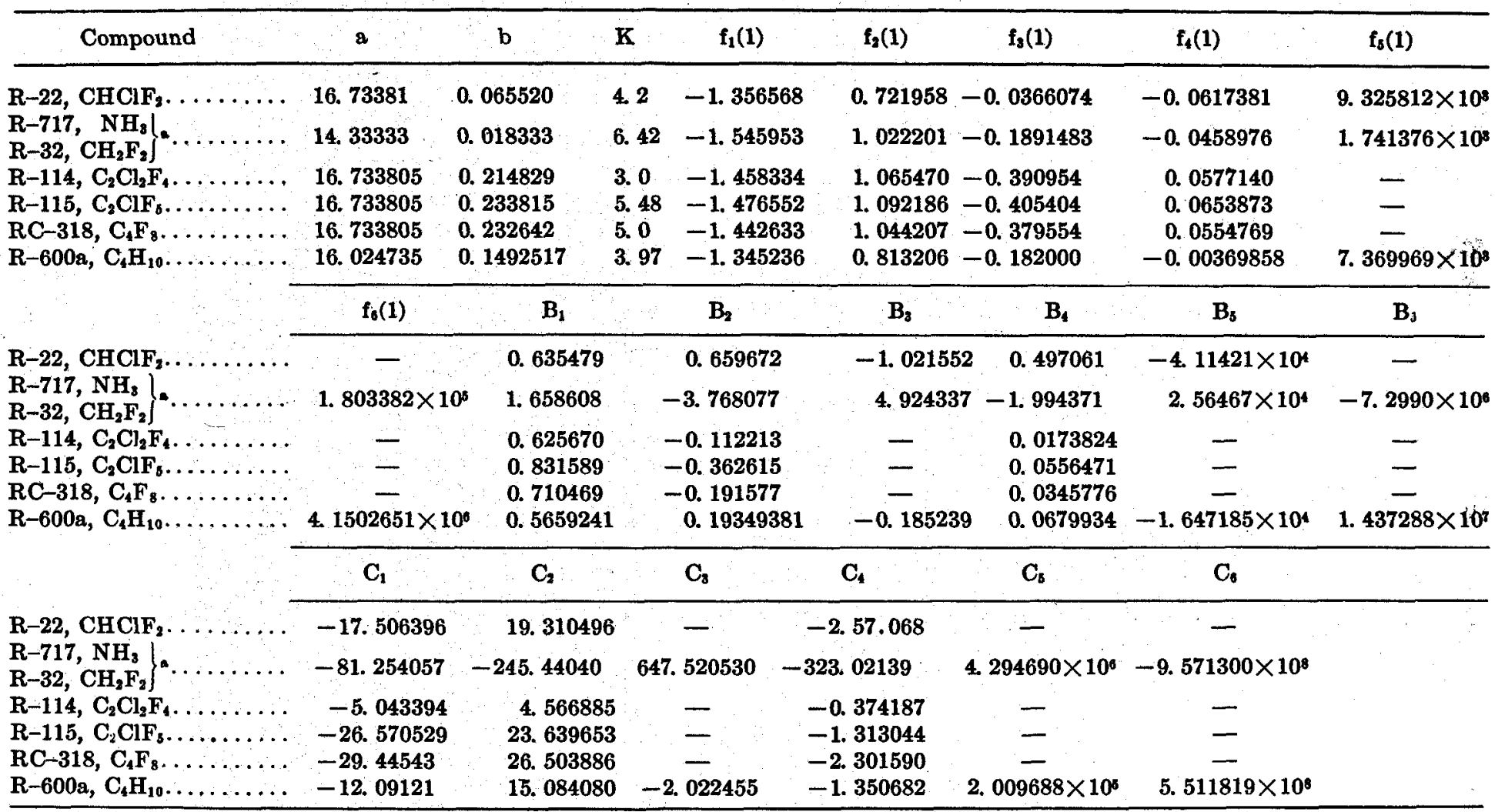

-Parameters for $\mathrm{R}-717\left(\mathrm{NH}_{3}\right)$ used for $\mathrm{R}-32$.

*Reproduced from Milora and Tester (17). 
analysis of the available experimental data. Unfortunately, accurate experimental data. on the properties of the fluids most likely to be used in geothermal Rankine cycles are seriously lacking, as already mentioned. An assessmunt of the accuracy of an equation of state should be based not only on how closely it reproduces the experimental data used in the development of the equation, but also on the accuracy of the experimental values themselves. Such an assessment should, therefore, start with a compilation and a careful scrutiny of the available experimental data. So far, the only such compilation is that prepared for isobutane by Kestin et al. ( $\mathscr{E 7})$. A comparison between the experimental results on isobutane on the one hand and the equations of Starling $(16,23)$, Eubank $(24,25)$, and Milora and Combs (28) is left for the future. Preliminary studies (29) show that discrepancies between alternative formulations may result in significant differences in the heating-surface requirements for a supercritical primary heat exchanger designed with the aid of different equations for isobutane (see chapter 2). The differences are more pronounced if the discrepancies occur close to the pinch point. Eskesen (26) performed a thermodynamic optimization study of isobutane cycles using both Starling's equation (23) and Milora's equation (28). This study showed no significant differences between the thermodynamic optima derived from the two equations. It should be noted, however, that because of numerical difficulties associated with Milora's equation in the liquid region, Eskesen had to generate approximate temperature-enthalpy curves in this region ensuring that chey merged with those predicted by the equation at high temperatures.

4.2.2.2. Thermodynamic properties of mixtures. The use of mixed working fluids may prove advantageous under certain operating conditions (25). For this reason it is important to evaluate the potential of mixtures for use as working fluids in geothermal binary cycles: a task that requires the knowledge of the thermodynamic properties of mixtures.

Most correlations for mixture thermodynamic properties are based on the corresponding correlations for the pure components supplemented by empirical combination rules. The BWR equation, for example, can be used both for pure fluids and mixtures (21). Starling (23) and Fish and Starling (30) developed computer programs for mixtures based on the modified BWR equation. The eleven parameters for the MBWR equation can be obtained from those for the corresponding pure fluids by means of a set of mixing rules proposed by Bishnoi and Robinsin (31) for the BWR equation (see (23), p. 220). The accuracy of these correlations has not been tested owing to the lack of experimental data for mixtures.

4.2.2.3. Transport properties. Although transport properties do not play a major role in the preliminary design optimization of geothermal binary cycles, reasonably accurate values of the viscosity and thermal conductivity 
of the working fluids are required in order to evaluate the heat transfer coefficients and the pressure losses encountered in the design stages. Reliable experimental data on the transport properties of the likely working fluids are practically nonexistent. A survey of the transport properties of isobutane which reveals the scarcity of data was given by Kestin et al. (27). Transport data for other potential working fluids are even rarer; particularly those for mixtures. Fortunately, transport properties for design need not be known to the same degree of accuracy as equilibrium properties. The resistance to heat transfer in the primary heat exchanger of a binary system, for instance, is dominated by the fouling effect and is, therefore, less dependent on the film coefficient on the working fluid side. The flow in the various components of the plant is likely to be highly turbulent. Consequently, the pressure loss factors will depend only weakly on the Reynolds number. In view of these factors, an estimate of the transport properties of the working fluid based on a crude correlation may be sufficient, at least for preliminary design. These crude estimates can be found in standard handbooks (see, e.g., Vargaftik (3E)).

4.2.2.4. Other properties. The thermodynamic and transport properties of a working fluid must be supplemented by information concerning such characteristics as chemical stability at operating temperatures, flammability, toxicity, impact on environment, chemical compatability with other materials in the system, and commercial availability. These factors, although secondary to the thermodynamic optimization process, may play a decisive role in the selection of the most suitable working fluid.

\section{List of symbols for section 4.2 .2}

f... Helmholtz specific free energy

g.... Gibbs specific free energy

$g^{l}$... Specific Gibbs free energy for saturated liquid state

$g^{*}$... Specific Gibbs free energy for saturated vapor state

$h$... Specific enthalpy

$h^{0}$... Specific enthalpy for ideal-gas

$P$... Pressure

$P, \ldots$ Reduced pressure

R... Universal gas constant

8.... Specific entropy

$T$... Thermodynamic temperature

$T_{r}$. Reduced thermodynamic temperature

u. . . Specific internal energy

$v$.... Specific volume

$v_{r} . . . \quad$ Reduced specific volume

$Z_{c}$. . Critical compressibility factor

ค... Molar density 


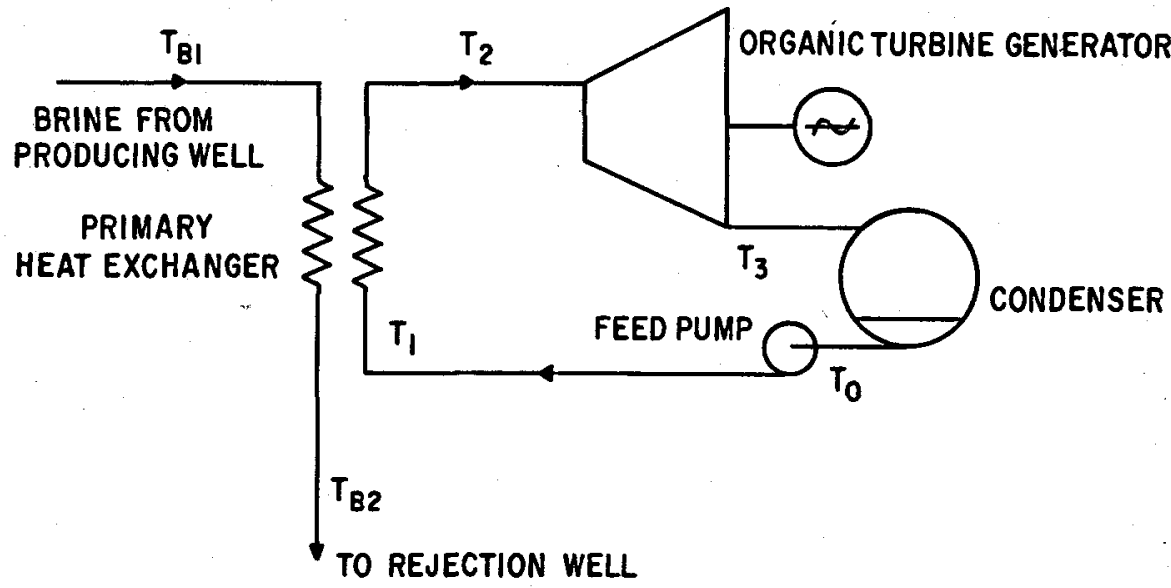

Fraure $4.58-$ Schematic of brine/binary cycle.

\subsubsection{Cycle thermodynamics (by J. H. Eskesen*)}

42.3.1. The Brine/Binary Cycle. A simple schmatic of the Brine/Binary Cycle is shown in figure 4.58. Brine enters the system through the heat exchanger where it transfers energy to the working fluid. A typical temperature enthalpy diagram for the heat exchanger process in a cycle operating at supercritical pressure is shown in figure 4.59. Brine and the organic fluid enter the heat exchanger at temperatures $T_{B 1}$ and $T_{1}^{\prime}$, respectively. If brine leaves the exchanger at temperature $T_{B 2}$ and a pinch tem-

*Medium Steam Turbine Dept., General Electric Co., Lynn, Mass.

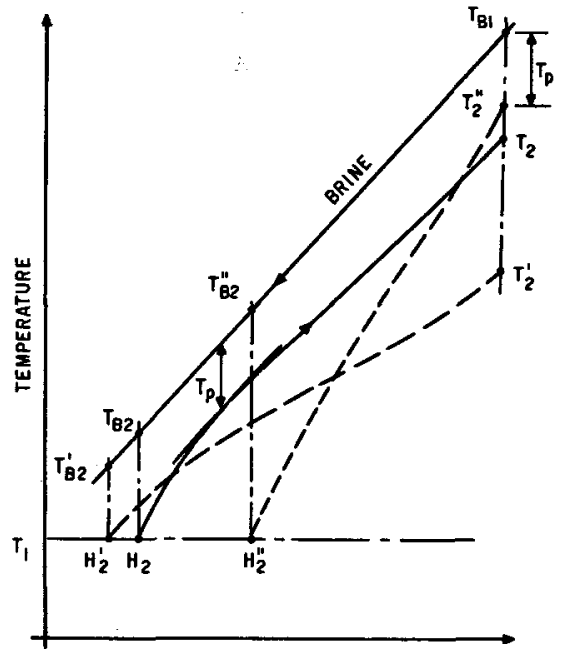

TOTAL ENTHALPY CHANGE (BTU)
Figure 4.59-Temperature/enthalpy diagram from primary heat exchange process in brine/binary cycle. 
perature $T_{P}$ is maintained between the two fluids, the organic fluid will exit the exchanger at temperature $T_{2}$.

In the following analysis, the performance of each cycle was calculated with specific output (in terms of well flow) optimized since this parameter has the greatest significance in terms of utilizing the geothermal resource. Such an optimization requires the heat exchanger pinchpoint temperature difference to be free to "float" since only the brine inlet temperature and organic fluid inlet temperature have known values. For maximum cycle output, the pinchpoint will occur at some position intermediate between the entrance and exit, as shown by heating and cooling paths of the organic fluid and brine depicted by the solid lines in figure 4.59. Should the pinchpoint occur at the brine inlet, the high turbine inlet temperature would tend to maximize the thermal efficiency, but it would also underutilize the geothermal resource, since the brine is discharged at the relatively high temperature $T^{\prime \prime}{ }_{B 2}$. The net result is a less than optimum cycle output. Conversely, a pinchpoint located at the brine outlet would produce the heating curve $\mathrm{H}_{2}{ }_{2} \mathrm{~T}_{2}{ }_{2}$ and, although it would maximize the heat recovered from the brine since the brine discharge temperature has now been reduced to $T^{\prime}{ }_{B 2}$, it would also produce a low turbine inlet temperature and hence a low turbine efficiency. Again a less than optimum cycle output would result.

Clearly, this technique of optimizing output requires a detailed knowledge of the temperature/specific enthalpy relationship at all points on the heating curve from the feed pump exit to the turbine inlet for any candidate working fluid. For most compounds of interest this can be accomplished readily using the equation of state described in section 4.2.2.

The performance of the Brine/Binary Cycle operating on a resource of pure water and using isobutane and isopentane as the working fluid is shown in figures 4.60 and 4.61. Net specific output is plotted against cycle efficiency for different turbine inlet pressures and resource temperatures. The various assumptions used in the analysis are listed in table 4.11.

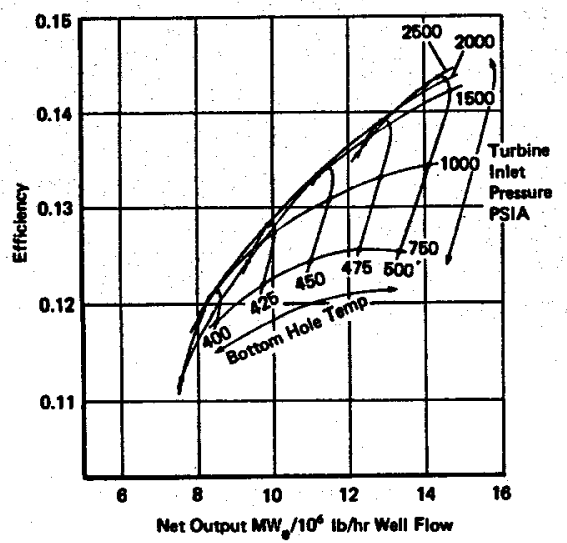

Fraure 4.60-Performance characteristics of brine/isobutane cycle. 


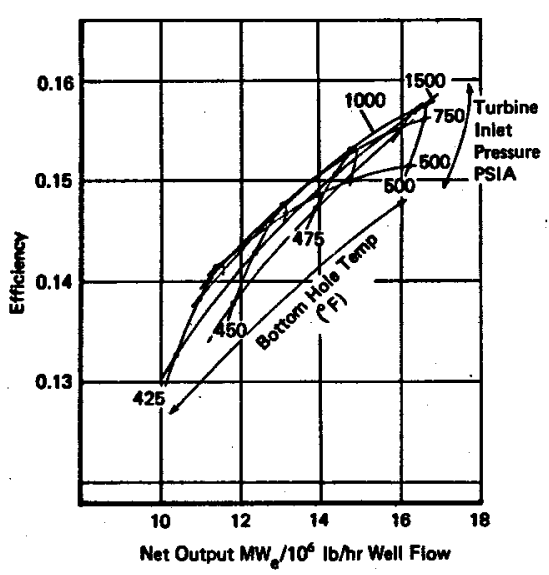

TABLE 4.11-List of specifications
FIGURE 4.61-Performance characteristics of brine/isopentane cycle.

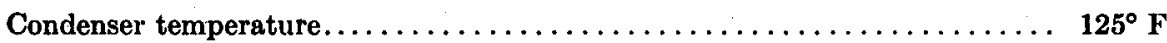

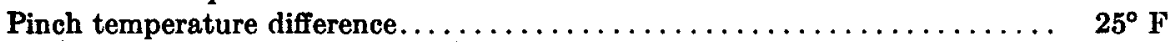

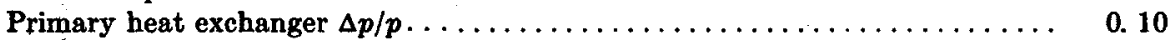

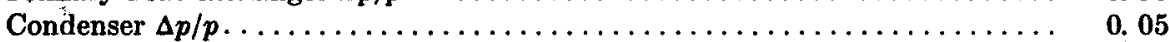

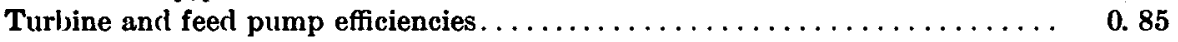

The use of fluorocarbons as working fluids is considered inappropriate for the temperature range considered since they can become unstable at temperatures much above $250^{\circ} \mathrm{F}$, especially in the presence of oil, steel, or copper, which act as catalysts for their chemical decomposition. For a comparison of their performance relative to other fluids, refer to 17 and 33.

It is evident from the two performance plots that there exists a single value of turbine inlet pressure (or pressure ratio) at which output is a maximum at a given resource temperature. However, for the temperature range considered, output changes very little with fairly wide variations in pressure about this optimum value. By maximizing output, the above calculations neglect, of course, all considerations regarding the condition of the expansion process. Ideally, the latter should remain dry to minimize droplet erosion damage in the turbine, and should also contain a minimum of superheat to reduce the cost of the heat rejection system. Also, the condition of minimum exhaust superheat should coincide with the condition of maximum output. This, in fact, is achieved with isobutane and isopentane at resource temperatures close to $400^{\circ} \mathrm{F}$ and $500^{\circ} \mathrm{F}$, respectively, as shown by the expansion lines in the pressure/enthalpy diagrams of figures 4.62 and 4.63 .

In the case of isobutane, the exhaust superheat increases with resource temperature on an almost equal basis. Clearly, if the expansion is to remain dry, some exhaust superheat is inevitable due to the shape of the saturation 


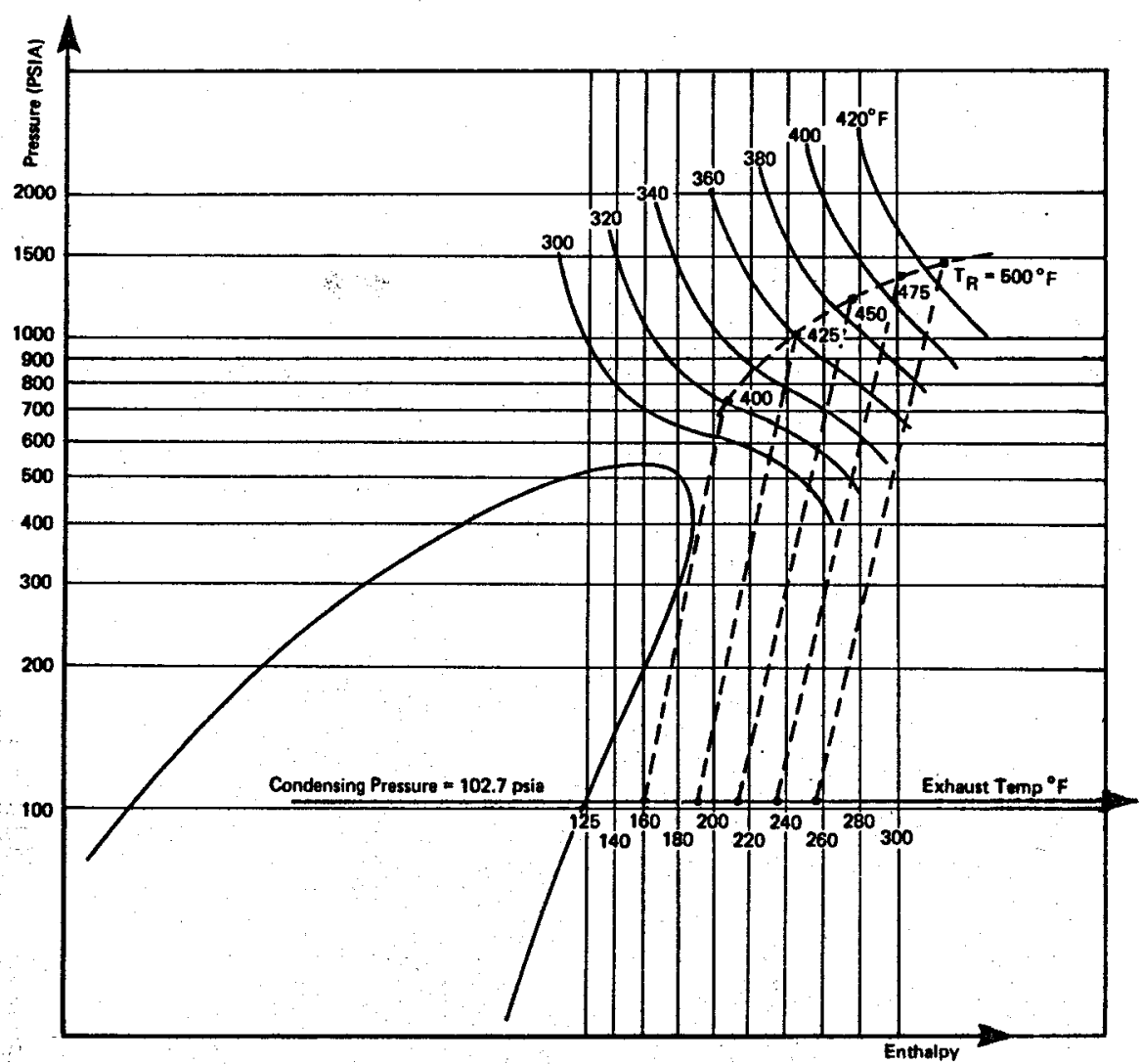

Fiaure 4.62-Pressure/enthalpy diagram for isobutane cycle.

dome. The minimum exhaust superheat for isobutane is approximately $35^{\circ} \mathrm{F}$, whereas for isopentane with its much higher critical temperature, it will be almost $100^{\circ} \mathrm{F}$. At resource temperatures below $490^{\circ} \mathrm{F}$, maximum output is obtained from isopentane with a partially wet expansion process. Again, there is almost a one-to-one ratio between the resource temperature and exhaust superheat.

If performance is compromised in favor of either reducing exhaust superheat in the case of isobutane or eliminating condensation in the case of isopentane, output will be as shown by the dashed lines in figure 4.64. The solid lines which show the maximum output are derived from figures 4.60 and 4.61 .

4.2.3.2 The Flash/Binary Cycle. The performance of the Flash/Binary Cycle depends, of course, on the number of flash stages employed. An increase in the number of stages simultaneously increases the cycle operating temperature, thereby increasing cycle efficiency, and decreases the temperature of the rejected brine, which increases the quantity of heat transferred 


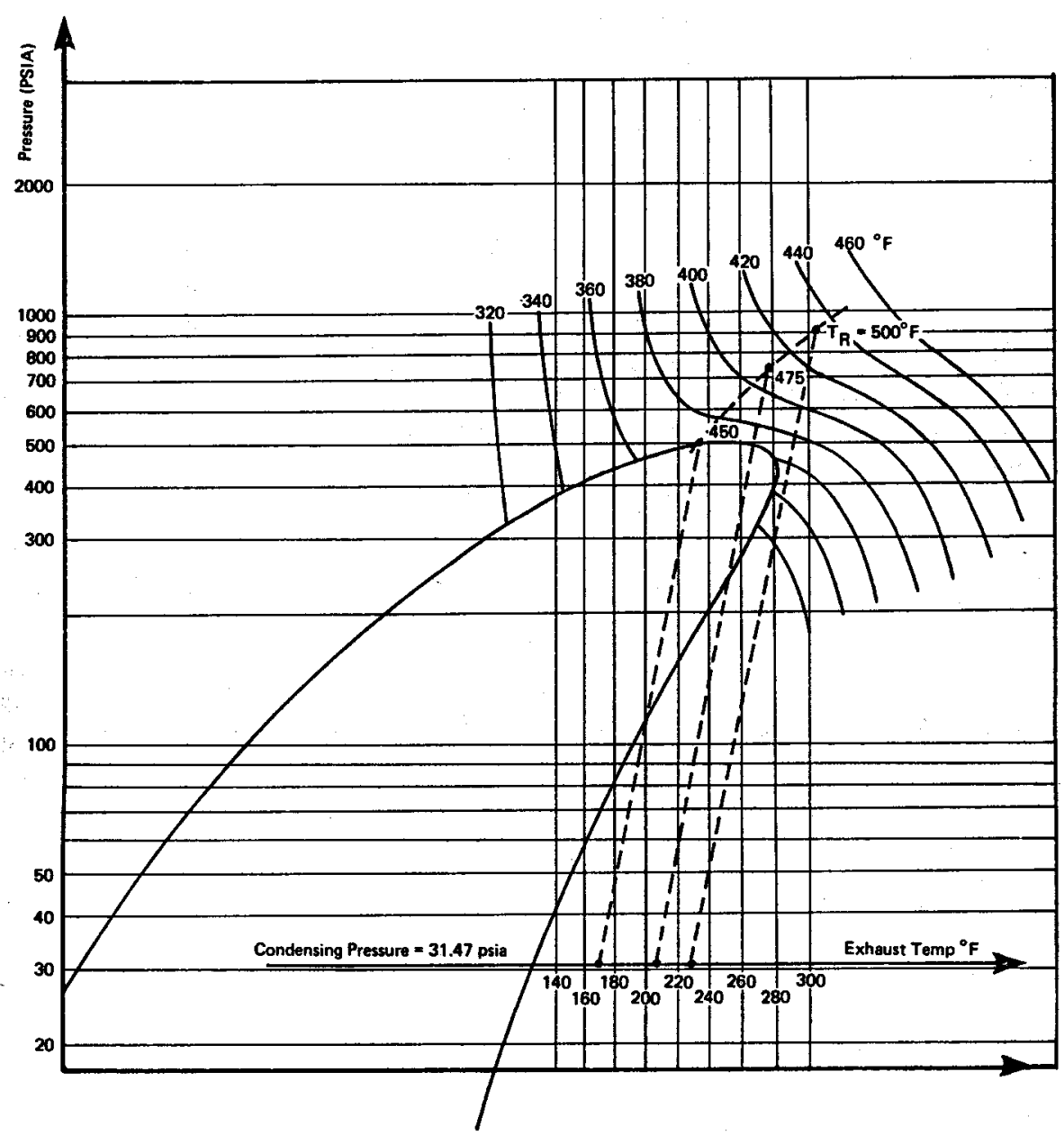

FrguRE 4.63-Pressure/enthalpy diagram for isopentane cycle.

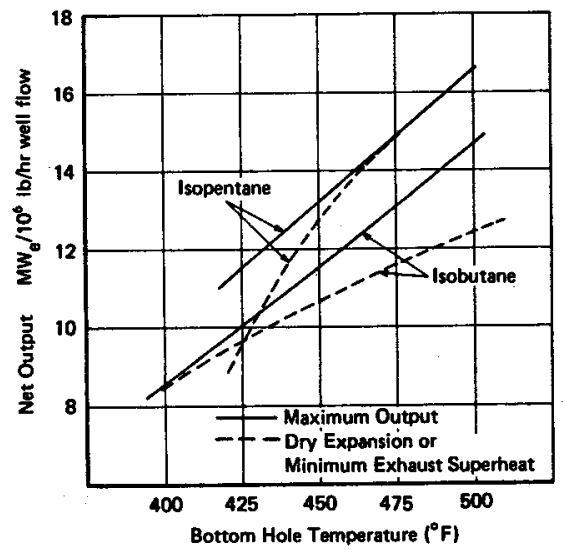

FIgUR 4.64-Output vs. bottom hole temperature for isobutane and isopentane brine/binary cycles. 
to the closed cycle. With a large number of flash stages, overall performance approaches that of the Brine/Binary Cycle. Unfortunately, such an arrangement is impractical. The large equipment required to accommodate the large specific volumes of steam at low flash temperatures, coupled with the fact that incremental performance gains diminish rapidly with additional stages, generally limit the number of flash stages to two. Under these conditions, output from the Flash/Binary Cycle will be approximately two thirds that from the Brine/Binary Cycle. Moreover, since large steam heat exchangers are used instead of compact brine units, the power is derived at considerably higher cost.

A schematic of a dual flash binary cycle is shown in figure 4.65. The organic compound circulates from the feed pump through the primary and secondary heat exchangers to the turbine and condenser. The primary steam which is condensed and subcooled is injected into the secondary heat exchanger where it mixes with secondary steam condensate at the same temperature. The condensate rejected from the cycle can be used as makeup for evaporation loss at the cooling towers. A temperature/enthalpy diagram for this process is shown by the solid lines in figure 4.66. In this case the resource is assumed to be free from gas and salt, and the organic cycle operates at supercritical pressure.

Thermodynamically, this dual flash heat transfer system is fairly complex. It has, in fact, four degrees of freedom-two more than in the case where liquid brine is utilized directly. Because of this added complexity, the calculations performed in this section do not optimize output as before, but instead fix conditions at entrance and exit of the overall heat exchanger process. A primary flash temperature is assumed and the temperature dif-

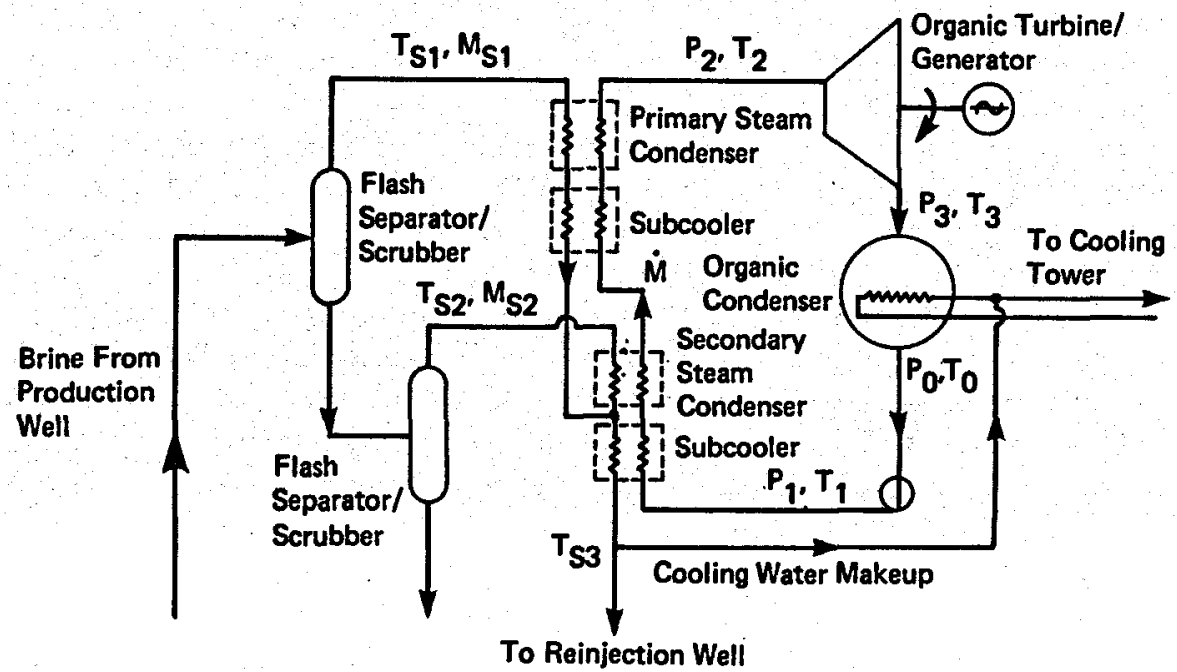

FIGURg 4.65-Schematic of dual flash/binary cycle. 


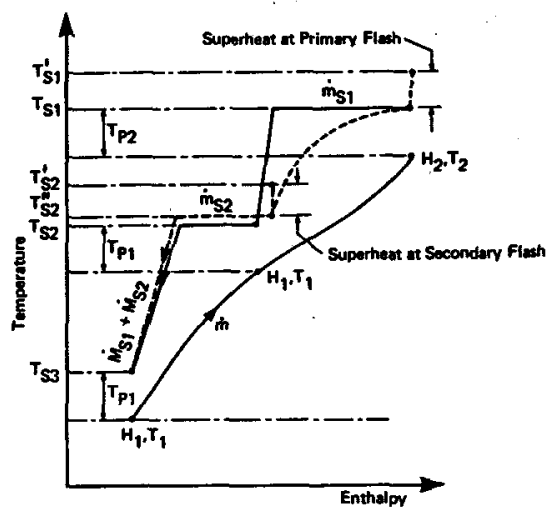

FrgURE 4.66-Temperature/enthalpy diagram for primary and secondary heat exchange processes in dual flash/binary cycle.

ferences between fluids at inlet and exit of each heat exchanger are all maintained at the minimum pinchpoint value.

In a dual fiash system, as with any multiple fiash arrangement, the second flash temperature is dependent upon the first. The energy balance in the primary exchanger

$$
\dot{m}_{s 1}\left(H_{f g 1}+\left(h_{s 1}-h_{s 2}\right)\right)=\dot{m}\left(H_{2}-H_{I}\right)
$$

must be compatible with that in the second exchanger

$$
\dot{m}_{s 2} H_{f g 2}+\left(\dot{m}_{s 1}+\dot{m}_{s 2}\right)\left(h_{s 2}-h_{s 3}\right)=\dot{m}\left(H_{I}-H_{1}\right)
$$

where $H_{f g}$ and $h$ refer to latent heat and sensible liquid enthalpy, respectively.

If the temperature difference between the two fluids at the junction between the two heat exchangers has some specified minimum value, then only the secondary flash temperature $T_{s 2}$ is unknown and can be established by iteration.

In this analysis, the temperature difference $T_{P I}$ between fluids at the intermediate point and the temperature differences $T_{P_{1}}$ and $T_{P_{2}}$ at entrance and exit of the overall heat exchange process were all assumed to be $25^{\circ} \mathrm{F}$. All other assumptions are as listed in table 4.11.

A typical performance plot for a dual flash binary cycle using $n$-butane as the working fluid is shown in figure 4.67. In this example, the resource is assumed to be at $450^{\circ} \mathrm{F}$. It is also assumed to contain no salt and no gas.

Unlike the dual flash steam turbine cycle, which exhibits optimum performance when the primary and secondary flash temperatures are more or less evenly distributed in the temperature interval between the source and sink, the dual flash binary cycle reaches peak performance at much lower flash temperatures. This is because the small reduction in cycle efficiency due to the lower operating temperature is more than offset by the increased flow of organic fiuid, which results from the increased yield of 
Frgure 4.67 - Performance characteristics of dual flash/N-butane cycle.

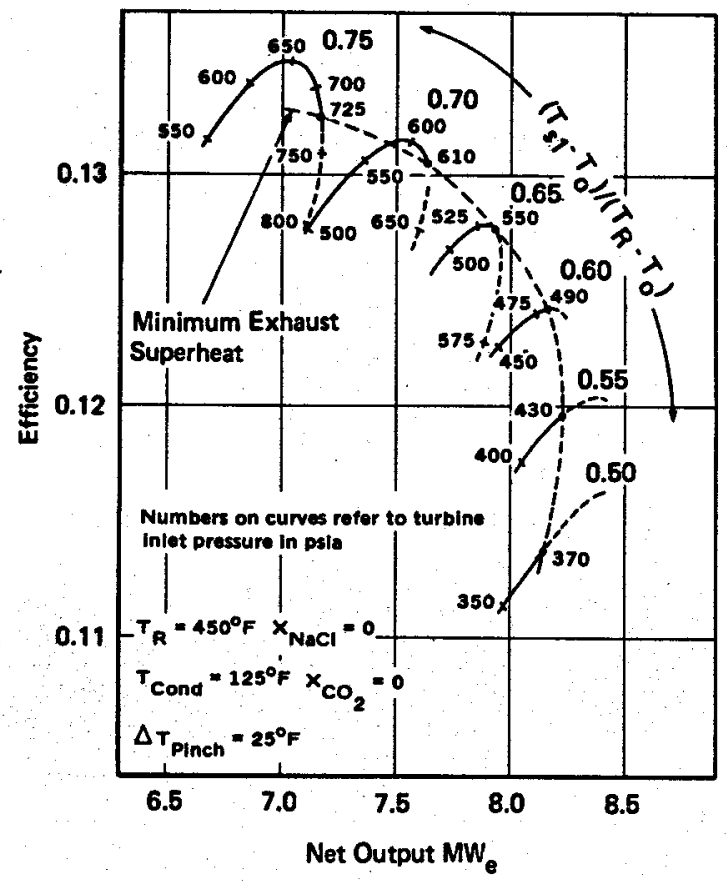

steam. The variation of cycle efficiency and steam and organic flow rates with primary flash temperature is shown in figure 4.68.

The dashed portion of each curve in figure 4.67 indicates a region in which the expansion process will be partially wet, and thus the point at

FraURe 4.68-Variations of steam and organic fluid mass flow rates and cycle efficiency with primary flash temperature.

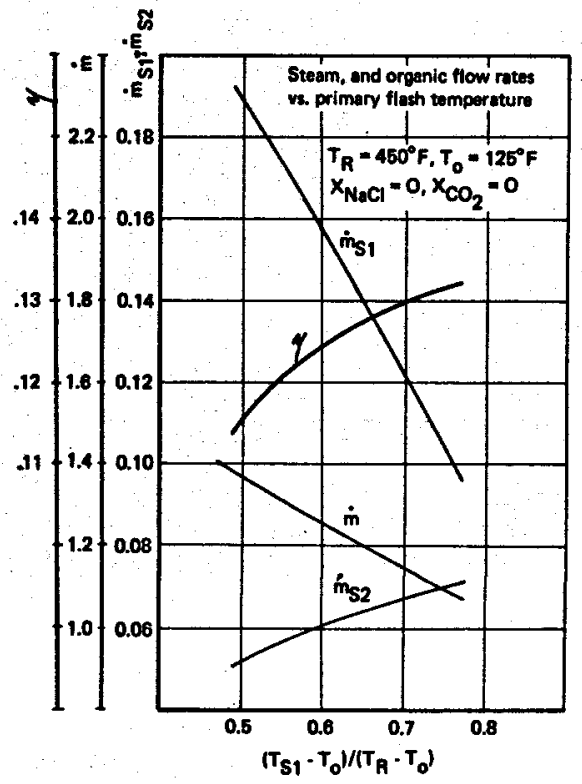


which the line becomes solid represents the condition where the expansion line lies tangent to the saturation curve. Any deviation from this point will either decrease quality or increase the degree of superheat.

At the higher primary flash temperatures, maximum output is obtained at more or less "ideal" operating conditions. At lower flash temperatures, output must be compromised in order to avoid condensation. Since the turbine inlet temperature falls with the flash temperature, so too does the operating pressure required to maintain a dry expansion. At the condition of maximum "permissible" output, the turbine inlet pressure is approximately 450 psia, which for $n$-butane is subcritical. The flash temperature ratio is 0.57 and, hence, the turbine inlet operates some $20^{\circ} \mathrm{F}$ below the critical temperature.

The performance of the $n$-butane cycle is compared with other working fluids operating with a dry expansion and minimum exhaust superheat in figure 4.69 for bottom hole temperatures ranging from 400 to $500^{\circ} \mathrm{F}$. Solid and dashed lines represent supercritical and subcritical operation respectively. Highest output is obtained from a subcritical n-butane cycle throughout the entire temperature range. The isobutane cycle, which generates approximately 7\% less output, operates at subcritical pressure up to a resource temperature of $460^{\circ} \mathrm{F}$ and at supercritical pressure at higher temperatures. Both propylene and propane, which generate considerably less output than either of the butane cycles, operate at supercritical pressure throughout, and because of their relatively low critical temperatures, with zero superheat in the turbine exhaust.

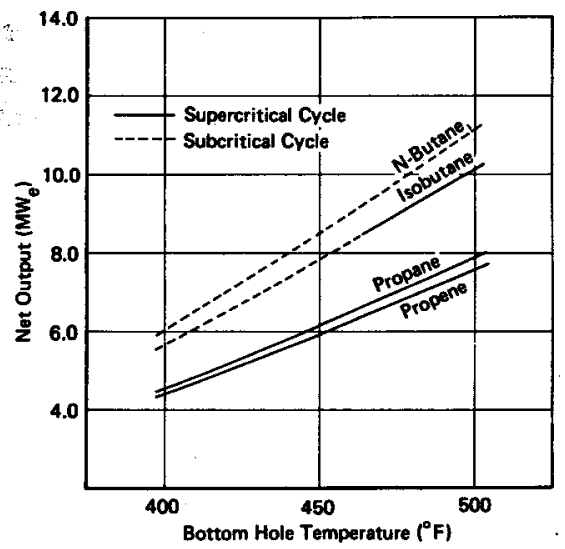

Frgure 4.69-Output vs. bottom hole temperature of dual flash/binary cycles.

\subsubsection{The effect of salinity and noncondensible gas on cycle performance}

The presence of salt in geothermal brines has two effects. First, it reduces the liquid specific enthalpy which degrades performance either through reduced heat exchange or reduced steam yield, and second it reduces the saturation pressure relative to temperature, so that steam which is in tem- 
FToure 4.70-Variation of steam superheat with flash temperature and salinity.

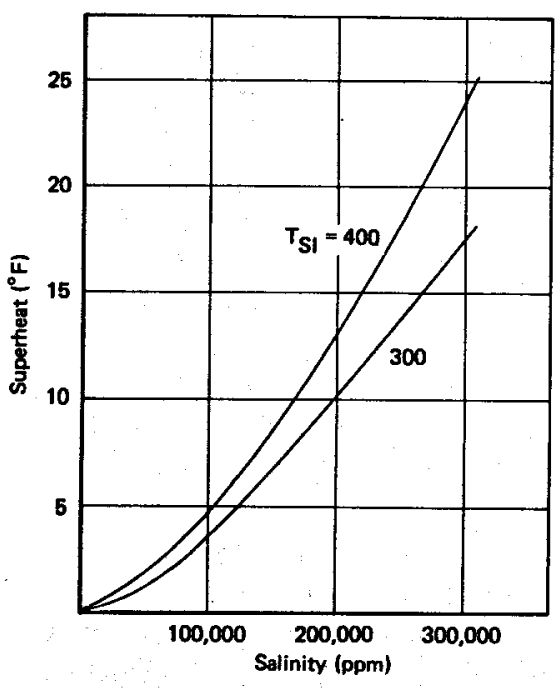

perature equilibrium with brine in the primary flash tank is initially superheated.

The relationship between steam superheat and salinity is shown for different temperatures in figure 4.70. Typically, steam flashed at $400^{\circ} \mathrm{F}$ from a resource containing $30 \%$ salt, will contain about $25^{\circ} \mathrm{F}$ of superheat. Compared to the latent heat of condensation, the enthalpy content of the superheat is small and it contributes very little to heating of the organic fluid as depicted in figure 4.66. Thus the temperature at the turbine inlet is dictated by the saturation temperature and not the superheat temperature of the primary steam. The overall effect of salinity on the performance of both the Brine/Binary Cycle and the Flash/Binary Cycle is summarized in figure 4.71. For salt concentrations up to $100,000 \mathrm{ppm}$, the effect on output is essentially the same for both cycles and output loss is approximately $1.5 \%$ for each percent of salt. For hypersaline brines, the performance loss is somewhat higher for the Flash Cycle than for the Brine Cycle.

FIGURE 4.71-Variation of cycle output with salinity.

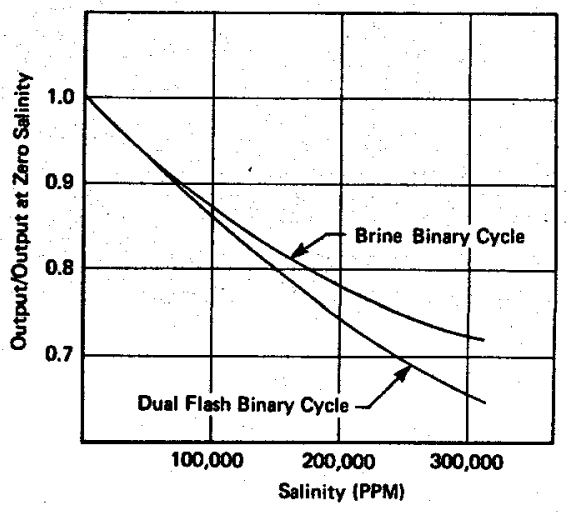


The performance of the Flash/Binary Cycle is further degraded by the presence of a noncondensible gas. Since the total pressure on the steam side of the heat exchanger will remain essentially constant, the reduction in steam mass due to condensation will cause the vapor pressure to fall, and the condensing temperature will fall also; the condensation process will, therefore, tend to follow the curved path depicted by the dashed line in the temperature/enthalpy diagram of figure 4.66. Clearly, the use of a supercritical organic cycle provides a better match with the condensation process than a subcritical cycle. The vapor which remains uncondensed at the primary heat exchanger exit at temperature $T_{82}$ is vented with the gas and is lost to the cycle. This vapor loss is, however, fairly small, and amounts to only about $4.5 \%$ of the total steam flow for $3 \% \mathrm{CO}_{2}$ in the brine. The fact that some vapor remains at the primary heat exchanger exit means that the secondary flash temperature will be greater than it would be with $\mathrm{CO}_{2}$ absent. This increase in the secondary flash temperature coupled with the vapor loss from the primary heat exchanger is responsible for the reduction in cycle output. The relationship between lost work and $\mathrm{CO}_{2}$ concentration for the $\mathrm{n}$-butane cycle described earlier operating on a $450^{\circ} \mathrm{F}$ resource is shown in figure 4.72. In this case, the output loss amounts to about $1 \%$ for each percent of gas.

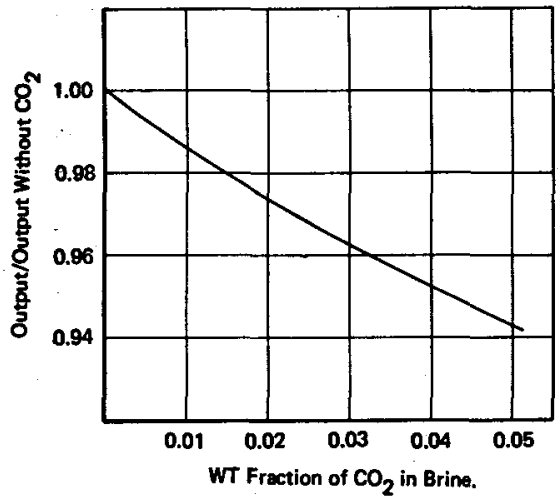

Figure 4.72-Variation of cycle output with $\mathrm{CO}_{2}$ constant.

4.2.4 Axial flow organic fluid turbines (By J. H. Eskesen and G. F. Kelley*)

The general design philosophy for axial flow organic fluid turbines is similar to that described for steam turbines in section 4.1.4. However, because the properties of organic compounds are considerably different from those of steam at the conditions of interest for geothermal applications, there will be some differences in their physical makeup. For example, the sonic velocity in an organic compound is approximately one half that in steam, thus the organic turbine of optimum design will either be one-half

*Both from Medium Steam Turbine Dept., General Electric Co., Lynn, Mass: 
the diameter of its steam counterpart or run at half its speed. Furthermore, organic fluid gas densities will be an order of magnitude greater than in steam while the work derived from an isentropic expansion will be an order of magnitude less. Hence, the mass flow rate required to produce the same output will be an order of magnitude greater with an organic fluid than with steam, although the volume flow rates will be about the same. The combination of high fluid density, short energy range and non-ideal nature of organic compounds emphasizes the need for careful design, especially in providing a minimum of pressure loss at the turbine inlet and exhaust.

The turbine electrical output can be expressed as:

where:

$$
E_{k v o}=\dot{m}\left(\eta_{i} \Delta H_{i s}-L_{e}\right) / 3412-L_{\text {rem }}
$$

$\dot{m}=$ turbine inlet mass flow rate $(\mathrm{lb} / \mathrm{hr})$

$\eta_{i}=$ turbine internal efficiency between entrance to the first stage (impact conditions) and the exhaust flange (static conditions) $\Delta H_{i,}=$ isentropic enthalpy drop between entrance to the first stage (impact conditions) and the exhaust flange (static conditions) $L_{s}=$ exhaust loss

$L_{\text {rem }}=$ aggregate of radiation, electrical and mechanical losses.

These terms were discussed in the previous section on steam turbines. In general, the discussion holds true for organic machines, although there are some exceptions.

The internal efficiency in this case can be expressed approximately as:

$$
\eta_{\imath}=0.9(1-7500 \mathrm{~N} / \dot{\mathrm{m}} \nabla)
$$

where $N$ is the number of parallel flows and $v$ is the specific volume at entry to the first stage.

The turbine exhaust loss is found by multiplying the total velocity head loss at the last stage and in the exhaust hood by the last stage internal efficiency (about 0.86 ). The leaving loss or energy leaving the last stage is calculated in the same manner described previously for steam turbines. The exhaust hood pressure loss incurred in moving fluid from the last stage to the exhaust flange will depend on the size of the exhaust hood, but will be approximately 0.3 to 0.5 times the velocity head at the exhaust flange. A third measure of loss is the exhaust flange velocity head itself which, depending upon its size relative to the leaving loss, may be used with the bood loss to define the total loss. If the exhaust flange velocity head is the larger, the exhaust loss is taken as the sum of the flange velocity head and the hood loss. If it is smaller, the exhaust loss will be the sum of the leaving loss and the hood loss. Where the leaving loss is subtantially greater than the flange velocity head, diffusing passages will be incorporated into 
the hood design. Generally, the gains from diffusing the exhaust flow tend to offset the hood loss and there is a net gain in performance. The leaving loss for a last stage designed for peak efficiency will be approximately 0.04 times the stage isentropic enthalpy drop.

4.2.4.1 Turbine configuration and stage design. If complex supersonic stage designs are to be avoided, the minimum number of stages will be obtained when the nozzle discharge velocity approaches the local sonic velocity. However, the number of stages is usually increased above the minimum requirement for two reasons. First, the reheat effect increases the enthalpy available to the stages, and second, the stage efficiences are usually improved due to the large passage areas and reduced relative velocities.

For highest efficiencies, the root diameter of all stages should be equal and, since there is generally poor leakage control at the root, the latter is normally designed with little or no reaction. Because the velocity ratio for peak efficiency increases with the degree of reaction, more reactive stages would require either larger root diameters or a larger number of stages. There is, of course, an upper limit to the number of stages actually employed. This is dictated by the maximum blade height to tip diameter ratio allowed and by the increased leakage losses which tend to offset and eventually exceed other gains.

The blade height to tip diameter ratio $\left(H_{B} / D_{P}\right)$ limits the annulus area per stage. The latter can be approximated reasonably well by assuming an axial leaving velocity equal to $20 \%$ of the stage isentropic velocity. Values of $H_{B} / D_{P}$ of 0.34 have been achieved in practice on some machines, although usually the ratio is kept below 0.25 to avoid having to design for complex three-dimensional effects.

Stage designs are, of course, also influenced by bucket stress limitation.s. Centrifugal stress is generally not a limiting factor because of the relatively low speed and/or the small stage diameters and blade heights. However, because the total turbine load is divided amongst relatively few stages, bucket root bending stress is of concern and is used to define the minimum bucket width, i.e.,

where

$$
W_{B}^{2}=\frac{26900 W_{S} H_{B}}{\sigma_{B} N\left(\frac{Z}{W_{B}^{2} t}\right) D_{P}^{2}\left(1-\frac{H_{B}}{D_{P}}\right)}
$$

$W_{B}=$ bucket width (in)

$W_{B}=$ stage loading in kilowatts

$B_{B}=$ bucket height (in)

$\sigma_{B}==$ bucket root bending stress (psi)

$N=$ shaft speed (rpm)

$Z=$ bucket section modulus

$t=$ bucket pitch (circumferential spacing, in)

$D_{p}=$ bucket pitch diameter (in) 
For estimating purposes, it may be assumed that $\sigma_{B}=5000$ psi and $Z / t W_{B}^{2}=0.02$. Actual values will depend on the particular manufacturer and the type of design.

The exhaust loss is determined by the design of the last stage and the type of exhaust hood. As noted previously, the magnitude of the velocity leaving the last stage compared to the velocity at the exhaust flange determines their relative contribution to the total loss. Depending on the design objective, advantageous changes may be possible which affect one velocity. without affecting the other.

Finally, the cost effectiveness of alternate designs should also be considered. The cost and overall performance of single flow machines should be compared with double-flow units. The large pressure losses at the turbine inlet and exhaust apply equally to the section of pipe between the turbine control valves and the heat exchangers and between the turbine exhaust flange and the condenser(s). Performance calculations for an $\mathrm{N}$ butane cycle in which the turbine inlet temperature and pressure were $310^{\circ} \mathrm{F}$ and $530 \mathrm{psia}$, respectively, show that a reduction of $1 \%$ in the pressure drop between the heat exchanger and turbine inlet results in an increase in turbine output of $1.1 \%$. Similar calculations show a $0.6 \%$ increase in output for a $1 \%$ decrease in exhaust pressure drop.

Since the volume flow rate is approximately the same for organic turbines and steam turbines with the same rating, the size of the inlet parts will also be about the same. However, because operating pressures are higher, the organic cycle requirement will be somewhat more expensive. Piping should be sized on a trial basis using a flow velocity in the range 50-70 fps. For the $\mathrm{N}$-butane cycle mentioned above, four velocity heads at $70 \mathrm{fps}$ are equivalent to a $3 \%$ inlet pressure loss. The pressure loss, of course, varies with the fourth power of pipe diameter and a tradeoff must always be made between performance loss and equipment cost. Since one size of pipe is likely to be used from the turbine inlet to the heat exchangers and also between the exhaust flange and condenser(s), the selection of turbine inlet and exhaust pipe size is of plant-wide importance.

4.2.4.2. Special design features. A cross sectional elevation of a $65 \mathrm{MW}_{\mathrm{e}}$, double-flow isobutane unit is shown in figure 4.73. Speed is $1800 \mathrm{rpm}$. Inlet conditions are 500 psia and $300^{\circ} \mathrm{F}$. Exhaust conditions range from 50 to 75 psia. The distance between bearing centerlines is $14^{\prime} 4^{\prime \prime}$. Inlet and exhaust openings are located in the lower half of the casing to minimize maintenance time during planned and unplanned outages. Although a hydrocarbon is used as the working fluid, steam turbine technology and steam path design philosophy are readily transferable to the organic gas path design.

Figure 4.74 shows the machinery arrangement. The turbine is supported from the foundation at both the front end and aft bearings. Another support is provided at the end of the generator. For this application, the 


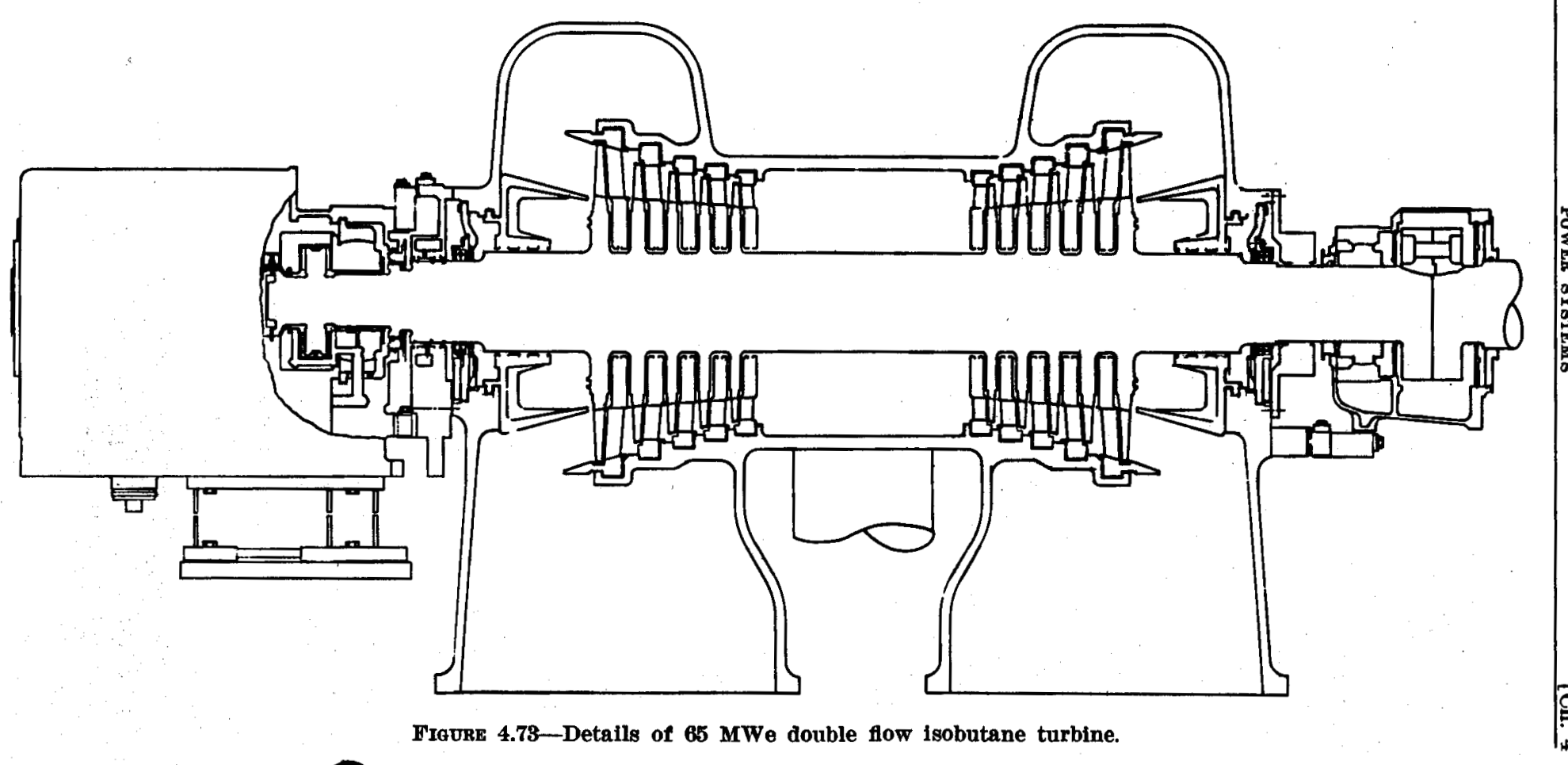




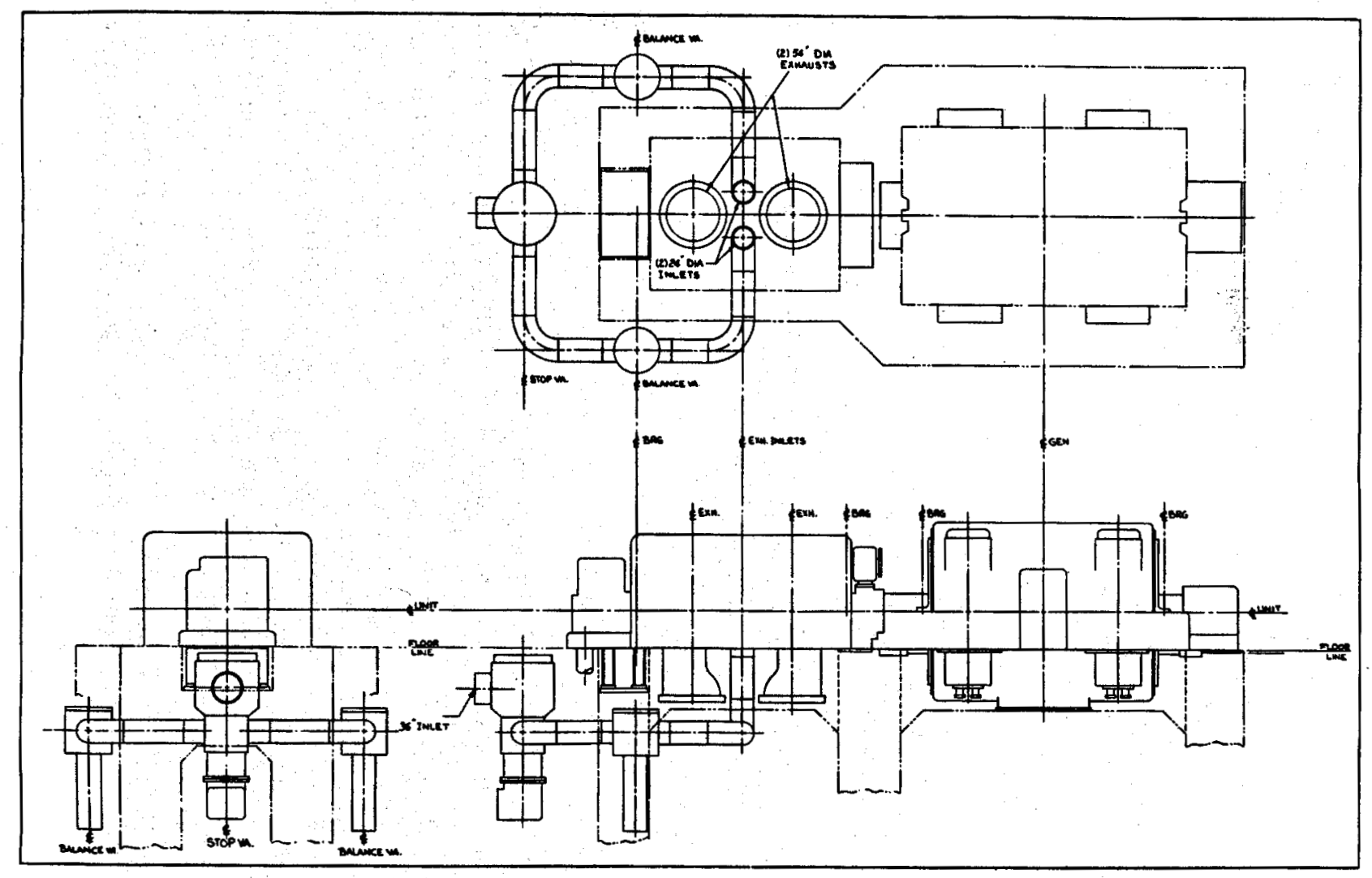

Froure 4.74-Details of turbomachinery layout for General Electric Company's proposition outline to San Diego Gas and Electric Company for a $65,000 \mathrm{~kW}$ turbine-generator. 
valving arrangement consists of a $36^{\prime \prime}$ stop valve with integral strainer, and two $24^{\prime \prime}$ balance-type valves. The generator is a 76,800 KVA hydrogen-cooled unit.

Sealing the hydrocabron gas in the turbine can be accomplished either with face seals or floating ring seals. Face seals (see figure 4.75, for example) consist of a spring-loaded carbon ring in contact with the rotating shaft. They have the advantage that relatively little sealing fluid is exposed to the turbine working fluid and no sealing fluid is required when the machine is shut down. A disadvantage is the finite life of the wear surface. Unlike other face seal designs which have a split construction, the face seal shown uses a solid carbon ring which requires some disassembly to service.

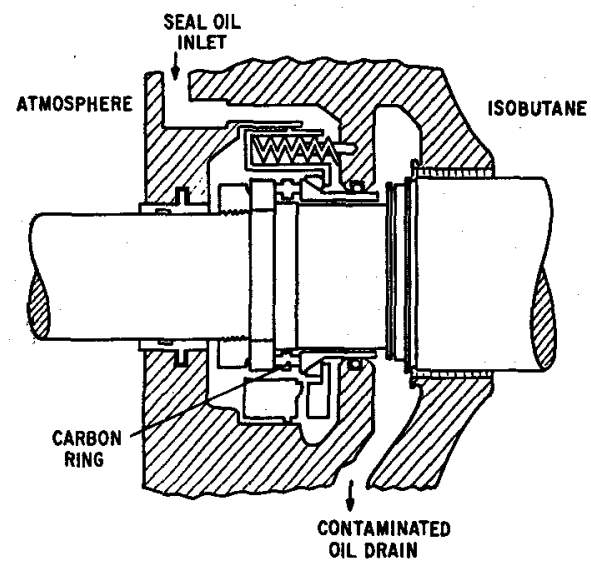

FigURE 4.75-Details of face seal.

The floating ring seal shown in figure 4.76 is the type regarded by G.E. as the most suitable for this particular application. In principle, the seal is similar to that used successfully on G.E.'s hydrogen-cooled generators for the past thirty years. Sealing is accomplished by a segmented bronze ring held against stationary retaining walls by a garter spring. Clearances $\left(C_{A}\right.$ and $\left.C_{I}\right)$ for a $14^{\prime \prime}$ diameter shaft are typically $0.003^{\prime \prime}$ and $0.015^{\prime \prime}$ for the gas side and air side, respectively. The major advantage of this design is its indefinite life and proven trouble-free performance. The main disadvantage is that relatively large quantities of sealing fluid are exposed to the turbine working fluid and sealing fluid pressure is required at all times including shutdown.

For the floating ring seal to be a viable candidate for this application, dissolved hydrocarbon must be efficiently separated in relatively large quantity from the sealing fluid. The detrainment system proposed by G.E. is shown in the schematic of the seal fluid system in figure 4.77. Under normal operation, seal fluid is pumped from a reservoir through a cooler and a filter to the hydrocarbon seals. A relief valve is used to recirculate excess seal fluid. The seal fluid flow is controlled by the differential pres- 


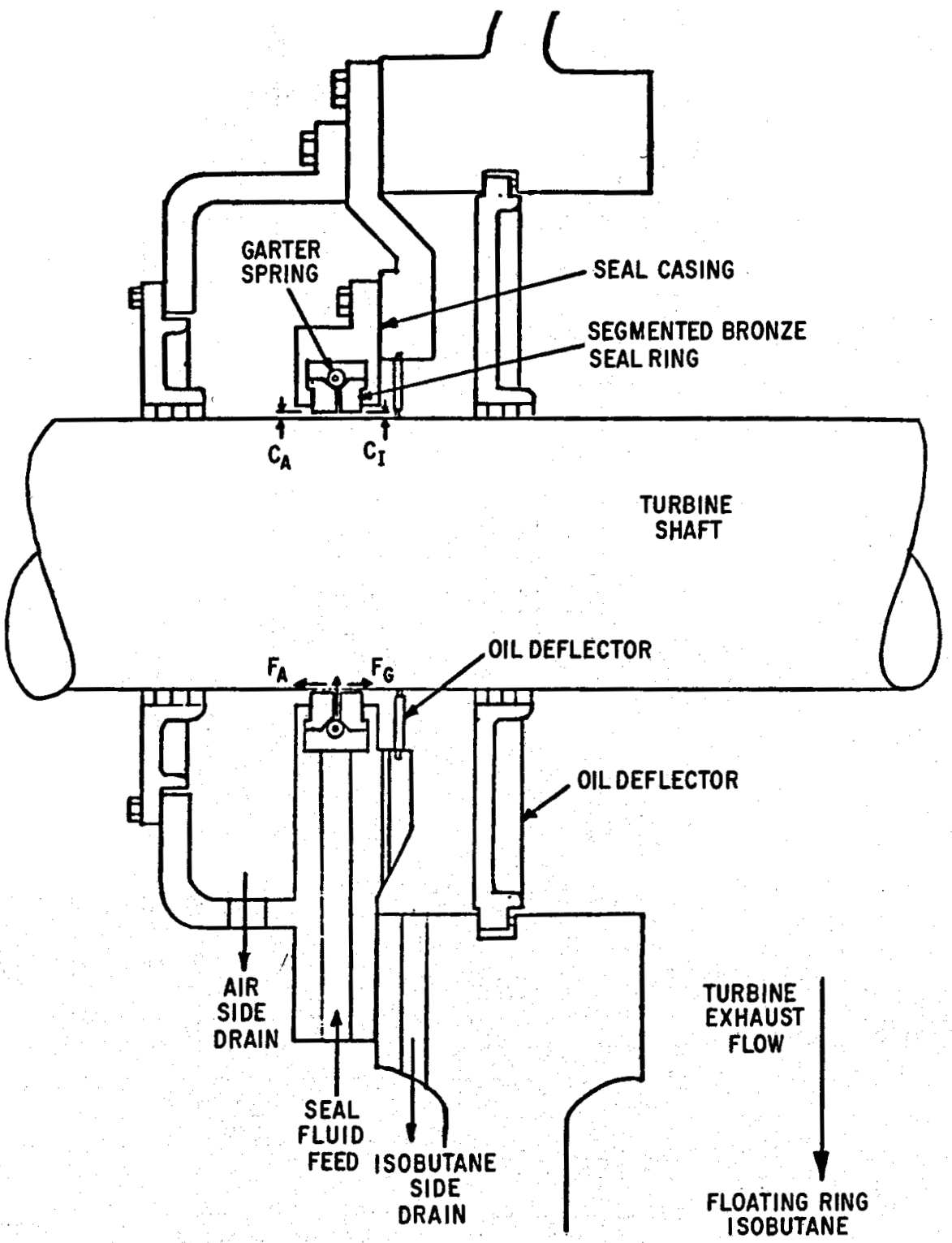

Fradre 4.76-Detalls of floating ring seal.

sure regulator which senses seal fiuid pressure and the hydrocarbon gas side pressure. During normal operation, seal fluid leaving the air side of the shaft seals is returned through a float trap directly back to the reservoir. Seal fluid passing to the hydrocarbon gas side of the seals enters a detraining chamber. Here a large surface area is provided which permits most of the isobutane entrained in the sealing fluid to pass to the seal chamber through the seal drain piping. 


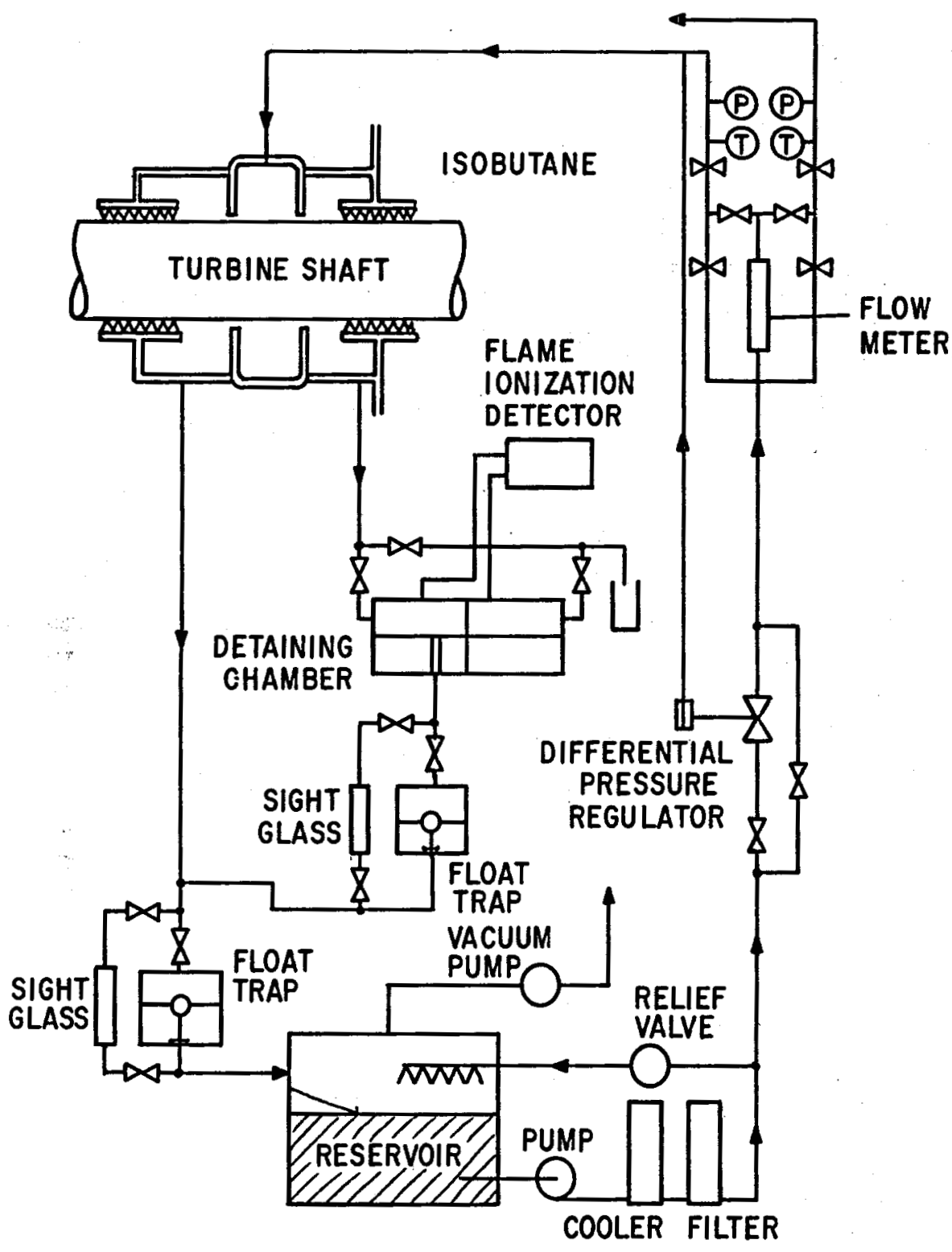

FrGURE 4.77-Detrainment systems for floating ring seal.

The detraining chamber is divided by a transverse partition into two equal sections, with the partition extending beneath the seal fluid operating level. A connection is located at the top of each section from which scavenged gas can be passed when required through a scavenged gas monitor. From the detraining chamber the hydrocarbon side seal fluid passes to a float trip which discharges seal fluid to the reservoir. With this ar- 
rangement, only periodic scavenging is required, since the reservoir utilizes a vacuum pump to remove trapped air from the seal fluid before it reaches the seals.

An aromatic phosphate ester can be used as the sealing fluid. It has fairly good lubricating properties, relatively low solubility in hydrocarbons and fairly rapid detrainment rates. Because rotating shaft seal designs are often sensitive to the sealing fluid, shaft speed, pressures, temperatures and working fluid to be sealed, a full-scale test of any seal should be performed to ensure reliability of the organic turbine.

\subsubsection{Brine heat exchangers (By R. H. Dart* and J. F. Whitbeck*)}

4.2.5. Geothermal fluid cycles and heat exchangers. The purpose of brine heat exchangers in a geothermal power system is to transfer the heat from the geothermal fluid to a secondary working fluid. Heat exchangers represent about $20 \%$ of the conversion system cost. Their selection and specifcation is one of the major tasks associated with the design of the power plant system.

The type of heat exchanger that is required for a specific power plant depends on the system design. The three different types of binary power cycles (a) saturated vapor cycle, (b) superheated vapor cycle, and (c) supercritical vapor cycle have been proposed for use in geothermal power systems. Within each of these types many variations are possible, again depending on the system design. For instance, a saturated vapor cycle might be designed to boil at two different pressure levels. Since many combinations are possible, only selected typical designs will be discussed to provide a basic review of heat exchangers as part of the geothermal cycle.

The saturated vapor cycle, shown schematically in figure 4.78, normally requires two separate heat exchangers, a preheater and a boiler (vapor generator). In the preheater the geothermal fluid heats the secondary working fluid to a temperature near that selected for vapor generation. The working fluid is next vaporized in the boiler. The saturated vapor from the boiler is then expanded in the turbine to produce power.

A superheated vapor cycle, shown in figure 4.79, is similar to the saturated vapor cycle, requiring both a preheater and a boiler. Additionally, a superheater is required in which the saturated rapor from the boiler is heated to a higher temperature at constant pressure. This superheated vapor is expanded in the turbine to produce power. Working fluids currently being considered for use in binary geothermal cycles, such as isobutane and pentane, tend toward increasing superheat when expanded in the turbine thus increasing the heat rejection requirements. The addition of superheat produces only small increases in the power output over the saturated vapor cycle due to lack of significant divergence of the lines

*Idaho National Hngineering Laboratory, Idaho Falls, Idaho. 


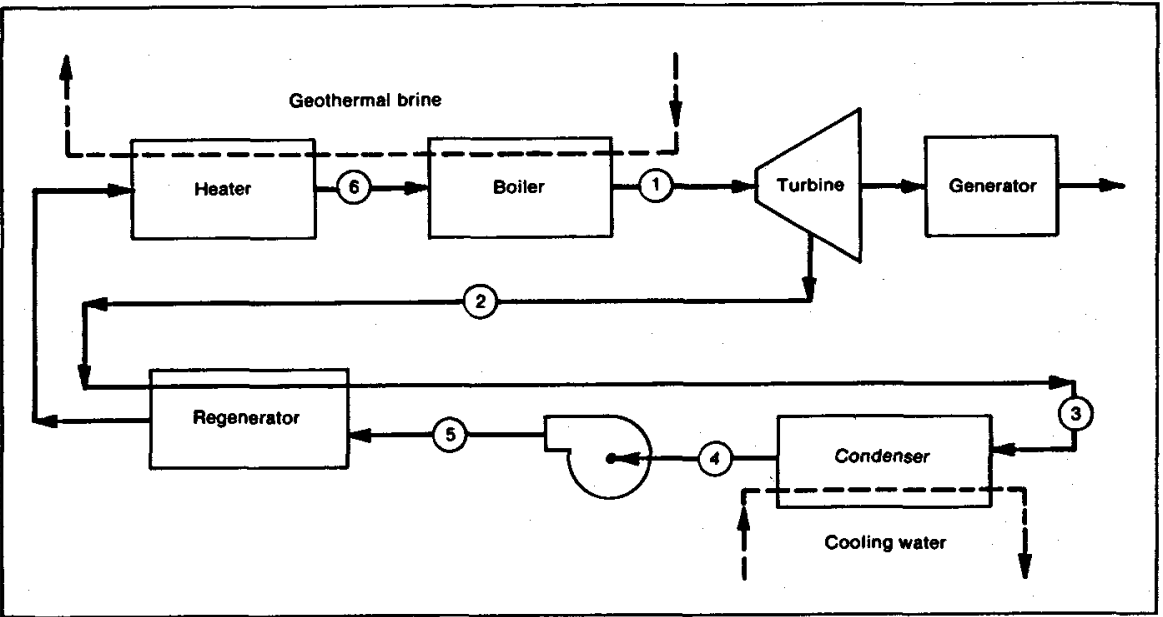

FiguRE 4.78-Saturated vapor cycle block diagram. 1=turbine inlet; $2=$ turbine outlet; $3=$ condenser inlet; $4=$ condenser outlet; $5=$ pump outlet, heater inlet; $6=$ boiler inlet.

of constant entropy (on a P-h diagram). Therefore, superheat cycles and hence the use of superheaters are not being considered for geothermal power cycles with the currently popular working fluids.

The supercritical vapor cycle, shown in figure 4.80 begins by pumping condensate from the condenser to a pressure higher than the critical pressure of the secondary working fluid. As the condensate liquid is heated, the specific volume changes. However, there is no phase change such as

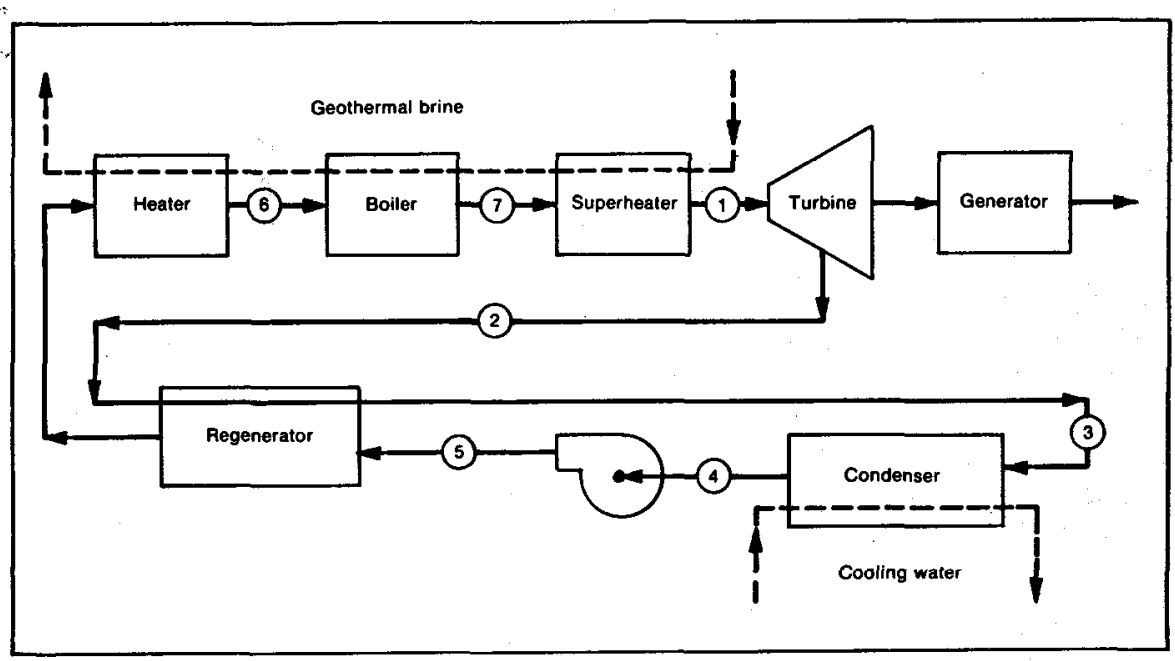

FraUke 4.79-Superheated vapor cycle block diagram. 1=turbine inlet; 2=turbine outlet; $3=$ condenser inlet; $4=$ condenser outlet; $5=$ pump outlet, heater inlet; $6=$ boiler inlet; $7=$ superheater inlet. 


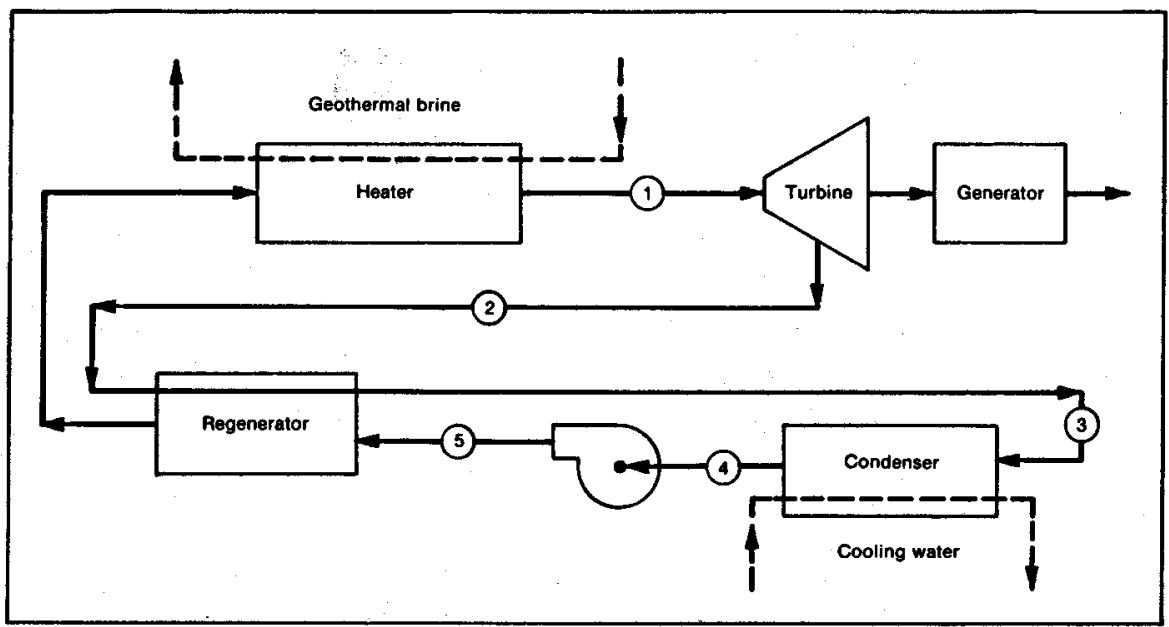

Figure 4.80-Supercritical vapor cycle diagram. $1=$ turbine inlet; $2=$ turbine outlet; $3=$ condenser inlet ; $4=$ condenser outlet ; $5=$ pump outlet, heater inlet.

occurs below the critical pressure. Since there is no distinct preheating and boiling as in the previous two cycles, the heat exchange equipment is different. In the supercritical cycle heat is transferred from the geothermal fluid to the high pressure secondary fluid, heating it to the maximum attainable temperature with the resource available. At this point, the secondary fluid is expanded through a turbine to produce power, as shown in figure 4.81 .

- Supercritical cycles may offer thermodynamic advantages as discussed in section 4.2.3 when used with brine temperatures above $400^{\circ} \mathrm{F}$. However, consideration must be given to the heat exchange equipment and the future degradation of the geothermal resource temperature. For most secondary working fluids, the required pressure would substantially increase heat exchanger and feed pump costs over either of the other cycles. The power requirement for the feed pump is also increased. Further, the temperature of the geothermal resource tends to decrease as it is used. Because of the design of supercritical heat exchangers, their performance would be severely degraded if an attempt was made to operate close to the saturation line when the resource temperature decreases. Thus, selection of the design operating conditions must address this possible decrease and provide an adequate degradation margin when specifying the supercritical heat exchangers.

In using the geothermal fluid, the fluid can be in either a vapor state or a liquid state. The first of these, the vapor state, is called a flash-binary system where the pressure on the geothermal fluid is reduced to below the saturation pressure at the temperature of the resource, therefore, producing a steam-water mixture. The steam is then separated from the water and directed to the heat exchangers. Multiple-flashes are used to stage the 


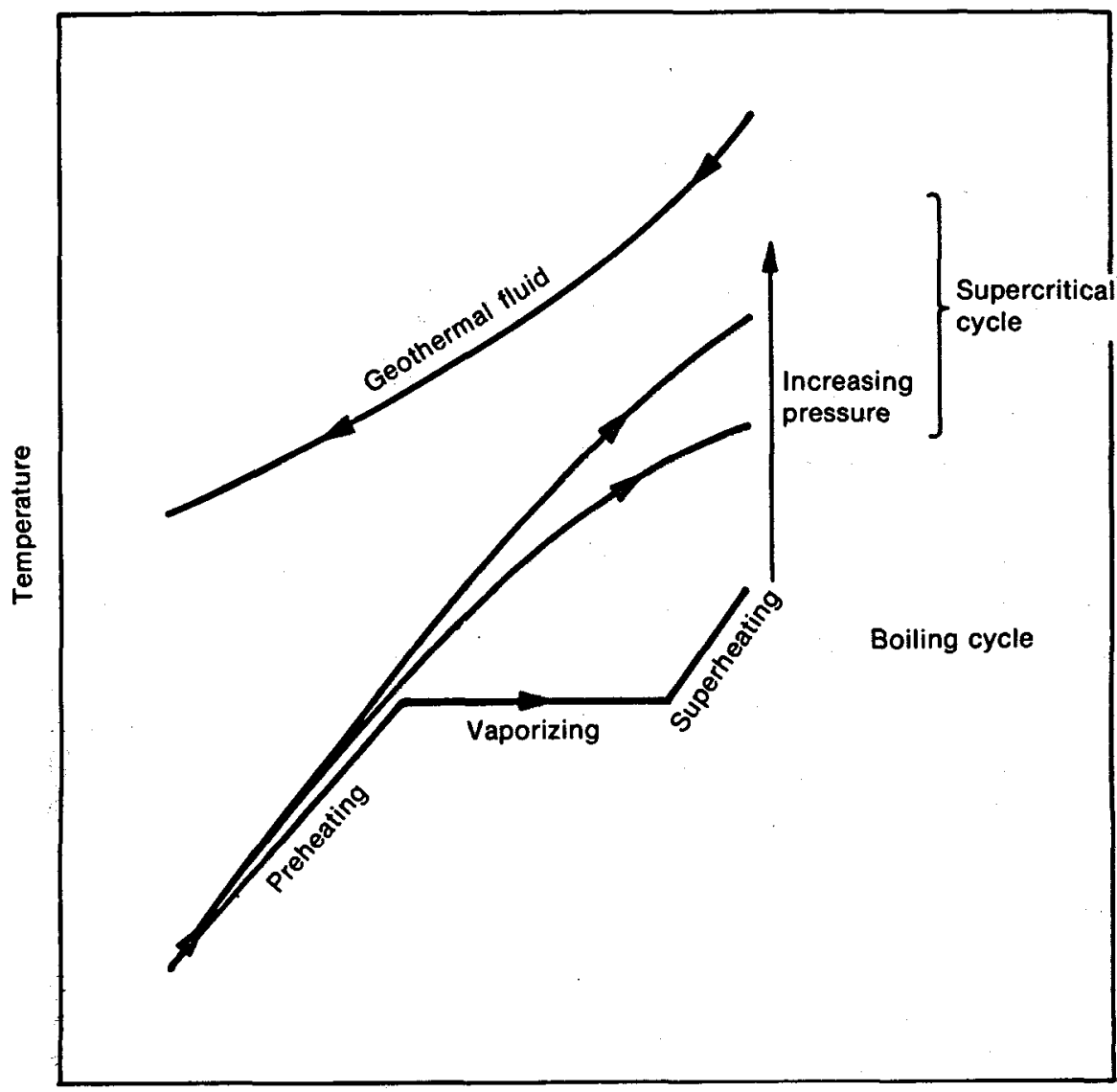

Length

FIGURE 4.81-Cycle temperature vs. length.

heating of the working fluid. In the liquid-binary system, the pressure is maintained on the geothermal fluid throughout the power cycle and heat is extracted from the geothermal fluid in the liquid state. The liquid geothermal fluid is directed through the heat exchangers where a portion of its heat is transferred to the secondary working fluid.

Geothermal heat exchanger size. Due to the inherently low thermal efficiency of binary geothermal power systems, the amount of heat to be transferred is large compared to the power output as shown by the following relationship.

Heat transferred to working fluid $=\frac{\text { Net power produced }}{\text { Thermal Efficiency }}$.

A typical binary geothermal power system has a thermal efficiency in the range of 8 to $15 \%$. With the above relationship, one can see that the amount of heat to be transferred is approximately 7 to 12 times the amount 
of power produced. In other thermal power plant systems, i.e., fossil and nuclear, this range is from $2 \frac{1}{2}$ to 4 times the power produced. Thus, the geothermal power plant consists predominatly of heat exchangers for heat addition and waste heat rejection.

Various studies have shown that a heat exchanger surface of about $15 \mathrm{ft}^{2} / \mathrm{kW}$ is required; thus, a $50 \mathrm{MWe}$ geothermal plant requires about $750,000 \mathrm{ft}^{2}$. Heat exchanger weights run in the range of 3 to $7 \mathrm{lb} / \mathrm{ft}^{2}$ of heat transfer surface making the total weight of the heat exchangers for a $50 \mathrm{MW}$ plant about $3.75 \times 10^{\circ} \mathrm{lbs}$. Thus multiple parallel units will be required to satisfy the heat exchange requirement and, because of the very large size of the units, the costs will be significantly affected. Further discussion of the limitations on heat exchanger specification is given in subsequent sections.

Heat exchanger types. Various types of heat exchange devices have been suggested for use in geothermal power plants. Some of these are listed below :

(1) Direct Contact Heat Exchangers.

(2) Plate Heat Exchangers.

(3) Drilled Block Heat Exchangers.

(4) Coil Tube Heat Exchangers.

(5) Panel Heat Exchangers.

(6) Shell-and-Tube Heat Exchangers.

(7) Fluidized Bed Heat Exchangers.

Direct contact and fluidized bed heat exchangers are currently under development and are discussed separately in this book. Plate and panel heat exchangers, although very efficient, are limited to pressures much less than those encountered in the geothermal power systems and, therefore, are not currently being considered. Drilled block and coil tube heat exchangers are not made in the sizes required for a geothermal power plant. This leaves only the shell-and-tube heat exchanger as the currently most viable unit for use in geothermal Rankine cycle power plants. The shell-and-tube units required for the geothermal power application are very similar in almost all respects to units being provided by the heat exchanger industry to the petrochemical and other process industries.

4.2.5.2. Review of heat exchanger design principles. The design and specification of process heat exchangers is well covered in the literature and in standard heat transfer texts. Recommended sources are Kern's Process Heat Transfer(34) and Perry's Chemical Engineering Handbook(35). This section will, therefore, provide only a brief review of the principles and present typical equations which are in common use. Normally, heat exchangers are specified by the design agency which, depending upon their capability or experience, will either leave the design completely to the heat exchanger manufacturer or will specify the thermal design in some detail to ensure that system operating conditions are satisfactory or that the desired physical plant arrangements are achieved. 
A rough preliminary estimate of the heat exchanger size and performance is required for trade-off studies during the plant design, to provide a means of estimating capital equipment costs, and to check off design point performance of the power plant.

Design procedure outline. The design of heat exchangers generally is accomplished by following the steps listed below:

(1) Establish the desired process conditions (fluids involved, mass flow rates, pressures, inlet and outlet temperatures, or quality) from cycle performance and cost studies.

(2) Determine the geothermal fluid and the secondary working fluid properties for the temperature and pressure ranges of interest.

(3) Obtain the rate at which fouling occurs for both fluids, establish the required velocity range, and estimate the design fouling factor.

(4) Establish which fluid is to be on the inside of the tube (tube side) with the other being on the outside of the tube (shell side). Normally, if fouling is expected, the geothermal fluid would be put inside the tubes to facilitate cleaning.

(5) Calculate the amount of heat to be transferred from the process conditions.

(6) Make a preliminary estimate of the surface area required to transfer the amount of heat using the heat-transfer coefficient calculated for both of the fluids.

(7) Determine an initial configuration (tube length, number of tubes, number of passes, tube pitch bundle diameter, baffle type and spacing, etc.) to meet the required process conditions.

(8) Evaluate the capability of the initial configuration to fulfill the required fluid conditions (pressure drop, velocity) and heat transfer.

(9) Use the results of this evaluation to modify the configuration as necessary to meet all process conditions.

(10) Perform trade-off studies (velocity versus pressure drop, pressure drop versus heat exchanger area, etc.) to obtain the optimum configuration.

(11) Check final configuration to meet all the process conditions at the lowest possible cost.

Calculation of area requirements. (1) Heat exchange duty. The nominal process conditions necessary for both the geothermal fluid and the secondary working fluid are established from cycle performance and cost studies.

The heat exchange duty $q$ is derived from the process conditions as given by

$$
q=\dot{m} \Delta h
$$


The specific heat of liquid geothermal fluids is fairly constant over the temperature range normally encountered, however the specific heat of organic fluids may vary considerably. For a fluid where the specific heat can be assumed constant through the range of interest this relationship can be expressed by

$$
q=\dot{m} C_{p} \Delta T
$$

where the specific heat $C_{p}$ is the average specific heat. This relationship is satisfactory in a limited temperature range for most fluids which do not experience a change of phase such as preheating or superheating. However, $C_{p}$ varies greatly when the fluid is heated above the critical pressure and, therefore, cannot be taken as a constant or even as an average over the whole range of temperature change.

In a flash-binary system the amount of heat to be transferred is calculated using

$$
q=\dot{m}_{s}\left(h_{f g}\right)_{s}\left(X_{I}-X_{o}\right) .
$$

(2) Heat transfer surface area $\left(A_{0}\right)$. Once the amount of heat to be transferred in a heat exchanger has been determined, the next step is to calculate the amount of heat exchange surface area required to accomplish this transfer. The equation that defines this area is given below:

$$
q=U_{0} A_{0} \Delta T_{\mathrm{LM}} \quad \text { or } \quad A_{0}=\frac{q}{U_{0} \Delta T_{L M M}}
$$

The total overall heat transfer coefficient $U_{o}$ and the heat exchange surface area $A_{o}$ are both referenced to the surface on the outside of the tubes in Equation (4.58).

(3) Logarithmic mean temperature difference $\left(\Delta T_{L Y}\right)$. The logarithmic mean temperature difference $\Delta T_{L M}$ is obtained by integration of the differential equation $d q=U_{0} d A_{0} \Delta T$ over the length of the heat exchange path with the following assumptions:

(a) Steady state operation.

(b) Pure cocurrent or countercurrent flow along all tubes.

(c) Overall heat transfer coefficient is constant.

(d) Constant specific heat.

(e) Negligible heat loss.

Figure 4.82 is a plot of the temperature of the two fluids versus the length along the heat exchanger. This is a representative example of temperature versus length in a binary geothermal system. As can be seen from this figure, the available temperature difference between the geothermal fluid and the secondary working fluid is quite limited. In other thermal power systems temperature differences are generally much larger. This leads to the fact that the logarithmic mean temperature difference $\Delta T_{L I}$ 


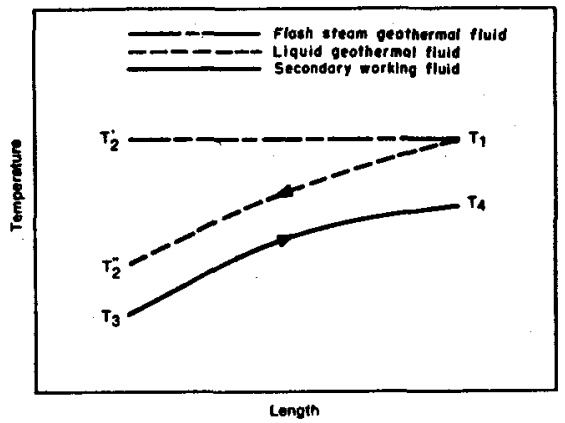

FIGURE 4.82-Preheater temperature vs. length.

is quite small. For ideal countercurrent or cocurrent flow the method for calculating this difference is as follows

$$
\Delta T_{L M}=\frac{G T T D-L T T D}{\ln \left[\frac{G T T D}{L T T D}\right]}
$$

where

$\Delta T_{L K}=$ Logarithmic mean temperature difference.

$G T T D=$ Greater terminal temperature difference.

$L T T D=$ Lesser terminal temperature difference.

Referring to figure 4.82 the-logarithmic mean temperature difference is

$$
\Delta T_{L M}=\frac{\left(T_{2}-T_{3}\right)-\left(T_{1}-T_{4}\right)}{\ln \frac{\left(T_{2}-T_{3}\right)}{\left(T_{1}-T_{4}\right)}} .
$$

The value of $\Delta T_{L u}$ calculated by the above equation assumes ideal countercurrent, cocurrent, or a change of phase of one of the fluids. In actual practice multipass units with partial crossflow are often required to meet all the process requirements. Correction factors must be applied to the logarithmic mean temperature difference. For most flow configurations the correction factor $F_{T}$ has been developed, as shown in figure 4.83 as a function of the terminal temperatures. The equation defining the heat exchanger that allows partial crossflow is

$$
q=U_{0} A_{0} F_{T} \Delta T_{L M}
$$

When the correction factor falls below 0.8 , other flow patterns should be considered because of the rapid change in $F_{T}$, that might be encountered if actual operating conditions did not conform exactly to the design point.

(4) Overall heat transfer coefficient $\left(U_{o}\right)$. The overall heat transfer coefficient $U_{0}$ is the reciprocal of the summation of the various resistances to heat transfer, as shown

$$
\frac{1}{U_{0}}=R^{\prime}{ }_{1}+R^{\prime}{ }_{2}+R^{\prime}{ }_{8}+R^{\prime}{ }_{4}+R^{\prime}{ }_{5}+\ldots+R_{n}^{\prime} .
$$



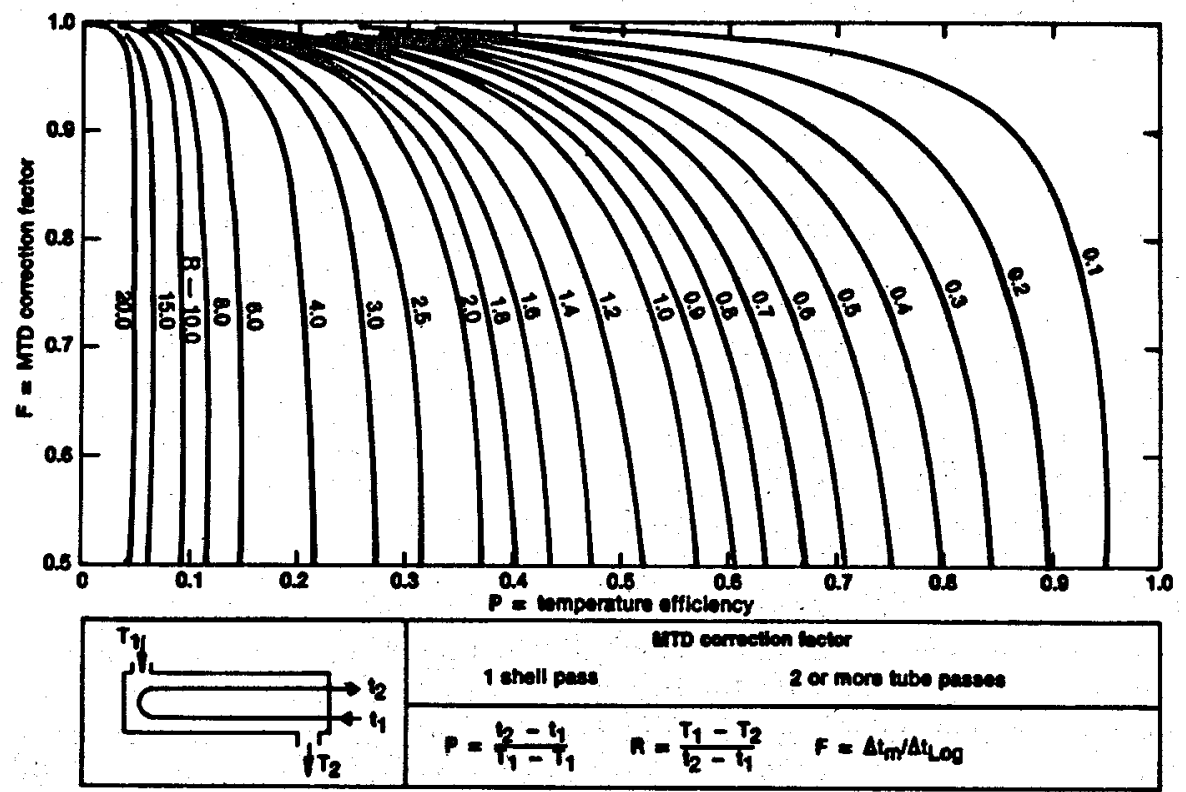

FraURE 4.83-Heat exchanger correction factor for shell-and-tube type exchangers having one shell pass and two or more tube passes.

Generally five resistances exist in a heat exchanger. Starting with the inside and referring each resistance to the outside surface area, these five are defined as

$$
\begin{aligned}
R^{\prime}{ }_{1} & =\text { Inside film resistance } \\
& =\frac{1}{h_{t}}\left(\frac{A_{o}}{A_{t}}\right) \\
R^{\prime}{ }_{2} & =\text { Inside fouling resistance } \\
& =r_{t}\left(\frac{A_{o}}{A_{t}}\right)
\end{aligned}
$$

$R_{8}^{\prime}=$ Tube wall resistance

$$
=\frac{D_{0}}{2 k_{w}} \ln \left(\frac{D_{o}}{D_{t}}\right)
$$

$$
\begin{aligned}
R^{\prime} & =\text { Outside fouling resistance } \\
& =r_{0} \\
R^{\prime} & =\text { Outside film resistance } \\
& =\frac{1}{h_{0}} .
\end{aligned}
$$


The resulting equation for the total resistance $R^{\prime}{ }_{T}$ referred to the outside area is

$$
\frac{1}{\bar{U}_{0}}=R^{\prime}{ }_{T}=\frac{1}{h_{i}}\left(\frac{A_{0}}{A_{i}}\right)+r_{i}\left(\frac{A_{0}}{A_{i}}\right)+\frac{D_{o}}{2 k_{w o}} \ln \left(\frac{D_{0}}{D_{i}}\right)+r_{0}+\frac{1}{h_{o}} .
$$

In most standard shell-and-tube heat exchangers the geothermal fluid is on the tube side with the secondary working fluid on the shell side; this assumption is made in the following discussion of equation 4.68. For most geothermal fluids the value of the inside fouling resistance $r_{i}$ is not known and must be assumed for the calculation or obtained from test data and other trade-offs. Many geothermal fluids may have a tendency to foul quite readily; therefore, the assumed fouling resistance may be quite large compared to the other resistances. Not having more accurate information available, the "typical" range of the fouling resistance $r_{i}$ is from $1.8 \times 10^{-4}$ to $7.0 \times 10^{-4} \mathrm{~K} \cdot \mathrm{m}^{2} / \mathrm{W}\left(0.001\right.$ to $\left.0.004 \mathrm{~h} \mathrm{ft}^{2 \circ} \mathrm{F} / \mathrm{Btu}\right)$ fluids. A more thorough examination of this resistance is included in a later section of this chapter.

The value of the outside fouling resistance $r_{o}$ is determined by the secondary working fluid used in the cycle. Most fluids available for this type of service do not foul readily and thus offer a small fouling resistance to heat transfer. The fluids being considered, i.e., the fluorocarbons and hydrocarbons generally have a resistance value in the range of 0 to $1.80 \times$ $10^{-4} \mathrm{~K} \cdot \mathrm{m}^{2} / \mathrm{W}$ ( 0 to $0.001 \mathrm{~h} \mathrm{ft}^{20} \mathrm{~F} / \mathrm{Btu}$ ).

The wall resistance is determined by the thickness of the wall and the tube material. For most preliminary calculations this resistance can be neglected. However, it should be included in the final sizing of the heat exchanger or when extended surfaces are being considered.

The inside film coefficient $h_{i}$ is unique to the type of system to be used, i.e., flash-binary or liquid-binary. In the flash-binary system steam is condensed on the inside of tubes to transfer heat to the secondary working fluid. The steam is likely to contain minerals which will foul the heat exchanger; therefore, steam scrubbers are normally used on the flash-binary system.

The treatment of condensation inside or outside tubes is complicated by the need to determine the controlling forces on the film, either gravity or vapor shear. In addition, all geothermal fluids contain dissolved gas, some in excess of $1 \%$ by weight. Since much of this gas is released when flashing occurs, the flashed steam may contain a significant amount of noncondensable gases which are known to reduce condensing heat transfer coefficients since the water vapor must diffuse through the noncondensable gas to reach the tube surface.

Detailed determination of the required heat transfer area when noncondensable gas is present requires a step-wise calculation procedure such as the one originated by Colburn and Hougen (36). Most methods currently used are modifications of this original method to simplify the calculation. Kern (34) provides details of the calculational procedure. 
Rohsenow and Hartnett(37) provide a brief outline of the procedure as modified by Votta(38) and in addition give a comparatively simple procedure for estimating the condensing film coefficient which yields conservative results. In some geothermal areas the amount of noncondensables is very small or significant amounts can be removed by preflashing the geothermal fluid before flashing the steam for heat exchanger use. Tradeoff studies are required that compare the penalty of the preflash to the improved heat transfer. If design fouling factors are large, it is doubtful if removal of noncondensables by preflashing will be practical unless extremely large amounts of noncondensables exist.

Where the steam does not contain significant noncondensables, the condensation coefficient may be computed from several available correlations. When vapor shear is not controlling, the Dukler theory summarized in Perry's Chemical Engineering Handbook (35) or the formulation of Hartnett et al. given in the Handbook of Heat Transfer by Rohsenow and Hartnett(37) may be used. Both of these references also provide means to estimate the condensation coefficient when vapor shear is controlling. Collier (39) also provides a detailed treatment of the enhancement in heat transfer by vapor shear. An approximate value of the condensing film coefficient can be obtained from the following equation if the shear forces dominate the film flow and insignificant amounts of noncondensable gases exist $(40)$.

$$
h_{i}=\frac{k_{L}}{D_{i}}(0.024)\left(\frac{D_{t} G_{T}}{\mu_{L}}\right)^{0.8}\left(\frac{C_{p \mu}}{K}\right)_{L}^{0.43} \frac{\left(\frac{\rho}{\rho_{m}}\right)_{t}^{0.5}+\left(\frac{\rho}{\rho_{m}}\right)_{o}^{0.5}}{2}
$$

where

$$
\begin{aligned}
& G_{T}=\text { Total mass velocity } \\
& \left(\rho / \rho_{m}\right)_{t}=1+\frac{\rho_{L}-\rho_{v}}{\rho_{v}} X_{t} \\
& \left(\rho / \rho_{m}\right)_{0}=1+\frac{\rho_{L}-\rho_{v}}{\rho_{v}} X_{0} .
\end{aligned}
$$

For a liquid-binary geothermal system the value of the inside film coefficient $h_{t}$ is calculated using the following correlation from SiederTate(41).

$$
h_{t}=\frac{k_{L}}{D_{i}}(0.027)\left(\frac{D_{i} G_{T}}{\mu_{L}}\right)^{0.8}\left(\frac{C_{p} \mu_{L}}{k_{L}}\right)^{1 / 3}\left(\frac{\mu_{b}}{\mu_{w}}\right)^{0.14}
$$

The outside film coefficient will be discussed later in this chapter when the particular types of heat exchangers, i.e., preheater, boiler, and superheater are defined in detail.

When all of the resistances are known, substitution into the equation for the overall heat transfer coefficient will result in obtaining its value. For most geothermal systems the overall heat transfer coefficient is small 
relative to other thermal power system heat exchangers, typically the value ranges from 300 to $3000 \mathrm{~W} / \mathrm{m}^{2} \cdot \mathrm{K}$ (50) to $500 \mathrm{Btu} / \mathrm{h} \mathrm{ft}{ }^{\circ}{ }^{\circ} \mathrm{F}$ ).

Considering the above discussion and the (a) large amounts of heat to be transferred, (b) limited logarithmic mean temperature difference, and (c) small overall heat transfer coefficient imply that there are very large heat transfer surface area requirements for the heat exchangers in a binary geothermal power system.

This very brief introduction into the basic heat transfer in geothermal systems leads into a discussion of the types of shell-and-tube heat exchangers employed to accomplish these tasks.

4.2.5.3 Heat exchangers. Standard shell-and-tube heat exchangers. Standard shell-and-tube heat exchangers are generally a cylindrical shell with multiple tubes running inside the shell. Figure 4.84 shows the typical components of a standard shell-and-tube heat exchanger. One fluid passes through the tubes and out the exchanger, and the other fluid circulates on the outside of the tubes within the cylindrical shell. Heat is transferred from one fluid to the other through the walls of the tubes in the heat exchanger. The flow path of the fluid on the outside of the tube is directed throughout the heat exchanger by means of baffling. These baffles are visible in figure 4.84 .

Generally, when specifing or discussing a standard shell-and-tube heat exchanger, the flow patterns and shell configuration types are more easily seen if the heat exchanger is broken into three distinct parts; the front end, the shell type, and the rear end. These three types are shown on figure 4.85 which is a reprint from the Standard of Tubular Exchanger Manufacturers Association. This figure shows the various standard types of these three parts of an exchanger. The front and the rear end type typically indicate the flow path of the fluid inside the tubes of the exchanger. The

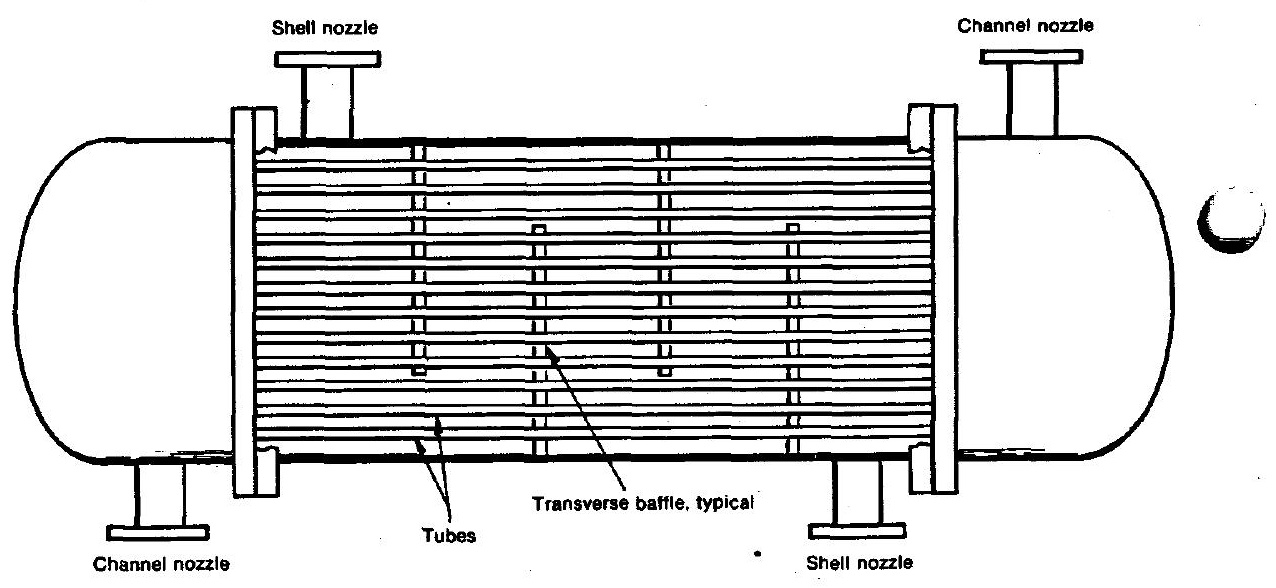

FIGURE 4.84-Typical shell-and-tube heat exchanger. 


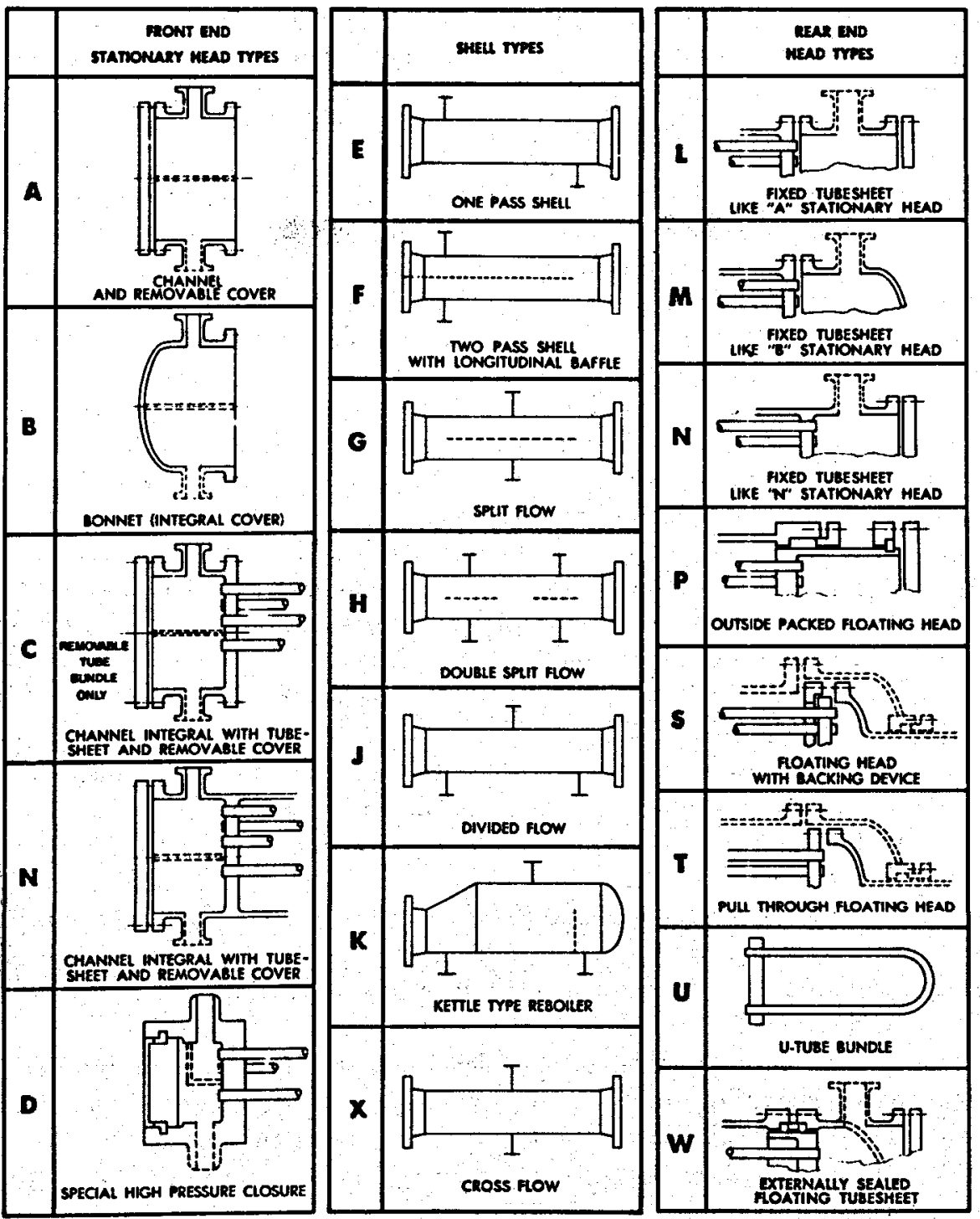

FIOURE 4.85-Heat exchanger nomenclature.

shell type indicates the flow pattern or path of the fluid on the outside of the tubes.

Figure 4.85 shows the standard of the industry for describing heat exchangers, and throughout the following section it will be used frequently to describe the various heat exchangers applicable in geothermal systems.

(1) Preheaters. The purpose of the preheater is to take the secondary fluid condensate from the condenser and preheat it to a temperature close to the saturation temperature and pressure of the boilers. As dis- 
cussed earlier, there are two distinct types of geothermal systems that are used for: this type of service; a flash-binary system and a liquid-binary system. The flash-binary system condenses steam on one side of the exchanger and preheats the secondary fluid on the other side of the exchanger. In the liquid-binary system, liquid geothermal fluid on one side of the exchanger preheats the secondary working fluid liquid on the other side of the exchanger. Generally, in either type of system, the geothermal fluid or the flash steam circulates through the inside of the tubes of the heat exchanger while the secondary working fluid circulates on the outside of the tubes on the shell side of the heat exchanger. This arrangement is based upon ease of cleaning scale that the geothermal fluid may deposit.

(a) Heat exchanger type and flow path options. For preheating service, various flow paths and configuration options are available from the various types of heat exchangers. For instance, looking back at figure 4.85 , preheating can be accomplished by any one of shell types $\mathbf{E}, \mathbf{F}, \mathbf{G}, \mathbf{H}$, or $\mathbf{J}$. Each of these heat exchangers has particular applications in geothermal systems. However, when selecting a heat exchanger for a particular service, consideration must be given to all shell types and flow patterns within the heat exchanger to obtain the optimum design.

in Another option available when specifying the design of a heat exchanger is the number of passes on the tube side. This can vary from a single pass up to 16 to 20 passes. However, with more than one pass on the inside of the tube in a liquid-binary system, the deviation from a true countercurrent flow causes a decrease in the effectiveness of the heat exchanger (due to an increase in area). Therefore, one must attempt to achieve true counter-current flow throughout the heat exchanger. For a flash-binary system the temperature of the condensing steam is constant; therefore it "does not suffer this decrease in effectiveness due to the multiple passes through the tubes.

There are many variables to consider when specifying the design of a heat exchanger. Many of these are somewhat of a designer's choice, for example, a fixed tube sheet versus a floating head tube sheet.

In a fixed tube sheet design, a tube sheet is welded to the shell on both ends of the heat exchanger. The tubes are routed from one tube sheet to the other and are attached permanently to each. In a floating head type exchanger, neither tube sheet is attached solidly to the shell, permitting removal of the complete tube bundle, including the tube sheet and the tubes. This allows the removal of the bundle for cleaning or replacement. However a floating head exchanger results in higher cost. Therefore, economics plays a major role in the selection of heat exchangers.

The very large heat transfer areas required for geothermal plants mean that large multiple units are required. In that case fixed tube sheets are most practical, since most places would not have on-site facilities to remove, handle, and lift the units. 
A U-tube bundle is generally not used in the service where fouling is expected to be significant and mechanical cleaning is going to be necessary. The cleaning devices currently available do not have the capability of cleaning the bends in the U-tube bundle. This leads to decreased effectiveness, higher pressure drop inside the tubes, and possible plugging of tubes. However, if in some situations a U-tube bundle could be used in a geothermal system, it would have only one tube sheet and thereby create a less expensive heat exchanger. The U-tube bundle must have an even number of passes on the tube side since the tubes must always come out at one tube sheet end. Therefore, there is a penalty for the loss of true counter-current flow and this loss must be weighed against the decrease in cost due to not having two tube sheets.

The number of tube passes in a heat exchanger is mainly determined by the required heat transfer surface and the required cross-sectional flow area on the tube side to maintain a certain minimum velocity. For most geothermal systems, where fouling is expected to occur, this minimum velocity is $1 \mathrm{~m} / \mathrm{s}$ ( $3 \mathrm{ft} / \mathrm{s}$ ) to avoid giving the fouling material time to plate out on the heat exchange surface thereby increasing the fouling resistance on the inside of the tubes. As this velocity increases, the inside film coefficient is increased; however; the pressure drop is also increased so there is a trade-off of pressure drop versus heat exchanger surface area. The "optimum" velocity stated in reference (9) is $11 / 2$ to $21 / 2 \mathrm{~m} / \mathrm{s}(5$ to $7 \mathrm{ft} / \mathrm{s})$.

Another design consideration is the type of tube material, because as the velocity increases, erosion of the tubes or tube entrance areas may become a problem. In the case of a flash-binary system, where steam is routed through the inside of the tubes, this velocity upper limit is not as important as it is in the liquid-binary system. In the liquid-binary system the upper limit of the velocity limits the inside film coefficient. Typically in a liquid system with the pressure drop consideration, the velocity inside the tubes should be maintained between 1 to $3 \mathrm{~m} / \mathrm{s}$ ( 3 to $10 \mathrm{ft} / \mathrm{s})$.

(b) Preliminary sizing criteria. For preliminary sizing of the preheater in a geothermal system, the amount of heat to be transferred must be calculated as previously described in section 5.2.2. The cycle analysis of the system as discussed in a previous section of this chapter will generally give the terminal temperatures for the geothermal fluid and the secondary working fluid. The mass flow rate of both these fluids is also determined from the cycle analysis of the system. Next, by knowing the mass flow rate, the terminal temperatures, and using the fact that the specific heat is constant throughout the range of interest the amount of heat to be transferred can be obtained by the relationship

$$
q=\dot{m} C_{p} \Delta T
$$

The next step in the preliminary sizing of preheaters of the geothermal system is to calculate the true countercurrent logarithmic mean tempera- 
ture difference $\Delta T_{L Y}$ as described above. Next determine the outside overall heat transfer coefficient $U_{0}$. The method to accomplish this has already been described. All of the resistances to heat transfer with the exception of the outside film coefficient were described in detail in that section. The following is given to calculate the outside film coefficient for preliminary sizing $(43)$ :

$$
h_{0}=\frac{k_{L}}{D_{0}}(\alpha)\left(\frac{D_{0} G_{\max }}{\mu_{L}}\right)^{0.6}\left(\frac{C_{p} \mu_{L}}{k_{L}}\right)^{1 / 3}
$$

where: $\alpha=0.198$ or 0.156 for triangle or square pitch respectively.

When the outside film coefficient has been determined, the overall coefficient can then be calculated.

Knowing the overall heat transfer coefficient $U_{0}$, the amount of heat to be transferred $q$, and the logarithmic mean temperature difference $\Delta T_{L, 4}$, the required heat transfer surface area $A_{0}$ can be determined by the following

$$
A_{0}=\frac{q}{U_{0} \Delta T_{L M}}
$$

This gives the preliminary indication of the surface area required to provide the necessary heat exchange for preheating the secondary working fluid to the conditions specified. From this, the number of tubes, the length of the tubes, and the required number of tube passes, can be determined.

(c) Use of extended surface. Organic fluids, i.e., fluorocarbons and hydrocarbons, generally have a small film coefficient. The most common method used to improve the outside film coefficient is to use externally finned tubes. The application of this type of tube is limited when a large inside fouling resistance is anticipated. When this resistance is referred to the outside surface area the resistance becomes quite signfiicant, thereby lowering the improvement due to the finned tubes. However, the use and possible improvement in heat transfer from these tubes should be investigated before final selection of the preheater for a binary geothermal power system. The low fin tubes generally used with liquids provide about $21 / 2$ times the outside heat transfer of a straight tube of the same size. The improvement in the overall heat exchanger design, if any, must be balanced against the increased cost which is about two times that of a plain tube of the same size and material.

(2) Boilers. The boiler in a binary geothermal system receives the flow of the liquid secondary working fluid from the preheater at near saturation conditions, then transfers heat from the geothermal fluid vaporizing the secondary working fluid.

As in the previous discussion, two distinct types of geothermal systems are used for this service: a flash-binary and a liquid-binary. In the flashbinary system the flashed steam is condensed on the inside of the tube, 
thereby vaporizing the secondary working fluid on the outside of the tube. In a liquid-binary system the liquid geothermal fluid inside the tubes is cooled by vaporizing the secondary working fluid.

(a) Heat exchanger types and flow path options. For this service the most common shell type (see figure 4.85) is the kettle reboiler or shelltype $\mathrm{K}$. This type of unit allows the proper disengagement space above the tube bundle, so that the liquid droplets will not be carried out the exit due to entrainment. Other shell types could be used but would require an external vapor-liquid separator.

Another option available is the number of tube passes. The number of tube passes is primarily determined by the heat exchange surface area required and the cross-sectional flow area necessary to maintain a minimum velocity of $1 \mathrm{~m} / \mathrm{s}(3 \mathrm{ft} / \mathrm{s})$ in the geothermal fluid to minimize fouling on the inside tube surface. Contrary to the case of the preheaters, the number of tube passes does not change the effectiveness of the boiler, due to the isothermal condition on the outside of the tubes.

There are many variables to consider when specifying the design of a boiler. The cost advantage of the fixed tube sheet over the floating head is not as significant in a kettle type reboiler as it is in the other shell types used in preheating service. The advantage of the fixed tube sheet is that mechanical cleaning of the inside of the tubes is accomplished without removal of the tube bundle from the shell.

A U-tube bundle is commonly used in kettle reboilers in cases where fouling on the inside of the tubes will not require mechanical cleaning. This is not the case in most geothermal applications; however, this alternative should be considered during the selection process.

A device that is frequently required as part of the boiler is an internal demister or "knock-out plate" installed before the exit nozzles on the shell side of the exchanger. The purpose of this device is to remove any liquid entrained in the vapor. This establishes the vapor quality necessary for admission to the turbine. A typical vapor quality requirement specified is less than $0.5 \%$ liquid.

The liquid level of the secondary working fluid must be maintained in the boiler above the height of the tube bundle. This requires that the necessary nozzles and instrumentation be installed on the shell.

(b) Preliminary sizing criteria. The following method describes the preliminary sizing of a boiler in a binary geothermal system.

The conditions at the inlets and outlets of both the geothermal fluid and secondary working fluid are established in the cycle analysis of the system. From this the amount of heat to be transferred can be obtained using

$$
q=\dot{m}_{W F}\left[h_{f \xi}+C_{p}\left(T_{s a t}-T_{I N}\right)\right]_{W F}
$$

For liquid-binary

$$
q=\dot{m}_{O F} C_{p} \triangle T_{G F}
$$




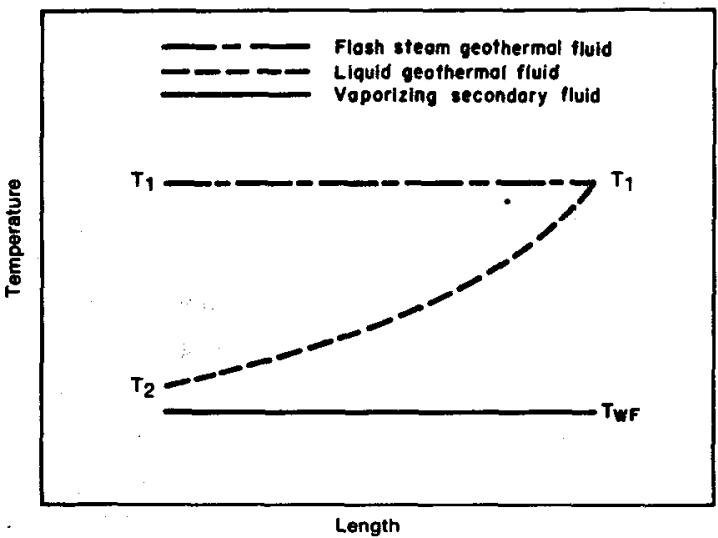

FradRr 4.86-Boiler temperature $\nabla 8$. length.

For flash-binary

$$
q=\dot{m}_{s}\left(h_{f g}\right)_{8}\left(X_{I}-X_{0}\right) .
$$

Next determine the logarithmic mean temperature difference. As seen from figure 4.86 the $\Delta T_{L Y}$ for a flash-binary system boiler is equal to the difference in the saturation temperature of the two fluids or

$$
\Delta T_{L M}=T_{s}-T_{W r} .
$$

For a liquid-binary system the logarithmic mean temperature difference is given by

$$
\Delta T_{L M}=\frac{\left(T_{1}-T_{2}\right)_{G F}}{\ln \left[\frac{T_{1}-T_{W F}}{T_{2}-T_{W F}}\right]}
$$

The method presented above for determining the overall heat transfer coefficient $U_{0}$ is complete with the exception of the calculation of the outside film coefficient. The following relationship (44) is recommended for obtaining this film coefficient for preliminary sizing of a kettle type boiler.

$$
h_{o}=0.00658\left(p_{c}\right)^{0.89}(q / A)^{0.7}\left[1.8\left[\frac{p}{p_{c}}\right]^{0.17}+4\left[\frac{p}{p_{c}}\right]^{1.2}+10\left[\frac{p}{p_{c}}\right]^{10}\right]
$$

This equation involves the heat flux $(q / A)$ which implies an iterative solution may be necessary to obtain the overall heat transfer coefficient for the boiler. In this equation pressures are in psia, heat flux in Btu/h-ft and $h_{o}$ is in $\mathrm{Btu} / \mathrm{h}-\mathrm{f}^{2}-^{\circ} \mathrm{F}$.

In boiling heat transfer there is a limit to the amount of heat that can be transferred per unit area. This limit is known as the maximum heat flux. The maximum heat flux $(q / A)_{\max }$ can be predicted by (45)

$$
(q / A)_{\max }=61.6 t_{p} \rho_{\vartheta} h_{f g} / D_{o} \sqrt{n}\left[g \sigma\left(\rho_{L}-\rho_{v}\right) / \rho_{v}^{2}\right]^{1 / 4}
$$


where:

$\begin{aligned} t_{y} & =\text { Tube pitch }(\mathrm{ft}) & p_{\mathrm{L}} & =\text { liquid density }\left(\mathrm{lb}_{\mathrm{m}} / \mathrm{ft}^{3}\right) \\ D_{0} & =\text { tube outside diameter }(\mathrm{ft}) & h_{\mathrm{fg}} & =\text { latent heat }\left(\mathrm{Btu} / \mathrm{bb}_{\mathrm{m}}\right) \\ n & =\text { number of tubes } & g & =\text { gravitational const. }\left(\mathrm{ft} / \mathrm{h}^{2}\right) \\ \rho_{\mathrm{o}} & =\text { vapor density }\left(\mathrm{lb}_{\mathrm{m}} / \mathrm{ft}^{3}\right) & & \sigma=\text { surface tension }\left(\mathrm{lb}_{\mathrm{t}} / \mathrm{ft}\right)\end{aligned}$

When the outside film coefficient has been determined, the overall heat transfer coefficient can be calculated using the method discussed previously.

With the overall heat transfer coefficient $U_{0}$, the amount of heat to be transferred $q$, and the logarithmic mean temperature difference $\Delta T_{L M}$, the required heat transfer surface area $A_{0}$ can be determined by

$$
A_{o}=\frac{q}{U_{o} \Delta T_{L M}}
$$

This gives a preliminary indication of the surface area required to provide the necessary vapor flowrate at the conditions specified. With this information the number of tubes, the length of the tubes, and the required number of tube passes can be determined.

(c) Use of extended surface. Boiling organic fluids generally have small film coefficients. Various methods have been proposed for improving the outside film resistance coefficient of boiling secondary working fluids in binary geothermal systems. Some of the augmentation techniques which should be considered are listed below :

(1) Fluid additives, electrostatic fields, surface or fluid vibrations.

(2) Coiled wires, inlet vortex generators, twisted tapes, displaced promoters, roughed surface, pocked surface, spirally grooved tubes.

(3) An endless variety of finned surfaces.

These and other augmentation techniques have been investigated for use in binary geothermal system as reported in reference (46).

By far the most common of these augmentations is the externally finned tubes. These tubes would seem to have application in binary geothermal systems. However when a large fouling resistance on the inside of the tube is referred to the equivalent outside surface of a finned tube, this results in a large fraction of the total resistance; therefore the improvement, if any, over a bare surface is generally quite small.

The use, possible improvement, and combinations of these augmentation techniques should be investigated before selection of the boiler for a binary geothermal power system.

(3) Superheaters. The purpose of the superheater is to transfer heat from the geothermal fluid to the secondary working fluid saturated vapor as it comes from the boiler. This transfer is done at constant pressure, thus resulting in a superheated vapor at the exit.

(a) Heat exchanger types and flow path options. The acceptable shell types, design philosophy, and discussion presented above in the subsection 
on the preheaters, are similar for superheaters. Refer to that section for details.

(b) Preliminary sizing oriteria. For preliminary sizing of the superheaters in a geothermal system, the basic methodology given above in the subsection on preheaters should again be followed.

(1) Calculate the amount of heat to be transferred $q$.

(2) Calculate the countercurrent logarithmic mean temperature difference $\Delta T_{L M}$.

(3) Determine the overall heat transfer coefficient $U_{0}$.

Once these three values are obtained, the outside heat transfer surface can be calculated using the following

$$
A_{o}=\frac{q}{U_{0} \Delta T_{L M}} .
$$

This calculation gives the preliminary indication of the size requirement to provide the necessary heat exchange area for superheating the secondary working fluid to the conditions specified. From this area the number of tubes, length of the tubes, and required number of the tube passes can be determined.

(c) Use of extended surface. Generally, the calculated outside film coefficient for superheating most secondary working fluids is quite low. This condition indicates that various types of extended surface tubes should be examined to determine if an improvement is possible under the conditions specified. A method for this examination is presented in reference (47).

(4) Supercritical primary heaters. The purpose of the supercritical primary heaters is to transfer heat from the geothermal fluid to the supercritical secondary working fluid. A fluid at a pressure above the critical pressure does not have a distinct phase change that is seen in subcritical fluids. The properties and the mechanisms of heat transfer in the supercritical state are not readily available. The reader is referred to the references (48-5E) for data on supercritical heat transfer which generally relates to cryogenic applications. Recent tests with isobutane by the Lawrence Berkeley Laboratory indicates that a conservative representation of the heat transfer can be obtained by using the conventional Dittus-Boelter equation and breaking the heat exchanger model into a sufficient number of nodes to account for the variation in fluid properties through the heat exchanger.

Ordering information: Specification sheet and applicable codes and standards. When all the items necessary to place the order for a heat exchanger are determined, there are certain industry practices and procedures which make the purchase much less difficult.

The industry standard for specifying heat exchangers is a Specification Sheet from the Tubular Exchanger Manufacturers Association Standard (TEMA) (see figure 4.87). The information blanks on this sheet are to be 
HEAT EXCHANGER SPECIFICATION SHEET

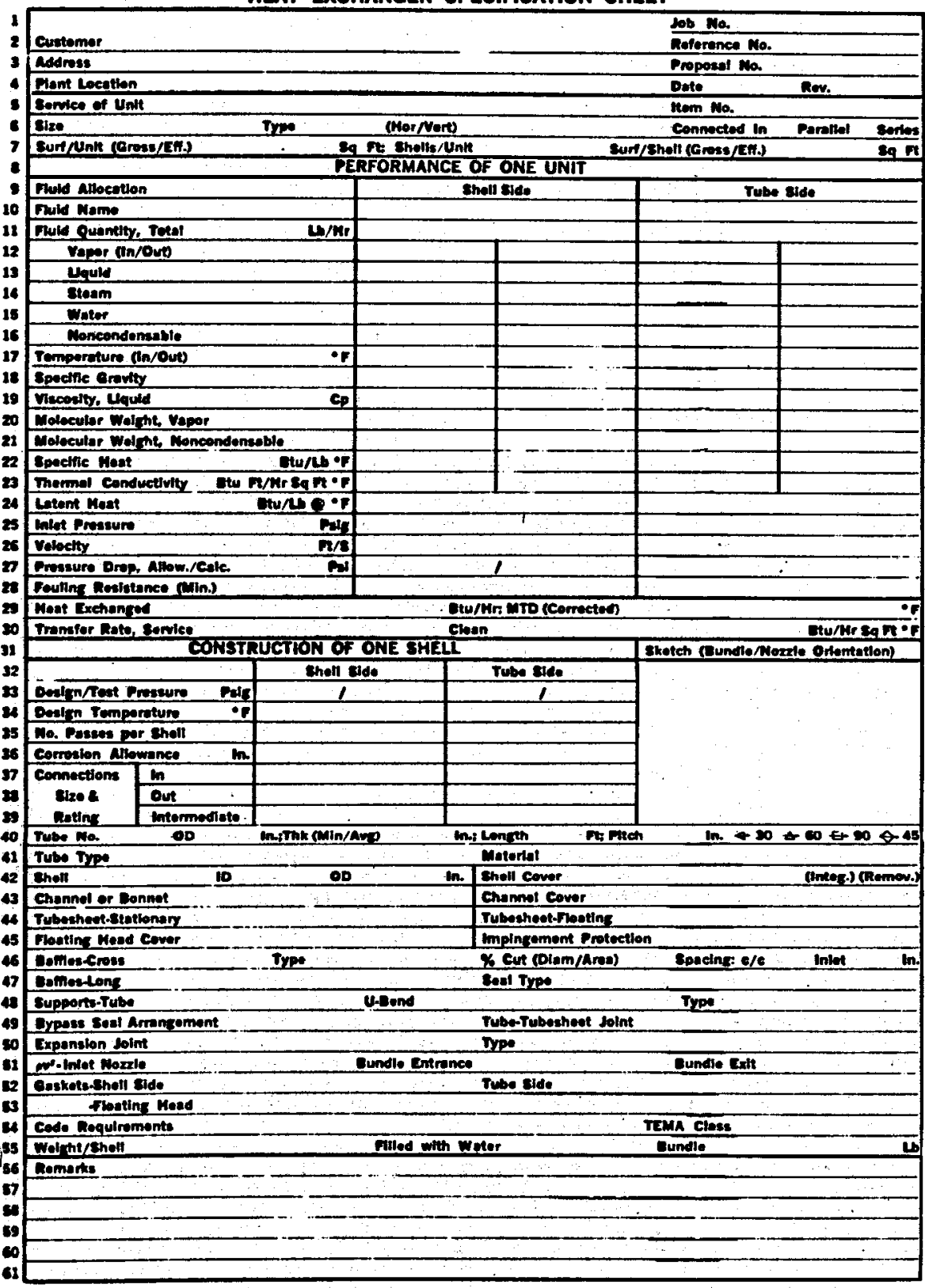

FIaURE 4.87-Heat exchanger specification sheet.

filled in as much as possible by the purchaser. This gives the vendor a general idea of the requirements, along with any special or design constraints necessary for this particular heat exchanger. The more complete the design of the exchanger the more complete this specification sheet 
should be. Other specification sheets are available from different sources which primarily list the same information in a different format.

Many codes and standards have application in the design, fabrication, and installation of heat exchangers. The person specifying these should know that adequate protection and design constraints are imposed so as to provide a safe and reliable heat exchanger without overspecifying and conflicting requirements. In view of this, the available codes and standards should be reviewed, a few of which are listed below :

(1) Standards of Tubular Exchanger Manufacturers Association (TEMA Standard Class R).

(2) American Society of Mechanical Engineers Boiler and Pressure Vessel Code (ASME Section VIII, Division 1).

(3) American Petroleum Institute Standard (API-660).

Optimization and trade-off studies. As previously mentioned; the performance of a heat exchanger is generally improved by increasing the velocity of the fluids. This is due to the increase in the film coefficients and the decrease in the fouling resistance. However, as the velocity increases so does the pressure drop which increases the costs of pumping. These two opposing costs indicate that there is an optimum point where the total overall cost is at a minimum. To evaluate this situation, an accurate method of determining these effects is needed. Once these are obtained, the velocity versus the total cost plot will reveal the minimum cost.

The smallest difference in the terminal temperature or "pinch point" is also used in optimizing heat exchanger design.

As this difference in temperature increases, the logarithmic mean temperature also increases, which reduces the required heat transfer surface area. However, as this difference in temperature is increased, a thermodynamic penalty is incurred which must be compared with the saving in capital cost to determine the design point.

4.2.5.4 Mechanical and system design considenations. Physical limitations, system design, performance considerations, and economics affect the specification of geothermal heat exchangers. Some of the more significant factors are discussed in this section.

Mechanical design and physical considerations. (1) Heat exchanger size limitations. As the size of a particular heat exchanger increases, the unit cost (cost/unit surface area) decreases. This is true up to a certain size. At a surface area of approximately 1850 to $3720 \mathrm{~m}^{2}\left(20,000\right.$ to $\left.40,000 \mathrm{ft}^{2}\right)$ the unit cost of the heat exchanger surface becomes essentially constant. This is due to the increased handling cost and material thickness for the large diameter bundles.

The length of the tubes also affects the cost of the required heat exchanger surface. As an example an exchanger with $1850 \mathrm{~m}^{2}\left(20,000 \mathrm{ft}^{2}\right)$ of surface area with $18 \mathrm{~m}(60 \mathrm{ft})$ tubes would be approximately 5 to $7 \%$ 
less expensive than that same surface with $12 \mathrm{~m}(40 \mathrm{ft})$ tubes. The practical limit to the length of the tubes is the production shop capability limit. This limit is generally between 18 and $25 \mathrm{~m}(60$ to $80 \mathrm{ft})$.

The outside diameter of the tubes is another design option. The smaller the outside diameter of the tubes the greater the amount of surface area that can be exposed in a given size or diameter of a shell. Standard tubes are manufactured in outside diameters as small as $1 \mathrm{~cm} \mathrm{(} 3 / 8$ in); however in most geothermal systems where fouling is expected and mechanical cleaning will be necessary, the practical lower limit on the outside tube diameter is $2 \mathrm{~cm}(3 / 4$ in). This will ensure that the means are available to mechanically clean the inside tube wall.

Other design considerations related to the size of the heat exchanger are the outside shell diameter and overall heat exchanger weight. For the large surface area requirements of most geothermal applications, the larger the shell diameter, the smaller the number of shells required. The limit on the outside diameter and overall weight of the heat exchanger is established by the shipping, handling, or manufacturing capability. Most manufacturers of large heat exchangers have the capability to produce units with diameters greater than $2.5 \mathrm{~m}$ (100 in) and total weights of approximately 250 metric tons ( 300 short tons). The practical limit is established by shipping and handling considerations. These limits vary by location, but generally restrict the overall size and weight of the item to be shipped. These considerations should be part of the initial investigation to determine what are the limits on heat exchanger size.

(2) Cost impact of heat exchanger materials. After the required amount of heat transfer surface area has been determined, the largest single element influencing the cost of the heat exchanger is the material of construction. For most geothermal systems carbon steel is the choice of material for the shell parts. This includes the outside shell, channel and channel covers, and nozzles. The most important selection to be made is that of the material of the tubes. Since the tubes represent approximately 60 to $75 \%$ of the cost of the exchanger, this item has a significant impact on the cost of the heat exchanger. Common tube materials are given in table 4.12 and the relative order of cost is shown with carbon steel being the least expensive and Hastelloy being the most expensive.

The tube material selection should be based on tests of various materials with the geothermal fluid under consideration. This method is currently the only method that will produce conclusive results for a reliable choice of materials. The lack of experience and inability to generalize the available data are the primary reasons that analytical methods are not available for the selection of tube materials.

Another material choice to be made is that of the tubesheets. The tubesheets form the shell pressure boundary with the tubes and must be a compatible material. Also, the material must resist the corrosive attack of the geothermal fluid. This consideration can be a part of the experiment to 
TABLE 4.12-Relative cost of common tube materials

\begin{tabular}{|c|c|}
\hline Material & $\begin{array}{l}\text { Approximate } \\
\text { relative ma- } \\
\text { terial cost }\end{array}$ \\
\hline 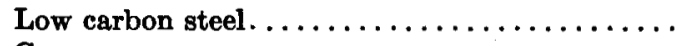 & 1.0 \\
\hline 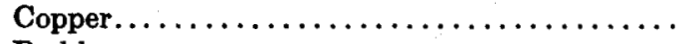 & 1. 1 \\
\hline Red brass. . . . . . . . . . . . . . . . . . & 1.2 \\
\hline 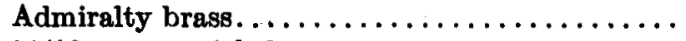 & 1. 3 \\
\hline 90/10 copper-nickel. $\ldots \ldots \ldots \ldots \ldots \ldots \ldots \ldots$ & 1.6 \\
\hline $70 / 30 \ldots \ldots \ldots \ldots \ldots \ldots \ldots \ldots \ldots \ldots \ldots \ldots \ldots$ & 1.8 \\
\hline 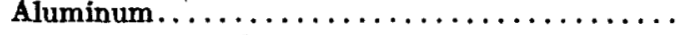 & 2.0 \\
\hline 304 stainless steel. $\ldots \ldots \ldots \ldots \ldots \ldots \ldots \ldots \ldots$ & 2. 5 \\
\hline 316 stainless steel $\ldots \ldots \ldots \ldots \ldots \ldots \ldots \ldots \ldots$ & 3. 0 \\
\hline 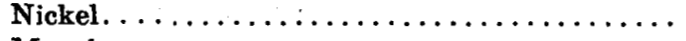 & 5. 0 \\
\hline 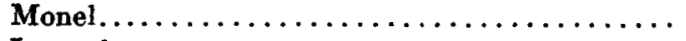 & 5. 0 \\
\hline Inconel $\ldots \ldots \ldots \ldots \ldots \ldots \ldots \ldots \ldots \ldots \ldots$ & 8. 0 . \\
\hline 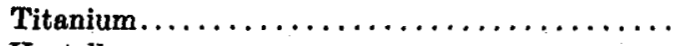 & 12. 0 \\
\hline Hastelloy $\ldots \ldots \ldots \ldots \ldots \ldots \ldots \ldots \ldots \ldots$ & 16. 0 \\
\hline
\end{tabular}

determine the tube material by including common tubesheet material in the test samples.

Once the proper materials have been determined, an evaluation should be made between a clad tubesheet and a tubesheet of homogeneous material. The selection of one versus the other is an economic evaluation of the cost of the materials and the bonding method proposed. Two methods are generally used when bonding a cladding over another material; weld overlay and explosive bonding. Both of these methods have been used quite successfully ; so the selection is a matter of economic choice.

The use of a tubesheet material which is the same as the shell material eliminates the potentially significant problems of a large bimetallic weld between the tubesheet and shell. In addition, selection of tubesheet materials similar to tube materials may present difficulties in obtaining satisfactory forgings in the sizes required.

(3) Cost impact of design pressure. The design pressures, on both the shell and tube sides are another item for consideration in the selection process. As the design pressure increases, naturally the cost also increases. This is due to the increase in material thickness required to contain the pressure. The effect of the tube side is generally not significant due to the low pressure i.e., less than $2 \mathrm{MPa}(300 \mathrm{psi}$ ) assuming that the geothermal fluid must be placed on the tube side for ease of cleaning. However, on the shell or secondary working fluid side, the pressures involved are generally much more significant. Design shell side pressures of 5 to $7 \mathrm{MPa}(600$ to $1000 \mathrm{psi}$ ) are typical for geothermal binary power systems. However, some exchangers (in supercritical cycle applications) may operate at pressures of $1500 \mathrm{psi}$ or more. The effect on the cost of the heat exchanger due to the shell side design pressure is shown in table 4.13 where geothermal fluid 
TABLE 4.13-Effect of shell side design pressure on heat exchanger cost

\begin{tabular}{|c|c|}
\hline $\begin{array}{c}\text { Design pressure } \\
\text { MPa (psi) }\end{array}$ & $\begin{array}{c}\text { Heat ex- } \\
\text { changer } \\
\text { relative } \\
\text { cost }\end{array}$ \\
\hline$\ldots \ldots \ldots \ldots \ldots \ldots \ldots \ldots \ldots$ & 1. 0 \\
\hline $4(600) \ldots \ldots$ & 1. 3 \\
\hline $5(750) \ldots \ldots \ldots \ldots \ldots \ldots \ldots \ldots \ldots \ldots \ldots \ldots \ldots$ & 1.6 \\
\hline $7(1000) \ldots \ldots \ldots \ldots \ldots \ldots \ldots \ldots \ldots \ldots \ldots \ldots \ldots$ & 2. 0 \\
\hline $8(1200) \ldots \ldots \ldots \ldots \ldots \ldots \ldots \ldots \ldots \ldots \ldots \ldots$ & 2. 5 \\
\hline
\end{tabular}

fouling deposits can be removed and cleaned with chemicals the lowest cost heat exchangers are obtained if the lower pressure geothermal fluid is used on the shell side.

An indirect consideration when using a flammable secondary fluid is the impact of the design pressure of the heat exchangers, particularly the condenser on the physical size and hence cost of the plant flare system. Specifying a design pressure greater than required by normal operating conditions can significantly reduce vent and flare system costs. Additional considerations are simplified operational procedures and response to abnormal or casualty situations that may result from increasing the design pressure of the heat exchangers.

(4) Miscellaneous design considerations. (a) Thermal expansion. For fixed tubesheet heat exchangers the difference in thermal expansion be$t$ ween the tubes and the shell must be considered. The Tubular Exchanger Manufacturers Association (TEMA) standard presents a method for calculating the thermal stresses that determine the need for an expansion joint in the shell. A general rule-of-thumb is that if the tube to shell temperature differential is $28^{\circ} \mathrm{C}\left(50^{\circ} \mathrm{F}\right)$ or greater, an expansion joint should be installed in the shell. Normally, upset or startup conditions of the plant can provide temperature differences greater than $28^{\circ} \mathrm{C}$.

(b) Vibration. Tube vibration is another consideration which can become serious if neglected. The TEMA standard has a listing of unsupported span for various tubing. Anytime this maximum distance is exceeded the possibility of damaging tube vibration is greatly increased. These standards provide design guidelines by which to check or review proposed designs.

(c) Impingement protection. Impinging fluids create both vibration and erosion problems. The TEMA standard recommends a maximum value of the momentum flux, ${ }_{p} V^{2}=2230 \mathrm{~kg} / \mathrm{m} \cdot \mathrm{s}^{2}\left(1500 \mathrm{lb} / \mathrm{ft} \mathrm{s}^{2}\right)$ for single phase fluids without protection from impingement. For other fluid near the boiling point this value of ${ }_{\rho} \nabla^{2}$ is reduced to $745 \mathrm{~kg} / \mathrm{m} \cdot \mathrm{s}^{2}\left(500 \mathrm{lb} / \mathrm{ft} \mathrm{s} \mathrm{s}^{2}\right)$. For all vapors and two-phase mixtures impringement plates or distribution plates are installed at the inlet of the impinging fluid. 
(d) Design loading. The internal and external structural members and the nozzles should be analyzed for both static and seismic loading. The type of loadings to be considered are given in reference (53).

(e) Vent and drains. A frequently disregarded item that becomes critical after installation is the venting and draining system. This system allows removal of undesirable elements, such as air, water, or impurities that tend to collect in the heat exchangers. Also, this system allows removal of all fluids contained in the heat exchanger for maintenance and safety purposes.

4.2.5.5 System and thermal design considerations. (1) Distribution and magnitude of thermal resistances. When heat exchangers represent such a large part of the system cost, it is desirable to evaluate what can be done to reduce their size. The heat exchanger area is a function of the duty, the logrithmic mean temperature difference, and the overall heat transfer coefficient. For a given system the duty is fixed and the temperature difference becomes, largely, a function of system performance optimization.

As described earlier, the overall heat transfer coefficient is made up of the sum of five resistances:

$R^{\prime}{ }_{1}$-Tube side film.

$R^{\prime}{ }_{2}$-Tube side fouling.

$R^{\prime}{ }_{3}$-Tube wall.

$R^{\prime}{ }_{4}$-Shell side fouling.

$R^{\prime}{ }_{5}$-Shell side film.

Once the value of each of these resistances has been determined for a particular design, the impact of changing individual coefficients can be determined from a plot of the heat.exchanger size reduction ratio against each thermal resistance.

Figures 4.88 and $4.89\left(46^{\circ}\right)$ are two sample plots for representative heat exchangers which show the effect on the overall thermal resistance (heat exchanger size) of a reduction in any one of the resistances. The initial values upon which these curves are based are shown on the figures. The geothermal fluid is on the tube side and a rather significant design fouling factor was assumed. Both figures show that this fouling factor dominates the total resistance. As an example, this resistance (Curve 2, Figure 4.89 is reduced to half its original value $\left(R / R_{l}\right)_{2}=0.5$, a size reduction of over $30 \%\left[\left(L_{I}-L\right) / L_{I}\right]_{2}=0.32$ will result. The impact of reducing any of the other resistances will have a much smaller effect.

The next highest resistance is due to the shell side film coefficient which reflects the poor thermal properties of the organic compounds proposed as working fluids in geothermal cycles. If fouling from the geothermal fluid were not a problem (as might be the case with some of the cleaner fluids), then consideration could be given to putting the working fluid on the in- 


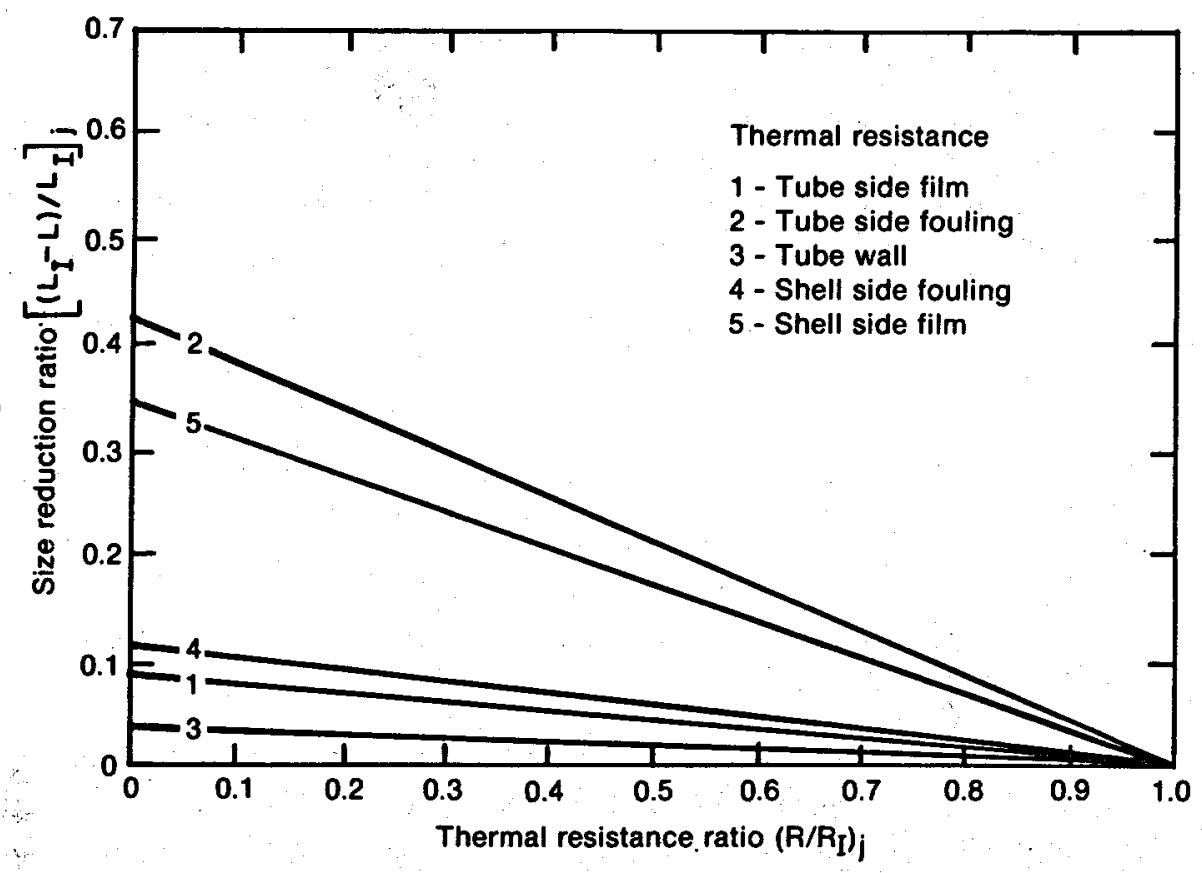

FraURe 4.88-Boiler thermal resistances. Initial resistance values $\left(\mathrm{h}-\mathrm{ft}^{\mathrm{x}}-{ }^{\circ} \mathrm{F} /\right.$ Btu) $\times 10^{3}: R_{1}^{\prime}=0.57, R_{2}^{\prime}=3.0, R_{8}^{\prime}=0.23, R^{\prime}=1.0, R_{8}^{\prime}=3.06$.

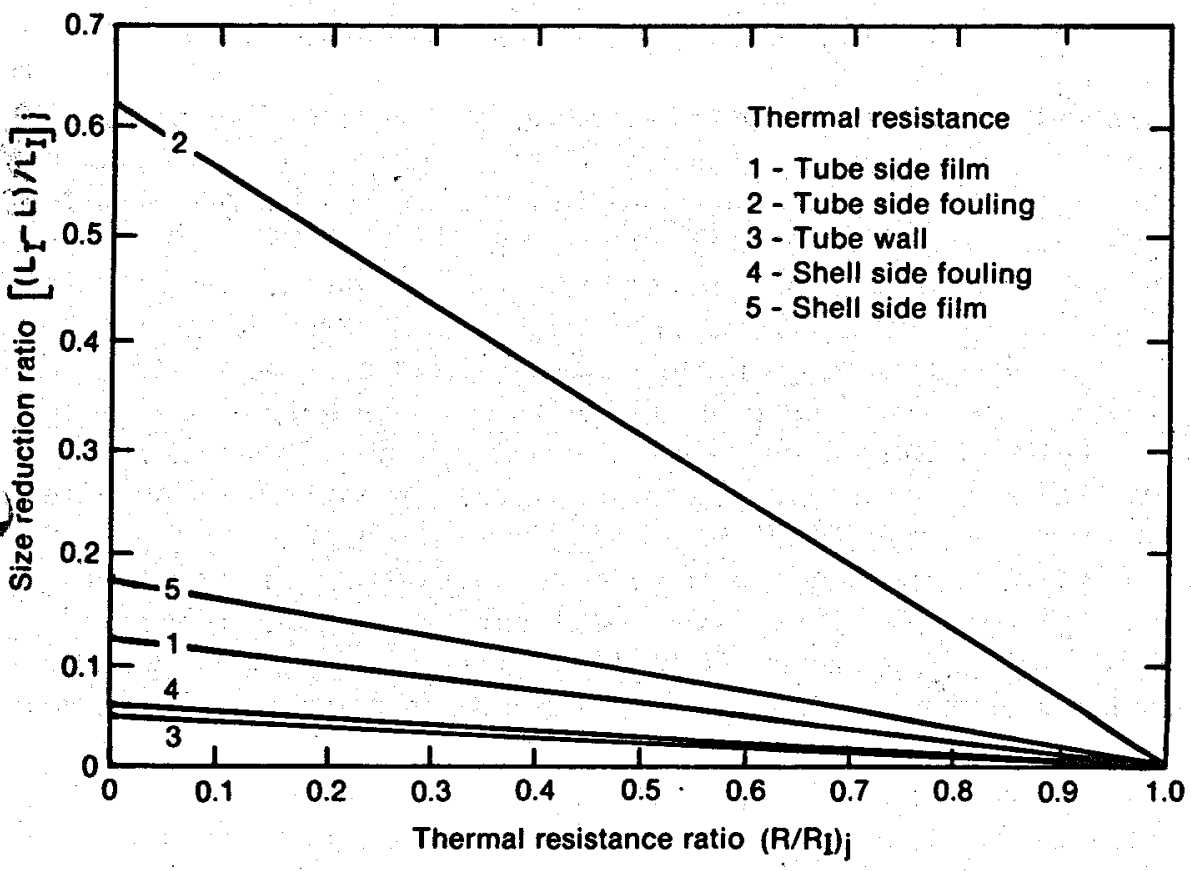

Figure 4.89-Preheater thermal resistances. Initial resistance values (h-ft"- $\bullet$ / Btu) $\times 10^{3}: R_{1}^{\prime}=0.59, R_{2}^{\prime}=3.0, R_{3}^{\prime}=0.22, R^{\prime}=1.0, R_{5}^{\prime}=2.98$. 
side of the tube where the heat transfer coefficient will be a stronger function of fluid velocity. This approach provides the additional advantage of significantly reducing the volume of working fluid in the system which is a very important consideration in commercial plants.

Typical values of all thermal resistances except that due to fouling on the geothermal side are given in table 4.14.

TABLE 4.14-Typical thermal resistances

\begin{tabular}{|c|c|c|}
\hline & $K \cdot m^{2} / W$ & h.ft ${ }^{2} .^{\circ} \mathrm{F} / \mathrm{Btu}$ \\
\hline \multirow[t]{2}{*}{ 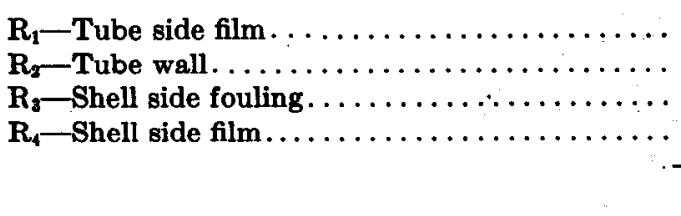 } & $\begin{array}{l}\text { 8. } 28 \times 10^{-5} \\
\text { 3. } 88 \times 10^{-6} \\
\text { 1. } 76 \times 10^{-4} \\
\text { 5. } 29 \times 10^{-1}\end{array}$ & $\begin{array}{l}0.47 \times 10^{-3} \\
0.22 \times 10^{-3} \\
\text { 1. } 0 \times 10^{-3} \\
\text { 3. } 0 \times 10^{-3}\end{array}$ \\
\hline & 8. $27 \times 10^{-4}$ & 4. $69 \times 10^{-3}$ \\
\hline
\end{tabular}

The tube side fouling resistance $R^{\prime}{ }_{2}$ due to the geothermal fluid must be added to the sum given in table 4.14 to determine the total resistance $R^{\prime}$ r. The value selected may have a great influence on the heat exchanger cost. For example, a value of $5.29 \times 10^{-4} \mathrm{~K} \cdot \mathrm{m}^{2} / \mathrm{W}$ would result in a total value of $R^{\prime}{ }_{T}=1.4 \times 10^{-3} \mathrm{~K} \cdot \mathrm{m}^{2} / \mathrm{W}$ which represents a $64 \%$ increase in surface area and, hence, a proportionate increase in capital cost. This great cost sensitivity justifies performing fouling tests to make a careful evaluation of the fouling resistance.

In addition to the added cost of the heat exchanger, fouling has a major impact on the operation and control of the geothermal power system. In a clean condition the heat exchangers will have 20 to $100 \%$ excess surface area. The design fouling rate may not be reached for nearly a year. This results in the heat exchangers performing far beyond the design conditions. The operation and control techniques must be able to take care of this situation. This results in more expensive control systems. Also, in the boilers a clean coefficient provides the worst case for the maximum heat flux. If the maximum allowable heat flux is exceeded in the boilers, vapor blanketing of the tubes may occur and create an unstable condition. Severe( vibration can occur with damage to the heat exchanger.

Therefore, a primary objective must be to determine the actual fouling in the particular geothermal system and to reduce and control that fouling. It is also apparent that the large change in $R_{T}$ between the clean and the fouled condition may have a significant effect in power plant design and operation.

A few predictive methods have been proposed for determining a fouling rate $(53-57)$. However, most of these deal with cooling water and take into account the deposition rate, the removal rate, and the conductivity of the deposits. There are presently no predictive methods for the generalized 
geothermal power system. To determine the actual fouling rate, developmental tests must be conducted on the particular geothermal water to be used in the heat exchangers. At the present time, this testing represents the best available method of determining the fouling rate.

(2) Selection and control of design fouling factors. The fouling from geothermal fluid is the major factor in determining the surface area requirement of the heat exchangers. Other causes of fouling must also be considered.

(a) Secondary working fuid fouting. The fluids being considered for use as secondary working fluids in binary geothermal systems are fluorocarbons and hydrocarbons. Most handbooks recommend using fouling resistances of $1.8 \times 10^{-4} \mathrm{~K} \cdot \mathrm{m}^{2} / \mathrm{W}\left(0.001 / \mathrm{h}-\mathrm{ft}^{2}{ }^{\circ} \mathrm{F} / \mathrm{Btu}\right)$ or less for these fluids. However, geothermal system temperatures are relatively low and the working fluids are clean; thus very little fouling from the secondary working fluid is expected to occur. It is recommended that a maximum value of $8.81 \times 10^{-5} \mathrm{~K} \cdot \mathrm{m}^{2} / \mathrm{W}\left(0.0005 / \mathrm{h}-\mathrm{ft}^{2}{ }^{\circ} \mathrm{F} / \mathrm{Btu}\right)$ be used for the fouling resistance of the secondary working fluid. Some users recommend that no fouling factor be used for a clean fluid like isobutane. If adjustments in system operation could compensate for minor fouling, if it occurred, the use of a zero fouling factor could result in a $5 \%$ reduction in unit size (see figure 4.89). This assumption would have little consequence on preheater performance in a plant designed to take advantage of minimum ambient conditions since the preheater unit is then slightly oversized for all but the minimum conditions.

(b) Geothermal fuid fouling. Major fouling sources. Heat exchanger fouling may be the result of mineral deposition, such as silica scale formation on the tube surface, or it may be the result of a corrosion film or a combination of both.

Deposition fouling. Geothermal fluids contain minerals that could cause severe fouling of a heat exchanger. The most significant of the minerals are: silica, calcium sulfate, calcium carbonate, and muscovite (a potassium mica). Should these minerals plate out on heat exchanger tubes, a drastic reduction in the amount of heat transferred would occur.

The severity of the problem depends on how near the solution is to a saturated condition, the kinetics of the process, and whether the condition can be controlled to minimize the potential for deposition.

For example, if sufficient pressure can be maintained on the geothermal fluid to prevent the release of carbon dioxide, the potential for calcite deposition would be eliminated. However, whether or not this type of control is possible is dependent upon the geothermal resource. If the geothermal fluid is saturated with carbon dioxide at bottom-hole pressure and temperature, a down-well pump cannot be installed to provide the required pressure to compensate for the static head loss as the fluid moves up the well. However, when the resource temperature is lower and the dissolved carbon dioxide is not near saturation, it is entirely 
practical to locate a pump in the well at an elevation that will prevent release of carbon dioxide and thereby prevent fouling of the heat exchangers.

Little can be done to control silica deposition except to design the system so that geothermal fluid temperature is maintained above that which would cause precipitation. Some control can be achieved through $\mathrm{pH}$ control; however, to provide the low $\mathrm{pH}$ required upstream of a heat exchanger would cause severe corrosion problems.

Some geothermal fluids have shown a tendency to form muscovite. A microscopic polycrystalline form, which has the feel of a heavy sticky grease, has been observed to plate out on the tubes of experimental heat exchangers in which the fluid velocity was low. Larger crystals have been observed to grow in very low velocity (or dead) regions of experimental heat exchangers. This material would have a marked impact on heat exchanger performance when it covers the heat transfer surface. The tendency to deposit in regions of low velocity indicates that inspection of water boxes should be conducted periodically. The formation of muscovite depends upon the fluid pressure, temperature, and composition. At present there is no way that the formation of this substance can be controlled and heat exchanger thermal design should consider the tendency of muscovite to be formed.

Calcium sulfate has an inverse solubility and, therefore, would not normally represent a scaling problem since temperature decreases through the heat exchangers.

Corrosive fouling. Many materials normally considered for heat exchanger tubes react with the geothermal water to cause extensive corrosion and fouling. Oxidation of carbon steel has occurred when no free oxygen was thought to exist in the water. This result leads to the supposition that a low-level metal-water reaction takes place. Nickel-copper alloys have been found to corrode badly in relatively clean geothermal water. In these cases a significant fouling rate was observed, but tests also proved the materials unsuitable for use as heat exchanger tubes due to excessive corrosion. These examples point out the need to conduct actual tests at the geothermal site and suggest that corrosion fouling may not be a significant problem since tube materials which exhibit significant corrosion probably have an unacceptable life.

Heat exchanger cleaning methods. Four common methods for cleaning heat exchangers are (a) continuous scraping of the surface, (b) periodic manual cleaning, (c) chemical cleaning, and (d) continuous or automatic cleaning. Any one or any combination of these methods may be best for a particular geothermal system as testing and experience is accumulated.

Continuous scraping of the surface uses a device installed in each tube of the heat exchanger that removes the scale as it builds up. These devices 
are very expensive to purchase and operate. This should be used as a Iast resort.

Manual cleaning involves taking the heat exchanger out of service, disassembling it, and performing a sequence of mechanical and chemical cleaning operations. This method is frequently used in the industry as a means of control of the scale buildup.

Chemical cleaning requires taking the heat exchanger out of service and circulating a mild acid solution through it to soften the built-up scale. This sludge is then washed out with high velocity water. The problem with chemical cleaning is that not all scale buildups are broken down by an acid. To use this method, the determination must be made as to whether the scale deposited by the geothermal water can be broken down by chemicals. Chemical cleaning by mild acids most easily removes deposits of calcite. However, removal of silica or muscovite requires the use of inhibited hydrofluoric acid. Where chemical cleaning is used it is important to evaluate its corrosive effect on heat exchanger materials.

Continuous or automatic cleaning systems require injecting small "sponge" balls continuously in the inlet of the heat exchanger. These balls are randomly forced through the heat exchanger tubes by the system pressure drop and then are retrieved in a downstream trap. The sponges come in a variety of textures and hardnesses. They can clean a wide variety of scales from the tubes. Currently, there is an upper temperature limit that the small balls can withstand. This limit is in the range of 80 to $90^{\circ} \mathrm{C}$ $\left(180\right.$ to $\left.200^{\circ} \mathrm{F}\right)$. Higher temperature balls are in the development stage. This method can be used continuously or intermittently, and it does not affect normal operation of the heat exchanger.

Other methods that have been proposed are :

(1) Chemical inhibitors.

(2) Seeding.

(3) Maintaining pressure.

(4) Electrolytic control.

(5) Increased tube velocities.

The most reliable results can be obtained by testing various methods in the actual geothermal fluid.

The selection of design fouling factors for the geothermal side. The design fouling factor can have a very significant impact on cost of the heat exchangers. Variations between the clean and fouled condition, if large, can result in system design and operational problems. Since no reliable means are available to predict heat exchanger fouling, testing is required and ideally tests should be run with water representing the mix of all wells that the power plant will be subjected to for the temperature drop expected in the plant. Assuming that such test data are available, the rate of fouling can be established. It is important to note that the selection of the design fouling factor value implies that the time required to achicve this value is 
acceptable and that when the design value is reached that it is not exceeded. Normally, this means that the heat exchanger is cleaned when the design value is reached. Therefore, the problem becomes one of determining the most economical cleaning frequency for a given fouling rate. An article by A. C. Mueller (58) covers the subject of cleaning frequency. A slight modification of Mueller's work by D. T. Neill (46), resulted in the following approach.

The fouling rate is assumed to be linear and that cleaning of the tubes will always result in a residual fouling factor; thus, the fouling resistance as a function of time is given by

$$
R^{\prime \prime}=b+a \theta
$$

and the cleaning frequency is given as

$$
N^{2}=\frac{(a)\left(U_{c}\right)(U C C)(C R F+A O C F)}{\left[1+\left(b \times U_{c}\right)\right](C L C)}
$$

where

$N=$ Number of cleanings per year.

$a=$ The linear fouling rate.

$b=$ Residual fouling resistance after cleaning.

$U_{c}=$ Overall heat transfer coefficient of the "clean," i.e., zero fouling, condition.

$U C C=$ Unit capital cost of the heat exchange surface.

$C R F=$ Capital recovery factor.

$A O C F=$ Annual operating and maintenance cost except for cleaning and expressed as a fraction of $U C C$.

$C L C=$ Cost of heat exchanger cleaning expressed as ( $\$ /$ unit area).

The following example problem is given to illustrate the use of this equation.

Example: Calculate the cleaning frequency for a preheater assuming the following conditions and determine the design fouling factor.

As a result of preliminary sizing and the assumption of a tube side design fouling factor of $.003 \mathrm{~h}-\mathrm{ft}^{2}{ }^{\circ} \mathrm{F} / \mathrm{Btu}$, a preheater contains $1574,3 / 4 \mathrm{in}$. diameter $\times 32 \mathrm{ft}$ long low fin tubes having an inside surface area of 6530 $\mathrm{ft}^{2}$ and an outside area of $22,060 \mathrm{ft}^{2}$. It is estimated that cleaning the inside of each tub requires 2 cleaning passes of 10 sec each employing a 2man crew. Disassembly and preparation work, cleanup, and reassembly after cleaning require a 3 -man shift each. Labor costs are $\$ 15 / \mathrm{hr}$. The capital cost of the heat exchanger is $\$ 12 / \mathrm{ft}^{2}$ of inside surface are. Operating and maintenance costs in addition to the above cleaning costs are $1 \%$ of the capital costs. The capital facilities are amortized over 30 years 
at a $15 \%$ rate of return. The "clean" heat transfer coefficient is 150 $\mathrm{Btu} / \mathrm{h}-\mathrm{ft}^{2}-{ }^{\circ} \mathrm{F}$ and the fouling equation is

$$
R^{\prime \prime}=0.005+0.0025 \theta
$$

for $\theta$ in years and $\mathrm{R}^{\prime \prime}$ in $\mathrm{h}-\mathrm{ft}^{2} \mathrm{-}^{\circ} \mathrm{F} / \mathrm{Btu}$ based upon field tests or assuniption. The total cleaning costs are

$$
\frac{2 \times 10 \times 1574 \times 2 \times 15}{3600}+2 \times 8 \times 3 \times 15=\$ 982 .
$$

The cleaning costs per unit area are $982 / 6530=\$ 0.1504 / \mathrm{ft}^{\mathrm{q}}$.

The capital recovery factor is $\mathbf{0 . 1 5 2 3}$.

The fouling coefficients are $a=0.0025 ; b=0.0005$.

The optimum number of cleanings per year is given by

$$
\begin{gathered}
N^{2}=\frac{(0.0025)(150)(12)(0.1523+0.01)}{(1+0.0005 \times 150)(0.1504)} \\
N^{2}=\frac{0.7304}{0.1617}=4.52 \\
N=2.13
\end{gathered}
$$

If the heat exchanger is to be cleaned every 6 months, the fouling resistance to use in seizing the heat exchanger is

$$
\begin{gathered}
R^{\prime \prime}=0.0005+0.0025(0.5) \\
R^{\prime \prime}=0.00175
\end{gathered}
$$

(Note: iteration will change this value.)

The cleaning costs assumed in the above example do not include any penalty due to lost productivity while the plant is down. Such losses are very real; however, overall plant economic calculations normally assume a plant is down about $20 \%$ of the time. Surely twice a year cleaning can be done within the outage allowance.

(3) Subcooling at the preheat outlet. Ideally, the geothermal fluid heats the working fluid to boiler temperature as it leaves the condenser. In the boiler only the heat requird to vaporize the working fluid is added. In actual practice, the working fluid must be subcooled as it leaves the preheater to provide a safety margin to prevent subcooled nucleate boiling in the preheater and to prevent excessive flashing across the boiler feed control valve. In a conventional steam power plant the feedwater temperature 
leaving the last feedwater heater is 55 to $85^{\circ} \mathrm{C}$ below the boiler temperature. Geothermal plants cannot afford such large margins and thus provide relatively little temperature difference. Some sensible heating must be done in the boiler which lowers the brine utilization slightly. Many factors determine the actual subcooling. Heat exchanger manufacturers provide conservatism in the design of a preheater and as a result the unit is slightly oversized for the intended service. This tends to reduce the logarithmic mean temperature difference required and, therefore, the pinch point is reduced, reducing the subcooling margin. The potential for fouling and the tendency to provide conservative designs will lead many designers to provide excess area in the heat exchangers through application of the fouling resistance. The consequence of this approach is to provide a heat exchanger which is oversized when clean and which only operates at its design point when the maximum allowable fouling has occurred (at which time it is due for shutdown and cleaning). Thus, from this point of view alone, the power plant operates off its optimized design point the majority of the time. Because of the fixed geothermal supply, feed pump capacity, and turbine nozzles, no advantage can be taken of the increased heat transfer capability during periods of operation prior to reaching the maximum allowable fouling.

Geothermal power plants can increase their output significantly if they are designed to take full advantage of the seasonal and daily variations in sink temperature. However, when this is done, heat exchangers must be designed for the lowest temperature of the working fluid leaving the condenser. Thus, when the ambient temperature (sink) is high, less heat must be added to the working fluid to raise it from the condenser outlet temperature to the boiler temperature; the heat exchanger is, therefore, oversized for this condition.

The use of a high fouling factor and excess area above that needed to handle the minimum sink temperature condition result in a heat exchanger (preheater) that is oversized at some time during operation. The effect of these choices is to reduce the subcooling at the preheater outlet. With this many factors to consider, design fouling resistances, vendor conservatism, additional refinements to handle minimum condensate temperature, control valve flashing margins, and boiler inlet subcooling, it is desirable to minimize as many variables as possible. One approach to achieve this minimization is to specify no fouling factors, or very minimal ones at most. This decision would eliminate excess area and reduce capital cost. The effect of fouling, if any, would be handled by adjusting plant conditions slightly. If possible the preheaters and boilers should be purchased from the same vendor so that conservatism is applied to the proper component. For example, if significant excess area is provided in the preheater, the subcooling to the boiler exit will be reduced and flashing across the feed control valve may be a problem. However, if a single vendor supplies both components, then the preheater can be marginally designed or underde- 
signed and the conservatism applied to the boiler. Such options should be considered in the overall definition of system and the specification of the heat exchanger.

\subsubsection{Divect contact binary cycles* (By Harold R. Jacobs** and Robert F. Boehm**)}

4.2.6.1 Introduction. Binary cycles are extremely attractive for use with geothermal brines at resource surface temperatures above $150^{\circ} \mathrm{C}$ when the brine is very low in dissolved solids. However, many liquid dominated geothermal fields produce brines below $150^{\circ} \mathrm{C}$, and many of these brines are heavily laden with dissolved solids. The use of conventional heat exchangers make binary cycles appear uneconomical for production of electrical power in these cases. Thus, unconventional heat exchangers have been investigated. At the University of Utah Jacobs and Boehm**, in 1973, first suggested the use of direct contact heat exchangers to overcome the problem of fouling of conventional heat exchangers by geothermal brines and provide increased heat transfer coefficients between the brine and secondary working fluids.

The use of direct heat exchangers is not a total panacea for all problems concerned with production of electricity from geothermal brine, although they do in fact eliminate heat exchanger fouling and provide greatly improved heat transfer characteristics. A direct contact binary cycle introduces concern for working fluid loss by its partial solubility in the brine, increased parasitic losses if the brine pressure needs to be increased to match that of the working fluid, and the elimination of noncondensibles (coming from the brine) in the condenser. Despite these difficulties, numerous investigators $(60-63)$ have indicated significantly lower electrical costs as compared to conventional binary and even flash systems, depending upon field production costs and resource quality. In this section the primary differences between design of direct contact binary cycles and conventional binary cycles are enumerated.

\subsubsection{Direct contact binary cycle thermodynamics. Consider the simple} direct contact cycle shown in figure 4.90 . The brine from the well condition A, may be at a pressure only slightly above its saturation pressure. For a

\footnotetext{
* An abbreviated form of this review has appeared in the literature and is noted as reference (59).

**H. R. Jacobs and R. F. Boehm, Dept. of Mechanical Engineering, University of Utah, Salt Lake City, Utah, first conceived direct contact application to binary cycles in May 1973. A patent disclosure was filed with the University of Utah Patent and Product Development Office on Aug. 13, 1973 (no additional action was taken). The concept was first proposed to NSF-RANN, Oct. 1973 by CEP 73-089 "A New Application for Utilization of Warm Geothermal Water in Power Production" revised proposal entitled "Feasibility Study of the Application of Direct Contact Heat Exchangers to Power Cycles Utilizing Brines," submitted July 1974, funded January 1975.
} 


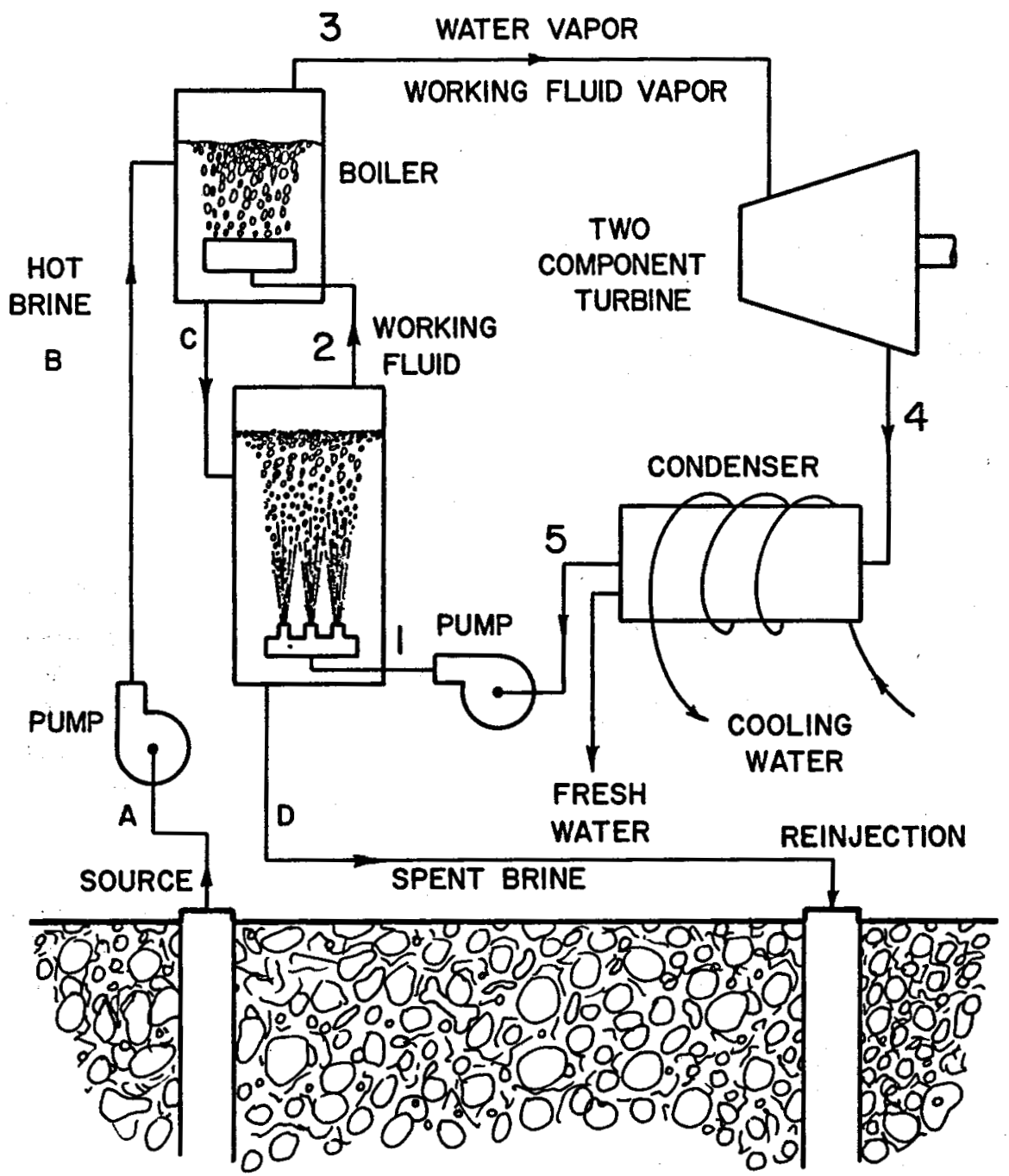

FIGURE 4.90-Typical direct contact cycle.

given working fluid this could be considerably below the ideal pressure for the turbine entrance conditions, 3 . In that case a brine pressure boost pump is necessary to provide the brine at condition $\mathrm{B}$ where $P_{B}=P_{3}$. The net work produced by the cycle is reduced by this required pump work below that possible for a standard binary cycle where the brine pressure can be considerably below that of the working fluid, since the two fluids are separated in a conventional heat exchanger. It is possible, however, that the smaller approach temperatures, $T_{\sigma}-T_{2}$, that could be achieved by a direct contact heat exchanger might compensate for this increased pump work. In addition the selection of the working fluid may allow for reducing the brine pump work. 
Depending upon the intimacy of the mixing between the working fluid and the brine, a loss of working fluid will occur due to its solubility in the brine. Conservatively; it will be at equilibrium conditions at the temperature and pressure at which the brine leaves the system, $T_{D}$ and $P_{D}$. In the simple cycle of figure $4.90, P_{D}=P_{\mathrm{B}}$. The degree of salinity of the brine affects the solubility. The higher the salinity the lower the solubility. In this fact it is clear that the poorer the conditions are for the use of conventional heat exchangers, the better they are for direct contact heat exchangers! However, it must be remembered that any loss of working fluid increases the cost of producing the electricity.

The above discussion points out that in comparing direct contact binary cycles to standard binary cycles, the operating pressure takes on increased significance in the selecting of the working fluid. The solubility of the working fluid is introduced as a new parameter which can completely eliminate from contention some fluids that looked attractive for a conventional binary cycle. As an example, in some cases ammonia may have desirable thermodynamic properties but is eliminated due to its high solubility in water. (Its toxicity also pases a hazard.)

Another factor unique to the direct contact cycle is that the fluid entering the turbine is always a mixture. That is, if the cycle is supercritical there will be water in the working fluid according to its solubility in the working fluid. If the cycle is subcritical the amount of moisture in the vapor will be dependent upon its partial pressure, which may be calculated in a similar way to that in which one calculates the saturated water content of the atmosphere. For example, given the temperature of the vapor leaving the primary heat exchanger, $T_{3}$, the equation of state for water yields the pressure

$$
P_{\mathrm{E}_{2} \mathrm{O}_{(\mathbf{3})}}
$$

for which the specific volume is also known. If the pressure at 3 is known,

$$
P_{W \pi_{3}}=P_{3}-P_{\mathrm{B}_{2} \mathrm{O}_{(8)}}
$$

From the working fluid equation of state one can find

$$
v_{W} r_{3} .
$$

The mass ratio of water to working fluid in the vapor is thus

$$
M_{\mathrm{H}_{2} \mathrm{O}} / M_{W F_{3}}=v_{W r_{3}} / v_{\mathrm{H}_{2} \mathrm{O}_{(a)}}
$$

\footnotetext{
*Actual values of specific volume must be used as neither fiuid behaves as a perfect gas (compressibility effects are extremely important). Use of perfect gas relations can lead to considerable error.
} 
As an example, with pentane as the working fluid, $T_{3}=130^{\circ} \mathrm{C}\left(266^{\circ} \mathrm{F}\right)$ with $P_{\mathbf{s}}=13.5$ atmospheres,

$$
M_{\mathrm{H}_{2} \mathrm{O}(3)} / M_{\text {Pent (3) }}=0.0487 \text {. }
$$

Thus, a mixture of nearly five percent water vapor would be required to expand through the turbine. As the water vapor has a much greater enthalpy than pentane, the energy density is increased (available enthalpy per unit mass of vapor mixture). It has been shown at the University of Utah that this results in a smaller turbine size and lower mass flow rates than would be possible with pentane alone (64). Thus, a definite advantage is shown for the direct contact binary cycle that was not previously recognized as the decrease in turbine size indicates a decrease in cost. (See section 4.2.6.6 for detailed discussions and comparisons for different fluids.)

In attempting to establish a criteria for fluid selection, J. Whitbeck at EG\&G, Idaho attempted, in 1975, to calculate the relative size of turbines. Such an analysis indicated that the size varied approximately as the inverse of the molecular weight of the secondary fluid raised to a power. Since most potential working fluids have higher molecular weights than water, the presence of water vapor reduces turbine size by reducing the effective molecular weight. This is discussed in detail in section 4.2 and in the report by Bliss et al. (64), in which a modification of the theory of Balje (65) is given.

Due to the many aspects that make direct contact geothermal cycles unique, and the lack of availability of a means of analysis, the development of the computer program DIRGEO* was initiated [Riemer et al. (66)]. The program was designed to use available information and new data or techniques as they became available. Thus, DIRGEO carries out most of its analysis utilizing subroutines. Subroutines exist for calculating thermodynamic properties, carrying out turbine analyses, heat exchanger design, etc. $(66-69)$.

Figure 4.91 shows the main program hierarchy as it now exists. Current modifications include extension of the subroutine PREHET to analyze a variety of liquid-liquid direct contact preheaters including spray columns, baffle columns, turbulent pipe heat exchangers, and mechanically agitated columns. Another subroutine is to be added to design the condenser system including a variety of direct contact condensers. A third addition will allow for design of systems for working fluid recovery and separation of water from working fluid in the condenser. The latter is partially included within the present computer code by assessing the potential recovery by. flashing the brine to a specified pressure prior to rejection. The hardware requirements necessary for this type of system have not been included. A total costing package also needs to be included.

*This program was developed through DOE funding and is available through the University of Utah or EG\&G-Idaho, Inc. 


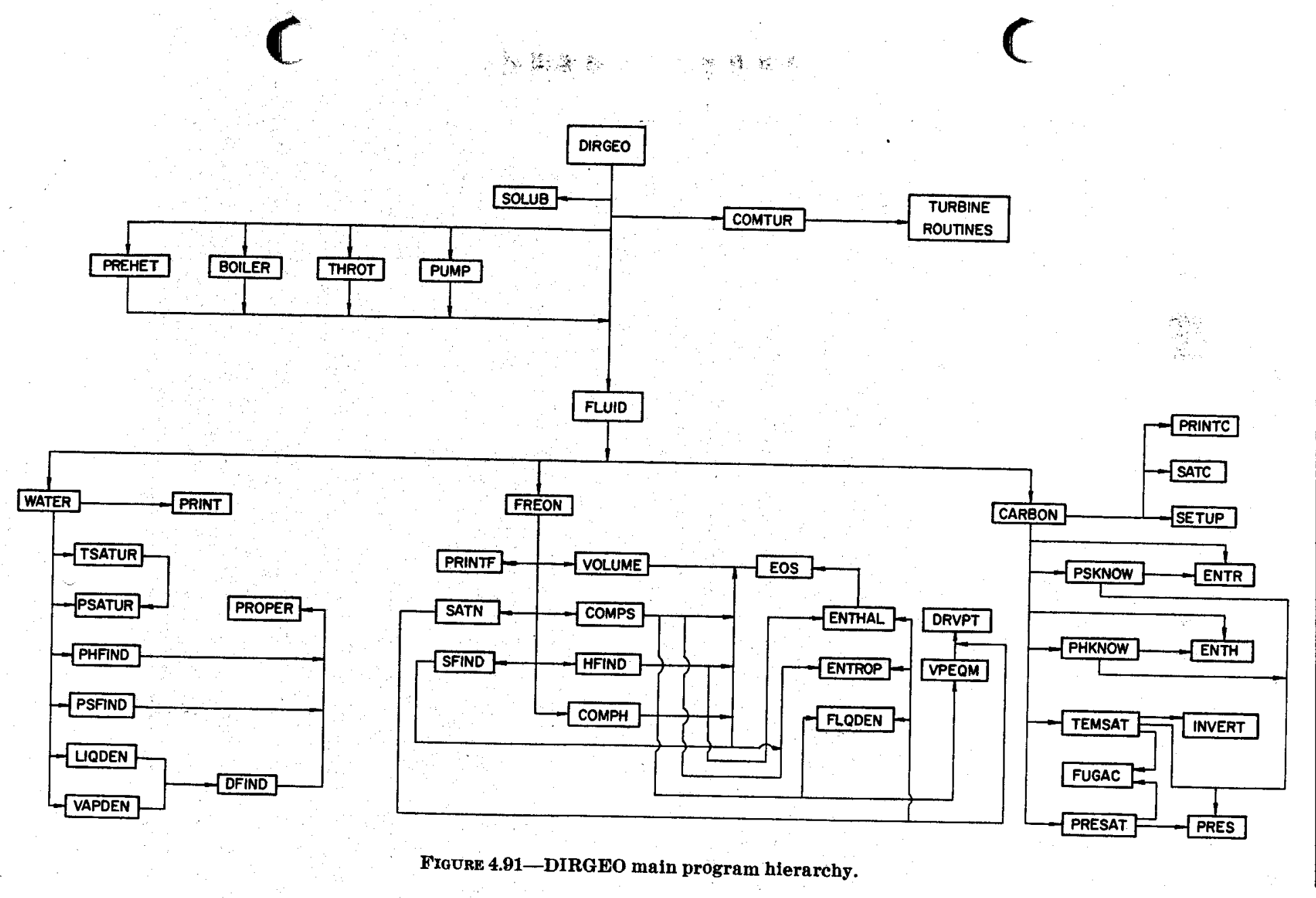


The main cycle program DIRGEO differs from binary cycle computer programs in that it must analyze a turbine with a binary mixture as a working fluid, as well as assess fluid losses and a wide range of possible. types of direct contact heat exchangers. No basic difference from a thermodynamic viewpoint occurs in boilers; however, the direct contact preheat heat exchangers can be of either the parallel flow type or the counter flow type. Of the parallel flow type only a turbulent pipe mixer is practical from a heat transfer standpoint; however, since even they can only provide one theoretical stage, counter flow type preheaters are preferred. DIRGEO is capable of analyzing systems using either parallel or counterflow exchangers.

To handle configurations with parallel flow preheaters, it became necessary to develop a unique system for numbering the thermodynamic states. The numbering sequence starts with the boiler inlet brine condition being denoted as one. The boiler exit to the turbine was numbered two. The exit state of the last turbine stage is then two plus the number of turbine stages. The condenser exit state number is the number of turbine stages plus three. The numbering sequence must next account for the number of preheater stages, if any. The preheater states are numbered for the secondary fluid consecutively from the condenser to the boiler. The brine states are numbered starting from the boiler exit as the number of turbine stages plus two times the number of preheater stages plus 6 through to the exit from the final preheat stage. Secondary processes on the brine, after exiting the final preheater, would be numbered from there. Figure 4.92 shows a typical cycle with two parallel flow direct contact preheaters.

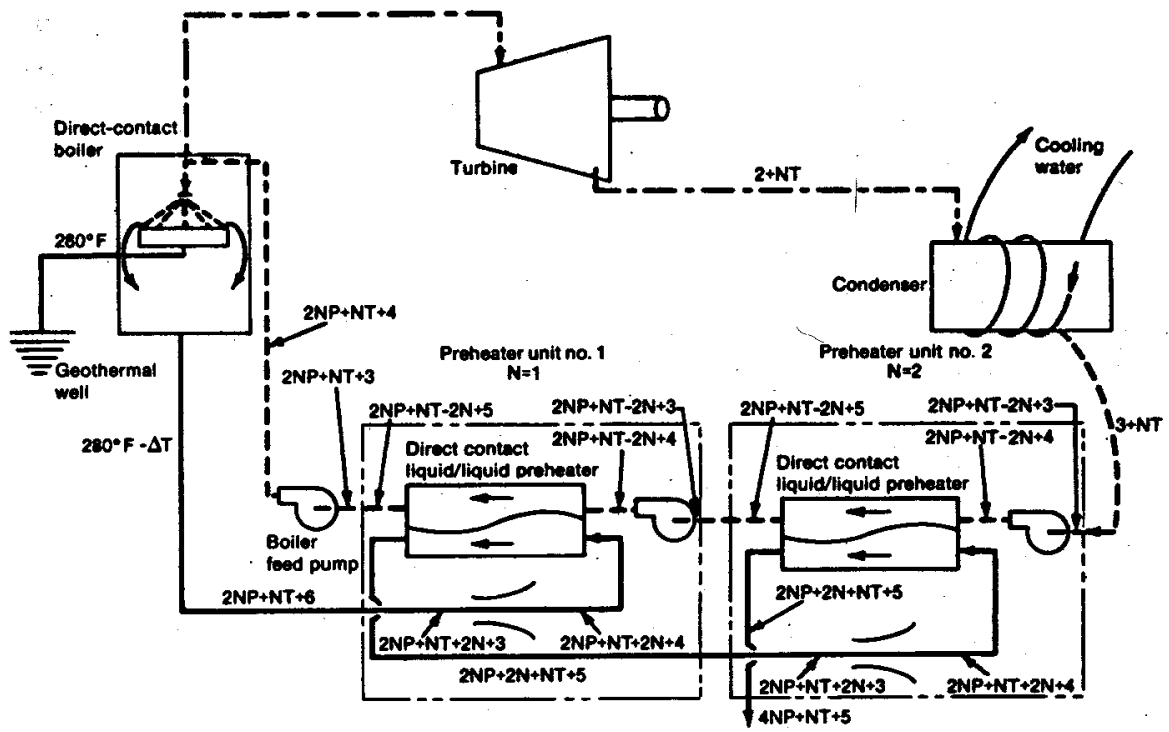

FIoURE 4.92-Schematic diagram of a direct contact cycle indicating the state numbering system. 


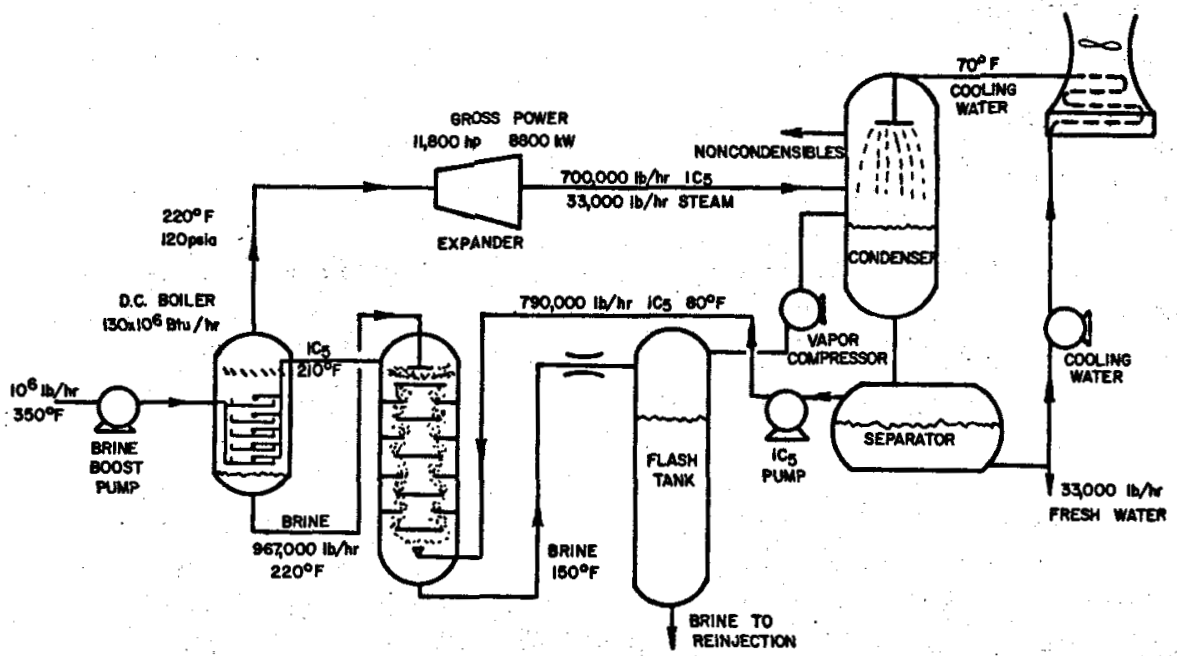

Fiodre 4.93-Direct contact binary geothermal cycle-moderate temperature.

When a counter-current type preheater is used there is normally a requirement for one preheater and probably a single pump. Thus, the boiler feeder pump would require no work as the pump in front of the first preheater would in fact be the boiler feed pump. Some of the so-called countercurrent direct contact heat exchangers do not really give counter-current flow. This may be particularly true of a large diameter-to-height ratio spray column, as will be discussed later. Consider the cycle shown in figure 4.93 and its temperature-duty chart, figure 4.94. It is obvious that four theoretical stages* are required, but a large diameter-to-height spray column may only be able to achieve one stage without internal vertical baffling. If no baffling is used two preheaters and an interstage pump might be required.

The computer program, DIRGEO, is presently equipped to handle the following fluids as potential working fluids in a direct contact cycle: $R$ 113, R-114, R-11, R-12, R-13, R-14, R-21, R-22, R-23, butane, ethane,

*A theoretical stage is defined by the temperature steps shown by the dashed lines on figure 4.94. A stage is in effect a perfect mixed contactor.

Fiqure 4.94-Temperature vs. duty for the contactors of figure 4.93 .

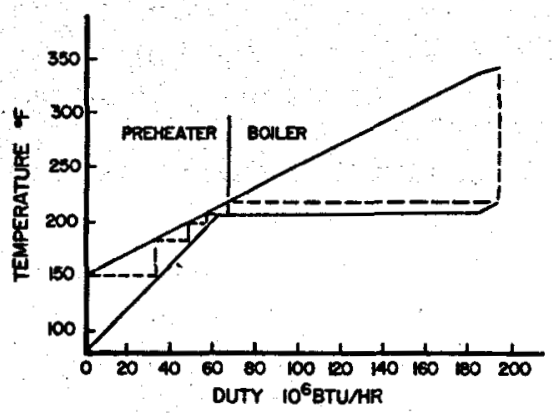


ethlyene, heptane, hexane, isobutane, isopentane, methane, octane, pentane, propane, and propylene. It is planned to add the following five cyclo-hydrocarbons: cyclo-pentadiene, cyclo-pentane, cyclo-pentene, methyl-cyclobutane, and methyl-cyclo-pentane. The latter five compounds were selected, at the end of a thorough search of the literature, as possible direct-contact binary cycle working fluids.

For detailed information on the computer program and its use, a users manual is available through DOE, Idaho Falls, Idaho; The University of Utah, Department of Mechanical Engineering, Salt Lake City, Utah; or the Geothermal Directorate of DOE in Washington, D.C.

\subsubsection{Typical direct contact binary oycle performance. Comparisons of} the performance of three working fluids in a direct contact power cycle have been made for a variety of cycle conditions ( $\% 0)$. Pentane, isobutane and R-113 are the working fluid candidates that have been examined most thoroughly, though the program (DIRGEO) is capable of examining many other fluids. The Thermodynamic Figure of Merit (TFM) has been taken as the primary measure of the cycles' thermodynamic efficiency and used as the basis for thermodynamic optimization. (The optimum TFM also implies the optimum value of brine flow/ $\mathrm{kw}-\mathrm{h}$ of net power.) Though thermodynamic optimization will not necessarily imply cost optimization, it is still one essential feature required for comparing relative merits of different working fluids.

The Thermodynamic Figure of Merit (TFM) is used since thermal efficiency is not an adequate performance indicator when using a sensible heat source such as geothermal brines. TFM is defined as the net power output of the cycle divided by the heat available in the brine. It can be written

$$
T F M=\frac{P}{Q_{a c t}} \frac{Q_{a c t}}{Q_{b}}=\eta \frac{\left(T_{s}-T_{s}\right)}{\left(T_{s}-T_{\infty}\right)}
$$

$P=$ Net power produced

$Q_{a e t}=$ Energy transferred from the brine

$Q_{b}=$ Energy that could be transferred from the brine if it were reduced to the ambient temperature

$\eta=$ Conventional thermal efficiency

$T_{s}=$ Brine source temperature

$T_{e}=$ Brine exit temperature from the system

$T_{\infty}=$ Ambient temperature.

In calculating the results to be presented in this section the following assumptions were made:

Boiler approach temperature $=2.8^{\circ} \mathrm{C}\left(5^{\circ} \mathrm{F}\right)$

Counter flow preheater

Turbine adiabatic efficiency $=86 \%$

Pump efficiency $=80 \%$ 
Single turbine stage

Net power output 50MWe

Brine specific heat $\mathrm{Cp}=1.0 \mathrm{Cal} / \mathrm{gm}-\mathrm{C}(1 \mathrm{Btu} / \mathrm{lbm}-\mathrm{F})$

$0^{\circ}$ superheat in boiler

Figure 4.95 shows how the TFM varies with boiler pressure for three working fluids. These calculations were performed for a $138^{\circ} \mathrm{C}\left(280^{\circ} \mathrm{F}\right)$

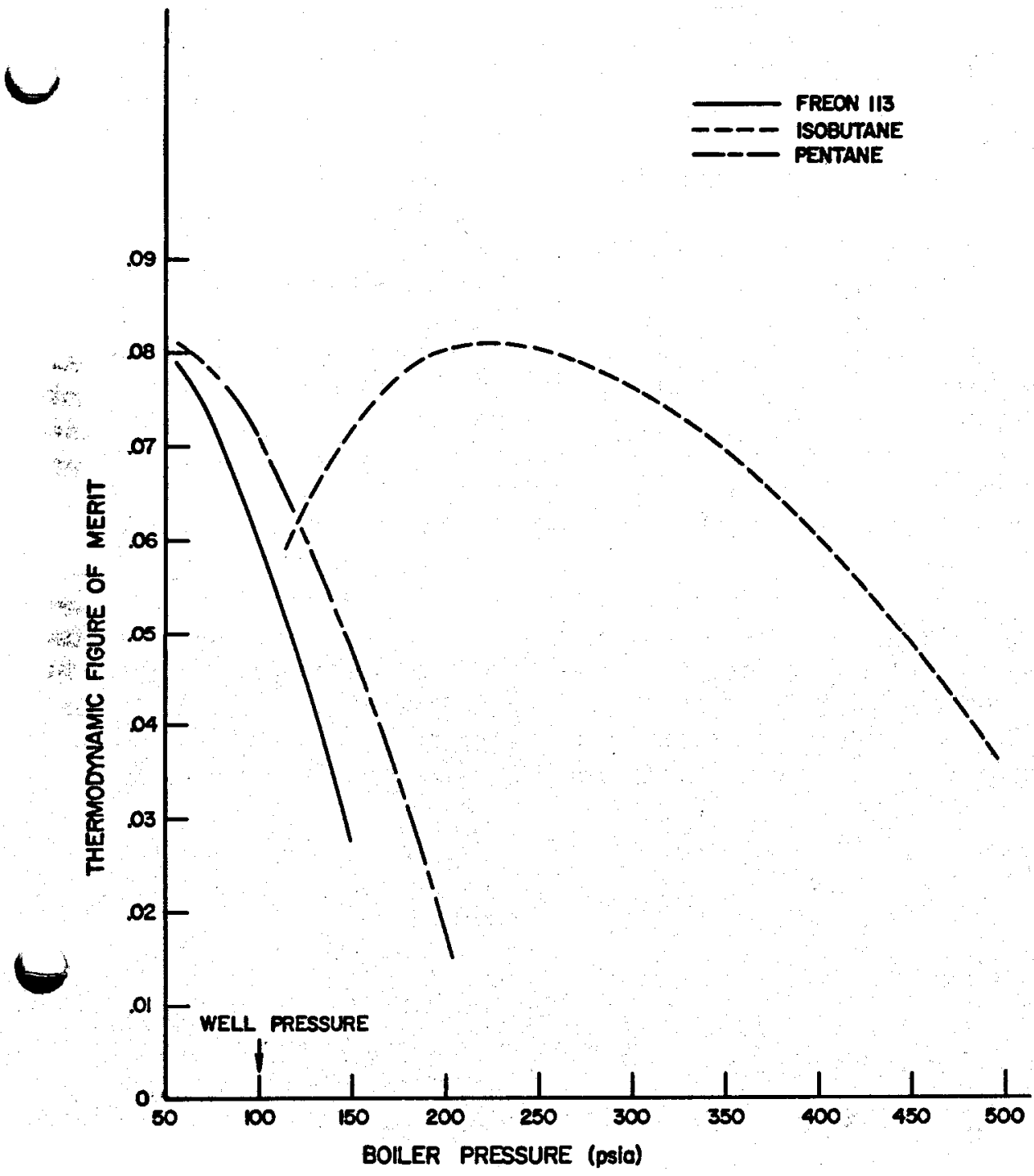

Figure 4.95-Thermodynamic figure of merit for three working fluids and a geothermal source temperature of $280^{\circ} \mathrm{F}$; Brine inlet temperature $280^{\circ} \mathrm{F} ; 0^{\circ}$ superheat; $80^{\circ} \mathrm{F}$ condenser temperature; 1 turbine stage; 10 preheater stages (effectively countercurrent). 
geothermal source temperature, a $27^{\circ} \mathrm{C}\left(80^{\circ} \mathrm{F}\right)$ condenser temperature and a 100 psia well pressure. The TFM reaches a maximum for the isobutane cycle at a pressure of 225 psia. At higher pressures there is insufficient temperature drop in the brine and at lower pressures it is necessary to pump more isobutane and there is a smaller pressure drop across the turbine. The TFM for the pentane and R-113 cycles increases steadily with decreasing boiler pressure until the pressure reaches the saturation pressure of the incoming brine.

It can be seen that the same TFM can be attained using either pentane or isobutane in a binary cycle using $138^{\circ} \mathrm{C}$ brine. Thus selection of the best working fluid for this low temperature cycle must be made on the basis of other considerations. The pentane cycle operates at a lower pressure which results in a lower capital investment in the heat exchanger vessels. But a pentane condenser will be at subatmospheric pressures when the condenser temperature is below approximately $38^{\circ} \mathrm{C}$. This poses the potential hazard of oxygen leaking into the system. Thus the additional cost of high pressure isobutane vessels must be weighed against the cost of safeguards such as an oxygen detector in the pentane condenser. Of course, explosive danger is maximized when the fuel to oxidizer ratio is low; thus, it may well be safer to operate a low pressure condenser system with pentane rather than a high pressure butane system with its potential danger by leaks into the atmosphere. The R-113 cycle offers good thermodynamic performance at low source temperatures and the advantage of operating with a nonflammable fluid. As will be shown in a later section of this chapter, the cost of R-113 lost in solution in the spent brine, and the large turbine diameter required, may be excessive.

At higher geothermal source temperatures the isobutane shows better performance than either pentane or R-113. Figure 4.96 shows the best TFM attainable in a subcritical binary cycle as a function of the source temperature. As mentioned earlier, at $280^{\circ} \mathrm{F}\left(138^{\circ} \mathrm{C}\right)$ the three fluids have

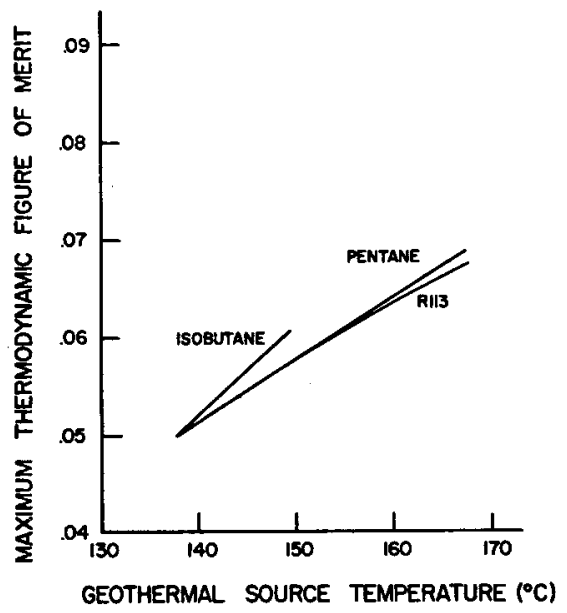

Figure 4.96-The optimum thermodynamic figure of merit attainable with three different working fluids: Condenser temperature $=43^{\circ} \mathrm{C}$., Boiler approach temperature $=2.8^{\circ} \mathrm{C}$. 
the same TFM. But at higher temperatures the isobutane cycle is superior. This is primarily because of the lower vapor pressures of the pentane and R-113. The boiler vapor exit temperature must remain higher than otherwise desirable to prevent flashing of the brine as it enters the boiler. This reduces the utilization of the brine. It is clear from this figure that fluid selection can be very dependent on the conditions of each individual well. At source temperatures above approximately $150^{\circ} \mathrm{C}$ isobutane may be the best fluid for a subcritical cycle. But at temperatures below $150^{\circ} \mathrm{C}$ the choice must be made with many considerations other than TFM in mind.

The effect of condenser temperature on cycle efficiency is shown in figure 4.97. As expected the TFM is strongly dependent upon the condensing temperature.

Fraure 4.97-The effect of condenser temperature on the optimum thermodynamic figure of merit: Source temperature $=149^{\circ} \mathrm{C}$., Boller approach temperature $=2.8^{\circ} \mathrm{O}$.

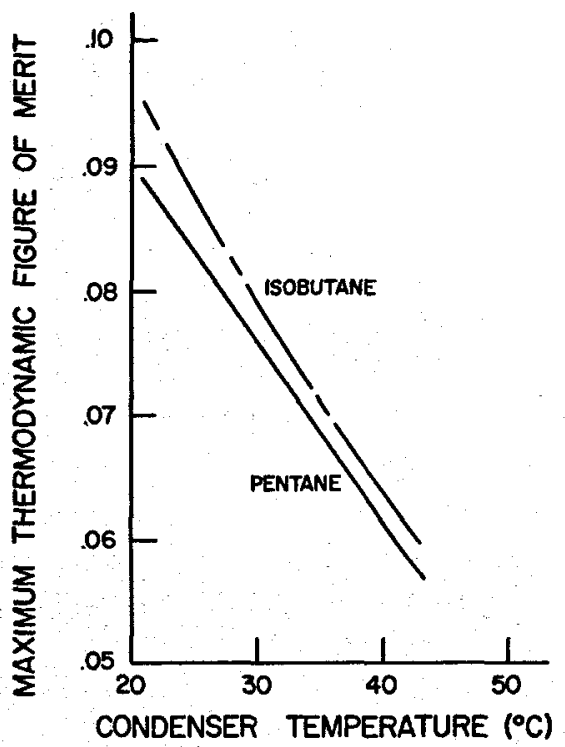

4.2.6.4 Worleing fuid losses in direot contact system. A potential difficulty with direct contact heat exchanger binary systems is loss of working fluid in the spent brine. To assess the severity of the problem the equilibrium solubilities of working fluids in brine at conditions encountered in the heat exchangers must be known. Equilibrium solubilities are of interest for two reasons. Calculation of the fluid loss rate, assuming equilibrium solubility is reached, places an upper limit on the loss rate (in the absence of carryunder). This immediately allows economic assessment of the worst possible case for comparison with other heat exchanger systems. Also, knowledge of the equilibrium solubility must be available to calculate the mass transfer in the heat exchanger and determine a more accurate estimate of the actual fluid loss rate.

Sufficient data on the solubility of all potential working fluids in water is lacking, particularly in the presence of dissolved salts and at tempera- 
tures typical of that for brine exit from a geothermal direct contact binary power plant. However Hellstrom et al. (71) have measured the equilibrium solubility in water of n-pentane, isobutane, R-113 and R-114 at a variety of temperatures and salinities. From a thermodynamic standpoint these fluids are among the best candidates for use as a working fluid with geothermal brines. Hellstrom et al. (71) found that Henry's Law for dilute solutions applies in the temperature and pressure range of interest. Henry's Law states that the concentration (in ppm by mass) of solute gas in a dilute solution is directly proportional to the partial pressure (in atm) of the solute vapor above the liquid solution. This is valid for partial pressures up to the saturation pressure. For pressures higher than the vapor saturation pressure (when there are both liquid and vapor phases of the working fluid present) the concentration is equal to the value at the saturation pressure. In explicit form:

where

$$
\begin{array}{lll}
\text { Sol. }=H \cdot P & \text { when } & P<P_{\text {sat }} \\
\text { Sol. }=H \cdot P_{\text {sat }} & \text { when } & P>P_{\text {sat }}
\end{array}
$$

Sol. $=$ solubility in $\mathrm{ppm}$ by mass

$H=$ Henry's Law Constant

$P=$ Partial pressure of vapor above the solution (atm)

$P_{\text {sat }}=$ Saturation pressure of solute fluid

Henry's Law constant is a strong function of the solution temperature and salinity as well as the solute fluid type.

Results of measurements of $H$ are shown in figures 4.98-4.101 for n-pentane, isobutane, R-113 and R-114 respectively. It can be seen that as tem-

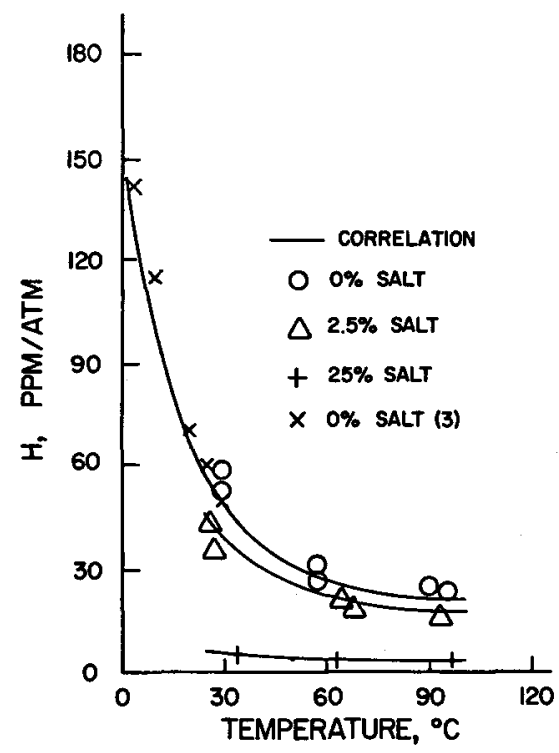

Frgure 4.98-Solubility of pentane in aqueous and saline solutions. 
Froure 4.99-Solubility of isobutane in aqueous and saline solutions.

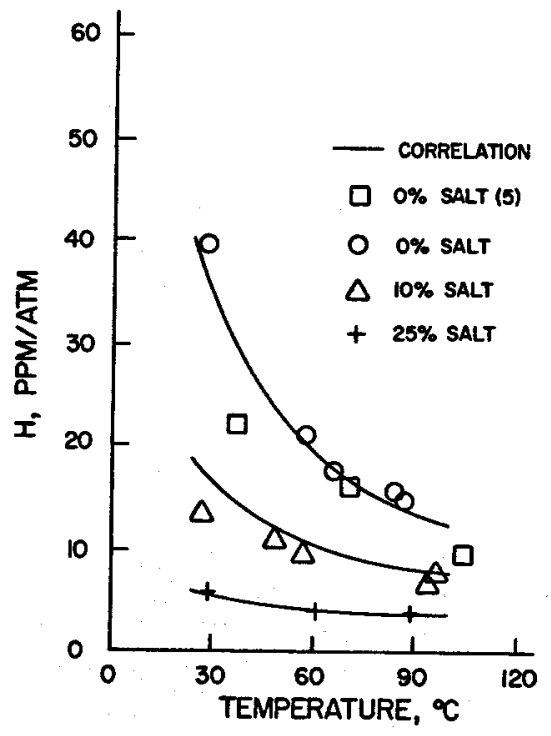

perature increases $\boldsymbol{H}$ decreases, and as salinity increases $H$ decreases again. The dependence of solubility upon salinity is favorable to the use of direct contact heat exchangers with highly fouling brines. Brines with high total dissolved solids content which may foul shell-and-tube exchangers will result in low fluid loss in the nonfouling direct contact exchangers.

The solubilities shown in figures $4.98-4.101$ can be correlated by an equation of the form:

$\ln (H)=A+1000 B / T+\mathrm{C} \ln (T / 1000)$ $+W(D+1000 E / T+F \ln (T / 1000))$

FraURe 4.100-Solubility of refrigerant-113 in aqueous and sallne solutions.

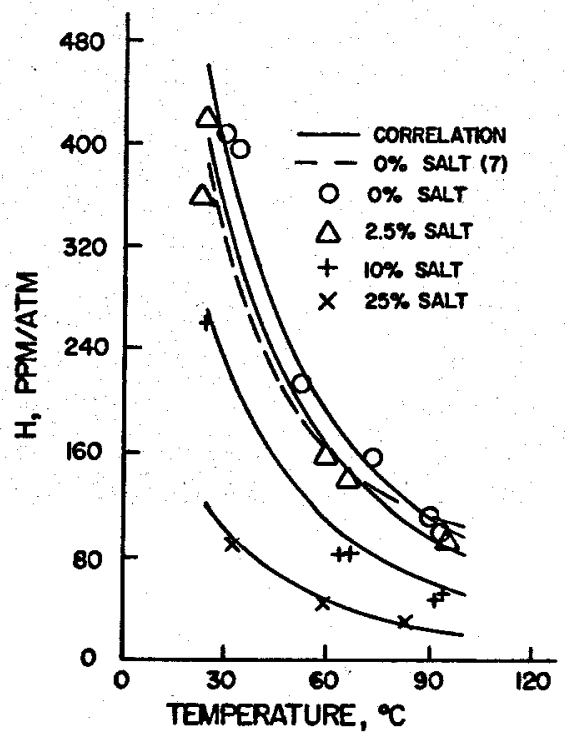




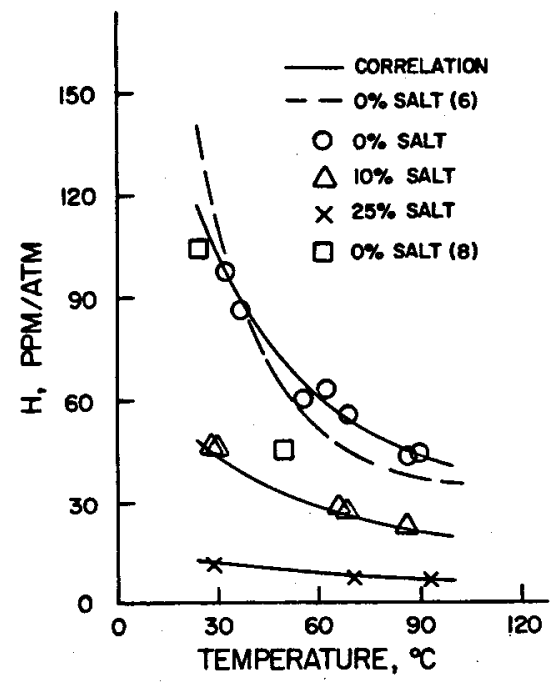

FraURE 4.101-Solubility of refrigerant-114 in aqueous and saline solutions.

where

$$
\begin{aligned}
H & =\text { Henry's Law constant } \\
T & =\text { Temperature }\left({ }^{\circ} \mathrm{K}\right) \\
W & =\text { Weight percent } \mathrm{NaCl}
\end{aligned}
$$

and $A, B, C, D, E, F$ are constants to be determined for each fluid. Values of these constants for each of the four working fluids are given in table

\begin{tabular}{|c|c|c|c|c|c|c|}
\hline Fluid & $\boldsymbol{A}$ & $B$ & $C$ & $D$ & $E$ & $F$ \\
\hline Pentan & 2. 6781 & 14. 158 & 38. 134 & -0. 055112 & -0.20640 & -0.54294 \\
\hline $\mathrm{R}-113$ & -0.82656 & 5. 2801 & 8. 8971 & -0.012415 & -0.073427 & -0.26167 \\
\hline $\mathrm{R}-114$ & 0. 82009 & 6. 2443 & 14.063 & -0.076257 & -0.22683 & -0.61829 \\
\hline Isobutane. & -0.61425 & 7. 0329 & 15. 946 & 0.095826 & 0.055289 & 0. 29560 \\
\hline
\end{tabular}
4.15. The curves calculated for each fluid are also shown in the figures.

TaBLE 4.15-Constants used in equation 4.85

The Henry's Law constants of the four fluids are compared in figure 4.102. The values are nearly identical for pentane and isobutane. But it must be kept in mind that the vapor pressure of isobutane is higher than that of pentane. Therefore, at a given temperature, the solubility of isobutane will be greater than that of pentane. It may also be greater than R-113 depending upon condenser temperature. $R-114$ appears to always show the highest solubilities at a given temperature of the four fluids even though $I I$ is greater for R-113.

The presence of noncondensible gases such as $\mathrm{N}_{2}$ and $\mathrm{CO}_{2}$ in the geothermal fluid can influence working fluid loss. The presence of these gases 
FiguRe 4.102-Comparison of solubilities of four fluids in a $10 \%$ saline solution.

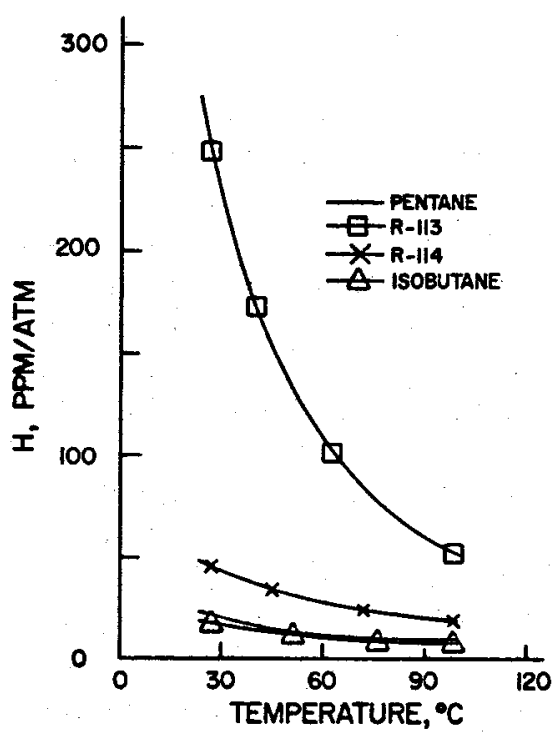

may reduce the solubility in the brine. The noncondensible gases will in large measure come out of solution in the brine as it enters the boiler. This is because the partial pressure of the gas over the brine will drop sharply as the brine comes in contact with the working fluid. The noncondensible gases will pass from the boiler to the condenser by way of the turbine. At this point the condenser will retain the gases and its pressure will continue to rise unless the noncondensibles are vented from the condenser. In the condenser the partial pressure of the working fluid will be high compared to that of the noncondensibles. Hence, as the noncondensibles are vented large amounts of working fluid vapor may also be vented. Thus, the condenser vent gases will have to be treated to prevent this loss.

As an example consider an isobutane cycle with a $40^{\circ} \mathrm{C}$ condenser temperature and $0.5 \%$ (by mass) noncondensibles in the geothermal brine. In the condenser the partial pressure of the isobutane will be 77 psia. If the partial pressure of the noncondensibles (here assumed to $\mathrm{N}_{2}$ ) is allowed to increase to 10 psia before venting, the ratio of the mass of isobutane to the mass of $\mathrm{N}_{2}$ vented will be approximately

$$
\frac{\dot{m}_{\text {leob }}}{\dot{m}_{\mathrm{N}_{2}}}=\frac{P_{1 \mathrm{ob}}}{P_{\mathrm{N}_{2}}} \frac{(\mathrm{Mol} . \mathrm{wt} .)_{\mathrm{loob}}}{(\mathrm{Mol} . \mathrm{wt} .)_{\mathrm{N}_{2}}}=16
$$

Thus isobutane will be vented with the noncondensibles at a rate equal to approximately eight percent of the total brine flow rate for $0.5 \%$ noncondensibles in the brine. This magnitude of fluid loss is clearly unacceptable and steps must be taken to greatly reduce the effect of noncondensibles. 
The noncondensibles must be removed from the brine before it contacts the working fluid if working fluid losses are to be kept to a minimum. This can be done most simply by flashing the brine to a pressure just slightly below its saturation pressure and stripping the noncondensibles with the small amount of steam. This can reduce the level of noncondensibles to a very manageable point without a great sacrifice in cycle performance (7\%).

The noncondensibles remaining in the brine through a flashing operation will be flashed from the brine in the boiler and collect in the condenser. By refrigerating and compressing the gases vented from the condenser most of the working fluid can be condensed and recovered. As long as the total amount of noncondensibles in the condenser is small the parasitic load of compressors and refrigeration for the vented gases will be very small. For example, a $50 \mathrm{MWe}$ plant using partial flashing of the inlet brine (assumed $138^{\circ} \mathrm{C}$ ) and a refrigerated condenser vent could reduce the isobutane loss to $42 \mathrm{~kg} / \mathrm{h}$ in the vented gases. This compares with approximately a $5 \times 10^{5} \mathrm{~kg} / \mathrm{h}$ loss if no recovery techniques are attempted. The parasitic load of the recompression and refrigeration would be the power requirements of a $6 \mathrm{KW}$ compressor and $0.2 \mathrm{MW}$ refrigeration unit, and the flash expansion of the inlet brine would lower its temperature only approximately $1^{\circ} \mathrm{C}(63)$.

4.2.6.5 Recovery of working fluid from spent brine. In section 4.2.6.3 the equilibrium solubilities of four possible working fluids in saline solutions were presented. If working fluid loss were equal to that calculated from equilibrium solubility considerations, then operating costs could be significantly affected. It is important, therefore, to devise techniques for recovery of working fluid from the spent brine.

Two methods for fluid recovery have been investigated to date. The first involves sparging of the working fluid from the brine by bubbling a gas such as $\mathrm{CO}_{2}$ through the brine. The working fluid will diffuse into the $\mathrm{CO}_{2}$ in a mass transfer column. After the $\mathrm{CO}_{2}$ leaves the column the working fluid can be removed from the $\mathrm{CO}_{2}$ by condensation. The second method of fluid recovery involves expanding the spent brine to a low pressure and allowing the working fluid to flash off. Since the solubility of the fluid is proportional to its partial pressure above the brine, decreasing the pressure over the brine will be very effective at reducing the fluid loss. This method, however, may require additional pumping of the spent brine for reinjection into the ground. Considering the problem of separating sparging gas from working fluid however, it could be less expensive than gas sparging.

Gas sparging has been investigated at the University of Utah using a simple column with sparging gas supplied from a $\mathrm{CO}_{2}$ bottle (70). The concentration of the working fluid in the water is measured using a gas chromatograph. Preliminary results indicate $\mathrm{CO}_{2}$ sparging is an effective means of removing pentane from water. 
FIGURE 4.103-Relative solubility in a $10 \%$ $\mathrm{NaCl}$ brine flashed to the pressure of a $30^{\circ} \mathrm{O}$ condenser.

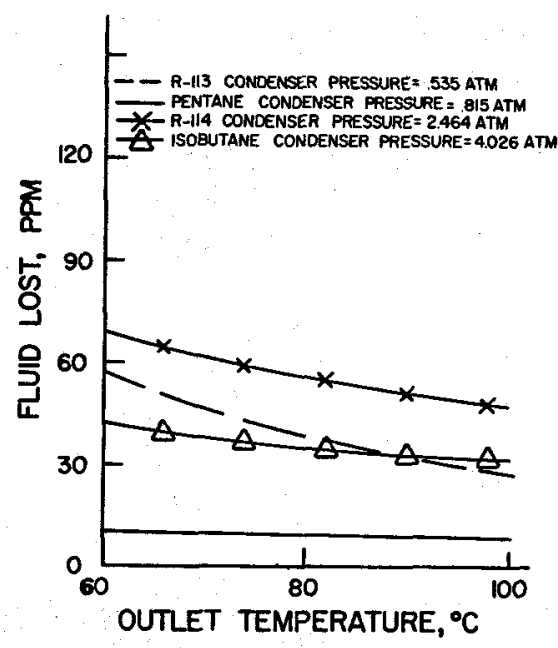

Flashing the working fluid from the brine offers a simple and effective means of fluid recovery. One method that would require little additional equipment would be to expand the spent brine in a chamber exposed to the condenser pressure. This would drop the partial pressure of the working fluid over the spent brine to a value less than that of the fluid partial pressure in the condenser. If the flash chamber were kept at a pressure slightly greater than the condenser pressure the recovered working fluid vapor would pass to the condenser. Figure 4.103 shows the equilibrium solubilities of four working fluids in $10 \% \mathrm{NaCl}$ solution when the brine is flashed to the pressure of a $30^{\circ} \mathrm{C}$ condenser. Figure 4.104 shows actial fluid loss for a net 50. MWe plant if the brine is expanded to the pressure of a $43^{\circ} \mathrm{C}$ $\left(110^{\circ} \mathrm{F}\right)$ condenser. Clearly, pentane is the most desirable fluid because of its low Henry's constant and low vapor pressure, if this system of recovery were used. If all fluids were flashed to the same pressure the results would follow the curves of figure 4.102.

Fluid losses may be reduced $75 \%$ by flashing the brine to the condenser pressure (assuming equilibrium once again). The cost for this flashing would be the pumping power required to boost the brine pressure high

Figuke 4.104-Working fluid loss rates in thermodynamic optimum $50 \mathrm{MWe}$ cycles when $10 \%$ salt brine is flashed to the pressure of a $43^{\circ} \mathrm{O}$ condenser.

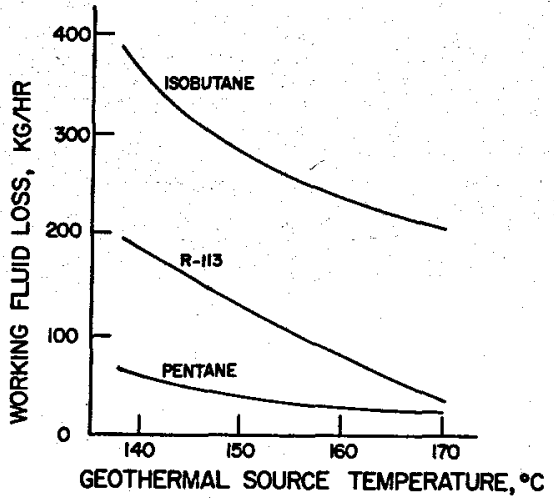


enough for reinjection. This could result in a $10 \%$ savings in the total power cost. If the brine must be boosted to 300 psia for reinjection there would be approximately a 4-5\% decrease in net power output from the plant. The 5\% (approximately) net savings in conjunction with the mitigation of possible environmental effects of working fluid release from the plant presents a clear case for use of recovery techniques.

4.2.6.6 Direct contact cycle turbine considerations. The vapor flowing through the turbine in a direct contact binary plant is a combination of water vapor and working fluid vapor. In this regard it is a different situation than either the flash system or the "conventional" binary system using a "pure" working fluid.

From a thermodynamic standpoint, one must consider the expansion of a binary mixture in analyzing the flow through a turbine. A mixture when it undergoes an isentropic expansion does precisely that: it undergoes the expansion as a mixture. This means that a net increase in entropy of one of the fluids must equal the decrease in entropy of the other if one analyzes each fluid utilizing its pure phase entropy. The fluids do not each separately undergo an isentropic expansion.

It has been shown by Bliss et al. (64) that the following relationships must hold for a two fluid mixture isentropic expansion.

$$
\dot{m}_{\mathrm{m} 1 \mathrm{x}} \dot{S}_{\mathrm{m} 1 \mathrm{x}}=\left(\dot{m}_{\mathrm{E}_{2} \mathrm{O}} S_{\mathrm{E}_{2} \mathrm{O}}\right)_{\text {in }}+\left(\dot{m}_{W p} S_{W r}\right)_{\text {In }}=\left(\dot{m}_{\mathrm{H}_{2} \mathrm{O}} S_{\mathrm{H}_{2} \mathrm{O}}\right)_{\text {out }}+\left(\dot{m}_{W F} S_{W F}\right)_{\text {out }}
$$

If one assumes constant flow rates exist, then it is also true that

$$
\frac{\dot{m}_{\mathrm{H}_{2} \mathrm{O}}}{\dot{m}_{\text {WF }}}=\frac{\dot{m}_{\mathrm{B}_{2} \mathrm{O}}}{\dot{m}_{\text {WF out }}} \equiv m_{R}
$$

and if volume changes due to the possible presence of condensed mass are neglected, then the mixture components should expand at the same rate, so

$$
\frac{v_{\mathrm{H}_{2} \mathrm{O}}}{v_{W F \text { in }}}=\frac{v_{\mathrm{H}_{2} \mathrm{O}}}{v_{W F \text { out }}}
$$

Equations 4.86-4.88 must be solved simultaneously together with the equations of state of the two fluids. Thus, in general this requires a computer to determine the exit state as the solution can be found only by iteration.

For the special case where both fluids partially condense within the turbine, utilization of equations $4.86-4.88$ results in

$$
X_{\mathrm{H}_{2} \mathrm{O}_{\text {out }}}=\frac{S_{m i z}-S_{W F, L}-a\left(S_{W F, V}-S_{W F, L}\right)-m_{R} S_{\mathrm{H}_{2} \mathrm{O}, L}}{b\left(S_{W F, V}-S_{W F, L}\right)+m_{R}\left(S_{\mathrm{B}_{2} \mathrm{O}, V}-S_{\mathrm{H}_{2} \mathrm{O}, \mathrm{L}}\right)}
$$

-This is the condition of isentropic flow of the mixture mentioned above. Note that the entropy of mixing is not included, since it will not change between the two states of the mixture. 
where

and

$$
a=\frac{m_{R}\left(v_{\mathrm{B}_{2} \mathrm{O}, V}-v_{W F, L}\right)}{v_{W V, V}-v_{W F, L}}, \quad b=\frac{m_{R}\left(v_{\mathrm{B}_{2} \mathrm{OV}}-v_{\mathrm{B}_{2} \mathrm{OL}}\right)}{v_{W F V}-v_{W F L}}
$$

$$
X_{F_{\text {out }}}=\frac{m_{R}\left(v_{\mathrm{H}_{2} \mathrm{O}, L}+X_{\mathrm{H}_{2} \mathrm{O}, \text { out }}\left(v_{\mathrm{H}_{2} \mathrm{O}, V}-v_{\mathrm{H}_{2} \mathrm{O}, L}\right)\right)-v_{W F, L}}{v_{W F, V}-v_{W F, L}}
$$

Both water and working fluid are likely to condense in the turbine if the saturation line on a $T-S$ diagram is negatively sloped for both fluids. Multiple condensation also occurs for fluids which have positively sloped saturation lines if the inlet state is chosen near the critical point, although for most of these fluids the condenser pressure is low enough that the process line emerges from the vapor dome before reaching the condenser pressure.

If either the water or working fluid condenses while the other becomes superheated, then the temperature must be found that satisfies the relation for entropy, the volume ratios and the condenser pressure. In the typical case water condenses and the fluid is superheated. In searching for the correct temperature, only one of the relations need not be satisfied momentarily. For example, guess a temperature above the condenser temperature (and certainly less than the inlet temperature). The pressure of the superheated fluid is found by subtracting the saturated pressure of the water (computed at the guessed temperature) from the condenser pressure and now all the remaining state variables can be found. The quality is determined from the entropy relation:

$$
X_{\mathrm{B}_{2} \mathrm{O}_{\text {out }}}=\left(\frac{S_{m i x}-S_{W}}{m_{R}}\right) \frac{1}{\left(S_{\mathrm{H}_{2} \mathrm{O}, v}-S_{\mathrm{E}_{2} \mathrm{O}, z}\right)}
$$

The difference in the volume ratio is found next:

$$
Y=\frac{\left[v_{\mathrm{H}_{2} \mathrm{O}, L}+X_{\mathrm{H}_{2} \mathrm{O}}\left(v_{\mathrm{H}_{2} \mathrm{O}, V}-v_{\mathrm{H}_{2} \mathrm{O}, L}\right)\right]}{v_{\mathrm{H}_{2} \mathrm{O}, \text { in }}}-\frac{v_{W F}}{v_{W F, \text { In }}}
$$

From experience it is known that when $Y$ is less than 0.01 , sufficient accuracy has been achieved. Therefore, the search in temperature continues until $Y$ is less than 0.01 .

The remaining possibility is that both the water and fluids are superheated. Since the pressure and temperature are now independent of each other for both the water and fluid, a search must be carried out allowing the temperature and one of the pressures to vary. Since water is usually near the saturation line if superheated, it is convenient to vary the water pressure. As in the last case, the fluid's pressure is the difference between the condenser pressure and the water pressure. In dimensionless form the relations for entropy and specific volume which are to be driven to zero are:

$$
Y=1-\frac{S_{W F}+m_{R} S_{\mathrm{B}_{2} \mathrm{O}}}{S_{\mathrm{m} 1 \mathrm{x}}}
$$




$$
Y=1-\frac{V_{W F}}{m_{R}\left(v_{\mathrm{E}_{2} \mathrm{O}}\right)}
$$

The actual state search is similar to the isentropic search but now the entropies are placed by enthalpies. For example, the total entropy is replaced by the actual exit enthalpy which is found from the adiabatic efficiency. But since the hydraulic efficiency is used in turbine theory, the approximation is made that the adiabatic efficiency is approximately equal to the hydraulic efficiency, although they are not mathematically equivalent.

Modification of similarity turbine theory for equilibrium expansions. Once the isentropic enthalpy drop $(\Delta H)$ and the actual exit specific volume $\left(v_{E}\right)$ are known, the rotative speed and diameter can be computed using a modification of Balje's theory (65). From Balje's efficiency map and design graphs a particular design is chosen. For example, at the optimal values the specific speed is 111 and the specific diameter is 1.15. Using these conditions Bliss et al. (64) derived the following specifications for an axial flow turbine:

The optimum rotative speed in rpm

and the diameter is

$$
N=8.51 \frac{\left(H_{\text {Total }_{\text {in }}}-H_{\text {Total }_{\text {oxlt }}}\right)^{0.76}}{\sqrt{Q_{\text {Total }}}}
$$

$$
D=8.79 \sqrt{Q_{\text {Total }}} /\left(H_{\text {Total In }_{\text {in }}}-H_{\text {Total exit }}\right)^{0.25}
$$

where the total volume flow rate, $Q_{\text {Total }}\left(\mathrm{m}^{3} / \mathrm{s}\right)$, is

$$
Q_{\text {Total }}=\frac{0.0624 \text { Power }}{\eta \Delta H}
$$

Another useful quantity in turbine design is the energy density. This is defined as:

$$
E_{r}=\Delta H / v_{\text {e }} \text { Total }
$$

This quantity has been shown to correlate roughly inversely with turbine costs and thus has been used to compare turbine costs when selecting potential working fluids.

Since the primary factor in determining turbine size is energy density, this important variable is compared for the various fluids in figure 4.105. Note that this increases with increasing pressure fiuids, primarily through the specific volume divisor.

The actual variation in turbine diameter and rotative speed for the six fluids and single stage operation is shown in figures 4.106-4.111. Two items should be noted in passing. The use of the term "optimum" on both ordi- 
Frauke 4.105-Comparison of the energy density of the six fluids.

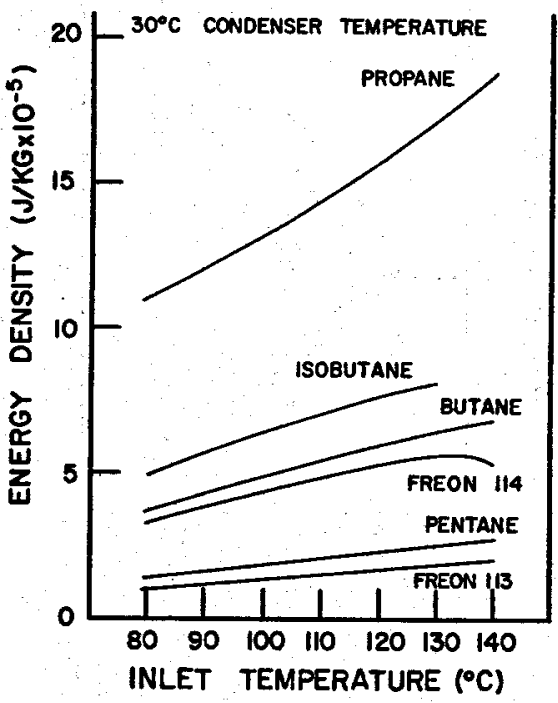

Frgure 4.106-Freon 113 optimum diameter and rotation rate. The net turbine power is ten megawatts.

Fraure 4.107-Freon 114 optimum diameter and rotation rate. The net turbine power is ten megawatts.
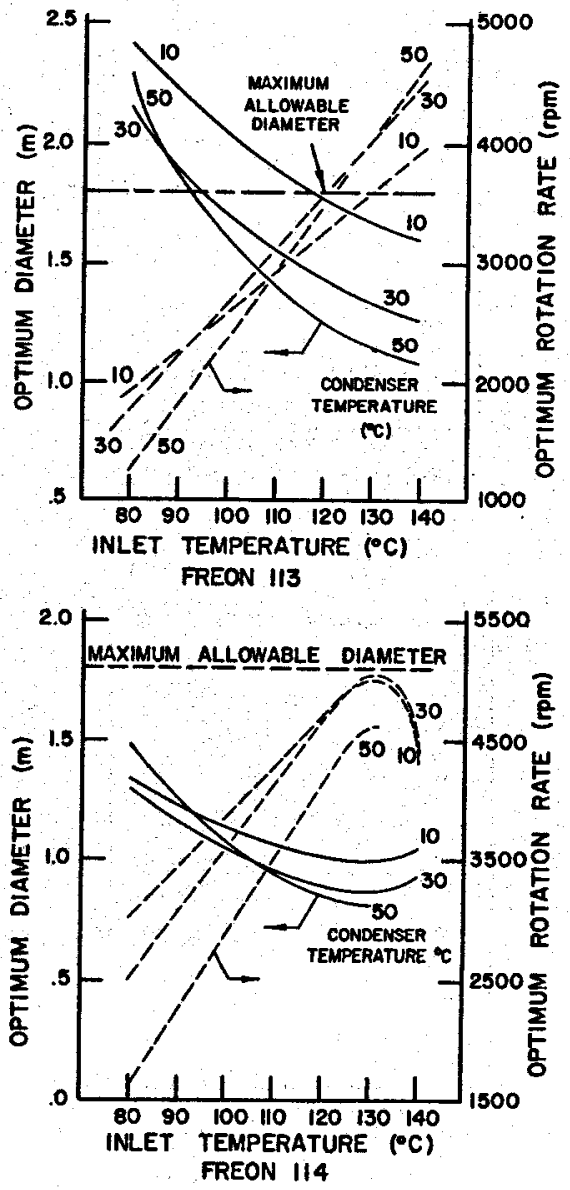


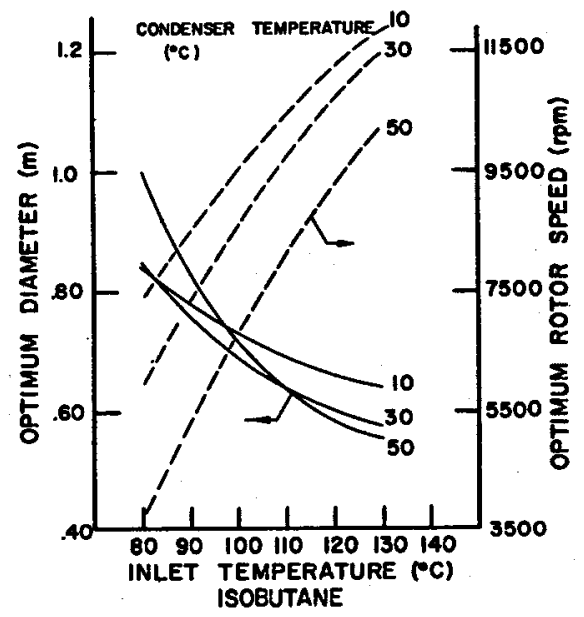

FIgUR: 4.108-Isobutane optimum diameter and rotation rate. The net turbine power is ten megawatts.

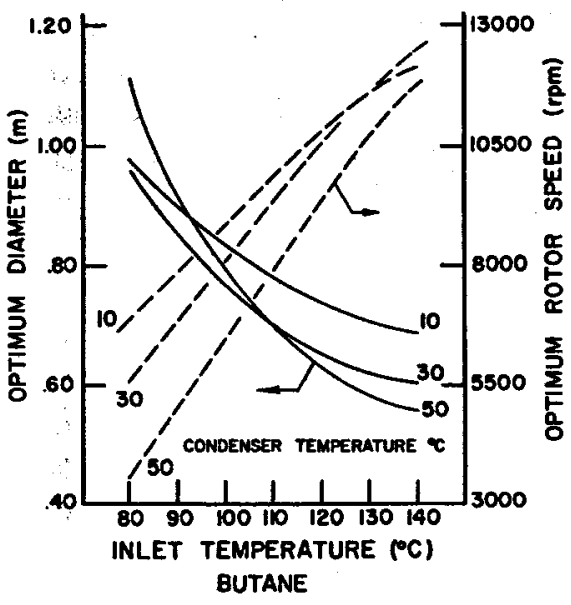

Frgure 4.109-Optimum diameter and rotation rate of butane. The net turbine power is ten megawatts.

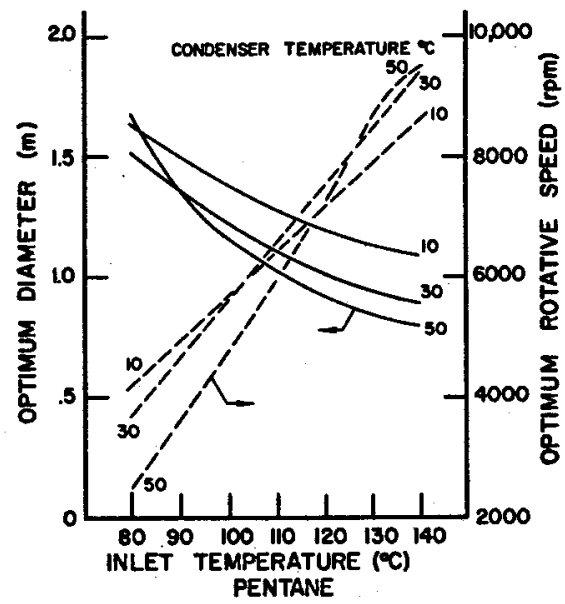

Fraure 4.110-Optimum diameter and rotation rate of pentane. The net turbine power is ten megawatts. 
Frauke 4.111-Optimum diameter and rotation rate of propane. The net turbine power is ten megawatts.

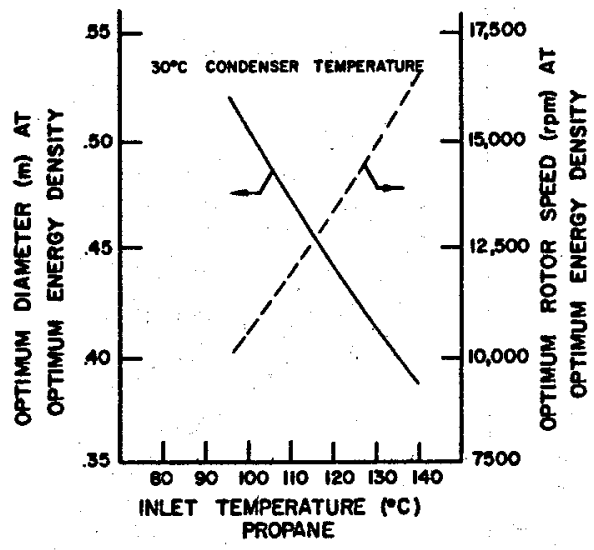

nate scales refers to the fact that these results were all evaluated at the optimum efficiency point (approximately $90 \%$ ) as defined by Baljé. A second item noted there is that a "maximum allowable diameter" is shown on some graphs. This value corresponds to a rotor about six feet in diameter and is simply used to bring attention to the fact that some fluids may require overall diameters (rotors plus case plus other items) that may be too large to be easily transported.

A comparison of the various turbine parameters for three different turbine output powers is shown in figure 4.112. As might be expected the variations in diameters and speeds with output power are not linear.

Variation of the exit quality with operating conditions is of great interest. Some concern might reasonably exist regarding the amount of moisture in the turbine passages. However, as shown in figure 4.113 , the total exit quality (defined as the mass of vapor divided by the total mass) is generally very high (moisture low) for situations typical of those proposed for direct contact binary geothermal power plants.

Fugure 4.112-Optimum diameter and rotation rate of pentane for different turbine powers.

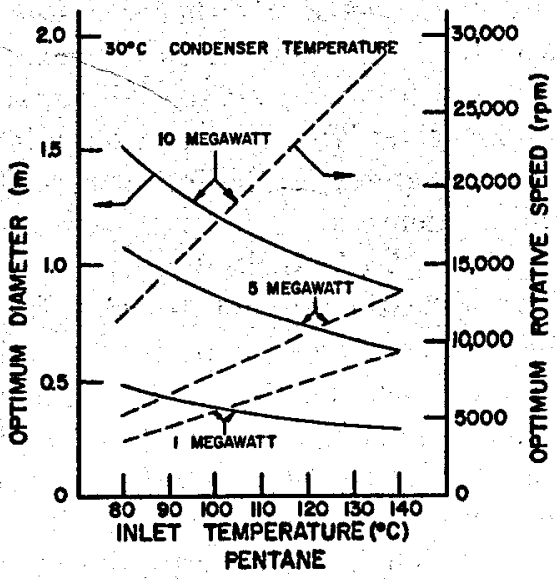




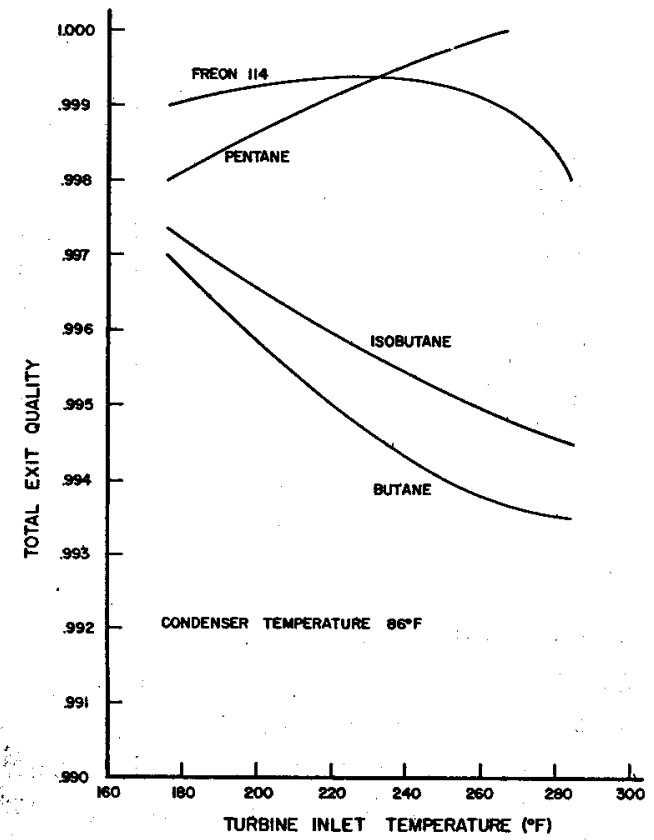

Fraver 4.113-Total turbine exit quality $\mathbf{t s .}$ inlet temperature.

4.2.6.7 Direct contact heat exchangers. In a geothermal cycle all of the heat exchange equipment, boilers, preheaters and condensers, can be of the direct contact type as long as the working fluid is immiscible in water. Direct contact heat exchange can take place in simple mixers followed by fluid separators, in parallel flow of separated layers or in counterflow with either separated layers or with one fluid dispersed in a continuous phase.

Direct contact heat exchange equipment follows the general design for mass transfer equipment in terms of the fluid mechanics; however, sizing of the equipment cannot normally be accomplished by using a heat-mass transfer analogy. Thus, one is required to obtain heat transfer data for the particular type of heat exchangers. The preponderance of data in the literature is restricted to either gas-liquid or liquid-liquid heat exchange, with heat transfer data for heat exchangers with phase change restricted to work with condensers or boilers studied for desalination or geothermal applications ( $(70)$. This section will discuss the design of the direct contact heat exchangers in the following order : preheaters (liquid-liquid), boilers, and condensers.

(a) Preheaters. Studies $(70,75)$ have indicated that laminar parallel flow preheaters are not practical for geothermal application due to the low thermal conductivity of most candidate working fluids (isobutane, isopentane, hexane, R-113, etc.). Thus they will be excluded from this discussion. Turbulent mixers, although they can provide a volumetric heat transfer coefficient of $100,000 \mathrm{Btu} / \mathrm{hft}^{30} \mathrm{~F}\left(6.57 \mathrm{MW} / \mathrm{m}^{3 \circ} \mathrm{C}\right)$, only offer one theoretical stage and thus must be staged as shown in figure 8 of reference (76) which has been reproduced in figure 4.115. The number of stages 
FrgORE 4.114-Temperature vs. duty for the contactors of figure 4.93 .

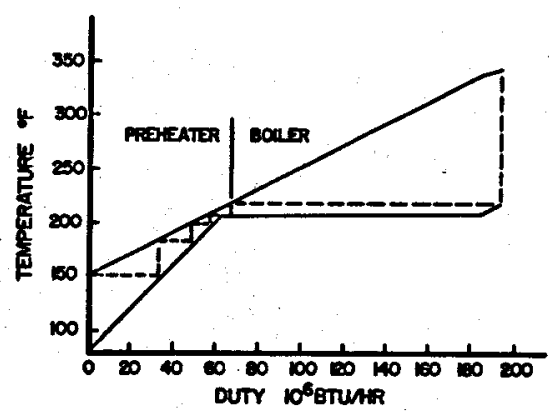

depend upon the choice of working fluid. The example of figure 4.115 is for the system of figure 4.93 with heat duty shown in figure 4.114. This type of system, in addition to interstage pumping and expanders, requires the use of compact settlers which are relatively expensive. The intimate mixing that takes place in the system and the time required for separation would most certainly assure excellent mass transfer also; therefore, for this system the working fluid dissolved in the brine would probably reach the equilibrium solubility levels. This in turn would necessitate a means of recovery for the working fluid. Thus, although providing excellent heat transfer, turbulent mixers are not recommended for geothermal application as preheaters. The only types of equipment recommended are the countercurrent mass transfer devices where one fluid is dispersed in the second immiscible fluid. These types of equipment are discussed by Fair (74). The potential heat transfer equipment are (1) spray towers, (2) baffle towers, (3) perforated plate towers, (4) packed towers and (5) mechanically agitated direct contacters, schematics of which are shown in figure 4.116.

Spray towers. Spray towers have received the most attention as direct contact liquid-liquid heat exchangers due to the simplicity of their design. As can be seen in figure 4.116 a spray tower consists of a vertical column, an injection nozzle for each fluid, working fluid and brine, and exit ports. Normal operation would theoretically have the heat transfer taking place

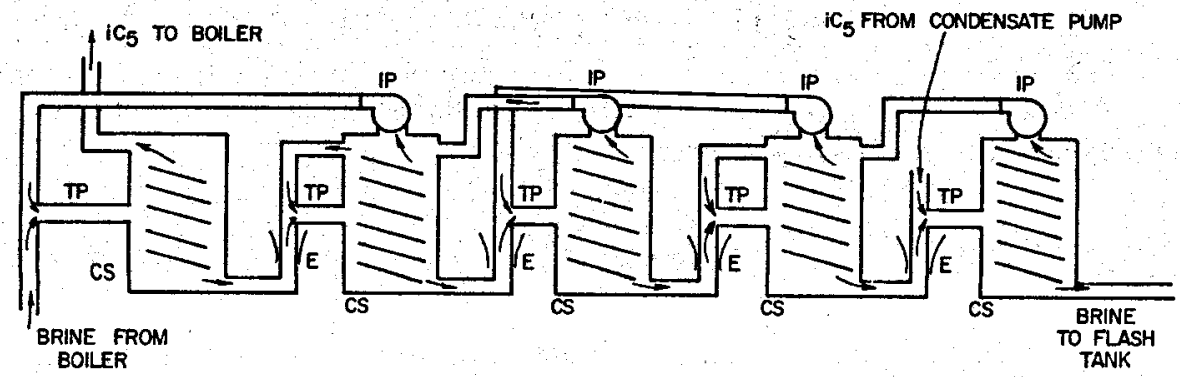

Fiauke 4.115-Five-stage concurrent flow (turbulent pipe mixer) preheater system. CS-compact settler; TP-turbulent pipe mixer; $\mathrm{E}$-expander; IP-interstage pump; $10_{\sigma}$-isopentane. 


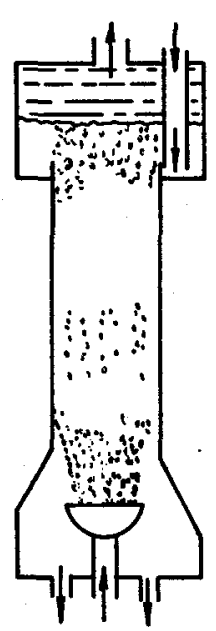

SPRAY

TOWER

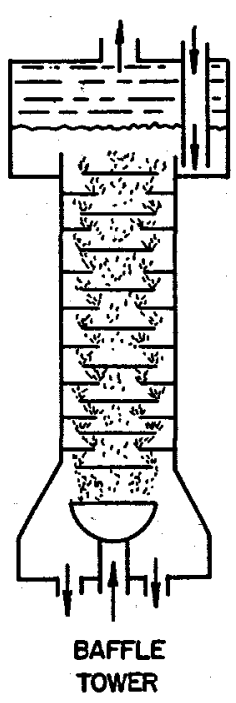

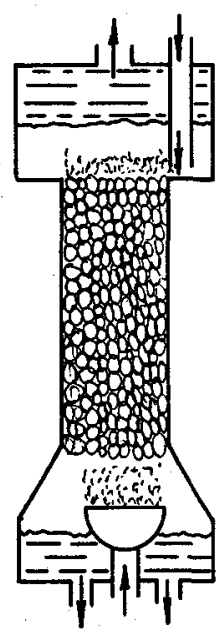

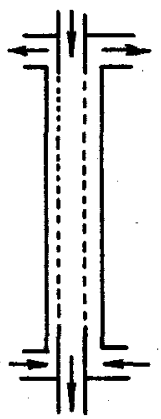

WETTED WALL TOWER

FigUre 4.116-Schematic of various types of direct contact counterflow devices.

between the two inlets with coalescence occuring a small distance above. Coalescence of the dispersed phase is induced by a screen made of an oleophilic or hydrophilic material depending upon whether the working fluid or brine is dispersed. The poor thermal conductivity of most candidate working fluids for geothermal power applications dictates that the working fluid be the dispersed phase.

Design of a spray tower heat exchanger can be carried out following the procedure outlined by Letan (7/7). The technique can be used when the column Reynolds number is $\leq 2300$. That is, heat exchangers can be scaled when the column Reynolds number indicates laminar flow. When the flow is turbulent, size scaling of spray towers is not possible. The volumetric heat transfer used in sizing the heat exchanger can be determined by the wake shedding model of Letan and Kehat (78) or by the simple correlation with hold-up which can be inferred from the data of Woodward (79).

The procedure for design of the heat transfer section of the tower proceeds as follows:

The terminal drop velocity must first be calculated. This is achieved from a balance of the gravity force by the drag yielding

$$
f V_{T}^{2}=\frac{4}{3} d_{p}\left(\frac{\rho_{d}-\rho_{c}}{\rho_{c}}\right)
$$

where $f$ is the friction factor, and it depends upon the drop Reynolds number,

$$
R e_{o}=\frac{V_{T} d_{p} \rho_{c}}{\mu_{c}}
$$


If it is assumed that the drops behave like solid smooth spheres, then $f$ varies as follows

$$
\begin{array}{ll}
R e_{0}<0.1 & f=24 / R e_{o} \\
2<R e_{o}<500 & f=18.5 / R e_{0}^{0.6} \\
500<R e_{0}<2 \times 10^{s} \quad & f=0.44 \\
2 \times 10^{5}<R e_{0} & \therefore f=0.2
\end{array}
$$

The above correlations are reasonable for $d_{p}<4 \mathrm{~mm}$. For a multiple droplet system Richardson and Zaki (80) proposed a relationship between slip velocity and holdup.* Utilizing this relationship Letan derived the following relationship to calculate the holdup at flooding, ${ }^{* *} \phi_{f}$, for a specified flow ratio, $R=Q_{d} / Q_{c}$ :

$$
(m+1)(1-R) \phi_{f}{ }^{2}+(m+2) R_{\phi_{r}}-R=0 .
$$

$m$ is dependent upon $R e_{o}$ as follows:

$$
\begin{aligned}
& R e_{0}<0.2 \\
& m=3.65 \\
& 0.2<R e_{o}<1 \\
& 1<R e_{o}<500 \\
& m=4.35 R e_{0}^{-0.03}-1 \\
& m=4.45 R e_{o}^{-0.1}-1 \\
& R e_{o} \geq 500 \\
& m=1.39
\end{aligned}
$$

For safe preservation of stable flow conditions Letan ( 77$)$ recommends operation at

$$
\phi<0.9 \phi_{t}
$$

The superficial velocity of the continuous phase may then be calculated from the equation,

$$
V_{c}=\frac{V_{T} \phi(1-\phi)^{m+1}}{R(1-\phi)+\phi}
$$

The column diameter can then be calculated from the equation

$$
D=2 \sqrt{\frac{Q_{c}}{\pi V_{c}}}
$$

Calculation of the column heat transfer length necessitates knowledge of the volumetric heat transfer. As noted earlier either the wake shedding model of Letan and Kehat (78) or the simple correlation of Woodward (79) provide adequate prediction. This conclusion was verified by experiments with isobutane dispersed in geothermal brines and sea-water by Suratt and Hart (62). Their experiments utilized a six inch diameter Elgin spray trower. The tower was constructed with a heat transfer zone

\footnotetext{
* Holdup, $\phi$, is defined as the volume fraction occupied by the dispersed phase.

**Flooding is defined as the point. where the dispersed phase may be swept backward by the continuous phase. That is the limiting operation of the tower.
} 
which was $6 \mathrm{ft}-7$ in. long. The actual number of transfer units (NTU) achieved varied from 1.55 to 3.37 with volumetric heat transfer coefficients varying from 469 to $4,053 \mathrm{Btu} / \mathrm{ft}^{3 \circ} \mathrm{F}$ depending upon flow rates and holdup. These data can be found tabulated in the reference report. The results for the preheater are consistent with both the data of Woodward (79) and the model of Letan and Kehat (78) where the drop Reynolds number $\leqslant 2300$. Data obtained by Kehat and Berg also agree with both the correlations. Although the Letan-Kehat (78) model appears to be slightly more accurate, the simple correlation of Woodward* is easier to use and is recommended for preliminary sizing of the towers. The calculations are carried out as follows, using the Woodward correlation :

$$
\begin{gathered}
U_{n}=12000 \frac{\mathrm{Btu}}{\mathrm{hft}^{3^{\circ} \mathrm{F}} \phi} \\
l=\frac{\left[V_{\rho} C_{p}\left(T_{1 \mathrm{n}}-T_{\text {out }}\right)\right]_{\text {cont. phase }}}{U_{v} \times L M T D}
\end{gathered}
$$

Ûsing the Letan-Kehat model (applicable for $R \mathrm{e}_{o}>30$ )

where

$$
l=\left[\left(\frac{T_{d_{\text {out }}}-T_{c_{\text {out }}}}{T_{d_{1 \mathrm{n}}}-T_{c_{\text {out }}}}\right) e^{M / R}-1\right] \frac{r}{\mu S}-\frac{1}{\alpha_{1}}\left(\frac{1}{S}+1\right)
$$

$$
S=\frac{\alpha_{1}+\frac{\mu}{r}-\frac{r_{\mu}}{P M}\left[\exp \left(\frac{M}{r}\right)-1\right]}{\alpha_{2}-\alpha_{1}}
$$

where

where

$$
\alpha_{1.2}=\frac{-\mu}{2}\left[\left(\frac{1}{M}+\frac{1}{r}-\frac{1}{P}\right) \pm \sqrt{\left(\frac{1}{M}+\frac{1}{r}+\frac{1}{P}\right)^{2}-\frac{4}{M r}}\right]
$$

$$
P=\frac{V_{c}+M V_{d}}{V_{d}}=\frac{1}{R}+M \text {. }
$$

$M$ is the ratio of the volume of the wake to the volume of a drop and is a function of the holdup $\phi . M$ is approximately 0.8 for $0.2 \leqslant \phi \leqslant 4.0$. It varies nearly linearly from 1.10 at $\phi=0$ to 0.8 at $\phi=0.2$. For values of $\phi>0.45, M$ decreases rapidly to 0.30 at $\phi=0.70$. $\mu$ is the volume of wake elements shed per drop volume and unit length $\left(\mathrm{cm}^{-1}\right)$. The data of Letan and Kehat (78) indicate values of 0.03 for $0.2 \leqslant \phi \leqslant 1.4$ with a linear increase from 0.017 at $\phi=Q$ to 0.03 at $\phi=0.2$. For $0.4 \leq \phi \leq 0.70 \mu$ decreases nearly linearly from 0.03 to 0.02 .

For a simple spray column, the work of Steinmeyer and Woodward (82) indicated that considerable back-mixing could take place in a tower

-The correlaton of Woodward appears to deviate from data recently obtained at the University of Utah when $Q_{d} / Q_{\text {. }}$ is less than 1.75 . However, the deviation is such as to make the correlation yield a conservative design. 
of low aspect ratio, $U / d$. Results of numerous investigators including Suratt and Hart (62) and Letan and Kehat (78) indicate that acceptable operation occurs when $l / d \geqslant 10$. Thus, it is recommended that the design of such towers be restricted to this aspect ratio.

Data from DSS Engineers (62), Woodward (79), and Garwin and Smith (83) is compared to a correlation developed experimentally by Plass et al. (84) in figure 4.117. The lines represent the correlation for various values of $R$, and is in good agreement with the Letan theory discussed above.

Details of the end designs (for convergence) and the injectors should follow the recommendations of Treybal (85). Basically these coalescence zones should reduce the velocities to within 0.2 to 0.7 of the velocities within the tower proper. Elgin spray towers are designed to do this by increasing the radii at the equivalent of a $16^{\circ}$ expansion.

Baffled towers. Baffled towers (horizontal baffles) overcome the disadvantage of spray towers in that the baffles limit the backmixing to the region between baffle plates. However, the region between plates is nearly isothermal. Thus, it provides any number of theoretical trays depending upon the mixing efficiency between plates and the number of plates. Fair (74) indicates that such columns have been used with gas-liquid systems as heat exchangers, but no data has been published for liquid-liquid systems. To complicate the design further no mass transfer data on baffle

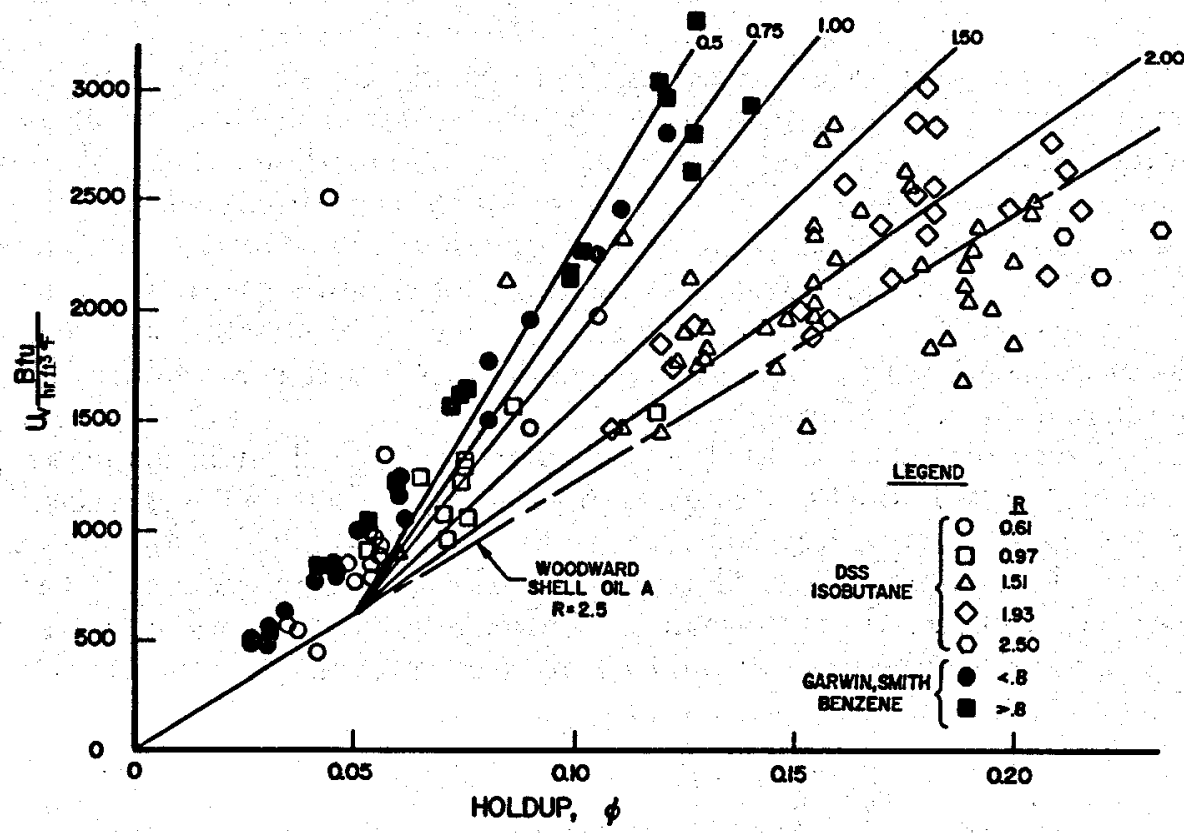

Fiaure 4.117-Plot of spray column liquid/liquid direct contact heat transfer. Data from several investigations. Lines indicate various values of volumetric flow ratio. 
columns has been published; however, as a mass transfer device they are about $50 \%$ as efficient as perforated plate towers. They do, however, allow for a greater throughput. General preliminary design would utilize the $E_{n}$ for sieve towers multiplied by $50 \%$ (85). Baffle plate towers are also more applicable to fouling situations than sieve towers and, thus, can be used with heavily laden brines with low maintenance.

Sizing of baffle plate towers can be carried out following the steps outlined by Scheiman $(86,87)$ for baffle tower hydraulics. The analysis basically limits the flow rates to near flooding conditions in the minimum flow area of the tower. Heat transfer characteristics could be represented, lacking data, by decreasing by $50 \%$ the value of the volumetric heat transfer coefficient obtained for sieve plate towers for the same holdup, or by utilizing the correlation for spray towers given by Woodward (79). Additional data is needed, however. Experiments have been conducted by Ben Holt Co. (88); however, all data includes phase change, and thus it is difficult to interpret the results. $E_{n}$ values varying from 0.30 to 0.70 were reported, however.

Sieve plate towers. Sieve plate towers or perforated plate towers (see figure 4.116) are widely used in industry for mass transfer equipment. Towers of up to twelve feet in diameter have been constructed. Sheinbaum $(60)$ in 1975 suggested their use as direct contact heat exchangers for geothermal applications. They have an advantage over both baffle plate and spray towers in that they offer potentially better performance as either a mass transfer or a heat transfer device. The advantage lies in the fact that the dispersed phase is continuously reformed. Thus in comparison to a spray tower drops are regularly stripped of any attached wake and in comparison with a baffle plate tower the drops formed can be controlled in size. However, sieve plate towers have considerably lower throughput than either the baffle tower or spray tower of the same dimensions. Both baffie and sieve plate towers limit back-mixing to the region between plates. Spray towers can suffer from backmixing, and according to Letan and Kehat (78) ineffectively utilize their height due to the attached wake on the drops. Sieve plate towers suffer from the fact that they are subject to fouling and have low throughput.

Heat transfer data is lacking on sieve plate towers and published mass transfer data is limited to designs such as shown in figure 4.116. Treybal (85) suggests that a very conservative estimate might utilize the data published for spray towers. Thus, Woodward's (79) correlation could be used. This penalizes the performance estimate. Mass transfer data indicates tray efficiencies of between 30 and $60 \%$ are achievable (85) without much difficulty.* Tray efficiency is defined as

$$
E_{n}=\frac{T_{n+1}-T_{n}}{\left(T_{n+1}-T_{n}\right)_{\text {eross temp }}}=\frac{\dot{Q}_{\mathrm{act}} n}{\dot{Q}_{\text {eross temp }}}
$$

* Similar results for a three phase tower are reported for $E_{*}$ by the Ben Holt Company (88). 
where all temperatures refer to the continuous phase (see the dutytemperature curve of figure 4.94). Another technique to estimate the heat transfer would be to estimate the heat transfer coefficient to be equal to that of the wake growth period of drops in a spray tower as reported by Letan and Kehat (78).

Typically sieve towers are constructed with trays spaced from 6 inches to 24 inches apart with 16 to 18 inches typical for large towers. This would correspond well to the wake formation and transition zone for the shedding wake model of Letan and Kehat (78). Thus it might be expected that values of the volumetric heat transfer coefficient would be about fifty percent higher for sieve plate towers than for spray towers. It is thus recommended that for preliminary design

$$
U_{v}=18,000 \phi \frac{\mathrm{Btu}}{\mathrm{hft}^{8 \circ} \mathrm{F}}
$$

could be used. (For baffle towers, since they have only $50 \%$ of the efficiency of sieve powers a value of

$$
U_{v}=9000 \phi_{\frac{\mathrm{hft}}{8 \circ \mathrm{F}}}
$$

could be used.)

Sieve plate powers are typically constructed with perforations in the plates of $1 / 8$ in to $1 / 4$ in in diameter arranged in $1 / 2$ in to $3 / 4$ in square or triangular spacing. If a working fluid with a high surface tension is used the smaller diameter is recommended. The larger diameter holes normally allow for greater throughput. The smaller diameter is recommended unless the brine is heavily fouling, since conduction in the drops dominates the heat transfer for most candidate working fluids.

In carrying out the design of a sieve type tower the analysis proceeds as follows:

(1) Set the orifice hole size, $d_{0}$

(2) The maximum orifice velocity is calculated from the equation

$$
V_{0}=2.69\left(\frac{d_{f}}{d_{0}}\right)^{2}\left(\frac{\sigma / d_{j}}{.5137 \rho_{d}+0.471 \rho_{c}}\right)^{0.5}, \frac{f t}{8}
$$

where $\sigma$ is the surface tension, $P_{d}$ is the density of the diffuse phase and $\rho_{c}$ of the continuous phase (in $\mathrm{lb}_{m} / \mathrm{ft}^{3}$ ), and $d_{j}$ is the emitted jet diameter which is calculated from either

$$
\frac{d_{o}}{d_{g}}=0.485\left[\frac{d_{0}}{(\sigma / g \Delta \rho)^{0, \delta}}\right]+1
$$


for

$$
d_{0} /\left(\frac{\sigma}{g \Delta \rho}\right)^{0.5}<0.785
$$

or

for

$$
\frac{d_{o}}{d_{j} .}=\frac{1.51 d_{0}}{(\sigma / g \Delta \rho)^{0.5}}+0.12
$$

$$
d_{o} /\left(\frac{\sigma}{g \Delta \rho}\right)^{0.5}>0.785
$$

(3) Knowing the volumetric flow rate of the dispersed phase, $Q_{d}$, the area of the perforations is calculated

$$
A_{\text {pert }}=\frac{Q_{d}}{V_{0}}
$$

(4) Depending upon the selected hole spacing chosen (e.g., for $d_{o}=1 / 8$ in. and a $1 / 2$ in. triangular or rectangular spacing) calculate the area of the perforated trays, $A_{\text {tray. }}$.

(5) Assume the continuous phase flows through a downspout at the terminal velocity of a drop rising through a still continuous phase equation 4.98 , and calculate the downspout area.

$$
A_{\text {down }}=\frac{Q_{c}}{V_{t}}
$$

(6) As there should be no perforations under a downspout the crosssectional area of the tower should be

$$
A_{\text {tower }}=A_{\text {tray }}+2 A_{\text {down }}
$$

(7) The diameter of the tower is then equal to

$$
\sqrt{\frac{4 A_{\text {tower }}}{\pi}}
$$

The drops rise through effectively a cross flow of the continuous phase; thus, the drops rise at the terminal velocity of a drop rising in a still continuous phase. The holdup can thus be calculated.

$$
\phi=\frac{V_{d}}{V_{t}}=\frac{Q_{d}}{A_{\text {tower }} V_{t}}
$$

(8) Knowing the holdup the volumetric heat transfer coefficient can be calculated from equation 4.110. The height of the heat transfer zone is then calculated as per equation 4.106. 
(9) Tray spacing, $S$, should be approximately 18 inches as discussed earlier. Thus the number of trays is given by

$$
N=\frac{l}{S}+2
$$

rounded off to the next larger integer.

The two extra trays indicated in equation 4.119 allow for coalescence zones. Thus, the coalescence height can be smaller than for a spray tower. Typically, the coalescence zone at each end of the tower should be from $0.5 D_{\text {tower }}$ to $1.0 D_{\text {tower. }}$

Other tower designs. A variety of other towers present possible heat exchangers. These include rotating disk towers, Lightnin CM contractors, etc. These types of equipment have been constructed to large sizes (12 ft in diameter); however, they introduce additional parasitic losses. Jacobs (76) in a recent paper has indicated that they offer a viable alternative as a direct contact heat exchanger for geothermal application if compatible seals are found for the power shafts.

(b) Direct contact boilers. Direct contact boiling of the working fluid can take place in either ' $a$ volume boiler or a surface boiler. $A$ volume boiler is one in which the volatile fluid is dispersed in the hot continuous phase, while a surface boiler is one where the volatile fluid is sprayed onto the surface of a pool of a hot immiscible phase. Direct contact boiling experiments have been carried out with both types of heat exchangers using such fluids as hexane, pentane, isobutane, and R-113. These are the fluids most commonly mentioned for a direct binary cycle.

Volume type direct contact boilers are primarily of the spray-column type shown in figure 4.118. This type of boiler was first proposed by Sideman and Gat (89) as a possible device for desalination of sea-water. Experiments were conducted with pentane as the working fluid and volumetric heat transfer coefficients, $U_{v}$, of $12,500 \mathrm{Btu} / \mathrm{hft}^{\mathrm{3}}{ }^{\circ} \mathrm{F}$ were reported. Blair et al. (90), with equipment similar to that of Sideman, conducted experiments with R-113 to assess the effect of having a volatile fluid whose liquid was more dense than the continuous phase. Due to the turbulence induced at high flow rates problems were encountered with some drops of working fluid being swept out of the heat exchanger with the continuous phase (water). This phenomena is termed carryunder, and is a function of the design of the device as well as the relative temperature levels of the dispersed and continuous phases. Due to the carryunder problem, however, the maximum observed $U_{v}$ was only $4260 \mathrm{Btu} / \mathrm{hft}^{\mathrm{8}} \mathrm{F}$ without carryunder occurring. Sims (88) conducted experiments, utilizing hexane as the working fluid, with both a spray-time column and with column internals such as sieve trays, intalox saddles, and disk-donut baffles. All of the above used a column approximately 3 inches $(7.5 \mathrm{~cm})$ in diameter. The data of Sideman and Gat (89) and Blair et al. (90) were gathered from near saturation conditions, while Sims' experiments were run such 


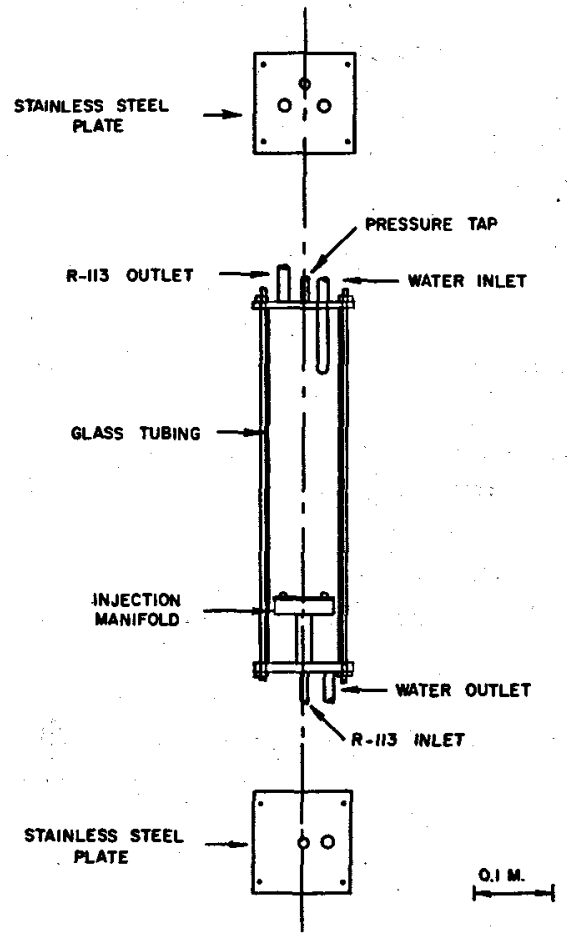

FTaUR: 4.118-Assembly drawing of a volume boller test vessel.

that the columu had to operate both as a boiler and a preheater. Volumetric heat transfer coefficients were not reported but overall heat transfer effectiveness was reported at values ranging from 30 to $70 \%$. Surratt and Hart (62) have carried out direct contact boiler experiments in a six inch (15 cm) column, of similar design to that shown in figure 4.118, using isobutane as the volatile fluid. They later carried out experiments under DOE Contract No. E-(40-1)-4893 using actual geothermal brines at the East Mesa Geothermal Test facility with a single Elgin spray column used as both the preheater and boiler.

The volume boiler studies of Blair et al. (90) and of Sideman and Gat (89) indicated that complete vaporization of the working fluid can take place in very shallow columns of water or brine. This fact together with the carryunder problem for working fluids more dense than water led Jacobs et al. (91) to introduce the shallow injection tray shown in figure 4.119. No problem was encountered with liquid droplets leaving the tray as long as continuous phase exit temperatures exceeded by $5^{\circ} \mathrm{C}$ the saturation temperature of the working fluid. The data acquired indicated heat transfer characteristic nearly the same as a surface type boiler for identical operating conditions.

Deeds et al. (92) investigated a surface type boiler as an alternative to the volume boiler. Several types of configurations for surface boilers were 


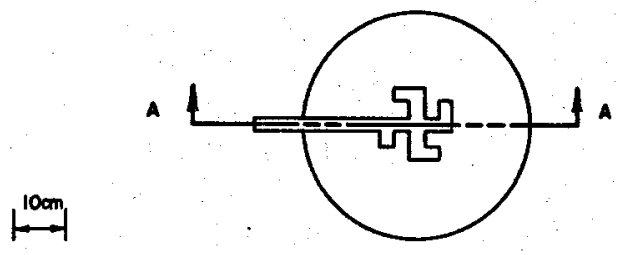

Frouke 4.110-Volume type tray boiler.

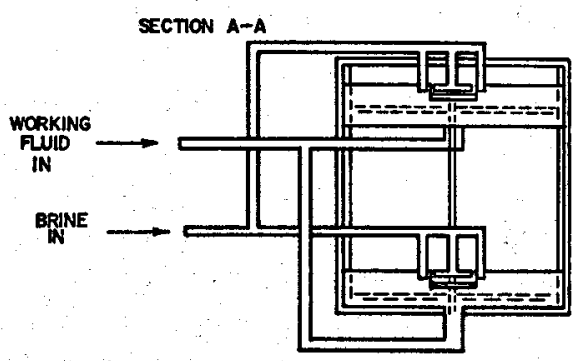

considered in a later study (91) including that shown in figure 4.120. All worked equally well. The tray configuration of figure 4.120 was utilized with both R-113 and commercial grade pentane as working fluids. The above work led to the correlation of the experimental heat transfer data in terms of the Stanton Number, which is identical to the Number of Transfer Units, NTU, commonly used for a comparison basis in chemical equipment design. The resulting correlation equation is

$$
S t=\frac{U_{A} A}{\left(M C_{p}\right)_{d . p . z .}}=\frac{Q}{L M T D\left(M C_{p}\right)_{d . p .2}}=2.0(J a P r)_{d . p . x_{0}}{ }^{0.0}\left(\frac{M_{C p}}{M_{d p}}\right)^{0.16}
$$
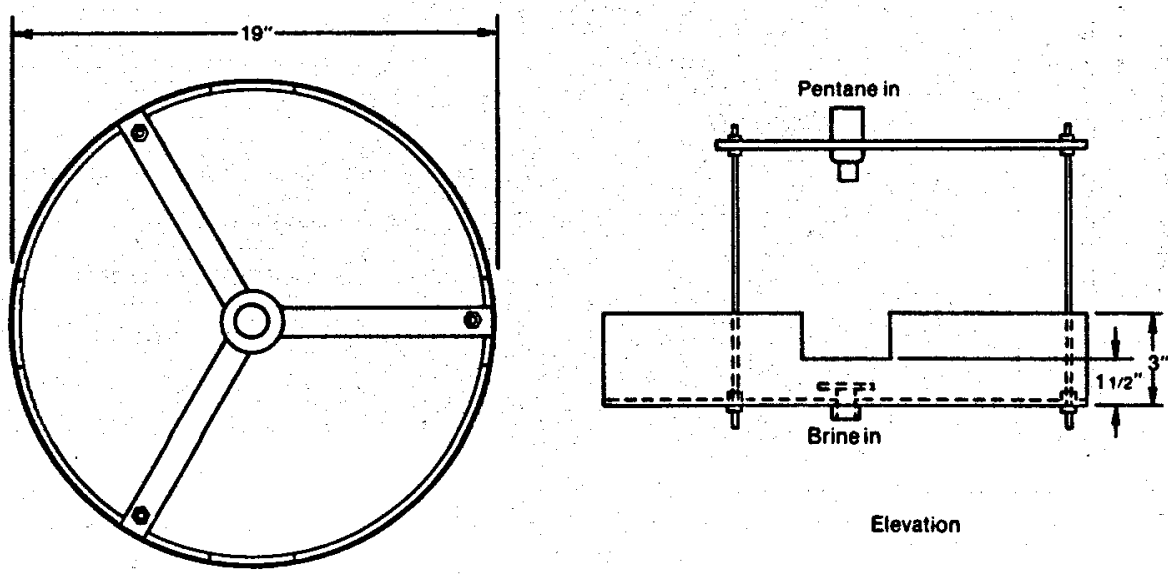

Plan

Figurd 4.120-The circular "source flow" surface boller tray. 
Data for all but the pentane studies are shown in figure 4.121. The pentane studies should be published shortly. Figure 4.121 also includes spray tower studies of Suratt and Hart (62) and Sims (88). The shallow tray volume boiler data for R-113 is also included. The general agreement is obvious for all of the data. Deviations are most pronounced when subcooling is significant (the +'s) and when the actual volume in which the boiling takes place, and thus the LMTD, is uncertain as is the case with the limited data of Suratt and Hart (62) and Sims (88) presented on the figure.

Direct utilization of equation 4.120 to determine the surface heat transfer coefficient. $U_{A}$, is, in general, difficult due to the somewhat arbitrary assignment of the surface area in the Stanton Number. For example, if the assignment was the initial surface area of the drops in a spray, if it were known, one value for the heat transfer coefficient would be obtained. However, the turbulence that occurs in a tray, as was observed by Jacobs, et al. (91) could well induce an increase in area by breaking down the drops into ones of smaller size prior to ebullition. Thus, an over prediction of the heat transfer coefficient could result. Since the Stanton Number is equivalent to the number of transfer units, NTU, based upon the thermal capacitance of the dispersed phase, it could be used to distinquish relative size of tho heat exchangers for different applications. For example, the

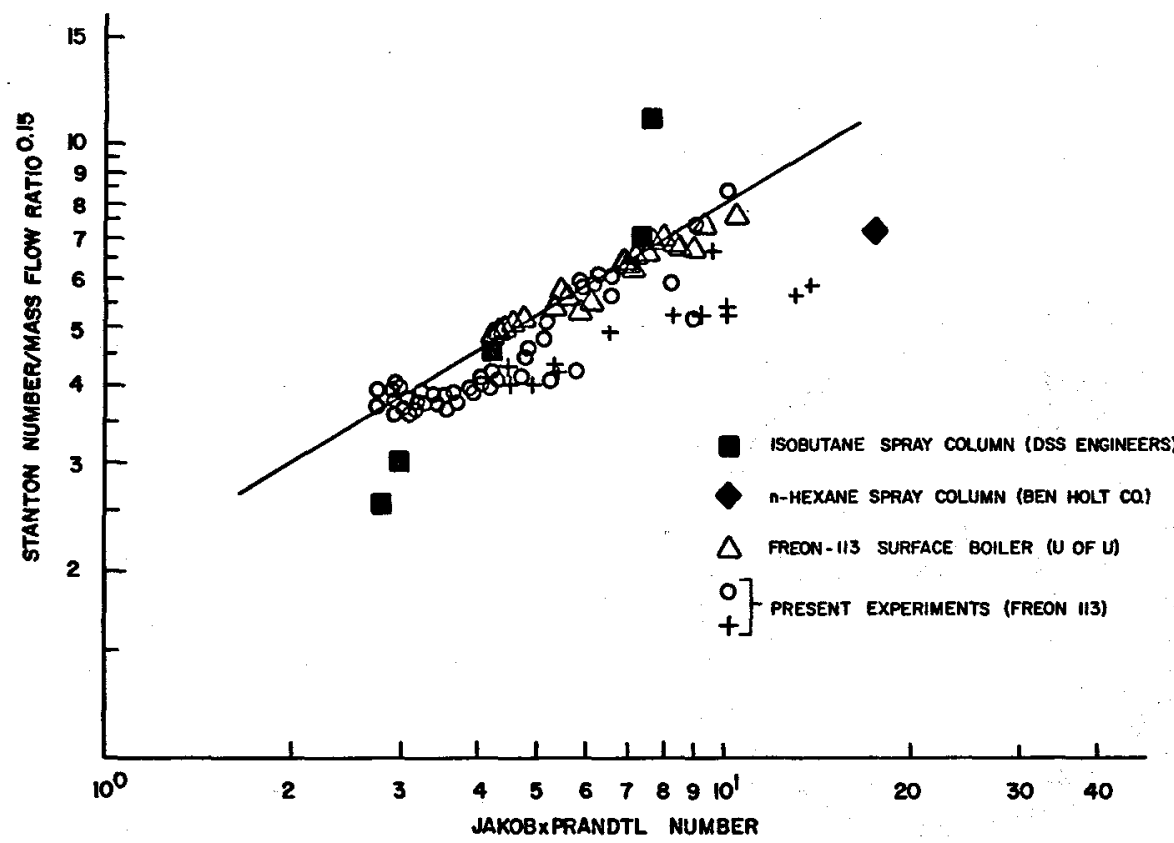

NON-DIMENSIONAL HEAT TRANSFER VERSUS JAKOBXPRANDTL NUMBERS

Figure 4.121-Non-dimensional heat transfer vs. Jacob $\times$ Prandtl numbers. 
size of the required heat exchanger is inversely proportional to the number of NTU's. One can thus evaluate relative size of the heat exchangers using different fiuids for the same resource. As an example a comparison is made for R-113, pentane, and isobutane for optimum geothermal direct contact cycles for a $143^{\circ} \mathrm{C}, 290^{\circ} \mathrm{F}$, geothermal resource in figure 4.122. The

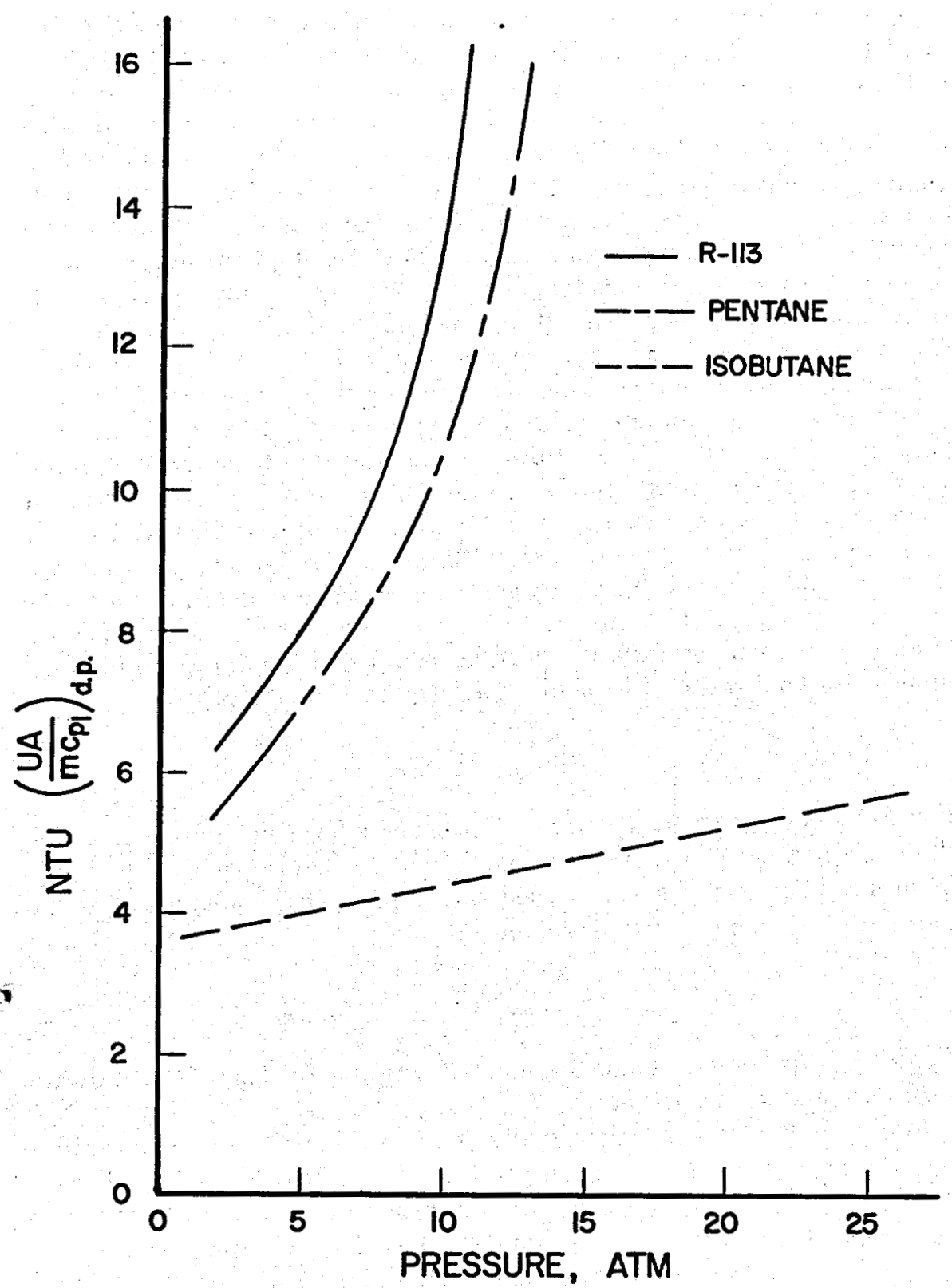

TIGURe $4.122-$ NTU vs. direct contact boller pressure, $143^{\circ} \mathrm{C}$ brine, $0^{\circ} \mathrm{C}$ subcooling. 
size of the heat exchangers as expressed by the NTU clearly indicates that the selection of pentane and R-113 yields smaller heat exchangers. However, the size of the heat exchangers does not dictate the choice of working fluid, although they indicate one of the cost items in a geothermal power plant. Total plant costs, as they affect electrical power costs, must be considered.

In designing a direct contact boiler it is important to fully utilize the available brine. Thus it is important to determine the maximum loading of the working fluid in the brine and to understand the role of the working fluid selection on the minimum mass ratio of brine to working fluid. This may be determined after selecting the boiler pressure from a simple energy balance in which it is assumed that the working fluid and water vapor exit at saturation conditions and the brine exists at the saturation temperature of the working fluid. As shown in the example of figure 4.123 it is clear that this is a thermodynamic property of the working fluid selection. In order to approach the theoretical minimum, even with high heat transfer coefficients, requires a certain contact time (or residence time) between the brine and working fluid. Theoretically the residence time would have to be infinite for the working fluid to indeed lower the temperature of the brine to the saturation temperature of the working fluid. How close one can approach the minimum mass ratio can be ascertained from experiments. Figures 4.124 and 4.125 indicate that with R-113 and isobutane that close to the theoretical limits are achievable. For the case of R-113 sufficient experiments have been performed to determine a correlation equation for the minimum achievable mass flow ratio (see Jacobs et al. (70)). Perhaps a more important measure of the approach to minimum mass flow ratio is the achievable approach temperature

$$
\left(T_{\text {brino }} \text { oxit }-T_{\text {sat }_{\text {trF }}}\right)
$$

For R-113 this is indicated in nondimensional form in figure 4.126. For the large number of experiments conducted it is shown that as the minimum mass flow ratio is approached the "Approach Temperature" seems to reach a limit between 0.07 to 0.1 for

$$
\left(T_{\text {brine }_{\text {exit }}}-T_{\text {sat }_{W F}}\right) /\left(T_{\text {brine }_{\text {In }}}-T_{\text {nat }_{W F}}\right) .
$$

Typically this limit is about $5^{\circ} \mathrm{C}$ or $9^{\circ} \mathrm{F}$. Suratt and Hart (6Q) indicate a similar value for isobutane.

For preliminary estimation of direct contact boiler performance, it is recommended that approach temperatures be limited to $50^{\circ} \mathrm{C}$ or larger. This can be used as a means of obtaining the practical limitations of the mass flow ratio (brine/working fluid) unless the preheater flow requirements dictate larger values. For example, the shape of the saturated liquid line for isobutane will normally dictate a larger value as the approach 


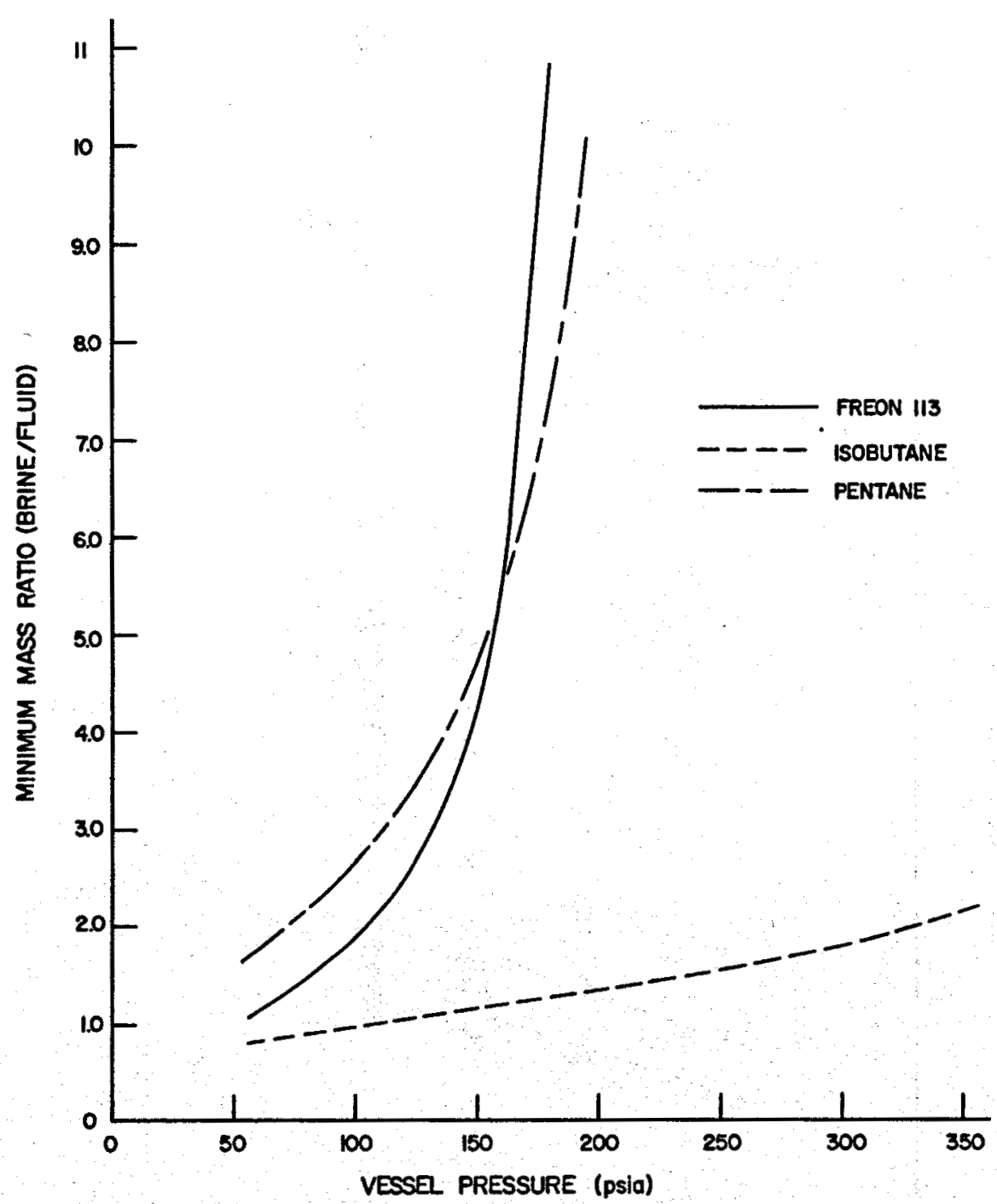

Fiqubi 4.123-Minimum attainable mass ratio calculated from an energy balance (5 $\mathrm{F}^{\circ}$ approach temperature), brine temperature of $290^{\circ} \mathrm{F}, 0^{\circ}$ subcooling.

temperature can be closer in the preheater for selection of isobutane as a working fluid; and of course, the brine must remain hotter than the working fluid throughout the entire heating.

For utilization of moderate temperature brines, $250-350^{\circ} \mathrm{F}$, the report of Suratt and Hart indicates that $D_{0}=9375 \mathrm{Btu} / \mathrm{hft}^{3 \circ} \mathrm{F}$ would be acceptable for isobutane as a working fluid. Based on the R-113 data of Jacobs et al. ( $\% 0$ ) a value of $13.750 \mathrm{Btu} / \mathrm{hft}{ }^{30} \mathrm{~F}$ could be conservatively used for R-113. For isopentane or commercial grade pentane a value of $12,500 \mathrm{Btu} /$ $\mathrm{hft}^{\mathrm{O}} \mathrm{F}$ could be used based on the results of Sideman and Gat (89) and of 


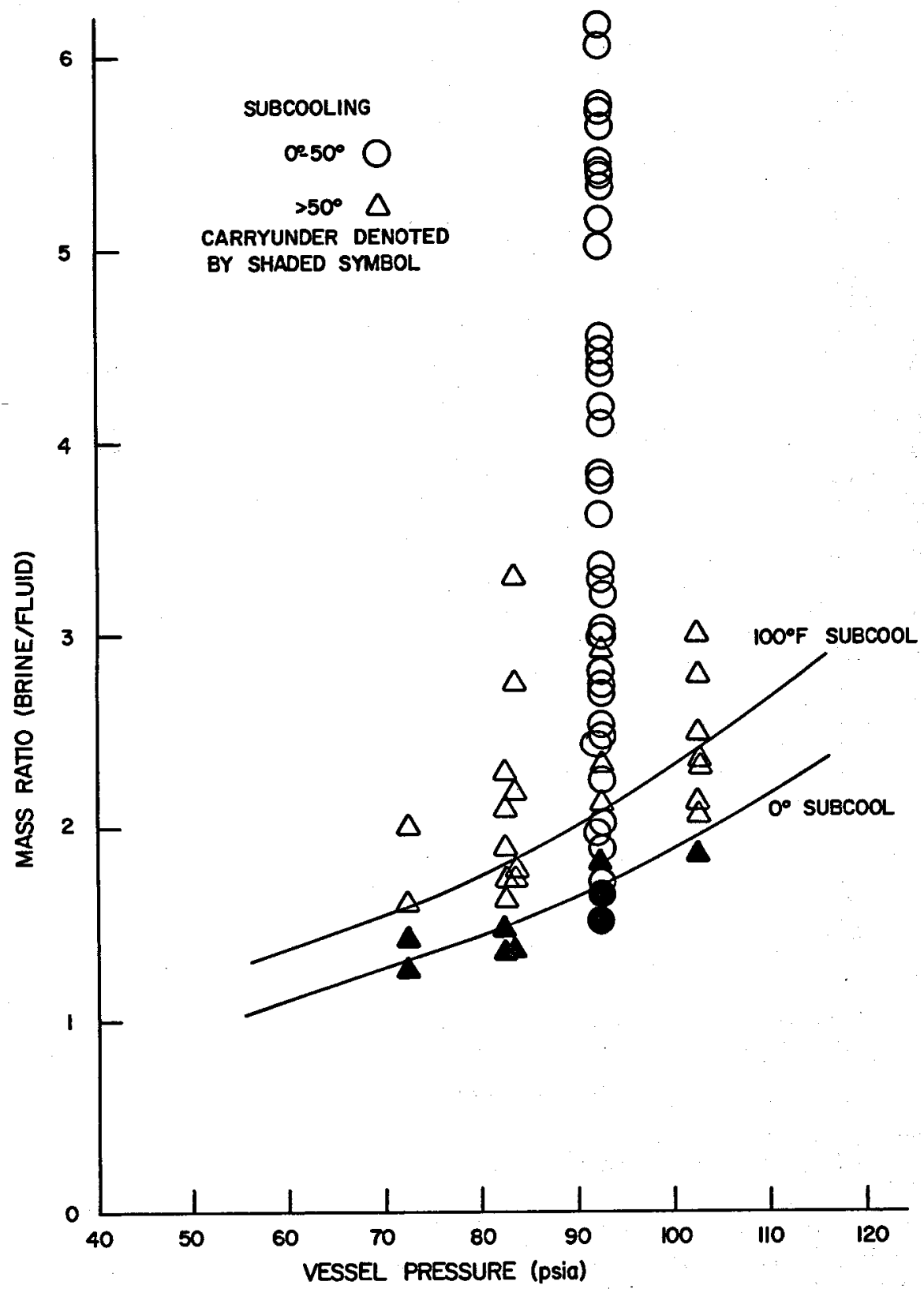

Frguke 4.124-Comparison of actual mass ratios and the predicted minimum for a low-pressure-drop nozzle, working fluid-R113, brine inlet temperature of $290^{\circ} \mathrm{F}$. 


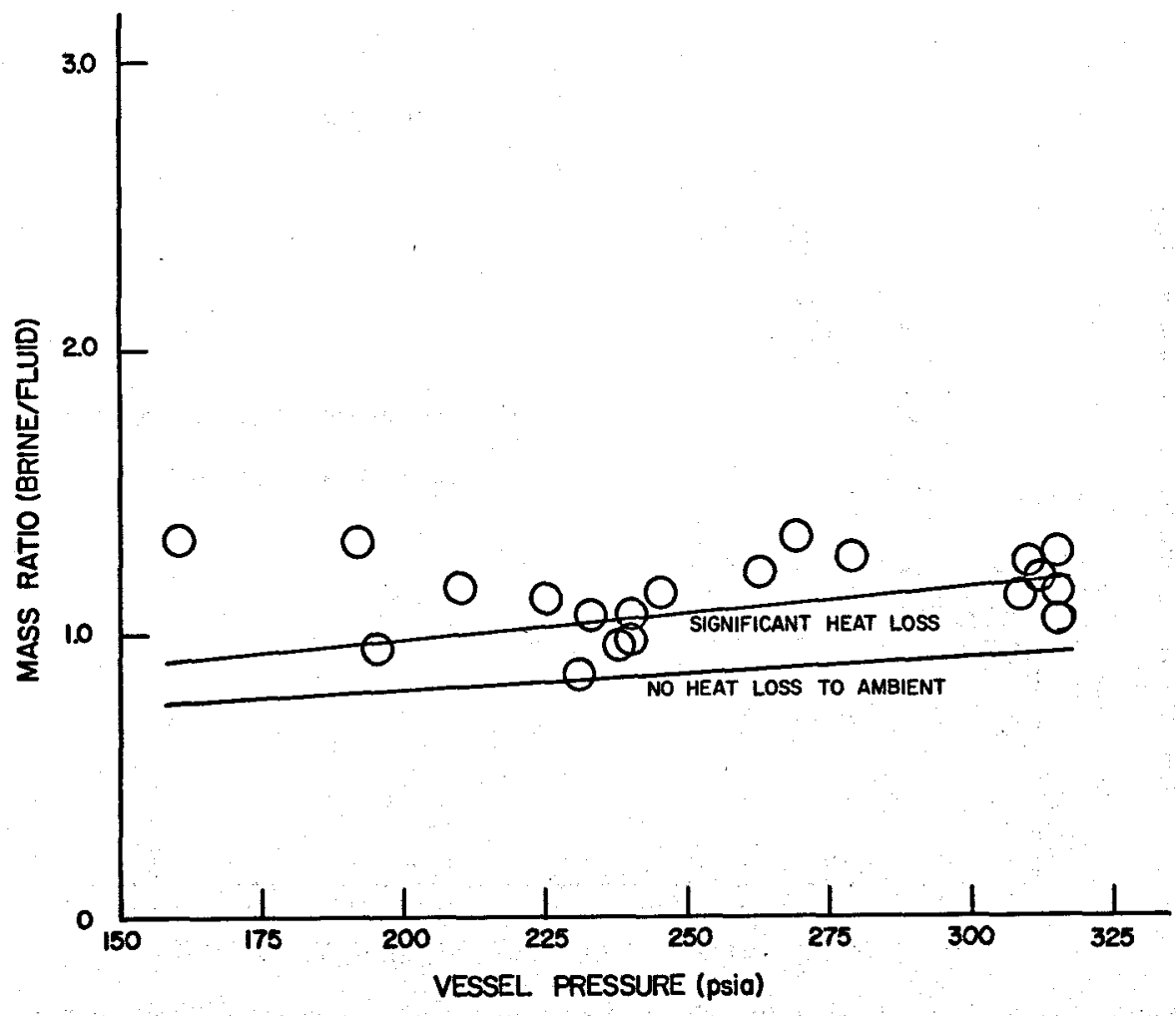

Frgure 4.125-Comparison of actual mass ratios and the predicted minimum for a volume-type boller, Suratt and Hart [1962]. No carryunder data points were reported; working fluids-isobutane, brine inlet temperature $335^{\circ} \mathrm{F}(330-340), 0^{\circ}$ subcooling.

the University of Utah experiments at East Mesa (not reported as of this writing).

(c) Direct contact condensers*. With the development of direct contact heat exchangers for the preheating and boiling functions in a binary cycle, the single greatest remaining equipment cost involves the condenser. Since the quantities of heat that must be handled by these devices are large (almost the same as that transferred in the heat addition portion of the cycle), and since the condensing temperature has such a profound effect on the cycle performance (see section 4.2.6.2), the overall success of the binary cycle could be profoundly affected by the condenser design. The use of direct contact condensers together with dry cooling towers or hybrid closed loop cooling towers offers potential reduction in costs and lower condensation temperatures.

Direct contact condensers operating in geothermal power cycles face a somewhat different situation than do the heat addition devices. This is in addition to the obvious aspect of boiling versus condensation. Since gen-

- A more comprehensive summary of the literature is given in reference (98). 


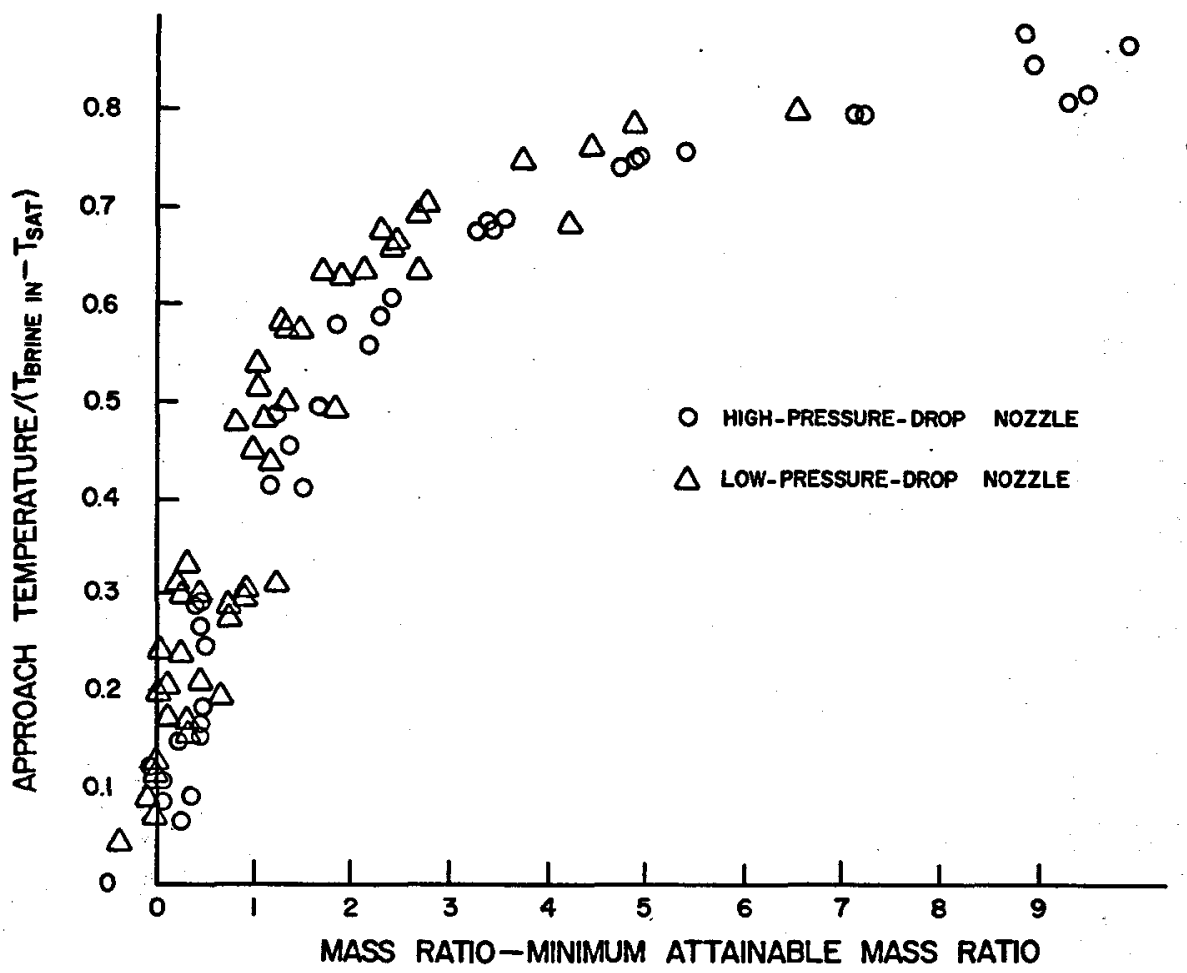

FIoURE 4.126--Normalized approach temperature in the surface-type direct contact boller, working fluid--R113.

erally clean water can be used for condensing, there is essentially no fouling problem. If the condenser is tied to a cooling tower through the cooling water loop, there is not a serious working fluid loss problem through solubility. effects. This is due to the fact that the recirculated water is essentially a closed system that will saturate with working fluid, causing no further loss of working fluid. Direct contact condensers can be used with conventional binary cycles as well as direct contact binary cycles.

If the potential of a direct contact condenser is to be evaluated, three general effects must be assessed. These relate to the heat transfer performance, equipment costs, and the cooling tower penalties and/or fluid loss possibilities. The heat transfer performance should be superior to conventional shell and tube designs. The capital investment may be considerably different for the direct contact condenser. Although the condenser itself should be less expensive than a tube and shell condenser, it will in general require a closed cooling tower in order to avoid loss of working fluid. A closed cooling tower together with a direct contact condenser may approach or be more expensive than a tube and shell condenser with an open wet cooling tower. However, if a dry cooling tower is to be used a direct 
contact condensing system will be less expensive. It also should be noted in passing that direct contact condensers also offer a means of separation of noncondensibles (degasification of the working fiuid) which can be a problem in a direct contact binary cycle. Although other techniques dealing with degasification exist (see section 4.2.6.4) this could be an important characteristic. Work in this area is just beginning; therefore these various factors remain to be analyzed.

Direct contact condensers have been known for a considerable period of time; however, little is published as to their design. Primarily they have been used for condensing steam, as open feedwater heaters or for solvent recovery in petroleum refineries. In most cases the same fluid is used for condensing as is the vapor, and as such they are known as single phase condensers. The most common form of direct contact condenser is the barometric or low level condenser used in steam power plants. This type of condenser works by having drops of a cold fluid fall through a saturated vapor. Another method, more commonly applied to feedwater heaters, is having saturated or superheated vapor bubble through a liquid pool or stream. A third could be the use of a packed bed condenser. A good overview of various aspects of direct contact condensation was published a few years ago by Fair $(\boldsymbol{F} /)$.

The direct contact condenser that might be applied to the direct contact geothermal power plant would of necessity be condensing a mixture of steam and an immiscible working fluid. In general the working fluid would consist of more than $90-95 \%$ by mass of the vapor. It thus differs from the previously mentioned condensers in that two phases are present in the condensed liquids. As both steam and working fluid are condensing the heat transfer is not necessarily reduced, as is the case when a noncondensible gas is present within the vapor. For geothermal application it is advantageous to use water as the coolant to induce the condensation due to its higher thermal conductivity and heat capacity when compared to typical working fluids.

The types of equipment that can be used for direct contact condensers are primarily based on whether one chooses to have condensation on drops or by collapsing bubbles. However, condensation on thin films (packed beds) is also possible. The type of equipment can also be selected on the basis of whether or not desuperheating makes up part of the heat load (73). Thus, duty as well as the basic mechanism constitute the means of categorizing equipment.

For condensation of saturated vapor there is no obvious advantage of counter-current versus co-current flow. Thus, most direct contact condensers for this application are in fact really co-current devices. The actual physical arrangement of counter current flow may be advantageous, however, if appreciable amounts of noncondensible gases are present, to aid in deaerating the condenser. 


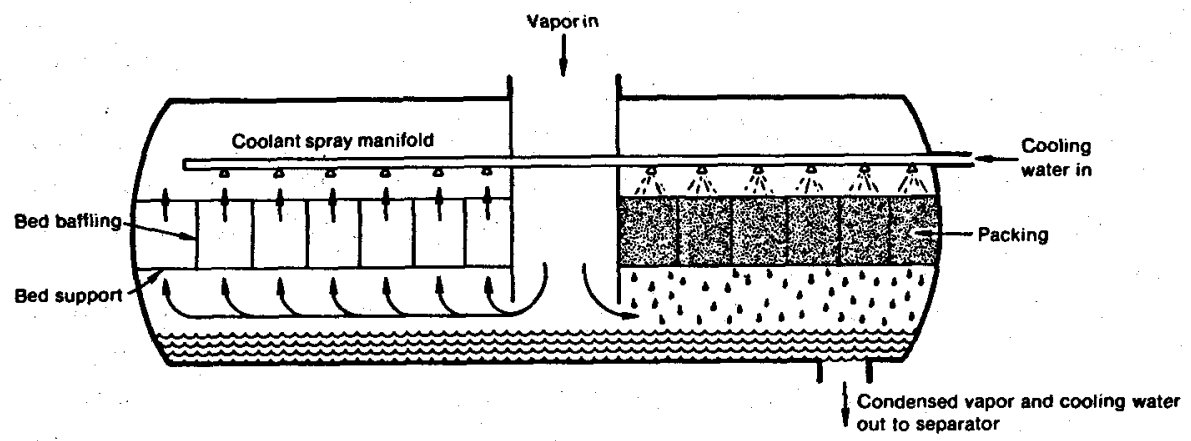

Frouke 4.127-Packed bed type direct contact condenser.

Film type direct contact condensers. In order to obtain large surface areas and thus large volumetric heat transfer coefficients in a film type condenser, this type of condenser is designed as a packed bed, and is shown schematically in figure 4.127 . A variety of bed materials can be used for packing such as Raschig, Lessing, and Pall rings and Berl and Intaloz saddles. Expanded metal lath could also be used.

Packed beds have been used in designs of sea water evaporation plants at the University of California and some information has been published (94) on their design. Harriott and Wiegandt (95) designed a packed bed condenser using $1 / 2$ inch Intalox saddles for the condensation of methylene chloride using water. Other studies concerned with packed beds include a study of a gasoline condenser (96) and condensation of isobutane on packed ice (97). Although volumetric heat transfer coefficients achieved were reported in all of these papers no design information in the form of a usable correlation was reported.

Detailed information related to condensation on thin films has been discussed by Tamir and Rachmilev (98) and Murty and Sastri (99). The first deals with the condensation of an immiscible fluid on a thin laminar film of water flowing over a sphere while the latter applies to condensation on a falling film of coolant the same as the vapor. These papers offered a semi-theoretical rationale that could be applied to the local heat transfer coefficients in packed beds.

Thomas et al. (100) report experiments in a six inch (15 cm) diameter packed bed condenser. His experiments have dealt with the condensation of R-113 on a water film. He used both $1.9 \mathrm{~cm}$ diameter spheres and $1.9 \mathrm{~cm}$ Berl saddles for packing. Flow rates, temperatures and packing depth were varied. The data was correlated in terms of both Stanton Number and HTU (Height of a Transfer Unit). Data from Wilke et al. (94) using Arochlor to condense water on $1.25 \mathrm{~cm}$ Raschig rings was also correlated. The data fitted within $\pm 15 \%$ the following correlation

$$
S t=\frac{2.5\left(K_{c} / K_{L}\right)^{0.5}}{J a^{0.6} H^{0.6} C^{0.3}}
$$


where

$$
\begin{aligned}
S t & =\frac{\bar{h} a}{(\dot{m} / A)_{L} C_{P L} a_{w 0}} \\
J a & =\frac{h_{f g}}{C_{p L}\left(T_{a a t}-T_{L, \text { to }}\right)} \\
C & =\frac{\dot{m}_{L} C_{P L}}{\dot{m}_{C} C_{P C}} \\
H & =\frac{\text { Bed Height }}{\text { Packing Size }}=\frac{z}{d} \\
a & =\frac{\text { Surface Area of Wetted Packing }}{\text { Volume }} \\
q & =(\text { LMTD } z \bar{h} a A
\end{aligned}
$$

Note that in the above correlation the value of $a$ is the wetted packing area/unit volume. For spheres, complete wetting of the packing is obtained while for Berl Saddles and Raschig Rings only $50 \%$ of the manufacturers reported surface area per unit volume is successfully wetted. This was shown in reference $(100)$ by injecting dye-laden coolant into the tower and examining the packing as well as by visual observation during operation of the tower.

Drop-type direct contact condensers. Although referred to as "droptype-direct contact condensers" this classification includes all types of condensers where the vapor is the continuous media and the condensation takes place on either drops or jets of the dispersed phase. Typical of such devices are the so-called barometric or low level condensers sometimes used in steam power plants and shown in figure 4.128. These systems are variations on a simple spray tower as shown in figure 4.129. In attempting to obtain more compact exchangers, tray-type condensers sometimes referred to as "jet-type condensers" are also used. The tray-type devices all enhance the heat transfer by allowing the coolant and condensate to mix on the trays and thus offer a higher heat transfer by eliminating temperature gradients within the drops and controlling drop coalescence as well as increasing the vapor holdup.

Most of the information available dealing with "drop" direct contact condensers is directed toward condensation of steam or the condensation of a vapor on its own liquid. Some "drop-jet" configurations have been used for systems of immiscible liquids. However, comparisons between the packed bed performance and single tray performance showed lower approach temperatures with the tray arrangement (95).

In order to design direct contact "drop" type condensers knowledge of the heat transfer to individual drops as well as a spray is required. The problem of heat transfer to a single drop is essentially a nonlinear con- 


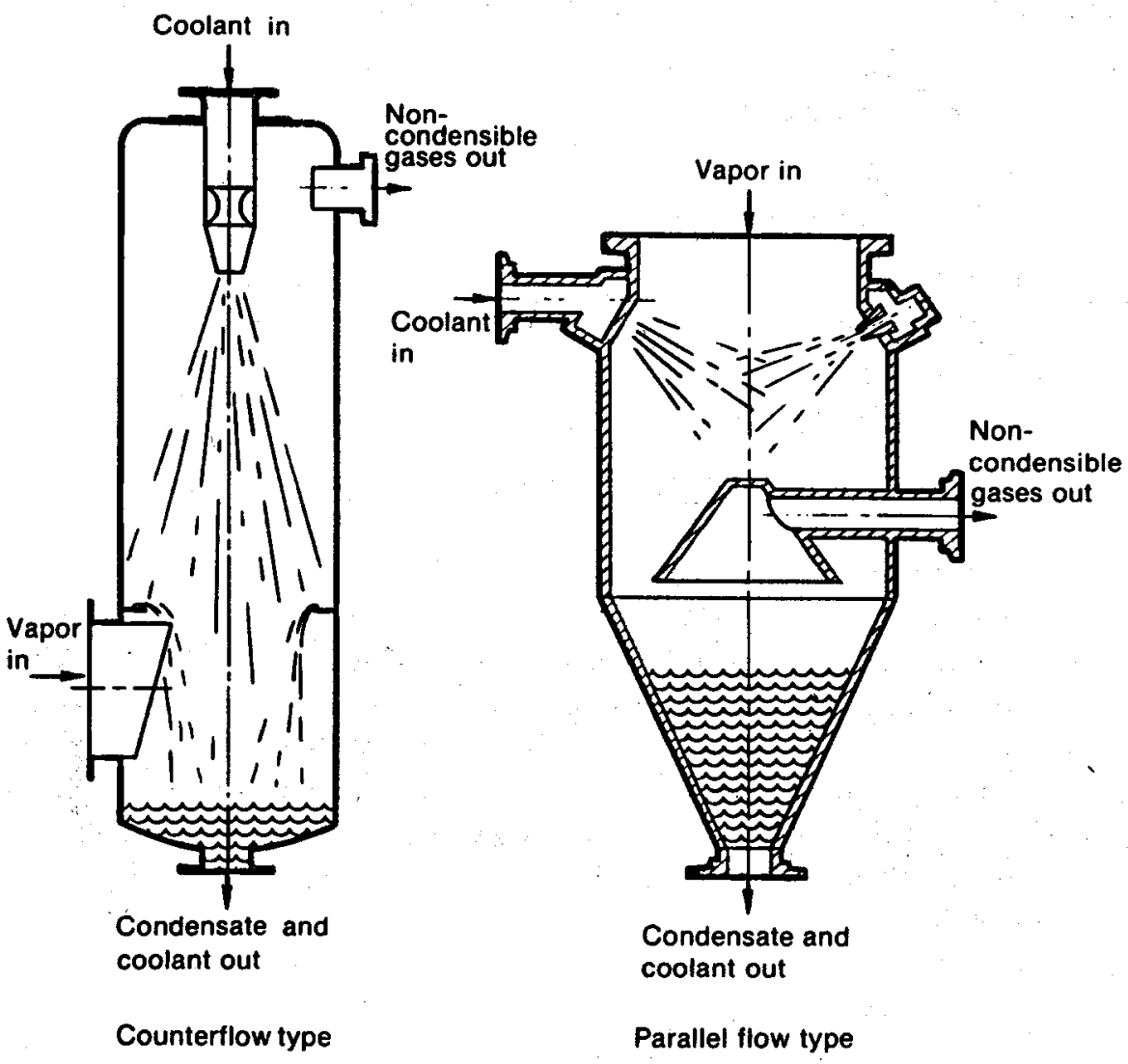

FroURe 4.128-Two designs of barometric condensers.

duction problem for drops of $3 \mathrm{~mm}$ diameter and smaller. The problem is made nonlinear by the growth of the condensate layer. Thus only numerical solutions or experimental measurements are possible to determine the individual drop heat transfer. Jacobs and Cook (101) have carried out numerical evaluations and compared their results with the experiments of Ford and Lekic (102) for steam condensing on water drops. See figure 4.130. Even for this condition of high heat of vaporization and thus a thin condensate film and reasonably large thermal conductivity of the condensate, the resistance of the condensate cannot be neglected. Thus the analytical solutions which neglect drop growth cannot be utilized.

The paper by Jacobs and Cook (101) provides some information on typical heat transfer coefficients for single drops with R-113 and pentane condensing on water. An effectiveness, $\phi$, which is defined as the limiting growth in the drop due to condensation is presented as a function of the nondimensional time, $\tau=a_{A} t / R_{i}{ }^{2}$. Here $\alpha_{A}$ is the thermal diffusivity of the spray fluid, and $R_{i}$ is the initial drop radius. Using these parameters, figures $4.130,4.131$, and 4.132 were derived for three potential working 
Ergure 4.129-Simple spray tower.

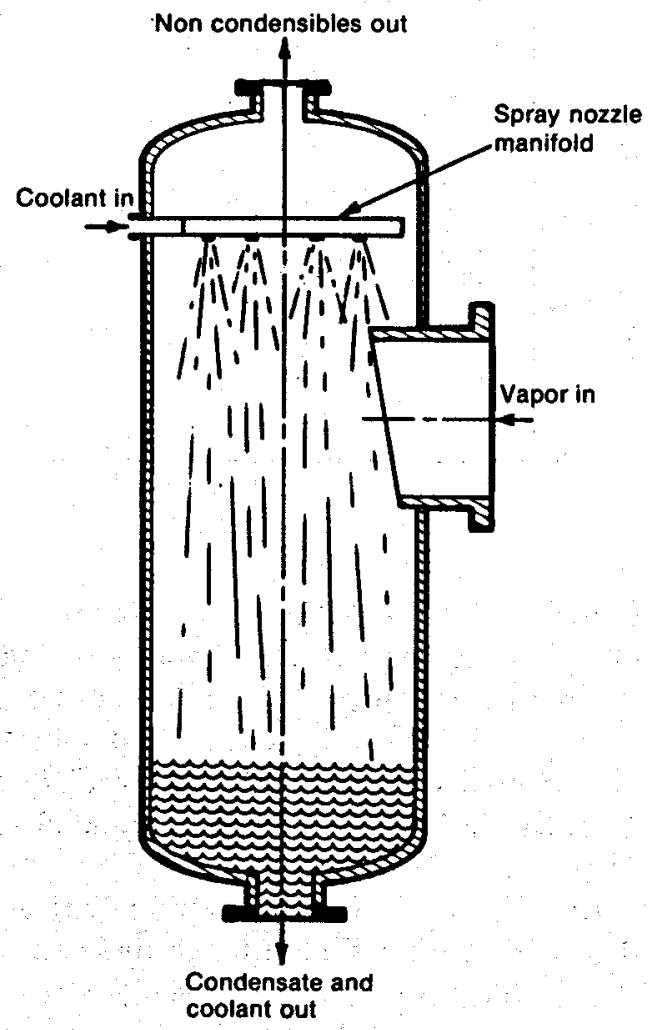

Fiave 4.130-Drop growth rate for steam condensing on a water drop for $T_{\text {atot }}-T_{1}=50^{\circ} \mathrm{C}$.

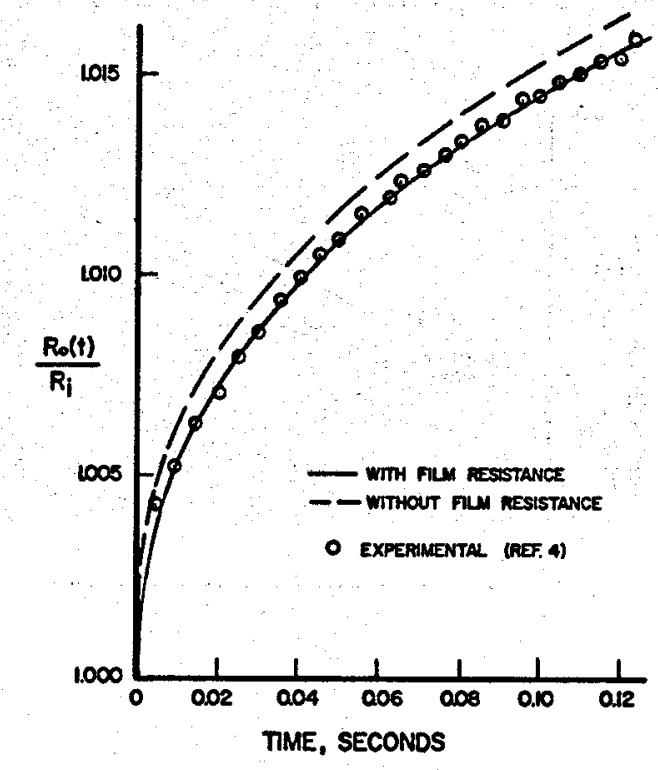




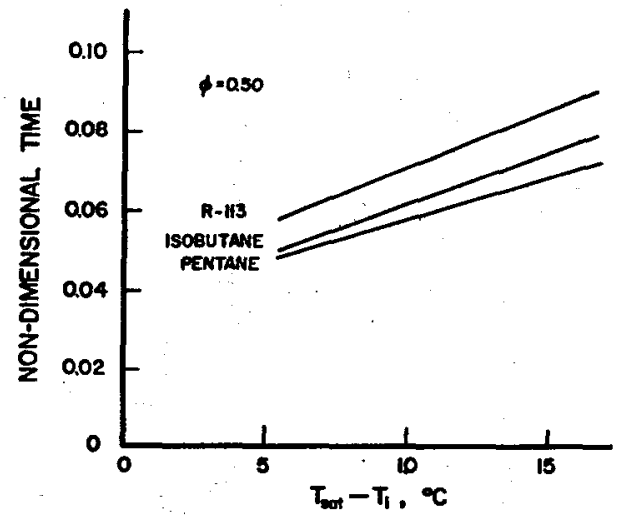

Fraure 4.131-Non-dimensional con. densation time as a function of initial driving force, $T_{\text {sat }}-T_{1},{ }^{\circ} \mathrm{C}$.

fluids: R-113, isobutane, and pentane. If one were to utilize a constant effectiveness, figures 4.131 and 4.132 indicate typical times required to reach that value given the subcooling of the drop. From this, heat exchanger height can be determined. Curves such as provided in figure 4.133 can be used to determine the effectiveness given a heat exchanger size, $\tau$. Note that $\tau$ can be used as a size assuming terminal velocity for rigid drops falling in a still vapor.

In order to deal with the fact that a spray will have a distribution of drop sizes rather than a fixed diameter, one must evaluate the statistics of sprays and the possibility of coalescence of drops. This problem was treated by Isachenko and Kushnyrev (103). In carrying out the analysis, however, the heat transfer to an individual drop was over-simplified, and an example was provided for a particular drop diameter distribution. Thus further analysis needs to be made. However, the single drop model of Jacobs and

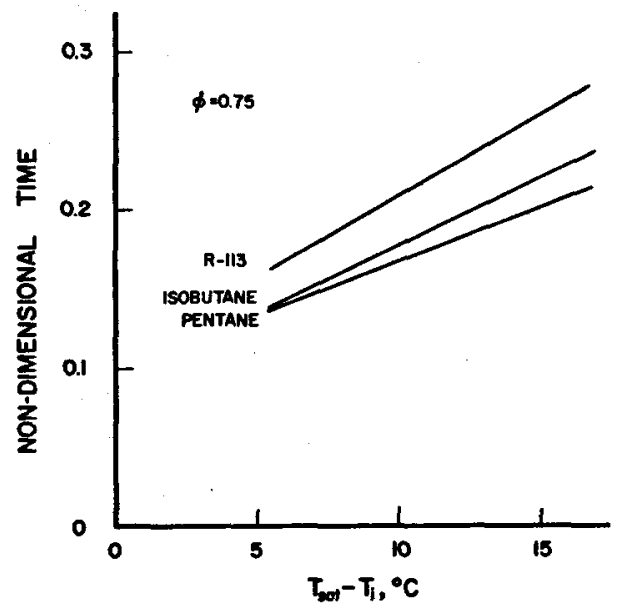

FrGURE 4.132-Non-dimensional condensation time as a function of initial driving force, $T_{a t}-T_{1},{ }^{\circ} \mathrm{C}$. 
Frgure 4.133-Comparison of condensation effectiveness for a fixed size condenser.

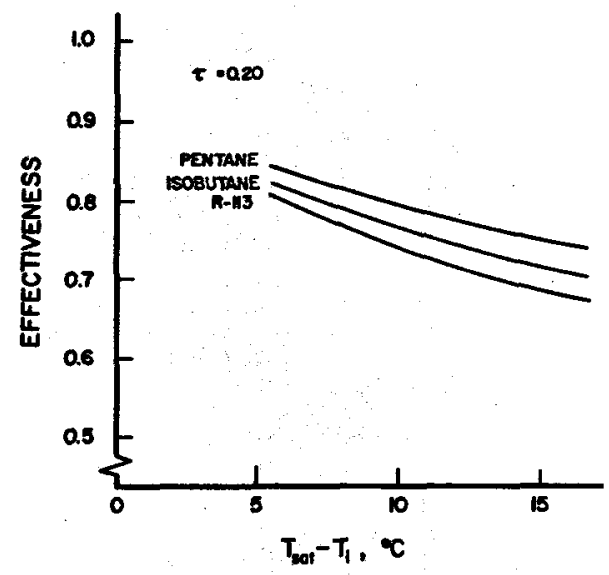

Cook (101) can be combined with the statistics model of Isachenko and Kushnyrev (103) to properly estimate the heat exchanger size properly.

For preliminary design the work of Jacobs and Cook (101) can be used assuming a statistical average initial drop diameter.

Bubble type direct contact condensers. Bubble type direct contact condensers include all those systems where the condensing vapor is injected directly into a continuous pool or stream of cold liquid. This type of device has been of interest as an open feed-water heater and as a vapor suppression system associated with nuclear reactors. Other applications are found in use in sea water distillation. The several types of designs, as shown in figure 4.134, differ basically in the behavior of the continuous phase.

Studies have been carried out for condensing organic vapors in a pool of water (104). In another study, pentane bubbles were condensed in pentane and compared to condensation in water (105). This latter study shows clearly the advantage of the use of high conductivity fluid for the continuous phase. More recently, Jacobs et al. (106) have investigated the condensation of one phase within a second immiscible liquid phase analytically. They solved the integral energy equations for the condensate and the external boundary layer assuming the velocity in both was equal to the potential flow over a sphere for an approach velocity equal to the mean bubble rise rate. The bubble collapse predicted is given by

$$
\frac{R(t)}{R_{i}}=\left[1-0.6049\left(R e_{L} P r_{t}\right)^{1 / 2} \phi J a^{*} \frac{\rho_{f}}{\rho_{0}} F o_{L}\right]^{2 / 3}
$$

In the above equation the subscript $L$ refers to the continuous liquid phase, $v$ the vapor, and $f$ the condensate film. $F o_{L}$ is the Fourier modulus based on liquid properties,

$$
J a^{*}=\rho_{L} C p_{L}\left(T_{\text {mat }}-T_{\infty}\right) / \rho_{s} h_{\rho k}
$$




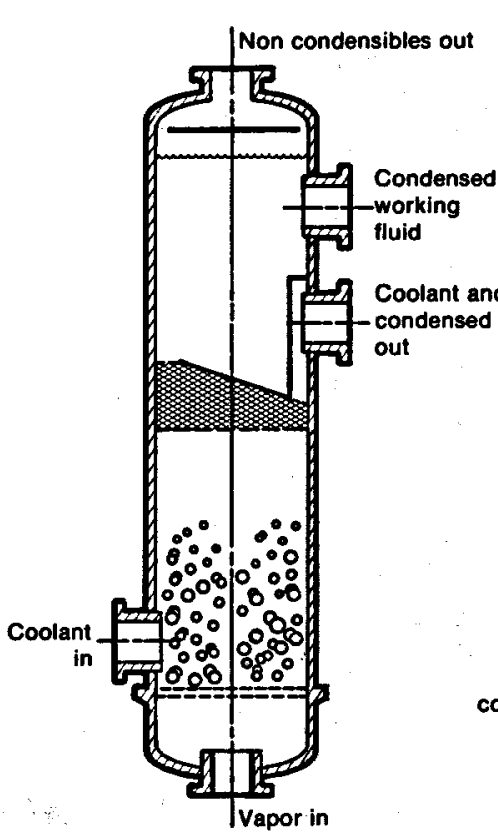

Parallel flow bubble type condenser with coalescence screens

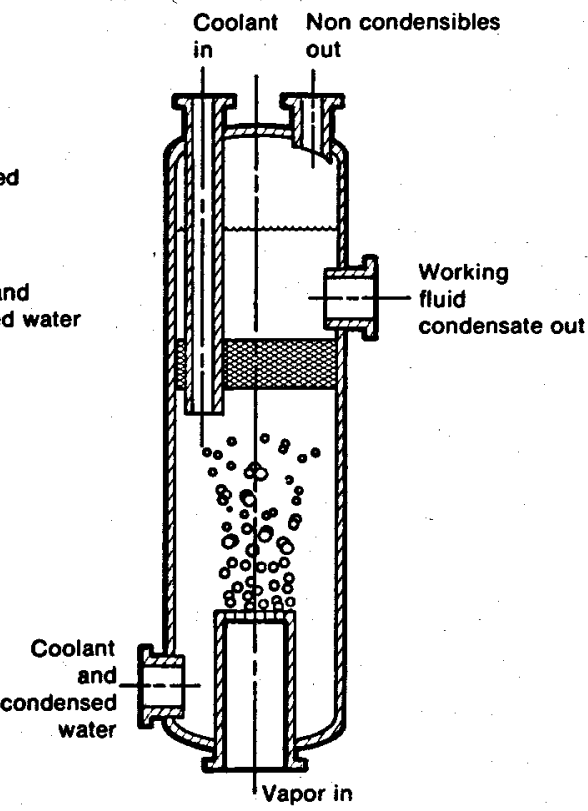

Countercurrent bubble type condenser with coalescence screens

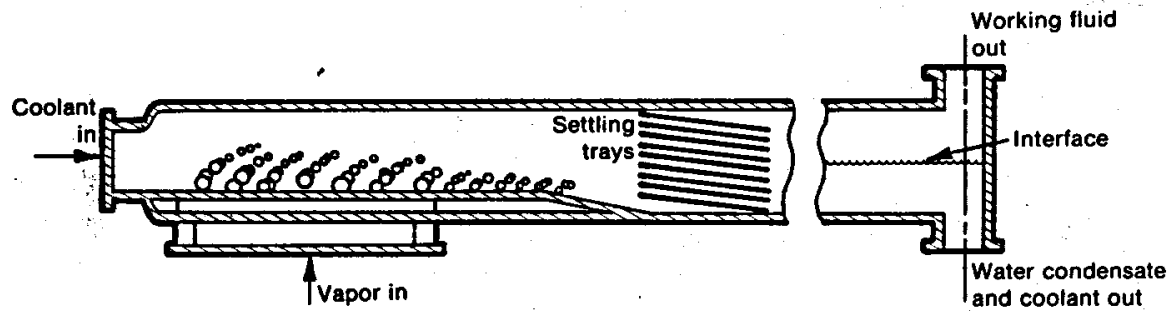

Crossflow bubble type condenser with settler

Frourd 4.134-Some bubble-type direct contact condensers.

and $\phi$ is given by the equation

and

$$
\phi=\sqrt{C_{1}^{2}+2 C_{1}}-C_{1}
$$

$$
C_{1}=\frac{0.75 K_{f}}{J a^{*} K_{L}}
$$

When the results of equation 4.122 were applied to the experimental results of Isenberg et al. (107), it was found that it overpredicted the collapse. Jacobs and Major (108) have developed an improved model by analyzing the actual hydrodynamics of a collapsing bubble. They show no 
apparent change, thus indicating that the problem was due to diffusion of noncondensibles.

Sideman and Moalem (10\%) have carried out numerical analyses for multiple bubbles which should be applicable to the design of actual condensers when used with an accurate representation of single bubble collapse as well as the multibubble hydrodynamics. As pointed out by Sideman and Moalem (105) the velocity for a bubble in a bubble swarm can be used in an equation such as equation 4.121. The velocity for: a bubble is

$$
V_{\infty}^{m}=V \frac{(1-\epsilon)^{2}}{1-\epsilon^{5 / 3}}
$$

( $c$ is the fractional holdup. $c$ can be calculated if one supposes bubble spacing and number of bubbles in a row if they move vertically.) It should be noted that the bubble rise relative to the heat exchanger wall, $V_{b}$, is given by

$$
V_{\infty}^{m}=V_{o} \pm V_{\imath}+\text { Counter-current }
$$

Here $\nabla_{l}$ is the superficial velocity of the continuous liquid phase. Assuming vertical bubble rows and bubble spacing or frequency an energy balance on the continuous liquid can be used to estimate the temperature of the liquid phase to be used in equation 4.121. Following this procedure Sideman and Moalem (105) predicted volumetric heat transfer coefficients of a multiple bubble pentane vapor condenser to be typically $U_{V}=27,000$ $\mathrm{Btu} / \mathrm{hft}^{30} \mathrm{~F}$ when the bubbles were released at intervals equal to $1 / 26$ of the time for complete bubble collapse and nozzles spaced at 4 initial bubble diameter intervals, and water was the coolant. The results of their study also indicated that counter-current operation was more efficient than cocurrent. The $U_{v}$ given above is typical of what should be obtainable in either the cross-current or counter-current condensers of figure 4.134 for typical working fiuids. Analyses need to be carried out, however, for the actual situation and using an improved model for the single bubble collapse.

Direct injection of vapor into liquid flowing turbulently in a tube is anther effective condensation concept $(109,110)$. Heat transfer rates associated with condensing steam of nearly $400,000 \mathrm{Btu} / \mathrm{hft}^{30} \mathrm{~F}$ were demonstrated. It is not thought that such high values would be obtainable with other fluids.

Superheated vapor. When the vapor to be condensed is superheated, the coolant must remove the sensible heat within the vapor as well as the heat of vaporization. For this type of duty there is a definite advantage to a counterfiow system. The basic mechanisms of liquid film (packed bed), drop and bubble systems are all applicable; however, changes in design are necessary to ensure complete or nearly complete condensation of the vapor 
and avoidance of loss of working fluid with any noncondensible gases that may be present. Typical equipment systems might be the counter-current designs discussed under previous sections.

The heat transfer in the superheat regime is governed by liquid-gas heat transfer relation. These are discussed by Fair $(73,74)$, Sideman (89), and Jacobs (99) among others for a wide variety of equipment designs for all three mechanisms. The heat transfer coefficients attainable for removal of sensible heat are notably smaller than with changes of phase and are nominally controlled by the gas side heat transfer. Typically the heat transfer coefficients obtained for removal of sensible heat may vary from 100 to $2000 \mathrm{Btu} / \mathrm{hft}^{3 \circ} \mathrm{F}$. These values are several orders of magnitude below those obtainable for condensation. It can thus be seen that for even $5-10 \%$ of the total heat load superheat can lead to a significant increase in the size of the condenser-cooler.

\subsubsection{Nomenclature for Subsection 4.2.6}

$A \ldots \ldots \ldots \ldots$ Area

$A, B, C, D, E, F$. Constants given in table 4.15

$a, b, \ldots \ldots \ldots$. Quantities given in equation 4.89

$C \ldots \ldots \ldots \ldots$ Ratio of mass flow specific heat products

$C_{p} \ldots \ldots \ldots \ldots$ Specific heat

d............. Diameter

$E \ldots \ldots \ldots \ldots$ Energy density

$E_{k} \ldots \ldots \ldots \ldots$ Tray heat transfer efficiency

e............ Energy density

$F_{0} \ldots \ldots \ldots \ldots$ Fourier number

$f \ldots \ldots \ldots \ldots \ldots$ Friction factor

g. . . . . A . Acceleration of gravity

H. . . . . . . Henry's Law constant, enthalpy, or bed height

$J a \ldots \ldots \ldots \ldots$ Jakob number

K.......... Thermal conductivity

l. .......... Length of tower

LMTD . . . . . . . Log mean temperature difference

$M . \ldots \ldots \ldots \ldots$ Ratio of droplet wake volume to droplet volume

$m \ldots \ldots \ldots \ldots$ Mass or parameter used in equation 4.100

$\dot{m} . \ldots \ldots \ldots \ldots$ Mass rate of flow

$m_{1} \ldots \ldots \ldots \ldots$ Mass flow ratio

P............ Pressure

Pr........... Prandtl number

Q........... Heat transfer or volume rate of flow

$R \ldots \ldots \ldots \ldots$ Volumetric flow ratio or radius

Re.......... Reynolds number

$S \ldots \ldots \ldots \ldots$ Entropy or quantity defined in equation 4.108

Sol............ Solubility of gas in liquid

St............ Stanton number 
T.......... Temperature

t............ Time

TFM......... Thermodynamic Figure of Merit, defined on page 420

U............. Overall heat transfer coefficient

$V \ldots \ldots \ldots \ldots$ Volume or velocity

v............. Specific volume

$W \ldots \ldots \ldots \ldots$ Weight percent $\mathrm{NaCl}$

$X \ldots \ldots \ldots \ldots$ Quality

$Y \ldots \ldots \ldots \ldots$ Difference in volume or entropy ratios

GREEK BYMBOLS

$\alpha_{1} \ldots \ldots \ldots \ldots \ldots$ Thermal diffusivity of spray fluid

$\alpha_{1,2} \ldots \ldots \ldots \ldots \ldots$ Quantity defined in equation 4.109

c.............. Fraotional holdup

$\phi \ldots \ldots \ldots \ldots \ldots$ Holdup or effectiveness

$\eta \ldots \ldots \ldots \ldots$ Efficiency

$\mu \ldots \ldots \ldots \ldots \ldots$ Dynamic viscosity or volume of wake elements shed

ค............. Density

$\sigma \ldots \ldots \ldots \ldots$ Surface tension

r......... Dimensionless time

A........... Area

act............ Actual

b........... Brine or bubble

c.............. Continuous phase

d............. Dispersed phase

down.......... Downspout

e............. Exit

$f \ldots \ldots \ldots \ldots \ldots$ Flooding value or condensate film

fg............ Vaporization

$\mathrm{H}_{2} \mathrm{O} \ldots \ldots \ldots$ Water

i............ Initial

in ............ Inlet

isob........... Isobutane

j............. Jet

L.......... Liquid

$\operatorname{mix} . . . \ldots \ldots \ldots$ Mixture

N2.......... Nitrogen

$n \ldots \ldots \ldots \ldots$ Tray or stage number

o............ Spherical or orifice

out.......... Outlet

p........... Particle or drop

pent........... Pentane

S. . . . . Source

sat........... Saturated 


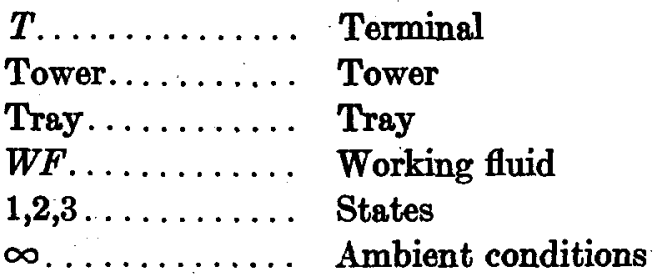

References* for section 4.1 and 4.2

(1) Ellis, A. J. and Golding, R. M., 1963. "Solubility of Carbon Dioxide above $100^{\circ} \mathrm{C}$ in Water and Sodium Chloride Solutions," Am. J. Sci. 261 : 47.

(2) Silvester, L. F. and Pitzer, K. S., 1976. "Thermodynamics of Geothermal Brines I Thermodynamic Properties of Vapor-Saturated $\mathrm{NaCl}$ Solutions from 0-300 ${ }^{\circ}$ C," TID-4500-R64 LBL Univ. of California.

(3) Horlock, J. H., 1966. "Axial Flow Turbines," Butterworths Press, London.

(4) DiPippo, R., 1978. "A Summary of the Technical Specifications of the Geothermal Power Plants in the World," Report Number C00/4051-14, CATMEC/8, Brown University, Providence, R.I.

(5) DiPippo, R., 1978. "Geothermal Power Plants of Japan: A Technical Survey of Existing and Planned Installations," Report Number C00/4051-16, CATMEC/9, Brown University, Providence, R.I.

(6) Kestin, J., 1968. A Course in Thermodynamics, vol. I, Blaisdell, Waltham, Mass.

(7) Kestin, J., 1968. A Course in Thermodynamics, vol. II, Blaisdell, Waltham, Mass.

(8) Keenan, J. H., Keyes, F. G., Hill, P. G., and Moore, J. G., 1969. Steam Tables (International edition-metric units); Wiley, New York.

(9) Kestin, J. and Dorfman, J. R., 1971. A Course in Statistical Thermodynamics, Academic Press, New York.

(10) Sengers, J. V. and Levelt-Sengers, J. M. H., 1976. "Critical Phenomenon in Classical Fluids," Progress in Liquid Physics, p. 103.

(11) A.P.I. Research Project, No. 44, 1953. "Selected Values of Physical and Theromdynamic Properties of Hydrocarbons and Related Compounds," Carnegie Institute of Technology, Pittsburg, Pa., pp. 560, 582-3, 596, 612, 705.

(12) Chao, J., Wilhoit, R. C., and Zwolinski, B. J., 1973. "Ideal Gas Thermodynamic Properties of Ethane and Propane," J. Phys. Chem. Ref. Data, vol. 2, pp. $427-37$.

(13) Chao, J., and Zwolinski, B. J., 1975. "Ideal Gas Thermodynamic Properties of Ethylene and Propylene," J. Phys. Chem. Ref. Data, vol. 4, pp. 251-261.

(14) Chen, S. S., Wilhoit, R. C., and Zwolinski, B. J., 1975, "Thermodynamic Properties of Isomerization of N-butane and Isobutane," J. Phys. Chem. Ref. Data, vol. 4, pp. 859-69.

(15) Chen, S. S. and Zwolinski, B. J., 1976. "Ideal Gas Thermodynamic Properties of Six Chlorofluoromethanes," J. Phys. Chem. Ref. Data, vol. 5, pp. 571-80.

(16) Starling, K. E., Sleipcevich, C. M., Fish, L. W., Gin, K. M., Aboul-Foutoh, K. H., Kumar, K. H., Lee, T. J., Milani, J. S., Zemp, K. L., 1978. "Development of Working Fluid Thermodynamic Properties Information for Geothermal Cycles: Phase I," Report Number ORO-5249-2, University of Oklalahoma, Norman, Okla.

*References denoted as "DOF Report" are avallable from NTIS, Springfield, Va., under thè number given. ASME papers are avallable in most major technical libraries. 
(17) Milora, S. L. and Tester, J. W., 1976. Geothermal Energy as a Source of Electric Power, The MIT Press, Cambridge, Mass.

(18) Earnest, G., and Busser, J., 1970. "Ideal and Real Gas-State Heat Capacities

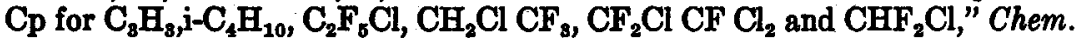
Therm., vol. 2, pp. 787-91.

(19) American Society of Heating, Refrigerating and Air-Conditioning Engineers, 1969. "ASHRAE Thermodynamic Properties of Refrigerants," ASHRAE, Inc., New York.

(20) Benedict, M., Webb, G. B., and Rubin, L. C., 1940. "An Empirical Equation for Thermodynamic Properties of Light Hydrocarbons and Their Mixtures: I. Methane, ethane, propane and butane,"J. Chem. Eng., vol. 50, p. 101.

(21) Reid, R. C., Prausnitz, J. M., and Sherwood, T. K., 1977. The Properties of Gases and Liquids, 3rd ed., McGraw-Hill, New York.

(22) Martin, J. J., 1967. "Equations of State," Ind. Eng. Chem., vol. 59, pp. 34-52.

(23) Starling, K. E., 1973. Fluid Thermodynamic Properties for Light Petroleum Systems, Gulf Publishing Co., Houston.

(24) Das, T. R., Reed, C. O., and Eubank, P. T., 1973. "PvT Surface and Thermodynamic Properties of N-butane," J. Chem. Eng. Data, vol. 18, pp. 243-52.

(25) Das, T. R., Reed, C. O., and Eubank, P. T., 1973. "Pv'T Surface and Thermodynamic Properties of Isobutane," J. Chem. Eng. Data, vol. 18, pp. 253-262.

(26) Eskesen, J.. H., 1977. "Study of Practical Cycles for Geothermal Power Plants," General Electric Report Number UC-66/C00-2619-1.

(27) Kestin, J., Khalifa, H. E., and Kumar, B., 1978a. "Thermodynamic and Transport Properties of Isobutane: A Survey of Available Data," Report Number C00/4051-35, CATMEC/27, Brown University, Providence, R.I.

(28) Milora, S. L. and Combs, S. K., 1977. "Thermodynamic Representations for Ammonia and Isobutane,". Report Number ORNL/TM-5847, Oak Ridge National Lab., Tenn.

(29) Kestin, J., Khalifa, H. E., and Kumar, B., 1978b. "Critical Evaluation of Three Equations of State for Isobutane," to be published.

(30) Fish, L. W. and Starling, K. E., 1975, "HSGC A Mixture Thermodynamic Properties Computer Program," Report Number ORO-4044-2, University of Oklahoma, Norman, Okla.

(31) Bishnoi, P. R. and Robinson, D. B., 1972. "New Mixing Rules for BWR Parameters to Predict Mixture Properties," Can.J. Chem. Eng., vol. 50. p. 101.

(32) Vargaftik, N. B. 1975. Tables of the Thermophysical Properties of Liquids and Gases, Wiley, New York.

(33) Eskesen, J. H., 1977. "Study of Practical Cycles for Geothermal Power Plants," ERDA Report Number COO-2619-1.

(34) Kern, D. K., 1950. Process Heat Transfer, McGraw-Hill, New York.

(35) Perry, R. H. and Chilton, C. H., Chemical Engineering Handbook, 5th ed., 1973, sections 10 and 11, McGraw-Hill, New York.

(36) Colburn, A. P. and Hougen, O. A., 1934. "Design of Cooler Condensers for Mixtures of Vapors with Noncondensing Gases," Ind. Eng. and Chem., vol. 26, p. 1178.

(37) Rohsenow, W. M. and Hartnett, J. P., Handbook of Heat Transfer, 1973, McGraw-Hill, New York.

(38) Votta, F., Jr., "Condensing from Vapor Gas Mixtures," Chem. Eng. Proc. 1964, vol. 71, p. 223.

(39) Collier, J. G., 1972. Convective Boiling and Condensation, McGraw-Hill, New York.

(40) Boyko, L. D. and Kruzkilin, G. N., 1967. "Heat Transfer and Hydraulic Resistance during Condensation of Steam in a Horizontal Tube and in a Bundle of Tubes," Int. J. of Heat and Mass Transfer, vol. 10, p. 361. 
(41) Sieder, E. N. and Tate, G. E., 1936. "Heat Transfer and Pressure Drop of Liquids in Tubes," Ind. Eng. and Chem., vol. 28, pp. 1429-1435.

(42) Lombard, G. L., 1975. Test and Evaluation of a Geothermal Heat Exchanger, EPRI publication $37 \mathrm{~b}$.

(43) Perry, R. H. and Chilton, C. H., 1973. Chemical Engineers' Handbook, 5th ed., pp. 10-16, McGraw-Hill, New York.

(44) Mostinskii, I. L., 1963. "Application of the Law of Corresponding States to Calculation of Heat Input and Critical Thermal Flows in the Presence of Boiling Liquid," Teploenergetika, No.4, pp. 66-71.

(45) Palen, J. W. and Small, W. M., 1964. "A New Way to Design Kettle and Internal Reboilers," Hydrocarbon Processing, vol. 43, p. 11.

(46) Neill, D. T., 1976. "Geothermal Shell and Tube Heat Exchanger Augmentation," TREE-102S, EG\&G Idaho, Inc.

(47) Kern, D. Q. and Kraus, A. D., 1972. Extended Surface Heat Transfer, McGrawHill, New York.

(48) Bringer, R. P. and Smith, J. M., 1957. "Heat Transfer in Critical Region," AIChE J., vol. 3, p. 49.

(49) Dickinson, N. L. and Welch, C. P., 1958. "Heat Transfer to Supercritical Water," Trans. of ASME, vol. 80, p.747.

(50) Koppel, L. B. and Smith, J. B., 1961. "Turbulent Heat Transfer in the Critical Region," Conf. on Int. Dev. in Heat Transfer, part I, ASME, pp. 585-590.

(51) Goldman, K., 1961. "Heat Transfer to Supercritical Water at 5000 psi Flowing at High Mass Flow Rates Through Round Tubes," Conf. on Int. Dev. in Heat Transfer, part I, ASME, pp. 561-568.

(52) Koppel, L. B. and Smith, J. B., 1962. "Laminar Flow Heat Transfer for Variable Physical Properties," J. of Heat Transfer, ASME, vol. 84, p. 151.

(53) ASME Boiler and Pressure Vessel Code, section VIII, paragraph UG-22, p. 16, 1977.

(54) Taborek, J., et al., 1972. "Predictive Methods for Fouling Behavior," Chem. Eng. Prog., vol. 68, No. 7.

(55) Taborek, J., et al., 1972. "Fouling: The Major Unresolved Problem in Heat Transfer," Chem. Eng. Prog., vol. 68, No. 2.

(56) Kern, D. Q. and Seaton, R. E., "A Theoretical Analysis of Thermal Surface Fouling," paper presented at Symp. on Air-cooled Heat Exchanges AIChE 51st Annual Meeting, December 1958.

(57) Kern, D. Q., 1966. "Heat Exchanger Design for Fouling Service," Proc. of the 3rd Int. Heat Transfer Conf., vol. I, p. 170, Chicago, Ill.

(58) Mueller, A. C., 1954. "Thermal Design of Shell and Tube Heat Exchangers for Liquid-to-liquid Heat Transfer," Research Bulletin No. 121, Engineering Experiment Station, Purdue University.

(59) Jacobs, H. R. and Boehm, R. F., 1978. "Electrical Production from Moderate Temperature Geothermal Brines," Emerging Energy Technologies-1978, ASME, New York, pp. 11-18.

(60) Sheinbaum, I., 1975. "Direct Contact Heat Exchangers in Geothermal Power Production," ASME Paper No. 75-HT-52, ASME/AIChE Heat Transfer Conf.

(61) Sheinbaum, I., 1976. "Power Production from High Temperature Geothermal Waters," Proc. of the 11th IECEC, Lake Tahoe, Nev., vol. 1, pp. 778-785.

(62) Suratt, W. B. and Hart, G. K., 1977. "Study and Testing of Direct.Contact Heat Exchangers for Geothermal Brines," DSS Engineers, Inc., Ft. Lauderdale, Fla. DOE Report ORO-4893-1.

(63) Harris, J. S., Stewart, G. G., Rogers, V. C., Hansen, A. C., and Boehm, R. F., 1977. "Conceptual Design and Evaluation of Geothermal-Driven $50 \mathrm{MWe}$ 
Power Plants," Proc. of the First Annual Meeting of the Gecthermal Resources Council, pp. 131-134.

(64) Bliss, R. W., Boehm, R. F., and Jacobs, H. R., 1976. "Analysis of Binary Vapor Turbines," University of Utah. DOE Report IDO/1549-7.

(65) Balje, O. E., 1962. "A Study on Design Criteria and Matching of Turbomachines: Part A-Similarity Relations and Design Criteria of Turbines," J. of Eng. for Power, pp. 83-102.

(66) Riemer, D. H., Jacobs, H. R., and Boehm, R. F., 1976. "Analysis Of Direct Contact Binary Cycles for Geothermal Power Generation (Program DIRGEO)," University of Utah. .DOE Report IDO/1549-5.

(67) Riemer, D. H., Jacobs, H. R., Boehm, R. F., and Cook, D. S., 1976a. "A Computer Program for Determining the Thermodynamic Properties of Light Hydrocarbons," University of Utah. DOE Report IDO/1549-3.

(68) Riemer, D. H., Jacobs, H. R., and Boehm, R. F., 1976b. "A Computer Program for Determining the Thermodynamic Properties of Freon Refrigerants," University of Utah. DOE Report IDO/1549-4.

(69) Riemer, D. H., Jacobs, H. R., and Boehm, R. F., 1976c. "A Computer Program for Determining the Thermodynamic Properties of Water," University of Utah. DOE Report IDO/1549-2.

(70) Jacobs, H. R., Boehm, R. F., and Hansen, A. C., 1977. "Application of Direct Contact Heat Exchangers to Geothermal Power Production Cycles," Project Review, Dec. 1, 1974-May 31, 1977, Grant E(10-1) 1549 and Contract E(10-1)1523, DOE Report IDO/1549-8.

(71) Hellstrom, G. W., Jacobs, H. R., and Boehm, R. F., 1976. "The Solubility of Selected Secondary Fluids for Use in Direct Contact Geothermal Power Cycles," University of Utah. DOE Report IDO/1549-6.

(72) Shaffer, C. J., 1976. "Geothermal Steam Plant Modeling and Power Trade-off Studies," Aerojet Nuclear Corp. DOE Report ANCR-1295.

(73) Fair, J. R., 1972. "Designing Direct-Coolers/Condensers," Chem. Eng., vol. 79, pp. 91-100.

(74) Fair, J. R., 1972a. "Process Heat Transfer by Direct Fluid Phase Contact," AlChE Symposium Series 118, vol. 68.

(75) Johnson, R. W., Jacobs, H. R., and Boehm, R. F., 1975. "Direct Contact Heat Transfer Between Two Immiscible Liquids in Laminar Flow Between Parallel Plates," University of Utah. DOE Report IDO/1549-1.

(76) Jacobs, H. R., 1977. "Evaluation and Design Considerations for Liquid-Liquid Direct Contact Heat Exchange for Geothermal Applications," ASME Paper No. 77-HT-2, ASME/AIChE National Heat Transfer Conf.

(77) Letan, R., 1976. "Design of a Particulate Direct Contact Heat Exchanger: Uniform Countercurrent Flow," ASME Paper 76-HT-27, ASME/AIChE Heat Transfer Conf.

(78) Letan, R. and Kehat, E., 1968. "The Mechanism of Heat Transfer in a Spray Column Heat Exchanger," AIChE J., vol. 14, No. 3, pp. 398-405.

(79) Woodward, T., "Heat Transfer in a Spray Column," Chem. Eng. Prog., vol. 57, pp. 52-57.

(80) Richardson, J. F. and Zaki, W. N., 1954. "Sedimentation and Fluidization," Part I, Trans. of the Inst. of Chem. Eng., vol. 32, pp. 35-53.

(81) Kehat, E. and Berg, A., 1972. "Spray Column Heat Exchanger System," Technion Research and Development Foundation, Ltd., Haifa, Israel, Final Report CE 72/64.

(82) Steinmeyer, D. E. and Woodward, C. E., 1969. "Liquid-Liquid Heat Transfer in a Large Diameter Spray Column," Chem. Eng. Prog. Symp. Series 92, vol. 65 . 
(83) Garwin, L. and Smith, B. D., 1953. "Liquid-Liquid Spray-Tower Operations in Heat Transfer," Chem. Eng. Prog., vol. 49, No. 11, pp. 591-601.

(84) Plass, S. B., Jacobs, H. R., and Boehm, R. F., 1979. "Direct Contact Heat Exchanger Operating Characteristics," University of Utah. DOE Report IDO/ 1523-5.

(85) Treybal, R. E., 1963. Liquid Extraction, 2nd ed., McGraw-Hill, New York.

(86) Scheiman, A. C., 1965. "Sizing of Baffle Plate Towers," Petro./Chem. Engr., vol. 37, No. 3 .

(87) Scheiman, A. C., 1965a. "Effect of Baffle Spacing on the Porformance of Baffle Plate Towers," Petro./Chem. Engr., No. 4, vol. 37.

(88) Sims, A. F., 1976. "Geothermal Direct Contact Heat Exchange," The Ben Holt Co., Pasadena, Calif. Final Report, ERDA Contract No. E(04-3) 1116.

(89) Sideman, S. and Gat, Y., 1966. "Direct Contact Heat Transfer with Change of Phase: Spray-Column Studies of a Three-Phase Heat Exchanger," AIChE J., vol. 12, No. 3, pp. 296-303.

(90) Blair, C. K., Boehm, R. F., and Jacobs, H. R., 1976. "Heat Transfer Characteristics of a Three-Phase Volume Boiling Direct Contact Heat Exchanger," University of Utah. DOE Report IDO/1523-1.

(91) Jacobs, H. R., Plass, S. B., Hansen, A. C., and Gregory, R., 1977. "Operational Limitations of Direct Contact Boilers for Geothermal Applications," ASME Paper No. 77-HT-5, ASME/AIChE National Heat Transfer Conf.

(92) Deeds, R. S., Jacobs, H. R., and Boehm, R. F., 1976. "Heat Transfer Characteristics of a Surface Type Direct Contact Boiler," University of Utah. DOE Report IDO/1523-2.

(93) Jacobs, H. R. and Fannar, H., 1977. "Direct Contact Condensers-A Literature Survey," University of Utah. DOE Report IDO/1523-3.

(94) Wilke, C. R., et al., 1963. "Direct Contact Heat Transfer for Sea Water Evaporation," Chem. Eng. Prog., vol. 52, No. 12, pp. 69-75.

(95) Harriott, P. and Wiegandt, H., 1968. "Countercurrent Heat Exchange with an Immiscible Transfer Agent," AIChE J., vol. 10, No. 5, pp. 755-758.

(96) Hu, S. C., 1956. "Direct Contact Gasoline Condenser," Petrol. Eng., vol. 28, No. 1, pp. 12-18.

(97) Wiegandt, H. F., 1960. "Office of Saline Water Progress Report No. 41."

(98) Támir, A. and Rachmilev, I., 1974. "Direct Contact Condensation of an Immiscible Vapor on a Thin Film of Water," Int.J. of Heat and Mass Transfer, vol. 17, pp. 1241-1251.

(99) Murty, N. S. and Sastri, V. M. K., 1974. "Condensation on a Falling Laminar Film," Proc. of the 1974 Int. Heat Transfer Conf., vol. III, pp. 231-235.

(100) Thomas, K. D., Jacobs, H. R., and Boehm, R. F., "Direct Contact Condensation of Immiscible Fluids in Packed Beds," University of Utah. DOE Report IDO/1523-4.

(101) Jacobs, H. R. and Cook, D. S., 1978. "Direct Contact Condensation on a Noncirculating Drop," Proc. of the Sixth Int. Heat Transfer Conf., vol. 2, pp. 389393.

(102) Ford, J. D. and Lekic, A., 1973. "Rate of Growth of Drops During Condensation," Int.J. of Heat and Mass Transfer, vol. 16, pp. 61-64.

(103) Isachenko, V. P. and Kushnyrev, V. I., "Condensation in Dispersed Liquid Spray," Proc. of the Fifth Int. Heat Transfer Conf., vol. III, pp. 217-220.

(104) Harris, B. R., 1970. "The Condensation of Organic Vapour by Direct Contact with Static Water," N.E.L. Report No. 453, pp. 30-40.

(105) Sideman, S. and Moalem, D., 1974. "Direct Contact Heat Exchangers: Comparison of Counter and Co-current Condensers," Int. J. of Multi-Phase Flow, vol. 1, No. 4, pp. 555-572. 
(106) Jacobs, H. R., Fannar, H., and Beggs, G. C., 1978. "Collapse of a Bubble of Vapor in an Immiscible Liquid," Proc. of the Sixth Int. Heat Transfer Conf., vol. 2. pp. 383-388.

(107) Isenberg, J., Moalem, D., and Sideman, S., 1970. "Direct Contact Heat Transfer with Change of Phase: Bubble Collapse with Translatory Motion in Single and Two-Phase Systems," Proc. of the Fourth Int. Heat Transfer Conf., vol. 5, paper B2.5.

(108) Jacobs, H. R. and Major, B., "Heat Transfer in Condensation of a Single Bubble in an Immiscible Liquid Phase Including Buoyancy Effects in the Condensate Film," in preparation.

(109) Bankoff, S. G. and Mason, J. P., 1962. "Heat Transfer from Surface of Steam Bubble in Turbulent Subcooled Liquid Steam," AIChE J., vol. 8, No. 1.

(110) Grossman, P. and Wyss, E., 1962. "Determination of Heat and Mass Transfer Coefficients Between Vapor and Inert Gas," Chem. Engr. Tech., vol. 34, No. 11, p. 755.

\subsection{Hybrid Fossil-Geothermal Systems (By H. E. Khalifa*)}

\subsubsection{Introductory remarles}

The extraction of work from low-grade, liquid-dominated geothermal resources requires the generation of a vapor working fluid that can be efficiently expanded in a turbine. The need for generating a vapor working fluid arises from our inability to design successfully an efficient expander for low-quality vapor-liquid mixtures. ** Consequently, a vapor working fluid has to be generated either directly from the geothermal fluid by flashing and separation (see section 4.1) or indirectly in a secondary fluid loop by means of a heat exchanger (see section 4.2). In both cases entropy is produced in the process of bringing the working fluid to a condition suitable for admission to a conventional steam turbine or organic fluid turbine.

The entropy production in a geothermal flash steam system results mainly from the isenthalpic flash processes as well as from the inefficient expansion of the separated steam in the wet region. In an organic-fluid binary cycle, entropy is generated in the primary heat exchanger where the liquid geothermal fluid supplies heat (exergy) to the organic working fluid. The two fluids differ considerably in their thermodynamic and transport properties. This results in a pronounced pinch in the temperature profiles and, consequently, in large temperature differences away from the pinch point. It is due to these irreversibilities that as much as $50 \%$ of the available work is lost even in thermodynamically optimized binary and double flash systems for typical geothermal resource conditions. [Milora and Tester, 1976]. This large percentage loss can be tolerated so long as the cost of improving the utilization efficiency of geothermal power systems outweighs the savings resulting from the improvement.

-Division of Engineering, Brown. University, Providence, R.I.; presently with United Technologies Research Center, East Hartford, Conn.

* The status of the development of total-flow expanders is discussed in section 4.4. 
The irreversibilities inherent in the conventional utilization of fossil fuels for the generation of electricity differ markedly from those in geothermal power generation. The work losses in a conventional coal fired steam power plant, for example, result primarily from limiting the turbine inlet temperature to values that seldom exceed $540^{\circ} \mathrm{C}$. This value, which is dictated by the economic considerations of material selection, is considerably lower than the flame temperature in the furnace of the steam generator. It can be shown by simple thermodynamic arguments that, even if all the heat were added at $540^{\circ} \mathrm{C}$, nearly $40 \%$ of the available work from the fuel will be dissipated through the irreversible process of heat transfer in the steam generator. In fact, the losses are even higher than $40 \%$ since the feedwater enters the steam generator at temperatures that are considerably lower than $540^{\circ} \mathrm{C}$.

The trend in the development of steam power plants has always been in the direction of increasing the average temperature of heat addition. This is achieved through increasing the initial steam parameters and throngh the application of the principles of regenerative feedwater heating and interstage reheating [see Skrotzki and Vopat, 1960; Haywood, 1967]. A modern sub- or super-critical steam power plant operating at $540^{\circ} \mathrm{C}$ with single or double reheat and with seven or eight feedwater heaters can achieve a utilization efficiency* of $40-42 \%$.

The foregoing arguments demonstrate that fossil fuels are better ntilized if we confine their use to supplying heat to the working fluid at high temperature. However, in order to achieve this, the working fluid has to be preheated by other means. Traditionally, this has been done by bleeding steam from the turbine at various extraction points and using it for feedwater heating. If the same can be achieved with lower entropy production, the fossil-fuel utilization efficiency can be improved. In other words, the utilization efficiency can be improved in a steam power plant if a low-grade (low temperature) medium is used for preheating the feedwater instead of the relatively high-grade, superheated steam bled from the turbine. It is in this context that geothermal energy, and other lowgrade energy sources, can be made to play an important role. The idea of using low-grade waste heat for feed water heating was discussed by Sheldon [1967] in connection with combined cycles.

Hybrid fossil-geothermal energy conversion systems thus emerge as those in which geothermal and fossil energy are combined in a thermodynamically optimum manner. More specifically, in a hybrid power plant, geothermal energy is confined to the low temperature part of the system whereas the fossil fuel is confined to the high temperature part.

The term hybrid fossil-geothermal systems, however, is not limited to the feedwater preheating system discussed above. We shall use this term to describe any system in which both geothermal energy and fossil fuel

*The term utilization efficiency is used here instead of the usual thermal efficiency. The rationale behind this use is given in section 4.3.2.1 and also in chapter 3 . 
energy are converted into work as for example when a fossil fuel is used for superheating geothermal steam produced either directly from a dry steam well or indirectly by flashing a geothermal liquid. A system of this type was proposed in 1924 by P. Caufourier. Caufourier's [1924] "hybrid" system comprised four flash stages each followed by a superheater. This system was reanalyzed in 1978 by $R$. DiPippo [1978a]. More recently, C. R. James [1970] studied the possibility of adding a fossil superheater to the geothermal power plants at Wairakei, New Zealand. So far, no such arrangement has been implemented. The only central power station in which the "hybrid" concept has been utilized is Consolidated Edison's Indian Point Unit 1 nuclear power plant which incorporated an oil-fired superheater [El-Wakil, 1962].

In the remainder of this section we discuss the thermodynamics of hybrid fossil-geothermal energy conversion systems and we identify the criteria that are likely to have a strong influence on the design and economics of these systems. We then follow with an evaluation of a number of geothermal sites in the Western U.S. which are considered potential candidates for the construction of a hybrid fossil-geothermal power plant of the feedwater preheating type. The thermodynamic analysis is based on the work of Khalifa, DiPippo and Kestin [see DiPippo, et al., 1977, 1978; Khalifa, 1977; Khalifa, et al., 1978a, b; Kestin, et al., 1978]. The design and economic studies are based on two reports submitted by the City of Burbank to the Department of Energy [see Burbank, 1977; Simay, et al., 1978].

\subsubsection{Thermodynamics of hybrid energy conversion systems}

The performance of an energy conversion system receiving both lowgrade and high-grade energy cannot be rationally described in terms of the thermal efficiencies and the coefficients of performance ordinarily defined for systems receiving heat from a single reservoir. A quantity of heat, $Q$, added at a low temperature is not thermodynamically equivalent to the same quantity of heat added at a high temperature. For this reason, the performance of a hybrid system should be expressed in terms of paraneters that reflect the different "thermal ranks" of the two resources. This is achieved by assessing the two resources on the basis of their exergy or available work and not on the basis of their energy or heat content (see chapter 3). The thermodynamic development given in the next section follows very closely this given by Khalifa et al. [1978b].

4.3.2.1 Available work and entropy production. In an open system, the available work (exergy) relative to a dead state $\left(P_{o}, T_{o}, \ldots\right.$ ) is given by

$$
W^{\circ}=H-H_{0}-T_{0}\left(S-S_{0}\right),
$$


in which we assumed that only one stream of substance flows in and out of the system (see chapter 3 ). If the process comprises a chemical reaction such as the combustion of a fossil fuel in which the reactants and products exist at $P_{0}$ and $T_{0}$, then

$$
W^{\circ}=H_{0}(\mathrm{R})-H_{0}(\mathrm{P})-T_{0}\left[S_{0}(\mathrm{R})-S_{0}(\mathrm{P})\right],
$$

in which $(R)$ and $(P)$ refer to reactants and products, respectively. Equation 4.126 can be rearranged to read

$$
W^{\circ}=G_{o}(\mathrm{R})-G_{o}(\mathrm{P})=-\Delta G_{o}
$$

where $G_{0}$ is the Gibbs free energy at $\left(P_{0}, T_{0}\right)$. As mentioned in chapter 3, for the fossil fuels commonly used in the power generation industry $\Delta G$ is not much different from the calorific value, i.e., the heat of combustion of the fuel [see Kestin, 1968]. Thus

$$
W^{\circ}=-\Delta G_{0} \simeq-\Delta H_{0}
$$

The available power for a stream, $\dot{m}_{z}$, of a geothermal fluid is, therefore, given by

$$
\dot{W}_{s}^{\circ}=\dot{m}_{\varepsilon}\left[h_{g}-h_{0}-T_{0}\left(s_{s}-s_{0}\right)\right]
$$

whereas the available power for a supply, $\dot{m}_{f}$, of fossil fuel is

$$
\dot{W}_{f}^{\circ}=-\dot{m}_{f} \Delta G_{f}=-\dot{m}_{f} \Delta H_{f}
$$

In these equations the subscripts $g$ and $f$ refer to geothermal and fossil, respectively. The total power available to a hybrid energy conversion system receiving a geothermal fluid at the rate of $\dot{m}_{z}$ and a fossil fuel at the rate of $\dot{m}_{j}$ is

$$
\dot{W}_{i}^{\circ}=\dot{W}_{s}^{\circ}+\dot{W}_{s}^{\circ}
$$

In an actual energy conversion system, the power output will depend on the rate of entropy production, $\dot{\theta}$, in the system. This is expressed by

$$
\dot{W}=\dot{W}^{\circ}-T_{\dot{d}} \dot{\theta},
$$

with $T_{0} \theta$ representing the rate of work dissipation in the system. It is customary to express the power losses in actual systems through the introduction of utilization efficiencies, $\eta_{*}$. Thus equation 4.132 is usually replaced by

$$
\dot{W}=\eta_{\mathbf{a}} \dot{W}^{\circ}
$$


The values of the utilization efficiencies for various types of energy conversion methods are established for state-of-the-art systems. For example, the state-of-the-art value for fossil-fuel plants, $\eta_{f}^{*}$, is about $0.35-0.40$. This is determined by the thermal efficiency, $\eta_{t h}$, of advanced steam power cycles $(0.40-0.45)$ as well as by the efficiency of modern steam generators $(\sim 0.9)$. It is not surprising that the utilization efficiency, $\eta_{u}$, and the thermal efficiency, $\eta_{t h}$, are about equal for fossil-fuel plant's. This is a direct consequence of equations 4.128 and 4.130 which imply that

$$
\eta_{u}=\dot{W}_{f} / \dot{W}_{f}^{\circ}=-\dot{W}_{f} /\left(\dot{m}_{f} \Delta G_{f}\right) \simeq-\dot{W}_{f} /\left(\dot{m}_{f} \Delta H_{f}\right)=\eta_{t h} .
$$

The utilization efficiency for state-of-the-art geothermal energy conversion systems, $\eta_{k}^{*}$, ranges from 0.5 to 0.7 [Milora and Tester, 1976]. The lower limit corresponds to dual-flash systems and the upper limit corresponds to binary-fluid systems.

4.3.2.2 Figures of merit. The maximum power that can be generated from the separate use of a geothermal fluid input, $\dot{m}_{g}$, and a fossil fuel input, $\dot{m}_{f}$, to two separate state-of-the-art power plants, one geothermal and the other fossil, is given by

$$
\dot{W}_{i}^{*}=\dot{W}_{\varepsilon}^{*}+\dot{W}_{f}^{*}=\eta_{\mathrm{g}}^{*} \dot{W}_{\mathrm{s}}^{*}+\eta_{\mathrm{s}}^{*} \dot{W}_{\mathrm{s}}^{\circ}
$$

Here the asterisk refers to state-of-the-art values. We can; therefore, define a utilization efficiency for the combination of the two separate plants. That is

$$
\eta_{i}^{*}=\dot{W}^{*} / W_{i}^{\circ}
$$

Figure 4.135 is a schematic representation of the two separate plants and of the hybrid plant receiving the same inputs. If $\dot{W}_{h}$ represents the output

FigURE 4.135-Schematic representation of hybrid systems.
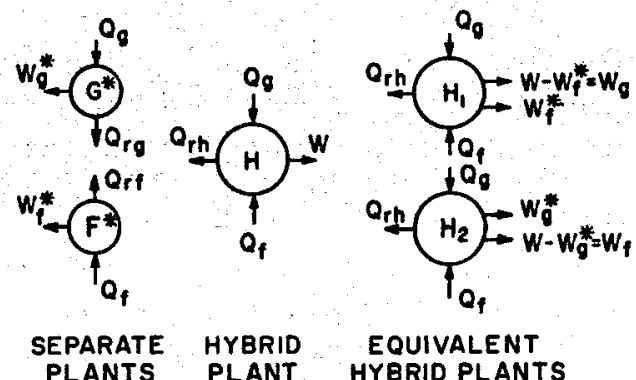
of the hybrid plant when receiving the same fossil and geothermal input, then the hybrid utilization efficiency is

$$
\eta_{h}=\dot{W}_{h} / \dot{W}_{i}^{\circ}
$$

The hybrid plant will be thermodynamically superior to the two separate plants if

$$
\eta_{h}>\eta_{s}^{*}
$$

This gives rise to a definition of a figure of merit

$$
F=\eta_{h} / \eta_{s}^{*},
$$

the numerical value of which has to be greater than unity if the hybrid system is to prove superior to the two separate state-of-the-art systems. In terms of $\dot{W}_{n}, \dot{W}_{j}^{*}$ and $\dot{W}_{s}^{*}$, the figure of merit may be expressed as

$$
F=\dot{W}_{h} /\left(\dot{W}_{g}^{*}+\dot{W}_{f}^{*}\right) .
$$

This is the same figure of merit defined by DiPippo, Kestin, and Khalifa [1977].

In some cases, it may be more important to assess the efficiency with which one of the two resources is being utilized in a hybrid power plant when the other is assumed to be exploited at its state-of-the-art level. For this purpose we define two additional figures of merit associated with the two equivalent hybrid configurations shown in figure 4.135. The first is the fossil figure of merit, defined by

$$
F_{f}=\left(\dot{W}_{h}-\dot{W}_{g}^{*}\right) / \dot{W}_{s}^{*},
$$

and the second is the geothermal figure of merit, defined by

$$
F_{g}=\left(\dot{W}^{*}-\dot{W}_{f}^{*}\right) / \dot{W}_{g}^{*}
$$

The first of these two figures determines whether the fossil fuel is better utilized in a hybrid power plant or in a separate state-of-the-art fossil-fuel power plant; the second one is the geothermal analogue. Naturally, $F^{\prime}>1$ also implies $F_{p}>1$ and $F_{z}>1$.

4.3.2.3. State-of-the-art fossil and geothermal systems. Since the performance of a hybrid fossil geothermal energy conversion system has to be judged in comparison with that of individual state-of-the-art fossil and geothermal power plants, the definition of the latter should be made clear. 
The state of the art in fossil fuel utilization is exemplified by a modern steam power plant that operates at a subcritical (usually $16.5 \mathrm{MPa}$ ) or a supereritical (usually $24 \mathrm{MPa}$ ) pressure and at an initial steam temperature of $540^{\circ} \mathrm{C}\left(1005^{\circ} \mathrm{F}\right) .^{*} \mathrm{~A}$ simplified flow diagram of a typical state-of-the-art arrangement is shown in figure 4.136. The arrangement includes two interstage reheat superheaters and seven regenerative feedwater heaters. Cycles of this kind can achieve thermal efficiencies of the order of 42-45\% [Szewalski and Khalifa, 1978; DiPippo et al., 1977]. The feedwater heaters raise the temperature of the feedwater from the condenser hotwell temperature $\left(35-45^{\circ} \mathrm{C}\right)$ to over $250^{\circ} \mathrm{C}$ at the economizer inlet. The amount of steam bled for feedwater heating can be as high as $35 \%$ of the turbine throttle flow. In order to improve the efficiency of the steam generator an air preheater is usually installed in the flue-gas passage between the economizer and the stack.

Frave 4.136-Simplified flow diagram of a state-of-the-art steam power plant.

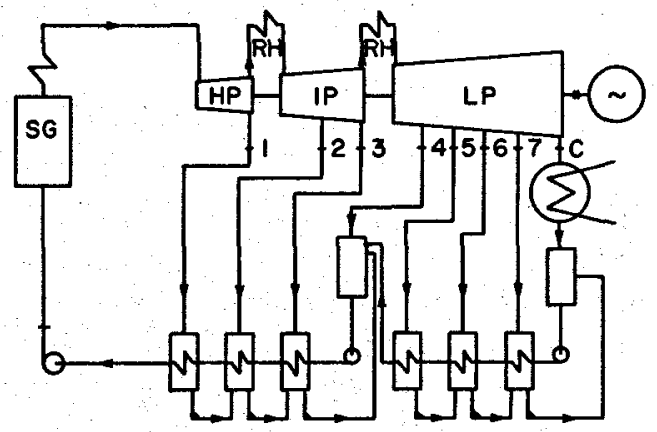

Although the state of the art in fossil fuel utilization is fairly well defined, there is less agreement on what constitutes the state of the art in geothermal power plants. A survey of existing and planned geothermal power plants around the world [DiPippo, 1978b] reveals that existing commercial geothermal power plants utilizing liquid-dominated hydrothermal reservoirs are all of the flash or separating type of either one or two stages. The only exceptions are a $1 \mathrm{MW}$ pilot binary power plant at Otake, Japan [DiPippo, 1978c] and an unoptimized $11 \mathrm{MW}$ pilot binary plant now under construction at East Mesa, California [Dambly, 1978; DiPippo, 1978d]. On the basis of the available information it can be established that the highest utilization efficiency achieved in the existing installations, including the pilot binary plants in Japan and in the U.S. is about 0.6. If we confine the state-of-the-art to commercial plants only this figure drops to 0.55 or lower. Therefore, we shall identify the state of the art for the utilization of liquid-dominated hydrothermal resources as a double-flash or a binary power plant with a utilization ef-

*Initial steam temperatures as high as $650^{\circ} \mathrm{C}\left(1200^{\circ} \mathrm{F}\right)$ have been tried at the Eddystone power plant in Pennsylvania. Economic and reliability considerations, however, do not justify this high operating temperature. 
ficiency of 0.6. This estimate also agrees with the thermodynamic optima obtained by Milora and Tester [1976] if the heat rejection temperature is adjusted from $26.7^{\circ} \mathrm{C}$ to about $35^{\circ} \mathrm{C}$ as is more likely to be the case. Examples of optimized dual-flash and binary systems can be found in sections 4.1 and 4.2 .

4.3.2.4 Other performance parameters. The utilization efficiencies and the figures of merit defined in section 4.3.2.2 determine adequately the thermodynamic performance of a hybrid fossil-geothermal energy conversion system. They do not, however, determine whether a hybrid arrangement is economically advantageous in comparison with separate utilization. The latter question can only be answered after a complete design and economic analysis of a hybrid power plant has been carried out. Nevertheless, some of the economic aspects can be admitted parametrically by introducing the adjusted figure of merit $F_{\xi}$ defined by

$$
F_{\xi}=\dot{W}_{\mathrm{a}} /\left(\dot{W}_{f}^{*}+\xi \dot{W}_{\xi}^{*}\right)
$$

Here the parameter $\xi$ is a geothermal/fossil work equivalence factor and accounts for the different nature of the two resources. Its value depends primarily on the unit cost of generating work from the geothermal fluid relative to the unit cost of generating work from the fossil fuel at the same site. In a broad sense, $\xi \dot{W}^{*}$, is the fossil-equivalent of the geothermal power $\dot{W}^{*}$. The value of $\xi$ exceeds unity if the unit cost of geothermal work is higher than that for fossil work and vice versa.

Another important parameter that is likely to affect the design and siting of a hybrid power plant is the so-called work amplification factor, $\psi$ [Khalifa et al., 1978]

$$
\psi=\dot{W}_{a} / \dot{W}_{s}^{*}
$$

which expresses the relative capacity of a hybrid plant constructed at a geothermal site of a given power potential $\left(\dot{W}^{*}\right)$. It is noted that $F, F_{f}, F_{g}$ and $\psi$ are related by the two equations

$$
\begin{gathered}
F=\psi /\left(1+\psi-F_{g}\right), \\
F_{f}=(\psi-1) /\left(\psi-F_{g}\right) .
\end{gathered}
$$

Finally, since a hybrid power plant is less dependent on fossil fuel for a specified plant capacity, it may be of interest to introduce a fossil-fuel conservation parameter, $\phi$. This is defined for a hybrid plant by

$$
\phi_{h}=1-\left(\dot{W}_{f}^{*} / \dot{W}_{n}\right)=F_{\mathrm{z}} / \psi
$$


Its value measures the fractional savings in fossil fuel relative to an all-fossil power plant generating the same power as the hybrid plant. The corresponding parameter for separate utilization is

$$
\phi_{s}=1-\left(\dot{W}_{f}^{*} / \dot{W}_{*}^{*}\right)=F / \psi \text {. }
$$

The fossil fuel saving attributed to the superior utilization efficiency of the hybrid system is the difference between $\phi_{h}$ and $\phi_{s}$, i.e.,

$$
\phi=\phi_{h}-\phi_{s}=\left(F_{s}-F\right) / \psi \text {. }
$$

It is worth noting that, relative to an all-fossil power plant, the cost of fossil-fuel-related equipment in a hybrid power plant would be multiplied by the factor $\left(1-\phi_{h}\right)$ which is less than unity. If the power demand is to be met by both fossil and geothermal power plants, operating separately, this factor is only $(1-\phi)$ which is expected to be somewhat higher than $\left(1-\phi_{h}\right)$ but still less than unity.

In the next sections we obtain numerical values for the various performance parameters for two hybrid arrangements: the geothermalpreheat system and the fossil-superheat system.

\subsubsection{The geothermal-preheat system}

The essence of the hybrid fossil-geothermal energy conversion concept is to combine the utilization of the two resources in a thermodynamically optimum way. This implies that the use of geothermal energy should be confined to the low-temperature part of the system and that of the fossil fuel to the high-temperature part, as already mentioned. Of the various arrangements in which this can be achieved, the geothermal-preheat system is probably the most significant, since its implementation requires minimum extrapolation of available steam power plant technology. We shall dedicate most of the remainder of this chapter to the thermodynamic, design, and economic analysis of this type of system.

4.3.3.1 Geothermal preheating of feedwater. An examination of the flow diagram of figure 4.136 reveals that if a liquid geothermal fluid is available, it can be used in a heat exchanger to replace some or all of the regenerative feedwater heaters between the condenser and the steam generator. By so doing, the amount of steam bled from the turbine for feedwater heating will be reduced, resulting in an increase in the turbine output for the same amount of fossil fuel burned in the steam generator. Figure 4.137 contains a flow diagram of a system in which the first three feedwater heaters have been replaced by a geothermal heat exchanger. Naturally, the number of feedwater heaters replaced will depend on the temperature of the geothermal liquid. The geothermal heat exchanger to be employed 


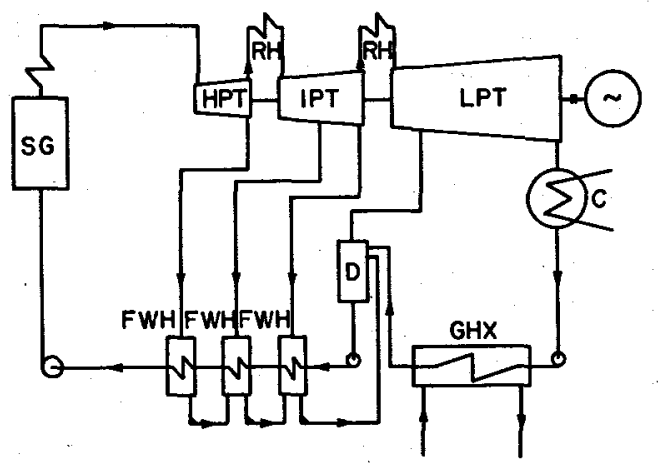

Figure 4.137-Simplified flow diagram of the geothermal feedwaterpreheating arrangement.

here should be of the surface type to avoid mixing the highly purified feedwater with the saline geothermal liquid. Its design would resemble, to a large extent, that of the primary heat exchanger in a binary power plant (see chapter 3). Since the two fluids flowing in the geothermal feedwater heater are, for all practical purposes, incompressible with constant specific heats, the temperature distribution in the heat exchanger will exhibit no pinching and the temperature difference can be made nearly uniform along the heat transfer surface. Not only does this simplify the design of the heat exchanger, but also it results in a lower rate of entropy production for a specified minimum temperature difference.

The introduction of geothermal preheating in place of regenerative preheating has an additional thermodynamic advantage : the feedwater heating process is accomplished without extracting steam from the turbine. - Since the expansion line in a modern fossil steam turbine runs almost Fully in the superheat region, regenerative feedwater heaters, particularly the high pressure ones, usually comprise a desuperheating zone; the temperature differences in these heaters exhibit a pronounced pinch and the entropy production in them is relatively high. These problems do not exist if the heating fluid is the geothermal liquid as it will be in a hybrid plant of the preheat type. Figure 4.138 shows typical temperature-heat transfer characteristics for a feedwater heater receiving superheated steam from the turbine and a geothermal preheater.

4.3.3.2 Thermodynamic analysis. It was shown by DiPippo, Kestin, and Khalifa [1977] that in order for a geothermal-preheat hybrid system to be thermodynamically viable, geothermal preheating should be considered only in cycles that are very close to the state-of-the-art cycles discussed in section 4.3.2.3. This is due to the fact that all the figures of merit are based on a comparison with state-of-the-art systems. If the geothermal preheat principle is grafted onto a cycle that is considerably inferior to the reference, state-of-the-art, cycle, the advantages to be gained from the hybrid combination may be completely wiped out. Consequently, geothermal pre- 


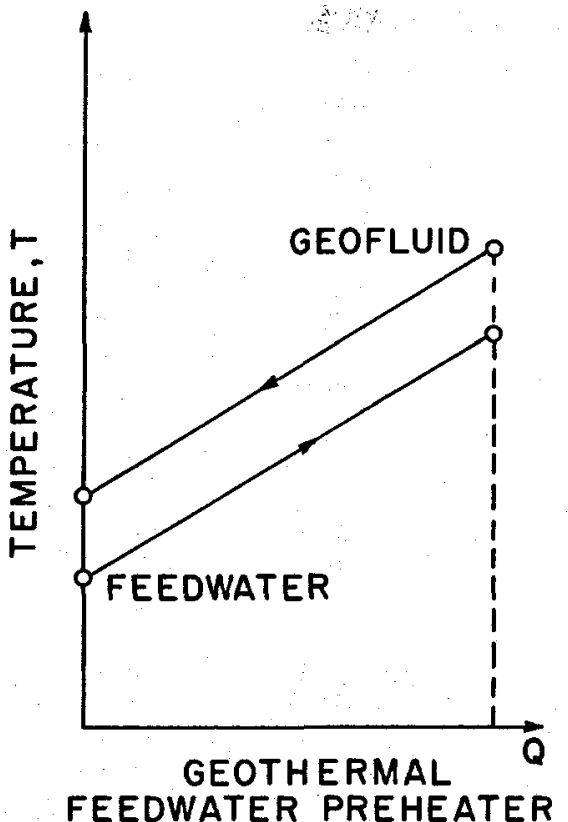

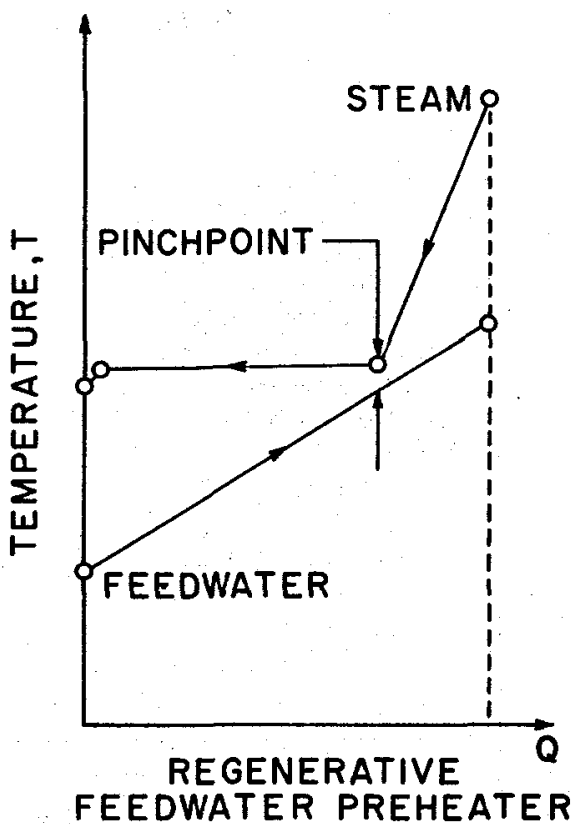

FIGURE 4.138-Typical temperature distributions in feedwater heaters :

Left=Geothermal ; Right =Regenerative.

heating is introduced only as a modification of state-of-the-art steam power cycles.

Assumptions and methodology. The performance parameters $F, F_{t}$, $F_{q}, \psi$, and $\phi$ were computed for both subcritical and supercritical cycles. The characteristics of the two cycles are given in table 4.16 [see also DiPippo et al., 1977]. No attempt has been made to optimize the reheat or the bleed conditions beyond the application of the conventional "rules of thumb" [Haywood, 1967 ; Salisbury, 1950].

Since the steam generator in the hybrid arrangement is essentially identical to that used in a conventional fossil power plant, no account has been made of the efficiency of the steam generator in the computation of the figures of merit. In other words the fossil fuel contribution is based on the exergy delivered to the feedwater in the steam generator rather than the exergy of the fossil fuel. This quantity is the same for the conventional and the hybrid systems. It was also assumed that the geothermal fluid enters the heat exchanger as a compressed liquid as would be the case in pumped wells, and that a constant temperature difference of $10^{\circ} \mathrm{C}$ $\left(18^{\circ} \mathrm{F}\right)$ was maintained in the heat exchanger.

In both the subcritical and the supercritical cases the analysis was carried out for a state-of-the-art geothermal utilization efficiency, $\eta^{*}{ }_{g}$, of 0.6 . The thermal efficiericy of the two basic cycles was computed by means of a computer program designed for the passive optimization of advanced 
TaBLE 4.16-Characteristics of the steam cycles

Subcritical Supercritical

Initial steam temperature, ${ }^{\circ} \mathrm{C} \ldots \ldots \ldots \ldots \ldots \ldots$

Initial steam pressure, $\mathbf{M P a} . \ldots \ldots \ldots \ldots \ldots$

Number of reheat stages.

Reheat temperature, ${ }^{\circ} \mathrm{C} \ldots \ldots \ldots \ldots \ldots \ldots \ldots \ldots$

First reheat pressure, $\mathrm{MPa} . \ldots \ldots \ldots \ldots \ldots$.

Second reheat pressure, $\mathrm{MPa} . \ldots \ldots \ldots \ldots \ldots$.

Condenser pressure, $\mathrm{kPa} \ldots \ldots \ldots \ldots \ldots \ldots$

Turbine isentropic efficiencies:

High pressure. . ..................

Intermediate pressure................

Low pressure......................

Dryness frection at exhaust.

Number of feedwater heaters

Bleed pressures, $\mathrm{MPa}$ :

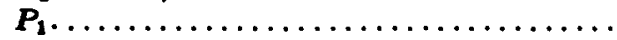

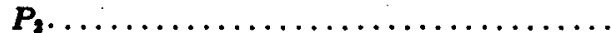

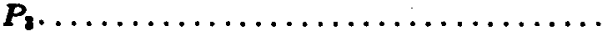

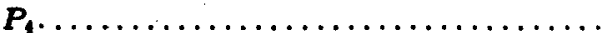

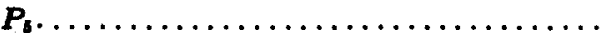

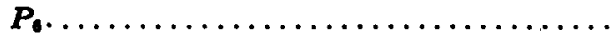

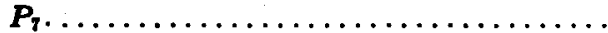

Pressure loss in heat exchangers. ...........

Pump efficiency. . . . . . . . . . . . . . . . .

Terminal temperature difference in feedwater

heaters, ${ }^{\circ} \mathrm{C} . \ldots \ldots \ldots \ldots \ldots \ldots \ldots \ldots$

Final feedwatert emperature, ${ }^{\circ} \mathrm{C} . \ldots \ldots \ldots \ldots$

Cycle efficiency......................
540

16. 5

1

540

3. 9

5. 5

0. 82

0.86

0. 82

0.95

7

\section{9}

1. 92

0. 99

0.45

0.21

0.08

0. 035

$10 \%$

0.8

2
241

0. 428
540

24. 0

2

540

5. 9

2. 0

5. 5

0. 82

0. 86

0. 85

0. 88

7

5. 9

3. 5

2. 0

0. 86

0. 40

0. 17

0. 066

$10 \%$

0.8

2

266

0. 446

steam power cycles [Szewalski and Khalifa, 1978]. The properties of steam were derived frum the fundamental thermodynamic equation of Keenan, Keyes, et al. [1969], which was incorporated as a subroutine in the computer program.

The figures of merit were computed for a range of geothermal fluid temperatures extending from the reinjection temperature, $T \sim 45^{\circ} \mathrm{C}$ $\left(113^{\circ} \mathrm{F}\right)$ to beyond $250^{\circ} \mathrm{C}\left(482^{\circ} \mathrm{F}\right)$. The procedure involved replacing an increasingly higher number of feedwater heaters with a geothermal heat exchanger until all seven of them have been replaced. Each replacement results in an increase in the mass flow rate in the downstream section of the turbine.

Figures of merit. The adjusted figure of merit $F_{\varepsilon}$ for the subcritical installation is shown in figure 4.139 and that for the supercritical is shown in figure 4.140. The figure of merit $F$ corresponds to $\xi=1.0$. The dashed lines correspond to a geothermal utilization factor of 0.7 which is beyond the state-of-the-art at present. The superiority of the hybrid systems is demonstrated even for situations in which $\xi$ exceeds unity. A supercritical 
Figure 4.139-Adjusted figure of merit, $F$, for a subcritical hybrid system.

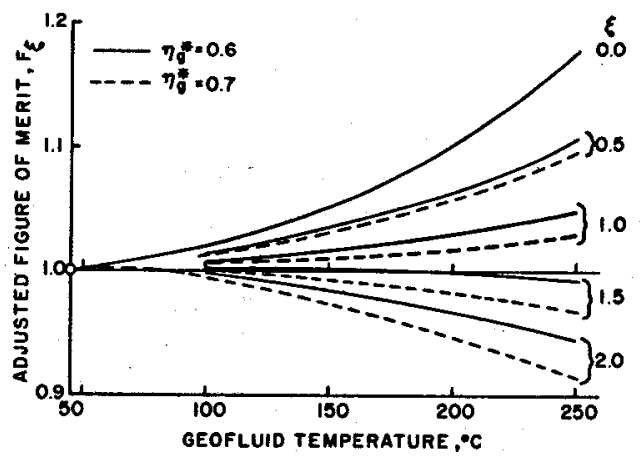

hybrid installation receiving a geothermal fluid at $200^{\circ} \mathrm{C}\left(392^{\circ} \mathrm{F}\right)$, for example, produces 3 percent more work than a combination of a state-ofthe-art geothermal system $\left(\eta^{*}=0.6\right)$ and a state-of-the-art fossil-fuel system $\left(\eta_{f}^{*} \simeq \eta_{t h}=0.45\right)$.

Frgoke 4.140-Adjusted figure of merit, $F_{\text {, }}$ for a supercritical hybrid system.

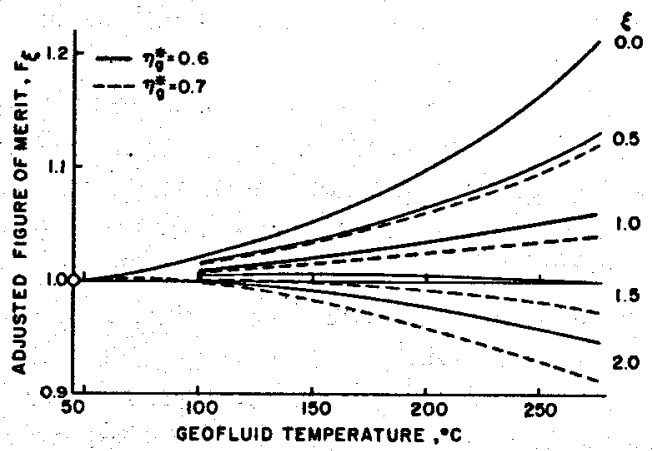

The figures of merit $F_{g}$ and $F_{l}$ for the two systems are shown in figures 4.141 and 4.142 respectively. The geothermal figure of merit shows an impressive improvement in the utilization of the geothermal resource, especially for low temperature resources. Even when we take the highly optimistic value of $\eta_{0}^{*}=0.7$, nearly $40 \%$ more work can be produced from a geothermal fluid at $200^{\circ} \mathrm{C}\left(392^{\circ} \mathrm{F}\right)$, while utilizing the fossil fuel at its

Figure 4.141-Geothermal figure of merit, $\boldsymbol{F}_{g}$.

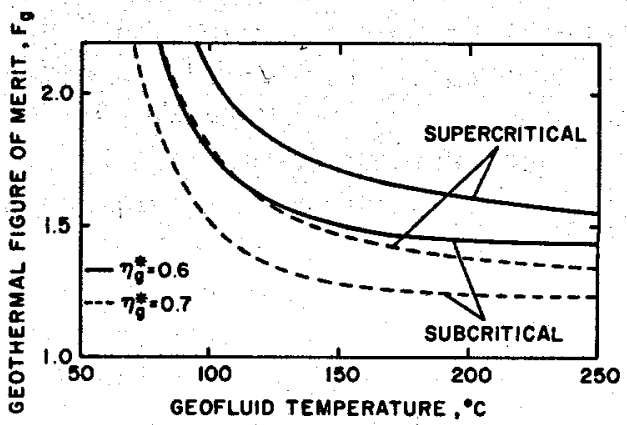




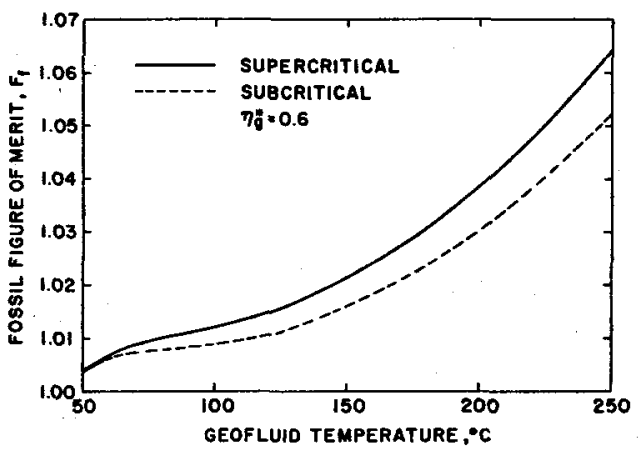

Fioure 4.142-Fossil figure of merit, $F_{t}$

state-of-the-art level $\left(\eta_{t h}=0.45\right)$. The improvement is even more impressive for the more realistic value of $\eta^{*}{ }_{g}=0.6 ; F_{g}$ being 1.6. The fossil figure of merit indicates that nearly $4 \%$ more work can be produced from the same amount of fossil fuel consumed while attributing to the geothermal resource the highest amount of work it can produce by state-of-the-art systems $\left(\eta_{g}{ }_{g}=0.6\right)$ when the geofluid temperature is $200^{\circ} \mathrm{C}\left(392^{\circ} \mathrm{F}\right)$.

\subsubsection{Design and siting considerations. Since the successful design of} a power plant requires, among other things, a careful selection of the site with respect to the sources of fuel and cooling water as well as with respect to the demand center, it is important to evaluate those design parameters that are likely to influence the siting of a hybrid fossil-geothermal power plant. Naturally, the determination of the optimum site requires a careful, site-specific analysis, as will be discussed in section 4.3.5.

The work amplification factor, $\psi$, and fossil fuel conservation parameter, $\phi$, are two quantities that fall in this category. The work amplification factor, $\psi$, is intimately related to the size of the hybrid power plant to be constructed at a given geothermal site or, equivalently, to the required productivity of the geothermal resource if it were to support a hybrid power plant of a given capacity. This is likely to play a major role in the economics of hybrid power plants. The fossil fuel conservation parameter, on the other hand, tells how much fossil fuel will be saved if hybrid, rather than separate, utilization is adopted. It is also clear that $\phi$ will determine, in part, the fossil-fuel-related costs.

The variation of $\psi$ and $\phi$ with the geothermal fluid temperature is shown in figures 4.143 and 4.144 respectively. The dashed lines represent the subcritical case whereas the solid lines represent the supercritical case. For a geofluid temperature of $200^{\circ} \mathrm{C}$ we notice that a supercritical hybrid plant will develop nearly 17 times as much power as the geothermal site alone can support $(\psi=17)$. Under these conditions a $750 \mathrm{MW}$ hybrid power plant needs a geothermal resource that is capable of supporting a $45 \mathrm{MW}$ state-of-the-art geothermal power plant. Furthermore, the fossil fuel consumption of the hybrid plant will be about $3.5 \%$ lower than that of a state-of-the-art fossil power plant developing the balance between 
Frgure 4.143-The work amplification factor, $\psi$.

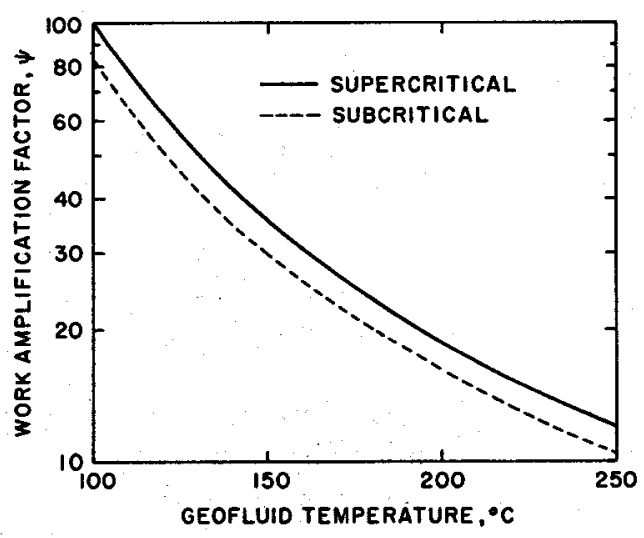

$750 \mathrm{MW}$ and $45 \mathrm{MW}$, i.e., 705 MW. In comparison with an all fossil power plant of $750 \mathrm{MW}$ capacity, the hybrid power plant consumes about $10 \%$ less fossil fuel.

Another important design criterion is the relative increase in the mass flow rate in the turbine low-pressure section and into the condenser associated with the omission of the extraction points. This is expressed by the ratio $\mu_{h}$ which is given by

$$
\mu_{h}=\left(\dot{m}_{c}\right)_{h} /\left(\dot{m}_{c}\right)_{\rho}
$$

in which $\dot{m}_{c}$ is the specific condenser mass flow rate $(\mathrm{kg} / \mathrm{kWh})$. The subscripts $f$ and $h$ refer to fossil and hybrid, respectively. Typically $\left(\dot{m}_{c}\right) \simeq 2 \mathrm{~kg} / \mathrm{kWh}$. The ratio $\mu$ gives a rough idea about the expected increase in the size of the low-pressure turbine of a hybrid power plant relative to a fossil power plant of the same capacity. This is shown graphically in figure 4.145 as a function of the geothermal fluid temperature. The difference between sub- and supercritical systems is insignificant here. For a geofluid temperature of $200^{\circ} \mathrm{C}$, the expected increase in turbine exhaust mass flow (condenser mass flow) is about $25 \%$. It should be remembered, however, that the turbine in the hybrid power plant has replaced two turbines; one in each of the separate fossil and geothermal

Froure 4.144-The fossil-fuel conservation parameter, $\phi$.

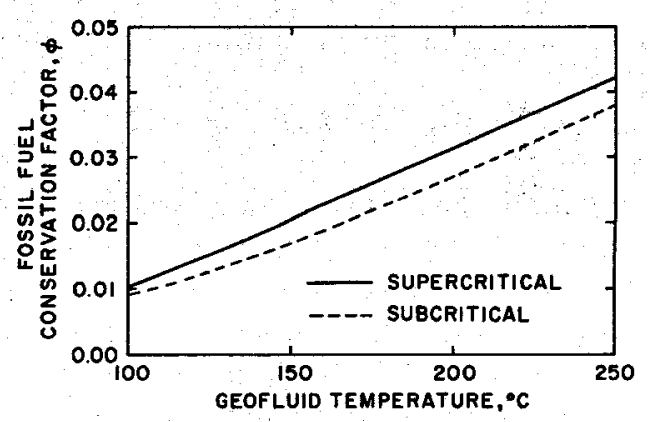




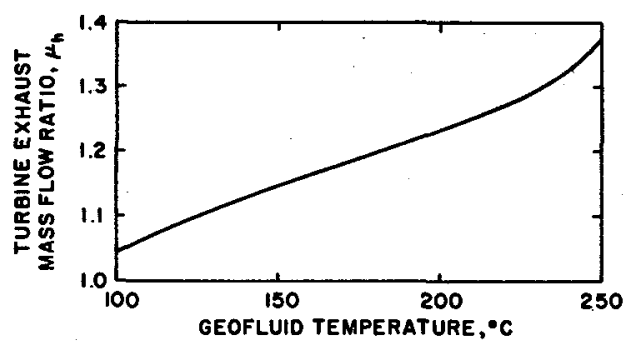

Fraure 4.145-Turbine exhaust mass flow ratio. $\mu_{\boldsymbol{n}}$.

systems. If we combine the condenser mass flow rate in the two separate systems, assuming that the geothermal system is of the double-flash type, we find that the mass flow ratio

$$
\mu_{s}=\left(\dot{m}_{c}\right)_{s} /\left(\dot{m}_{c}\right)_{s}
$$

is consistently higher than that for the hybrid system, $\mu_{h}$. In equation 4,150 $\left(\dot{m}_{c}\right)_{\text {, is }}$ the combined specific condenser mass flow for the separate plants and is given by

$$
\left.\left(\dot{m}_{c}\right)_{s}=\frac{1}{\psi}\left(\dot{m}_{c}\right)_{\varepsilon}+\left(1-\frac{1}{\psi}\right)^{\left(\dot{m}_{c}\right.}\right)_{e}
$$

where $\left(\dot{m}_{c}\right)_{g}$ is the specific exhaust mass flow rate per unit power generated in a state-of-the-art geothermal steam power plant. Typically $\left(\dot{m}_{c}\right)_{z}=7-15$ $\mathrm{kg} / \mathrm{kWh}$ for geothermal liquids in the temperature range $250-175^{\circ} \mathrm{C}$. Equations 4.150-1 in combination with the typical values of $\left(\dot{m}_{c}\right)_{g}$ and $\left(\dot{m}_{c}\right)$, quoted above, indicate that $\mu_{s} \simeq 1.3$ for a geothermal fluid at $200^{\circ} \mathrm{C}$. This shows that the low pressure turbine and condenser in a hybrid power plant will have to cope with a lower flow rate than the combined value of its separate counterparts. Under these conditions, it is reasonable to expect that the turbine/condenser system in the hybrid power plant will be cheaper than its counterparts in the separate plants.

These considerations lead to the conclusion that a hybrid power plant will most likely be less expensive to build than a combination of two separate state-of-the-art plants. A more detailed discussion of the economics of hybrid power plants is given in section 4.3.5 of this chapter.

\subsubsection{The fossil-superheat systems}

Although the application of fossil superheaters in geothermal steam systems was proposed as long ago as 1924 [see DiPippo, 1978a], no such arrangement exists to date. More recently, geothermal steam systems employing fossil superheaters have been analyzed [James, 1970; Khalifa, 1977; Correia, 1978; DiPippo et al., 1978]. This section contains a summary of the thermodynamic analyses given in the last three references. 
4.3.4.1 The use of conventional superheaters in geothermal-steam systems. In a geothermal steam power plant steam is produced either directly (vapor-dominated systems) or indirectly by flashing and separation (liquid-dominated systems). In both cases the steam enters the turbine nearly dry and saturated. The expansion of this steam in the turbine proceeds in the wet region resulting in a lower expansion efficiency and, in some cases, excessive blade erosion [Moore and Sieverding, 1976]. In order to avoid serious erosion damage it is necessary to limit the exhaust dryness fraction to not less than 0.88 , even though practices such as blade hardening, the use of stellite strips and the application of moisture removal techniques have been commonly implemented. An apparent advantage of geothermal steam superheating is, therefore, the reduction of the amount of moisture in the turbine. Not only will this simplify the design and operation of the steam turbine, but also it results in a higher expansion efficiency.*

In order thermodynamically to justify the use of a fossil-fuel superheater ahead of the turbine, the fossil fuel utilization efficiency in such an arrangement should, at least, be equal to that achieved in a state-of-the-art fossilfuel plant, i.e., $\left(\eta_{f}^{*} \sim 0.42\right)$. Since the superheater represents an augmentation of a basic, direct, single-flash or double-flash geothermal system, it is logical to assess the merit of the superheater by comparing the performance of the augmented system with that of the basic system. Therefore, we attribute to the fossil fuel an amount of power $\dot{W}_{f}$ given by

$$
\dot{W}_{f}=\dot{W}_{n}-\dot{W}_{z}^{b},
$$

in which $\dot{W}_{\varepsilon}^{b}$ is the output of the basic system under its optimum operating conditions. If the basic system is a double-flash system then $\dot{W}_{\varepsilon}^{*}$ and $W_{z}^{*}$ are likely to be identical since, by stipulation, a double-fiash system is at, or very close to, the state-of-the-art in geothermal energy conversion. The figures of merit $F, F_{f}$ and $F_{g}$ become

$$
\begin{aligned}
& F=\dot{W}_{\mathrm{a}} /\left(\dot{W}_{s}^{b}+\dot{W}_{f}^{*}\right), \\
& F_{f}=\left(\dot{W}_{h}-\dot{W}_{g}^{b}\right) / \dot{W}_{f}^{*},
\end{aligned}
$$

and

$$
F_{z}=\left(\dot{W}_{n}-\dot{W}_{f}^{*}\right) / \dot{W}_{s}^{b}
$$

whereas the work amplification factor $\psi$ becomes

$$
\psi=\dot{W}_{h} / \dot{W}_{g}^{b}
$$

*According to the Bauman rule [Baumann, 1921] 1\% moisture present in a stage is likely to cause about $1 \%$ deterioration in the efficiency. 
These reduce to the ordinary figures of merit if the basic system is identical in performance with a state-of-the-art geothermal power plant, as noted above.

One-stage systems. One-stage hybrid fossil-geothermal systems are modifications of the simplest form of geothermal power plants in which natural steam is obtained (i) directly from the reservoir or (ii) from a flash/separation process. A flow diagram of a one-stage system is shown in figure 4.146 together with its representation on a T-s diagram. A steamsteam regenerator may precede the fossil-fired superheater depending on the initial condition of the steam.
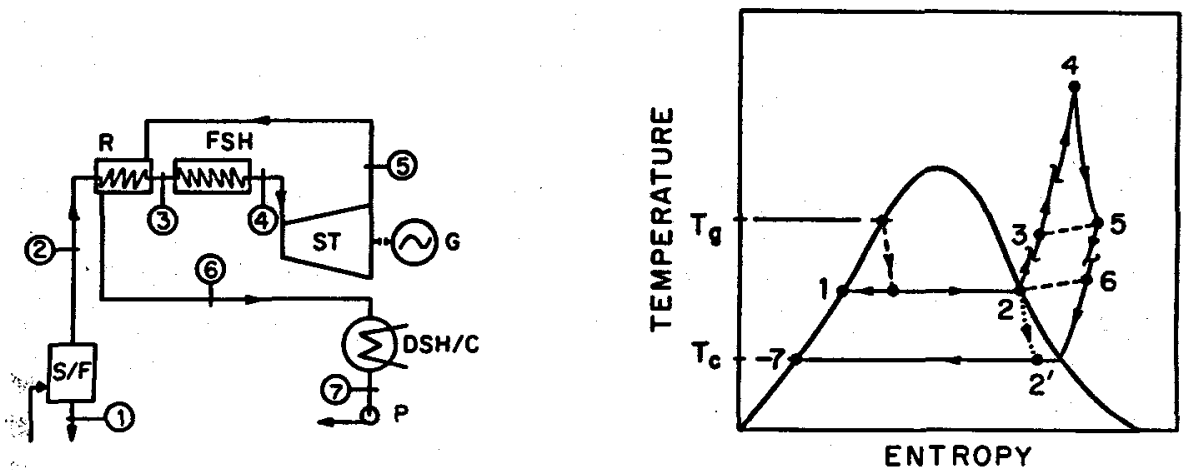

Figure 4.146-One-stage fossil-superheat system and its $T-8$ representation.

A thermodynamic analysis of this system was carried out for arrangements with and without the regenerator (Correia, 1978; DiPippo et al., 1978]. The results are based on the assumptions given in table 4.17.

TABLE 4.17.-Assumptions for thermodynamic analysis

Condenser temperature

$46^{\circ} \mathrm{C}\left(115^{\circ} \mathrm{F}\right)$

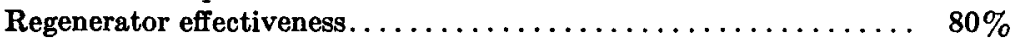

Minimum temperature difference in regenerator. . . . . . . . . $20^{\circ} \mathrm{C}\left(36^{\circ} \mathrm{F}\right)$

Pressure losses in heat exchangers. . . . . . . . .

Thermal efficiency of state-of-the-art power cycles, $\eta^{*} f \ldots \ldots \ldots, 0.42$

Dry expansion efficiency..................... 85

The expansion efficiency for wet steam was obtained from a modified Baumann rule [DiPippo et al., 1978]. Figure 4.147 depicts the figures of merit $F, F_{f}, F_{g}$ as a function of the steam superheat temperature, when the expansion line was restricted to the dry region. The limiting superheat temperatures $T_{4}^{{ }_{1,2,3}}$ correspond to steam temperatures of 150,175 , and $200^{\circ} \mathrm{C}$, respectively. In all cases, the figures of merit exceed unity indicating superiority of the hybrid arrangement, even though the thermodynamic conditions did not allow the use of a regenerator. The results 
Fiaube 4.147-Figures of merit for one-stage systems (dry expansion only) : - $F_{n},-\cdots-F_{0}$ $---F$.

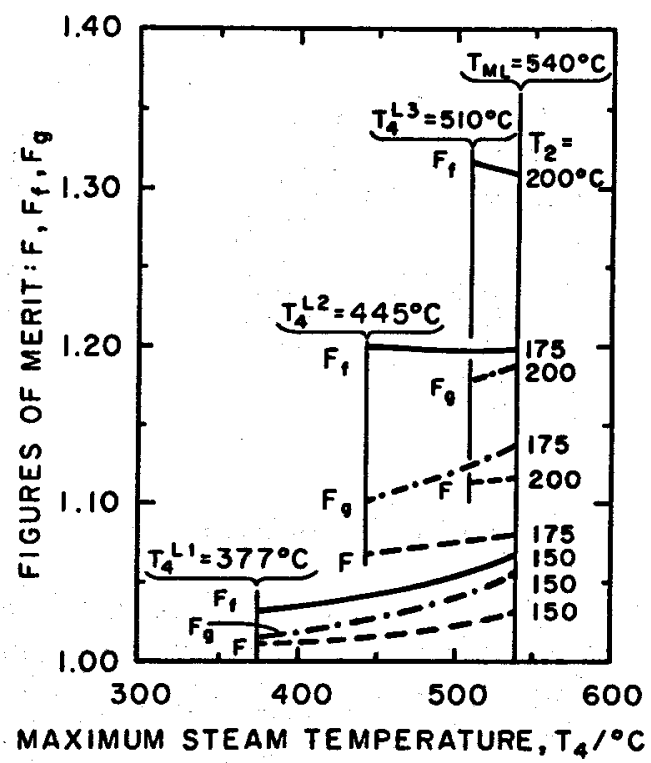

indicate, for example, that superheating the geothermal steam from $175^{\circ} \mathrm{C}$ to $540^{\circ} \mathrm{C}$ yields a fossil figure of merit of 1.20 and a geothermal figure of merit of 1.14. This case roughly corresponds to The Geysers.

Figure 4.148 shows the figures of merit $F_{f}$ and $F_{g}$ as a function of the steam temperature for one-stage systems with and without a regenerator. It can be seen that, without a regenerator, fossil superheating is thermodynamically superior only when the geothermal steam temperature exceeds $130^{\circ} \mathrm{C}\left(265^{\circ} \mathrm{F}\right)$. On the other hand, the addition of a regenerator is only possible for geothermal steam temperatures below $143^{\circ} \mathrm{C}\left(290^{\circ} \mathrm{F}\right)$, if the superheat temperature is not to exceed $540^{\circ} \mathrm{C}\left(1005^{\circ} \mathrm{F}\right)$. It can also be seen that the regenerative system is superior to the nonregenerative system up

Fiaure 4.148-Figures of merit for one-stage system (max. temp. $=540^{\circ} \mathrm{C}$, metallurgical limit).

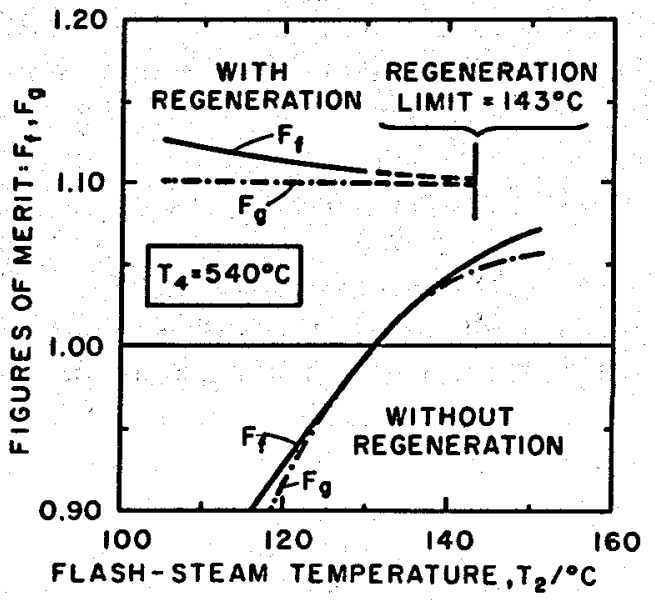



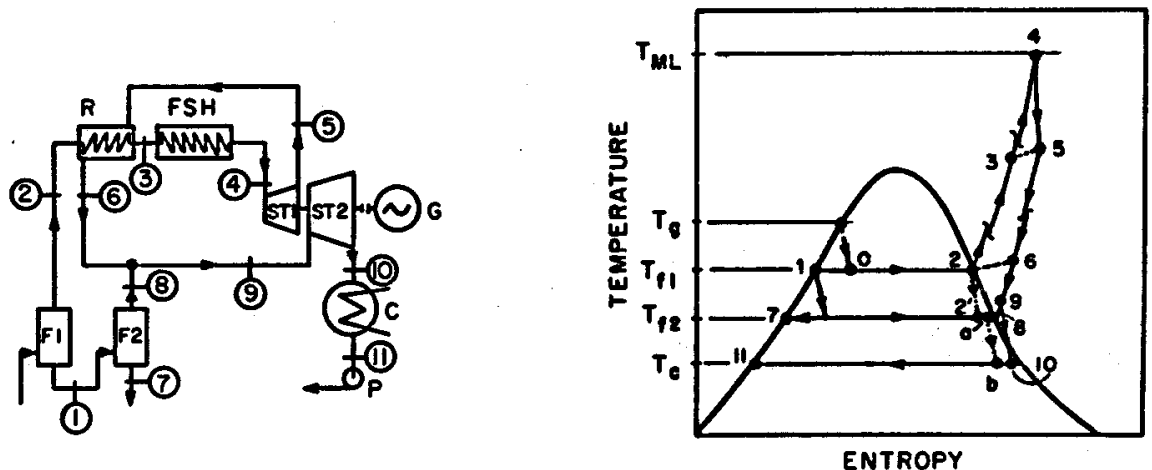

FrgURE 4.149-Two-stage fossil-superheat system and its $T-8$ representation.

to the limit of regeneration. At high steam temperature, however, a nonregenerative system is the only feasible fossil-superheat hybrid system.

Two-stage systems. Double-flash systems constitute the cutting edge in geothermal power plant technology. Correia [1978] has analyzed a large number of arrangements in which a fossil-superheater can be added to a double-flash system. The most promising arrangement is shown schematically in figure 4.149 together with its representation on a $\mathrm{T}$-s diagram. A steam-steam regenerator is introduced between the first flash/separator and the fossil-fired superheater.

The figures of merit $F, F_{f}$, and $F_{\theta}$ for the two-stage system of figure 4.149 are shown plotted as a function of the geofluid temperature in figure 4.150. The results were obtained under the assumptions given in table 4.17 and for a superheat temperature of $540^{\circ} \mathrm{C}\left(1005^{\circ} \mathrm{F}\right)$. The optimum flash temperatures in this case were found to be not much different from those for conventional double-flash systems [see Correia, 1978]. It can be seen that superheated double-flash systems are thermodynamically superior over a wide range of geofluid temperature. For example, a geofluid at $225^{\circ} \mathrm{C}\left(437^{\circ} \mathrm{F}\right)$, flashed twice in a two-stage hybrid plant of the proposed type, produces about $9 \%$ more work than a conventional double-flash system $\left(F_{g}=1.09\right)$ while utilizing the fossil fuel at a $42 \%$ thermal efficiency. The same plant has a fossil figure of merit $F_{f}=1.30$ and an overall figure of merit $F=1.07$.

4.3.4.2 Design considerations. One of the main advantages of the proposed fossil-superheat hybrid systems is that the components utilize established technologies that exist in the geothermal, steam turbine and gas turbine industries. The turbine that would be required for these hybrid plants would be nearly identical to the low-pressure turbines used in conventional steam power plants. Owing to the reduction in the steam moisture content effected by the superheater, the turbines in the hybrid systems would be simpler than the wet-steam turbines used in geothermal- 
Fiatre 4.150-Figures of merit for two-stage systems.

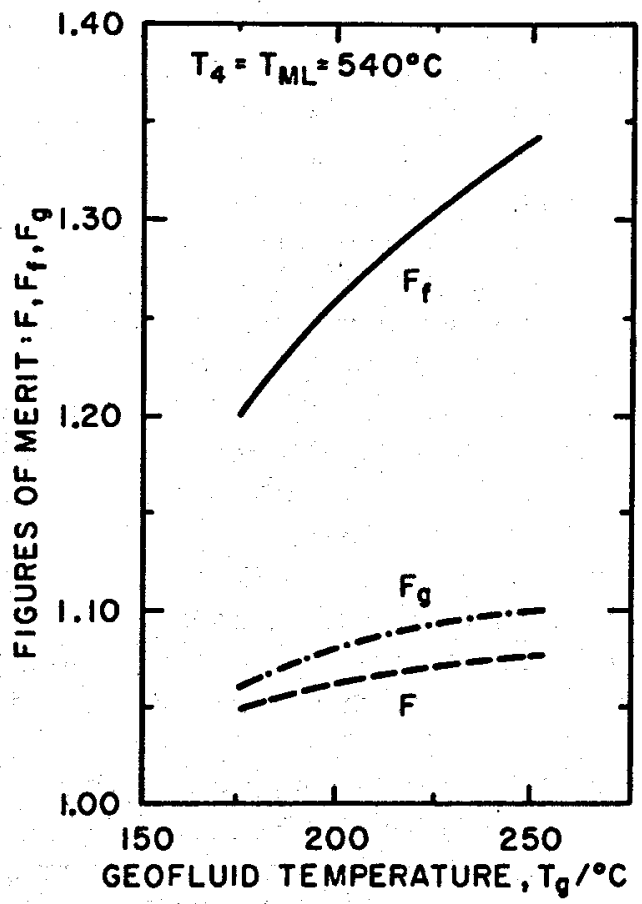

steam plants. The steam-steam regenerator of the hybrid plant would be similar in many respects to the gas-gas regenerator used in stationary gas turbine power plants. The economic feasibility of this type of hybrid plant should, of course, be evaluated on a site-by-site basis.

The application of the fossil superheat principle may prove to be an attractive proposition in sites where both a hot geofluid and a sufficient amount of fossil fuel are readily available. A prime example of these sites can be found on the Gulf coast of the United States where geopressured fluids containing considerable amounts of dissolved methane can be produced. These resources lend themselves to hybrid utilization including the possible application of a gas turbine topping loop as was proposed by Khalifa [Khalifa et al. 1978a].

\subsubsection{Design and economic criteria}

The thermodynamic superiority of the hybrid systems is not sufficient, in itself, to justify the construction of a hybrid power plant instead of two, separate, state-of-the-art plants for fossil and geothermal energy. The ultimate selection between hybrid and separate plants is determined by the economic merits of each.

It was argued in the previous sections that the economic feasibility of hybrid power plants can only be addressed on a site-by-site basis since the cost of transporting the fossil fuel to the geothermal site may constitute a major fraction of the total running costs of the plant. In this section we 
provide a discussion of the important design and economic criteria that would affect hybrid power plant analysis. Although the discussion will center mainly on the geothermal-preheat arrangement, many of the criteria discussed should be applicable to the other hybrid systems. The economic assessment is based on the work conducted under the supervision of the City of Burbank, Calif. [1977, 1978].

In recognition of the nation's goal to depend less on oil and natural gas as sources of power, coal is selected as the fossil fuel. The use of geothermal energy for preheating the feedwater in a coal-fired steam power plant may offer a number of additional benefits. These reside in the possibility of using the geothermal fluid, typically at a temperature $T_{\mathrm{g}}<250^{\circ} \mathrm{C}$, for coal drying and beneficiation, air preheating, flue-gas reheating, and general heating in the power house. In a conventional coalfired power plant, these low temperature heating requirements are usually met through the use of an auxiliary boiler or the use of bled steam. The following discussions, however, disregard these possibilities and concentrate on the use of geothermal energy for feedwater heating only.

4.3.5.1. Plant siting. Geothermal power plants have to be constructed at or very close to the geothermal field due to the impracticality of piping hot geothermal fluids over large distances. In general, the geothermal resource may not be optimally located with respect to the sources of coal, cooling water, or to the electric demand center. Therefore, despite its thermodynamic superiority, a hybrid power plant may prove to be economically unattractive.

In order conservatively to assess the economic competitiveness of hybrid power plants one has to select a reference, optimally located all-coal plant. Ideally, the reference plant should also be at or very near to the state of the art and should be of about the same capacity as the proposed hybrid plant to ensure reliable comparison.

Major plant siting factors. The optimum location of any coal-fired steam power plant is determined on the basis of the following considerations

(1) availability, quality and cost of coal

(2) availability of cooling and make-up water

(3) availability of power transmission lines.

In addition to these considerations, the siting of a hybrid power plant; is further constrained by a number of site-specific environmental considerations emanating from the relatively hostile nature of the geothermal effluents and the seismicity of geothermal resource areas.

A summary of the basic siting guidelines considered in the studies of the City of Burbank $[1977 ; 1978]$ is given in the chart of figure 4.1.51 for a number of possible coal sources $\mathrm{C}_{1}, \mathrm{C}_{2}, \ldots$, etc. and a number of known geothermal resource areas KGRA 1, 2, 3, . ., etc. The optimum location of a hybrid power plant is the one which is economically most competitive with the reference all-coal plant. 


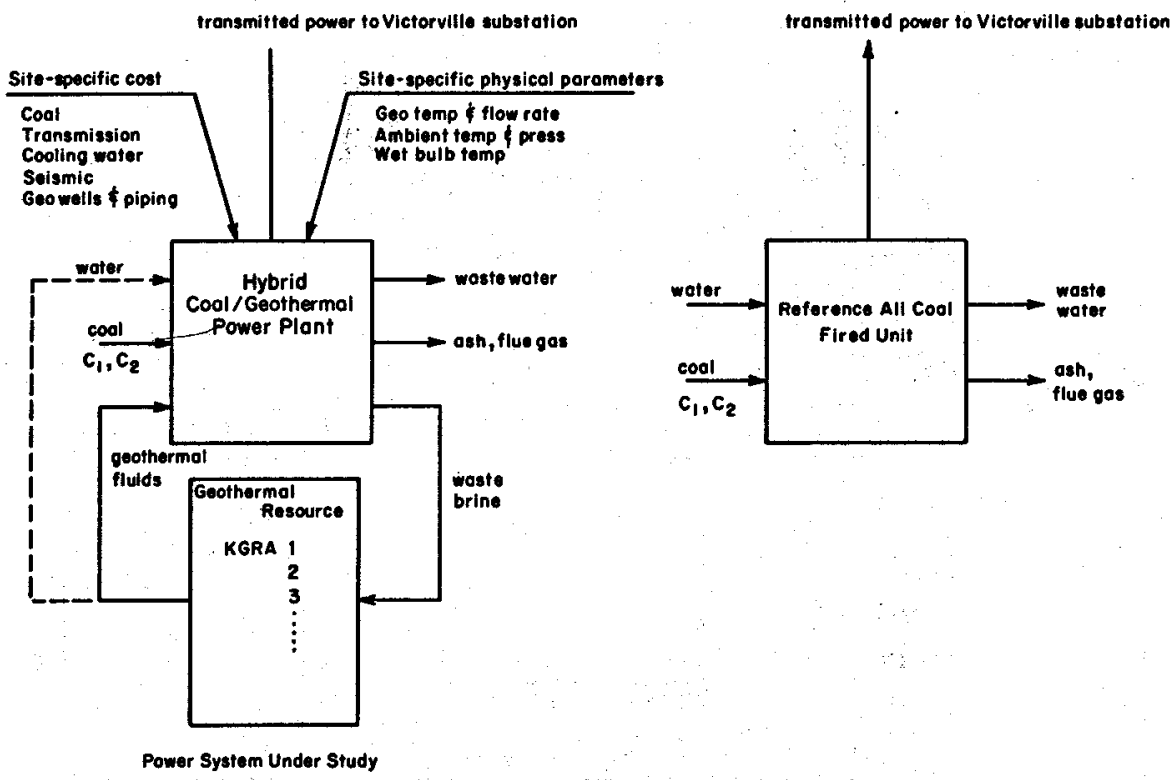

FraUke 4.151-Summary of basic siting guidelines.

4.3.5.2 Design guidelines and assumptions. It was shown in section 4.3.3.3 that for a given output, the hybrid power plant will have a lower fossil fuel consumption. This results in a smaller steam generator and a lower expenditure for coal handling and processing equipment relative to an allcoal power plant of the same capacity. It was also shown that owing to the omission of some of the extraction points in the turbine, the exhaust mass flow rate will increase and the intermediate and the low pressure cylinders in the turbine will have to be enlarged. The same is also true for the condenser and the heat rejection system in the hybrid plant compared with those in the reference coal plant.

The design of the hybrid plant will be similar in many respects to the reference, all-coal plant. The studies conducted by the Pacific Sierra Research Corporation for the City of Burbank [1977; 1978] are based on a sub-critical reference coal plant. This plant is modelled after a proposed $4 \times 750 \mathrm{MW}$ steam power plant known as the Intemountain Power Project (IPP) which was to start operation in 1986. The IPP plant comprised four subcritical, single-reheat units operating at $17.3 \mathrm{MPa}$ (2490 psia) and $540^{\circ} \mathrm{C}\left(1005^{\circ} \mathrm{F}\right)$ with a net heat rate of $10.54 \mathrm{MJ} / \mathrm{kWh}(9990 \mathrm{Btu} /$ $\mathrm{kWh}$ ), which corresponds to an overall efficiency of $34.2 \%$.

The site-specific studies concentrated on known geothermal resource areas (KGRA) in California, Nevada, and Utah. These resources have downhole temperatures ranging from $177^{\circ} \mathrm{C}$ to $340^{\circ} \mathrm{C}$ with wellhead temperatures typically in excess of $200^{\circ} \mathrm{C}$. Consequently it was decided that all regenerative feedwater heaters except the highest temperature one will 


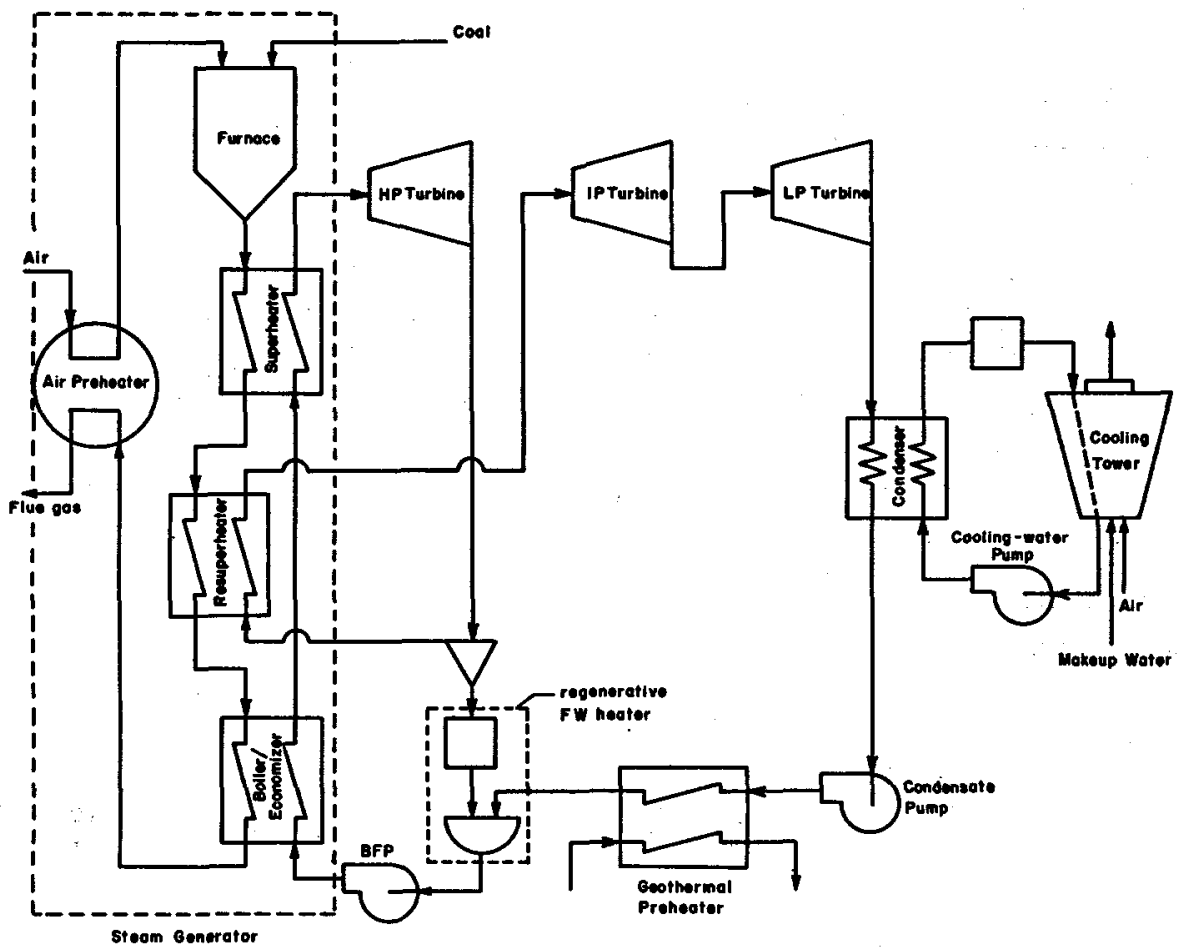

Frgure 4.152—Simplified flow diagram of the hybrid plant used in site-specifte studies.

be replaced by a geothermal feedwater preheater. A simplified cycle layout is given in figure 4.152 .

The dry turbine-expansion efficiency in the hybrid plant was taken as 0.85 instead of the 0.90 value considered in the design of the reference IPP coal plant. This constitutes an additional penalty on the hybrid power plant. The condenser pressure in both the hybrid plant and the reference IPP coal plant was taken as $9.7 \mathrm{kPa}(1.4 \mathrm{psia} \simeq 2.9$ in $\mathrm{Hg})$; this corresponds to a condensing temperature of about $45^{\circ} \mathrm{C}\left(113^{\circ} \mathrm{F}\right)$.

4.3.5.3 Design optimization. The design of a hybrid coal-geothermal power plant at any given site was optimized subject to the assumptions and constraints discussed in the preceding section. The goal of the optimization was to minimize the cost of delivered electric energy $(\phi / \mathrm{kWh})$. Throughout the study, care was taken to ensure that the performance of the various plant components is achievable within the current state of the art and conforms to modern engineering practices.

Optimization calculations were performed using a modified version of the program GEOTHM [Green and Pines, 1974]. The modified version of the program, known as GEOTHMF, is explained in the City of Burbank reports $[1977,1978]$. The optimization procedure is illustrated in figure 4.153 . 


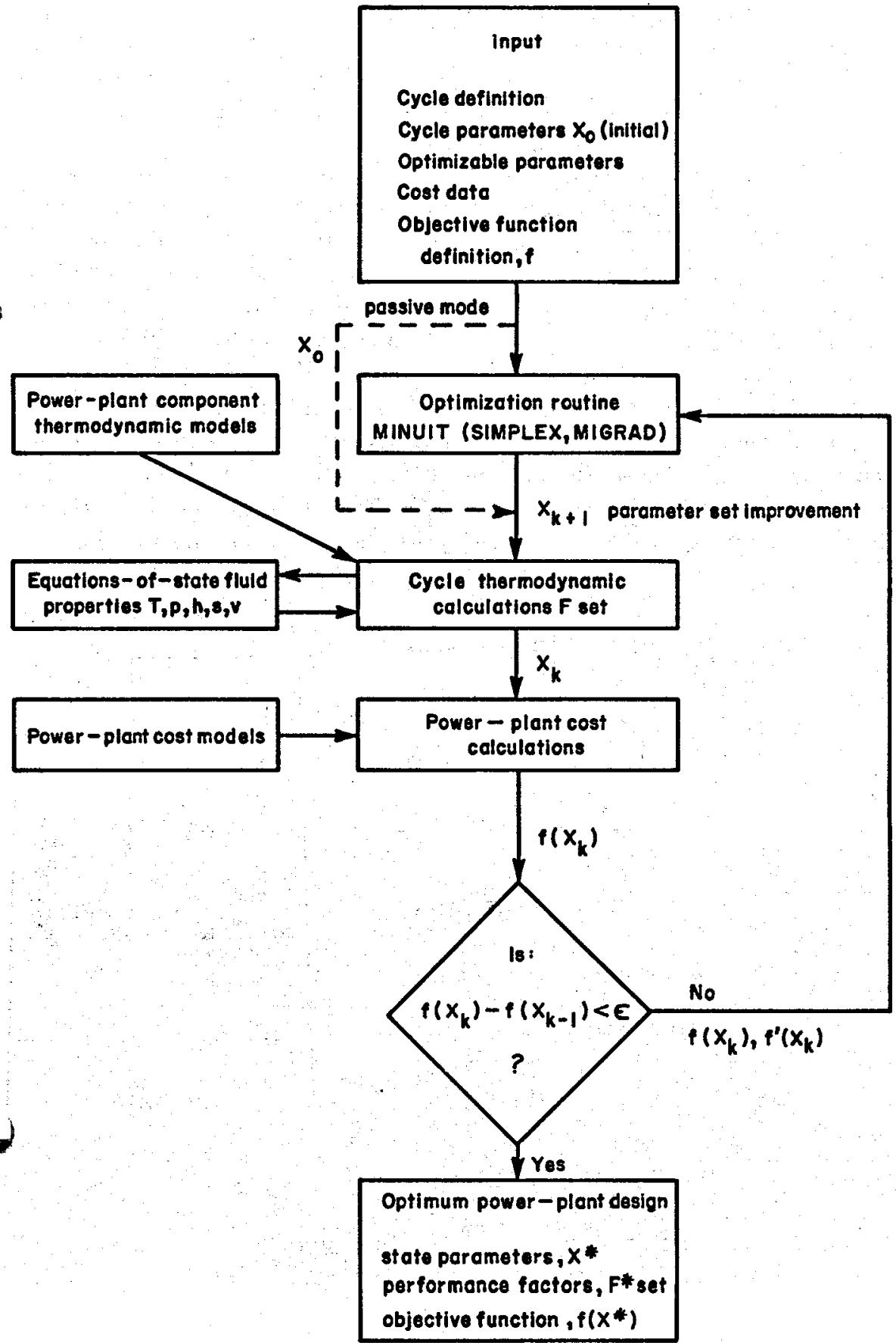

Fraure 4,153-Optimization procedure according to Program GEOTHM. 
4.3.5.4 Site-specific studies. The map shown in figure 4.154 shows the locations of ten known geothermal resource areas (KGRA) in the states of California, Nevada, and Utah, as well as the locations of three coal fields in Utah. These cover a wide span of resource characteristics and represent a wide variety of environmental conditions.

Geothermal resource characteristics. Complete information on geothermal resource characteristics is not available. Reasonable assumptions, however, can be combined with existing resource data to present a realistic model of resource behavior. Table 4.18 contains estimates of the downhole conditions $\left(T_{d h}, P_{d h}\right)$, the wellhead conditions $\left(T_{w h}, P_{w h}\right)$ and the flow rates for each of the ten resources. The table also includes an estimate of the average number of wells required for a $750 \mathrm{MW}$ hybrid plant [Burbank, $1977 ; 1978]$. The amount of dissolved solids at all but the Niland resource is only a few thousand parts per million. If present in large enough concentrations, dissolved solids could result in excessive corrosion and scaling of the surfaces that come in contact with them. This can significantly reduce the overall heat transfer coefficient in the geothermal heat exchanger.

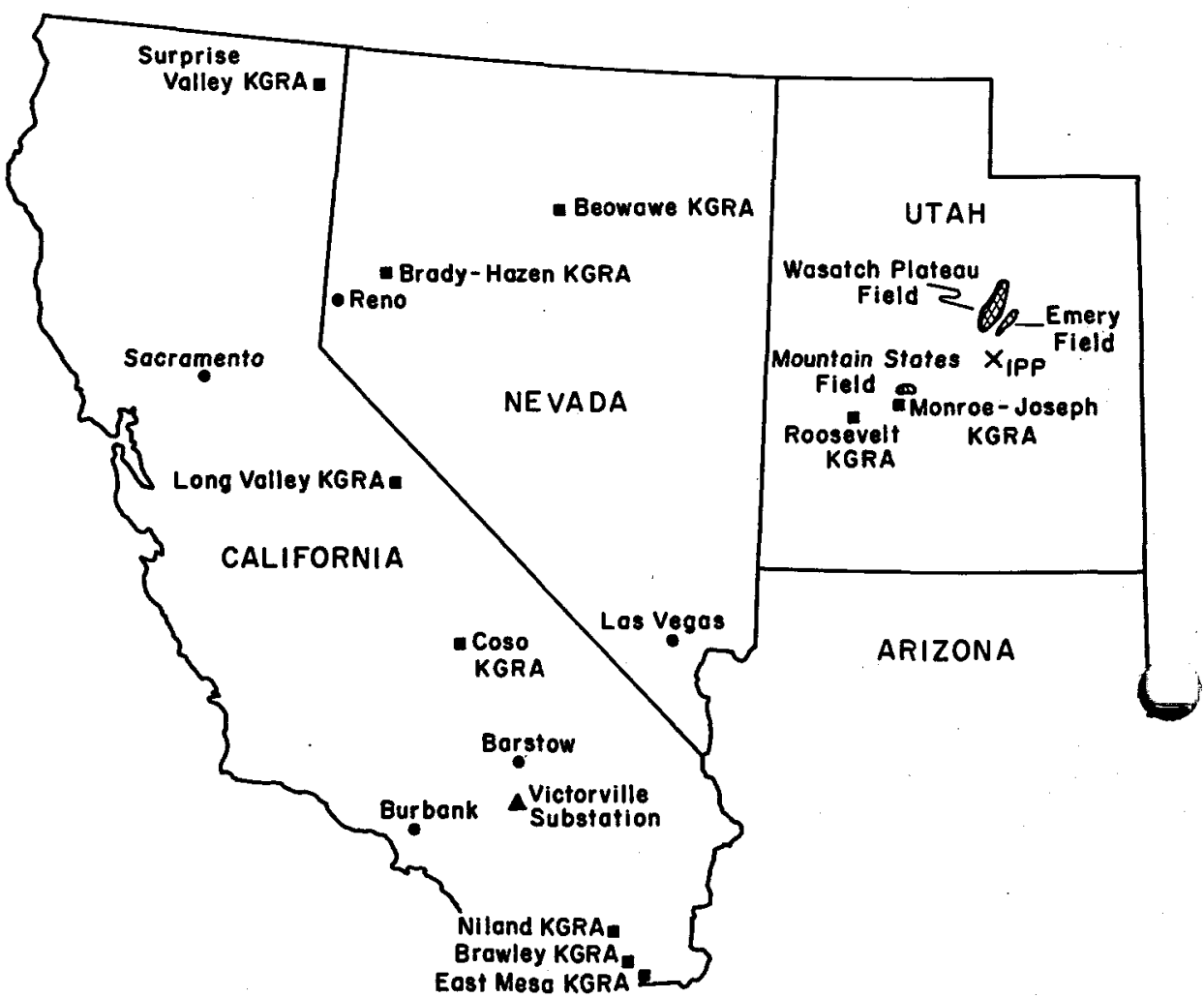

Fiaure 4.154-A map of ten geothermal sites in Callfornia, Nevada and Utah and the nearest conl mines in Utab. 
TABLE 4.18-Geothermal resource characteristics

\begin{tabular}{|c|c|c|c|c|c|c|}
\hline Resource & $\begin{array}{r}T_{d k} \\
{ }^{\circ} \mathrm{C}\left({ }^{\circ} \mathrm{F}\right)\end{array}$ & $\begin{array}{r}P_{d i} \\
M P a(p s i)\end{array}$ & $\begin{array}{r}T_{-A} \\
{ }^{\circ} \mathrm{C}\left({ }^{\circ} \mathrm{F}\right)\end{array}$ & $\begin{array}{r}P_{\infty h} \\
M P a \text { (psi) }\end{array}$ & $\begin{array}{r}\stackrel{\dot{m}}{t / h r / w e l l} \\
(k \mathrm{lb} / \mathrm{hr} / \text { well })\end{array}$ & $\begin{array}{r}\text { Annual } \\
\text { well } \\
\text { requirement }\end{array}$ \\
\hline Brawley, Calif. & $260(500)$ & 4. 7 (681) & $236(457)$ & 3. $13(454)$ & $406(896)$ & 6 \\
\hline Coso, Calif..... & $260 \cdot(500)$ & 4. 7 (681) & $236(457)$ & 3. $13(454)$ & $406(896)$ & 7 \\
\hline East Mesa, Calif. & $200(392)$ & 1. $56(226)$ & $182(359)$ & $1.03(150)$ & $234(515)$ & 9 \\
\hline Long Valley, Calif. & $177(350)$ & $0.93(135)$ & $160(320)$ & $0.62 \quad(90)$ & $181(398)$ & 11 \\
\hline Niland, Calif . . . . . . . . $\ldots \ldots \ldots \ldots$ & $340(644)$ & $14.61(2118)$ & $309(588)$ & $9.74(1412)$ & $454(1000)$ & $\mathbf{3}$ \\
\hline Suprise Valley, Calif . . . . . . . . . . . . . . & $189(375)$ & $1.31(191)$ & $174(345)$ & $0.88(127)$ & $175(385)$ & 11 \\
\hline Beowawe, Nev. . . . . . . . . . . . . . . & $216(420)$ & 2. $13(309)$ & $196(385)$ & 1. $42(206)$ & $327(720)$ & 7 \\
\hline Brady-Hezen, Nev....... & $214(417)$ & 2. $06(299)$ & $194(382)$ & 1. $38(200)$ & $269(593)$ & 8 \\
\hline Monroe-Joseph, Utah ............. & 177. $(350)$ & $0.93(135)$ & $160(320)$ & $0.62 \quad(90)$ & $181(398)$ & 12 \\
\hline Roosevelt, Utah. . . . . . . . . . . . . . & $274(525)$ & 5. $85(848)$ & $249(480)$ & 3. $9 \quad(565)$ & $454(1000)$ & 5 \\
\hline
\end{tabular}


The degradation of the heat transfer surfaces due to scaling was taken into account by assuming that the value of the overall heat transfer coefficient in the geothermal feedwater heater is less than half the corresponding value for clean surfaces. Also, the annual operation and maintenance costs for the geothermal heat exchanger were taken as double those for a conventional heat exchanger of a similar design. At Niland, a multiflash design was selected for the geothermal preheater owing to the high salinity of the geofluid [Simay et al., 1978].

Comparison between hybrid and all-coal power plants. Table 4.19 contains a comparison between cost optimized $750 \mathrm{MW}$ hybrid power plants constructed at the ten sites and the reference all-coal power plant. The cost of a $\mathrm{kWh}$ (delivered at Victorville, Calif.) is normalized with respect to that produced by the reference all-coal plant. The table also includes a synthesis of the cost components : coal, plant, transmission, and geothermal. The fifth column in the table represents the relative cost of electric energy produced by a reference coal power plant constructed at the geothermal site rather than at the optimum location of such a plant (close to the coal mines). The last column gives the percentage savings if a hybrid plant were to be built instead.

The comparison shows that hybrid power plants constructed at Roosevelt and Monroe-Joseph in Utah, not far from the coal mines, offer about $10 \%$ and $7.5 \%$ savings in the cost of electric energy relative to the reference, all-coal plant, respectively. The other sites are not economically competitive with this ideally located coal power plant. When coal has to be transported to or very close to the geothermal site, however, all hybrid plants become more attractive economically than the corresponding all coal plant; the advantage ranging from a marginal $0.5 \%$ for the MonroeJoseph site in Utah to a sizable $12 \%$ for the Brawley site in California. It should be remembered, however, that the comparison is done under the most conservative conditions and that the geothermal fiuid has not been utilized to its full potential for such functions as coal beneficiation, cooling tower make-up and other low temperature heating applications in the power plant. These uses may tilt the balance further in favor of the hybrid plants. Table 4.20 contains the values of the figures of merit and the work amplification factors for the ten sites.

The cost comparisons given above are based on an all-coal reference power plant of the same capacity as the hybrid plant. It is unlikely that electricity generated from liquid dominated geothermal resources will be cheaper than that generated by an ideally located state-of-the-art coal power plant. The hybrid power plant may, thus, appear even more attractive if it is compared with two, separate, geothermal and coal power plants, each individually optimized. For example, the most promising hybrid plant (at Roosevelt) will have a $14 \%$ advantage over a combination of a $69 \mathrm{MW}$ binary power plant at Roosevelt Hot Springs and a $681 \mathrm{MW}$ state-of-the-art coal power plant ideally located with respect to the coal 
TABLE 4.19-Cost of energy for a 750-MW hybrid plant compared with that of an all-coal plant located at the same site

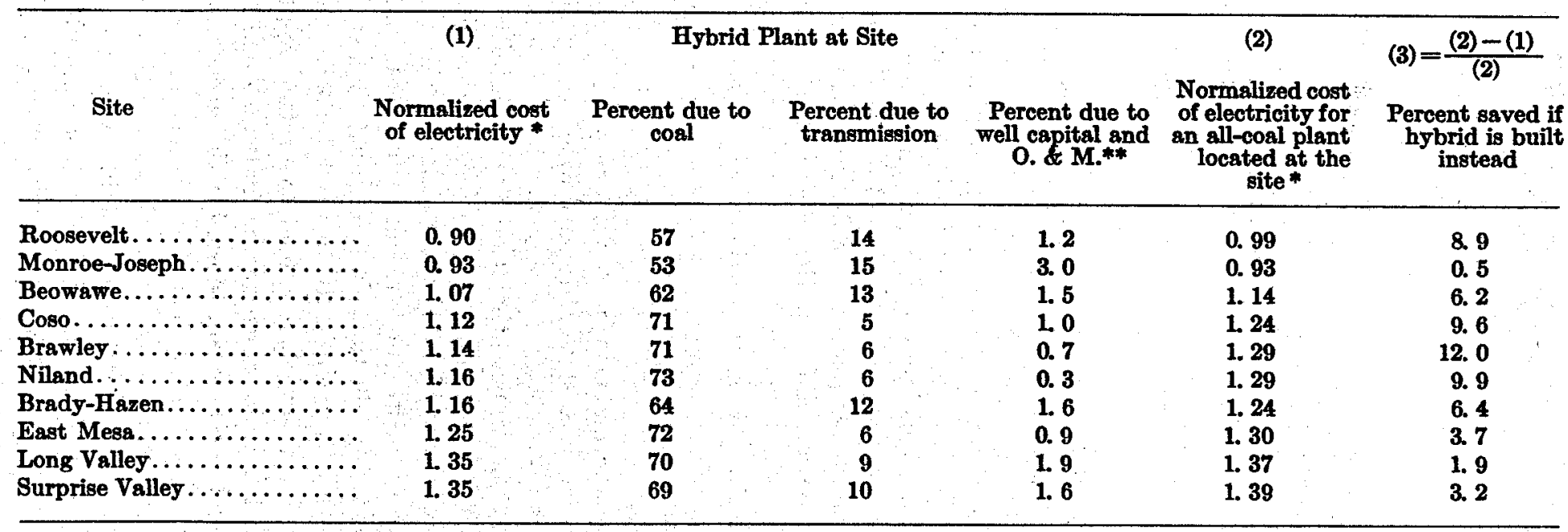

* Normalized with respect to the cost of electricity generated by the reference all-coal plant.

* The balance represents the cost of the plant. 
TABLE 4.20-Figure-of-merit values for cost-optimized $750-M W$ hybrid plants at each of 10 geothermal sites

\begin{tabular}{|c|c|c|c|c|}
\hline Site & $F$ & $F_{\varepsilon}$ & $F_{r}$ & $\psi$ \\
\hline \multicolumn{5}{|l|}{ California sites: } \\
\hline$\ldots \ldots \ldots \ldots \ldots$ & 1. 09 & 2. 03 & 1. 10 & 12. 1 \\
\hline Coso................... & 1.06 & 1. 69 & 1. 07. & 11. 7 \\
\hline East Mesa................ & 1. 03 & 1. 68 & 1.03 & 22.1 \\
\hline Long Valley................. & 1.03 & 1.91 & 1.03 & 32.6 \\
\hline Niland......... & 1. 04 & 1. 52 & 1.05 & 12. 1 \\
\hline Surprise Valley.............. & 1.03 & 1.86 & 1.03 & 26.8 \\
\hline \multicolumn{5}{|l|}{ Nevada sites: } \\
\hline Beowawe $\ldots \ldots \ldots \ldots \ldots \ldots \ldots$ & 1.07 & 2.27 & 1.08 & 18. 3 \\
\hline Brady-Hazen. . . . . . . . . . . . & 1. 08 & 2. 38 & 1. 08 & 19. 2 \\
\hline \multicolumn{5}{|l|}{ Utah sites: } \\
\hline Monroe-Joseph............... & 1.04 & 2.12 & 1.04 & 30. 0 \\
\hline Roosevelt. . . . . . . . . . . . . & 1. 07 & 1.72 & 1. 08 & 10. 9 \\
\hline
\end{tabular}

mines in Utah. This figure is based on a work amplification factor $\psi=10.9$ (see table 4.20 above) and an assumed cost of geothermal electricity about $50 \%$ higher than that generated by the coal power plant.

The results of the optimization studies also demonstrate that the capital cost of a hybrid power plant is not likely to be much different from conventional coal power plants of the same capacity. For example, the cost per $\mathrm{kW}$ of installed capacity in a hybrid power plant ranges from 0.96 (Roosevelt) to 1.05 (East Mesa) that of the reference coal plant.

\subsubsection{Conclusions}

Hybrid fossil-geothermal energy conversion systems are thermodynamically superior to separate state-of-the-art fossil and geothermal energy conversion systems over a wide range of operating conditions. This fact is demonstrated by the higher utilization efficiencies of the two resources achievable in the hybrid system. The use of geothermal fluids in a hybrid power plant improves considerably their utilization and permits the efficient exploitation of geothermal resources of marginal temperatures $\left(<150^{\circ} \mathrm{C}\right)$ for power production. It is recalled that such marginal resources cannot be used economically to produce power by conventional methods; their use was largely confined to heating applications.

There are several ways in which geothermal and fossil resources can be utilized in a hybrid arrangement, notably : the geothermal-preheat system anc the fossil-superheat system. The two arrangements can be combined in a compound hybrid system as proposed by Khalifa et al. [1978a]. The compound system is particularly suitable when a two-phase liquidvapor mixture is available at the wellhead. The liquid can be used in a geothermal-preheat system while the vapor is used in a fossil-superheat 
system whose superheater is placed in the steam generator of the former system. Other hybrid systems may include a gas turbine topping loop [Khalifa et al., 1978a] or a multi-flash geothermal feedwater heater [Simay et al., 1978].

A hybrid power plant has to be located at the geothermal field due to the impracticality of transporting hot geothermal fluids over distances exceeding about $2 \mathrm{~km}$. In general the geothermal field is not optimally located with respect to the sources of the fossil fuel, the cooling water and transmission networks. Therefore, while the thermodynamic advantages of the hybrid system are obvious, the economic feasibility of it depends on site-specific considerations.

The energy cost comparisons of a $750 \mathrm{MW}$ hybrid plant at ten geothermal sites in California, Nevada, and Utah demonstrate that there are sites at which a hybrid power plant is more economical than a state-ofthe-art coal-fired steam power plant optimally located. A comparison with the same coal power plant located at the geothermal site reveals that the hybrid plant is always economically superior to the coal plant. This latter comparison is more valid under the circumstances, that the fossil fuel is transported to or very near to the geothermal site for one reason or another. In other words, if the fossil fuel has to be transported to a location near the geothermal site anyhow, then it is more economical to utilize it in a hybrid power plant than in a state-of-the-art fossil power plant. This is particularly applicable to oil or to coal when, for example, institutional regulations necessitate its transportation to where it is supposed to be utilized (rather than utilizing it at its source).

Hybrid power plants can be even more economical if some of the geothermal fluid is used for coal drying and benefication, for providing low temperature heat, or for supplying cooling tower make-up water. It is noted that the last use may be a very significant one in areas where an adequate supply of water is not available.

The capital cost of a hybrid power plant of the geothermal-preheat type differs very little from that for conventional fossil plants of the same capacity. This is because the cost of the geothermal feedwater heater and the additional cost of the turbine and condenser are more than offset by the reductions in the cost of the steam generator and by the cost savings resulting from the omission of the conventional feedwater heaters.

\subsubsection{Referenoes}

Baumann, K., 1921. "Some recent developments in large steam turbine practice," J. Inst. Elect. Eng., vol. 59, p. 565.

Burbank, City of, 1977. "Site-specific analysis of hybrid geothermal/fossil power plants," Report prepared for the U.S. DOE/DGE, No. TID-27926.

Burbank, City of, 1978. "Continuing site-specific and design analysis of hybrid geothermal/fossil power plants," Report prepared for the U.S. DOE/DGE (see Simay, et al.). 
Caufourier, P., 1924. "Recent developments in the utilization of the earth's heat," Mech. Eng. (ASME). vol. 46, No. 8, p. 448.

Correia, R. J., 1978. "The optimization of some hybrid fossil-geothermal energy conversion systems," Sc. M. Thesis, Brown University.

Dambly, B. W., 1978. "Heat exchanger desgin for geothermal power plants," Proc. 1Sth IECEC, vol. 2, p. 1102.

DiPippo, R., 1978a. "An analysis of an early hybrid fossil-geothermal power plant proposal," Geothermal Energy, vol. 6, No. 3, p. 31.

DiPippo, R., 1978b. "A summary of the technical specifications of the geothermal power plants in the world," Brown University Report No. CATMEC/8 (COO4051-14).

DiPippo, R., 1978c. "Geothermal power plants of Japan: a technical survey of existing and planned installations," Brown University Report No. CATMEC/9 (COO4051-16).

DiPippo, R., 1978d. "Geothermal power plants of the United States: a technical survey of existing and planned installations," Brown University Report No. CATMEC/14 (COO-4051-20).

DiPippo, R.. Kestin, J., and Khalifa. H. E., 1977. "Hybrid fossil-geothermal power plants," ASME paper No. 77-WA/Ener-2.

DiPippo, R., Khalifa, H. E., Correia, R. J., and Kestin, J., 1978. "Fossil superheating in geothermal steam power plants," Proc. 13th IECEC, vol. 2, p. 1095.

El-Wakil, M. M., 1962. Nuclear power engineering, McGraw-Hill, New York, p. 359.

Green, M. A., and Pines, H. S., 1974. "A thermodynamic process program for geothermal power plant cycles," LBL Report No. LBL-3060.

Haywood, R. W., 1967. Analysis of engineering cycles, Pergamon Press, Oxford.

James, C. R., 1970. "Superheating of geothermal steam for power," New Zealand Eng., vol. 27, No.12, p. 325.

Keenan, J. H., Keyes, F. G., Hill, P. G., and Moore, J. G., 1969. Steam tables: International edition-Metric units, J. Wiley, New York.

Kestin, J., 1968. A course in thermodynamics-Vol. 2, Blaisdell, Waltham, Mass.

Kestin, J., DiPippo, R., and Khalifa, H. E., 1978. "Hybrid geothermal-fossil power plants," Mech.Eng. (ASME), vol. 100, No. 12, pp. 28-35.

Khalifa, H. E., 1977. "Superheated flash systems: A type of hybrid plant," Minutes of the 6th meeting of the Centers for the Analysis of Thermal/Mechanical Energy Conversion Concepts, Brown University Report No. CATMEC/5 (COO-4051-9).

Khalifa, H. E., DiPippo, R., and Kestin, J., 1978a. "Hybrid fossil-geothermal power plants," Proc. 5th Energy Technology Conference (ETC), p. 960.

Khalifa, H. E., DiPippo, R., and Kestin, J., 1978b. "Geothermal preheating in fossilfired steam power plants," Proc. 13th IECEC, p. 1068.

Milora, S. L., and Tester. J. W., 1976. Geothermal energy as a source of electric power, MIT Press, Cambridge, Mass.

Moore, M. J. and Sieverding, H. C., eds., 1976. Two-phase steam flow in turbines and separators, Hemisphere/McGraw-Hill, Washington/New York.

Salisbury, J. K., 1950. Steam turbines and their cycles, J. Wiley, New York.

Sheldon, R. C., 1967. "Application of exhaust heat recovery combined cycle," General Electric Report No. HPT-7/2M.

Simay, G. L., Anno, G. H., and Dore, M. A., 1978." Continuing site-specific and design analysis of hybrid geothermal/fossil power plants," Report prepared for DOE/DGE (see Burbank [1978]).

Skrotski, B., and Vopat, W., 1960. Power station engineering and economy, McGrawHill, New York.

Szewalski, R., and Khalifa, H. E., 1978. "A new approach for increasing the thermal efficiency of steam power cycles," ASME paper No. 78-JPGC-Pwr-2. 
4.3.8 Nomenclature

LATIN
F.
G.
$H$
$m$.
$P \ldots \ldots \ldots \ldots$ pressure
$Q \ldots \ldots \ldots \ldots$ heat transfer; quantity
S........... entropy
T........... temperature
$W, w \ldots \ldots \ldots \ldots$ work
figure of merit
Gibbs function
enthalpy
mass

GREEK
$\eta$
$\theta$
efficiency; utilization efficiency entropy production
$\ldots \ldots \ldots \ldots \ldots$ turbine exhaust mass flow ratio
$\xi \ldots \ldots \ldots \ldots \ldots$ geothermal/fossil work equivalence factor
$\phi \ldots \ldots \ldots \ldots \ldots$ fossil-fuel conservation factor
$\ldots \ldots \ldots \ldots \ldots$ work amplification factor

SUPERSCRIPTS

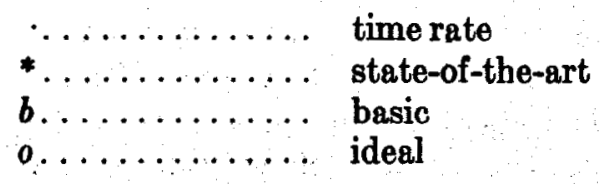

SUBSCRIPTS

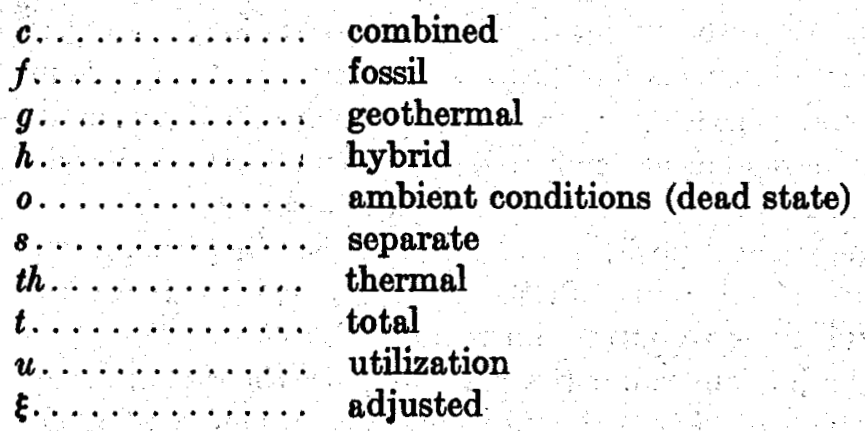

\section{ABBREVIATIONS}

C.......... condenser

D.......... deaerator

DSH......... desuperheater

$F^{*} \ldots \ldots \ldots \ldots$ state-of-the-art fossil fuel plant 
FSH. ........ fossil superheater

FWH. . . . . . feedwater heater

G*........ state-of-the-art geothermal plant

GHX......... geothermal heat exchanger

H.......... hybrid plant

HP, HPT . . . . . high-pressure turbine

IP, IPT . . . . . . intermediate-pressure turbine

LP, LPT. . . . . . low-pressure turbine

R.......... regenerator

RH.......... reheat

S/F.......... separator/flash tank

SG.......... steam generator

ST . .......... steam turbine

\subsection{Status of the development of the total flow system for electric power production from geothermal energy (By A. L. Austin*, edited by D. J. Ryley**)}

\subsubsection{Introdruction}

Events during the last few years have focused worldwide attention on the increasing need for clean, inexpensive energy supplies with particular emphasis on development of nonfossil sources. In the U.S.A., geothermal energy is currently receiving wide interest as one alternate energy source, particularly for electric power generation. Geothermal energy is defined here as the thermal energy stored in deposits of dry steam, hot water, and hot dry rock. Although dry steam deposits are technologically the easiest to exploit, their occurrence is estimated to be only about one-twentieth as common as hot water deposits. On the other hand, while there may be immense amounts of energy stored in hot dry rock, no technology yet exists for recovery of this energy nor has significant exploration been carried out yet to determine if and where exploitable deposits exist. Consequently, during the next decade geothermal energy development in the U.S. will likely emphasize exploitation of the water-dominated resource.

Temperatures of the water deposits of primary interest vary from $150^{\circ} \mathrm{C}$ to $300^{\circ} \mathrm{C}$ with total dissolved solids (TDS) ranging from less than $0.1 \%$ to over $25 \%$. Although these resources constitute a significant energy resource, there are two major constraints that will influence the rate of development. First, the range of chemical conditions encountered will likely require special conversion systems. In some cases, economic utilization of high temperature-high salinity brines has not yet been proven feasible.

*Lawrence Livermore Laboratory, Livermore, Calif.

**Division of Engineering, Brown University, Providence, R.I. 02912; permanent address: Dept. of Mechanical Engineering, University of Liverpool, Liverpool, England. 
Second, economic considerations require development of conversion machines with highest efficiencies in order to minimize the number of wells per unit of electrical capacity. In the U.S. an accelerated effort is currently underway, supporting a broad-based research and development program. Much of this work is directed toward new conversion systems in an attempt to increase opportunities for utilization of hostile fluids and for improved economics.

\subsubsection{Oharacteristics of wellhead fuids}

Before proceeding, it is of value to summarize briefly the nature of the fluids produced by hydrothermal wells: During the last ten years, considerable attention has been given to understanding hydrothermal systems and the characteristics of well flow from hot water deposits. Models of hot water systems have been described by Muffler and White [1972], White [1973], Facca [1973], James [1967, 1970a, 1970b], and Gould [1974], among others, in which mechanisms are proposed for production from hydrothermal systems which are hot enough to produce two-phase flow by flashing in the wellbore.

Since limited data are readily available to illustrate a wide variety of conditions, an approximate evaluation is relatively easy to obtain by numerical solution of the momentum and continuity equations for adiabatic steady flow up a well. Table 4.21 lists the results of such calculations [Austin et al., 1973 and Johnson, 1974]. The reservoir conditions and assumed conditions for well design were chosen arbitrarily, but are generally representative of field conditions. The well flow rates calculated are those at the well head pressures for which the thermal energy extraction rate is maximum. Actual fluid production rates and energy content, however, will be adversely affected by the presence of dissolved solids. It is estimated [Grens, 1975] that for each $1.0 \%$ increase in these dissolved solids, there may be a reduction of up to 0.8 to $0.9 \%$ in energy extraction rate, but experimental verification of these calculations is needed. Nevertheless, neglecting this condition the characteristics given in table 4.21 are found to be reasonably consistent with the limited data available in the literature and will be used here as the basis for any system calculations appearing in this chapter.

There are two reasons to consider downhole pumping. One is to increase production from low temperature deposits, and the other is to maintain liquid flow from higher temperature deposits. This may be especially important to suppress precipitation and scale formation in surface equipment associated with the Binary Cycle concept (see section 4.2). For application in the higher temperature brines, problems of reliability are particularly serious. As yet, proven pumps have not been demonstrated. There are several concepts under development, and this work should be encouraged. 
TABLE 4.21-Calculated geothermal well characteristics for the self-pumping mode of production

\begin{tabular}{|c|c|c|c|c|c|c|c|c|c|}
\hline \multirow{2}{*}{\multicolumn{2}{|c|}{$\begin{array}{c}\text { Reservoir } \\
\text { temperature } \\
\end{array}$}} & \multicolumn{8}{|c|}{ Wellhead characteristics } \\
\hline & & \multicolumn{2}{|c|}{ Temperature } & \multicolumn{2}{|c|}{ Pressure } & & & \multicolumn{2}{|c|}{ Enthalpy } \\
\hline${ }^{\circ} \mathrm{C}$ & $\left({ }^{\circ} \mathrm{F}\right)$ & ${ }^{\circ} \mathrm{C}$ & $\left({ }^{\circ} \mathrm{F}\right)$ & $\mathbf{M P a}$ & $\left(\frac{1 b}{i n^{2}}\right.$ & a) & por $\%$ & $\frac{\mathbf{k J}}{\mathbf{k g}}$ & $\left(\frac{B t u}{\mathrm{Ib}}\right)$ \\
\hline \multirow[t]{3}{*}{$\begin{array}{l}177 \\
204 \\
260 \\
300\end{array}$} & $\begin{array}{l}(351) \\
(399) \\
(500) \\
(572)\end{array}$ & $\begin{array}{l}138 \\
163 \\
199 \\
223\end{array}$ & $\begin{array}{l}(280) \\
(325) \\
(390) \\
(433)\end{array}$ & $\begin{array}{l}0.344 \\
0.676 \\
1.517 \\
2.482\end{array}$ & $\begin{array}{r}(50 \\
(98 \\
(220 \\
(360\end{array}$ & & $\begin{array}{r}7.4 \\
8.3 \\
13.7 \\
18.9\end{array}$ & $\begin{array}{r}740.1 \\
862.9 \\
1113.4 \\
1308.4\end{array}$ & $\begin{array}{l}(318.2) \\
(371.0) \\
(478.7) \\
(562.5)\end{array}$ \\
\hline & & \multicolumn{4}{|c|}{ Flow rate in (see note 2) } & \multicolumn{4}{|c|}{$\begin{array}{c}\text { Thermal energy extraction rate } \\
\text { (see note 3) }\end{array}$} \\
\hline & & \multicolumn{2}{|c|}{$f=.02$} & \multicolumn{2}{|c|}{$f=.04$} & & & \multicolumn{2}{|c|}{$f=.04$} \\
\hline${ }^{\circ} \mathrm{C}$ & $\left({ }^{\circ} \mathrm{F}\right)$ & $\frac{\mathrm{kg}}{\mathrm{m}^{2} \mathrm{~g}}$ & $\left(\frac{l b}{f t^{2} s}\right)$ & $\frac{\mathrm{kg}}{\mathrm{m}^{2} \mathrm{~s}}$ & $\left(\frac{\mathrm{lb}}{\mathrm{ft}^{2} \mathrm{~B}}\right)$ & $\frac{\mathbf{M} \mathbf{W}_{\mathrm{t}}}{\mathbf{m}^{2}}$ & $\left.\frac{\mathrm{MW}}{\mathrm{ft}^{2}}\right)$ & $\frac{M W_{1}}{m^{2}}$ & $\left(\frac{M W_{1}}{f t^{2}}\right)$ \\
\hline $\begin{array}{l}177 \\
204 \\
260 \\
300\end{array}$ & $\begin{array}{l}(351) \\
(399) \\
(500) \\
(572)\end{array}$ & $\begin{array}{l}1708.9 \\
2270.4 \\
2978.3 \\
3222.5\end{array}$ & $\begin{array}{l}(350) \\
(465) \\
(610) \\
(660)\end{array}$ & $\begin{array}{l}1391.5 \\
1830.9 \\
2319.2 \\
2441.3\end{array}$ & $\begin{array}{l}(285) \\
(375) \\
(475) \\
(500)\end{array}$ & $\begin{array}{r}914.9 \\
1496.2 \\
2701.8 \\
3552.1\end{array}$ & $\begin{array}{l}(85) \\
(139) \\
(251) \\
(330)\end{array}$ & $\begin{array}{r}742.7 \\
1205.6 \\
2109.7 \\
2691.0\end{array}$ & $\begin{array}{l}(69) \\
(112) \\
(196) \\
(250)\end{array}$ \\
\hline
\end{tabular}

Notes: 1. Well depth, $1524 \mathrm{~m}(5000 \mathrm{ft})$; production casing, $0.194 \mathrm{~m}(7 \mathrm{~s} / \mathrm{s}$ in) O.D., $0.172 \mathrm{~m}$ (6.77 in) I.D.; Area $=0.023 \mathrm{~m}^{2}\left(0.25 \mathrm{ft}^{2}\right)$.

2. Calculations are based on thermodynamic properties of pure water, $f=$ Moody friction factor.

3. The thermal energy extraction rate is calculated with reference to saturated liquid enthalpy at $48.9^{\circ} \mathrm{C}\left(120^{\circ} \mathrm{F}\right)$, In S.I. Units, $\dot{Q}=\dot{m}\left(h_{2}-205\right)$, fps Units, $\dot{Q}=\dot{m}\left(h_{2}-87.9\right)$.

\subsubsection{Energy conversion concepts}

For recovery and conversion of the energy in water-dominated resources, only three basic conversion concepts exist. These are: (a) the flashed steam system, (b) the binary cycle concept, and (c) the total flow concept. A fourth concept envisages combinations of these systems, i.e., hybrid systems.

For electric power generation, the development of hybrid systems may be necessary to achieve the most effective utilization of hydrothermal resources. This may be especially the case, for example, where large amounts of noncondensible gases exist, or where unique conditions are present allowing both electrical and nonelectrical uses of the energy. Any serious consideration of hybrids, as defined here, however, must begin with a thorough understanding of individual system components over the complete range of operating conditions. Hence, the development of hybrids awaits further development of the basic concepts.

Currently, only the flashed steam system is in commercial use. The binary cycle concept has not yet found application, nor has even a small 
complete system been field-tested in the United States. The total flow concept has been the subject of considerable laboratory tests, but also has not yet been field-tested. Consequently, only the flashed steam system will be used here for performance comparisons. For that reason, a short discussion of the basic features of the flashed steam system is now presented as preparation for the following detailed discussion of the total flow concept. Further information on flashed steam systems is given in section 4.1.

4.4.3.1 The flashed steam system. In the early 1960's, New Zealand pioneered the large-scale recovery and conversion of energy in hot water deposits using the Flashed Steam method. A great deal of information has been published, and operational flashed steam power plants now exist in several other countries [see chapter 10]. Consequently, the technology can be considered proven, and future advances will likely lie in areas of more refined system components, power system economics, and reservoir management techniques. Since this is the only proven system with a substantial operational history, its general performance characteristics will be used here as a basis for comparison of future concepts.

Figure 4.155a illustrates schematically the elements of a single-flash system Isenthalpic pressure reduction of the wellbottom product occurs prior to and at entry to the flash separator which separates the vapor and liquid fractions. The accompanying Temperature-Entropy chart in figure 4.155b illustrates the basic thermodynamic process involved. For simplicity, the pressure drop between separator and turbine inlet is neglected here since it is largely dependent on well spacing and detailed plant design. The most

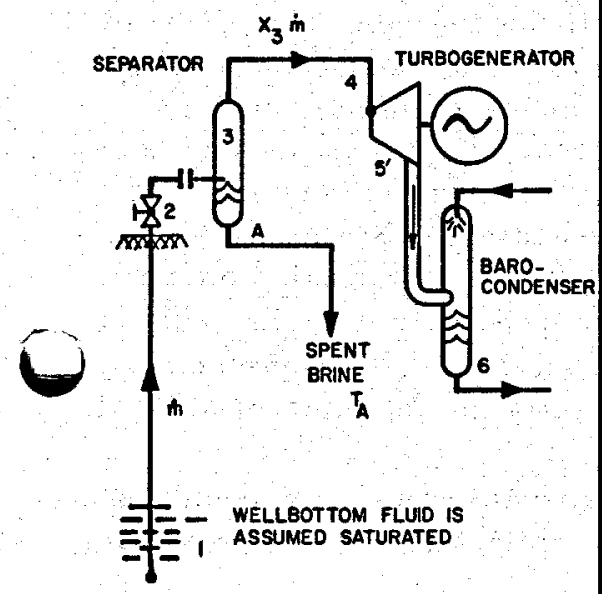

A. SYSTEM COMPONENTS

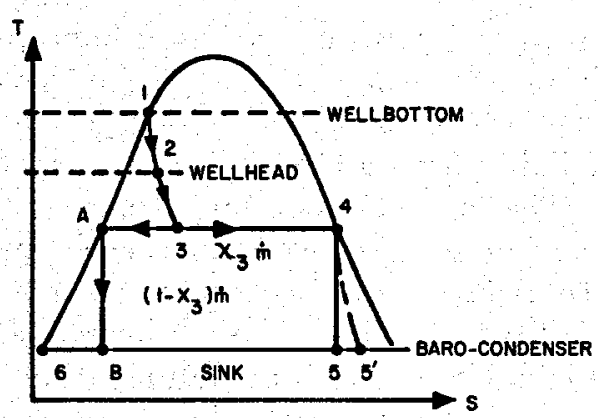

NEGLECTING KINETIC AND POTENTIAL ENERGIES; NET POWER OUT $=x_{3} m\left(h_{4}^{-h_{5}}\right) e_{0}$ POWER LOST IN SPENT BRINE $=m\left(1-x_{3}\right)\left(h_{A}-h_{B}\right)$ OVERALL THERMAL EFFICIENCY $=\frac{x_{3}\left(h_{4}-h_{5}\right) e_{0}}{h_{2}-h_{6}}$

B. THE PROCESS

Frauke 4.155-The flashed-steam system. 
obvious point is that a substantial fraction of the available energy is discarded in the separated liquid.

Overall plant thermal efficiencies are generally below $10 \%$ for a single flash system. Greater utilization of the fluid energy, however, can be achieved with multiple flashing (see section 4.1).

For high salinity brines, carryover of solids into the vapor fraction is considered a serious limitation to the Flashed Steam system. Consequently, associated technical advances are needed in the areas of improved methods of separation or scrubbers to minimize carryover of solids in the steam fraction, and ways to increase tolerance of conventional steam turbines to entrained solids.

In order to allow comparison of the various concepts in a later section, the performance of the Flashed Steam system is now estimated for the wellhead fluids in table 4.21. A condensing temperature of $49^{\circ} \mathrm{C}$ and a $10 \%$ reduction in power output to account for internal plant pumping requirements is assumed. Results are shown in figure 4.156 in terms of the resource utilization, $\mathrm{kWh} /$ metric ton of wellhead output, i.e., the net specific energy output.

4.4.3.2 The total flow concept. Based on fundamental thermodynamic principles, a direct expansion from wellhead to sink condition has the potential for conversion of the greatest fraction of the available energy. Comparison of figure 4.157 with figure $4.155 \mathrm{~b}$ indicates that the Total Flow process (expansion from 2 to 3) provides an upper bound on system efficiency. For example, regardless of the number of stages of separations used in the Flash Steam System, there will always be some useful energy discarded with the separated liquid in the last flash stage. Although the Total Flow concept is simple, and would provide the most direet means of geothermal energy conversion, it will require the development of efficient, reliable machines for two-phase expansion of the wellhead fluid.

The concept is not new, but until now practical applications have been lacking. It is believed that the first published documentation on tests of a Total Flow device consist of some brief comments by Naymanov (1970). In his paper on the flashed steam plant at Pauzhetka, he makes reference to limited tests on a hydraulic turbine operated directly from the wellhead product. He also notes that the machine tested was far from optimum and that improvements are expected. The potential performance of a Total Flow process is shown in figure 4.156.

It should be emphasized here that this comparison is based only on thermodynamic considerations, and the assumptions used for the respective engine efficiencies of the systems shown. Figure 4.156 shows that to gain the advantages shown, a total flow expander must have an engine efficiency of $70 \%$, a performance as yet unrealized. Although the performance of steam turbines for geothermal applications may increase as geothermal energy developments proliferate, the potential for the Total Flow concept remains 


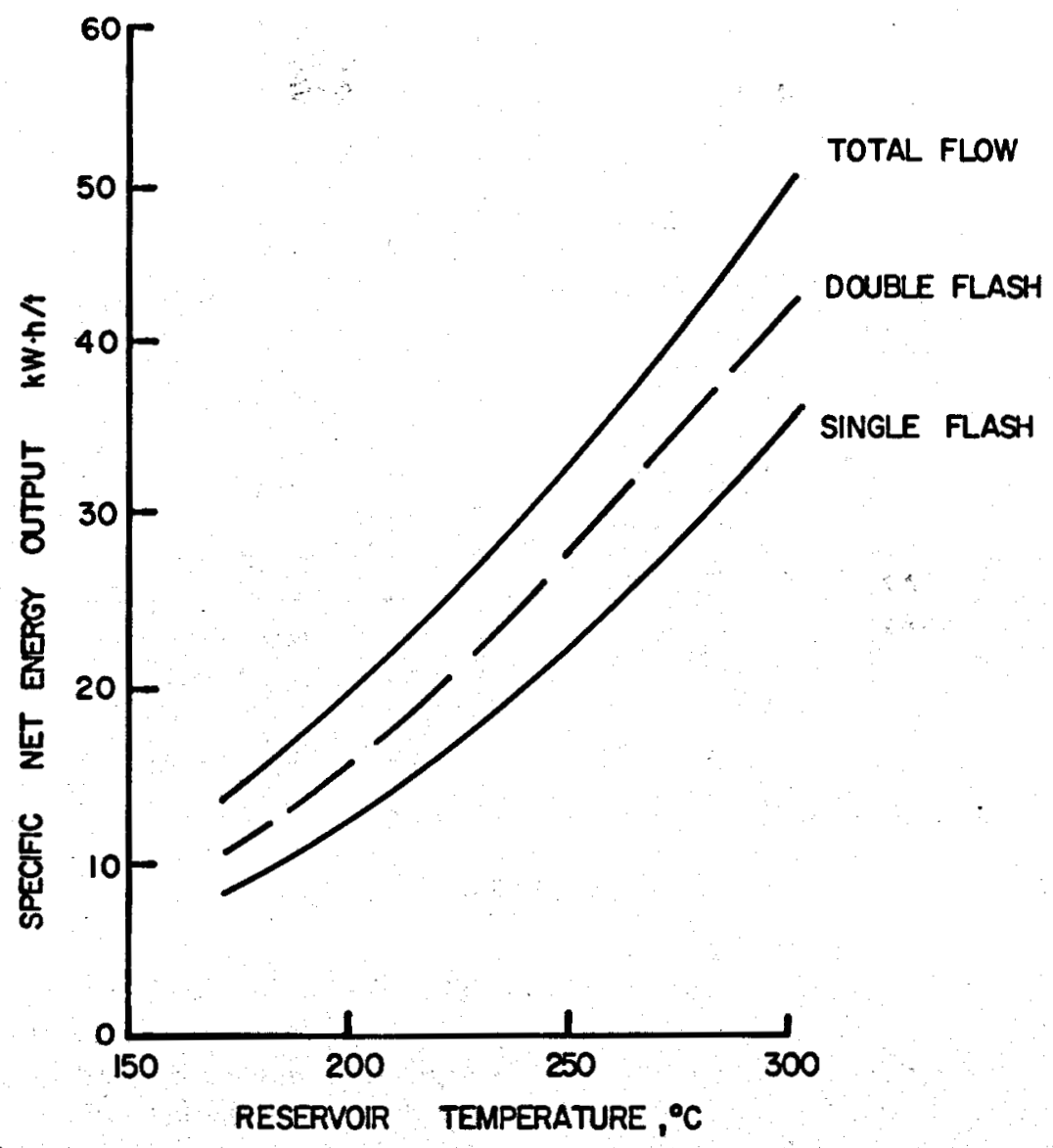

Frauke 4.156-Performance comparison of total flow concept with the flashed steam system. Single flash-75\% engine efficiency; double flash-75\% engine efficiency, both stages; total flow-70\% expander efficiency ; all systems assumed to have $10 \%$ parasitic losses; non-condensibles- $0 \%$; condensing temperature equals $49^{\circ} \mathrm{C}$ , $\left(120^{\circ} \mathrm{F}\right)$; calculations based on properties of pure water.

especially promising because of its simplicity, and hence potentially lower capital costs. It should also be noted that figure 4.156 illustrates comparison of processes, not machines. It is not yet known if the same total flow expander would work at $70 \%$ efficiency over the working fluid temperature/enthalpy range shown. It may be that different expanders will be needed at the lower temperature range than that at the higher range. More research and testing of candidate expanders over all working fluid conditions needs to be completed before this basic question can be answered. Because of the potential importance of the total flow process and because its development will add a third dimension to geothermal conversion technology, the balance of this chapter will concentrate on the required features of total flow expanders. 


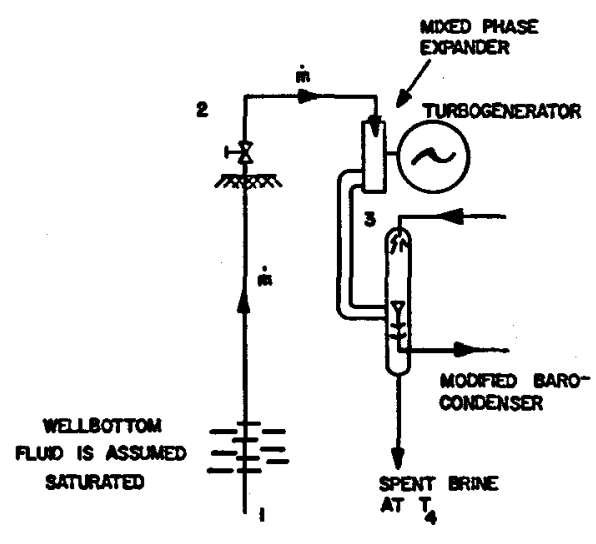

A. ststen componarts

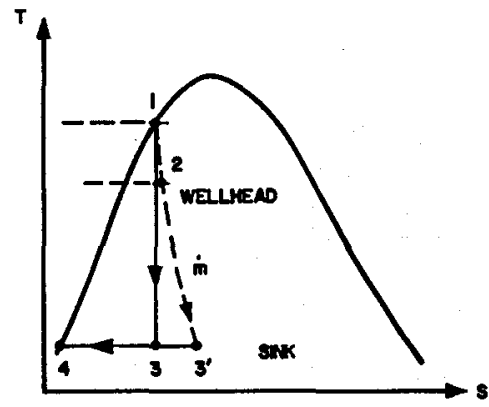

NEQLECTING KMETKC AND POTENTAL ENERGES NET POWER art $=\dot{m}\left(h_{2}-h_{3}\right) \theta_{6}$

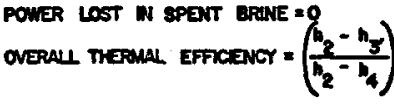

B. The PROcEss

Froure 4.157-The total flow concept.

Total flow expander characteristics. The geothermal environment demands design simplicity and flexibility to allow use of corrosion/erosion resistant materials, incorporation of precipitation and scale methods, and a means to minimize capital costs. Also, in order to gain the full advantages of the Total Flow process, it is necessary to extract the maximum available energy from the wellhead product by expansion to as low a back-pressure as possible. It can be shown that for each wellhead condition listed in table $4.21,40 \%$ of the useful work is obtained by expansion below atmospheric pressure to the sink condition of $49^{\circ} \mathrm{C}(3.5 \mathrm{in} \mathrm{Hg})$. Volume expansion ratios of the fluid range from about 300 (for $300^{\circ} \mathrm{C}$ fluids) to about 70 (for the $177^{\circ} \mathrm{C}$ fluids). This compares with expansion ratios of 50 to 20 for flashed steam turbines operating from the vapor fractions of the same wellhead fluids. Consequently, the Total Flow expander must be capable of complete expansion to recover the available energy, and must also be able to accommodate large volume flow rates. In addition to these requirements, candidate expanders must be able to withstand the presence of significant quantities of dissolved solids. Precipitation of silica and heavy metal sulfides during expansion can cause rapid formation of scale, and the corrosive and erosive actions of the brines will be major problems. These will likely require design simplicity, particularly with respect to minimizing the number of moving parts and swept surfaces, ease of mainte- 
nance, and long-term reliability. A single stage expander is most desirable, but staging may be feasible in some cases.

Table 4.22 lists the basic classes of expanders which have been considered for use in the Total Flow process. It is not possible here to give a detailed description of each, nor is this the only way to classify them. However, two types should be first treated individually: pure reaction machines and the multiple-disk (or bladeless) turbine.

TABLE 4.2.2-Olasses of expanders for total flow applications

\section{Impulse/reaction machines}

Axial flow-Curtis/Rateau steam turbine

Radial inflow-Francis turbine and multiple disc drag turbine

Radial outflow-rotating nozzle (pure reaction). Hero's turbine multiple disc turbine-bladeless impulse or reaction drag turbine.

2. Positive displacement machines

Helical screw expander

Rotating oscillating vane machine

3. Impulse machines

Tangentlal flow-Pelton wheel, Re-entry turbine

Axial flow-DeLaval, Curtis turbine

Impulse/reaction machines. Generally, reaction devices are expected to find limited application. Since a pressure and temperature drop is required in the rotating component, scale formation, if it occurs, will be difficult to control or remove. Further, maximum power output requires a high ratio (approaching unity) of top speed to absolute fluid nozzle exit velocity which leads to high speeds and high stresses. In addition, there are practical problems of maintaining rotation seals, of modifying the geometry as wellhead pressure drops with time, and of lowered nozzle efficiency due to segregation of liquid and vapor in the rotating passage. For saturated liquid inlet conditions, however, enthalpy drop is lower across the turbine; hence, rotational speed is lower, resulting in reduced working stresses. Depending on the achievable nozzle efficiency under these conditions, the radial outflow turbine (Hero's turbine) may be a practical candidate expander.

The multiple-disk turbine consists of a series of closely spaced thin disks mounted side by side on a shaft. Fluid enters through nozzles and is injected into the spaces between the disks to follow an inward spiral path to a central exhaust port. During this passage, the fluid exerts a frictional shear stress on the disks, resulting in a net torque on the shaft. Since no detailed analysis for two-phase flow operation has been made, it is not possible to comment on the applicability of this device. Since the basic mechanism for transfer of momentum is frictional drag, and the possibility that the entrained liquid droplets will be thrown radially outward by centrifugal forces, one can only speculate that turbine efficiencies may be low. Considerable work has been done to analyze similar 
machines twr operation from single-phase fluids. The reader is referred to Rice [1975] for these details, and Possell [1973] for information on machines he has built.

Positive-displacement machines. As a class, positive-displacement expanders are limited in volume flow-rate capacity relative to turbomachines. Fundamentally this is due to internal losses related to sonic velocity in the fluid. Consequently, these expanders must be physically large to produce significant power output.

The helical rotor expander is a positive-displacement device which operates by direct expansion of the two-phase fluid meshing rotors, as shown in figure 4.158. The fluid enters through a nozzle control valve into the high pressure pocket at $A$. As the rotors revolve, the pocket elongates continually, giving rise to a successively increasing volume from $\mathbf{B}$ to $\mathbf{E}$, where exhaust occurs. This device is mechanically simple, and has the advantage of self-cleaning as a result of rotor-to-rotor and rotor-to-case relative motion. McKay and Sprankle [1974] have reported operating experience with a helical rotor machine expanding brines in the Cerro Prieto and East Mesa geothermal fields. They reported that no scale deposition problem had been detected during 1,000 hours of operation. This unit also has recently undergone a series of clean-water test at the Lawrence Livermore Laboratory Geothermal Test Facility in order to investigate the mechanical performance under a range of inlet fluid thermodynamic conditions [Weiss et al., 1975].

The unit tested was an air compressor unit with $152.4 \mathrm{~mm}$ (6-inch) rotors modified by R. Sprankle of the Hydrothermal Power Co., Ltd. Inlet pressures to the rotors was varied from $168 \mathrm{kPa}(24.4 \mathrm{psia})$ to 527

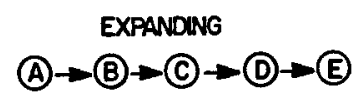

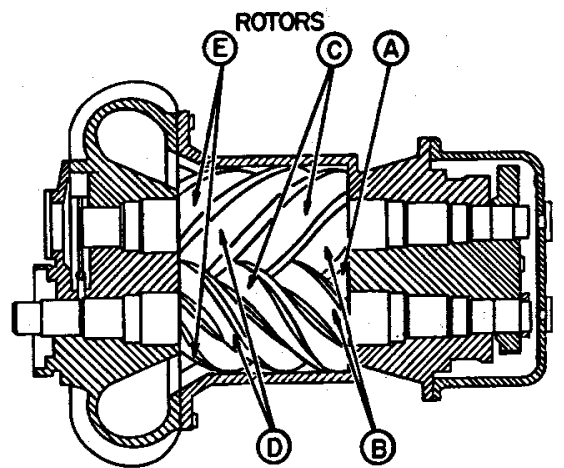

Plan section view

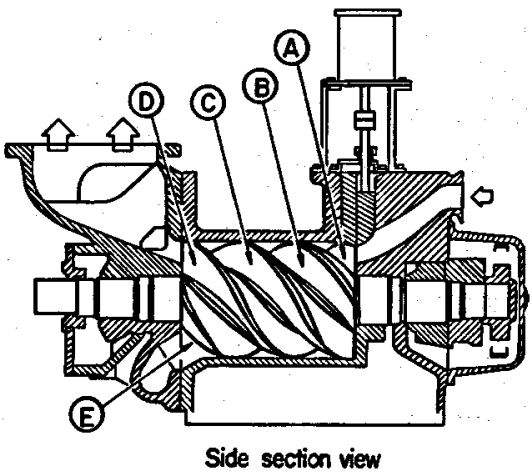

Side section view

Fioure 4.158-Felical rotor expander: The working fluid is admitted at $A$. The effective passage expands in volume as the fluid traverses the passage in the sequence B-C-D-E. 
$\mathrm{kPa}$ (76.5 psia), with vapor fractions (quality) ranging from $11.6 \%$ to $33.3 \%$. In all tests the exhaust pressure was one atmosphere. Maximum engine efficiences of $49 \%$ at $16 \mathrm{~kW}$ for $3,000 \mathrm{rpm}, 53 \%$ at $23 \mathrm{~kW}$ for 4,000 $\mathrm{rpm}$, and $55 \%$ at $30 \mathrm{~kW}$ for $5,000 \mathrm{rpm}$ were observed. The latter figure corresponded to a utilization rate of $104 \mathrm{~kg} / \mathrm{kWh}(228 \mathrm{lb} / \mathrm{kWh})$.

It was concluded that the helical rotor expander is a viable candidate machine for conversion of energy from hydrothermal wells by the Total Flow process. Additional experimental work is in progress at the Lawrence Livermore Laboratory to explore the complete operating characteristics of another machine designed specifically for the geothermal hybrid applications.

In addition, House [1976] has completed an analysis of potential applications for the helical rotor expander. He concludes that engine efficiencies will generally be below $70 \%$ because of an expansion ratio limitation of 15 and a maximum pressure differential of $758 \mathrm{kPa}(110 \mathrm{psi})$ imposed by conditions of mechanical strength. With reference to the reservoir conditions in table 4.21 , he calculates expander sizes for single stage expansion to $49^{\circ} \mathrm{C}$. His results indicate that a $40 \mathrm{MWe}$ machine will have rotor diameters varying from $12.7 \mathrm{~m}(41.6 \mathrm{ft})$ to $9.0 \mathrm{~m}(29.6 \mathrm{ft})$ with lengths varying from $19.0 \mathrm{~m}(62.4 \mathrm{ft})$ to $13.5 \mathrm{~m}(44.4 \mathrm{ft})$, respectively. For a $10 \mathrm{MWe}$ output, these sizes are reduced by half. These larger sizes can be reduced to more reasonable values by staging or by using the expander in combination with vapor turbines. It appears that, because of the large sizes required for single stage expansion to subatmospheric conditions, more suitable applications for the helical rotor expander are for noncondensing, low-power output uses or in hybrid systems with helical rotor exhaust pressures above one atmosphere [see also Elliott, 1975].

Further work is required and is in progress to more completely investigate the potential of these machines for specific applications. The high capital loss resulting from the unavoidably large physical dimensions of positive displacement devices may limit their use for central power generation.

Impulse machines. Based on the present understanding of all requirements, and particularly the need for inherently simple, compact machines, pure impulse devices have significant advantages. Because of geometric considerations the axial flow machine currently appears to be the most promising configuration for the Total Flow application. Figure 4.159 is a simplified view of an axial flow impulse turbine, and also illustrates the basic elements of other impulse machines. Expansion of the two-phase wellhead product through a converging-diverging nozzle converts the brine thermal energy at high wellhead pressures at 2 to kinetic energy in the form of a high velocity fluid stream at the backpressure 3 '. The nozzle velocity coefficient, $\eta$, is the ratio of actual velocity to the ideal exit velocity from an isentropic expansion from $2-3$, both velocities being taken for a homogeneous mixture. The wheel efficiency, $e_{v}$, is a measure of 

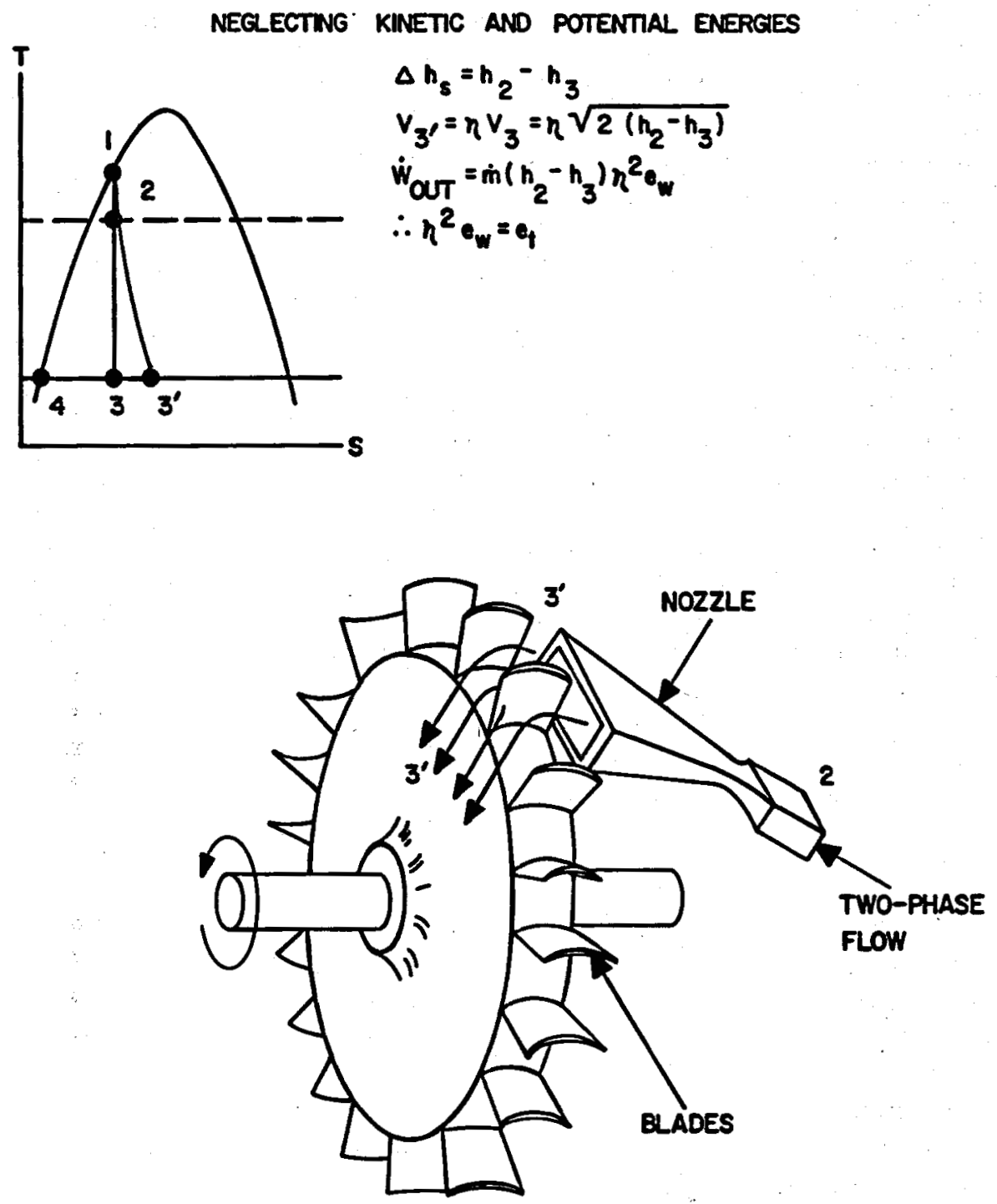

Frguke 4.159-The axial-flow impulse turbine.

the ability of the wheel to convert the fluid kinetic energy to shaft work. It is a complex function of blading geometry, turbulence, fluid friction, entrance and exit losses, fanning losses, etc. The turbine engine efficiency, $c_{t}$, then will be $\eta^{2} e_{v}$, as noted in figure 4.159. The factor $\eta^{2}$ represents the nozzle efficiency, or its ability to convert thermal energy into kinetic energy.

It is clear that the basic problem of designing an efficient total flow impulse turbine is twofold : development of efficient nozzles for expansion 
of two-phase fluids, and development of efficient blading for momentum transfer.

Nozzle development. For years the conventional wisdom has been that the presence of more than about $5 \%$ moisture in steam will severely reduce expansion efficiency due to slip between phases. This view has been widely held and probably has been the result of the historical technical direction taken in the steam turbine industry. It is instructive to think in terms of the right and left-hand side of the T-s diagram for steam. Typically, conventional steam power systems involve expansion of saturated or superheated steam where the process traverses lines of decreasing quality during the expansion to subatmospheric pressures; i.e., liquid droplets are created by condensation during the expansion. For geothermal applications, the expansion (see figure 4.157) takes place on the left side of the T-s chart, where lines of increasing quality are traversed; i.e., liquid is being eliminated by evaporation during the expansion. Consequently, in the latter case, the liquid fraction is diminishing and the liquid masses whether entrained or swept along flow boundaries tend to decrease in size and segregate. For example, for $18 \%$ quality inlet to $34 \%$ quality exit, the liquid droplets would, if dispersed and monodispersed in size, occupy only about $0.02 \%$ of the volume and would be spaced, on the average, tens of droplet diameters apart. This is contrary to conventional steam power experience of the right-hand side expansion where liquid is created, and droplets tend to agglomerate. Consequently, it appears that the conventional wisdom may not apply to expansion of low-quality steam, and that nozzles can be designed with high velocity coefficients for this process.

As part of the experimental work at the Geothermal Test Facility [Weiss and Shaw, 1975] at Livermore, Alger [1975], in order to develop high efficiency nozzles, has recently designed and tested nozzles of circular cross-section, and has measured nozzle thrust coefficients in the 0.92 to 0.95 range. This has increased confidence that development of turbine nozzles with coefficients greater than 0.9 can be achieved.

Experimental thrust coefficients $C_{T}$ are presented in figures 4.160 and 4.161 as a function of nozzle backpressure. The different curves demonstrate the effects of various nozzle inlet pressures and qualities while the inlet enthalpy remained substantially constant (Maximum variation $= \pm 23$ $\mathrm{kJ} / \mathrm{kg}$ ). The graphs include data for nozzles No. 2, No. 3, and No. 4 (see figure 4.162), since the experimental errors involved made it impossible to distinguish differences between the respective data for each nozzle, as initially expected. By comparing figures 4.160 and 4.161 it is seen that the nozzles appear to operate more efficiently at higher plenum chamber pressures for a given back pressure. Probably the factors with the greatest influence on this phenomenon are the complex shock wave processes occurring for the different operating conditions. However, all the curves approach the optimum operating conditions with thrust coefficients in the 


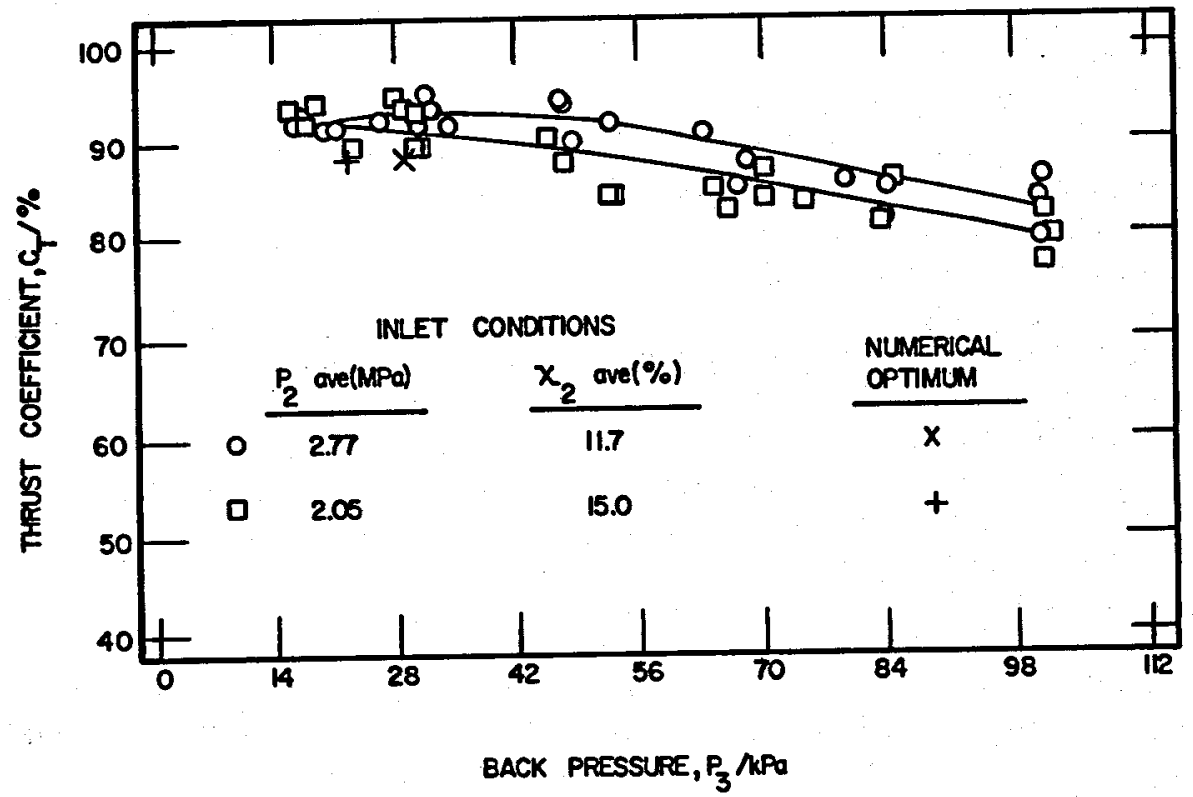

Fịgue 4.160-Thrust coefficient data as a function of back pressure and nozzle inlet conditions for nozzles No. 2, No. 3, and No. 4 .

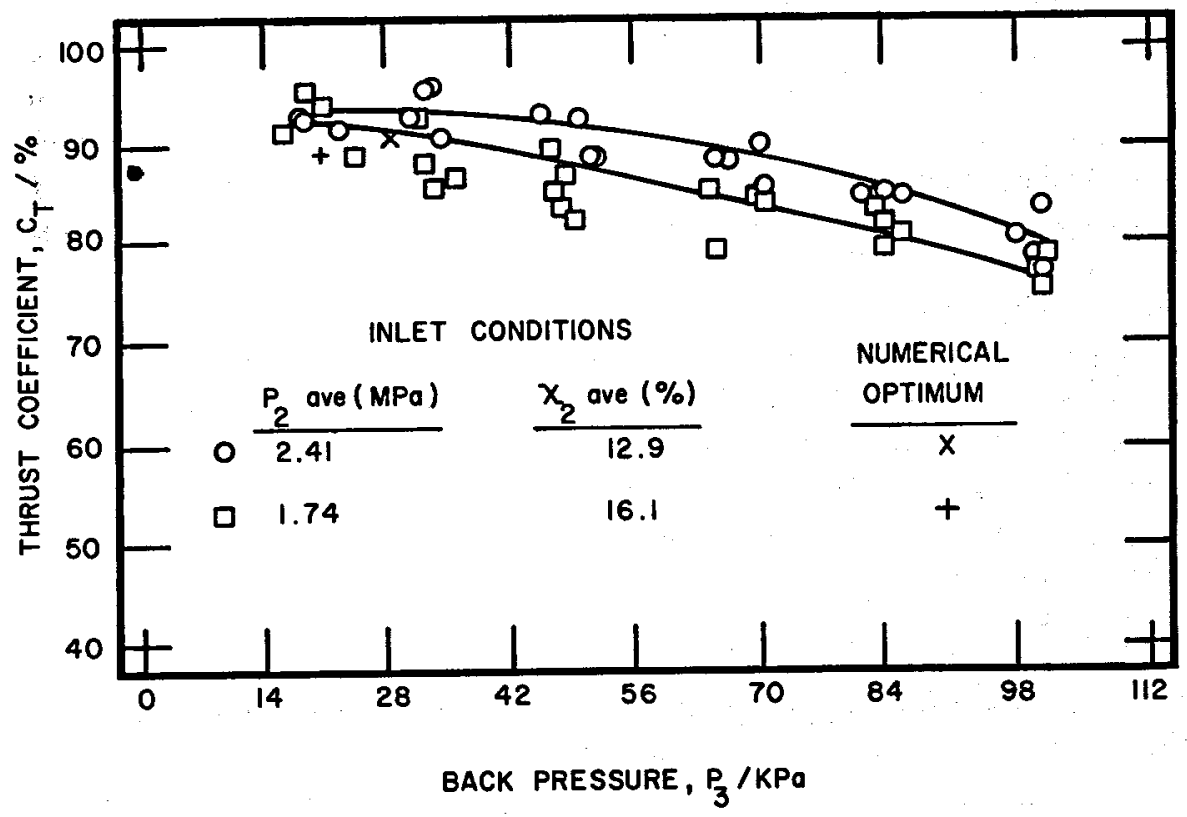

FIGURE 4.161-Thrust coefficient data as a function of back pressure and nozzle inlet conditions for nozzles No. 2, No. 3, No. 4. 
Fraune 4.162-Nozzle numerical

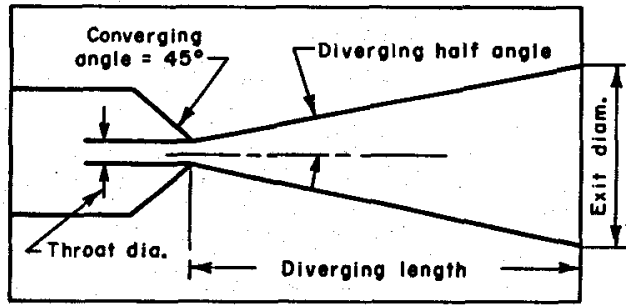
designations and dimensions.

\begin{tabular}{|c|c|c|c|c|}
\hline Nozzle & $\begin{array}{c}\text { Throot } \\
\text { dio. } \\
\left(10^{-3} \mathrm{~m}\right)\end{array}$ & $\begin{array}{c}\text { Exit } \\
\text { dio. } \\
\left(10^{-2} \mathrm{~m}\right)\end{array}$ & $\begin{array}{c}\text { Diverging } \\
\text { length } \\
\left(10^{-2} \mathrm{~m}\right)\end{array}$ & $\begin{array}{c}\text { Diverging } \\
\text { onglo }\left(^{\circ}\right)\end{array}$ \\
\hline 2 & 6.401 & 3.183 & 6.048 & 12 \\
3 & 6.401 & 3.183 & 8.077 & 9 \\
4 & 6.401 & 3.183 & 12.129 & 6 \\
7 & 9.017 & 5.664 & 22.720 & 6 \\
\hline
\end{tabular}

range of 92-94\%. As previously indicated, this represents nozzle efficiencies in the range of $85-88 \%$. The silhouette of the issuing jet was photographed under conditions of varying back pressure ranging from over-expansion through design to under-expansion. It was confirmed that the peak thrust location corresponds to the operating condition where no shock or expansion waves are present.

Additional analytical work on two-phase nozzle design [Comfort, et al., 1976] and fundamental mechanics of two-phase flow, further verify the conclusion that two-phase expansion can be efficiently accomplished by correct nozzle design. Experimental work is also continuing on development and testing of nozzles with square cross-section for application to the geometric requirements of the impulse turbine schematically illustrated in figure 4.159. Preliminary test results of square cross-section nozzles indicate that this geometry causes no significant loss in performance [Alger, 1976].

It should be noted, however, that most of the work to date lias centered around design of machines uniquely suited for the thermodynamic conditions of the high temperature resources in the Imperial Valley; i.e., the $300^{\circ} \mathrm{C}$ reservoirs with wellhead conditions listed in table 4.21 . Work is in progress to explore application and design of total flow expanders and systems for the lower temperature fluids, but finalized results are not yet available.

Momentum transfer in the turbine blading. One of the main factors contributing to losses in wheel efficiency is the interaction of liquid droplets with the turbine blade during passage of the two-phase supersonic flow. As a result of experimental work and analytical studies, Comfort [1977a, b] has estimated the range of possible wheel efficiencies, as shown in figure 4.163. The lower bound represents very conservative conditions as noted, while the upper bound represents an ideal efficiency based on geometry 


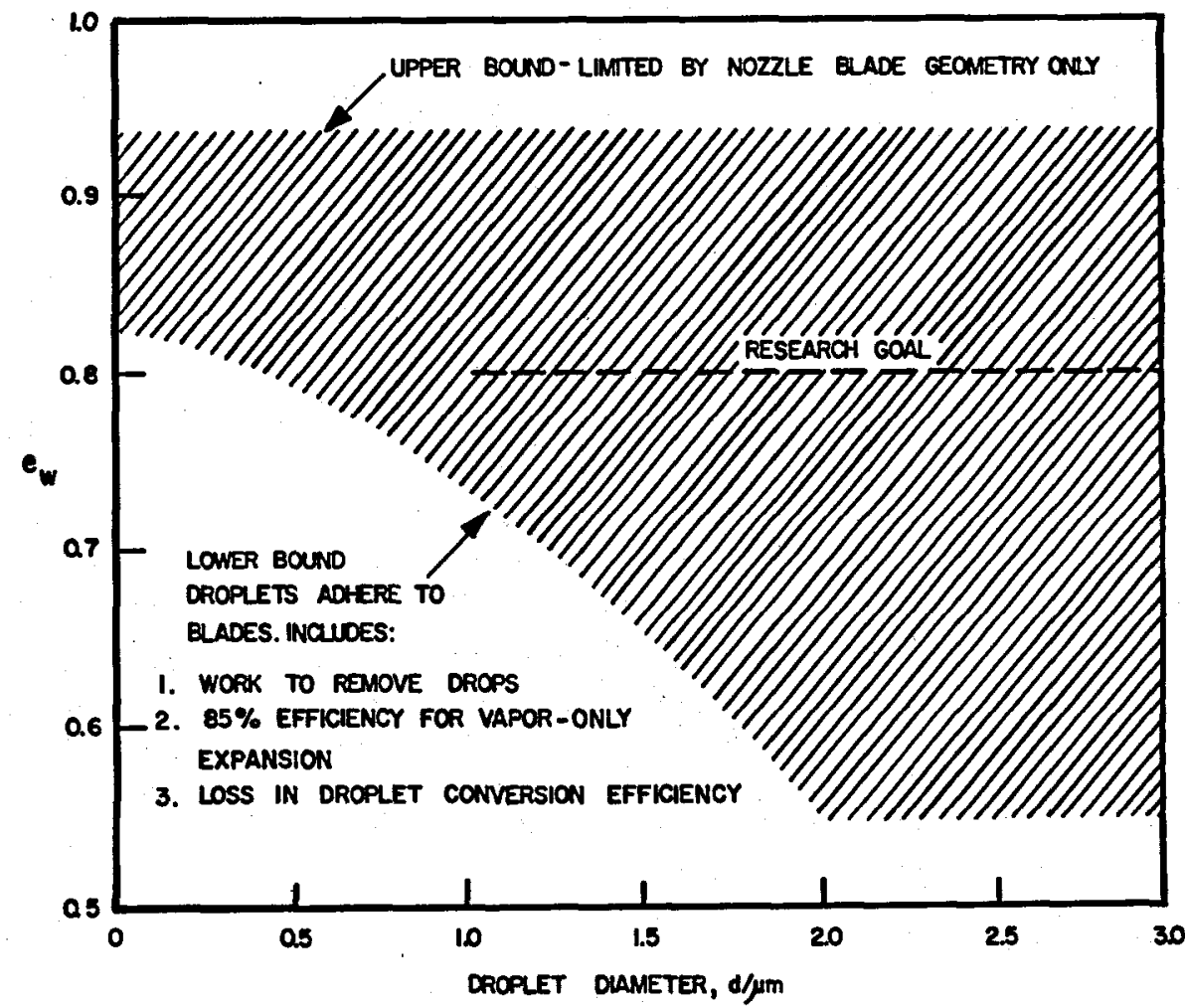

Figure 4.163-Estimated range of possible wheel efficiencies for an axial llow impulse turbine.

alone. There is some preliminary experimental evidence that droplet sizes less than 6 microns may be typical. The point of figure 4.163 is that there is a wide latitude of possibilities, and much experimental work is yet to be done before wheel efficiencies can be more accurately determined. It should be noted in passing, however, that even if the lower bound of $55 \%$ cannot be exceeded, the Total Flow process via the impulse turbine competes favorably with the single flash system. This may have future significance since the Total Flow concept may be the only possibility for utilization of the high temperature, but high salinity, brines.

The fundamental problem is to produce for inlet to the blade entrained liquid subdivided into droplets small enough to allow the vapor drag forces to direct them around the blade curvature without deposition. If liquid strikes the blade it adheres and is thrown radially outward (Coriolis loss) causing a loss in efficiency. Assume that the liquid content enters the blade as a size-monodisperse population of droplets of diameter $d$. If drop collision, coalescence and deposition is absent, it is a straightforward task to write the equations of motion for droplet traversal as shown below. 
Frovre 4.164-Notation for droplet trajectory calculations.

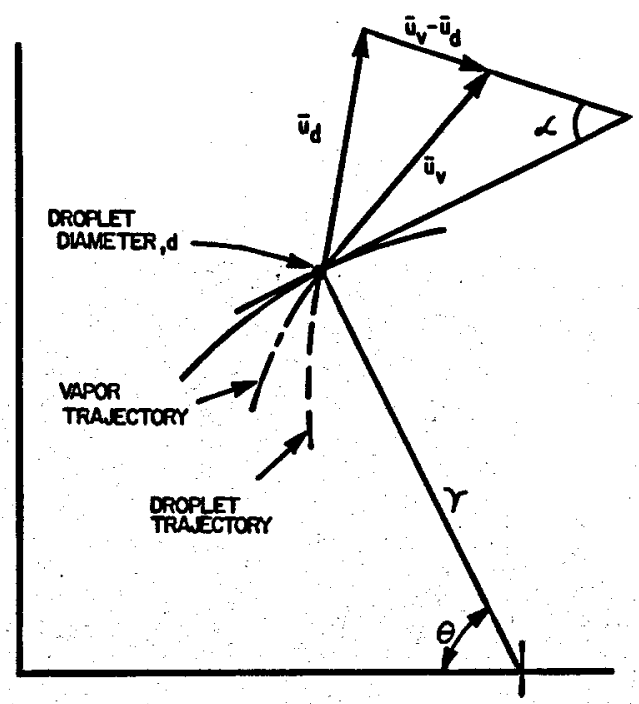

Referring to Fig. 4.164

$$
\begin{aligned}
& F_{\mathrm{drag}}=\frac{1}{2} \rho_{0} C_{p}\left(\frac{\pi d}{4}\right)^{2}\left(\bar{U}_{0}-\bar{U}_{d}\right)\left|\bar{U}_{0}-\bar{U}_{d}\right| \\
& V_{\mathrm{rel}}=\sqrt{\left(U_{v_{\theta}}-U_{d_{\theta}}\right)^{2}+\left(U_{\mathrm{v}_{r}}-U_{d_{r}}\right)^{2}} \\
& =\sqrt{\left(U_{v_{\theta}}-r \frac{d \theta}{d t}\right)^{2}+\left(U_{v_{r}}-\frac{d r}{d t}\right)^{2}} \\
& C_{D}=F\left(\frac{p_{B} V_{\mathrm{rel}} d}{\mu_{\mathrm{v}}}\right) \\
& F_{\mathrm{drag} \theta}=\left|\bar{F}_{\mathrm{drag}}\right| \cos \alpha, \quad F_{\mathrm{drag} \text { r }}=\left|\bar{F}_{\mathrm{drag}}\right| \sin \alpha \\
& \cos \alpha=\frac{U_{v_{\theta}}-r d \theta / d t}{V_{\text {rel }}} ; \quad \sin \alpha=\frac{U_{v_{\mathrm{r}}}-\frac{d r}{d t}}{V_{\text {rel }}}
\end{aligned}
$$

The equations of motion are:

$$
\begin{gathered}
\theta: \frac{1}{2}\left(\frac{\pi d^{2}}{4}\right) \rho_{D} C_{D}\left(U_{\theta \theta}-\frac{r d \theta}{d t}\right) V_{\mathrm{rel}}=\rho_{d}\left(\frac{\pi d^{3}}{6}\right)\left(r \frac{d^{2} \theta}{d t^{2}}+2 \frac{d \theta}{d t} \frac{d r}{d t}\right) \\
r: \frac{1}{2}\left(\frac{\pi d^{2}}{4}\right) \rho_{D} C_{D}\left(U_{\nabla_{r}}-\frac{d r}{d t}\right) V_{\mathrm{rel}}=\rho_{d}\left(\frac{\pi d^{3}}{6}\right)\left(\frac{d^{2} r}{d t^{2}}-r\left(\frac{d \theta}{d t}\right)^{2}\right)
\end{gathered}
$$

Numerical solutions of these two coupled equations give droplet trajectories for a given droplet size, initial slip, vapor velocity, and blade curva- 


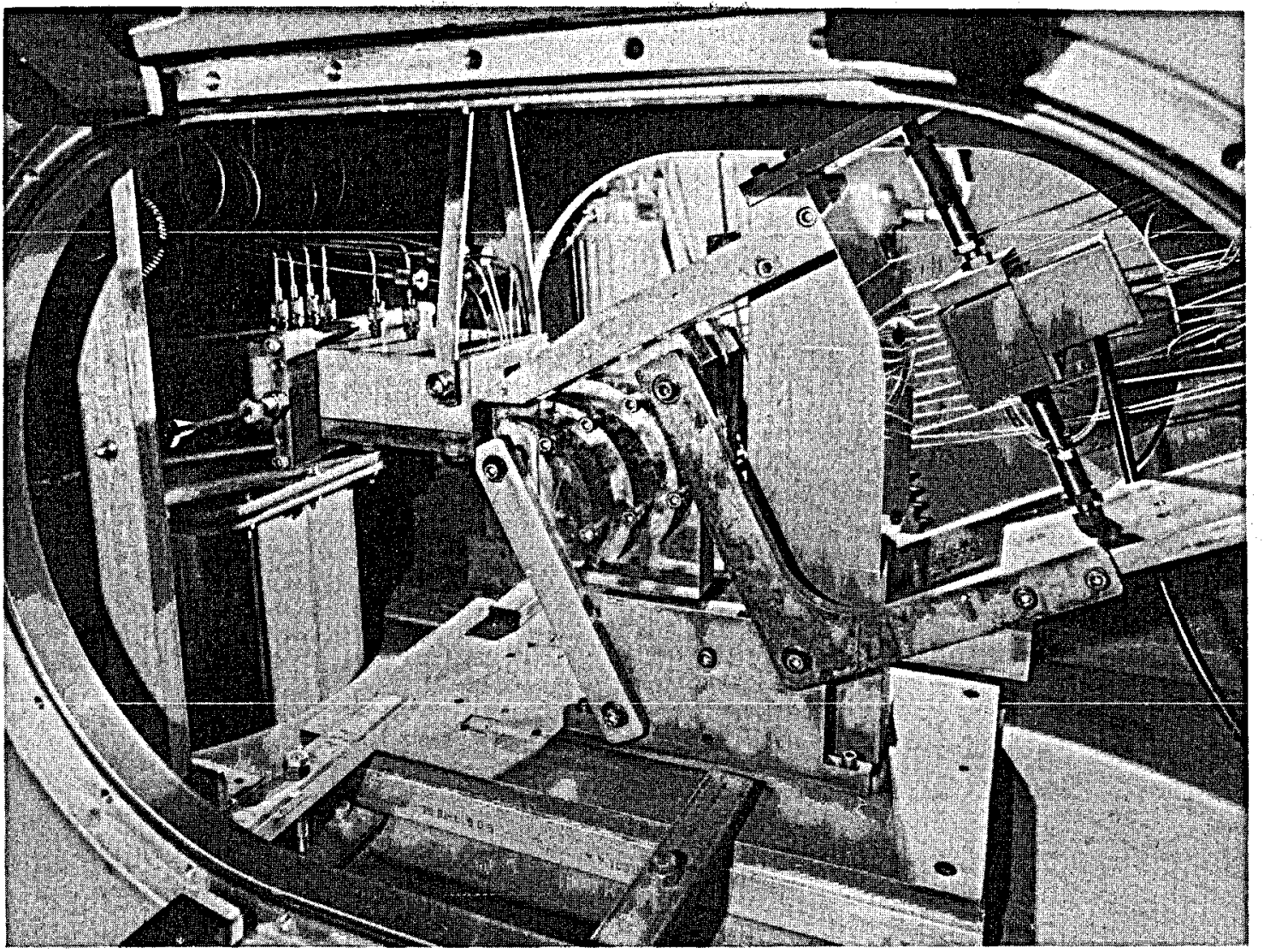

Figure 4.165-Apparatus for testing blade thrust and pressure distribution. (Photo by Lawrence Livermore Laboratory.) 
ture. Experimental work has been completed on characterizing droplet/ blade interactions, and effects on blade efficiency; i.e., the ability of the blade to transfer the momentum of the two-phase flow from the nozzle. Currently, this consists primarily of static blade testing with the aparatus, shown in figure 4.165, which allows both blade thrust and pressure distribution measurements. The nozzle is designed to produce a fluid velocity equal to the relative fluid velocity over a moving blade so that the static test system is an approximate kinematic equivalent of the actual conditions. This device will be used for detailed investigations of droplet/blade interactions, blade configurations, and verification of analytical techniques to be ultimately used for turbine design.

The results of these experiments indicate that the droplet trajectory profiles generally follow the calculated paths by comparing photographs of the flow around blades (statically positioned) with the calculated trajectories as shown in figure 4.166. These experiments and additional analytical work on droplet/blade interaction and two dimensional/two-phase flow indicate that droplet sizes, for the test conditions relevant to the $300^{\circ} \mathrm{C}$ fluids (table 4.21), are between 2 and 10 microns, with the average being about 6 microns.

The major research effort will be directed towards reducing droplet diameters to less than 1 micron. The effect of droplet size on wheel efficiency is shown in figure 4.167. The lower dashed curve is consistent with figure

STEAM ENTRY CONDITIONS AT A:

PRESSURE $103.4 \mathrm{KPa}\left(15,16 \mathrm{bb} / \mathrm{in}^{2}\right)$

TEMPERATURE $.100^{\circ} \mathrm{C}\left(212^{\circ} \mathrm{F}\right)$

VELOCITY $427 \mathrm{~m} / \mathrm{s}(1400 \mathrm{ft} / \mathrm{s})$

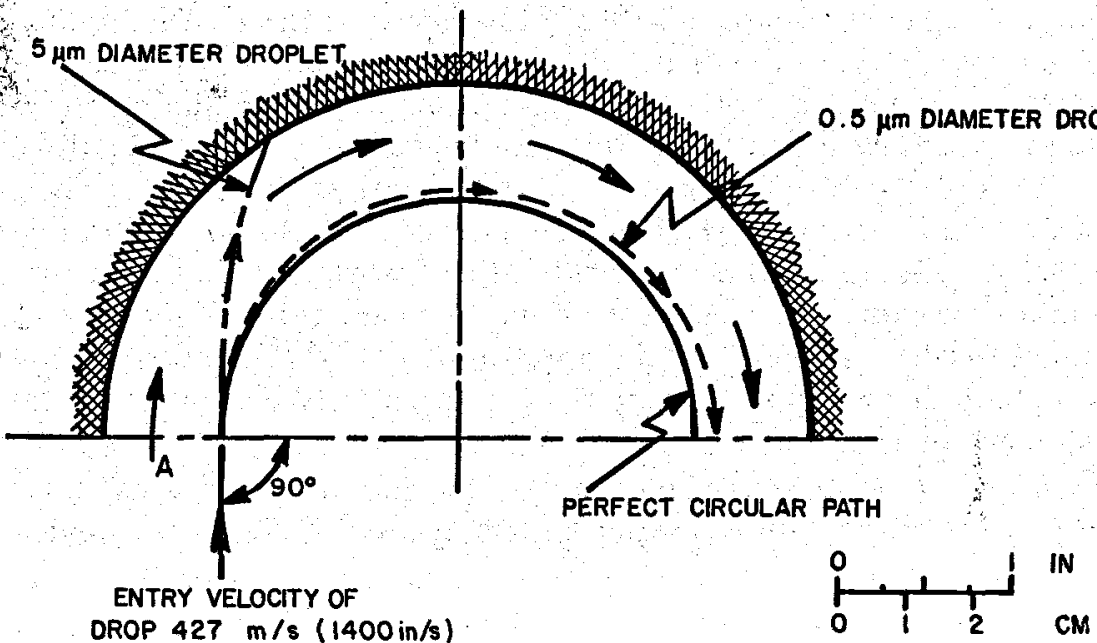

Figure 4.166-Calculated trajectories of droplets traversing a $180^{\circ}$ turn. Steam entry condition at $\mathrm{A}$ : Pressure $103.4 \mathrm{kPa} .\left(15.16 \mathrm{lb} / \mathrm{in}^{2}\right)$; temperature $100^{\circ} \mathrm{C}\left(212^{\circ} \mathrm{F}\right)$; velocity $427 \mathrm{~m} / \mathrm{s}(1400 \mathrm{ft} / \mathrm{s})$. 


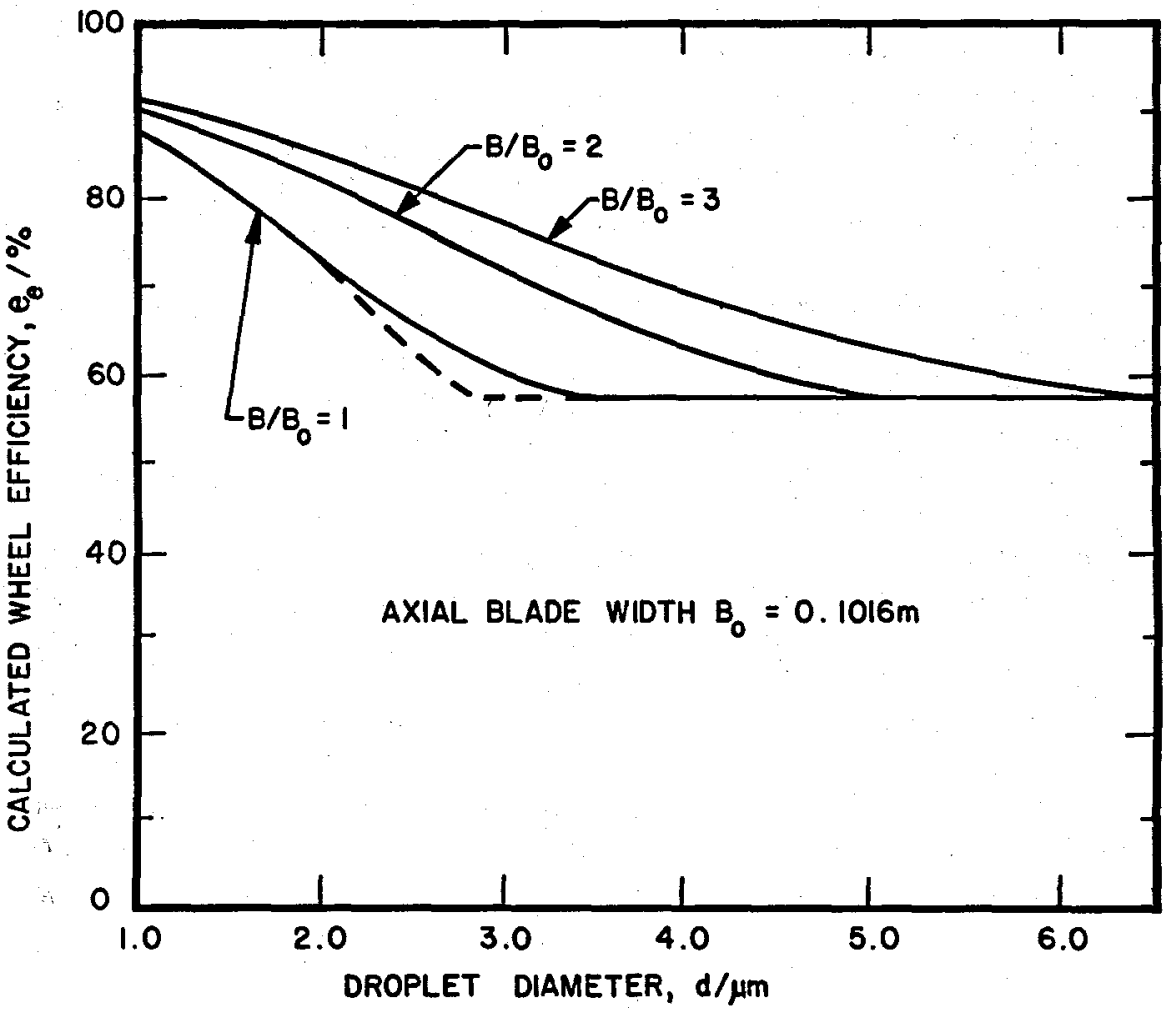

FigURE 4.167-Idealized rotor performance as a function of droplet diameter for various blade widths.

4.164 for a symmetric blade of $0.1016 \mathrm{~m}$ (4 in) axial width, $B_{0}$. The significant point here is that even if droplets cannot be reduced to less than a micron, increasing blade width will partially compensate by adding about $10 \%$ to the wheel efficiency. The major gain in efficiency, of course, will be made by droplet size reduction. There are several methods for droplet breakup currently being investigated. Final conclusions on achievable engine efficiencies must await the results of this work and testing of turbines of advanced design, incorporating the necessary features for droplet breakup. In order to determine the applicability of the impulse turbine for two-phase flow, performance tests of a specifically designed turbine have been completed.

Performance tests. A single stage, axial flow, impulse turbine has been designed and tested at reduced output, since only a single nozzle was usedabout 5\% admission [Comfort, 1977a]. A special rotor was built so that wide blades with sharp leading and trailing edges could be designed in anticipation of special problems associated with two-phase fluid dynamics. Blade width was made large to increase the radius of curvature of the flow path so that droplets would have a maximum proability of passing between 
the blades without impacting their surfaces. Sharp edges were necessary in order to minimize phenomena associated with supersonic relative velocities within the blade passage.

In order to simplify construction, shorten development time, and to minimize costs, the rotor was designed with integral blades and was fabricated from a 7075-T6 aluminum forging. Aluminum was chosen for its high strength-to-weight ratio and machinability.

Figure 4.168 shows the rotor before an electrodeless nickel plating was applied to the blede surfaces for water droplet erosion protection. The plated rotor is not suitable for brine exposure. It was designed only to have sufficient life for the laboratory testing program. The final machining on the rotor hub was completed after plating and the finished part was then assembled with the steel shafting. The rotor assembly was balanced, and assembled into the rotor housing (figure 4.169). A single nozzle was used for the machine because of limited flow-rate capabilities of the test facility. The nozzle was suspended with a four-bar linkage so that axial thrust could be measured independently during performance testing of the expander, figure 4.170 .

A dynamometer assembly, consisting of hydraulic pump/motor was used both as a brake and as a motive source. Performance of the expander was measured by using the brake mode, while disk friction and windage losses were measured by using the hydraulic motor to drive the rotor.

The operating conditions used for the performance testing are summarized in table 4.23. These operating conditions are selected to be representative of the thermodynamic conditions of well outputs from the reservoirs of the Salton Set Geothermal Field.

TABLE 4.23-Test conditions

Fluld state at nozzle entrance
$P,=2.53 \mathrm{MPa}\left(867 \mathrm{lb} / \mathrm{in}^{2}\right)$
$\boldsymbol{c}_{0}=$ quality $=14 \%$
$T_{0}=224^{\circ} \mathrm{C}\left(434^{\circ} \mathrm{F}\right)$
$h_{0}=1.2 \mathrm{MJ} / \mathrm{kg}(626 \mathrm{Btu} / \mathrm{lbm})$
$m=0.59 \mathrm{~kg} / \mathrm{s}(1.31 \mathrm{lbm} / \mathrm{s})$

Wrhaust pressure and temperature $P_{0}=0.0137 \mathrm{MPa}\left(2 \mathrm{lb} / \mathrm{ln}^{2}\right)$ $T_{0}=52^{\circ} \mathrm{O}\left(126^{\circ} \mathrm{H}\right)$

The maximum engine efficiency for the single-nozzle test was observed to be $23 \%$ at a blade speed ratio (the ratio of the mean blade speed to the homogeneous isentropic mixture velocity of the fluid exiting the nozzle) of 0.24. Testing was done on three separate occasions and showed good repeatability. Operation was smooth and quiet. The nozzle thrust coefficient was 0.83 during testing with the rotor. This was lower than the 0.94 thrust coefficient measured during previous tests of the nozzle alone. 


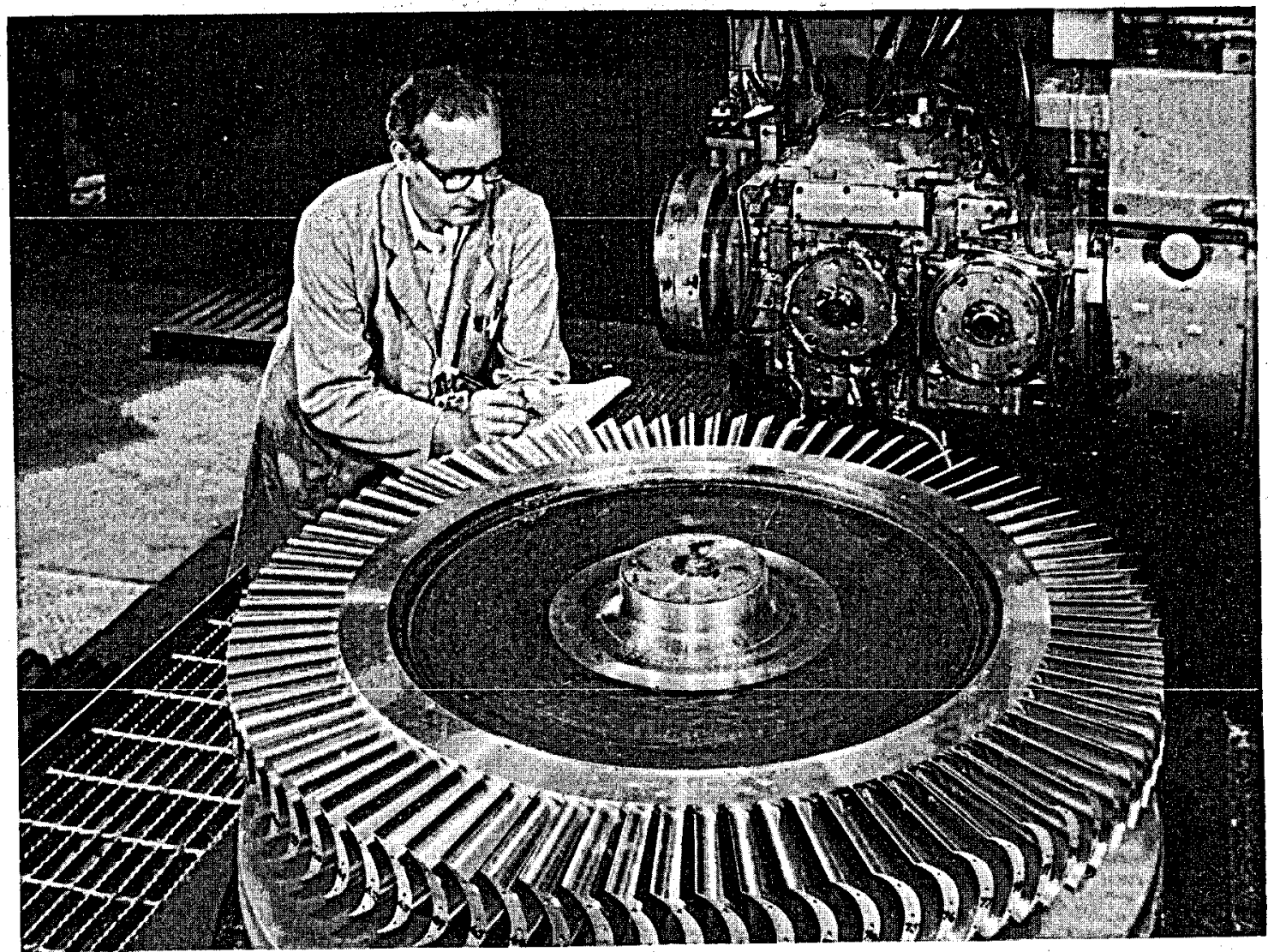

FraUke 4.168-Completed rotor before plating (Photo by Laurence Livermore Laboratory.) $\mathrm{C}$ 


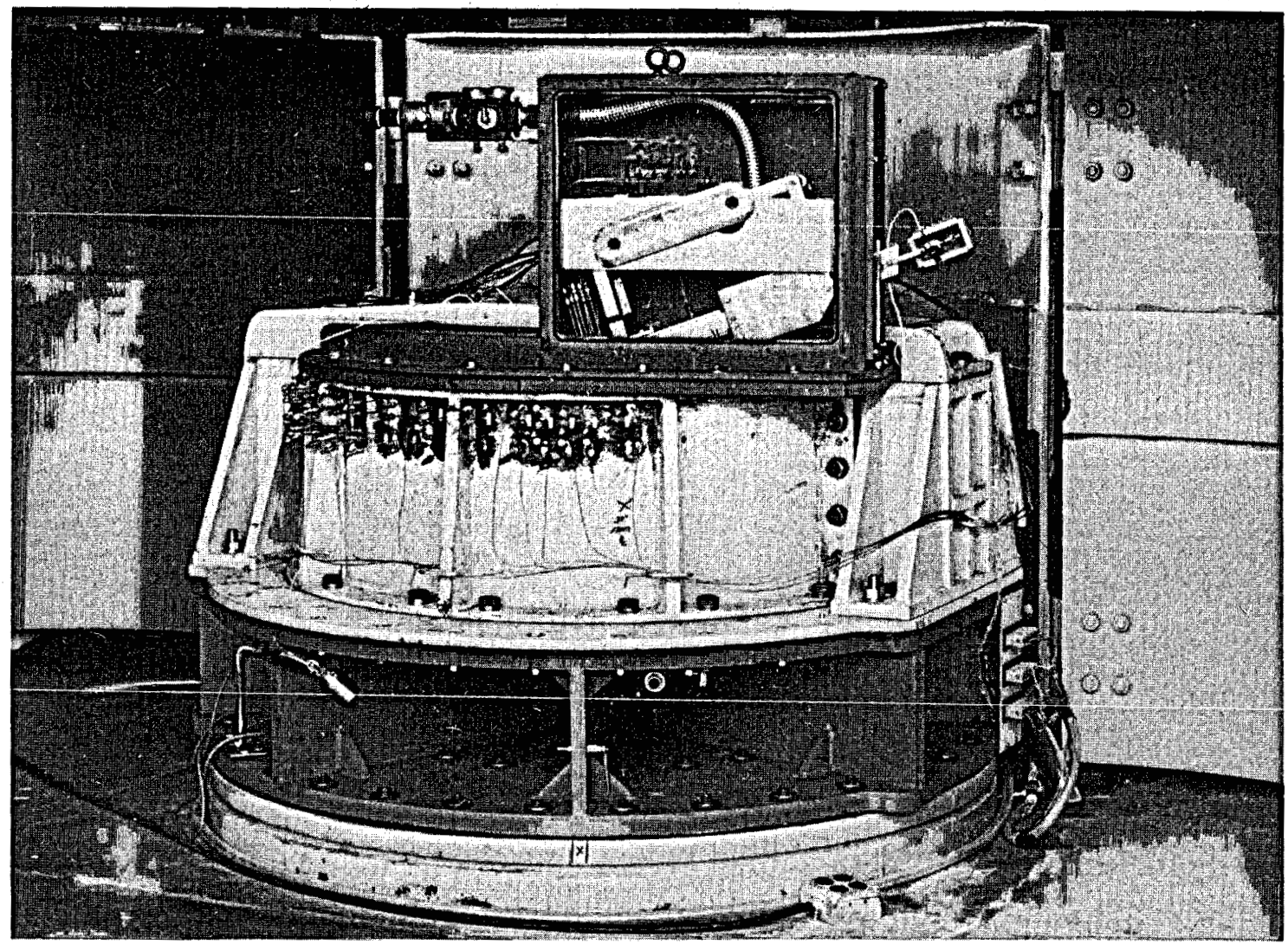

FIGURE 4.170-Measuring the nozele axial thrust during performance testing of the expander. (Photo by Lawrence Livermore Laboratory.)

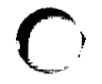


The nozzle thrust coefficient, $C_{r}$, is defined as:

$$
C_{T}=\frac{T}{\dot{m} V_{s}}
$$

where $T$ is the measured thrust, $\dot{m}$ is the measured mass flow rate, and $V$, is the homogeneous mixture isentropic velocity. Although radial pressure gradients associated with blade rotation are not as severe in two-phase conditions as would be expected in standard vapor turbines, they were probably large enough to explain the lower performance. Larger separation between the nozzle and rotor as well as improved nozzle design should eliminate this problem.

A numerical model was developed and was used to predict expander performance. The model included calculation of droplet trajectories within the blade passage to determine what happened to the liquid. In addition to standard vapor turbine losses, special losses associated with droplet impact and removal from the blades were included in the model. Static cascade measurements in two-phase flow were used to determine the performance of blades identical to those on the rotor. This information was used to normalize the vapor flow portion of the model. Measured values of combined disk friction and windage were used to normalize the disk friction and windage model in the perdictive technique.

The model was designed to allow extrapolations of performance both for full admission and for changes in droplet diameter. Single-nozzle performance predictions were very successful, as will be shown, and encourage belief in the validity of the extrapolations.

The present numerical model is only adequate for impulse designs and cannot be used to select detailed blade contours because the vapor and liquids are not fully coupled; i.e., droplets are affected by the vapor, but the vapor is assumed to be unaffected by the droplets and thermodynamic effects arising from paddle work are assumed to be absent. In order to design adequately more advanced blade and nozzle contours, a completely coupled model for two-dimensions, based on an existing one-dimensional two-phase flow calculation technique is necessary and is currently being developed.

The details [Comfort, 1977b] of the numerical model are beyond the scope of this document. To provide the reader with some insight, however, into the extrapolation between the single-nozzle and full admission results, a simplified model will be presented here to demonstrate some of the characteristics to be expected.

Assuming for this simplified model that no slip exists between the vapor and liquid entering the turbine blades, one may write the expression for blade efficiency, $e_{b}$. For an impulse turbine with the ratio of mass flow rate of vapor to mixture equal to $x$, relative velocity coefficients for the vapor 
and the liquid equal to $\lambda_{\nabla}$ and $\lambda_{L}$, blade speed ratio (blade speed/nozzle velocity) $\beta$, and nozzle angle $\theta$ to the plane of the wheel, one may write:

where

$$
e_{b}=2 \beta\left[x\left(1+\lambda_{V}\right)+(1-x)\left(1-\lambda_{L}\right)\right](\cos \theta-\beta)
$$

$$
\lambda_{V}=\left(\frac{V_{r_{2}}}{V_{r_{1}}}\right)_{\text {vapor }} \quad, \quad \lambda_{L}=\left(\frac{V_{r_{2}}}{V_{r_{1}}}\right)_{\text {uquld }}
$$

$\nabla_{r}$ is a relative velocity and the subscripts 1 and 2 refer to blade entry and exit.

For a given blade speed ratio and nozzle angle, no higher conversion efficiency can be achieved than that indicated by equation 4.160 with

$$
\lambda_{F}=\lambda_{L}=1
$$

If all of the droplets impact the blade, then $\lambda_{L}=0$, which reduces the efficiency of the liquid kinetic energy conversion by $50 \%$. If some of the liquid escapes impact, the blade efficiency expression must be expanded to include those effects. To maintain a simplified approach, the analysis herein will assume that all of the liquid impacts the blade, i.e., $\lambda_{L}=0$. Actual numerical results to be presented in the next section do not require this simplification.

The optimum speed ratio can be defined by differentiating $e_{b}$ with respect to $\beta$ and equating the derivative to zero:

whence

$$
\frac{\partial e_{b}}{\partial \beta}=0=2\left[x\left(1+\lambda_{V}\right)+(1-x)\left(1+\lambda_{L}\right)\right][\cos \theta-2 \beta]
$$

$$
\beta_{\mathrm{opt} \text { Imum }}=\frac{1}{2} \cos \theta
$$

To convert the blade efficiency to an engine efficiency, $e_{t}$, the losses due to disk friction and to radial liquid removal, $e_{d}$ and $e_{c}$, must be subtracted from the blade efficiency modified by the square of the nozzle thrust coefficient:

where

$$
e_{t}-C_{T}^{2}\left(e_{b}-e_{c}-e_{d}\right)
$$

$$
\begin{gathered}
e_{c} \propto a f\left(\beta^{2}\right) \\
e_{d} \propto g\left(\rho, \beta^{2.85}\right)
\end{gathered}
$$

where $f$ and $g$ denote "function of ..." The quantity $a$ in the expression for the liquid removal represents the fraction of the liquid mass flow rate which must be removed radially, while $\rho$, in the disk friction and windage loss expression refers to the effective density of the fluid surrounding the rotor. 
The ideal optimum speed ratio is valid only when the disk friotion and windage, and pumping losses are small relative to the first term. For a single-nozzle test, the disk friction and windage and liquid removal losses can severely affect the blade speed ratio associated with the peak efficiency, shifting it toward a lower value. This, in turn, decreases the blade efficiency because the blade speed ratio is reduced. For full admission, the disk friction and windage loss, for a given blade speed ratio, is inversely proportional to the mass flow rate, while the liquid removal loss is proportional to the mass flow rate if all droplets impact the blade and are radially removed. Thus, the liquid removal loss is not diminished relative to power output for increased admission, whereas the disk friction and windage loss fraction is reduced. As admission is increased, the optimum blade speed ratio increases, but since the liquid removal loss is proportional to the blade speed ratio squared, the loss fraction increases.

With this brief introduction to some of the phenomena involved, the results (from the numerical model) will next be compared with the experimental results and then the numerical model will be used to extrapolate to full admission and to an advanced design. Figure 4.171 vertifies that results from the numerical model compare very well with the experimental results. As noted, the upper calculated band assumes that disk friction and windage losses are associated with the vapor density only, while the lower band assumes that they are a function of the two-phase mixture density. The upper and lower limits of each of the bands are determined by nozzle modeling uncertainty and are fully described by Comfort [1977b]. The results of static cascade testing indicated that all entering droplets impacted the blade passages and left at negligible velocity. Droplet size estimates indicate that the droplets are probably between 2.7 and 7 microns in diameter. Results of the performance predictions indicate that they are greater than 2.2 microns because this is the largest size of droplet that can pass through the blade passage without impact. Hence, if droplets are greater than 2.2 microns in diameter, all droplets impact the blade passage-as is indicated by the results. The blade speed ratio indicated in figure 4.171 for the peak power point of the experimental data lies between the two calculated bands. This is significant because, as was shown, the optimum blade speed ratio for this impulse turbine is primarily dependent apon the disk friction and windage and losses associated with radial removal of liquid droplets which have impacted the blades. The fact that the optimum blade speed ratio for the bounding calculations spans the measured optimum speed ratio indicates that the mechanisms of disk friction, windage, and liquid removal are well modeled. Assuming all droplets impact the blades and are removed radially, one would expect that the vapor density would best approximate the fluid surrounding the majority of the rotor. The results indicate that this is not the case. Liquid droplets may be splashing off the rotor housing walls and remixing with the vapor, increasing the effective density of the fluid mixture around the rotor and 


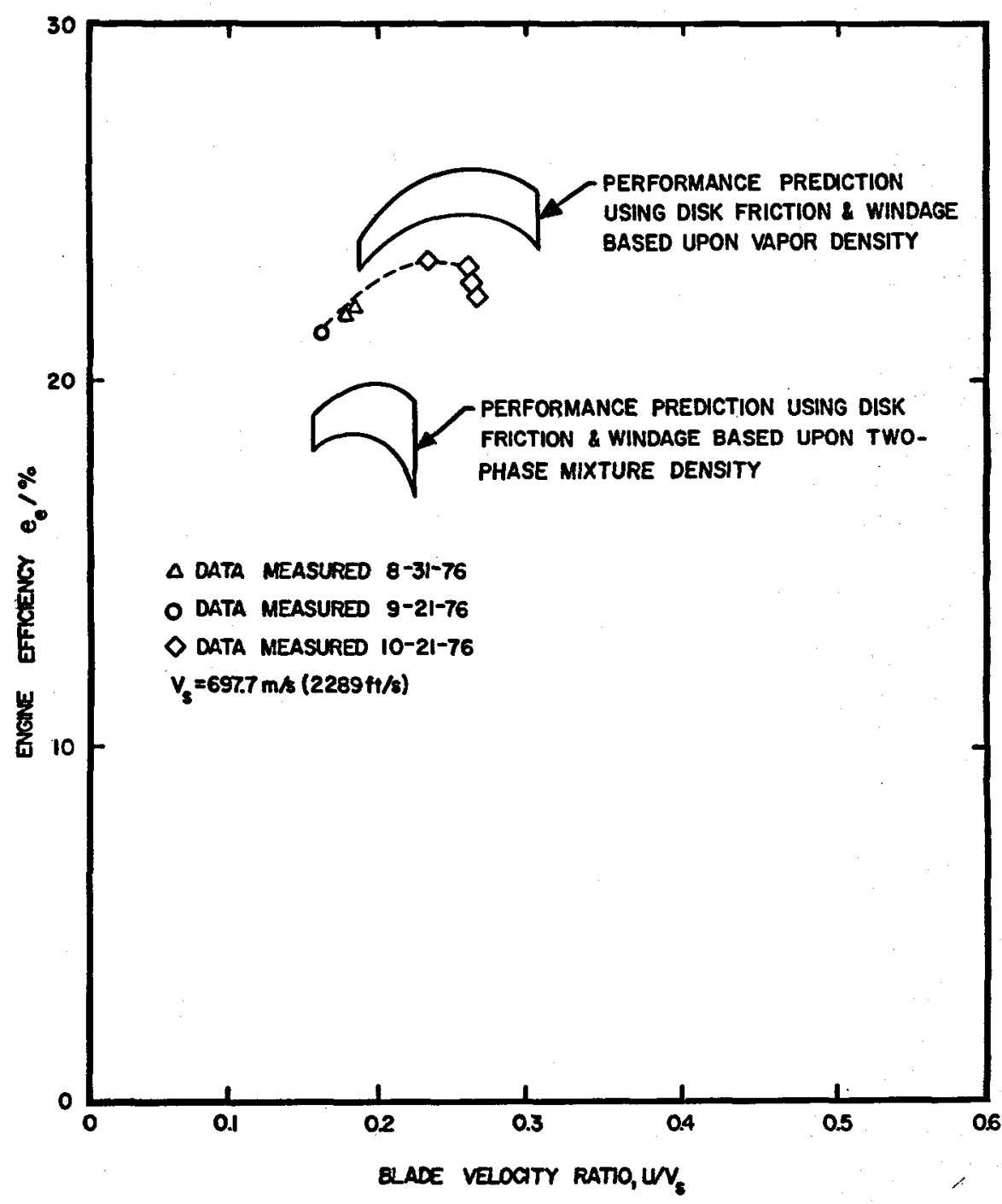

FIGURE 4.171-Comparison of experimental data with turbine performance model predictions.

consequently increasing the friction forces in addition to the power necessary to accelerate relatively low velocity water particles.

Figure 4.172 shows extrapolations to a full admission performance for the existing rotor design and to an advanced design. It should be noted that the full admission results reflect the nozzle thrust coefficients previously measured for the nozzle in the laboratory. Otherwise, the calculation contains the same parameters for the full admission calculation as for the partial admission calculation. The increase in performance is due primarily to the diminution of the effects of disk friction and windage 


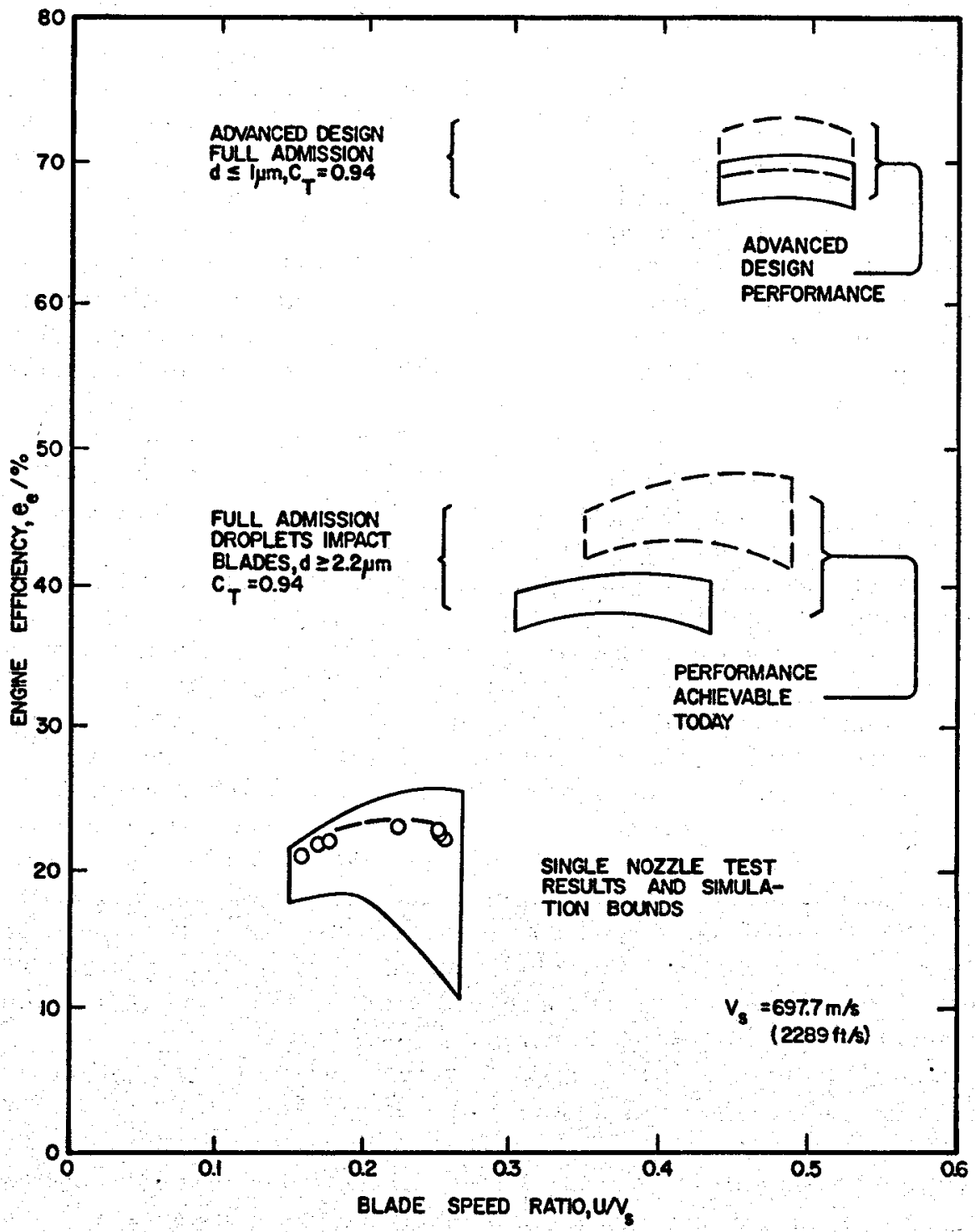

FIGURE 4.172-Extrapolations using the numerical performance model.

since this loss becomes very small in comparison with full admission power input, while it is rather large compared with that of partial admission. This diminution allows the rotor to attain a higher speed ratio, enhancing the engine efficiency. Two bands are used to represent the extrapolated performance of a full admission design for droplet diameters greater than 2.2 microns, and with an assumed nozzle thrust coefficient of 0.94. The difference between the upper and lower bands (dashed and solid lines, respectively) is the radial liquid removal losses. The loss associated 
with the radial removal of liquid from the blades is included in the lower band (solid lines). Though this loss is certain in the single-nozzle design, it is not clear that it will exist in the full admission machine because the nearly continuous flow may force the liquid through the blades without significant radius change. The upper band (dashed lines) indicates the displacement of the lower band (solid lines) due to removal of the losses associated with radial pumping of the liquid from the blades. The upper bound of both bands is calculated assuming disk friction and windage loss is controlled by the vapor density and that the slip ratio (the ratio of average liquid velocity to average vapor velocity at the exit of the nozzle) is approximately 0.9 . The lower bound of both bands is calculated assuming that the disk friction and windage loss is controlled by the mixture density and that the slip ratio is approximately 0.7. For the full admission performance, the slip ratio, rather than the fluid density assumed for the disk friction and windage, is the major cause of the difference between the upper and lower bounds of each band.

The advance design assumes that the droplet size has been reduced to 1 micron, and that the thrust coefficient remains 0.94 . Under those circumstances it would be expected that the liquid and vapor leave the nozzle with very nearly the same velocity. The upper bound of the lower band (solid lines) is based upon vapor turbine correlations of vapor friction losses and the assumption of vapor-controlled disk friction and windage. The lower bound of the lower band is based upon blade vapor performance consistent with results from static cascade tests and assumes that the mixture density controls disk friction and windage. The upper band for this case (dashed lines) indicates the performance if liquid radial removal losses are omitted. The change resulting from the omission is not as great as in the previous case (full admission with droplet diameters greater than 2.2 microns) because only a small fraction of the liquid impacts the blades when the droplets are 1 micron in diameter.

The single-nozzle, full admission extrapolation, and advanced design results may be compared in another way. Table 4.24 represents a summary of losses associated with the peak efficiency points corresponding to the data and extrapolations shown in figure 4.172. It should be remembered that this table does not indicate causality, but rather a loss summary at a particular operating condition. For example, from the single nozzle results, one might conclude that the disk friction is not a deterministic loss mechanism. However, disk friction is not an independent function, just as the other losses listed are not independent functions. In the case of disk friction, its nearly cubic relationship with blade speed ratio and its large relative magnitude compared to the power output capability of a single nozzle test forces the blade speed ratio to be considerably off-optimum. This, in turn, results in the significant loss ("geometry and nonoptimum blade speed ratio") which results directly from blade efficiency relationships as previously shown. 
TABLe 4.24-Loss distribution at peak efficiencies for single nozzle and for extrapolations to full admission and advanced designs

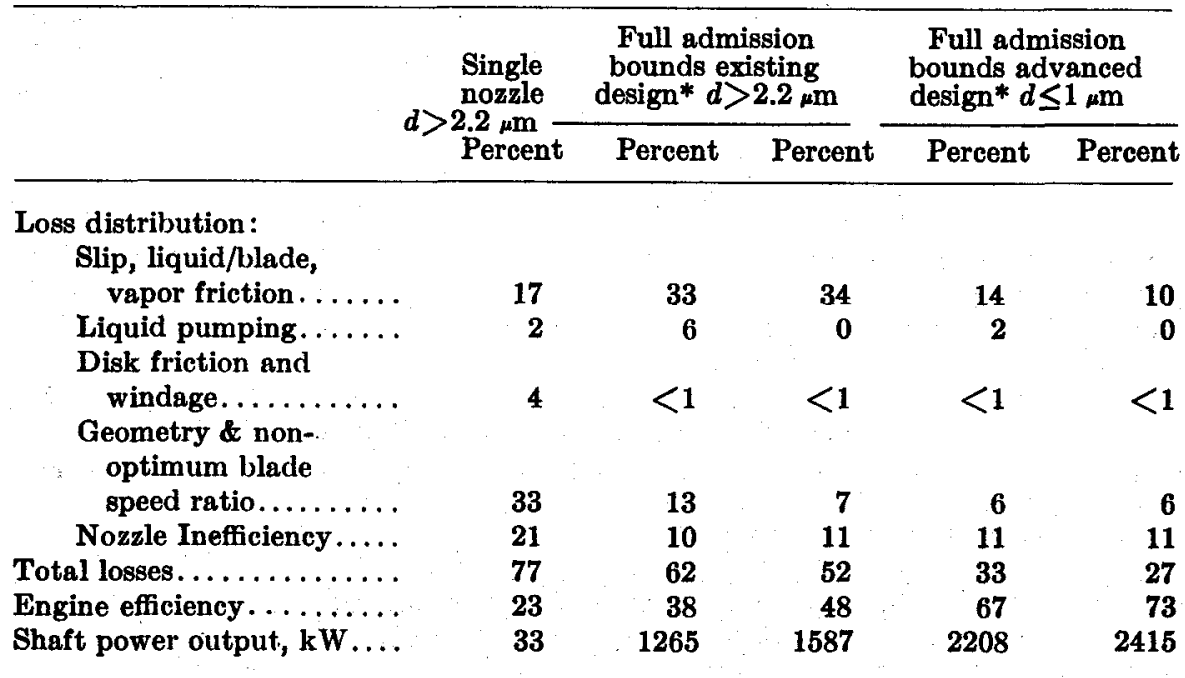

Note: Shaft output assumes no losses in raw fluid distribution system for full admission.

*23 nozzles.

Performance potential of the impulse turbine. In summary, considerable improvement can be expected in turbine performance as a result of droplet size reduction. The performance indicated for droplets smaller than 1 micron also requires that sufficient two-dimensional analytical methods are developed to improve two-phase blade and nozzle design. Indoed, it appears possible to achieve the research goal of 70 percent engine efficiency for the machine. Using the test conditions (table 4.23) as representative, a $70 \%$ engine efficiency converts to a resource utilization rate (water rate) for pure water of $21 \mathrm{~kg} / \mathrm{kWh}(47 \mathrm{lb} / \mathrm{kWh}$ ) gross, i.e., exclusive of the parasitic loads which would occur in a typical power plant application. This represents a significant improvement over conventional conversion systems operating with the same conditions. The important implication is that the number of wells required for a given power output is correspondingly reduced, which in turn, reduces the initial capital investment since the cost of wells is dominant.

The present state-of-the-art for the impulse turbine is already competitive with existing systems (table 4.25 ). The $38-48 \%$ engine efficiency, obtained from the test results, converts to $87-69 \mathrm{lb} / \mathrm{kWh}$ respectively. Also, preliminary cost estimates indicate that a 2 MWe total flow system, including condensing and cooling, and fabricated from brine-tolerant materials, would cost about $750 \$ / \mathrm{kW}$. This is clearly already competitive with conventional systems which generally are estimated to cost about $800 \$ / \mathrm{kW}$ for $50 \mathrm{MWe}$ sizes. Even without significant improvements in 
TABLE 4.25-Resource utilization performance comparisons

Water rate*

$\mathrm{lb} / \mathrm{kWh}$

(gross)

Total flow impulse turbine system:

Inlet: $2.53 \mathrm{MPa}\left(367 \mathrm{lb} / \mathrm{in}^{2} \mathrm{abs}\right), 14 \%$ quality

Exit: $13.8 \mathrm{kPa}\left(2 \mathrm{lb} / \mathrm{in}^{2} \mathrm{abs}\right)$

Existing design-full admission extrapolation (38-48\% efficiencies) $\ldots \ldots \ldots \ldots 69-87$

Advanced design - full admission, $\left(70 \%\right.$ efficiency) ${ }^{* *} \ldots \ldots \ldots \ldots \ldots \ldots \ldots .47$

Other systems (calculated for same test conditions)

Single flash $(\mathbf{7 5} \%$ turbine efficiences) $\ldots \ldots \ldots \ldots \ldots \ldots \ldots \ldots \ldots \ldots \ldots \ldots$

Double flash $(\mathbf{7 7 \%}, \mathbf{7 8 \%}$ HP and LP turbine efficiencies) .......... 54

Helical rotor expander (50\% efficiencies with atmospheric exhaust) . . . . 110

*Pure water.

**Turbine engine efficiencies are quoted.

design, performance, and fabrication methods for production, the total flow impulse turbine is already competitive if the economics of geometric scaling are considered.

\subsubsection{Comparison of total flow expanders. In order to achieve their high-} est efficiencies, all expanders must be designed uniquely for site specific conditions. Hence, it is not possible to provide a detailed comprehensive comparison on all candidate expanders to provide a general assessment. Each resource type will likely require a special conversion system or combination of systems (hybrids). It is instructive, however, to estimate the spectrum of relative sizes to produce a nominal $10 \mathrm{MWe}$ (gross) from the range of wellhead conditions listed in table 4.21. Figure 4.173 summarizes calculations [House, 1976] comparing the single stage axial flow impulse turbine with a single stage helical rotor expander. Both machines are required to exhaust at $49^{\circ} \mathrm{C}$ (3.5 in $\mathrm{Hg}$ ), condensing temperature, and both are assumed to have 70\% engine efficiencies, even though this may be optimistic for the helical rotor expander. Rotor or wheel diameter $D$ is arbitrarily chosen as the size criterion. This is not entirely useful since the positive displacement devices will likely have lengths greater than the diameters, while the impulse turbine width is very much less than its diameter.

Figure 4.173 gives approximate diameter ranges as shown. These simple comparisons clearly indicate the size advantage of the impulse turbine. Although no comprehensive system study has yet been made, these results give some idea of relative machine sizes and, implicitly at least, give an indication of relative costs to be expected. Again, it should be emphasized that such a single parameter comparison must be viewed with caution. Site specific conditions, requirement for hybrid systems or combinations of expanders, and specialized applications will be important factors influ- 


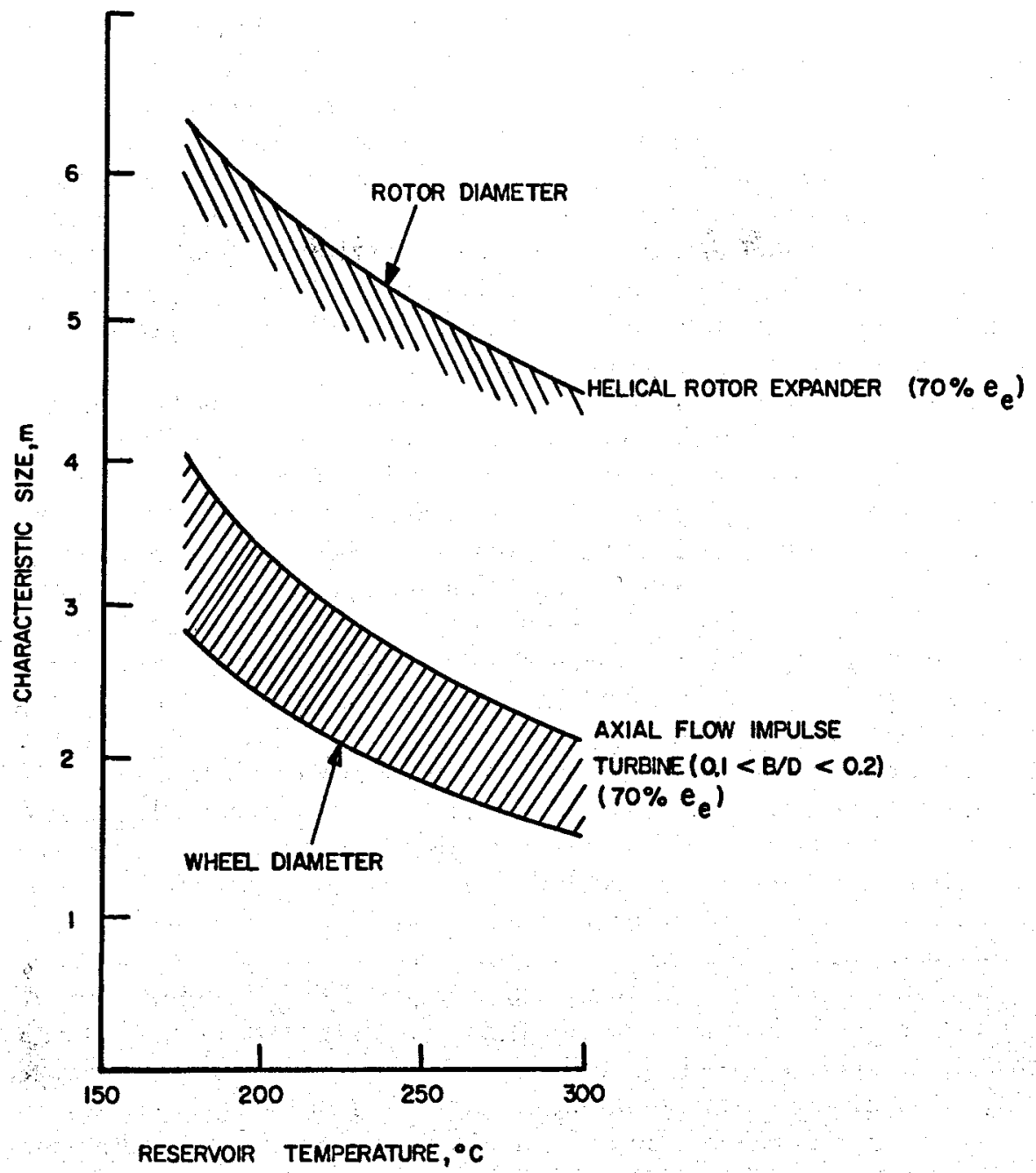

FIGURE 4.173-Relative sizes of total flow expanders working to $49^{\circ} \mathrm{C}(11.0 \mathrm{kPa})$ sink condition (10 MW capacity).

encing the ultimate choice of expanders. Nevertheless, the size advantage of the impulse device is a major consideration along with its relative mechanical simplicity. It should be mentioned that the helical rotor expander size could be reduced by accepting a loss in efficiency for a smaller size undergoing an incomplete expansion.

\subsubsection{Brine chemistry effects}

Even though this section is limited to discussion of energy conversion concepts, it would not be complete without some reference to the ability of the engines under review to withstand the hostile environment produced 
by operation on the high salinity geothermal brines. As previously noted, the helical rotor expander has an inherent feature for self-removal of scale, and the relatively low fluid velocities through the machine serve to reduce problems of erosion of the rotors. The impulse turbine, because of high fluid velocities across the blades, will require special materials for erosion resistance. Since all of the pressure (and temperature) drop occurs in the nozzle, a non-rotating component, there are several opportunities for scale control, such as keeping the nozzle wall hot, periodic flexing, "porous" nozzles for boundary layer control, chemical treatment of the brine to inhibit silica precipitation, and use of polymeric liners.

Considerable work has been completed toward field testing methods for scale control and materials evaluation for corrosion/erosion resistance [Tardiff, 1977]. We have established that scale deposition can be eliminated by acidification. Dropping the $\mathrm{pH}$ value from 5.6 at the wellhead to below 4.5 by addition of about 100 to $200 \mathrm{ppm}$ of hydrochloric acid completely eliminates scaling of nozzles when brine is expanding from wellhead (about $220^{\circ} \mathrm{C}$ ) to atmospheric conditions. Post-test examination of sectioned nozzles subjected to treated and untreated brine showed that control nozzles scaled at a rate of about $0.25 \mathrm{~mm} / \mathrm{h}$, while other test nozzles remained clean when exposed to acidified brine. A rough cost analysis shows that acidification by $\mathrm{HCl}$ will add less than $2 \mathrm{mils} / \mathrm{kWh}$ to the cost of energy, indicating that the method will likely prove economically feasible as well. Also, experimental evidence now exists that acidification delays the formation and stabilizes the colloidal suspension of silica in the cooled brine. Thus, plugging of reinjection wells by normally occurring suspended solids might be avoided.

In addition, concurrent tests of turbine blade materials subjected to the high velocity acidified brine streams leaving from the test nozzles indicate that titanium alloys, particularly $T \mathrm{~T}-6 \mathrm{~A} 1-4 \mathrm{~V}$, are corrosion/erosion resistant. Although test durations were generally less than $100 \mathrm{~h}$, the results are encouraging. The reader is referred to chapter 6 for a detailed discussion of the problems involved in brine utilization.

\subsubsection{A possible total flow system}

Although there are not yet precise indicators of the outcome of current geothermal development efforts, it is likely that each system will find a unique place. The present view is that the Total Flow Process will, however, emerge as a reality in some form. One possible system utilizing the impulse turbine is shown in figure 4.174 which is an artist's conception synthesizing the technical facts currently available. The basic element is a horizontal axial flow turbine wheel fed by fluid passing through nozzles spaced around the periphery. Condensing would be accomplished by a modified barometric condenser designed to separate the vapor fraction from the liquid in order to isolate the cooling system. 


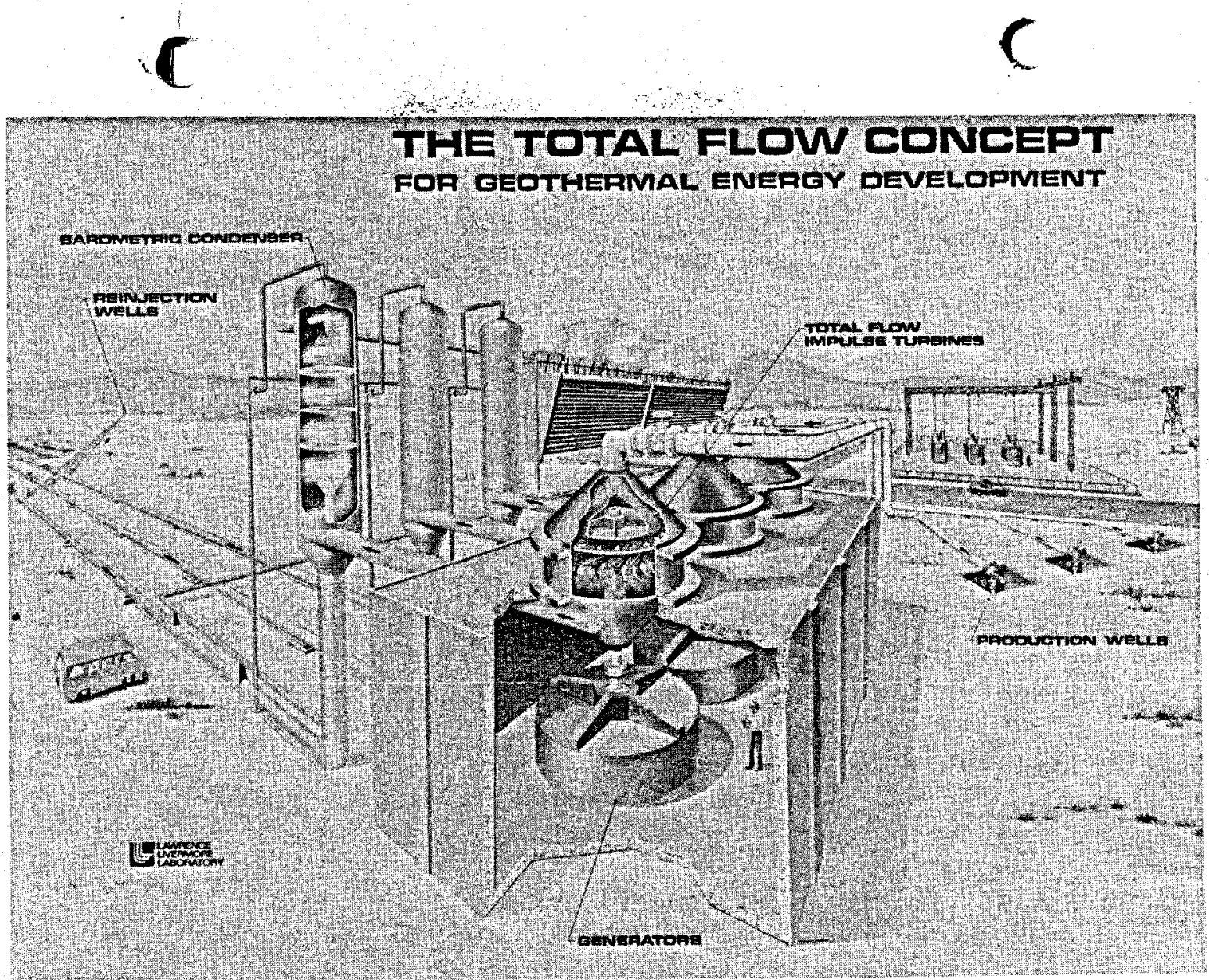

H'TQUR: 4.174-Artist's conception of complete plant. 
The significant conclusion is that the recent test data on turbine performance, the field tests on scale control, and the promising results on materialtests all indicate that the Total Flow Concept has moved from a far-out to a near-term technology for geothermal applications. Although much more work needs to be done to establish performance limits and reliability, it can be clearly concluded that technical feasibility is established, the key technical issues are clear, strategies for development are defined, and the economics of the concept are promising.

The above discussion has emphasized technical aspects and no attempt has been made to produce explicit economic evaluations. Future costs, material ayailability and financial factors are speculative at the time of writing. Reliable economic analysis requires design data and proven system components which do not yet exist.

\subsubsection{References}

Alger, T., 1976. "The Performance of Two-Phase Nozzles for Total Flow Geothermal Impulse Turbines," Presented at the 2nd U.N. Symposium on Development and Use of Geothermal Resources, San Francisco, Calif., May 20-29, 1975.

Alger, $T$., unpublished data, private communication.

Austin, A. L., G. H. Higgins, and J. H. Howard, 1973. "The Total Flow Concept for Recovery of Energy from Geothermal Hot Brine Deposits," Lawrence Livermore Laboratory, UCRL-51366, April.

Comfort, W., T. Alger, W. Giedt, W. Crowe, 1976. "Calculation of Two Phase Dispersed Droplet-in-Vapor Flows Including Normal Shocks," LLL Report UCRI78426, July, 1976. Also presented at the ASME Winter Annual Meeting, New York, December.

Comfort, W., 1977a. "Interim Report on Performance Tests of a Total Flow Impulse Turbine for Geothermal Applications," LLL Report UCID 17411, March (1977). Also: Intersociety Energy Conversion Conf.

Comfort, W. J., 1977b. "The Design and Evaluation of a Two-Phase Turbine for Low Quality Steam-Water Mixtures," Lawrence Livermore Laboratory, UCRL 52281, May.

Elliott, D., 1975. "Comparison of Brine Production Methods and Conversion Processes for Geothermal Electric Power Production," EQL No. 10, July. Environmental Quality Laboratory, Pasadena, Calif.

Facca, G., 1973. "The Structure and Behavior of Geothermal Fields," Geothermal Energy, Edited by C. H. Armstead, UNESCO, Paris, pp. 61-69.

Gould, T. L., 1974. "Vertical Two-Phase Steam-Water Flow in Geothermal Wells," Jour. Pet. Tech., August, pp. 833-842.

Grens, J. Z., 1975. "Effects of Salinity on Geothermal Well Performance," LLL Report UCID-16791, May.

House, P. A., 1976. "Helical Rotor Expander Applications for Geothermal Conversion," LLL Report UCRL-52043, April.

James, R., 1967. "Optimum Wellhead Pressure for Geothermal Power,"New Zealand Engineering, vol. 22, p. 221.

James, R., 1970a. "Factors Controlling Borehole Performance," Geothermics, Special Issue 2, p. 1502.

James, R., 1970b. "Power Station Strategy;" Geothermics, Special Issue, 2, pp. 16761687. 
Johnson, P., 1974. "Model to Calculate Flow and Energy from Geothermal Wells," LLL Internal Engr., Note ENE 74-9, April 5.

McKay, R. A. and R. S. Sprankle, 1974. "Helical Rotary Screw Expander Power System," Conf. on Res. for Dev. of Geothermal Energy Resources, Sponsored by NSF, Rept. NSF-RA-N-74-159, Pasadena, Sept. 23-25, pp. 301-309.

Muffer, J. J. P., and D. E. White, 1972. "Geothermal Energy," The Science 1'eacher, vol. 39, No. 3, pp. $1-4$.

Naymanov, O. S., 1970. "A Pilot Geothermoelectric Power Station in Pauzhetka, Kamachatka," Geothermics, Special Issue No. 2, vol. 2, pt. 2, pp. 1563-1564.

Possell, C. R., 1973. "Bladeless Turbines as a Geothermal Prime Mover and Potential Reinjection Pump," Presentation to Symp. on "New Sources of Energy," Univ. So. Cal., May 9 (General Ener-Tech., San Diego, Calif).

Rice, W., 1975. Dept. of Mech. Engr., Ariz. State Univ., Tempe, Ariz.

Steidel, R. F., Jr., H. Weiss, and J. E. Flower, 1977. "Performance Characteristics of the Lysholm Engine as Tested for Geothermal Power Applications in the Imperial Valley," LLL, UCRL-80151, August.

Tardiff, G., 1977. "Chemistry and Materials Technology for Utilization of HighSalinity Brines," LLL, Intersociety Energy Conversion Conf., Washington, D.C.

Weiss, H., and G. Shaw, 1975. "Geothermal Two-Phase Test Facility," Presented at the Second U.N. Symp. on Dev. and Use of Geothermal Resources, San Francisco, Calif., May 20-29.

Weiss, H., R. F. Steidel, and A. Lundberg, 1975. "Performance Test of a Lysholm Engine," LLL Report UCRL-51861, July 3.

White, D. E., "Characteristics of Geothermal Resources," Geothermal Energy, Edited by P. Kruger, and C. Otte, Stanford Univ. Press, pp. 69-95.

\subsubsection{Bibliography}

Austin, A. L. and A. W. Lundberg, "A Comparison of Methods for Electric Power Generation from Geothermal Hot Water Deposits," Preprint 76-WA/ENER-10, Presented at Winter Annual Meeting of the ASME, New York, November 17-22, 1974.

Beaulaurier, L. O., "Binary Thermodynamic Power Cycles Applied to Geothermal Fluids," Bechtel Corp., San Francisco, Calif., Paper presented at the First Geothermal Implementation Conf., Wairakei, New Zealand, May 1974.

Crowe, C. T., "Conversion Equations for Vapor-Droplet Flows Including Boundary Droplet Effects," LLL Report UCRL-52184, December 1976.

Hinrichs, T. C., San Diego Gas and Electric Co., Imperial Valley Geothermal Activities-A Status Report," Conf. on Res. for the Development of Geothermal Energy Resources, Sponsored by NSF, Rept. NSF-RAN-159, Sept. 23-25, 1974, pp. 194206.

Kuwada, J. T., "Geothermal Power Plant Design," AICHe Symp. Series, No. 129, vol. 69 (1972), pp. 439-444

Moskvicheva," V. N. and A. E. Popov, "Geothermal Power Plant on the Paratunka River," Geothermics (1970), Special Issue No. 2, pp. 1562-1571.

Wehlage, E. F., "KROV-A Machine with Promise for Geothermal," Geothermal Energy, April 1974, pp. 6-12.

\subsubsection{Nomenclature}

$B \ldots \ldots \ldots$ Blade width. . . . . . . . . . . . . . m

$C . \ldots \ldots$. Coefficient

D....... Wheel diameter. . . . . . . . . . . . . . m

$F \ldots \ldots \ldots$ Aerodynamic drag. . . . . . . . . . . N 
$P \ldots \ldots$ Absolute pressure.

$\mathrm{MPa}$

$T \ldots \ldots \ldots$ Absolute temperature............. K

T....... Thrust......................

$U \ldots \ldots \ldots$ Velocity $\ldots \ldots \ldots \ldots \ldots \ldots \ldots \ldots \ldots \ldots \ldots \ldots, \mathrm{m} / \mathrm{s}$

$V \ldots \ldots \ldots$ Velocity....................

a....... Liquid fraction removed radially

$d . \ldots \ldots$. Droplet diameter................. $\mathrm{m}$

e........ Efficiency, loss

$f$........ Moody friction factor

$g \ldots \ldots \ldots$ Gravitational constant............. m/ $\mathrm{s}^{2}$

$l \ldots \ldots \ldots$ Specific enthalpy .................. kJ/kg

s........ Specific entropy.................. kJ/kg K

t....... Temperature................... ${ }^{\circ} \mathrm{C}$

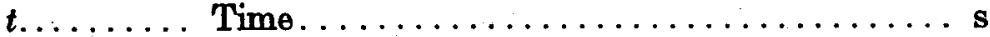

$u, v \ldots \ldots$ Velocities....................

$x . \ldots \ldots$ Dryness fraction

a. . . . . . Angle defined on figure 4.164

B. . . . . . Blade speed/Nozzle steam speed

$\eta$. . . . . Nozzle velocity coefficient

A....... Velocity ratio

$\mu \ldots \ldots \ldots$ Viscosity . . . . . . . . . . . . . . .

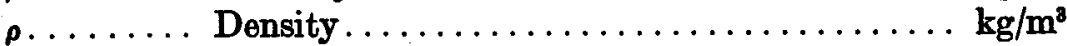

$\dot{m} \ldots \ldots \ldots$ Flowrate .................... kg

Q. . . . . Enthalpy rate................. kJ $/ \mathbf{s}$

$r, \theta \ldots \ldots$ Polar coordinates

$C_{D} \ldots \ldots$. Drag coefficient

SUBSCRIPTS, ETC.

b............ Blade

c........... Loss arising from radial removal of liquid

$d \ldots \ldots \ldots \ldots$ Loss arising from disk friotion

e........... Engine, exhaust

l............ Liquid

r........... Relative

s............ Isentropic

t........... Turbine

T......... Thrust

$v \ldots \ldots \ldots \ldots$ Vapor

w............ Turbine wheel

o........... Reservoir

$1,2,3 \ldots \ldots \ldots$ State points

$\Delta . \ldots \ldots \ldots \ldots$ Finite change in ...

A prime (') denotes a polytropic

$A$ bar () denotes a vector quantity 


\section{Chapter 5}

\section{Waste Heat Rejection from Geothermal Power Stations}

\subsection{General (By R. C. Robertson*)}

\subsubsection{Introduction}

This study of waste rejection from geothermal power stations is concerned only with the heat rejected from the power cycle. The heat contained in reinjected or otherwise discharged geothermal fluids is not included with the waste heat considered here. The heat rejected from Rankine power cycles is primarily the heat of condensation of working fluid, a quantity that may be defined in terms of the thermal efficiency of the cycle, $\eta$, as $Q_{\text {in }}(1-\eta)$, where $Q_{\text {in }}$ is the net heat input to the working fluid cycle.** In flashed-steam systems, $Q_{\text {in }}$ may be considered as the difference between the enthalpy of the steam at the turbine throttle and the enthalpy of the condensate at the condenser hot well times the mass flow rate of the steam to the turbine. This study does not consider the heat contained in the underflow from the flashtanks in such systems as part of the heat rejected from the power cycle. By following this definition of the waste heat to be rejected, this study can discuss various methods of waste heat dissipation without regard for the particular arrangement to obtain heat from the geothermal source.

Fundamental to all heat-power systems working on the Rankine cycle is that a portion of the heat supplied to the cycle must be rejected. Fossilfueled plants presently waste about $60 \%$ of their heat input, nuclear-fueled plants about 70\%, and geothermal power plants, because of the low thermal efficiency inherent to relatively low-temperature heat sources, $85 \%$ or more. Figure 5.1 shows the ratio between the amount of heat rejected from a

* Oak Ridge National Laboratory, Oak Ridge, Tenn.

* Where feasible, this chapter gives SI units followed in parentheses by the commonly used English units. Conversions were made by using the following accepted reference : American Society for Testing and Materials, Standard for Metric Practice, E 380-76, Philadelphia (1976). The method to show factors for converting units is llustrated by the following example: $\mathrm{Btu} / \mathrm{hr} \cdot \mathrm{ft} \cdot{ }^{\circ} \mathrm{F}=\mathrm{W} \cdot \mathrm{m} / \mathrm{m}^{2} \cdot \mathrm{K} \times 0.577789$. This conversion states that, to obtain the units of $\mathrm{Btu} / \mathrm{hr} \cdot \mathrm{ft} \cdot{ }^{\circ} \mathrm{F}$, values expressed in $\mathrm{W} \cdot \mathrm{m} / \mathrm{m}^{*} \cdot \mathrm{K}$ should be multiplied by 0.577789 . 


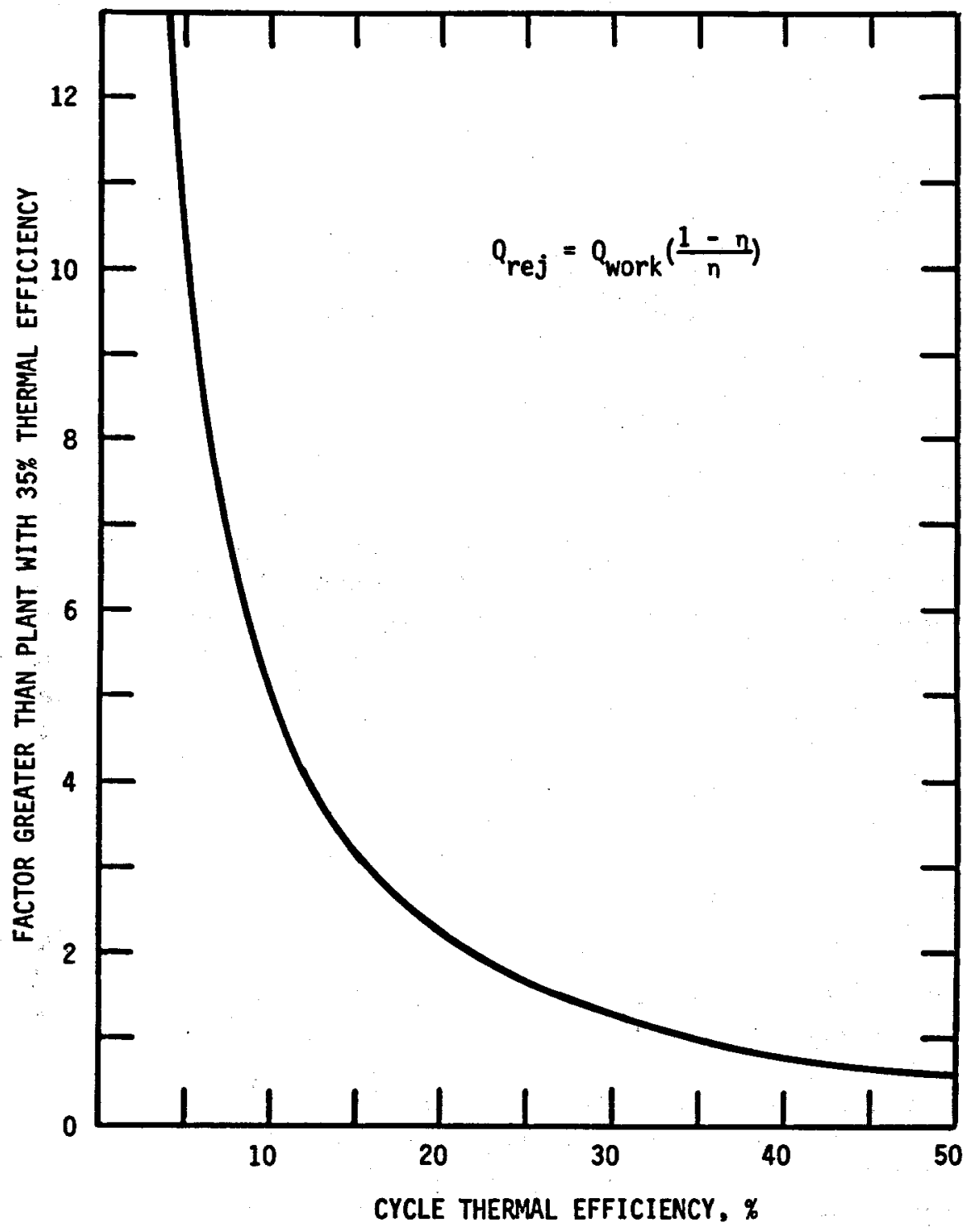

Figure 5.1-Cycle heat rejection vs. thermal efficiency compared to a cycle having an efficiency of $35 \%$.

power cycle at various thermal efficiencies and the amount rejected from a power cycle having an efficiency of $35 \%$.

Essentially all of the waste heat discharged from a thermal power station is ultimately absorbed by the earth's atmosphere, regardless of the method used for heat dissipation. The methods may differ, however, in the lowest effective sink temperature for the cycle that can be realized, a factor having an important influence on the thermal efficiency of the cycle. The 
methods may also differ in costs, water consumption rates, and such environmental impacts as noise, drift deposition rates, fogging and icing potentials, and aesthetic appearances. With the exception of cooling coils that are operated dry, all of the heat dissipation methods involve the evaporation of water, either in a cooling tower, from a spray pond, or from increased evaporation rates at the surface of a lake or river due to raising the water temperature.

The large amount of heat wasted from thermal power cycles has been studied intensively to search for useful applications. Because the thermal energy exists at temperatures only a few degrees above ambient and because power stations are often well removed from places where the heat could be used for space heating, economic considerations of pumping and piping costs have thus far limited practical use of the rejected heat to only a few special situations. However, rising energy costs and fuel conservation measures will undoubtedly change this picture, and industries may someday locate near geothermal power stations to take advantage of the waste heat.

The waste heat rejection system for a geothermal power plant will cost proportionately more of the total station cost than the waste heat portions of conventional plants. The amount of heat to be rejected per kilowatt of output will be three to six times greater than that of a nuclear plant (figure 5.1). Because geothermal stations will tend to be smaller in size, equipment costs per kilowatt will be greater. The auxiliary power requirements, such as pumping, will tend to be proportionately higher. If dry or wet/dry cooling towers are required, the cost of the waste heat rejection system can be substantially higher. It is too early to tell how much the use of binary cycles will add to the cost of geothermal stations, but this cost may be significant. The presence of hydrogen sulfide in the off-gases can require more expensive materials to combat corrosion and may necessitate off-gas scrubbers. Noncondensable gases may be higher than in conventional systems, affecting heat transfer area requirements and gas-handling costs. In view of these considerations, the waste heat rejection system for a geothermal power plant assumes an importance essentially equal to that of the steam supply or turbine-generator system and should receive as much attention in effecting the most economical arrangement.

Selection of a site for nuclear-and fossil-fueled power stations is influenced strongly by such considerations as the availability of a suitable heat sink, nearness to load centers, and acceptable environmental impacts, but geothermal power plants must bo located where the energy is found. Thus, methods of waste heat rejection must make optimal use of what is available, and this availability is often limited. At the present time, the greatest U.S. potential for geothermal energy is found in the relatively hot, watershort areas of the Imperial Valley of Southern California. Regardless of the geographical area, however, water conservation is now an issue of prime importance in the siting of almost any power station. Economic 
operation of small-scale, demonstration geothermal power plants with sufficient water available for cooling tower makeup is misleading if amounts of makeup water needed for a large power complex at the same location are simply not available. For example, a 500-MW (e) geothermal complex with an average thermal efficiency of $15 \%$ would require an 'annual average water makeup rate of about $0.9 \mathrm{~m}^{3} / \mathrm{sec}(14,700 \mathrm{gpm})$ and an annual consumption of $29 \times 10^{6} \mathrm{~m}^{3} /$ year $(23,700$ acre-ft/year). This problem probably exists even if condensate from a flashed-steam geothermal cycle is used for the cooling tower makeup because an equivalent amount of water may be needed from some other source to be reinjected into the ground to prevent subsidence. Large stations at such sites would thus require use of significantly more expensive dry or wet/dry cooling towers.

\subsubsection{Typical waste heat rejection systems and general design considera- tions}

The heat to be dissipated from a geothermal power cycle consists almost entirely of the heat of condensation of the turbine exhaust vapor. The condensers will be either direct-contact or surface types. The circulated coolant will in most cases be water, which will give up its heat in a spray pond or cooling tower. The towers will be either wet, dry, or a combination of the two, and, though natural draft towers may be considered for larger stations, the flow of air will probably be induced by fans. Direct condensation of the steam in air-cooled coils may be feasible for some installations. Simple schematic flow diagrams of typical possible heat rejection system arrangements for a flashed-steam cycle with surface condenser and wet mechanical-draft cooling tower are shown in figure 5.2. Figure 5.3 exhibits binary cycles using wet mechanical-draft towers, and figure 5.4 shows the Heller-type cycle using a direct-contact condenser in conjunction with aircooled coils. Figure 5.5 exemplifies the air-cooled coil with direct condensation of the exhaust steam.

Studying trends in waste heat rejection system designs by examining existing or planned geothermal power stations is not conclusive at this time. Examples of almost all kinds can be found. For instance, The Geysers field in Califormia uses direct-contact condensers in conjunction with wet mechanical-draft cooling towers. Both barometric leg and lowlevel types of condensers are used, the latter being the most recently installed. The Cerro Prieto Station in Mexico uses direct-contact condensers with barometric legs and wet mechanical-draft cooling towers. A Bechtel study for 50-MW (e) stations at Heber and Niland, California, differ in that the former is a flashed-steam system using a direct-contact condenser and the latter is a binary (isopentane) cycle with a horizontal shell-andtube condenser. Both cycles employ wet mechanical-draft cooling towers. There are many examples in Europe of air-cooled coils used either for 
EVAP. \& DRIFT

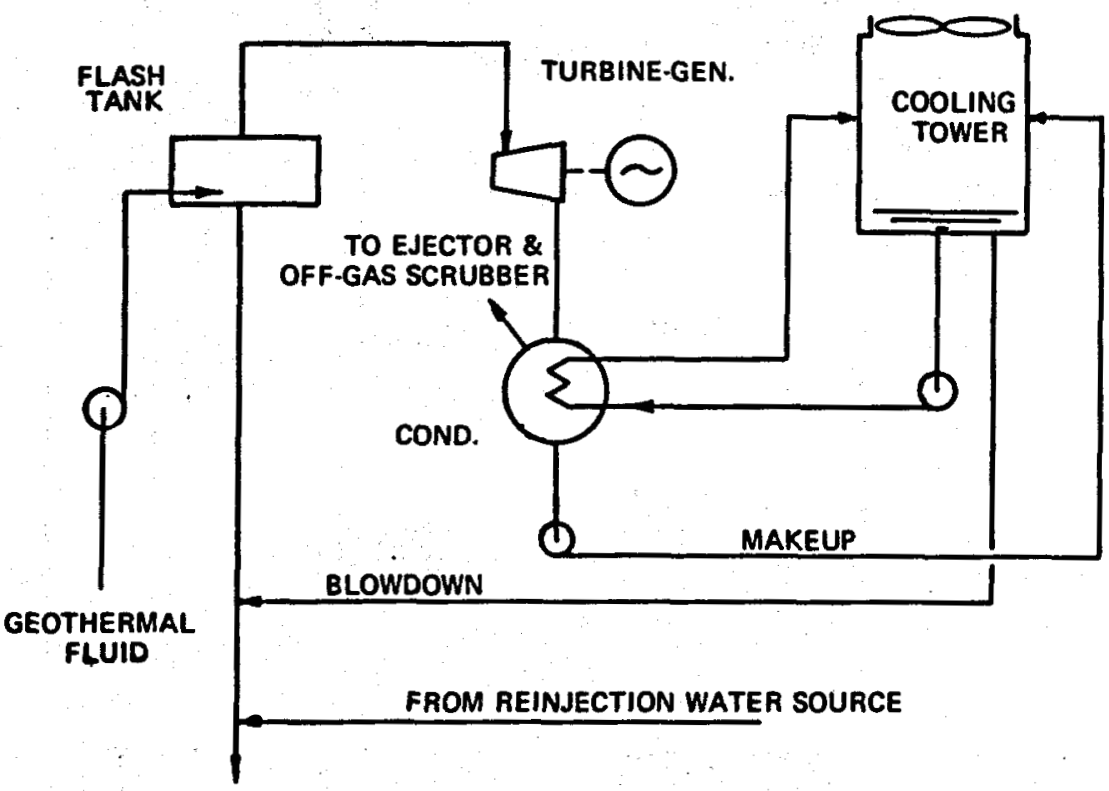

Froune 6.2-Flashed-steam cycle using, surface condenser and wet mechanical-draft cooling tower.

direct condensation of the turbine exhaust steam or for cooling the circulated condenser coolant. The only consistency noted thus far at the various stations is that the U.S. geothermal applications have been too small in size or located in a climate too dry to encourage use of natural-draft cooling towers.

Although the waste heat rejection systems for geothermal power stations are relatively simple in concept, selection and design of a dissipation system will be influenced strongly by the relatively high capital and operating costs and by the effects on the station performance. The waste heat rejection system can have an important influence on obtaining licenses and construction permits because of water consumption and other environmental impacts. The designer of the waste heat system must strive toward

1. lowest capital costs,

2. lowest auxiliary power requirements,

3. lowest cooled water temperature (highest station efficiency),

4. ability to meet peak loads,

5. reliability and minimum downtime,

6. clean circulating water that will not corrode or foul heat transfer surfaces,

7. lowest evaporative water losses, 
EVAP. \& DRIFT

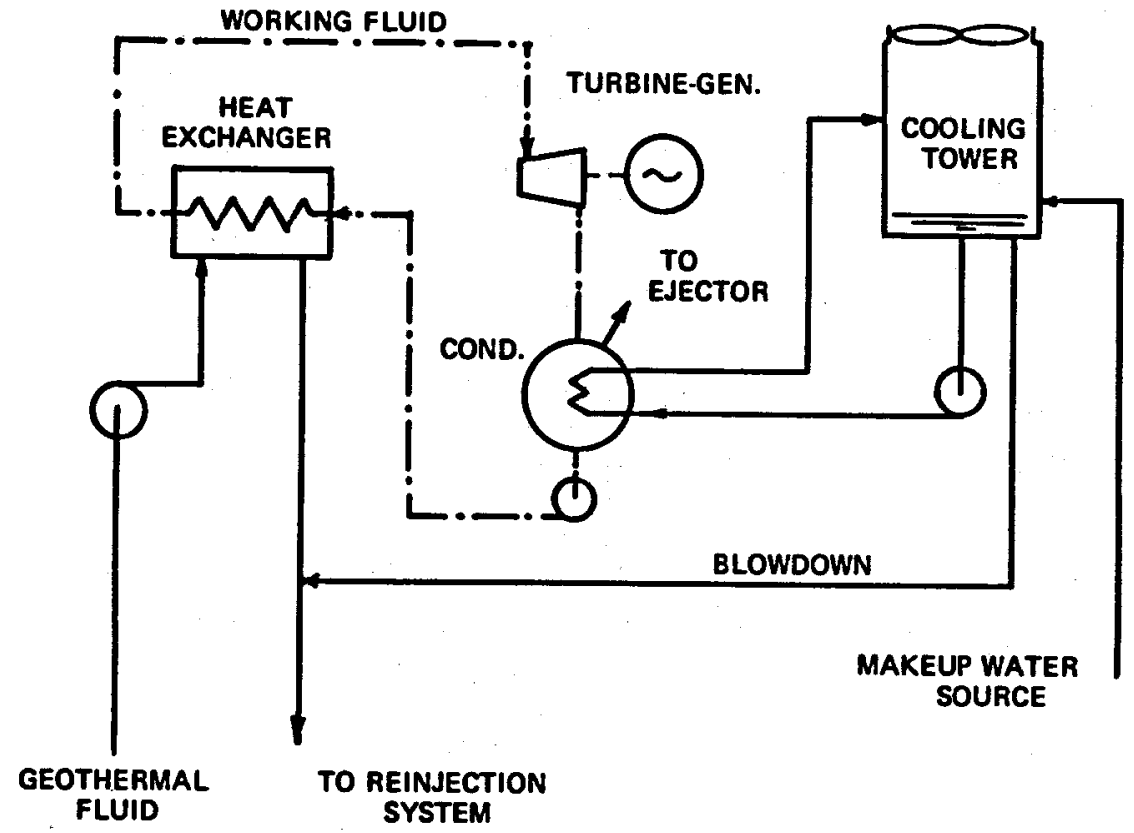

Frgune 5.3-Binary cycle using surface condenser and wet mechanical-draft cooling tower.

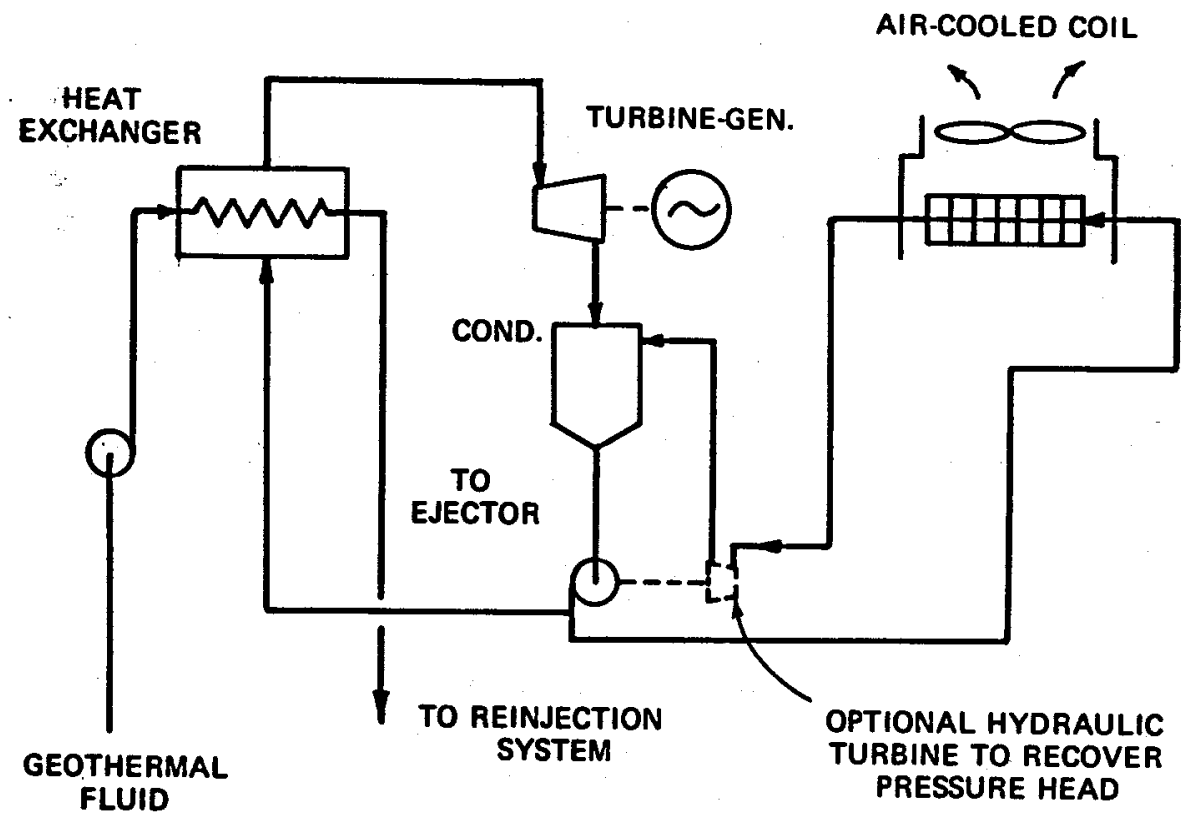

FraUka 5.4-Heller-type cycle using closed heat-exchanger, direct-contact condenser, and dry-type cooling tower. 


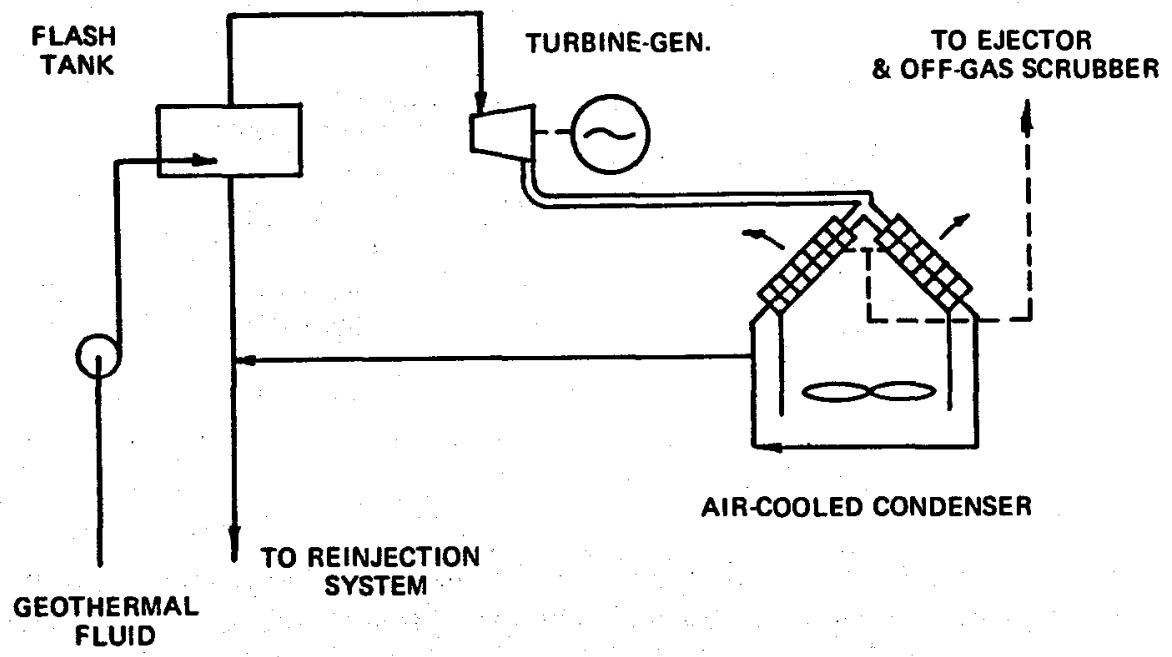

FraUR 6.5-Flashed-steam cycle with direct condensation of steam in dry cooling tower.

8. acceptable environmental impacts, such as control of noxious gases, thermal and chemical discharges, noise, etc., and

9. reasonable delivery and construction schedules.

Many of the above factors are overlapping, interrelated, and perhaps in opposition, and the selected design must be a compromise among these many demands. At the present time, there are relatively rapid changes taking place in state and federal regulations, tax structures, costs of capital and labor, escalation rates, and conventional fuel costs. The latter influences the production cost of electricity, with which the geothermal stations compete, as well as affects the costs of reserve capacity to meet outages and peak loads.

As discussed in the previous section and illustrated in figure 5.1, the amount of heat to be rejected from a station is strongly dependent on the thermal efficiency of the power cycle. The amount of heat rejected per megawatt (electrical) of station capacity is indicated in table 5.1. To this rejection must be added the miscellaneous waste heat sources, such as generator cooling, vent condensers, and air conditioning. Installations in arid regions will impose unusual circumstances that can add to costs.

Hydrogen sulfide scrubbers may be required in off-gas systems. Because of the lack of experience and relatively wide choices that can be made in types of systems, materials, and equipment, there are no reliable guidelines for estimating the costs of waste heat rejection systems for geothermal applications. In fossil- and nuclear-fueled stations where the waste heat rejection systems may amount to approximately $15 \%$ of the total capital cost, some geothermal station cost estimates indicate that the waste heat systems may amount to $30 \%$ of the total capital cost. 
TABLE 5.1-Heat rejected as a function of the thermal efficiency of the power cycle

\begin{tabular}{ccc}
\hline & \multicolumn{2}{c}{$\begin{array}{c}\text { Heat rejected per megawatt } \\
\text { (electrical) of station capacity }\end{array}$} \\
\cline { 2 - 3 } $\begin{array}{c}\text { Thermal efficiency } \\
\text { (percent) }\end{array}$ & $M W(\mathrm{t})$ & $(\mathrm{Btu} / \mathrm{hr})$ \\
\hline & & \\
5 & 19.00 & $64.9 \times 10^{\circ}$ \\
10 & 9.00 & $30.7 \times 10^{\circ}$ \\
15 & 5.67 & $19.3 \times 10^{\circ}$ \\
20 & 4.00 & $13.7 \times 10^{\circ}$ \\
\hline
\end{tabular}

\subsubsection{Waste heat utilization}

This study is concerned only with the waste heat rejected from the power cycles of geothermal power stations. Thus the broader subject of thermal uses for geothermal energy will not be discussed except to note that geothermal heat utilization has been studied at the Oregon Institute of Technology. The proceedings of the international conference held there in 1974 contain many references to successful applications of geothermal heat, such as those in Hungary, Iceland, and New Zealand (1).* The Idaho National Engineering Laboratory also has a program related to local and regional uses of geothermal heat. Although the technology is of interest, these activities are generally concerned with uses for geothermal heat and not with the utilization of relatively low-temperature heat that exists in turbine exhaust steam.

There are many examples of multipurpose, or cogeneration, power stations that partially expand steam in a turbine generator and then use the relatively high-temperature exhaust steam for industrial purposes, space heating, etc. Because geothermal power plant steam turbines will generally be supplied with relatively low-temperature saturated steam and because other higher-temperature heat sources may be available from the geothermal fluid, it seems doubtful that multipurpose cycles of this kind would have significant use at geothermal installations. The following comments are directed to the use of waste heat at conventional turbine discharge temperatures.

There is continuing interest in the utilization of the waste heat from power stations. Because the amounts rejected are so large, the use of even a small percentage of it would represent important energy savings. There have been relatively few useful applications of the waste heat to date, however, primarily because of poor economics. It is usually uneconomical to convey the heat for several miles, either as very low-pressure, highspecific-volume steam or as warm water only a few degrees above ambient temperature, because of pumping, piping, and right-of-way costs. The utilization factor (i.e., the ratio of actual heat use to design capacity) is of particular importance in the cost analysis. The reliability of the waste

*References for section 5.1 appear on p. 552. 
heat supply is also an important consideration if, for example, standby oil- or gas-fired boilers and fuel storage must be provided to protect against freezing and loss of a valuable greenhouse crop. An additional factor is that whereas the utility may initially give the heat away and encourage its use if it lowers cooling tower operating costs, the time may come when it decides that the waste heat is a marketable product. All of these aspects affect the delivered cost of the heat. The delivered cost, in 1977 dollars, should be below about $\$ 3.40 / \mathrm{MW}(\mathrm{t})\left(\$ 1 / \mathrm{Btu} \times 10^{\circ}\right)$ in order to be economical.

In discussing why there has been relatively little use of central power station waste heat, Beall ( $(2)$ stated that the stations need to seek a variety of waste heat users that could be clustered about the station so that all could benefit from a total thermal load large enough to allow a low-cost system. For example, if the utility could get one commitment for large greenhouses, another for fish cultures, one for raising chickens and for egg production, the heat delivery system costs could be substantially less than for a single waste heat project. The absence of organized effort in this respect and the lack of profit incentives for the utility (other than those that could accrue from good public relations or from rental of unused land) may be the reason why present-day applications are primarily of a demonstration nature.

In a project near Eugene, Oregon, warm water from a paper mill was used to provide frost protection, irrigation, subsoil heating, and crop cooling in the summer. The project, while not necessarily economical, was successful in protecting the field crops from frost and in increasing greenhouse yields by soil heating. Heat utilization in greenhouse is particularly attractive because of the high cash value of the crops that can be grown. For example, at a demonstration now under way at Becker, Minnesota, warm water from a $1400-\mathrm{MW}(\mathrm{e})$ power plant will provide soil and air heating for a 0.2-ha (0.5-acre) greenhouse. The Tennessee Valley Authority (TVA) has several heat utilization projects under way, including a greenhouse demonstration similar to the Minnesota project, a catfish culture demonstration, and tests of effects of soil heating on crop yields. The TVA has received funds from the Environmental Protection Agency to demonstrate use of waste heat from a power station to stimulate the growth of algae from livestock wastes, with the algae being subsequently fed to amur (carp) fish. The fish will then be harvested for livestock food (3). A bioconversion facility is under construction at Lamar, Colorado, to use waste heat from a local plant to warm digesters that will produce methane gas from the raw manure of 50,000 feedlot cattle. The methane will be burned in the power station boiler. Both algae grown in the effluent purification process and also a portion of the waste solids will be sold as a protein source for cattle feed. Other solids will be used as fertilizer (4). There are numerous other demonstration projects. 
Some of the best geothermal sites in the United States are in the lower Imperial Valley of California where many food crops are grown. It may be that food drying, greenhouse heating, and canning operations would profit from use of the waste heat from geothermal power cycles rather than using prime heat from the geothermal wells. The temperature of the steam exhausting from the turbine of a station using dry cooling towers would be high enough for absorption refrigeration system, such as those operating on the lithium-bromide cycle. This refrigeration could freeze food, provide cold storage, and be used for air conditioning. The steam temperature would also be high enough for use in water-desalting plants, which may become profitable in the Imperial Valley because of the shortage of potable water.

\subsubsection{Water availability and the law}

In 1972 Congress enacted amendments to the Federal Water Pollution Control Act (FWPCA), which generally required the use of the best available technology to dissipate heat produced in the generation of electric power. Subsequent guidelines, proposed by the EPA in 1974, found that this goal could be met only by closed recirculating cooling systems.

Peterson and Sonnichsen studied the regional limitations of surfacewater supplies with respect to the consumptive use requirements of wet cooling towers and spray ponds (5). A primary objective of the study was to determine the regional needs for dry cooling towers. The conclusion drawn by the study is that, except for isolated cases where water for cooling is physically unavailable or in short supply, there are economic alternatives to dry or wet/dry cooling up to about 1990 . It was predicted that between 1990 and 2000 there would be increased use of water. After the turn of the century, major to severe water problems will have developed in the lower Colorado and California regions, and moderate to major problems in the Great Basin, Upper Colorado, Rio Grande, Texas Gulf, Missouri, and Middle Atlantic regions (6). Shifting societal pressures could, of course, alter these predictions.

Unfortunately, the regions considered now to be most promising for the development of geothermal energy are in areas with the most severe water shortages. The geothermal power industry should have need for large dry cooling towers well in advance of other types of electric generating stations and may have to develop much of the technology.

Although use of cooling towers for heat dissipation would reduce the sometimes severe environmental impacts associated with once-through cooling systems, it is recognized that wet cooling towers are not without their drawbacks (3). Aside from increased costs, towers can cause discharges of vapor plumes, ground level fog, undesirable aerosol drift (especially when saline water is used for makeup) and can generate noise,

- References for sect. 5.1 are listed on p. XXX. 
be visually conspicuous, and last, but perhaps most importantly in watershort areas, consumptively evaporate significant quantities of water. A 50-MW (e) geothermal power station with an overall thermal efficiency of $10 \%$ and a concentration factor of 2 in the cooling towers would require about $0.4 \mathrm{~m}^{3} / \mathrm{sec}(6000 \mathrm{gpm})$ of makeup water. Moore ( 7$)$ used a rather novel approach to illustrate the large amount of water consumed by evaporation in wet cooling towers for conventional (fossil and nuclear) power stations. He estimated that a typical 1000-MW(e) plant would need a runoff area in $\mathrm{km}^{2}$ equal to $224 / r$, where $r$ is the runoff rate in centimeters per year (an area in square miles equal to $34 / r$, where $r$ is in inches per year). In the Northeastern United States, if $10 \%$ consumption of a runoff rate of $86 \mathrm{~cm} /$ year ( $34 \mathrm{in}$./year) is allowed, about $26 \mathrm{~km}^{2}$ (10 sq miles) would be needed. If only about $1 \%$ of a runoff rate of $5 \mathrm{~cm} /$ year (2 in./year) in an arid region is permitted, then about $4400 \mathrm{~km}^{2}(1700$ sq miles) are required.

Expansion of electric power at today's reduced growth rates indicates a future need for cooling tower makeup water that will further stress an intensely competitive situation with regard to water availability. Water of the relative merits of water uses, such as irrigation vs. cooling tower not only consume water, but if the untreated blowdown is returned to a diminished stream, the concentration of solids and impurities is increased downstream.

Increasing demands will be placed on the courts to decide water rights issues. Each state has its own laws and regulations concerning water use, and although there has been much progress in achieving uniformity, the disparities are still sufficient to make a detailed treatment of the subject beyond the scope of this discussion. In brief, Montana, Idaho, Wyoming, Nevada, Utah, Colorado, Arizona, and New Mexico as a holdover from the early gold mining days recognize the appropriation doctrine, which says that a pioneer who first takes and uses water can continue to do so and that between competing users priority will be given to the first user. The water need not be utilized in the same watershed as the one from which it is taken. The doctrine also permits market transfer of the rights as if they were property. In the more water-plentiful Eastern states of Michigan, Maine, Now Hampshire, Vermont, New York, Connecticut, Massachusetts, Rhode Island, Pennsylvania, New Jersey, Delaware, Illinois, Indiana, Ohio, Missouri, Kentucky, Virginia, West Virginia, Arkansas, Tennessee, Alabama, Georgia, South Carolina, and Louisiana the common doctrine is riparian law which gives the owners of land adjoining the streams the superior right to use of the water. Minnesota, Wisconsin, Iowa, Maryland, North Carolina, and Florida use riparian law plus statutory regulations. Washington, Oregon, California, North Dakota, South Dakota, Nebraska, Kansas, Oklahoma, Texas, Mississippi, Alaska, and Hawaii use laws that are a combination of appropriation and riparian rights $(8)$. States sharing the watershed of a river may act jointly, as in 
the upper and lower Colorado River compacts (9). Superimposed on the laws and regulations of the states are federal controls, such as the Wild and Scenic Rivers Act, the Wilderness Area Act, the National Park System, the National Forests, the National Wildlife Refuges and Ranges, and the various water pollution and environmental protection regulations. The legal aspects are thus complex and the subject of much litigation.

Despite the weight given to precedent by the courts, legal decisions are influenced by changing societal pressures, and in no area is this more evident perhaps than in water rights rulings. Decisions handed down a few years ago may no longer seem proper when viewed in the light of today's water demands. Courts will become increasingly involved in evaluation of the relative merits of water uses, such as irrigation vs. cooling tower makeup. The stakes are very high, and the technical and economic aspects in such controversies may tend to get lost in the intensely political climates in which the issues will be settled.

\subsubsection{References}

(1) P. J. Lienau and J. W. Lund, eds., "Multipurpose Use of Geothermal Energy," in Proceedings of the International Conference on Geothermal Energy for Industrial, Agricultural, and Commercial-Residential Uses, Oregon Institute of Technology, Klamath Falls, Oreg., October 1974.

(2) S. E. Beall, Jr., "Waste Heat: A Neglected Resource," in Proceedings of the EPRI Workshop on Dual Energy Use Systems, EPRI EM-718-W, Yarmouth, Maine, 1977.

(3) D. J. Graham, "EPA Views on Waste Heat Management and Utilization," p. I-3 in Proceedings of the Conference on Waste Heat Management and Utilization, University of Miami, Coral Gables, Fla., May 1977.

(4) "Success of a Big Flop," Mech. Eng. 100(3), 52-53 (1978).

(5) D. E. Peterson and J. C. Sonnichsen, Assessment of the Requirements for Dry Towers, HEDL-TME-76-82, Hanford Engineering Development Laboratory (September 1976).

(6) M. O. Surface, Power Eng. 81(9), 42-50 (1977).

(7) F. K. Moore, "Problems of Dry Cooling," p. II-C-109 in Proceedings of the Conference of Waste Heat Management and Utilization, University of Miami, Coral Gables, Fla., May 1977.

(8) R. J. Moses, "Where Is the Water Coming From?," pp. 42-45 in Cooling Towers, American Institute of Chemical Engineers, New York, 1972.

(9) M. B. Holburt and B. J. Gindler, "Legal Aspects of Salinity Caused by Cooling Towers," pp. 54-58 in Cooling Towers, American Institute of Chemical Engineers, New York, 1972.

\subsection{Condensers (By R. C. Robertson*)}

\subsubsection{General}

All of the thermal power systems discussed in this study assume a Rankine cycle with a turbine as the prime mover. To obtain good Rankine

* Oak Ridge National Laboratory, Oak Ridge, 'lemn. 
cycle thermal efficiencies, the turbine exhaust pressure must be as low as can be economically attained with the available cooling water or air temperature. Table 5.2 lists the condensing pressure associated with the condensing temperatures of the five working fluids most commonly used in geothermal power cycles: water, ammonia, Freon-22, isobutane, and isopentane.* For the thermodynamic properties of working fluids, the references given in table 5.2 are recommended, but other sources are usually adequate. A convenient reference for these and other working fluids is chapter 31 of the ASHRAE Handbook of Fundamentals (1).**

TABLE 5.2-Saturation 'pressure of common working fluids as a function of temperature

\begin{tabular}{|c|c|c|c|c|c|c|c|c|c|c|c|}
\hline \multirow[b]{2}{*}{${ }^{\circ} \mathrm{C}$} & \multirow[b]{2}{*}{$\mathbf{F}$} & \multicolumn{2}{|c|}{ Water a } & \multicolumn{2}{|c|}{ Ammonia b } & \multicolumn{2}{|c|}{ Freon-22 } & \multicolumn{2}{|c|}{ Isobutane $d$} & \multicolumn{2}{|c|}{ Isopentane } \\
\hline & & $\mathbf{k P a}$ & psia $^{e}$ & $\mathbf{k P a}$ & psia & $\mathbf{k P a}$ & psia & $\mathbf{k P a}$ & psia & $\mathbf{k P a}$ & \\
\hline 5 & 59 & & & & & & & & & & \\
\hline & 68 & & & & & & & & & & 1 \\
\hline & 77 & 3. 1 & 0.4 & 10 & & & & & & & \\
\hline 0 & 86 & 4. 2 & 0.6 & 11 & & & & & & & 3. \\
\hline 35 & 95 & 5. 628 & 0.8 & 13 & & & & & & & 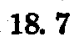 \\
\hline 10 & 104 & 7.3 & & 1557 & 22 & 15 & 2 & & 76 & & \\
\hline 5 & 11 & 9 & & 17 & & 17 & & & & & \\
\hline 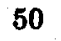 & 12 & & & 2 & & & & 679 & & & \\
\hline 5 & 13 & & & & & & & 767 & 11 & & \\
\hline 0 & 14 & & & 26 & & & & 863 & & 272 & \\
\hline 5 & 14 & 25.030 & & 2953 & & 2607 & & 967 & & 312 & \\
\hline 0 & 158 & 31. 190 & 4. 5237 & 3317 & 481. 1 & 2996 & 434.5 & 1080 & 156.6 & 355 & U1. \\
\hline
\end{tabular}

- J. H. Keenan and F. G. Keyes, steam Tables-Metric Units, Wiley, New York, 1969.

b. L. Milora and S. K. Combs, Thermodynamic Representations of Ammonia and Isobutane, ORNL/TM-5847 (May 1977).

- Handbook of Fundamentals, American Society of Heating, Refrigeration, and AirConditioning Engineers, New York, 1972.

d K. E. Starling, Fluid Thermodynamic Properties for Light Petroleum Systems, Gulf Publishing Company, Houston, 1973.

$\cdot \mathrm{kPa}($ kilopascal) $=$ psia $\times 6.894757$.

The exhaust pressure of a high-efficiency steam turbine must be well below atmospheric. The vacuum is achieved by condensing the exhaust steam, which also serves the important function in closed cycles of allowing recovery of the condensate. The degree of vacuum obtained depends on the turbine loading, the amounts of noncondensable gases present in the condenser because of inleakage and other sources, the cleanliness of

*The Starling ( $(2)$ data for isobutane is at $5.6^{\circ} \mathrm{C}\left(10^{\circ} \mathrm{F}\right)$ intervals, and the isopentane data is, in part, at $11.1^{\circ} \mathrm{O}\left(20^{\circ} \mathrm{F}\right)$ intervals. Straight-line interpolation was therefore not used in table 5.2 for values requiring interpolation of the Starling data. The equation $p=\exp (a+b / T+c$ ln $T)$, which gives good agreement for $p-T$ relationships, was used to write three simultaneous equations based on representative points for the temperature in question. The solution gave values of $a, b$, and $c$ that were used to calculate the intermediate temperature.

**References for sect. 5.2 are listed on p. 598. 
the condenser tube surface, and most importantly the condensing temperature of the steam as influenced by the temperature of the cooling water (or other heat sink) available. The condensing temperature is usually in the range of 3 to $6^{\circ} \mathrm{C}\left(5\right.$ to $\left.10^{\circ} \mathrm{F}\right)$ above the average temperature of the cooling water used as the heat sink or about $8^{\circ} \mathrm{C}\left(15^{\circ} \mathrm{F}\right)$ above the average dry-bulb temperature of the ambient air if dry cooling towers are used. Tests show a decrease in steam consumption for a given power output of about 6 to $8 \%$ for each $25 \mathrm{~mm}$ (1 in.) of mercury reduction of exhaust pressure in the absolute pressure range of 50 to $127 \mathrm{~mm}(2$ to 5 in.) of mercury. However, the specific volume of steam increases rapidly with a decrease in pressure, and the physical size of the exhaust system becomes proportionately larger and more expensive as the exhaust pressure is reduced. The properties of steam are also such that in the turbine the amount of moisture in the steam increases progressively during the expansion process in the turbine. The amount of moisture present in the last stages of the turbine is often the limiting factor in the expansion process. The optimum design exhaust conditions will thus vary with the steam and cooling-water costs.

Important to the thermal efficiency of a steam cycle is that the turbine operate at the design exhaust, or back, pressure. If the back pressure is higher than the design pressure, expansion in the turbine is incomplete and the heat rate increased. If the back-pressure is lower than the rated value, the steam velocity leaving the last turbine stage tends to exceed sonic values, and the turbine will "choke," also tending to increase the heat rate. Typically, the exhaust pressure of a steam turbine is allowed to vary by 25 to $76 \mathrm{~mm}$ ( 1 to $3 \mathrm{in}$.) of mercury. Maintaining the pressure within this narrow range requires careful operation to accommodate such variables as the plant electric load, cooling-water temperatures, fouling of heat transfer surfaces, etc.

The amount of noncondensable gases present in the condenser is dependent on the tightness of the system against air inleakage, the amounts of gases entrained or dissolved in the steam supply to the turbine, and the amounts of gases released by chemical reactions in the water. Thermal power stations utilizing steam flashed from a geothermal fluid may have to contend with relatively large amounts of noncondensable gases being swept through the turbine and into the condenser. The noncondensable gases, even in amounts less than $1 \%$ of the throttle steam flow, can reduce markedly the performance of the condensing equipment unless adequate provisions to accommodate and remove these gases are provided. The hydrogen sulfide, which may make up a high precentage of the noncondensable gases, is toxic and corrosive and has an objectionable odor even in very small concentrations. Means will be required at most installations to collect and dispose of the condensables in an approved manner. Cooling-system equipment probably will require special corrosion protection. The system designer must keep in mind the time required to lower 
the condenser pressure to the design turbine back pressure for startup, Special high-capacity pumping equipment, called the "hogging" system, is needed if the time is kept to within reasonable limits (about 30 min to $1 \mathrm{hr}$ ). Many power stations have two-stage pumps or ejectors, and some arrange the first stage for hogging.

Steam condensers are not normally designed for high pressures on the shell side and are generally limited to about $138 \mathrm{kPa}(20 \mathrm{psi})$ above atmospheric pressure. A sudden loss of coolant could cause the condenser pressure to mount rapidly, and protection must be provided against overpressure. Blowout disks of thin metal are often used because these can be large enough to release quickly the necessary volume of steam.

Because steam condensers operate at high vacuum, the possibility exists that under some abnormal condition condensate could be drawn from the hot well back up into the unit, possibly allowing liquid to enter the offgas pump or, in extreme cases, to damage the turbine blades. Vàcuum breakers, or equivalent protection, have to be provided.

The above eomments apply to condensing systems for steam turbines. In contrast, working fluids other than water result in cycles having pressures greater than atmospheric throughout, and air inleakage into the systems is not as great a problem. In fact, the condensing pressures are high enough in Freon-22 and ammonia systems to make it more economical at times to use several small condensers rather than a single large shell designed to withstand the pressure. Another distinct difference between the use of water and other working fluids is that although the thermodynamic properties of water result in a turbine exhaust in the saturated vapor region, the exhausts are in the superheated region when using isobutane, Freon-22, or ammonia. Because the heat transfer from a superheated vapor to a cooled surface is significantly lower than from a condensing vapor to the surface, in some cases it may be more economical to install desuperheaters between the turbine and the condenser.

\subsection{Effect of condensing temperatures on geothermal station performance}

Geothermal power cycles generally have lower working fluid vaporizing temperatures than conventional nuclear- or fossil-fueled cycles. Examination of the Carnot efficiency term, $\left(T_{1}-T_{0}\right) / T_{1}$, shows that the lower the heat source temperature, $T_{1}$, the more sensitive the efficiency becomes to the sink temperature, $T_{0}$. (Khalifa (3) has made a detailed study of the effect of the sink temperature on the performance of ideal cycles; see also section 5.7.) The sink temperature is a function of the temperature of the available cooling water, which will vary seasonally. Plants relying on dry cooling towers for heat dissipation, for example, would have unusually wide swings in the cooling-water temperature because of variations in the dry-bulb temperature between summer and winter. Figure 5.6 shows the 
effect on the performance of water and isopentane cycles designed for a $48.9^{\circ} \mathrm{C}\left(120^{\circ} \mathrm{F}\right)$ condensing temperature when operating at above and below the design point.

The values shown in figure 5.6 are for illustrative purposes and reflect only the change in available energy with exhaust pressure; they do not include the relatively small effects of the exhaust pressure on the internal efficiency of the turbine. Among other things, the internal efficiency is a function of the exhaust-end loading of the turbine-a turbine with light loading showing more improvement as exhaust pressures are lowered below the design point than one with heavy loading that cannot accommodate increased velocities. Applying steam-turbine-based condensing pressure adjustment factors to the internal efficiency of isopentane turbines would be particularly inappropriate. At the present time, definitive data is not readily available on the effects of exhaust pressure variations on the performance of isopentane units.

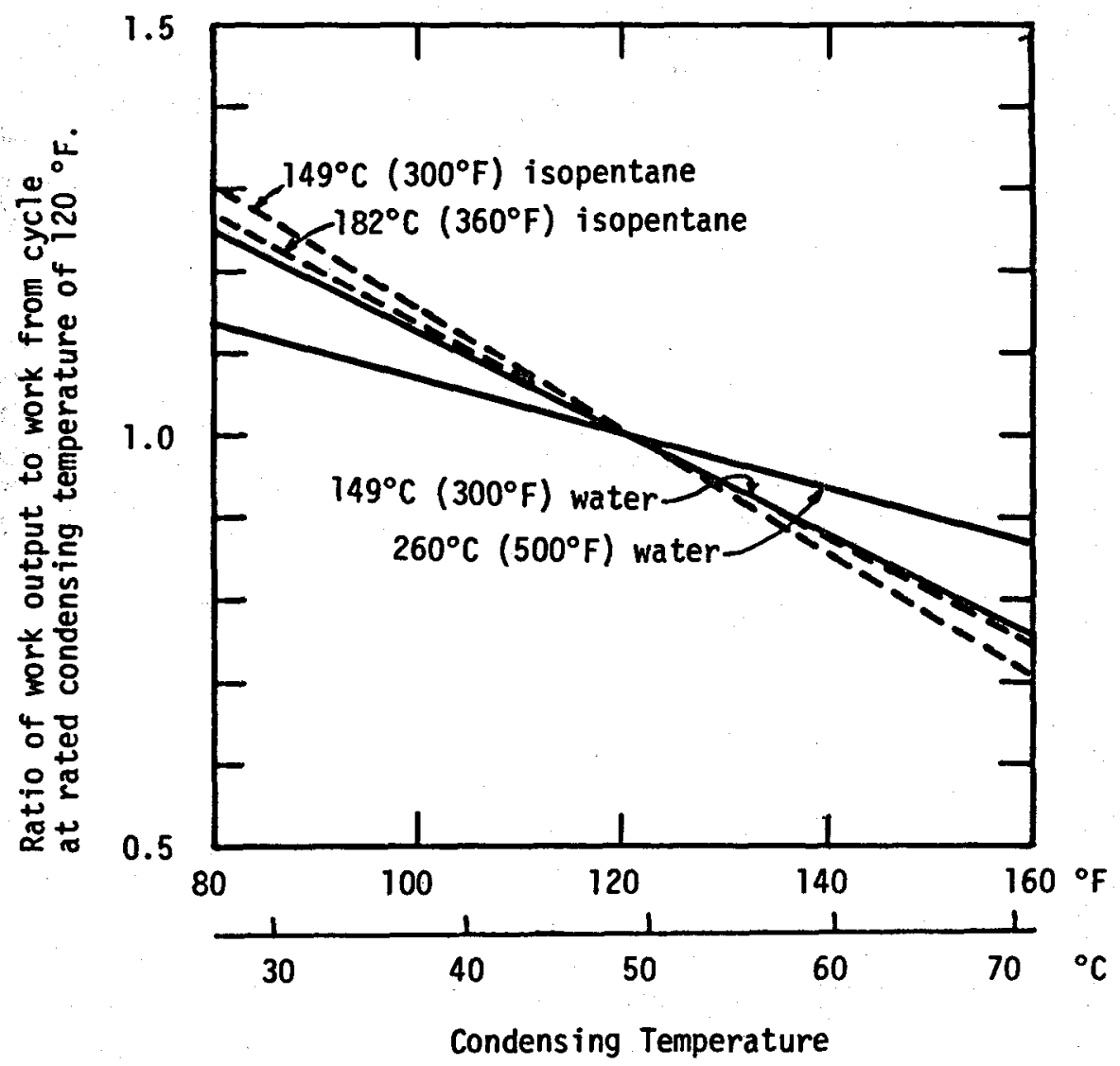

FIGURE 5.6-Effect of condensation temperature on useful work output of water and isopentane power cycles. Does not include effects on turbine internal efficiency. See text. 
Figure 5.6 shows that the reduction in work output due to a condensing temperature increase is about equal to the increase in work output when the condensing temperature is decreased by an equal amount. If the design point is selected judiciously, seasonal swings in the condensing conditions would not seriously affect the annual average power production rate. Short-term effects can be substantial, however, particularly if they result in the need to purchase power to make up for lost capacity.

\subsubsection{Direct-contact condensers}

5.2.3.1 General. In a typical direct-contact condenser, the vapor is condensed by spraying the subcooled liquid of the same fluid into it. Condensation occurs on the falling, relatively cool, liquid droplets. The most common forms are the low-level and barometric-leg types used to condense the turbine exhaust in steam power plants. Another form bubbles the vapor to be condensed through a pool or stream of the liquid. Both of these types, having only a single fluid present, are termed "single-fluid" condensers and are discussed in section 5.2.3.2. Direct-contact condensers are being considered for binary geothermal power cycles where the turbine exhaust would be condensed by direct contact with a different immiscible fluid. This type of condenser is called a "two-fluid" type and is discussed in section 5.2.3.8.

5.2.3.2 Single-fluid direct-contact condensers. In a typical single-fluid direct-contact condenser, cooling water is sprayed into the turbine exhaust steam, and condensation occurs on the water droplets. The splashing action at saturation temperature provides good deaeration. The terminal temperature difference (i.e., the temperature difference between the leaving water and the condensing steam temperature) theoretically could be zero, but in actual practice may be as high as $6^{\circ} \mathrm{C}\left(10^{\circ} \mathrm{F}\right)$. For a given cooling-water inlet temperature, the direct-contact condenser will provide lower turbine back pressures than would a surface condenser.

Direct-contact condensers tend to be simpler in design than surface condensers, and they have appreciably lower initial costs, particularly in geothermal power applications where the direct-contact condensers do not require complex internals. There are not as many leakage problems with spray condensers as with the multiplicity of tube joints in surface condensers. Unlike the latter, the spray condensers require little maintenance or cleaning, and the heat transfer performance does not deteriorate with time. Spray condensers may occupy about one-third the space of a surface condenser for the same duty, and there will be a corresponding reduction in costs of turbine pedestals and other concrete work.

The disadvantages of direct-contact condensers are mainly associated with the fact that the condensate is mixed with the cooling water. The contaminated condensate would require deaeration and treatment before 
it could again be used as boiler feedwater. This factor of water quality prevented widespread use of direct-contact condensers in large steam power stations for several decades. It was not until the relatively recent interest in dry cooling towers and the Heller system that the direct-contact condensers have again come into limited use. In this system, as was indicated in figure 5.4. the condenser water is cooled in a closed loop in an air-cooled coil so that it can be maintained at a high quality and with low gas content. Geothermal power cycles have also given impetus to the use of direct-contact condensers because the condensate is not recovered in many instances. If deaeration of the condensate and minimum subcooling are not of particular interest, condensers do not need a complicated internal arrangement of nozzles, baffles, and trays.

A further disadvantage of direct-contact condensers is that near saturation conditions at the hot-well pump inlet necessitate that the coolingwater pumps operate with low-net-positive suction heads if flashing is to be avoided. The pumps that circulate cooling water to the condensers may also operate at a higher head than pumps that supply water to a surface condenser. In the latter, the only pumping head is due to fluid friction, and the whole system operates above atmospheric pressure. In directcontact condensing systems used in conjunction with air-cooled coils (as in the Heller arrangement), operation of the coil portion of the system above atmospheric pressure to minimize air inleakage is desirable. In this case, the water pumps must supply this head plus the pressure drops at the spray nozzles. [The latter is usually in the range of about $34.5 \mathrm{kPa}$ (5 psi) ]. In theory, a hydraulic turbine could be used between the coils and the condenser as a pressure letdown device to recover a portion of the pumping head, but this system may be marginal and each particular case needs to be studied. To prevent flooding of the condenser in the Heller system in the event of failure of the water-circulating pumps, slow-closing stop valves are needed in the supply line to the water spray nozzles. The air-cooled coils also need to be protected from any excessive pressure surges in the condenser (4). Mixing, or direct-contact, condensers can be classified as either 1) barometric or 2) low-level types.

1. A barometric condenser is shown in figure 5.7. The turbine exhaust enters at the top of the mixing chamber where it meets the cooling water, which is either injected by spray nozzles or allowed to splash to form curtains through which the steam must pass. The condensed steam and cooling water collect in the bottom of the vessel and drain into a tail pipe [10.4 $\mathrm{m}(34 \mathrm{ft})$ or more in height], which acts as a barometric leg or column to allow the condensate to flow out by gravity through a water seal, or air trap. This arrangement eliminates the need for the condensate pump, vacuum breaker, and pressure-relief devices but has the disad-

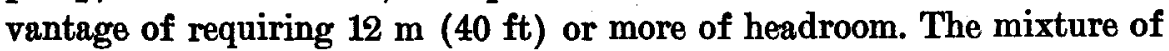
noncondensable gases and water vapor collects at the top of the vessel after being in contact with the coolest water, and the gas is removed by 


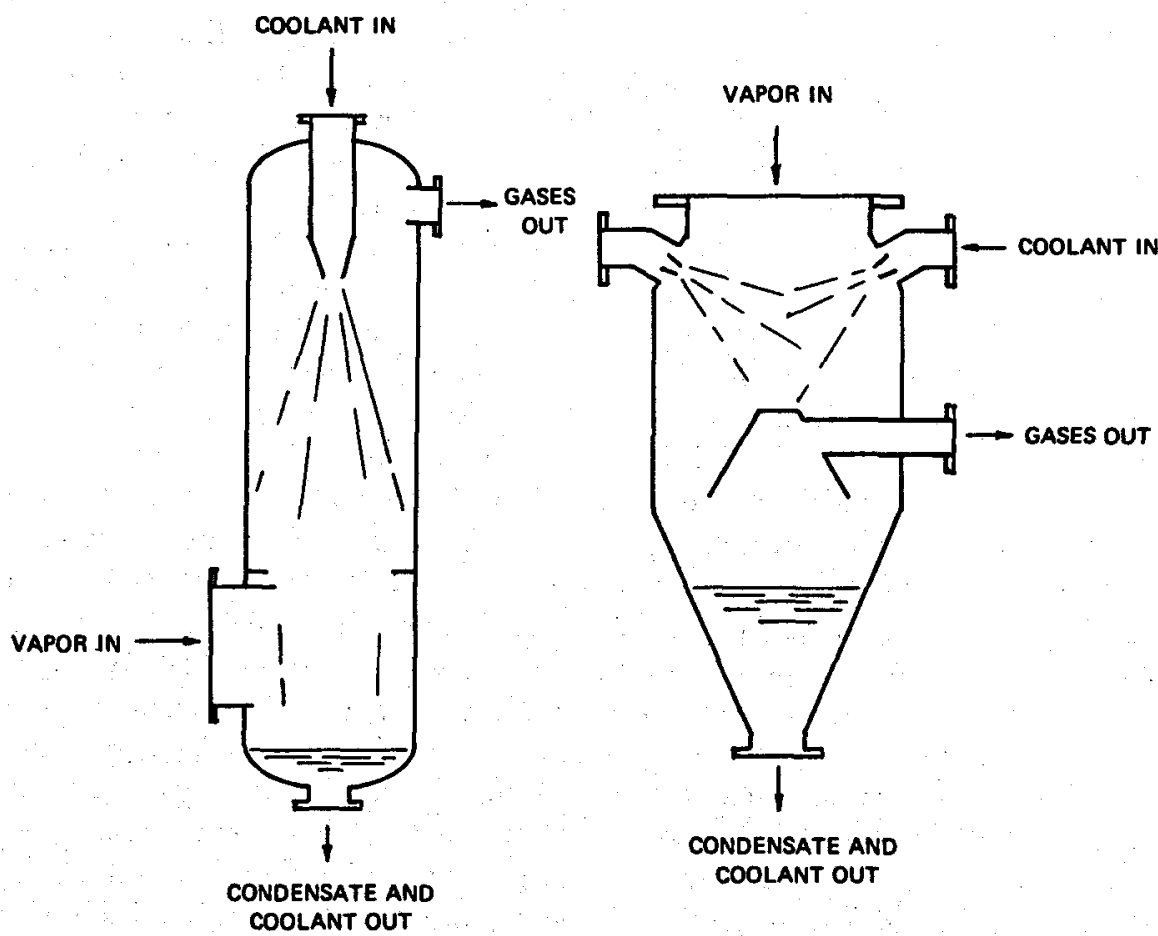

FIGURE 6.7--Schematic of flow arrangement in direct-contact condensers : (a) Counterflow and (b) parallel flow. Source: H. R. Jacobs and Heimer Fannar, Direct Contaot Condensers-A Literature Survey, DGE/1523-3, UTEC 77-081, Mechanical Engineering Dept., University of Utah, Salt Lake City, [February 1977], figure 2.A (2-1).

either vacuum pump or steam ejector. Mixing condensers can differ in design according to whether the steam flow is countercurrent to the water spray, as in figure 5.7(a), or parallel to the spray, as in figure 5.7(b), but the performance characteristics are similar.

2. A low-level direct-contact condenser may be essentially the same as a barometric condenser except that the condensate is removed by pumping rather than by gravity flow through the barometric leg. Elimination of the tail pipe usually makes it possible to install the condenser in the optimum position directly coupled to the turbine exhaust. The space requirements are no more than those for a surface condenser. The condensate removal can be effected by either centrifugal pumps, the kinetic energy of water jets, or a combination of the two.

A variation of the low-level direct-contact condenser is the multijet ejector condenser. Here, the cooling water flows at high velocity from converging jets into a Venturi section that aspirates the exhaust steam into the throat and condenses it. This arrangement has the advantage of 
removing the noncondensable gases along with the vapor and can achieve high vacuums. The cooling-water consumption is higher than the consumption for the mixing chamber type of condenser. However, for relatively small geothermal applications (such as well head installations) where the amount of noncondensable gases are relatively high and unpredictable, the ejector condenser may be considered.

The shells for direct-contact condensers have typically been made of carbon steel. However, the Bechtel Corporation study for a 50-MW(e) geothermal power plant at Heber, California, proposed that the low-level direct-contact condenser shells be fabricated of reinforced concrete designed for $517 \mathrm{kPa}$ (75 psia) and full vacuum (5). A condenser of similar design is being installed at Hatchabaru, Japan (6). The interior surface of the concrete would be impregnated with an epoxy mixture to seal against air inleakage through hairline cracks. Satisfactory operating experience with similarly sealed concrete vessels in desalting plants is cited by Bechtel (5). The weight of the concrete shells is sufficient to anchor the condensers even where groundwater elevations are relatively high.

Satisfactory surface contact between the vapor and the cooling water can be achieved by the sprays alone, but a combination of sprays and cascades provides better deaeration. As in any condensing system, noncondensable gases must be removed continuously if the vacuum and performance are to be maintained. (Section 5.2.4.4 explains the effect of noncondensable gases on condenser performance.) Interior baffles must be provided to direct the gases to one or more takeoff points. Although vacuum pumps are now gaining in favor (section 2.4.4), two-stage steamactuated ejectors are commonly employed for scavenging.

Calculations of the cooling-water requirements for mixing condensers ean be based on simple energy balances. The Heat Exchange Institute (7) recommends that for steam turbines the difference between the enthalpy of the entering steam and the enthalpy of the leaving mixture be taken as $2210 \mathrm{~J} / \mathrm{g}(950 \mathrm{Btu} / \mathrm{lb})$. Design of the mixing chamber has evolved over a number of years and is based largely on judgment and experience.

The heat transfer processes in the condenser are complex and highly dependent upon the physical dimensions of the system. Development of mathematical models for spray condensers would depend on knowing stripping and diffusion coefficients. Much of this information is considered proprietary. The two parameters that probably have the greatest influence on the performance are the surface area of the condensing water in contact with the steam and the relative velocity between the steam and the condensing water. There is, then, an advantage to smaller water droplets and longer fall times. A terminal temperature difference of about $3^{\circ} \mathrm{C}$ $\left(5^{\circ} \mathrm{F}\right)$ is common practice, although this is dependent on the amount of noncondensable gases present. The Electric Power Research Institute (8) has investigated the modeling of direct-contact condensers so that the dimensions and costs can be roughly estimated. The model makes assump- 
tions such as the holes in the trays are $1.27 \mathrm{~cm}(0.5 \mathrm{in}$.) in diameter, the height of the water in the tray is six times the hole diameter, and the height of the condenser from the bottom of the first tray to the water outlet is twice the diameter of the tray. Such rules of thumb are sufficient for the modeling purposes intended but are, of course, not reliable design guides. In design of the units, major manufacturers (such as IngersollRand) rely heavily on previous experience and experimental testing programs. There is very little specific design information in the literature.

Direct-contact condensers are commonly used with air-cooled coils, as in the Heller system. Convincing arguments can also be made for use of surface condensers (section 5.3.5.6).

\subsubsection{Two-fluid direct-contact condensers. In geothermal binary power} cycle applications, this type of condenser would condense the turbine exhaust vapor mixture by direct contact with a cooling fluid that is immiscible with the working fluid. The vapor may be condensed by contact with sprayed droplets from the cooling fluid, by bringing the vapor into contact with a film of the coolant liquid, or by bubbling the vapor through a pool of the cooling fluid. The working fluids generally considered for this type of geothermal cycle are light hydrocarbons and halogenated hydrocarbons, and the obvious selection for the coolant is water because of its superior thermal properties, lower pumping energy requirements, and lower cost. A typical binary geothermal cycle, direct-contact condenser application would condense a mixture of about 90 to $95 \%$ working fluid (such as isobutane or isopentane) and about 5\% steam by transferring heat (1) into water droplets through a water film or (2) from collapsing vapor bubbles into a water pool.

Unlike direct-contact boilers or heat exchangers, which are of primary interest in geothermal cycles because they reduce the scaling and fouling problems, direct-contact condensers would be justified mainly on the basis of lower capital costs, closer approach temperature, and more efficient separation of the two fluids. Direct-contact condensers bringing the working fluid vapor into contact with falling water droplets would not be unlike the single-fluid direct-contact types described in section 5.2.3.2. Film-type direct-contact types would use a packed bed of rings or saddles. Bubble-type condensers have been of interest primarily as open feedwater heaters and vapor suppression systems in reactor containments and in condensers for seawater distillation.

Jacobs and Fannar (9) have reviewed the state of the art of directcontact condensers and have published a comprehensive literature survey on the subject, covering both U.S. and British sources. May of the above comments on direct-contact condensers were extracted from their work. Work is in progress at the University of Utah's Mechanical Engineering Department on direct-contact heat exchangers (10). These tests are related to those now being conducted at East Mesa, California, by DSS Engi- 
neering (Ft. Lauderdale, Florida) on mixing-type heat exchangers. The DOE-sponsored tests at The Great Lakes Chemical Company in El Dorado, Arkansas, will also investigate direct-contact boilers and condensers.

\subsubsection{Surface condensers}

5.2.4.1 General. Surface-type condensers are most commonly used in large, modern steam power stations. This usage stems primarily from the need to recover the high-quality condensate for return to the boiler. In binary geothermal cycles, the surface condenser must be used to separate the working fluid and the condenser coolant. The condensers are the shelland-tube type, and almost without exception the steam or other working fluid is in the shell side and the coolant flows through the tubes. The term "surface condenser" is now reserved for tubular condensers of this design (11).

A diagrammatic section through a horizontal, two-pass, shell-and-tube condenser is shown in figure 5.8. The coolant enters a water box on one end and flows through the lower half of the tube bundle to a water box on the other end; the flow then reverses and returns through the upper half of the tube bundle. Single-pass condensers have the water inlet and outlet on opposite ends. Although single-pass condensers tend to be lower in initial cost, they may not produce as good and as high a vacuum and sometimes do not fit well into the piping layout. In general, these con-

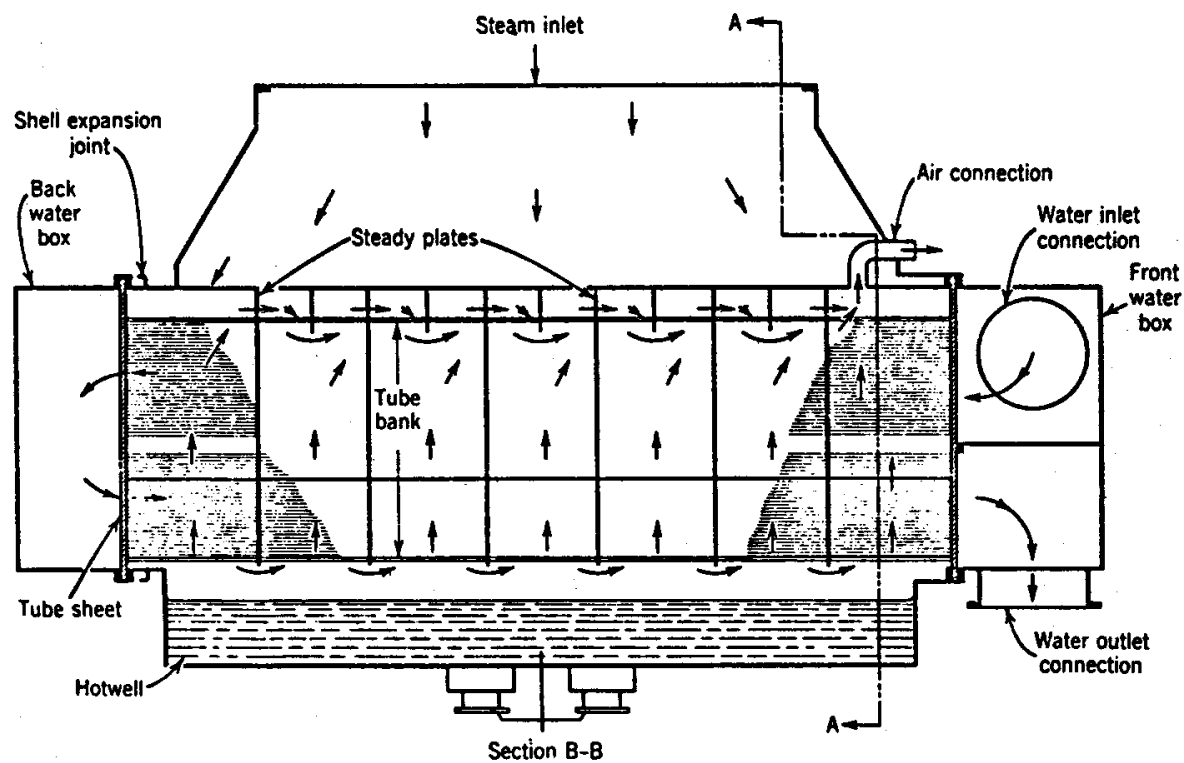

Figure 5.8-Sections through a typical two-pass surface condenser for a large steam power plant. (Courtesy of Allis Chalmers Corporation) 
densers are used when circulating water is plentiful and where the fixed pumping head is not high. Single-pass condensers usually require less surface area but more circulating water than do multipass condensers. To keep the coolant velocity in the tubes sufficiently high for good heat transfer, it is necessary to use either relatively small diameter tubes or relatively few tubes of longer length. A velocity of about $1.8 \mathrm{~m} / \mathrm{sec}(6$ $\mathrm{ft} / \mathrm{sec}$ ) or more is usually considered sufficient. In general, tubes of less than 1.6-cm (\%/8-in.) OD clog too easily, and tubes of $2.5-\mathrm{cm}$ (1-in.) OD and larger require excessive amounts of water to achieve desirable velocities. Long tube lengths cause more thermal expansion problems and require more room at the ends of the condenser to clean and replace tubes. Combinations of the above factors tend to make the two-pass arrangement favorable for most applications, including the steam power field. The colder water in the first pass is capable of condensing more steam, and the division of the duty is often about $60 \%$ in the first pass and $40 \%$ in the second.

Relatively large volumes of water are required for condensing service. A geothermal power station with a thermal efficiency of about $15 \%$ would need about $0.16 \mathrm{~m}^{3} / \mathrm{sec}(2500 \mathrm{gpm})$ of cooling water per $\mathrm{MW}(\mathrm{e})$ of installed capacity. Thus, pipes supplying the water are of relatively large diameter and pose layout problems. A current trend is toward use of fiberglass-reinforced plastic pipes in some portions of the system because of their light weight in comparison to the steel and concrete pipes conventionally used.

One of the major difficulties in the design of surface condensers is accommodating the diffierential expansion of the tubes and the shell. Although various arrangements are used, the most common is an expansion joint that permits one tube sheet to move independently of the shell. Tubes are usually joined to the tube sheets by roller expansion, a method that is suitable for commonly used tubing materials and that will give satisfactory leak-tightness for most steam turbine condenser applications. Other methods do not prove to be as effective. Brazing, for example, requires large furnaces for vacuum brazing, and soldering may compromise corrosion resistance. Adhesives, such as the epoxies, involve very strict quality control if they are to be effective. Welding of the tubes on the face side gives the most leak-tight joints and is essentially the only alternative when using less formable materials, such as titanium. However, welding is more expensive and requires care to prevent cracking at the welds. Despite care in design and manufacture, surface condensers may develop leaks between the shell-side and the tube-side fluids. The designer must arrange for access to plug leaky tubes and to repair joints, as well as allow sufficient room (tube pull space) to replace tubes.

The concentration of noncondensable gases on the shell side increases progressively in the direction of the vapor flow. The takeoff to the non- 
condensable gas-removing equipment should therefore be located near the end of the vapor path where the greatest density of the gases occurs. The sweeping effect of the steam flowing through the condenser is an important factor in concentrating the noncondensable gases at the bottom of the condenser and in scavenging them from condensing surfaces. Stagnant zones where the gas could collect should be avoided. Provisions should be made for cooling gas that is not condensed to reduce the size of the gas-purging equipment and to remove as much moisture (working fluid) as possible from the gas. These provisions can be accomplished by shrouding some of the tubes to draw the gases over the cooled surfaces.

A stream velocity of 30 to $60 \mathrm{~m} / \mathrm{sec}(100$ to $200 \mathrm{ft} / \mathrm{sec})$ through the first row of tubes is good practice at vacuums of about $660 \mathrm{~mm}$ (26 in.) of mercury, and 60 to $120 \mathrm{~m} / \mathrm{sec}(200$ to $400 \mathrm{ft} / \mathrm{sec})$ is used at vacuums of about $737 \mathrm{~mm}$ (29 in.) of mercury The steam-side pressure drop varies from about $1.3 \mathrm{~mm}(0.05 \mathrm{in}$.) of mercury to $13 \mathrm{~mm}(0.5 \mathrm{in}$.) of mercury.

The cooling-water velocity through the tubes is usually in the range of 1.8 to $2.4 \mathrm{~m} / \mathrm{sec}$ (6 to $8 \mathrm{fps}$ ). The tube diameters are commonly 20 to 25 $\mathrm{mm}(3 / 4$ to $1 \mathrm{in}$.) in outside diameter, and tube lengths vary from about 5 to $10 \mathrm{~m}$ (15 to $30 \mathrm{ft}$ ). For freshwater service, the tubes are ordinarily of a copper alloy, such as admiralty metal (70\% copper, $29 \%$ zinc). Saline water installations may use a nickel alloy, such as Monel, or titanium. A tube wall thickness of 18 British wire gage (BWG), $1.25 \mathrm{~mm}$ or 0.049 in., will withstand ordinary circulating system pressures and is commonly used. Tube sizes are shown in table 5.3, and mechanical and physical properties aro given in table 5.4. At the present time, tubes with outside diam-

TABLE 5.3-Heat exchanger and condenser tube data .

\begin{tabular}{|c|c|c|c|c|c|c|}
\hline \multirow{2}{*}{$\begin{array}{l}\text { Tube } \\
\text { OD, } \\
\text { in. }\end{array}$} & \multirow[b]{2}{*}{ BWG } & \multirow{2}{*}{$\begin{array}{l}\text { Wall thick- } \\
\text { ness, in. }\end{array}$} & \multirow[b]{2}{*}{ ID, in. } & \multirow{2}{*}{$\begin{array}{c}\text { Flow area } \\
\text { per tube, } \\
\text { in. }\end{array}$} & \multicolumn{2}{|c|}{ Surface per lin $\mathrm{ft}, \mathrm{ft}^{2}$} \\
\hline & & & & & Outside & Inside \\
\hline \multirow[t]{5}{*}{$1 / 2$} & 12 & 0. 109 & 0. 282 & 0.0625 & 0. 1309 & 0.0748 \\
\hline & 14 & 0.083 & 0.334 & 0. 0876 & & 0.0874 \\
\hline & 16 & 0.065 & 0. 370 & 0.1076 & & 0.0969 \\
\hline & 18 & 0.049 & 0.402 & 0.127 & & 0. 1052 \\
\hline & 20 & 0.035 & 0. 430 & 0.145 & & 0.1125 \\
\hline \multirow[t]{9}{*}{$3 / 4$} & 10 & 0. 134 & 0.482 & 0.182 & 0. 1963 & 0.1263 \\
\hline & 11 & 0.120 & 0.510 & 0.204 & & 0.1335 \\
\hline & 12 & 0.109 & 0. 532 & 0. 223 & & 0. 1393 \\
\hline & 13 & 0.095 & 0. 560 & 0.247 & & 0. 1466 \\
\hline & 14 & 0.083 & 0. 584 & 0. 268 & & 0. 1529 \\
\hline & 15 & 0.072 & 0.606 & 0. 289 & & 0.1587 \\
\hline & 16 & 0.065 & 0.620 & 0. 302 & & 0.1623 \\
\hline & 17 & 0. 058 & 0.634 & 0. 314 & & 0.1660 \\
\hline & 18 & 0.049 & 0.652 & 0.334 & & 0. 1707 \\
\hline
\end{tabular}


TABLE 5.3-Heat exchanger and condenser tube data -Continued

\begin{tabular}{|c|c|c|c|c|c|c|}
\hline \multirow{2}{*}{$\begin{array}{c}\text { Tube } \\
\text { OD, } \\
\text { in. }\end{array}$} & \multirow[b]{2}{*}{ BWG } & \multirow{2}{*}{$\begin{array}{l}\text { Wall thick- } \\
\text { ness, in. }\end{array}$} & \multirow[b]{2}{*}{ ID, in. } & \multirow{2}{*}{$\begin{array}{r}\text { Flow area } \\
\text { per tube, } \\
\text { in.? }\end{array}$} & \multicolumn{2}{|c|}{ Surface per lin $\mathrm{ft}, \mathrm{ft}^{3}$} \\
\hline & & & & & Outside & Inside \\
\hline \multirow[t]{11}{*}{1} & 8 & 0.165 & 0.670 & 0.355 & 0.2618 & 0.1754 \\
\hline & 9 & 0. 148 & 0.704 & 0. 389 & & 0. 1843 \\
\hline & 10 & 0. 134 & 0.732 & 0.421 & & 0.1916 \\
\hline & 11 & 0. 120 & 0. 700 & 0.455 & & 0. 1990 \\
\hline & 12 & 0.109 & 0. 782 & 0.479 & & 0. 2048 \\
\hline & 13 & 0.095 & 0.810 & 0. 515 & & 0. 2121 \\
\hline & 14 & 0.083 & 0. 834 & 0. 546 & & 0.2183 \\
\hline & 15 & 0.072 & 0.856 & 0. 576 & & 0. 2241 \\
\hline & 16 & 0. 065 & 0. 870 & 0. 594 & & 0. 2277 \\
\hline & 17 & D. 058 & 0.884 & 0.613 & & 0. 2314 \\
\hline & 18 & 0. 049 & 0.902 & 0.639 & & 0.2361 \\
\hline \multirow[t]{11}{*}{$1 \%$} & 8 & 0. 165 & 0. 920 & 0.665 & 0.3271 & 0. 2409 \\
\hline & 9 & 0.148 & 0.954 & 0. 714 & & a. 2498 \\
\hline & 10 & o. 134 & 0. 982 & 0.757 & & 0. 2572 \\
\hline & 11 & 0.120 & 1. 01 & 0.800 & & 0.2644 \\
\hline & 12 & 0.109 & 1.03 & 0.836 & & 0.2701 \\
\hline & 13 & 0.095 & 1.06 & 0.884 & & 0.2775 \\
\hline & 14 & 0.083 & 1.08 & 0.923 & & 0.2839 \\
\hline & 15 & 0.072 & 1.11 & 0.960 & & 0.2896 \\
\hline & 16 & 0.065 & 1. 12 & 0.985 & & 0.2932 \\
\hline & 17 & 0.058 & 1.13 & 1. 01 & & 0.2969 \\
\hline & 18 & 0.049 & 1. 15 & 1.04 & & 0.3015 \\
\hline \multirow[t]{11}{*}{$11 / 2$} & 8 & 0.165 & 1. 17 & 1. 075 & 0. 3925 & 0. 3060 \\
\hline & 9 & 0. 148 & 1.20 & 1. 14 & & 0.3153 \\
\hline & 10 & 0. 134 & 1.23 & 1. 19 & & 0. 3222 \\
\hline & 11 & 0.120 & 1.26 & 1. 25 & & 0. 3295 \\
\hline & 12 & 0.109 & 1. 28 & 1. 29 & & 0. 3359 \\
\hline & 13 & 0.095 & 1. 31 & 1. 35 & & 0. 3436 \\
\hline & 14 & 0.083 & 1. 33 & 1. $40^{\circ}$ & & 0.3490 \\
\hline & 15 & 0.072 & 1. 36 & 1. 44 & & 0. 3552 \\
\hline & 16 & 0.065 & 1. 37 & 1.47 & & 0.3585 \\
\hline & 17 & 0.058 & 1. 38 & 1. 50 & & 0.3627 \\
\hline & 18 & 0.049 & 1. 40 & 1. 54 & & 0.3673 \\
\hline
\end{tabular}

- Conversion factors: $\mathrm{mm}=\mathrm{in} . \times 25.40 ; \mathrm{mm}^{2}=\mathrm{in} .{ }^{2} \times 645.160 ; \mathrm{m}^{2} / \mathrm{m}=\mathrm{ft}^{2} / \mathrm{ft} \times 0.30480$. Source: Donald Q. Kern, Process Heat Transfer, McGraw-Hill, New York, 1950.

eters in even fractions of an inch and with wall thickness specified in BWG are still being manufactured in the United States. Conversion factors for the SI system are given in footnotes to the tables.

Because the cleanliness of the condenser surfaces has a significant influence on the heat transfer and on the performance of the power cycle, the cooling-water treatment and the tube-cleaning system are very important adjuncts to the condensing system. These aspects are discussed in section 5.2.4.5. 
TABLE 5.4-Mechanical and physical properties of condenser tube materials =

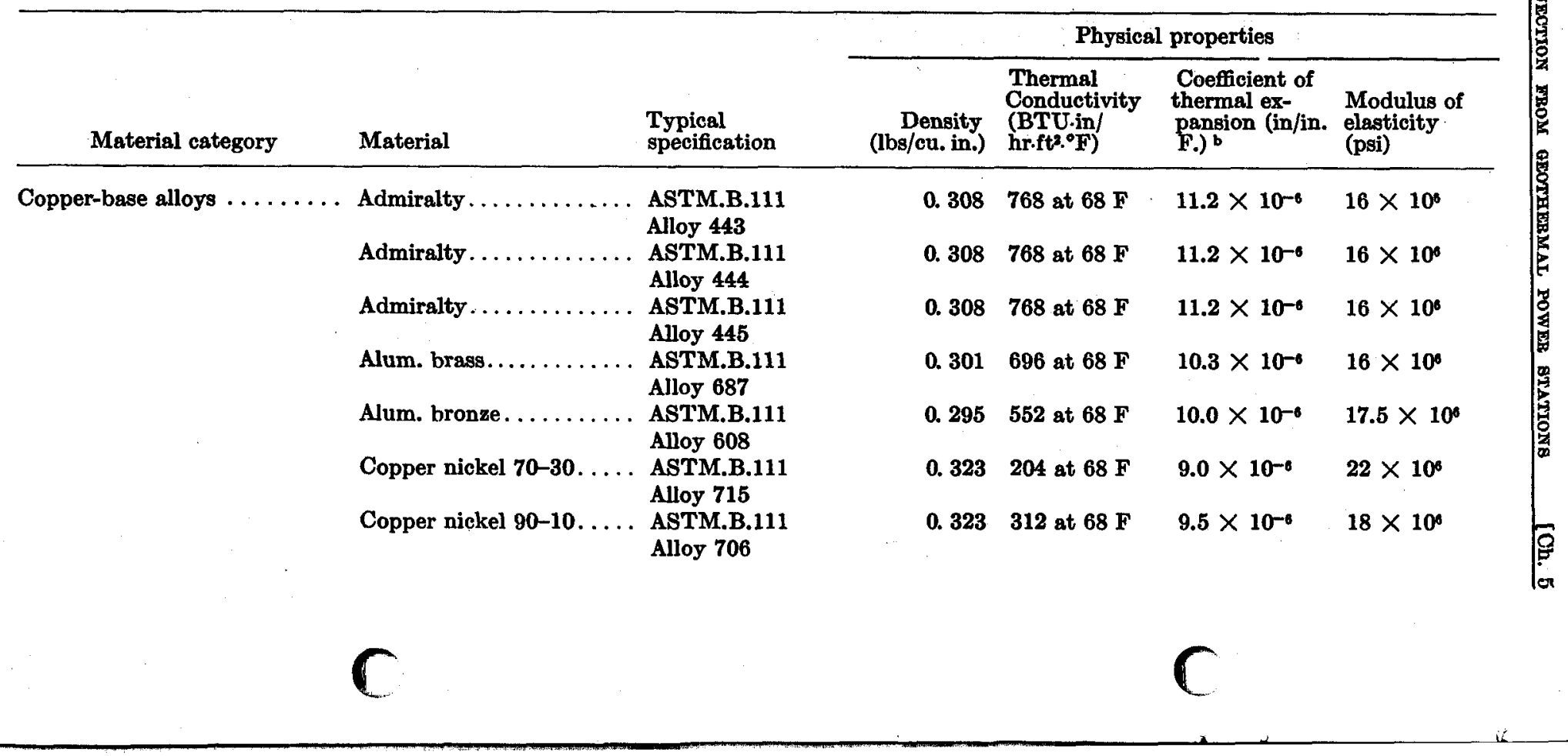


Arsenical copper......... ASTM.B.111 Alloy 142

Copper iron 194.

Stainless steels. . . . . . . . . Stainless steel.

Stainless steel

Stainless steel

Stainless steel

Titanium

Titanium

Titanium

Carbon steel.

Alloy 194

ASTM.A.249

Type 304

ASTM.A.249

Type 316

ASTM.A.269

Type 304

ASTM.A.269

Type 316

ASTM.B.338

Grade 1

ASTM.B.338

Grade 2

Carbon steel
0. 323

1344 at $68 \mathrm{~F}$

$9.8 \times 10^{-6}$

$17 \times 10^{6}$

0.3171800 at $68 \mathrm{~F} \quad 9.0 \times 10^{-0}$

$17.5 \times 10^{5}$

\begin{tabular}{|c|c|c|c|}
\hline 0.29 & 113 at $212 F$ & $9.9 \times 10^{-6}$ & $28 \times 10^{5}$ \\
\hline 0.29 & 113 at $212 \mathrm{~F}$ & $9.0 \times 10^{-6}$ & $28 \times 10^{4}$ \\
\hline 29 & 113 at $212 F$ & $9.9 \times 10^{-6}$ & $28 \times 10^{6}$ \\
\hline 0.29 & 113 at $212 \mathrm{~F}$ & $9-0 \times 10^{-1}$ & $28 \times 10^{\circ}$ \\
\hline 0.163 & $\begin{array}{c}\text { Approximately } \\
114 \text { at } 68 \mathrm{~F}\end{array}$ & $5.1 \times 10^{-6}$ & $14.9 \times 10^{6}$ \\
\hline 0.163 & $\begin{array}{l}\text { Approximately } \\
114 \text { at } 68 \mathrm{~F}\end{array}$ & $5.1 \times 10^{-6}$ & $14.9 \times 10^{6}$ \\
\hline
\end{tabular}

Conversion factors: $1 \mathrm{bf} / \mathrm{in.}^{2} \times 6894.757=\mathrm{Pa}$, or $\mathrm{N} / \mathrm{m}^{3}$; $\mathrm{lbm} / \mathrm{in} .{ }^{3} \times 27,679.90=\mathrm{kg} / \mathrm{m}^{2} ; \mathrm{BTU} \cdot \mathrm{in} . / \mathrm{hr} \cdot \mathrm{ft}{ }^{2} .^{\circ} \mathrm{F} \times 0.144279=\mathrm{W} / \mathrm{m} \cdot \mathrm{K} ; \mathrm{in} . / \mathrm{in} .{ }^{\circ} \mathrm{F}$ $\times 1.4=\mathrm{m} / \mathrm{m} \cdot \mathrm{K}$.

b Temperature ranges: copper-base alloys, 68-572 F; stainless and titanium, 32-600 F; carbon steel, mean $150 \mathrm{~F}$.

Source: Standards for Surface Condensers, 6th ed., Heat Exchanger Institute, New York, 1970. 
5.2.4.2 Heat transfer in surface condenser. The resistances to transfer of heat from the condensing vapor on the shell side to the fluid flowing inside the tubes of a surface condenser are expressed as

where

$$
\frac{1}{U_{o}}=\frac{1}{h_{o}}+\frac{A_{o}}{A_{t}} \frac{1}{h_{i}}+R_{f o}+\frac{A_{o}}{A_{i}} R_{f i}+\frac{D_{0} \ln \left(D_{o} / D_{i}\right)}{2 k}
$$

$U_{0}=$ overall heat transfer coefficient based on the outside surface area of the tube, $\mathrm{W} / \mathrm{m}^{2} \cdot \mathrm{K}\left(\mathrm{Btu} / \mathrm{hr} \cdot \mathrm{ft}^{2} \cdot{ }^{\circ} \mathrm{F}\right)$;

$h=$ film coefficient, $\mathrm{W} / \mathrm{m}^{2} \cdot \mathrm{K}\left(\mathrm{Btu} / \mathrm{hr} \cdot \mathrm{ft}^{2} \cdot{ }^{\circ} \mathrm{F}\right)$;

$A=$ area, $\mathrm{m}^{2}\left(\mathrm{ft}^{2}\right)$;

$R=$ resistance, $\mathrm{m}^{2} \cdot \mathrm{K} / \mathrm{W}\left(\mathrm{hr} \cdot \mathrm{ft}^{2} \cdot{ }^{\circ} \mathrm{F} / \mathrm{Btu}\right)$;

$D=$ tube diameter, $m(f t)$;

$k=$ thermal conductivity of the tube wall, $\mathrm{W} / \mathrm{m} \cdot \mathrm{K}\left(\mathrm{Btu} / \mathrm{hr} \cdot \mathrm{ft}^{2} \cdot{ }^{\circ} \mathrm{F}\right)$;

Subscripts: $o=$ outside, $i=$ inside, $f=$ fouling.*

Two of the most frequently used heat transfer correlations for laminar, filmwise condensation of a single vapor on the outside of a smooth, horizontal tube are (12)

where

$$
h_{o}=0.951\left(\frac{k_{f}^{3} \rho_{f}^{2} g}{\mu_{f}} \cdot \frac{L}{w}\right)^{1 / 3}=0.725\left(\frac{k_{f}^{3} \rho_{f}^{2} g}{\mu_{f}} \frac{h_{f g}}{N D \Delta t}\right)^{1 / 4}
$$

$h_{0}=$ outside film coefficient, $\mathrm{W} / \mathrm{m}^{2} \cdot \mathrm{K}\left(\mathrm{Btu} / \mathrm{hr} \cdot \mathrm{ft}^{2} \cdot{ }^{\circ} \mathrm{F}\right)$;

$k_{f}=$ thermal conductivity of the condensing liquid, $W / m \cdot K$ $\left(\mathrm{Btu} / \mathrm{hr} \cdot \mathrm{ft} \cdot{ }^{\circ} \mathrm{F}\right)$;

$p_{f}=$ density of the condensing liquid, $\mathrm{kg} / \mathrm{m}^{3}\left(\mathrm{lbm} / \mathrm{ft}^{3}\right)$;

$g=$ gravitational acceleration, $\mathrm{m} / \mathrm{sec}^{2}\left(\mathrm{ft} / \mathrm{hr} \mathrm{r}^{2}\right)$;

$\mu_{f}=$ absolute viscosity of the condensing liquid at film temperature, $\mathrm{Pa} \cdot \sec (\mathrm{lbm} / \mathrm{ft} \cdot \mathrm{hr})$;

$L=$ length of tubes, $\mathrm{m}$ (ft);

$w=$ flow rate of condensate from the lowest point on the condenser surface, $\mathrm{kg} / \mathrm{sec}(\mathrm{lbm} / \mathrm{hr})$;

$h_{f g}=$ latent heat of raporization of the condensing fluid, $\mathrm{W} \cdot \mathrm{sec} / \mathrm{kg}$ (Btu/lbm);

$N=$ number of tubes in the vertical tier;

$D=$ tube outside diameter, $\mathrm{m}(\mathrm{ft})$;

$\Delta t=$ temperature difference between the saturation temperature of the condensing fluid and the tube surface. $\mathrm{K}\left({ }^{\circ} \mathrm{F}\right)$.

Condensation in steam-power condensers is almost always laminar. The first correlation is convenient when the amount of fluid to be condensed is known; the second is useful when the difference between the condensing temperature and the tube surface temperature is available. Some selected

*Conversion factors: $\mathrm{W} / \mathrm{m}^{2} \cdot \mathrm{K}=\left(\mathrm{Btu} / \mathrm{hr} \cdot \mathrm{ft}^{2} \cdot{ }^{\circ} \mathrm{F}\right) \times 5.67827$

$\mathrm{W} / \mathrm{m} \cdot \mathrm{K}=\left(\mathrm{Btu} \cdot \mathrm{ft} / \mathrm{hr} \cdot \mathrm{ft}^{2} \cdot{ }^{\circ} \mathrm{F}\right) \times 1.73073$ 
values for the thermal conductivity, absolute viscosity, and specific heat and density of ammonia, Freon-22, isobutane, and water are listed in table 5.5. Values of the outside condensing film coefficient, $h_{r}$, have been calculated using the properties from this table and the above equations at 15,40 , and $60^{\circ} \mathrm{C}$ for ammonia, Freon-22, isobutane, and water as functions of $L / w$ and $h_{f g} / N D \Delta t$, as shown in tables 5.6 and 5.7. The values of $h_{o}$ at a condensing film temperature of $40^{\circ} \mathrm{C}\left(104^{\circ} \mathrm{F}\right)$ have been plotted

TABLE 5.5-Selected properties of liquid ammonia, Freon-22, isobutane, and water at temperatures of 16,40 , and $60^{\circ} \mathrm{C}$

\begin{tabular}{|c|c|c|c|}
\hline \multirow[b]{2}{*}{ Fluid } & \multicolumn{3}{|c|}{ Properties for given temperatures } \\
\hline & $15^{\circ} \mathrm{C}$ & $40^{\circ} \mathrm{C}$ & $60^{\circ} \mathrm{C}$ \\
\hline \multicolumn{4}{|c|}{$\boldsymbol{L}=$ =thermal conductivity, $\mathrm{W} \cdot \mathrm{m} / \mathrm{m}^{2} \cdot \mathrm{K}$} \\
\hline $\begin{array}{l}\text { Ammonia.. } \\
\text { Freon-22.. } \\
\text { Isobutane.. } \\
\text { Water.... }\end{array}$ & $\begin{array}{l}0.505 \\
0.0928 \\
0.111 \\
0.592\end{array}$ & $\begin{array}{l}0.445 \\
0.0803 \\
0.101 \\
0.631\end{array}$ & $\begin{array}{l}0.400 \\
0.0704 \\
0.0935 \\
0.654\end{array}$ \\
\hline \multicolumn{4}{|c|}{$\mu=$ absolute viscosity, $\mathrm{Pa} \cdot \sec$ or $\mathbf{k g} / \mathbf{m} \cdot \mathrm{sec}^{b}$} \\
\hline $\begin{array}{l}\text { Ammonia.: } \\
\text { Freon-22. } \\
\text { Isobutane. } \\
\text { Water. }\end{array}$ & $\begin{array}{l}0.000160 \\
0.000213 \\
0.000179 \\
0.00112\end{array}$ & $\begin{array}{l}0.000122 \\
0.000183 \\
0.000142 \\
0.000632\end{array}$ & $\begin{array}{l}0.0000984 \\
0.000162 \\
0.000122 \\
0.000452\end{array}$ \\
\hline
\end{tabular}

$c_{\mathbf{p}}=$ specific heat, $\mathbf{J} / \mathbf{k g} \cdot \mathrm{K}$ or $\mathbf{W} \cdot \mathbf{s e c} / \mathbf{k g} \cdot \mathbf{K} b$

Ammonia.................. $\quad \mathbf{4 6 7 8}$

Freon-22................. 1217

Isobutane................. $\quad 2450$

Water..................... 4192

$\rho=$ density, $\mathrm{kg} / \mathrm{m}^{3}$

Ammonia.$\ldots \ldots \ldots \ldots \ldots \ldots \ldots \ldots .618$

Freon-22 $\bullet . \ldots \ldots \ldots \ldots \ldots \ldots \ldots \ldots \ldots, 1232$

Isobutane $\bullet . \ldots \ldots \ldots \ldots \ldots \ldots \ldots \ldots, \quad 563$

Water d.................... $\quad 999$
4870

1323

2647

4179

5117

1495

2843

4188

$h_{f}=$ latent heat vaporization, $\mathrm{MJ} / \mathrm{kg}$ or $\mathrm{MW} \cdot \mathrm{sec} / \mathrm{kg}$
Ammonia . . . . . . . . . . . . . . . .
1. 21
1. 10
1. 00
Freon-22 $0 . \ldots \ldots \ldots \ldots \ldots \ldots \ldots$.
0. 193
0. 167
0. 141
Isobutane ${ }^{\prime} \ldots \ldots \ldots \ldots \ldots \ldots \ldots$
0.337
0. 307
0. 280
Water d
2. 47
2. 41
2. 36

- Conversion factors: $\mathrm{k}:(\mathrm{W} / \mathrm{m} \cdot \mathrm{K}) \times 0.577780=\mathrm{Btu} / \mathrm{hr} \cdot \mathrm{ft} \cdot{ }^{\circ} \mathrm{F} ; \mu:(\mathrm{Pa} \cdot \mathrm{sec})$ or $(\mathrm{kg} / \mathrm{m} \cdot \mathrm{sec}) \times 2419.09 \mathrm{lbm} / \mathrm{ft} \cdot \mathrm{hr} ; c_{7}:(\mathrm{J} / \mathrm{kg} \cdot \mathrm{K})$ or $(\mathrm{W} \cdot \mathrm{sec} / \mathrm{kg} \cdot \mathrm{K}) \times 0.0002388=$ Btu/lbm : ${ }^{\circ} \mathrm{F} ; \rho:\left(\mathrm{kg} / \mathrm{m}^{3}\right) \times 0.062428=1 \mathrm{bm} / \mathrm{ft}^{3} ; h_{f g}:(\mathrm{J} / \mathrm{kg})$ or $(\mathrm{W} \cdot \mathrm{sec} / \mathrm{kg}) \times 429.5911=$ Btu/lbm.

b Thermophysical Properties of Refrigerants, American Society of Heating, Refrigeration, and Air-Conditioning Engineers, New York, 1976.

- Handbool of Fundamentals, American Society of Heating, Refrigeration, and AirConditioning Engineers, New York, 1972.

d J. H. Keenan et al., Steam Tables, Thermodynamic Properties of Water, Including Vapor, Liquid and Solid Phases, Wiley, New York, 1969. 
TABLE 5.6-Condensing film coefficient outside of horizontal tubes as a function of $L / w$ at temperatures of 15,40 , and $60^{\circ} \mathrm{C}$

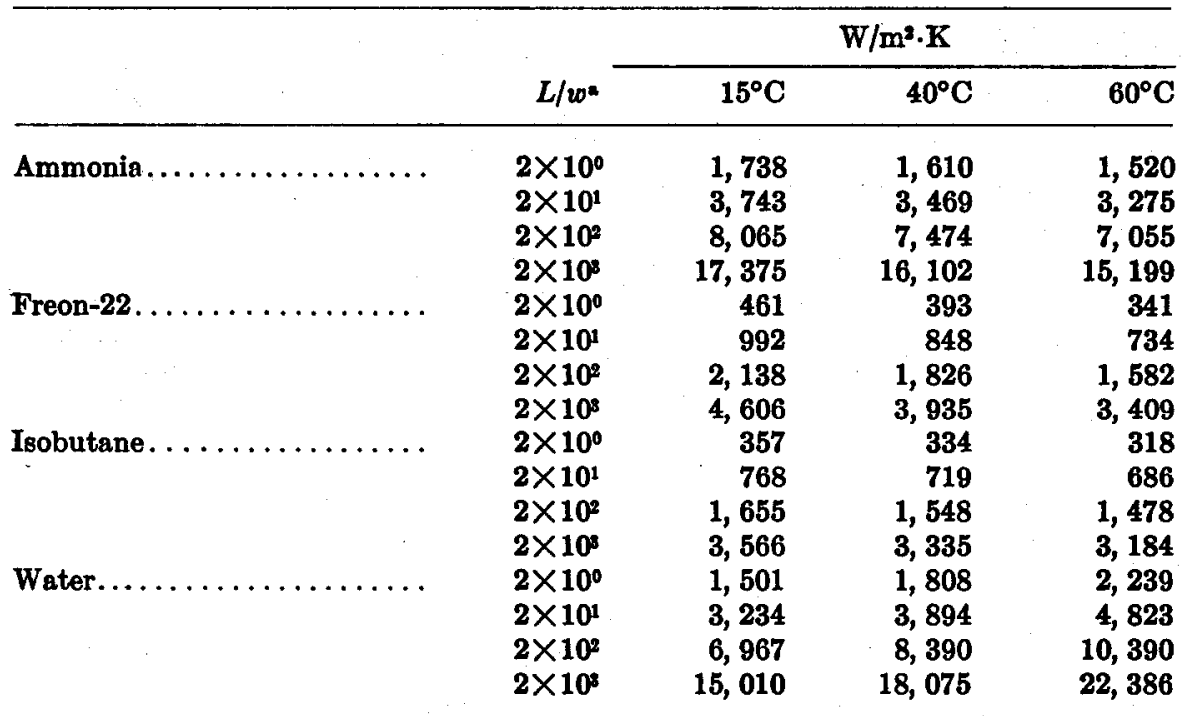

- Notes and conversion factors: $L=$ length of tubes, $\mathrm{m} ; w=$ flow rate of condensate from lowest point of condensing surfaces, $\mathrm{kg} / \mathrm{sec} ;\left(\mathrm{W} / \mathrm{m}^{2} \cdot \mathrm{K}\right) \times 0.176110=\mathrm{Btu} / \mathrm{hr}$. $\mathrm{ft}^{3} \cdot{ }^{\circ} \mathrm{F} ;(\mathrm{m} \cdot \mathrm{sec} / \mathrm{kg}) \times 413.3789 \times 10^{-\mathrm{i}}=\mathrm{ft} \cdot \mathrm{hr} / \mathrm{lbm}$.

TABLE 5.7-Condensing film coefficient outside of horziontal tubes as function of $h_{f} / N D \Delta t$ at temperatures of 16,40 , and $60^{\circ} \mathrm{C}$

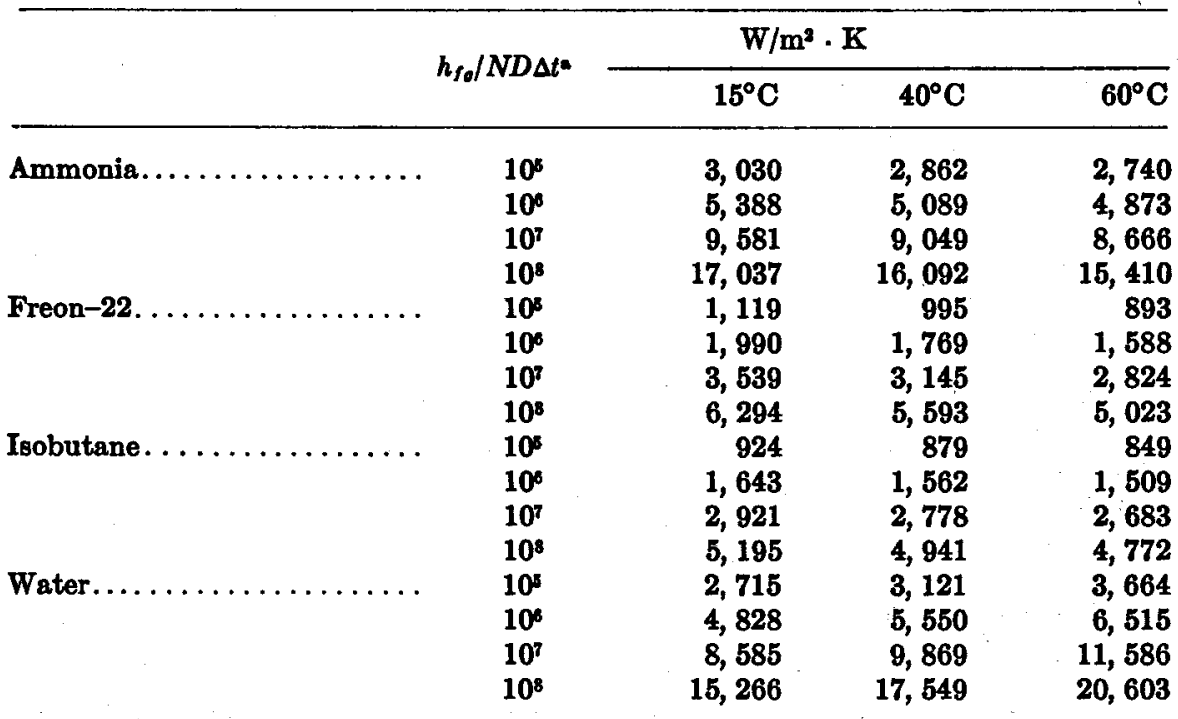

- Notes and conversion factors: $h_{f_{\varepsilon}}=$ latent heat vaporization of condensing fluid $\mathrm{J} / \mathrm{kg}$, or $\mathrm{W} \cdot \mathrm{sec} / \mathrm{kg} ; N=$ number of tubes in vertical tier; $D=$ outside diameter of tubes, $\mathrm{m} ; \Delta t=$ temperature difference across film, ${ }^{\circ} \mathrm{C} ;\left(\mathrm{W} / \mathrm{m}^{2} \cdot \mathrm{K}\right) \times 0.176110=$ $\mathrm{Btu} / \mathrm{hr} \cdot \mathrm{ft}^{2} \cdot{ }^{\circ} \mathrm{F} ;\left(\mathrm{W}^{\circ} \cdot \mathrm{sec} / \mathrm{kg} \cdot \mathrm{m} \cdot \mathrm{K}\right) \times 72.80023 \times 10^{-6}=\mathrm{Btu} / 1 \mathrm{bm} \cdot \mathrm{ft} \cdot{ }^{\circ} \mathrm{F}$. 
as a function of $L / w$ in figure 5.9. The effect of the presence of noncondensable gases on the outside film coefficient is discussed in section 5.2.4.4.

For water, the resistance to heat transfer in the boundary layer inside liquid-cooled surface condenser tubes may be one of the most important of the resistances. In a steam power condenser, the condition inside the tube is almost always in the turbulent, forced-convection regime, and the following relationship is commonly used :

where

$$
\frac{h_{s} d}{k}=0.023\left(\frac{d V \rho}{\mu}\right)^{0.8}\left(\frac{\mu c_{p}}{k}\right)^{0.4}
$$

$h_{i}=$ inside film heat transfer coefficient,

$$
\mathrm{W} / \mathrm{m}^{2} \cdot \mathrm{K}\left(\mathrm{Bta} / \mathrm{hr} \cdot \mathrm{ft}^{2} \cdot{ }^{\circ} \mathrm{F}\right) ;
$$

$d=$ inside diameter of tube, $\mu \mathrm{m}$ ( $\mathrm{ft}$ );

$k=$ thermal conductivity of fluid, $\mathrm{W} \cdot \mathrm{m} / \mathrm{m}^{2} \cdot \mathbf{K}\left(\mathrm{Btu} / \mathrm{hr} \cdot \mathrm{ft} \cdot{ }^{\circ} \mathrm{F}\right)$;

$\nabla=$ velocity in tube, $\mathrm{m} / \mathrm{sec}(\mathrm{ft} / \mathrm{hr})$;

$\rho=$ density of fluid, $\mathrm{kg} / \mathrm{m}^{3}\left(\mathrm{lbm} / \mathrm{ft}^{\mathrm{s}}\right)$;

$\mu=$ absolute viscosity of fluid, $\mathrm{Pa} \cdot \sec (\mathrm{lbm} / \mathrm{ft} \cdot \mathrm{hr})$;

$c_{p}=$ specific heat of fluid, $\mathrm{W} \cdot \mathrm{sec} / \mathrm{kg} \cdot \mathrm{K}\left(\mathrm{Btu} / \mathrm{lbm} \cdot{ }^{\circ} \mathrm{F}\right)$.

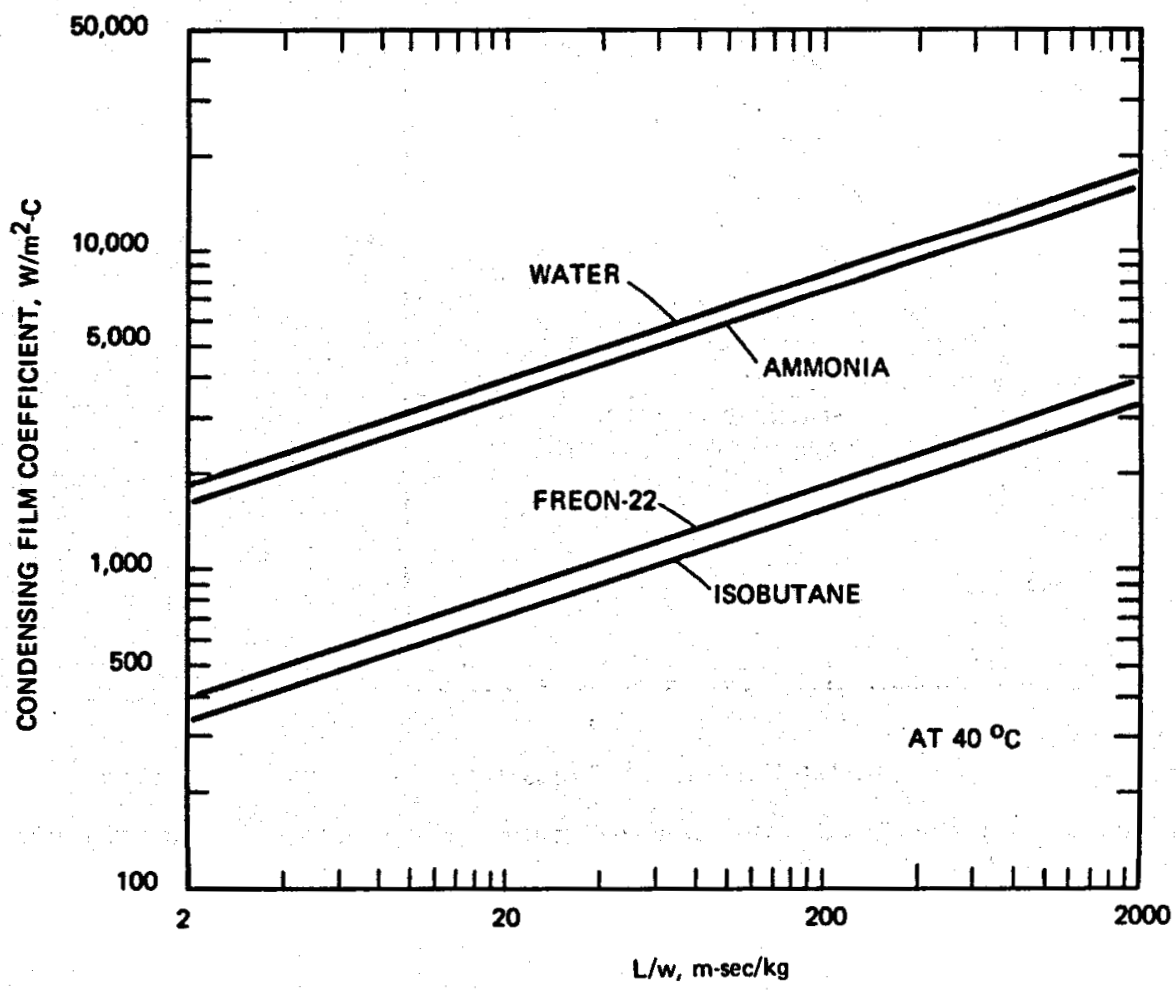

Frauge 5.9-Condensing film heat transfer coefficient at $40^{\circ} \mathrm{O}\left(104^{\circ} \mathrm{F}\right)$ as a function of $\mathrm{L} / \omega$. Refer to Table 5.6 where $B \mathrm{tu} / \mathrm{hr} \cdot \mathrm{ft}^{2} \cdot{ }^{\circ} \mathrm{W}=\mathrm{W} / \mathrm{m}^{2} \cdot \mathrm{K} \times 0.176110$. 
All of the thermal properties of the fluid flowing inside the tube are evaluated at the bulk temperature. The inside film coefficient for $2.25-\mathrm{cm}$ (7/8-in.) OD No. $18 \mathrm{BWG}$ tubes for water in the temperature range of $15^{\circ} \mathrm{C}$ $\left(59^{\circ} \mathrm{F}\right)$ to $60^{\circ} \mathrm{C}\left(140^{\circ} \mathrm{F}\right)$ is plotted in figure 5.10 as a function of the velocity inside the tube. Adjustment factors for other tube diameters are also given in figure 5.10. The heat transfer coefficient decreases with temperature, which negates slightly the advantages of using colder water as the coolant.

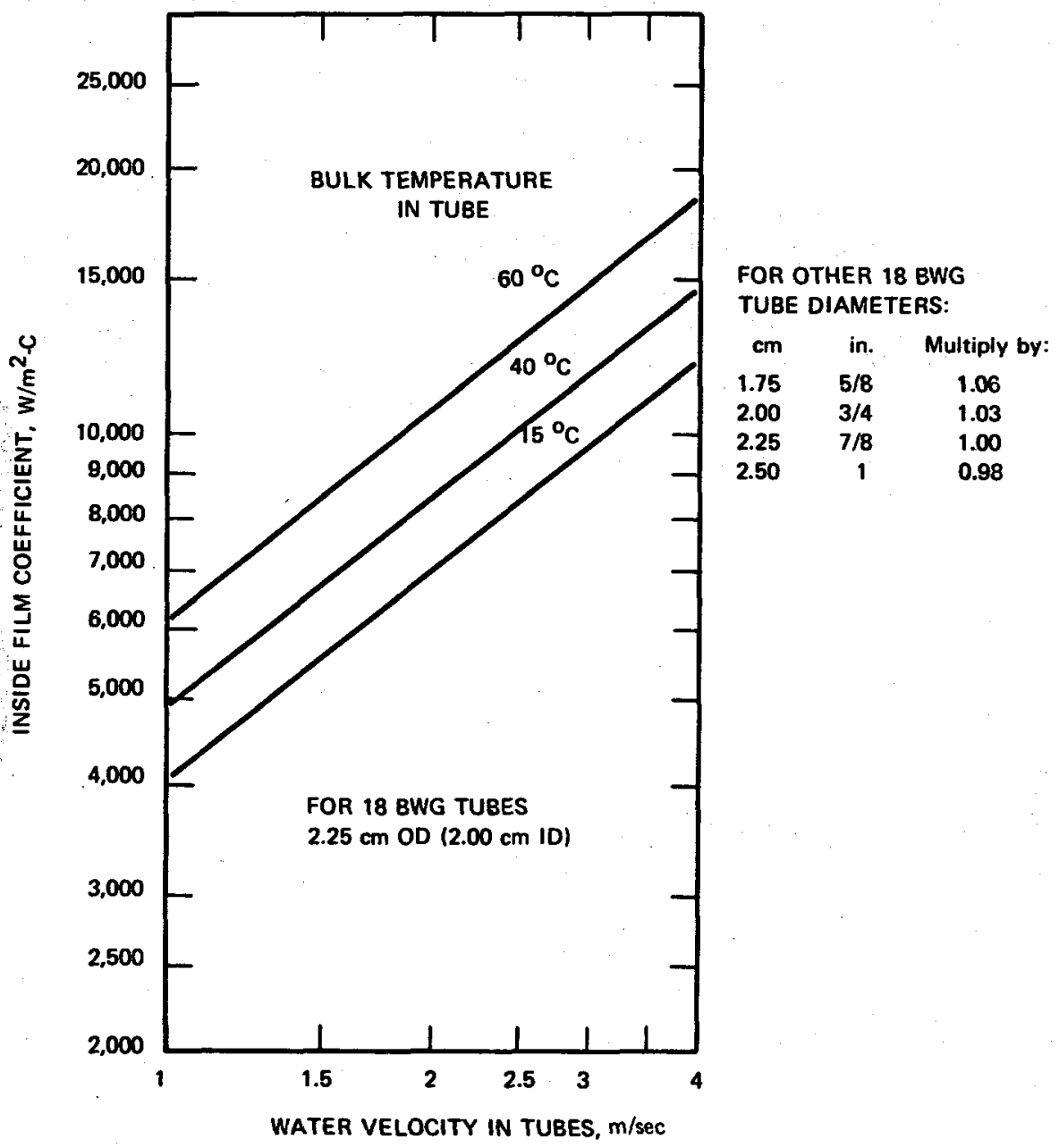

Fraune 5.10-Inside liquid water flm heat transfer coefficient as function of water velocity in No. $18 \mathrm{BWG}$ tubes $\left(\mathrm{W} / \mathrm{m}^{3} \cdot \mathrm{K} \times 0.176110=\mathrm{Btu} / \mathrm{hr} \cdot \mathrm{ft}^{2} \cdot{ }^{\circ} \mathrm{F}\right)$. 
The resistance to heat transfer in the tube wall is a function of the wall thickness and the conductivity of the metal. Table 5.4 shows the thermal conductivities of some of the commonly used condenser tubing materials. The conductivity increases with temperature in some metals (e.g., aluminum, brass, and the stainless steels) and decreases with temperature in materials such as copper, steel, iron, etc. However, over the temperature range of usual application in steam-power condensers, the changes are not great. In any event, the resistance to heat transfer due to the wall is such a small percentage of the total resistance that the variation of the thermal conductivity with temperature need not be taken into account. A log mean thickness for the tube wall may be used instead of the wall thickness (as indicated in the equation), but here again the refinement will have only a small effect on the calculated overall heat transfer coefficient for the condenser.

Although there may seem to be an incentive to use smaller diameter tubing to obtain the maximum heat transfer surface per unit volume in the condenser, tubes smaller than 15-mm ( $\%$-in.) OD become plugged too easily and are excessively difficult to clean. In larger sizes of condensers, tube diameters of $22 \mathrm{~mm}(\% \mathrm{in}$.) and $25 \mathrm{~mm}(1 \mathrm{in}$.) are used so that the tube length can be increased without causing excessive frictional pressure losses.

The resistance of the foulants on the tube surface is typically taken as about $0.00018 \mathrm{~m}^{2} \cdot \mathrm{K} / \mathrm{W}\left(0.001 \mathrm{hr} \cdot \mathrm{ft}^{2} \cdot{ }^{\circ} \mathrm{F} / \mathrm{Btu}\right)$ for tubes that use relatively clean water and that need only occasional cleaning. Fouling resistances of about one-fifth of this value may be attained using very clean water and frequent regular cleaning of the surfaces. For relatively dirty surfaces, which might be encountered when using seawater as the coolant, the resistance should probably be taken as five times the above value. The performance of enhanced-surface tubing is particularly vulnerable to fouling (section 5.2.4.8).

In power plant applications, where water is condensed outside of smooth tubes and coolant water flows through the tubes, the resistances may be distributed as follows : 1) $20 \%$ due to the outside film coefficient, 2) $4 \%$ due to the tube wall resistance, 3) 55 to $60 \%$ due to the inside film coefficient, and 4) about 15 to $20 \%$ due to the fouling on both sides of the tube. One source (13) states that the distribution is usually $18 \%$ due to the outside film, $8 \%$ due to fouling outside the tube, $2 \%$ due to the tube wall, 33\% due to fouling inside the tube, and $39 \%$ due to the inside film coefficient. The difference presumably lies in the degree of fouling considered normal. The major resistances are the inside film coefficient and the resistance of the dirt and slime deposits if the tubes are not clean. The overall heat transfer coefficient, $U_{o}$, with the area based on the outside 
diameter of the tubes and water on both sides of the tubes, will probably fall in the 2300 - to $4000-\mathrm{W} / \mathrm{m}^{2} \cdot \mathrm{K}\left(400-\right.$ to $\left.700-\mathrm{Btu} / \mathrm{hr} \cdot \mathrm{ft}^{2} \cdot{ }^{\circ} \mathrm{F}\right)$ range (figure 5.11). Correction factors for other tube materials are given in table 5.8 and in figure 5.19. For other than typical installations and where fluids other than water are used, one must examine the individual resistances. The film coefficients are relatively well studied and the literature extensive, but data on fouling resistances is not as easily available because of the variations between specific applications. Also, such studies do not lend themselves as well as a systematic approach and to university-related research projects. There is often the dilemma of the design engineer who can calculate the film coefficients and the wall resistance in detail because information is readily available but can do little to account accurately for noncondensable gases and fouling, which can be major resistances to the heat transfer.

TABLE 5.8-Correction factors for any tube gage or material other than No. 18 BWG admiralty metal with which to multiply the heat transfer coefficients obtained from figure 5.11

\begin{tabular}{|c|c|c|c|c|c|c|c|}
\hline \multirow{2}{*}{ Tube materials } & \multicolumn{7}{|c|}{ Tube wall gauge- $\mathrm{BWG}$} \\
\hline & 24 & 22 & 20 & 18 & 16 & 14 & 12 \\
\hline Admiralty metal. & 1. 06 & 1. 04 & 1. 02 & 1.00 & 0.96 & 0.92 & 0.87 \\
\hline Arsenical copper. . & 1. 06 & 1. 04 & 1. 02 & 1. 00 & 0.96 & 0.92 & 0.87 \\
\hline Aluminum....... & 1. 06 & 1. 04 & 1. 02 & 1. 00 & 0.96 & 0.92 & 0.87 \\
\hline Aluminum brass. & 1.03 & 1. 02 & 1.00 & 0.97 & 0.94 & 0.90 & 0.84 \\
\hline Aluminum bronze. & 1. 03 & 1. 02 & 1.00 & 0.97 & 0. 94 & 0.90 & D. 84 \\
\hline Muntz metal..... & 1.03 & 1. 02 & 1. 00 & 0.97 & 0.94 & 0.90 & 0.84 \\
\hline 90-10 Cu-Ni. . & 0.99 & 0.97 & 0.94 & 0.90 & 0.85 & 0.80 & 0. 74 \\
\hline 70-30 Cu-Ni... & 0.93 & 0.90 & 0.87 & 0.82 & 0.77 & 0.71 & 0.64 \\
\hline $\begin{array}{l}\text { Cold-rolled low carbon steel...... } \\
\text { Stainless steels: }\end{array}$ & 1.00 & 0.98 & 0.95 & 0.91 & 0.86 & 0.80 & 0.74 \\
\hline Type 410/430... & 0.88 & 0.85 & 0.82 & 0.76 & 0.70 & 0.65 & 0.59 \\
\hline Type 304/316. & 0.83 & 0.79 & 0.75 & 0.69 & 0.63 & 0.56 & 0.49 \\
\hline Type 329. & 0.78 & 0.76 & 0.74 & 0.69 & 0.65 & 0.60 & 0. 54 \\
\hline Titanium (tentative)... & 0.85 & 0.81 & 0.77 & 0.71 & - & - & 一 \\
\hline
\end{tabular}

Source: Standards for Surface Condensers, 6th ed., Heat Exchanger Institute, New York, 1970.

For a detailed treatment of heat transfer, the reader should consult the literature-such as the text of McAdams (12). The American Society of Heating, Refrigerating, and Air-Conditioning Engineers' (ASHRAE) Handbook of Fundamentals (1) contains a good summary of heat transfer relationships (chapter 2), and compilations of thermophysical properties are given in chapter 14. The ASHRAE work also serves as a reference for geothermal applications because, in addition to water, it covers such fluids as isobutane, ammonia, and Freons. 


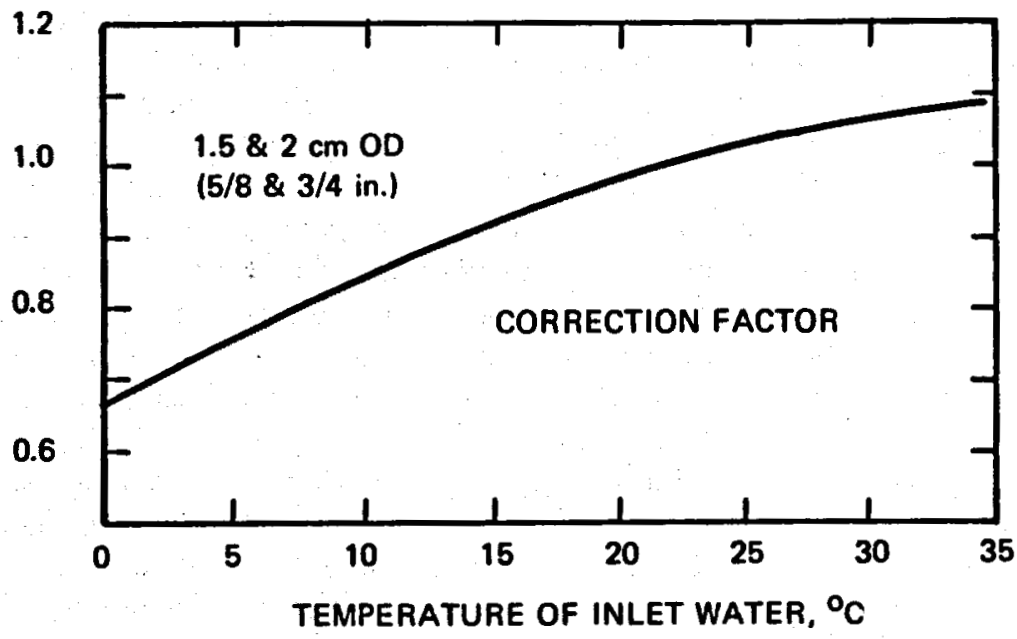

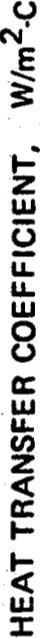

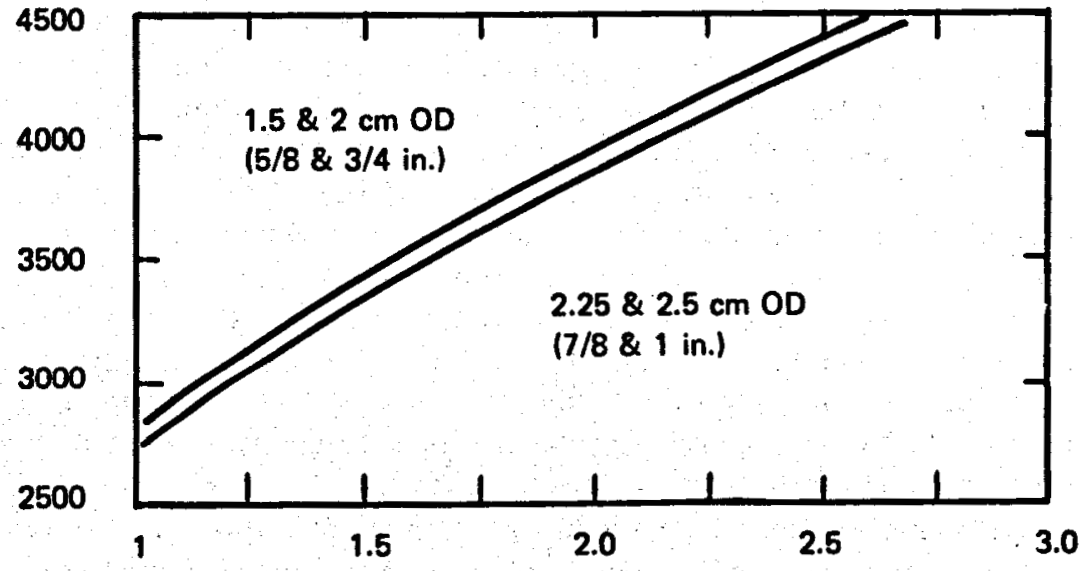

VELOCITY, $\mathrm{m} / \mathrm{sec}$

To obtain

Btu/hr-ft ${ }^{2} \cdot F$
Multiply

$W / m^{2} \cdot K$

$\mathrm{m} / \mathrm{sec}$
By

0.176110

$\mathrm{ft} / \mathrm{sec}$
0.3048

Fioune 5.11-Overall heat transfer coefficient for condensing on No. 18 BWG Admiralty metal tubes, for a cooling-water temperature of $21^{\circ} \mathrm{C}\left(70^{\circ} \mathrm{F}\right)$, based on external surface area of tube. A fouling factor of 0.85 is commonly applied to the coefficients. Source: Standards for Surface Condensers, 6th ed., Heat Exchanger Institute, New York, 1870. 
5.2.4.3 Multipressure condensers. Turbines with compounded low-pressure ends may use a separate condenser shell for each of the turbine exhausts. The cooling water may be arranged to flow through the condensers either in parallel or in series. With parallel flow, the condensing steam temperatures will be essentially the same. With series flow, the temperature in each condensing zone will be different, and the average temperature will be less than for the parallel-connected arrangement. The former is termed a "single-pressure" system and the latter a "multipressure" system. The lower average backpressure for the multipressure arrangement improves the cycle heat rate. In closed cycles, an improvement to the heat rate can also be made by passing the condensate from the lower-pressure condenser into the higher-pressure unit for direct contact with the condensing steam, thereby raising the average temperature of the condensate above the temperature that could be attained in a single-pressure system. In general, multipressure systems are most advantageous in systems with low terminaltemperature differences and high temperature-rises (ranges) for the cooling water.

Although multipressure arrangements improve the cycle efficiency, the capital costs of the system are greater than those of a single-pressure system. The turbines must be designed for the specific exhaust pressures, and lower back-pressures will increase the capital cost. The water-circulating pumps will require more power because of the increased pumping head needed for the series flow arrangement, possibly causing the required piping layouts to be more expensive. Palmer and Miller (14) point out that, rather than operating at reduced back-pressure, it may be more economical to reduce the surface area and the water flow rates by amounts that will result in the same heat rate as that for a single-pressure system. The savings in capital and operating costs in this arrangement frequently exceed the savings resulting from reduced heat rates.

An evaluation must be made of each particular application to weigh the heat rate advantages of the multipressure arrangement against the relative simplicity and lower initial cost of the single-pressure system. The potential heat rate gain for multipressure systems is difficult to estimate because of the complex relationships existing among the low-pressure turbine, the condenser, and the first low-pressure heater (15). Because the cost differentials require detailed study, it is difficult to present any generalized rules concerning which of the arrangements will be the best choice. A first approximation of the amount the condensing temperature will be lowered can be obtained from the Palmer and Miller (14) equation shown below. This expression assumes that the total duty, total heat transfer area, and total temperature rise of the cooling water remain the same in all cases and are divided equally among the condensing zones. The overall heat transfer coefficient and the log-mean $\Delta t$ are assumed to be the same in each unit as they are in a single condenser. The relationships among the temperature range $(T R)$, the terminal temperature difference, $(T T D)$, and the initial 
temperature difference (ITD) are shown in figure 5.12 for a two-zone surface condenser. The difference between the single-pressure condensing temperature and the average multipressure condensing temperature, $\Delta T_{8}$, is then given by Palmer and Miller (14) as

where

$$
\Delta T_{s}=I T D-\frac{T R(n-1)}{2 n}-\frac{T R}{n}\left[\frac{\left(\frac{1}{1-R}\right)^{1 / n}}{\left(\frac{1}{1-R}\right)^{1 / n}-1}\right]
$$

$\Delta T,=$ difference between the single-pressure condensing steam temperature and the average multipressure condensing temperature, ${ }^{\circ} \mathrm{F}$,

$n=$ number of condensing zones,

$T R=$ total temperature range of cooling water for single-pressure condenser, ${ }^{\circ} \mathrm{F}$,

$I T D=$ initial temperature difference between entering cooling water and condensing steam for single-pressure condenser, ${ }^{\circ} \mathrm{F}$, $(I T D=T R+T T D)$,

$T T D=$ terminal temperature difference,

$R=T R / I T D$.

If the terminal temperature difference is zero (ITD $=T R$ and $R=1$, the above expression reduces to

$$
\Delta T_{\mathrm{a}}=T R\left(\frac{n-1}{2 n}\right)
$$

Values of $\Delta T_{8}$ are plotted against $T R$ in figure 5.13 for $T T D_{8}$ of $0,1.5$, 2.5 , and $4^{\circ} \mathrm{C}$. For typical conditions with a temperature range of 8 to $11^{\circ} \mathrm{C}$ $\left(15\right.$ to $\left.20^{\circ} \mathrm{F}\right)$ and a terminal temperature difference of about $2.8^{\circ} \mathrm{C}\left(5^{\circ} \mathrm{F}\right)$, the value of $\Delta T^{\prime}$, is 0.7 to $1.1^{\circ} \mathrm{C}\left(12\right.$ to $\left.2.0^{\circ} \mathrm{F}\right)$. If the single-pressure condenser were condensing at $32^{\circ} \mathrm{C}$ and $36 \mathrm{~mm}$ of mercury absolute $\left(90^{\circ} \mathrm{F}\right.$ and 1.42 in. of mercury absolute), the resulting decrease in the heat rate due to the reduced turbine back-pressure would be in the range of 0.9 to $3.5 \mathrm{~W} / \mathrm{kW}$ ( 3 to $12 \mathrm{Btu} / \mathrm{kWhr}$ ). There would also be a reduction in the heat rate of 0.9 to $1.5 \mathrm{~W} / \mathrm{kW}$ ( 3 to $5 \mathrm{Btu} / \mathrm{kWhr}$ ) because of increased condensate temperature. With direct-contact condensers, the value of $\Delta T_{a}$ would be higher, about $2.8^{\circ} \mathrm{C}\left(5^{\circ} \mathrm{F}\right)$, and the corresponding gains in heat rate would be greater. However, it is not clear whether geothermal power stations in the near-term of the art will have more than one condenser per turbine and thus be suitable for multipressure arrangements. Further, the added complexity on the basis of relatively small improvements to the cycle heat rate may not be justified.

When using thermodynamic fluids other than water, the condensing pressures at ordinary condensing temperatures may be high enough to 


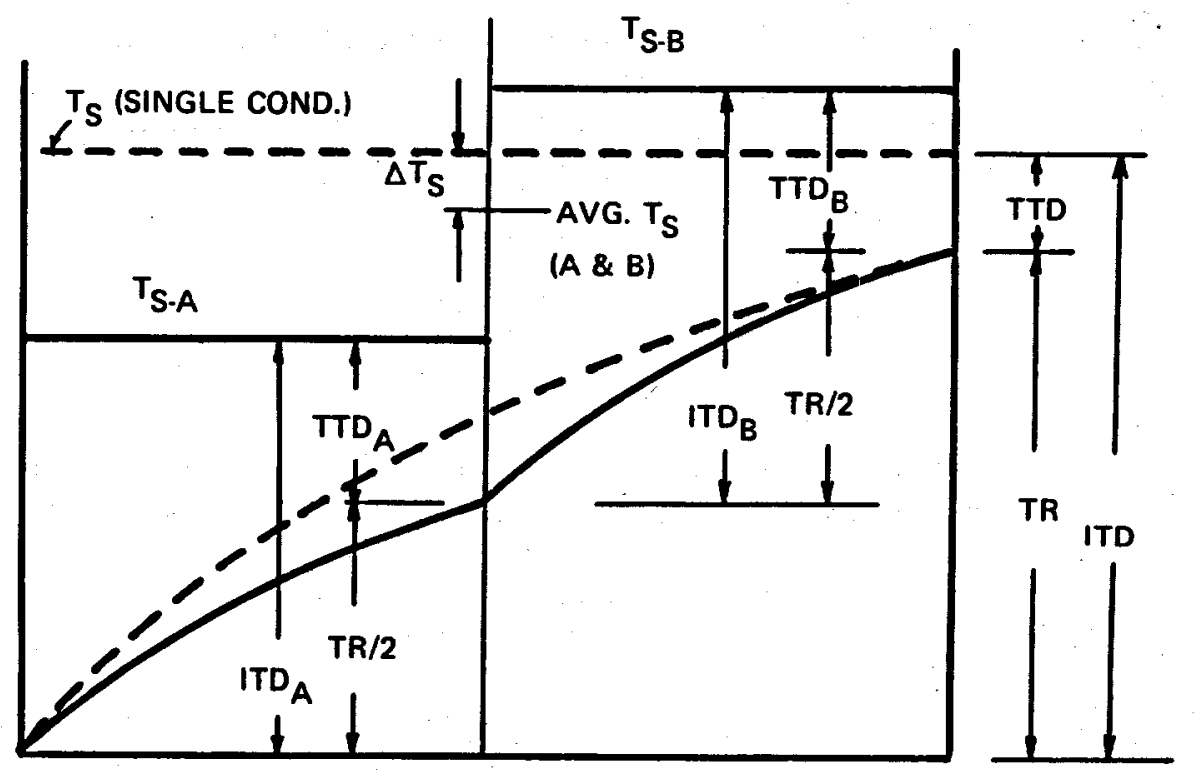

TEMPERATURE RELATIONSHIPS IN TWO-ZONE CONDENSER

$$
\begin{aligned}
& T_{S}=\text { CONDENSING STEAM TEMPERATURE } \\
& \text { ITD }=\text { INITIAL TEMPERATURE DIFFERENCE } \\
& \text { TTD }=\text { TERMINAL TEMPERATURE DIFFERENCE } \\
& T R=\text { TEMPERATURE RANGE }
\end{aligned}
$$

Figure 6.12-Temperature relationships in multipressure condensing system with two condensers in series in the cooling-water circuit.

require the use of multiple condenser shells, which could be connected in series in the cooling-water circuit. The gain in efficiency resulting from the reduced back-pressure for these fluids has not been studied fully. Moreover, sufficient cost information has not been accumulated to serve as a basis for judgment at this time.

5.2.4.4 Noncondensable gases. The percent of noncondensable gases in geothermal steam varies from well to well but averages less than $1 \%$ by weight. Typical ranges of concentrations of the various gases in geothermal steam at The Geysers are shown in table 5.9. Carbon dioxide is by far the major constituent, amounting to 75 to $95 \%$ of the noncondensables. The flashed-steam system at Cerro Prieto, Mexico, has steam entering the turbines which contains impurities in the following average amounts: $\mathrm{CO}_{2}$, $14,000 \mathrm{ppm} ; \mathrm{H}_{2} \mathrm{~S}, 1500 \mathrm{ppm} ; \mathrm{NH}_{4}, 110 \mathrm{ppm}$; chlorine, $0.8 \mathrm{ppm}$; sodium, $0.4 \mathrm{pm} ; \mathrm{SiO}_{2}, 0.2 \mathrm{ppm}(16)$. Although hydrogen sulfide $\left(\mathrm{H}_{2} \mathrm{~S}\right)$, a highly toxic gas, is present in much smaller amounts, it can be detected by smell 


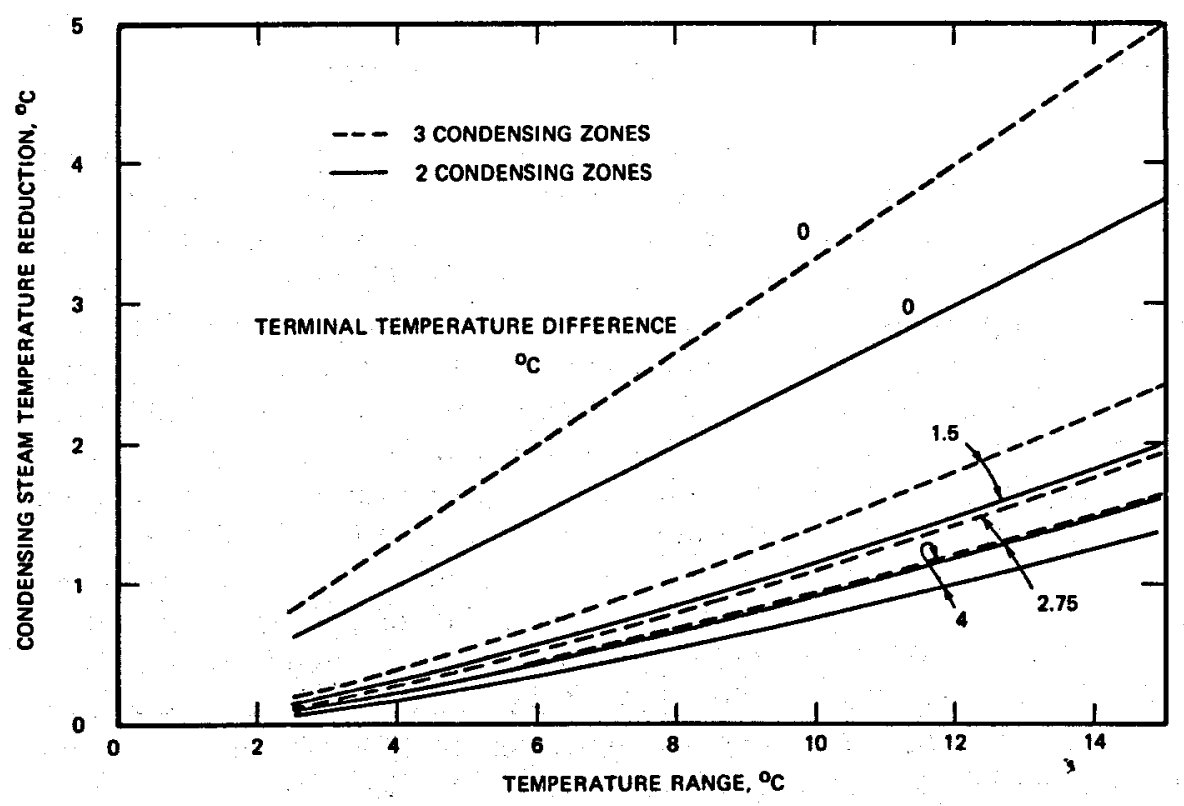

FrguRx 6.13-Difference in condensing temperatures between single-pressure condenser and inultipressure arrangements.

at such low concentrations that a layman's impression is that it exists in large amounts at geothermal power installations. Its odor is a nuisance at concentrations as low as $0.07 \mathrm{ppm}$, and it causes eye irritation at $1 \mathrm{ppm}$. Prolonged exposure at concentrations of $100 \mathrm{ppm}$ can be fatal, and about $1 \mathrm{hr}$ of exposure to concentrations above $600 \mathrm{ppm}$ is fatal. The potential hazard of $\mathrm{H}_{2} \mathrm{~S}$ is increased because it cannot be detected by smell at the higher concentrations. Mercury and radon, which may be present in trace amounts at some wells, are of particular concern because they are also toxic

TABLE 5.9-Percent by weight of constituent gases in geothermal steam at The Geysers

\begin{tabular}{|c|c|c|c|}
\hline Gas & Low & High & Design \\
\hline Carbon dioxide. & 0. 0884 & 1.90 & 0. 79 \\
\hline Hydrogen sulfide. & 0. 0005 & 0.160 & 0.05 \\
\hline Methane. . . . . . . . . . . . . . & 0. 0056 & 0.132 & 0.05 \\
\hline 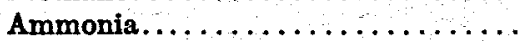 & 0.0056 & 0. 106 & 0.07 \\
\hline Nitrogen $\ldots \ldots \ldots \ldots \ldots \ldots \ldots \ldots$ & 0.0016 & 0.0638 & 0.03 \\
\hline Hydrogen $\ldots \ldots \ldots \ldots \ldots \ldots \ldots \ldots$ & 0.0018 & 0.0190 & 0.01 \\
\hline 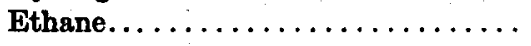 & 0.0003 & 0. 0019 & \\
\hline Total. & 0. 120 & 2. 19 & 1. 00 \\
\hline
\end{tabular}

Source: J. P. Finney, The Design and Operation of The Geysers Power Plant, Geothermal Energy, ed. by Paul Kruger and Carel Otte, Stanford University Press, Stanford, Calif., 1973, table 1, p. 148. 
at very low concentrations ( $(16)$; see also chapter 10). Ammonia is a potential hazard, but it usually exists at too low a concentration to be of concern (17).

Geothermal power systems, particularly those utilizing steam flashed from geothermal fluids, may have to contend with significant amounts of noncondensable gases being swept through the system and into the turbine condenser. The gases reduce the turbine efficiency by expanding with less enthalpy drop than steam (5), but, perhaps more importantly, the gases can reduce markedly the performance of the condensing equipment. Othmer (18) investigated the effect of noncondensable gases in 1929, and his work was substantiated by Henderson and Marchello (19) in 1969 when they used steam-air and toluene-nitrogen mixtures condensing on a horinzontal pipe. Othmer (as indicated in figure 5.14) showed that $1 \%$ of gas by volume in the steam to a surface condenser with a temperature difference of about $11^{\circ} \mathrm{C}\left(20^{\circ} \mathrm{F}\right)$ can cause the condensing coefficient to be about $6250 \mathrm{~W} / \mathrm{m}^{2} \cdot \mathrm{K}\left(1100 \mathrm{Btu} / \mathrm{hr} \cdot \mathrm{ft}^{2} \cdot{ }^{\circ} \mathrm{F}\right)$ compared to about $11,400 \mathrm{~W} / \mathrm{m}^{2} \cdot \mathbf{K}\left(2000 \mathrm{Btu} / \mathrm{hr} \cdot \mathrm{ft}^{2} \cdot{ }^{\circ} \mathrm{F}\right)$ when no gas is present. Figure 5.14 illustrates that if the gas concentration is $2 \%$ by volume the condensing coefficient is only about $4260 \mathrm{~W} / \mathrm{m}^{2} \cdot \mathrm{K}\left(750 \mathrm{Btu} / \mathrm{hr} \cdot \mathrm{ft}^{2} \cdot{ }^{\circ} \mathrm{F}\right)$.

Keeping in mind that the total pressure in a condenser is the sum of the partial pressures of the water vapor, air, hydrogen sulfide, carbon dioxide,

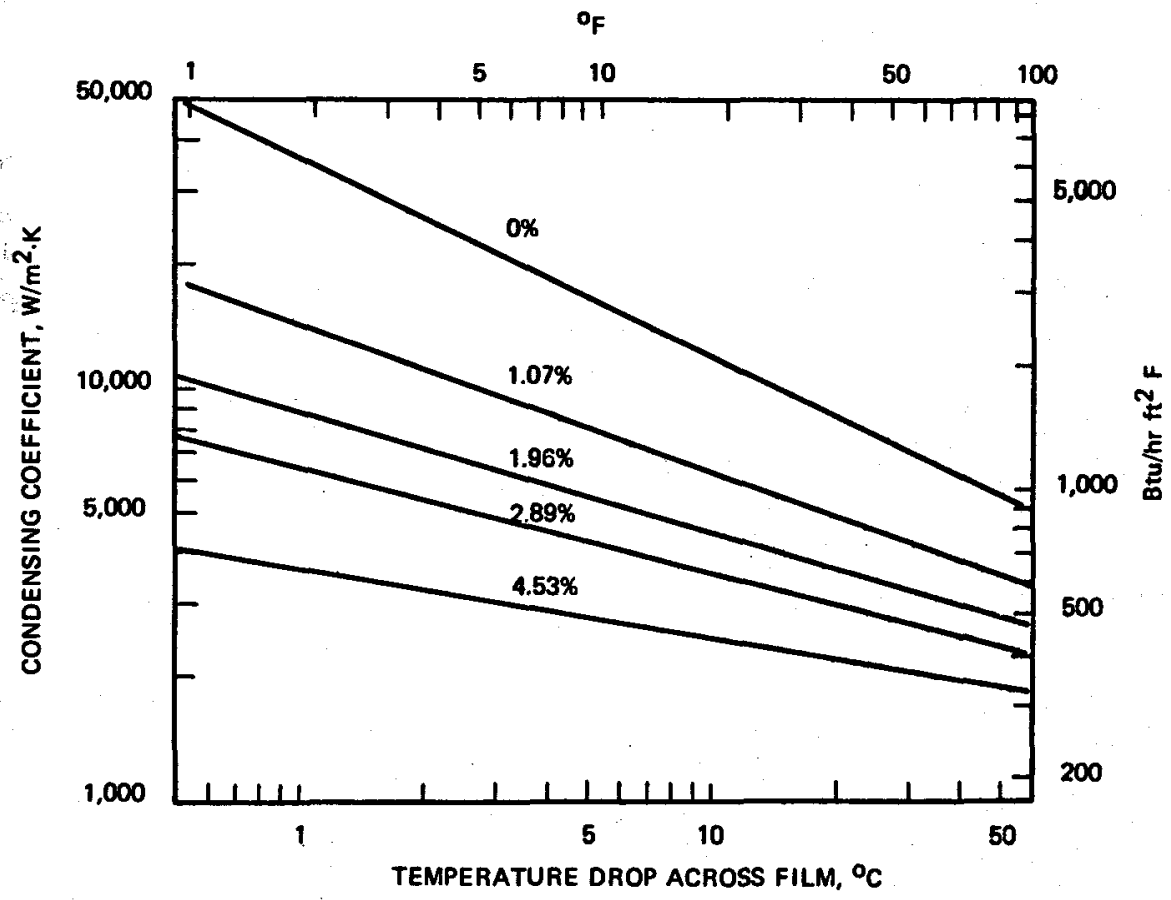

FraUne. 5.14-Influence of air on the condensing film heat transfer coefficient of $110^{\circ} \mathrm{C}$ $\left(230^{\circ}{ }^{\circ}\right)$ steam. Source: D. F. Othmer, Ind. Eng. Chem. 21, 576 [1929]. 
or any other gases that may be present (Dalton's Law), the major undesirable effects of noncondensable gases on the condensing process in surface condensers can be explained as follows :

1. As the water vapor proceeds through the condenser shell, with only a relatively small pressure drop due to flow friction, condensation causes the proportion of the noncondensable gases to increase and the partial pressure of the water vapor to decrease. The condensing temperature of the water vapor is thereby reduced, as well as the effective temperature differences for heat transfer. Increasing amounts of noncondensable gases therefore reduce the temperature difference across the tube wall.

2. The water vapor, driven by the partial pressure difference, will move toward the cooler walls of the tubes and in doing so will carry the noncondensable gases with it to the tube walls. The gas film surrounding the tubes, unless adequately swept away by the stream velocities, acts as a barrier through which the water vapor must diffuse. The rate of condensation is thus controlled by the laws of vapor diffusion through a film of noncondensable gases (12) rather than the usual laws of heat transfer by conduction and convection. This effect can cause a significant reduction in the overall heat transfer coefficient.

3. The water vapor pressure difference that must exist to cause diffusion of the vapor through the gas film causes a further reduction of the effective temperature difference for heat transfer.

4. The increase in the total bulk pressure in the condenser caused by the presence of the noncondensable gases represents a corresponding increase in the turbine exhaust pressure and a reduction in the enthalpy drop experienced by the steam in expanding through the turbine. Consequently the thermal efficiency of the power cycle is reduced.

5. The steam jet ejectors, or the vacuum pumps, necessary to remove the noncondensable gases from the condenser to prevent $a$ buildup of the gases require an energy input that is large enough to have an important effect on the thermal efficiency of the cycle. Increases in the rate at which noncondensable gases enter the system thus demand correspondingly greater energy expenditures for the gas removal.

6. In conventional power cycles, the noncondensable gases can be vented from the system to the atmosphere without incurring significant environmental problems. Most geothermal power cycles, however, may have hydrogen sulfide or other objectionable condensable gases that will require capital expenditures for scrubbers.

These aspects interact to make the analysis of the condensing process with noncondensable gases present relatively complex, and the heat transfer relationships under such conditions have not been explored fully. The condenser designer must be careful not to apply heat transfer correlations or data that were taken on single tubes, where gas blanketing may not have been significant, to tube bundles. (This is also true because the rain of condensate on lower tubes in the bundles can cause flooding and significant 
impairment of the heat transfer coefficient.) Vendors of "off-the-shelf" equipment provide extra surface to compensate for the presence of noncondensable gases, for the cleanliness of surfaces, for the operation at offdesign conditions, etc. The amount allowed is a matter of judgment and experience and is based on performance data for specific applications. Vendors use calculating procedures that are usually considered proprietary.

Eissenberg (20) tested a tube bundle with condensation taking place in the presence of varying amounts of noncondensable gas (nitrogen). He then correlated the combined effects of the amount of gas, the temperature difference, the steam temperature, and the steam velocity, using a modified Colburn-Hougen mass transfer factor. A critical steam mass velocity was found, below which noncondensables tended to accumulate on the surfaces. This minimum rate is a function of the condenser design and the condensing rate. Eissenberg suggests that rather than provide additional condensing surface to compensate for the presence of relatively large and unknown amounts of noncondensable gases, extra steam ejector or vacuum pump capacity would perhaps be as effective and require less capital expenditure (21).

Noncondensable gases are conventionally removed from condensers by either steam-jet ejectors or by vacuum pumps. Single-stage units can operate at condenser pressures down to 100 to $200 \mathrm{~mm}$ (4 to 8 in.) mercury absolute, but two stages or more are needed for lower pressures. The gaswater vapor mixture entering an ejector or pump typically will contain about $30 \%$ gas and about $70 \%$ water vapor by weight. As the condensing temperature increases, the water vapor portion increases. An intercooler between the stages is advantageous in reducing the gas temperature and the power requirements, and substantial amounts of water can be removed in the intercooler.

Frequently the first stage of a two-stage ejector or vacuum pump unit has a high capacity and is used alone during startup as a hogger to reduce the condenser pressure to the operating range. Another common arrangement is to provide two units (one of which is for standby), and interconnections allow the first stages of both units to operate together for hogging. Even with such special provisions, it may require $30 \mathrm{~min}$ to an hour to pump the condensing system down sufficiently for startup.

Steam-jet ejectors have the advantage over vacuum pumps of having no moving parts; therefore, they require less maintenance, do not need lubrication, have lower initial costs, are not threatened by slugs of water in the suction, and tend to produce higher vacuums. Vacuum pumps have significantly lower operating costs, generally do not generate as much noise, and lend themselves better to computer-controlled systems. Some systems may use a combination of the two, with the ejectors used for the first stage and for hogging. With increased fuel costs in power stations, operating 
costs are becoming more important, and there is a trend in modern steampower stations to use pumps rather than ejectors.

The vacuum pumps are most commonly the rotary type, including the liquid-ring, rotary-screw, or the sliding-vane type. The liquid-ring units, such as those manufactured by Nash, have an advantage in that slugs of water in the suction can be accommodated, making an inlet separator unnecessary. The rotary-screw type, such as manufactured by IngersollRand does require a separator, and the bearings must be lubricated. Seals and oil slingers are designed to prevent loss of oil into the pumped fluid. The sliding-vane pump (exemplified by the Allis-Chalmers units) requires lubricants to be introduced into the pumped fluid at the suction and removed by wire mesh demisters, separators, and settling tanks at the exit. Typical oil consumption rates for small units are around 4 liters ( 1 gal) per day ( $2 E)$.

The power requirements for noncondensable gas removal, whether it be steam for ejectors or electricity to drive vacuum pumps, increase almost linearly with the amount of gases to be handled. This effect, and the general method of calculating condenser noncondensable gas pressures, is illustrated in the equation below.

Dalton's Law states that the total pressure is the sum of the partial pressures of the constituent gases. The partial pressure of the water vapor at a given condensing temperature may be found in tables of the thermodynamic properties of water (23) or calculated from equations of state. The partial pressure of a constituent gas may be found from the perfect gas relationship

$$
p=\frac{8314.91 w t}{M v_{g}}
$$

where

$p=$ partial pressure of the gas, $\mathrm{N} / \mathrm{m}^{2}$ or $\mathrm{Pa}\left(\mathrm{N} / \mathrm{m}^{2} \times 0.00014505=\mathrm{psi}\right)$, $w=$ weight of the gas per unit weight of the steam in the condenser,

$t=$ condensing temperature, $\mathrm{K}$,

$M=$ molecular weight of the gas: $a i r=28.967, \mathrm{H}_{2} \mathrm{~S}=3408$, and $\mathrm{CO}_{2}=44.005$,

$v_{\varepsilon}=$ specific volume of steam at condensing temperature, $\mathrm{m}^{3} / \mathrm{kg}$ $\left(\mathrm{m}^{8} / \mathrm{kg} \times 16.0184=\mathrm{ft}^{3} / \mathrm{lb}\right)$.

A temperature drop across the gas film surrounding the tube can be assumed (perhaps $3^{\circ} \mathrm{C}$ ) and the partial pressures at the tube wall calculated. The pressure fraction of each constituent gas is also the mole fraction, and if one knows the molecular weights of the gases, the weight fraction of each can be calculated. The weight of the gas-water vapor mixture that must be removed from the condenser per unit mass of steam entering can then be determined and the pumping effort estimated.

Mah (24) has calculated the steam consumption for one- and two-stage ejectors for various amounts of gas present. Figure 5.15 shows steam requirements at $690 \mathrm{kPa}(100 \mathrm{psi})$ absolute operating steam. Adjustment 

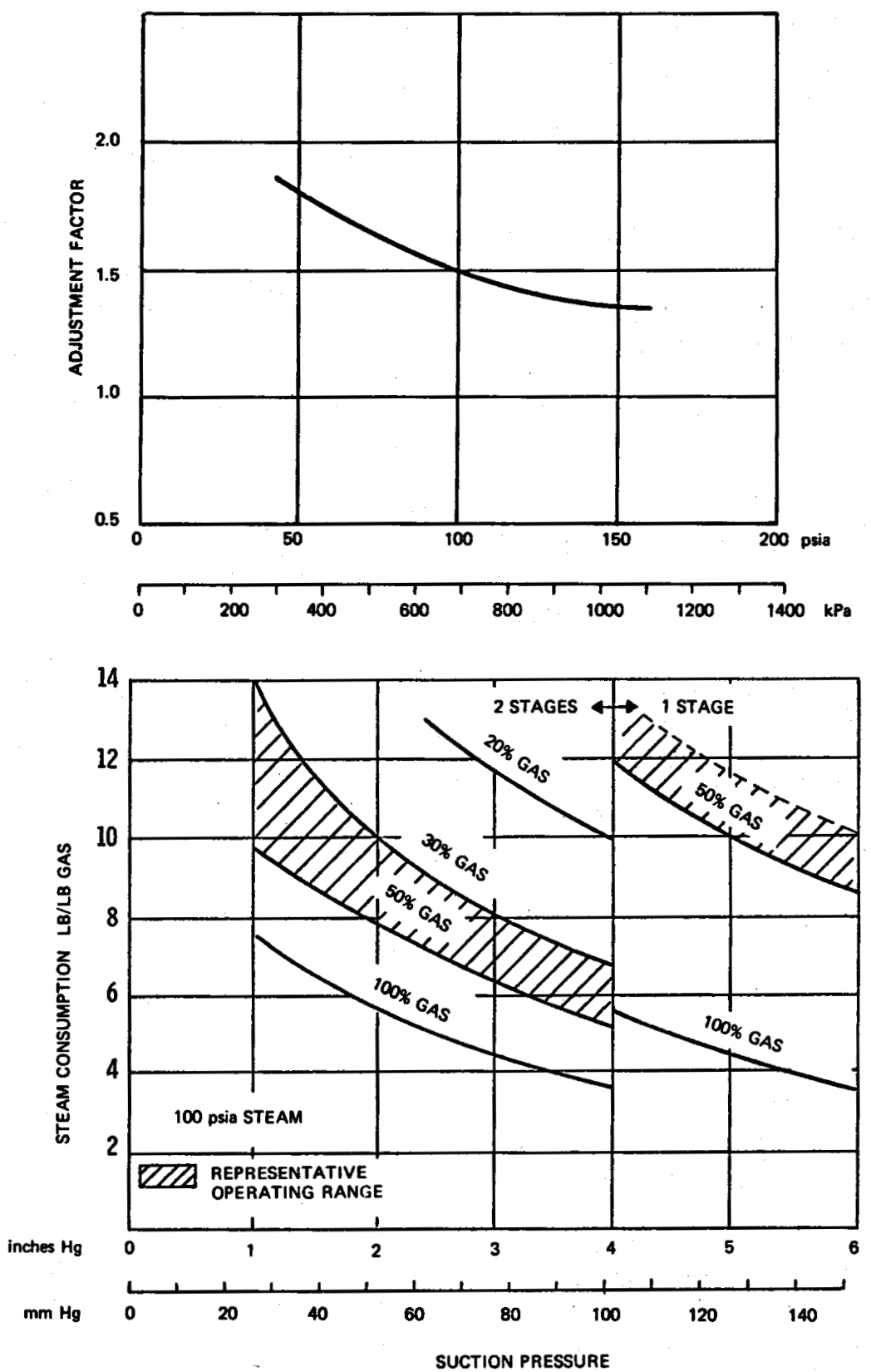

Figure 5.15-Steam requirement for ejectors as a function of the amount of noncondensable gases present and ejector suction pressure when using $690 \mathrm{kPa}(100$ psia) saturated steam supply. Adjustment factors for other steam pressures are given in the top graph. Source: Clifford Mah, Effect of Noncondensable Gases on the Performance of Rankine Cycles, presented at the Eighth CATMEC Meeting, San Diego, Callf., Feb. 21, 1978. Reprinted by permission of the Aerojet Energy Conversion Company. 
factors for other steam supply conditions are given in figure 5.15. The amount of steam required for the ejectors as a percentage of the condenser flow can then be estimated as a percentage of the condenser flow (figure 5.16). If vacuum pumps are used, the work of compression is calculated assuming two-stage compression with optimum intercooler pressure (determined for the mixture by iteration) and assuming a compression efficiency of $83 \%$. The estimates are given in figure 5.17 as a function of the amount of noncondensable gases to be handled. The power requirements for both ejectors and pumps are almost linear with the amount of gas to be handled, and the power expenditure becomes significant at amounts of over about 1\%. (For simplicity, both figures 5.16 and 5.17 were calculated assuming that the noncondensable gases consisted of equal weights of air and carbon dioxide. The graphs should not be used for design purposes without verifying the appropriateness of these and the several other assumptions.)

The presence of noncondensable gases in a direct-contact, or mixing, condenser does not have as serious an effect on the heat transfer performance as in surface condensers, but the gases must be removed from the condenser if the low turbine back-pressure is to be maintained. The amount of gases to be removed from the mixing condenser, however, may be considerably greater than for an equivalent surface condenser because of the dissolved or entrained gases in the cooling water sprayed into the unit. As the cooling

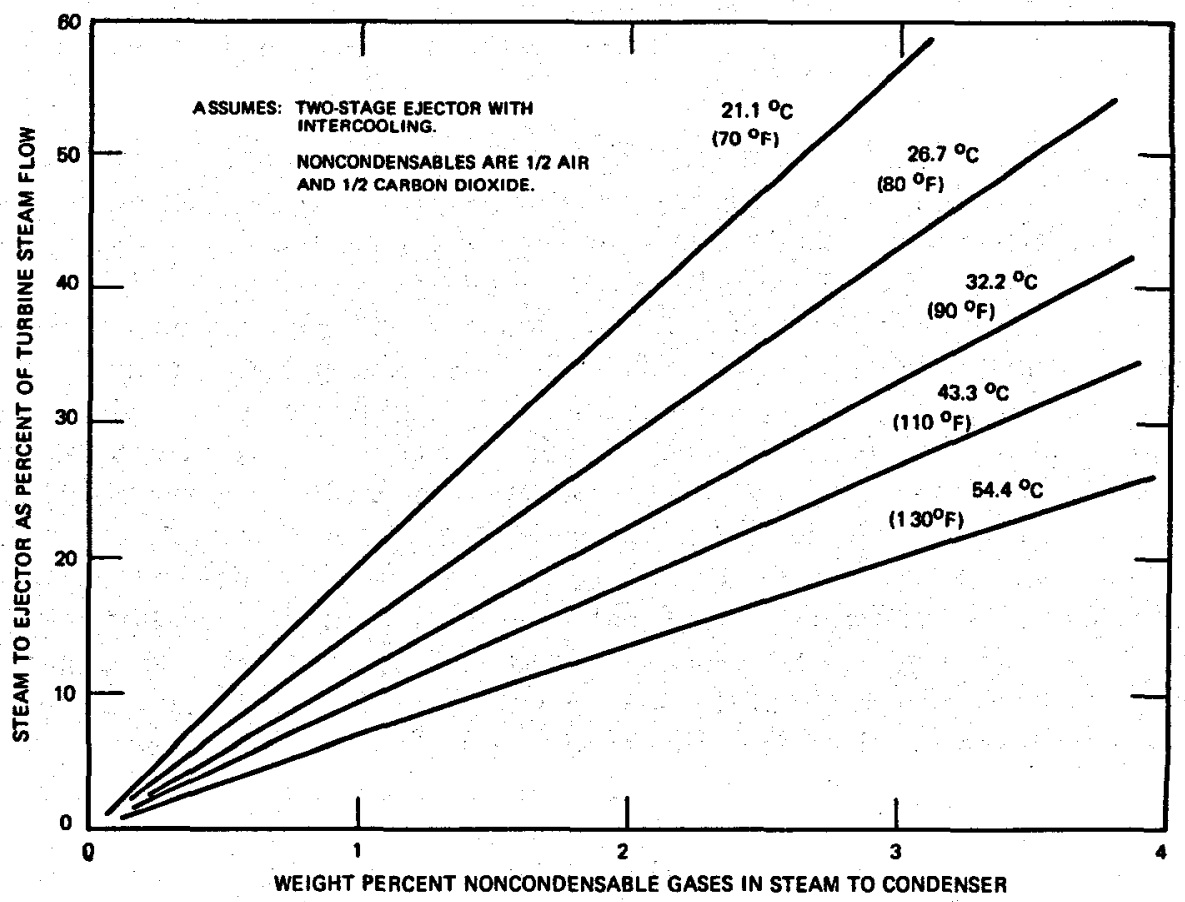

Figure 5.16-Two-stage ejector steam consumption to remove noncondensable gas from surface condenser. Note assumptions. 


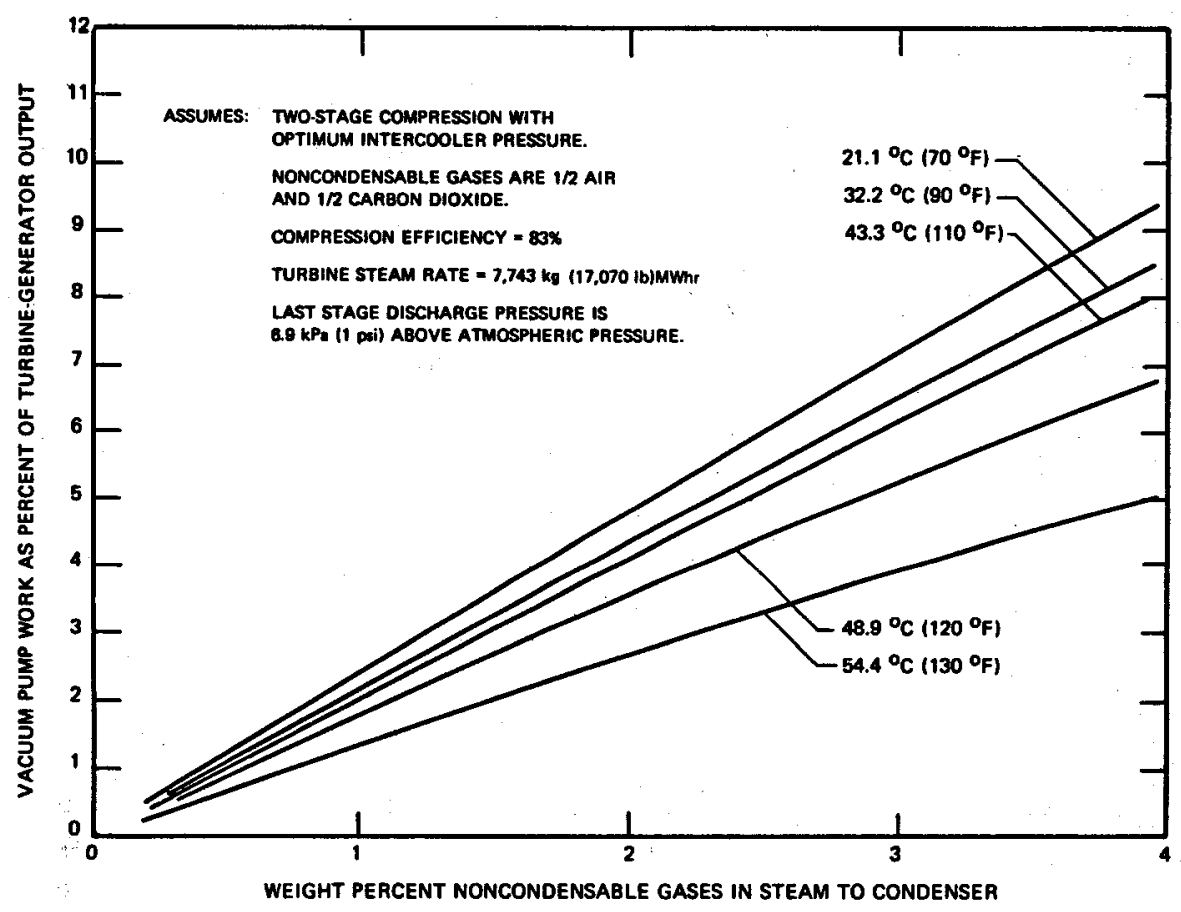

Figure 5.17-Estimated two-stage vacuum pump work to remove noncondensable gases from surface condenser. Do not use for estimating purposes without checking the several assumptions shown in the figure.

water enters the mixing condenser, it is both heated and reduced in pressure. Both of these processes reduce gas solubility. Analysis of the performance of direct-contact condensers is impeded by the need to know stripping and diffusion coefficients, which have not been studied extensively to date.

The ejector steam consumption at various operating geothermal power installations is shown by Mah (24) in figure 5.18. About 5\% of the total steam flow is typical of the amount needed to operate the ejectors at most stations; however, at Cerro Prieto, Mexico, the consumption rate is $15 \%$. 5.2.4.5 Condenser tube fouling. In selecting the site for a power station, much emphasis is placed on achieving the lowest available average sink temperature because this temperature has a direct influence on the thermal efficiency of the Rankine cycle. Equal attention should be given, however, to the quality of the cooling water because reduction of surface condenser capacity through fouling of the tubes can also have a direct bearing on the cycle efficiency and the useful life of the equipment. If periodic plant shutdowns are required for cleaning of condenser tubes, fouling rates can have a significant impact on the costs of producing electric power.

Geothermal power stations will probably use wet cooling towers to the extent that makeup water is available. A wide variety of situations will exist at geothermal sites regarding the quality of the water. At geothermal 
Fraure 5.18-Ejector steam consumption at some operating geothermal power stations. Source: Clifford Mah, Effect of Noncondensable Gases on the Performance of Rankine OUcles, presented at the Eighth CATMEO Meeting, San Diego, Calif., Feb. 21, 1978. Reprinted by permission of the Aerojet Energy Conversion Company.

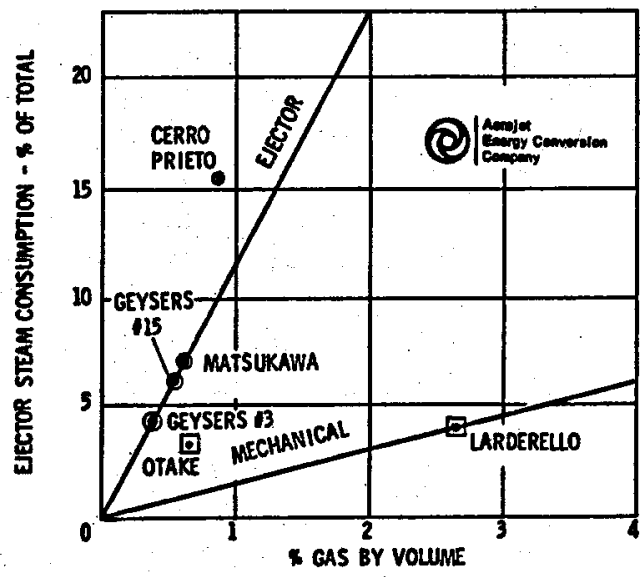

stations using steam flashed from a geothermal fluid, the condensate can be used as makeup for the cooling towers. The quantity of condensate available should be sufficient because the heat given up by condensation of a unit mass of steam can be dissipated in the tower by evaporation of a unit mass of the condensate. Although the quality of the makeup water will be relatively high in such systems, the quality of the water circulated through the condensers will be dependent on the cycles of concentration in the towers and on the amounts of dust, fumes, insects, and other atmospheric pollutants washed from the air that passes through the cooling towers. Makeup water taken from groundwater or surface water supplies may be so high in dissolved or suspended solids that clarifiers and other treatment would be necessary. Generally, the large quantities of water needed for cooling tower makeup make it uneconomical to provide extensive treatment, but where the only alternative is the use of dry cooling towers, relatively elaborate water treatment facilities may be more economical. For example, the proposed Sundesert Nuclear Power Station near Blythe, California, would have cleaned up high salinity water taken from the Palo Verde Outfall Drain for use as cooling tower makeup. In more typical circumstances, the quality of the makeup water is high enough so that the only necessary treatment is periodic additions of small amounts of chlorine to retard the buildup of biological growths in the circulating systems. These amounts are usually added as hypochlorites, but where relatively high chlorine addition rates are required and saline water is available, studies have indicated that it may be more economical to generate chlorine by electrolysis.

The use of relatively dirty water will cause deposits such as sediments, scale, algae, and slime on the condenser tube surfaces and markedly reduce the condenser heat transfer coefficient. The amount of deposits present will obviously depend upon the deposition rate and the time elapsed since the last cleaning. Buildup of deposits can be rapid when using water of poor quality; instances causing a 15 to $20 \%$ reduction in condenser capacity 
after $10 \mathrm{hr}$ of operation have been cited (25). Factors influencing the rate of fouling and the types of deposits are the kind of metal used for the tubes, the character of the tube surface, the water velocity through the tubes, and cooling-water properties such as temperature, dissolved solids, $\mathrm{pH}$, and bacterial content.

Shutdown of power stations for manual cleaning of condenser tubes can be costly because of revenue loss from sale of power; thus, economic studies are required to equate the cost of condenser capacity loss against shutdown costs. Presentation of guidelines with regard to typical cleaning schedules is impossible because of the great difference between fouling tendencies at specific plants. In the absence of definitive information on the average amount of deposits, a factor of 0.80 to 0.85 is commonly applied to the overall heat transfer coefficient to take care of fouling and other uncertainties. A common design fault is not to allow enough excess area. On the other hand, care should be taken not to be too generous with this excess capacity because it is expensive. Furthermore, when commencing operation with clean tubes in an oversized condenser, the plant operator may cut back on the coolant flow rate, thereby reducing the water velocity through the tubes and increasing the wall temperatures. Both of these processes tend to hasten the buildup of fouling deposits.

Several methods have been developed, or are proposed, for cleaning condenser tubes without taking the unit out of service. These methods include Amertap, MAN, water jets, slurries of abrasives, hydraulically propelled brushes, and possible pretreatments. One of the more commonly used methods is the Amertap system (13). Amertap involves using the coolant pressure to force sponge rubber balls through the tubes on the average of about one every $5 \mathrm{~min}$. The balls wipe the surface and materially aid in maintaining the condenser efficiency. They are recovered from the effluent water and recirculated. The length of time the balls can be used before replacement varies with the specific application. The MAN system consists of a stiff brush retained in each condenser tube by suitable end-cages. The circulating-water piping is arranged to allow periodic reversal of flow. Each flow reversal drives the brush through its respective tube (26). Although the economics of mechanical tube-cleaning systems generally favor larger power stations, the systems have been used in smaller applications. However, no specific rules can be given concerning their usefulness in geothermal power plants. Consideration of the costs of mechanical cleaning systems must include a comparison between the installation and operating costs and the cycles of concentration in the cooling tower.

Besides causing deterioration of the heat transfer rate, deposits can also accelerate corrosion of the tubes. Some of the more commonly used tubing materials are copper, cupro-nickels, aluminum, stainless steel, and titanium. When stainless steel is used as tubing material, two of the more troublesome deposits are calcium carbonate containing chlorides and hydrous oxides of maganese (in cases where seawater is circulated). Tub- 
ing materials containing no copper are particularly susceptible to the deposition of slimes. The tubing material itself and the cooling water may be incompatible, particularly if saline water is used. The stress corrosion cracking of stainless steels, the pitting of aluminum, and the incompatibility of ammonia and the copper-bearing alloys are particular areas of trouble. Despite the fact that the literature contains a great deal of information, much study is needed on the corrosion of condenser tubes in geothermal applications. Use of titanium tubes eliminates many of the concerns about corrosion but at some cost penalty, as discussed in section 5.2.4.7.

The condensers are often supplied in the purchase of steam turbine generators. In such cases, the vendor assumes responsibility for meeting the performance specifications for the condenser. However, the burden may be on the purchaser to specify correctly the cooling-water quality that will exist and to maintain the quality during operation. If condensers of special design are fabricated, the manufacturer guarantees only to meet the fabrication specifications, leaving the responsibility for performance with the customer or his consultants. As in any instance where knowledge and experience are important, such information tends to have market value and is not freely given. Much of the investigative work on condenser fouling, condenser design, and condenser costs, etc., is considered proprietary; there is relatively little definitive information available in the open literature.

\subsubsection{Condenser tube failure. A comprehensive study of 30 power sta-} tions disclosed that the major impact of surface condenser tube leakage is the value of the electric power generation lost when the unit is taken off-line to repair the leaks (27). Very small leaks can be detected by analysis of the water chemistry of the turbine cycle, and nearly all of the surveyed stations have automatic analyzers for this purpose. Hydrotesting of the steam side was reported as the most sensitive method of locating a leak, but plastic film or foam applied to the tube sheet of an evacuated condenser is also used.

The tube exposure environment was defined in terms of three circulating-water categories : freshwater once-through, salt water, and wet cooling towers with freshwater makeup. Three condenser service sections were also defined: impingement section, main condensing section, and air removal section. In the main condensing section in freshwater-cooled condensers, all the commonly used materials have a high probability of lasting the lifetime of the plant. In the air removal section, however, Admiralty metal tubes gave less satisfactory service. In the saltwater-cooled condensers, it was found that, of all the materials surveyed, only titanium had a high probability of lasting the lifetime of the plant without the need for retubing. Aluminum-brass, aluminum bronze, and 90-10 coppernickel have less than a $50 \%$ probability of lasting 40 years with only $10 \%$ 
of the tubes plugged. The study was less definitive in evaluating materials used in wet cooling tower systems. Stainless steel tubes appear to give good service in both once-through and cooling tower systems. The Bechtel publication, Steam Plant Surface Condenser Leakage Study, (gY), contains an extensive bibliography on condenser tube materials, failure modes, and cleaning methods.

Approximately one-half of the failures of tubing are directly attributable to vibration damage ( $\left.\mathscr{R}^{7}\right)$. Tube vibration is usually caused by high shell-side cross-flow steam velocities in the upper portions of the tube bundle or at poorly baffled drain lines. Improper support plate spacing or steam flow distribution or unusual condenser operating conditions are typical sources of vibration problems. The major excitation forces causing tube vibration result from the cross-flow steam velocity. The resulting drag force and vortex shedding cause tubes to vibrate at the natural frequency, $f_{n}$, given by the following equation $(27)$ :

where

$$
f_{n}=C\left(g E I / w L^{4}\right)^{1 / 2}
$$

$g=$ gravitation constant,

$E=$ modulus of elasticity,

$I=$ second moment of area of the tube cross section,

$w=$ weight per unit length of the tube filled with water,

$L=$ tube span between supports,

$C=$ end support constant (28).

The deflection, $Y$, of the vibrating tube is given proportionally as (R7)

where

$$
Y \propto k W_{D} L^{4} / E I
$$

$W_{D}=$ (drag) force per unit length causing the deflection, $k=$ end support constant (28).

For a given steam flow condition, $W_{D}$, amplitude reduction may be accomplished by (1) decreasing the tube span, $L$; (2) increasing the modulus of elasticity, $E$; or (3) increasing the moment of inertia, $I$. The natural frequency will also increase with these changes. Chenoweth has prepared a comprehensive report on the state of the art on the prediction of flowinduced vibrations in shell-and-tube heat exchangers (29).

5.2.4.7 Titanium for condenser tube service. There will be an incentive to use titanium for condenser tubes at some geothermal plants because of relatively severe operating conditions. Although the superior resistance of titanium to corrosion and erosion has been known since the 1950 's, its use has been limited because of its comparative high cost. However, the decreasing price of titanium in the 1970's, the increasing costs of other tubing materials, and the increased worth of reducing plant downtime for con- 
denser maintenance have all brought titanium into a more competitive position (30).

Titanium is equal in strength and toughness to stainless steels and has better resistance to corrosion in severe applications. Table 5.10 shows that it has good abrasion resistance, is not subject to stress corrosion cracking or crevice corrosion, and will not corrode in the presence of sulfides, chlorides, mercury, and other man-made pollutants in the cooling water. On the steam side, titanium tubing is not attacked by noncondensable gases such as carbon dioxide, ammonia, and oxygen. It is also resistant to the erosive action of the high-velocity steam entering from the turbine exhaust.

TABLE 5.10-Comparative corrosion resistance of tube materials

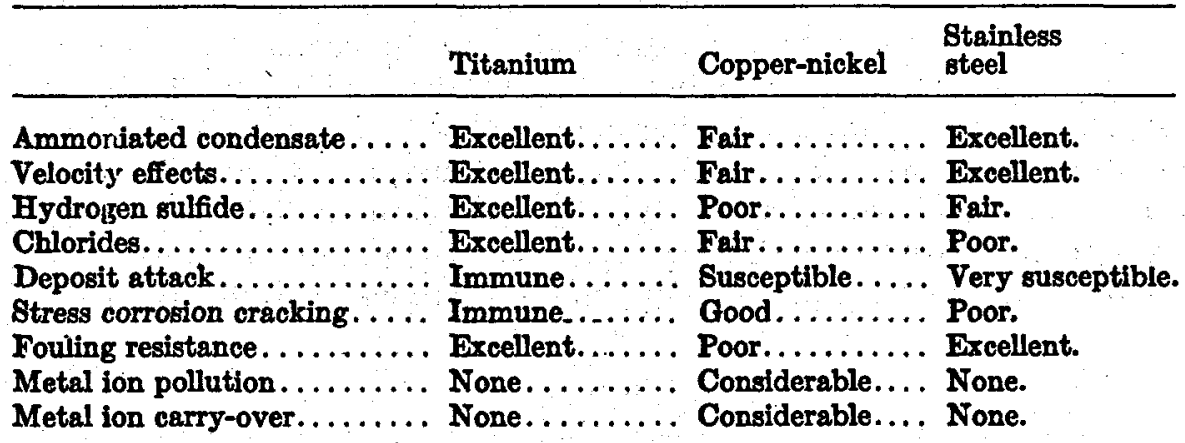

Source: Titanium tubing for Surface Condenser Heat Exchanger Service, Timet Bulletin SC-4, Titanium Metals Corporation.

Because titanium tends to retain a smooth surface, it resists biological fouling to a better degree than the commonly used tubing materials. Cleanliness factors for titanium, like stainless steel, are in the 0.8 to 1.0 range as compared to a value of 0.85 commonly used for other materials.

The thermal conductivity of titanium is about 16 to $20 \mathrm{~W} / \mathrm{m} \cdot \mathrm{K}(109$ to $138 \mathrm{Btu} \cdot \mathrm{in} / \mathrm{hr} \cdot \mathrm{ft}^{2} \cdot{ }^{\circ} \mathrm{F}$ ), as shown in table 5.4 , which is about the same as the thermal conductivity of the 304,316 , and 347 stainless steels but less than that of 410 or 501 stainless. The conductivity is less than that of the copper-nickel alloys by a factor of about 2 , less than that of admiralty metal by a factor of about 7 , and less than that of aluminum by a factor of about 10 . In heat transfer through condenser tubes, however, the resistance of the wall is usually relatively small in comparison to the film coefficients and fouling resistances. Further, the higher strength of titanium and the essentially zero allowance needed for corrosion and erosion allow use of No. 22 BWG tubing rather than the No. 18 BWG usually used for other materials. Because the resistance to cavitation and erosion is good, it may be economical to design for higher. velocities in the tubes, perhaps 2.4 to $3 \mathrm{~m} / \mathrm{sec}$ (8 to $10 \mathrm{fps}$ ), which can improve the inside film coefficient by 25 to $30 \%$ over those obtained with 
more conventional lower velocities. Figure 5.19 shows the relative heat transfer performance of titanium tubes compared to other materials if credits are taken for fouling factors, water velocities, and wall thickness. On this basis, titanium compares favorably with the coefficients of some of the other commonly used tubing materials, although still falling short of aluminum or admiralty metal.

Number 22 BWG titanium and stainless steel and No. 18 BWG coppernickel alloys will all have about the same resistance to vibration. This factor affects the spacing of tube supports and is of particular importance when considering replacement of existing tubes with titanium because the spacing of the tube supports cannot be easily altered.

One of the most common and economical methods of joining titanium tubes to tube sheets is by roller expansion. Mechanical bonds are subject to leakage, however, and where the consequences of leakage are severe, such as in the mixing of highly saline water with ammonia, etc., the joints may not be acceptably tight. Joints such as $\mathbf{O}$-rings and $\mathbf{X}$-rings have been used, but they also may not meet exacting leakage specifications. Welding, usually on the face side, produces the most leak-proof joints. There are many examples of successful welding of titanium tubes to titanium sheets using inert atmosphere techniques. Explosion bonding has been used successfully to join titanium to titanium, or titanium to steel tube sheets.

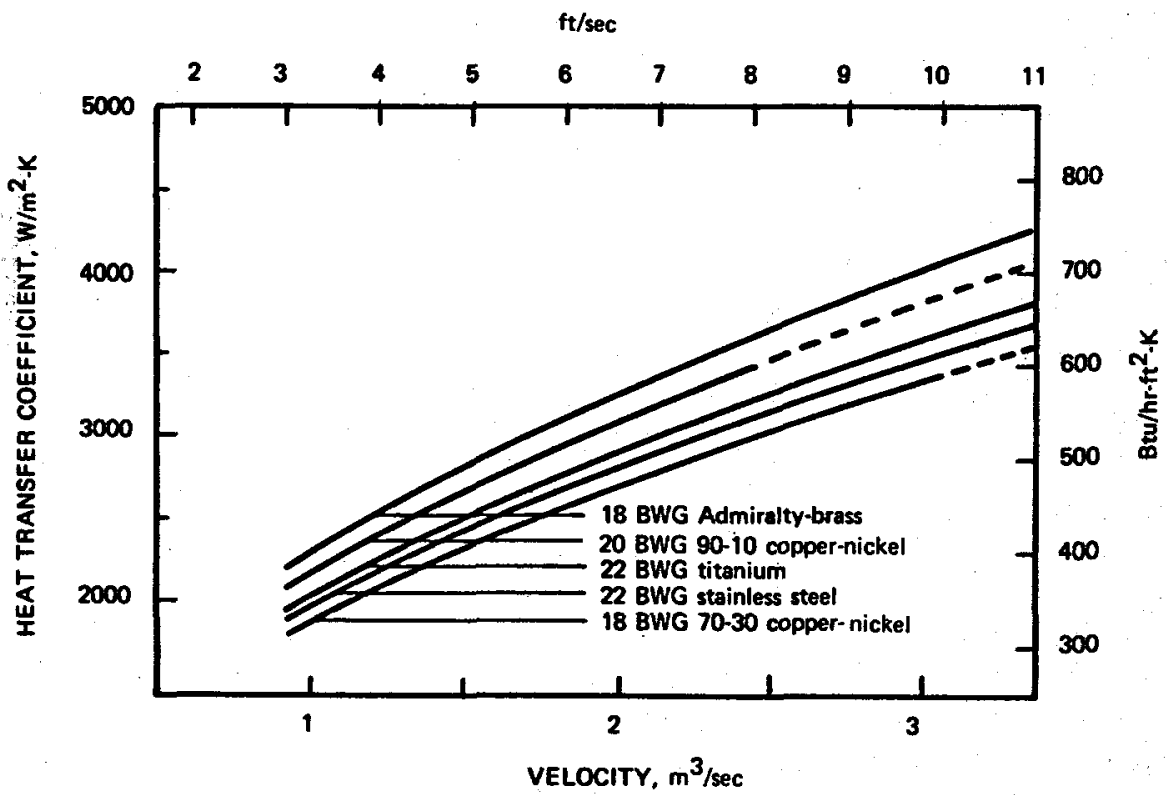

Figure 5.19-Overall heat transfer coefficient as a function of water velocity in 2.5-cm (1-in.) OD tubes. The values shown are the result of applying appropriate fouling factors and adjustments for wall thermal conductivities to the heat transfer coefficients. Source: Titanium Tubing for Surface Condenser Heat Exchanger Service, Timet Bulletin SC-4, Titanium Metals Corporation. 
Titanium may also be successfully brazed to titanium or steel using either a vacuum or high-purity inert atmosphere. Silver braze alloys are the most useful (31).

The 1977 cost of uninstalled titanium tubing was in the order of $\$ 54 / \mathrm{m}^{2}$ $\left(\$ 5 / \mathrm{ft}^{2}\right)$. This cost was subject to specific market conditions, the quantity purchased, and the purchase specifications, such as the degree of testing and inspection required. An appreciation of the comparative cost of titanium may be seen in table 5.11, which lists 1975 costs of some common tube materials.

TABLE 5.11-Comparative costs of condenser tubing in 1975

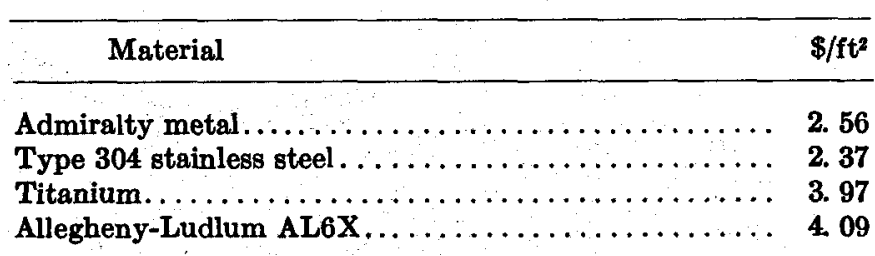

Source: J. K. Rice, "Evaluating Cooling Systems with Zero Aqueous Discharge," pp. 81-86 in The 1976 Generation Handbook, McGraw-Hill, New York, 1976.

5.2.4.8 Enhanced-surface condenser tubes. The Oak Ridge National Laboratory has investigated the performance of vertical condenser tubes with fluted outside surfaces. The studies, initiated in 1964 to improve the performance of water-desalting plants, were encouraging and thought to have application in obtaining power from geothermal sources and ocean temperature gradients. The mechanism by which fluted surfaces improve the condensation heat transfer performance of a vertical tube is illustrated in figure 5.20. The surface tension forces in the condensate film act to draw the liquid from the crests into the troughs, thereby reducing the resistance to heat transfer in the crest areas. Although the resistance is increased somewhat in the trough areas, the net effect is an improvement in the heat transfer performance over that attained with conventional smooth tubes (32).

Experimental studies have been made of the performance of vertical tubes with enhanced surfaces on which various fluorocarbons, ammonia, and isobutane were condensed (3Q). The tubes were $2.21 \mathrm{~cm}(7 / 8 \mathrm{in}$.) to $2.54 \mathrm{~cm}$ ( 1 in.) OD and had the cross-sectional profiles shown in figure 5.21. Most of the tubes tested were of aluminum, but other materials (33) were studied also (figure 5.21). The heat fluxes for ammonia varied from about 5000 to $50,000 \mathrm{~W} / \mathrm{m}^{2}\left(1600\right.$ to $\left.16,000 \mathrm{Btu} / \mathrm{hr} \cdot \mathrm{ft}^{2}\right)$. When condensing fluorocarbons or isobutane, the heat fluxes varied from 5000 to 30,000 $\mathrm{W} / \mathrm{m}^{2}\left(1600\right.$ to $\left.10,000 \mathrm{Btu} / \mathrm{hr} \cdot \mathrm{ft}^{2}\right)$. The condensing coefficient was found to improve by factors of 4 to 7 times over that of a smooth tube, depending on the heat flux and the geometry of the flutes (32). The condensing film coefficients obtained when condensing ammonia are shown in figure 5.22, and the coefficients for condensing isobutane are shown in figure 5.23. The 


\section{CONDENSING SIDE}

(fluted outside surface)

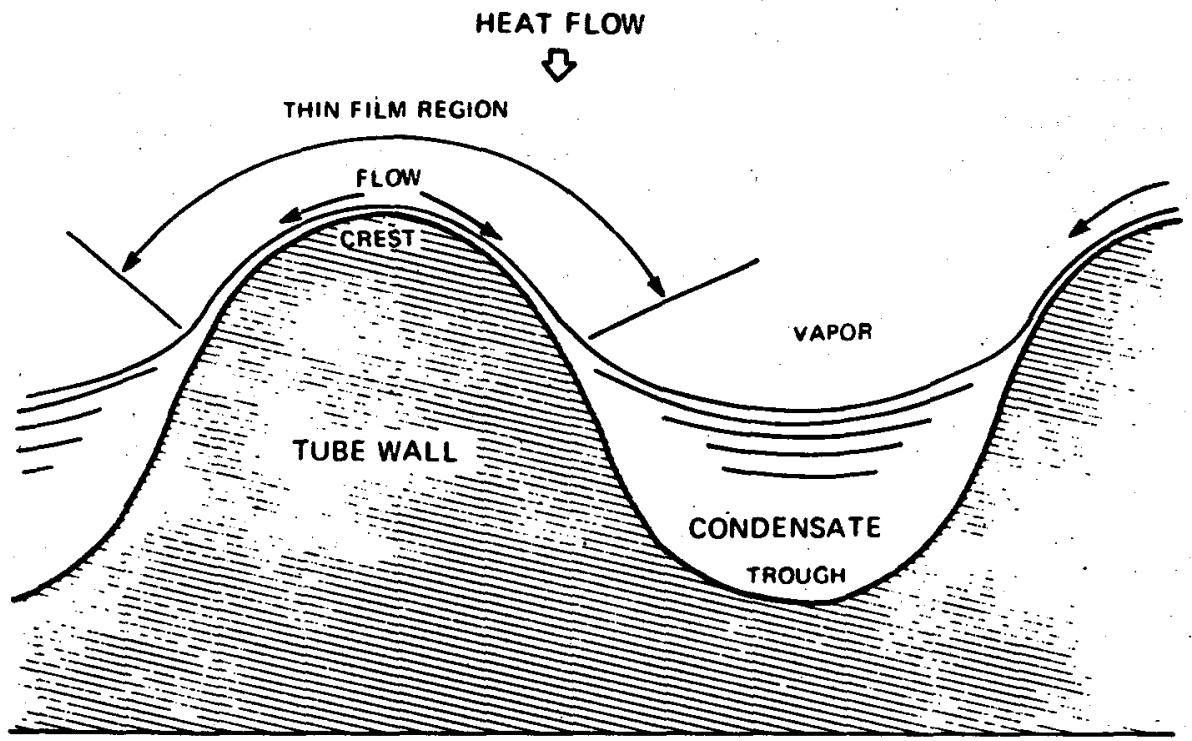

\section{WATER SIDE}

(smooth inside surface)

FraURE 5.20-Fluted tube principle of operation (condensation mode). Surface tension forces act to push condensate from crests into troughs. Source: $\mathbf{S}$. K. Combs, in Experimental study of Heat Transfer Enhancement for Ammonia Oondensing on Vertical Fluted Tubes, ORNL-6356 [April 1978].

most efficient flute geometry depends on the surface tension of the condensed liquid, on the flute efficiency for condensate drainage, and possibly in some situations, on the conductivity of the tube wall. When condensing ammonia (figure 5.22), the tube with 60 square ridges (Tube $\mathrm{E}$ ) gave somewhat lower condensing coefficients than the tube with 48 corrugations (Tube F). When condensing isobutane, however, Tube $\mathbf{E}$ gave a higher composite condensing coefficient (figure 5.23). The condensing coefficients shown are based on the actual area of the tube surfaces. Even though type $F$ tubes gave higher coefficients for condensing ammonia, the fact that type $\mathrm{E}$ tubes have more surface area per unit length (figure 5.21) would make this tube outperform the type $F$ tubes with ammonia on a unit-length basis (32). In measuring the film coefficients when using isobutane, the resistance of the tube walls is negligible in comparison to that of the liquid film. In the case of ammonia, however, the relatively high coefficients of the ammonia add importance to the tube wall conductivity, and as a result the heat transfer performance in those studies is reported in figure $\mathbf{5 . 2 2}$ on 


\begin{tabular}{|c|c|c|c|c|c|c|}
\hline $\begin{array}{c}\text { Cross } \\
\text { section }\end{array}$ & $\begin{array}{c}\text { Tube } \\
\text { des- } \\
\text { igna- } \\
\text { tion }\end{array}$ & Material & $\begin{array}{c}\text { External } \\
\text { perimeter } \\
(\mathrm{cm})\end{array}$ & $\begin{array}{c}\text { External } \\
\text { surface area } \\
\left(\mathbf{m}^{2}\right)\end{array}$ & $\begin{array}{l}\text { Num- } \\
\text { ber of } \\
\text { external } \\
\text { flutes }\end{array}$ & $\begin{array}{l}\text { Num- } \\
\text { ber of } \\
\text { internal } \\
\text { flutes }\end{array}$ \\
\hline
\end{tabular}
A Aluminum
8. 00
0. 0973

$\left\{\int_{2}^{2 m}\right.$ B Al-brass

11. 94

0. 1296

12

12

$\{$ C Al-brass

8. 90

0.0967

20

20<smiles>C1CCCCCC1</smiles>

D CuNi (80 10)

8. 90

0. 0967

36

36<smiles>C1CCCCCC1</smiles>

E Aluminum

12. 71

0. 1490

60

o

( $\mathrm{F}$ Aluminum

8. 26

0. 0964

48

o

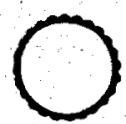

G Aluminum

9. 75

0.1143

24

0

H Aluminum

14. 00

0. 1522

42

34

Aluminum

26. $61 / 8.00 \cdot 0.3110 / 0.0873$

- $A$ duplicate of tube A. with 36 stainless steel blades loosely attached.

-Numerator includes blades; denominator is base tube only.

Figure 5.21-Characteristics of fluted tubes. Source : J. W. Michel et al., Dnergy Div. Annu. Prog. Rep. Period Ending Bept. 1977, ORNJ-6364, Table 5.2, p. 182. 


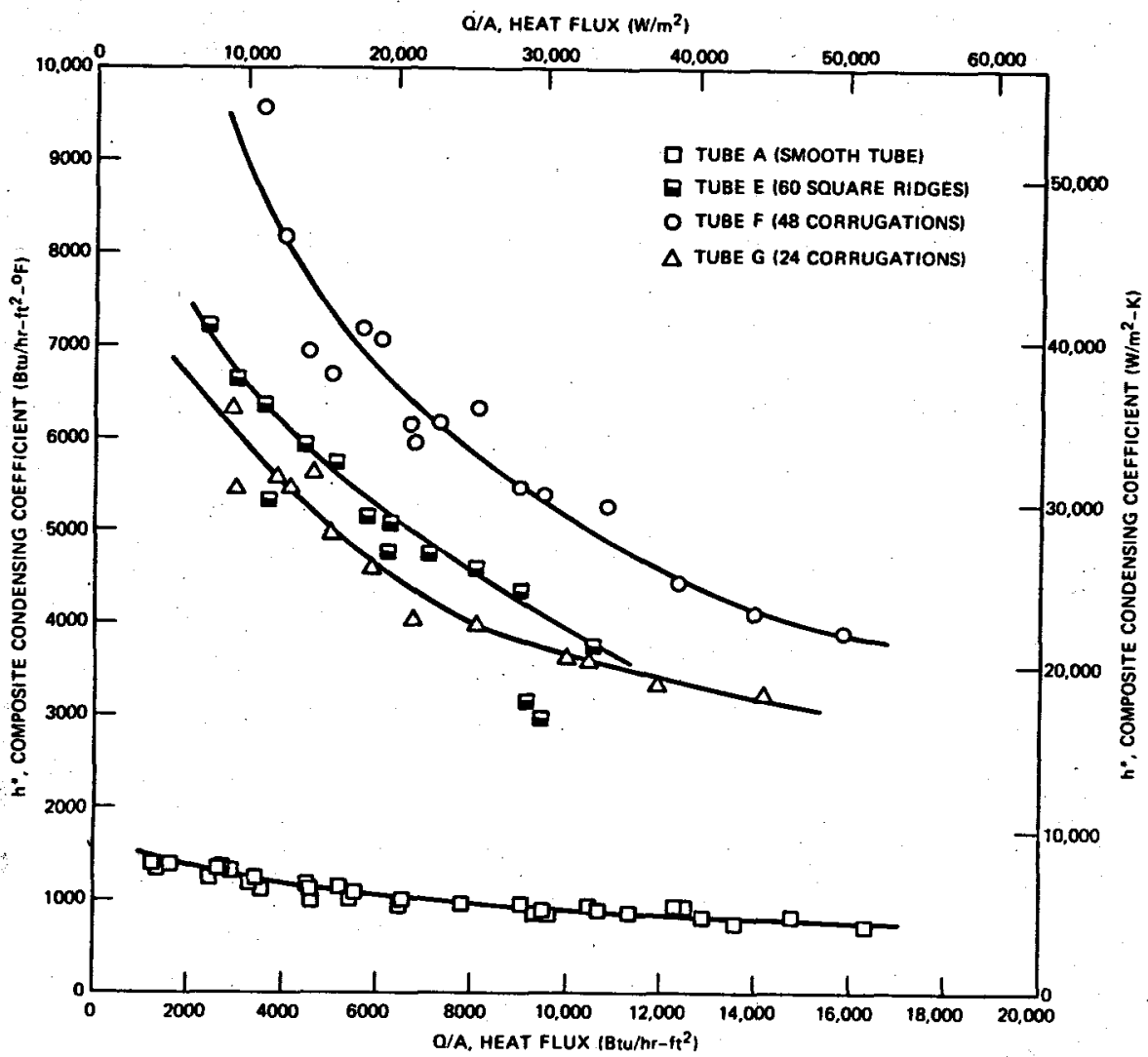

FrGURE 5.22-Composite condensing heat transfer coefficients for ammonia using enhanced-surface tubes. Source: S. K. Combs, An Experimental Study of Heat Transfer Enhancement for Ammonia Condensing on Verticle Fluted Tubes, ORNL5356 (April 1978).

the basis of a composite coefficient* that includes both the liquid film and the tube wall resistances. (32)

Condensate flowing down the vertical tubes increases the liquid film thickness in the lower sections to cause "flooding" and a marked reduction in the heat transfer performance. This effect is less pronounced when condensing ammonia rather than isobutane, possibly because the higher latent heat of vaporization of the ammonia results in less condensate. The flooding effect when condensing isobutane can be significantly improved by equipping the tubes with drain-off skirts located about every $30 \mathrm{~cm}(12$ in.) along the tube length. The skirts divert the condensate away from the tube wall and result in the improved performance indicated in figure 5.23. When this effect is combined with the improvements caused by the en-

*No completely satisfactory method has been developed to compute the wall resistance for a fluted tube. 


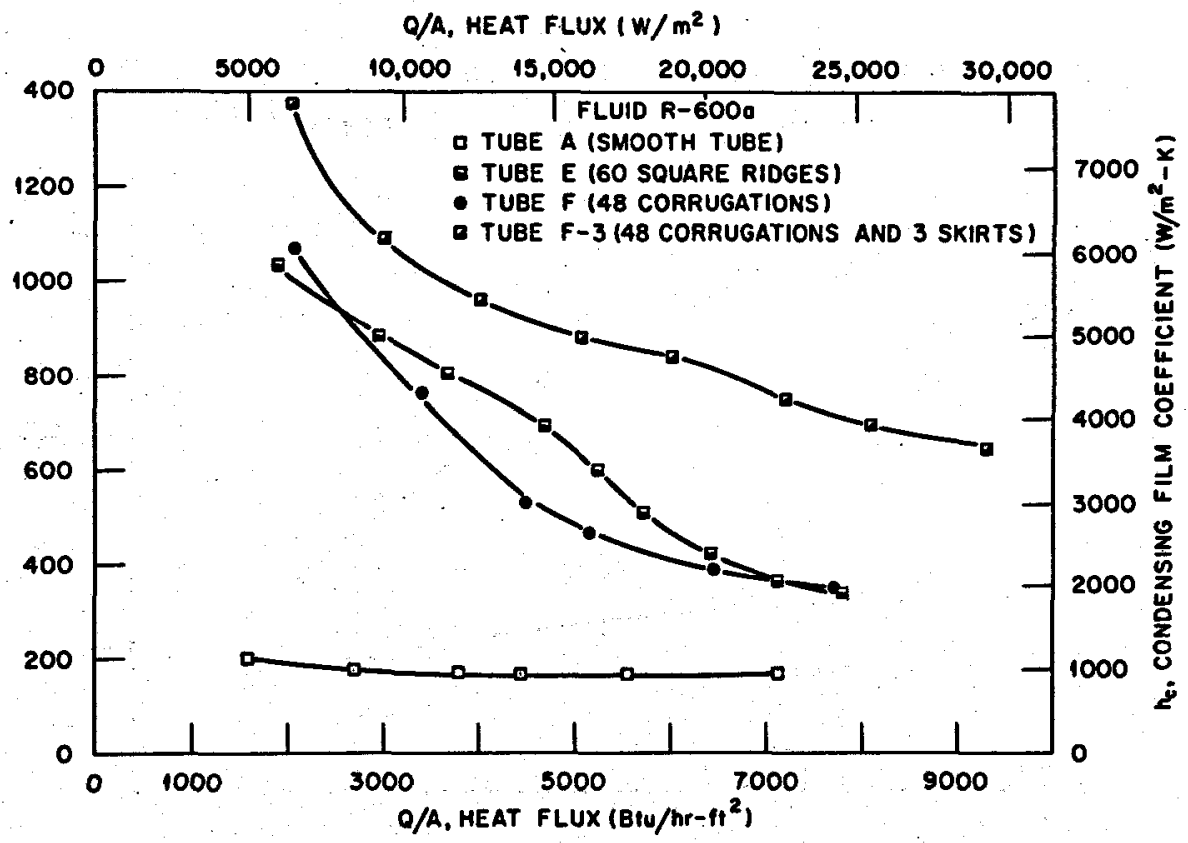

FrgURE 6.23-Condensation heat transfer coefficient for isobutane using enhancedsurface tubes. Sonrce: J. W. Michel et al., Energy Div. Annu. Prog. Rep. Period Ending Sept. 1977, ORNL-5364, Fig. 5.4, p. 185.

hanced surfaces, the result is strikingly better performance for the system. over that attained with nonskirted smooth vertical tubes (32).

Fouling of enhanced tube surface has a more pronounced effect on the heat transfer coefficient than fouling of smooth tubes. Figure 5.24 shows the deterioration of the overall heat transfer performance on the enhanced Tube F (with drain-off skirts) and a smooth tube, type A, as the fouling resistance is increased. With relatively clean water and occasional cleaning, the fouling resistance will normally fall in the $0.00009-0.0002 \mathrm{~m}^{2}$. ${ }^{\circ} \mathrm{K} / \mathrm{W}\left(0.0005-0.001 \mathrm{hr} \cdot \mathrm{ft}^{2} \cdot{ }^{\circ} \mathrm{F} / \mathrm{Btu}\right)$ range. The effect on enhanced surfaces would be significant if the fouling resistance were about five times higher, as may be encountered with relatively dirty cooling water or infrequent cleaning. The mechanical cleaning systems will thus probably be particularly important for enhanced tube systems. To date, the comparative effects of noncondensable gases on the performance of enhanced- and smooth-surfaced tubes have not been studied extensively.

The enhanced-surface tubing can be formed to U-tubes if filled with a low-temperature alloy during the bending process. An experimental fourpass 40-tube, vertical condenser of U-tube design has been fabricated and will be tested at East Mesa in the California Imperial Valley. The unit will condense isobutane containing a small percentage of water vapor and noncondensable gases. The neoprene drain-off skirts are sealed to the 


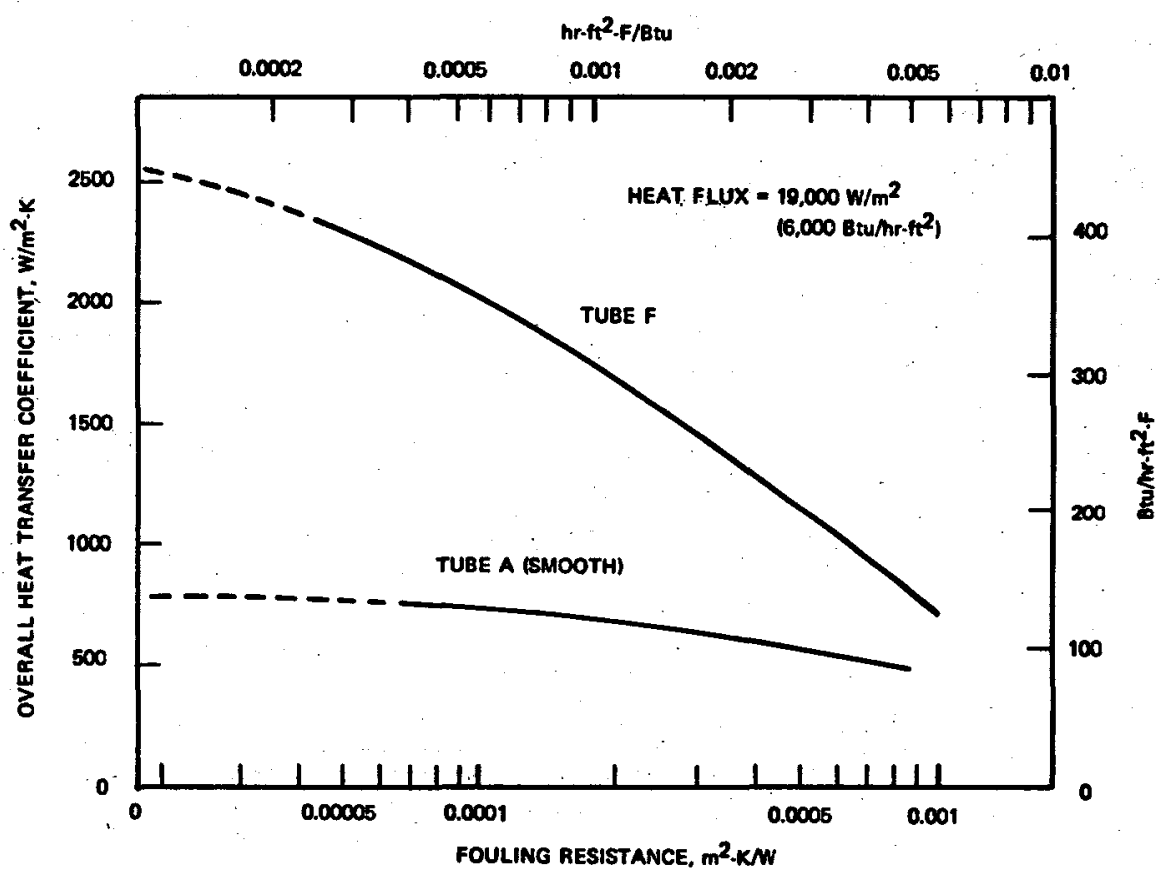

Froukg 6.24- Effect of fouling resistance on overail condensing heat transfer coefficient of enhanced-surface tubes.

tubes with an adhesive that is compatible with isobutane and other materials in the system. The skirts will also serve as cross-baffles to direct the flow of vapor across the tube bundle and to act as vibration dampers.

Manufacturing facilities are currently available for production of enhanced-surface tubing in quantity, generally by extrusion or by drawing. If manufactured in large quantities, the incremental fabrication cost for forming the special surface becomes small. Enhanced-surface tubes contain about $20 \%$ more material than plain tubes of the same inside diameter and wall thickness, and large-order prices would probably be in about this same proportion.

\subsubsection{References}

(1) Handbook of Fundamentals, American Society of Heating, Refrigerating and Air-Conditioning Engineers, New York, 1972, chapter 31.

(2) K. E. Starling, Fluid Thermodynamic Properties for Light Petroleum Systems, Gulf Publishing Company, Houston, 1973.

(3) H. E. Khalifa, Effect of Seasonal Variations of Ambient Temperatures on Performance of Low-Temperature Power Cycles, COO/4051-10 (CATMEC Report No. 19), Brown University, Providence, R.I. (June 1978).

(4) Report of Current Standards for Condensers and Condensing System Pumps for Air-Cooled Steam Power Plants, TID-26515, R. W. Beck and Associates (December 1973). 
(5) Conceptual Design of Commercial 50-MWe (net) Geothermal Power Plants at Heber and Niland, California, SAN-1124-1, Bechtel Corporation (October 1976).

(6) K. Aikawa and M. Soda, "Advanced Design in Hatchobaru Geothermal Power Station," presented at the Second United Nations Symposium on the Development and Use of Geothermal Resources, San Francisco, Calif., May 20, 1975.

(7) Standards for Direct-Contact Barometric and Low-Level Condensers, 5th ed., Heat Exchange Institute, 1970.

(8) Electric Power Research Institute, Brine Chemistry and Combined Heat/Mass Transfer, ER-635, interim report, Battelle Pacific Northwest Laboratories (January 1978), Appendix D.

(9) H. R. Jacobs and H. Fannar, Direct Contact Condensers-A Literature Survey, DGE/1523-3, UTEC 77-081, Mechanical Engineering Department, University of Utah, Salt Lake City (February 1977).

(10) H. R. Jacobs, R. F. Boehm, and A. C. Hansen, Application of Direct-Contact Heat Exchangers to Geothermal Power Production Cycles, TDO/1549-8, Mechanical Engineering Department, University of Utah, Salt Lake City (January 1978).

(11) D. Q. Kern, Process Heat Transfer, McGraw-Hill, New York, 1950.

(12) W. H. McAdams, Heat Transmission, McGraw-Hill, New York, 1954.

(13) W. I. Kern, "Continuous Tube Cleaning Improves Performance of Condensers and Heat Exchangers," Chem. Eng. 82 (Oct. 13, 1975).

(14) W. E. Palmer and E. H. Miller, "Why Multipressure Condenser-Turbine Operation," p. 437 in Proceedings of the American Power Conference, vol. 27, Illinois Institute of Technology, Chicago, 1965.

(15) R. L. Coit, Power 117, 87-89 (June 1973).

(16) Ronald DiPippo, Geothermal Power Plants of Mexico and Central America, COO/4051-26 (CATMEC Report No. 18), Brown University, Providence, R.I. (July 1978).

(17) Western Energy Resources and the Environment: Geothermal Energy, EPA600/9-77-010 Environmental Protection Agency (May 1977), p. 68.

(18) D. F. Othmer, Ind. Eng. Chem. 21, 576 (1929).

(19) C. L. Henderson and J. M. Marchello, J. Heat Transfer 91, 447-50 (August 1969).

(20) D. M. Eissenberg, "Tests of Enhanced Horizontal Tube Condenser Under Conditions of Horizontal Steam Cross Flow," p. HE 2.1 in the Proceedings of the Fourth International Heat Transfer Conference, Paris-Versailles, 1970, vol. 1, Elsevier, Amsterdam, 1970.

(21) D. M. Eissenberg, personal communication.

(22) William O'Keefe, Power, 117, 49 (December 1973).

(23) J. H. Keenan et al., Steam Tables, Thermodynamic Properties of Water Including Vapor, Liquid and Solid Phases, Wiley, New York, 1969.

(24) Clifford Mah (Aerojet Energy Conversion Co., Sacramento), "Effect of Noncondensable Gases on the Performance of Rankine Cycles," presented at the Eighth CATMEC Meeting, San Diego, Calif., Feb. 21, 1978.

(25) W. I. Kern, Combustion 47, 18-27 (August 1975).

(26) Steam Plant Surface Condenser Leakage Study, vol. 1, EPRI NP-481, Bechtel Corporation (March 1977), pp. 2-24.

(27) Steam Plant Surface Condenser Leakage Study, vols. 1 and 2, EPRI NP-481, Bechtel Corporation (March 1977).

(28) Standards of Tubular Exchanger Manufacturers Assoc., 6th ed., Tubular Exchanger Manufacturers Association, New York, 1978, sec. 12.

(29) J. M. Chenoweth, Flow-Induced Vibrations in Shell-and-Tube Heat Exchangers, SAN/1273-1 (February 1977). 
(30) Titanium Tubing for Surface Condenser Heat Exchanger Service, Timet Bulletin SC-4, Titanium Metals Corporation:

(31) R. J. Beaver, State of the Art-Survey of Joinability of Materials for OTEC Heat Exchangers, ORNL/TM-6284, to be published.

(32) S. K. Combs, An Experimental Study of Heat Transfer Enhancement for Ammonia Condensing on Vertical Fluted Tubes, ORNL-5356 (January 1978).

(33) J. W. Michel et al., Energy Div. Annu. Prog. Rep. Period Ending Sept. 1977, ORNL-5364, pp 181-90

\subsection{Heat dissipation systems and equipment (By R. C. Robertson*)}

\subsubsection{General}

Electric power stations are normally classified in terms of their net electrical capacity in megawatts. This classification provides a mental image of the general size and cost of the plant, with the steam supply system and the turbine-generator unit dominating. In picturing a geothermal power station, however, it is necessary to include the waste heat rejection system as one of the dominant features. A 50-MW(e) geothermal power plant, for example, would probably require a wet cooling tower of the size usually associated with a 250- or 300-MW (e) conventionally fueled station. If the geothermal plant were located in a watershort area, the cooling towers would probably have to be the wet/dry or dry type, adding further to the cost and size of the equipment. The waste heat rejection system for a geothermal plant is therefore a principal feature of the station, and selection of the equipment is one of the major design considerations.

In view of the growing scarcity of water, the Department of Energy, the Electric Power Research Institute, and others have recognized the probable future need for wet/dry and dry cooling towers for conventionally fueled as well as geothermal power plants, and have sponsored a relatively large number of studies on the subject. Although this review cannot be exhaustive, selected references will be presented to establish the general state of the art and the probable trends as they relate to nearterm geothermal power.

\subsubsection{Once-through cooling systems}

Once-through cooling systems take water from an abundant source, such as an ocean, large lake, or river; pump it through the turbine condenser, where the water temperature is raised 8 to $11^{\circ} \mathrm{C}\left(15\right.$ to $\left.20^{\circ} \mathrm{F}\right)$; and return it to the source. This method is usually the most economical means of heat rejection from a power station. Capital costs of a oncethrough system for a geothermal power plant would probably fall in the range of $\$ 15$ to $\$ 30$ per kilowatt of installed capacity. Up until the 1960 s

*Oak Ridge National Laboratory, Oak Ridge, Tenn. 
it was the most favored method of heat rejection, and water availability was a prime requirement in selecting a site for a new power station. However, once-through cooling systems usually have more environmental impact than other methods of heat dissipation because of the relatively large amounts of water that must be drawn into the intakes. A geothermal power station with a thermal efficiency of about $15 \%$ would require about $0.17 \mathrm{~m}^{3} / \mathrm{sec}(6 \mathrm{cfs})$ of cooling water per megawatt electrical of installed capacity.

The primary environmental impacts are the entrainment of fish eggs and plankton, which have a high mortality rate in the passage through the condenser, and the killing of fish due to impingement on the intake screens (1).* Attempts to prevent fish from entering the intake area, for example, by means of air-bubble curtains or underwater noise generators, have achieved only limited success. Equipping the traveling screens with fish lifts, or baskets, has given better results, but the impacts are still being evaluated and are of concern. To keep impingement losses within reason, it is necessary to design water velocities approaching the screens low enough for fish to escape laterally and to provide a passageway for the fish to return to the water body. An approach velocity greater than $0.3 \mathrm{~m} /$ sec (1 fps) is usually considered unacceptable. (The approach velocity is not to be confused with the face velocity at the screen. The latter takes into account the obstruetions to flow due to the wire mesh, screen support frames, and structures. The free area for flow is usually taken as about $65 \%$ of the total face area.)

The discharge of the heated water back into the source can create objectionable zones of elevated temperatures that can disturb migration patterns of fish, influence spawning, or be lethal to some aquatic species (2). Heating of significant volumes of water to temperatures greater than $32^{\circ} \mathrm{C}\left(90^{\circ} \mathrm{F}\right)$, or to temperatures of 1.7 to $2.8^{\circ} \mathrm{C}\left(3^{\circ}\right.$ to $\left.5^{\circ} \mathrm{F}\right)$ in excess of ambient, usually violates state water quality criteria and raises serious questions of environmental acceptability. A design objective is to mix the discharged water as rapidly as possible with the receiving water by use of jets, or nozzles. The desirable distance for the nozzles to be submerged beneath the surface, and the spacing between them, is site specific (3). In many instances, the only acceptable arrangement is a diffuser pipe that distributes the water over a relatively large area.

Fouling of the condenser heat transfer surfaces is a primary consideration in once-through cooling systems, particularly if the water is drawn from an ocean or estuary. Few locations exist today where water is available in sufficient quantity and is also of high enough quality to be used without chemical treatment and/or routine mechanical cleaning of the condenser tubes.

Based on present knowledge of the most feasible locations for geothermal power stations, it is reasonable to conclude that water sources are

*References for sect. 5.3 are listed on p. 641 . 
not likely to be available for once-through cooling systems. In any event, once through systems are now so lacking in favor with the Environmental Protection Agency and other regulatory bodies that construction permits are most difficult to obtain.

\subsubsection{Cooling lakes and ponds}

The costs and environmental impacts of using relatively large amounts of land for a cooling lake, the lack of suitable sites, and the evaporation and seepage losses from such a water body have all generally discouraged construction of lakes solely for the purposes of waste heat dissipation. If, however, it is desirable to provide a storage lake for other purposes, such as for recreation, to ensure an adequate water supply during dry seasons, to implement stream flows, or to control runoff, then use of the same lake for heat dissipation may be an attractive possibility. One important advantage of lakes as a heat sink is that they have a thermal inertia which enables a power station to better meet daytime peak loads. Lakes created to serve power stations have historically assumed recreational and wildlife importance, and aspects such as fish impingement on the intake screens, waterfowl habitat, minimum drawdown to protect swimming and boating, and aesthetic aspects have become serious environmental issues.

A water body will naturally evaporate at a rate of 2.5 to $5 \mathrm{~mm}(0.1$ to 0.2 in.) per day, depending upon the meteorological conditions. If the surface temperature of the water is raised by using it as a heat sink for a power cycle, the surface evaporation rate increases. This induced evaporation will not be as great as that required in a cooling tower to dissipate the same amount of heat because the water body has the advantage of also losing heat by radiation. The total of the natural plus induced evaporation rates, however, can be greater than the water consumption of a cooling tower having the same duty. Water seepage from an unlined or leaky impoundment may also be a significant water loss. Solely from the standpoint of water conservation, construction of a lake specifically for the purposes of heat dissipation is likely to be a poor choice when compared to spray canals or wet cooling towers.

A rough notion of the lake area required to dissipate heat can be obtained by assuming that $4000 \mathrm{~m}^{2}$ (1 acre) can dissipate about $1.5 \mathrm{MW}$ $\left(5 \times 10^{6} \mathrm{Btu} / \mathrm{hr}\right)$ of heat. It must be cautioned, however, that this value can vary widely with the water temperature, the wind velocity, and other meteorological conditions. Construction costs can also vary markedly, depending on the site location, character of the terrain, and whether the basin must be lined to reduce seepage losses. In 1976, cooling lakes for nuclear power plants were estimated to cost in the range of $\$ 14$ to $\$ 22$ per kilowatt of installed capacity; a geothermal power station rejecting two to four times as much heat per kilowatt could thus have 1978 costs of over $\$ 100$ per kilowatt. 
The rate of heat transfer from a water surface has been studied by several investigators. Some of the more representative results have been obtained using the approach of Edinger and Geyer (4). The method involves the concept of an equilibrium temperature, $t_{E}$, and a surface heat exchange coefficient, $K$. The heat flux from the surface is expressed as

$$
\phi=K\left(t_{s}-t_{E}\right),
$$

where $t_{\mathrm{a}}$ is the actual water surface temperature and $t_{E}$ is defined as the water surface temperature that, for a given set of meteorological conditions, makes the back-radiation, evaporation, and conduction losses equal to the heat inputs by solar radiation. A water body with $t_{s}$ greater than $t_{B}$ will tend to decrease in temperature, and $t_{s}$ will approach $t_{E}$. If $t_{s}$ is less that $t_{k}$, the opposite will be true. The surface heat exchange coefficient, $K$, is defined to give the incremental change of net heat transfer induced by an incremental change in the water surface temperature. In 1973 Ryan and Harleman (5) devised a method for approximating the, values of $t_{E}$ and $K$. The procedure summarized below is taken from that source. (For a more detailed treatment, see references (4) and (5).)

Input data:

$t_{D}=$ dew-point temperature, ${ }^{\circ} \mathrm{F}$,

$t_{a}=$ ambient air temperature measured $6 \mathrm{ft}$ above surface, ${ }^{\circ} \mathrm{F}$,

$\mathrm{RH}=$ relative humidity, as a decimal,

$W=$ wind speed above surface, $\mathrm{mph}$,

$\phi_{d}=$ direct incoming solar radiation, Btu/day $\cdot \mathrm{ft}^{2}$ (see figure 5.25),

$C=$ Brundt coefficient (i.e., a function of the air temperature and the ratio of the measured solar radiation to the clear-sky solar radiation). A typical value is $\mathbf{0 . 6}$.

Calculate:

$$
\begin{aligned}
& T_{a}=t_{a}+460,{ }^{\circ} \mathrm{R}, \\
& e_{a}=(25.4)(\mathrm{RH}) \exp \left[17.62-\left(9500.8 \cdot T_{a}\right)\right], \mathrm{mm} \mathrm{Hg}, \\
& \phi_{a}=4.18 \times 10^{-8}\left(T_{a}\right)^{4}\left(C+0.031 \sqrt{ } e_{a}\right), \\
& \phi_{r}=\phi_{a}+\phi_{d}
\end{aligned}
$$

Assume $t_{E}$ and calculate:

$$
\begin{aligned}
& T^{*}=\left(t_{s}+t_{D}\right) / 2+460,{ }^{\circ} \mathrm{R} \\
& \beta=\left[25.4(9500.8) \exp 17.62-9500.8 \cdot T^{*}\right] /\left(T^{*}\right)^{2} \text {, } \\
& t_{k}=\frac{\phi_{r}+17 W\left(\beta t_{D}+0.255 t_{a}\right)-1600}{23+17 W(\beta+0.255)} \text {. }
\end{aligned}
$$

Assume a new value for $t_{E}$, repeat previous step, and continue iteration until a satisfactory value is found for $t_{s}$. 


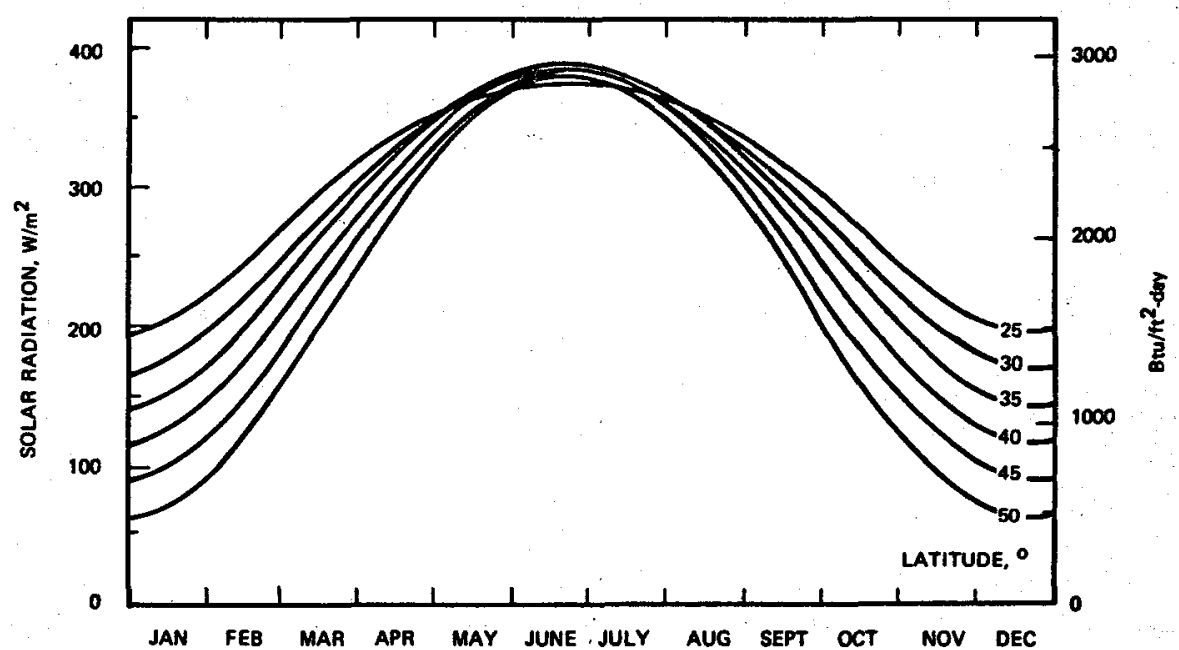

FTgURE 5.25-Clear sky radiation. Source: J. R. Edinger and J. C. Geyer, Cooling Water studies for Edison Electric Institute, Project No. RP-49-Heat Exchange in the Environment, The Johns Hopkins University, Baltimore, June 1, 1965.

Calculate:

$$
\begin{aligned}
T_{s}= & t_{s}+460,{ }^{\circ} \mathrm{R}, \\
e_{s}= & 25.4 \exp \left(17.62-9500.8 / T_{s}\right), \mathrm{mm} \mathrm{Hg}, \\
T_{s-s}= & T_{s} /\left[1-(0.378 / 760) e_{s}\right],{ }^{\circ} \mathrm{R}, \\
T_{a-s}= & T_{a} /\left[1-(0.378 / 760) e_{a}\right],{ }^{\circ} \mathrm{R}, \\
\Delta \theta_{s}= & T_{s-s}-T_{a-{ }^{\circ}} \\
t_{s}^{*}= & 0.55 t_{s}+0.45 t_{R}, \\
K= & 23+(\beta+0.255)\left[14 W+22.4\left(\Delta \theta_{v}\right)^{1 / 3}\right] \\
& +7.5\left(\Delta \theta_{v}\right)^{-2 / 3}\left[e_{s}-e_{a}+0.255\left(t_{s}^{*}-t_{a}\right)\right], \mathrm{Btu} / \mathrm{day} \cdot \mathrm{ft}^{2} \cdot{ }^{\circ} \mathrm{F} .
\end{aligned}
$$

The literature contains a relatively large amount of information on cooling pond performance. Gibbons and Pike $(6)$ have listed more than sixty studies on cooling ponds. Jirka, Abraham, and Harleman ( $(7)$ have assessed the techniques used to predict temperature distributions in ponds. Field temperature data for heated surface discharges into Lake Michigan have been analyzed by Kyser, Paddock, and Policastro ( 8 ). Neill and Gibbons $(9)$ discuss in some detail the procedures for sizing a cooling pond for a thermal power plant using steam turbines with a surface condenser. They show that the optimum size depends upon many parameters, including the plant efficiency, local climate, turbine exhaust temperature, condenser area, the water circulation rate, etc. The work is based on performance data taken under summer conditions in the southeastern United States. Mixing and thermal stratification in the pond are included as parameters. Some of the results are summarized in figure 5.26. In a sample calculation assuming midsummer conditions for a fossil plant having a thermal effi- 
ciency of $41 \%$, Neill and Gibbons estimate about $10,000 \mathrm{~m}^{2}$ (2.5 acres) of pond area would be required per megawatt (electrical) of installed capacity. Assuming the same conditions, but a geothermal plant with an efficiency of $15 \%$, about four times that area would be required per megawatt (electrical); if the efficiency is $10 \%$, about 6.4 times that area, or $65,000 \mathrm{~m}^{2}$ (16 acres), would be needed per megawatt (electrical) of capacity. These adjustment factors must also be used with figure 5.26 if it is applied to geothermal stations of like efficiencies.

\subsubsection{Spray ponds and canals}

- In contrast to cooling lakes or ponds, where the water is cooled primarily by evaporation from the surface, spray ponds and canals spray the water to be cooled into the air. By increasing the evaporation rate, the land area requirements are only about $5 \%$ of those needed for a cooling lake. The cooling process, which is about $80 \%$ by evaporation and $20 \%$ by convection, is essentially the same as that taking place in a cooling tower except that it occurs in the open atmosphere and the air flow is not induced, or channeled, as in a tower.

Spray ponds have been widely used in the past by industry and by smaller power plants. Some of the advantages are simplicity, low maintenance, ease of repair, and relatively low operating power requirements.

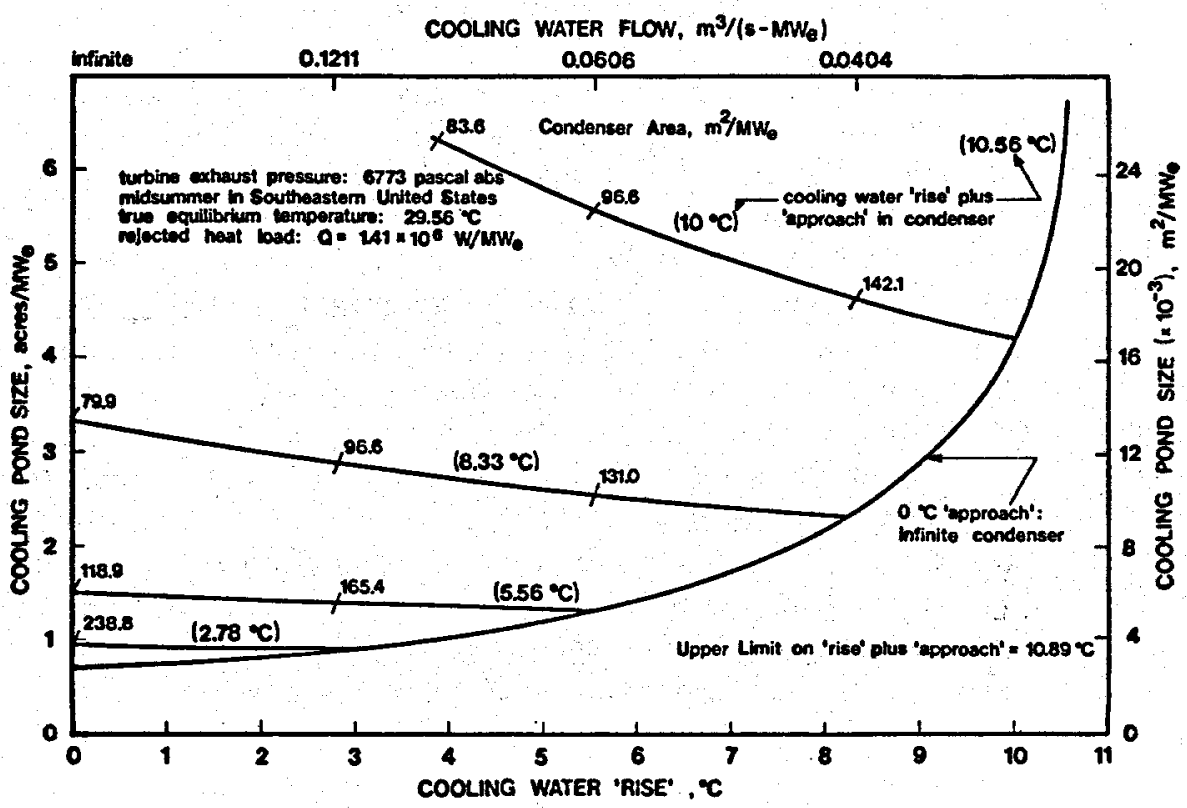

Frguke 5.26-Cooling pond size as function of temperature range and condensing temperature. Source: J. S. Nelll and J. H. Gibbons, Sizing a Cooling Pond for a Power Plant, 75-WA/HT-63, American Society of Mechanical Engineers [August 1975]. 
Spray ponds are less visible than cooling towers and are judged by many to be more aesthetically acceptable. The noise level created by a spray pond of equivalent duty would probably be about equal to that of a natural-draft cooling tower but is probably less than that of a mechanical-draft cooling tower. The fogging effects of a spray pond tend to be more localized, and drift losses also tend to be confined to the immediate area, although more recent data indicate that the drift deposition may be more widespread than was first thought. Some important disadvantages of spray ponds and canals include the following: the land area requirements are substantially greater than those for cooling towers; the performance, being subject to the wind speed, is more variable; there may be freeze-up problems in the wintertime; the approach to the wet-bulb temperature is limited; and the design factors relating the fluid mechanics and thermodynamics are more complex and less well studied than those of cooling towers. Whether spray ponds or canals are preferred over cooling towers is thus very site specific as to land costs and other factors, and each case must be evaluated on an individual basis.

Two different types of spray systems are in use: 1) the traditional fixed-pipe system and 2) the modular, or unit-powered, system. The fixedpipe arrangement consists of an array of nozzles fed by a central pump, and all the spray nozzles operate in parallel. The water to be cooled is sprayed into the air only once. The flow of sprayed water collected in the catch basin is not particularly directed. The modular system is comprised of floating units, each consisting of a pump and spray nozzles, moored in a canal so that the water flowing through the canal will pass in series through the modular units. A given particle of water is thus sprayed into the air many times in a single pass through the canal system. The temperature of the particle will approach the wet-bulb temperature of the air that is ambient to the last module in the series.

There has been considerable study to develop nozzle designs with low pressure drops and efficient spray patterns. Spray nozzles can be classified as pressure nozzles, spinning-disk types, and pneumatic, or gas-atomizing, nozzles. Pressure nozzles are most commonly used in spray ponds. Of this type, the so-called hollow-cone, ramp-bottom nozzle is widely used. It has a large free passageway, no interior vanes, and the right-angled inlet is offset to impart a whirling action that creates a hollow cone of spray water, as indicated in figure 5.27. Also, as shown in figure 5.27, air is induced downward into the central part of the cone by the relatively high velocity of water in the jet. The nozzles are usually arranged in groups of four. A typical ramp-bottom nozzle delivers $0.0033 \mathrm{~m}^{3} / \mathrm{sec}(53 \mathrm{gpm})$ with a pressure drop of $48 \mathrm{kPa}(7 \mathrm{psi})$ and $0.0040 \mathrm{~m}^{3} / \mathrm{sec}(64 \mathrm{gpm})$ with a pressure drop of $69 \mathrm{kPa}(10 \mathrm{psi})$. A rule of thumb is that the water will rise about $0.044 \mathrm{~m}$ for every $\mathrm{kPa}$ of pressure drop; thus the height of the spray cone for a nozzle with a $\Delta P$ of $48 \mathrm{kPa}$ (7 psi) installed $1.52 \mathrm{~m} \mathrm{(5 \textrm {ft } )}$

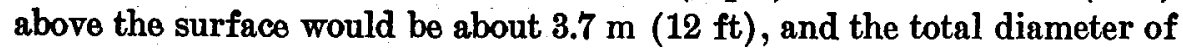



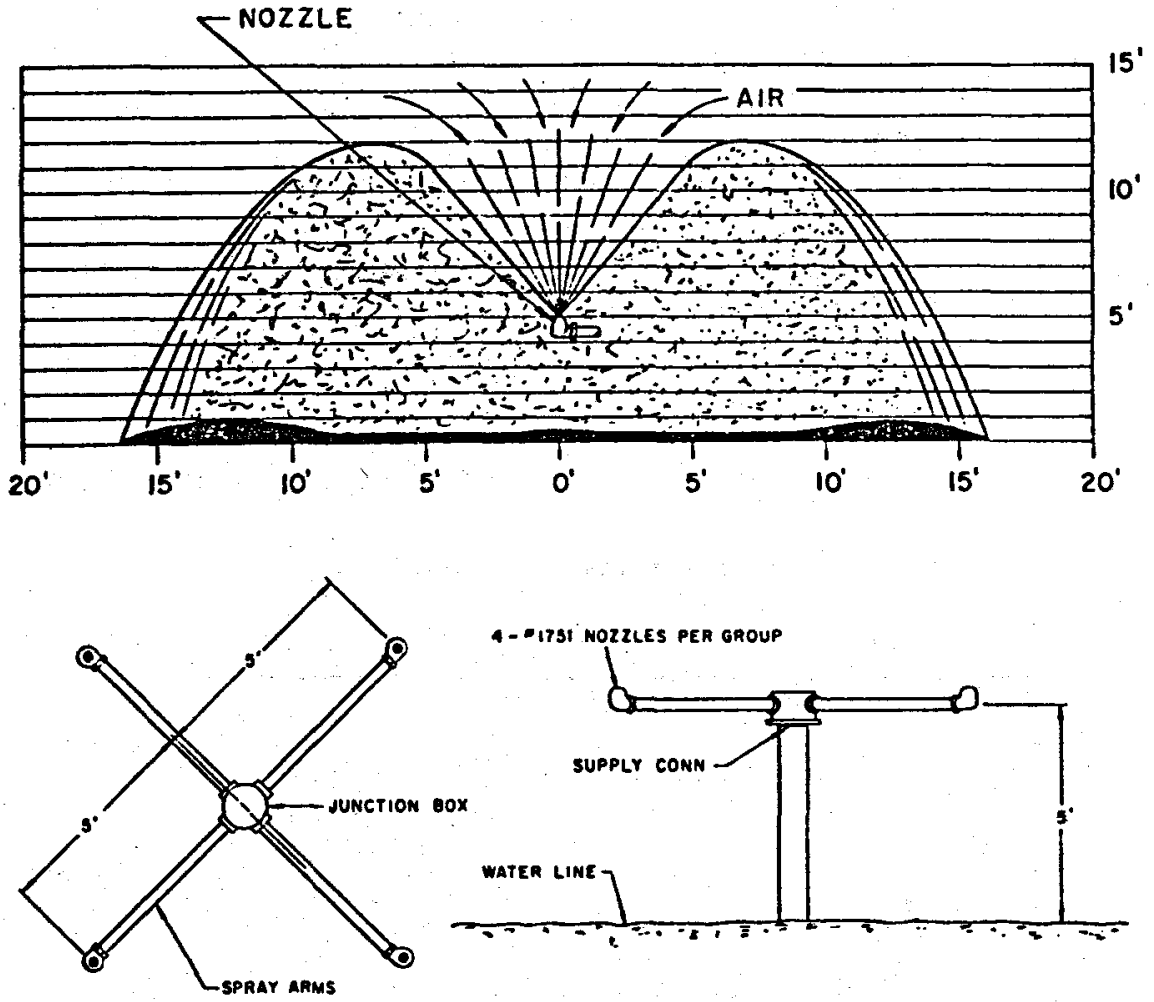

Frgure 5.27-Spray pattern and distribution. Source: E. Hebden and A. M. Shah, Effects of Nozzle Performance on Spray Ponds. Proceedings of the American Power Conference, vol. 38, p. 1449, nlinois Institute of Technology, Chicago, 1976.

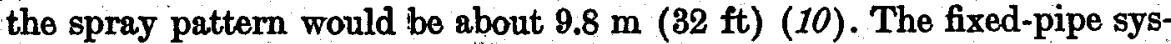
tem produces relatively small drop sizes, in the order of less than $1 \mathrm{~mm}$ in diameter. The smaller drops enhance evaporation but increase the drift rate.

The modular system is now widely favored over the fixed-pipe arrangement for power plant applications. Much of the following discussion about modular units has been taken from Ryan and Myers (11). The flow rate of 0.003 to $0.004 \mathrm{~m}^{3} / \mathrm{sec}(40$ to $70 \mathrm{gpm}$ ) per nozzle mentioned above for the fixed-pipe systems contrasts sharply with the $0.16 \mathrm{~m}^{8} / \mathrm{sec}(2500$ gpm) typically delivered from each nozzle of a modular system. Drop sizes are much larger than in the fixed-pipe system, being in the order of 5 to $10 \mathrm{~mm}$ in diamoter, and thus drift losses also tend to be less. Each module customarily has four nozzles with the spray pattern for each being about $12.2 \mathrm{~m}(40 \mathrm{ft})$ in diameter. The total power requirements for a module with four nozzles is about $56 \mathrm{~kW}(75 \mathrm{hp})$. The modules are moored in symmetrical rows along the width and length of the canal. The performance is better when the wind direction is perpendicular to 
the canal, because air movement along the length tends to cause interference between the sprays and raise the local wet-bulb temperature. The spray pattern characteristies of unit sprays have been analyzed and reported in the literature (12).

One approach to evaluating the performance of modular spray systems is to use overall performance information to construct simplified design curves. A set of these curves, developed by the Tennessee Valley Authority (TVA) (13), is illustrated in figure 5.28. The use of the curves is explained in the figure caption.

A more rigorous approach is to estimate the thermal efficiency of a single module as a function of the water temperature, wet-bulb temperature, and wind speed and then estimate the behavior of the system of modules, in-

Number of sprays per million gpm

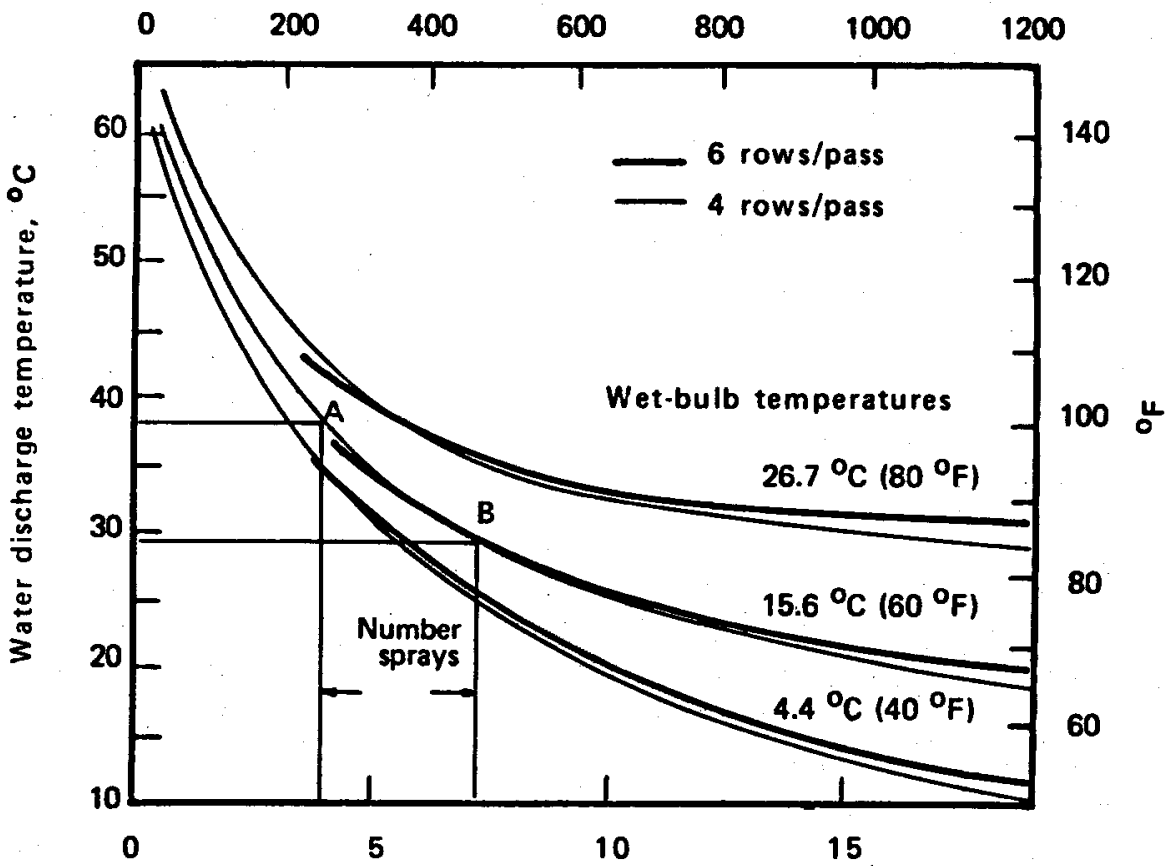

Number of sprays per $\mathrm{m}^{3} / \mathrm{sec}$

FTaURE 5.28-Simplifed spray pond design curves developed by TVA for $8 \mathrm{~km} / \mathrm{h}$,

(5 mph) wind. Use of curves is explained by the following example: For hot water temperature of $38^{\circ} \mathrm{C}\left(100^{\circ} \mathrm{F}\right)$ and wet-bulb temperature of $15.6^{\circ} \mathrm{C}\left(60^{\circ} \mathrm{F}\right)$ [Point A], a flow rate of $31.5 \mathrm{~m}^{3} / \mathrm{sec}\left(0.5 \times 10^{6} \mathrm{gpm}\right)$, and four rows per pass, the number of sprays per cubic meter for each second is 3.9. For an allowable discharge temperature of $29.4^{\circ} \mathrm{C}\left(85^{\circ} \mathrm{F}\right)$ [Point $\mathrm{B}$ ], the number of discharge sprays is $7.2 \mathrm{per} \mathrm{m}^{8} / \mathrm{s}$. The number of sprays required is (7.2-3.9)31.5 $=104$ units. Source : C. Bowman, Tennessee Valley Authority, Knoxville, Tenn., private communication with $\mathbf{P}$. J. Ryan, Bechtel, San Francisco. 
cluding the interference effects of the sprays. A widely used method of estimating the module performance is the so-called NTU Model. The module efficiency at a given wind speed is represented by the number of transfer units (NTU), a dimensionless quantity defined as follows (11):

where

$$
\overline{N T U}=\frac{c_{w} \Delta T}{\left[h\left(T_{B}\right)+h\left(T_{C}\right)\right] / 2-h\left(T_{w b a}\right)},
$$

$c_{20}=$ specific heat of water,

$h=$ total heat (sigma function) of air-vapor mixture of evaluated $T$,

$\boldsymbol{T}_{H}=$ nozzle (hot) water temperature,

$T_{C}=$ sprayed (cold) water temperature,

$\Delta T=T_{B}-T_{C}$,

$T_{w b a}=$ locial wet-bulb temperature.

Hoffman (14) obtained empirical values of the average.NTU as a function of wind speed (figure 5.29). These values check reasonably well with field data, according to Porter and Chen (15), who back-calculated from field data for NTU values (figure 5.29). The differences between the bestfit data and the summer data is apparent, as is also the difference between these data and the Hoffman values.

Another approach to evaluating module performance is the cellular model, which examines the heat and mass transfer relationships from a single water droplet. Various modifications and improvements have been made of the original Elgawhary model, (16) and good agreement has been obtained with field data using a typical drop diameter of $5 \mathrm{~mm}$. Because a comprehensive discussion of the cellular model cannot be included here, the reader is referred to Porter and Chaturvedi (17).

The performance of a system of modules is evaluated by taking each row as a separate channel. A fraction of the flow in the channel is assumed through a module, cooled, and mixed with the remaining flow in the channel. The mixed flow then proceeds to the next module. At each module the spray water temperature, the wind speed, and the local wetbulb temperature are estimated. The temperature of the spray water is obtained from the individual module performance analysis and from an energy balance, as outlined above. The wind speed is obtained from local meteorological data or assumed to have a typical value of $8 \mathrm{~km} / \mathrm{hr}(5$ $\mathrm{mph}$ ). The local wet-bulb temperature is an important parameter in estimating the performance of the system. A common assumption is that the wet-bulb temperature increases by 1.1 to $1.7^{\circ} \mathrm{C}\left(2\right.$ to $\left.3^{\circ} \mathrm{F}\right)$ at the first row and 0.3 to $0.6^{\circ} \mathrm{C}\left(0.5\right.$ to $\left.1^{\circ} \mathrm{F}\right)$ at each subsequent row thereafter. The local wet-bulb temperature, $T_{10 b a}$, may also be defined in terms of an interference factor:

$$
T_{w b a}=T_{w b}+f\left(T-T_{w b}\right)
$$




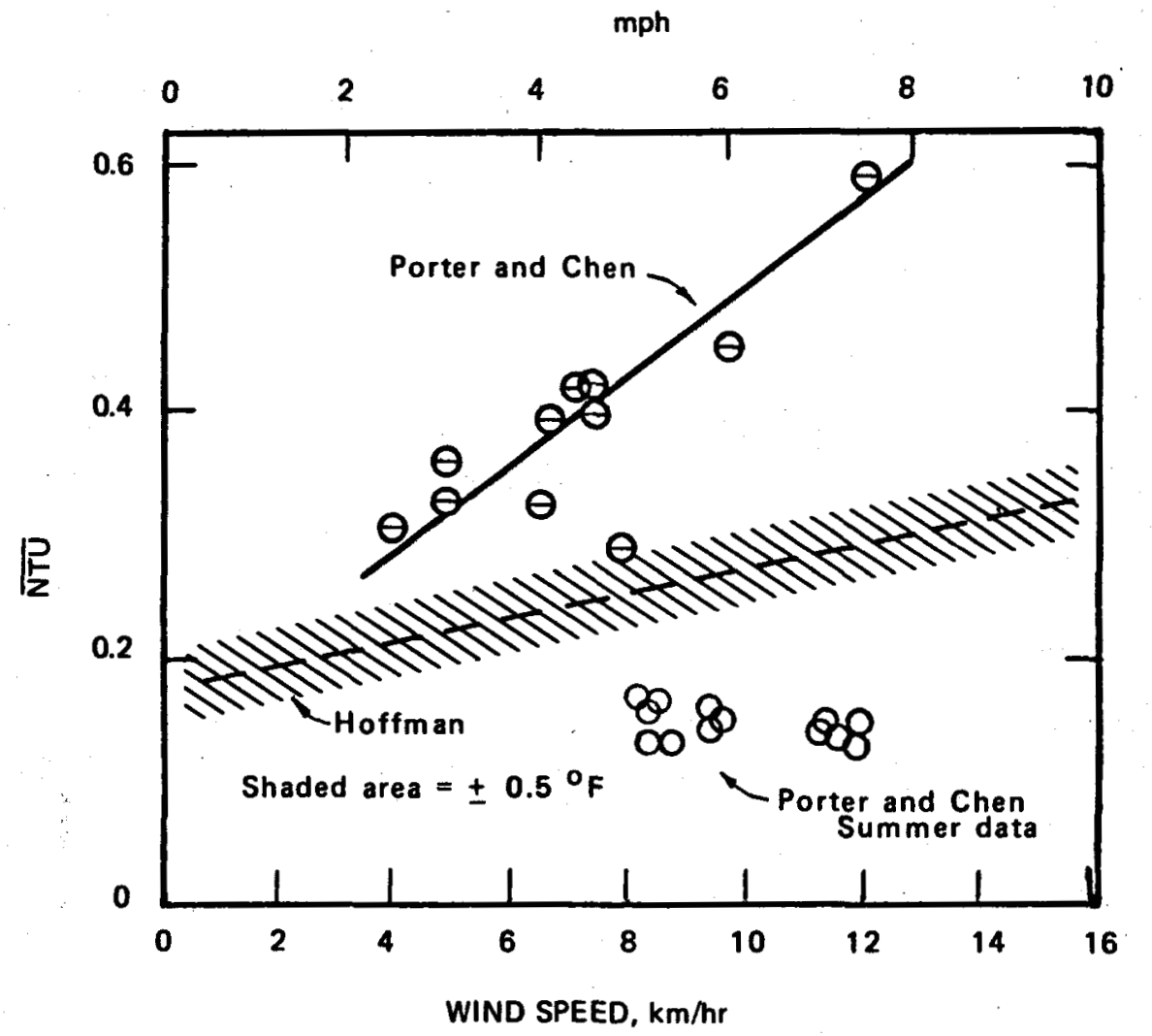

Frguke 5.29-Numler of transfer units for spray ponds vs. wind speed. Source : D. P.

Hoffman, Spray Cooling for Power Plants, p. 702 in Proceedings of the American Power Conference, vol. 35, Illinois Institute of Technology, Chicago, 1973. R. W. Porter and K. H. Chen, J. Heat Transfer, 96, 286-91 [August 1974].

where $T$ is the water temperature, $T_{W b}$ is the upwind wet-bulb temperature and $f$ is the interference factor. An average interference factor may be approximated by

$$
\bar{f}=\frac{1}{n}[0.18+0.26(n-2)] .
$$

where $n$ is the number of rows of modules (11). More rigorous methods of evaluating interference factors are given in the literature (17) but are beyond the scope of this section.

Present practice is for the plant designer to lay out the overall arrangement of the spray pond or canal but to leave the selection of the number of modules required to the supplier, who thus assumes responsibility for the performance of the system. Because the performance characteristics of spray modules are usually considered proprietary by the vendors, little application data are published. Although some predictive models have 
been developed, as briefly mentioned above, all of the models involve the use of empirical, or even arbitrary, factors, and considerable caution is advised in using them to design large systems. Examples are given by Ryan and Myers (11) in which the number of modules estimated for a given set of conditions using different models and assumptions differed by a factor of 2.5. There are several instances where the spray canal performances at actual generating stations have been underestimated and modifications have been required.

Until relatively recently it was assumed that the large-diameter drops associated with the modular units would quickly fall to the ground if blown outside the confines of the catch basin and that significant drift deposition would not occur further than about $100 \mathrm{~m}$ (100 yd) from the basin. However, Feder (18) has published drift data that extend the possible range of important drift deposition. Environmental Systems Corporation reported drift measurements made at a large spray canal installation at wind speeds varying from 8 to $24 \mathrm{~km} / \mathrm{hr}$ (5 to $15 \mathrm{mph}$ ), as shown in figure 5.30. The salinity of the sprayed water was $22,000 \mathrm{ppm}$. The drift deposition rate as far as $3 \mathrm{~km}(10,000 \mathrm{ft})$ downwind was found to be twice that of the background (upwind) values, and some vegetation damage was noted as far away as $2 \mathrm{~km}(6500 \mathrm{ft})$ from the basin (19).

\subsubsection{Cooling towers}

5.3.5.1 Introduction. Because of the decline in use of once-through cooling systems, most large power stations installed recently in the United States rely on evaporative cooling for waste heat rejection. This method consists of evaporation of a small portion (1 to $3 \%$ ) of the condenser circulating water to cool the remainder of the stream by 8 to $16^{\circ} \mathrm{C}(15$ to $30^{\circ} \mathrm{F}$ ).

Although spray ponds and canals have some use, the greater proportion of evaporative cooling is accomplished in cooling towers. All evaporative, or wet, cooling towers operate on the same basic principle of bringing the water to be cooled into intimate contact with a moving airstream where about $75 \%$ of the water-cooling process takes place by evaporation and the remainder by conduction to raise the dry-bulb temperature of the air. The airstream usually leaves the tower very close to saturated condition. Cooling tower designs vary in the manner in which the water surface is presented to the air (droplets vs. film), the arrangement of the water and air flows (crossflow vs. counterflow), and the manner in which the air flow is created (mechanical draft vs. natural draft). Each arrangement, as will be discussed subsequently, has particular advantages and disadvantages.

The performance of natural-draft cooling towers is more sensitive than the mechanical-draft type to local meteorological conditions. Natural-draft towers were first developed extensively in England and portions of Europe. Here the low wet-bulb temperatures and high relative humidities, coupled 


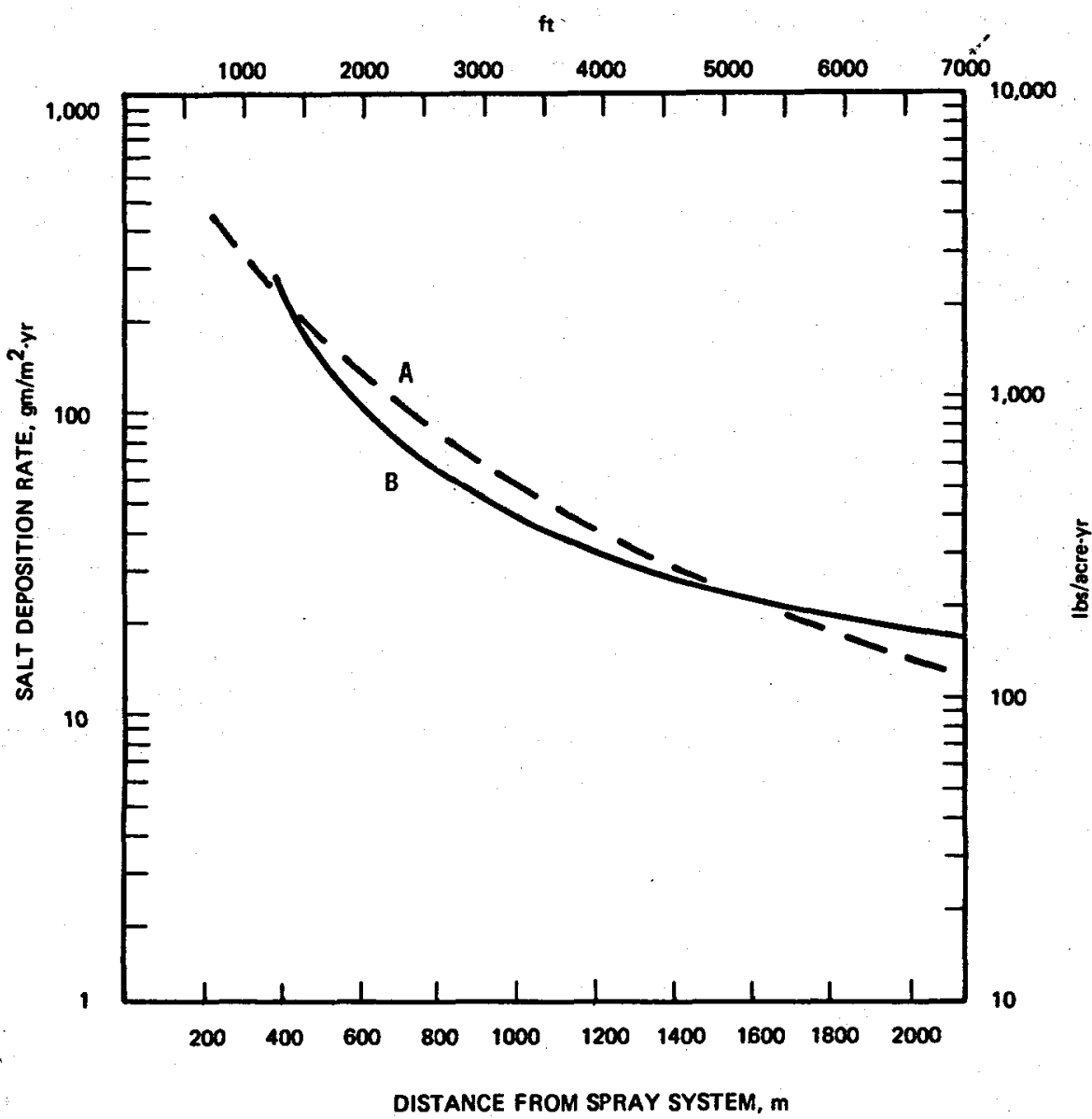

FIGURE 5.30-Some measured salt deposition rates from spray canals as a function of distance from source. Curve $A$ is based on data from ref. (18) with TDS in canal water of $5000-7000 \mathrm{ppm}$. Curve $B$ is based on data from ref. (19) with TDS in canal water of about $22,000 \mathrm{ppm}$.

with maximum station loads that tend to occur in the winter when ambient air temperatures are lowest, provide favorable operating conditions. By contrast, natural-draft towers are ill-suited to the southwestern United States where wet-bulb temperatures tend to be high, relative humidities are low, and the maximum loads occur in the summer due to air-conditioning demands. Because the geothermal power sites currently thought to have the most promise in the United States occur in southern California, naturaldraft cooling towers may have little current application for geothermal energy power stations.

A distinctly different form of heat rejection is dry cooling. The water to be cooled, or the steam (or other working fluid) to be condensed, is confined inside extended surface tubes over which the air passes. Because there is 
no evaporation, the method relies entirely on conduction to raise the drybulb temperature of the airstream. This method of cooling has been used for many years by industry and for air-conditioning applications in the arid regions of the sauthwestern United States. In small sizes, the arrangement is usually referred to as air-cooled coils, but in larger sizes (such as for power stations) it is commonly referred to as dry cooling towers. Dry towers have not been used to any great extent in the United States to date because of their relatively high cost and downgrading effect on plant thermal efficiency, but the growing scarcity and cost of water will undoubtedly change this situation. As has been stated, today one would probably look at dry cooling last-tomorrow one may have to look at it first (20).

A detailed discussion of cooling tower theory is not included here. In brief, in a wet cooling tower, heat is removed from the circulating water by the transfer of sensible heat due to the temperature difference between it and the air and by the transfer of latent heat equivalent to the mass transfer that results from evaporation of a portion of the water into the air stream. In 1925, Merkel (21) ingeniously combined these two processes into a single equation, which is based on the enthalpy difference as the driving force (the specific heat of the water is assumed to be unity).

where

$$
L d t=K a d V\left(h^{\prime}-h\right)=G d h
$$

$L=$ mass flow rate of the circulating water,

$t=$ temperature of the circulating water,

$K=$ overall unit conductance, based on enthalpy as the driving force,

$a=$ area of water interface,

$V=$ active tower volume per unit area,

$h^{\prime}=$ enthalpy of moist air at the bulk water temperature,

$h=$ enthalpy of the moist air,

$G=$ mass flow rate of the air.

Among the several simplifying assumptions usually made in applying this equation is that, in making the mass balance, the evaporation loss is ignored. Development of the equation has been summarized in many texts and references; Baker and Shryock (22) made a comprehensive review of the subject in 1961. Because the equation does not lend itself to direct mathematical solution, it is usually solved by some means of mechanical integration that considers the relative motion of the airstreams and water streams in counterflow and crossflow cooling towers. Advent of the computer made it possible to develop comprehensive sets of curves to aid in analyzing tower performance (23) and to mathematically model cooling tower processes. These models, however, depend on coefficients that need verification by field testing; many are considered proprietary. Simplified approximations of the cooling tower process are often sufficiently accurate, and many such methods have been described in the literature. One method, for example, follows Merkel's total heat theory and, embodying 
Lichnestain's empirical relationships, results in an equation subject to iterative solution (24). The ASHRAE Guide and Data Book is one of the better references (25).

Selection of the optimum design for a cooling tower is very site specific and is influenced by a large number of factors, such as land area requirements, quality of makeup water, environmental considerations, costs of labor and materials, worth of electricity, capitalization costs, etc. The large number of variables, including the input of historical meteorological data for the site, as well as the iterative nature of the solutions, has led to considerable reliance on computer analyses. The computer models, together with necessary performance information, are considered proprietary by most manufacturers. The majority of mechanical-draft cooling towers in the United States have been furnished by Marley, Ecodyne, Zurn Industries, Research-Cottrell, and Westinghouse. Natural-draft towers have been provided primarily by Marley and Research-Cottrell.

\subsubsection{Definitions of terms used with cooling towers. The following terms} are often employed in discussing cooling towers:

Approach-The difference between the temperature of the cooled water leaving the tower and the ambient wet-bulb temperature.

Blowdown-The water discharged from the cooling tower basin to control concentration of salts and other impurities in the circulating water (section 5.3.5.8).

Circulation rate-The rate at which the water taken from the cooling tower basin circulates through the condenser system.

Cold-water temperature-The temperature of the cooled water leaving the tower.

Condenser terminal difference-The difference in temperature between the water leaving the condenser and the condensing steam temperature.

Cooling range, or range-The difference between the temperature of the water entering and leaving the tower.

Oycles of concentration-A comparison of dissolved solids in makeup water with solids in the circulating water. This value usually varies from about 2 to 20 (section 5.3.5.8).

Drift, or drift rate-The water lost from the tower as droplets entrained in the effuent airstream. Typical values are 0.001 to $0.2 \%$ of the circulatingwater rate.

Dual-service condenser-A surface condenser with divided water boxes that allows use of two separate cooling-water circulating systems.

Evaporation rate-The water lost from the tower by evaporation of a portion of the circulating water into the air stream.

Fill, or packing-The internals of a cooling tower, which, either by causing splashing of the falling water or by presenting films (wetted surfaces), provides maximum water-air interface. 
Heat load, or duty-The heat removed from the circulating water in the cooling tower. It is usually expressed in megawatts (Btu/hr).

Hot water temperature-The temperature of water entering the tower.

Hyperbolic cooling tower-The shape of many natural-draft cooling tower shells.

$L / G$ ratio-The ratio of the weight of water circulated in a cooling tower to the weight of air passing through the tower.

Makeeup-The water added to the cooling tower basin to replace that water lost by evaporation, drift, blowdown, and leakage. The relationship between these water losses and cycles of concentration is discussed in section 5.3.5.8.

Packaged cooling tower-These towers are small enough to be factoryassembled and require little or no field erection.

Parallel path-Wet/dry cooling towers are sometimes referred to as parallel path towers because the air flow is usually in parallel through the two sections.

Recirculation-The percentage of the exhausted air that reenters the tower.

Total dissotved sotids (TDS) -Total dissolved solids, usually expressed as ppm, contained in the circulating water.

Water loading-The circulating-water flow rate expressed in cubic meter per square per minute $\left(\mathrm{gpm} / \mathrm{ft}^{2}\right)$ of effective horizontal wetted area of the tower.

Wet/dry cooling towers-Towers provided with both wet and dry sections. The airstreams usually move in parallel paths through the wet and dry portions, then combine before being exhausted by a single fan. The water usually flows in series, first through the dry coil and then through the wet section. This type of tower can control visible plumes and reduce annual water evaporation rates.

5.3.5.3 Wet mechanical-draft cooling towers. Mechanical-draft cooling towers employ motor-driven fans to provide a positive air flow through the tower fill. The units may be designed for the fans to provide either forced or induced draft, but the latter is more commonly used in larger, present-day towers. The water to be cooled is pumped to the top of the tower, distributed through headers, then falls to the basin at the bottom over a series of splash boards, or slats. The direction of the air flow relative to the falling water droplets may be either countercurrent or cross flow. Typical induced draft, crossflow and counterflow, wet mechanicaldraft cooling tower modules are shown in figure 5.31. The principal adadvantages of counterflow towers are that the process is more efficient and that they can be adapted better to restricted spaces. The more widely used crossflow type has the advantages of lower air-side pressure drops and more uniform distribution of both airstreams and water streams. Each module, or cell, is a separate unit with its own fan, and the louvered open- 

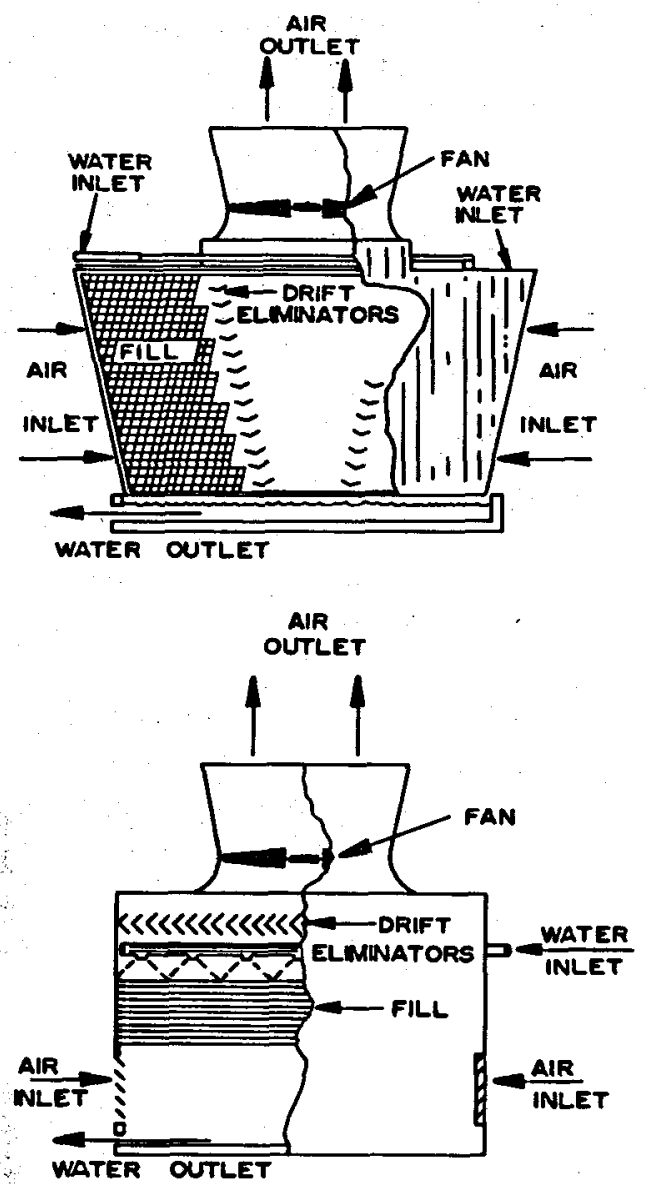

Froúbe 5.31-Mechanical-draft cooling towers. Upper figure is cross flow tower. Lower figure is counter flow tower. Source: J. D. Holmberg and O. L. Kinney, Draft Technology for Cooling Towers. The Marley Company, Mission, Kansas, 1973.

ings are on only two sides-permitting the cells to be arranged side by side in long rows up to $120 \mathrm{~m}(400 \mathrm{ft})$ in length in a so-called rectangular layout. (A recent development in wet mechanical-draft cooling towers is the circular configuration discussed in section 5.3.5.4.) The sloped trapezoidal sides of the tower conform to the path of the falling water profile as it is pulled toward the center by the airstream that is flowing horizontally. This shape eliminates unused fill space and reduces the basin size and cost. The geometry also facilitates ice melting because, with the fans turned off, the warm water will spill down over the louvers.

Internal supports may be redwood, treated fir, concrete, or cast iron. The fill hangers in which the slats are mounted are often glass-reinforced polyester. The splash boards, or slats, may be polyvinyl chloride (PVC), asbestos cement board (ABC), or plastic. The tower basin is reinforced concrete. Concrete may also be used to a greater extent in the future for the support structures. Although they have an initial cost of about 1.5 times that of wood towers, the improved fire resistance of the concrete towers both eliminates the need for sprinkler systems and lowers the insurance 
rates. The growing trend toward use of concrete and plastics in cooling towers will produce longer life and less maintenance. This aspect is of particular importance in geothermal power stations where the presence of hydrogen sulfide can cause relatively severe corrosion of metal cooling tower fittings. For this reason, stainless steel will also probably be used increasingly for the hardware in cooling towers for geothermal plants.

Large present-day mechanical-draft towers may have fans with high-

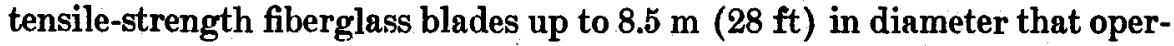
ate at top speeds of $60 \mathrm{~m} / \mathrm{sec}(12,000 \mathrm{fpm})$ and are driven by $150-\mathrm{kW}$ (200-hp) motors. A gear reducer and an extension shaft are provided so that the drive motor operates outside the moist airstream. Even larger towers, with $300-\mathrm{kW}$ (400-hp) motors driving fans with blades $12 \mathrm{~m} \mathrm{(40}$ $\mathrm{ft}$ ) in diameter, may possibly be developed in the near future. Each fan discharges into a premolded fiberglass vent stack designed to recover up to about $75 \%$ of the velocity head. The air typically exhausts from the stack at about $10 \mathrm{~m} / \mathrm{sec}(30 \mathrm{fps})$.

The reinforced concrete basin at the bottom of the tower collects the cooled water and acts as a sump for the circulating-water pumps. The basin is sized to hold several hours of inventory in the event that the makeup supply is lost. A drain is provided for removal of silt and is combined with an overflow pipe. Screens are provided at the pump suction.

The drift eliminators, indicated in figure 5.31 consist of baffles arranged to change the direction of air flow and catch most of the water droplets entrained in the airstream by impingement on the baffles. More complex baffling provides lower drift rates but adds to the initial cost and the airside friction losses. Drift rates for mechanical-draft cooling towers are typically in the range of 0.05 to $0.2 \%$, but because of present-day concerns for the environmental impacts of drift deposition, drift rates as low as $0.001 \%$ have been specified. Section 5.3 .5 .9 provides a further discussion of drift and methods of measurement.

Wet mechanical-draft cooling towers may be classified as large, intermediate, and small (or package) units. The larger cells, or modules, may be about $15 \mathrm{~m}(50 \mathrm{ft})$ high, $21 \mathrm{~m}(70 \mathrm{ft})$ wide, and $12 \mathrm{~m} \mathrm{(40} \mathrm{ft)} \mathrm{deep.}$ The top of the fan stack can be as high as $30 \mathrm{~m}$ (100 ft) above grade level. These large cells can cool up to $1 \mathrm{~m}^{8} / \mathrm{sec}(15,000 \mathrm{gpm})$ of circulating water and have fans up to $8.5 \mathrm{~m}(28 \mathrm{ft})$ in diameter driven by $150-\mathrm{kW}$ $(200-\mathrm{hp})$ motors. Intermediate sizes handle flow rates of 0.02 to $0.4 \mathrm{~m}^{3} / \mathrm{sec}$ ( 300 to $6000 \mathrm{gpm}$ ) and may have fan diameters of 3 to $5 \mathrm{~m} \mathrm{(10} \mathrm{to} 16 \mathrm{ft}$ ) driven by motors of $19-$ to $45-\mathrm{kW}$ (25- to $60-\mathrm{hp}$ ) capacity. Packaged units may vary in capacity from about 1 to 100 liters $/ \mathrm{sec}(15$ to $1500 \mathrm{gpm})$ of circulating water, have fan motors from less than 1 to $19 \mathrm{~kW}$ (1.5 to 25 $\mathrm{hp}$ ), and have a wide variety of designs and materials, including forceddraft counterflow arrangements. These relatively small factory-assembled packaged units have their greatest application in air conditioning (25). 
The circulating-water flow rates required for geothermal power stations will depend on the plant thermal efficiency and the plant electrical generating capacity. If a typical cooling-water temperature range of $11^{\circ} \mathrm{C}$ $\left(20^{\circ} \mathrm{F}\right)$ is assumed, a plant with a thermal efficiency of $5 \%$ would require a circulating rate of about 0.4 liters $/ \mathrm{kW} \cdot \sec (6.5 \mathrm{gpm} / \mathrm{kW})$. With an efficiency of $10 \%$, the rate would be about 0.2 liters $/ \mathrm{kW} \cdot \mathrm{sec}(3.1 \mathrm{gpm} /$ $\mathrm{kW}$ ), and with $15 \%$ efficiency, the rate would be about 0.1 liter $/ \mathrm{kW} \cdot \mathrm{sec}$ $(1.9 \mathrm{gpm} / \mathrm{kW})$. The relationships between makeup water addition rates, blowdown, evaporation loss, and drift and concentration of dissolved solids in the circulation water are discussed in section 5.3.5.8.

Mechanical-draft cooling towers are typically designed for wet-bulb temperatures of 19 to $28^{\circ} \mathrm{C}\left(66\right.$ to $\left.82^{\circ} \mathrm{F}\right)$, ranges of 7 to $17^{\circ} \mathrm{C}$ (12 to $\left.30^{\circ} \mathrm{F}\right)$, approaches of 6 to $11^{\circ} \mathrm{C}\left(10\right.$ to $\left.20^{\circ} \mathrm{F}\right)$, evaporation losses of 1.5 to $2.5 \%$, drift losses of 0.02 to $0.2 \%$, and blowdown rates of 0.5 to $3 \%$ of the water circulation rate (20). The wet-bulb temperature is the most important parameter in designing a wet cooling tower for a given site. Because the maximum wet-bulb temperature that has historically occurred at a given location will probably exceed greatly the average value, designing for the maximum would result in an oversized tower. Selection of a design wet-bulb temperature that will not be exceeded more than 2 or $3 \%$ of the time is customary. Designing for the minimum wet-bulb temperature can also be considered (section 5.5).

Multiple-cell towers are versatile in that they can be designed for a broad range of capacities by varying the number of cells used. A broad variety of cooling system requirements can be met by varying the fan speed and other operating parameters. Drift-rate specifications can be met by arrangement of the drift eliminators and fill-packing materials and configurations; fill height and packing depths can be optimized for specific design requirements. The modular arrangement of mechanical-draft towers has another distinct advantage in that, if the installed capacity is later demonstrated to be inadequate, it is relatively simple to add more cooling capacity.

The air-water vapor mixture leaving mechanical-draft cooling towers may at times be cooler than the air entering; that is, the plume from the tower may have negative buoyancy. The orientation of the tower with respect to the prevailing wind direction can have an important influence on recirculation, areas of drift deposition, icing, and ground-level fogging. In general, recirculation will be at a minimum if the row of cells is at right angles to the wind direction and located well away from structures, trees, or terrain features that could restrict or defiect air movements into and away from the units. Recirculation will tend to be at maximum when the wind is blowing along the line of towers. On the other hand, larger plumes tend to be lofted to higher altitudes than smaller ones because of the entrainment effect, and $a$ wind blowing along the line of cells tends to combine the effluent into a larger plume. This effect may help with prob- 
lems of ground-level fogging during certain months of the year but may or may not help drift deposition problems in that it may be preferable for the major amount of the drift to be deposited within the plant boundaries rather than on public or private lands. Section 5.3.5.9 includes further discussion of drift. Tower-induced icing and snowfall effects on plant structures, nearby highways, etc., must also be taken into consideration when siting and orienting the cooling towers. Because the ground effects of the relatively short mechanical-draft towers are greater than those of the much taller natural-draft towers, the mechanical-draft types may have to be located at a greater distance from the turbine building and perhaps spread over a greater area, resulting in a proportionate increase in land and piping costs.

The construction time for large wet mechanical-draft cooling towers may be about six months. Field erection costs can vary widely depending on the tower size and geographical location but may be roughly estimated at about one-fourth of the total tower cost. Fire protection systems, if required, can add about $15 \%$ to the capital cost. In 1974, some adjusted costs of large mechanical-draft towers were reported as varying from about $\$ 1$ to $\$ 2.23$ per kilowatt of fossil-fired steam station capacity (24). If adjusted to a geothermal station having only $10 \%$ thermal efficiency and to 1978 costs with an average inflation rate of $7 \%$ per annum, the costs could range between about $\$ 10$ to $\$ 20$ per kilowatt of installed capacity.

6.3.5.4 Circular mechanical-draft cooling tovers. A relatively recent configuration for wet cooling towers is the cross-flow, circular mechanicaldraft type developed by Marley. An overall view and a half-section of this type of tower are shown in figure 5.32. The tower fill is arranged in a larger annular area, as in a natural-draft tower, with an array of induceddraft fans clustered in the center to replace the chimney of the naturaldraft type. The advantages of the arrangement over a rectangular mechanical-draft layout are that recirculation effects are reduced and that the plume from the circular tower will be lofted to greater heights to reduce ground-level fogging and drift problems. The circular layout also will probably reduce the ground area needed, circulating-water piping costs, and fan power requirements. The advantages of the circular tower aver the natural-draft type include a lower profile that makes it less visible, a lower capital cost, and probably a greater ability to resist seismic disturbances. It will also operate in meteorological conditions that would not be tolerable for a natural-draft tower.

As with natural-draft towers, the circular mechanical-draft type will be most economical in larger sizes. The first full-scale installation of this tower type was in 1973-74 at the 500-MW (e) Jack Watson Station of the Mississippi Power Company at Gulfport. The plume behavior of the operating tower has conformed well with the predictions obtained from model tests. (26) This circular type of tower has been specified for several 

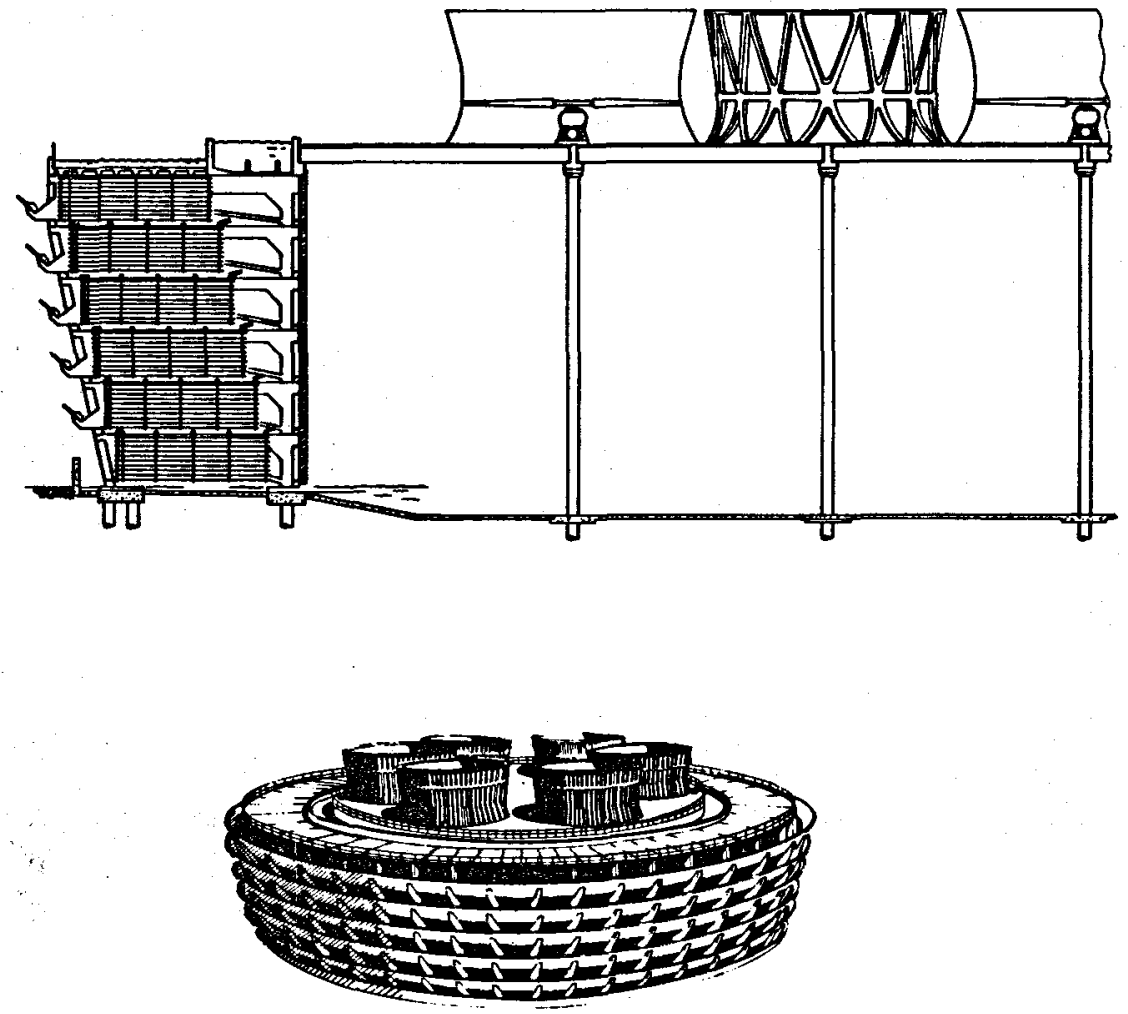

FIGURE 5.32-Oircular mechanical-draft cooling towers. Source : Round Towers, Publication RT-75, The Marley Company, Mission, Kans.

power station projects now planned or under construction. The costs of the towers will probably not be significantly greater than that of mechanical-draft towers in a rectangular layout, particularly when land and piping costs are considered.

The circular mechanical-draft cooling tower will probably find application for large geothermal power stations. It will function in arid regions where the natural-draft type will not, may help with drift problems at certain sites, and will offer economies in land costs and fan power consumption.

5.3.5.5. Wet natural-draft cooling towers. Natural-draft cooling towers may have limited use in geothermal power plant applications because they are best suited for very large installations and they do not function well in climates having high wet-bulb temperatures and low relative humidities, such as occur in the Imperial Valley region of southern California. The seismic activity and ground subsidence tendencies often associated with geothermal sites may also be a deterrent to their use. Nevertheless, because a 100-MW (e) geothermal power plant may reject as much heat 
as a $600-\mathrm{MW}$ (e) fossil-type station and potential geothermal resources are not necessarily confined to arid, seismically active regions, naturaldraft cooling towers cannot be completely eliminated from consideration.

The selection of natural-draft rather than mechanical-draft towers for many installations in the United States attests to their advantages in circumstances that permit their use. The favorable conditions may be summarized as

1. ambient conditions of low average wet-bulb temperature and high relative humidities;

2. a combination of low wet-bulb temperature and high inlet and exit water temperatures, that is, a broad cooling range and a large value for the approach temperature;

3. relatively large wintertime loads;

4. long amortization period;

5. relatively large station size;

6. need to restrict ground-level fogging and drift to a minimum; and

7. sites where visual impact, aircraft interference, etc., are not a problem.

Although the primary design parameter for mechanical-draft towers is the wet-bulb temperature, both the wet-bulb temperature and the relative humidity are important to the design of a natural-draft tower (27).

As in mechanical-draft towers, there are two basic types, the crossflow and the counterflow. In this former the fill or packing is located in a ring outside the base of the tower and the inside serves primarily as a chimney. In the counterflow type, the fill is inside the base and elevated so that the air entering around the periphery moves upward through the falling water droplets. The counterflow design provides more efficient heat transfer because the coolest water contacts the coolest air. In the crossflow arrangement, the air and water are distributed more uniformly, and there is less air-pressure drop across the fill. Sketches of both types of towers are shown in figure 5.33. Both arrangements are in use, and selection depends upon the operating requirements of a particular site.

The fill may consist of either splash- or film-type packing. In the splash type, usually used in crossflow towers, the water to be cooled falls over wave-shaped slats in such a manner that the droplets are constantly reforming and presenting fresh interfaces for exchange of heat and mass (28). In the film type, the fill consists of multiple vertical surfaces where the water flows down in thin continuous films. Although the film type occupies less volume and generally requires less shell height, it is more subject to clogging. The splash packing is easier to repair and replace.

The hyperbolic shape of a natural-draft cooling tower matches the natural air flow through the unit, but, perhaps more importantly, it has strength characteristics that permit economizing on materials of construc- 


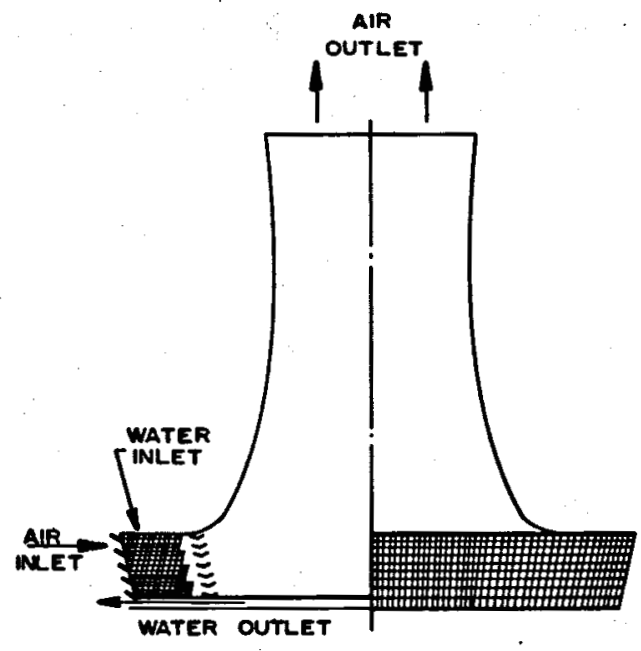

HYPERBOLIC NATURAL DRAFT CROSS-FLOW TOWER

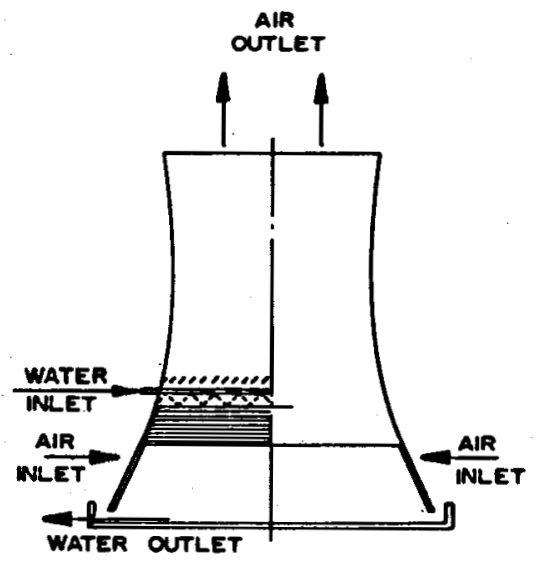

FraUre 5.83-Wet natural-draft cooling towers. Source: J. B. Dickey and R. E. Cates, Managing Waste Heat with the Water Oooling Tover, 2d. ed., The Marley Company, Mission, Kans., 1970.

HYPERBOLIC NATURAL DRAFT

COUNTER-FLOW TOWER

tion. The shell of a natural-draft cooling tower may be fabricated of reinforced concrete, of structural steel with aluminum skin, or, as at Schmehausen, Germany, of a suspended cable net with an aluminum skin (29). Reinforced concrete has been used almost exclusively in the United States. Concrete shells are poured by leapfrogging forms and construction platforms up the structure and usually require about two years for completion. The shells must be designed for the dead weight of the tower plus loads resulting from buckling, vibrations, wind, seismic forces, and thermal stresses. Induced stresses due to poor subsoil or nonuniform settling must 
also be considered and may take on more importance in geothermal areas subject to subsidence. The shells are surprisingly thin and, in some towers, are only about $15 \mathrm{~cm}$ (6 in.) in thickness at the waist. Models have been developed for analysis of the membrane stress to minimize the shell thickness required (30). The design wind load is usually $161 \mathrm{~km} / \mathrm{hr}(100 \mathrm{mph})$.

The shells of natural-draft towers are more subject to seismic damage than mechanical-draft towers, particularly those of wooden construction. Micro-earthquakes, that is, earthquakes with magnitudes of less than 4 on the Richter scale, have been observed near many geothermal areas around the world, including The Geysers and the Imperial Valley. However, earthquakes having magnitudes greater than 4.5 and the potential to cause significant surface damage have rarely been observed in geothermal areas. One possible explanation is that the frequent mircro-earthquakes in geothermal areas may tend to relieve regional tectonic stress, thus reducing the possibility of a major earthquake. Earthquakes have been associated with the injection of fluids into oil fields, and it is hypothesized that similar events could occur as a result of geothermal development. Much remains to be learned in this area, and detailed seismic monitoring is being conducted at The Geysers and in the Imperial Valley (31).

An obvious difference between natural-draft and mechanical-draft cooling towers is that, although in the latter the air movement is somewhat under the control of the plant operators, in the natural-draft type the air flow rates vary with the meteorological and other tower operating conditions. Also, the water pumping costs will probably be less for a mechanicaldraft tower. This is, however, more than offset by the auxiliary power savings made by natural-draft towers in not needing fans; the power to operate the fans of a mechanical-draft tower can amount to 0.5 to $1 \%$ of the total plant operating costs. Tower maintenance costs will also be appreciably higher for the mechanical-draft type, primarily because of the fans, gear reducers, and motor drives. Because mechanical-draft towers usually require four to five times more land area than natural-draft towers of the same duty, piping and grading costs will be correspondingly greater. Environmental impacts, such as ground-level fogging and icing are signifcantly less for the natural-draft tower, and there are fewer problems with recirculation. The capital cost of natural-draft towers, however, may be three to four times those of mechanical-draft units for smaller stations. As the size increases, however, there may be a crossover point at which the economics will favor the natural-draft type.

The size and appearance of natural-draft towers may be an important factor in their selection. Even though the economics might not be overwhelmingly in their favor, it is suspected that they are specified in some cases simply because of the distinctive hyperbolic shape. The pros and cons of the appearance of the towers was very well summed up by one writer ( $(20)$ : "The stark simplicity of the structure, the pleasing symmetry, and graceful upsweep of ribbed concrete-these excite the eye, stir the 
mind-yet they are offensive to some, who consider them disruptive elements imposed by man on a fast-dwindling rural landscape."

A variation of the natural-draft tower is the fan-assisted type. The tower fill arrangement is much the same as for a counterflow type, but fans are arranged around the periphery to force air into the tower and thereby reduce the stack height required. The capacity of the tower becomes less dependent upon the meteorological conditions, and the tower height may be less obtrusive. The reduced tower height makes the unit perform in a manner similar to the circular mechanical-draft type discussed in section 5.3.5.4.

5.3.5.6 Dry cooling towers. General. In dry cooling towers, the heat to be rejected from the power cycle is transferred through the walls of an air-cooled heat exchanger to raise the dry-bulb temperature of the airstream. Power cycles using dry cooling towers are illustrated in figures 5.4 and 5.5.

Unfavorable economics in the past have resulted in relatively little interest in dry cooling towers in the United States. Rather than use dry towers where conventional sources of water are not available, the electric utilities have found that it is generally more economic to find water by some means (such as buying agricultural land for the water rights, piping sewage treatment plant effluent; using salt water, or pumping groundwater). The growing scarcity of even these water sources, however, and the unacceptable environmental impacts that may be attendant to their use are now drawing more attention to use of dry cooling methods. The Department of Energy (DOE) has sponsored several studies of both dry and wet/dry towers. These subjects cover the state of the art, economics, and projected future needs in light of available water supplies in the United States.

Dry cooling towers have been used in Europe for 15 years or more, as listed by Miliaras (32) in table 5.12. In the United States, the Wyodak plant-a joint project at Gillette, Wyoming, of the Black Hills Power and Light Company and the Pacific Power and Light Company-is the most notable example at the present time. This 330-MW (e) station is the largest in the world using dry cooling towers. A power station using a dry air-cooled condenser supplied by CE-Lummus has also been completed recently at Valdez, Alaska (33). Dry cooling towers are of two types, direct and indirect.

Direct. In the direct arrangement, the turbine exhaust. is ducted to an extended-surface, air-cooled heat exchanger. In conventional steam-power cycles, the condensate is collected and returned to the boiler via the feedwater heating system. When the vapor is condensed at pressures less than atmospheric, provisions must be made for purging of noncondensable gases. If the condensing vapor is steam, then the exhaust ducting must be

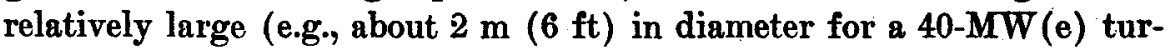


TABLE 5.12-Generating stations with dry air-cooled coils rejecting heat to atmosphere

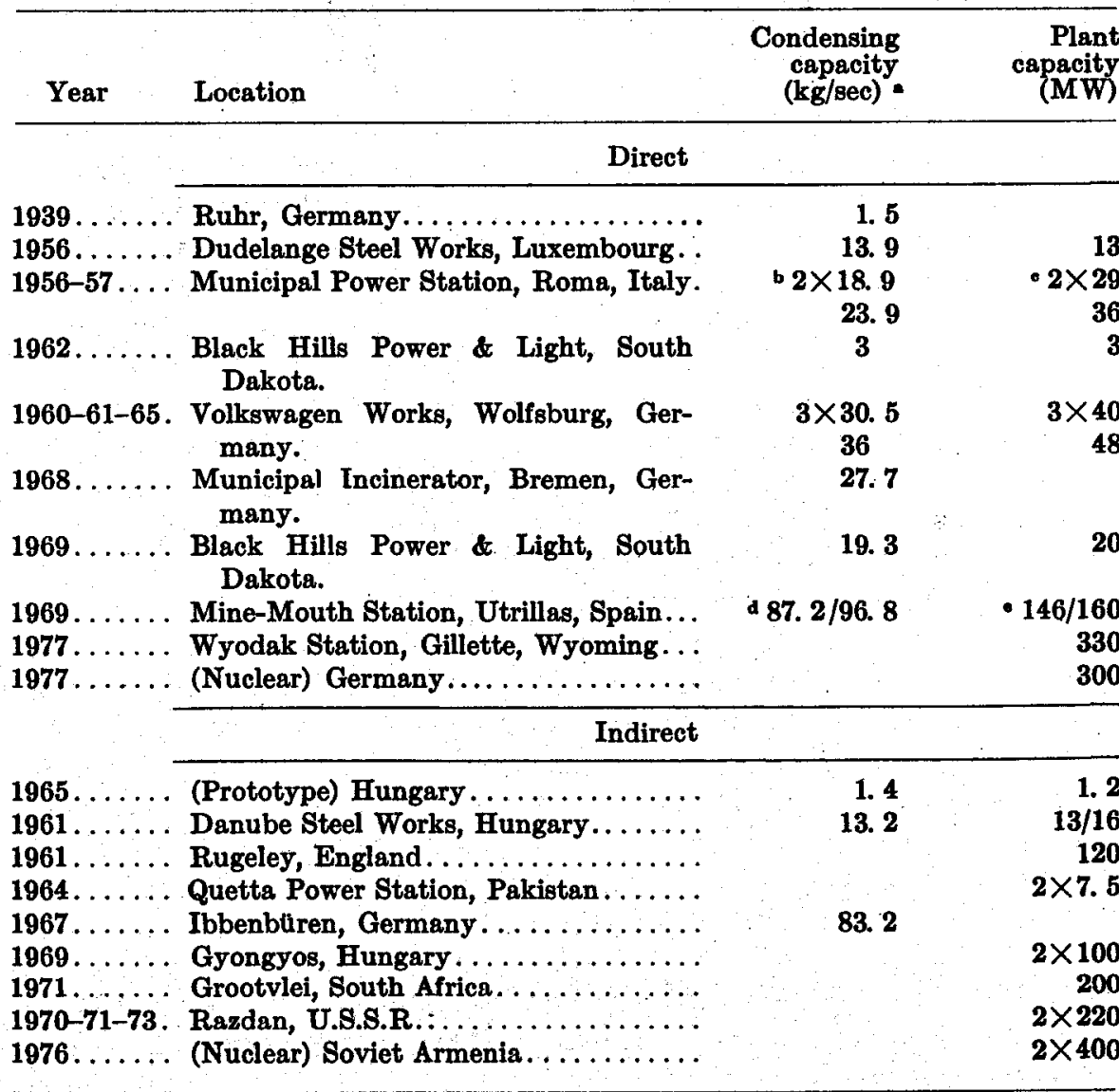

- kg/sec $\times 7936.64=1 \mathrm{bm} / \mathrm{hr}$.

b Read as 2 units of $18.9 \mathrm{~kg} / \mathrm{sec}$ condensing capacity each.

- Read as 2 units of $29 \mathrm{MW}$ condensing capacity each.

d Read as 2 units of 87.2 and $96.8 \mathrm{~kg} / \mathrm{sec}$ condensing capacity each.

- Read as 2 units of 146 and $160 \mathrm{MW}$ condensing capacity each.

Source: E. S. Miliaras, Power Plants with Air-Cooled Condensing Systems, MIT Press, Cambridge, 1074.

bine) to keep exhaust pressure-drop losses acceptably low but, at the same time, sufficiently flexible to accommodate the pipe stresses. Mechanicaldraft is used on most dry-type towers constructed to date, but studies have indicated that, although the initial costs are mare than twice that of mechanical-draft types (34), natural-draft towers may also be feasible.

The air-cooled coils are usually made up of parallel-connected banks (commonly arranged in a "W" form) with the fans located underneath. The vapor is distributed to the heat exchangers through headers, which may be arranged to deliver the steam either to the top or to the bottom of the extended-surface coils. With top delivery, in what is called the uniflow 
arrangement, the condensate flows down the inside walls of the tubes in the same direction as the vapor flow, and the pressure drop caused by the flow will result in a saturation temperature for the condensate several degrees below the entering vapor temperature. With the vapor delivered to the bottom of the exchangers, in a counterflow arrangement, the vapor flows upward against the down-flowing condensate. Although the condensate leaves at the entering steam temperature, the counterflow arrangement is not as efficient in terms of heat transfer and requires more area. A combination of the uniflow and counterflow arrangements can also be used.

Indirect. In the indirect system, the exhaust vapor from the turbine is condensed by a coolant circulated through the condenser and to the dry cooling tower where the heat is transferred in extended-surface, aircooled heat exchangers. The condensers can be either the surface or directcontact type. An indirect system using a direct-contact condenser, called the Heller system, is illustrated in figure 5.4. The condensers may be connected in multipressure arrangements (section 5.2.4.3).

Although a surface condenser could be used with the indirect system, all units up to the present time have used direct-contact condensers in a Heller-type system. This usage permits a condensing steam temperature lower by the amount of the terminal temperature difference that would have been required for the surface condenser, resulting in lower plant heat rates and capital costs. However, a 1973 study made by Beck and Associates (35) for 1000-MW (e) fossil and nuclear power plants, in which both mechanical-draft and natural-draft dry cooling towers were considered, indicated that the cost of producing electricity using surface condensers was competitive with the direct-contact condensers and that the surface condensers offered significant operating advantages. Although the study was based on plant sizes much larger than those presently considered for geothermal power installations, on meteorology typical of the eastern United States, and on fuel costs that are no longer applicable, the factors involved in the assessment are of interest.

To maintain air in-leakage into the working fluid (steam) within practical limits, the water that is inside the dry cooling coils should operate above atmospheric pressure. When using surface-type condensers, this requirement can be easily accomplished. When using direct-contact condensers, however, the condenser effluent must be pumped up to pressure for passage through the air-cooled surfaces and then let down in pressure before it is sprayed into the direct-contact condenser. (figure 5.4). The pressure reduction can be either through a throttling valve or through a hydraulic turbine direct-coupled to the condensate pump where about 80 to $90 \%$ of the pressure head can be recovered. However, this aspect adds to the cost and complexity of the direct-contact condenser system. A further operating advantage of the surface condenser is that, because the coolant and the working fluid do not mix, it can be used in cycles where the working fluid is not water or where a fluid other than water is used as the 
coolant. For example, a glycol solution can be used as the coolant to protect the air-cooled coil from freezing. The Beck (35) study considered a $30 \%$ (by volume) inhibited ethylene glycol solution and an increase in electrical production costs of 0.07 to 0.17 mills $/ \mathrm{kWhr}$ over the costs when using plain water. Ammonia has also been considered as a heat transport fluid (to be discussed subsequently).

One of the distinguishing features of all dry-type cooling towers is that the temperature at which the turbine exhaust steam is condensed is dependent on the ambient dry-bulb temperature rather than primarily on the wet-bulb temperature, as in evaporative-type cooling towers. Typically, the condensing pressure for a dry-type cooling tower system will be in the order of $203 \mathrm{~mm}$ ( $8 \mathrm{in}$.) of mercury absolute as compared to 64 to $102 \mathrm{~mm}$ (2.5 to 4 in.) of mercury absolute for a wet cooling tower. The high back-pressure will necessitate a different design for the turbine if the size of the dry cooling tower and the capital costs are to be kept to a minimum. High back-pressure turbines have been produced in Europe in sizes up to about $200 \mathrm{MW}$ (e) by eliminating the last row of blades of a conventional turbine; this design allows operation at back-pressures up to about $380 \mathrm{~mm}(15 \mathrm{in}$.) of mercury absolute. To offset the loss of turbine power, the high-pressure end was also modified to take a greater steam flow rate. In the United States, General Electric markets a high backpressure turbine. The GE unit provided for the Wyodak plant has laststage blades only about one-half as long as those in a low back-pressure turbine. Allis-Chalmers has completed designs for a high back-pressure unit and, if the need develops, could start supplying them by 1983 . Both General Electric and Allis-Chalmers report that to date, however, there has been relatively little interest in dry cooling requiring high backpressure units (34).

Also resulting from the dependency of dry cooling towers on the drybulb temperature of the ambient air is that one must either 1) design for high dry-bulb temperatures and operate at efficiencies significantly less than the plant would be capable of if designed for lower dry-bulb or 2) suffer a loss in capacity when the ambient dry-bulb temperatures exceed the design value. This effect is particularly disadvantageous in regions where air-conditioning loads cause peaks on the system to occur at times of maximum dry-bulb temperature. Two ways to offset this situation are to use a combination of wet and dry cooling towers (section 5.3.5.7) or to wet the outside surface of the dry cooling tower during periods of high drybulb temperature and peak loads. This latter arrangement, called "deluge cooling" (see below) has a tendency to foul the outside surfaces with deposits left from the evaporation of the water and to create corrosion problems. In any event, both ways require the consumptive use of water during the hot season when water supplies tend to be restricted.

The performance of dry cooling towers is more sensitive than that of wet towers to wind and thermal inversion effects. Dry towers can be 
severely affected by high winds, probably because of the altered air fiow across heat exchanger surfaces. Even at moderate wind speeds, wind interactions at the tower exit can be important. The effect of rain impinging directly on the heat exchanger surfaces could be expected to improve the performance, but in the case of natural-draft towers, rain falling through the rising air column will cool it and reduce the draft. Moore and Torrence (36) have studied wind effects on dry natural-draft towers at Rugeley, England; Grootvlei, South Africa; and Ibbenburen, West Germany. The performances at Rugeley and Ibbenburen are said to be reduced during heavy rain and fog. On the other hand, forced-draft dry towers at Wolfsburg, Germany, and Pignataro Majori, Italy, are said to have improved performances during rain. Moore (37) has developed performance equations for evaluating the aerodynamic losses in dry cooling towers and discusses various bundle configurations.

The prospect of future electric power generation depending heavily on dry cooling towers has led to studies of methods of improving the performance and reducing the cost of the extended-surface heat exchangers. These studies have included methods for forming extended metal surfaces, such as the Curtis-Wright configuration with which it is claimed that manufacturing costs are substantially less and that a lowered pressure drop of the fluid through the exchanger can lead to significant savings in pumping costs (38). Another approach is a foam-metal material proposed by ERG, Inc. Plastic tubes or plastic sheets have also been proposed by Roma at Italimpianti and Battelle-Geneva. (The air-side heat transfer coefficient dominates the process, and the conductivity of the wall is not a major concern.) Although the cost analysis is presently inconclusive, these designs may have a potential for being economically attractive. Some other, more revolutionary, designs have been proposed that may or may not have promise. One of these consists of metal disks that rotate through the water to be cooled and the moving airstream to transport the heat from the water to the air. An oil layer on the water.would inhibit evaporation, but fouling of the surfaces and emulsification of the oil film are problems yet to be resolved (33).

As mentioned above, a surface condenser used in conjunction with a dry cooling tower offers the possibility of a fluid other than water being used as the heat transport medium. A study by Franklin Institute, BattelleNorthwest, and Union Carbide under grants from DOE and the Electric Power Research Institute (EPRI) determined that ammonia was the most economical transport fluid (33). The system would condense the turbine exhaust steam by use of ammonia, which would be evaporated in the process. The ammonia vapor would then be condensed in a dry cooling tower and recycled. The arrangement with the lowest cost utilized water deluge on the tower during the hottest ambient conditions to effect water savings of $80 \%$ over the amount of makeup water required for an all-evaporative cooling system. The estimated cost of the system is 15 to $30 \%$ lower than 
for a conventional wet/dry tower arrangement (38). The major advantages of the amponia system are that (1) less surface area is required, reducing the tower size and cost; (2) smaller transfer lines are needed between the tower and the turbine condenser; (3) freezing problems in the air-cooled exchanger are eliminated; and (4) no pumping power is required to move the vapor from the condenser-boiler to the tower and very little power is needed to return the liquid ammonia for recycle.

A mechanical-draft dry cooling tower will probably cost five times as much as a wet mechanical-draft tower if the turbine back-pressure is about $305 \mathrm{~mm}$ (12 in) of mercury absolute and about ten times as much if the pressure is $127 \mathrm{~mm}$ ( $5 \mathrm{in}$ ) of mercury absolute (24).

5.3.5.7 Wet/dry cooling towers. General. Wet/dry cooling towers combine evaporative and dry cooling of the circulating water. A typical wet/ dry tower with the air flowing in parallel through the wet and dry sections is shown in figure 5.34. (Wet/dry cooling towers are sometimes referred

Frauke 5.34-Wet/dry mechanicaldraft cooling tower. Source: J. D. Holmberg and O. L. Kinney, Drift Technology for Cooling Tovers, The Marley Company, Mission, Kans., 1973.

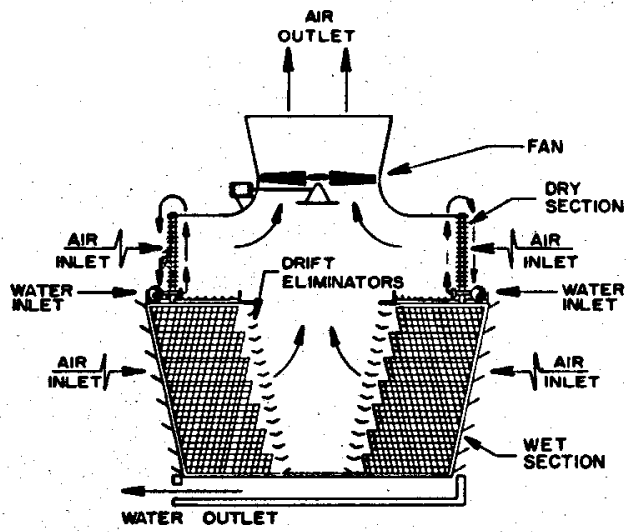

to as parallel-path towers.). The dry portion handles essentially all the cooling load when dry-bulb temperatures are low, and the wet portion serves as supplemental capacity when needed, such as in the summer months when dry-bulb temperatures are high. Wet/dry towers have a significantly higher cost than a wet or dry tower alone but offer the following advantages:

1. The visibility of the effluent plume can be controlled and essentially eliminated, if desired.

2. The water temperature leaving the cooling tower can be maintained at a sufficiently low value year-round to permit use of a low back-pressure turbine.

3. The evaporative loss of cooling water can be reduced substantially below that required if wet cooling alone were used.

4. The system is better able to meet peak loads than if dry cooling towers alone were used. 
The relative importance of these factors is site specific, but at most geothermal power installations, the water consumption rate and the ability to meet summertime peak loads will probably be the major considerations.

Visible plume control. Although the visibility of the plume emitted from the cooling towers is likely to be of little concern in the climate of most geothermal plants, the psychrometric relationships are of interest. The changes that the properties of the air undergo in passing through a single-structure wet/dry cooling tower (figure 5.34) are illustrated in figure 5.35. The conditions depicted are most likely to occur during wintertime operation at low dry-bulb temperatures and high relative humidities. If a wet cooling tower alone were used in these circumstances, with ambient air entering at Point 1 in figure 5.35 and the air-water vapor mixture leaving the tower essentially saturated at Point 2, the effluent plume would mix with the ambient air along Line 1-2 and pass through the supersaturated region to form a visible vapor cloud, or plume. If a wet/dry tower were used, the evaporative process would perform as just stated, but the dry section would heat the air along Line 1-3, and the effuent from the wet and dry sections would mix along Line $2-3$, with the resultant condition at Point 4. When this mixture leaves the tower and mixes with the ambient air along Line $1-4$, the state point lies outside the supersaturated region and the vapor is not visible. The proportion of the duty carried by the wet and dry sections can be varied in the design, and the dampers can be adjusted during operation to provide visible plume control. Wet/dry

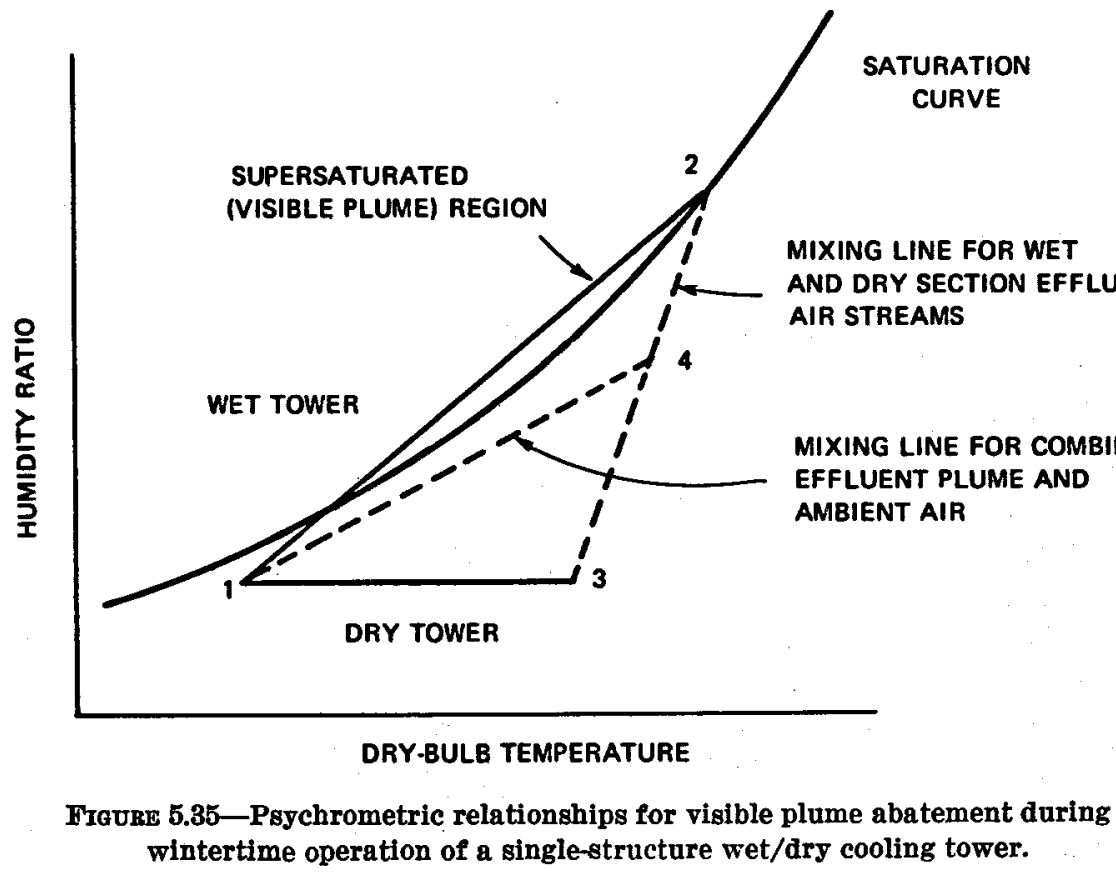


towers have demonstrated the ability to virtually eliminate plune emissions. Landon and Houx (39) are among those studying the plume: abatement aspects of wet/dry cooling towers.

Flow paths for air and water. Wet/dry towers may be arranged with the circulating water flowing in parallel or in series; in the series arrangements, either the wet or the dry section can be upstream of the other. The performance of the various arrangements can be compared in terms of cooling capacity, water evaporation rates, capital and operating costs, and environmental impacts. Although all these figures of merit are important, it seems certain that water conservation will have priority at most geothermal power installations in the Southwest. To obtain the lowest evaporation rates, the dry cooling section should carry as much of the heat rejection load as possible. A greater mass flow rate of air is needed through the dry section than through the wet section; a series flow path for the air results in a significant mismatch in this regard. Further, a greater initial temperature difference (ITD) is obtained when air at ambient conditions enters both the wet and dry sections, thereby increasing the capacity and minimizing the evaporation rate. A parallel path for the air flow is thus a common practice for wet/dry cooling towers.

Conclusions cannot be as readily drawn with regard to the water path. Loscutoff (40) studied this aspect, and although his work was preliminary and concerned primarily with comparative performances and evaporation rates, the principles involved are of significance. The simplifying assumption was made that the heat rejection capacity of a cooling tower can be expressed as a function of the ITD as follows:

$$
Q=K\left(t_{\text {ITD }}\right)^{n}
$$

where $K$ is a constant, and the exponent, $n$, is a function of the type of tower and the wet-bulb temperature. Loscutoff (40) used $n=1$ for mechanical-draft dry towers, $n=1.3$ for natural-draft dry towers, $n=1.4$ for mechanical-draft wet towers, and $n=1.8$ for natural-draft wet towers [at a wet-bulb temperature of $18.3^{\circ} \mathrm{C}\left(65^{\circ} \mathrm{F}\right)$ ]. The ITD is taken as the difference between the entering water temperature and the ambient dry-bulb temperature in the case of the dry cooling towers and as the difference between the entering water temperature and the ambient wet-bulb temperature for the wet cooling towers. By assuming $K$ to be constant for a given tower type, the performance of the various arrangements as they affect the ITD was compared. Loscutoff $(40)$ concluded that, from the standpoint of capacity, series flow in the water path is better than parallel flow. Also, with series flow the capacity is slightly better if the dry section comes first when ambient dry-bulb temperatures are low and slightly better if the wet section comes first when ambient wet-bulb temperatures are high. The differences were very small, though, and do not appear to be 
conclusive. The evaporation rates, however, are significantly less with the series arrangement and with the circulating water flowing first through the dry section.

With the series flow path, if the full flow of the circulating water is first through the dry section and then the wet section, the temperature range for the water in the wet section will be smaller than ordinarily achieved in wet cooling towers. By reducing the size of the wet tower and increasing the range by bypassing a portion of the water flow around it, there would generally be a cost savings.

An advantage of the parallel-path arrangement is that, by use of separate or dual-service condensers, the coolant flow paths through the dry and wet sections can be kept entirely separate. Some considerations in this regard are as follows:

1. The relatively dirty, oxygen-laden, and chemically treated water from the wet cooling towers will present more corrosion problems to the materials commonly used for extended-surface heat exchangers than would the water that could be circulated in a closed loop through the dry coils. An antifreeze solution or other coolant fluid could be circulated through the dry section.

2. If separate or dual-service condensers are used, the condenser tubes cooled by the fluid circulated in the closed dry section loop will be significantly less subject to fouling. (Nitrogen-blanketing is sometimes used to protect extended-surface heat exchangers from corrosion when the system is drained for shutdown).

3. The additional circulating pumps and piping required for separate systems is offset to some extent by the by-pass and flow-regulating valves needed in a series-connected system.

4. In a parallel-connected system, the greater flow through the dry section when the wet section is removed from service will improve the water-side heat transfer coefficient, lower the cooling range, and increase the temperature difference in the condenser. One result of this is that the wet tower can be removed from service at a higher ambient dry-bulb temperature and thus conserve makeup water in the wet section.

Deluge cooling for dry towers. A variation of the wet/dry tower, which has promise as a method of increasing the capacity of dry cooling towers during peak loads or periods of high ambient dry-bulb temperatures, involves the wetting of a portion of the dry surface. This method, called deluge cooling, is a compromise between wet cooling and dry cooling methods and minimizes water consumption while reducing the performance penalties associated with all-dry systems.

In deluge cooling, an excess of water is used to wet the surface, and the runoff is collected and recirculated. The transfer of heat is greatly 
enhanced. Factors of 2.5 are cited as commonly attainable (41), but much higher factors are mentioned for certain conditions (40). The wetted coils act much as a wet cooling tower, and although the heat transfer augmentation is greatest for higher air flow rates, it may be advantageous to reduce the rate of air flow to resemble more closely the $L / G$ ratios commonly used in wet towers. There are added problems from corrosion and deposition of solids on the intermittently wetted surfaces, however, and these have yet to be resolved satisfactorily.

Kreid, Johnson, and Faletti (41) have made a comprehensive study of a method of approximating the heat transfer relationships from a wettedfinned heat exchanger, using the heat transfer performance of dry surfaces as a base. The analysis shows that the equations describing the combined latent and sensible heat transfer from a wet surface may be transformed to an approximate equation that involves the product of the heat transfer coefficient and a driving potential. For a wet surface, this potential is the moist-air enthalpy difference between the surface and the coolant stream.

A heat exchanger with a low ITD has more to gain from deluge cooling than one with a higher ITD. There is substantial enhancement of the heat transfer even if the entering air is saturated, because the surface saturation temperature will be higher than the air temperature. The rate of water consumption will be greater than if the same amount of cooling were achieved in a conventional wet cooling tower, but the evaporation rate will not be as great as for the adiabatic cooling method described below.

Wiles et al., of Pacific Northwest Laboratory (4P) have made a detailed cost analysis of a deluge wet/dry cooling system. In the system studied, ammonia was selected to transport the heat from the turbine exhaust to the ambient air. The system uses a horizontal-tube, vertical, plate-finned heat exchanger developed by the HOOTERV Institute, Budapest, Hungary, and licensed in the United States by Babcock and Wilcox. Although this type of surface is more expensive than spiral-wrapped, finned-tube surfaces, it was judged that the flat surfaces were better adapted to deluge wetting. Of the various parameters assumed in the study, perhaps one of the more important is the assumption that loss in electrical generating capacity would be made up by gas turbine power, costing 24 mills/kWhr. The primary thrust of the study, however, was to evaluate the water consumption aspects. A 1000-MW (e) power plant under the assumed operating conditions would require about $11 \times 10^{8} \mathrm{~m}^{3} /$ year (9000 acre-ft/year) of makeup water if evaporative cooling towers were used. If no water were available, it is estimated that an all-dry cooling system would add about 2.4 mills/ $\mathrm{kWHr}$ to the production cost; if about $3 \times 10^{6} \mathrm{~m}^{3} /$ year (2500 acre-ft/year) of water were available annually for consumptive use in deluge cooling, the incremental cost would be about 1.5 mills $/ \mathrm{kWhr}$ (figure 5.36). The cost 


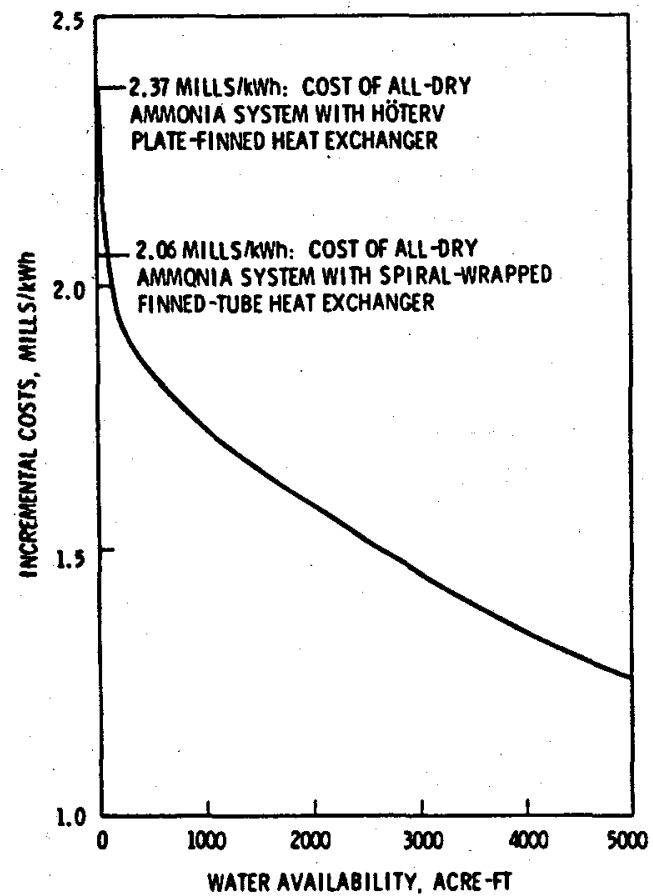

Figuke 5.36-Incremental cost of electricity attributable to a deluged dry cooling coil system as a function of the annual water avallability to a 1000-MWe fossilfueled power plant. ( $\mathrm{m}^{2} /$ year $=$ acre-ft/year $\times$ 1283.5). Source: L. E. Wiles et al., $A$ Description and Cost Anatyols of a Deluge Dry/Wet system, PNL-2498, Paciflc Northwest Laboratory [June 19781.

savings using deluge cooling result primarily from specifying a smaller heat exchanger and from lower turbine exhaust pressures (figure 5.37).

The potential advantages of deluge cooling in achieving the water conservation of dry towers without the high cost of wet/dry towers and in meeting peak load conditions appears sufficient to warrant continued research and development in this area.

Evaporative, or adiabatic, cooling. One method of increasing the capacity of a dry cooling tower during peak loads or periods of high drybulb temperature would be to increase the temperature difference for heat

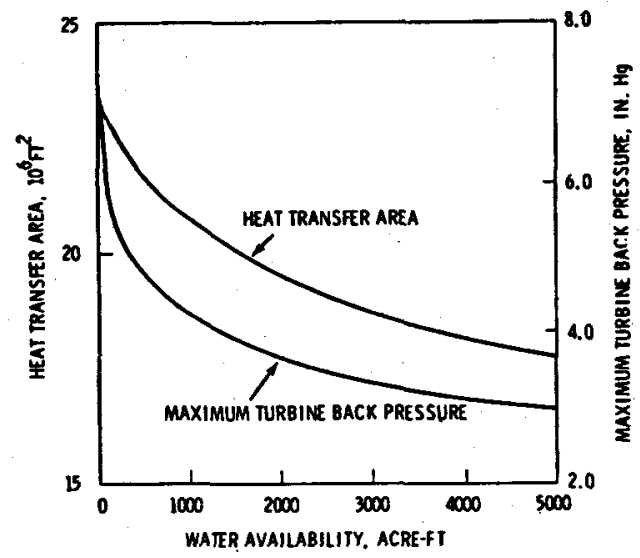

Fraurs 5.37-Optimized heat transfer area and maximum turbine back pressure as a function of the annual water availability to a 1000-MWe fossil-fueled power plant. $\quad\left(\mathrm{m}^{8} /\right.$ year $=a c r e-f t /$ year $\times 1233.5$ ). Source: L. E. Wiles et al., $A$ Description and Cost Anatysis of Deluge Dry/Wet System, PNL-2498, Pacific Northwest Laboratory [June 1978]. 
transfer by cooling the air before it passes over the coils. This method could be achieved by evaporating water into the air in an adiabatic process that is commonly used in dry climates where the wet-bulb temperature is substantially below the dry-bulb temperature. (The heat exchanger coils, however, would not operate with wet surfaces as in the deluge system mentioned above.) The adiabatic cooling process is enhanced by decreasing the size of the water droplets sprayed into the air, but there is a tradeoff with the amount of power required for atomization. The quantity of water evaporated in the adiabatic cooling of air is significantly greater (perhaps about $50 \%$ ) than the amount of water that would be evaporated to handle the incremental peak load in a conventional wet cooling tower. As mentioned in the previous subsection, the amount of water evaporated is also greater than that required for deluge cooling, but, if operated carefully, there will not be the same tendency for corrosion and scaling as in the intermittently wetted surfaces of the deluge system. Adiabatic cooling for an all-dry cooling system, handling the entire system heat rejection duty, may enable the plant to meet the peak loads at high ambient temperature conditions without the high cost of a wet/dry system.

Separate or single structures. The wet and dry sections of a wet/dry cooling tower can either be housed in a single structure (figure 5.34) where there is a common fan or be kept separate as more or less conventional wet and dry cooling towers. Smith and Larinoff (43) have summarized some of the considerations involved in choosing between single and separate structures for wet/dry cooling towers:

1. Air recirculated into the dry section from the wet will contain moisture and chemicals used for water treatment that will accelerate corrosion of the extended-surface heat exchangers. A single-structure arrangement is more susceptible to recirculation problems because, with separate structures, the towers can be located to minimize the effect.

2. The single-structure configuration relies on louvers and damper doors to regulate the flow of air between the wet and dry sections. The dampers are relatively large and must operate in moist and corrosive conditions. Separate structures do not require dampers but lack the "fine tuning" aspects of the damper system.

3. Separate structures with separate fans provide more latitude in the design and in selecting operating modes.

4. Freeze protection is more difficult with single structures.

5. Plume abatement is more effective with a single structure because the effluent of the wet and dry sections can be mixed in the optimum proportions.

6. Separate structures will generally have a higher cost, although this difference tends to decrease in the larger sizes. 
Smith and Larinoff (43) concluded that the various possible configurations did not have a significant influence on condensing steam temperatures nor on the annual water evaporation rates.

5.3.5.8 Concentration relationships in wet cooling towers. The rate that makeup water must be added to a wet cooling tower is the sum of the rates at which water is lost from the tower system by evaporation, blowdown, drift, and leakage. The blowdown rate determines the level to which the concentration of dissolved solids in the water are allowed to accumulate. The concentration factor, or cycles of concentration, is defined as the ratio of the total dissolved solids (TDS) in the circulating (or blowdown) water to the TDS in the makeup water. Where the environmental impacts of the blowdown may be a serious problem and ample makeup water is available, the concentration factor may be as low as 2 to 4 . The proposed Sundesert Nuclear Station near Blyth, California, was an example of the other extreme, where even low-quality makeup water would have been scarce. The blowdown would have been so laden with salt that it was to have been disposed of by evaporation. A concentration factor of about 20 was proposed, and side-stream clarifiers were to have been used in the circulating system. The Sundesert conditions may be typical of those for large geothermal power plants located in the Imperial Valley of southern California.

The relationships between the mass flow rate per unit time of makeup, blowdown, evaporation, and drift rates can be formulated in terms of the concentration factor (on a weight basis).

Let:

$M=$ makeup rate,

$B=$ blowdown rate,

$E=$ evaporation rate,

$D=$ drift rate,

$C=$ concentration of solids in stream, $\mathrm{lb} / \mathrm{lb}$,

$C F=$ concentration factor, or cycles of concentration.

Then, if leakage is ignored,

$$
\begin{aligned}
M & =B+E+D, \\
C F & =C_{B} / C_{M}, \\
C_{M} M & =C_{B} B+C_{B} D, \\
C_{M} & =C_{B}(B+D) / M, \\
C F & =C_{B} /\left[C_{B}(B+D) / M\right] .
\end{aligned}
$$

It then follows that

$$
\begin{aligned}
C F & =M /(B+D), \\
B & =[E /(C F-1)]-D, \\
M & =C F[E /(C F-1)], \\
E & =(C F-1)(B+D) .
\end{aligned}
$$

The makeup water rates required for power stations with various thermal efficiencies and concentration factors are shown in table 5.13. 
TABLE 5.13-Makeup water requirements versus cycle efficiency and concentration factor

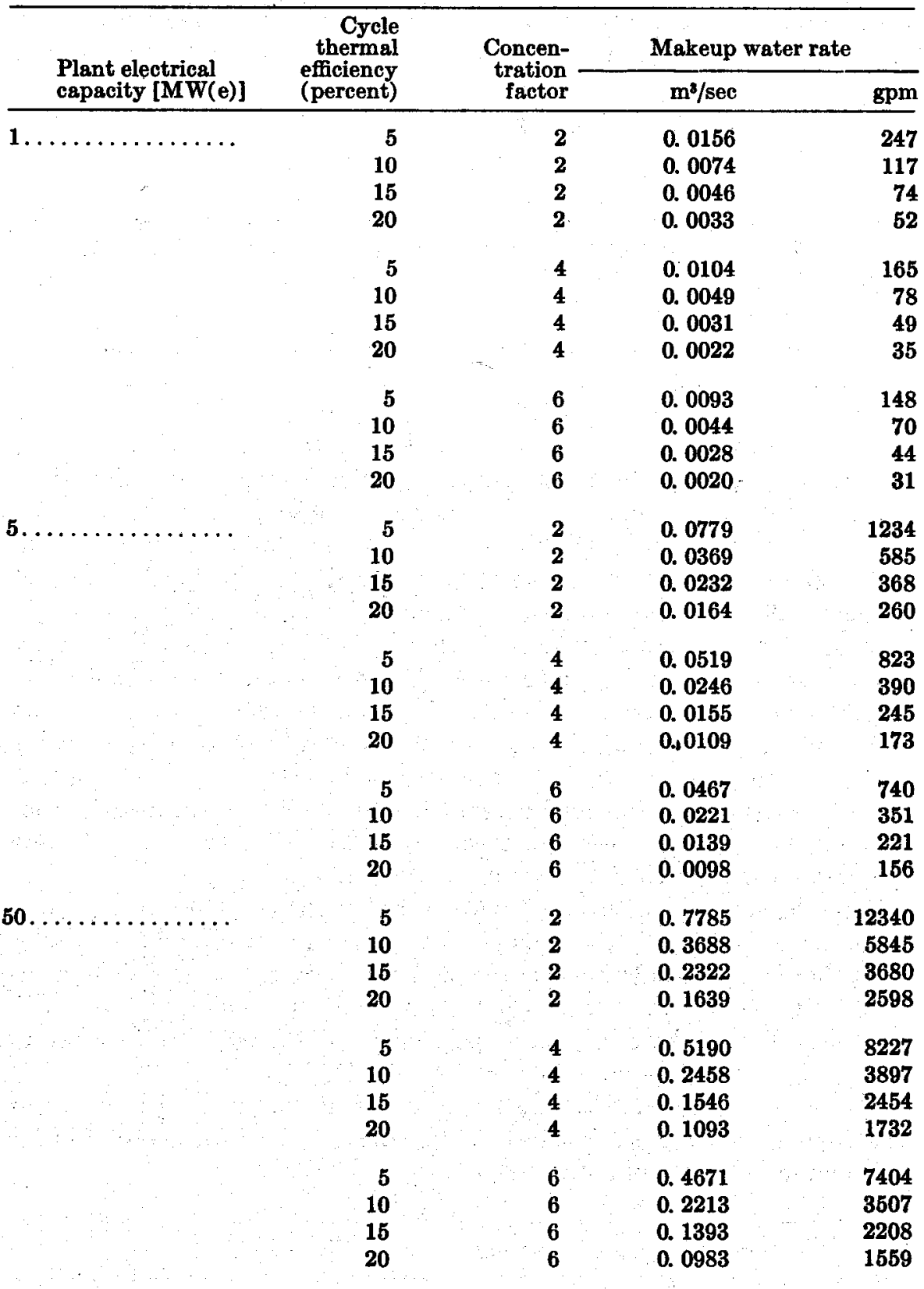

5.3.5.9 Drift from wet cooling systems. Drift is the portion of the spray pond or cooling tower circulating water that becomes entrained in the moving air stream and is carried out of the system in droplet form. The amount of drift is commonly expressed as a percentage of the circulatingwater flow rate on a weight basis. However, the amount of drift from a 
tower is not a strong function of the water loading but is primarily dependent on air flow rates and velocities. Drift may also be expressed as the weight of the droplets per unit weight of air, in parts per million (ppm) :

$$
\operatorname{ppm}=\frac{\% \text { drift }}{100} \times 10^{6} \times \frac{L}{G}
$$

where $L / G$ is the weight ratio of the water and air flow rates. Cooling tower drift rates vary over a wide range, from about 0.001 to $0.2 \%$. At a typical $L / G$ ratio of 1.5 , this amount is equivalent to 15 to $3000 \mathrm{ppm}$ of drift in the air stream.

The percentage of drift is small, and the water lost from the tower due to drift is insignificant in comparison to that lost by evaporation. Drift does not contribute significantly to the visibility of cooling tower plumes. The primary concerns with regard to drift are the environmental impacts of the salts that are dissolved in water droplets being deposited in the vicinity of the cooling tower, and the possibility for icing of nearby roads and equipment during the winter months. Salt deposition due to drift, for example, in the power station electrical switchyard can affect insulator efficiency and accelerate corrosion. A frequent complaint is salt spotting of windows and finishes of automobiles parked near the cooling towers. More importantly, some forms of vegetation may be damaged by the chlorides and other salts dissolved in the circulating water. Plants differ markedly in the amount of salt they can tolerate at various times in the growing season. This aspect is of considerable concern and is often one of the environmental impacts that is an issue in the granting of construction permits for power plants using spray ponds or cooling towers for waste heat rejection.

It can be assumed with very little error that the concentration of salts in the drift droplets is the same as that in the tower circulating water. Even though the droplets travel through the tower in an air stream. saturated with moisture, the transient time is small (less than 1 min even in tall towers), and there is little opportunity for the droplets to grow in size.

The size distribution of the water droplets in drift varies with the tower design and operating conditions but typically may be about as follows for a mechanical-draft cooling tower (44):

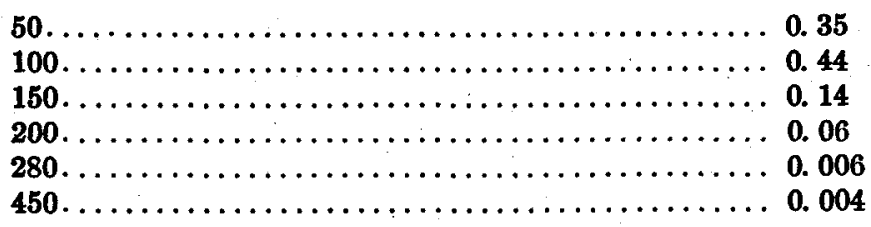


The magnitude of the drift problem can be appreciated by considering that if a cooling tower for a $50-\mathrm{MW}(\mathrm{e})$ geothermal power station had a thermal efficiency of $10 \%$, an $11^{\circ} \mathrm{C}\left(20^{\circ} \mathrm{F}\right)$ water temperature range, cooling tower makeup water having $500 \mathrm{ppm}$ TDS, a concentration factor of 5 in the towers, a tower drift rate of $0.005 \%$, and a plant capacity factor of 0.8 , then a total of about $3.0 \times 10^{4} \mathrm{~kg}\left(6.7 \times 10^{4} \mathrm{1b}\right)$ of salt and other dissolved solids would leave the tower each year and be deposited within a few miles of the tower. If the wind tends to be from the same quarter all year, the annual deposition rate would be concentrated in a smaller area than if the wind direction were more variable. Maximum deposition rates tend to be within about $1.6 \mathrm{~km}$ (1 mile) of mechanical-draft towers and can amount to 10 or more $\mathrm{g} / \mathrm{m}^{2}$. year $(100 \mathrm{lb} /$ acre year $)$. As a general rule, greater amounts cause concern for the biota, depending on the kinds of vegetation involved, the season of the year, and the amount of rainfall available to wash the plants and to leach the salt from the soil.

The power plant designer can influence the average drift deposition rate in a particular area by consideration of the (a) prevailing direction of the wind, (b) quality of the makeup water and cycles of concentration, (c) tower height and exit velocity, (d) drift droplet size distribution, and (e) drift eliminator performance and other tower design features.

Until a few years ago economics determined such things as tower location and design; however, today the environmental impacts of drift are a major influence. Prior to making design decisions, the drift deposition rates of various cooling tower layouts, designs, and operating parameters are now calculated using either onsite or nearby meteorological data taken over a period of several years. Where salt-sensitive crops are grown, it may be that a seasonal sensitivity can be correlated with seasonal variations in the prevailing wind direction. Mechanical-draft towers cause more severe drift deposition problems than do natural-draft towers because the latter lofts the drift higher and disperses it over a wider area. Mechanical-draft towers that take advantage of the greater buoyancy of multiple plumes, such as the circular mechanical-draft type, also reduce the ground-level drift deposition rates.

A water droplet carried in an air stream has horizontal and vertical components of velocity. The magnitude of the vertical component is the resultant of the upward velocity due to being lifted by the air stream and. the gravity-induced fall of the droplet. The fight path of an airborne drop is also affected by drag and momentum, the former being a function of the diameter squared and the latter a function of the diameter cubed. It is thus evident that the smaller droplets are more likely to remain airborne, and, after exiting from the tower, will have longer trajectories. It is also clear why a mechanical-draft cooling tower with greater air velocities at the exit will sweep larger drops from the tower than will natural-draft structures. 
Drift eliminators for cooling towers use baffles to change the direction of the air flow so that entrained water droplets will impinge on and be trapped by the baftle surface. Care is taken to drain the eliminators so that water will not be reentrained. In addition to the direction change, the eliminator baffles may be followed downstream by a honeycomb-type "polisher." The honeycomb surfaces strip additional droplets from the air stream and also give more opportunity for gravity settling of the droplets. The best location for drift eliminators in a cooling tower is away from the water splash in the fill and where the air flow through the plane of the eliminators will be uniform. The general location of the eliminators is between the fill and the fan plenum, as indicated in figures 5.31 and 5.34. The eliminator baffles are commonly designed in either a herringbone or sinusoidal wave pattern and may be fabricated of asbestos-cement board (28). Yao and Schrock (45) are among those studying improved designs for drift eliminator baffles. As the efficiency of the drift eliminators is increased, the capital costs and the fan power requirements also tend to increase. The compromise of these factors is often weighted in favor of lower drift rates because of the current sensitivity to environmental impacts.

During the past few years, improvements in techniques for measuring draft confirmed that actual drift rates from towers were substantially below the values of about $0.2 \%$ that manufacturers had been citing up to that time. Guaranteed drift rates of $0.05 \%$ are now commonplace, and values as low as $0.001 \%$ may now be specified. Improvements in measurement techniques have also contributed to the drift eliminator designs in that the performance of various arrangements can be more meaningfully tested.

In measuring drift, values for both the amount leaving the tower and the droplet size distribution are needed for input into the predictive models used to calculate drift deposition. It is difficult to measure the drift rate in a cooling tower because the quantity of drift is very small compared to the other forms of water present (45). One method used to estimate the amount of drift is to make a chloride balance on the tower. A more recent method is termed "isokinetic sampling." Several arrangements of this sampling method have been tried, but probably the most. effective is to draw samples from points in a grid pattern in the effluent stream and trap the dry solids after evaporation of all the moisture in the sample. These are then washed from the sampling tube and the solution analyzed for the amount of a tracer, such as magnesium, existing in known amounts in the circulating water. Size distributions of the droplets can be investigated using sensitized paper and counting the number of water spots of various sizes after exposure to the air stream. A method now under study and development is an electro-optical system based on the lightscattering of laser beams. This method, termed "Particle Instrumentation by Laser Light Scattering" (PILLS) (46), has some limitations due to 
background fog but has the advantage of also indicating droplet size distributions.

Webb, Schrecker, and Guild (47) have described application of the sensitive paper, isokinetic sampling, and PILLS methods to the Potomac Electric Power Company's (PEPCO) natural-draft tower at Chalk Point, Maryland, in an attempt to validate various salt drift transport and deposition models. This work was jointly sponsored by the State of Maryland, the Electric Power Research Institute (EPRI), the Energy Research and Development Administration (ERDA), and PEPCO. Concern over the salt effects on the local tobacco crops was a motivating factor.

Laskowski (48), Roffman and Grimble (49), and Israel and Overcamp (50) are among those having developed mathematical models for predicting drift deposition. The Oak Ridge National Laboratory (ORNL) developed a fog and drift model for assessing environmental reports for nuclear power stations $(51,52)$. The necessity for preparing these reports has led to use of consultants by the electric power industry to perform the various required studies and analyses. Some of these consultants have also developed models for predicting drift transport and deposition but consider them to be proprietary. In 1976 ORNL offered the developers of drift deposition models the opportunity to compare the results if each used his model to analyze the same set of conditions. Nine parties responded, and the results have been described by Chen (58). In general, there was satisfactory correspondence. Overcamp (54) has also made a sensitivity study and analysis of cooling tower drift deposition models. A test was made by Jallouk, Kidd, and Shapiro (55) in 1974 at cooling towers located in Oak Ridge which use chromium and zinc in the circulating water for corrosion control. The uptake of these elements was measured in the surrounding vegetation to obtain measurement of drift transport and deposition. Taylor, Gray, and Parr (56) found good correspondence with the tests and the predictions made using the ORFAD model.

To date, there are no reliable mathematical models for predicting the amount of ice buildup at various points from a cooling tower. The icing potential at a given installation may be surveyed, however, by noting from the predictive models the amount of wintertime drift deposition in critical areas, such as a nearby highway, and by equating this to the number of hours the temperature falls below freezing. Significant icing normally occurs only close to the base of mechanical-draft towers and is usually not a problem at a distance of a few hundred meters (yards). Few icing problems have been associated with natural-draft cooling towers.

\subsubsection{References}

(1) C. P. Goodyear, C. C. Coutant, and J. R. Trabalka, Sources of Potential Biological Damage from Once-Through Cooling Systems of Nuclear Power Plants, ORNL/TM-4180 (July 1974).

(2) C. C. Coutant, Crit. Rev. Environ. Control 1(3), 341-81 (1970). 
(3) R. C. Y. Koh and L-N Fan, Mathematical Models for Prediction of Temperature Distribution Resulting from the Discharge of Heated Water into Large Bodies of Water, Contract 14-14-12-570, Tetra Tech, Pasadena, Calif. (October 1970).

(4) J. R. Edinger and J. C. Geyer, Cooling Water Studies for Edison Electric Institute, Project No. RP-49-Heat Exchange in the Environment, Johns Hopkins University, Baltimore, Md., June 1, 1965.

(5) P. J. Ryan and D. R. F. Harleman, Analytical and Experimental Study of Transient Cooling Pond Behavior, Report 161, Massachusetts Institute of Technology, Parsons Laboratory for Water Resources and Hydrodynamics, Cambridge (January 1973).

(6) J. H. Gibbons and F. P. Pike, A Study of Selected Cooling Pond Design Techniques, SRO-701-1 (1973).

(7) G. H. Jirka, G. Abraham, and D. R. F. Harleman. Assessment of Techniques for Hydrothermal Prediction, final report, Massachusetts Institute of Technology, Parsons Laboratory for Water Resources and Hydrodynamics, Cambridge (1974).

(8) J. M. Kyser, R. A. Paddock, and A. J. Policastro, Analysis of Three Years of Complete Field Temperature Data from Different Sites of Heated Surfaces Discharges into Lake Michigan, ANL/WR-75-2, Argonne National Laboratory (August 1974).

(9) J. S. Neill and J. H. Gibbons, Sizing a Cooling Pond for a Power Plant, 75WA/HT-63, American Society of Mechanical Engineers (August 1975).

(10) W. E. Hebden and A. M. Shah, "Effects of Nozzle Performance on Spray Ponds," p. 1449 in Proceedings of the American Power Conference, vol. 38, Illinois Institute of Technology, Chicago, 1976.

(11) P. J. Ryan and D. M. Myers, "Spray Cooling: A Review of Thermal Performance Models," p. 1473 in Proceedings of the American Power Conference, vol. 38, Illinois Institute of Technology, Chicago, 1976.

(12) S. L. Soo, "System Considerations in Spray Cooling and Evaporation," p. 1482 in Proceedings of the American Power Conference, vol. 38, Illinois Institute of of Technology, Chicago, 1976.

(13) C. Bowman, Tennessee Valley Authority, Knoxville, Tenn., private communication with P. J. Ryan, Bechtel Corporation, San Francisco.

(14) D. P. Hoffman, "Spray Cooling for Power Plants," p. 702 in Proceedings of the American Power Conference, vol. 35, Illinois Institute of Technology, Chicago, 1973.

(15) R. W. Porter and K. H. Chen, J. Heat Transfer, 96, 286-91 (August 1974).

(16) A. M. Elgawhary, Spray Pond Mathematical Model for Cooling Fresh Water and Brine, Ph.D. dissertation, Oklahoma State University, Stillwater, July 1971.

(17) R. W. Porter and S. K. Chaturvedi, "Atmospheric Spray-Canal Cooling Systems for Large Electric Power Plants," p. IV-C-121 in Proceedings of the Conference on Waste Heat Management and Utilization, University of Miami, Coral Gables, Fla., May 1977.

(18) W. A. Feder, "Measurement and Effects of Drift from an Evaporative Cooling System on Surrounding Vegetation," Proceedings Symposium on Environmental Effects of Cooling Tower Emissions, Univ. of Maryland, PPSP-CPCTP-22, May 2-4, 1978.

(19) K. R. Wilber, Evaluation of Cooling Systems Proposed for Virginia Pover Company's Surry Units 3 and 4, TPR-104, Environmental Systems Corporation, Knoxville, Tenn. (August 1977).

(20) "Cooling Towers," Power 117, 5.1-5.24 (March 1973).

(21) F. Merkel, "Verdunstungskuchlung," VDI-Forschungsarb. No. 275, 1925.

(22) D. R. Baker and H. A. Shryock, J. Heat Transfer 88, 339-50 (August 1961). 
(23) Cooling Tower Institute, Cooling Tower Performance Curves, Houston, 1967.

(24) T. D. Kolflat, Power Eng. 78, 32-39 (January 1974).

(25) "Equipment," Chap. 21 in ASHRAE Guide and Data Book, American Society of Heating, Refrigerating and Air-Conditioning Engineers, New York, 1972.

(26) J. B. Dickey et al., "Debut of the Round Mechanical Draft Cooling Tower," presented at the American Power Conference, Chicago, April 23, 1975.

(27) J. B. Dickey and R. E. Cates, Managing Waste Heat with the Water Cooling Tower, 2d ed., The Marley Company, Mission, Kans., 1970.

(28) J. D. Holmberg and O. L. Kinney, Drift Technology for Cooling Towers, The Marley Company, Mission, Kans., 1973.

(29) W. Erdman, VGB Kraftwerkstech 57(3), 206-15 (March 1977) (in German).

(30) J. K. W. To and W. S. Hemp, Minimum Weight Design of Cooling Towers, N76-30612, Department of Engineering Science, Oxford University, United Kingdom (1975).

(31) Western Energy Resources and the Environment; Geothermal Energy, EPA600/9-77-010 Environmental Protection Agency (May 1977).

(32) E. S. Miliaras, Power Plants with Air-Cooled Condensing Systems, MIT Press, Cambridge, 1974.

(83) M. O. Surface, Power Eng. 81, 42-50 (September 1977).

(34) J. P. Rossie et al., Cost Comparison of Dry-Type and Conventional Cooling Systems for Representative Nuclear Generating Plants, TID-26007, R. W. Beck and Associates (March 1972).

(85) J. P. Rossie et al., Economics of the Use of Surface Condensers with Dry-Type Cooling Systems for Fossil-Fueled and Nuclear Generating Plants, ID-26514, R. W.Beck and Associates (December 1973).

(36) - F. K. Moore and K. E. Torrance, Air Flow in Dry Natural-Draft Cooling Towers Subject to Wind, Cornell University, Ithaca, N.Y., December 1977.

(37) F. K. Moore, "Problems of Dry Cooling," p. II-C-109 in Proceedings of the Conference on Waste Heat Management and Utilization, University of Miami, Coral Gables, Fla., May 1977.

(38) R. T. Alleman et al., "Dry/Wet Cooling Towers with Ammonia as Intermediate Heat Exchange Medium," p. IV-C-163 in Proceedings of the Conference on Waste Heat Management and Utilization, University of Miami, Coral Gables, May 1977.

(89) R. D. Landon and J. R. Houx, Jr., Plume Abatement and Water Conservation with the Wet/Dry Cooling Tower, The Marley Company, Mission, Kans., 1973.

(40) W. V. Loscutoff, Preliminary Evaluation of Wet/Dry Cooling Concepts for Power Plants, BNWL-1969; Battelle Pacific Northwest Laboratories (January 1976).

(41) D. R. Kreid, B. M. Johnson, and D. W. Faletti, Approximate Analysis of Heat Transfer from the Surface of a Wet Finned Heat Exchanger, ASME Paper 78HT-26, American Society of Mechanical Engineers, February 1978.

(42) L. E. Wiles et al, $A$ Description and Cost Añalysis of a Deluge Dry/Wet System, PNL-2498, Pacific Northwest Laboratory (June 1978).

(43) E. C. Smith and M. W. Larinoff, Power 120, 78 (May 1976).

(44) Draft Environmental Statement, Sundesert Nuclear Plant, Units 1 and 2, Docket Nos. STN 50-582 and 50-583, U.S. Nuclear Regulatory Commission, January 1978.

(45) S. C. Yao and V. E. Schrock, Aerodynamic Design of Cooling Tower Drift Eliminators, ASME Paper 75-WA/Pwr-5, American Society of Mechanical Engineers, 1975.

(46) F. M. Shofner et al., "Measurement and Interpretation of Drift-Particle Characteristics, p. 427 in Cooling Tower Environment-1974, CONF-740302, Technical Information Service, ERDA (1975). 
(47) R. O. Webb, G. O. Schrecker, and D. A. Guild, "Drift from the Chalk Point Natural-Draft Brackish Water Cooling Tower: Source Definition, Downwind Measurements, Transport Modeling," p. VIII-A-25 in Proceedings of the Conference on Waste Heat Management and Utilization, University of Miami, Coral Gables, Fla.. May 1977.

(48) S. M. Laskowski, "Mathematical Transport Model for Salt Distribution from a Saltwater Natural-Draft Cooling Tower," p. 598 in Cooling Tower Environment-1974, CONF-740302, Technical Information Service, ERDA (1975).

(49) Amiram Roffman and R. E. Grimble, "Drift Deposition Rates from Wet Cooling Systems," CONF-740302, p. 585 in Cooling Tower Environment-1974, Technical Information Service, ERDA (1975).

(50) G. W. Israel and T. J. Overcamp, "Drift deposition Model for Natural-Draft Cooling Towers," CONF-740302, p. 614 in Cooling Tower Environment-1974, Technical Information Service, ERDA (1975).

(51) J. V. Wilson, ORFAD, A Computer Program to Estimate Fog and Drift from Wet Cooling Towers, ORNL/TM-4658 (January 1975).

(52) M. E. LaVerne, The Oak Ridge Fog and Drift Code (ORFAD) User's Manual, ORNL/TM-5201 (January 1977).

(53) N. C. J. Chen, A Review of Cooling Tower Drift and Deposition Models, ORNL/TM-5357 (June 1977).

(54) T. J. Overcamp, "Sensitivity Analysis and Comparison of Salt Deposition Models for Cooling Towers," p. VI-C-117 in Proceedings of the Conference on Waste Heat Management and Utilization, University of Miami, Coral Gables, Fla., May 1977.

(55) P. A. Jallouk, G. J. Kidd, and T. Shapiro, Environmental Aspects of Cooling Tower Operation: Survey of the Emission, Transport, and Deposition from the $K-31$ and $K-39$ Cooling Towers at ORGDP, K-1859 (February 1974).

(56) F. G. Taylor, D. D. Gray, and P. D. Parr, "Interception and Retention of Cooling Tower Drift on Vegetation," paper presented at the Cooling Tower Institute Annual Meeting, Houston, Tex., January 1976 (ESD Publication 872, Environmental Sciences Division, Oak Ridge National Laboratory).

\subsection{Phased cooling (By R. C. Robertson*)}

In power stations with evaporative cooling ponds or towers having a significant diurnal difference in cooling capability, significant reductions in water consumption may be possible by storing a portion of the warmed circulating water for nighttims heat dissipation. This arrangement has been termed "phased cooling."

MacFarlane, Goodling, and Maples (1) studied a phased-cooling concept in which two storage ponds were proposed, one to store cooled water to supply the condenser during hot daytime temperatures and the other to store the effluent warmed water. During the night, when conditions are more favorable for cooling, the warmed water is cooled and returned to the first pond. It was concluded that phased cooling might cut evaporation losses about in half, depending on the storage capacity provided in the ponds. The analysis was based on meteorological conditions in the southeastern United States, and allowance was made for about $1.3 \mathrm{~m} /$ year ( $52 \mathrm{in} / \mathrm{year}$ ) of rainfall into the ponds and into the evaporation basin used for heat dissipation.

\footnotetext{
*Oak Ridge National Laboratory, Oak Ridge, Tenn.
} 
With phased cooling, essentially the same total amount of heat must be dissipated, but by postponing the heat release, the duty of the cooling equipment is increased accordingly. Costs, however, are not necessarily increased in direct proportion because of the size factor and because of the advantageous nighttime cooling conditions. Depending on the availability of land and on other construction costs of the water storage basins, phased cooling might reduce water consumption with less expense than would be required for either wet/dry or dry cooling towers. Phased cooling would have another important economic advantage in that the stored cooled water would increase the station's ability to meet peak daytime loads.

A 50-MW (e) geothermal power station with an overall thermal efficiency of $10 \%$ and an $11^{\circ} \mathrm{C}\left(20^{\circ} \mathrm{F}\right)$ rise in the circulating-water temperature might require a cooled-water storage pond of about 5 ha (11 acres) if the water depth averaged $6 \mathrm{~m}(20 \mathrm{ft})$. This amount of water would be for $8 \mathrm{hr}$ of storage. The optimum storage time would have to be determined by analysis but could well be less than $8 \mathrm{hr}$. A warm-water storage pond of about equal size would also be required. The construction cost of two 5-ha (11 acre) ponds would vary widely but might be in the order of 0.5 million. Although site-specific economic studies will be needed to evaluate the potential of the phased-cooling concept, the preliminary indication is that the arrangement has promise for some locations.

Reference

(1) J. A. MacFarlane, J. S. Goodling, and G. Maples, Combustion 48(8), 6-12 (February 1975).

\subsection{Variable, or "floating," power cooling concept (By R. C. Robertson*)}

A power plant is customarily designed for a constant power output that can be assured year-round, as determined by the capacity of the heat rejection system at reasonable worst-case conditions. However, in some special cases it may be more economical to design for a power output that will vary as the capacity of the waste heat rejection system is affected by ambient conditions. The cooling system would operate at full capacity in response to daily and seasonal changes in ambient conditions and the turbine exhaust pressure would be varied to allow the turbine to generate the maximum amount of power possible at that condition. This concept of variable power output has been termed "floating" power.

If sufficient prime-mover capacity is provided in a variable-power plant designed to produce the same net power as a fixed-capacity plant under worst-case summer conditions, it can generate increasingly more power as

*Oak Ridge National Laboratory, Oak Ridge, Tenn. 
the ambient temperatures decline from the design values. The penalty in capital cost charges in providing the greater capacity will tend to be offset by the greater amount of power produced. Only the turbine, generator, and electric auxiliary equipment need be sized for the maximum attainable power output. To maximize the output of the variable-power cycle, the turbine should be designed to operate at peak efficiency at a backpressure corresponding to the annual mean ambient temperature.

The thermodynamic properties of organic hydrocarbons allow turbines to operate over a wide range of back pressures with minor degradation of peak design efficiencies. The design and cost of an organic-fluid turbine to operate in the variable power mode is therefore not radically different from one built to operate at a fixed exhaust pressure. The thermodynamic properties of steam, however, are not compatible with the variable power output mode and the penalties in costs and efficiencies could be excessive. Advantages of the variable-power output concept will be greater at plant locations where there are wide swings in the available sink temperature as a result of diurnal and seasonal changes. The advantages also tend to be greater for plants with higher average condensing temperatures, which is a characteristic of systems using dry cooling. Further, the concept also favors power cycles that have only moderate thermal efficiencies, such as those dependent on low-temperature heat sources. It can thus be seen that geothermal power stations, and particularly those using dry cooling, are very likely candidates for the variable-power concept.

Pines et al. (1) made a study of variable power output for a 50-MW (e) binary geothermal power station concept for Heber, California. (The 50-MW (e) conceptnal designs for Heber discussed in section 5.6 are for a flashed-steam rather than a binary system.) Both evaporative and dry cooling system are considered. The study made use of the computer model GEOTHM to optimize the system design parameters in each case for minimum electrical energy production costs. The power production costs of fixed capacity plants were compared to variable power output plants. The equipment efficiencies and costs used as input parameters were obtained by applying scaling factors to information taken from a study made for the Electric Power Research Institute (EPRI) by HoltProcon $(\mathscr{L})$ of a $50-\mathrm{MW}(\mathrm{e})$ binary-cycle station located at Heber. Isobutane was used as the working fluid, and the dry cooling concept assumed direct condensation of the isobutane in a finned-tube tower. It was assumed that the additional power generated by the variable power output concept had the same monetary worth as that generated by the fixedcapacity plant. Seasonal shifts in the dry cooling cycle performance, based on the climatology of Heber, were taken into account.

The results of the Pines et al. (1) study are summarized in figure 5.38. In comparison to the $50-\mathrm{MW}(\mathrm{e})$ of net power produced by the baseloaded plant (based on design conditions that would exist $99 \%$ of the 

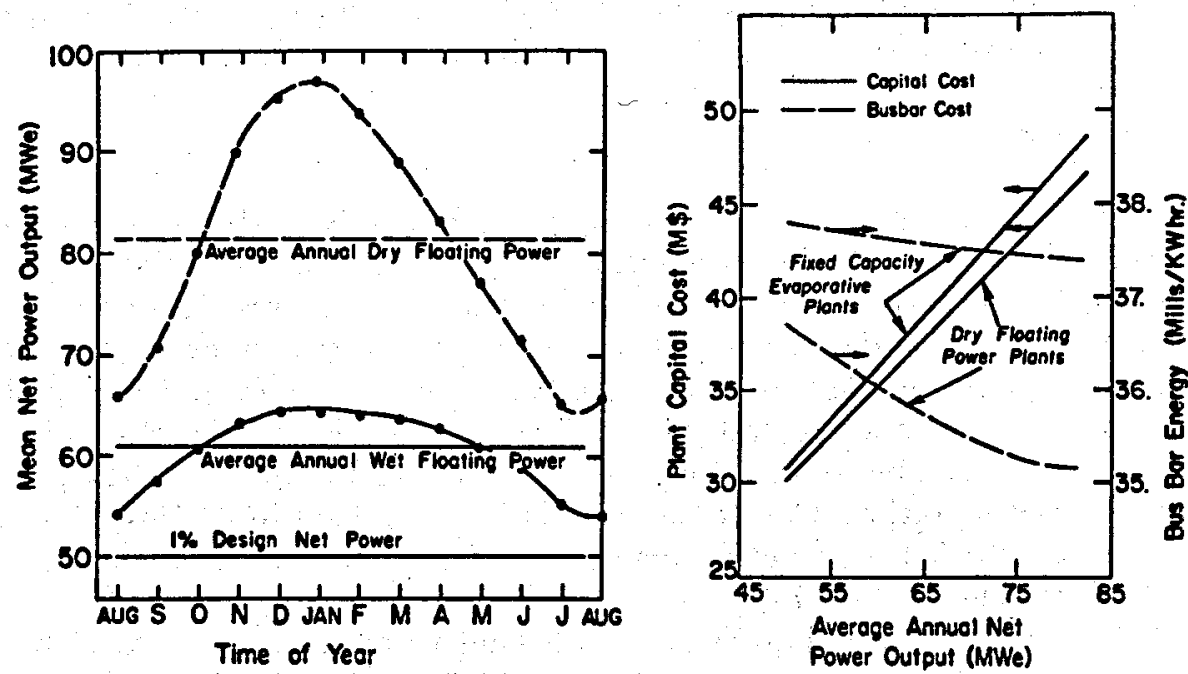

FIaUR 6.88-(left) Seasonal variation of net output of "floating" power evaporative and dry-cooled blaary geothermal power plants at Heber, OA., which would generate $60 \mathrm{MWe}$ (net) if designed on $1 \%$ basis, and (right), plant capital costs and busbar energy costs of base-loaded evaporative-cooled and "floating" dry-cooled plants as function of the annual average power output. Source: H. S. Pines et al., Floating Dry Cooling, 4 Oompetitive Alternative to Evaporative Oooling in a Binary Oycle Geothermal Power Plant, LBL-7087, Lawrence Berkeley Laboratory [July 1978], paper presented at the American Soclety of Mechanical Engineers 1978 Winter Annual Meeting at San Francisco, December 10-15, 1978. Reprinted by permission.

time), the average annual net power output of the variable power concept using wet cooling towers is about $61 \mathrm{MW}(\mathrm{e})$. When using dry cooling, the annual average net output is about $81 \mathrm{MW}(\mathrm{e})$, as shown in figure 5.38(a). The average power output is greater than $50 \mathrm{MW}(\mathrm{e})$ because the monthly mean ambient temperatures are always lower than the design value. The electricity production (busbar) costs, compared in figure 5.38 (b) show about a $10 \%$ lower cost for the variable power-output concept. The study concluded that geothermal power stations operating on the binary cycle and using dry cooling can be as economical as base-loaded plants using wet cooling towers.

\section{References}

(1) H. S. Pines, M. A. Green, W. L. Pope, and P. A. Doyle, Floating Dry Cooling, A Competitive Alternative to Evaporative Cooling in a Binary Cycle Geothermal Power Plant, LBL-7087, Lawrence Berkeley Laboratory (July 1978); American Society of Mechanical Engineers' 1978 Winter Annual Meeting, San Francisco, December 10-15, 1978.

(2) V. W. Roberts, Geothermal Energy Conversion and Economic Case Studies, EPRI-301, Holt/Procon (November 1976). 


\subsection{Heat rejection equipment in $50-M W(e)$-station conceptual de-} signs at Heber and Niland, California (By R. C. Robertson*)

\subsubsection{General}

Study of existing geothermal power plants has limited usefulness because the economic and environmental aspects of power plant design have changed markedly in the past few years. Perhaps of more interest are the recent conceptual designs made by Bechtel (1)** of two different types of power cycles for the proposed geothermal power stations at Heber and Niland in the Imperial Valley of southern California. Also worth noting is a United Engineers $(\mathscr{Z})$ study of a wet/dry cooling tower for the proposed Heber station. The studies were based on a plant of $50 \mathrm{MW}(\mathrm{e})$ net capacity; stations of greater capacity would be comprised of a multiplicity of the 50-MW (e) units.

The geothermal fluids at Heber and Niland are quite different. At Heber the design temperature of the fluid at the plant boundary is $170^{\circ} \mathrm{C}\left(338^{\circ} \mathrm{F}\right)$, and at Niland it is $228^{\circ} \mathrm{C}\left(443^{\circ} \mathrm{F}\right)$. At Heber the quantity of total dissolved solids (TDS) in the fluid is about $14,000 \mathrm{ppm}$, but at Niland it is $250,000 \mathrm{ppm}$. (The nonondensable gas content is about the same at 0.3 to $0.5 \%$ by weight.) A two-stage flashed-steam system was selected for Heber, and a multistage binary system using isopentane as the working fluid was proposed for Niland. The salient features of the heat rejection systems of the two stations are compared in table 5.14. The auxiliary power requirements are listed in table 5.15, and the estimated costs of the heat rejection equipment and total plant, in last quarter 1976 dollars, are given in table 5.16.

\subsubsection{Heber}

The Heber concept includes two different design approaches to accommodate the expected droop in the brine temperature during the lifetime of the plant. The first considers a constant brine flow rate with drooping power output and the second, increased brine flow rate and constant power output. Athough power stations are traditionally designed for a constant electrical output over the life of the station, there is no technical reason for not designing for decreasing power capacity if this produces the better economics (see section 5.5). The study points out that use of the two different design approaches could produce significantly different design concepts for the station. The discussion here will be based primarily on the constant power output approach.

A highly simplified flow diagram of the two-stage flashed-steam system proposed for Heber is shown in figure 5.39. Geothermal fluid at downhole

* Oak Ridge National Laboratory, Oak Ridge, Tenn.

**References for sect. 5.6 are listed on p. 655. 
TABLE 5.14-Salient features of the heat rejection systems and other aspects of the conceptual designs of the Heber and Niland geothermal power stations"

\begin{tabular}{lll}
\hline & Heber $^{\text {b }}$ & Niland \\
\hline
\end{tabular}

Net electrical capacity, $\mathrm{MW}(\mathrm{e}) \ldots \ldots \ldots \ldots 50 \ldots \ldots \ldots$

Geothermal fluid at plant boundary:

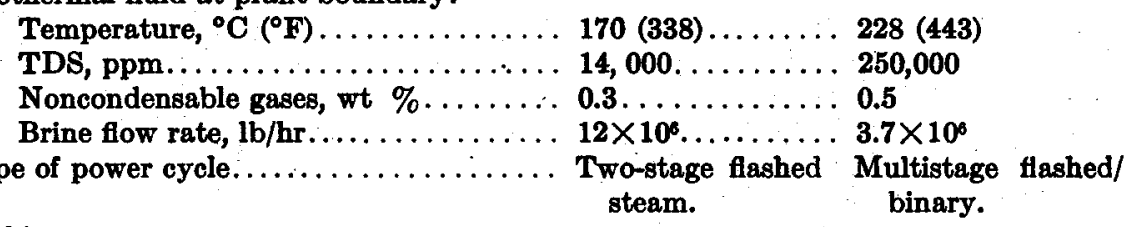

Turbine:

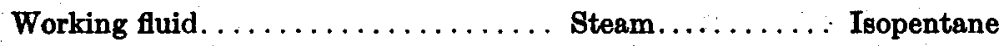

Throttle pressure, psia . . . . . . $\ldots \ldots .41 .8 / 18.0 \ldots \ldots \ldots 550$

Exhaust pressure, psia. . . . . . . $1.96 \ldots \ldots \ldots \ldots 28.8$

Turbine internal efficiency, $\% \ldots \ldots 77 / 79 \ldots \ldots \ldots 85$

Condenser type . . . . . . . . . . . . . . Direct-contact. . . Shell-and-tube

Heat sink. . . . . . . . . . . . . . . Wet mechanical- Wet mechanicaldraft towers. $\quad$ draft towers.

Heat rejected in towers, $\mathrm{Btu} / \mathrm{hr} \ldots \ldots \ldots \ldots 1.58 \times 10^{0} \ldots \ldots \ldots 8.56 \times 10^{8}$

Cooling water flow rate, $g p m \ldots \ldots \ldots \ldots, 104,000 \ldots \ldots \ldots 74,400$

Water temperatures, in/out $\left({ }^{\circ} \mathrm{F}\right) \ldots \ldots \ldots \ldots 116 / 87 \ldots \ldots \ldots \ldots 110 / 87$

Makeup water required, $\mathbf{g p m} \ldots \ldots \ldots \ldots \ldots 3380 \ldots \ldots \ldots \ldots$

Makeup water source............... Condensate....... Alamo River

Reinjection water source. . . . . . . . . New River. ..... Tower blowdown

River water consumption, acre-ft/year d ... $3972 \ldots \ldots \ldots \ldots 3397$

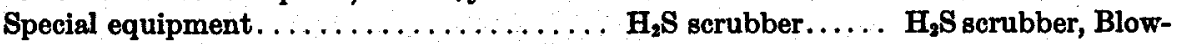
down deaerator, Isopentane storage

Cycle thermal efficiency, $\%$

9.8. . .

Specific net energy, Whr/lb brine

$4.2 \ldots \ldots \ldots \ldots 13.6$

Estimated total cost, $\$ 1,000 \cdot$.

$36,000 \ldots \ldots \ldots \ldots 39,200$

\begin{tabular}{|c|c|c|}
\hline $\begin{array}{l}\text { To obtain } \\
\text { column I }\end{array}$ & $\begin{array}{l}\text { Multiply } \\
\text { column II }\end{array}$ & $\begin{array}{l}\text { by } \\
\text { column III }\end{array}$ \\
\hline $\begin{array}{l}\mathbf{k g} / \mathbf{s e c} \\
\mathbf{k P a} \\
\mathbf{M W}(\mathbf{t}) \\
\mathbf{m}^{3} / \mathbf{s e c} \\
\mathbf{m}^{3} / \mathbf{s e c} \\
\mathbf{W h r} / \mathbf{k g}\end{array}$ & $\begin{array}{l}\mathrm{lbm} / \mathrm{hr} \\
\text { psia } \\
\text { Btu/hr } \\
\text { gpm } \\
\text { acre-ft/year } \\
\text { Whr/lbm }\end{array}$ & $\begin{array}{l}125.998 \times 10^{-0} \\
6.89476 \\
293.071 \times 10^{--} \\
6.309 \times 10^{-5} \\
3.9113 \times 10^{-b} \\
2.2046\end{array}$ \\
\hline $\begin{array}{l}\text { - Assumes } \\
\text { - Assumes } \\
\text { d Based o } \\
\text { - In last-q } \\
\text { Source: A } \\
\text { ower Plan } \\
\text { orporation }\end{array}$ & $\begin{array}{l}\text { itput. } \\
\text { idand, } \\
\text { ilaco }\end{array}$ & $\begin{array}{l}\text { for Commercial Geothermal } \\
\text { ort, SAN-1124-2, Bechtel }\end{array}$ \\
\hline
\end{tabular}

conditions of $173^{\circ} \mathrm{C}\left(344^{\circ} \mathrm{F}\right)$ and $855 \mathrm{kPa}(124$ psia) enters two highpressure flash vessels at $170^{\circ} \mathrm{C}\left(338^{\circ} \mathrm{F}\right)$ and $793 \mathrm{kPa}(115 \mathrm{psia})$, at a rate of $1512 \mathrm{~kg} / \mathrm{sec}\left(12.0 \times 10^{8} \mathrm{lb} / \mathrm{hr}\right)$. A total of $114.4 \mathrm{~kg} / \mathrm{sec}\left(908 \times 10^{3} \mathrm{lb} / \mathrm{hr}\right)$ of $310-\mathrm{kPa}(45-\mathrm{psia})$ saturated steam is produced and supplied to the 
TABLE 5.15-Auxiliary power requirements for the $50-M W(e)$ (net) Heber and Niland geothermal power stations

\begin{tabular}{|c|c|c|}
\hline & \multicolumn{2}{|c|}{ Power requirements $(\mathrm{kW})$} \\
\hline & Heber $\bullet$ & Niland b \\
\hline Brine reinjection pumps... & 3870 & 1190 \\
\hline Circulating water pumps. . . . . . . . . . & 2930 & 2130 \\
\hline Ejector condenser pumps. ............. & 40 & \\
\hline Condenser vacuum holding pumps.......... & 85 & \\
\hline Low-pressure feed pumps............ & & 400 \\
\hline Makeup water pumps.................... & & 80 \\
\hline Blowdown reinjection pumps............. & & 160 \\
\hline Scrubber water supply pumps. . . . . . . . . . & 15 & 10 \\
\hline 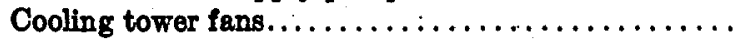 & 1180 & 840 \\
\hline Other services, estimated. . . . . . . . . . . . . . & 800 & 230 \\
\hline Total auxiliary power. & 8430 & 5050 \\
\hline
\end{tabular}

- Heber concept with constant power output.

- Niland concept with regeneration.

Source: Advanced Design and Economic Consideration for Commercial Geothermal Power Plants at Heber and Niland, California, Final Report, SAN 1124-2, Bechtel Corporation (October 1977).

throttle of two $3600-\mathrm{rpm}$, dual-admission steam turbines that are directconnected to a common electrical generator having a gross output of 58.4 MW (e). Turbine internal efficiencies are 77\% for the high-pressure unit and $79 \%$ for the low-pressure unit. The unflashed portion of the geothermal fluid flows to the two low-pressure fiash vessels where a total of $75.6 \mathrm{~kg} / \mathrm{sec}$ $\left(600 \times 10^{3} \mathrm{lb} / \mathrm{hr}\right)$ of $124-\mathrm{kPa}(18-\mathrm{psia})$ steam is produced and supplied to the low-pressure inlet of the turbine. The remaining $1336 \mathrm{~kg} / \mathrm{sec}\left(10.6 \times 10^{\circ}\right.$ $\mathrm{lb} / \mathrm{hr})$ of unflashed geothermal fluid, along with about $8.8 \mathrm{~kg} / \mathrm{sec}\left(70 \times 10^{3}\right.$

TABLE 5.16-Total installed costs of heat rejection equipment and total plant costs at Heber and Niland, California

\begin{tabular}{|c|c|c|c|c|c|}
\hline & \multicolumn{5}{|c|}{ 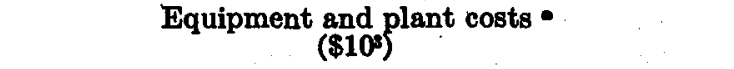 } \\
\hline & \multicolumn{3}{|c|}{ Heber } & \multicolumn{2}{|c|}{ Niland } \\
\hline & Base & $\begin{array}{r}\text { Constant } \\
\text { output }\end{array}$ & $\begin{array}{l}\text { Constant } \\
\text { flow rate }\end{array}$ & $\begin{array}{r}\text { Without } \\
\text { regenera- } \\
\text { tion }\end{array}$ & $\begin{array}{l}\text { With re- } \\
\text { generation }\end{array}$ \\
\hline Regenerator & & & & & 1,010 \\
\hline Condensers. & 840 & 850 & 880 & 3,440 & 2,990 \\
\hline Cooling towers.......... & 1,290 & 1,290 & 1,415 & 1,220 & 1,010 \\
\hline Total plant. . . . . . . . . & 35,000 & 36,000 & 37,500 & 39,500 & 39,200 \\
\hline Total $\$ / \mathbf{k} \mathbf{W} \ldots$ & 700 & 720 & 7.50 & 790 & 784 \\
\hline
\end{tabular}

- In last-quarter 1976 dollars. 


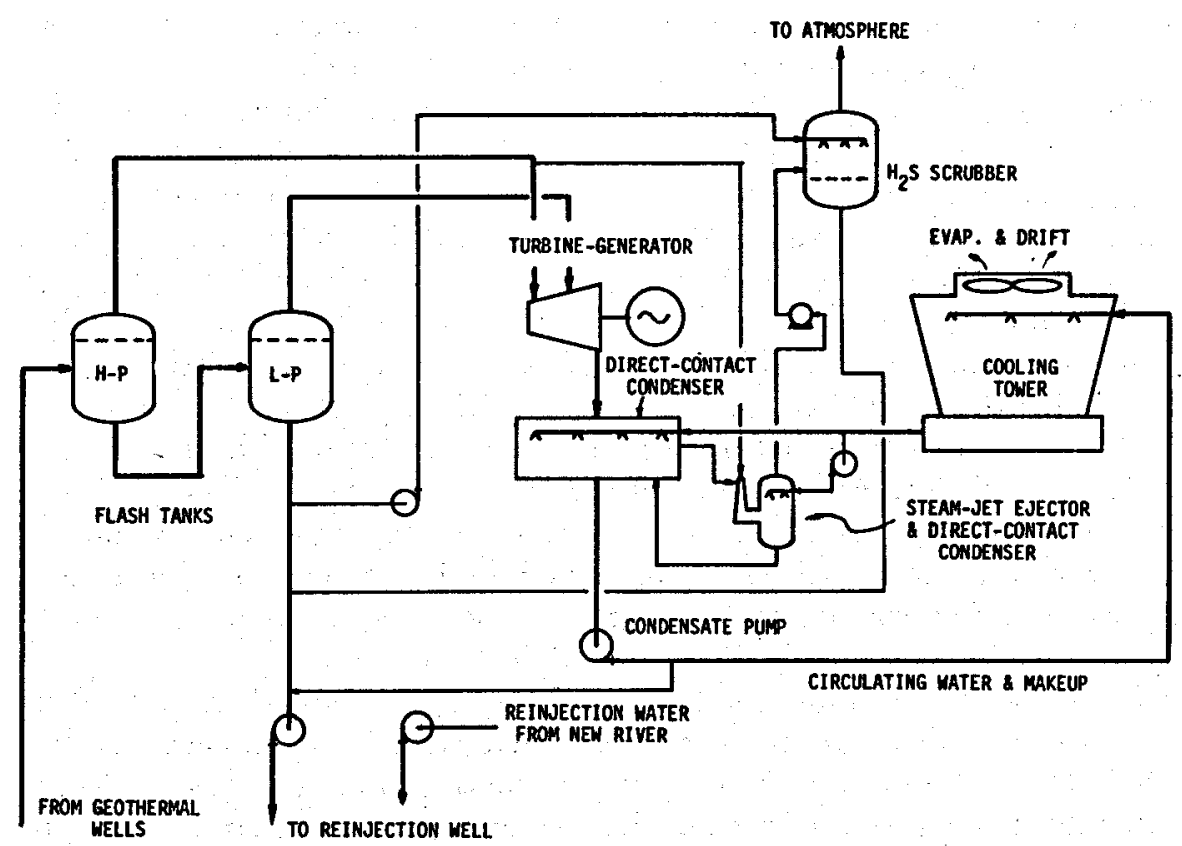

Fiaure 5.39-Simplifled flow diagram of two-stage flashed-steam power cycle for 50-MWe geothermal power station at Heber, California. Source: Advanced Design and Economic Considerations for Commercial Geothermal Pover Plants at Heber and Niland, Oalifornia, Final Report, SAN-1124-2 Bechtel Corporation [October 19771 .

$\mathrm{lb} / \mathrm{hr}$ ) of cooling tower blowdown, is pumped at about $106^{\circ} \mathrm{C}\left(223^{\circ} \mathrm{F}\right)$ and $2172 \mathrm{kPa}(315 \mathrm{psia})$ into the reinjection wells. System output is controlled by varying the rate of brine flow to the flash tanks.

At design conditions, cooling water enters the condenser at $30.6^{\circ} \mathrm{C}$ $\left(87^{\circ} \mathrm{F}\right)$, and, after mixing with the steam condensate, is pumped to the mechanical-draft cooling towers at $46.7^{\circ} \mathrm{C}\left(116^{\circ} \mathrm{F}\right)$ at a rate of $6564 \mathrm{~kg} / \mathrm{sec}$ $\left(52.1 \times 10^{6} \mathrm{lb} / \mathrm{hr} ;\right.$ or $\left.104,117 \mathrm{gpm}\right)$. The condenser, a low-level, directcontact, or spray, type located directly beneath the turbine, is constructed of reinforced concrete and is $8.5 \mathrm{~m} \mathrm{(31} \mathrm{ft)} \mathrm{wide} \times 10.4 \mathrm{~m}(34 \mathrm{ft}) \mathrm{high} \times$ $15.9 \mathrm{~m} \mathrm{(52} \mathrm{ft)}$ long. The inside surface is sealed with an epoxy resin compound. The condenser duty is estimated to be $410.3 \mathrm{MW}(\mathrm{t})\left(1.40 \times 10^{\circ}\right.$ $\mathrm{Btu} / \mathrm{hr}$ ). The condenser. was designed on the basis that the temperature of the condensing steam would exceed that of the mixture leaving the condenser by about $5.6^{\circ} \mathrm{C}\left(10^{\circ} \mathrm{F}\right)$. Noncondensable gases are removed in two stages; the first is a steam-jet ejector and the second a mechanical vacuum pump. A steam-jet ejector could be used, though, for the second stage during the early life of the plant before the geothermal fluid temperature decreases. The noncondensable gases pass through a hydrogen sulfide scrubber before release to the atmosphere. It is tentatively proposed that 
the scrubbing medium be concentrated brine taken from the second-stage flash tanks, with small amounts of alkali added if required.

The cooling towers are the evaporative, mechanical, induced-draft type

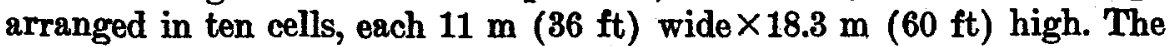
design wet-bulb temperature is $26.1^{\circ} \mathrm{C}\left(79^{\circ} \mathrm{F}\right)$, and the average evaporation and drift rate is given as $182.7 \mathrm{~kg} / \mathrm{sec}\left(1.45 \times 10^{8} \mathrm{lb} / \mathrm{hr}\right.$, or $\left.2898 \mathrm{gpm}\right)$. Based on a blowdown rate of $8.8 \mathrm{~kg} / \mathrm{sec}\left(70 \times 10^{3} \mathrm{lb} / \mathrm{hr}\right.$, or $\left.140 \mathrm{gpm}\right)$, the concentration factor is about 21 . Because the amount of water available from condensing the steam exceeds the makeup rate required for the towers, the small excess will be reinjected along with the unflashed geothermal fluid. A small amount of hydrogen sulfide may be dissolved in the condensate and carried over to the cooling tower, where there will be a tendency for it to come out of solution and be released to the atmosphere. Although the amount is estimated to be small and within acceptable limits, this aspect needs further investigation, and it is possible that hydrogen sulfide removal equipment would be needed for the condensate.

The amount of geothermal fiuid reinjected will be less than that taken from the ground by an amount approximately equal to the evaporation rate in the cooling towers. If necessary to control ground-level subsidence, water taken from the New River will be reinjected in separate wells. It may be necessary to chemically treat this water prior to reinjection to make it compatible with the downhole geothermal fluid.

\subsubsection{Niland}

A simplified flow diagram of the Niland binary isopentane multistage flash system is shown in figure 5.40. Two cases were studied by Bechtel, one with regenerators in the turbine exhaust and the other a base case without regeneration. The regeneration case, shown in figure 5.40, is the system discussed below.

As previously stated, the geothermal fluid temperature at the Niland site is higher than at Heber, being about $288^{\circ} \mathrm{C}\left(550^{\circ} \mathrm{F}\right)$ downhole and about $228^{\circ} \mathrm{C}\left(443^{\circ} \mathrm{F}\right)$ at the plant boundary. The composition of the geothermal fluid, or brine, is close to one-fourth solids, or about $250,000 \mathrm{ppm}$, by weight. Almost all the brine supplied to the plant will be reinjected. As indicated in figure 5.40, the brine enters the separator-heat exchanger as a two-phase mixture of steam and brine. The flashed steam passes through a mist eliminator and condenses on the exterior of the heat exchange tubes, giving up heat to the isopentane flowing inside the tubes. The condensate falling off the tubes mixes with residual brine and flows to the next lower stage where the process is repeated.

The isopentane circulates at a rate of about $706 \mathrm{~kg} / \mathrm{sec}\left(5.6 \times 10^{\circ} \mathrm{lb} / \mathrm{hr}\right)$. It is pressurized to a supercritical pressure of about $3985 \mathrm{kPa}$ (578 psia) and a temperature of $88.3^{\circ} \mathrm{C}\left(191^{\circ} \mathrm{F}\right)$ before it enters the tubes of the regenerator and multistage flash unit. The superheated isopentane vapor, 


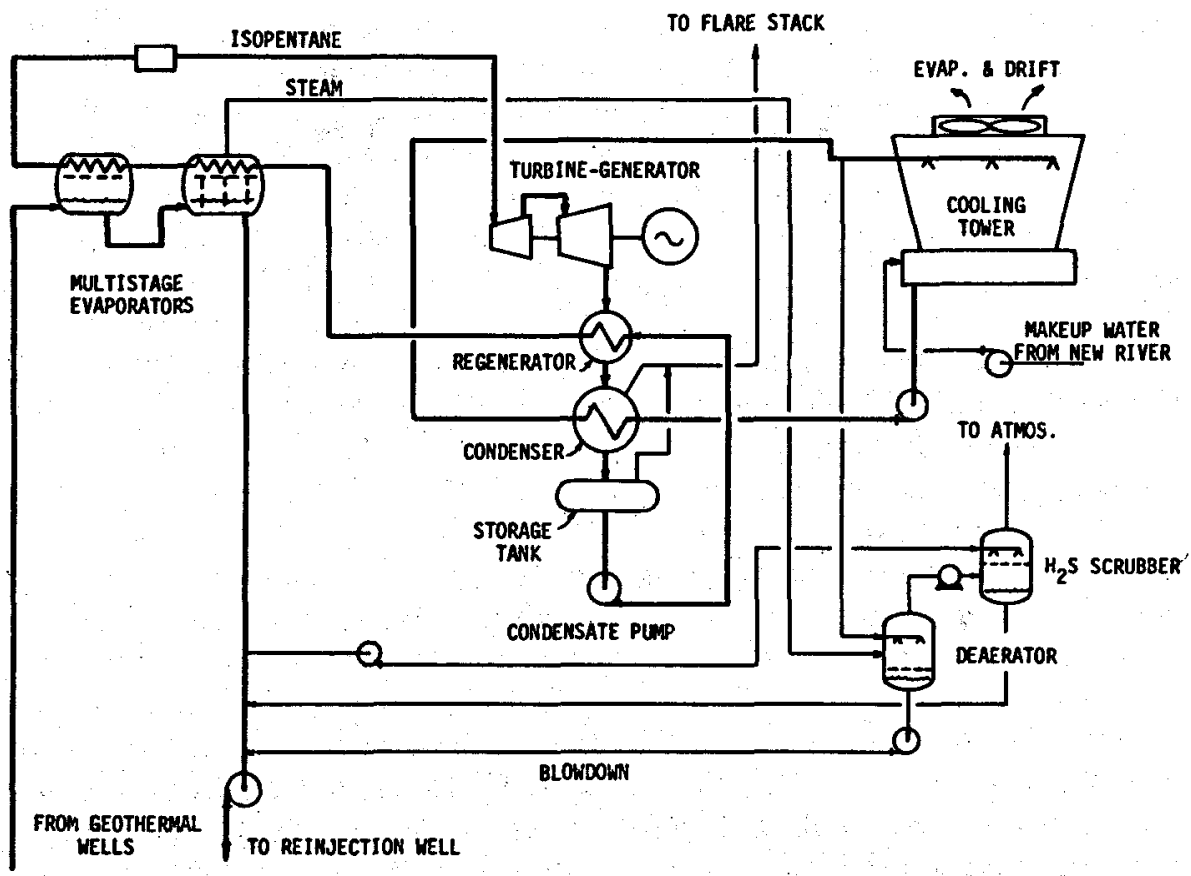

Figure 5.40-Simplified flow diagram of multistage evaporation binary power cycle for 50-MWe geothermal power station at Niland, California. Source: Advanced Desion and Economic Oonsiderations for Commercial Geothermal Ponver Plants at Heber and Niland, Callfornia, Final Report, SAN-1124-2, Bechtel Corporation [October 1977].

at $3792 \mathrm{kPa}(550 \mathrm{psia})$ and $199^{\circ} \mathrm{C}\left(390^{\circ} \mathrm{F}\right)$, enters the high-pressure turbine and expands to about $827 \mathrm{kPa}(120 \mathrm{psia})$ and $135^{\circ} \mathrm{C}\left(275^{\circ} \mathrm{F}\right)$ before further expansion in the low-pressure turbines to $226 \mathrm{kPa}(32.8 \mathrm{psia})$ and $106^{\circ} \mathrm{C}\left(223^{\circ} \mathrm{F}\right)$. The turbines are direct-connected to a 3600 -rpm electric generator having a gross output of $55.6 \mathrm{MW}(\mathrm{e})$. The turbine exhaust vapor, still in the superheated state, flows to the shell side of the two shelland-tube regeneration heat exchangers where the temperature is reduced to $54.4^{\circ} \mathrm{C}\left(130^{\circ} \mathrm{F}\right)$ in heating the "boiler" feed from $47.2^{\circ} \mathrm{C}\left(117^{\circ} \mathrm{F}\right)$ to $88.3^{\circ} \mathrm{C}$. $\left(191^{\circ} \mathrm{F}\right.$.) The exhaust vapor then enters the shell side of the surface-type condenser. Condensation is at about $48.9^{\circ} \mathrm{C}\left(120^{\circ} \mathrm{F}\right)$ near the entrance but because of a $20.7-\mathrm{kPa}$ (3-psi) pressure drop through the condenser is completed at about $45.6^{\circ} \mathrm{C}\left(114^{\circ} \mathrm{F}\right)$. The two condensers are the horizontal shell-and-tube type, each consisting of a $1.9 \mathrm{~cm}(0.75-\mathrm{in}$.) thick shell, $3.7 \mathrm{~m}(12 \mathrm{ft})$ in diameter and $18.3 \mathrm{~m}$ (60 ft) long, equipped with copper-nickel tubes. The condensation pressure is in the 172-193 $\mathrm{kPa}$ (25-28 psia) range, and because it is above atmospheric, the noncondensable gases can be vented without use of ejectors or vacuum pumps. The gases are vented through a flare stack to burn off combustibles before release to the atmosphere. The isopentane condensate flows by gravity to a 
storage tank. Cooling water is circulated through the condensers at a rate of $4.7 \mathrm{~m}^{3} / \mathrm{sec}(74,400 \mathrm{gpm})$. The water enters at $30.6^{\circ} \mathrm{C}\left(87^{\circ} \mathrm{F}\right)$ and leaves at $43.3^{\circ} \mathrm{C}\left(110^{\circ} \mathrm{F}\right)$, resulting in a cooling duty of $251 \mathrm{MW}(\mathrm{t})$ $\left(857 \times 10^{\circ} \mathrm{Btu} / \mathrm{hr}\right)$. The water is circulated to a mechanical-draft evaporative cooling tower that consists of seven cells and has an overall length of $77 \mathrm{~m}(252 \mathrm{ft})$ and width of $16 \mathrm{~m}(53 \mathrm{ft})$. The design wet-bulb temperature is $26.1^{\circ} \mathrm{C}\left(79^{\circ} \mathrm{F}\right)$ and the approach is $4.4^{\circ} \mathrm{C}\left(8^{\circ} \mathrm{F}\right)$. The evaporation rate is given as about $0.13 \mathrm{~m}^{3} / \mathrm{sec}(2078 \mathrm{gpm})$. The concentration factor is about 3 , and the blowdown is deaerated before reinjection along with the geothermal fluid. The gases vented from the deaerator are removed by a steam-jet ejector and pass through a hydrogen sulfide scrubber before release to the atmosphere. Aibout $0.19 \mathrm{~m}^{3} / \mathrm{sec}(3058 \mathrm{gpm})$ of makeup water for the cooling tower will be obtained from the Alamo River, where two 100\%-capacity, vertical, centrifugal pumps, each developing-40-m (132 $\mathrm{ft}$ ) of head at $3600 \mathrm{rpm}$, will be installed in an intake structure.

In brief, the effect of adding regeneration to the cycle is to improve the cycle efficiency from about $13.9 \%$ to $16.5 \%$, which, for the same 50 MW (e) output, reduces the duty of the heat rejection system from about $290 \mathrm{MW}(\mathrm{t})\left(9.9 \times 10^{8} \mathrm{Btu} / \mathrm{hr}\right)$ to $252 \mathrm{MW}(\mathrm{t})\left(8.6 \times 10^{8} \mathrm{Btu} / \mathrm{hr}\right)$ and allows use of seven cooling tower cells rather than eight. The isopentane flow rate through the condenser is increased by use of regeneration from about $338 \mathrm{~kg} / \mathrm{sec}\left(2.68 \times 10^{6} \mathrm{lb} / \mathrm{hr}\right)$ to $355 \mathrm{~kg} / \mathrm{sec}\left(2.82 \times 10^{6} \mathrm{lb} / \mathrm{hr}\right)$. The geothermal fluid flow rate would remain the same, but the reinjection temperature would be raised by use of regeneration from $68^{\circ} \mathrm{C}\left(154^{\circ} \mathrm{F}\right)$ to $109^{\circ} \mathrm{C}\left(229^{\circ} \mathrm{F}\right)$. Although use of regeneration reduces the total plant cost by less than 1\% (table 5.16), the significant aspect is that coolingwater consumption is reduced by $19 \%$.

\subsubsection{Heber with wet/dry cooling tower}

Because of the scarcity of water in the Imperial Valley of southern California, United Engineers (2) made a study of a 50-MW(e) Heber concept using a wet/dry tower rather than a conventional mechanicaldraft evaporative type. The study postulated saving various amounts of cooling tower makeup water. In the assumptions used in the study, listed in table 5.17 , notice that a loss-of-capacity penalty charge of $\$ 1450 / \mathrm{kW}$ was applied. (The estimated cost of the waste heat rejection system using conventional mechanical-draft evaporative cooling towers was estimated at about $25 \%$ of the total station cost.)

Reducing the water consumption to $40 \%$ of what it would be using conventional wet towers would make (1) the capital costs of the waste heat rejection system about 1.5 times greater and (2) the total cost, after capacity and operating penalties are applied, about 3 times greater. The total cost to produce electricity, shown in table 5.18, is about 1.4 times greater than for a plant using conventional wet towers. If the water con- 
TABLE 5.17-Parameters used in study of wet/dry cooling towers for $50-M W(e)$ Heber geothermal plant
Year of pricing
1985
Average plant capacity factor. . . . . . . . .
Annual fixed charge rate..................... $17 \%$
Plant life........................... 30 years
Capacity penalty charge rate.................. $\$ 1450 / \mathrm{kW}$

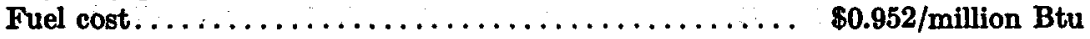
Operation and maintenance cost.............., $9.36 \mathrm{mills} / \mathrm{kWhr}$
Water cost............................ 30 $/ 10^{3} \mathbf{~ g a l ~}$

Source: United Engineers, Engineering and Economic Evaluation of Wet and Wet/Dry Cooling Systems for a Geothermal Pover Plant, Contract EY-76-C-02-2477, unpublished data, September 1977.

sumption were to be reduced to $5 \%$ of that required for conventional towers the effects would be striking. The cost of the waste heat rejection system, after penalties are applied, is about 6 times greater, and the total cost to produce electricity is about 1.6 times greater. The study concluded that relatively small geothermal power plants tied into large grids might operate more economically using conventional rather than wet/dry towers and would not be base-loaded except in the winter months. In the summer, during extremely adverse conditions for heat rejection, the capacity would be allowed to drop off or the plant would be shut down completely.

TABLE 5.18-Effect of varying the amount of water conserved on cost to produce electricity at Heber

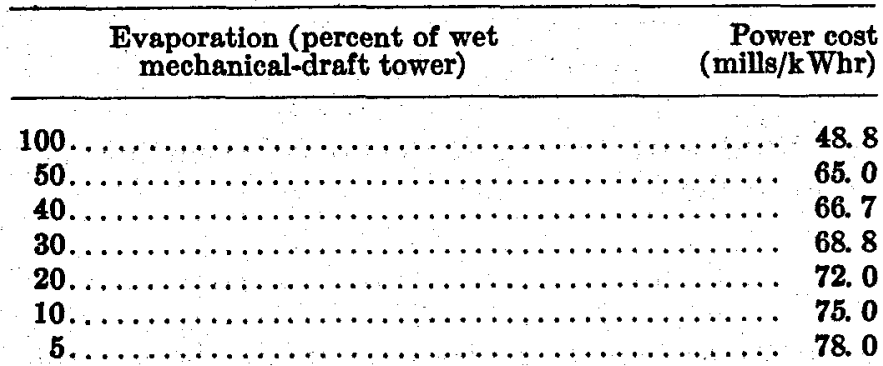

Source: United Engineers, Engineering and Economic Evaluation of Wet and Wet/Dry Cooling Systems for a Geothermal Pover Plant, Contract EY-76-C-02-2477, unpublished data, September 1977.

\subsubsection{References}

(1) Advanced Design and Economic Considerations for Commercial Geothermal Power Plants at Heber and Niland, California, Final Report, SAN-1124-2, Bechtel Corporation (October 1977).

(2) United Engineers. Engineering and Economic Evaluation of Wet and Wet/Dry Cooling Systems for a Geothermal Power Plant, Contract EY-76-C-02-2477, unpublished data, September 1977. 
5.7 Effect of fluctuations in ambient temperature (By H. E. Khalifa*)

\subsubsection{Introduction}

The heat rejection temperature in a vapor power cycle is determined primarily by the temperature of the available cooling medium. The cooling medium, be it water or air, exists at ambient temperatures that exhibit pronounced seasonal variations. The thermal efficiency of a power cycle improves with a lower heat rejection temperature and vice versa. It can be shown by simple thermodynamic arguments that the thermal efficiency is more sensitive to changes in the heat rejection temperature than it is to equal changes in the heat addition temperature. It is also known that the effect of a certain change in the heat rejection temperature on cycle efficiency is greater for lower heat addition temperatures. This indicates that the effect of seasonal fluctuations in the heat rejection temperature on the performance of low temperature power cycles, such as those applied in the utilization of geothermal energy, will be considerably more significant than it is in large fossil fuel steam power plants. In the first case maximum temperatures of only $150-250^{\circ} \mathrm{C}$ are expected whereas in the latter maximum temperatures as high as $600^{\circ} \mathrm{C}$ have been applied.

\section{7 .2 Ideal case}

Consider a geofluid at $T_{b}$ (constant) fed to the heat exchanger of a binary-fluid system and reinjected at $T_{r}$. Assume also that the sink temperature is a known function of time given by

$$
T_{\mathrm{o}}=T_{\mathrm{o}}(t)
$$

The maximum ideal work that can be obtained from this geofluid (see figure 5.41) is given by

$$
W^{\circ}(t)=h_{b}-h_{o}(t)-T_{o}(t)\left[s_{b}-s_{o}(t)\right]
$$

For an incompressible fluid with a constant specific heat, $c$, this becomes

$$
W^{\circ}(t) \simeq c\left\{T_{\mathrm{o}}-T_{0}(t)-T_{0}(t) \ln \left[T_{\mathrm{o}} / T_{\mathrm{o}}(t)\right]\right\} .
$$

The heat exchanger has to be designed with a finite temperature difference for economic reasons. In view of this limitation, we introduce a new definition of the ideal work

$$
\bar{W}^{\circ}(t) \simeq c\left\{T_{b}-T_{r}(t)-T_{o}(t) \ln \left[T_{b} / T_{r}(t)\right]\right\}
$$

*Division of Engineering, Brown University, Providence, R.I.; now with United Technologies Research Center, East Hartford, Conn. 
FraUre 5.41-Simplified T-8 diagram for an ideal geothermal power cycle: Shaded area represents the work gain due to a drop of sink temperature from $T_{\text {oo }}$ to $\boldsymbol{T}_{\text {o. }}$

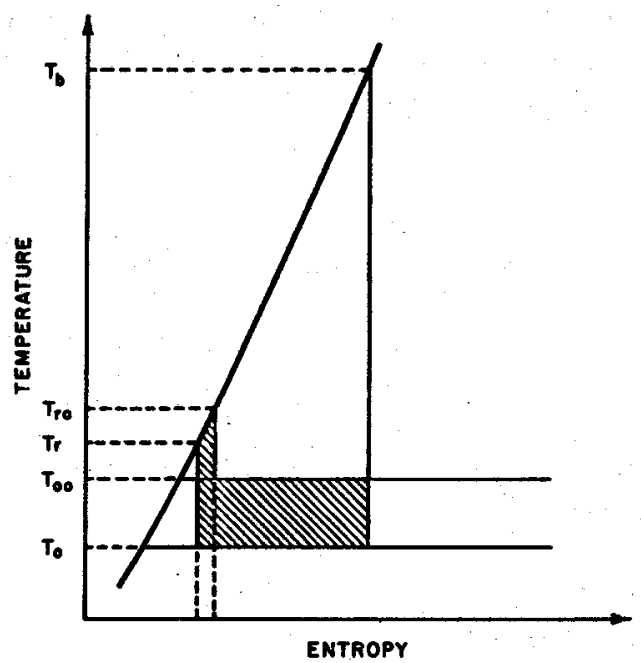

The nature of the dependence of $T_{r}$ on time is determined by the design of the heat exchanger as well as by $T_{0}(t)$ itself. Assuming that the heat exchanger receives the same amount of brine, $\dot{m}_{b}$, regardless of the time of the year, we may write

$$
\dot{m}_{c_{b}}\left(T_{b}-T_{r}\right)=\dot{m}_{f} c_{f}\left(T_{f}-T_{o}\right),
$$

in which the subscript $f$ refers to the working fluid. Furthermore,

$$
\dot{m}_{b} C_{b}\left(T_{b}-T_{r}\right)=A U\left(T_{r}-T_{0}\right),
$$

where $U$ is the overall heat transfer coefficient and $A$ is the surface area of the heat exchanger. Solving equation 5.18 for $T_{r}$ we obtain

$$
T_{r}(t)=\left[A U T_{0}(t)+\dot{m}_{b} c_{b} T_{b}\right] /\left(A U+\dot{m}_{b} c_{b}\right) .
$$

Denoting the sink temperature at an arbitrary datum point by $T_{o o}$ and the reinjection temperature at this point by $T_{r o}=T_{o o}+\delta$, we obtain

$$
A U=\dot{m}_{b} c_{b}\left(T_{b}-\delta-T_{o o}\right) / \delta
$$

Therefore,

$$
T_{r}(t)-T_{0}(t)=\delta \times\left(T_{b}-T_{0}(t)\right) /\left(T_{b}-T_{o o}\right) .
$$

If this is substituted into equation (5.16), we obtain the dependence of $\bar{W}^{\circ}(t)$ on $t$. The time-averaged available work, $\bar{W}_{a}^{\circ}$, can be obtained from

$$
\bar{W}_{a}^{\bullet}=\frac{1}{\tau} \int_{0}^{\tau} \bar{W}^{\circ}(t) d t
$$


where $\tau$ is the duration of an ambient temperature cycle (e.g., one year). The time-averaged ideal work differs from the ideal work at the datum point by a factor

$$
\bar{\gamma}=\bar{W}_{a}^{\circ} \bar{W}_{o}^{\circ}
$$

whose instantaneous value is given by

$$
\gamma(t)=\bar{W}^{\circ}(t) / \bar{W}_{\bullet}^{\circ}
$$

This instantaneous work correction factor will fluctuate between a maximum

$$
\sigma_{o}^{+}=\bar{W}_{\max }^{\circ} / \bar{W}_{\theta}^{\circ}
$$

and a minimum

$$
\sigma_{o}{ }^{-}=\bar{W}_{\min }^{\circ} / \bar{W}_{o}^{\circ}
$$

The instantaneous work correction factor $\gamma(t)$ is shown plotted in figure 5.42 for a sinusoidal ambient temperature variation of amplitude $\theta=20^{\circ} \mathrm{C}$, i.e.,

$$
T_{o}(t)=T_{\infty o}+\theta \cos (2 \pi t / \tau) .
$$

The chronogram of figure 5.40 indicates that the positive excursion in $T_{0}$ produces an ideal work deficiency only slightly smaller than the surplus resulting from the negative excursion in $T_{0}$. This is illustrated in figure 5.43 , which shows the dependence of the time-averaged work correction fac-

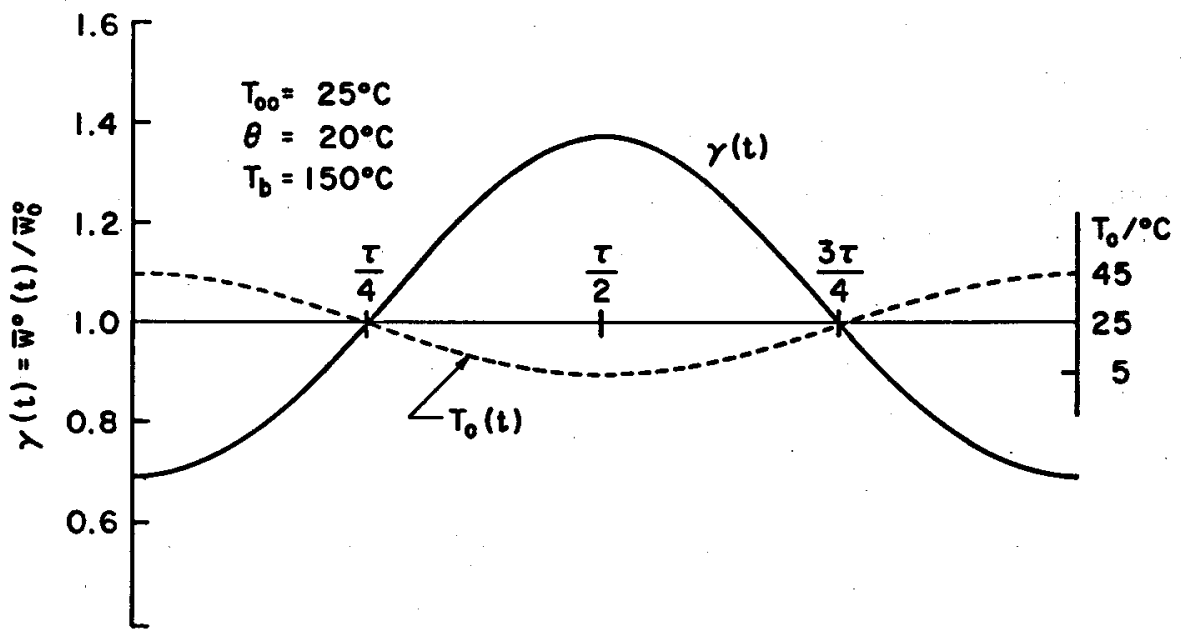

Figure 5.42-A chronogram of the sink temperature and output fluctuations for the Ideal cycle : $\longrightarrow \gamma(t),---T_{0}(t)$. 
tor, $\bar{\gamma}$, on the ambient temperature amplitude, $\theta$, for various geofluid temperatures $T_{b}$. The results, which are almost independent of the temperature difference, $\delta$, indicates that even for an ambient temperature fluctuation of $\pm 15^{\circ} \mathrm{C}$, the time-averaged ideal work does not differ from the ideal work at the datum point by more than $1 \%$.

Figure 5.44 shows a plot of the work fluctuation factors $\sigma^{+}$and $\sigma_{0}$ for $T^{\prime}{ }_{00}=25^{\circ} \mathrm{C}$ and $\delta=10^{\circ} \mathrm{C}$. The lower line $\left(\sigma_{0}^{-}\right)$can be thought of as a measure of the dependable output of the ideal system. It can be seen that for an ambient temperature fluctuation of $\pm 15^{\circ} \mathrm{C}$ the output of an ideal system changes from $82 \%$ of the output at the reference point $\left.\left(T^{\prime}\right)\right)$ to $120 \%$ of the reference output. If the datum point is adjusted upward to the maximum ambient temperature so that the output does not fall at any time below the reference output, the ideal system willl be capable of producing nearly $45 \%$ more work when the ambient temperature is at its lowest value.

\subsubsection{Behavior of actual systems}

In an actual system, the entropy production in the various components of the system results in a lower work output for the same amount of heat added. This means that the amount of heat rejected by an actual system is higher than that rejected by an ideal system utilizing the same geofluid. State-of-the-art binary-fluid systems produce only about $60 \%$ of the available work in the geofluid and, consequently, reject nearly $60 \%$ more heat

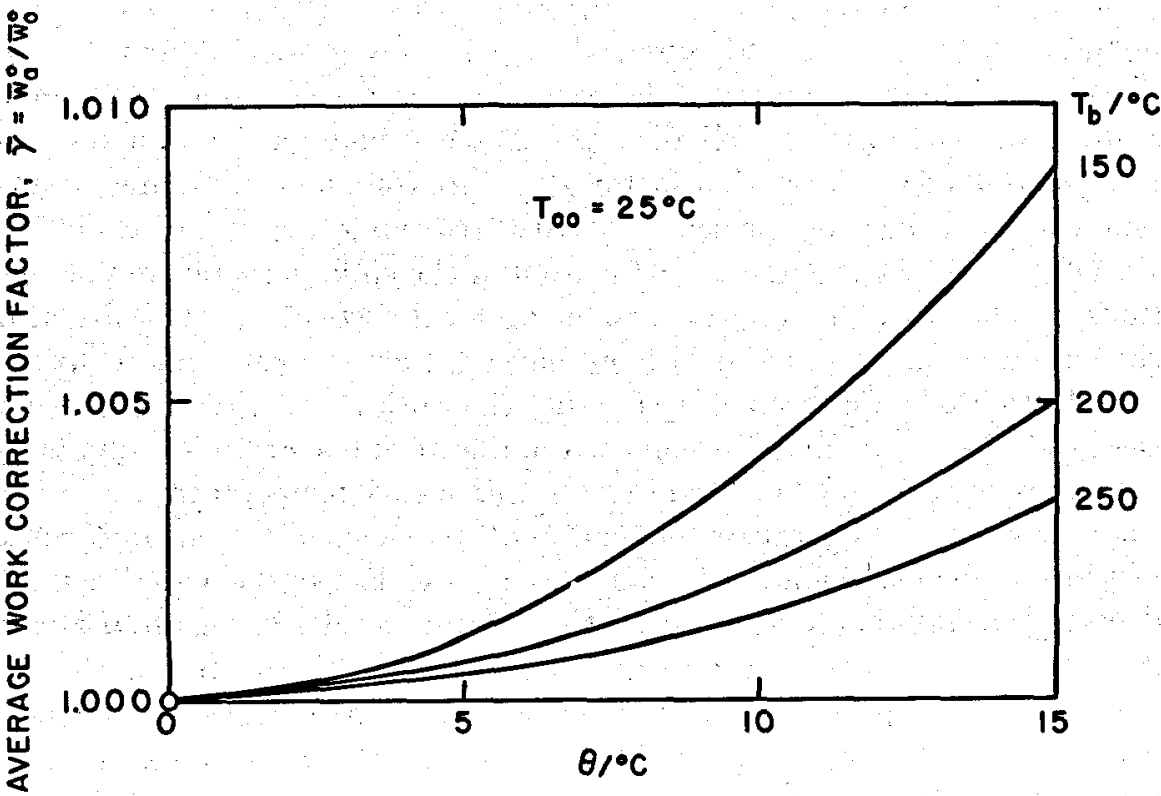

Fraure 5.43-The season-average work correction factor, $\bar{\gamma}$, for the ideal cycle. 


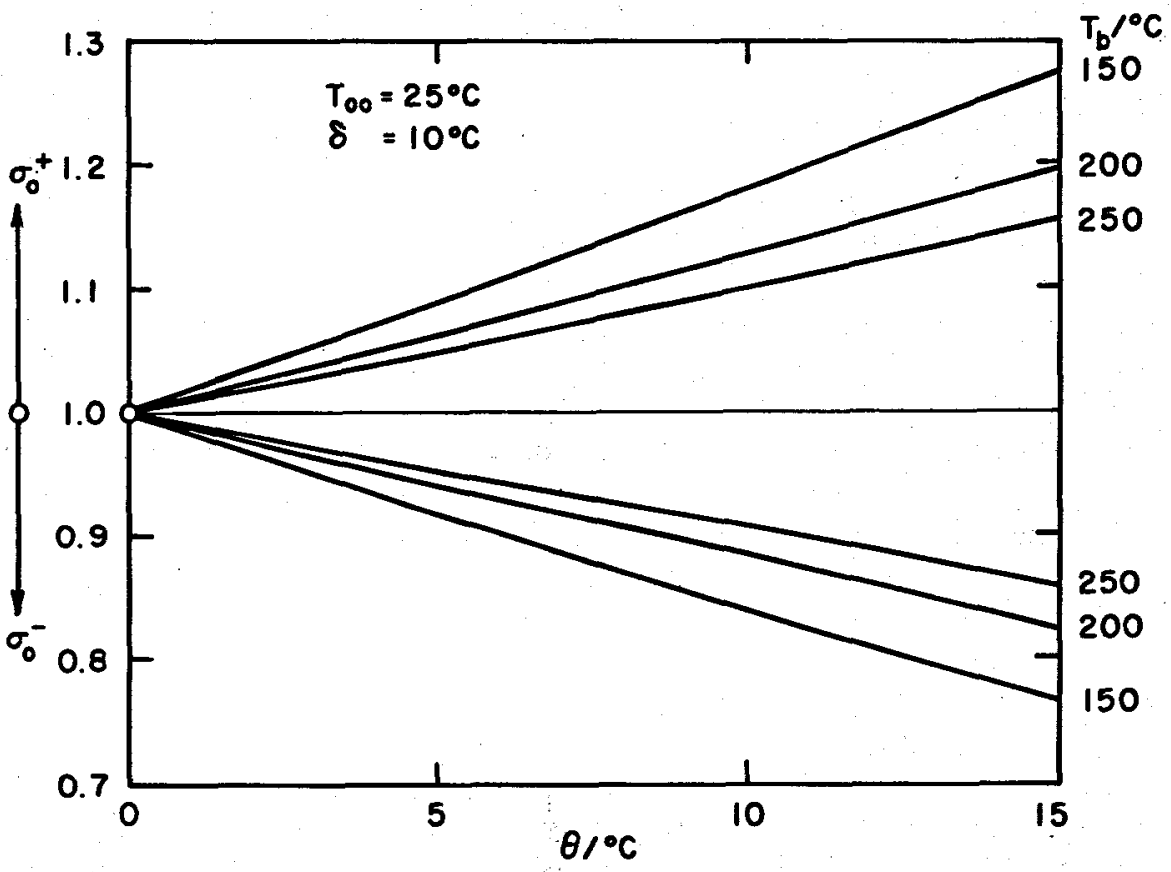

Frgure 5.44-The work fluctuation parameters $\sigma^{+}$and $\sigma^{-}$, for the ideal cycle.

than the corresponding ideal systems. It is to be expected, therefore, that a perturbation in the heat rejection temperature will have a more pronounced effect on an actual system than it has on an ideal system.

An approximate analysis of the heat rejection process in actual binary systems was conducted by Khalifa (1). The maximum and minimum values $\sigma^{+}$and $\sigma^{-}$of the correction factor $\gamma(t)$ were computed for a binary system with a utilization efficiency, $\eta_{u}=0.6$, receiving a goefluid at $200^{\circ} \mathrm{C}$. Figure 5.45 shows $\sigma^{+}$and $\sigma^{-}$as a function of the sink temperature fluctuations, $\theta$. The corresponding results for an ideal system $\left(\eta_{u}=1.0\right)$ are also shown for comparison. It can be seen that in the actual cycle, sink temperature fluctuations can produce up to twice the work fluctuations in the ideal case, the effect being more pronounced in the work loss at higher sink temperatures than in the work gain at the lower sink temperatures. For the example cited, a temperature fluctuation of $+15^{\circ} \mathrm{C}$ produces an $18 \%$ work loss in the ideal case and more than a $31 \%$ work loss in the actual case. A drop in the sink temperature of $15^{\circ} \mathrm{C}$, however, results in a gain of about $20 \%$ and $33 \%$ in the ideal and actual cases, respectively. It can also be noticed that the positive amplitude of the work fluctuations is not much different from the negative one. This should lead to a near cancellation of the effect of the seasonal temperature fluctuations as was found for the ideal case. 


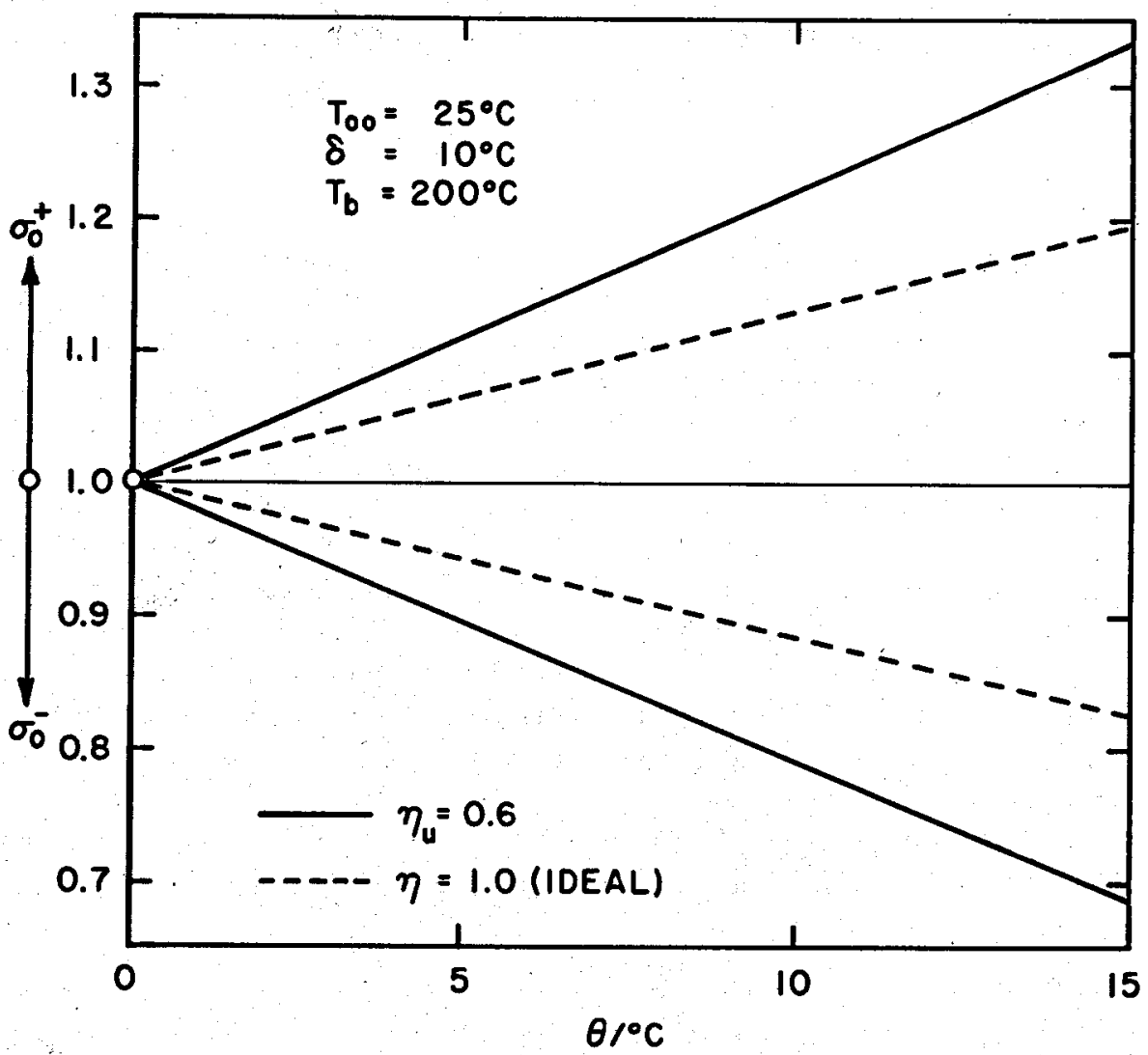

FraURE 5.45--The work fluctuation parameters $\sigma^{+}$and $\sigma^{-}$for an actual cycle. The dashed lines are for the corresponding ideal cycle.

\subsubsection{Choice of the design point}

So far, we have expressed the various fluctuation parameters as nondimensional quantities normalized with respect to the output of the cycle at a datum point. This datum point was chosen as the average sink temperature, $T_{o o}$, for convenience. Naturally, this datum cannot be chosen as the design point if a dependable output is to be guaranteed owing to the considerable loss of output effected by an increase in the sink temperature above the datum. For power plants employing cooling towers, it is customary to design the plant for a wet-bulb temperature that is not exceeded more than $5 \%$ of the time during the summer (June-September) (2). This will have the effect of placing the design output very close to the firm (dependable) output previously defined. For a sinusoidal variation in sink temperature, the design sink temperature $T_{\text {od }}$ nearly coincides with the maximum sink temperature $T_{o o}+\theta$ owing to the flatness of the cosine 
curve at its extrema. If we normalize the various quantities with respect to the design output $W_{d}^{\circ}$ rather than the datum value $W_{0}^{\circ}$ we obtain values of $\gamma(t), \bar{\gamma}$ and $\sigma_{0}^{+}$that are modified by a multiplicative factor

$$
\lambda=1 / \sigma^{-} \text {。 }
$$

This modification results in a much more pronounced effect of the sink temperature fluctuations. For example, at $T_{b}=200^{\circ} \mathrm{C}$ and $\theta=15^{\circ} \mathrm{C}$, the work correction factor of figure 5.43 will increase from 1.005 to 1.218 ; that is an average output that is $22 \%$ higher than the design output. The maximum work for the same căse will be $45 \%$ higher than the design work (the firm output). The chronogram of figure 5.42 will show a unidirectional fluctuation of the output with respect to the design work, i.e., $\gamma(t)$ will always be greater than unity. For the actual system analyzed in an approximate manner by Khalifa (1) the maximum work at $\theta=15^{\circ} \mathrm{C}$ will be about $94 \%$ higher than the design work. The average output over one year will exceed the design output by as much as $46 \%$ at the same value of $\theta$. Figure 5.46 depicts the dependence of $\sigma_{d}^{+}$on $\theta$. It is noted that due to the choice of the normalization factor, $W_{d}^{\circ}, \sigma_{d}$ is unity for all values of $\theta$.

Ambient temperature fluctuations, therefore, have a drastic effect on the potential output of low-temperature power cycjes. The severe excur-

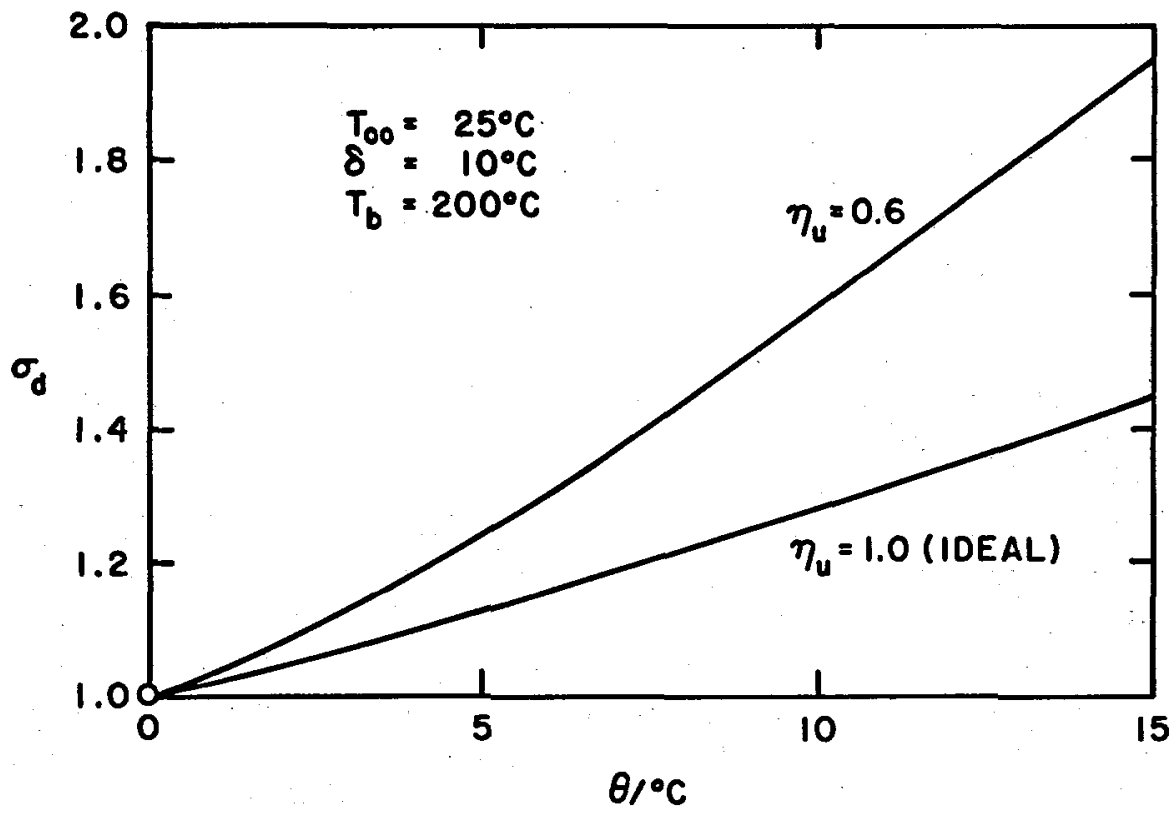

Fraurs 5.46-The work fluctuation parameter relative to design conditions, $\sigma^{+}$. The dashed line is for the corresponding ideal cycle. 
sions in the output are likely to have a strong influence on the design and optimization of systems utilizing low temperature resources. The impact of this on the economics of power generation from geothermal resources should be carefully assessed before choosing among possible energy conversion systems, especially if dry cooling systems or dry/wet cooling systems are to be employed. Two studies of this kind are worthy of mention; one about the effect of floating the heat rejection temperature in binary systems employing wet cooling towers (3), and the other applies the same approach to dry cooling systems (4). In both cases, it was found that there is an economic advantage to be gained by floating the heat rejection conditions rather than designing for the highest ambient wet- or dry-bulb temperatures. These computer studies confirm the conclusion that geothermal power plants need not be designed for the worst heat rejection conditions, particularly if they are to operate as part of a large utility system endowed with sufficient reserve power.

\subsubsection{References}

(1) Khalifa, H. E., 1978. Effect of seasonal variations of ambient temperatures on the performance of low temperature power cycles, Brown University report No. CATMEC/19.

(2) Marks, L. S., 1967. Standard Handbook for Mechanical Engineers, 7th ed., McGraw-Hill, New York, p. 9-94.

(3) Pines, H. S., Pope, W. L., Green, M. A., Doyle, P. A., Silvester, L. F., and Fulton, R. L., 1978a. The thermodynamic and cost benefits of a floating cooling geothermal binary cycle power plant at Heber, California, LBL report No. LBL-7040 (April 1978), also Proc. Annual Meeting of the Geothermal Resource Council, July 25-28, 1978.

(4) Pines, H. S., Green, M. A., Pope, W. L. and Doyle, P. A., 1978b. Floating dry cooling, a competitive alternative to evaporative cooling in a binary cycle geothermal power plant, LBL report No. LBL-7087 (July 1978). 


\title{
Chapter 6
}

\section{Materials Selection Guidelines for Geothermal Power Systems}

\author{
(By M. F. Conover, P. F. Ellis II, and A. M. Curzon*)
}

\subsection{Introduction}

Important to the development of geothermal energy is the effect that corrosion and materials problems can have on efficiency and downtime. Proper materials selection requires a knowledge of process stream characteristics that can contribute to equipment failure. The chemical composition, temperature, and velocity of a geothermal stream vary depending on geothermal source, the power cycle chosen, and even on the point within any given cycle. Further, fabrication practices, equipment configuration, and operating stresses influence materials performance. Results from materials testing using actual geothermal fluids as well as operational experience from existing geothermal power plants can help to provide a basis for materials selection. This chapter is a summary of the report by DeBerry et al. [1978], which should be consulted for details.

\subsection{Geothermal power cycles}

A thermodynamic power cycle is the process employed to extract and utilize geothermal energy to produce electricity. Methods used in the power cycle to produce steam or other vapor to drive a turbine depend on characteristics of the geothermal fluid. Four general types of geothermal resources found in the United States are steam-dominated, liquiddominated, hot dry rock, and geopressured resources. National interest in electric generation is focused on the first two types of resources, and it is these resources for which typical power cycles are described.

Nine generalized power cycles are potentially applicable to steam- and liquid-dominated geothermal resources. They are listed and classified in table 6.1 according to whether the source is steam- or liquid-dominated and whether it is recovered by natural pressure or pumping.

* Radian Corporation, Austin, Tex. 


\section{TABLE 6.1-Potential geothermal power cycles}

Steam-Dominated Sources
- Direct Expansion Cycle
Liquid-Dominated, Natural Pressure Sources
- Single Flash Steam Cycle
- Dual Flash Steam Cycle
- Direct Binary Cycle
- Flashed Steam Binary Cycle
- Two-Phase Expander Cycle
Liquid-Dominated, Pumped Sources
- Direct Binary Cycle
- Flashed Steam Binary Cycle
- Two-Phase Expander Cycle

The power cycles include three major process steps: recovering geothermal fluid from the well, producing steam or other vapor to drive a turbine, and recovering condensate and noncondensable gases. Power cycles differ mainly in the methods used to generate steam or other vapor to drive the turbine. The Rankine Cycle uses steam directly from steam-dominated sources. Single and dual flash cycles employ a change in pressure to separate steam from a liquid-dominated source. Binary cycles use a secondary fluid as an intermediate heat transfer medium. In direct binary cycles, vapor to drive the turbine is produced from the second liquid by heat exchange with the geothermal fluid. In flashed steam binary cycles, steam is separated from the geothermal fluid and used to vaporize the second liquid. Two-phase expander cycles use a mixture of both vapor and liquid from the geothermal fluid to drive the turbine.

Power cycles are also classified based on the method of recovering geothermal fluid from the well. Liquid-dominated resources can be recovered either by natural pressure or by a downhole pump. Recovery by natural pressure has the advantage that little hardware is required down the borehole, reducing the cost and complexity of equipment installation and maintenance. Downhole pumping can be used to increase well production, keep noncondensable gases dissolved, control scaling, and prevent uncontrolled chemical changes in the wellhead fluid caused by flashing during the recovery process. The economic advantage of higher well flow rates from pumping may offset the cost of installation and maintenance of downhole pumps.

In selecting a power cycle for a particular geothermal site, consideration must be given to scaling potential and the concentration of noncondensable gases in the process stream. Scaling tendencies of a given source depend on its temperature and the concentration of certain species, namely silica, calcium, carbonate, sulfate, and heavy metal ions. Scaling affects cycle choice, but requires a number of tradeoffs and cannot be generalized. Noncondensable gases must be continuously removed from condensers and heat 
exchangers. Because of the pump work required to remove noncondensable gases from the turbine condenser, in the United States flashed steam cycles are generally applicable for resources with noncondensable gas concentrations less than $3 \%$ (by weight of steam). Intermediate binary cycles are a useful alternative to the use of gas ejectors and compressors for resources with higher noncondensable gas concentrations.

\subsection{Corrosion modes for metals in geothermal systems}

Corrosive attack of metals can occur in several forms:

Uniform (or general) corrosion-A general, all-over attack of the metal surface. Uniform corrosion is often promoted by chloride, ammonia species, or hydrogen ions, and allowances can usually be made.

Pitting-A localized form of attack such that pits develop in the metal surface. Pitting is ofen associated with the breakdown of a passivation film or surface scale. Initiation and penetration rate of pits are unpredictable.

Crevice corrosion-Similiar to pitting in that it is a localized attack. Unlike most other forms of corrosion, it is geometry-dependent, occurring in fabrication crevices of equipment or under scale deposits. Initiation and penetration rates of crevice corrosion are unpredictable.

Stress corrosion cracking $(S C C)-\mathrm{A}$ catastrophic type of failure promoted by a combination of stress and the presence of chloride ion in the environment. The presence of oxygen and increasing temperature increase the severity of attack.

Sulfide stress oracking (SSC)-Catastrophic failure of high strength steels exposed under stress to environments containing $\mathrm{H}_{2} \mathrm{~S}$ in an aqueous phase. In contrast to stress corrosion cracking, the severity of SSC decreases with increasing temperature and oxygen has little, if any, effect. On the other hand, low pH greatly accelerates failure.

Hydrogen blistering-Occurs in low strength steels exposed to aqueous solutions containing $\mathrm{H}_{2} \mathrm{~S}$. Rupture may occur when hydrogen trapped in voids accumulates at a sufficient pressure. The material need not be under stress for hydrogen blistering to occur.

Intergranular corrosion-Severe localized corrosion at or adjacent to grain boundaries, with little or no attack on the bodies of the grains. The alloy disintegrates (grains fall out) and/or loses its strength. Intergranular corrosion results from improper heat treatment.

Galvanic coupling-Occurs when two dissimilar metals are electrically connected. The less noble material will be attacked. Materials may be ordered in a galvanic series (by increasing nobility) to help in materials selection. Care must be taken since the order of metals may change with variations in chemistry and temperature.

Corrosion fatigue-Occurs when cyclic stresses are imposed on a material in a corrosive environment. The corrosion fatigue limit is the greatest unit stress that may be applied under given conditions of stress, rate of stress application, temperature, and corrosive environment without caus- 
ing it to fail in a given number of cycles of stress (Wescott, 1938). The combined effects of cyclic stress and corrosion are often far more severe than the simple sum of their actions.

Dealloying-The dissolution of one component of an alloy.

Erosion corrosion-Accelerated metal loss caused by impingement of high-velocity fluid, droplets, or particulates. Erosion corrosion can be serious in the wet end of turbines or at sites of two-phase flow.

Cavitation-Accelerated local corrosion promoted by the formation and collapse of vapor bubbles near a metal surface.

\subsection{Corrosive species in geothermal fluids}

Geothermal fluids contain seven key chemical species that produce a significant corrosive effect on metallic construction materials. Some generalizations about the corrosive effects of these species are discussed below :

Hydrogén ion $(p H)$-The general corrosion rate of carbon steels increases rapidly with decreasing $\mathrm{pH}$, especially below $\mathrm{pH} 7$. Passivity of many alloys is $\mathrm{pH}$ dependent. Breakdown of passivity at local areas can lead to serious forms of attack, e.g., pitting, crevice corrosion, and stress corrosion cracking.

Chloride-Chloride causes local breakdown of passive films which protect many metals from uniform attack. Local penetration of this film can cause pitting, crevice corrosion, or stress corrosion cracking. Uniform corrosion rates can also increase with increasing chloride concentration, but this action is generally less serious than local forms of attack.

Hydrogen sulfide-Probably the most severe effect of $\mathrm{H}_{2} \mathrm{~S}$ is its attack on certain copper and nickel-copper alloys. These metals have performed well in sea water but are practically unusable in geothermal fluids containing $\mathrm{H}_{2} \mathrm{~S}$. The effect of $\mathrm{H}_{2} \mathrm{~S}$ on iron-based materials is less predictable. Accelerated uniform attack occurs in some cases and inhibition in others. High-strength steels are often subject to sulfide stress cracking. $\mathrm{H}_{2} \mathrm{~S}$ may also cause hydrogen blistering of steels. Oxidation of $\mathrm{H}_{2} \mathrm{~S}$ in aerated geothermal process streams increases the acidity of the stream.

Carbon dioxide-In the acidic region, $\mathrm{CO}_{2}$ can accelerate the uniform corrosion of carbon steels. The $\mathrm{pH}$ of geothermal fluids and process streams is largely controlled by $\mathrm{CO}_{2}$. Carbonates and bicarbonates can display mild inhibitive effects.

Ammonia-Ammonia can cause stress corrosion cracking of copper alloys. It may also accelerate the uniform corrosion of mild steels.

Sulfate-Sulfate plays a minor role in most geothermal fluids. In some low chloride streams, sulfate will be the main aggressive anion. Even in this case, it rarely causes the same severe localized attack as chloride.

Oxygen-The addition of small quantities of oxygen to a high-temperature geothermal system can greatly increase the chance of severe localized corrosion (especially SCC) of normally resistant metals. The corrosion of carbon steels is sensitive to trace amounts of oxygen. 
Transition metal ions-"Heavy" or transition metal ions might also be included as key species. Their action at low concentrations on most construction materials is ill-defined. However, the poor performance of aluminum alloys in geothermal fluids may be due in part to low levels of copper or mercury in these fluids. Salton Sea geothermal fluids contain many transition metal ions at greater than "trace" concentrations. Some oxidized forms of transition metal ions $\left(\mathrm{Fe}^{+3}, \mathrm{Cu}^{+2}\right.$, etc.) are corrosive, but these ions are present in the lowest oxidation state (most reduced form) in geothermal fluids. Oxygen can convert $\mathrm{Fe}^{+2}$ to $\mathrm{Fe}^{+3}$ which is another reason to exclude oxygen from geothermal streams.

Typical concentrations of the above species in fluid from known geothermal resource areas (KGRA's) are listed in table 6.2.

Scaling or solids deposition is another aspect of geothermal fluid chemistry that influences materials performance. Precipitation of liquid phase species in solution or on equipment surfaces can influence corrosion rates and cause erosion. The composition of the scale-forming solids and the rate of precipitation depend on fluid composition and specific process stream conditions, so scale-forming species are not included in the list of key species.

Weighing the relative significance of the above species is difficult for several reasons. First, the aggressiveness of a particular species varies from one material to the next. Often, the interaction of two or more species can affect materials differently from each species alone. Also, the temperature dependence of corrosion by a given species is often undefined. Finally, the importance of a given species depends on the form of attack.

\subsection{Performance of metals in geothermal systems}

Operating experience and field testing in a variety of geothermal applications can lead to generalizations of material performance. These generalizations are discussed in the following three sections for metals exposed to liquid, condensate, and steam geothermal streams.

\subsection{1-Metals performance in wellhead and flashed liquid streams}

In addition to geothermal operating experience and field tests with geothermal fluids, materials performance data from sea water distillation plants has been considered. (Sea water is somewhat comparable to geothermal fluid.) The primary corrosion modes for each of several classes of metals are discussed below. This discussion is summarized in table 6.3.

6.5.1.1 Mild and low alloy steels. The low cost, availability, and ease of fabrication of low carbon steels (mild steels) make them attractive construction materials for geothermal power plants. However, the reliability 
of these steels depends upon their applications in the power plants. By taking appropriate precautions, mild steels can be used for thick-walled applications in contact with most geothermal fluids. Thin-walled applications will be limited by the susceptibility of these materials to localized attack such as pitting and crevice corrosion.

- Uniform and localized corrosion-Uniform and localized corrosion are the two main modes of corrosion of low strength mild steels in geothermal system. Results of a variety of geothermal field tests indicate that uniform corrosion rates are generally about 1 to $10 \mathrm{mpy}$ (mils per year) when the $\mathrm{pH}$ is greater than 6 and the chloride concentration is less than $2 \%$. (Rapid increase in corrosion rate occurs below $\mathrm{pH} 6$ and above $2 \%$ chloride.) Localized corrosion occurs to some extent in most fluids and becomes predominant in fluids where uniform corrosion is less severe. Chloride ion is the main initiator of localized attack. Hydrogen sulfide can increase the severity of localized corrosion.

Several operating conditions can accelerate the corrosion of mild steels. The introduction of small quantities of oxygen can greatly increase uniform corrosion and initiate pitting and crevice corrosion. High flow rates in conjunction with entrained solids in the stream can cause erosionassisted corrosion. The best flow rate for the use of carbon steels is in the 5-7 fps range.

Scales formed on steel by precipitation from geothermal fluids are porous and prone to cracking. Corrosive attack can occur at these small exposed areas, particularly if the steel is galvanically coupled to a more noble metal.

Mill scale left on steel can accelerate localized corrosion, especially in the presence of chlorides. Protective coatings should be used to minimize uniform and localized attack of exterior surfaces:

- Sulfide stress cracking-Sulfide stress cracking can result in brittle failure of high strength alloys exposed to aqueous $\mathrm{H}_{2} \mathrm{~S}$ while under stress. Resistance to SSC generally increases with increasing temperature, decreasing stress, decreasing yield strength, decreasing $\mathrm{H}_{2} \mathrm{~S}$ concentration, and increasing $\mathrm{pH}$. Steels containing more than $1 \%$ nickel are especially sensitive.

- Hydrogen blistering-Hydrogen blistering occurs in low strength steels exposed to aqueous solutions containing $\mathrm{H}_{2} \mathrm{~S}$ and has been a problem at the Wairakei geothermal plant [Marshall and Tombs, 1969]. Voids are required for blistering and "killed" (void-free) steels resist blistering. Though not necessarily subject to blistering, voids in welds may accumulate molecular hydrogen and burst. Stress is not required for hydrogen blistering.

6.5.1.2 Stainless steels. The uniform corrosion rate of most stainless steels in geothermal fluids is low, but many are subject to the more serious forms of corrosion: pitting, crevice corrosion, stress corrosion cracking, 


\section{TABLA 6.2.-Typical concentrations of key corrosive chemical species in fuid from seven KGRA's}

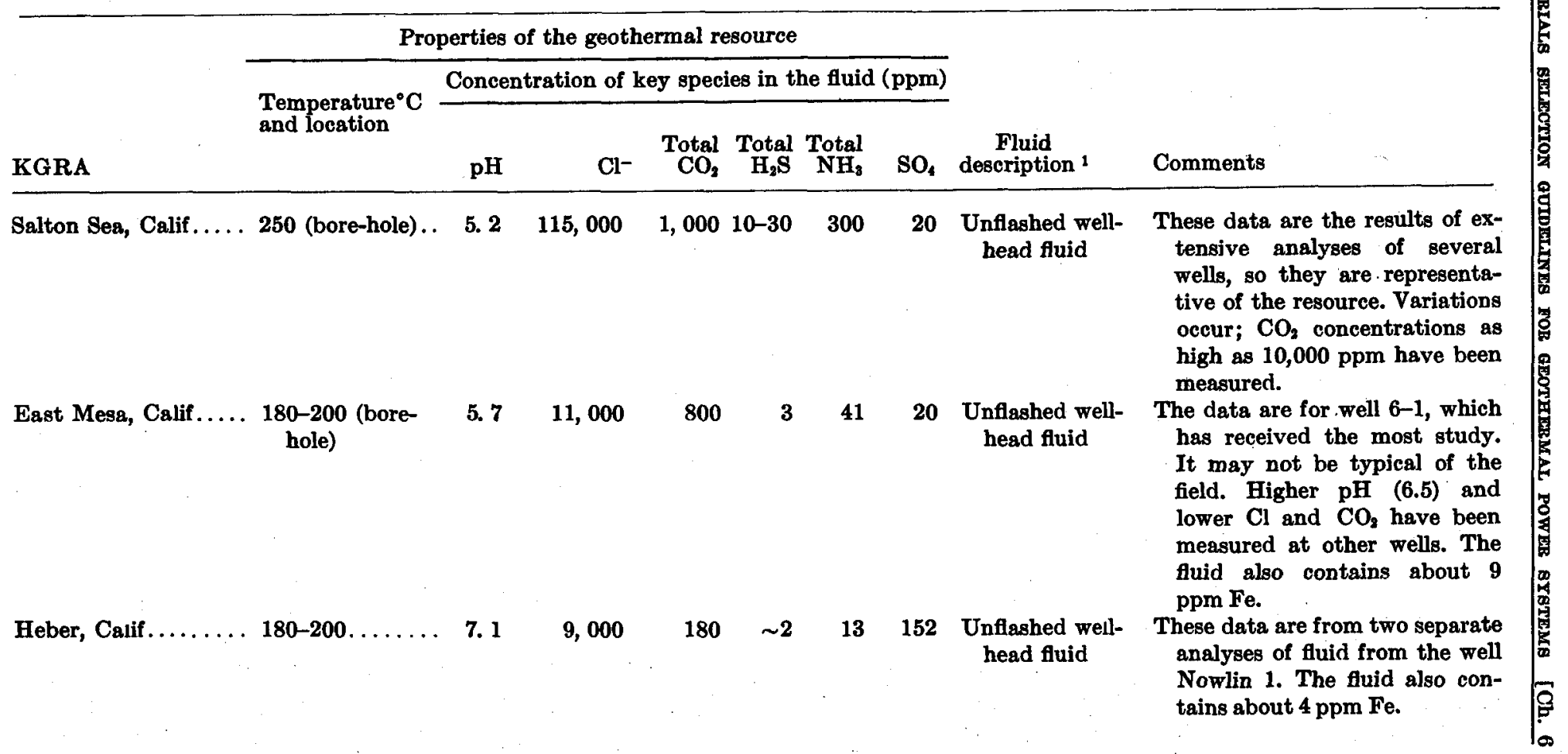



Calif.

\section{Baca (Valles Cal- dera) N. Mex. \\ 171 (well-head at 110 psig)}

6. 8

3, 770

128

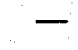

59

Flashed fluid

Beowawe, Nev. ..... 132 (well-head).. 9.3

50

209

6

3

89 Flashed fluid

Raft River, Ind..... 146 (bore-hole).. 7.2

780
60

0. 1
261 Unflashed fluid
These data are for well Endogenous 4. It is the only well for which $\mathrm{H}_{2} \mathrm{~S}$ concentrations were measured. Results of analyses of other specles in fluids from other wells in the area agree with the results for this well.

These data represent the results of three similar analyses of flashed fluid from well Baca II. They are not representative of values in the unflashed fluid.

These data are representative of wells Vulcan 2, 3, and 4. Data for $\mathrm{H}_{2} \mathrm{~S}, \mathrm{CO}_{2}, \mathrm{NH}_{3}$, and $\mathrm{pH}$ are not representative of the unflashed fluid.

These data are for well RRGE 1 which is well characterized. Well RRGE 2 has a similar composition. Well RRGE 3 has a similar composition except for $\mathrm{Cl}^{-}$, which is about 3 times higher.
1 Because these measurements were made at different points (i.e., before or after flashing), the source fluids cannot be directly compared. Often during flashing, chloride concentration increases while $\mathrm{CO}_{2}$ and $\mathrm{H}_{2} \mathrm{~S}$ decrease. An increase in pH will generally result. 
TABLE 6.3.-Forms and causes of corrosion for metals in liquid geothermal strearns and ways to prevent attack

\begin{tabular}{|c|c|c|c|c|}
\hline Material & $\begin{array}{l}\text { Major forms of } \\
\text { corrosion }\end{array}$ & $\begin{array}{l}\text { Main environmental } \\
\text { factors }\end{array}$ & Limits and precautions & Other comments \\
\hline Mild and low alloy steels.. & $\begin{array}{l}\text { Pitting, crevice........ } \\
\text { Sulfide stress cracking. . } \\
\text { Hydrogen blistering.... } \\
\text { Galvanic coupling..... }\end{array}$ & 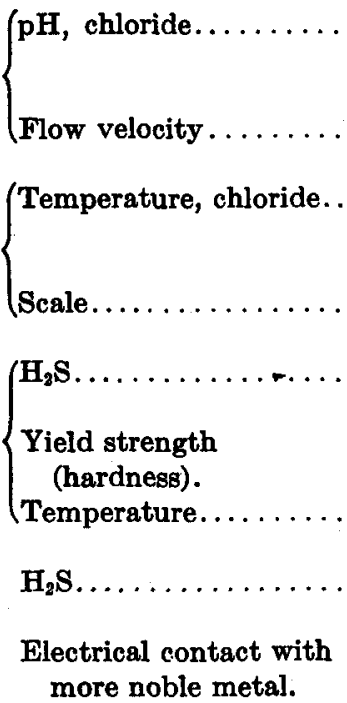 & $\begin{array}{l}\text { Rapid rate increase below } \\
\text { pH6. Rapid rate increase } \\
\text { above } 2 \% \text { Cl. } \\
\text { Limit flow to } 5-7 \text { fps. } \\
\text { Susceptibility increase with } \\
\text { increasing temperature and } \\
\text { chloride concentration. } \\
\text { Remove mill scale; avoid de- } \\
\text { posits. } \\
\text { Can occur at very low } \mathrm{H}_{2} \mathrm{~S} \\
\text { levels. } \\
\text { Use low strength material } \\
\text { wherever possible. } \\
\text { Hazard greater at lower tem- } \\
\text { peratures. } \\
\text { Use void-free materials...... } \\
\text { Avoid coupling close to large } \\
\text { area of cathodic metal. }\end{array}$ & $\begin{array}{l}\text { Complex interactions. } \\
\text { Possible at very low } \mathrm{H}_{2} \mathrm{~S} \text { con- } \\
\text { centrations. } \\
\text { More severe when material has } \\
\text { porous coating or scale. }\end{array}$ \\
\hline
\end{tabular}




\section{Stainless steels:}

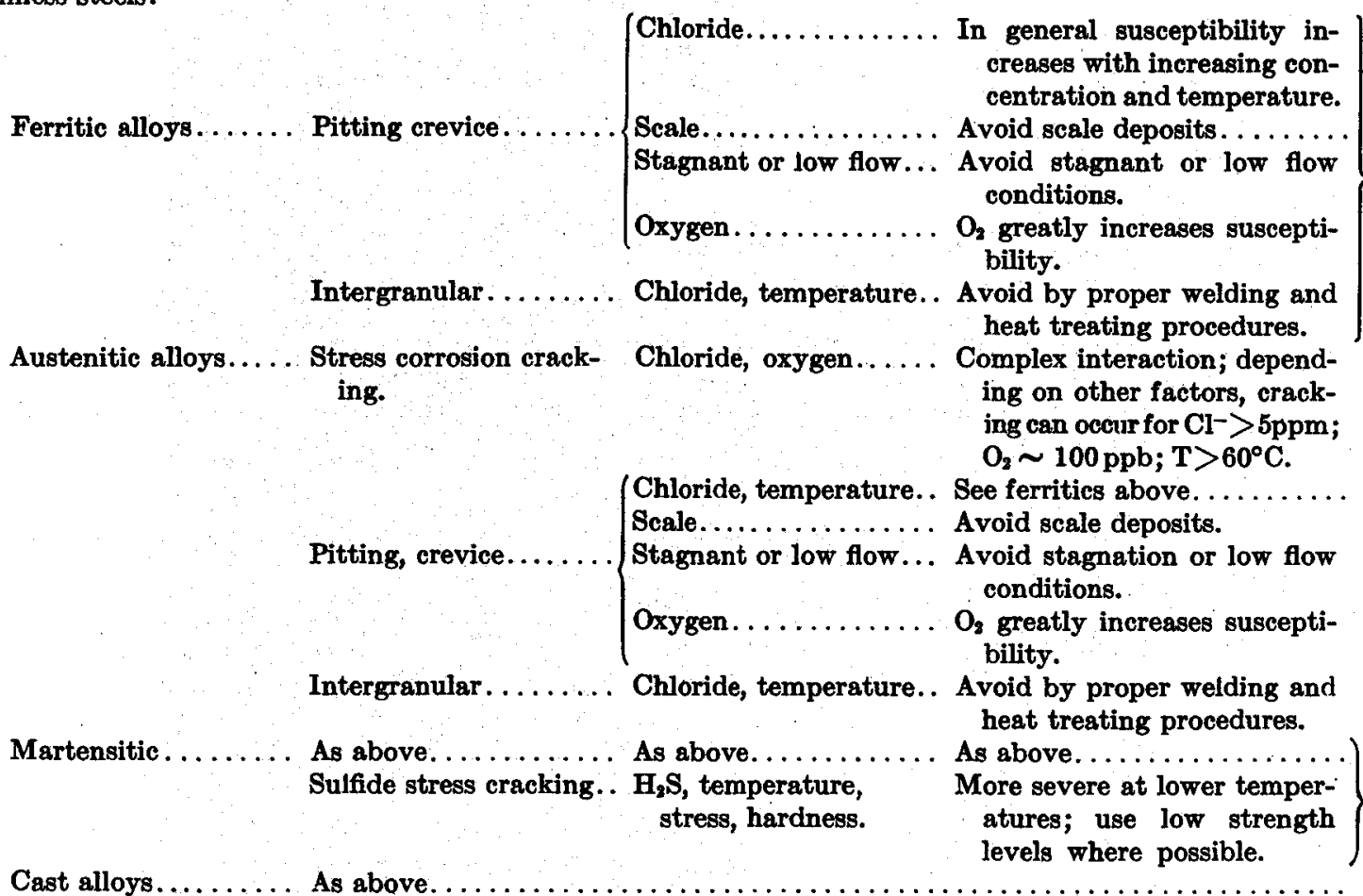

Lower allows may also have high uniform rates in severe environments; $\mathrm{O}_{2}$ is a hazard. Higher alloys are much more resistant; $\mathrm{Cr}$ and $\mathrm{Mo}$ most effective alloying agent.

Hazard increases with increase in $\mathrm{Cl}, \mathrm{O}_{2}, \mathrm{~T}$; some alloys more resistant; protect exterior surfaces.

Resistance increase with Mo content; avoid mechanical crevices.
General corrosion resistance depends on composition.

See comments for equivalent wrought alloy; good crevice corrosion resistance needed for pumps and valves. 
TABLE 6.3.-Forms and causes of corrosion for metals in liquid geothermal streams and ways to prevent attack-Continued

\section{Material}

Major forms of

corrosion

Main environmental

factors

Limits and precautions

Other comments

Titanium alloys

Crevice, pitting.

Chloride, temperature, pH.

Galvanic coupling. .... Electrical contact with

Nickel alloys........ Crevice, pitting..... Chloride, temperature,. Similar to stainless steels ex-

Copper alloys........ Pitting, uniform dealloying.

$\mathrm{H}_{2} \mathrm{~S}$, chloride, temperature.

Ammonia, pH

Other metals: ing.

Cobalt alloys.

Zirconium and Tantalum.

Aluminum ... . . . . Pitting, crevice.
$\mathrm{Hg}_{\mathrm{g}}$ and $\mathrm{Cu}$ ions, $\mathrm{pH}$ chloride, temperature.
Maximum temperature for resistance depends on chloride and $\mathrm{pH}$.

Coupling to large area of more active metal may cause hydrogen embrittlement of $T i$. cept higher alloys more resistant to crevice corrosion; high flow rates.

\begin{abstract}
cause attack.
\end{abstract}
pH and alloy dependence

Avoid galvanic coupling to steel or other active metal.

Several alloys have much better resistance than pure Ti. Precracked $T i$ may undergo stress corrosion cracking.

Resistance depends on alloy composition; may be susceptible to hydrogen embrittlement when coupled to steel. vironment.

Several alloys have good sulfide stress cracking resistance at high strength.

Resistan to low pH, hot chloride solutions:

Poor results obtained in geothermal tests. and construction material. Usefulness limited to $\mathrm{H}_{2} \mathrm{~S}$ en- 
sulfide stress cracking, intergranular corrosion, and corrosion fatigue. Stainless steels have been used in geothermal environments, but care must be taken in their selection and application.

- Pitting and crevice corrosion-Crevice corrosion can be a serious problem in stainless steels since they are frequently used in complex equipment. Susceptibility to localized corrosion increases as the chloride content of the environment increases. Pitting potential increases with increasing temperature.

The pitting and crevice corrosion resistance of stainless steels is strongly dependent on their $\mathrm{Cr}$ and Mo contents. Tests in deaerated artificial sea water indicated increased resistance with the addition of $\mathrm{Cr}$ and Mo [Pessall and Nurminen 1974].

- Stress corrosion cracking-Austenitic stainless steels are susceptible to SCC in hot chloride solutions. Ferritic stainless steels are generally more resistant. SCC depends on chloride and oxygen concentrations, pH, temperature, stress, and alloy composition.

Severity of cracking increases with temperature. For any given concentration of chloride, oxygen, and $\mathrm{pH}$, a "lower critical temperature" exists below which SCC does not occur. Stress is required for SCC, but there is no evident lower critical stress. Time to fracture decreases sharply. at stress at or above the yield point. In the range normally found in geothermal environments, bulk $\mathrm{pH}$ is not a major factor.

Nickel is the constituent having the major effect on susceptibility to SCC in chloride solutions. Immunity from chloride stress cracking is not normally obtained unless the nickel content is less than $1 \%$ or greater than 45\% [Watkins and Green, 1976; Latanision and Staehle, 1967]. Additions of molybdenum and silicon improve resistance to SCC [Lizlovs, 1977 ; Dundas, 1975 ; Loginow et al., 1972].

- Intergranular corrosion-Intergranular corrosion occurs in austenitic stainless steels when they are sensitized (i.e., heated in the $510-790^{\circ} \mathrm{C}$ range) [Fontana and Greene, 1967]. When stainless steels are welded, a zone called the heat affected zone, or HAZ, along each side of the weld is heated into the sensitizing range. $\mathbf{H A Z}$ is a site of intergranular attack, often called weld decay.

Intergranular corrosion can be controlled in three ways. First, the material can be quench-annealed or solution annealed (heated to high temperature, typically $1065^{\circ} \mathrm{C}$ to $1120^{\circ} \mathrm{C}$, and water quenched). $\mathrm{HAZ}$ intergranular corrosion can be controlled by lowering the carbon content below $0.03 \%$. The addition of stabilizers such as niobium or titanium can also help prevent intergranular attack [Fontana and Greene, 1967].

Ferritic stainless steels are also subject to intergranular corrosion, a]though the range of sensitizing temperatures has not been established. The prevention measures described above for austenitic steels generally apply to ferritic stainless steels. 
- Sulfide stress cracking-Martensitic and ferritic stainless steels are susceptible to SSC, while austenitic steels tend to be immune. SSC is more severe at lower temperatures. Low strength steels are more resistant to sulfide stress cracking.

6.5.1.3 Titanium and titanium alloys. Titanium and its alloys have given good results in all but the most extreme environments when tested for geothermal applications. Titanium was used successfully for hydrogen and oil coolers exposed to aerated cooling water/condensate at the Cerro Prieto geothermal facility [Geothermal Resources Council, 1976]. Two other heat exchanger materials had failed in this environment.

- Uniform corrosion-The uniform corrosion rate of titanium and titanium alloys tested in geothermal fluids has been less than $0.3 \mathrm{mpy}$, and under even the worst conditions has not exceeded 5 mpy.

Increasing temperature and chloride concentration do not increase uniform corrosion of titanium alloys. Experience in sea water desalination plants indicates that fluid velocities of $30 \mathrm{fps}$ have no effect on uniform corrosion. Titanium is also very resistant to impingement and cavitation damage [George et al., 1975].

- Pitting and crevice corrosion-No significant local corrosion should occur in environments with less than $10 \%$ chloride. Desalination and chemical process industry experience show that crevice corrosion in tight crevices may be a problem in high-temperature, high-chloride solutions similar to Salton Sea fluid. Pitting may be an occasional problem.

Some titanium alloys are much more resistant to local corrosion than commercially pure titanium. Ti-0.2 Pd and TiCode-12 show particularly good resistance.

- Galvanic coupling and hydrogen embrittlement-Titanium is cathodic to most other metals in saline environments. If the titanium area is large compared to the metal to which it is coupled, the second metal may corrode severely. Since titanium is the cathode in most galvanic couples, hydrogen can be formed on titanium coupled to an active metal. Titanium is capable of absorbing hydrogen and becoming embrittled [Covington, 1977]. Some Ti-Ni alloys are susceptible to hydrogen embrittlement in desalination service [George et al., 1975].

- Stress corrosion cracking-Commercial titanium alloys are not considered to be susceptible to cracking in $3 \% \mathrm{NaCl}$ solutions at ambient temperatures. However, precracked specimens of many fail rapidly in $3 \%$ $\mathrm{NaCl}$ solutions. This behavior indicates that the resistance of some titanium alloys is dependent on the integrity of the protective oxide film and not on the intrinsic resistance of the alloy lattice [Boyd, 1967]. SCC should, therefore, not be a major problem, provided that components are not precracked during fabrication and that the design does not allow excessive vibration of titanium parts. 
The susceptibility of precracked titanium alloys to SCC is adversely affected by aluminum, tin, manganese, cobalt, and/or oxygen content. Some alloys containing more than $6 \%$ aluminum are especially susceptible. Additions of molybdenum, niobium, or vanadium reduce or eliminate the susceptibility to chloride-enhanced propagation of cracks in precracked specimen [Boyd, 1967].

6.5.1.4 Nickel-based alloys. High nickel alloys are frequently used to combat severe corrosion problems. The Ni-Cr-Mo alloys appear to be the most applicable to high temperature geothermal fluids. Inconel 625 and Hastelloy C-276 are particularly resistant to corrosion. They can tolerate very high flow rates and occasional aeration. Similar alloys containing iron in place of molybdenum face competition from the most resistant stainless steels, but may find application where their mechanical properties are desirable. Some nickel-based alloys are susceptible to sulfide stress cracking in the presence of $\mathrm{H}_{2} \mathrm{~S}$, or to cathodic hydrogen embrittlement when coupled to more active metals. Others are very resistant. $\mathrm{Ni}-\mathrm{Cu}$ alloys will have limited usefulness in geothermal streams containing even trace quantities of $\mathrm{H}_{2} \mathrm{~S}$.

6.5.1.5 Copper-based alloys. The use of copper alloys in geothermal fluids is severely limited by the relatively high concentrations of sulfide found in most sources. The Raft River KGRA, with a low sulfide concentration of $0.1 \mathrm{ppm}$, appears to be an exceptional case. Even in this fluid the performance of copper-nickel alloys has been very poor. While some nickel-free brasses and bronzes have performed well in testing, dealloying of some copper alloys has been observed [Miller, 1977].

The cracking of some copper-based alloys while exposed to ammonia or ammonia derivatives is known as "season cracking" [Fontana and Greene, 1967]. Provided $\mathrm{NH}_{3}$ and $\mathrm{NH}_{4}^{+}$levels are low, cracking by ammonia species in the liquid phase of geothermal fluid should be limited to stagnant areas. Susceptibility of copper-zinc brasses to cracking increases with increasing zinc concentration.

\subsubsection{Other metallic materials. A number of other metals and alloys} either may have important specialized but limited uses in geothermal applications or have not shown promise in geothermal tests.

Cobalt alloys may find application in services requiring high strength combined with resistance to sulfide stress cracking and in services requiring wear resistance.

Zirconium and tantalum may be considered for severe, hot acid chloride service such as injection nozzles for acidifying fluid with hydrochloric acid.

Aluminum alloys have not shown good resistance in tests conducted in direct contact with geothermal fluids. Pitting and attack due to galvanic coupling are particularly severe. 


\subsubsection{Performance of metals in condensate streams}

While much of the information given for liquid streams in section 6.5.1 is also appilcable to condensate and steam environments, there are some additional considerations for these streams. The corrosivity of condensate streams depends to a large extent on the following interacting factors.

(a) Efficiency of steam separation and thus the chloride content of the condensate.

(b) Quantity of the flashed noncondensable gases $\mathrm{CO}_{2}, \mathrm{H}_{2} \mathrm{~S}$, and $\mathrm{NH}_{3}$ that are absorbed by the condensate.

(c) $\mathrm{pH}$ of the condensate resulting from absorption of the above gases.

(d) Aeration or mixing with aerated water.

The effects on metals of $\mathrm{pH}, \mathrm{H}_{2} \mathrm{~S}, \mathrm{CO}_{2}, \mathrm{NH}_{3}$, and oxygen described in section 6.4 for liquid streams are applicable here. Although condensate streams have relatively low chloride concentrations, their potential corrosivity should not be underestimated.

For example, assuming $25 \%$ flashing of a wellhead liquid containing $1 \%$ chloride and $0.05 \%$ liquid carryover, the condensate would contain about $20 \mathrm{ppm}$ chloride. This is approximately equal to the minimum chloride concentration needed to cause pitting of plain steels at $25^{\circ} \mathrm{C}$ [Szklarska-Smialowska, 1971]. If the condensate is aerated and the temperature is greater than $60^{\circ}$ to $80^{\circ} \mathrm{C}$, stress corrosion cracking of austenitic stainless steels could occur at this chloride concentration.

\subsubsection{Performance of metals in contact with steam from liquid-dominated sources}

Steam from liquid-dominated geothermal fluids has corrosion characteristics of its own, but general corrosivity is dominated by two properties common to the saline fluid and condensate streams.

Carryover of entrained liquid provides the chloride needed for localized attack. High-velocity impingement of droplets is conducive to localized attack. Efficient steam separation and steam scrubbing are important, but may not preclude attack. For a given steam separation and scrubbing efficiency, corrosivity may depend on the chloride content and corrosivity of the liquid stream.

Areas where local condensation may occur are subject to attack by low $\mathrm{pH}$ condensate containing $\mathrm{H}_{2} \mathrm{~S}, \mathrm{CO}_{2}, \mathrm{NH}_{4}{ }^{+}$and some chloride. Most noteworthy of these locations are the low-pressure turbine section, liquid traps and poorly insulated or stagnant parts of steam transfer sections. The latter should be eliminated by design.

- Corrosion fatigue-Corrosion fatigue is a potential problem in turbines driven by geothermal steam. Tests on carbon steels and low and middle alloy steels in fresh, salt and sea water show that fatigue endur- 
ance limits in a moderately corrosive medium (i.e., salt water) are practically independent of the chemical composition of the steel [Mehdizadeh et al., 1966]. However, variations in steam composition can significantly impact the endurance limit. Increased concentrations of $\mathrm{O}_{2}, \mathrm{CO}_{2}, \mathrm{HCO}_{-s}$, and $\mathrm{H}_{2} \mathrm{~S}$ severely reduce the endurance limit while often causing sulfide stress cracking, pitting, or hydrogen blistering as well. Chloride appears to have no significant effect on the fatigue endurance of low alloy steels.

Stainless steels are more resistant to corrosion fatigue than the low alloy and carbon steels. Chromium is the most effective alloying element in the absence of $\mathrm{H}_{2} \mathrm{~S}$, while nickel is more effective against $\mathrm{H}_{2} \mathrm{~S}$ [Wescott, 1938]. Best results are obtained with a combination of chromium and nickel [Gilbert, 1956]. Molybdenum is also beneficial [Wescott, 1938].

- Exfoliation-Exfoliation of iron sulfide scales from steam lines is another potential source of damage to turbines operating directly on flashed steam. Iron sulfide coatings form on steel pipes carrying steam containing $\mathrm{H}_{2} \mathrm{~S}$. There is a tendency for these coatings to crack and flake off. If this occurs in lines upstream of the turbine, the scale particles can be carried to the turbine causing erosion and possibly erosion-corrosion damage.

A much slower exfoliation of magnetite scales has caused serious damage to turbines in high temperature-high pressure fossil fuel plants. This experience accentuates the need for close monitoring and frequent inspection of geothermal turbines.

\subsection{Nonmetallic materials}

The search for construction materials in geothermal environments has concentrated primarily on metallic materials, but applications of nonmetallic materials are receiving increasing attention. Nonmetallic materials are required in some geothermal operations such as elastomers in drilling operations. In other areas, they may be cost-effective replacements for metallic materials. Nonmetallic materials have some advantages. They are generally resistant to corrosion at conditions that may adversely affect metals and alloys, and their installation costs may be lower than for metals. However, nonmetallic materials are subject to degradation, and geothermal fiuids severely test their durability. Nonmetallics are not useful in heat transfer equipment.

The performance of nonmetallic materials in geothermal environments is in the early stages of investigation, and the test results are somewhat limited. Some comparisons and trends may be found by examining the results of nonmetallics in desalination fluids and from conventional drilling technologies. Nonmetallic materials that may find geothermal application are discussed below.

Concrete polymer composites-The durability of polymer concrete is dependent upon the aggregate composition. Above $218^{\circ} \mathrm{C}$, only polymer 
concrete materials containing mixtures of silica sand and portland cement have been resistant to geothermal brine and steam.

Cements-Polymer concretes and inorganic cements such as $\mathbf{C}-\mathbf{S}$ cements and phosphate-bonded glass cements are being investigated as potential cementing materials. Corrosion resistant cements may also find applications as lining materials.

Elastomers-Research is presently being conducted to evaluate the application of elastomers as packer seals and drill bit cone cutter seals.

Fiber Reinforced Laminates-Fiber reinforced plastic (FRP) laminates may be useful because of their high corrosion resistance and reasonable cost. Their potential applicability is based on tests in desalination environments, and testing in geothermal environments is required.

Additional materials that are potentially applicable for geothermal use include thermoplastics, fiber reinforced plastic and coated pipe, and paint and coatings.

\subsection{References}

Boyd, W. K. "Stress Corrosion Cracking of Titanium and Its Alloys," Fundamental Aspects of Stress Corrosion Cracking, Ohio State University, September 1967, Conference Proceedings, pp. 593ff.

Covington, Loren C., 1977. "Titanium Solves Corrosion Problems in Petroleum Processing," Met. Prog., pp. 38-45.

DeBerry, D. W., P. F. Ellis, and C. C. Thomas, "Materials Selection Guidelines for Geothermal Power Systems: First Edition," Doc. No. ALO/3904-1, Radian Corporation, September 1978.

Dundas, H. J., "Effect of Molybdenum on Stress Corrosion Cracking of Austenitic Stainless Steel," Ann Arbor, Mich., Climax Molybdenum Co., September 1975.

Fontana, Mars G. and Norbert D. Greene, Corrosion Engineering, N.Y., McGrawHill, 1967.

George, P. F., J. A. Manning, Jr., and C. F. Schrieber, "Desalination Materials Manual," Dow Chemical Co., May 1975.

Geothermal Resources Council, Second Workshop on Materials Problems Associated with the Development of Geothermal Energy Systems, El Centro, Calif., May 1976, Proceedings, BuMines OFR 128-76, PG 261 349, Davis, Calif., 1976.

Gilbert, P. T., "Corrosion-Fatigue," Metall. Rev., 1, 379-417 (1956).

Latanision, R. M. and R. W. Staehle, "Stress Corrosion Cracking of Iron-NickelChromium Alloys," Fundamental Aspects of Stress Corrosion Cracking, Ohio State University, September 1967, Conference Proceedings, p. 214ff.

Lizlovs, E. A., "Corrosion Resistance of Types 316 and 317 Stainless Steels in Simulated $\mathrm{SO}_{2}$ Scrubber Environment," J. Electrochem. Soc. 124(12), 1887 (1977).

Loginow, A. W., J. F. Bates, W. L. Mathay, "New Alloy Resists Chloride Stress Corrosion Cracking," Mater. Perform. 11(5), 35 (1972).

Marshall, T. and A. Tombs, "Delayed Fracture of Geothermal Bore Casing Steels," Aust. Corros. Eng., 13(9), 7 (1969).

Mehdizadeh, Parvis, R. L. McGlasson, and J. E. Landers, "Corrosion Fatigue Performance of a Carbon Steel in Brine Containing Air, $\mathrm{H}_{2} \mathrm{~S}$ and $\mathrm{CO}_{2}$," Corrosion, 22(12), 325 (1966).

Miller, R. L., "Results of Short-Term Corrosion Evaluation Tests at Raft River," TREE-1176, DOE Contract EY-76-C-07-1570, EG\&G Idaho, Inc., October 1977. 
Pessall, N. and J. I. Nurminen, "Development of Ferritic Stainless Steels for Use in Desalination Plants," Corrosion, 30, 381 (1974).

Szklarska-Smialowska, Z, "Review of Literature on Pitting Corrosion Published Since 1960," Corrosion, 27 (6), 223 (1971).

Watkins, M. and J. B. Green, "Corrosion Testing of Highly Alloyed Materials for Deep, Sour Gas Well Environments," J. Pet. Tech., 1976, 698-704.

Wescott, Blaine B., "Fatigue and Corrosion Fatigue of Steels," Mech. Eng., 60, 813 (1938). 


\title{
Chapter 7
}

\section{Economic Considerations}

\author{
(By C. H. Bloomster * and P. F. Maeder**)
}

\subsection{Purposes of economic analysis}

There are two related purposes for economic analysis: 1) to determine whether a course of action is worth undertaking and 2) to determine which of several possible courses of action is best. Although the ensuing decisions, in both cases, usually involve judgments of factors in addition to those included in the economic analysis, the economic analysis provides essential information in an organized, systematic framework which has a strong influence on these decisions. It is important, however, to distinguish between the analysis and the decision and to emphasize their separation. Economic analysis is an aid to decision-making and not a substitute for it.

In the development of new technology, technical and economic feasibility become inseparable. The "commercialization" of a new technology usually starts a process of reducing costs and improving performance through design and innovation. Economic considerations guide the direction and magnitude of the technical effort. In the end commercialization is achieved through the efficient organization of labor, materials, and capital to implement the new technology.

A wide variety of economic considerations enter into the commercialization process at different stages. Initially, the concern is with the magnitude of the potential benefits of the new technology and which of the potential development paths offer the best opportunities for both economic and technical success. Cost effectiveness analysis are often employed at this stage. Also, in the very early "conceptual" stages of technology development, economic analyses are used to define performance and cost targets for the research and development programs.

As the development program progresses, the possible paths and design alternatives tend to proliferate. During this period, economic and technica]

\footnotetext{
*Battelle Pacific Northwest Laboratories, Richland, WA.

**Division of Engineering, Brown University, Providence, RI.
} 
feasibility analyses combine to help weed out the least promising paths so that resources can be concentrated on the most promising paths.

As technology approaches the "commercialization" stage, economic analyses strongly influence investment and marketing decisions. Questions on financing alternatives, plant capacity, pricing, expected rate of return, risk and uncertainty must be evaluated.

This chapter deals with the various applications of economic analyses throughout the development of a new technology-from concept to commercialization. Although the analytical techniques tend to vary with the specific application, the analyses share the common purpose of determining and achieving the most efficient allocation of resources. The analytical techniques, which apply to other technologies as well, will be discussed in the context of geothermal energy. Although the treatment is necessarily brief, a bibliography is provided for more thorough study.

\subsection{Basic concepts and terminology}

Basic to the understanding of economic analyses is the relationship between time and money. An immediately available sum is more valuable than the identical sum in the future. Money increases in value with time; money decreases in value when moved backwards in time.

The term discounted cash flow describes the time value of money. The discount rate establishes the relationship between the value of money in one period and another, such that,

where

$$
A=\frac{B}{(1+i)^{N}}
$$

$A=$ value in the reference period

$B=$ value in another period

$i=$ discount rate expressed as a fraction per period

$N=$ number of periods between $B$ and $A$ ( $N$ is positive when $B$ is in the future and negative when $B$ is in the past.)

Usually $N$ is in years and $i$ is thought of as an interest rate per year.

In most economic analyses life cycle costing is used. Life cycle costing simply means that all costs and revenues throughout the life of the project are included in the analyses. For a geothermal development project, these might begin with exploration costs, continuing with field development and power plant construction costs, operating expenses, and taxes, and conclude with reclamation and salvage costs. The costs and revenues for each year constitute the cash flow which, when combined with the discount rate, becomes the discounted cash flow. The preceding equation can be restated to cover multiperiod cash flows as follows:

$$
A=\sum_{N=a, b}\left(\frac{1}{(1+i)^{N}}\right) C_{(N)}
$$


where

$A=$ the cumulative value in the reference period

$C_{(N)}=$ the cash flow in period $(N)$

$a=$ the initial period

$b=$ the final period

$a$ and $b$ must be indexed to the reference period

$i=$ the discount rate

$N=$ the period

Again, usually $N$ is in years and $i$ is the annual interest rate.

The costs and revenues associated with the development of a geothermal resource might occur over a period of $\mathbf{4 0}$ years or more. Typically, costs for exploration, reservoir development and power plant construction occur over a period of several years prior to power production and the generation of revenues. For illustration, the cash flows associated with the Ahuachapán Geothermal Project in El Salvador are shown in table 7.1. This project consists of three power plants (Units 1, 2, and 3) which began operation in 1975, 1976, and 1980 (projected).

TABLE 7.1-Historic and projected life cycle cash flow for the Ahuachapan geothermal project

\begin{tabular}{|c|c|c|c|c|}
\hline Year & $\begin{array}{r}\text { Capitalized } \\
\text { costs } \\
(\$ \text { millions })\end{array}$ & $\begin{array}{r}\text { Operating } \\
\text { expenses } \\
(\$ \text { millions })\end{array}$ & $\begin{array}{r}\text { Power } \\
\text { generation } \\
\left(\begin{array}{c}\text { millions } \\
\mathrm{kWh})\end{array}\right.\end{array}$ & Remarks \\
\hline $\begin{array}{l}1965 \ldots \ldots \ldots \\
1970 \ldots \ldots \ldots \\
1972 \ldots \ldots \ldots \\
1973 \ldots \ldots \ldots \\
1974 \ldots \ldots \\
1975 \ldots \ldots \ldots \\
1976 \ldots \ldots \\
1977 \ldots \ldots \ldots \\
1978 \ldots \ldots \\
1979 \ldots \ldots \\
1980 \ldots \ldots \\
1981 \ldots \ldots \\
1982-1998 \\
1999 \ldots \ldots \\
2000 \ldots \ldots \\
2001 \ldots \ldots \\
2002 \\
2003 \\
2004 \ldots \ldots \\
\end{array}$ & $\begin{array}{r}1.6 \\
1.9 \\
3.1 \\
6.2 \\
13.0 \\
12.3 \\
15.4 \\
2.4 \\
12.3 \\
15.4 \\
4.4\end{array}$ & $\begin{array}{l}0.1 \\
0.5 \\
0.8 \\
0.8 \\
1.0 \\
1.0 \\
1.0 \\
1.0 \\
1.0 \\
0.8 \\
0.5 \\
0.5 \\
0.5 \\
0.5\end{array}$ & $\begin{array}{r}72 \\
279 \\
400 \\
418 \\
418 \\
494 \\
662 \\
662 \\
662 \\
453 \\
264 \\
264 \\
264 \\
264\end{array}$ & $\begin{array}{l}\text { Exploratory drilling. } \\
\text { Deep drilling. } \\
\begin{array}{l}\text { Field development and } \\
\text { construction for units } \\
1 \text { and } 2 . \\
\text { Completion of unit 2, } \\
\text { completion of disposal } \\
\text { canal, and field de- } \\
\text { velopment and con- } \\
\text { struction for unit } 3 \text {. }\end{array}\end{array}$ \\
\hline
\end{tabular}

Present worth refers to the value in the current year of a cash flow stream. In the preceding equation, $A$ is the present worth when the reference period is the current year. Sometimes present worth is used more loosely and refers to the first year of the project life. In this case, $a$ 
in the preceding equation would be zero and correspond to the reference year. At other times present worth may be used to refer to the first year of plant operation when revenues are first generated. The present worth factor is $\left(\frac{1}{1+i}\right)^{N}$ for year $N$.

Future value refers to the value in a future period of a single payment today or of a stream of payments over a period of years. It is identical to present worth except that the reference period is in the future. The future worth factor is the reciprocal of the present worth factor, $(1+i)^{N}$.

Net present value refers to the present worth of a discounted cash flow usually involving both revenues and costs. By convention, revenues are positive and costs are negative.

Internal rate of return refers to that discount rate, $i$, which equates investment costs with net revenues. It usually refers to the earnings rate on equity capital. At the internal rate of return, the net present value is zero. Internal rate of return is frequently used by industry as the measure of the worth of a capital investment and thus serves as a basis for ranking alternative investments.

Effective interest rate (after tax) is a concept frequently employed in discounted cash flow analysis. It comes about because interest on debt is tax deductible. The effective interest rate (after tax) is :

where

$$
i_{(\mathrm{etr})}=(a)(e)+(1-a)\left(i_{d}\right)(1-T X R)
$$

$$
\begin{aligned}
i_{\text {(et) }} & =\text { effective interest rate } \\
a & =\text { fraction equity } \\
(1-a) & =\text { fraction debt } \\
e & =\text { earnings rate on equity } \\
i_{d} & =\text { interest rate on debt }
\end{aligned}
$$

$T X R=$ combined federal and state income tax rate

In many analyses the discount rate is the effective interest rate.

Inoremental costs have two common definitions. In one case they refer to the costs of continuing a project over and above the sunk costs. In the other case they refer to the additional costs (or savings) of an alternative project when compared to a reference project.

Constant dollars refer to dollars of constant value to a reference year. Real dollars, real costs, and deflated dollars are synonomous terms.

In contrast, inflated dollars refer to the monetary values which are affected by inflation. Current dollars and current costs are synonomous terms. Inflated dollars are related to constant dollars by the rate of inflation.

Illustrated in tables 7.2 and 7.3 are cash flows which might be representative of a geothermal power development. The costs in table 7.1 are shown in constant dollars. The costs in table 7.3 show the impact of $5 \%$ annual escalation rate on all costs. In table 7.4 a discounted cash flow 
TABLE 7.2-Illustrative life cycle cash flow for geothermal reservoir and power plant (All costs in constant \$1600)

\begin{tabular}{|c|c|c|c|c|c|c|c|}
\hline Year & $\begin{array}{l}\text { Field } \\
\text { exploration }\end{array}$ & $\begin{array}{c}\text { Field } \\
\text { development }\end{array}$ & $\begin{array}{l}\text { Field } \\
\text { operation }\end{array}$ & $\begin{array}{l}\text { Power plant } \\
\text { construction }\end{array}$ & $\begin{array}{l}\text { Power plant } \\
\text { operation }\end{array}$ & $\begin{array}{l}\text { Cumulative } \\
\text { cash flow }\end{array}$ & Remarks \\
\hline $1 \ldots \ldots \ldots \ldots$ & 100 & & & & & 100 & Initiate exploration. \\
\hline $2 \ldots \ldots \ldots \ldots$ & 200 & . & & & $\ldots$ & 300 & Field geology. \\
\hline $3 \ldots \ldots \ldots \ldots$ & 300 & .. & $\ldots$ & $\ldots \ldots$ & $\ldots \ldots \ldots$ & 600 & Lease acquisition. \\
\hline $4 \ldots \ldots \ldots \ldots$ & 400 & & & 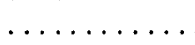 & $\ldots$ & 1,000 & Geophysical exploration. \\
\hline $5 \ldots \ldots \ldots \ldots$ & 1,000 & & & & $\therefore$ & 2,000 & Exploration well. \\
\hline $6 \ldots \ldots \ldots \ldots$ & $\ldots \ldots \ldots$ & 2,000 & & & & 4,000 & Drill production wells. \\
\hline $7 \ldots \ldots \ldots \ldots$ & $\ldots \ldots \ldots$ & 3,000 & & $\cdots$ & & 7,000 & Drill production wells. \\
\hline $8 \ldots \ldots \ldots \ldots$ & $\ldots$ & 3,000 & 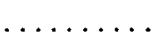 & 5,000 & & 15,000 & Begin power plant const. \\
\hline $9 \ldots \ldots \ldots \ldots$ & $\ldots \ldots \ldots \ldots$ & 3,000 & $\ldots \ldots \ldots$ & 15,000 & & 33,000 & Continue field \& plant const. \\
\hline $10 \ldots \ldots \ldots \ldots$ & $\ldots \ldots \ldots \ldots$ & 2,000 & $\ldots \ldots \ldots$ & 10,000 & $\ldots$ & 45,000 & Complete field \& plant const. \\
\hline $11 \ldots \ldots \ldots \ldots$ & $\ldots$ & $\ldots \ldots$ & 1,200 & $\ldots \ldots$ & 800 & 47,000 & Power plant operation begins. \\
\hline $12 \ldots \ldots \ldots \ldots \ldots$ & $\cdots$ & $\ldots$ & 1,200 & $\ldots$ & 800 & 49,000 & \\
\hline $13 \ldots \ldots \ldots \ldots$ & $\ldots$ & $\ldots$ & 1,200 & & 800 & 51,000 & \\
\hline $14 \ldots \ldots \ldots \ldots$ & 一 & - & - & - & - & - & $\begin{array}{l}\text { Identical operating costs continue through } \\
\text { year } \mathbf{4 0} \text {. }\end{array}$ \\
\hline- & - & 一 & - & - & - & - & \\
\hline- & - & - & - & - & - & - & \\
\hline - & - & - & - & - & - & - & \\
\hline $40 \ldots \ldots \ldots \ldots$ & $\ldots$ & $\ldots$ & 1,200 & $\ldots$ & 800 & 105,000 & Power plant operation ends. \\
\hline
\end{tabular}


analysis is shown for the field exploration cost shown in tables 7.2 and 7.3. For the constant dollar case the discount rate is assumed to be $5 \%$. The equivalent discount rate under $5 \%$ inflation is $10.25 \%$, as shown. Note that the present value is identical in each case.

The inconsistent use of constant dollars, inflated dollars, and different time frames among analyses causes much confusion and makes comparisons of results among alternatives very difficult. This point will be illustrated later.

TABLE 7.3-Effect of Inflation on the Illustrative Life Cycle Cash Flow for Geothermal Reservoir and Power Plant (Costs in $\$ 1000$ from table 7.1 escalated at 5\%/yr)

\begin{tabular}{|c|c|c|c|c|c|c|}
\hline Year & $\begin{array}{r}\text { Field } \\
\text { explora- } \\
\text { tion }\end{array}$ & $\begin{array}{r}\text { Field } \\
\text { develop- } \\
\text { ment }\end{array}$ & $\begin{array}{r}\text { Field } \\
\text { operation }\end{array}$ & $\begin{array}{l}\text { Power } \\
\text { plant con- } \\
\text { struction }\end{array}$ & $\begin{array}{r}\text { Power } \\
\text { plant } \\
\text { operation }\end{array}$ & $\begin{array}{l}\text { Cumulative } \\
\text { cash flow }\end{array}$ \\
\hline & 100 & & & & & 100 \\
\hline 2. & 210 & & & & & 310 \\
\hline 3. & 331 & & & & & 641 \\
\hline & 463 & & & & . & 1,104 \\
\hline $5 \ldots \ldots$ & 1,215 & 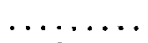 & & . & . & 2,319 \\
\hline $6 \ldots \ldots$ & $\ldots \ldots$ & 2,553 & & & $\ldots$ & 4,872 \\
\hline $7 \ldots \ldots$ & $\ldots$ & 4,020 & & $\cdots$ & .. & 8,892 \\
\hline 8. . & $\ldots$ & 4,221 & & 7,035 & & 20,148 \\
\hline 9 & $\ldots$ & 4,432 & $\cdots$ & 22,162 & & 46,742 \\
\hline 10. & $\ldots$ & 3,103 & $\ldots \ldots$ & 15,513 & & 65,358 \\
\hline $11 \ldots \ldots$ & $\ldots$ & $\ldots$. & 1,955 & $\ldots \ldots$ & 1,303 & 68,616 \\
\hline 12. & $\cdots$ & o & 2,052 & $\ldots \ldots$ & 1,368 & 72,036 \\
\hline- & - & - & - & - & - & 一 \\
\hline- & - & - & - & - & - & - \\
\hline- & - & - & - & - & - & - \\
\hline 40. & & & 8,046 & $\cdots$ & 5,364 & 281,816 \\
\hline
\end{tabular}

TABLE 7.4.-Illustrative discounted cash flow

(Field exploration cost from tables 7.1 and 7.2)

\begin{tabular}{|c|c|c|c|c|c|c|}
\hline \multirow[b]{2}{*}{ Year } & \multicolumn{3}{|c|}{ Constant dollar case } & \multicolumn{3}{|c|}{ Inflated dollar case } \\
\hline & Payment & $\begin{array}{r}\text { Present } \\
\text { worth } \\
\text { factor }\end{array}$ & $\begin{array}{r}\text { Present } \\
\text { value } \\
\text { at } 5 \% \text {. }\end{array}$ & Payment & $\begin{array}{r}\text { Present } \\
\text { worth } \\
\text { factor }\end{array}$ & $\begin{array}{r}\text { Present } \\
\text { value } \\
\text { at } 10.25 \%\end{array}$ \\
\hline & 100 & 1. 000 & 100 & 100 & 1.000 & 100 \\
\hline & 200 & 0.952 & 190 & 210 & 0.907 & 190 \\
\hline & 300 & 0.907 & 272 & 331 & 0. 822 & 272 \\
\hline & 400 & 0.863 & 345 & 463 & 0. 746 & 345 \\
\hline 5. & 1,000 & 0.822 & 822 & 1,215 & 0.677 & 822 \\
\hline Total pres & ent value $i$ & $\operatorname{ar} 1 \ldots$ & 1,729 & & & 1,729 \\
\hline
\end{tabular}

- Discount Rate in Constant dollars $=\frac{\text { Discount Rate Under In }}{\text { Rate of Inflation }}$

$$
1.05=\frac{1.1025}{1.05}
$$




\subsection{Cost accounting}

Proper cost accounting is essential to economic analyses. Cost accounting from the income tax standpoint is usually the most appropriate basis for economic analyses since it accurately reflects the actual cash flow situation. The correct allocation of costs is essential not only to economic analyses, but to cost control and effective decision making. Determining the correct allocation is not a trivial task; correct allocation depends on the purpose and point of view of the analysis. Errors in economic analyses can often be attributed to faulty cost accounting. There are two aspects to cost allocation. First, when more than one product is produced, costs have to be distributed between the products. Second, it is desirable to know what part of the total production costs is attributed to each element of the production process. The cost accounting treatment of the major cost categories used in geothermal energy economic analyses is described below.

\subsection{Definitions}

Capital costs, which refer to assets with a useful life of more than one year, are cash outflows in the year or years that they are incurred. Capital costs are expensed through depreciation, depletion, or amortization charges over the useful life of the assets. To the extent that these charges offset income taxes, they become cash inflows.

Operating costs are incurred each year over the production period. Operating costs are of two types, variable costs and period costs. Variable costs, as previously defined, vary with the level of production and commonly include the labor and materials which enter the final product. Some overheads are tied to the labor and materials and are thus variable costs. Period costs refer to those yearly costs, such as insurance, taxes, interest, and administrative overheads which do not vary with the level of output. Operating costs are expensed in the year incurred; they are cash outflows.

Several types of federal, state, and local taxes affect the cost of geothermal energy. To be useful for decision making purposes, economic analyses usually must include provision for the significant taxes. Of these, the most important is the income tax. Since nearly all costs, including other taxes, are deductible from revenues for income tax purposes, the effect of the income tax rate pervades the entire analysis through its impact on the timing and deductibility of these costs.

Revenue taxes, in various forms, are assessed by state and local governments as a percentage to sales revenues. These are usually important only when they impact differentially the alternatives under study.

Ad valorem taxes, again in various forms, are assessed by state and local governments on the basis of the value of real property. They are important in capital-intensive industries such as geothermal. They are also 
important to natural resource industries, such as geothermal, since the value of the in situ reserves may be subject to tax; this in turn, may affect the relative rates of producing and proving reserves. The bases for assessing these taxes vary sharply from state to state.

Severance taxces are assessed by some state governments on the value or quantity of natural resource production. In this manner, their treatment corresponds to that for a revenue tax. Severance tax rates vary from state to state and resource to resource.

Interest on debt is deductible for income tax purposes. Therefore, the effective interest rate to a company is less than the market rate since the reduction in income tax payments partially offsets the interest payments.

Depreciation is the expensing of capital assets which have a limited useful life. Since the capital costs have already been incurred, depreciation is a partial recovery of the capital costs through the reduction in income taxes. Depreciation thus leads to a cash inflow. The basis for depreciation is usually the useful life of the asset, but the shortest period allowed by the tax regulations is usually preferred by the taxpayer. Depreciation can be accelerated or straight line. Accelerated depreciation, either "sum of the years digits" or "double declining balance," is nearly always used for income tax accounting since it leads to larger earlier tax reductions. For this reason economic analyses usually assume accelerated depreciation. Straight line depreciation is only used for calculational simplification.

Depletion is somewhat analogous to depreciation; however, it applies specifically to the extraction of natural resources. There are two types of depletion-cost depletion and percentage depletion. Depletion allowances result in cash inflows because they are noncash expenses which reduce income taxes.

Cost depletion refers to expensing the asset cost of a natural resource as it is produced. The asset cost is established by the total of the acquisition cost and the subsequent cost of developing the resource for production. The allowable depletion rate per unit of production is the value of the resource divided by the estimated number of units of the natural resource which will be produced. The annual cost depletion expense is the product of the annual production and the depletion rate.

Cost depletion for geothermal energy would apply only to geothermal reservoirs. The lease acquisition cost and the exploration and development costs incurred in preparing the lease for production would form the cost basis for depletion. This cost, divided by the estimated potential geothermal energy production, would yield the allowable rate for cost depletion. The potential production could be expressed in energy units (e.g., Gigajoules) or physical units (e.g., cubic meters or kilograms).

Percentage depletion allowance is the percentage of gross revenues from natural resource sales which can be expensed for income tax purposes. 
Percentage depletion is allowed for most natural resources; the allowablerate varies with each natural resource. Percentage depletion is independent of any cost basis.

Tax regulations permit the taxpayer to elect either cost depletion or percentage depletion, whichever is more favorable. Under the 1978 Energy Tax Act, geothermal deposits are eligible for percentage depletion. The percentage allowed in 1979 is $22 \%$. This rate falls gradually to $15 \%$ for years after 1983.

Intangible drilling costs - Intangible drilling costs for geothermal wells may be expensed in the year incurred. Only the tangible part of drilling costs, generally casing and wellhead equipment, need be capitalized. Intangible drilling costs are usually the greater portion, $60-80 \%$ of the total drilling cost.

Invesiment tax credits are direct reductions, dollar for dollar, in income taxes. The investment tax credit is taken as a percentage of the depreciable capital investment in the first year the asset is placed in service. The allowable percentage, currently $10 \%$ for most qualifying investment, is specified by law.

Royalties are payments to the owners of mineral property. They are usually expressed as a percentage of production or revenues resulting from mineral sales. As such, their treatment is similar to the severance tax.

Salvage value is the value received for a capital asset after the asset is removed from service. It is a cash inflow. Salvage value may affect the depreciation rate.

Working capital is the day to day funds required to run a business. It is defined to be the current assets minus the current liabilities. Inventories are the main variable affecting the working capital requirement. Working capital is nondepreciable. Working capital is recovered through the sale of the assets it represents.

Land is also a nondepreciable capital asset. The value of the land is recovered through its sale, usually at the completion of the project. The difference between the sales price and the purchase price is treated as a capital gain or loss. If the original purchase price includes a bonus for the mineral assets, the bonus can be recovered through cost depletion.

Primary product, coproduct, and byproduct allocation-The proper allocation of costs between products is an important consideration. If a single or primary product is produced, then all costs are allocated to that product. If a byproduct is also produced, then only the incremental costs of preparing and marketing the byproduct are allocated to the byproduct. If coproducts are produced, then some basis must be found for allocating the costs between the products. Oftentimes, no rational and unique basis exists and the allocation is arbitrary. The distinction between a byproduct and a coproduct is generally based on the ability of the primary product to support the costs of production, but this distinction is not always clear-cut or applied consistently. 


\subsection{The income statement}

The income statement (table 7.5) is a useful way to illustrate the relationship between revenues, expenses, taxes, and income. Scanning down

TABLE 7.5. Illustrative income statement

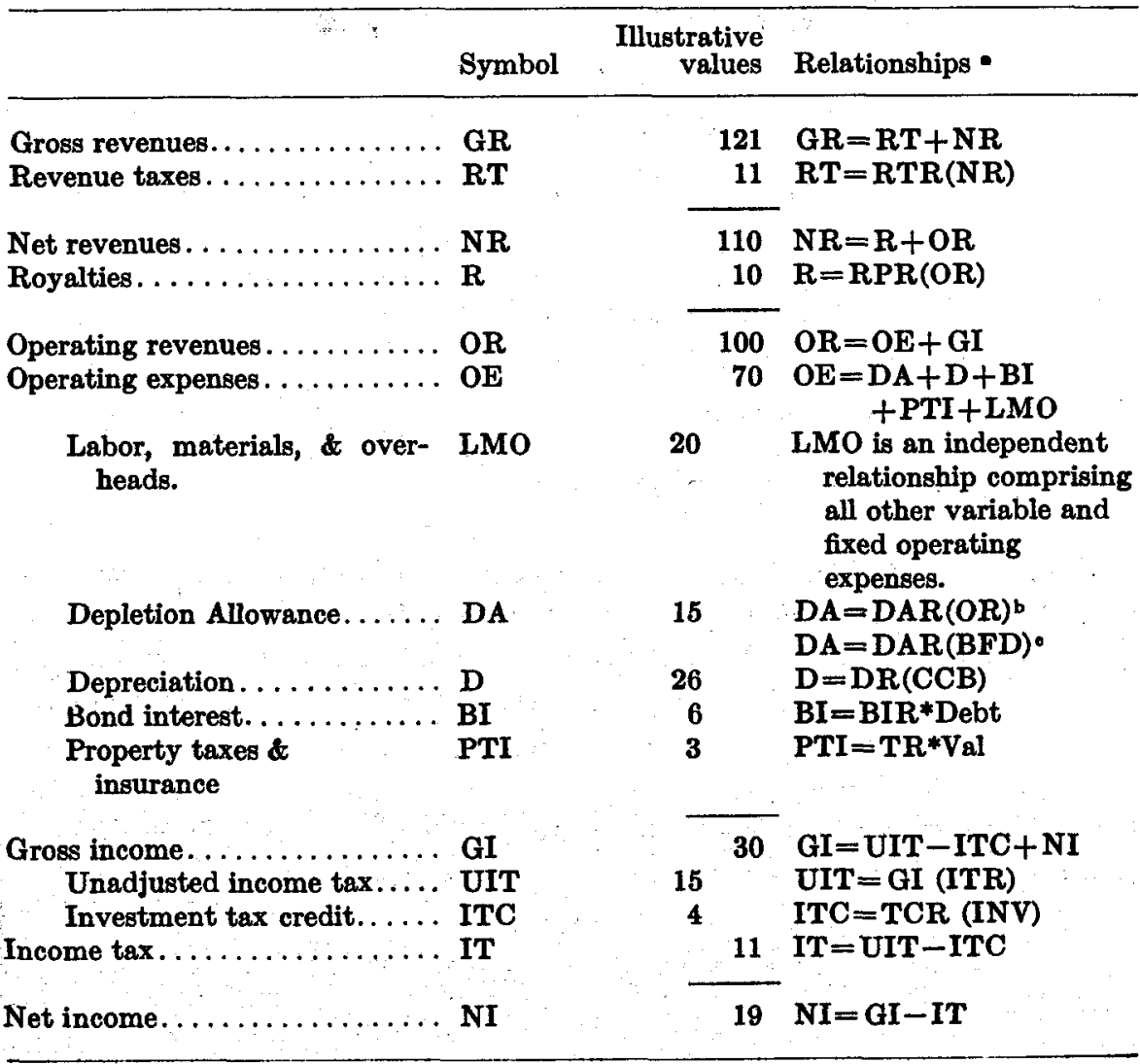

The Return on Equity $=\frac{\mathrm{NI}}{\text { Owners Equity }}$

- New symbols are defined below:

$\mathbf{R T R}=$ Revenue tax rate

$\mathbf{R} \mathbf{P R}=$ Royalty payment rate

$\mathrm{DAR}=$ Depletion allowance rate

BFD $=$ Capitalized cost basis for depletion

$\mathbf{D} \mathbf{R}=$ Depreciation rate

$\mathrm{CCB}=$ Capital cost basis for depreciation

BIR $=$ Bond interest rate

Debt $=$ Principal amount of bonds

TR = Combined property tax and insurance rate

VAL $=$ Assessed cost or other basis for property taxes and insurance

ITR = Income tax rate

TCR = Investment tax credit rate

INV = Investment placed in service

b For percentage depletion.

- For cost depletion. 
the relationships column in the income statement, everything except LMO is seen to be related either to other items in the income statement or to items normally included in the balance sheet. Thus, it is possible to derive the value of an unknown item from other items. For instance, using the first four relationships, royalties, $R$, could be derived from the revenue taxes, the royalty payment rate, and the revenue tax rate, as follows:

$$
R=\left(\frac{R P R}{1+R P R}\right)\left(\frac{R T}{R T R}\right)
$$

For analytical purposes, these relationships are extremely useful. In particular, the fundamental relationship between return on equity, net income, and equity shown at the bottom of the income statement is widely used in cost accounting models since most of the items in the income statement can, in turn, be related to net income.

\subsection{Analytical methods}

\subsubsection{Net present value method}

In this commonly used method, the net present value of an investment is determined by discounted cash flow analyses. The discount rate and the cash flows are specified. By convention, revenues are positive and costs are negative. If the net present value is positive, the actual rate of return on the investment is higher than the discount rate. If the net present value is negative, the return is lower. The return is equal to the discount rate when the net present value is zero. Net present value analysis is illustrated in example A.

EXAMPLE A-Net present value analysis

$\begin{array}{llllr}\text { Year } 0 & \text { Year 1 } & \text { Year 2 } & \text { Year 3 } & \begin{array}{r}\text { present } \\ \text { value }\end{array}\end{array}$

Present worth factor at $\mathbf{1 0}$ percent...............

Revenues...............

Present value............

Costs. . . . . . . . . . . .

Present value...........

1. 000

$\mathbf{0}$

$\mathbf{0}$

$\$ 200$

$\$ 200$

$\begin{array}{rr}.9091 & .8264 \\ \$ 200 & \$ 200 \\ \$ 182.82 & \$ 165.28 \\ \$ 100.00 & \$ 100.00 \\ \$ 90.91 & \$ 82.64\end{array}$

8264

$$
\begin{array}{rr}
7513 & \ldots \ldots \ldots \\
\$ 200 & \ldots \ldots \ldots \\
\$ 150.26 & \$ 497.36 \\
\$ 100.00 & \ldots \ldots \ldots \ldots \\
\$ 75.13 & -\$ 448.68
\end{array}
$$

Net present value

$\$ 48.68$

Obviously, if the specified discount rate is the minimum rate required to undertake an investment, only projects with zero or positive net present values would be undertaken. 
If two or more otherwise identical investments are being evaluated, the investment with the highest net present value would yield the highest rate of return and would be preferred, other things being equal.

\subsubsection{Unit cost determination}

A variant of the net present value method is used to determine the unit cost of energy production. The unit cost of energy is the most common metric used to compare all forms of energy.

The unit cost of energy production can be determined from the expression

$$
U C=\frac{\sum_{N=1, n v} P W_{(N)}\left(\operatorname{Cap}_{(N)}+\operatorname{Exp}_{(N)}+\operatorname{Taxes}_{(N)}\right)}{\sum_{N=1, n y} P W_{(N)}\left(\text { Energy Production }_{(N)}\right)}
$$

where

$$
\begin{aligned}
P W_{(N)} & =\text { the present worth factor in year } N \\
\operatorname{Cap}_{(N)} & =\text { the capital cost in year } N \\
\operatorname{Exp}_{(N)} & =\text { the cash expenses in year } N \\
\operatorname{Taxes}_{(N)} & =\text { the tax payments in year } N \\
\text { Energy Production } & =\text { the units of energy produced in year } N \\
n y & =\text { the economic life of the project } \\
U C & =\text { the unit cost of energy over the life of the } \\
& \text { project }
\end{aligned}
$$

The numerator is the present value of the energy production costs. By transferring the denominator, the left-hand side of the equation becomes the present value of the energy revenues. When the revenues and costs are equated, the net present value is zero, and the rate of return on the project exactly equals the discount rate.

\subsubsection{Internal rate of return}

This is one of the most common methods used in ranking investments. In this method the investment, costs, and revenues must be specified over the life of the project. In order to specify revenues projections of the market price and production over the life of the project must be made. The internal rate of return is the discount rate, $i$, which equates the present worth of the investments to the present worth of the net revenues. Net revenues equal gross revenues minus operating costs. The net revenues may be expressed on a before tax or after tax basis.

$$
\sum_{N=a, n y}\left(P W_{(N)}\right)\left(\text { Investment }_{(N)}\right)=\sum_{N=a, n y}\left(P W_{(N)}\right)(\text { Net Revenues }(N))
$$


where

$$
\begin{aligned}
P W_{(N)} & =\left(\frac{1}{1+i}\right)^{N} \\
a & =\text { initial period of capital investment } \\
n y & =\text { final period of plant operation }
\end{aligned}
$$

Projects with the highest internal rates of return are usually preferred, other things being equal. In many firms, projects must achieve a specified minimum rate of return, sometimes called the hurdle rate, to be considered as a possible investment. Internal rate of return analysis is illustrated in example $B$.

Example B. Internal rate of return analysis-Present Worth of Investment $=$ Present Worth of Net Revenues.

For an investment of $\$ 200$, we will receive $\$ 100$ at the end of each year for 3 years. Calculate the internal rate of return.

$$
(\$ 200)\left(\frac{1}{1+i}\right)^{0}=\$ 100\left(\frac{1}{1+i}\right)^{1}+\$ 100\left(\frac{1}{1+i}\right)^{2}+\$ 100\left(\frac{1}{1+i}\right)^{3}
$$

where, solving for $i$

$$
i=23.38 \%
$$

\subsubsection{Differential analysis}

This is a simplified form of present value analysis in which only the differential impacts of each alternative relative to a reference case are considered. This has two advantages: forcing the analysis on the relevant issues and saving work by eliminating the common elements among the alternatives. It has two potential disadvantages: losing sight of major objectives (seeing the trees and not the forest) and overemphasizing small differences, relative to the total, between alternatives. Differential analysis can also be used with the internal rate of return method.

Differential analyses find application most frequently in the optimization of subsystems as, for instance, in design tradeoff studies.

\subsubsection{Payback period}

This form of analysis was widely used in the past. It has been replaced almost entirely by discounted cash flow analysis. Nonetheless, payback period is still commonly used to describe the relative attractiveness of an investment.

The payback period was defined simply as the length of time it takes to pay back the cash outlays associated with an investment. The payback period analysis did not consider the time value of money. Nor did it consider the earnings after the payback period or the total profitability of 
the investment opportunity. The payback funds were generated from net income either through new sales or decreased costs. The projects with the shortest payback periods were generally preferred. "Rules of thumb," usually 2 to 5 years, were used to set the maximum acceptable payback period for the firm or industry.

\subsubsection{Fixed charge rate}

Discounted cash flow analysis can be simplified by using the fixed charge rate approach. In capital-intensive industries, such as geotherma], most of the costs of production are related to the initial capital investment. These capital investment related costs can be transformed into an equivalent uniform series of annual costs by using the fixed charge rate. In this approach, the initial capital investment is simply multiplied by the fixed charge rate (for example, $20 \%$ or .20) to yield the equivalent annual cost over the life cycle of the project. This is a uniform series somewhat analogous to the uniform monthly payments on a home mortgage.

Usually included in the fixed charge rate are provisions for bond interest payments, return on equity, bond repayments, recovery of equity, income taxes, property taxes and insurance, and interim capital replacement. Maintenance and operating costs might also be included in the fixed charge rate if they can be directly related to the initial investment. Thus, many of the expense items shown in an income statement can be included in the fixed charge rate.

All other annual costs are added to the annualized costs determined by the fixed charge rate (see example $C$ ). Costs of otherwise identical alternatives can be compared on a total annual cost basis; the lowest is best, other things being equal. Or, the total annual cost can be divided by the annual production to determine the unit cost, which can also serve as a basis for comparison.

The appropriate fixed charge rate is unique to a company and a project. The rate depends on the capitalization, bond interest rate, rate of return on equity, effective income tax rate, life of the project, and the appropriate rates for property taxes, insurance, interim capital replacements and any other factors which are included in the fixed charge rate.

Example C. Fixed charge rate-Assume an initial investment of $\$ 1$ million, annual operating costs of $\$ 100,000$, a fixed charge rate of 0.20 , and an annual production rate of 1000 units.

Annual Fixed Charges. . . . . . . . $\$ 200,000$

Annual Operating Costs. . . . . . . . 100, 000

Total Annual Cost.........\$300, 000

Unit Cost of Production. . . . . . . . . $\$ \$ \$ 300$ 
For a given firm and constant project life, the fixed charge rate is fairly constant. For this reason many utilities use it.

The fixed charge rate is calculated in the following manner :*

where

$$
F C R=c r f+\frac{k}{(1-k)}(c r f-t c f)
$$

$F C R=$ the fixed charge rate

crf = capital recovery factor (level annual fraction of initial capita] required to recover investment plus interest)

$$
=\frac{i(1+i)^{n}}{(1+i)^{n}-1}
$$

$t c f=\operatorname{tax}$ credit factor (This converts the uneven sum-of-the-years digits depreciation 'schedule into an equivalent, uniform annual income tax credit.)

$$
=\frac{2}{n(n+1) i}\left(\frac{n}{p w f}-1\right)
$$

$k=$ average income tax rate weighted average of federal and state tax

$p w f=$ uniform series present worth factor $=1 / \mathrm{crf}$

$n=$ economic life of facility in years

$i=$ effective cost of capital to the utility taking into consideration the tax credit for bond interest

$$
=b \cdot i_{b}(1-k)+(1-b) i_{e}
$$

$i_{e}=$ weighted average cost of equity as a fraction (preferred stock and common equity)

$i_{b}=$ bond interest rate as a fraction

$b=$ fraction of capital provided by bonds

This formulation of the fixed charge rate includes recovery of investment, income taxes, bond interest, and return on equity. It can be expanded to include other factors such as property taxes, insurance, and inaintenance, if these can be related to the initial capital investment.

Typical values for the fixed charge rate can vary from 0.12 for utility projects with long useful lifetimes to 0.30 for projects with short useful lifetimes undertaken by firms which rely on higher cost equity financing. Fixed charge rate values outside this range may also apply in some instances.

*The authors are indebted to R. W. McKee, Battelle, Pacific Northwest Laboratories, for this formulation of the fixed charge rate. 


\subsubsection{Analysis using the capital recovery factor}

This form of analysis is widely applied to engineering economic analysis. It is analogous to the fixed charge rate method with the capital recovery factor, as defined above, replacing the fixed charge rate. Since the capital recovery factor does not include provision for income taxes, these analyses usually exclude the impact of income taxes. This type of analysis is appropriate where income taxes are either absent, as with governmentfinanced projects, or not influential to the investment decision. For instance, this method is often used in design tradeoff analyses.

Of course, income taxes can be included in the analysis by adding them separately. In either case, $i$ must be defined consistently in the formula for the capital recovery factor as either a before-tax or an after-tax rate of return. However, income taxes are usually handled more conveniently using the fixed charge rate method.

\subsubsection{Cost effectiveness, benefit-cost, and value analyses}

These types of analyses are very similar applications of life cycle costing and discounted cash flow analysis. Often the terms are used interchangeably without distinction. Cost effectiveness analysis has been so widely applied and debated recently that a detailed theoretical or historical treatment need not be repeated here. A large body of literature has accumulated on the subject in the past decade. The purpose of cost effectiveness analysis is to maximize an economic efficiency, social welfare, or mission objective ( $\mathrm{s}$ ) or some combination of these.

The early use of benefit-cost analysis concentrated on the economic effciency aspects related to the benefits of flood control, reclamation, navigation, and power versus the cost of river basin development projects. In its simplest form, benefit-cost analysis is equivalent to net present value analysis, except that a ratio is obtained rather than a difference; i.e.,

\section{Net Present Value $=$ Present Worth Benefits-Present Worth Costs}

$$
\text { Benefit-Cost Ratio }=\frac{\text { Present Worth Benefits }}{\text { Present Worth Costs }}
$$

The benefits in this case are expressed as monetary revenues or savings and the costs are monetary costs.

During and following World War II, benefit-cost analysis was greatly expanded when applied to problems of cost and military effectiveness and the term cost effectiveness came into widespread use. More recently, there has been further expansion and application to social welfare objectives in the fields of education, health care, environmental impacts, and the abatement of poverty. In most cost effectiveness studies such as those just mentioned, different segments of society often benefit unequally from the 
alternatives being evaluated. Several criteria have been proposed to determine whether society as a whole is better off or worse off. These criteria usually fail to be definitive, and most cost effectiveness analyses are performed from a specific point of view.

In recent years, the definition of benefit-cost analysis has been expanded to include nonmonetary benefits and costs; e.g., environmental impacts, societal impacts, etc. In these cases the common metric, monetary value, is not applicable and the simple benefit-cost ratio cannot be drawn. The expanded definition recognizes the wide impacts that some projects have on many segments of society. The benefit-cost methodology in this case tries to make explicit the wide range of value judgments which enter into these projects and to determine the relationships between monetary costs and alternative (nonmonetary) value judgments, both singly and in combination.

Cost effectiveness analysis is similar, and often synonymous, to the expanded definition of benefit-cost analysis. The purpose of cost-effectiveness analysis is to determine the relationships between costs and the effectiveness of various alternatives to meet certain specified objectives. One of two approaches is usually.employed-a fixed cost approach or a fixed effectiveness approach. In the fixed cost approach each alternative is allocated the same fixed budget to accomplish the objectives of the mission. This is the most common approach when the budget is fixed; the objective is to accomplish the most good with the available funds. The evaluation then seeks to determine which alternative most nearly meets all of the objectives of the mission. Since many different measures of effectiveness are usually involved, the overall ranking of effectiveness requires developing relationships between these measures. The theoretical basis for developing these relationships is found in the concepts of ordinal and cardinal utility theory.

The fixed effectiveness approach is analytically easier to use. In this approach each alternative is developed to the point that it meets all of the objectives of the mission. The alternatives can then be compared simply on cost. This approach is applied to programs and projects in which definitive goals are sets; the objective is to minimize cost.

In some analyses it is not possible to use either the fixed cost or fixed effectiveness approach. In these cases the evaluation of cost effectiveness is dependent on developing a common metric of effectiveness using utility theory or using the concepts of game theory to select the dominant or preferred alternatives.

Combinations of mixed costs and effectiveness are usually analyzed as tradeoffs from a "reference case." That is, the incremental costs of achieving additional levels of effectiveness from the reference case are determined. The fixed cost and fixed effectiveness approaches also usually permit some limited tradeoff analyses around the reference point. 
Value analysis is similar to cost effectiveness analyses. It is usually characterized by developing a common metric, "a figure of merit," to relate one or more attributes. The evaluation then relates the costs to the magnitude of the figure of merit for each alternative.

The points of controversy surrounding these analyses usually center around the basis for assigning relative values to the various benefits, measures of effectiveness, or figures or merit. What is viewed as a value to one segment of society is often viewed as a penalty to another segment. Other points of controversy concern whether the value of the cost effectiveness analysis itself is worth its cost and whether cost effectiveness analysis stifles innovation. In spite of these criticisms, cost effectiveness analyses are among the most commonly used tools of management science and find wide application throughout government and industry.

\subsubsection{Sensitivity analysis}

Sensitivity analysis, also called parametric analysis, allows the analyst and decision maker the opportunity to determine the independent impact of each important factor on the end result. In sensitivity analysis, one parameter is varied incrementally over its expected range of values while all other factors are held constant. In this way, the rate of change in the end result with incremental changes in the parameter is determined. This impact can either be linear or nonlinear. The process is repeated for each parameter under study. Thus, the most significant factors are readily identified. Sensitivity analysis is particularly important in determining the potential impact of known uncertainties on the end result.

\subsection{Sensitivity of geothermal electricity production cost to technical and financial factors}

The sensitivity of power costs to several factors is discussed in this section. The analysis is based on the reference cases given in table 7.6, with

TABLE 7.6-The reference cases

\begin{tabular}{|c|c|c|c|c|c|c|c|}
\hline \multirow[b]{2}{*}{ Case } & \multirow{2}{*}{$\begin{array}{l}\text { Suface } \\
\text { technology }\end{array}$} & \multirow{2}{*}{$\begin{array}{l}\text { Well- } \\
\text { head } \\
\text { temp. } \\
\left.{ }^{\circ} \mathrm{C}\right)\end{array}$} & \multirow{2}{*}{$\begin{array}{l}\text { Well } \\
\text { flow } \\
\text { rate } \\
\left(10^{*}\right. \\
\text { lb/hr) }\end{array}$} & \multirow{2}{*}{$\begin{array}{r}\text { Cost } \\
\text { per } \\
\text { well } \\
(\$ 1,000)\end{array}$} & Plant size & (MWe) & \multirow{2}{*}{$\begin{array}{r}\text { Tota } \\
\text { cost of } \\
\text { power } \\
\text { (mills/ } \\
\mathrm{kW}-\mathrm{hr} \text { ) }\end{array}$} \\
\hline & & & & & Gross & Net & \\
\hline & $\begin{array}{l}\text { Steam; } 2 \text { Plant } \\
\text { Flash } \ldots \ldots \ldots\end{array}$ & 250 & 10 & 500 & of & 53. 0 & 17. \\
\hline & Binary/Isobutane.. & 250 & 750 & 500 & 55 & 46. 1 & 19. 5 \\
\hline & Binary/Isobutane.. & 200 & 500 & 500 & 55 & 44. 5 & 28. 2 \\
\hline & Binary/Isobutane.. & 160 & 250 & 500 & 55 & 45. 9 & 85. 3 \\
\hline
\end{tabular}

- The internal power consumption influences the comparison of these reference cases. The total cost of power from the plant is the generating cost at the busbar for each unit of net output for that system. Power used internally is not available for sale. The internal power consumption is much higher for the binary cycle (Cases $A-b, B$, and $\mathbf{C})$. 
financing and tax assumptions in table 7.7. The discussion is partly based on the analysis given in a previous study. Although the costs change with different conditions, assumptions and rates of inflation, the general trends remain valid, nevertheless.

TABLE 7.7-Financing and tax assumptions

Reservoir (\%) Powerplant (\%)

Capitalization

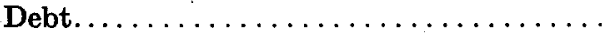

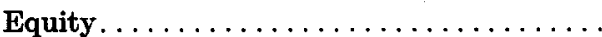

Bond Interest Rate...................

Return on Equity. . . . . . . . . . . . . .

Federal Income Tax Rate................

State Income Tax Rate. . . . . . . . . . . . . . .

Property Tax Rate. . . . . . . . . . . . . .

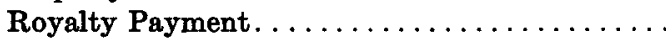

Revenue Tax Rate....................

\section{9}

41

8

12

48

7

2.5

The costs of generating electricity are conveniently divided into two main components-energy supply costs and power plant costs. Power plant costs refer to the capital and operating costs of the power plant, excluding the energy supply, and are sensitive, among other things, to plant size, power cycle, plant efficiency and load factor. Energy supply costs are derived from reservoir development and operation and are analogous to the oil, coal and nuclear fuel costs in conventional power plants. Geothermal energy supply costs are very sensitive to wellhead temperature, well flow rate and well cost. These three parameters determine, to a large extent, the economic value of a geothermal resource.

In order to properly evaluate a geothermal energy supply, it is necessary to examine more closely the role of the temperature of the geothermal fluid, since it is this property which largely determines the value of a given quantity of fluid. While the energy supply costs vary directly with the inverse of the flow rate and are essentially proportional to the well costs, there is no such simple relationship with temperature. In fact, the influence of temperature is the most significant one, and we have to make use of thermodynamics to make the transition from temperature of the geothermal fluid to its value as an energy resource.

\subsubsection{Influence of wellhead temperature}

As the fluid was moving through the geological formation, heat was transferred to it from its surroundings, increasing its temperature and enthalpy. Thermodynamics teaches us that only part, sometimes only a small part, of the energy contained in this enthalpy can be transformed into useful "available" work. The rest of the energy must be "rejected" to 
the environment as part of the functioning of a thermal machine. The energy which must be rejected defines a "dead state" from which no work can be extracted in the environment in which the machine works. Given the temperature, $T_{0}$, and pressure, $P_{0}$, for the "dead state"*, it is possible to calculate, in general terms, the minimum amount of heat that has to be rejected for an ideal system.

Minimum heat rejected : $Q_{\mathrm{RES}}=T_{0}\left(s-s_{0}\right)$

where:

$T_{0}=$ absolute temperature of dead state

$s=$ entropy of geothermal fluid at wellhead

$8_{o}=$ entropy of geothermal fluid at dead state $\left(T_{o}, P_{o}\right)$

The maximum available work, or exergy, of the geothermal fluid at the wellhead is, then, equal to the enthalpy of the geothermal fluid at the wellhead, $h$, minus its enthalpy at the dead state, $h_{o}$, minus the minimum heat rejected. Thus,

$$
\text { exergy: } e=h-h_{0}-T_{0}\left(8-8_{0}\right)
$$

In the case of electricity generation from geothermal resources, the minimum heat rejected, $T_{0}\left(s-s_{0}\right)$, is quite large relative to the available enthalpy, $h-h_{0}$. Thus the exergy; or available work, emerges as the proper measure of the value of the geothermal fluid. The cost of the geothermal fluid per unit mass $(\$ / \mathrm{lb}$ or $\$ / \mathrm{kg}$ ), or its price if it is purchased, therefore, should be based on its excergy. (BTU/lb or $\mathrm{KJ} / \mathrm{kg}$ ) and not on its enthalpy. $\dagger$

*If potential energy is important, as with hydroelectric power, the elevation of the fluid above the "dead state" must also be considered.

†Fossil fuels are traditionally sold on the basis of their enthalpy. This is valid because the exergy of a fossil fuel is very close to its enthalpy of combustion, or heating value. The $T_{\bullet}\left(8-8_{0}\right)$ term, in this case, is very small; in fact it can be positive or negative, depending on the tuel. However, inefficiencies in the electrical conversion process lead to a utilization efficiency of about $40 \%$ for fossil fuels in modern, large power plants. In generating electricity with gas turbines, the utilization efficiency drops to less than $25 \%$. An ideal fuel cell or an ideal thermal conversion plant without temperature limitations or losses could yield a utilization eficiency close to $100 \%$. A geothermal plant could also approach $100 \%$ utilization efficiency (electrical output work/exergy at wellhead) were it not for-losses in flashing, turbines, heat transfer equipment, etc. Geothermal energy, however, cannot be sold on the basis of Its enthalpy alone, as discussed above. It follows also that simple price comparisons between geothermal fluids and fossil fuels, on an enthalpy basis, are invalid. Such comparisons must be based on the end use and must include the cost and efficiencies of the technologies employed. For electrical generation the busbar cost, mills $/ \mathbf{k W h}$, is an appropriate basis for comparison. Since geothermal energy can also be used directly for space heating, as is done widely in Iceland and in other parts of the world, comparisons between the value of a geothermal fluid for heating versus its value for electrical generation must also be based on the end use and the technologies emplojed. In heating, the full amount of energy, the enthalpy $h-h_{0}$, would be available. In electrical generation, only the exergy is available. However, the electrical conversion process can be reversed for heating. Heat can be withdrawn from the environment to 
Table 7.8 illustrates the effect of temperature on the electrical energy produced by a well with a flow rate of $500,000 \mathrm{lb} / \mathrm{hr}$. As the temperature increases from $125^{\circ} \mathrm{C}$ to $250^{\circ} \mathrm{C}$, assuming saturated water at the wellhead, the enthalpy increases by a factor of $2.3(51.5 / 22.0)$, but the energy increases by a factor of $4.4(13.5 / 3.04)$ and the net electrical power generation increases by a factor of $5.7(4.6 / 0.8)$. This clearly points out the extreme sensitivity of the geothermal resource temperature. The $250^{\circ} \mathrm{C}$ geothermal fluid is much more valuable for electrical generation purposes than $125^{\circ} \mathrm{C}$ fluid; much more valuable than the simple enthalpy difference would import.

The net electrical power generation combines the effect of both energy and utilization efficiency. The utilization efficiency, which is a measure of

TABLE 7.8-Effect of temperature on electric production from geothermal wells at flow rate of $500,000 \mathrm{lb} / \mathrm{hr}(63 \mathrm{~kg} / \mathrm{s})$

\begin{tabular}{|c|c|c|c|c|c|}
\hline $\begin{array}{l}\text { Wellhead Temperature. .... } \\
\text { Enthalpy Rate: }\end{array}$ & 125 & 150 & 200 & 250 & ${ }^{\circ} \mathrm{C}$ \\
\hline Maximum $\ldots \ldots \ldots \ldots$ & 26. 5 & 33. 2 & 47. 1 & 61.8 & $\begin{array}{l}\text { MW(Thermal)/ } \\
\text { Well }\end{array}$ \\
\hline Actual * . . & 22. 0 & 27. 7 & 39.2 & 51.5 & $\begin{array}{l}\text { MW(Thermal)/ } \\
\text { Well }\end{array}$ \\
\hline Exergy Rate Actual. & 3. 04 & 4. 59 & 8. 49 & 13. 50 & $\begin{array}{l}\text { MW(Thermal)/ } \\
\text { Well }\end{array}$ \\
\hline \multicolumn{6}{|l|}{ Electric Power: } \\
\hline Gross. . . . . & 1. 0 & 1. 8 & 3. 9 & 5. 5 & MWe/Well \\
\hline Net $b \ldots \ldots \ldots \ldots \ldots$ & .8 & 1.5 & 3. 2 & 4. 6 & MWe/Well \\
\hline \multicolumn{6}{|l|}{ Utilization Efficiency: ${ }^{c}$} \\
\hline Gross ............. & 32. 9 & 39. 2 & 45. 9 & 40.8 & $\%$ \\
\hline Net... & 26. 3 & 32. 7 & 37. 7 & 34. 1 & $\%$ \\
\hline
\end{tabular}

- The maximum is based on the specified well flow rate. The actual is based on the reduced average flow rate using $20 \%$ excess producing wells. Enthalpy and exergy are based on a dead state, or sink temperature, of $25^{\circ} \mathrm{C}$.

b After subtracting internal power consumption.

- For a reference binary isobutane cycle.

(Continued)

heat, let us say, a building by expending only a fraction of the energy delivered in work, as is done commonly by heat pumps. The value comparisons in this case should include the cost, efficiency, and reliability of the delivery of the common end product, e.g., space heat, to the consumer by each of the alternative delivery systems. (See, for example, C. H. Bloomster, L. L. Fassbender, and O. L. McDonald, Geothermal Energy Potential for District and Process Heating Applications in the U.S.-An Economic Analysis, BNWL-2311, Battelle Northwest, Richland, Wash.) In cases in which the potential end uses of the geothermal fluid are diverse, as for instance, space heating for homes versus electrical generation for a mine, value can be determined by comparing costs, efficiencies, and reliabilities of the geothermal system with a reference system, the best substitute energy system, for each end use. The value of the geothermal fluid for each end use is then derived from the relative cost and benefits of the geothermal system compared to the reference system for each end use, by applying the techniques of cost effectiveness analysis. 
inefficiencies in the power plant and generating equipment, increases from $26 \%$ to $34 \%$ over the same range of temperatures for a projected isobutane binary system.

In figure 7.1, the effect of wellhead temperature (assuming saturated liquid) on power cost is shown. As the temperature increases from $150^{\circ} \mathrm{C}$ to $250^{\circ} \mathrm{C}$ (less than doubling the temperature difference to the environment, i.e., $125^{\circ}$ to $225^{\circ}$ ), the power cost is cut to approximately one third. The power cost includes both the energy supply costs and the power plant costs. Not only do the energy supply costs tend to decrease with increasing temperature as discussed above, but the power plant costs also tend to decrease with increasing temperature because less flow is required to generate the same amount of power from higher temperature fluids than from lower temperature fluids. The size, and hence the cost, of much of the power plant equipment, e.g., piping turbine and heat exchangers, is directly related to the fluid flow rate.

\section{7 .8 Flow rate}

Power costs also vary inversely with well flow rate (figure 7.2). Power costs are much more sensitive to flow rate at lower temperatures than at higher temperatures because the thermal to electric conversion efficiency increases rapidly with temperature. As previously mentioned, well flow rate and temperature are two of the most important resource parameters in the cost relationship. The importance of the well flow rate to power cost is that, for a constant temperature, the power production potential from a well is proportional to flow rate. Therefore, the number of wells and the

FiguRe 7.1-Effect of temperature on power cost.

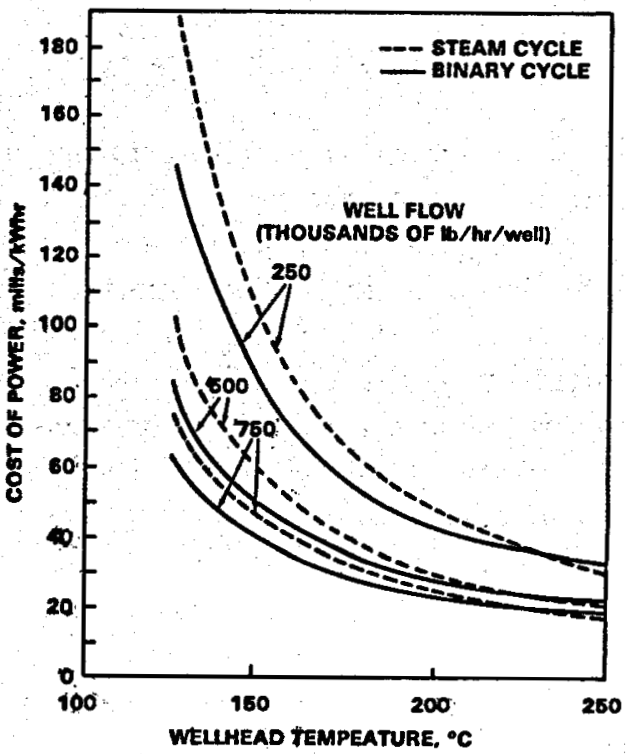




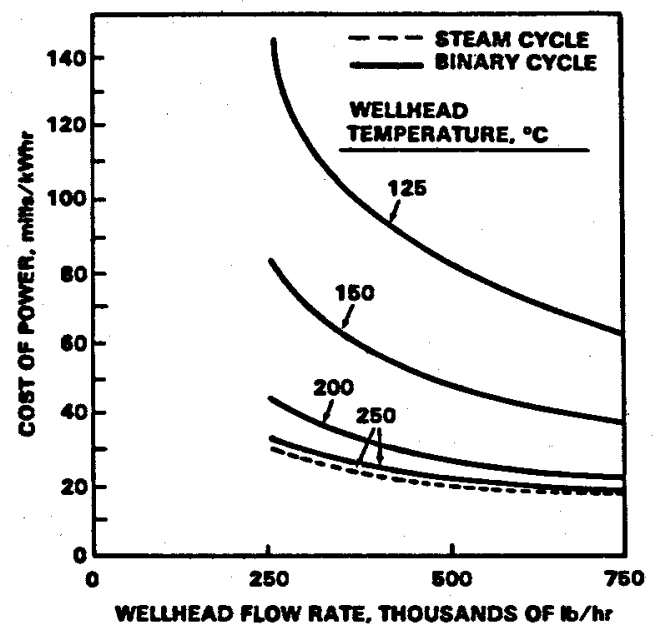

Figure 7.2-Effect of flow rate on the cost of power.

cost of the energy supply to the power plant are directly related to the well flow rate.

The cost of the fluid gathering and transmission system is also related to the well flow rate; for a given power plant capacity, lower flow rates require more wells and an increased length of transmission. This increase results in higher costs for pipes, higher costs for pumping where required, and higher energy losses. This increased cost of fluid transmission related to the number of wells required to supply a power plant effectively limits the maximum economic size of geoethermal power plants as discussed later.

\section{7 .3 Well cost}

Other things being equal, power costs are directly related to the cost of the geothermal wells (figure 7.3). The effect of the well cost is much greater on lower quality (lower temperature and flow) resources. Since temperature and flow, to a large extent, are determined by nature, and since power plant costs, as shown later, are not subject to wide variation, the well cost is probably the single most important determinant of the economic viability of a geothermal resource, particularly a lower temperature resource. The intercepts on the $\mathrm{Y}$ axis in figure 7.3 (where the well cost is extrapolated to zero) show the relatively low variation in power cost attributable to all factors other than well cost for three geothermal resources of widely different quality.

To some extent, the well flow rate can be increased through applying well stimulation techniques such as hydrofracturing, acid leaching, pumping, well workovers and others. The costs associated with stimulation are usually included in the cost of the well, and it is the optimization of well flow versus cost which is paramount. 


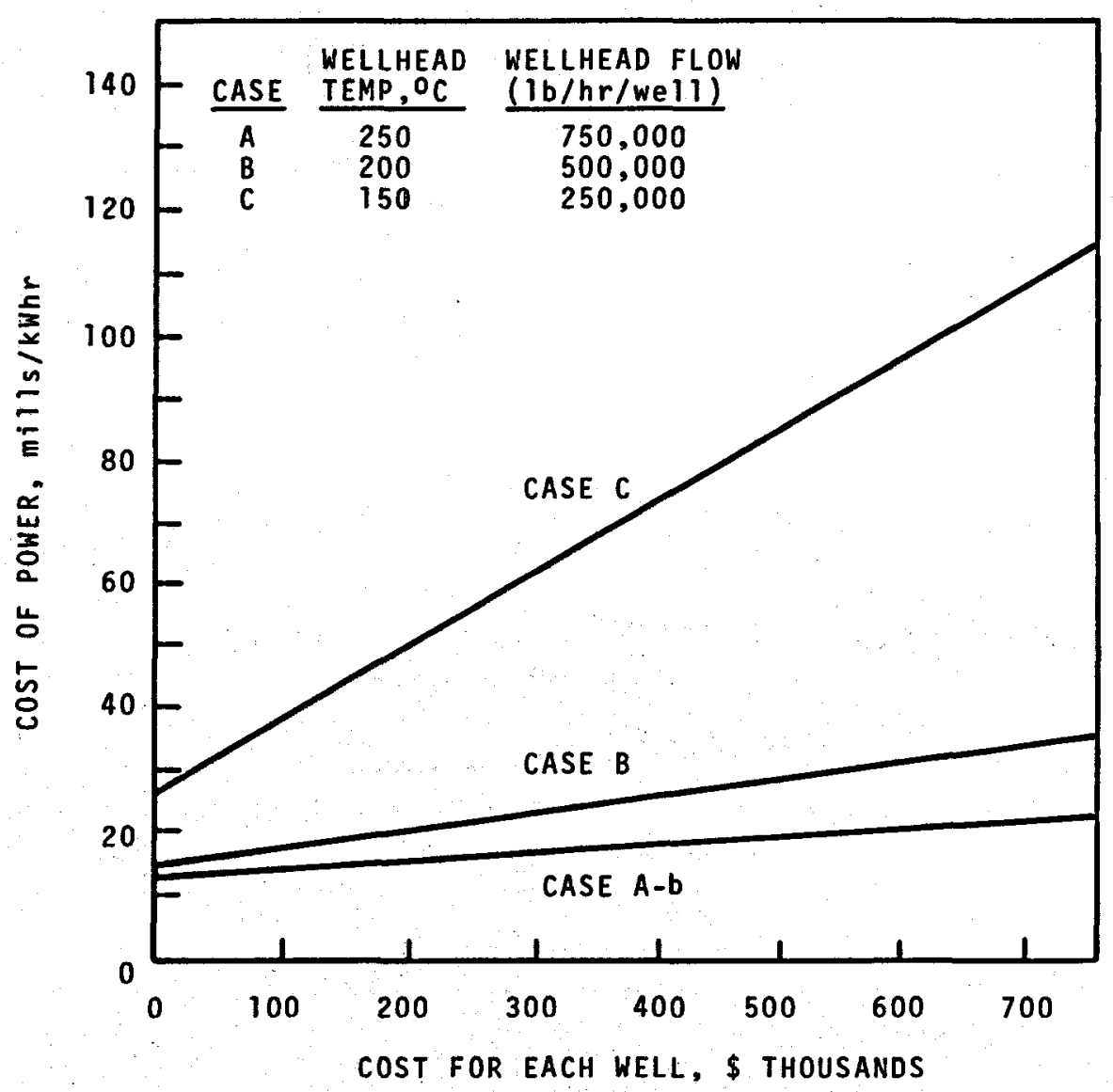

FIGURE 7.3-Effect of well cost on the cost of power.

\subsubsection{Power plant capacity}

Costs decrease rapidly with increasing plant capacity to about $50 \mathrm{MW}$ (figure 7.4). Over $50 \mathrm{MW}$, power costs gradually decline for high-quality resources (e.g., Cases A and B). For low-quality resources (e.g., Case C), a minimum power cost is reached in the 50 to $100 \mathrm{MWe}$ range. The minimum is much more apparent for Case $B$, when a steam cycle with flashing in the field is used. Here the larger, more costly, steam transmission lines lead to a well-defined optimum power plant capacity near $50 \mathrm{MW}$.

The optimum power plant capacity represents an economic tradeoff between the cost of fluid transmission and the economies of scale (figure 7.5) achieved with power plant size. Since larger power plants require more wells, the distance and cost of fluid transmission increases with power plant capacity. The optimum plant capacity, therefore, tends to increase with increasing fluid quality and all other factors which tend to reduce the 


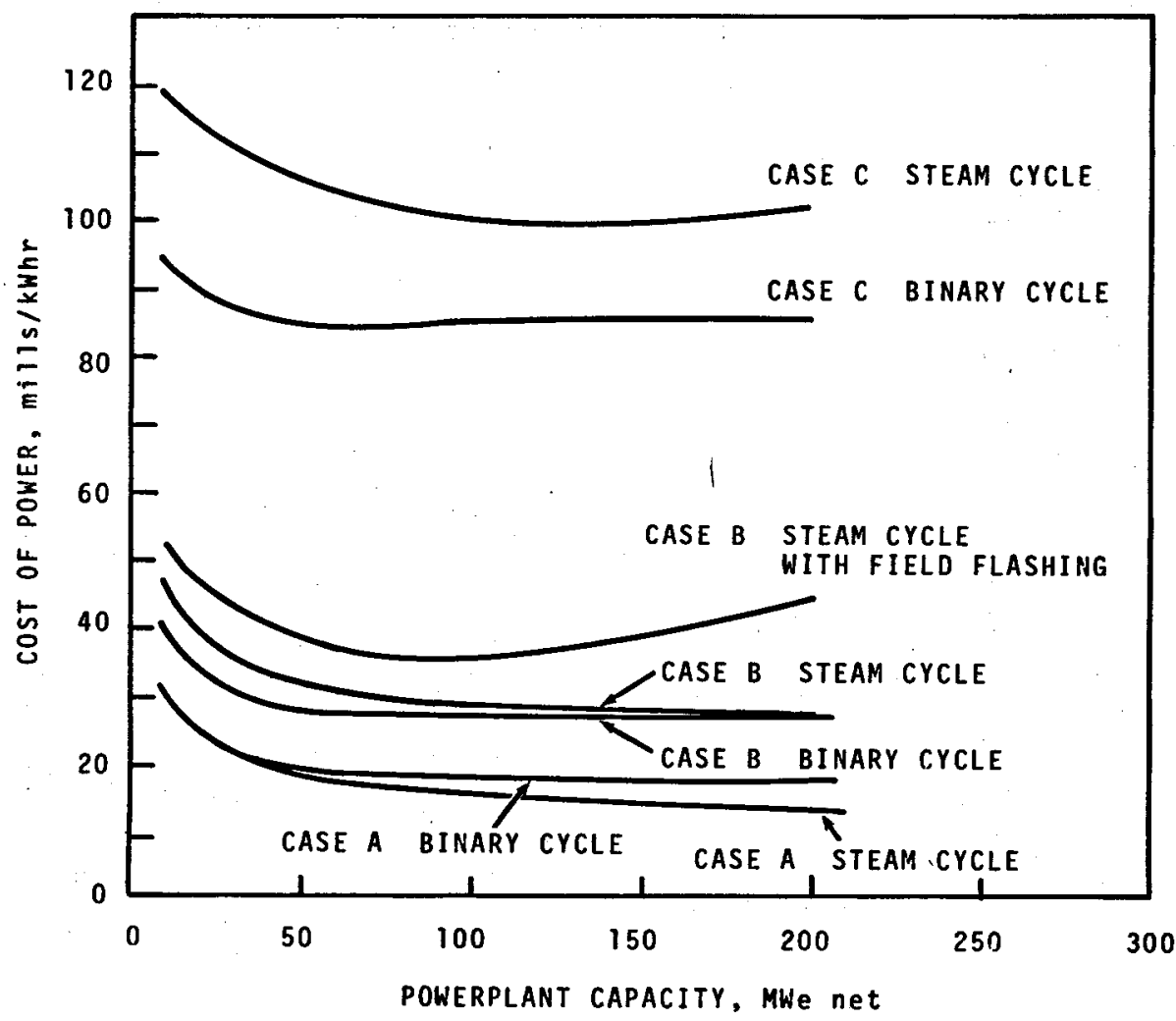

Figros 7.4-Effect of powerplant capacity and power cycle on the cost of power.

cost of the energy supply, such as higher temperature, higher flow rate, lower well spacing, and lower drilling cost.

There have been suggestions that small standardized power plants might be mass-produced in factories for less unit cost than field constructed plants. If so, then the optimum plant size might correspond to the output

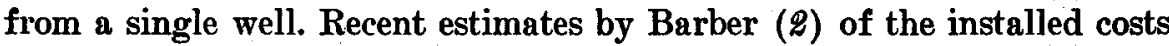
for small Rankine cycle units in production quantities show these units to be potentially attractive for this application. At $1 \mathrm{MW}$ power output, the installed cost was estimated at only $\$+00 / \mathrm{kW}$, excluding heat rejection equipment.

The smaller plants, of course, would incur problems that the larger plants avoid. For example, connecting and dispatching from many small generating sources within a large utility electrical grid would probably cost more than from fewer larger sources. Also, the larger centrally located plant could use one large heat rejection unit. The small plants would each require one of their own which could result in a greater cost. The economic potential for wellhead power plants has not been demonstrated at this time. 


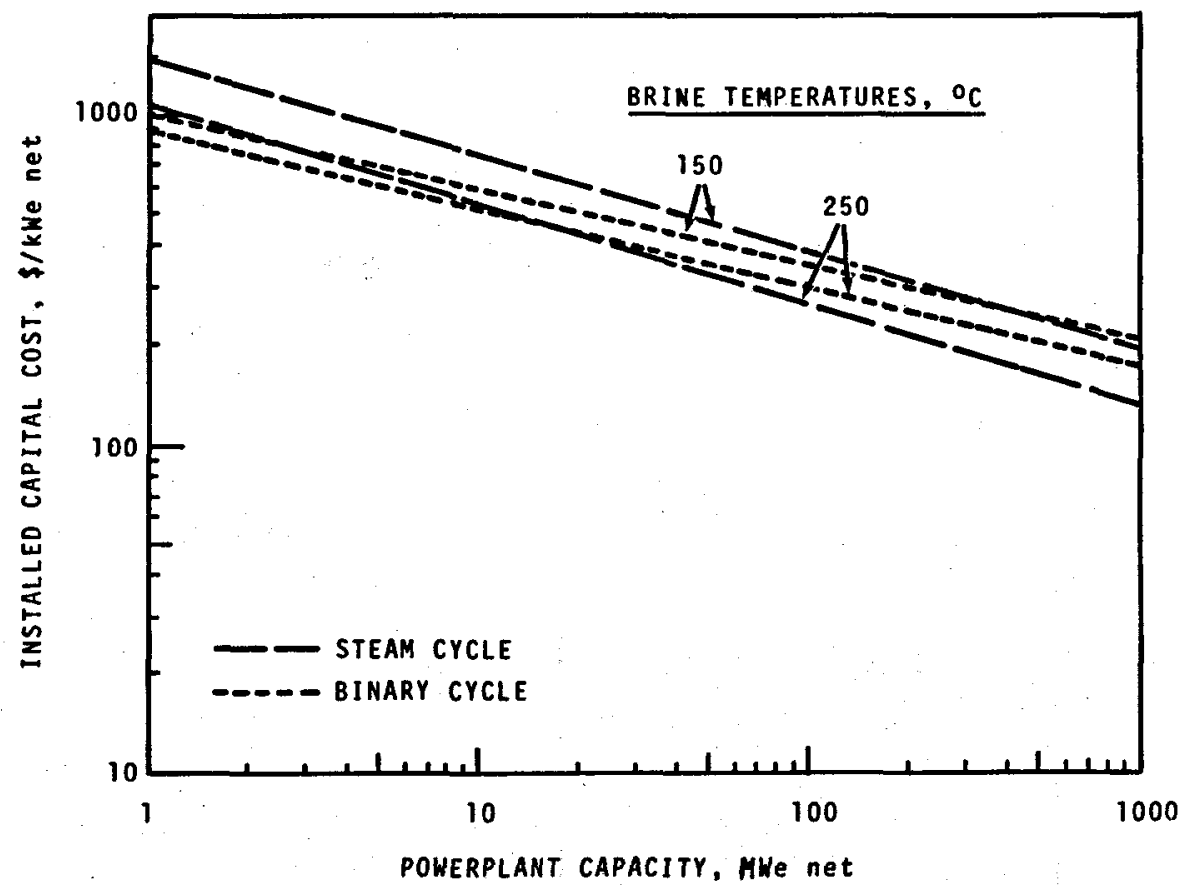

Fuore 7.5-Economies of scale for geothermal power plants.

\subsubsection{Conversion efficiency}

The utilization efficiency determines the amount and, therefore, the cost of geothermal fluid required by the power plant. An increase in conversion efficiency would reduce the quantity of geothermal fluid required in direct proportion. Increases in efficiency might be achieved through reduced losses or greater energy recovery, such as multistage flashing, higher temperature drops across the heat exchanger, or the "total flow" cycle. An optimum efficiency occurs when the reduced costs of the energy supply are exactly offset by the increased costs of the energy recovery system.

Because the cost of the energy supply makes up a greater proportion of the total cost of power in lower quality resources, increases in efficiency are particularly effective in reducing costs for these resources.

\subsubsection{Load factor}

Since a large fraction of the costs associated with geothermal power are fixed costs related to the initial capital investments, the cost of power increases rapidly as the load factor decreases (figure 7.6). For this reason efforts should be made to achieve as high a load factor as practicable. Variable costs which will be proportionally low in most geothermal applications are derived primarily from replacement wells and, hence, are determined by the replacement rate and the well cost. 


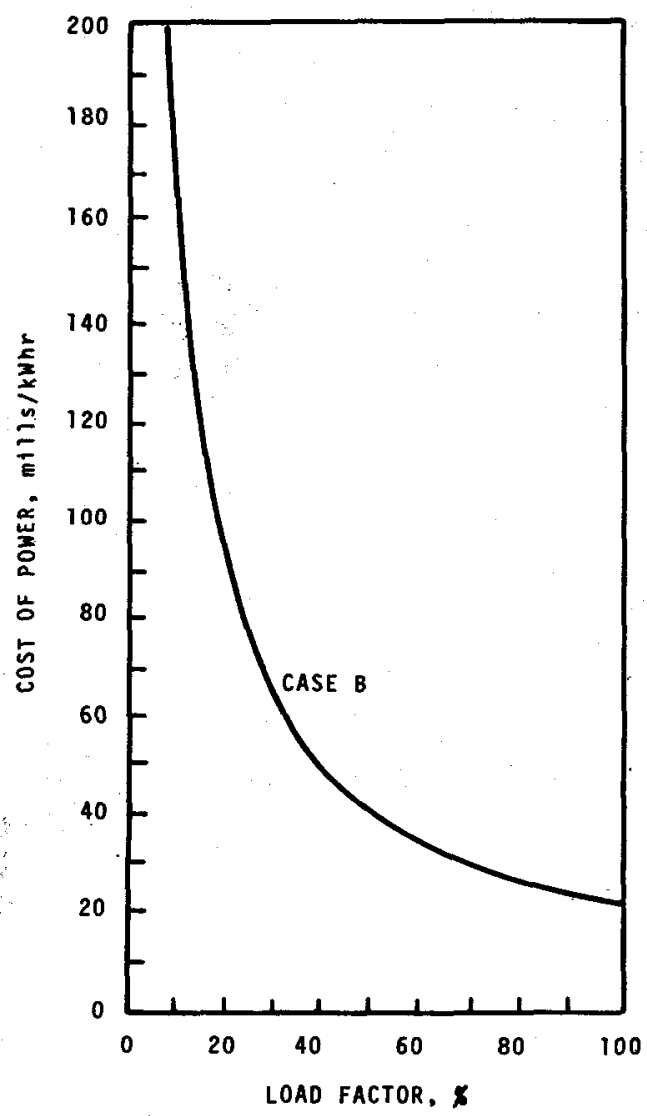

Fraure 7.6-Effect of load factor on unit costs.

\subsubsection{Power cycle}

These analyses considered two power cycles, the binary cycle and flashed steam. The binary cycle is based on isobutane as the working fluid. The flashed steam cycle is based on a double flash at the plant. Under the specified conditions, the isobutane binary cycle appears more economic than the steam cycle below about $225^{\circ} \mathrm{C}^{*}$ (see figure 7.2). Power plants using the steam cycle, however, are closely competitive, running about $10 \%$ higher in total power costs at $200^{\circ} \mathrm{C}$ and $20 \%$ higher at $150^{\circ} \mathrm{C}$. The breakeven temperature and comparative advantage of either cycle could vary over a wide range depending on the relative costs of the energy supply and power plant, the noncondensible gas content, scaling rates, and other factors.

However, because of the lack of experience with binary cycle power plants, there is considerable uncertainty in their capital and operating

*In more recent analyses by one of the authors (C.H.B.) based on new data, this erossover point occurs in the range of $175^{\circ} \mathrm{C}$ to $200^{\circ} \mathrm{C}$. However, the steam and binary cycle still appear closely competitive over the entire temperature range. 
costs and their performance. The sensitivity of power costs to these uncertainties is as follows: A 50\% increase in our capital cost estimates for binary plants would shift the breakeven temperature, at which the power costs for the steam and binary cycles are equal, down to about $200^{\circ} \mathrm{C}$, but this $50 \%$ increase in plant cost would only increase the total power cost by $4.5 \mathrm{mills} / \mathrm{kWh}$ for the $150^{\circ} \mathrm{C}$ resource and even less for higher temperature resources. A decrease in capital cost would have the opposite effect.

Part of the uncertainty in capital costs is related to uncertainties in the rate of scale formation in the heat exchangers. Scale formation reduces the heat transfer coefficient. If frequent cleaning for scale removal is impractical, then a lower design heat transfer coefficient is required. Lower heat transfer coefficients require larger heat exchangers, increasing the capital cost. Uncertainties in the scaling rate could also lead to higher capital costs for spare heat exchangers which might be employed to avoid excessive down time for scale removal.

Uncertainties in power plant operating costs, which are small, would in general, not have a significant impact on power costs-except for uncertainties in the cost of scale removal. Excessive scaling rates could lead to prohibitive operating costs for scale removal. Scaling rates, resulting from silica deposition, would tend to increase with temperature because of the higher silica solubility and greater $\Delta T$ across the heat exchanger.

Uncertainties in the performance of the binary cycle, whether caused by scaling or other factors, might be manifested by a reduction in load factor. The effect of the load factor on power costs is significant as discussed previously.

\subsubsection{Finanoial factors}

The discount rate, which is determined by the cost of capital, has an important effect on the cost of power because of a large proportion of this cost is derived from the initial capital investment. Higher discount rates, of course, imply higher costs for interest and earnings on equity. Higher discount rates also lead to lower present values for future power production.

Because of the capital intensive nature of geothermal energy, inflation in construction costs and well drilling costs has a large impact on the cost of power. On the other hand, inflation subsequent to construction of the power plant and reservoir will have a relatively small effect on power costs because the principal costs are related to the initial capital investment and the subsequent operating costs are low.

Tax policies may also have a significant impact on the cost of geothermal power. In particular, the investment tax credit is effective because of the proportionally large initial capital investment requirement. Tax policies which permit expensing intangible drilling costs are also effec- 
tive in reducing the cost of geothermal energy because a large part of the costs is incurred in drilling wells. Expensing intangible drilling costs is more beneficial with lower quality resources since drilling costs are proportionally higher. Intangible drilling costs relate to the nonsalvageable costs, mainly labor and supplies of well drilling. The percentage depletion allowance is also effective in reducing geothermal energy costs and proportionally more effective with lower quality geothermal resources.

\subsection{Infiation}

The high rates of inflation in the recent past have tended to confound energy cost comparisons. The reference time period, the method of treating inflation, and differences in the anticipated rates of inflation can have a profound effect on the reported costs of otherwise identical situations as the following examples will illustrate.

Example I. Constant dollar analysis in present (1978) dollars with no subsequent inflation-This example covers analyses in which costs are estimated in today's dollars. This method provides comparisons with today's energy prices and with alternatives which are also estimated in today's dollars.

Assumptions: A $100,000 \mathrm{~kW}$ power plant is estimated to cost $\$ 100$ million to build today. It produces power at $70 \%$ plant factor for 30 years. Operating costs are $\$ 2$ million per year. All costs are in constant 1978 dollars. For simplicity, we will assume the power plant is financed under conditions which lead to an annual fixed charge rate of $15 \%$ on the capital investment. (A 15\% fixed charge rate would correspond to project financing at, roughly, a $10 \%$ cost of capital.) What is the cost of power?

Annual Power Production.............

Annualized Capital Cost.............

Annual Operating Cost.............

Total Annual Cost............

$613 \times 10^{6} \mathrm{kWh} / \mathrm{yr}$

$\$ 15,000,000$

$\$ 2,000,000$

Cost of Power.

$\$ 17,000,000$

27.7 mills $/ \mathrm{kWh}$

Example II. Cost of power in constant (1978) dollars with subsequent inflation-This example is similar to example I, except that we will assume that the general level of inflation is $5 \% / \mathrm{yr}$ throughout the entire time period. We will also assume that capital and operating costs escalate at $5 \% / \mathrm{yr}$, which means they remain constant in 1978 dollars. Under the same financing conditions as example $I$, the real cost of capital is lower than the market rate by the rate of inflation, as shown previously in table 7.4. Again, for simplicity, we will assume that this adjustment for the real cost of capital lowers the fixed charge rate to $9 \%$. This corresponds 
roughly to a $5 \%$ cost of capital. The cost of power, in constant 1978 dollars, is shown below under these assumptions.

\begin{tabular}{|c|c|}
\hline Annualized Capital Cost at $9 \%$. & $\$ 9,000,000$ \\
\hline Annual Operating Cost. & $\$ 2,000,000$ \\
\hline ost of Po & $\begin{array}{l}\$ 11,000,000 \\
17.9 \text { mills } / \mathrm{kWr}\end{array}$ \\
\hline
\end{tabular}

The distinctions between example I and example II are important. Example I becomes identical to example II when we assume (1) the cost of capital in example $I$ is in reality expressed in current dollars, and (2) the rate of inflation is identical in both examples. Then, the cost of capital in example $I$ is lowered by the rate of inflation, and the real cost of capital and the cost of power in examples I and II are equal.

Note that in example I the annualized capital cost is constant at $\$ 15$ million/yr, irrespective of the subsequent rate of inflation. The annualized capital cost in example $I$ is based on the actual cost of capital for the example project, and, much like a home mortgage, the constant annual payments are required over the project financing period to cover financing charges and amortization of the investment. The subsequent rate of inflation then determines the real return on capital.* The high rates of inflation in the recent past have led to many capital investment situations in which the real returns on capital have been very low or even negative.

Examples I and II differ only by the anticipated rate of inflation, zero in I and 5\% in II, and the resulting impact on the real cost of capital. As shown, this can have a substantial impact on the calculated cost of power.

\footnotetext{
*The argument is sometimes put forth that the market rate of interest provides for the anticipated rate of inflation; although this argument has some merit over the short term, when viewed in the context of long term capital investments, there is little historical evidence to support this position. The market rate of interest on long term debt responds in a more volatlle manner to the Immediate supply and demand for capital in the classical sense rather than to the long run trend of inflation. For instance, the low Interest rates of the fortles and flftles were poor predictors of subsequent inflation. The rates of return on equity, in either constant or current dollars, appear to respond more to the business cycle and competitive conditions than to the rate of infiation. For example, the rates of return on equity vary substantially from one Industrial sector to another, and, within a sector, the rates of return vary sharply between companies. To further complicate comparisons, the rates of return in financial reporting are commonly expressed as the return in current dollars on the book value of the assets which is based on historic cost. Thus, it should not be assumed that a given market rate of interest or return on equity automatically implies a particular rate of inflation over the life of the asset. Rather, the anticipated rate of Inflation should be explfitly provided for in the analysis. Long-term debt flnancing has some advantages in controlling the cost of capital. If the market rate of interest falls, companies can refinance. In highly leveraged companies, this tends to improve earnings on equity. On the other hand, if the market rate of interest rises, the low interest rates on existing debt are secure until the debt matures.
} 
Example III. Constant dollar analysis in future (1985) dollars-This example illustrates situations in which the desired comparisons are the actual costs at the time at which power plant operation begins (assumed to be 1985 in this example). This type of analysis is particularly important when costs for alternative energy sources are expected to escalate differentially.

Assumptions: The power plant capital and operating costs in example I escalate at $5 \% / \mathrm{yr}$ for seven years. All other assumptions remain the same.

Capital Cost (1985) .

Operating Cost (1985)....................

Annualized Capital Cost at $15 \% \ldots \ldots \ldots \ldots \ldots$

Annual Operating Cost

Total Annual Cost...................
$\$ 140,000,000$

$\$ 2,800,000$

$\$ 21,000,000$

$\$ 2,800,000$

$\$ 23,800,000$

$38.8 \mathrm{mills} / \mathrm{kWh}$

Example IV. Cost of power in inflated dollars in a future year (2014)This type of analysis is used to calculate the future cost of power under specified conditions.

Using the same assumptions as in example III and assuming operating costs continue to escalate at $5 \% \mathrm{yr}$, the cost of power is calculated for the 30th year (2014 in this example) of plant operation.

Annualized Capital Cost (at $15 \%$ ) . . . . . . . . . $\$ 21,000,000$

Operating Cost (2014).................. $\$ \mathbf{\$ 1 1 , 5 0 0 , 0 0 0}$

Total Annual .Cost (2014) . . . . . . . . . $\$ \$ \$ 32,500,000$

Cost of Power..................... 53.0 mills $/ \mathrm{kWh}$

These four examples demonstrate that the reported costs can vary widely for apparently identical conditions. (Examples I and II are not identical.) Therefore, it is imperative when comparing different analyses that they be placed on the same basis. All of the above analyses are "correct," depending on the assumptions and timeframe adopted. The selection of the "correct" method depends on the definition or purpose of the analysis.

\subsection{References}

(1) C. H. Bloomster and C. A. Knutsen. "The Economics of Geothermal Electricity Generation from Hydrothermal Resources." BNWL-1989. Battelle, Pacific Northwest Laboratories, Richland, Wash., 1976. (The reader is referred to this report for more detailed assumptions and other sensitivity analyses.)

(2) R. C. Barber. "Solar Powered Organic Rankine Cycle Engines-Characteristics and Costs." Proceedings, Eleventh Intersociety Energy Conversion Engineering Conference, State Line, Nev., vol. II, p. 1154, Sept. 12-17, 1976. 


\subsection{Bibliegraphy}

The following works may be helpful in amplifying certain aspects of this chapter:

W. J. Baumal, Economic Theory and Operations Analysis. Prentice-Hall, 1965.

C. H. Bloomster, et al., GEOCOST: A Computer Program for Geothermal Cost Analysis. BNWL-1888, Battelle, Pacific Northwest Laboratories, Richland, Wash., February 1975.

J. M. Campbell, Petroleum Reservoir Property Evaluation. Campbell Petroleum Series (2), Collier Drive, Norman, Okla. 73069, 1973.

P. C. Fishburn, Decision and Value Theory. John Wiley and Sons, Inc., 1964.

Hinrichs and Taylor, Program Budgeting and Benefit-Cost Analysis. Goodyear Publishing Co., Pacific Palisades, Calif., 1969.

Charles T. Horngren, Cost Accounting-A Managerial Emphasis. Prentice-Hall, Inc., Englewood Cliffs, N.J., 1972.

Richard A. Johnson, et al., Operations Management-A Systems Concept. Houghton Mifflin Co., Boston, Mass., 1972.

A. Kaufmann, The Science of Decisionmaking. McGraw-Hill, 1968.

R. D. Luce and H. Raiffa, Games and Decisions. John Wiley and Sons, Inc., 1958.

Lyden and Miller, Planning, Programming, Budgeting: A Systems Approach to Management. Markham Publishing Co., Chicago, Ill., 1971.

P. D. Newendorp, Decision Analysis for Petroleum Exploration. The Petroleum Publishing Co., P.O. Box 1260, Tulsa, Okla. 74101.

Stanley P. Porter, Petroleum Accounting Practices. McGraw-Hill, New York, N.Y., 1965.

Franklin J. Sternmole, Economic Evaluation and Investment Decision Methods. Investment Evaluations Corporation, 2000 Goldenview Drive, Golden, Calif., 1974.

John Von Neumann and Oskar Morgenstern, Theory of Games and Economic Behavior, Princeton Univ. Press, Princeton, N.J., 3rd Edition, 1953. 


\title{
Chapter 8
}

\section{Criteria for Selection and Conceptual Design Optimization}

\author{
8.1 Criteria for selection (By A. L. Floyd, ${ }^{*}$ R. Iregui, ${ }^{* *}$ F. D. Dunn, ${ }^{* *}$ \\ and G. Simay*)
}

\subsubsection{Introduction}

The purpose of this section is to provide a sound method by which the reader can select the best resource and power plant cycle to satisfy the needs of his market.

The basic purpose of the power system is to supply electric power at an economically competitive cost to the customer on demand. The process of selection of the type of power plant to be installed in the system requires evaluation of the power market. The value of electric energy to this market is influenced by many complex conditions such as market demand, load factors, and generation sources. Competitive sources of electric energy include geothermal, fossil fuel, hydroelectric, and nuclear power generating plants, each of which can play a major role in determining the value of electric energy.

Once the market characteristics have been established, the cost of the geothermal energy must be developed as an initial step in geothermal plant selection. The cost varies with each resource and must be determined for the particular resources being considered. Once these two factors, market value and energy cost, have been established, the difference is the amount available for conversion of the geothermal energy into electric energy. The power plant performs this energy conversion.

The flow diagram shown in figure 8.1 illustrates the selection process. The amortization life of a power plant is relatively long, thirty to thirtyfive years, and the plant construction may require from two to eight years depending on type and permitting review. The investment in the power plant takes place during these early years, and the returns from the elec-

\footnotetext{
*City of Burbank, Callf.
}

** Rogers Engineering Co., San Francisco, Calif. 


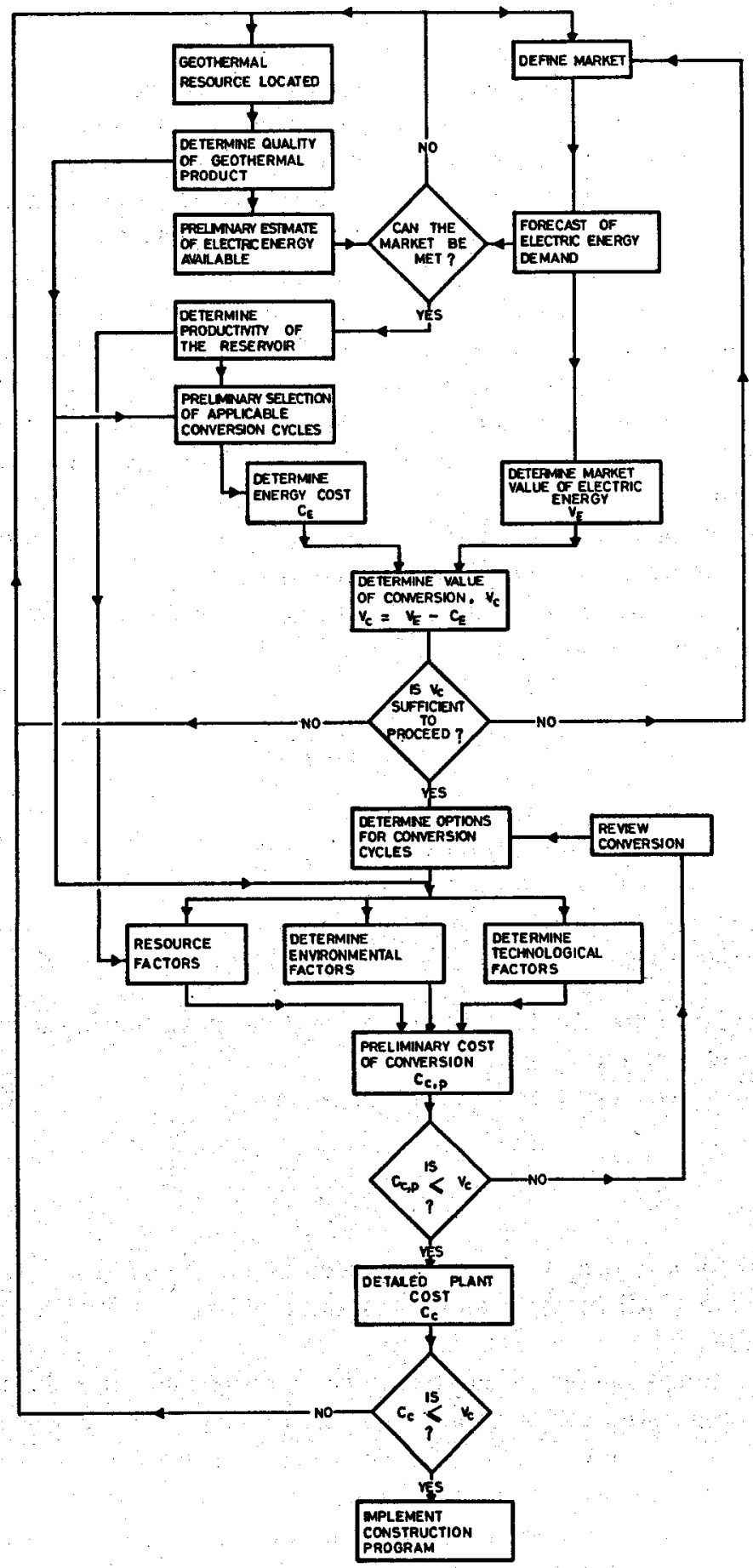

Figure 8.1-Selection process diagram. 
tric energy sold, which pay for this investment, takes place over the amortization period of thirty or so years.

The decision as to the size and type of energy conversion system takes place in the present, but is based upon considerations relative to future sales of power, future cost of fuel, future operating cost, and future investments. Because of interest charges on investment, the impact of inflation on sales, labor and energy charges, and the uncertainties of future events, it is necessary to employ analytical predictive techniques to bring these present considerations of many future anticipations to a common basis for judgment. There are a number of techniques available for doing this type of economic analysis; these are discussed in standard text books. The two most generally used methods are the present value and the equivalent annual cost (EAC) approaches. The EAC is useful when the annual cost of a unit of electric energy generated is required. The present value technique brings future cash flows-payments or receipts-into present values by discounting them at a selected time value of money-interest rates, return on investment-and estimating the probability that the cash flow will occur. (See also Chapter 7.) That is:

$$
P V=\sum_{m, n} \frac{P_{m, n} \cdot C_{m, n}}{\left(1+i_{m}\right)^{n}}
$$

where

$P V=$ present value of the future cash flows,

$C_{m, n}=$ the cash flow, $C_{m}$, in year $n$,

$P_{m, n}=$ the probability of $C_{m}$ occurring,

$i_{m}=$ the discount factor primarily determined by cost of capital.

The equivalent annual cost is equal to the present value times the capital recovery factor at a discount rate $i_{m}$.

The capital recovery factor $(C R F)$ is given by:

$$
C R F=\frac{i_{m}\left(1+i_{m}\right)^{n}}{\left(1+i_{m}\right)^{n}-1}
$$

In general for any proposed program, such as a new power plant, the tota] present value of all future cash flows should be positive for the venture to be profitable.

This technique is convenient to apply when considering the type and size of power plant to construct, as in many cases the present value of much of the cash flow can be estimated prior to determining the power conversion system. For example, the present value of all future electric energy sales can be estimated. The present value (cost) of future geothermal energy required (assuming $100 \%$ or other estimate for conversion of available work) can be estimated. Transmission and distribution costs 
can also be brought to present value. If these costs alone exceed return from sales, there is no justification for converting the geothermal energy to electric energy for market. If the net present value is positive, then judgments can be made as to the possibility of developing, constructing and operating geothermal power plants within this present value margin. This present value of conversion can contribute to the decisions relative to geothermal resource, market, size, and type of power plant.

The power plant system required to satisfy a changing market can usually be met most economically with a mixture of generating equipment wherein some equipment operates on a continuous basis as near as possible (base load), and other equipment operates for shorter periods (intermediate and peak load). Considerable cost savings in operations and maintenance can be achieved by locating these various types of converters in the same area. Thus the selection of the conversion generating equipment may include more than one type for a given market, resource, and facility.

The selection of the conversion equipment becomes iterative since the market may in many cases be variable, as may the energy cost, conversion cycles, generation mix, and the means of meeting environmental requirements. Each of these factors will be discussed below. Since most of these are complex and involve specialized sciences and arts, only selected simplified illustrations are given. Depending on the particular problem being attacked, other techniques may be justified, and are discussed in a number of references.*

\subsubsection{Market factors}

The market sets three basic requirements for the power generating system : the value of the energy, the demand for power, and the total energy required. The power generating system may be chosen to satisfy only part of the market or all of it. It can be all geothermal or a mixture of geothermal and other systems. An understanding of the market requirements is essential for the logical selection of the conversion system. Each of the three market factors, demand, total energy, and value are reviewed below.

\subsubsection{Demand. The market places a demand for power upon the power} plant to which it responds up to its total capacity. This demand for power varies with each hour of the day, each day of the week, each season of the year, and from year to year. How this demand varies depends upon the consumer mix, i.e., upon the relative sizes of the residential, commercial, and industrial segments. In concentrated industrial markets the demand will be subject to wide variations correlated with the local economy and industrial plant loading. Gnowth in peak demand can be very rapid

\footnotetext{
"For example, Bloomster, O. H., "Economic Analysis of Geothermal Energy Costs." Battelle Pacific Northwest Laboratories, Richland, November, 1975.
} 
for newly developing markets, and slow for mature markets. Growth in minimum demand can be slow in the presence of high growth for peak demand. Since the power plant is to be constructed to satisfy demand in the future, starting in 2-8 years and continuing for an additional 30-35 years, the problem of forecasting this demand becomes very complex and uncertain. A detailed discussion of market forecasting is not warranted here, but only the necessary general factors are covered to show how they influence the selection of generating equipment.

In general the market will be in existence at the time the initial planning for a new plant takes place, and the new plant will be required to meet market growth and to replace older equipment being retired. Some of the electric load characteristics can be taken from the present market. Figure 8.2 shows how the demand for power might vary as a function of the time of day for a particular market. This will differ for each market and for each day. The demand or load curve is plotted as the percent of peak load. Considering only this one day it can be observed that up to about $30 \%$ of the peak load is required $100 \%$ of the time. Higher percentages of peak load are required for lesser portions of the time. It is convenient to modify this demand curve to show the percent of peak demand versus percent of day required. Figure 8.3 shows that a power plant with a capacity exactly equal to the peak demand would be operating at below $60 \%$ of its capacity about $52 \%$ of the time.

The power demand is not constant for every day of the year. The peak demand for some days in a year can be considerably higher than other days. By combining a year's data of daily information of the type shown in figure 8.3, a plot can be made for any particular year. For the example chosen, figure 8.4 shows that a power plant with a capacity exactly equal to the peak demand would operate below $60 . \%$ of its capacity $75 \%$ of the time.

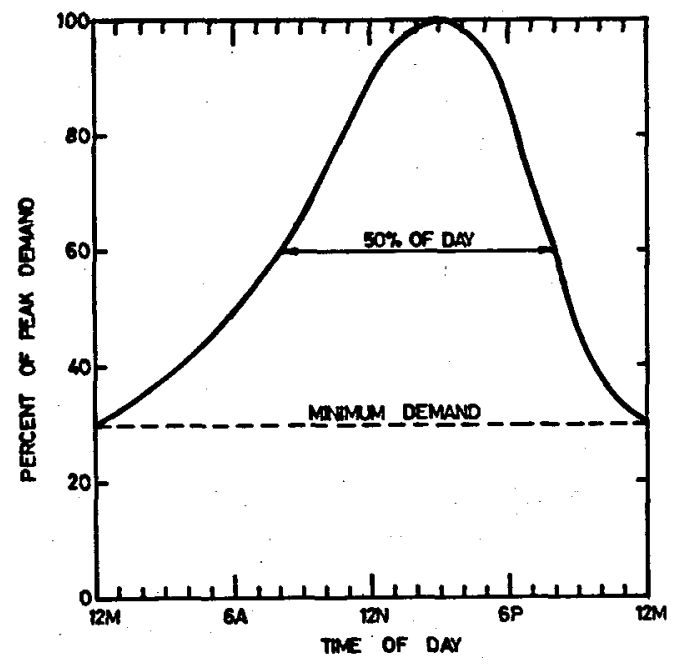

Figure 8.2-Power demand vs. time of day. 
Fraure 8.3-Power demand vs. percent of day.

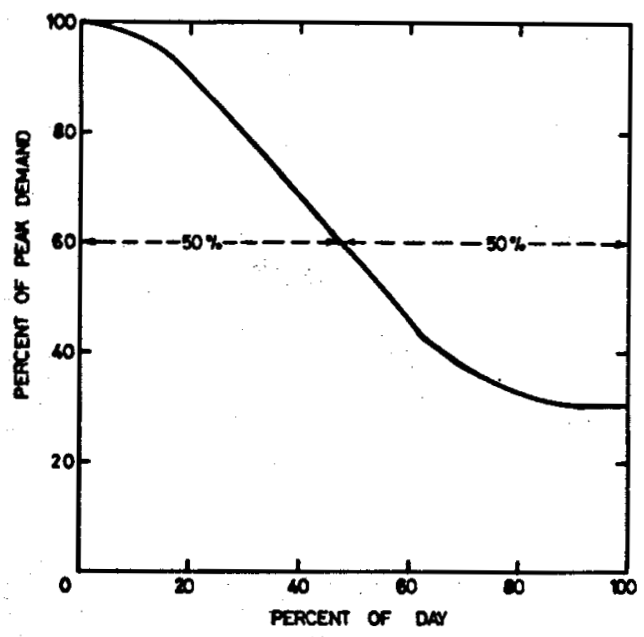

This market curve can be roughly forecast for the period of operation of the power plant by estimating peak demand growth, total energy consumption, minimum demand, and assuming a similar form of the curve for each year. Total energy consumption is given by the area beneath the demand curve. Such a composite must be considered in the planning and construction of power plants which will take up the future growth.

8.1.2.2 Value of electric energy. The price of electric energy is subject to competitive factors, existing technology, and the laws of supply and demand. Most utilities have transmission lines connecting them with other utilities and power generating plants from which power can be purchased. As the demand on the interconnected system varies from day to day and from season to season, the price of the power varies. For example, in the spring after a wet winter in areas having large hydroelectric power plants,

Frauke 8.4-Power demand vs. percent of year.

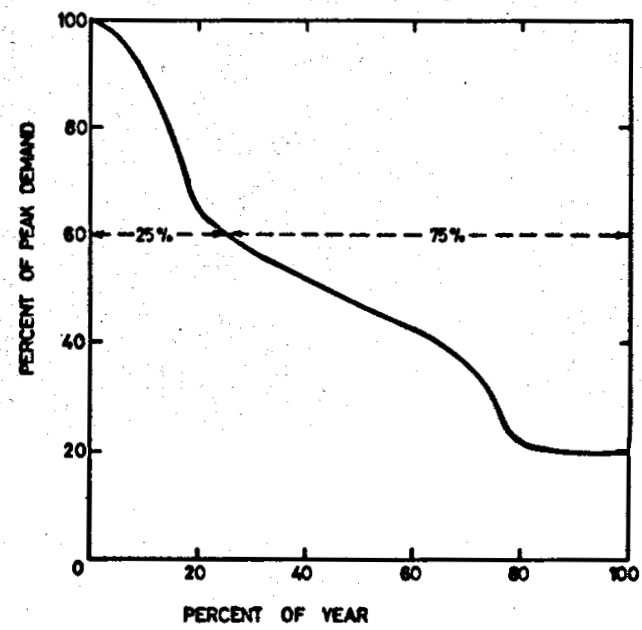




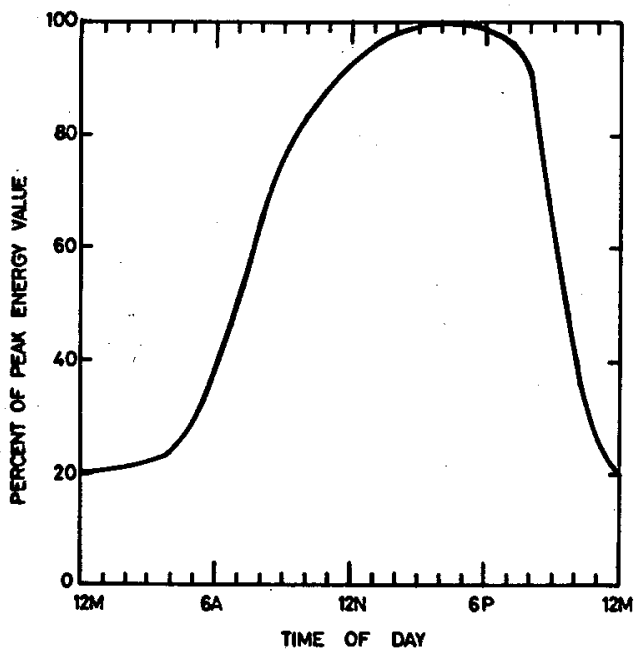

Froure 8.5-Value of energy $\mathbf{~} \mathbf{}$. time of day.

power can become a surplus item and can be purchased at a very low rate. At peak demand when power must be generated from lower efficiency equipment and transmitted on fully-loaded lines, the price of the energy is much higher.

The value of energy varies in a manner similar to the demand load curve. Figure 8.5 shows an example of how the average value of electric energy might vary over a particular day and closely approximates the load demand curve (cf. figure 8.2). Similarly the value varies over the year. This value is more convenient to plot in terms of the percent of time the energy is demanded as shown on figure 8.6. This can be estimated for each year the proposed new power plant will be in operation by applying price escalation factors. Care must be exercised to account for different

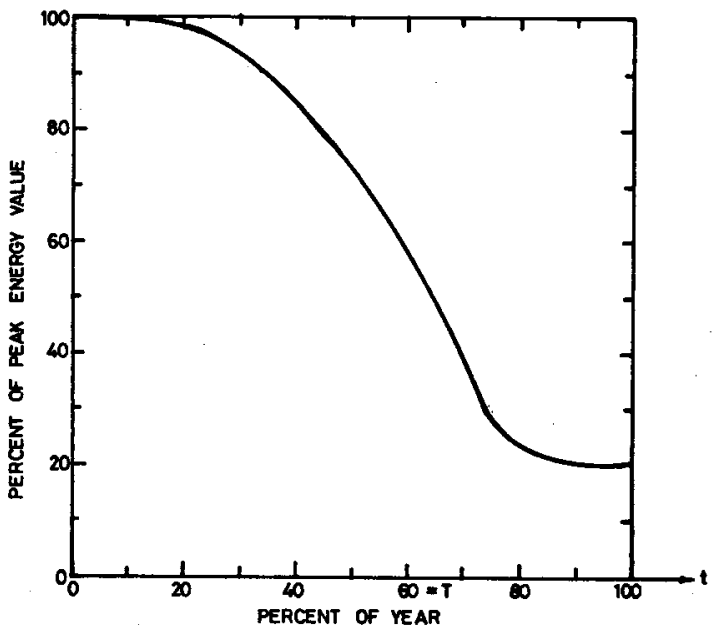

Frouks 8.6-Value of energy vs. time percent of year. 
escalations that may be present. Peak or short-term power may escalate faster or slower than base or high-percentage-use power depending on the market and competitive conditions.

8.1.2.3. Market value vs. time supplied. The above discussion centers on the unit cost of electric energy as it varies with the time of day and precent of day. A power plant operating over the entire day then supplies electric energy having a value that varies over this time period. The average value of this power over the day is determined by integrating the unit value over time. That is:

$$
\bar{V}(T)=(1 / T) \int_{0}^{T} V(t) d t
$$

where

$\bar{V}\left(T^{\prime}\right)$ is the unit average value of electric energy delivered $T \%$ of the time,

$V(t)$ is the unit value delivered at time $t$,

$t$ is the percent of time.

Figure 8.7 shows this evaluation for various percentages $T$ of the time supplied: For power delivered $100 \%$ of the time, the unit average value is about $60 \%$ of the maximum value. Over the total period the value varies, as shown by figure 8.6 , from the peak value to $20 \%$ of the peak value. Figure 8.7 shows how this average per unit value varies with the percent of the time supplied.

8.1.2.4. Market value v8. capacity. Figure 8.4 shows that if a plant were built to supply $20 \%$ of the peak demand (assuming that other plants supplied the rest), this plant could operate $100 \%$ of the time. The total market value of sales for this $20 \%$ plant then would be given by :

$$
M V(0.2)=\int_{0}^{100 \%}(0.2) D_{m} V(t) d t
$$

where

$M V(0.2)$ is the market value of the electricity from the $20 \%$ capacity plant,

$D_{m}$ is the maximum demand,

$V(t)$ is the unit value delivered at time $t$,

$t$ is the percent of time.

For convenience, it is customary to use a normalized value, established by dividing by the total market value, $M V(100 \%)$ :

$$
M V(100 \%)=\int_{0}^{100 \%} C(t) V(t) d t,
$$

where $C(t)$ is the demand curve given in figure 8.4 
If a second plant of incremental capacity, $d C$, is added, it will only be able to operate at $100 \%$ capacity in conjunction with the $20 \%$ capacity plant during that period of time when the demand load exceeds its incremental capacity by $20 \%$ of the total demand. Thus its market value is:

$$
\begin{gathered}
M V(d C)=\int_{0}^{t_{1}}(d C) V(t) d t, \\
C\left(t_{1}\right)=0.2+d C .
\end{gathered}
$$

If this value is then added to the previous $20 \%$ value, the total market for a plant of size $0.2 D_{m}+d C$ is obtained. Thus the market value for any plant of size $C_{0}$, where $C_{0} \leqslant D_{m}$, can be determined by :

$$
M V\left(C_{0}\right)=\int_{0}^{c_{0}} \int_{0}^{T} V(t) d t d C
$$

where $T$ satisfies $C(T)=C$. But

$$
\int_{0}^{T} V(t) d t=T \bar{V}(T)
$$

where $\bar{\nabla}(T)$ is given by figure 8.7.

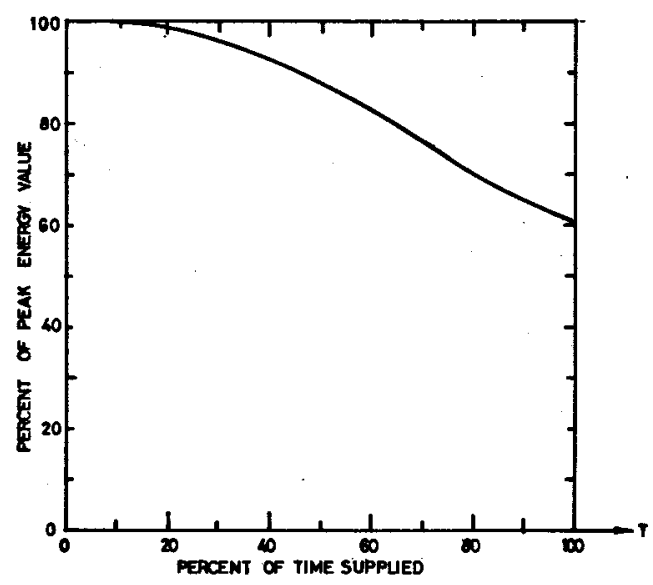

FIaURE 8.7-Average value of energy v8. percent of time supplied.

The value of $T$ is obtained from figure 8.4 for various values of $C$ :

$$
M V\left(C_{0}\right)=\int_{0}^{C_{0}} T \bar{V}(T) d C .
$$

It is convenient to normalize this by dividing by the value of $M V(100 \%)$. Figure 8.8 shows the result of this evaluation for the example shown on figures 8.4 and 8.6. The major portion of the market must be satisfied by 
Froure 8.8-Comparison of market value to plant capacity.

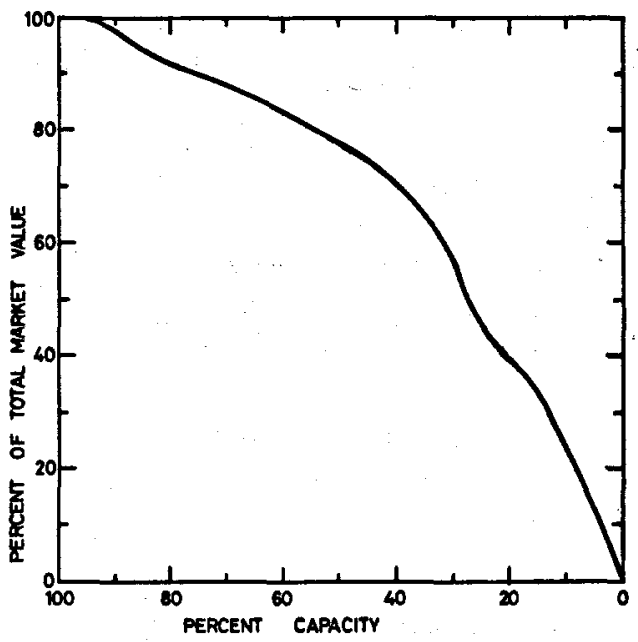

that portion of the plant that does not operate $100 \%$ of the time or that operates at less than full capacity.

8.1.2.5 Present values. The market value vs. capacity utilization should be estimated for each year the plant is to operate over its life. This series of values should then be brought back to present value using a consistent discounting method. This information will then indicate the market that a new proposed power plant must satisfy, and the murket value (in present worth) of electrical energy. The market value of the electric energy generated by the proposed plant must exceed the cost of the electric energy (also in present worth) to make the plant economically sound.

8.1.2.6 General comments. The estimation of the future market for electric power can be performed by a number of techniques ranging from simple trend projections to very complex calculations involving probability ranges, extensions to other markets, modifications to existing types of competitive generating systems, etc. The size, application, and regional location of the power plant determine the degree of investigation warranted for market-value determination. Much of the necessary information exists within the utilities that the power plant will serve since they are continuously planning for growth in power generation to meet the future demand. In these cases the utility can supply the market value.

\subsubsection{Operating factors}

The reliable delivery of electric power requires the utility to be capable of meeting total demand at all times. The utility has a selection of types of generating systems it can employ to do this. The utility's objective is to have available for operation a mix of generating systems that will allow satisfying demand at the lowest total cost. As indicated above, the 
relative value of power varies with total demand; however, this value is largely determined by competitive factors.

8.1.3.1 Cost of operations. The cost of operating the generating system can be considered to consist of two parts, a fixed cost and a variable cost. The fixed cost is the cost of the capital investment, time obsolescence, standby maintenance, available personnel, and safety and security needs to assure the capability to respond to demand. The variable cost comprises, in general, the cost of the fuel (or energy cost) and the repairing of equipment.

The first approximation of these costs for a particular generating system can be considered to be linear, as expressed below :

where

$$
\sigma_{o}=\sigma_{f}+U \sigma_{v}
$$

$C_{0}=$ Total operating cost,

$C_{f}=$ Total fixed cost,

$C_{v}=$ Total variable costs at full plant capacity,

$U=$ Fractional utilization of plant capacity.

The unit cost of electric energy produced varies with the utilization of the total capacity. This is given by:

where

$$
C_{\mathrm{e}}=\left(C_{t} / U+C_{v}\right) / C
$$

$C_{0}=$ Cost per kilowatt $\cdot$ hour,

$C=$ Capacity of the generating system.

In the selection of the generating systems, a trade-off is made between fixed cost and variable cost. Low variable cost systems, (i.e., high efficiency) involve a higher fixed cost and higher standby costs. On the other hand, low fixed cost systems with rapid start-up capability involve much higher variable costs. Figure 8.9 illustrates this. Peaking units have the

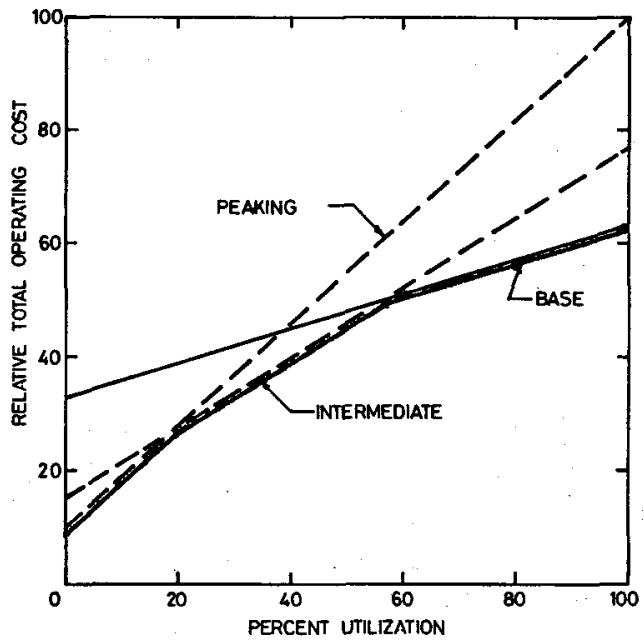

FrgUre 8.9-Total operating cost v8. ntilization. 
lowest operating cost up to approximately $20 \%$ utilization because of the low fixed cost. Intermediate units have an advantage between 20 and $55 \%$ utilization, whereas base-load units are the most economical between 55 and $100 \%$ utilization. Since technology improvements on base-type generation are aimed at reducing the variable cost, i.e., through increases in efficiency, intermediate units will often be older, former base-type generating units that have been amortized. Thus the capital cost is reduced although standby costs are still high. Figure 8.10 illustrates the relative unit cost of electric energy produced by the three types of generating systems at various percent utilization factors.

8.1.3.2 Meeting demand-the generating mix. The utility selects its mix of generating equipment to satisfy the demand at the lowest cost and with high reliability. The utility must meet each daily demand requirement (figure 8.2) as it varies over the year (figure 8.4). Although excess capacity must bo available for growth and economic variations, the discussion here will center on the percent utilization over a one-year period, and on the three types of generation mentioned above to meet that requirement. For the example chosen (figure 8.4), over the one-year period on the average approximately $50 \%$ of the plant capacity will be used, although for a short period, the total capacity will be used.

As shown earlier, base-load generation is most economical between 55 and $100 \%$ utilization of plant capacity (see figures 8.9 and 8.10 ). Supplying $40 \%$ of the market capacity from this generating system will allow $85 \%$ utilization over the year for the example shown on figure 8.4. Part of the time, about $20 \%$, the base-load generator will be operating at $50 \%$ capacity, however, the base-load generation will be operating at full capacity about $65 \%$ of the time.

Frauge 8.10-Unit energy cost vs. utilization.

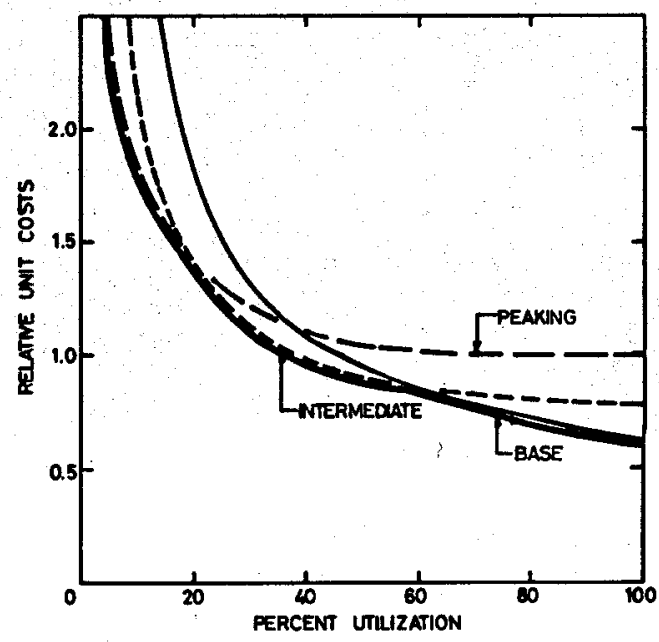


Using figure 8.4 as the plant relative demand, the average utilization of capacity in relation to the installed capacity can be determined by integrating and dividing by the total installed capacity. That is,

where

$$
U_{c}=(1 / C) \int_{0}^{c} t(c) d c
$$

$D_{c}$ is the utilization of capacity, 0 ,

$t$ is the percent utilization, which by figure 8.4 is a function of capacity.

This information is plotted on figure 8.11 for the example. Also shown is the minimum capacity utilization, namely the capacity divided by the minimum demand (0.2 for the example in figure 8.4 ). Thus for the $40 \%$ of peak load capacity the average curve shows $85 \%$ utilization with a minimum of $50 \%$.

Sizing the base-load generator at $60 \%$ of peak gives $70 \%$ average utilization with a minimum of $33 \%$. This is still an efficient use of the baseload generator since it is most efficient down to $60 \%$. However, care must be exercised because the demand is an average over the life of the plant, and the early years can result in uneconomical operation.

For the example chosen, the base-load will be assumed to represent $60 \%$ of the peak demand and thus has an average utilization of $70 \%$ according to figure 8.11.

The remaining capacity must be supplied by peaking and intermediate generators. Since geothermal systems are applicable to base-load units requiring large capital investments and having low incremental costs, peaking and intermediate generation will not be discussed here.

In addition to meeting demand it is usually necessary to have some reserve capacity in case of a failure or some other emergency. As the base

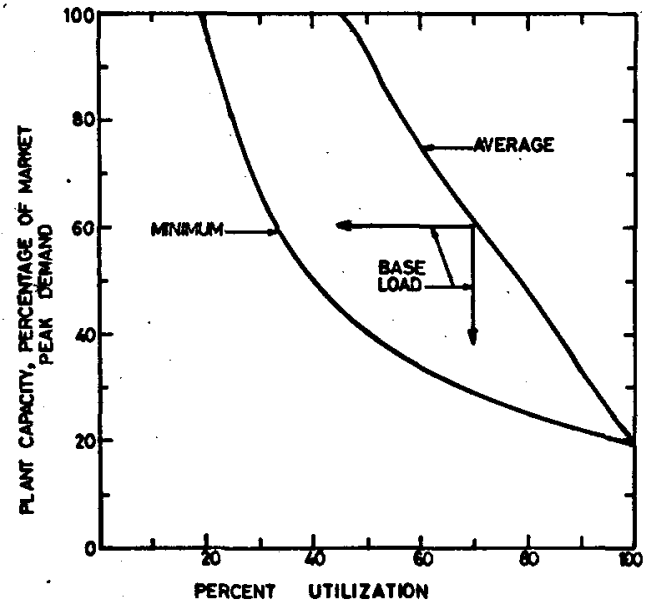

Frouke 8.11-Capacity utilization v8. relative capacity. 
Fiaure 8.12-Comparison of market value to capacity utllization.

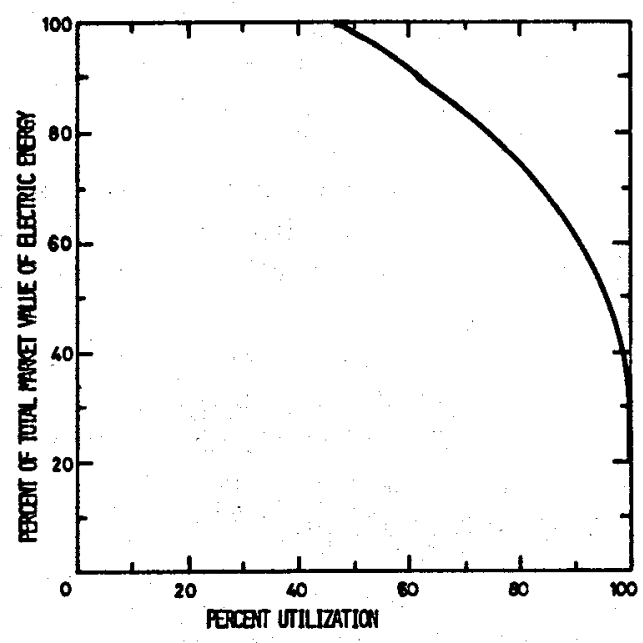

and intermediate load generating systems will usually consist of a number of individual generators, a failure of one will not remove all of the capacity. Most of the time the system will be operating below capacity and can act as part of its own reserve. However, for the peak season and peak time of day, additional reserve may be required. For this condition, the use of a peaking-type generator would be the most economic selection because of the very low utilization rate.

8.1.3.3 Retum. A plot of the market value relative to plant capacity was shown earlier in figure 8.8. Using the data presented in figure 8.11, we can now plot these data as a function of capacity utilization. The resulting curve is given in figure 8.12 and shows the comparison of the market value in relation to plant utilization.

Froune 8.18-Comparison of return for various plant capacitles.

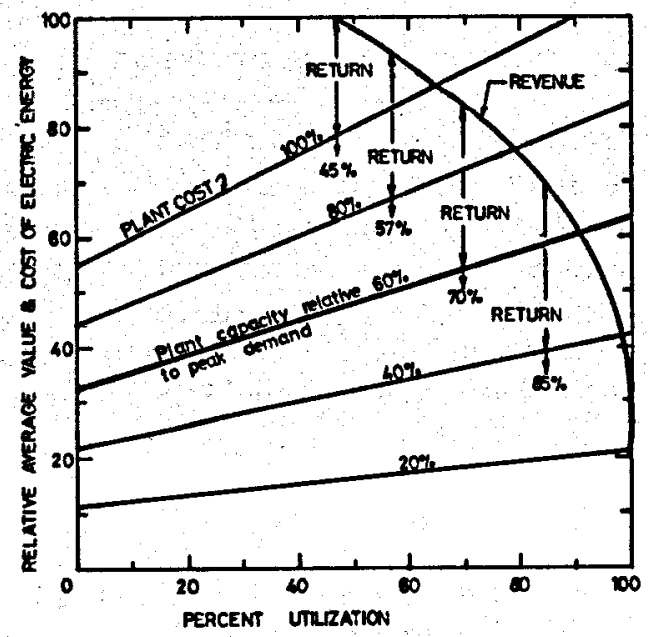


Using the data from figure 8.9 for the base generator and assuming the costs are to the same scale on figures 8.9 and 8.12 for a plant sized at $60 \%$ of total peak demand, the cost of operation can be compared to market value. This curve is shown in figure 8.13 by the heavy line labeled $60 \%$. By figure 8.11 the percent utilization of the capacity for the $60 \%$ sized base generator would be $70 \%$. At $70 \%$ utilization the difference between the market value and the $60 \%$ base generator cost is the return, also shown on figure 8.13.

By direct scaling of costs, $20,40,80$, and $100 \%$ plant sizes are also shown. As can be seen in this comparison, the $40 \%$ and $60 \%$ size plants give the greatest return. It is important to note that a $40 \%$ plant is assumed here to cost $40 / 60$ times as much as a $60 \%$ plant. This assumes an economyof-scale factor of unity. This factor generally varies between 1.0 and 0.6 , and thus the $60 \%$ size could have an advantage over the $40 \%$ size.

\subsubsection{Financing and cash flow}

Construction of a power plant usually requires use of debt financing. The details of the process of financing are covered in many texts elsewhere. However, debt service affects the planning and selection of size for the power plant.

The market for electric energy is usually a growing market and the selection of conversion equipment is based, in part, upon the present value of that market. The return from the operation of the power plant is very sensitive to the utilization of the power plant. If the market is growing rapidly and the power plant is designed for the total market over its thirty-five year life, the utilization of the plant may be low for the first few years of its operating life, likely resulting in low or even negative cash flows during the initial years.

The cash flow from the sale of electricity must be sufficient to service the debt and committed equity capital at all times. Therefore, it is necessary (after a selection of size and mix of geothermal energy conversion systems) to make a year-by-year cash flow analysis using the market forecast for each year. If this cash flow is not sufficient to service the debt on the power plant, then the plant size and perhaps the conversion system may have to be changed to assure sufficient cash flow. Increments could be added as the market grows. If the cash flow analysis shows that a smaller plant should be considered, the future market should be analyzed again and the market segment reduced to be compatible with the smaller size. The selection process should then be repeated (The reader may also consult Ohapter 7 for another discussion on financial considerations).

\subsubsection{Summary of selection process}

The previous sections have discussed (1) the needs of the power market, (2) how it is affected by capacity and demand factors, and (3) the financ- 
ing and cash flow needed for power plant construction. In addition, the factors which must be considered to obtain preliminary cost data for converting geothermal energy to electric energy have been addressed.

Figure 8.1, presented at the outset of our discussion, shows in summary the iterative process of analysis required to determine whether a geothermal resource which has been discovered can be used to satisfy a portion of the power market.

8.2 Conceptual design optimization (By W. L. Pope, P. A. Doyle, H. S. Pines, R. L. Fulton, L. F. Silvester, J. M. Angevine*)

\section{Q.1 Introduction}

No recent document has appeared with a description of the state-ofthe-art of power plant economic design optimization. It is the goal of this chapter, when used with the wealth of information presented in related chapters, to provide the reader sufficient material and interest to appreciate the complexities involved in the design of geothermal power plants and to overcome them.

8.2.1.1 Complexity of geothermal power plant designs. Because of the inherent complexity of geothermal power plant design calculations, sophisticated computer codes are obviously necessary. System design codes in current use differ considerably in generality, formality, basic structure, fluid property accuracy and treatment, convergence algorithms and criteria (and therefore general accuracy, consistency, and speed), and optimization methodology. These codes have been used in comparative studies of hydrothermal energy conversion systems with a variety of technical and economic assumptions and/or "simplifications." Consequently, economic feasibility consistency has been lacking in previously reported studies of even the simplest geothermal energy conversion systems.

A higher degree of reporting consistency will be necessary if the geothermal community expects private investors to commit funds so that hydrothermal geothermal power can be demonstrated as the viable alternative we all believe it to be.

8.2.1.2 Inconsistencies in previous work. New energy technologies develop slowly. Those alternatives on the edge of economic feasibility tend to move faster, because there are fewer obvious technical, environmental, and social impediments. Because of the successful development of geothermal power plants at vapor dominated resources (The Geysers in Northern California, for example), hydrothermal geothermal power development obtained the initial industrial and federal stimuli required for rapid growth. However, real progress has been disappointingly slow. Reporting

-All of Lawrence Berkeley Laboratory; University of California, Berkeley, Calif. 
inconsistencies have contributed to a higher than necessary perceived level of risk.

8.2.1.3 Causes of the inconsistencies. In our view, inconsistencies in the relative thermodynamic and economic performance reported for the simple hydrothermal geothermal energy conversion processes are the result of three factors:

1. differences in degree of system characterization,

2. differences in design approach and measures of optimality or goodness, and

3. differences in economic analysis tools.

We will discuss each of these factors briefly as they apply to simple hydrothermal energy conversion processes in order to arrive at a general measure of optimality which can be applied to all types of energy conversion systems.

Degree of system characterization. Previous comparative studies of various alternative energy conversion processes for specific hydrothermal resources have frequently been conducted with little or no regard for the producibility of the resource. The "boundary conditions" for various plant types are assumed to be equivalent and the fuel cost is treated as "immaterial"- that is a simple add-on, or "over the fence" price. In some early studies irreversibilities in the heat rejection system have been ignored, resulting in overly optimistic brine utilization efficiency expectations.

The various conversion alternatives were "optimized" after making several simplifying assumptions about resource productivity and the best design was the one which provided the electrical energy at the lowest busbar (or load center) energy cost. Depending on the formality of the analysis, reported results differ. Some analyses assume economically unjustified (low) temperature differences in the non-work-producing elements of the cycle and either tend toward low specific fuel consumption (high brine utilization efficiency) or optimistic plant capital costs (high cycle efficiency).

As previously mentioned, some analyses assume the unit fuel costs are the same. The thermodynamic availability, productivity, injectivity, and longevity of the resource have a strong influence on the selected plant design and, therefore, the overall optimum system design. The cost of fuel to the plant depends upon the plant load and upon the manner in which the "brine" is produced and disposed. Different surface conversion systems require different wellhead conditions and, therefore, different production and injection scenarios. Because optimum systems are not compared, the selected "optimum" conversion process is questionable. The optimum conversion process for a geothermal power plant is not, in general, the one which utilizes the fuel most effectively. This will be discussed in the next section and quantified with example problems. 
Desigu approach-previous measures of goodness. The traditional approach to power plant design has relied heavily on thermodynamics as a measure of economic grodness. This is the result of the large practical experience base which has developed around fossil fueled steam power plants and the fact that the calorific value of the fuel (or heat of combustion) is not significantly different from the available work, $W^{\circ}$, or exergy, (1) of the fuel relative to a chosen dead state. However, the simple economic "rules-of-thumb" applicable to fossil fueled plants are not general and cannot be applied directly to geothermal systems.

For example, in a fossil fired steam power plant either the heating value of the fuel or metallurgical limits determine the maximum cycle temperatures. The low density of steam at the turbine exhaust plus very well established prime mover and heat rejection system technology (and economics) have determined the minimum cycle temperature. This means that the maximum cycle efficiency or minimum plant cost per unit mass of fuel is fixed for a given type of fossil fuel plant. Consequently, the minimum busbar energy cost system is determined by simply optimizing the fuel utilization.

For the organic fluid (binary) Rankine cycle geothermal power plant, on the other hand, no such simple economic rule applies. For example, if one were to maximize the thermodynamic cycle efficiency to achieve minimum plant cost, the fuel cost would go to infinity. Similarly, if one sought the absolute maximum fuel utilization efficiency, the plant cost would approach infinity as non-work-producing temperature steps in the cycle approach zero to minimize cycle irreversibilities. In this case a more general design objective is needed for the system as a whole.

When minimum busbar energy cost is the design objective, the optimum geothermal power plant (or total system) design is one in which neither the plant nor the fuel are utilized at peak thermodynamic levels. The minimum busbar cost geothermal power plant design, nevertheless, is not intrinsically different than the minimum busbar cost fossil fueled plant. In both cases state-of-the-art optimality is the result of a complex tradeoff between the competing forces of thermodynamics and economics applied to the plant and the fucl. The geothermal power plant simply has fewer constraints or more degrees of freedom. The minimum busbar energy cost geothermal system obviously cannot be determined from thermodynamic considerations alone.

When current economics are applied to optimized plants, we find that the economically achievable fuel utilization efficiency is no better for the all geothermal power plant than it currently is for state-of-the-art fossil fueled plants, i.e., about $40 \%$ (Q)).

However, by restricting the geofluid use to sensible heat addition with subsequent reduction of entropy production, higher utilization efficiencies can be achieved. See, for example, the discussion of a hybrid geothermalfossil fueled plant in Section 4.3. 
Economic analysis tools. There should be little disagreement at this point as to what constitutes "goodness." Although thermodynamics will always impose limits to maximum achievable performance, economics always has been and always will be the only universally accepted measure of commercial system optimality.

Unfortunately, for a given level of thermodynamic characterization, an economic optimization requires another dimension of input detail. The quality of this additional input (the cost factors) is frequently open to question. For comparative studies of competing alternatives, economic consistency and relative costs assume added importance. This added degree of complexity has provided much of the stimulus for the development of newer, more sophisticated system design codes which incorporate the latest developments in thermodynamics (1), economics, and optimization theory.

In the next section we describe features of some of the promising system design codes under development with DOE/DGE support.

\section{R.Q Features of state-of-the-art codes}

Some of the more sophisticated and generally useful codes are designed with (1) formal economic and thermodynamic process routines, (2) modular structure, (3) separate, extensive fluid properties routines, (4) detailed process design routines, (5) efficient coding, and (6) multiparameter optimization (MPO) capabilities. The more recent simulators also include (7) simple, user oriented, interactive input features complemented with, (8) data sufficiency/consistency checks performed prior to execution, (9) general thermodynamic logical constraints to avoid computations on unrealistic variable combinations during optimization, (10) easily understood printed thermodynamic and economic output, and (11) flexible, state-ofthe-art contour and 3-D plotting capabilities.

8.2.2.1 Ongoing research. Government and industry are sponsoring research that will provide information on (1) new process components (heat exchangers, turbines), (2) improved fluid properties (brines, mixtures of light hydrocarbons), (3) scaling behavior of geothermal brines, and (4) reservoir and well flow data compilation and modeling development. A useful geothermal system design code will incorporate this information when it is available.

8.2.2.2 Keeping abreast. The responsible process designer should become aware and stay abreast of the more general theory (1) and the many promising new capabilities made available with recent system software developments, particularly MPO techniques. Not only will MPO techniques most likely guarantee convergence on the global optimum design objective for a system with many independent "optimizable parameters," the new codes with MPO capabilities virtually eliminate the need for the designer to perform subsequent "sensitivity analyses" or parametric studies on 
each of the optimizable parameters. MPO techniques offer the theoretician an extremely valuable tool to test and/or validate various hypotheses which may be intuitively obvious, but analytically intractable. Examples are presented.

\subsubsection{Current software limitations}

It is equally important that the process designer be exposed to current limitations of the new software. Some of the more important or obvious existing limitations of even the best geothermal power plant design simulators in the open literature follow.

1. Reliable subsystem cost and off-design performance characteristics are lacking.

2. Financial routines differ. Built-in "standard" financial assumptions are so different that radically different estimates of "levelized busbar cost" result for the same set of capital cost input data.

3. The plant design routines are coupled only to a zeroth order reservoir simulator, or completely uncoupled.

4. Two-phase production well flow is poorly simulated, if at all.

5. Chemical kinetics are poorly simulated, if at all.

6. Logical conversion system synthesizers for creating configuration or operation alternatives do not exist. The design performance is a direct product of the specified configuration and the chosen mode of operation.

7. Codes, in general, lack adequate documentation.

Items 2 through 5 have been identified and are getting the requisite attention and support from industry and DOE/DGE. In some cases adequate subsystem simulators exist; they just have not been coupled to the overall plant design simulator. Item 1 is, of course, lacking in generally available codes, but these features are being incorporated by industry as the codes gain industrial acceptance.

Whether or not item 6 is important depends entirely on the experience and/or creativity of the system designer or synthesizer, and errors of omission are possible. (See, for example, section 8.2.5.5.)

Item 7 is a particularly nagging problem. It is not unusual to get "burned" using someone else's routines. Technical and financial limitations, assumptions, approximations, equations solved, convergence criteria satisfied, etc., must be stated in the user manual. It is the responsibility of the code developer to provide this documentation if general use is anticipated.

We feel that the best way to overcome these current limitations is through vigorous feedback among system and component designers from industry, reservoir engineers, chemists, theoreticians, economists, and system design code developers.

The remainder of this chapter is devoted to a brief description of how these new codes work, and how they have been used for the conceptual 
design, and economic optimization of various simple energy conversion systems coupled to idealized hydrothermal geothermal resources. A promising, possibly new, optimization algorithm is described, and the results of sample calculations are presented for two basic hydrothermal energy conversion systems.

\subsubsection{System design selection criteria}

The selection of the "best," or economically most attractive, plant/field design for a known or specific geothermal resource is a multiply iterative process even after the value of the energy conversion to a utility or grid has been estimated for a particular assumed future market. Section 8.1 has outlined a method which utilities might use to determine the power requirement, market forces, and grid suitability for preconceptual level energy converson costs.

In this section, a rational computer design optimization method is described which might be used by an architect engineering firm to make reasonable estimates of the resource energy price, determine the best alternative for converting this resource energy into electrical power, and finally establish the most probable busbar energy cost.

8.2.4.1 Utility perceptions. The "best" energy conversion alternative as perceived by the utility, or "customer," is defined in figure 8.1 as that plant/ field design configuration which maximizes the value of the energy conversion, $\nabla_{c}$.

\subsubsection{Constraining the problem for the designer. This problem can be} posed for the system designer in another way. Given the energy demand, a resource capable of supporting the demand, and minimum values of acceptable rates of return to the producer (estimable but infiuenced by the producers total market) and the utility (fixed) based on current and projected operating costs and costs of capital, determine the plant/field design configuration which minimizes the busbar (or load center) energy cost, $O_{\mathbf{r}}$.

It is important to recognize here that, in general, when geothermal power plant conceptual design trade-off studies are being done between various candidate resources, processes, and working fluids, a contract with the producer probably hasn't been signed, so the unit cost of the resource energy is not known. In addition, it is generally not valid to say we can design or compare various plants on the assumption that the unit brine cost (either per unit mass or per unit energy extracted) is the same for all alternative plants.

The cost and number of wells and the productivity and longevity of the resource depend on how the resource is produced and on the plant(s) load and, therefore, influence the cost of the brine, or "fuel," to the plant. This "fuel cost" has a significant and predictable influence on the resulting 
overall optimum system design, its busbar energy cost, and the marketability of the power.

This means that in addition to all the financial assumptions that must be made regarding the plant, the method described here requires that similar (and potentially less credible and stationary) financial assumptions be made regarding the field or resource.

This complex problem was addressed by B. Holt in 1976 and is discussed at length (3). Holt used the cost-of-service approach to arrive at the probable brine cost "in accordance with generally accepted practices in the petroleum industry" and made all the required assumptions regarding exploration costs, well productivity, then current drilling costs, producers minimum required rate of return, depletion and intangible drilling costs, inflation, escalation, etc.

\subsubsection{Overall system model-the design objective. For screening plant/} resource alternatives and subsequent conceptual designs, we assume that Holt's basic system analysis model applies. We price out the brine and the plant costs; establish the minimum or optimum busbar (or load center) energy cost for each plant/field configuration alternative; compare the final results of each alternative; and define as the busbar energy cost, the best of all the alternatives. This is the system design objective.

This energy cost along with the predicted cash flow, capacity factor, plant life, estimated off-design daily and seasonal performance capabilities, and environmental impact information is then fed back to the utility (or customer) for comparison with other proposed power plant alternatives.

If all the requirements of the grid are met by the proposed geothermal power plant within the utility's or investor's defined acceptable level of risk or economic uncertainty, and the proposed geothermal plant is the "best" economic and environmental alternative available to the utility, chances are good that the geothermal power plant will be built.

\subsubsection{Synthesis of plant/field alternatives}

In this section we briefly list some of those factors which will have a relatively strong influence on busbar energy cost in simple hydrothermal energy conversion systems, so they can be used for preliminary screening.

This system preliminary screening discussion must not be taken out of context. We only discuss the simplest hydrothermal energy conversion "cycles" for the purpose of illustrating a common general technique. The cycles discussed here will be limited to the simple, organic fluid (binary) Rankine cycle and the two stage flashed steam (or separating flashed steam) process.

The comparison criteria used in each category will be economics. The conclusions should bo intuitively obvious when taken in context; however, 
some degree of controversy is unavoidable. As systems are synthesized and screened, the plant and field capital cost tally must be maintained and periodically upgraded along with the thermodynamic calculations, or poor decisions may result. Most useful system simulators provide this capability. Very crude component cost estimates are better than none at all, and no cost optimization can be performed without them.

\subsubsection{Resource characteristics. The resource temperature (thermody-} namic availability), resource productivity, quality, salinity, noncondensible gas content, and scaling potential will largely determine the number and types of alternative plant designs which need to be considered in the preliminary screening process. Because resource characteristics are too variable and complex to treat in this section alone, the reader is referred to chapter 2.

8.2.5.2 More complex cycles. It is always possible to improve the thermodynamic performance, cycle efficiency; or resource utilization efficiency of the simple conversion systems by adding additional heating and/or cooling stages, and various power recovery devices. This is especially true for subcritical binary cycles. However, the point of diminishing-economicreturn is quickly reached as systems get more complex. The cycle efficiency improvement with increasing number of stages is simply the result of increased first-stage temperature. If an alternate working fluid exists with a sufficiently low critical temperature and critical pressure, it is quite possible that a slightly supercritical simple binary cycle with this new fluid would be more cost-effective than the previous subcritical cycle with multiple stages.

8.2.5.3 Candidate cycle elimination-trends. Low temperature hydrothermal resources will generally favor organic fluid (binary) Rankine cycle conversion systems, whereas flashed steam plants will tend to be best for higher temperature resources (4). For low to moderate temperature $\left(150^{\circ} \mathrm{C}\right.$ to $\left.200^{\circ} \mathrm{C}\right)$ hydrothermal resources, if the noncondensable gas content in the brine is very high (greater than, say, $2.0 \%$ by weight), conventional, simple flashed steam cycles (condensing) can probably be eliminated in the screening (see figure 8.14) (5).

On the other hand, if the resource temperature is very high and the brine is of extremely high salinity (say greater than roughly 50-100,000 ppm), or has a high scaling potential (the Niland area in southern California, for example), conventional simple binary cycles probably need not be considered.

Furthermore, if the cost of drilling wells (or, more accurately, cost per unit convertible power) is expected to be very high at a particular resource, chances are good that the flashed steam cycles will drop out simply because of the inherently higher brine requirement (and, therefore, increased "fuel" 


\section{WEIGHT PERCENT OF NON - COND: IK FIRST FLASH STEAM}

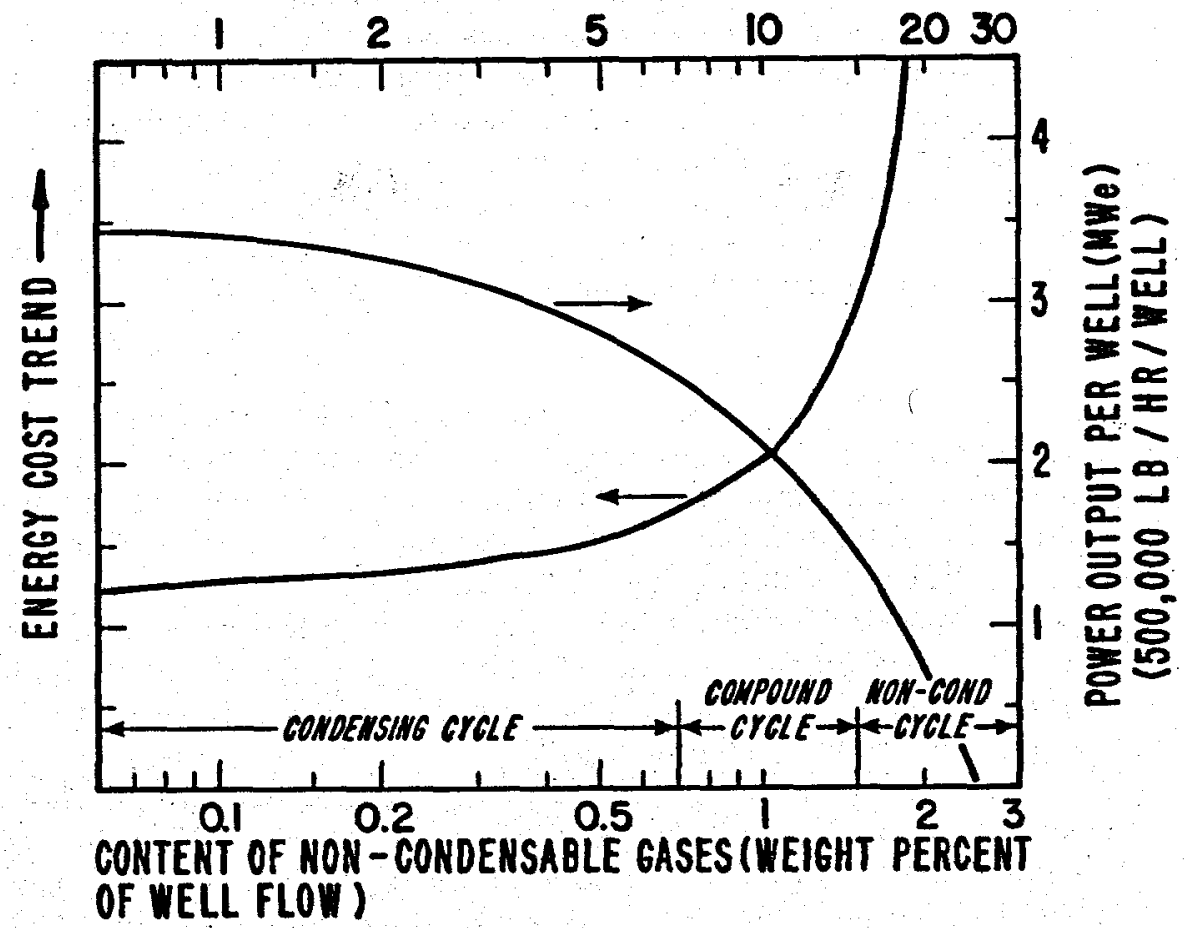

Frgore 8.14--Influence of noncondensable gases on the power output per well and economics of a condensing flashed steam energy conversion cycle (fixed flow rate per well). It is seen that for a content of noncondensable gases larger than about 1.5 weight percent of total well flow, the net power output per well for a condensing cycle approaches zero and the energy cost approaches infinity. Figure reproduced with energy costs deleted with permission from reference 6. Basis: Downhole temperature $200^{\circ} \mathrm{C}\left(892^{\circ} \mathrm{F}\right)$; double flash system; condensing pressure 4 in $\mathrm{Hg}$; capital cost $\$ 750,000$ includes well and prorata for gathering, flash and reinjection costs; $O$ and $M-\$ 90,000$ year/well, cost of capital $-21 \%, 30$ years-zero salvage value.

cost) unless the resource temperature is high (say greater than about 200 to $250^{\circ} \mathrm{C}$ ).

However, as might be expected, the screening process will usually not be this simple. For a particular resource to warrant consideration at all, it will probably have relatively low salinity, scaling potential, and noncondensable gas content unless the productivity is unusually high. Furthermore, because the salinity and scaling potential of U.S. hydrothermal reserves appear to increase with increasing resource temperature, it is likely that the temperature of near term technically exploitable candidate resources will be in the low to medium temperature regime $\left(150^{\circ} \mathrm{C}\right.$ to $\left.250^{\circ} \mathrm{C}\right)$ where the energy cost of many hydrothermal conversion alternatives is about the same. This complicates the screening process. 
8.2.5.4 Candidate cycle simplification-shortcuts. Nevertheless, there are shortcuts to minimize the complexity of the screening process. For example, if the preliminary screening process has narrowed the selection down to a detailed comparison between, say, a simple binary cycle and a twostage flashed steam process, then to find the better of the two, one may not need to characterize the influence of noncondensable gas removal in the condenser of the flashed stẹam process. That is, if the binary cycle is better assuming zero noncondensables in the flashed steam process, it will be better for any noncondensable gas content (see figure 8.14) (5) at the same resource.

8.2.5.5 The sink temperature-floating cooling. The lower the source temperature of any thermodynamic energy conversion process, the stronger the influence of the sink temperature (1) on process performance. The variability of the sink temperature should be considered when evaluating the performance of organic fluid (binary) Rankine cycles.

If the conceptually optimized, baseloaded binary cycle has a competitive busbar cost of energy for a fixed, extreme (say 1-5\%) design wet bulb temperature, the annual average busbar cost of energy in a Floating Cooling mode can be lower (see figure 8.15).

If a market exists for the significant excess power that could be produced by the binary cycle during those daily and seasonal periods when the wet bulb temperature is low, the organic fluid (binary) Rankine cycle operating in the floating cooling mode could be even more attractive. This floating cooling concept is discussed in detail $(7),(8),(9)$. A decisive economic evaluation is in reference $(9)$. (See chapter 5.)

The floating cooling concept has also been considered for binary cycles with dry cooling towers for areas where cooling water is in short supply.

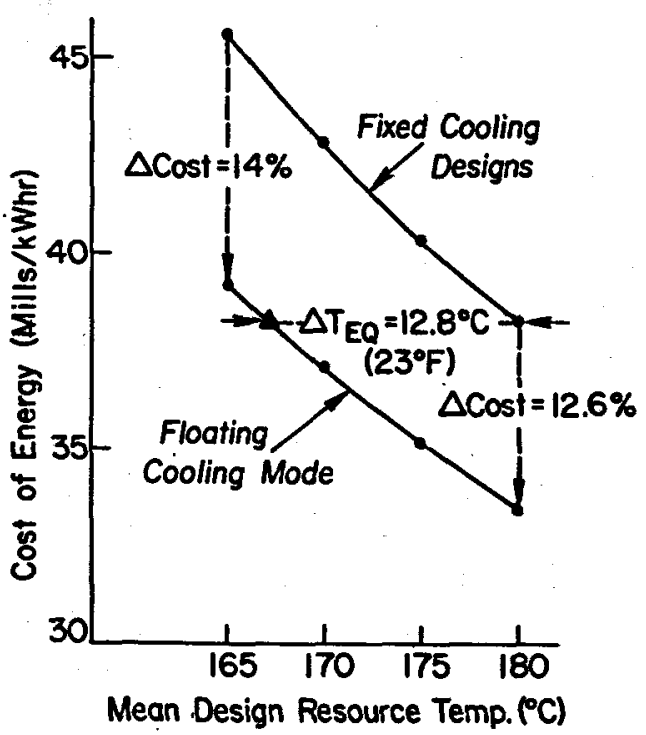

FIGUre 8.15-Influence of chosen design operating mode of organic fluid (binary) Rankine cycles on the busbar energy cost. In the floating cooling mode, signiflcantly more power can be generated if the condensing temperature is allowed to "fleat" with daily and seasonal variations of the sink temperature. This plot illustrates the potential reduction of the basbar energy cost for binary cycles designed to deliver $50 \mathrm{MWe}$ (net) at the peak (1\%) wet bulb temperature, if off-peak excess power can be sold at the same base rate (reference 9). 
Depending upon how the utility values the excess power available during normally off-peak periods, the computed energy costs can be competitive (10). The implementation of floating cooling plants depends now largely on their acceptability, or value, to the grid.

Floating cooling techniques provide no significant improvement in flashed steam plants. In the flashed steam process the turbine exit conditions cannot be changed sufficiently to follow the daily or seasonal wet and dry bulb swings, and thus generate significantly more power, because of specific volume limitations.

8.2.5.6 Cycle state point consistency-assumptions. When considering various candidate cycles for a given resource, the system designer must bo careful that exchanger pinch points and other cycle states and boundary conditions are appropriate. However, the foregoing statement does not imply that the plant thermodynamic state parameters should be the same for all cycles, resource temperatures, or working fluids in the prescreening.

For example, in the screening of candidate working fluids for binary cycles, the comparison could, of course, be simplified if equal pinch points, condensing temperatures, and cooling tower range or approach were assumed, but the results can be severely biased by this simplification. If the fluids have markedly dissimilar molecular weights or critical properties, erroneous "best fluid" conclusions are quite possible. Economic optimizations using MPO techniques fortunately obviate the need to make many of these simplifying assumptions. This will be discussed later.

8.2.5.7 Configuration assumptions-when complexities might pay. Similar arguments are important relative to the assumed cycle configuration. Depending on the resource (or wellhead) temperature and the working fluid critical temperature, some simple supercritical binary cycles "optimize out" with considerable superheat in the turbine exhaust, simply because of working fluid, cycle configuration, U-factor, and cost input assumptions. If this same cycle were reoptimized with a regenerative exchanger coupling the turbine exhaust and working fluid pre-heat streams, the reduction in cycle heat rejection would increase cycle efficiency, reduce cooling water make-up requirements, and chances are that the busbar cost would be improved. (See chapter 5.) When investigating the regenerative exchanger addition to the simple binary cycle, the tube/shell side fluid stream choice can be important to the cycle (11).

8.2.5.8 Oyole subsystem assumptions-overall heat transfer coefficient. Because of otherwise significantly increased complexity and computation time, optimizations of overall geothermal energy conversion systems are generally performed with simplistic, first and second law heat exchanger simulations. The overall heat transfer coefficients are input. Section 4.2.5 contrins an excellent treatise of the complex considerations involved in arriving at these input overall U-factors. 
The primary heaters of geothermal binary cycle energy conversion systems are particularly bad actors, by typical exchanger standards, because of radically varying thermodynamic and transport properties and the diffculty of predicting the kinetics of complex brines. Fouling behavior and rates are extremely site specific, and because generally applicable kinetic theories simply do not exist, small scale on-site exchanger tests are usually necessary.

When the results of these on-site tests have been reduced to reasonable estimates of fouling rates, subsystem calculations on the primary heater can be performed. A completely general method for arriving at the optimum cleaning frequency, or optimum design fouling factor (and therefore $U$-factor) by such a subsystem optimization is described in reference (12).

Figure 8.16 is an example of the relative sensitivity of the total plant heat supply cost, $\boldsymbol{X}_{\text {ror }}$, to the exchanger pinch point temperature difference, the design cleaning frequency, and the pressure drops for the supercritical primary exchanger array of a proposed $50 \mathrm{MWe}$ (net) isobutane binary cycle power plant on the Heber resource (3). The strong impact of pinch point and fouling factor are obvious and must be anticipated when requesting exchanger quotations.

8.2.5.9 Cost and financial assumptions. Another potential designerimposed screening bias exists via subsystem costs. Although little reliable information is published regarding typical subsystem costs, no system cost optimization is possible without a multitude of input assumptions. The economic optimum design is the result of a complex trade-off among the various subsystem thermodynamic irreversibilities and their resulting costs based on these input cost assumptions. The thermodynamic performance of the optimum design is a dependent result of the cost optimization. If the input costs are way out of line, the computed thermodynamic performance at the "optimum cost" will also be unrealistic.

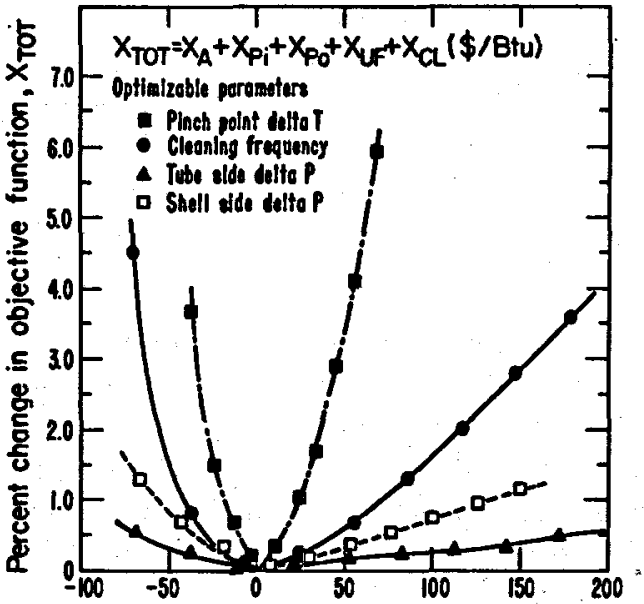

Percent change in optimizable parameter
Figure 8.16-Subsystem considerations. Influence of the sensitivity of the total heat supply cost, $\bar{X}_{\text {TOT, }}$, to various parameters of the design of the primary heat exchanger for a 50 MWe (net), supercritical isobutane binary cycle power plant proposed (reference 3) for the Heber resource. At the optimum condition, a unique relationship exists between the fouling rate, the design U-factor, the design cleaning frequency, and economic factors of the heat supply system (reference 12). 
FrqURE 8.17-Influence of well cost on optimum plant thermodynamic state conditions and heat exchange temperature differences for fixed source (wellhead) and sink (wet bulb) temperatures. Both plants are 50 MWe (net) isobutane binary cycles optimized for minimum busbar energy cost (reference 13).

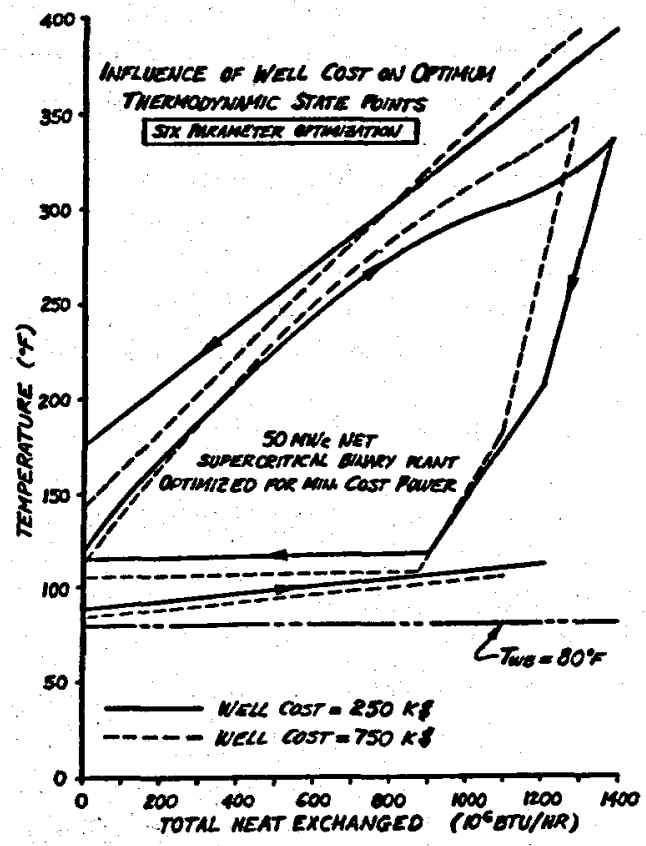

Figure 8.17 is a dramatic example of how different well cost assumptions (fixed flow rate per well) affect the computed optimum plant state conditions and therefore the thermodynamic performance and busbar cost (13). As the well cost increases (increasing fuel cost), the optimum supercritical binary cycle turbine inlet state approaches the transposed critical temperature line (14). This will be discussed in more detail in section 8.2.9.5.

8.2.5.10 Working fiuid selection for binary cycles. Step-by-step methods for the preliminary selection or elimination of possible working fluids for the organic fluid (binary) Rankine process are discussed in detail in chapters 3 through 6 of Milora and Tester's text (15).

Although generally applicable techniques are described - that is, minimization of total system irreversibility - this criteria alone introduces thermodynamic biases. It should be also pointed out that the related working fluid selection criterion used (utilization efficiency, $\eta_{u}$ ) only measures relative fuel cost. In this discussion the system design objective is minimum busbar energy cost.

However, idealized cycle net work calculations can be performed in parallel on the working fluid loop to eliminate the poor thermodynamic performers. If this approach is used, it should be kept in mind that the working fluid specific volume at turbine exhaust conditions and the design overall pressure ratio will influence the size and rotational speed, and therefore cost, of axial flow expanders. This cost difference for various working fluids can be large. There are, of course, many other economic 
factors which obviously influence the working fluid choice, and the previous step-by-step list has already introduced too much selection complexity.

If one of the newer cycle simulators is available, it is usually best to defer working fluid final choices until each of the better ones has been cost optimized. This is especially true if multiparameter optimization (MPO) routines exist in the cycle simulator. With MPO techniques, much more decisive working fluid choices can be made, because the many independent cycle state parameters can be cost optimized for each candidate fluid. The choice is then made on system economic grounds.

\subsubsection{Plant boundary assumptions-coupling to the reservoir}

We have briefly described several groups of variables the designer deals with in the preliminary screening process which influence the selected plant designs and thus the busbar energy costs. To reiterate, these are listed below:

1. Cycle above ground configuration and complexity.

2. Working fluid selection.

3. Brine temperature, salinity, chemistry and noncondensable gases.

4. Thermodynamic state points, pinch point temperature differences, and U-factors.

5. Environmental temperatures (i.e., wet and/or dry bulb) and their variations.

6. Subsystem and component cost and efficiency asssumptions.

7. System capacity factor or availability.

8. Subsystem life and recurring capital costs.

9. Overall financial considerations.

With these items plus some assumplions about wellhead conditions, well flow rate and cost (or brine cost) we could simply stop here, "optimize" what we have, and report the resulting "busbar energy cost" to the utility. However, these latter assumptions require much more accurate guesses than those above, and the results might be of little value. Resource characteristics and detailed well-field design (depth, diameter(s), spacing, costs, and drawdown factor) influence the most economic well flow rate and wellhead conditions. These conditions differ from system to system.

8.2.6.1 Brine production and disposal. The thermodynamic availability, productivity, injectivity, and longevity of the resource have a strong influence on the selected plant configuration and the computed busbar energy cost. The cost of the brine (fuel) to the plant depends upon the manner in which the brine is produced (and disposed). Different surface conversion systems usually require different production wellhead conditions and, therefore, different production (and/or injection) design scenarios. The system designer must couple the "plant" to the "resource" in some way to properly characterize these extremely important effects. 
8.2.6.2 Injection pumping. Federal, state, and local restrictions will require that the brine be disposed of in some environmentally acceptable manner. The considerations and implications of several disposal alternatives are discussed extensively in chapter $\theta$.

In this section we assume that injection pumping is a viable option, and attempt to characterize pumping costs for a simple, idealized subcooled liquid resource. We assume that the reservoir is semi-infinite in areal extent and that break-through considerations, recharge, and temperature decline are immaterial. We further assume that reservoir flow velocities are low and the reservoir is of uniform permeability and porosity (Darcy's law applies), and is "bounded" above and below by low permeability strata (groundwater pollution not possible). Although we make no attempt to characterize subsidence, gross subsidence affects will probably be mitigated with brine injection.

It should be emphasized that the foregoing assumptions will be gross over-simplifications in many cases. For example, these calculations ignore "interference effects," production well deterioration or "skin effects," and the difference in viscosity between the injected fluid and the bulk resource fluid (see chapter 2).

Interference effects (between adjacent wells and reservoir boundaries) can be characterized with a more detailed reservoir model. To include skin effects explicitly requires information from each particular reservoir. Because this is an additive series resistance, an implicit simplifying assumption herein is that the production zone skin impedance is included in the drawdown factor $(46,47,48,49)$.

The overall effect of these "idealizations" on resource productivity and injectivity, however, is not conservative.

Ideal injection pumping parasitic power (heat loss and well friction ignored) requirements can be estimated for this idealized resource if the well depth, well flow rate, drawdown, shut-in reservoir pressure, and injection pump exit specific volume are known (see section 2.6) (16) and viscosity differences between injected fluid and resource fluid are ignored.

The well depth, reservoir drawdown, and shut-in pressure are highly site specific. The degree to which they're known dictates the accuracy of the injection pumping power estimate. The magnitude of the injection pumping power requirement depends in addition on the resource temperature and the above ground cycle type, or plant exit conditions. Trends are depicted in figure 8.18. With the right combinations of the above, no pumping at all is required; the brine simply flows back into the resource under the influence of gravity. The degree to which the injection pumping power must be known depends not only on its absolute magnitude, but also on the ratio of the plant gross-to-net power output. Production and injection pumping power are not only higher, but also much higher percentages of total parasitic power in simple (pumped) flashed steam plants 


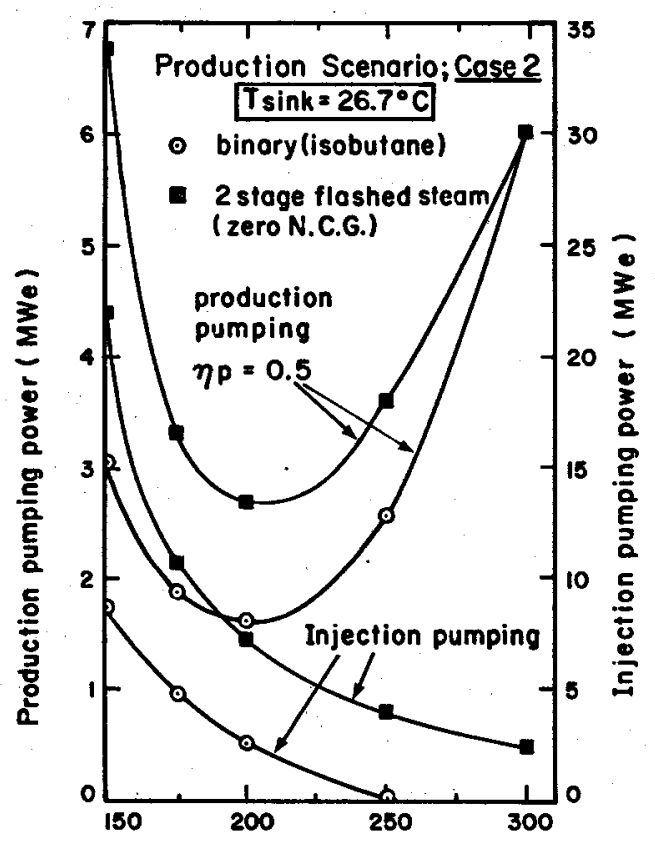

Resource temperature ( $\left.C^{\circ}\right)$
FTeUre 8.18-Comparison of produetion and injection power requirements for equal pressure resources. $50 \mathrm{MWe}$ (net) minimum busbar cost optimized, simple binary (isobutane) and two stage flashed steam plants coupled to idealized (zeroth order) subcooled liquid (pure $\mathrm{H}_{2} \mathrm{O}$ ) hydrothermal resources. All spent fluids injected. The cycles optimized are shown in figures 8.27 and 8.28. Both plants assume the brine is produced at the wellhead as a saturated liquid with suitable down-hole, high speed centrifugal pumps, shaft driven from the surface. Production well mass flow rate: $81.9 \mathrm{~kg}$ / sec $(650,000 \mathrm{lb} / \mathrm{hr})$; injection: $163.8 \mathrm{~kg} / \mathrm{sec}$. Both production and injection wells are assumed frictionless and adiabatic. Production pump adiabatic efficiency : $\eta_{p}=0.5$, $K_{\mathrm{DD}}=22.8 \mathrm{kPa} /(\mathrm{kg} / \mathrm{s}), H_{\mathrm{w}}=1830$ m.

than in binary cycle plants. Including viscosity terms would reduce the injection pumping power difference somewhat.

8.2.6.3 Production pumping. It is well known that the well flow rate has a significant effect on the brine energy cost and thus the busbar energy cost (see figure 8.19). If the normal (self flowing) flash point depth at maximum flow conditions is not too close to the bottom of the well, pro-

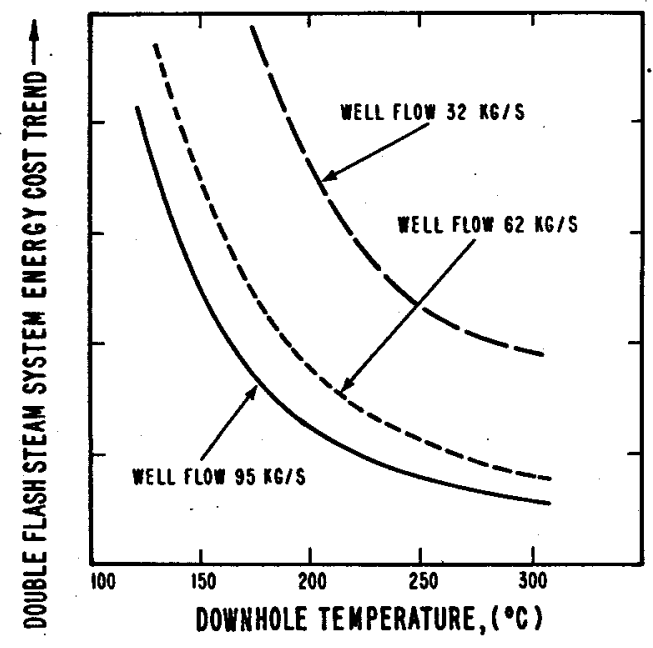

Frauke 8.19-Busbar energy cost trends as a function of resource temperature and well flow rate for double flash steam systems (reference 6). 
duction pumping can be employed to increase the flow rate (see section 2.6).

Although limited data exist for long-term production pumping, there is little doubt that reliable commercial downhole pumps will be developed. Increases of about a factor three in well productivity (compared to free flowing conditions) have been demonstrated $(17)$ at the Heber resource $\left(180^{\circ} \mathrm{C}\right)$ for binary cycle applications (saturated liquid at the wellhead) with a modest power requirement.

However, for lower or higher resource temperatures, but constant resource pressure, the same drawdown factor, pump adiabatic efficiency, and well depth (different pump depth), this pumping power requirement increases significantly (see figure 8.18 ). At $300^{\circ} \mathrm{C}$ the production pump work would be about a factor of six to eight higher to maintain unflashed conditions at the wellhead.

The high production pumping power requirements at low resource temperatures (see figure 8.18) are the result of low brine utilization efficiency (high total flow rate). The high temperature behavior is the result of decreasing flash point depth (high pump head).

Therefore, considering the high cost of wells, the relatively low pumping power requirement in the low-to-medium temperature regime (figure 8.18), the characteristic decay behavior of self-flowing wells (16), and the potential for increased scaling with significant two phase flow pressure drop, future binary cycle power plants will probably use some type of downhole production pumps.

\subsubsection{Should production wells for flashed steam plants be pumped? For} flashed steam power plants, however, brine pumping power requirements are relatively high by comparison. Although it might be necessary to pump the production wells at some resources to avoid serious scaling problems, the penalties can be high (see figure 8.18). For the medium to higher temperature $\left(200^{\circ} \mathrm{C}\right.$ to $\left.300^{\circ} \mathrm{C}\right)$ resources, where flash plants are normally best, if production pumping were required, the economic scales could tip back in favor of the binary cycles because of increased plant size.

Figure 8.20 illustrates the relative gross electric output power requirement for 50MWe (net), busbar cost optimized, two stage flashed steam energy conversion systems for two different production scenarios and fixed drawdown factor. For pumped production wells (Case 2) with saturated liquid wellhead conditions, the plant gross output power requirement (and, therefore capital cost) can be the order of $5 \%$ to $15 \%$ higher than for free flowing production wells (Case 1) depending on the resource temperature.

Under normal circumstances, then, preliminary screening calculations would assume the production wells for flashed steam plants are free flowing. (See also Chap. 2 and ref. (16).) 


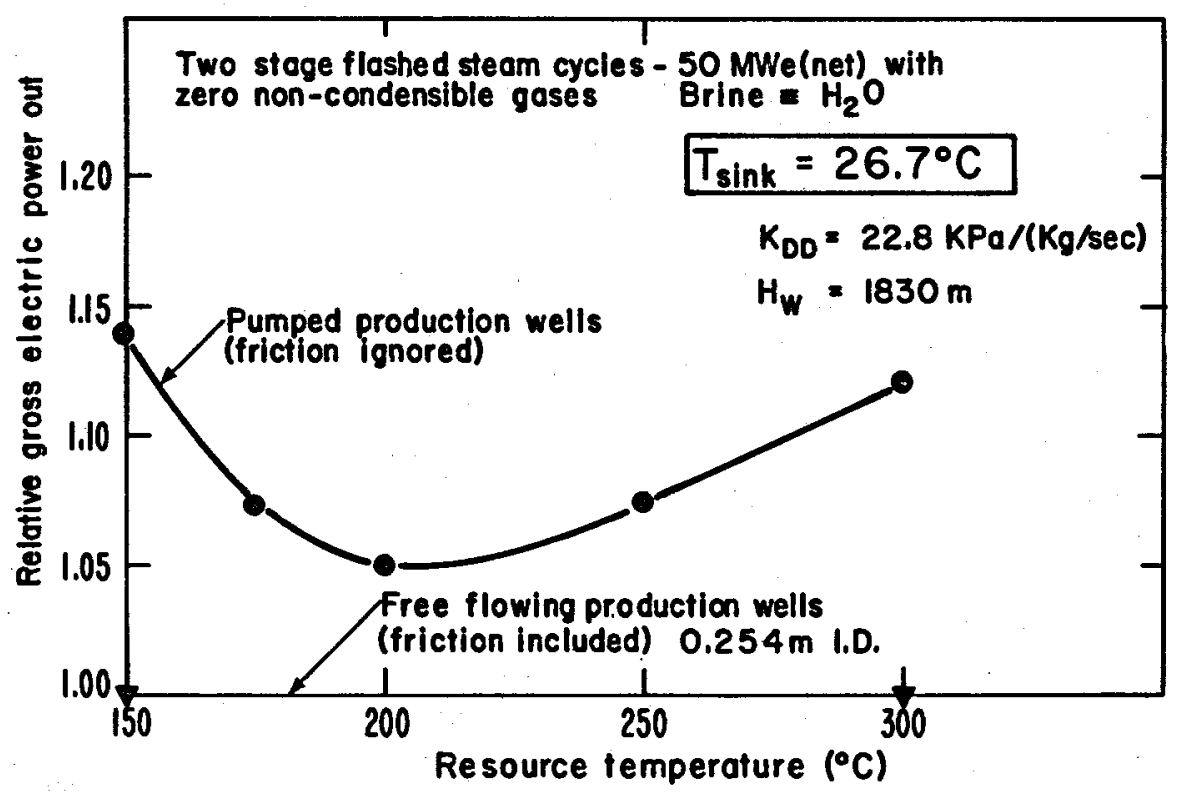

Figura 8.20-1Relative gross electric power output for minimum busbar cost-optimized, 50 MWe (net) two-stage flashed-steam energy conversion systems coupled to idealized, subcooled liquid, hydrothermal resources of various temperatures but equal pressure. All spent fluids injected. The cycles optimized are shown in figure 8.27. $\mathrm{K}_{\mathrm{DD}}=22.8 \mathrm{kPa} /(\mathrm{kg} / \mathrm{sec}), H_{\mathrm{r}}=1830 \mathrm{~m}$. All costs and financial assumptions were normalized to EPRI ER-301 (Heber flashed steam plants), but $0.254 \mathrm{~m}$ I.D. production wells were arbitrarily assumed for case 1 . This analysis assumes the well cost for case 1 and case 2 are the same.

\subsubsection{Influence of well design}

Perhaps one of the most important reasons for characterizing the entire geothermal system (resource, wells, and plant) at any screening or design stage (conceptual, preliminary, etc.) is the significant effect of the "fuel" cost on the optimum system design.

For flashed steam plants with free flowing production wells, the detail design of the wells has a profound effect on the well mass flow rate. the wellhead conditions, and, therefore, the available energy at the wellhead (16). To minimize the number of wells (field capital investment), a mandatory requirement of any well-designed free flowing flashed steam production system is that the mass flow rate be at the peak, or near choked, condition.

To do this cost effectively for subcooled liquid at the well bottom, the wells will usually have at least two liner diameter steps. It is usually desirable that the first liner diameter step, or enlargement, be at the elevation in the well where the "brine" begins to change phase. Above this 
point velocities increase significantly, and temperature and pressure gradients magnify. Near the top of the well, the two phase mixture "effective velocity" approaches critical conditions where the onset of choking occurs (16).

If the well diameter were increased again just below this "choke point," the maximum flow rate attainable would increase for the same wellhead pressure. The second well diameter step, therefore, would logically be placed within a hundred or so meters from the top of the well to achieve the greatest mass flow or availability benefit for a given incremental well capital investment.

Just where these liner steps are placed and the magnitude of the diameter changes are obvious "optimizable parameters" in an overall optimum economic system design for a given resource. It is not at all clear, however, that the existing "art" of geothermal well design has seriously considered the now obviously important thermodynamic (16) and economic trade-offs between the free flowing well and flashed steam plant first stage turbine pressure and steam fraction (18). All that is needed is a reasonable thermal/hydraulic model of vertical two phase flow, and well costs characterized as a function of depth and diameter (ignoring scaling).

The Elliott homogeneous (zero-slip) vertical two phase flow routines (16) are adequate to demonstrate behavioral trends in lieu of more exact solutions which are under development (20). The DOE/DGE funding for the 50 MWe flashed steam Demonstration Plant at Valles Caldera (NM) will bring much valuable well economic data and design technology into the open literature.

Until these data become available, idealized calculations can be performed with the available information to illustrate trends. To decisively demonstrate the influence of the detailed design of production wells on the total (flashed steam) system busbar energy cost, one would normally have to "step" the well diameter as previously described. However, firstorder limiting behavior can be determined with a simpler, constant diameter, simulation.

Figure 8.21 is a simple, first order characterization of the effect of production well inside diameter on the minimum busbar energy cost (and other plant and field parameters) assuming the production well cost is a linear function of diameter. This plot shows that a plus or minus $30 \%$ variation in well diameter (also $\pm 30 \%$ in well cost) can have a $+5.9 \%$ to $-5.4 \%$ effect on the minimum busbar energy cost $(+11.6 \%$ to $-13.2 \%$ on field capital cost) of two stage flashed steam plants (phase separator first stage) on a $200^{\circ} \mathrm{C}$, idealized, subcooled liquid hydrothermal resource. This calculation assumes a drawdown factor of $22.8 \mathrm{KPa} /(\mathrm{Kg} / \mathrm{sec})$ and depth to the production (and injection) zone of $1830 \mathrm{~m} \mathrm{(6004} \mathrm{ft.).} \mathrm{Note}$ that the optimum production well flow rate increases linearly by $44.1 \%$ with a $30 \%$ increase in well diameter. 


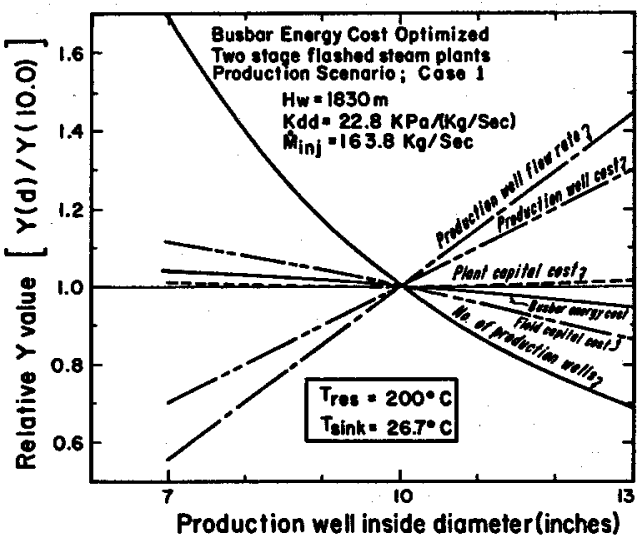

FIGURE 8.21-Approximate influence of production well inside diameter on optimum production well flow rate, number of production wells, and various costs for two-stage separating flashed steam plants on idealized, $200^{\circ} \mathrm{C}$, hydrothermal resource. Production well cost assumed to be linear function of well inside diameter $(300 \mathrm{~K} \$ /$ well for 10 inch production well). All injection wells (single phase) assumed to cost $300 \mathrm{~K} \$$. All other costs normalized to EPRI ER-301 (reference 3).

This relatively large influence on busbar energy cost would be even greater if optimum design, stepped diameter wells had been considered over the plus or minus $30 \%$ production well cost range.

\subsubsection{System analysis-computerized design optimization}

8.2.8.1. Optimization philosophy. Prior to describing the methodologies used in optimizing the design of a geothermal power plant, it is appropriate to define the role which optimization plays in the overall engineering design process. This topic is best addressed by quoting two experts in the field of applied mathematical optimization theory.

"The concept of optimization is now well-rooted as a principle underlying the analysis of many complex decision problems. It offers a certain degree of philosophical elegance that is hard to dispute, and it often offers an indispensible degree of operational simplicity. Using this optimization philosophy, one approaches a complex decision problem involving the selection of values for a number of interrelated variables, by focusing attention on a single objective designed to quantify performance and measure the quality of the decision. This one objective is maximized or minimized subject to the constraints that may limit the selection of decision variable values." (21) When one or more of the constraints or the objective function is nonlinear, the problem is a nonlinear programming problem.

"Optimization is important in all fields in which a measure of goodness exists. It is especially important in engineering, economics, and operations research. In a sense, all research and development is directed toward an optimal solution. Optimization should be the final of three steps. The first step is describing the system and the second is defining an objective function as a measure of goodness." (22)

"It is, of course, a rare situation in which it is possible to fully represent all the complexities of variable interactions, constraints, and appropriate objectives when faced with a complex decision problem. Thus, 
as with all quantitative techniques of analysis, a particular optimization formulation should only be regarded as an approximation. Skill in modeling to capture the essential elements of a problem, and good judgment in the interpretation of results are required to obtain meaningful conclusions. Optimization, then, should be regarded as a tool of conceptualization and analysis rather than as a principle yielding the philosophicallycorrect solution. Skill and good judgment, with respect to problem formulation and interpretation of results, is enhanced through concrete practical experience and a thorough understanding of relevant theory." (21)

"The chemical industry is among the leaders in using optimization techniques, although much of the reporting is company confidential. Problems in optimization occur in plant and equipment design and process control. It would be difficult to find a technical or economic area in the chemical industry in which optimization is not used. There are a number of reasons why engineers are interested in optimization. An important one is that intensive competition in the chemical process industry makes it necessary that equipment and systems operate at peak performance." (2R)

8.2.8.2. Algorithms. The thermodynamic and cost criteria which are selected as objective functions in geothermal plant design optimization problems are highly nonlinear, complex functions of the system's optimizable design parameters. The nature of these functional relationships will determine the optimization method, also known as an "algorithm," which is most suitable for the solution of the particular problem at hand. The design objective may be a "well-behaved" smooth continuous function of the system design parameters, in which case a gradient or Newton optimization algorithm will consistently converge upon the global optimum objective.

It is more likely, however, that the objective function will vary in a discrete, piece-wise continuous manner with respect to changes in the design parameters. For example, the cost of field development to a resource company is a "quantized," step-function of the number of wells drilled. A gradient or Newton optimization method cannot adequately deal with these nonsmooth "step-like" characteristics in the search for the global optimum design point. A direct search "stepping method," such as the "Simplex" algorithm is highly successful in dealing with these quantized functions. Both the continuous and discrete functional forms are encountered in the modelling and design of geothermal power plants.

Numerous nonlinear optimization codes are commercially available to the design engineer (23). These codes tend to specialize in solving problems of a particular functional form. The MINUITS (24) package of mathematical optimization routines, developed by the math and computing group at the CERN Laboratory in Geneva, Switzerland, has capabilities for solving both the continuous and the discrete type of problems discussed 
previously. MINUITS features the Davidon, Fletcher, Powell (25, 26) gradient method for optimizing continuous functions and the Simplex algorithm of Nelder and Mead (27) for optimizing functions of a quantized nature. The MINUITS package has, therefore, been selected for incorporation into the LBL developed GEOTHM code. MINUITS has consistently demonstrated its versatility and computational efficiency in dealing with the broad class of geothermal system design problems encountered by the LBL Cycle Studies Group (12, 28, 29, 30, 31), some of which are described in the remainder of this chapter.

\subsubsection{Optimization using the LBL GEOT'HM code}

8.2.9.1 Cycle characterization. Thermodynamic performance of a simple binary cycle can be completely specified $(18)$ by six thermodynamic state parameters as shown in figure 8.22 if component efficiencies are constant and small parasitic losses such as pressure drops in the heat exchangers and pipes are fixed or ignored. To use the optimization techniques described in reference (24), the user specifies some overall process objective function (i.e., minimum busbar cost, minimum capital cost, maximum brine thermodynamic yield, etc.) and selects some or all of the system independent thermodynamic state parameters as optimizable parameters (32).

Multiparameter optimization with GEOTHM and possibly other similar codes proceeds as depicted in figure 8.23. In addition to specifying first guesses to the optimizable parameters, these unconstrained, nonlinear MPO codes usually require specifications of upper and lower limits to each of
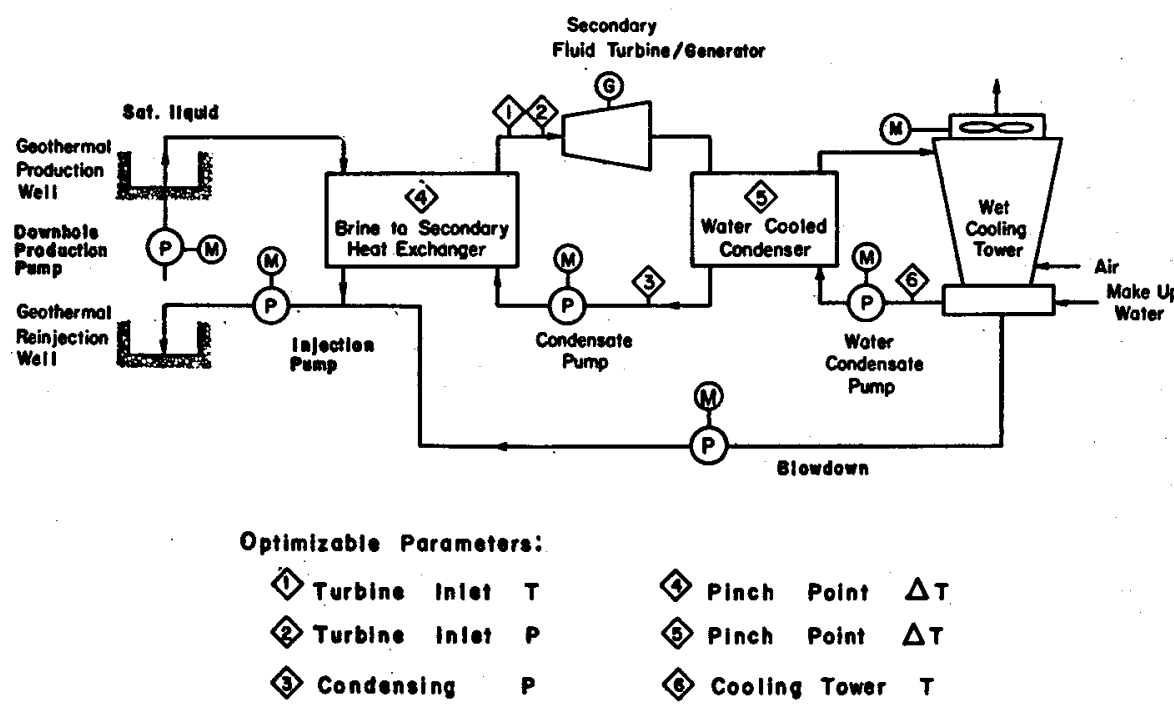

Fradre 8.22-Simplifled schematic of a simple organic fluid (binary) Rankine cycle without regenerative heat exchange. The six optimizable parameters completely characterize the thermodynamic performance of the plant. 


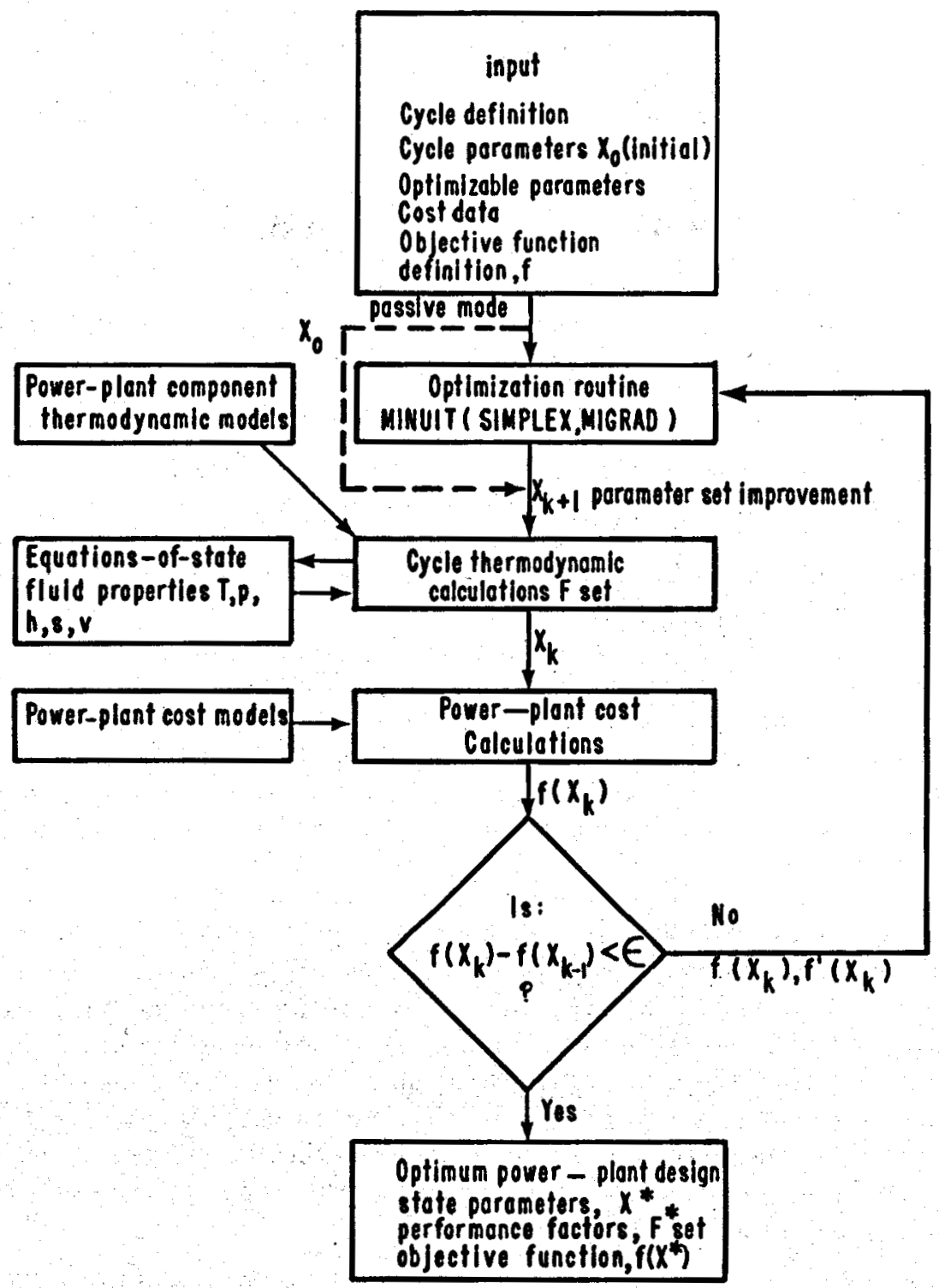

Froure 8.23-Simplified logle block diagram fllustrating calculations in the design optimization mode of the LBL-developed process simulator, GEOTHM. The MIGRAD routines of the CERN-developed MINUIT optimization program (reference 24) are most effective for a continuous objective function, whereas the SIMPLEX routines have been found to be best suited for discontinuous, step functions.

the optimizable parameters, and maximum allowable step sizes. These limits are functional constraints which can influence the selected optimum design either on the path toward the solution or at the final solution and they must, therefore, be chosen very carefully. These are briefly discussed 
in reference (24). With the first few cycles through the optimizer, the objective function and its numerical derivatives with respect to each of the optimizable parameters are computed. Using this information, the optimizer makes new choices for the optimizable parameters to converge finally on the optimum design.

8.2.9.2 Convergence criteria-computer generated noise. The value of the objective function is influenced by convergence criteria used in the solution of thermodynamic process and fluid property equations which require iterative numerical solution techniques. These techniques utilize information from numerical derivatives, $d f=f(x)-f(x-$ del $)$ where del is some user-specified step-size, to converge within some user-specified error tolerance (called an epsilon) of the exact solution. The design and optımization of the geothermal plant proceeds as a hierarchy of nested, interacting, numerically iterative calculations. This hierarchy is organized from top to bottom "levels" as follows: optimizer (objective function) $\rightarrow$ plant (net power balance) $\rightarrow$ thermodynamic proeesses (heat and mass balances) $\rightarrow$ fluid properties (state equations).

The design of a heat exchanger to achieve a specified pinch point temperature difference illustrates the interaction between thermodynamic process and fluid property calculations. The exchanger heat balance calculations are performed iteratively in order to converge upon the desired pinch condition. Each heat balance iteration, however, depends upon a number of fluid property calculations, each of which is also performed iteratively.

When convergence criteria are too slack, a high level of uncertainty is introduced into the calculations. This uncertainty appears as "random noise" or "bumpiness" superimposed upon the overall envelope of the design surface (see figure 2 of ref. (28)). If the level of this computer-generated noise is of a sufficient magnitude, it can prevent global convergence by the optimizer because the noise itself acts as numerous local minimum traps. It is therefore necessary to "tighten" the convergence criteria until the noise level is non-interfering. In the structure of the hierarchy of numerical calculations, it is essential to tighten the epsilons on all levels and to maintain their relative ranking.

8.2.9.3 Visualizing the design surface. In the course of the optimization sequence described in figure 8.23, the optimizer literally searches along a "design surface" for the global optimum plant design. This mathematical surface in an $n+1$ dimensional Euclidean space is composed of points corresponding to all the plant designs made possible from different combinations of the $n$ optimizable parameters.

In order to visualize this surface, it is necessary to fix the values of all but two of these optimizable parameters and then to plot the objective function, e.g., busbar cost, for different combinations of these two parameters. This is shown in figure 8.24 where the busbar cost is plotted as a 
Figure 8.24-Busbar energy cost design surface on turbine inlet coordinates for a $50 \mathrm{MWe}$ (net) isobutane binary cycle power plant with $180^{\circ} \mathrm{C}$, saturated liquid production wellhead conditions and $26.7^{\circ} \mathrm{C}$ wet bulb temperature. The global optimum was originally found after many previous optimization runs withont a priori knowledge of the existence of the local minimum in region B: This local minimum can prevent convergence at the global minimum.

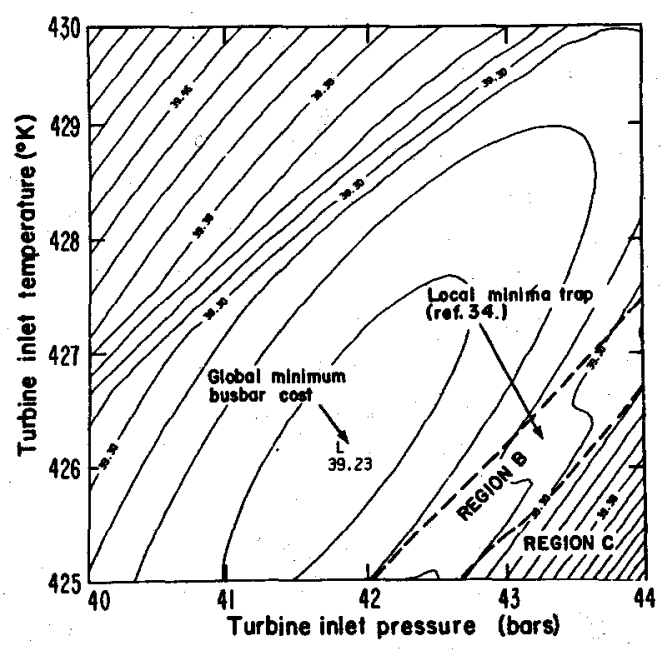

function of the turbine inlet temperature and pressure. Prior to producing this contour plot, the global minimum cost design (point $L$ is the point of minimum elevation on the design surface) was found by the GEOTHM optimization code. Then, four of the six optimizable parameters were fixed at their respective optimum values. Finally, a series of 900 passive designs $(30 \times 30)$ with variable turbine inlet temperature and pressure were used to generate the busbar energy cost data.

These design surface "visualizations" are extremely useful for understanding the functional relationships among the optimizable parameters and the objective function. For example, for the plant designs in figure 8.24 , the fuel is costed on a $\$ / B T U$ basis and the busbar cost is therefore seen to be a smooth, continuous function of the optimizable parameters. These plots also provide intuitive insight about the optimization sequence and about any potential difficulties which can prevent successful global convergence.

8.2.9.4 Local minimum trap. If a local minimum exists on the design surface which lies along the path taken by the optimizer, i.e., between the user-specified starting point and the global minimum, it is possible to converge upon the local minimum and be unable to "escape." Just such a local minimum exists on the busbar energy cost design surface of a typical supercritical Rankine cycle geothermal power plant. This local minimum is shown as region $B$ in figure 8.24. It corresponds to a region of the thermodynamic $p$-h diagram of the working fluid where the turbine inlet temperature and pressure are in the vicinity of the critical point.

This local minimum can be a computational nuisance. In the first place, this local minimum "Valley" resides in the immediate vicinity of the global optimum design point. Secondly, the value of the objective function at the local minimum is of nearly the same magnitude as the global minimum. 
These factors might not be apparent without a plot of the design surface such as figure 8.24.

8.2.9.5 The transposed critical temperature. Intrigued by the existence of the pronounced, sharp local minima on the busbar energy cost design surface, and the inability to explain it away as computer generated noise, Pope (14) noted that the locus of points representing the turbine inlet states on p-h coordinates for thermodynamic yield $\left(P_{\text {net }} / \dot{m}_{b}\right)$ optimized supercritical binary cycle plants (near infinite plant cost) intersect the working fluid "domes" at very near the critical point and roughly follow a constant specific volume line.

After plotting the transposed critical temperature (TPCT) line on the same p-h coordinates (which, of course, also originates at the critical point and very nearly follows a constant volume line), Pope postulated : if field or fuel costs clearly dominated, then the turbine inlet state for busbar cost optimized supercritical binary systems should fall on the TPCT line.

Five isobutane test cases were run at 3 different resource temperatures: $150^{\circ} \mathrm{C}, 175^{\circ} \mathrm{C}$, and $200^{\circ} \mathrm{C}$ with the well (or fuel) cost increased from "normal" levels by factors of 100 and 1000. All cases converged with the optimum cycle turbine inlet state on the TPCT line except the $200^{\circ} \mathrm{C}$ resource temperature case where the optimizer chose a lower pressure design point. This behavior is predictable considering the near-exponential maximum specific heat fall-off with departure from the critical point.

This specific heat capacity behavior is illustrated for isobutane in the 3-D plot, figure 8.25, using data calculated from the equation of state of reference (33). All pure fluids behave, more or less, the same way. In fact the contour plot for a light hydrocarbon mixture-specifically $80 \%$ isobutane, $20 \%$ isopentane-is "virtually" the same using the mixture equation of state from reference (33). We have not definitely established that the local busbar cost minima band found by Pines (34) is caused by the fluid specific heat behavior at the transposed critical temperature. Another related possibility should be investigated. If we were to compute the primary heater U-factor on a local zone basis (12) and account for real fluid behavior with an Eckert Number (52) the local cost minimum in figure 8.24 might "disappear."

8.2.9.6 Potential applications. Considering the fact that there are probably several emerging energy conversion technologies which fall into or near the "fuel cost dominated" regime (i.e., "collector costs" for terrestrial or orbiting solar power plants), further investigation of working fluid TPCT behavior appears warranted.

For geothermal binary cycles, it appears that TPCT behavior could be very useful in working fluid screening and selection. For example, if a working fluid (pure fluid or mixture) could be found for a particular re- 
ISOBUTANE TRANSPOSED CRITICAL LINE

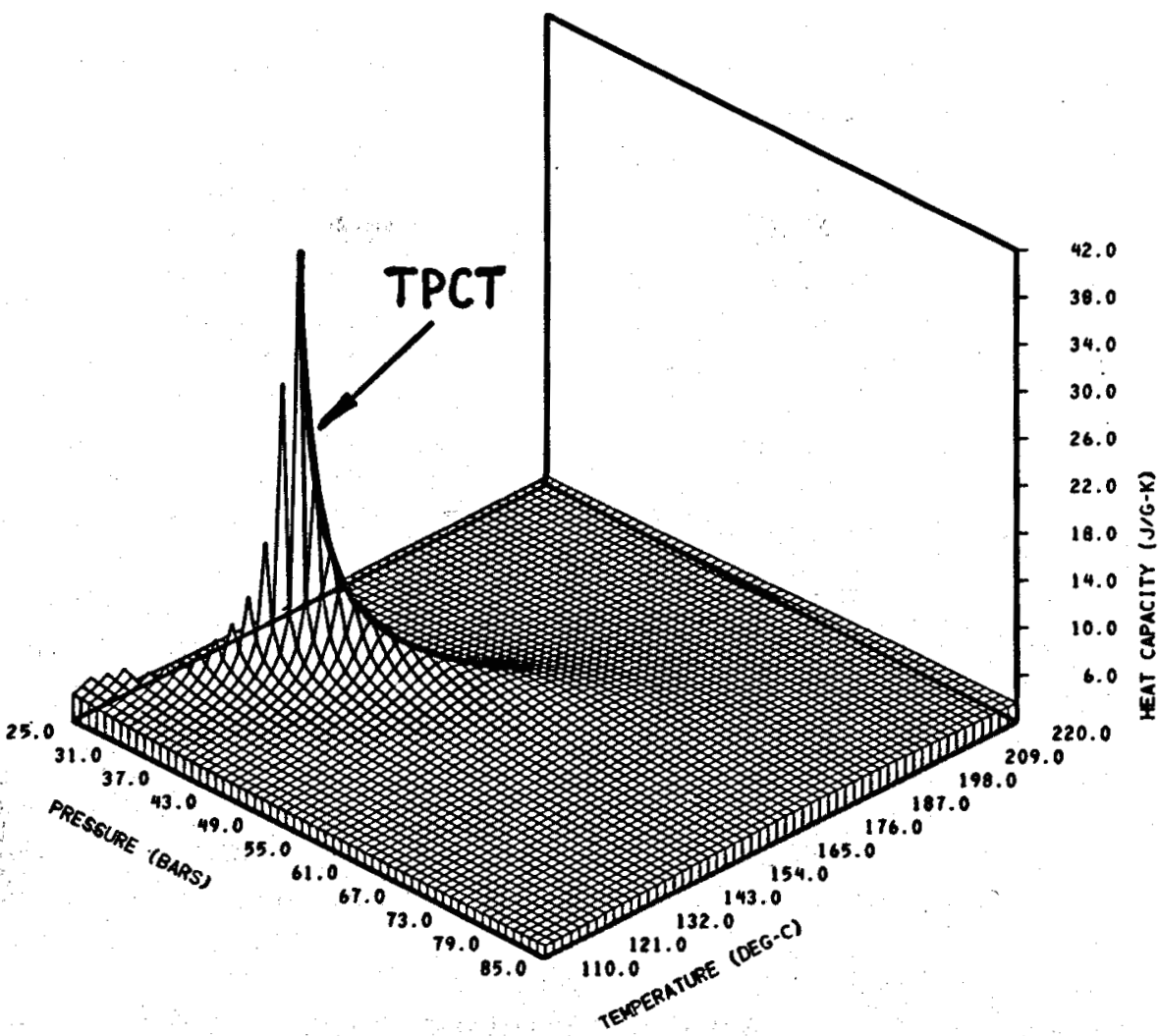

Fiaune 8.25-8-D plot of the heat capacity at constant pressure for lsobutane as a function of temperature and pressure. In the supercritical region the maximum specific heat occurs at different temperatures along a given isobar. These temperatures form a locus of points called the transposed critical temperature line.

source temperature such that when all the subsystem costs and thermodynamic irreversibilities are in balance the optimum turbine inlet state fell on or near the TPCT line, the local cost minimum (ostensibly caused by the TPCT) would be coincident with the "global" minimum and a very well defined minimum busbar cost system would result.

\subsubsection{Thermodynamic optimization as a prelude to cost optimization}

Soon after the supercritical Rankine cycle local minimum trap was found by Pines (34), Doyle found that an algorithm exists which appears to avoid it. Doyle's method (35) has been tested on simple geothermal binary cycles with 3 different working fluids (isobutane, isopentane, and propane) for resource temperatures of $150,175,200,250$, and $300^{\circ} \mathrm{C}$ (fifteen different test cases). 
After considerable frustration attempting to cost optimize these cycles without a systematic method for selecting the first guess numerical value, maximum step size, and upper and lower limits for the six variables in a simple binary cycle, Doyle tried a cost optimization using the selected cycle states from a previous thermodynamic optimization (a "yield," $P_{\text {net }} / \dot{m}_{b}$, maximization) as a first guess. The results were very encouraging.

Doyle tested this algorithm, now called "yield as a first guess" (YAFG), and it consistently worked on the 15 cases previously cited. He later reasoned that on a contour plot of the cost objective function, there should exist a point of maximum thermodynamic performance on any isocost contour, $C_{j}$. Extending this idea further, one can theorize that a path of maximum thermodynamic performance (POMTEP) exists between the global thermodynamic optimum (where plant costs approach infinity) and the global cost optimum. This will be investigated and discussed in reference (35).

In figure 8.26 we have plotted the path of two variables (the turbine inlet temperature and pressure) for a GEOTHM optimization routine (MIGRAD) (24), as the convergence sequence proceeds from the thermodynamic optimum brine yield, $\left(P_{\text {net }} / \dot{m}_{b}\right)$ opt, to the global busbar cost optimum. Keep in mind this is simply the projection of the path in three dimensions as the optimizer moves in seven dimensional space. Fortuitously, the path taken by the optimizer routine is remote from the local minima previously noted, and the YAFG algorithm has avoided the potential trap.

The YAFG algorithm has also been used with excellent results in the optimization of two stage flashed steam cycles for the five resource temperatures cited. Although the flashed steam cycles were easier to optimize (4 optimizable parameters for the simple cases studied) and do not have the binary cycle local minimum trap, the YAFG algorithm seems to work consistently.

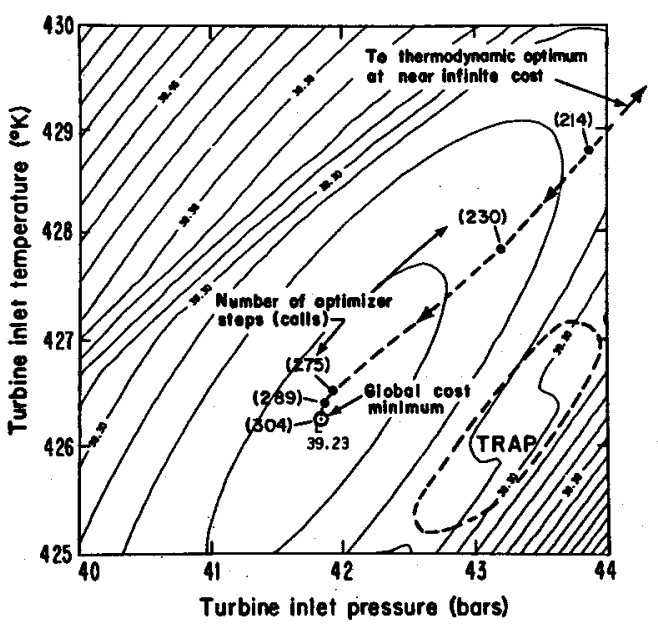

Fraure 8.26-Reproduction of figure 8.24 illustrating the path the optimizer followed in varying the turbine inlet temperature and pressure (along with the four other optimizable parameters) using the optimum thermodynamic brine yield as the first guess to the global cost optimum, YAFG (reference 35). The local minima trap has been avolded. The YAFG method converged on the global cost optimum in one optimization run. 


\subsubsection{GEOTHM example problems}

8.2.11.1 Introduction. In this section we define two basic hydrothermal energy conversion systems. In the next section we present the results of conceptual design optimizations performed with the Lawrence Berkeley Laboratory developed computer program, GEOTHM $(36,37,38)$. In these example problem optimizations, we will address geothermal power plant design methodology in the following areas:

1. The relationships between thermodynamics and economics as selection criteria for optimal plant design.

2. The capability of MPO techniques will be exploited in performing the complex trade-offs between thermodynamics and costs with a minimum of bias.

3. For the specific results obtained, a first-order attempt to rank the cycles and fluids considered on the basis of economic merit for a range of resource temperatures.

In order to address these design topics, the following computer modelling scenario has been devised. Three binary cycles, isobutane, isopentane, and propane (see figure 8.28) and two dual stage flash steam cycles, freeflowing and pumped production wells (see figure 8.27) will be optimized on separate bases of thermodynamics (specific net energy) and economics (busbar energy cost) for a range of resource temperatures. .

That the scope of these studies is restricted to the aforementioned working fluids and cycle configurations is purely an arbitrary decision by the author to establish a baseline for the study of the above topics. In reality, other cycle configurations and working fluids, e.g., single stage flashed steam or flash/binary hybrid cycles, may be just as appropriate. More general studies proposed in reference (13) will explore thermodynamic and economic trade-offs for a broader class of design alternatives and resource parameters.

8.2.11.2 Basic cycles considered. The two basic cycles characterized are:

(1) Simple two-stage flashed steam cycle and separating fiashed steam cycle (see figure 8.27 ).

(2) Simple organic fluid (binary) Rankine cycle (see figure 8.28).

8.2.11.3 General assumptions. Both cycles assume that the "brine" is pure $\mathrm{H}_{2} \mathrm{O}$. In the flashed steam system the condensing pressure is fixed at $4.0 \mathrm{in}$. $\mathrm{Hg}$. We do not have a detailed process routine in the GEOTHM code to adequately characterize steam turbine efficiency for a range of back pressure conditions. The noncondensable gas content is zero.

Both cycles assume that the hydrothermal resource is in the subcooled liquid state with resource pressure characterized by the hydrostatic head of ground water (saturated liquid at the ambient wet bulb temperature) 
at the production/injection well depth, $H_{w}$; the "zeroth order" reservoir model previously mentioned (section 8.2.6.2).

The well depth (to the production and injection zones) is constant at $1830 \mathrm{~m}(6004 \mathrm{ft})$ for all resource temperatures considered $\left(150^{\circ} \mathrm{C}\right.$ to $300^{\circ} \mathrm{C}$ ), so these sample problem results "represent" resources over a range of average geothermal gradients.

In all cases, the production and injection zone drawdown factor, $K_{\mathrm{DD}}$ (inverse of the "Productivity Index") is assumed to be $22.8 \mathrm{kPa} /(\mathrm{kg} / \mathrm{s})$.

This drawdown was measured at I.I.D. \#1 (39) in the Niland area, of the Salton Sea KGRA, but is considered about average for "good producers" in the Imperial Valley of California (40).

8.2.11.4 Production scenarios. Two different production scenarios are assumed in these studies. These are:

Production wells

Injection wells

Case 1:

(a) Flash............ Free flowing. . . . . . Pumped.

(b) Binary........... Pumped........... Pumped.

Case 2:

(c) Flash............ Pumped.$\ldots \ldots \ldots \ldots \ldots$ Pumped.

(d) Binary ........... Pumped............ Pumped (same as (b)).

In all cases except Case 1 (a) the well flow is simulated as single phase, frictionless, and adiabatic with the production wellhead state maintained at the saturated liquid condition by suitable downhole high speed, multistage centrifugal pumps shaft driven from the surface by electric motors. The downhole pump adiabatic efficiency assumed was conservative: $\eta_{p}=0.5\left(1^{\prime}\right)$.

For Case 1(a), the flashed steam cycle with free flowing production wells, we calculated the production wellhead conditions and optimum well flow rate using the simple Elliott (16) homogeneous (zero slip) adiabatic, vertical two phase flow approximations described in section 2.6. We used the "zeroth order" reservoir model and drawdown factors (described above), assumed an average "friction factor" of 0.008 (16), and a constant well inside diameter of $0.254 \mathrm{~m}$ ( 10.0 inches).

The assumptions and vertical two-phase flow approximations for Case 1(a) are admittedly crude. We have, however, connected the plant to the "resource" to investigate the implications of two general production scenarios for two simple but basically different optimized surface conversion systems over a broad range of resource temperatures (or geothermal gradients) for three typical working fluid candidates, "typical" resource drawdown conditions, and "average" well depths (resource pressures). 
8.2.11.5 Subsystem assumptions. For all cases presented the input assumptions in table 8.1 apply except as noted above :

TABLE 8.1-Subsystem assumptions

\begin{tabular}{|c|c|c|}
\hline Parameter & Binary cycle & Flashed steam \\
\hline Drawdown Factor, $K_{D D}(\mathbf{k P a} /(\mathrm{kg} / \mathrm{s}))$. & 22.8 . & 22.8 \\
\hline Well Depth (m)............... & 1830. & 1830 \\
\hline Well Cost (drilled and cased) (K\$). . & 300.0. & 300.0 \\
\hline Net Cycle Power output (MWe)... & 50.0. & $\mathbf{5 0 . 0}$ \\
\hline Plant Capacity Factor. .............. & $\ldots \ldots \ldots$ & 0.85 \\
\hline Design wet bulb temp $\left({ }^{\circ} \mathrm{C}\right) \ldots \ldots \ldots \ldots \ldots$ & $26.7\left(80^{\circ} \mathrm{F}\right) \ldots \ldots$ & $26.7\left(80^{\circ} \mathrm{F}\right)$ \\
\hline Expander Type............... & Radial inflow..... & $\begin{array}{l}\text { Double entry, } \\
\text { axial inflow }\end{array}$ \\
\hline Expander Adiabatic Efficiency (constant). & 0.85 . & $\begin{array}{l}0.70 \text { high pressure } \\
\text { stages }\end{array}$ \\
\hline & & $\begin{array}{l}0.65 \text { low pressure } \\
\text { stages }\end{array}$ \\
\hline Generator Efficiency... & 0.98 & 0.98 \\
\hline Motor Efficiencies (all).. & 0.95 & 0.95 \\
\hline $\begin{array}{l}\text { Pump Efficiencies (all) } \ldots \ldots \ldots \ldots \ldots \ldots \ldots \ldots \\
\text { Overall Heat Transfer Coefficients }\left(W / \mathrm{m}^{9 \circ} \mathrm{K}\right)\end{array}$ & $0.80 \ldots \ldots \ldots \ldots$ & 0.80 \\
\hline Supercritical Primary H.X.......... & $1514 \ldots \ldots$ & - \\
\hline Subcritical Primary H.X.......... & $1514 \ldots \ldots \ldots$ & - \\
\hline Pre-heating. . . . . . . . . . . . . & $1514 \ldots \ldots \ldots \ldots$ & - \\
\hline Boiling.................. & $1514 \ldots \ldots \ldots \ldots$ & - \\
\hline Superheating............ & $1514 \ldots \ldots \ldots \ldots$ & - \\
\hline Condensing. ........ & 567. & 3240 \\
\hline Desuperheating. & 238. & - \\
\hline
\end{tabular}

8.2.11.6 Costing assumptions-financial factors-normalization. Prior to performing any cost optimizations, we carefully normalized all subsystem costs and direct and indirect cost factors to those in reference $(3)$ in the following manner.

First we modelled the identical cycle configurations as those in reference (3) for the same source and sink conditions using the GEOTHM code and verified the mass flow rates and subsystem power requirements for the same stated subsystem efficiencies, working fluids, cycle state conditions, and pinch points.

Then we normalized all the subsystem cost factors (37) to achieve the same purchased costs as those in reference $(g)$. We then determined the values of the direct and indirect cost factors (see reference (15), chapter 6) which were necessary for the plant and field to achieve equal installed capital costs and $O$ and $M$ expenses as those stated in reference ( 3 ).

Finally we determined the required "effective fixed charge rates" which, when applied to the plant and field capital costs for the initial capital investment or beginning-of-life configuration, achieved the same plant and 
field annual expenses and busbar costs as those in reference (3). The preferred method of doing all this is described in chapter 7 .

These tedious, but effective, cost normalization procedures-were necessary for two reasons. First of all, general formal subsystem costing routines do not exist in the LBL GEOTHM code; adjustable cost coefficients must be normalized (37) by the user to vendors quotes or other data on a case-by-case basis depending on the rating, quality, materials, and type of subsystem (s) assumed.

Secondly, formal financial routines do not currently exist in the GEOTHM code which would allow the user to explicitly specify such things as (1) rate of return, (2) debt/equity ratio, (3) inflation rate, etc. These routines are currently being developed for GEOTHM, but will not be operational until approximately April 1979 (41).

Because of the subsystem cost and financial factor normalization technique we used, all those cost, financial factor, plant life, well replacement, and subsystem life assumptions stated in reference (3) also apply for the example problem results presented herein.

8.2.11.7 Modified assumptions. However, after the cost normalizations to reference (B) (Heber Plants) were performed, we modified some of the assumptions of reference (\$) to put all these $50 \mathrm{MWe}$ (net) plants on a consistent basis. Four modifications were made:

(1) Inclusion of production and injection parasitic power

(2) Number of "spare" production wells

(3) Equal cooling tower make-up water temperature

(4) Cooling tower blowdown injection

For example:

(1) In reference (3), the production and injection pumping systems were detailed and costed, but these parasitic power requirements were not included in the cases presented. We include all parasitic power requirements as shown in figures 8.27 and 8.28.

(2) It may be noted that the total brine flow rate and number of production wells specified in reference (3) for the base case binary cycle (Heber) allows for one extra production well (ostensibly a "spare" for well or downhole pump maintenance) whereas the Heber two stage flashed steam plant does not.

We assume one spare production.well (and pump if applicable) for all plants.

(3) It may also be noted that the cooling tower make-up water temperature for the Heber Binary Cycle of reference (3) was $90^{\circ} \mathrm{F}$, whereas the Heber flashed steam plant assumed $85^{\circ} \mathrm{F}$. For the single $80^{\circ} \mathrm{F}\left(26.7^{\circ} \mathrm{C}\right)$ wet bulb temperature cases presented here, we assume the cooling tower make-up water is available at $90^{\circ} \mathrm{F}\left(32.2^{\circ} \mathrm{C}\right)$ for all plants. 


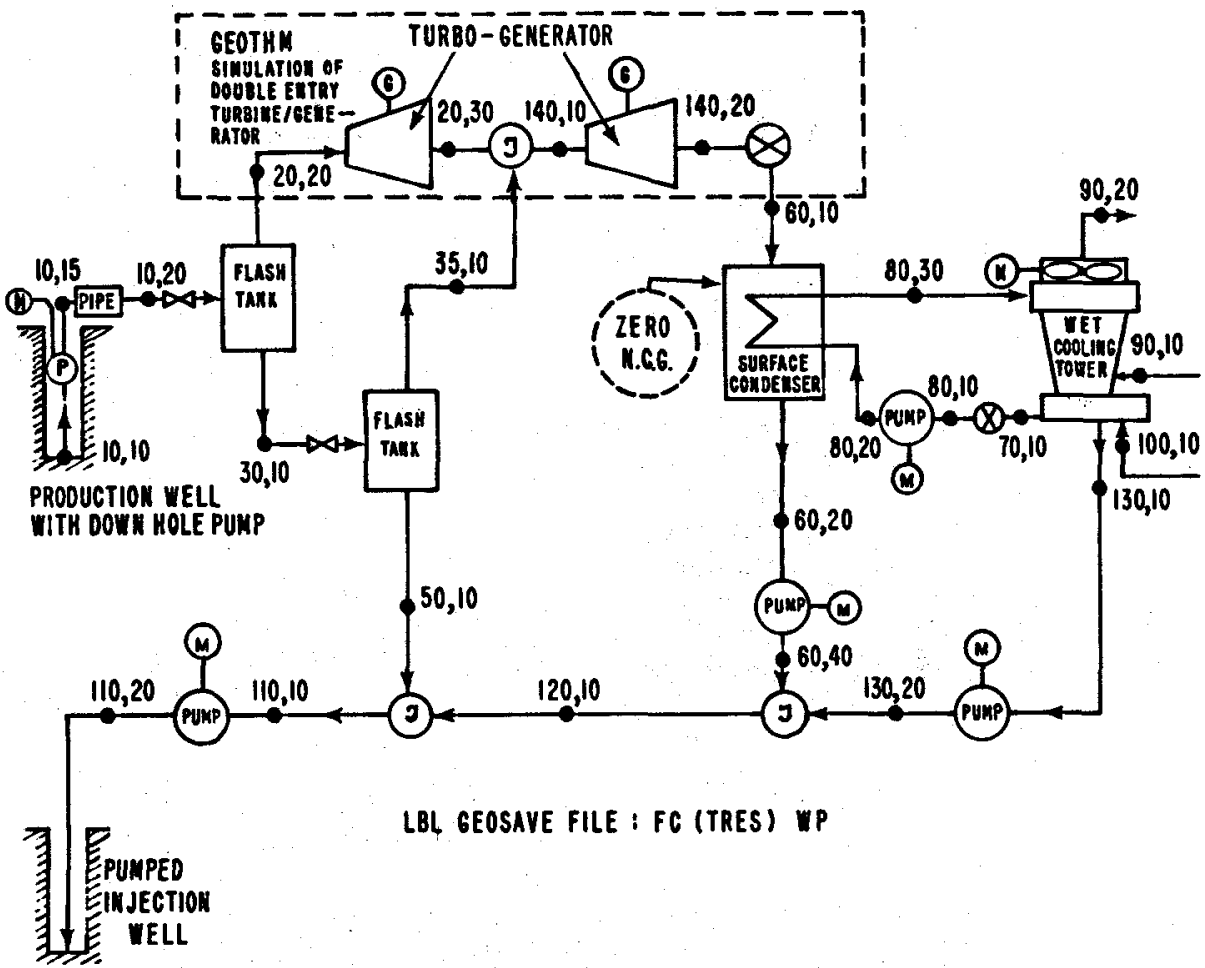

Frouke 8.27-Simple two-stage flashed steam system (pumped production wells) or separating fashed steam system (free-flowing two-phase production wells) as specifed for GEOTHM. The state point numbering system follows GEOTHM input conventions (reference 37). Optimizable parameters are listed in table 8.2. All brine (simulated by $\mathrm{H}_{3} \mathrm{O}$ ) and cooling tower blowdown are reinjected and all parasitic loads are Included in the design. The turbine back pressure is fixed at $4 \mathrm{in} \mathrm{Hg}$ and zero noncondensable gases are assumed. The simulator inserts an expansion valve in place of the infection pump if plant exit and resource conditions permit.

(4) We assume the cooling tower blowdown is injected with the spent brine and calculate the number of wells and power required to accomplish this.

8.2.11.8 Optimizable parameters. Table 8.2 lists the thermodynamic state parameters which were treated as "optimizable parameters" for the two simple cycle configurations of this study.

\subsubsection{Example problem results}

8.2.12.1 Highlights. The results of the example problems can be summarized briefly as follows:

1. Any single thermodynamic or cost category other than minimum busbar energy cost is a misleading criterion in an attempt to rank the 
TABLE 8.2-Optimizable parameters

A. Binary Cycle (saturated liquid wellhead conditions) :

1. Turbine inlet pressure

2. Turbine inlet temperature

3. Condenser pressure

4. Primary heat exchanger pinch point delta $T$

5. Condenser pinch point delta $T$

6. Cooling tower approach to wet bulb

B. Troo-Stage Flashed Steam (Zero noncondensible gases, 4.0 in. Hg turbine back pressure) :

(1) Production Scenario; CASE 1 (two-phase wellhead conditions)

1. Production flow rate per well

2. Second stage flasher pressure

3. Condenser pinch point delta $T$

4. Cooling tower approach to wet bulb

(2) Production Scenario; CASE 2 (saturated liquid rellhead conditions)

1. First stage flasher pressure

2. Second stage flasher pressure

3. Condenser pinch point delta $T$

4. Cooling tower approach to wet bulb

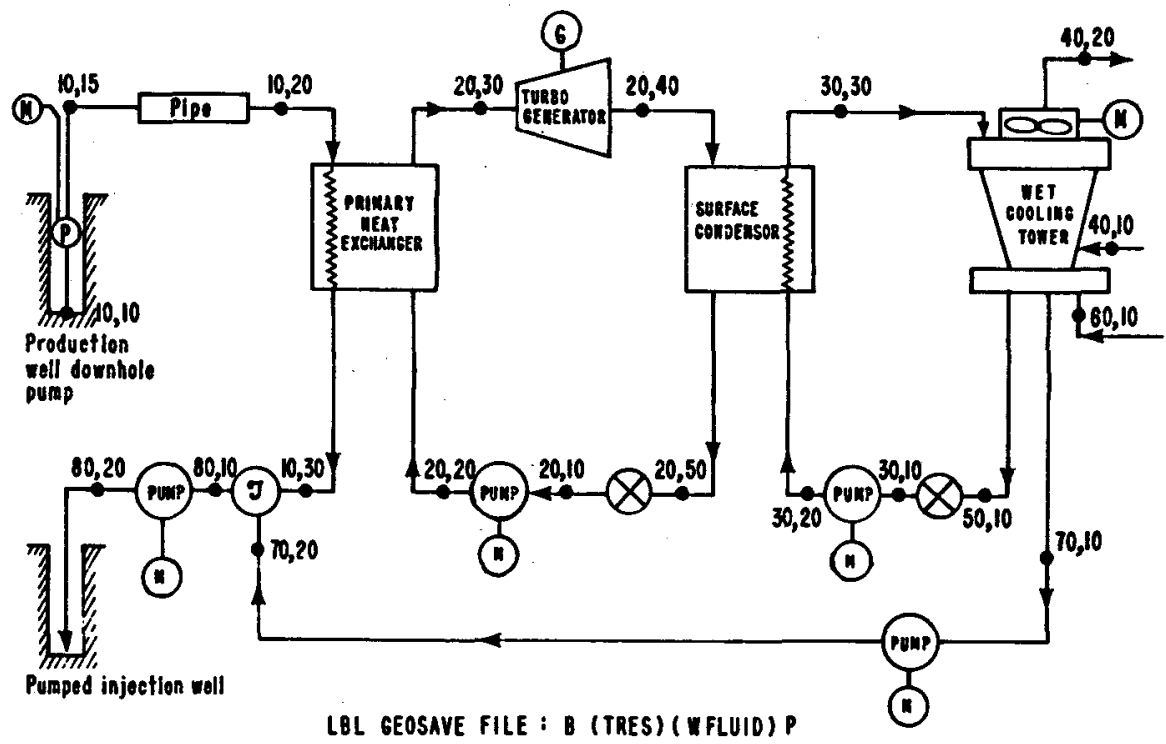

FraUke 8.28-Simple organic fluid (binary) Rankine cycle (without regenerative heat exchange) with pumped production wells as specified for GEOTHM. These systems were cost optimized for three different light hydrocarbon secondary working fluids. Optimizable parameters are listed in table 8.2. All brine (simulated by $\mathrm{H}_{2} \mathrm{O}$ ) and cooling tower blowdown are reinjected and all parasitic loads are included in the design. The simulator inserts an expansion valve in place of the reinjection pump if plant exit and resource conditions permit. 
relative economic merit of various conversion systems for a common resource. These stand-alone categories include wellhead utilization efficiency, brine specific net energy, plant capital cost, and field capital cost.

2. The relative economic ranking between flashed steam and binary cycle plants shifts significantly when production pumping requirements are considered in the sizing of the flashed steam plant. Pumping the production wells in the flashed steam plant displays this alternative in a relatively unfavorable manner (\$).

8.2.12.2 Discussion. Because thermodynamics alone is frequently used as a measure of competing geothermal process "goodness," it is appropriate that we discuss the significance of this selection criterion first. In figure 8.29 we have plotted the maximum wellhead "brine" utilization efficiency as a function of resource temperature for the two simple hydrothermal energy conversion processes described previously in figures 8.27 and 8.28. The wellhead utilization efficiency is simply the ratio of the useful work of the energy conversion process to the maximum available work (i.e., if the "brine" were expanded isentropically from the wellhead state to the sink (wet bulb) temperature). Each of the points on this plot represents cycles which have been thermodynamically optimized (see section 8.2.9.1) with system maximum specific net energy, or brine "yield," $\left(\boldsymbol{P}_{\text {net }} / \dot{m}_{\mathrm{b}}\right)$ as the objective function. For this optimization, the pinch point (not the mean)

FiguRe 8.29-Wellhead utllization efficiency for maximum thermodynamic brine yield optimized, 50 MWe (net) simple binary and twostage flashed steam energy conversion systems coupled to Idealized, subcooled liquid, hydrothermal resources of equal pressure. All spent fluids injected. The cycles optimized are shown In figures 8.27 and 8.28. Production and injection wells are frictionless and adiabatic except the free flowing flashed steam, where friction is included. $\quad K_{\mathrm{DD}}=22.8 \mathrm{kPa} /(\mathrm{kg} / \mathrm{s})$; $H_{m}=1830 \mathrm{~m}$. All costs immaterial.

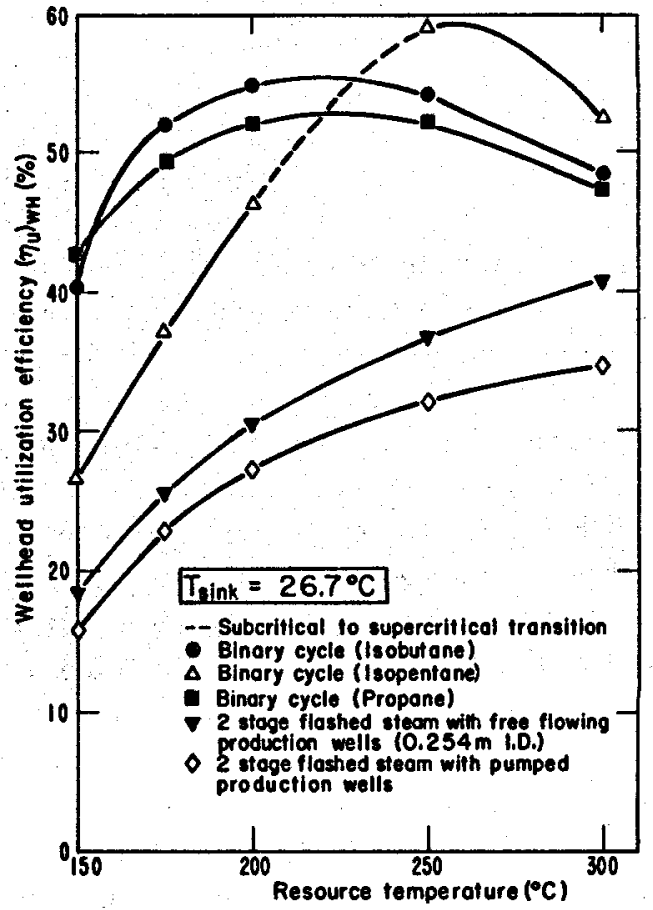


temperature differences of all nonwork producing elements of the cycle were zeroed whereas the remaining independent system thermodynamic state parameters (see table 8.2) were optimized. In each case all sub-system parasitic power has been considered including the heat rejection system and fluid production and injection systems. All costs for this thermodynamic optimization are immaterial.

The first point we wish to make regarding figure 8.29 is that our maximum theoretically achievable utilization efficiencies are, in general, lower than those reported in reference (15). There are three principle reasons for this:

1. Degree of system characterization.

2. The utilization efficiency defined here is based on the sink temperature as the dead state (1), not the condensing or "heat rejection temperature".

3. Our turbine inlet state and condensing pressures have been determined using the MPO capabilities of GEOTHM thus minimizing potential biasing assumptions. An exception is that we assumed a constant (4.0 in. $\mathrm{Hg}$ ) condensing pressure for all the flashed steam calculations.

The second point regarding figure 8.29 is that with brine utilization efficiency at the optimum thermodynamic condition as the selection criterion, a relative merit ranking between cycles and working fluids is clearly implied. We will later show that this relative goodness is not only a poor indication of relative busbar cost between cycles, but also a poor indicator of relative economic goodness between various working fluids in a binary cycle.

The third point regarding figure 8.29 is that the wellhead utilization efficiency for the free flowing flashed steam process (phase separator as a first stage) is in all cases higher than for the two stage flash stearn process with pumped production wells (saturated liquid wellhead conditions) for the same resource temperature.

We will return to figure 8.29 later to illustrate additional differences when minimum busbar energy cost is the objective function.

In figure 8.30 we have plotted the maximum wellhead "brine" utilization efficiency for the cycles and fluids previously discussed, but in this case, all points plotted represent designs which have been optimized with minimum busbar energy cost as the design objective (see table 8.2). For cost optimized designs the economically achievable resource utilization efficiency is the result of a complex trade-off between minimizing subsystem irreversibilities and minimizing subsystem costs.

The first point illustrated in figure 8.30 is that economically achievable brine utilization efficiencies are significantly lower than in figure 8.29 and reference (15). This has also been pointed out by Starling (4D). The main 
Frgure 8.30-Wellhead utilization efficiency for minimum busbar cost optimized, $50 \mathrm{MWe}$ (net) simple binary and two-stage flashed steam energy conversion systems coupled to idealized, sub-cooled liquid, hydrothermal resources of equal pressure. All spent fluids injected. The cycles optimized are shown in figures 8.27 and 8.28. Production and injection wells are frictionless and adiabatic except the free-flowing flashed steam. where friction is included. $K_{\mathrm{DD}}=$ $22.8 \mathrm{kPa} /(\mathrm{kg} / \mathrm{s}), H_{\varpi}=1830 \mathrm{~m}$. All costs and financial assumptions were normalized to EPRI ER-301 (Heber plants). Equal expander unit costs $(\$ / \mathrm{kW}$, gross) were assumed for all binary fluids. See section 8.2.11 for other assumptions.

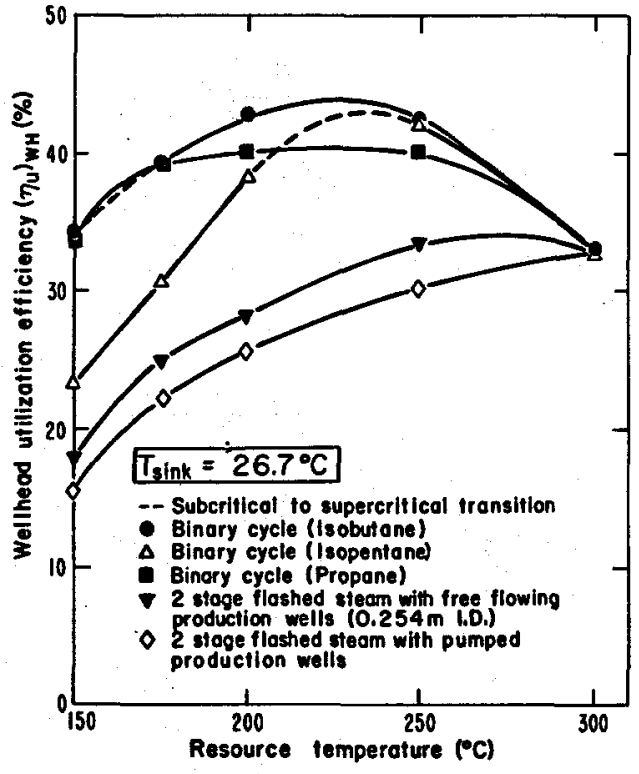

reason for the reductions from figure 8.29 values is increased system entropy production introduced in the heat exchange portions of the cycle as practical pinch points are adopted. The utilization efficiency reduction is less for the flashed steam cycles (at lower temperatures) because we have fixed the condensing pressure at "practical levels" ( $4.0 \mathrm{in} . \mathrm{Hg})$ for both the thermodynamic and the cost optimization (see section 8.2.11.3).

The second feature discernable from figure 8.30 is that isopentane no longer stands out at temperatures above say $230^{\circ} \mathrm{C}$ (see figure 8.29) when utilization efficiency at optimum busbar energy cost is the selection criterion.

It is interesting to note that all cycles "converge" upon virtually the same wellhead utilization efficiency at $300^{\circ} \mathrm{C}$. This is explained in the footnote below.*

*The two hydrothermal energy conversion systems considered will approach the same specific net energy at some high resource temperature (ostensibly about $300^{\circ} \mathrm{C}$ ) for cost optimized designs because of asymptotic thermodynamic performance trends indicated by binary cycles (see flgure 8.37). With the high maximum well flow rates we have assumed $(81.8 \mathrm{~kg} / \mathrm{s}$ for all pumped production wells and $163.8 \mathrm{~kg} / \mathrm{s}$ for all injection wells) the total number of wells required for all cases at $300^{\circ} \mathrm{C}$ is small (7-8). We have used a quantized field cost model to characterize discrete well costs. Therefore, for example, given the choice of either accepting a quantum field capital cost increase of about $\$ 600,000$ due to adding a well or adjusting the plant optimizable parameters to achleve a lower busbar cost with a smaller than $\$ 600,000$ increase in the plant cost, the optimizer chooses the latter in all cases at $300^{\circ} \mathrm{C}$. This forces the speciflc net energy (and therefore utilization efficiency) from being nearly equal for the pumped well cases to being exactly equal $( \pm 0.11 \%)$ at $300^{\circ} \mathrm{C}$. The free flowing flashed steam specific net energy is only $2.6 \%$ lower than the rest at a production well flow rate of $148 \mathrm{~kg} / \mathrm{s}$. 


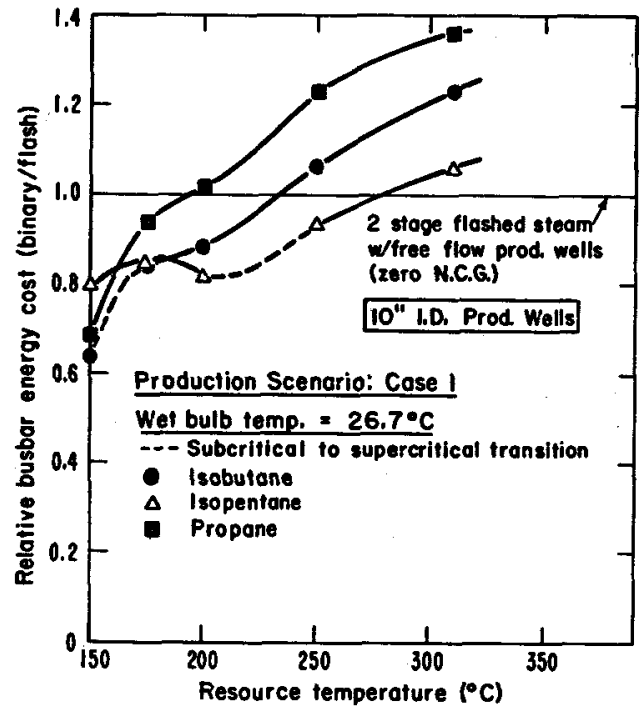

FIGURE 8.31 - Relative busbar energy cost for minimum busbar cost optimized, $50 \mathrm{HWe}$ (net) simple binary and two-stage flashed steam energy conversion systems coupled to Idealized, subcooled liquid, hydrothermal resources of equal pressure. All spent fluids injected. The cycles optimized are shown in figures 8.27 and 8.28. Production scenario : case $1 . K_{\mathrm{DD}}=22.8 \mathrm{kPa} /(\mathrm{kg} / \mathrm{s}), H_{\mathrm{w}}$ $=1830 \mathrm{~m}$. All costs and financia assumptions were normalized to EPRI ER-301 (Heber plants). The 10" I.D. coustant diameter production wells were arbitrarily assumed at no increase in cost over EPRI ER-301 assumptions. Equal expander unit costs $(\$ / \mathrm{kW}$, gross) were assumed for all binary fluids. See section 8.2.11 for other assumptions. Note: $300^{\circ} \mathrm{C}$ data points have been incorrectly plotted.

Figure 8.31, fortunately, sorts out the previous confusion from using thermodynamic criteria alone for selecting conversion system and working fluid alternatives. In figure 8.31 we have plotted the relative busbar energy cost (binary/flash) as a function of resource temperature for production scenario, Case 1(a) and 1(b). This plot indicates that not only is isopentane the best binary cycle working fluid (of the selected 3 ) for resource temperatures above about $230^{\circ} \mathrm{C}$ (see figure 8.29 ), it is the best binary cycle choice for all average resource temperatures above about $180^{\circ} \mathrm{C}$. This is consistent with Starling's (43) conclusion that the optimum working fluid (mixture) molecular weight increases with increasing resource temperature. According to these results, the isopentane binary cycle will be competitive with free flowing separating flash steam cycles for resource temperatures up to roughly $270^{\circ} \mathrm{C}$. This must be qualified by the figure caption statement; assuming the unit cost of first generation radial inflow geothermal expanders will be "about the same" (44). Rough comparative calculations of axial flow expander unit costs (15) (section 6.4) for these fluids do not support the foregoing assumption. Those rough calculations suggest the differences in binary cycle economic performance would be less than that indicated in figure 8.30.

Figure 8.32 is similar to figure 8.31 in all details except here the flashed steam process assumes pumped production wells with saturated liquid wellhead conditions, and a constant production well mass flow rate at all resource temperatures. 
The main difference noticeable between figures 8.31 and 8.32 is that binary cycle relative economic merit is displayed more favorably when the flashed steam cycles assume pumped production wells (Case 2) as in figure 8.32. This potential system designer bias has been pointed out by Elliott (45), was alluded to previously in section 8.2.6.4, and illustrated in figure 8.20.

The degree of difference between flashed steam plants with pumped and unpumped production wells is influenced by various free flowing production well design and cost assumptions described previously in section 8.2.7, and the resulting parasitic power influence on plant and field size.

Figure 8.33 illustrates that the manner in which fuel "costs" are evaluated can be important if various conversion systems are compared with fuel cost as a simple additive "over-the-fence" price. All data points on this plot were computed from the final results of minimum busbar energy cost optimized plants with the fuel cost determined by the "cost-ofservice" approach described in section 8.2.4.2. We simply offer this plot "in evidence" for a currently unresolved issue.

Figure 8.34 shows computed relative plant capital costs (binary/flash) for $50 \mathrm{MWe}$ (net) minimum busbar cost optimized designs assuming production scenario; Case 2 (pumped production wells with saturated liquid wellhead conditions in all cases). It can be noted from this plot that plant capital cost differences alone are also a poor indicator of relative busbar energy cost (see figure 8.32).

Figure 8.35 is a similar plot of computed relative field capital costs for Production Scenario Case 2. As with all previous singular thermodynamic or cost ranking "evaluators," relative field capital cost (proportional to

FiguRE 8.82-Relative busbar energy cost for minimum busbar cost optimized, 50 MWe (net) simple binary and two-stage flashed steam energy conversion systems coupled to ideallzed, subcooled liquid, hydrothermal resources of equal pressure. All spent fluids injected. The cycles optimized are shown in figures 8.27 and 8.28. Production scenario: case 2. $K_{D D}=22.8 \mathrm{kPa} /$ $(\mathrm{kg} / \mathrm{s}), H_{w}=1830 \mathrm{~m}$. All costs and financial assumptions were normalized to EPRI ER-301 (Heber plants). Equal expander unit costs $(\$ / \mathrm{kW}$, gross) were assumed for all binary fluids. See section 8.2.11 other assumptions.

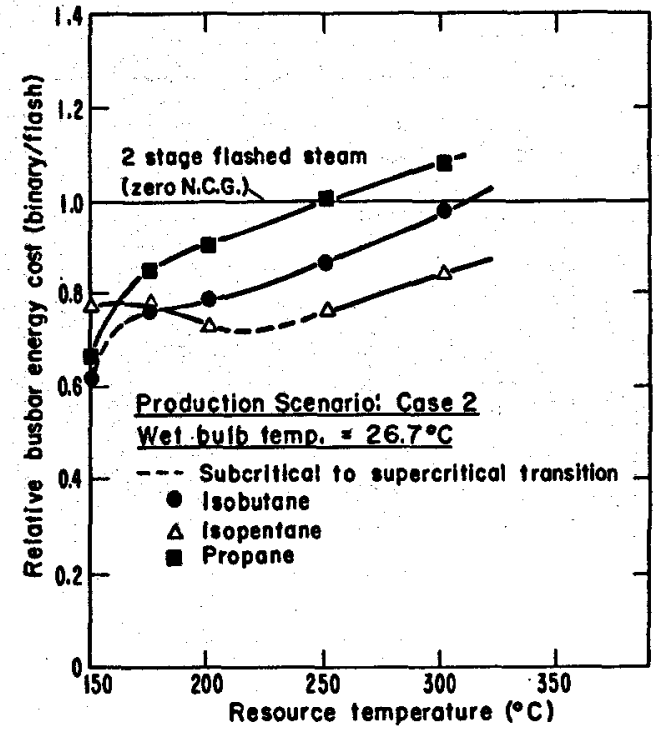




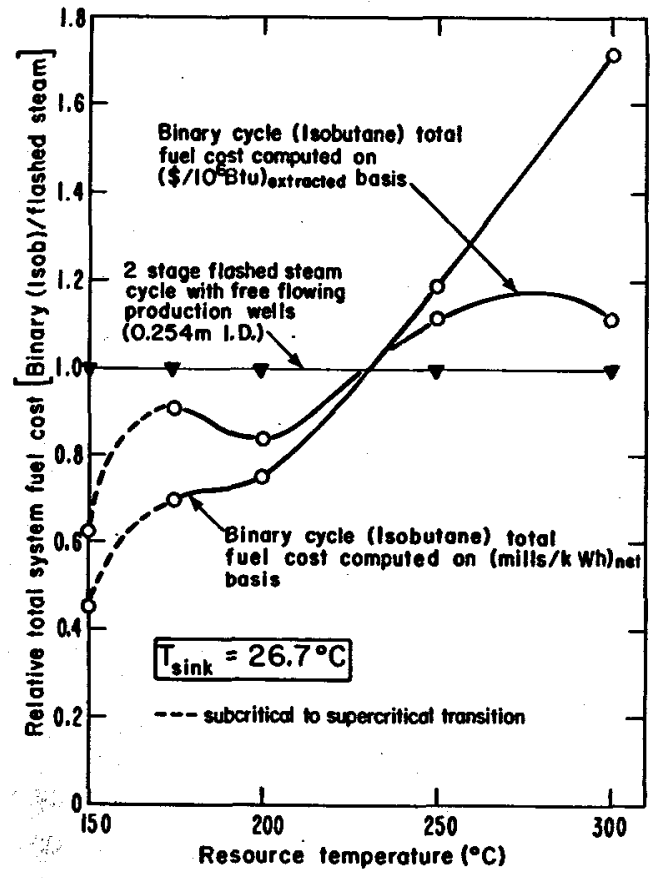

Figure 8.33-Relative total system "fuel" cost (annualized field capital and O\&M expenses and annual cost of brine, cooling water, and treatment chemicals) for minimum busbar cost optimized, 50 MWe (net) simple binary (isobutane) and two-stage flashed steam (free-flowing production wells) energy conversion systems coupled to idealized, subcooled liquid, hydrothermal resources of equal pressure. All spent fluids injected. The cycles optimized are shown in figures 8.27 and 8.28 . $K_{\mathrm{DD}}=22.8 \mathrm{kPa} /$ $(\mathrm{kg} / \mathrm{s}), H_{w}=1830 \mathrm{~m}$. All costs and financial assumptions were normalized to EPRI ER-301 (Heber plants), but $0.245 \mathrm{~m}$ I.D. production wells arbitrarily assumed for flashed steam plants. See section 8.2.11 for other assumptions.

number of wells or brine mass flow) does not properly rank relative busbar energy cost (see figure 8.32).

Therefore, if one were to compare geothermal energy conversion system alternatives by any of the foregoing "intuitively valid" criteria other than minimum busbar energy cost, inconsistencies in reported results will de-

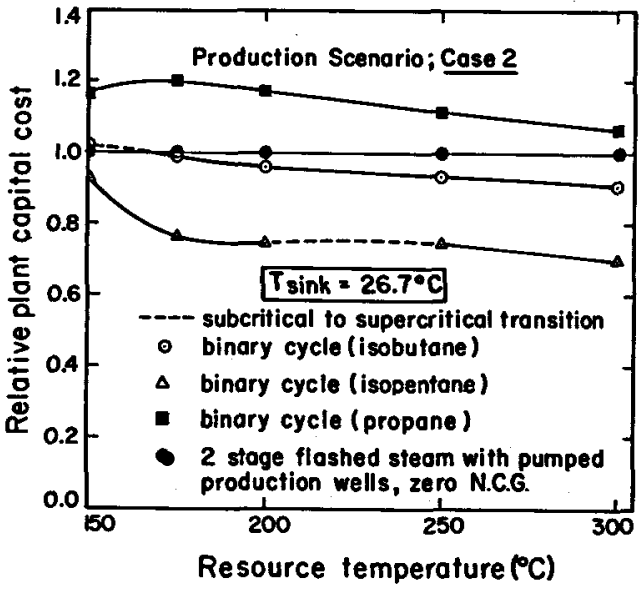

Figure 8.34-Relative plant capital cost for minimum busbar cost optimized, $50 \mathrm{MWe}$ (net) simple binary and two-stage flashed steam (case 2) energy conversion systems coupled to idealized, subcooled liquid, hydrothermal resources of equal pressure. All spent fluids injected. The cycles optimized are shown in figures 8.27 and 8.28. Production scenario: case $2 . K_{D D}=22.8 \mathrm{kPa} /(\mathrm{kg} / \mathrm{s}), H_{\text {. }}$ $=1830 \mathrm{~m}$. All costs and financial assumptions were normalized to EPRI ER-301 (Heber plants). Equal expander unit costs $(\$ / \mathrm{kW}$, gross) were assumed for all binary cycles, see section 8.2 .11 for other assumptions. Reinjection pump capital costs are included as plant capital costs. 
Frgure 8.35-Relative field capital cost for minimum busbar cost optimized, $50 \mathrm{MWe}$ (net) simple binary and two-stage flashed steam energy conversion systems coupled to idealized, subcooled liquid, hydrothermal resources of equal pressure. All spent fluids injected. The cycles optimized are shown in figures 8.27 and 8.28. Production

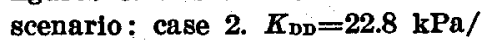
$(\mathrm{kg} / \mathrm{s}), H_{\mathrm{w}}=1830 \mathrm{~m}$. All costs and financial assumptions were normalized to EPRI ER-301 (Heber plants). Equal expander unit costs ( $\$ / \mathrm{kW}$, gross) were assumed for all binary cycles. See section 8.2 .11 for other assumptions.

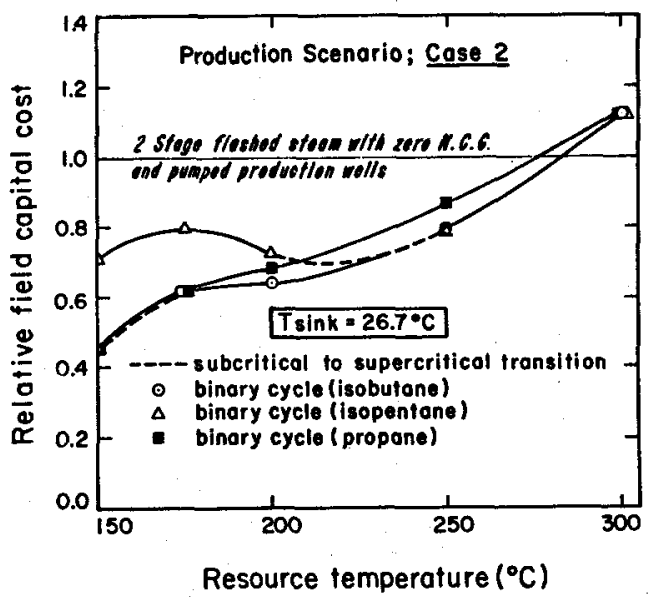

velop. We feel the foregoing discussion adequately demonstrates the validity of statements made in the beginning of this section (see section 8.2.1.1).

However, the degree of credibility of the system analysis can be measured by the individual and aggregate subsystem characterizations. We would be the first to admit to gross oversimplification in many of the process routines currently in the GEOTHM code and used in this study.

We regard this study as simply a first in-house attempt to connect the "resource" to the plant. Elliott's well routines have allowed this, providing a first-order characterization of a very complex total system. It is appropriate at this point to present the wellhead conditions computed for the "optimized" flashed steam plants of this study.

Figure 8.36 shows computed optimum wellhead state, flash point depth, and wellhead flow rate for $50 \mathrm{MWe}$ (net) minimum busbar cost optimized separating flashed steam power plants (see figure 8.27) for Production Scenario Case 1 (free flowing wells). This plot shows the degree of geothermal well characterization currently possible using the Elliott free flowing well routines (16) for a constant diameter well. It can be seen here that optimum wellhead pressures begin to increase rapidly at about $180^{\circ} \mathrm{C}$, whereas steam fraction rate increases do not significantly change until about $250^{\circ} \mathrm{C}$ (assuming adiabatic flow conditions).

The high optimum wellhead pressures computed here are symptomatic of our "degree of characterization" of steam turbine costs which are very elementary at this time. With more realistic expander cost models, the computed optimum wellhead pressures would obviously go down.

Figure 8.37 is the final plot of this section. In this plot we have superimposed the results of our calculations for two binary cycle working fluids and the free flowing flashed steam cycle over the known thermodynamic performance of two existing geothermal power plants and the Total Flow 


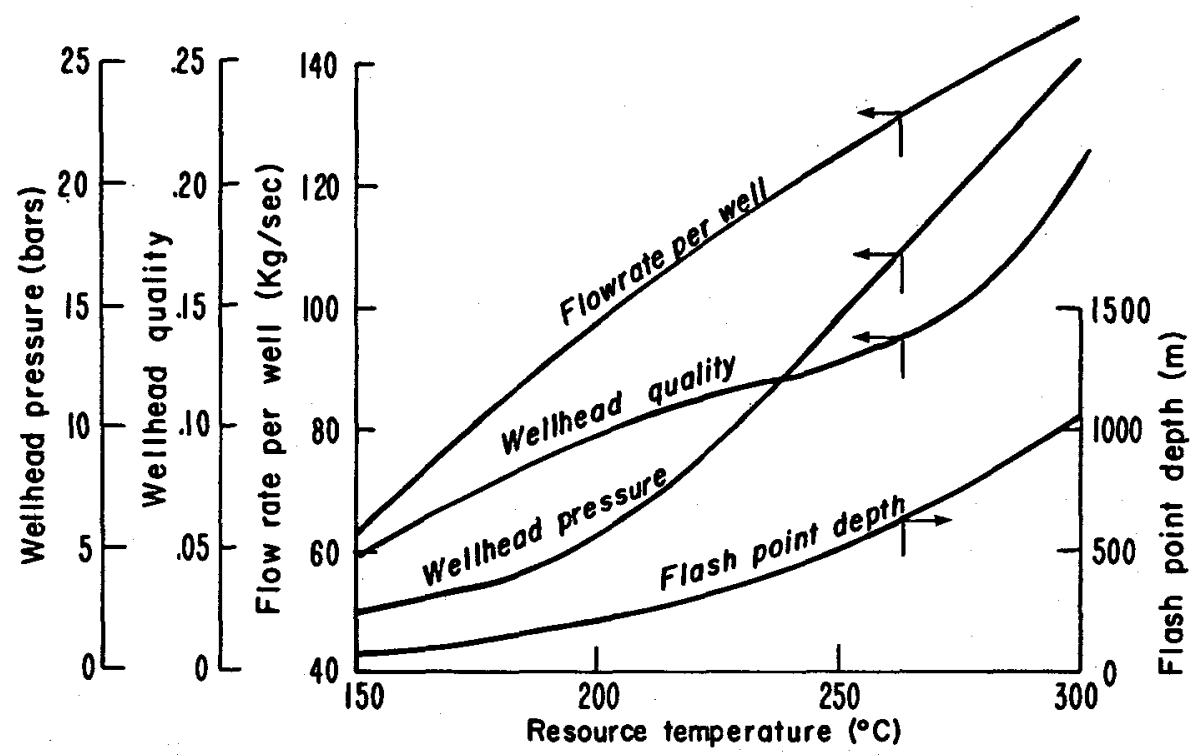

Fraure 8.36-Calculated optimum wellhead state conditions, flash-point depth, and mass flow rate for equal pressure, subcooled reservoirs. Two-stage flashed steam plant for production scenario, case 1 . System optimized for minimum busbar energy cost is shown in figure 8.27. Assumes "zeroth order" reservoir model and approximate vertical two-phase flow routines described by Elliott (reference 16). Well heat transfer ignored. $H_{w}=1830 \mathrm{~m}, 0.254 \mathrm{~m}$ I.D., $K_{\mathrm{DD}}=22.8 \mathrm{kPa} /(\mathrm{kg} / \mathrm{s})$.

process studied extensively by the Lawrence Livermore Laboratory (see section 4.4).

It can be seen here that the separating flashed steam process does not utilize the "brine" as effectively as the existing, more efficient, three stage Wairakei plant. A reverse order of performance, however, could be inferred using the early thermodynamic performance data from optimized plants in reference (15). We feel the relative thermodynamic performance shown in figure 8.37 lends a reasonable degree of credibility to all the GEOTHM optimized designs included in this report.

\subsubsection{Summary and conclusions}

Our perception of the state-of-the-art of hydrothermal geothermal energy conversion system design has been presented. We have introduced features of developing conceptual design aids and described current software limitations. We have suggested that some previously reported geothermal studies have been inconsistent and therefore contributed to an unnecessarily high level of investor's perceived risk.

Example problems for the simplest energy conversion systems have been used to demonstrate the inherent complexity of geothermal system design using even the most sophisticated techniques and have uncovered several 
Frgure 8.37-Speciflc net electric energy for various geothermal energy conversion systems. Detail specifications and performance of The Geysers plants are contained in reference 50 . The Wairakei energy conversion cycle has been described as "a multi-pressure, separated-steam, double-flash plant". Spent fluids are not injected. (See reference 51 for detalls.) The total flow curre was plotted from data in figure 4.156 of chapter 4, section 4.4 (LLL calculations assuming pure $\mathrm{H}_{2} \mathrm{O}$, zero N.C.G., 10\% parasitics) after converting to an expander adiabatic efficlency of $45 \%$. The binary steam curve are the calculated performance of busbar energy cost optimized cycles coupled to ideallzed, subcooled liquid (pure $\mathrm{H}_{2} \mathrm{O}$ ). hydrothermal resources of equal pressure. Costs and financial assumptions were normalized to EPRI ER-301 (Heber plants), All spent fluids injected. Production and injection wells are frictionless and adiabatic except flashed steam production wells (0.254 $\mathrm{m}$ I.D.), where friction is included and N.C.G. Ignored. $K_{\mathrm{DD}}=22.8 \mathrm{kPa} /$ $(\mathrm{kg} / \mathrm{sec}) ; H_{w}=1830 \mathrm{~m}$. curves and the two-stage fiashed

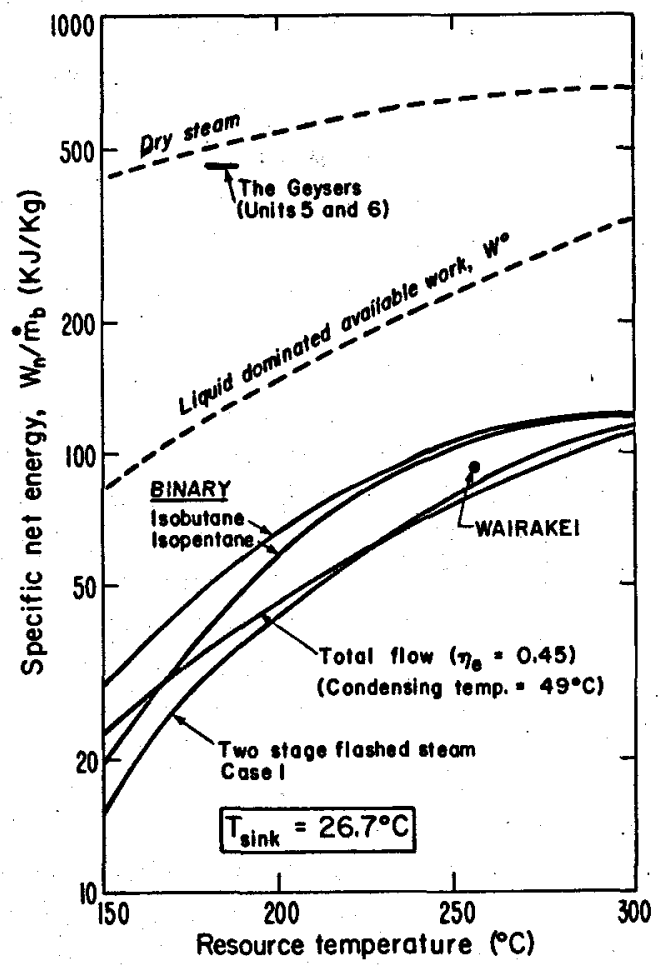

possible reasons for the reported inconsistencies. We have repeatedly stressed the importance of coupling the energy conversion process to the geothermal reservoir, and illustrated that valuable new insights into the problem can be achieved with even a primitive level of geothermal well characterization.

We also have shown that it is not possible to isolate any single facet of the geothermal system design process, e.g., subsystem thermodynamic performance or economic performance to determine absolute or relative goodness, without biasing the optimality of the systems as a whole. We have demonstrated, however, that minimum busbar energy cost is a consistent measure of commercial feasibility for geothermal systems as with any other established conversion technology.

The importance of thermodynamic optimizations stressed by Kestin, nevertheless, has been acknowledged: "It is . . recognized that the economic optimum in given circumstances is not coincident with the thermodynamic optimum. . . However, past experience shows that the latter 
contains valuable indications for the former and constitutes an indispensable first step." (1) We concur and have bsen able to expand on the significance of this statement. Thermodynamic optimization is the most reasonable first step to the problem solution. Use of the maximum specific net energy as a first guess to the cost optimization has been found to consistently converge on the global cost optimum. Thus a link between thermodynamics and economics has been established. This link is possibly unique, because it ties the optimum thermodynamic solution to the optimum economic solution. There is reason to believe that the optimization algorithm used here for geothermal power plants can be applied to other similar systems as well.

Perhaps the weakest existing link we've found in the geothermal system conceptual design process is the degree of system characterization-the connection between the plant and the reservoir. Studies which ignore the mutual interaction between the plant, the reservoir, and the wells cannot possibly portray the true economic life (and therefore feasibility) of hydrothermal systems as a whole. Even the relative rank between candidate conversion alternatives can only be crudely approximated.

Plant design technology is relatively well established $(3,11,53,54,55)$, except, possibly, in the areas of scale control, or mitigation, and corrosion. The state-of-the-alt of resource identification, assessment, and characterization has developed impressively in recent years (56). Geothermal reservoir engineering and well analysis techniques utilize state-of-the-art instrumentation, computer techniques, and theory of flow in porous media $(46,47,48,49)$. Studies are under way which will do much to improve our understanding of flow regimes and thermodynamics in vertical two-phase flow (19). Detailed economic design information for wells $(20)$ is forthcoming. Brine modification techniques ( $\left.5^{7}\right)$ have been developed for hypersaline brines, but the scaling behavior (chemical kinetics) of complex low salinity brines in geothermal wells must be better simulated (58) and included in the well flow-economic models to make rational future system decisions. Finally, we have shown in these studies that existing multiparameter optimization techniques have achieved a level of maturity such that they can be applied to geothermal systems on an industrial scale to perform the complex system economic trade-offs with a minimum of bias.

However, until the above major subsystem variables are coupled into an overall system thermodynamic-economic model, the true economic sensitivity of each on the others will remain unknown and potential system improvements may be overlooked. This overall system model could reduce reporting inconsistencies, and therefore, the level of risk portrayed to the geothermal investor.

\subsubsection{Notation}

$C_{E} \ldots \ldots \ldots \ldots$ busbar (or load center) energy cost

$C_{g} \ldots \ldots \ldots \ldots$ isocost contour on the busbar energy cost design surface 
$C_{p} \ldots \ldots \ldots \ldots$ specific heat capacity at constant pressure, $\mathrm{J} /\left(\mathrm{g}^{\circ} \mathrm{K}\right)$

$d \ldots \ldots \ldots \ldots$ well diameter, in, $m$

$d f \ldots \ldots \ldots \ldots$ numerical derivaive of the function $f$

del........... step-size used in numerical derivative calculations

$f\left(X_{k}\right) \ldots \ldots \ldots$ objective function evaluated at $X_{k}$

$f^{\prime}\left(X_{k}\right) \ldots \ldots \ldots$ first partial derivatives of the objective function with respect to each of the optimizable parameters, evaluated at $X_{k}$

$f\left(X^{*}\right) \ldots \ldots \ldots$ value of objective function evaluated at the optimum set of optimizable parameters $X^{*}$

$F^{*} \ldots \ldots \ldots \ldots$ set of performance factors, evaluated at the optimum condition

$G \ldots \ldots \ldots \ldots$ electrical generator in figures $8.22,8.27,8.28$

h.......... enthalpy, $\mathrm{J} / \mathrm{g}$

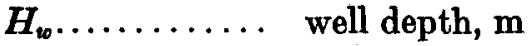

I.D......... production well inside diameter, in, $\mathbf{m}$

I.I.D......... Imperial Irrigation District

$K_{D D} \ldots \ldots \ldots$ drawdown factor, $\mathrm{kPa} /(\mathrm{kg} / \mathrm{s})$

KGRA ....... known geothermal resource area, a legal definition

$M \ldots \ldots \ldots \ldots$ electrical motor in figures $8.22,8.27,8.28$

$\dot{m}_{b} \ldots \ldots \ldots \ldots$ brine mass flow rate, $\mathrm{kg} / \mathrm{s}$

MPO........ multiparameter optimization

$n \ldots \ldots \ldots \ldots$ number of optimizable parameters

N.C.G....... noncondensible gases

$O$ and $M \ldots \ldots$ operation and maintenance

p.......... pressure, bars

$P$.......... power, megawatts (MWe)

POMTEP ..... path of maximum thermodynamic performance

s.......... entropy, $\mathrm{J} /\left(\mathrm{g}^{\circ} \mathrm{K}\right)$

$\Delta T \ldots \ldots \ldots$ temperature difference, $\mathrm{C}^{\circ}, \mathrm{K}^{\circ}$

$\Delta T_{E Q} \ldots \ldots \ldots$ equivalent temperature difference, $\mathrm{C}^{\circ}$

$T \ldots \ldots \ldots$ temperature, ${ }^{\circ} \mathrm{C},{ }^{\circ} \mathrm{K}$

TPCT ........ transposed critical temperature, ${ }^{\circ} \mathrm{C},{ }^{\circ} \mathrm{K}$

$T_{R E S} \ldots \ldots \ldots \ldots$ resource temperature, ${ }^{\circ} \mathrm{C},{ }^{\circ} \mathrm{K}$

$T_{S I N K} \ldots \ldots \ldots$ sink temperature, ${ }^{\circ} \mathrm{C}$

$T_{\text {WB }} \ldots \ldots \ldots \ldots$ wet bulb temperature, ${ }^{\circ} \mathrm{F},{ }^{\circ} \mathrm{C}$

$U$............ overall heat transfer coefficient, $\mathrm{W} / \mathrm{m}^{2 \circ} \mathrm{K}$

v........... specific volume, $\mathrm{cm}^{3} / \mathrm{g}$

$V_{c} \ldots \ldots \ldots \ldots$ value of energy conversion

$W^{0} \ldots \ldots \ldots \ldots$ available work or exergy (ref. 1 ), $\mathrm{kJ} / \mathrm{kg}$

$X_{0} \ldots \ldots \ldots \ldots$ initial vector of optimizable parameters

$X_{k+1} \ldots \ldots \ldots \ldots$ improved vector of optimizable parameters

$X_{k} \ldots \ldots \ldots \ldots, k$ th value of vector of optimizable parameters

$X^{*} \ldots \ldots \ldots \ldots$ solution vector

$X_{A} \ldots \ldots \ldots \ldots$ heat exchanger annual capital investment, \$/BTU

$X_{C z} \ldots \ldots \ldots$ annual cost of exchanger cleaning, \$/BTU 
$X_{P_{1}} \ldots \ldots \ldots \ldots$ annual cost of tube-side pumping power, $\$$ /BTU

$\boldsymbol{X}_{\boldsymbol{P}_{0}} \ldots \ldots \ldots \ldots$ annual cost of shell-side pumping power, $\$$ /BTU

$X_{\text {ror }} \ldots \ldots \ldots$ total annual heat supply cost, \$/BTU

$X_{\text {UF }} \ldots \ldots \ldots$ annual brine cost, $\$ /$ BTU

$Y \ldots \ldots \ldots \ldots$ variable in figure 8.21

YAFG....... (thermodynamic) Yield As First Guess (to a global cost optimum)

$\epsilon \ldots \ldots \ldots \ldots$ some arbitrarily small number

$\eta_{p} \ldots \ldots \ldots \ldots$ pump adiabatic efficiency

$\eta_{u} \ldots \ldots \ldots \ldots$ utilization efficiency, $\%$

$\left(\eta_{u}\right)_{w \boldsymbol{W}} \ldots \ldots \ldots$ wellhead utilization efficiency, $\%$

SUBSCRIPTS

e.......... expander

inj......... injection

n........... net

opt......... optimum value of any function

\subsubsection{References}

(1) J. Kestin, “Available Work in Geothermal Energy," Brown Univ., Rept. No. CATMEC/20, D.O.E. No. COO/4051-25, July 1978, Providence, R.I.

(2) H. E. Khalifa, R. DiPippo, and J. Kestin, "Geothermal Preheating in FossilFired Steam Power Plants," Division of Engineering Report, Brown University COO/4051-19, Providence, R.I., March 1978.

(3) V. W. Roberts (Project Manager), "Geothermal Energy Conversion and Economics-Case Studies," EPRI ER-301, Project 580, prepared by Holt/Procon, Ben Holt and Edward L. Ghormley (principal investigators), Electric Power Research Institute, Palo Alto, Calif., November 1976.

(4) C. H. Bloomster and C. A. Knutsen, "The Economics of Geothermal Electricity Generation from Hydrothermal Resources," BNWL-1989, UC-13, Battelle Pacific Northwest Laboratories, Richland, Wash.

(5) H. E. Khalifa and E. Michaelides, "The Effect of Noncondensable Gases on the Performance of Geothermal Steam Power Systems," Division of Engineering Report, Brown University COO/4051-36, Providence, R.I., November 1978.

(6) F. Dunn, Rogers Engineering, private communication with W. L. Pope, January 1979.

(7) C. J. Shaffer, "Floating Power Optimization Studies for the Cooling System of a Geothermal Power Plant," TREE-1164 EG\&G Idaho, Inc., Idaho National Engineering Laboratory, Idaho Falls, August 1977.

(8) H. E. Khalifa, "Effect of Seasonal Variations of Ambient Temperature on the Performance of Low Temperature Power Cycles," Division of Engineering Report, Brown University COO/4051-10, Providence, R.I., June 1978.

(9) H. S. Pines, W. L. Pope, M. A. Green, P. A. Doyle, L. F. Silvester, and R. L. Fulton, "The Thermodynamic and Cost Benefits of a Floating Cooling Geothermal Binary Cycle Power Plant at Heber, California," presented at the Geothermal Resources Council 1978 annual meeting, Hilo, Hawaii, July 25-28, 1978, LBL7040, April 1978, Lawrence Berkeley Laboratory, Berkeley, Calif. 
(10) H. S. Pines, M. A. Green, W. L. Pope, and P. A. Doyle, "Floating Dry Cooling, a Competitive Alternative to Evaporative Cooling in a Binary Cycle Geothermal Power Plant," presented at the 1978 Annual Winter Meeting of the ASME, San Francisco, Calif., December 10-15, 1978, LBL-7087, July 1978, Lawrence Berkeley Laboratory, Berkeley, Calif.

(11) Bechtel Corporation, "Advanced Design and Economic Considerations for Commercial Geothermal Power Plants at Heber and Niland, California," Final Report, SAN-1124-2, prepared for ERDA under Contract EY-76-C-03-1124, October 1977.

(12) W. I. Pope, H. S. Pines, R. L. Fulton, and P. A. Doyle, "Heat Exchanger Design-'Why Guess a Design Fouling Factor When It Can Be Optimized?'," presented at ASME Energy Technology Conference and Exhibition, November 5-9, 1978, Houston, Tex., LBL Report, LBL-7067, Lawrence Berkeley Laboratory, Berkeley, Calif.; published in Emerging Energy Technologies 1978, by the American Society of Mechanical Engineers, New York, N.Y.

(13) W. L. Pope, H. S. Pines, L. F. Silvester, M. A. Green, and J. D. Williams, "Multiparameter Optimization Studies on Geothermal Energy Cycles, LBL-7008, 1977.

(14) W. L. Pope, et al., "What Is the Significance of the Transposed Critical Temperature on Supercritical Rankine Cycles?" LBL-(TBD), to be issued, Lawrence Berkeley Laboratory, Berkeley, Calif.

(15) S. L. Milora and J. W. Tester, Geothermal Energy as a Source of Electric Power, Thermodynamic and Economic Design Criteria. The MIT Press, Cambridge, Mass., 1976.

(16) D. G. Elliott, "Comparison of Brine Production Methods and Conversion Processes for Geothermal Electric Power Generation," EQL Report No. 10, July 1975, Environmental Quality Laboratory, California Institute of Technology, Pasadena, Calif.

(17) "Feasibility Demonstration of the Sperry Down-Well Pumping System," COO/ 2838-1, Executive summary of the final report; May 1977, work performed under contract No. EY-76-C-02-2838, Sperry Research Center, Sudbury, Mass., prepared for the Division of Geothermal Energy, U.S. Department of Energy.

(18) R. Schroeder, LBL, private communication with W. L. Pope, February 23, 1979.

(19) A. E. Dukler, "Modeling Void Fractions: A New Method for Predicting Flow Regimes in Geothermal Wells," an invited lecture, Seventh Meeting of the Centers for the Analysis of Thermal/Mechanical Energy Conversion Concepts, Brown Univ. Report No. CATMEC/6, D.0.E. No. COO/4051-11, November 1977, Providence, R.I.

(20) C. C. Carson, Systems Studies Division, and J. Polito, Systems Analysis Division, Sandia Laboratories, Albuquerque, New Mexico, private communication at LBL, December 1978.

(21) D. G. Luenberger, Introduction to Linear and Nonlinear Programming, 1973, Addison-Wesley Publishing Company, Reading, Mass.

(22) L. R. Padgett and D. G. Nichols, "A Sequential Heuristic Method for Solving the General Nonlinear Programming Problem," presented in a symposium on Optimization Theory and Application, by the American Institute of Chemical Engineers, 74th national meeting, New Orleans, La., March 11-15, 1973.

(23) D. M. Himmelblau, Applied Nonlinear Programming, McGraw-Hill Book Company, New York, 1972.

(24) F. James and M. Roos, "MINUIT-A system for minimizing a function of $n$ parameters and computing the parameter errors and correlations," CERN Computer Center Program Library, Amended 20 June 1974. 
(25) R. Fletcher, "A New Approach to Variable Metric Algorithms," The Computer Journal, 13, pp. 317-322, 1970.

(26) R. F'etcher and M. J. D. Powell, "A Rapidly Convergent Descent Method for Minimization," The Computer Journal, 6, pp. 163-168, 1963.

(27) J. A. Nelder and R. Mead, "A Simplex Method for Function Minimization," The Computer Journal, 7, p. 308, 1967.

(28) M. A. Green, H. S. Pines, W. L. Pope, and J. D. Williams, "Thermodynamic and Cost Optimization Using Program GEOTHM," presented at the Geothermal Resources Council, San Diego, Calif., May 9-11, 1977, LBL-6303, April 1977, Lawrence Berkeley Laboratory, Berkeley, California.

(29) G. H. Anno, et al., "Site-Specific Analysis of Hybrid Geothermal/Fossil Power Plants," Pacific Sierra Research Corp., Report 705, Santa Monica, Calif., April 1977.

(30) M. A. Green, P. A. Doyle, H. S. Pines, W. L. Pope, L. F. Silvester, "The Optimization of Alternative Energy Cycles Using Program GEOTHM," presented at the Miami International Conference on Alternative Energy Sources, Miami, Fla., December 5-7, 1977, LBL-6308, December 1977.

(31) M. A. Green, H. S. Pines, P. A. Doyle, "Computer Design and Optimization of Cryogenic Refrigeration Systems," presented at the Seventh International Conference of Engineering, London, England, July 4-7, 1978.

(32) H. S. Pines and M. A. Green, "The Use of Program GEOTHM to Design and Optimize Geothermal Power Cycles," presented at the 11th IntersocietyEnergy Conversion Engineering Conference, Lake Tahoe, Nev., September 1217, 1976, LBL-4454, June 1976.

(93) K. E. Starling, Fluid Thermodynamic Properties for Light Petroleum Systems, Gulf Publishing Company, Houston, 1973.

(34) H. S. Pines, et al., "Numerical Optimization of Geothermal Energy Systems Using Program GEOTHM," LBL-(TBD), to be issued, Lawrence Berkeley. Laboratory, Berkeley, Calif.

(35) P. A. Doyle, et al., "Thermodynamic Optimization as a Prelude to Cost Optimization," LBI-(TBD), to be issued, Lawrence Berkeley Laboratiry, Berkeley, Calif.

(36) M. A. Green, H. S. Pines, "Program GEOTHM, a Thermodynamic Process Program for Geothermal Power Plant Cycles," presented at the CUBE Symposium at the Lawrence Livermore Laboratory, October 23-25, 1974, LBL-3060, 1974.

(87) M. A. Green, R. N. Healey, H. S. Pines, W. L. Pope, L. F. Silvester, and J. D. Williams, "GEOTHM-Part 1, A Users Manual for GEOTHM. (Computer Design and Simulation of Geothermal Energy Cycles.)," LBL publication-202, July 1977.

(38) L. F. Silvester and K. S. Pitzer, "Thermodynamics of Geothermal Brines I. Thermodynamic Properties of Vapor-Saturated $\mathrm{NaCl}$ (aq) Solutions from 0-300 ${ }^{\circ} \mathrm{C}$," LBL -4456 , Lawrence Berkeley Laboratory, Berkeley, Calif., January 1976.

(39) H. Helgeson, "Geologic and Thermodynamic Characteristics of the Salton Sea Geothermal System," American Journal of Science, vol. 266, pp. 129-166, March 1968.

(40) R. Schroeder, LBL, private communication with W. L. Pope, December 1978.

(41) J. Leigh, "Proposed Levelized Busbar Cost Module for LBL GEOTHM Model," Working Paper, Project No. 1526X, The Mitre Corporation, Metrek Division, McLean, Va., 1979.

(42) K. E. Starling, et al., "Resource Utilization Efficiency Improvement of Geothermal Binary Cycles-Phase I," Annual Report ORO-4944-4 (p. 85), University of Oklahoma School of Chemical Engineering and Materials Science, Norman, Okla., June 1976. 
(43) K. E. Starling, conclusion stated at presentation before the 4th Meeting of the Centers for the Analysis of Thermal-Mechanical Energy Conversion Concepts (CATMEC) held at Lawrence Berkeley Laboratory, Berkeley, Calif., January 24-25, 1977.

(44) R. Dakin, F. Leighton, M. D. Irvine, Rotoflow Corporation, meeting with LBL engineers, August 1978.

(45) D. G. Elliott, "Comparison between Electric Generating Costs for Binary and Flash Steam Plants at Heber," presented at the 6th Meeting of the Centers for the Analysis of Thermal-Mechanical Energy Conversion Concepts (CATMEC), held at the National Academy of Sciences, Washington, D.C., July 27-28, 1977.

(46) R. C. Earlougher, Advances in Well Test Analysis, Monograph, Soc. Petr. Engr., AIME, Dallas, 1977.

(47) T. N. Narasimhan and P. A. Witherspoon, "Geothermal Well Testing," The Burke Maxey Volume, Jour. Hydrology, North Holland Press, Amsterdam, 1979 (to appear).

(48) T. N. Narasimhan, R. C. Schroeder, C. G. Goranson, and S. M. Benson, "Reservoir Evaluation Tests, 1977, East Mesa, California," Paper No. 7482, Soc. Petr. Eng., AIME, 53rd Annual Meeting, Houston, Tex., October 1978.

(49) P. A. Witherspoon, T. N. Narasimhan, and D. G. McEdwards, "Results of Interference Tests from Two Geothermal Reservoirs," Jour. Petr. Tech., 30, 10-16, 1978.

(50) R. DiPippo, "Geothermal Potwer Plants of the United States-A Technical Survey of Existing and Planned Installations," Division of Engineering Report, Brown University, COO/4051-20, Providence, R.I., April 1978.

(51) R. DiPippo, "Geothermal Power Plants of New Zealand, Philippines, and Indonesia-A Technical Survey of Existing and Planned Installations," Division of Engineering Report, Brown University, COO/4051-23, Providence, R.I., June 1978.

(52) K. Yamagata, et al., "Forced Convective Heat Transfer to Supercritical Water Flowing in Tubes," Int. J. Heat and Mass Transfer, 15, pp. 2575-93, 1972.

(53) B. Holt, "Geothermal Power Plant Design Risks," Proceedings of the Second Geothermal Conference and Workshop held at Taos, N. Mex., June 20-23, 1978, prepared for EPRI Fossil Fuel and Advanced Systems Division, Vasel Roberts, Project Manager, EPRI WS-78-97, October 1978.

(54) T. R. Fick, et al., "Some Technical Risks in Geothermal Power Plants," Proceedings of the Second Geothermal Conference and Workshop held at Taos, N. Mex., June 20-23, 1978, prepared for EPRI Fossil Fuel and Advanced Systems Division, Vasel Roberts, Project Manager, EPRI WS-78-97, October 1978.

(55) N. A. Samurin, "Preliminary Design of Axial Flow Hydrocarbon Turbine Generator Set for Geothermal Applications," Proceedings of the Second Geothermal Conference and Workshop held at Taos, N. Mex., June 20-23, 1978, prepared for EPRI Fossil Fuel and Advanced Systems Division, Vasel Roberts, Project Manager, EPRI WS-78-97, October 1978.

(56) Lawrence Berkeley Laboratory, 1976 Second United Nations Symposium on the Development and Use of Geothermal Resources, Proceedings: Superintendent of Documents, U.S. Government Printing Office, Washington, D.C., 20402, 2465 p. (Library of Congress Catalog Card Number: 75-32682 ; GPO Stock No. 060000-00005-1).

(57) G. E. Tardiff, "Using Salton Sea Geothermal Brines for Electrical Power: A Review of Progress in Chemistry and Materials Technology-1976 Status," UCRI-79468, Lawrence Livermore Laboratory, Livermore, Calif., May 1977.

(58) D. W. Shannon (Project Manager), "Brine Chemistry and Combined Heat/ Mass Transfer," Interim Report, vol.'1, Battelle Pacific Northwest Laboratories, prepared for EPRI Fossil Fuel and Advanced Systems Division, EPRI ER-635, January 1978. 
8.3 Location and procurement of components (By A. L. Floyd* and G. Simay*)

\subsubsection{The designer's problem}

Although new technology may be needed, the complete design of a geothermal power plant will also require the use of many pieces of equipment, components, and materials that are in general use in present day operating power plants. These materials have undergone many years of improvement in design, fabrication, materials, and production techniques. In general they are directly applicable to the geothermal power plant when there is no interface with the geothermal environment or fluid, although for some the size will be nonstandard but nevertheless "state-of-the-art." Little or no special development for the geothermal power plant application can be expected. The designer should use these standard equipment, components, and materials where possible since the many years of experience behind their production and use will ensure a high degree of reliability, long life, and low cost.

Almost all of the electrical equipment, components, and materials fall in this category. These include generators, power transformers, auxiliary power transformers, power ducts, surge protection equipment, current transformers, protective relays, grounding transformers and resistors, generator main breakers, and automatic start up and shut down systems. All electrical auxiliary power systems and controls and all switchgear and cables are standard available items directly applicable to the geothermal power plants.

The general plant facilities all can be constructed from standard available systems, equipment, and materials; these include communications, cables, surveys, grounding, control and instrument panels, operator interface systems, safety and emergency systems, security systems, and control centers.

Transmission systems will be standard. Except for the protection against hydrogen sulfide, the electrical switchyard for plant and transmission interface will not differ from the designs generally used throughout the country. Equipment and systems used include circuit breakers, power transformers, disconnect switches, instrument transformers, direct connect systems, protective relays, control systems, supervisory control and monitoring, lighting protection, grounding, foundations, busing, structures, and support systems.

Most of the mechanical equipment will be standard items. These include pumps of all types used throughout the power plant for cooling water circulation, feed pumps to boilers where applicable for binary or hybrid systems, condensate pumping, waste pumping, fuel where applicable. Fans will also be standard.

*City of Burbank, Burbank, Calit. 
Fire control and air quality monitoring of cooling tower plume and drift also will use well established methods and equipments.

At present in the United States there are over 1,700 industrial concerns that supply these types of equipment, components, and materials. The designer's problem is one of determining from the vast number of choices available those combinations of equipments, parts, and materials that best solve his particular design problem. It is the large number of choices available that presents the designer with his most difficult problem. Information on these choices must be quickly accessible, up-to-date, and accurate, in order for the designer to arrive at the best design efficiently. In the past the designer has relied upon experience, salesmen, catalogs, and ivdex files. Modern automatic information-handling processes are now becoming available to cope with best design choices. One such system will be described in this section.

For some equipment it may be necessary to use specially-sized units, units constructed with special materials, or units that are otherwise modified. This does not in general present a special problem to the power plant designer except that he must now be especially aware of all of the factors necessary to ensure that the nonstandard equipment be completely specified, tested, and controlled so as to guarantee on-time delivery. This section will describe a typical management system for this purpose.

There are a large number of codes, specifications, and standards that are applicable to power plant construction. Industry codes that are applicable include:

American Concrete Institute Standards;

American National Standards Institute Standards;

American Society of Mechanical Engineers Codes and Standards;

American Society for Testing and Materials for Test and Specifications;

American Welding Work Standards, Specifications and Practices; American Water Works Association Standards;

National Fire Protection Association;

Underwriters Laboratories;

International Organization for Standardization;

International Electrotechnical Commission;

Federal Construction Regulations Service;

Federal Specifications Services.

Many others could have been included (see section 8.3.5.) The designers must be familiar with these standards and comply with them. Since they are continually being updated and modified, the designer must have access to the latest applicable information for each equipment, part, structure, or material. Standards information is now also becoming available in modern automatic information handling systems. 


\subsubsection{Available equipment and components}

The designer generally will have data available on the various equipment and components he has used in the past. These are usually the first items referenced. However, he should also make a search of all vendorsupplied equipment and components he plans to use to ensure that his selection is the best currently available for his application.

There are a number of methods available for doing this. As an example, we will describe the Visual Search Microfilm Files (VSMF) used by many major companies. Although at present these files have not been specifically organized for geothermal power plant needs, an extensive check was made using vendor data obtained from more than 1,000 suppliers of standard components, equipment, and materials applicable to geothermal power plants. Most of these were found to exist with the VSMF files; they were current and provided all of the necessary design information.

The VSMF Service Company, Information Handling Services, is now proceeding with the massive information organization task of preparing special files oriented toward the energy industry-sales, fossil, nuclear, geothermal-so that this data will be available and current in smaller files.

The VSMF system consists of more than 100 current and comprehensive data bases thoroughly indexed, cross referenced and constantly updated, containing supplier industry and government documents needed in product and facility design, manufacturing, construction, purchasing, R\&D, quality control, value analysis, maintenance, management, and more. Subscribers receive these data bases in microfilm cassettes which are indexed.

VSMF Services fall into three broad categories: Vendor Product Data Industry Codes and Standards, and Government Regulations, Specifcations, and Standards. Ideally, a search would utilize data from all three categories for design work, at least two for specification writing and possibly only one for vendor evaluation. The data bases have been systematized so that a data system can be tailored to a particular function, department, organization or industry simply by ordering the discrete services required.

In addition, company-generated data can be integrated into a data system to provide a single, comprehensive source of technical data utilizing common indexes and retrieval methods. Company proprietary standards, reliability data, vendor evaluation reports, etc., can be coded, indexed, and microfilmed, if desired.

The data bases and locator indexes are stored in microfilm cassettes to be used in any one of several 3M viewer/printers. A book form master index lists subject name against locator index cassette. The locator cassette 
then lists suppliers of the product in question versus the product cassette number and the frame number on which the desired information may be found.

The viewer/printers accept the cassettes and transport the microfilm past a projection lens at fast (or slow) speed so that the desired frames can be quickly located, viewed and then printed if desired. A large projection screen is provided for easy viewing of an entire document.

Products from competitive suppliers are grouped together in the product-oriented vendor services so that the use of VSMF data facilitates the determination of the best component available and also suitable alternates.

Periodically, every 15 to 180 days, depending on the volume and frequency of the data base, the subscriber receives revisions, updates, deletions, addenda, and new indexes.

Cost savings with this data system are many. In addition to the time saved in searching for equipment, building and construction products, industry codes and standards, government regulations, specifications and standards, there is a large saving in data management, which consists of bringing cassettes up to date.

The cost to the user of the VSMF services consists of the subscription to the needed files and reader/printer rental. The following is a list of some of the data bases available along with their costs :

Design Engineering (complete) $\ldots \ldots \ldots \ldots \ldots \ldots \ldots \$ \mathbf{\$ 7}, \mathbf{7 8 0 . 0 0}$

Documentation..................... 5, 120.00

Plant Engineering. .................... 4, 260.00

Building Products File with Selector. . . . .

Distributor Catalogs.................... $\mathbf{8 3 0 . 0 0}$

Metric Design...................... 2, 140.00

3M Reader/Printer-Annual Lease........... 1,818.00

(Prices effective as of February 1, 1979).

These data bases are similar to those that may be needed for the energy industry.

To illustrate the ease of searching for a particular item, suppose a turbine driven feed water pump was required for a system. The engineer would look in the VSMF Product/Subject Matter Index. The closest title to be found is Pump Hydraulic Multistage, Centrifugal, Horizontal (or Vertical) for which the Locator Code is E-35-07 (Index cassette letter, frame number, and column). The various manufacturers of this pump and the product file cassette number and page number on which the manufacturers will be found can be read from the Index cassette. The manufacturers' catalog pages giving specifications, drawings, and other technical information can be read from the Product File cassette. Like products are in close proximity on the film for ease of search and comparison. By press- 
ing a button on the control panel, hard copies of desired frames may be obtained. The search can be completed in five minutes or less.

Cassette storage units and microfilm reader/printers are so compact that a data center can be provided in the engineering area. Space for a catalog library is not required.

\subsubsection{Equipment and components to be modified or developed}

Whenever the search for an item which meets the minimum requirements for a specific application is unsuccessful, it becomes necessary to design an item which will meet the requirements. This is an engineering design decision which is influenced by many factors. Shall it be designed in-house or contracted out to a supplier? Considerations in making this decision include the design capabilities of plant engineers, whether an existing item of equipment can be modified to do the job given the extent of the modification, and, of course, the cost.

Whenever working with an outside supplier, it is necessary to provide him with requirements for design, development, manufacture, test, and delivery of an acceptable item. Drawings and specifications with any data requirements necessary to assess the progress of the design and integrate the item into the plant design, the delivery schedule, quantities required, and any special requirement such as special test equipment or spares must be furnished.

The minimum technical design requirements for the item should be stated in a specification or drawing and should contain performance requirements. These include electrical, fluid, or mechanical inputs and outputs; environmental requirements including necessary thermodynamic, chemical, seismic, or meterological; requirements relating to maintenance, reliability, safety, and human factors; and all structural requirements. Maximum envelope, mounting dimensions, electrical, or fluid connections should be specified if applicable. The specification should include all qualifications.

The technical documents specifying these requirements should not include data requirements, nontechnical contractual requirements, details of design, program plans, schedules, quantities, "motherhood" statements, objectives, or any other information. They should, however, include clear, concise, and specific statements of the technical requirements necessary to fulfill the minimum requirements of the application.

When the technical requirements for equipment or for systems to be developed are so extensive that it is not practical to specify them on a drawing, a specification should be prepared. The specification is always subsidiary to the drawing.

When a supplier is requested to design and develop a system or subsystem, he will determine the form, fit, function, and number of items in 
the system. It is often more practical to submit only a system specification with the original request and prepare the drawings for each item later.

The supplier's top assembly drawing is required for each item and should be specified in the final production release of the procurement drawing. This drawing along with all of the detail drawings specified in the top assembly drawing list of materials describing the detail design and satisfying the design requirements in the specification or procurement drawing are also required.

Other types of data may be required. The data requirements should be adequate but not excessive and should be established concurrently with the technical requirements for the hardware. The data should be described and listed separately from the specification or procurement drawing. Forms such as a data item sheet or a data item list like the one in table 8.3 may be useful in controlling the data requirements :

TABLE 8.3-List of typical supplier data

1. Electronic Component Parts List
2. Assembly Drawing
3. Outline/Assembly Drawing
4. Installation Drawing
5. Schematic Drawings
6. Interconnect Wiring Diagram
7. Input power requirements
8. Cooling requirements
9. Operation instructions
10. Alignment and Calibration Instructions
11. Solid State component fallure summary
12. Quality Conformance Inspection and Verification
13. Qualification test procedure
14. Qualification test report
15. Reliability prediction
16. Maintainabilty Program Plan
17. Maintenance Requirements Report
18. Technical Development Plan/Schedule

Special requirements to be imposed on a supplier that are generally applicable to all equipment procurement such as identification of the product, procedures for qualification testing, and procedures for handling data or document changes should be included in the purchase order for the equipment with the data.

A schedule should be prepared for each supplier-designed part, equipment or sub-system specifying when every time-critical action should be completed, from the preparation of the specification and/or control drawing of the item to the verification of the supplier's product. The schedule should include as a minimum the following:

(1) Procurement drawing and/or specification completion. 
(2) Various data required from the supplier such as proposals, drawings, and test procedures.

(3) Supplier data review completion by plant designers.

(4) Supplier selection.

(5) Request to purchase.

(6) Part, equipment, or sub-system "on dock."

(7) Verification testing of the item.

\subsubsection{Management of procurement}

A single procurement package for a part, equipment, or sub-system should be prepared including all necessary requirements such as :

(1) Finalized equipment specification and/or procurement drawing.

(2) All data requirements.

(3) All nontechnical requirements related to procurement.

The procurement package should be submitted to qualified suppliers with a request for quotation delivery, and a pricing schedule for equipment, data, special requirements, and spares.

To evaluate proposals for technical, cost, and management considerations, criteria should be prepared for equitable consideration of candidate suppliers. Supplier proposal compliance with requirements specified in the procurement package should be evaluated and a supplier determined.

A program for monitoring and controlling supplier-developed items, commensurate with the complexity and urgency of the item, should be established. The designer responsible for an item under development should monitor the supplier's progress in design development and conformance with the contract. He should revise procurement documentation for agreed-to changes following change procedures defined in the contract.

A data tracking system should be devised to receive and record data submittals, follow up on late or missing data, schedule evaluation of data, apprise suppliers of approval or rejection of this data, and follow up on resubmittals of rejected data.

The responsible designer should review supplier qualification test procedures, for those items requiring qualification testing, and should accept or reject the procedures based on compatibility with procurement documentation requirements. The designer should witness all qualification tests considered critical and should review qualification test results and verify that they comply with the applicable procurement documentation requirements. All production items should be examined and tested to the extent necessary to verify that all requirements of the specification and procurement drawings have been met. 


\subsubsection{Applicable codes and standards}

The following is a list of codes and standards filed in the VSMF inventory that may be of use in the design and construction of geothermal power plants:

(1) American Concrete Institute

(2) American Society of Mechanical Engineers

(3) American Society of Testing and Materials

(4) American Welding Society

(5) American Water Works Association

(6) National Fire Protection Association

(7) Underwriters Laboratories

(8) International Electro-technical Commission

(9) Federal Construction Regulations

(10) Federal Specification Service.

Other services which may be of interest include :

(1) Nuclear Regulatory Commission

(2) Gov't. Procurement Service Federal Supply Schedules

(3) Contractor Catalogs and Price List

(4) Federal Aviation Administration

(5) Institute of Electrical and Electronic Engineers

(6) National Electrical Manufacturers Association

(7) Industry Standards Locator Index

(8) American National Standards Institute

(9) American Petroleum Institute

(10) Society of Automotive Engineers.

The use of codes and standards files is very similar to that of the product data files. For instance, if a designer requires a standard for alternating current voltages, he would look in the VSMF book-form index or alphabetical title cassette and find MIL-STD-225. This standard is located in cassette number 5134 or 9082 . The required voltage standard is at frame 1345 in cassette number 9082. 


\title{
Chapter 9
}

\section{Environmental Considerations}

\author{
(By R. P. Hartley*, edited by R. DiPippo**)
}

\subsection{Regulatory approach and applicable laws}

\subsubsection{Overall perspective}

The total potential geothermal energy resource is immense; however, its availability for economical exploitation by existing technology is small compared to that total. Over most of the earth's surface, temperature inereases rather uniformly and modestly with depth, averaging about $25^{\circ} \mathrm{C} / \mathrm{km}$ [White, 1973]. Exploitation with present technologies can occur only in naturally anomalous situations that allow heat to move rapidly toward the surface and/or to be trapped at shallow depths. Anomalous conditions occur typically in areas of recent crustal disruption where folding, faulting, magmatic intrusions, and volcanism provide avenues for higher outward heat transport. In the United States such areas are generally found from the Rocky Mountains westward. An exception is the geopressured area of the Gulf Coast, which appears to be a large stable region of simple entrapment of normal outward heat flow. Search for and characterization of geological anomalies leading to commercially developable geothermal resources are basic first steps of geothermal investigation.

Several factors presently limit the exploitability and potential uses of a geothermal resource. These include temperature, the depth to the resource, the content of water and its long-term availability, the form of the water (liquid or vapor) and its pressure, and geographical location. The most desirable characteristics with respect to these factors are rather obvious, namely, hot, shallow, high-pressure steam in large volume near an energy load center. The search for these desirable characteristics has placed an emphasis on electric power production.

Recent estimates [ERDA-86, 1976] project a geothermal contribution equivalent to $6,000 \mathrm{MW}$ (megawatts) by 1985 and $39,000 \mathrm{MW}$ by the year

\footnotetext{
*Industrial Environmental Research Laboratory, Cincinnati, Ohio.

**Southeastern Massachusetts University, N. Dartmouth, Mass.
} 
2000, given a successful federally-assisted implementation program. For comparison, current electrical production in the United States is about 400,000 MW.

Most of the geothermal energy production, between now and the year 2000 , will probably be from hot water resources. Vapor-dominated resources are apparently rare, even though the majority of production in the world is presently from this type. Geopressured resources are not likely to make a major contribution in the period cited by the U.S. Department of Energy, DOE (formerly the U.S. Energy Research and Development Administration, ERDA), unless their natural gas content becomes exploitable.

The total waste water flow resulting from ERDA-projected energy production would be in the range of $4 \times 10^{\circ}$ to $8 \times 10^{\circ}$ liters/day $(1,000$ $2,000 \times 10^{8}$ gallons/day) in the year 2000 . Flows would be of the same order of magnitude as the once-through cooling water requirement for equivalent fossil-fueled electric power generation.

The method chosen for disposal of spent geothermal liquids will not be determined solely by pollution control reasons, particularly in power generation. In general, power generation will entail a long-term commitment at one site with sufficient high-temperature resources to maintain consistent production for at least 30 years. It is likely that in most places the rate of water withdrawal will significantly exceed natural replenishment; resource conservation is therefore desirable. The most feasible way to accomplish this is by returning the spent liquid to the reservoir. It is also possible that subsidence will be induced by high-volume withdrawal; injection may minimize this possibility. At the same time, injection to the reservoir would also minimize the likelihood of pollution. Both withdrawal and injection may affect seismicity by either increasing or decreasing the risk.

For purposes of establishing a perspective, it can be stated that power generation is usually sought first because electricity can be transported easier than heating fluids, from the generally remote geothermal areas, and that, although vapor-dominated (steam) resources are the most desirable, liquid-dominated (hot water) resources will prevail because of their greater abundance. The hottest resources will be developed first if power generation is the goal. Because of their usually higher salinities, high temperature liquid resources can potentially cause greater pollution problems, but they will probably be injected back to the reservoir. At the present time, major development activity is proceeding in the Imperial Valley, California, which apparently contains the highest salinity sources in the United States. Other areas of lesser salinity are in various stages of exploration.

All geothermal sources appear to contain dissolved gases that may prove to be, overall, the most troublesome pollutants. They must be removed in most power generation operations because they interfere with steam 
condensing. When removed, they must be disposed of, and some will require treatment. Unlike water, they cannot normally be injected.

In terms of national impact, geothermal energy conversion does not pose a major environmental threat. Local impacts could in some cases be severe; however, there is every reason to believe that potential pollution will, be economically controllable in most, if not all, cases.

\subsubsection{Geothermal energy pollution control regulatory approach}

The pollution control regulatory approach being adopted by the U.S. Environmental Protection Agency (EPA) [EPA, 1977 (B)] has been selected from the options available under EPA-administered laws. The appropriate sections of those laws are summarized below. Parts of several other federal laws, requiring or related to geothermal pollution control, are also summarized. In addition, the interaction of state and federal laws is briefly discussed.

The regulatory approach selected by EPA is designed to relate to the DOE development, demonstration, and commercialization schedule [ERDA-86, 1976; ERDA-76, 1976]. The regulatory objectives are to :

(1) establish point source emission and discharge limitations for environmentally damaging constituents by the onset (after 1981) of significant commercialization;

(2) provide guidance, periodically updated, to the time of significant independent commercialization (through the development and demonstration phases), on limitations that can be anticipated prior to facility construction, through the application of ambient standards and state-of-the-art control technology;

(3) minimize to the extent possible, by way of the same periodic guidance, uncertainties in emission and discharge requirements;

(4) develop and evaluate information, which supports guidance and regulations, throughout the precommercialization stage, in concert with the industry and other involved governmental agencies; and

(5) regulate geothermal pollution throughout the precommercialization period by application of the emission and discharge permit systems, which may be State-administered, with permit conditions based upon ambient standards, known or expected effects, state-of-theart technology, and environmental impact review. Periodic guidance will be issued by EPA with respect to these factors.

Any geothermal energy development is subject to many pollution control laws and regulations. The most significant of the federal laws, which apply to all industrial development, are :

Federal Water Pollution Control Act Amendments of 1972 (PI, 92500);

Clean Air Act as amended (PL 91-604 and PL 95-95); 
Safe Drinking Water Act (PL 93-523);

Resource Conservation and Recovery Act of 1976 (PL 94-580);

Noise Control Act of 1972 (PL 92-574); and

Toxic Substances Control Act (PL 94-469).

All but the last of the above federal laws allows and fosters delegation of authority to the states upon their meeting certain requirements. In effect, the federal laws extend down through state, regional, and local levels. Each of these is described in the following sections.

\subsubsection{Federal Water Pollution Control Act Amendments (FWPCA) of 1972}

Several sections of this Act apply to geothermal development. Probably the most significant sections are in Title III-Standards and Enforcement. Section 301 calls for the application of "best practicable control technology currently available" by July 1, 1977, for point sources other than publicly owned treatment works. This section further calls for the application of "best available technology economically achievable" by July 1 , 1983. This section further requires the elimination of all pollutants where technologically and economically achievable. Section 304 calls for the definition by the EPA of such technologies, and effluent limits attainable thereby, through the issuance of: "Effluent Guidelines" regulations. For the geothermal energy industry, those regulations have not yet been developed and are not currently scheduled. However, such regulations may be expected when the industry is firmly established and technologies have been demonstrated. Effluent Guidelines are promulgated, upon development, as regulations in 40 CFR Parts 402 through 699.

Section 303 of the FWPCA calls for the establishment and maintenance of receiving water quality standards for both interstate and intrastate surface waters. Such standards have been established by the States and approved by the Administrator (40 CFR Part 120). They are subject to periodic revision. The provisions of this section interact with those of Section 301 and prevail in establishing permit limitations where the application of Effluent Guidelines limits is not sufficient to meet receiving water quality standards. This is likely to be the case in many, if not most, areas of early geothermal energy development.

Section 306 of the FWPCA calls for the establishment of "national standards of performance" for new sources of water pollution after the EPA Administrator publishes a list of such sources. Past development of such standards indicates that they would be similar to "best available technology economically achievable." There is currently no schedule for establishing new source performance standards for the geothermal industry but they also can be expected in the future. New source performance standards are promulgated along with Effluent Guidelines in 40 CFR Parts 402 through 699 . 
The implementation of Effluent Guidelines and Water Quality Standards is carried out under authority of section 402 of the FWPCA by way of the "National Pollutant Discharge Elimination System" (NPDES). This requires a discharge permit based upon Effluent Guidelines and/or Water Quality Standards for any point source discharge to surface drainage. Permitting authority has been delegated to those States which have met implementation program requirements. Implementing regulations have been published in 40 CFR Part 125.

Section 308 of the FWPCA requires dischargers regulated by the Act to sample and maintain records of discharge loadings and make them available to authorized federal and state regulatory personnel. It also authorizes right of entry to the discharger's premises by those personnel. The recorded data must be gathered and maintained as prescribed in permit conditions, and may be used as evidence in enforcement of pollutant limitations.

\subsubsection{Clean Air Act as amended}

The Clean Air Act also has several sections which may significantly affect geothermal energy development.

Section 107 of the Clean Air Act allows and provides for the establishment of intrastate and interstate Air Quality Control Regions in which the states must provide implementation plans under section 110 for assuring air quality.

Under section 108 of the Clean Air Act and section 106 of the 1977 amendments, the Administrator of the Environmental Protection Agency may publish air quality criteria. Based upon the criteria, he then publishes national primary (to protect public health) and secondary (to protect public welfare) ambient air quality standards (section 109 of the Clean Air Act) for pollutants determined to have adverse effects. National air quality standards have thus far been established for six pollutants: particulates, sulfur dioxide, nitrogen oxides, hydrocarbons, petrochemical oxidants, and carbon monoxide (40 CFR Part 50). Lead may be added in the near future. Since the listed pollutants may not be significant in most geothermal sources, the importance of current ambient standards may not be great. However, the states may unilaterally include other constituents, and some have done so, e.g., hydrogen sulfide in California.

Section 111 of the Clean Air Act and section 109 of the 1977 amendments allow the Administrator of the Environmental Protection Agency to establish New Source Performance Standards for air pollutants from stationary source categories. Once established, these standards become applicable to all new sources in such a category, and further, the states must then establish emission limits for the same constituents from existing sources within that category. This is likely to be the principal route for 
federal regulation of air emissions, although such standards have not been developed yet for the geothermal industry. New Source Performance Standards are based upon best demonstrated economically achievable emission reduction, similar to the basis for water discharge National Standards of Performance. They are published as regulations in 40 CFR Part 60.

Section 112 of the Clean Air Act and section 110 of the 1977 amendments provide for the establishment of emission standards for hazardous air pollutants from stationary sources. Thus far, standards have been established for specific sources of mercury, asbestos, beryllium and vinyl chloride (40 CFR Part 61). These standards do not apply to geothermal sources.

Section 122 of the Clean Air Act Amendments of 1977 provides for the regulation of emissions of radioactive substances, cadmium and arsenic, all of which may be found in geothermal fluids.

\subsubsection{Safe Drinking Water Act}

This act is administered by the Environmental Protection Agency and allows and provides for State implementation of its provisions. Part $\mathrm{C}$ of the Act, "Protection of Underground Sources of Drinking Water," is of greatest significance to geothermal energy development in that it requires the promulgation of regulations to control underground injection. Reinjection is an integral part of most existing and proposed geothermal development. Regulations under this Act have been proposed (40 CFR 146), but their applicability to geothermal operations has not yet been established. Any regulations may be further extended by more restrictive state regulations. Reinjection permits will be required (as they already are in most states), the issuance of which is likely to be based upon an analysis of geological, hydrological, and injection system design and operational information.

Under the Geothermal Steam Act of 1970, the U.S. Geological Survey has issued Geothermal Resources Operational Orders, which include specific requirements for reinjection wells on Federal lands. Regulations which may be developed under the Safe Drinking Water Act for reinjection are not likely to be in conflict with the Operational Orders.

The Environmental Protection Agency already has some control over underground injection via NPDES permits using Administrative Order No. 5, which provides for approval of injection systems that are part of any other project subject to FPA regulation.

\subsubsection{Resource Conservation and Recovery Act of 1976}

The provisions of this Act, administered by the Environmental Protection Agency, are principally concerned with solid wastes. Subpart C- 
Hazardous Waste Management, important to geothermal energy development, involves regulatory control of storage, treatment, and disposal of potentially hazardous wastes in landfills and surface impoundments. The potentially hazardous wastes may be liquid, solid, or a combination. Wastes considered potentially hazardous are those which may cause or contribute to adverse effects on human health or the environment when not properly controlled. Regulations to be developed under the Act are likely to have significant ramifications for the geothermal industry in those cases where spent brine surface impoundments are used and where waste sludges are created, such as in the treatment of waters and noncondensible gases.

Section 3001 calls for the Administrator to identify and list hazardous wastes in conformance with criteria he must first establish. Sections 3002, 3003 , and 3004 require the establishment of standards for the identified hazardous wastes applicable to waste generators, transporters, and disposal operators, respectively. Complete traceable records are to be a principal feature of the regulations. Geothermal developers may be subject to all three sets of regulations.

Section 3005 requires permits for hazardous waste disposal facilities, with permits to be approved when certain conditions are met. Section 3006 authorizes the states to administer and enforce hazardous waste programs upon approval by the Administrator. Section 3007 authorizes access to any facility handling hazardous wastes and to its records for regulatory development and enforcement purposes.

Regulations have not yet been developed under any section of the Resource Conservation and Recovery Act, although they are imminent.

\subsubsection{Toxic Substances Control Act}

This Act is aimed principally at manufacturers and distributors of toxic chemicals, in order to control indiscriminate proliferation of such materials in the environment. The provisions of the Act can conceivably apply to minerals which might be commercially produced from geothermal development.

Section 4 may require testing by the producer to determine health and environmental effects and the degree of risk. Testing will be done in accordance with standards to be promulgated. Section 5 requires notice of intent and submission of test data prior to manufacture of new chemicals. Under section 6, the Administrator may prohibit the manufacture or distribution of chemical substances if he determines that such substances present an unreasonable risk. Section 8 requires maintenance of records and authorizes official access to such records.

The Toxic Substances Control Act, unlike the others thus far described, does not provide for State control of the program, but does allow states to apply rules not in conflict with the Act. 


\subsubsection{Noise Control Act of 1972}

This Act contains broad noise control provisions for regulating and labeling products, many of which are used at geothermal facilities. In addition, EPA has been given coordination authority of all programs of other Federal agencies relating to noise research and noise control. It has also been given authority to insure that all Federal facilities comply with appropriate Federal, State, and local noise regulations. Many states and local communities regulate noise, and the U.S. Geological Survey has noise regulations (in Geothermal Resources Operational Order 4) for developers on leased Federal lands.

\subsubsection{Other Federal laws pertaining to geothermal pollution control}

Pollution control considerations have been included in several other laws affecting geothermal energy development. These laws are aimed principally at (1) broad-scale encouragement of energy resource development or (2) broad-scale protection of environmental values. The most significant of the first type are the following:

- Geothermal Steam Act of 1970

- Federal Nonnuclear Energy Research and Development Act of 1974

- Geothermal Energy Research and Development Act of 1974.

The second type includes:

- Fish and Wildlife Coordination Act

- Endangered Species Act of 1973

- Wilderness Act

- Marine Protection, Research and Sanctuaries Act of 1972

9.1.9.1 Geothermal Steam Act of 1970. This Act is one of the most significant laws affecting the pace and direction of geothermal energy development. It essentially controls leasing of federal lands and all phases of post-lease operations on those lands; those lands include a large number of the known geothermal resource areas (KGRA's). The Department of the Interior, Bureau of Land Management, administers prelease and leasing requirements. The Department of the Interior, U.S. Geological Survey, administers post-lease requirements, through an "Area Geothermal Supervisor." Currently there is only one Area Geothermal Supervisor with broad responsibilities over most activities including those that result in air and water pollution.

On other than Federal lands, State and local regulations have generally been patterned after those of the Geothermal Steam Act.

The protection of the environment through regulation is provided for in section 24 of the Geothermal Steam Act. Regulations have been published in 30 CFR 270, under which the Area Geothermal Supervisor operates. 
Environmental provisions require preproduction studies, for at least one year, of air and water quality, noise and ecological systems. In addition, the regulations require compliance with all federal and state standards for air, water, land, and noise pollution. Geothermal Resource Operational Orders (GRO) are issued by the Area Geothermal Supervisor to implement the regulations. The principal set of environmental requirements is contained in GRO Order 4, which requires conformance with all federal and state air and water pollution control standards, and establishes detailed noise standards.

\subsubsection{Federal Non-Nuclear Energy Research and Development Act of} 1974. This is the Act which mandated the activities of the Department of Energy, DOE. One of those activities is the active encouragement of geothermal energy technology development through commercial demonstration. The Act (section 6(b)(3)(K)) also provides for the acceleration of the commercial demonstration of environmental control systems for energy technologies.

\subsubsection{Geothermal Energy Research and Development Act of 1974. This} Act authorizes and defines more specifically the responsibilities of the federal government, through the direction of DOE, in developing and demonstrating the commercial viability of geothermal energy conversion. The objectives of the Act are to be accomplished in concert with private developers through grants, contracts, and loan guarantees.

This Act includes a requirement for the development of environmentally acceptable processes (section 2(12)). More specifically, section 104 requires that the geothermal research and development program develop and evaluate improved waste control, disposal and monitoring methods; evaluate procedures; prepare environmental impact statements; and assure compliance with standards and criteria.

\subsubsection{National Environmental Policy Act of 1969. This Act has had} profound effects in calling public attention to the environmental consequences of major new projects. Section 102 of the Act requires an environmental impact statement for all major federal actions affecting the quality of the human environment. The Act produced a ripple effect in that most states have similar laws for state actions. In most cases of major development, an environmental impact statement can be anticipated at some stage prior to commercial energy production, whether it is on federal, state, or private land.

The environmental impact statement requirements at the federal level are applicable to geothermal development on federal lands and to any government-supported research and demonstration projects. In many cases, an initial environmental assessment report may indicate that the action is sufficiently significant to require a full impact statement. 
The impact statement must describe adverse impacts, including those caused by any kind of pollution, on society and its environment. It also must discuss alternatives to the proposed development and their consequences, and must describe irretrievable resource commitments. Environmental impact statements often require detailed field and analytical work and result in long, comprehensive reports. Details on the materials to be included have been published as regulations by several federal agencies. Examples of these are the general guidelines published by the Council on Environmental Quality (40 CFR 1500) and the more specific guidelines of ERDA for its projects (10 CFR 711). DOE has recently published "Guidelines to the Preparation of Environmental Reports for Geothermal Development Projects," which outline in detail the material to be included. Further useful information may be found in "Geothermal Handbook" prepared by the U.S. Fish and Wildlife Service.

\subsubsection{Fish and Wildlife Coordination Act; Endangered Species Act;} Wilderness Act; and Marine Protection, Research, and Sanctuaries Act. These federal laws, administered by the U.S. Fish and Wildlife Service, do not directly address pollution control and its requirements. Instead they allow for prohibition of or advisory action against certain activities in the interest of preserving wildlife habitats and esthetic values. They also may allow for or require mitigating measures where harm may occur.

\subsubsection{State and local pollution control laws and regulations}

It is not the intent of this section to detail the pollution control laws and regulations of the various state and local governments. Let it suffice to say that most of these regulations are tied to the implementation of federal regulations, generally by authority delegated to the states by the EPA Administrator. Generally, where the EPA Administrator feels that such delegated authority is not being implemented satisfactorily, he may retrieve or retain that authority. It is important to note that state and local regulations may impose restrictions on pollution discharges and emissions beyond those required by federal law, but may not be less restrictive.

Thus far, because federal laws are relatively weak, state and local regulations have dominated in control of solid wastes and noise from stationary sources. The degree of federal influence (with state implementation) will sharply increase in the area of solid wastes under the new Resource Conservation and Recovery Act of 1976. The control of noise pollution from stationary sources, including geothermal development activities, will likely continue to be at the discretion of state or local regulators, except for those operations on federal lands controlled by USGS noise regulations (GRO Order No. 4). 


\subsection{Pollution effects from geothermal energy operations}

\subsubsection{Sources of pollution}

The overwhelming preponderance of pollutants from geothermal energy conversion operations will derive from the geothermal fluid itself. Other potential pollutants, such as added chemicals, and materials emitted during exploration, development, and facility construction phases, are expected to be comparatively minor or transient in nature.

Geothermal fluids are expected to be utilized in many ways, including electric power production, space heating, industrial process heating, agricultural drying, and even water supply. By far the greatest volume of geothermal fluid is expected to be from liquid-dominated resources used for electric power production. The raw and spent fluids in power production from liquid-dominated resources are also likely to contain higher quantities of chemical contaminants and heat.

Regardless of the end uses, the processes and activities preceding these uses will have many similarities. Pollution sources can generally be subdivided into:

- Wellfield exploration, development, and construction activities.

- Fluid distribution and energy conversion system operations.

Each of these categories is discussed further in the following subsections.

9.2.1.1 Wellfield exploration, development, and construction activities. This category of sources can be further subdivided into the following:

- Access clearing and preparation

- Drilling

- Construction of fluid distribution and conversion facilities.

All of these sources are considered, with reasonable management, to be transient pollution sources and of minimal consequence in the overall geothermal development picture. Many of the pollutants may be significant for short periods and may not be totally controllable, especially those classed as fugitive emissions (released without control of flow or direction), such as road dust. Most pollutants in this category are generally considered more as nuisance-creating than as hazardous contaminants. The drilling and contruction activities and their associated surface disturbance have been well described in a preliminary report [Rascheri and Cook, 1976] prepared by the U.S. Geological Survey.

Access clearing is a part of all geothermal development from exploration through plant construction. Soil and vegetation are disturbed or destroyed and replaced by roadways and pipeline clearings. Pollutants 
are dust and water-borne silt, vegetation debris, and machinery noise and exhaust. Drilling site preparation includes the same pollutants.

The drilling process itself has the potential for more serious environmental contamination from the loss of drilling muds and possible well blow-outs. Such releases are accidental, but are almost totally preventable with present-day drilling practices. Drilling muds may be composed of various constituents such as bentonite, barite, perhaps chrome-lignite or chrome lignosulphonate, and sodium hydroxide [Matsuo, 1973]. Proprietary constituents may be included. Drilling mud disposal is generally subject to strict State solid waste regulations. Well cuttings may be subject to the same regulations. Well blowouts can contain any or all constituents of the geothermal fluid, described later in this chapter. Equipment operation during drilling can cause very high noise levels, particularly when compressed air is substituted for drilling, and upon entering the production zone.

Construction of fluid distribution and energy conversion facilities is similar to construction of most other industrial facilities, as are the associated pollutants. The pollutants derive from debris, runoff erosion, construction materials, and machinery operation. Soil dust, other airborne particulates, waterborne suspended solids, and noise are the principal pollutants. Most pollutants are generally considered to be in the non-point source and fugitive emissions categories.

9.2.1.2 Fluid distribution and energy conversion system operations. The principal pollutants, after the conversion facility is in operation, will derive from the geothermal fluids as they pass through the facility. Environment-contaminating discharges can potentially occur at the following sites within distribution and conversion systems.

- Wellhead (initial and periodic full-flow venting).

- Fluid phase separation (liquid phase wasting).

- Pipeline vents (continuous small stream venting).

- Steam scrubbing (venting of particulates).

- Steam condensation (condensate discharge).

- Condenser gas ejection (venting noncondensible gases).

- Cooling towers (condensate drift; fog formation; airborne contaminants).

- Cooling water discharge, with or without recycle.

- Air and/or water waste treatment (sludge and treated water and air discharges).

- Injection system (all or part of fluids returned to subsurface).

In some proposed systems, one or more of the listed sources will not exist, while in others all can be significant. The proportion that each of the sources contributes to the total discharges, and to the discharges to each medium (air, surface water, land, and subsurface), depends upon many 
factors. These factors include the type of conversion systems; the initial fluid state (temperature, pressure, and composition), cooling water source; cooling method; and whether waste water injection is practiced.

From an environmental standpoint the production of electrical power is likely to be the most significant near-term use of geothermal energy. In turn, the greatest pollution potential will likely be from moderate to high salinity liquid resources, in which up to 70,000 liters/megawatt hour would be discarded as spent liquid. A facility in such a resource area might be as shown schematically in figure 9.1, with potential pollution release points as depicted. This might be considered environmentally as a worst-case example where all releases would be directly to the air and surface drainage. Both ends of such a plant would have continuous discharges, from the wellhead separator and from the condenser, the latter being cooled by an external water supply. Condensate and cooling water discharges would constitute by far the largest pollution source.

Another facility might be as shown in figure 9.2, which is at the other extreme where the system is closed with potential releases contained and the excess fluids returned to the producing reservoir. The only significant waste loss would be heat to the atmosphere.

For systems other than power production, such as space heating, opcrations may be much simpler in principle, to the extent of merely passing the entire fluid flow through heat exchangers and discharging it to surface drainage or reinjection. Such a system might be as shown schematically in figure 9.3.

There are many possible variations in and between these schemes. For example, the scheme shown in figure 9.3 could be used as part of a power generation system, in which a recycled secondary fluid, heated in the heat exchanger, operates a turbine-generator. The schemes of figures 9.1 and

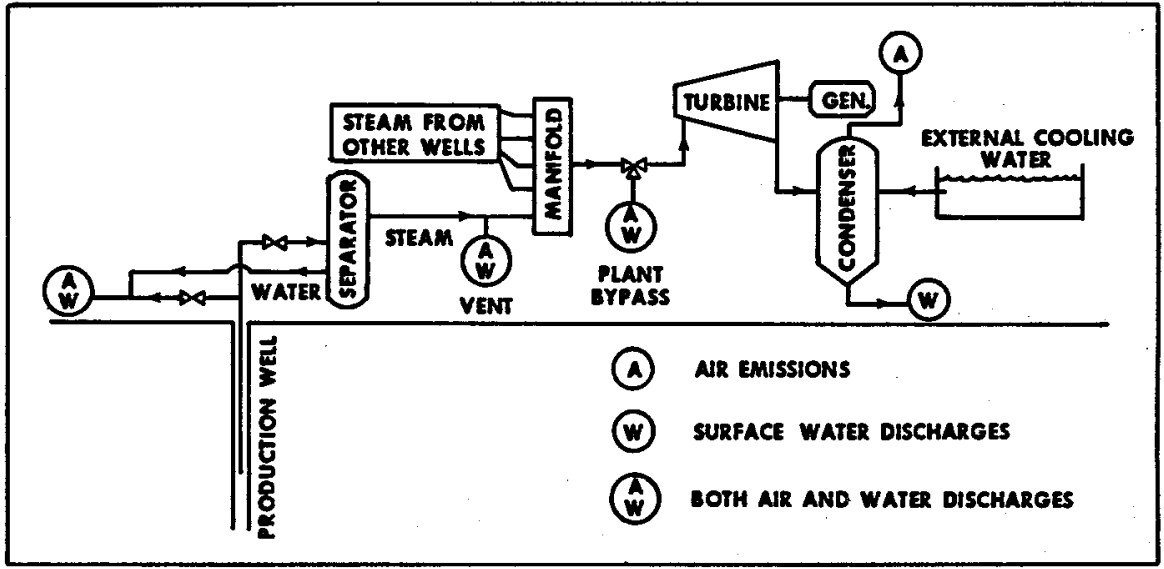

FrgURE 9.1-Simplified schematic diagram of open cycle geothermal electric power generation system operating on flashed steam. 


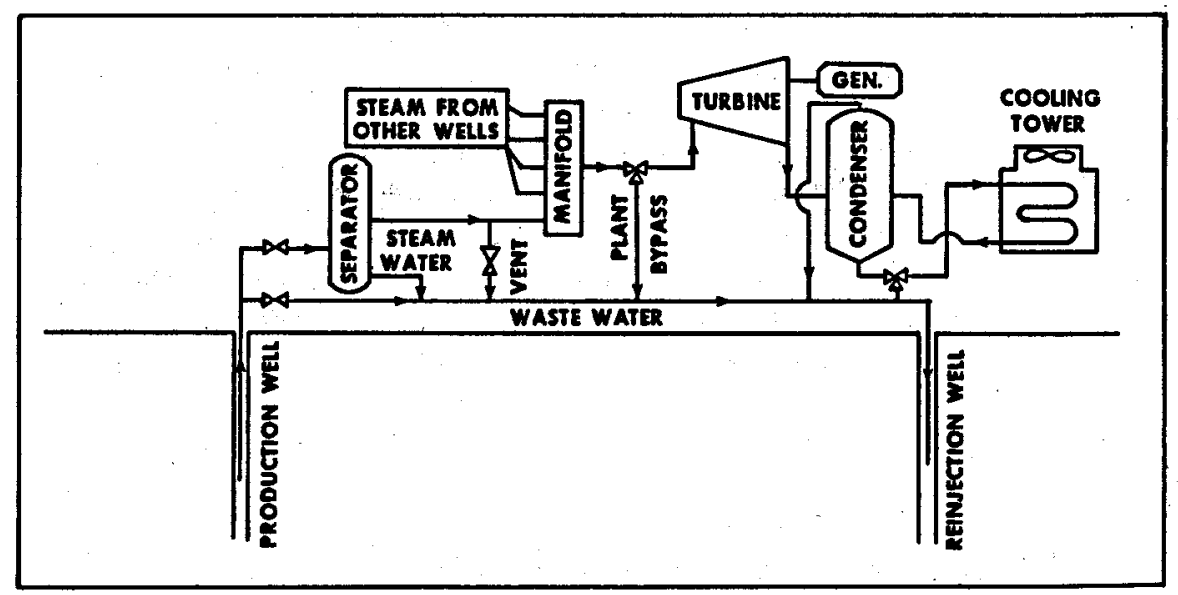

FrquRe 9.2-Simplified schematic diagram of closed loop geothermal electric power generation system operating on tlashed steam.

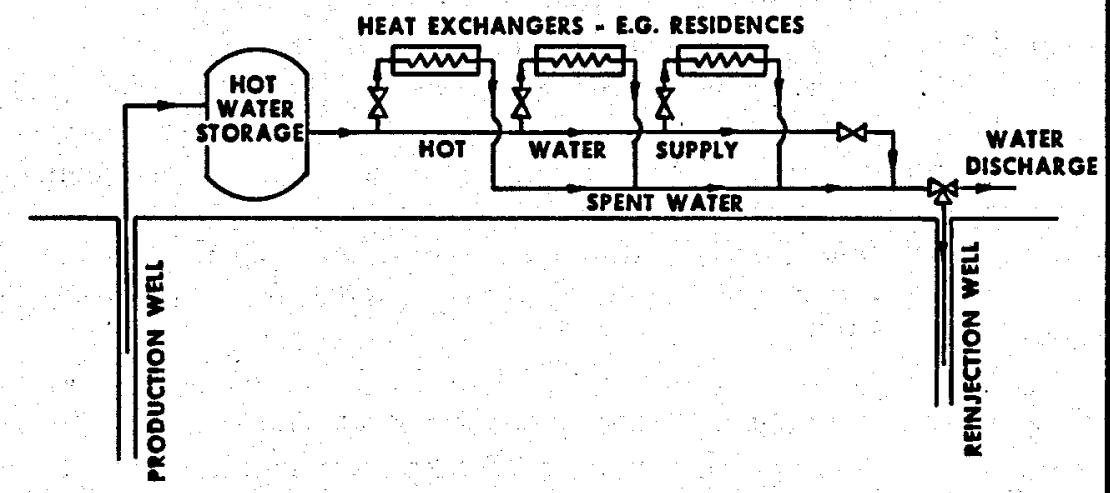

Froure 9.3-Simplified schematic diagram of non-electric use (space heating) of geothermal energy. 
9.2 can also be made more complex by multi-stage flashing, or simpler by passing the entire well flow through a turbine.

The principal point is that any discharge to the air, to surface drainage, to surface impoundments, or to injection, will be subject to regulatory control of some degree. Also the restrictions on those discharges are likely to be directly related to the number and concentrations of constituents in the discharged fluids, and to the fluid volume. They will in turn be directly related to the original character of the geothermal fluid.

If geothermal fluids must be treated for constituent removal, then solid wastes or more concentrated brines containing most of the fluid chemical constituents will result. These wastes will also be subject to confinement and other controls to prevent surface and ground water contamination. In some cases, brine constituents may be extracted for commercial sale and use.

\subsubsection{Pollutants derived from geothermal fuids}

The chemical characteristics of geothermal fluids vary greatly between reservoirs and to a lesser degree even within the same reservoir. The characteristics can also change with time, because of selective withdrawal and recharge factors.

Figure 9.4 lists some of the more significant chemical constituents of geothermal fluids and graphically depicts their ranges. All of the constituents are natural components of geothermal fluids. The information in figure 9.4 has been compiled from an examination of limited data from the literature and unpublished sources [Douglas, et al., 1976; Cosner, 1977; Sanyal, 1977]. Chemical data are now being gathered rather extensively so that the listed ranges will likely expand. Radioactive elements, except for radon gas, which is discussed later, have not been regarded thus far as significant in geothermal fluids.

Figure 9.4 is biased considerably by data from the Salton Sea KGRA (Imperial Valley, Calif.), where very high constituent concentrations are common. In order to add perspective, judgments have been made of ranges within which the majority of concentration measurements will likely occur when all geothermal fluids are considered together. Generally, spent water from most areas is expected to be comparable to or lower than sea water in salinity.

In general, low salinity or low total dissolved solids (TDS) are associated with relatively low concentrations of all constituents and vice versa. Higher temperature waters generally contain higher constituent concentrations except in volcanic areas such as Iceland and Hawaii.

Geothermal fluids range rather widely in hydrogen ion concentrations, with $\mathrm{pH}$ values generally between 2.0 and 8.5 . It appears that most unflashed geofluids in situ are below $\mathrm{pH} 7.0$ whereas at the surface they are above pH 7.0. Based on available measurements, it appears that fluids of highest salinity generally have the lowest $\mathrm{pH}$, and may be highly corrosive. 


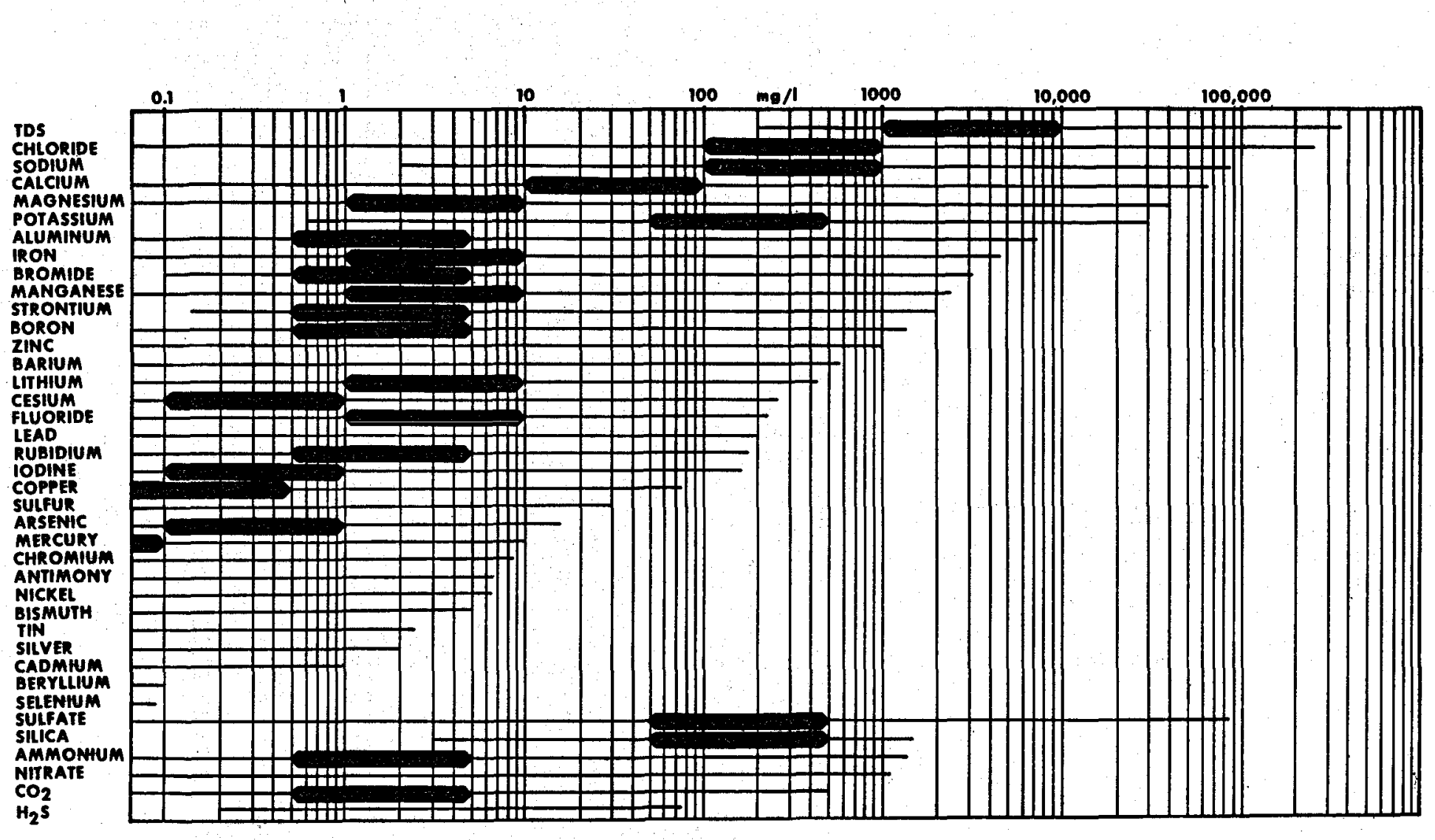

FrgURE 9.4-Ranges of chemical constituent concentrations in geothermal fluids. 
Noncondensible gases, those which do not condense at operating temperatures, are environmentally important constituents of geothermal fluids. They may be free gases or dissolved or entrained in the liquid phase. Hydrogen sulfide has been the component of greatest concern to this time. Noncondensible gases usually comprise between about $0.3 \%$ and $5 \%$ of flashed steam from geothermal fluids [Wood, 1973].

Figure 9.5 depicts the known ranges of noncondensible constituents as percentages of total noncondensible gases [Sanyal, 1977]. Also shown are their probable ranges in parts per million of total gases (including steam) in a steam system. In gas ejector emissions the concentrations can of course be much higher.

Radioactive elements are generally found in geothermal fluids in low concentrations. These include uranium and thorium isotopes, radium, and radon. Radon, a radioactive gas and one of the products of radium decay, is the most significant generally recognized radioactive component in geothermal fluids. A survey by EPA [O'Connell and Kaufman, 1976] of 136 geothermal manifestations showed a range of 13 to $14,000 \mathrm{pCi} / 1$ (picocuries per liter), with a median of about $510 \mathrm{pCi} / 1$. Figure 9.6 depicts the frequency of occurrence of radon concentrations measured during that survey. The concentrations show considerable variation geographically, with some regions having much higher concentrations than others.

Chemicals, such as acids, bases, and various flocculants and coagulants, may be added to geothermal fluids to minimize scaling and corrosion or to remove certain constituents. Although these chemicals may not in themselves be of great pollution consequence, consideration must be given to them (particularly metal compounds), because they may alter the geothermal liquid composition toward being more environmentally detrimental. Most such chemicals will likely be acids and/or bases used for $\mathrm{pH}$ adjustment.

Waste heat can be of major significance in geothermal electric power generation because of the relatively low efficiency of low-temperature con-

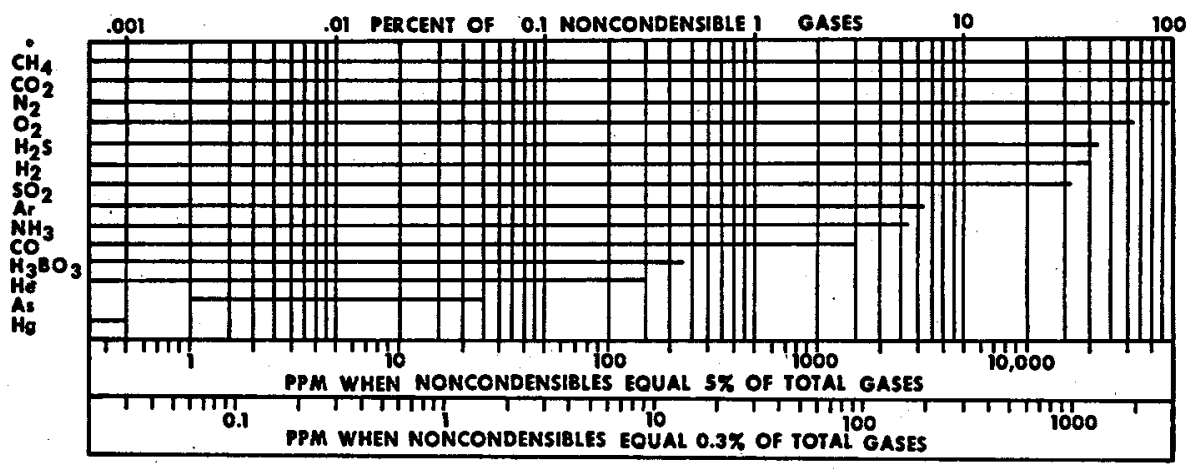

Figure 9.5-Noncondensible gases in geothermal fluids. 
Figure 9.6-Cumulative frequency distribution for radon-222 in geothermal waters.

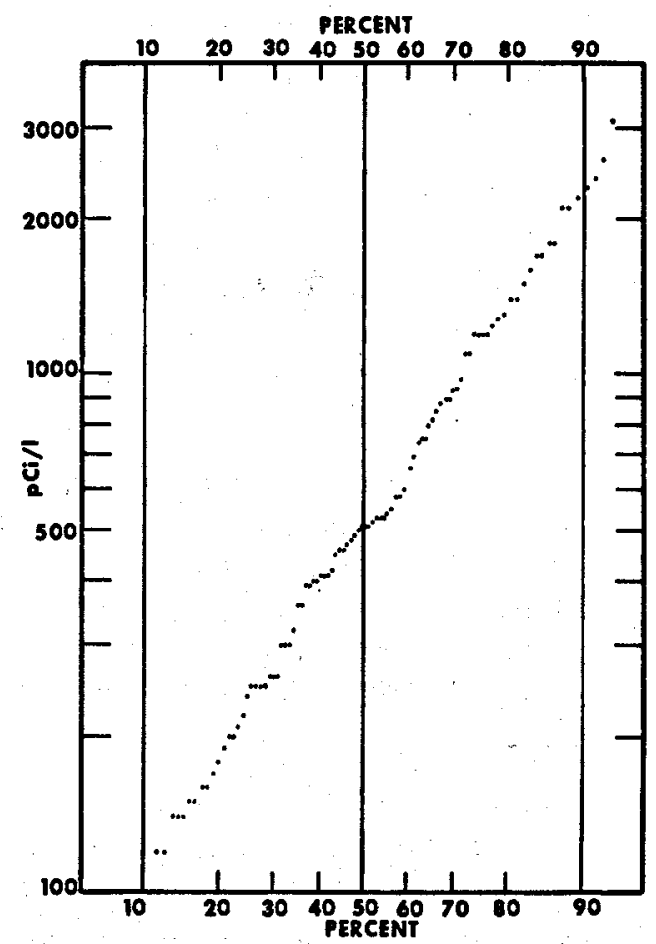

version. If external once-through cooling water is used, most of the waste heat from cooling will be discharged to surface waters. If cooling towers are used, with the cooling water recycled, and the blowdown reinjected, most of the waste heat will be dissipated to the surrounding air. Surface water discharges would be particularly detrimental with large volumes released at temperatures as high as $50^{\circ} \mathrm{C}\left(120^{\circ} \mathrm{F}\right)$.

Solid wastes may be produced by particle separators, scale removal, and as sludge from water treatment and gas scrubbing. Such wastes will include the pollutants of the geothermal fluid itself and any treatment chemicals used. If mineral recovery is practiced, the residual will also be solid wastes or bitterns. The constituents of geothermal solid wastes have the potential for leachate runoff and infiltration to ground water if not properly handled.

\subsubsection{Noise derived from geothermal operations}

In all industrial operations noise is a pollutant that must be accepted to some degree. In geothermal operations noise may be particularly objectionable, in part because the areas of operation will be generally remote and otherwise relatively quiet. The most significant potential sources are drilling (particularly with air) and steam flashing and venting. 
Table 9.1 lists examples of noise measurements at The Geysers power generating facility [PG\&E, 1975]. Noise levels from liquid-dominated sources will likely be similar. In general, noise level decreases from 3 to 6 . $\mathrm{dB}(\mathrm{A})$ with every doubling of distance [EPA, 1977(A)]. The expression $\mathrm{dB}(\mathrm{A})$ means "A-weighted" sound level measured in decibels above a reference sound pressure of 0.0002 microbars (20 micropascals). "Aweighting" weights the contributions of sounds of different frequency so that the response of the human ear is simulated [EPA, 1974].

The sound levels listed in table 9.1 can be compared to more well-known sources, some of which are [EPA, 1974; EPA, 1973] :

- quiet wilderness area, 20-30 dB(A)

- quiet suburban residence, 48-52 dB(A)

- business office, $50-60 \mathrm{~dB}(\mathrm{~A})$

- noisy urban area, 80-90 dB(A)

- adjacent to freeway, $90 \mathrm{~dB}(\mathrm{~A})$

- jet airplane at 100 feet, $120-130 \mathrm{~dB}(\mathrm{~A})$

As the data in Table 9.1 indicate, the most intense noise levels in geothermal operations result from steam venting. Muffiers of various designs are in common use, as described in section 9.5.4.

TaвLE 9.1-Sound Levels from Various Noise Sources at The Geysers, dBA, re 0.000\% $\mu b a r(20 \mu P a)$

[PG\&E, 1975]

\begin{tabular}{|c|c|c|c|c|c|}
\hline \multirow{2}{*}{$\begin{array}{l}\text { Source } \\
\text { No. }\end{array}$} & \multirow[b]{2}{*}{ Noise source } & \multirow{2}{*}{$\begin{array}{l}\text { Sound } \\
\text { level } \\
\mathrm{dB}(\mathrm{A})\end{array}$} & \multicolumn{2}{|c|}{ Distance } & \multirow[b]{2}{*}{ Comment } \\
\hline & & & $\mathbf{m}$ & $\mathrm{ft}$ & \\
\hline 1 & Drilling with air.... & 114 & 8 & 25 & $\begin{array}{l}\text { Steam entry of } \sim 81,720 \mathrm{~kg} / \mathbf{h} \\
(180,000 \quad \mathrm{bm} / \mathbf{h}) . \quad \text { No } \\
\text { muffler. }\end{array}$ \\
\hline 2 & Same as No. $1 \ldots \ldots$ & $\sim 74$ & 805 & 2640 & Same as No. 1. \\
\hline 3 & Drilling with air.... & 84 & 8 & 25 & 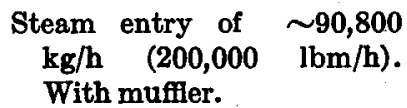 \\
\hline 4 & Same as No. $3 \ldots \ldots$ & $\sim 65$ & 76 & 250 & Same as No. 3. \\
\hline $\mathbf{5}$ & Same as No. 3. & $<50$ & 805 & 2640 & Same as No. 3. \\
\hline 6 & Steam well. . . . . . . . & $89 / 92$ & 14 & 45 & $\begin{array}{l}\text { Main valve closed, bleed } \\
\text { line exhausting freely. }\end{array}$ \\
\hline 7 & Same as No. $6 \ldots$. . & $73 / 75$ & $\mathbf{5 5}$ & 180 & Same as No. 6. \\
\hline 8 & Steam well. ....... & $59 / 62$ & 14 & 45 & $\begin{array}{l}\text { Main valve closed, bleed } \\
\text { equipped with silencer, ex- } \\
\text { hausting freely. }\end{array}$ \\
\hline 9 & Steam well... & 84 & 27 & 90 & $\begin{array}{l}\text { Muffled steam well exhaust- } \\
\text { ing through silencer, ex- } \\
\text { hausting freely. }\end{array}$ \\
\hline 10 & Steam well... & $105 / 110$ & 137 & 450 & $\begin{array}{l}\text { Main valve open, unsilenced. } \\
\text { Steam plume about } 46 \mathrm{~m} \\
(150 \mathrm{ft}) \text { high. }\end{array}$ \\
\hline
\end{tabular}


TABLE 9.1-Sound Levels from Various Noise Sources at The Geysers, $d B A$, re 0.0002 $\mu b a r(20 \mu P a)$-Continued

[PG\&E, 1975]

\begin{tabular}{|c|c|c|c|c|c|}
\hline \multirow{2}{*}{$\begin{array}{l}\text { Source } \\
\text { No. }\end{array}$} & \multirow[b]{2}{*}{ Noise source } & \multirow{2}{*}{$\begin{array}{l}\text { Sound } \\
\text { level } \\
\mathrm{dB}(\mathbf{A})\end{array}$} & \multicolumn{2}{|c|}{ Distance } & \multirow[b]{2}{*}{ Comment } \\
\hline & & & $\mathbf{m}$ & ft & \\
\hline 11 & Steam well. & $71 / 83$ & 914 & 3000 & $\begin{array}{l}\text { Main valve open, unsilenced. } \\
\text { Steam plume about } 46 \mathrm{~m} \\
(150 \mathrm{ft}) \text { high }\end{array}$ \\
\hline 12 & Steam line.......... & $92 / 94$ & 12 & 40 & Directly in front. \\
\hline 13 & Same as No. 12 . & $70 / 75$ & 91 & 300 & $15 / 25$ degrees off axis. \\
\hline 14 & $\begin{array}{l}\text { Testing well (big } \\
\text { well) }\end{array}$ & 107 & 8 & 25 & $\begin{array}{l}\text { (a) } 122,580 \mathrm{~kg} / \mathrm{h} \quad(270,000 \\
\mathrm{lbm} / \mathrm{h}) . \text { With muffler. }\end{array}$ \\
\hline 15 & Same as No. 14. . & $\sim 65$ & 805 & 2640 & Same as No. 14 \\
\hline 16 & Free venting well.... & 120 & 8 & 25 & $\begin{array}{l}\sim 90,800 \quad \mathrm{~kg} / \mathrm{h} \quad(200,000 \\
\mathrm{lbm} / \mathrm{h}) . \text { No muffler. }\end{array}$ \\
\hline 17 & Same as No. 16. . . . & $\sim 79$ & 805 & 2640 & Same as No. 16. \\
\hline 18 & $\begin{array}{l}0.6 \mathrm{~cm}(.25 \mathrm{in.}) \\
\text { bleed on shut-in } \\
\text { well }\end{array}$ & 84 & 8 & 25 & No muffler. \\
\hline 18 & Same as No. 18..... & $\sim 65$ & 76 & 250 & Same as No. 18. \\
\hline 20 & Same as No. 18. . & $<50$ & 805 & 2640 & Same as No. 18. \\
\hline 21 & $\begin{array}{l}\text { Steam line vents } \\
\text { from main line } \\
\text { mufflers of } 2 \\
\text { units. }\end{array}$ & 64 & 244 & 800 & $15 / 25$ degrees off axis. \\
\hline 22 & Power plant. . . . . . & 86 & 15 & 50 & $454,000 \mathrm{~kg} / \mathrm{h}\left(10^{\circ} \mathrm{lbm} / \mathrm{h}\right)$ \\
\hline 23 & Same as No. 22 . & $\sim 61$ & 805 & 2640 & Same as No. 22. \\
\hline 24 & $\begin{array}{l}\text { Steam jet gas } \\
\text { ejector. }\end{array}$ & 91 & 1. 5 & 5 & $\begin{array}{l}\text { Microphone height } 1.5 \mathrm{~m} \text { (5 } \\
\text { ft). Unit load unknown. }\end{array}$ \\
\hline 25 & $\begin{array}{l}\text { Steam jet gas } \\
\text { ejector. }\end{array}$ & 88 & 3 & 10 & $\begin{array}{l}\text { Microphone height } 1.5 \mathrm{~m} \text { (5 } \\
\text { ft). Unit load } 41 \mathrm{MW} .\end{array}$ \\
\hline 26 & Same as No. 25... & 86 & 6 & 20 & Same as No. 25. \\
\hline 27 & $\begin{array}{l}\text { Cooling tower for } 2 \\
\text { units. }\end{array}$ & 81 & 3 & 10 & $\begin{array}{l}\text { Microphone height } 1.5 \mathrm{~m} \mathrm{(5} \\
\text { ft). }\end{array}$ \\
\hline 28 & $\begin{array}{l}\text { Cooling tower for } 2 \\
\text { units. }\end{array}$ & 84 & 3 & 10 & $\begin{array}{l}\text { Microphone height } 1.5 \mathrm{~m} \mathrm{(5} \\
\text { ft). }\end{array}$ \\
\hline 29 & Same as No. 28. . . . & 80 & 12 & 40 & Same as No. 28. \\
\hline 30 & Same as No. 28. . . . & 72 & 43 & 140 & Same as No. 28 \\
\hline 31 & $\begin{array}{l}\text { Outside turbine gen- } \\
\text { erator building. }\end{array}$ & 72 & 8 & 25 & $\begin{array}{l}\text { One unit-44 MW; second } \\
\text { unit-54 MW. }\end{array}$ \\
\hline
\end{tabular}

\subsubsection{Environmental effects of geothermal pollutants}

9.2.4.1 General. Environmental effects are discussed herein only in very general terms. No attempt is made to detail the literature that may be available on toxicity, for example. It is recognized that much greater detail for mixtures unique to geothermal fluids may be justified as geothermal development progresses. It is also recognized that such detail will require complex analyses, both theoretical and empirical. Although a con- 
siderable number of elemental chemical analyses are available, the effects of mixtures of these elements are largely unknown. Often, it is the mixture of compounds that determines the level of environmental effects. The effects may be synergistic, antagonistic, or independent.

Under current laws, discharge permit limitations based upon guidelines and performance standards are the principal and preferred regulatory methods, unless such limitations still allow receiving media standards to be violated. In such cases, the permit limitations will be derived from effects-based media standards. They also may prevail where effluent guidelines and emission standards have yet to be developed; such is the case with the geothermal industry. The current receiving media standards most applicable to the geothermal industry are those for water quality. Table 9.2 lists the geothermal constituents and those regulated by existing water

TABLE 9.2-Pollutants limited by water quality standards in states with geothermal potential

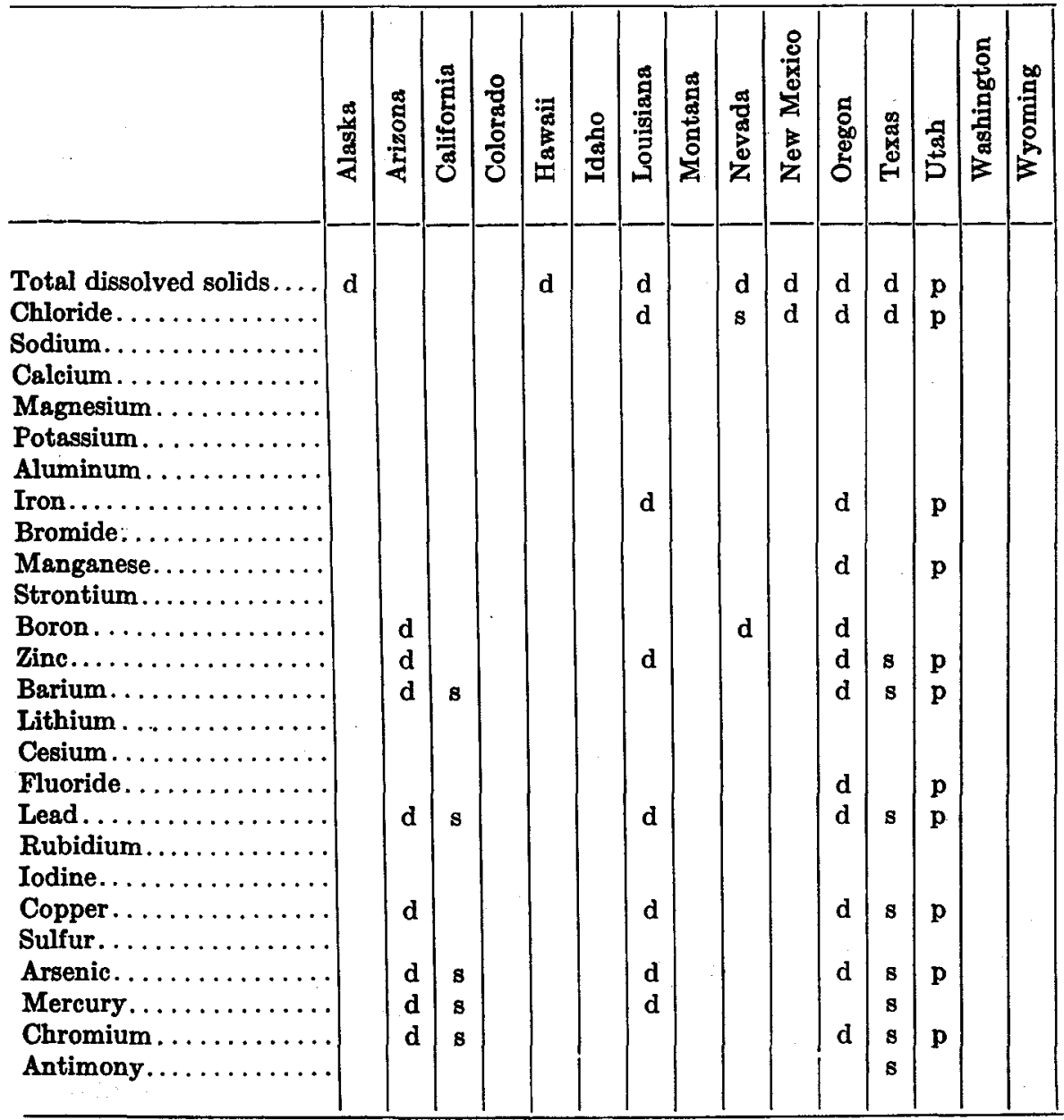

See footnotes at end of table. 
TABLE 9.2-Pollutants limited by water quality standards in states with geothermal potential-Continued

\begin{tabular}{|c|c|c|c|c|c|c|c|c|c|c|c|c|c|c|c|}
\hline . & 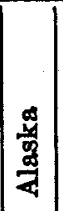 & 章 & 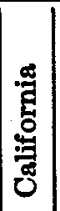 & 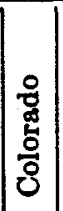 & 焉 & 总 & 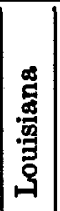 & 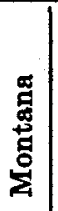 & 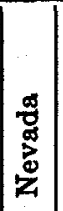 & 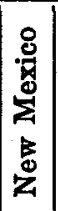 & $\begin{array}{c}\text { 号 } \\
\text { o } \\
\stackrel{0}{0}\end{array}$ & 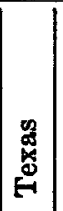 & $\begin{array}{l}\text { 击 } \\
\text { 号 } \\
\end{array}$ & 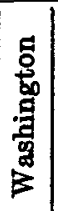 & 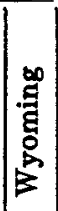 \\
\hline 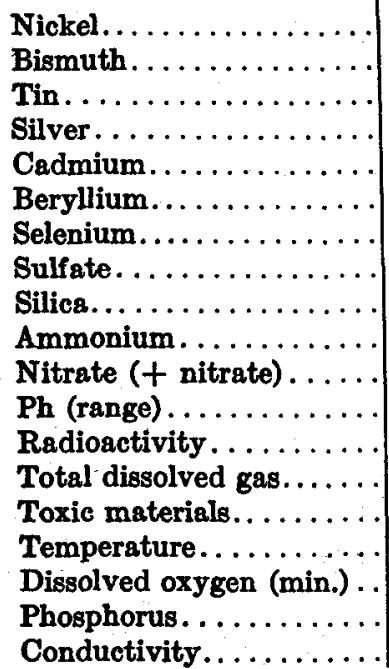 & $\begin{array}{l}d \\
d \\
d\end{array}$ & $\begin{array}{l}d \\
s \\
f \\
d \\
d\end{array}$ & $\begin{array}{l}\mathbf{s} \\
\mathbf{d} \\
\mathrm{d} \\
\\
\mathrm{d} \\
\mathrm{d}\end{array}$ & $\begin{array}{l}\mathbf{s} \\
\mathrm{s} \\
\mathrm{f} \\
\mathrm{d} \\
\mathrm{a}\end{array}$ & $\begin{array}{l}\mathrm{s} \\
\mathrm{B} \\
\mathrm{f} \\
\mathrm{d} \\
\mathrm{s}\end{array}$ & $\begin{array}{l}\text { s } \\
\text { s } \\
\text { s } \\
\text { s } \\
\text { d } \\
\text { B }\end{array}$ & $\begin{array}{l}8 \\
8 \\
8\end{array}$ & $\begin{array}{l}\text { s } \\
d \\
\text { s } \\
\text { s } \\
d \\
d\end{array}$ & $\begin{array}{l}\text { s } \\
\text { s } \\
\text { f } \\
d \\
g \\
d\end{array}$ & $\left|\begin{array}{l}\mathbf{s} \\
\mathrm{s} \\
\mathbf{s} \\
\mathrm{s} \\
\mathrm{d} \\
\mathrm{s} \\
\mathrm{d} \\
\mathrm{d}\end{array}\right|$ & $\begin{array}{l}\text { s } \\
s \\
s \\
d \\
s \\
d\end{array}$ & \begin{tabular}{|l}
8 \\
\\
8 \\
8 \\
8 \\
$d$
\end{tabular} & $\begin{array}{l}\mathrm{p} \\
\mathrm{p} \\
\mathbf{p} \\
\mathbf{p} \\
\mathbf{p} \\
\mathbf{s} \\
\mathbf{s} \\
\\
\mathrm{d} \\
\mathbf{s}\end{array}$ & $\begin{array}{l}\mathbf{s} \\
\mathbf{s} \\
\mathbf{s} \\
\mathbf{s} \\
\mathbf{d} \\
\mathbf{s}\end{array}$ & $\begin{array}{l}\mathbf{s} \\
d \\
f \\
d \\
s\end{array}$ \\
\hline
\end{tabular}

$d=$ criteria for designated waters; $s=$ criteria applied statewide $;=$ criteria conform with USPHS Drinking Water Standards, $1976 ; \mathrm{f}=$ free from toxic materials.

quality standards for those States with significant geothermal potential. As indicated by table 9.2, geothermal fluids may contain constituents not currently controlled by media standards.

9.2.4.2 Water pollutants. The following discussion of environmental effects is divided into areas of water use, as has been characteristic of water quality standards development. The potential water pollutants and their probable concentration ranges in geothermal waste fluids were shown in figure 9.4. Some geothermal reservoirs may produce waters of sufficient quality for many uses, including human consumption; however, this is not expected to be generally true.

Human use. Of greatest concern is the protection of public drinking water supplies. Spent geothermal liquids, in the amounts expected to be discharged, could have serious effects if allowed to enter drinking water sources. The effects of injection to ground water supplies could be disastrous, because such contamination might well be impossible to correct.

Table 9.3 provides some general toxicological information on compounds (mainly inorganic) containing each of the significant geothermal 
TABLE 9.3-Effects on humans of oral ingestion of compounds

\begin{tabular}{|c|c|c|c|c|c|c|c|c|c|}
\hline & \multirow{2}{*}{$\begin{array}{r}\text { Acute } \\
\text { toxicity } \\
\text { of } \\
\text { compounds }\end{array}$} & \multirow{2}{*}{$\begin{array}{r}\text { Chronic } \\
\text { toxicity } \\
\text { of } \\
\text { compounds }\end{array}$} & \multicolumn{6}{|c|}{ Systemic effects } & \multirow{2}{*}{$\begin{array}{l}\text { Drinking } \\
\text { water } \\
\text { standard } \\
(\mathrm{mg} / 1)\end{array}$} \\
\hline & & & Digestive & $\begin{array}{c}\text { Respira- } \\
\text { tory }\end{array}$ & Vascular & Nervous & Skeletal & Muscular & \\
\hline TDS $\ldots \ldots \ldots \ldots$ & 0 & 0 & $x$ & & & & & & 500 \\
\hline CI. . . . . . . & $\mathbf{0}$ & 0 & & & & & & & 250 \\
\hline 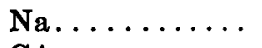 & $\mathbf{0}$ & 0 & & & $x$ & & & & $(*)$ \\
\hline CA. . . . . . & 0 & 0 & & & & - & & & \\
\hline $\mathbf{M g} \ldots \ldots \ldots \ldots$ & 1 & 0 & & $x$ & & $x$ & & & \\
\hline $\mathbf{K} \ldots \ldots \ldots \ldots$ & $0-2$ & 0 & $x$ & $x$ & $x$ & & & & \\
\hline Al........... & 0 & 0 & & & & & & & \\
\hline Fe........... & 0 & 0 & & & & & & & 0.3 \\
\hline $\mathrm{Br} \ldots \ldots \ldots \ldots$ & 2 & 0 & & & & $x$ & & & \\
\hline $\mathbf{M n} \ldots \ldots \ldots \ldots$ & 0 & 0 & & & & & & & 0.05 \\
\hline $\mathbf{S r} \ldots \ldots \ldots \ldots$ & 0 & 0 & & & & & & & \\
\hline B.......... & 2 & 2 & $x$ & & & $x$ & & & 1.0 \\
\hline $\mathbf{Z n} \ldots \ldots \ldots \ldots$ & 1 & 1 & $x$ & & & & & & 5.0 \\
\hline $\mathrm{Ba}, \ldots \ldots \ldots$ & 2 & 2 & $x$ & & $x$ & $x$ & & $x$ & $1.0 * *$ \\
\hline Li . . . . . . . & 2 & 2 & & & & $x$ & & & \\
\hline Cs........... & 0 & 0 & & & & & & & \\
\hline $\mathbf{F} \ldots \ldots \ldots \ldots$ & 3 & 3 & $x$ & & & $x$ & $x$ & $x$ & $1,4-2.4$ \\
\hline $\mathrm{Pb} \ldots \ldots \ldots \ldots$ & 3 & 3 & $x$ & & & $x$ & & & $0.05 * *$ \\
\hline $\mathbf{R b} \ldots \ldots \ldots \ldots$ & 0 & 0 & & & & & & & \\
\hline
\end{tabular}




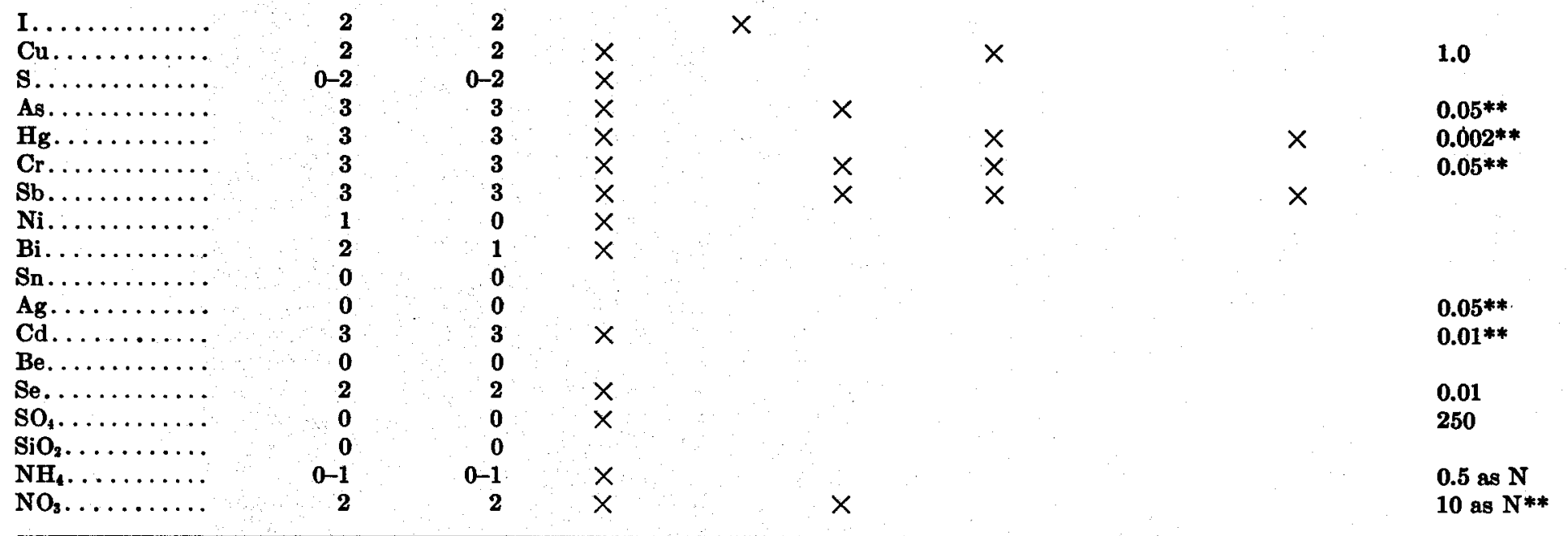

Toxicity ratings: 0 - usually not harmful or harmful only with overwhelming dosage; 1 - causes reversible changes which usually disappear after end of exposure; 2 - causes reversible or irreversible changes not severe tnough to cause death; 3-may cause permanent injury or death after ingestion of small quantities,

*Sodium intake must be limited for some cardiac patients, with a generally accepted limit of $20 \mathrm{mg} / \mathrm{l}$ in drinking water.

**Standard established by 40 CFR 142; all others are USPHS-recommended [USPHS, 1962]. 
fluid constituents. The toxicological information is related to direct undiluted oral ingestion [Sax, 1968; Gleason, et al., 1969]. No attempt is made to give toxic amounts because they are highly variable, depending frequently upon associated ions, the health of the individual, and the time over which the ingestion takes place.

Table 9.3 also includes the permissible or recommended maximum concentrations of constituents in public water supplies [USPHS, 1962; EPA, 1976 (A)]. Comparison of this list with toxicity levels indicates those constituents in geothermal fluids that may have pollutional significance, but are not mentioned in drinking water regulations. These are bromide, lithium, iodide, antimony, and bismuth. Although no drinking water standards have been established for these constituents, it would be fair to assume that, if such are developed, they will be something less than 1 $\mathrm{mg} / \mathbf{1}$ for each. Sulfides, nickel, and potassium from geothermal fluids may have potential health effects, but no limits can be suggested.

Each of the constituents in table 9.3, for which an acute and/or chronic toxicity level of 1 or higher is shown, should be viewed as subject to discharge control in geothermal operations. Control methods and their effecttiveness are discussed later.

Aquatic life. The EPA has recently published "Quality Criteria for Water," [EPA, 1976 (B)] in which many of the constituents found in geothermal fluids are not considered. Table 9.4 has been prepared largely from the information contained in that document, supplemented by others [NAS, 1973; FWPCA, 1968], in which much of the emphasis is on the protection of aquatic life from acute and chronic toxicity. Data in table 9.3 on humans gives cause to suspect that the same constituents may have effects upon aquatic life. Comparison of table 9.4 with table 9.3 shows then that there are many geothermal fluid constituents that may have significant effects upon aquatic life, but have not yet been included in criteria development. These constituents include:

- Aluminum

- Bromine

- Strontium

- Lithium

- Cesium
- Fluorine

- Rubidium

- Antimony

- Nickel

- Bismuth

One of the reasons that the above have not been included is that most have not normally been considered significant components of waste waters or of natural waters. This of course is not always true; for example, fluorides are significant components of natural waters in several areas. Criteria cannot be reasonably suggested here for those constituents that have not been covered in criteria development documents. As noted previously, such development requires complex analyses.

Caution should also be exercised in the use of the data in table 9.4, where no criteria are shown; e.g., arsenic, barium, and boron. These may exist 
TABLE 9.4-Aquatic life criteria for constituents in geothermal fluid-from "Quality Criteria for Water"

[EPA, 1976 (B)]

\begin{tabular}{|c|c|c|}
\hline Constituent & Criteria for marine water & Remarks \\
\hline 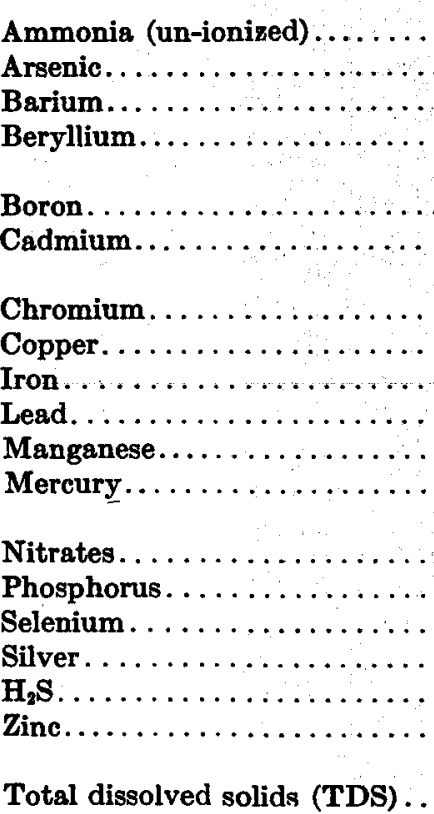 & 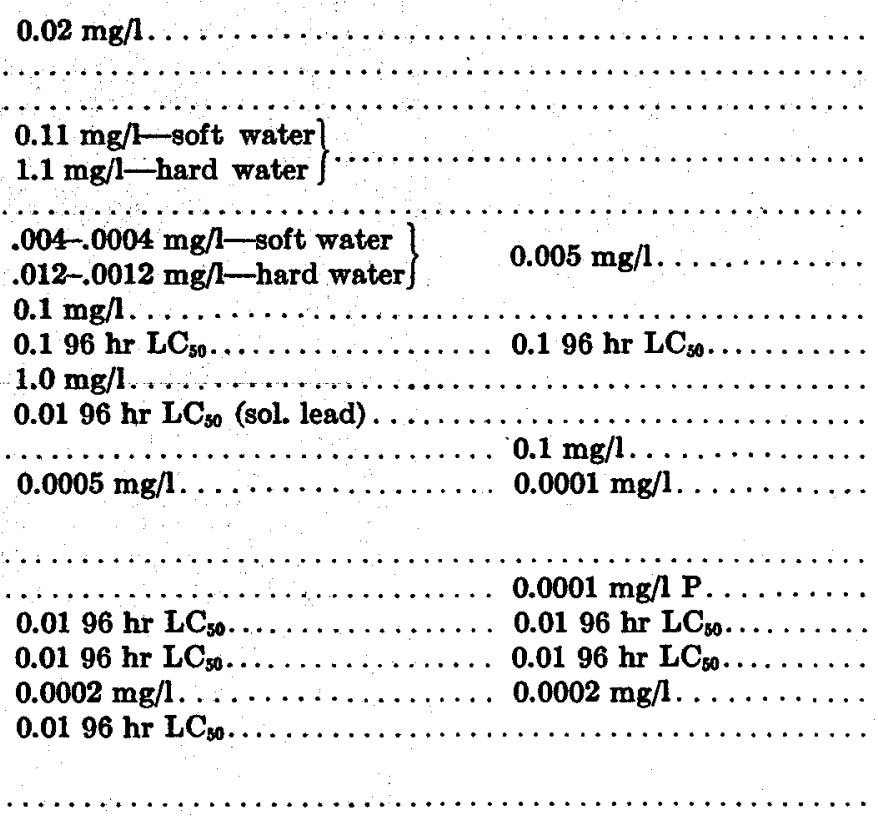 & $\begin{array}{l}\text { Toxicity pH dependent. } \\
\text { Daphnia impaired by } 4.3 \mathrm{mg} / 1 \text {. } \\
\text { Toxicity level }>50 \mathrm{mg} / 1 . \\
\text { Toxicity hardness-dependent. } \\
\text { Toxic to minnows at } 19,000 \mathrm{mg} / 1 \text {. } \\
\text { Toxic at }<0.5 \mathrm{mg} / 1 \text { all tests. } \\
\text { Toxicity varies with pH and oxidation state. } \\
\text { Toxicity alkalinity-dependent. } \\
\text { Toxicity variable. } \\
\text { Salmonids most sensitive fish. } \\
\text { Not a problem in fresh water. } \\
\text { High bio-accumulation and thus affects } \\
\text { human food. } \\
\text { Toxicity to fish }>900 \mathrm{mg} / 1 \text {. } \\
\text { Eutrophication factor. } \\
\text { Toxic at }>2.5 \text { mg/1. } \\
\text { Toxicity dependent on compound. } \\
\text { Toxic at very low levels. } \\
\text { Toxicity dependent on temperature, DO, } \\
\text { hardness. } \\
\text { Osmotic effects-variable. }\end{array}$ \\
\hline
\end{tabular}


in geothermal waters in much higher concentrations than regulatory agencies have had to deal with in other waters.

Waste heat may have particularly significant effects upon aquatic life. Excess heat, as expressed by artificial temperature rise or temperature fluctuations, can disturb aquatic communities to the extent of complete elimination and replacement by different species [Axtmann, 1975; EPA, 1976 (B) ]. Most water quality standards limit artificially induced stream

TABLE 9.5-Agricultural use criteria for constituents in geothermal fluids-from "Quality Criteria for Water"

$$
\text { [EPA, } 1967 \text { (B)] }
$$

\begin{tabular}{lll}
\hline $\begin{array}{l}\text { Livestock } \\
\text { watering }\end{array}$ & $\begin{array}{l}\text { Crop } \\
\text { irrigation }\end{array}$ & Remarks \\
\hline
\end{tabular}

Ammonia

No criteria suggested.

Arsenic......... $0.1 \mathrm{mg} / \mathrm{l} \ldots \ldots \ldots \ldots$ Toxicity to some crops at $0.5 \mathrm{mg} / 1$; no livestock criteria suggested.

Bariun.................... No criteria suggested.

Beryllium......... .001 to $.500 \mathrm{mg} / 1 \ldots$ Crop toxicity acidity dependent; no livestock criteria suggested.

Boron......... $0.75 \mathrm{mg} / 1 . \ldots \ldots \ldots$ Toxic to sensitive plants, e.g. citrus at $<1 \mathrm{mg} / 1$; no livestock criteria suggested.

Cadmium...................... Reduced crop yields at $1 \mathrm{mg} / \mathbf{l}$; crop accumulation related to zinc concentrations; no livestock criteria suggested.

Chromium.................. No criteria suggested.

Copper...................... Toxicity for plants begins at $0.1 \mathrm{mg} / \mathrm{l}$; no livestock criteria suggested.

Iron $\ldots \ldots \ldots \ldots \ldots \ldots \ldots \ldots \ldots$ No criteria suggested.

Lead...................... Toxic to plants at $<\mathbf{3 0} \mathbf{~ m g / 1}$; no criteria suggested.

Manganese....... $0.2 \mathrm{mg} /$ lsuggested for acidiphilic crops.

Mercury

Toxicity to plants increases with decreasing $\mathrm{pH}$; no livestock criteria suggested.

Bio-accumulation but no criteria suggested.

Nitrates..................... No criteria suggested; nutrient for crops.

Phosphorus. . . . . . . . . . . . . . . No criteria suggested; nutrient for crops.

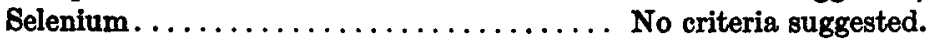

Silver...................... No criteria suggested.

$\mathrm{H}_{\mathrm{g}} \mathrm{S} . \ldots \ldots \ldots \ldots \ldots \ldots \ldots \ldots \ldots \ldots \ldots \ldots \ldots \ldots \ldots$ No criteria suggested.

Zinc....................... Toxic to some crops at 0.4 to $25 \mathrm{mg} /$, may cause iron deficiency in plants; no livestock criteria suggested.

Total dissolved solid $5,000-15,000 \mathrm{mg} / \mathrm{l}$ (TDS). suggested.

Osmotic effects in plants; variable harm to both plants and animals.

Sodium

Toxic to certain plants; ratio to other applications important; no criteria given. 
temperature rise outside mixing zones to $5^{\circ} \mathrm{F}\left(2.6^{\circ} \mathrm{C}\right)$ or less. Generally, the standards also include a maximum stream temperature tailored to the preferred temperature of native fish species.

The $\mathrm{pH}$ of surface waters has been related to productivity, with the most productive waters between $\mathrm{pH} 6.5$ and 8.5. Not only may acids and alkalis be toxic in themselves, but $\mathrm{pH}$ increases or decreases may increase the toxicity of various constituents, e.g., ammonia.

Agricultural use. Two uses are commonly included in considering pollution effects and water quality criteria for agriculture. These are livestock watering and irrigation. Criteria developed in "Quality Criteria for Water" [EPA, 1973] are listed in table 9.5 for those constituents that are found in geothermal waters. Again it must be emphasized that those criteria do not discuss many of the geothermal constituents that may be detrimental to agricultural use.

Criteria development for agricultural water uses has obviously not received the attention that it has for aquatic life and drinking water. This becomes obvious in a comparison of the number of criteria presented in tables 9.4 and 9.5.

Industrial water supply. As a general rule, industrial water supplies are adversely affected by excessive total dissolved solids concentrations, although there is wide variability in the quality of water used among various industries (see table 9.6) [NAS, 1973]. Geothermal fluids from many reservoirs could contribute large quantities of dissolved solids, which could be removed from industrial water supplies, but at a cost which in some cases would be prohibitive. Some industrial processes (e.g., food and beverages) may require as high or higher quality than drinking water, in order to maintain consistency of product quality.

TABLE 9.6-Total dissol ed solids concentrations of surface waters that hui 6 been used as sources for industrial water supplies

[NAS, 1973]

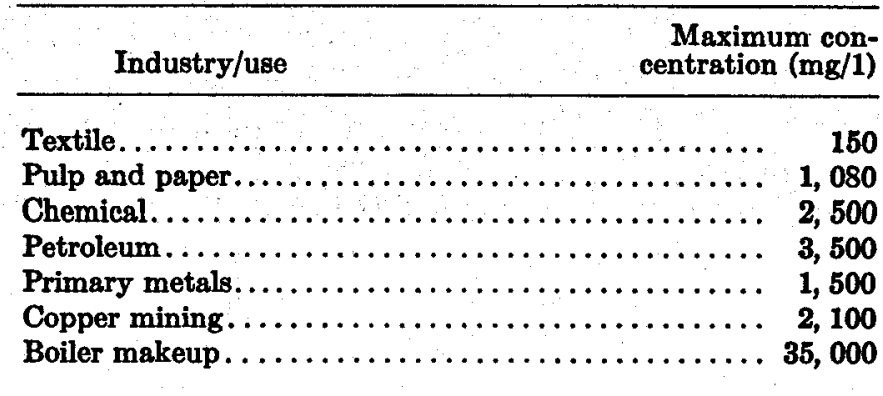


9.2.4.3 Air pollutants. The potential air pollutants and their probable ranges in geothermal steam and air emissions were shown in figure 9.5. Only one of them, sulfur dioxide, is now subjected to regulation from all stationary sources under the Federal Clean Air Act. Mercury vapor emissions are regulated by the Hazardous Air Pollutant section of the Clean Air Act only for mercury ore processing facilities, mercury cell chlor-alkali plants, and sewage sludge incineration. Hydrogen sulfide emissions are regulated by some states, but not by Federal regulations. Some of the noncondensible gases in geothermal fluids are ordinary, relatively innocuous components of the atmosphere and control is unnecessary.

Effects on humans. The greatest concern about any of the noncondensible gases is their effect on human health.

Table 9.7 shows the general inhalation effects of each of the significant gases contained in geothermal fluids [Sax, 1968]. The listed toxicity effects are derived from inhalation of high dosages in confined spaces. However, the relative toxicities and the existence of significant concentrations in geothermal air emissions may indicate which constituents are more likely to require control.

Carbon dioxide, nitrogen, and helium are relatively harmless, but may cause asphyxiation in massive doses. Hydrogen sulfide, sulfur dioxide, ammonia, carbon monoxide, arsenic, and mercury may cause serious harm upon inhalation of relatively small amounts.

Hydrogen sulfide appears to be universally present in geothermal fluids in quantities sufficient to be of environmental concern. That concern is increased by the odor nuisance resulting from very small concentrations of hydrogen sulfide. Even though in sufficient concentrations it is very toxic, the odor nuisance at low non-toxic levels creates public antagonism. Its toxicity effects may be significant in the immediate vicinity of the emission.

The information on hydrogen sulfide in table 9.8 is taken from a literature review by the U.S. Public Health Service [USPHS, 1969].

Hydrogen sulfide in the facility work environment (e.g., power plant) is likely to be of greater health significance than in relatively distant areas. The Occupational Safety and Health Administration regulations (29 CFR 1910.1000) list an acceptable ceiling concentration, without respiratory protection, of $20 \mathrm{ppm}$, with a maximum peak of $50 \mathrm{ppm}$ for a 10-minute exposure. The American Conference of Governmental Industrial Hygienists [ACGIH, 1976] currently recommends a time-weighted average limit over the work day or week of $10 \mathrm{ppm}$, with a short-term (15 minute) exposure limit of $15 \mathrm{ppm}$. Conformance with these criteria may obviate human health concerns outside the work environment.

Effects on plants and crops. Only hydrogen sulfide, sulfur dioxide, and boron (boric acid) in geothermal gases are currently recognized as potentially damaging to crops. Both hydrogen sulfide and sulfur dioxide are converted to acid of sulfates in the environment, which can be damaging to plants and crops when in high enough concentrations. Normally, 
TABLE 9.7-Effects on humans of inhalation of gases or vapors

[Sax, 1968]

\begin{tabular}{|c|c|c|c|c|c|c|c|c|c|}
\hline & \multirow{2}{*}{$\begin{array}{r}\text { Acute } \\
\text { toxicity }\end{array}$} & \multirow{2}{*}{$\begin{array}{l}\text { Chronic } \\
\text { toxicity }\end{array}$} & \multicolumn{4}{|c|}{ Systemic effects } & \multirow{2}{*}{$\begin{array}{r}\text { Fatal dose* } \\
\text { (ppm) }\end{array}$} & \multirow{2}{*}{$\begin{array}{c}\text { Odor } \\
\text { (ppm) }\end{array}$} & \multirow{2}{*}{$\underset{(\mathrm{ppm})}{\mathbf{M A C ^ { * * }}}$} \\
\hline & & & Respiratory & Vascular & Nervous & Muscular & & & \\
\hline $\mathrm{CH}_{4} \ldots \ldots \ldots$ & 1 & 1 & $x$ & $x$ & & & & $\because$ & \\
\hline $\mathrm{CO}_{2} \ldots \ldots \ldots$ & $\mathbf{0}$ & $\mathbf{0}$ & & & & & & & 5000 \\
\hline $\mathrm{N}_{2} \ldots \ldots \ldots \ldots$ & 0 & 0 & & & & $\therefore$ & & & \\
\hline $\mathrm{O}_{2} \ldots \ldots \ldots \ldots$ & 0 & o & & & & & & & \\
\hline $\mathbf{H}_{2} \mathbf{S} \ldots \ldots \ldots \ldots$ & 3 & 3 & $x$ & & & & $>1000$ & $>0.03$ & 10 \\
\hline $\mathrm{H}_{2} \ldots \ldots \ldots \ldots$ & $\mathbf{0}$ & $\mathbf{0}$ & & & & & & & \\
\hline $\mathrm{SO}_{2} \ldots \ldots \ldots$ & 3 & 2 & $x$ & & & & $400-500$ & 3 & 5 \\
\hline Ar......... & 1 & 0 & $x$ & & & & & & \\
\hline $\mathrm{NH}_{\mathbf{s}} \ldots \ldots \ldots \ldots$ & 3 & $\mathbf{u}$ & $x$ & & & & & & \\
\hline$c 0 \ldots \ldots \ldots$ & 3 & 1 & $x$ & $x$ & & & 4000 & & 50 \\
\hline $\mathrm{H}_{3} \mathrm{BO}_{3} \ldots \ldots$ & 2 & 2 & $x$ & & & & & & \\
\hline He......... & 1 & 0 & $x$ & & & & & & \\
\hline As. . . . . . . & 3 & 3 & $x$ & & $x$ & & & & \\
\hline $\mathrm{Hg}_{\mathrm{g}} \ldots \ldots \ldots \ldots$ & 2 & 3 & $x$ & & $x$ & $x$ & & & \\
\hline
\end{tabular}

Toxicity ratings: 0-usually mot harmful or only harmful with overwhelming doses; 1 -causes reversible changes which usually disappear after end of exposure; simple asphyxiants; 2 - causes reversible or irreversible changes not severe enough to cause death; 3 - may cause permanent injury or death after ingestion of small quantities.

* Fatal dose concentrations in air which cause death with less than one hour exposure.

** Maximum acceptable concentration-concentration in air which can be withstood continuously without noticeable harm. 
TABLE 9.8-Hydrogen sulfide effects on humans

[USPHS, 1969]

\begin{tabular}{|c|c|}
\hline $\begin{array}{l}\text { Concentrations } \\
\quad(\mathrm{ppm})\end{array}$ & Effects \\
\hline 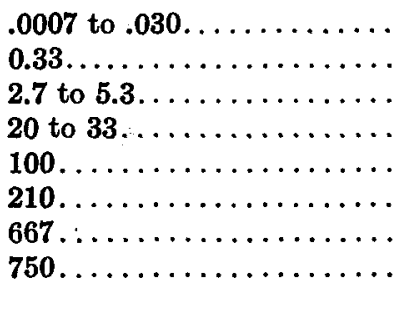 & $\begin{array}{l}\text { Odor threshold. } \\
\text { Distinct odor; can cause nausea, headaches. } \\
\text { Odor offensive and moderately intense. } \\
\text { Odor strong but not intolerable. } \\
\text { Can cause loss of sense of smell in a few minutes. } \\
\text { Smell not as pungent, probably due to olfactory paralysis } \\
\text { Can cause death quickly due to respiratory paralysis. } \\
\text { Virtually no odor sensation; death can occur rapidly, } \\
\text { upon very short exposure. }\end{array}$ \\
\hline
\end{tabular}

such concentrations will not be reached through geothermal emissions. Boron may also wash out of the air and damage plants, particularly citrus crops.

9.2.4.4 Noise pollution. Geothermal development may cause noise pollution that is intolerable at short distances without personal protection, particularly during drilling with compressed air, and high volume steam losses, including atmospheric flashing. Noise pollution, unlike water and air pollution, is contaminating only while it is occurring and only in the immediate vicinity of the source. Thus, its most serious consequences occur near the source and are directly related to the length of exposure. The effects are functions of intensity and exposure time. In geothermal development both can be large.

The effects upon humans of geothermal development noise can take many forms and can be physiological or psychological, or both. Effects include hearing loss, interference with communication, sleep disturbance, and stress reactions that can have long term health implications. This document does not attempt to precisely relate noise effects to noise levels, with respect to humans or other animal life. These relationships have been documented [EPA, 1974; EPA, 1973]. Occupational Safety and Health Administration requirements for the workplace specify that no worker be subjected to $115 \mathrm{~dB}(\mathrm{~A})$ for more than 15 minutes or to $90 \mathrm{~dB}(\mathrm{~A})$ for more than eight hours.

The noise limitations imposed upon geothermal operations on Federal lands specify a maximum level of $65 \mathrm{~dB}(\mathrm{~A})$ at the lease boundary or a distance of one-half mile from the source, whichever is greater.

9.2.4.5. Land-disposed wastes. The effects of pollution from land-disposed wastes should be similar to those described previously under Water Pollution, since contamination would be derived from leachate runoff and/ or percolation to ground water. 
9.2.4.6 Radiation. Radiation, from radioactive materials, is a known carcinogen. At present there is no level of exposure below which it is accepted that no biological damage occurs. Any radiation exposures resulting from geothermal operations would be caused by a redistribution of naturally occurring radioactive materials. The environmental effects could be due to external and internal irradiation. The transfer of radionuclides to man is commonly by ingestion of food and water and by inhalation.

\subsection{EPA suggested pollutant discharge limits}

\subsubsection{General}

The environmental Protection Agency has provided pollution control guidance by way of suggested pollutant emission and discharge limitations, based upon an analysis of available data as presented herein. It must be emphasized that the suggested limitations are not definitive, nor can they be until the character of the geothermal industry and associated technology is more firmly established with an adequate operational data base, including costs. Furthermore, health and environmental effects of many of the pollutants have not yet been adequately investigated. Such investigntions will also have an impact on future limitations, most likely in the direction of tightening of restrictions.

\subsubsection{Air pollutant limitations}

9.3.2.1 Hydrogen sulfide. Hydrogen sulfide is the only air pollutant from geothermal operations for which there is sufficient information to suggest emission limits. Several factors must be considered; these include existing ambient standards, health effects, range of concentrations in steam, and control technology.

Federal ambient air quality criteria do not include $\mathrm{H}_{2} \mathrm{~S}$. California has imposed a State ambient standard of $0.03 \mathrm{ppm}$ by volume as a 1-hour average, applicable state-wide. This state standard has had a profound effect at The Geysers in forcing control technology development. Not widely known is the fact that New Mexico has a standard of $0.003 \mathrm{ppm}$, one-tenth the concentration allowed in California. These state standards are based upon odor nuisance rather than health effects. The odor threshold is near $0.03 \mathrm{ppm}$.

As indicated in table 9.8, $\mathrm{H}_{2} \mathrm{~S}$ at less than $1 \mathrm{ppm}$ can have undesirable effects, although apparently it is not known to be a significant health hazard at that level. The current Occupational Safety and Health Administration regulations list an acceptable ceiling concentration of $20 \mathrm{ppm}$ without respiratory protection.

According to control technology information discussed later in section 9.4, about $90 \% \mathrm{H}_{2} \mathrm{~S}$ removal is the most that can be expected from geo- 
thermal fluids, using available control processes. In the case of Geysers this would be an emission average of 20 to $30 \mathrm{ppm}$, on a weight basis, of the total steam produced. This, of course, is not directly translated to an emission concentration, i.e., as an extreme, treatment of a stream of $100 \%$ $\mathrm{H}_{2} \mathrm{~S}$ might still result in an emission of $100 \% \mathrm{H}_{2} \mathrm{~S}$, although the amount might be only one-tenth as much.

Emission limits must thus be in weight per unit of time, per unit of production, or per unit of raw fluid used. In geothermal electric production the obvious units are megawatt hours or kilowatt hours. If electricity production at The Geysers is taken as $80 \%$ of the $502 \mathrm{MW}$ capacity, it produces an average of about $400 \mathrm{MW}$. If it is assumed that $\mathrm{H}_{2} \mathrm{~S}$ is produced at a rate of $812 \mathrm{~kg} / \mathrm{h}(1788 \mathrm{lhm} / \mathrm{h})$, then the raw load is about 2 $\mathrm{kg} / \mathbf{M W} \cdot \mathbf{h}$, including per-plant losses. Ninety percent reduction would result in an emission rate of $0.2 \mathrm{~kg} / \mathrm{MW} \cdot \mathrm{h}$. Such a limitation assumes total $\mathrm{H}_{2} \mathrm{~S}$ control, from the wellhead through the power plant.

Emission and ambient concentrations are related but are not definitely correlatable. Calculating an emission rate based strictly upon an ambient standard at the property line or some other point is not possible now and would certainly be site-specific.

Based upon the assumptions that (1) The Geysers situation is typical with respect to hydrogen sulfide raw loadings, (2) $90 \%$ removal can be economically accomplished, and (3) adverse environmental effects will not occur with this degree of removal, it is suggested that emissions be limited to $10 \%$ of the loading in the raw geothermal fluid. Assuming that raw loadings will range up to twice those at The Geysers, it is expected that such a limit will be equivalent to an average between 0.2 and 0.4 $\mathrm{kg} / \mathrm{MW} \cdot \mathrm{h}$ of normal power generation (rated capacity $\times$ plant factor). For perspective, these figures, for a $100 \mathrm{MW}$ capacity plant, translate to 16 to $32 \mathrm{~kg} / \mathrm{h}$. Facilities producing raw loads less than $0.2 \mathrm{~kg} / \mathrm{MW} \cdot \mathrm{h}$ of normal power generation probably will not require treatment.

It is expected that environmental damage from hydrogen sulfide will not occur if the suggested limits are met. The ambient air limit at The Geysers is $0.03 \mathrm{ppm}$ and is apparently met most of the time without treatment. Consistent $90 \%$ reduction should eliminate violations, particularly if individual sources remain dispersed.

9.3.2.2 Other noncondensible gases. Limitations have not been suggested by the EPA for other noncondensible gases and metal vapors because as yet they have not been of proven concern, removal technologies have not been described, and effects have not been shown.

\subsubsection{Water pollutant limitations}

By far the greatest volume of water in geothermal operations will be spent water variously contaminated by natural constituents from the geo- 
thermal reservoir. If the reservoir is dry steam-dominated, such as at The Geysers, the liquid will be principally condensate, relatively clean and low in volume. However, dry steam reservoirs are rare; the great bulk of useful geothermal energy will be derived from water-doininated reservoirs. From these, large volumes of water will be withdrawn.

Two kinds of waste water will, in most cases, result from electric power generation. One is the residual water left after flashing or otherwise extracting the heat. The second type is cooling water and condensate. The cooling water may be from an external source; however, in most cases it is likely to be condensate recycled through cooling towers. In the latter case, the waste would be excess condensate and blowdown.

Residual geothermal liquid may be at a high temperature and contain chemical constituents in quantities unacceptable for direct discharge to fresh waters. In a few cases, direct discharge to the ocean may be feasible where the waste characteristics are similar to sea water. Otherwise, treatment would be required for surface water discharges.

Alternative treatment technologies for geothermal brines will be discussed in section 9.5. They include evaporation ponds, forced evaporation and distillation, membrane filtration, and ion exchange. Except for totally contained evaporation ponds, which are taken to dryness, each of these technologies creates an even more concentrated brine residual that must be disposed of. At present, it does not appear that most of these technologies will be feasible for large volume treatment. Evaporation ponds may be, but very large areas would be required.

Subsurface injection of spent geothermal liquid to the producing reservoir now appears to be the most feasible disposal alternative. Because it has been demonstrated, and because it is considered necessary to minimize reservoir depletion and subsidence, injection is recommended. Injection of excess condensate is also feasible and is recommended. It can be injected along with, and may in fact facilitate by dilution, spent brine injection.

The suggested maximum limitation therefore, for spent brine and cooling water from geothermal electric power generation, is no discharge to surface waters except where the discharge quality is equivalent to or exceeds that defined by receiving water quality standards for chemical constituents and radioactivity.

The no-discharge limitation foresees subsurface injection in most cases. Thus, limitations must be established, in turn, for injection. Since it has the potential for contamination of ground waters used for other purposes, it is suggested that no change be allowed in the chemical or physical properties of waters outside the geothermal reservoir as a result of injection. This means injection in most cases to or below the geothermal reservoir. Ponding capability should be provided for containment of potential unplanned releases due to system failure. 


\subsubsection{Land-disposed waste limitations}

As discussed earlier, solid wastes are already subject to State regulation. Regulation is likely to soon become more restrictive under the newly enacted federal Resource Conservation and Recovery Act, particularly with respect to land-disposed toxic and hazardous materials.

Regulation of land-disposed waste generators, transporters, and disposal facilities may prescribe control methods that must be used. These methods will be applicable to geothermal land-disposed wastes such as drilling muds, well cuttings, and sludges resulting from treatment of gases and liquids, as well as surface impoundments of potentially hazardous wastes. Permanent exclusion and perpetual maintenance of disposal sites may be needed after plant de-commissioning.

The suggested limitations for geothermal solid wastes are total confinement and no significant emissions or discharges therefrom to the air, surface water or ground water. Wherever it is not possible to permanently contain the leachate, it must be further treated for removal of any contaminant that would have an adverse impact.

\subsubsection{Noise limitations}

The information presently available on noise and its effects is not sufficient to independently suggest limitations for geothermal operations. It is therefore suggested that limitations, similar to the U.S. Geological Survey regulations currently imposed on Federal lands be observed as a minimum at all sites. Thus the suggested limitation is $65 \mathrm{~dB}(\mathrm{~A})$ at the property line or at a distance of one-half mile from the source, whichever is greater. Several states have more restrictive limitations, and these should be observed. Regulations of the Occupational Safety and Health Administration limit noise, without ear protection, to a daily limit of 90 $\mathrm{dB}(\mathrm{A})$ for eight hours and $115 \mathrm{~dB}(\mathrm{~A})$ for 15 minutes.

Noise suppression technology for geothermal applications has not received a great deal of attention and can probably be improved significantly at relatively small cost. This in turn indicates that noise limits might become more restrictive in the future.

\subsection{Air pollution control technology}

This section describes pollution control technologies that are or may be applicable to gaseous discharges and emissions from geothermal energy conversion systems. It also examines the costs of those technologies to the extent that they can be determined.

Technologies to control air pollution from geothermal operations are directed primarily at incoming steam, condenser vent emissions, and cool- 
ing tower emissions. In all of these, hydrogen sulfide $\left(\mathrm{H}_{2} \mathrm{~S}\right)$ is the pollutant currently of greatest concern. Each of the described technologies removes hydrogen sulfide.

The technologies described herein either have not been applied to geothermal operations or have been applied on a very limited scale. Thus, in general, their applicability and their costs must be considered preliminary judgments based mainly upon the use of those technologies in other industrial sectors. Most of the following technology and cost information has been extracted from a preliminary comprehensive study done for EPA by TRW Inc. [Sung, et al., 1978].

\subsubsection{Stretford process}

A simplified flow diagram of the Stretford process is shown in figure 9.7. The process produces elemental sulfur and is applicable to those geothermal energy conversion processes condensing steam [Lasz]o, 1976]. It scrubs noncondensible gases from the condenser ejector with an aqueous solution containing sodium carbonate, sodium metavanadate, and anthraquinone disulfonic acid (ADA). An alkaline solution of sodium carbonate and bicarbonate is produced with the carbon dioxide present in the scrubbed gas stream. The gas stream is scrubbed countercurrently with the alkaline solution in the absorber, and hydrosulfide (HS-) is formed: The hydrosulfide is oxidized by 5 -valent state vanadate to form elemental sulfur and 4-valent state vanadate:

$$
\mathrm{S}^{-2}+2 \mathrm{~V}^{+5} \rightarrow \mathrm{S}+2 \mathrm{~V}^{+4}
$$

The above reaction is hindered by $\mathrm{pH}$ over 9.5 , thus the $\mathrm{pH}$ is controlled in the optimum range of 8.5 to 9.5 by adding sodium hydroxide. Scrubbing solution is regenerated by blowing air into the oxidizer, and the reduced vanadate is restored to the 5-valent state through a mechanism involving oxygen transfer by the ADA:

$$
\begin{aligned}
& \mathrm{V}^{+4}+\mathrm{ADA} \rightarrow \mathrm{V}^{+5}+\text { reduced } \mathrm{ADA} \\
& \text { reduced } \mathrm{ADA}+\mathrm{O}_{2} \rightarrow \mathrm{ADA}+\mathrm{H}_{2} \mathrm{O}
\end{aligned}
$$

Air blown into the oxidizer brings the suspended elemental sulfur to the surface. The sulfur froth is removed to the skim tank and is either filtered, centrifuged, or washed and melted to produce high quality sulfur. The Stretford process is over 99 percent effective, thus removing essentially all of the hydrogen sulfide from the condenser off gases. The overall reaction is:

$$
2 \mathrm{H}_{2} \mathrm{~S}+\mathrm{O}_{2} \rightarrow 2 \mathrm{H}_{2} \mathrm{O}+2 \mathrm{~S}
$$

A surface condenser rather than a direct contact condenser must be used with the Stretford process, to eliminate direct contact of the cooling water 


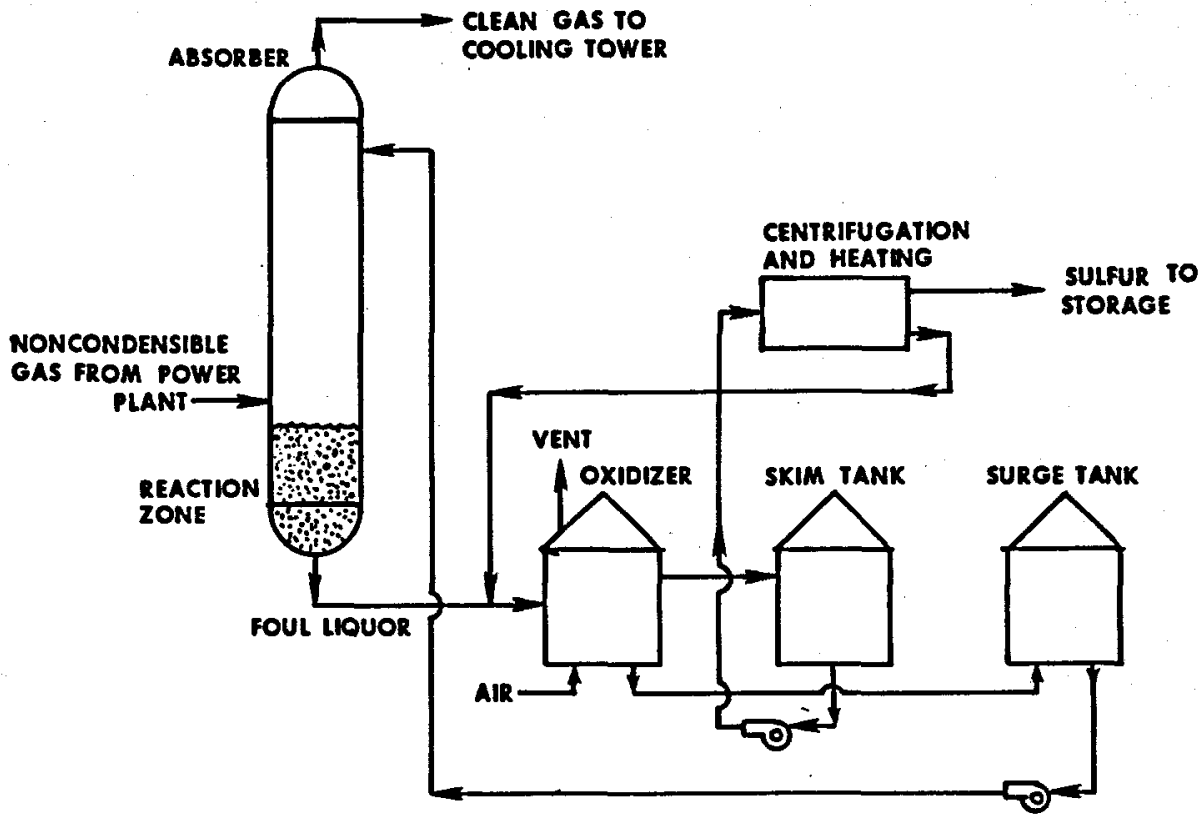

Figuri 9.7-A simplified flow diagram of the Stretford process.

with the condensate. Thus, the amount of water (condensate only-not cooling water) available for hydrogen sulfide to dissolve in is significantly reduced. Thus, with a surface condenser it is estimated that no more than 10 percent of the hydrogen sulfide will remain in solution with the condensate. The hydrogen sulfide dissolved in the condensate is stripped out of solution in the cooling tower and emitted to the atmosphere. Therefore, if a Stretford process is applied to a geothermal energy conversion system designed with a surface condenser, at least 90 percent of the hydrogen sulfide existing in the turbine discharge can be removed. The Stretford process will effectively control hydrogen sulfide emissions without any direct detrimental influence on the power cycle. However, the conventional geothermal energy conversion system requires redesigning to include the surface condenser.

Stretford process cost estimates are based on the process currently being designed for installation on one unit at the Pacific Gas and Electric Geysers facility in 1979. Capital costs include the differential investment required for a surface condenser in lieu of a direct contact condenser. Capital costs for desired cases, where hydrogen sulfide concentration or steam flow rates differ from those given for The Geysers base case, can be computed utilizing the following formulas [Griebe, 1977]:

$$
I A=I B\left(\frac{S A}{S B}\right)^{0.4} \text { for; } 0.5<S A<5 \text { metric tons of sulfur per dey }
$$


$I A=I B\left(\frac{S A}{S B}\right)^{0.5}$ for: $5<S A<250$ metric tons of sulfur per day

$S A=$ Metric tons of sulfur produced per day in the desired case

$S B=$ Metric tons of sulfur produced per day by the base case (The Geysers unit 14) Stretford process.

$I=$ Capital investment for the desired or base $(A$ or $B)$ Stretford process.

The following assumptions were used to estimate the annual capital and operating/maintenance costs for a Stretford unit:

- Amortization period : 15 years [SRI, 1977]

- Maintenance materials: 2 percent of the installed capital cost [Griebe, 1977]

- Maintenance labor: 10 percent downtime, requiring a two-man maintenance crew, earning approximately $\$ 30$ per hour

- Electrical power usage : 66 operating BHP per metric ton of sulfur produced per day [Griebe, 1977]

- Chemical cost: $\$ 35$ per metric ton of sulfur produced per day [Griebe, 1977]

- Sulfur credit : $\$ 20$ per metric ton

- Construction site : The Geysers

Costs, in mills/KWH, for power generation capacities ranging from 12.95 MW to 117.5 MW and a hydrogen sulfide concentration of $220 \mathrm{ppm}$ are presented in figure 9.8. A greater or lesser quantity of steam produced from other geothermal resources may be required to produce the same amount of electrical energy generated at The Geysers. Since the cost of a Stretford process is a function of the sulfur mass flow rate, costs will vary from those presented in figure 9.8 for other geothermal applications.

\subsubsection{Iron catalyst process}

The iron catalyst (or Ferrifloc) system has been developed by Pacific Gas and Electric Company and is presently in use for hydrogen sulfide

Fravas 0.8 - Costs for hydrogen sulfide removal for the Stretford process.

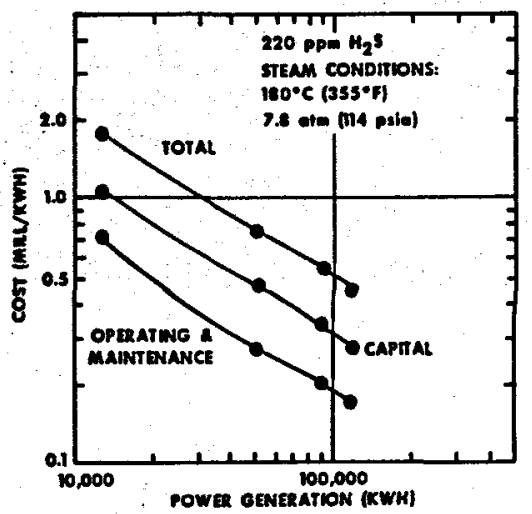




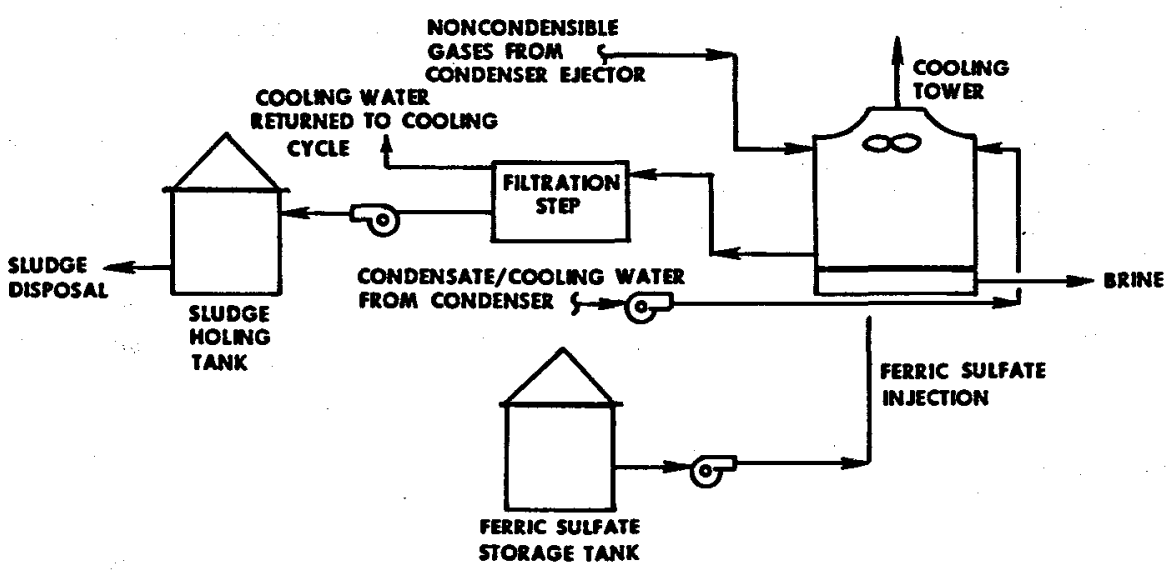

Fradre 9.9--A simplified flow diagram of the iron catalyst (or Ferrifloc) system.

control at The Geysers geothermal field [Fairfax and McCluer, 1972]. This system is applicable to geothermal conversion systems condensing steam and equipped with direct contact condensers. A simplified flow diagram of this process is shown in figure 9.9.

Ferric sulfate, in solution, is added to the cooling water, thus oxidizing the hydrogen sulfide contained in the aqueous phase. The noncondensible condenser ejector gases are ducted to the cooling tower and hydrogen sulfide is scrubbed by the falling water containing the ferric sulfate catalyst. Operational experience at The Geysers indicates that practically all of the hydrogen sulfide dissolved in the cooling water/condensate stream is stripped out into the air stream as it passes through the cooling tower. Therefore, any process controlling hydrogen sulfide emissions by treatment of the cooling water must be applied to the cooling water upstream of the cooling tower. The addition of ferric sulfate makes ferric ions available to react with the dissolved hydrogen sulfide, thus forming elemental sulfur, water, and ferrous ions. The reaction mechanism is given below :

$$
\begin{aligned}
& \mathrm{H}_{2} \mathrm{~S}(\mathrm{aq}) \rightarrow 2 \mathrm{H}^{+}+\mathrm{S}^{-2} \\
& \mathrm{Fe}_{2}\left(\mathrm{SO}_{4}\right)_{3} \rightarrow 2 \mathrm{Fe}^{+3}+3 \mathrm{SO}_{4}{ }^{-2} \\
& 2 \mathrm{Fe}^{+3}+\mathrm{S}^{-2} \rightarrow 2 \mathrm{Fe}^{+2}+\mathrm{S} \downarrow \\
& 2 \mathrm{Fe}^{+2}+1 / 2 \mathrm{O}_{2}+2 \mathrm{H}^{+} \rightarrow 2 \mathrm{Fe}^{+3}+\mathrm{H}_{2} \mathrm{O}
\end{aligned}
$$

The ferrous ions react with the oxygen encountered in the cooling tower to regenerate the ferric ions. Thus, the regenerated ferric ions are available and the hydrogen sulfide reaction repeats continuously to form elemental sulfur. The elemental sulfur produced by this process is removed from the cooling water by filtration. The original design for this system included the use of sand filters; however, significant plugging and main- 
tenance problenıs have been encountered at The Geysers facilities. To resolve these difficulties, alternative filtration systems are being investigated. The filtration step generates large quantities of toxic sludge that may cause disposal problems. An industrial waste disposal site or appropriate landfill disposal site is required.

The iron catalyst system results in significant corrosion rate increases in the condenser, cooling tower, and associated piping. Plugging problems will be similarly increased in all of the equipment in contact with the cooling water/condensate. The direct contact condensers presently operating at The Geysers with an iron catalyst system are clad with stainless steel. It is anticipated that the accelerated corrosion rate will reduce condenser life to seven years [Tolmasof, 1976]. Insoluble salts carried over into the cooling tower blowdown may cause plugging problems in the injection well, if the blowdown is reinjected. The iron catalyst system is the only present control technology in use to control hydrogen sulfide emissions from both the cooling tower and condenser ejector. The overall hydrogen sulfide removal efficiency from the power cycle for the iron catalyst system should be 90 to 92 percent, although such efficiencies have yet to be achieved consistently at The Geysers.

The iron catalyst system is currently in operation at The Geysers facility on three units. The installed capital cost of The Geysers unit 11 iron catalyst system [Laszlo, 1976] was used as a basis for the cost estimates presented. It includes a differential investment for sludge thickeners in lieu of sand filters [Galeski, 1977].

Capital costs for iron catalyst systems with steam flow rates differing from those at The Geysers can be calculated with the following formula:

$$
I A=I B\left(\frac{S T A}{S T B}\right)^{0.6}
$$

$S T A=$ Steam flow rate of desired iron catalyst system

$S T B=$ Steam flow rate of base case $(907,000 \mathrm{~kg} / \mathrm{h})$

$I=$ Capital investment for the desired or base $(A$ or $B)$ iron catalyst system.

The cost of the iron catalyst system is a function of the cooling water/ condensate flow rate, which is directly proportional to the steam flow rate. Therefore, the steam flow rate is an acceptable variable in the cost equation. Capital costs were assumed not to be affected by variations in hydrogen sulfide concentration. Operation and maintenance costs for electrical power and chemical usage are assumed to be linearly dependent upon : steam flow rate (with constant hydrogen sulfide concentration) and hydrogen sulfide concentration (with constant steam flow rate). Operation and maintenance costs are difficult to estimate because of the operational problems encountered at The Geysers [Allen, 1977]. 
The following assumptions were used for the iron catalyst annual capital and operation/maintenance cost estimates:

Amortization period: 15 years.

Maintenance materials : 1 percent of the installed capital cost.

Maintenance labor: 10 percent down time, requiring a two man crew earning approximately $\$ 30$ per hour.

Electrical power usage: $68 \mathrm{KW}$ [Galeski, 1977].

Ferric sulfate usage: $0.5 \mathrm{~kg}$ ferric sulfate per $\mathrm{kg}$ of hydrogen sulfide, with a low factor of 20 percent [Laszlo, 1976].

Ferric sulfate cost : $\$ 0.05$ per lb (0.11/kg) [Galeski, 1977].

Removal efficiency : 90 to 92 percent.

Construction site : The Geysers.

Costs, in mills per $\mathrm{kW} \cdot \mathrm{h}$, for power generation capacities ranging from $12.1 \mathrm{MW}$ to $110 \mathrm{MW}$ and a hydrogen sulfide concentration of $220 \mathrm{ppm}$ are presented in figure 9.10. Costs are based specifically on the operating conditions for The Geysers unit 11 power plant and should not be applied to geothermal energy conversion systems in general. At constant flow rates, costs increase with increasing $\mathrm{H}_{2} \mathrm{~S}$ concentrations.

\subsection{3. $E I C$ process}

The EIC process removes hydrogen sulfide from raw geothermal steam by scrubbing it with an aqueous solution of copper sulfate [EIC, 1976]. The hydrogen sulfide and copper sulfate react in a scrubber, forming a copper sulfide precipitate. The process is potentially valuable because it can remove hydrogen sulfide from the geothermal steam even while the plant may be shut down. Another benefit of an upstream scrubbing process

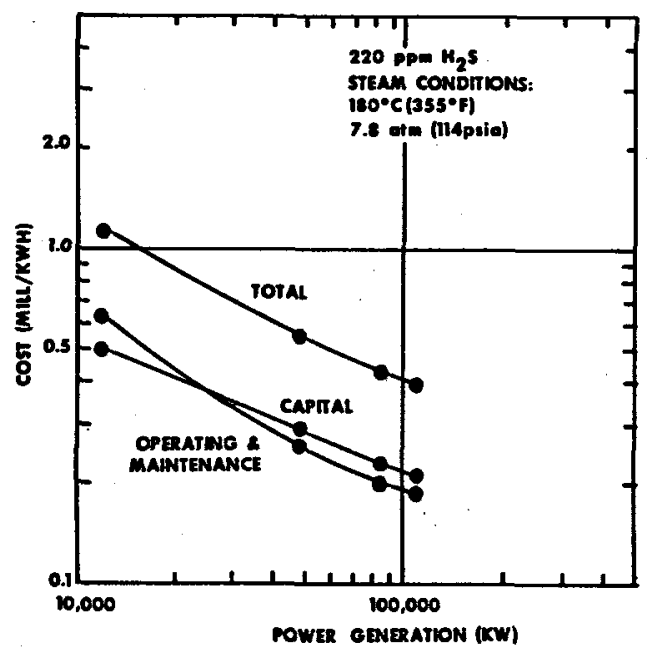

Fiaure 9.10-Costs for hydrogen sulfide removal for the iron catalyst system. 
is the reduction of corrosive effects of $\mathrm{H}_{2} \mathrm{~S}$ on the turbine and condensing/ cooling cycle equipment. This enables the use of standard materials of construction for the power plant equipment and piping. The EIC process removes hydrogen sulfide without significant degradation of steam quality (temperature and pressure). A simplified flow diagram of the EIC process, with regeneration by roasting, is shown in figure 9.11. Figure 9.12 shows the process with regeneration by leaching.

The process consists of three primary operations : scrubbing, liquid/solid separation, and regeneration. A packed column, sieve tray column, venturi scrubber, or spray scrubber could be used to provide sufficient contact time and interfacial area for mass transfer between the hydrogen sulfide and copper sulfide to occur. An eight-inch diameter single sieve tray column has been used in field tests at The Geysers. Hydrogen sulfide gas in the geothermal steam is absorbed in an aqueous solution containing dissolved copper sulfate and suspended copper oxide particles by the following reaction sequences:

$$
\begin{aligned}
& \mathrm{H}_{2} \mathrm{~S}(\mathrm{aq}) \rightarrow \mathrm{H}^{+}+\mathrm{HS}^{-} \\
& \mathrm{HS}^{-2} \rightarrow \mathrm{H}^{+}+\mathrm{S}^{-2} \\
& \mathrm{CuSO}_{4}(\mathrm{aq}) \rightarrow \mathrm{Cu}^{+2}+\mathrm{SO}_{4}^{-2} \\
& 2 \mathrm{H}^{+}+\mathrm{SO}_{4}^{-2} \rightarrow \mathrm{H}_{2} \mathrm{SO}_{4} \\
& \mathrm{Cu}^{+2}+\mathrm{S}^{-2} \rightarrow \mathrm{CuS}
\end{aligned}
$$

Overall reaction: $\mathrm{CuSO}_{4}+\mathrm{H}_{2} \mathrm{~S} \rightarrow \mathrm{CuS}+\mathrm{H}_{2} \mathrm{SO}_{4}$

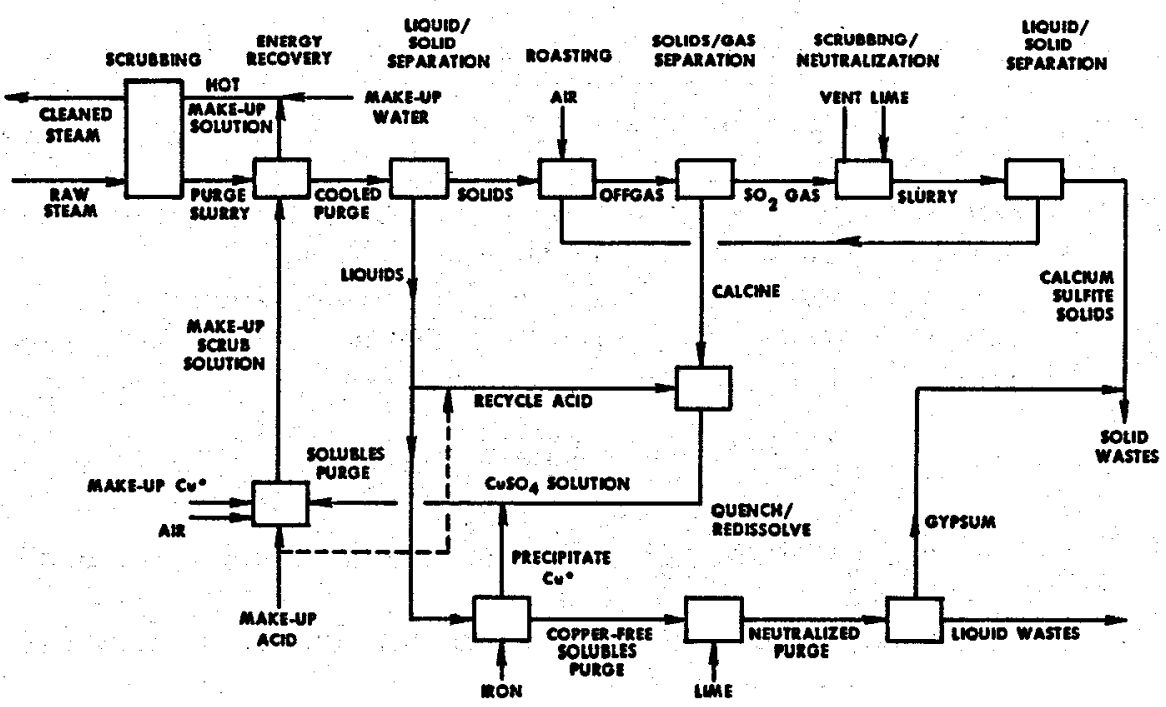

Dissolution

CEMENTATION

metrackation

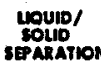

Pagess SEPARATLON SBPARATION

Figure 9.11-A simplifled flow diagram of the EIC process, with regeneration by roasting. 


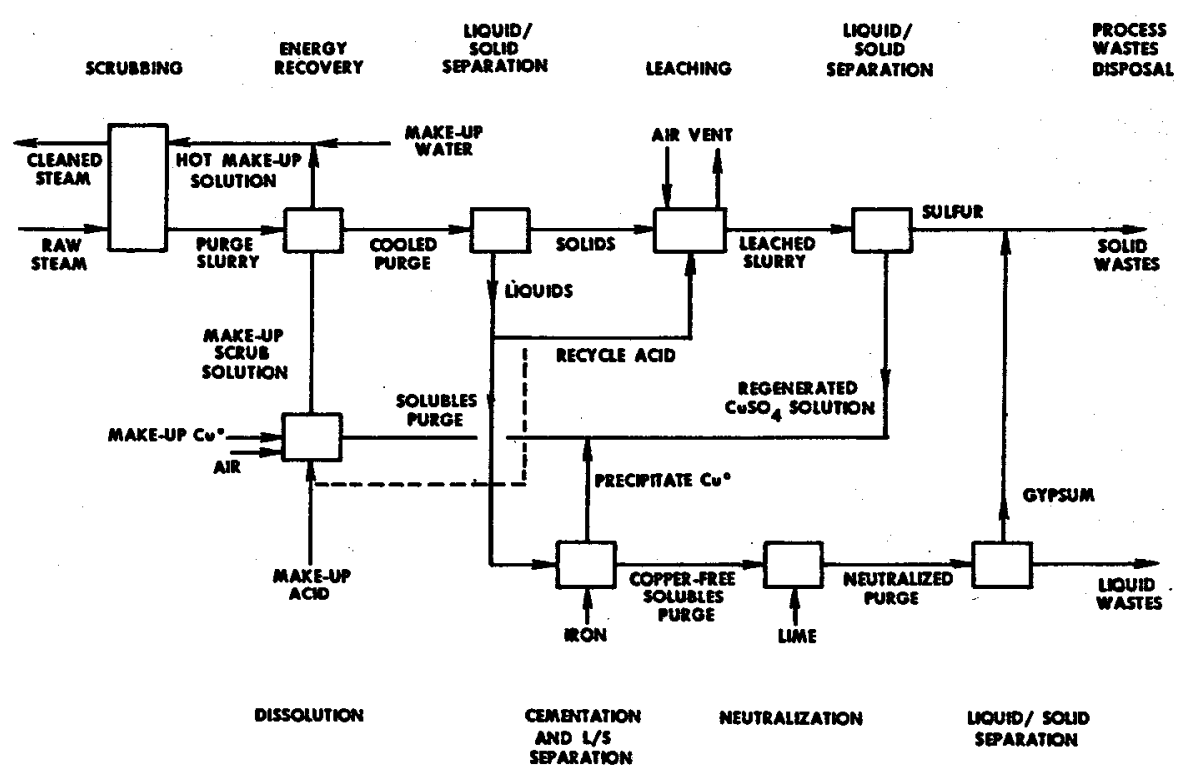

Fiaure 9.12-A simplified flow diagram of the EIC process, with regeneration by leaching.

$$
\begin{aligned}
& \mathrm{H}_{2} \mathrm{~S}(\mathrm{aq}) \rightarrow \mathrm{H}^{+}+\mathrm{HS}^{-} \\
& \mathrm{HS}^{-} \rightarrow \mathrm{H}^{+}+\mathrm{S}^{-2} \\
& \mathrm{CuO} \rightarrow \mathrm{Cu}^{+2}+\mathrm{O}^{-2} \\
& \mathrm{Cu}^{+2}+\mathrm{S}^{-2} \rightarrow \mathrm{CuS} \\
& \hline 2 \mathrm{H}^{+}+\mathrm{O}^{-2} \rightarrow \mathrm{H}_{2} \mathrm{O}
\end{aligned}
$$

Overall reaction: $\mathrm{CuO}+\mathrm{H}_{2} \mathrm{~S} \rightarrow \mathrm{CuS}+\mathrm{H}_{2} \mathrm{O}$

The two reaction chains given above produce a highly insoluble copper sulfide precipitate. The reactions given may be a partial list of the actual total reaction chain mechanism. In addition, some reduction of cupric ions occurs, resulting in a cuprous sulfide precipitate. The overall reaction for this mechanism is:

$$
\mathrm{Cu}_{2} \mathrm{SO}_{4}+\mathrm{H}_{2} \mathrm{~S} \rightarrow \mathrm{Cu}_{2} \mathrm{~S}+\mathrm{H}_{2} \mathrm{SO}_{4}
$$

The scrubbed steam passes through a mist eliminator to remove particulate matter before being expanded in the turbine.

Copper sulfide slurry purged from the scrubber column is pumped to a contrifuge to concentrate the slurry. The regeneration technique used will determine the requirements of the liquid-solid separation step. If roasting is used, a polishing filter may be necessary to remove fines entrained in the recycle system. If leaching is used for regeneration, unreacted coppcr sulfides and elemental sulfur will be contained in the residues, 
thus requiring the use of chemical flocculants together with filtration to obtain acceptable separation and clarification. In order to reduce copper sulfate losses, washing of the cake may be required. Clear liquid from the liquid/solid separation process is returned to the scrubber.

Fluid-bed roasting burns the copper sulfide/cuprous sulfide cake from the liquid/solid separation step with air to produce recoverable copper compounds. The roasting regeneration reactions are as follows:

$$
\begin{aligned}
& \mathrm{CuS}+2 \mathrm{O}_{2} \rightarrow \mathrm{CuSO}_{4} \\
& \mathrm{CuS}+3 / 2 \mathrm{O}_{2} \rightarrow \mathrm{CuO}_{2}+\mathrm{SO}_{2} \\
& \mathrm{SO}_{2}+1 / 2 \mathrm{O}_{2} \rightarrow \mathrm{SO}_{3}
\end{aligned}
$$

The above reactions are highly exothermic, and self-sustaining after startup. The solid copper sulfate and copper oxide are slurried and reintroduced into the scrubber for continued hydrogen sulfide removal. The sulfur dioxide and sulfur trioxide produced in the regeneration step are scrubbed by an ammoniacal solution. The liquid discharge stream from the sulfur dioxide scrubber is mixed with cooling tower blowdown and injected.

Oxygen pressure leaching is the second alternative for recovering copper compounds. The copper sulfide/cuprous sulfide cake requires approximately a two to four hour contact with pressurized oxygen (100 psia) to obtain acceptable conversion rates. The copper sulfide is oxidized to copper sulfate and elemental sulfur, the ratio being a function of residence time, $\mathrm{pH}$, and temperature. If desirable, operating conditions can be carefully controlled to increase elemental sulfur production in the leaching step. The possible reactions for copper sulfate regeneration by leaching are :

$$
\begin{aligned}
& \mathrm{CuS}+2 \mathrm{O}_{2} \rightarrow \mathrm{Cu}^{+2}+\mathrm{SO}_{4}^{-2} \\
& \mathrm{Cu}_{2} \mathrm{~S}+5 / 2 \mathrm{O}_{2}+2 \mathrm{H}^{+} \rightarrow 2 \mathrm{Cu}^{+2}+\mathrm{SO}_{4}^{-2}+\mathrm{H}_{2} \mathrm{O}
\end{aligned}
$$

The possible reactions for elemental sulfur formation are:

$$
\begin{aligned}
& \mathrm{CuS}+1 / 2 \mathrm{O}_{2}+2 \mathrm{H}^{+} \rightarrow \mathrm{Cu}^{+2}+\mathrm{S}+\mathrm{H}_{2} \mathrm{O} \\
& \mathrm{Cu}_{2} \mathrm{~S}+\mathrm{O}_{2}+4 \mathrm{H}^{+} \rightarrow 2 \mathrm{Cu}^{+2}+\mathrm{S}+2 \mathrm{H}_{2} \mathrm{O}
\end{aligned}
$$

The EIC process was field tested at The Geysers, unit 7 in December 1976. An eight inch diameter single sieve tray scrubbing column was used. Continuous scrubbing of $1000 \mathrm{lb} / \mathrm{hr}(450 \mathrm{~kg} / \mathrm{hr})$ of steam, containing 220 ppm hydrogen sulfide, was accomplished for 30 hours with efficiencies generally over 97 percent. Entrainment of copper from the scrubbed solution into the steam was less than measurable $(<0.05 \mathrm{ppm})$. In addition to hydrogen sulfide, approximately 80 percent removal of ammonia and boric acid was also observed. The field test scrubber was constructed from Carpenter $20 \mathrm{Cb} 3$ and showed excellent service under the field test operating conditions. Corrosion tests with various stainless steels have resulted in corrosion rates of less than 5 mils per year. 
Installed capital cost and operation/maintenance costs are summarized in the EIC Corporation Annual Status Report [EIC, 1976] for a $50 \mathrm{MW}$ geothermal power plant with steam conditions being those encountered for vent gases at the Niland geothermal loop experimental facility located in Imperial Valley, California. Capital costs for EIC units with hydrogen sulfide concentrations differing from that for the Niland facility were computed by utilizing the following formula :

$$
I A=0.85 I B\left(\frac{H A}{\overline{H B}}\right)^{0.6}+0.15 I B
$$

$H A=$ Hydrogen sulfide concentration of the desired EIC process.

$H B=$ Hydrogen sulfide concentration for the given case $(830 \mathrm{ppm})$.

$I=$ Capital investment for the desired or given $(A$ or $B)$ EIC process.

Eighty-five percent of the capital investment for the EIC process involves reactors, tanks, vessels, heat exchangers, filters, pumps, and other associated process equipment. The remaining 15 percent of the capital investment is allocated for the scrubbing tower. It is assumed that the capital investment for equipment associated with the liquid/solid separation and regeneration operations (85 percent of total) varies exponentially with hydrogen sulfide concentration according to William's sixth-tenth rule [Hesketh, 1973]. The capital investment for the scrubbing (15 percent of total) is assumed to depend upon steam flow rate and is relatively independent of hydrogen sulfide concentration.

Assumptions used to estimate the annual capital and operation/maintenance costs for an EIC unit are [EIC, 1976]:

- Amortization period: 10 years.

- Maintenance materials: 2 percent of the installed capital cost.

- Maintenance labor: 4 operators at $\$ 18,000$ per year; 1 maintenance man at $\$ 20,000$ per year; 1 supervisor at $\$ 22,000$ per year.

- Electrical power usage : $2,200,000 \mathrm{KWH}$ per year.

- Water usage: $10,000,000$ gallons $\left(37.85 \times 10^{6}\right.$ liters $)$ per year at $\$ 0.50$ per 1000 gallons (3785 liters).

- Chemical and process materials :

sulfuric acid -300 tons (273 metric tons) per year at $\$ 33$ per ton $(\$ 36.30 /$ metric ton $)$;

limestone-250 tons (227 metric tons) per year at $\$ 8$ per ton ( $\$ 8.80 /$ metric ton);

precipitated copper-37.5 tons (34 metric tons) per year at $\$ 1600$ per ton ( $\$ 1760 /$ metric ton); detinned scrap- -45 tons (41 metric tons) per year at $\$ 200$ per ton $(\$ 220 /$ metric ton); miscellaneous- $\$ 19,000$. 
Costs, in mills per $\mathrm{KWH}$, for power generation capacities ranging between $50 \mathrm{MW}$ and $500 \mathrm{MW}$ and a hydrogen sulfide concentration of 830 $\mathrm{ppm}$ are given in figure 9.13. The cost estimates presented for the EIC process were developed from a specific set of operating conditions and do not necessarily apply to geothermal resources with different operating conditions. At constant flow rates, costs increase with increasing $\mathrm{H}_{2} \mathrm{~S}$ concentration.

\subsubsection{Dowo oxygenation process}

The Dow oxygenation process removes hydrogen sulfide from geothermal brine at the wellhead; thus, it is applicable only to liquid-dominated resources. Removal of hydrogen sulfide at the wellhead should provide a less corrosive brine in the pipelines of the gathering field and a less corrosive brine or steam in the power cycle. The Dow process oxidizes the aqueous hydrogen sulfide by injecting oxygen directly into the geothermal brine [Dow, 1977]. Thorough mixing to facilitate contact of the brine and oxygen can be accomplished by using in-line mixers or a cocurrent packed tower.

The Dow oxygenation process has been tested on a small $3 \mathrm{gpm}$ (11.3 lpm) laboratory pilot-plant scale utilizing the in-line mixer system and shown to be technically feasible. Initially, catalytic agents were believed necessary to achieve acceptable reaction rates; however, addition of catalysts had no measurable effect. Hydrogen sulfide removal efficiencies at $350^{\circ} \mathrm{F}\left(175^{\circ} \mathrm{C}\right)$ and oxygen/sulfide mole ratio of $1.5: 1$ generally varied from 90 to 100 percent over a $\mathrm{pH}$ range of 5.2 to 11.3 .

Preliminary capital cost estimates for both the in-line and packed column systems have been developed by the Dow Chemical Company, based on the results of the laboratory investigation [Dow, 1977].

Costs, in mills $/ \mathrm{kW} \cdot \mathrm{h}$ for power generation capacities varying from $14.9 \mathrm{MW}$ to $347 \mathrm{MW}$ and with a $500 \mathrm{ppm}$ hydrogen sulfide concentration average about $8.5 \mathrm{mill} / \mathrm{kW} \cdot \mathrm{h}$. Computations of generation capacities were based on a double flash energy conversion system with 8 percent overall efficiency operating with brine conditions given previously. However, cost estimates for the Dow oxygenation in-line and packed column systems have been developed from specific data and conditions, and thus cannot be applied directly to geothermal resources in general.

\subsubsection{Solid sorbent process}

Battelle Pacific Northwest Laboratories has investigated numerous solid sorbents for the removal of hydrogen sulfide from geothermal steam [BPNL, 1976]. Battelle assumed that the following parameters should be 
Frauk: $9.13-$ Costs for hydrogen sulfide removal for the WIC process.
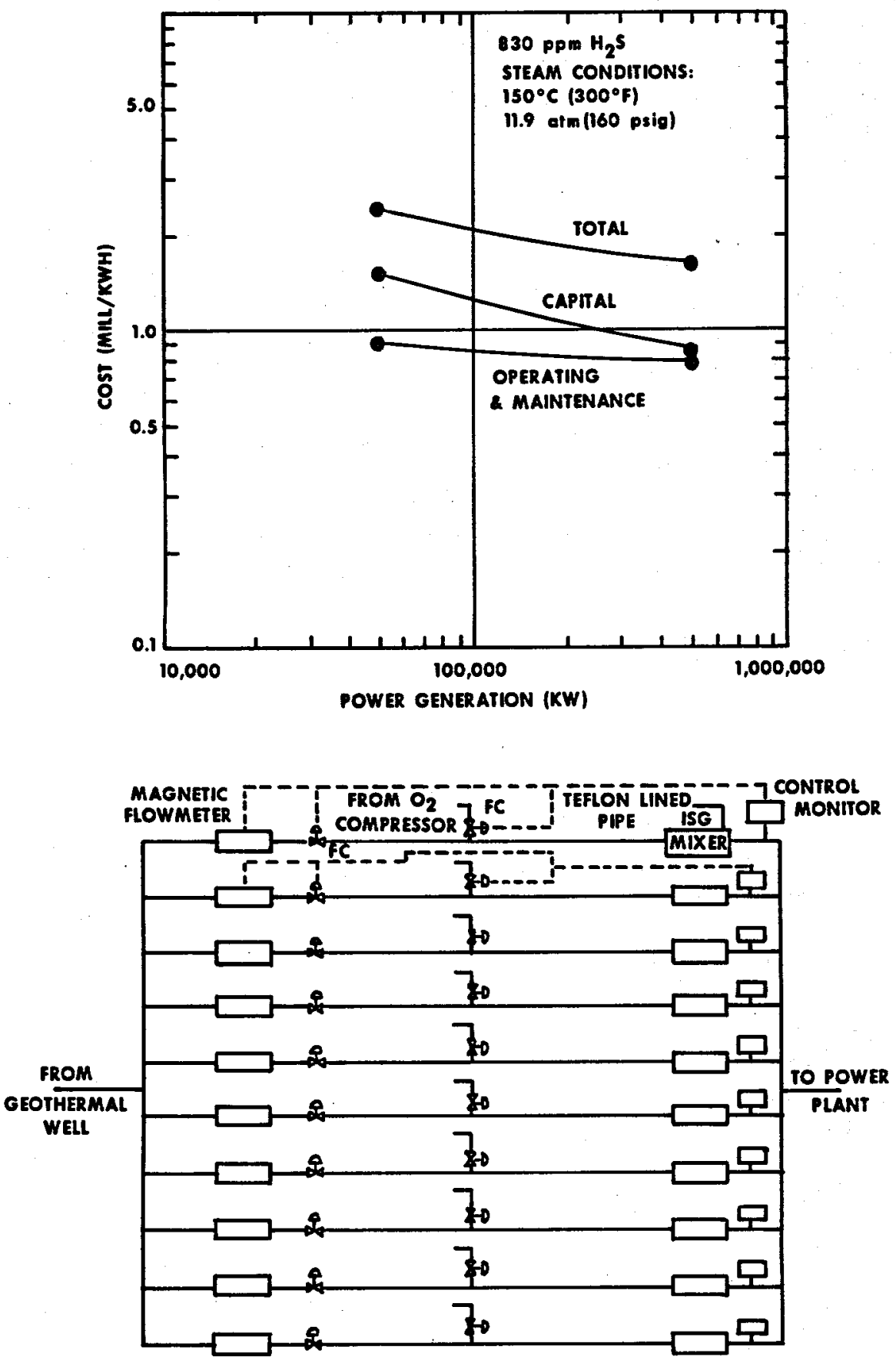
satisfied to establish a technically and economically viable hydrogen sulfide control process : minimum degradation of steam-regenerable sorbent; reasonably high sorption capacity; simple regeneration process; quick regeneration; and a stable or useful byproduct of regeneration. Zinc oxide produced the most favorable results among the numerous metal oxide and organic amine sorbents tested, because of its good sorbent qualities for removing hydrogen sulfide from simulated geothermal steam. Battelle's laboratory investigation has established, however, that a zinc oxide solid sorbent process is not economically viable for the removal of hydrogen sulfide from geothermal steam and recommends that no further work on solid sorbents be undertaken.

\subsubsection{Olaus process}

The Claus process is probably the best known process for recovering sulfur from gas streams containing hydrogen sulfide and sulfur dioxide. There are several variations of the process; a specific version of the Claus process flow diagram is shown in figure 9.14.

The process requires a specific concentration ratio between hydrogen sulfide and sulfur dioxide. This ratio is obtained by combusting part of the hydrogen sulfide to produce sulfur dioxide, which is mixed with the feed stream. The hydrogen sulfide and sulfur dioxide are reacted with each other in a series of converters to produce elemental sulfur, which is condensed out of the main gas stream. The converters contain an activated bauxite catalyst which accelerates the following reaction:

$$
2 \mathrm{H}_{2} \mathrm{~S}+\mathrm{SO}_{2} \rightarrow 3 \mathrm{~S}+2 \mathrm{H}_{2} \mathrm{O}
$$

A tail gas containing residual amounts of hydrogen sulfide and sulfur dioxide in moderate concentrations is treated by one of the following processes: recycling into the main process upstream of sulfur separation, transfer to another treatment process, or dilution into a large column of stack gases.

It is doubtful that the Claus process is suitable for removal of hydrogen sulfide from condenser ejector gases. The presence of moisture and carbon dioxide in the feed gas is detrimental to the Claus reaction. Carbon dioxide causes the following side reactions:

$$
\begin{aligned}
& \mathrm{CO}_{2}+\mathrm{H}_{2} \mathrm{~S} \rightarrow \mathrm{COS}+\mathrm{H}_{2} \mathrm{O} \\
& \mathrm{CO}_{2}+2 \mathrm{H}_{2} \mathrm{~S} \rightarrow \mathrm{CS}_{2}+2 \mathrm{H}_{2} \mathrm{O}
\end{aligned}
$$

The ejector gases will be saturated and the presence of water tends to reverse the catalyzed Claus reaction. 

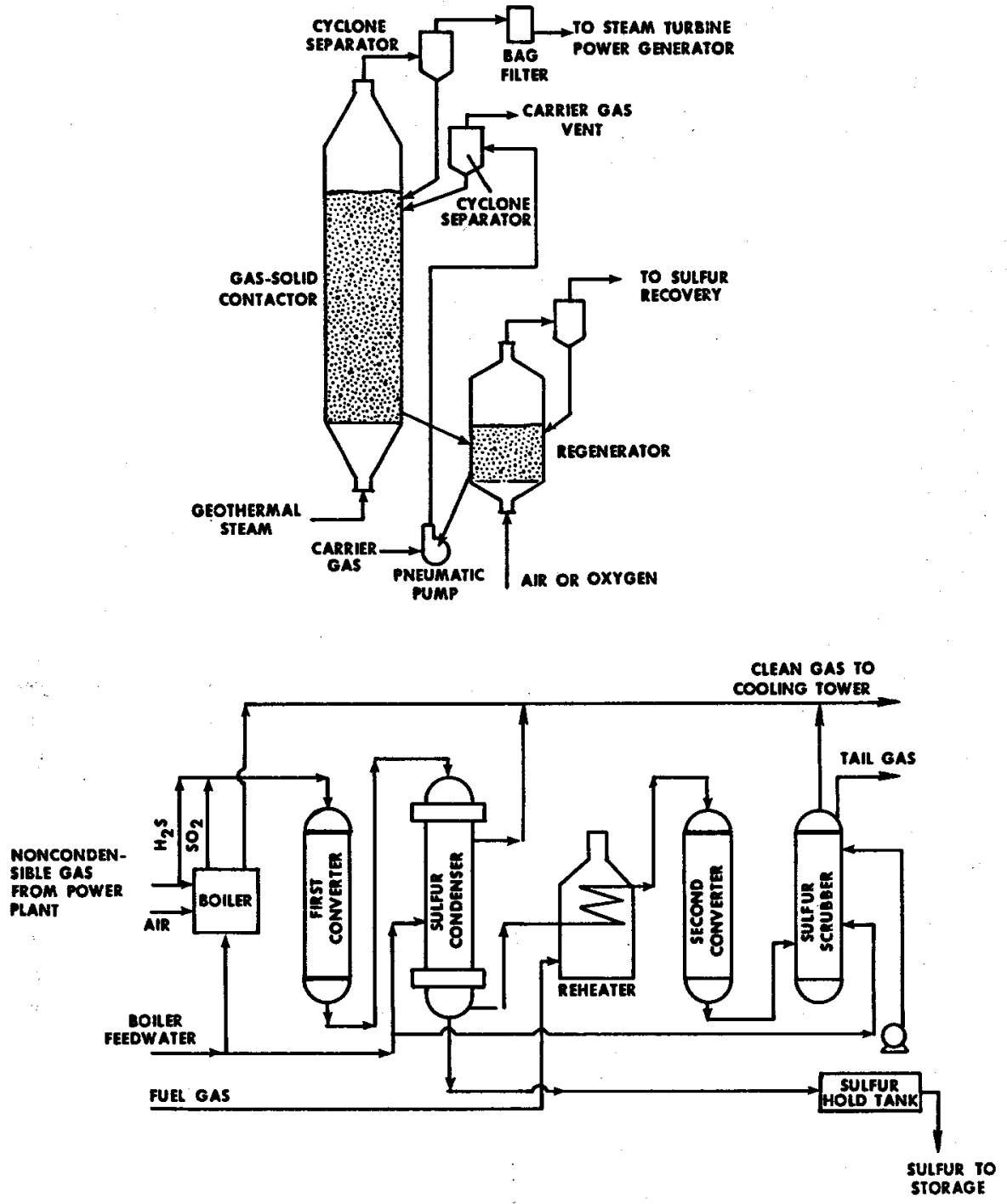

Figure 9.14-A specific version of the Claus process flow.

\subsubsection{Hydrogen peroxide process}

Hydrogen peroxide has been used to remove hydrogen sulfide from various wastewater streams. The applicability of $\mathrm{H}_{2} \mathrm{O}_{2}$ to geothermal cooling water/condensate is somewhat questionable at this time because of the high temperature environment. Hydrogen peroxide reacts with hydrogen sulfide in an acidic or neutral aqueous solution to produce elemental sulfur and water:

$$
\mathrm{H}_{2} \mathrm{O}_{2}+\mathrm{H}_{2} \mathrm{~S} \rightarrow \mathrm{S}+2 \mathrm{H}_{2} \mathrm{O}
$$


In alkaline solutions $(\mathrm{pH}>8)$, the sulfide ion reacts with hydrogen peroxide to produce sulfate and water:

$$
\begin{aligned}
& \mathrm{H}_{2} \mathrm{~S}(\mathrm{aq}) \rightarrow \mathrm{H}^{+}+\mathrm{HS}^{-} \\
& \mathrm{HS}^{-} \rightarrow \mathrm{H}^{+}+\mathrm{S}^{-2} \\
& \mathrm{~S}^{-2}+4 \mathrm{H}_{2} \mathrm{O}_{2} \rightarrow \mathrm{SO}_{4}^{-2}+4 \mathrm{H}_{2} \mathrm{O}
\end{aligned}
$$

The acidic or neutral reaction is catalyzed by a metal ion, such as the ferrous ion. The rate of the acidic reaction is greatly increased by an increase in temperature. It is interesting to note that four times the hydrogen peroxide is theoretically required to oxidize hydrogen sulfide in an alkaline solution than is required to oxidize that in an acidic solution.

The FMC Corporation has conducted laboratory experiments on oxidation of hydrogen sulfide in samples of cooling water/condensate streams taken from The Geysers power plant [Ecoview, 1976]. The experiments were conducted with various conditions of hydrogen sulfide solntion concentration, $\mathrm{pH}$, temperature, hydrogen peroxide/hydrogen sulfide weight ratio, and ferric sulfide catalyst concentration. The results from the experiments indicate that the hydrogen sulfide oxidation rate increases as a result of increases in (ranges tested given in parentheses) : initial hydrogen sulfide concentration $(2.3-12.5 \mathrm{ppm})$, temperature $\left(40^{\circ}-51^{\circ} \mathrm{C}\right)$, hydrogen peroxide/hydrogen sulfide weight ratio (0.9-3.9 and 400), and ferric sulfide concentration (0-2.0 ppm). An efficiency of 88 percent was obtained in less than three minutes, without the use of a catalyst, and using a hydrogen peroxide/hydrogen sulfide weight ratio of 1.9 and an initial hydrogen sulfide concentration of $12.5 \mathrm{ppm}$. The results from the FMC experiments indicate that the use of hydrogen peroxide for oxidation of hydrogen sulfide in geothermal cooling water/condensate is feasible. Hydrogen peroxide and sodium hydroxide are being injected into wellhead-vented steam at The Geysers to successfully control hydrogen sulfide.

\subsubsection{Ozone process}

The use of ozone to oxidize hydrogen sulfide in aqueous solutions has not been adequately investigated to evaluate its applicability for controlling emissions from geothermal sources. Ozone has previously been used to oxidize hydrogen sulfide in the gaseous phase. Elemental sulfur and sulfate are the most likely products of a hydrogen sulfide-ozone aqueous reaction:

$$
\begin{aligned}
& 3 \mathrm{H}_{2} \mathrm{~S}+\mathrm{O}_{3} \rightarrow 3 \mathrm{~S}+3 \mathrm{H}_{2} \mathrm{O} \\
& 3 \mathrm{H}_{2} \mathrm{~S}+4 \mathrm{O}_{3} \rightarrow 3 \mathrm{H}_{2} \mathrm{SO}_{4}
\end{aligned}
$$

Four times as much ozone is required to produce sulfate as is required to produce elemental sulfur. Because of the cost of producing ozone, the economic feasibility of this process may depend on which of the two reactions dominates. 


\subsubsection{Burner-8crubber process}

The burner-scrubber process incinerates the noncondensible condenser ejector gases and scrubs the combustion products with cooling water. The hydrogen sulfide contained in the ejector gases is burned to sulfur dioxide. The combustion gases are ducted to a scrubber where contact is made with cooling water, thus dissolving the sulfur dioxide. The dissolved sulfur dioxide reduces the $\mathrm{pH}$ of the cooling water, which increases the amount of hydrogen sulfide being removed with the noncondensible gases from the condenser. Thus, more hydrogen sulfide is incinerated, rather than remaining dissolved and being stripped from the cooling water into the air stream in the cooling tower. The sulfur dioxide may also oxidize the hydrogen sulfide dissolved in the cooling water to produce elemental sulfur, thus providing further abatement of hydrogen sulfide emissions. The burnerscrubber system has been field tested on The Geysers 27 MWe unit 4, which uses a direct contact condenser. Approximately 50 percent hydrogen sulfide removal was achieved [Laszlo, 1976]. This is about as much as can be done with this type of condensing system.

\section{9:4.10 Catalyst-scrubber process}

The catalyst-scrubber process is essentially the same as the burnerscrubber system, except the hydrogen sulfide is selectively oxidized to sulfur dioxide with a catalyst developed by the Union Oil Company. Since the hydrogen sulfide is oxidized without combustion, this system is potentially less complex and safer than the burner-scrubber process. The efficiency of the catalyst-scrubber process is also expected to be approximately 50 percent. This process was projected to be installed on The Geysers 53 MWe units 5 and 6 sometime in 1978.

\subsubsection{Deuterium process}

The Deuterium process removes hydrogen sulfide from geothermal steam upstream of the power plant. This process is proprietary and a process description is not currently available. The Deuterium Corporation holds the patent for heavy water, the production of which requires steam containing hydrogen sulfide.

\subsection{Liquid, solid, and noise pollution control technology}

\subsubsection{Wastewater treatment technologies}

Water pollution control technologies include wastewater treatment and ensuing wastewater disposal. The following discussion describes treatment technologies along with preliminary cost estimates. Depending upon the constituents and the amounts that must be removed, many of the treatment 
technologies may be used individually or in series. The treatment technologies are those applicable to the removal of suspended and dissolved solids.

9.5.1.1. Sedimentation. Sedimentation is a physical treatment operation that removes settleable solids from wastewaters. It is generally applied to raw wastewaters and to wastewaters that have been chemically treated to precipitate constituents. Any one of several configurations of settling ponds, tanks, and gravity separators may be used for sedimentation. Without other treatment, they will not remove significant amounts of dissolved or emulsified materials.

Sedimentation process efficiency is a function of temperature of the wastewater, the density and size of suspended particles, the amount and character of the suspended material, and settling time. Gravity separation can normally remove 50-65 percent of the suspended solids [Bond and Straub, 1973].

\subsubsection{Chemical precipitation. Chemical precipitation is a chemical treat-} ment process involving chemical addition, particle aggregation and particle precipitation. This treatment process is used to assist the sedimentation of colloidal and highly dispersed particles in the waste stream by aggregation and coalescence of small particles into larger more readily settleable or filterable aggregates. Some dissolved inorganic constituents may also be precipitated by chemical coagulants.

The function of chemical coagulation and mechanical flocculation of wastewater is the removal of suspended solids by destabilization of colloids and removal of soluble inorganic compounds, such as trace metals and phosphorus, by chemical precipitation or adsorption on chemical floc. Coagulation involves the reduction of surface charges of colloidal particles and the formation of complex hydrous oxides or precipitates. Coagulation is essentially instantaneous in that the only time required is that necessary for dispersing the chemical coagulants throughout the liquid. Flocculation involves the bonding together of the congulated particles to form settleable or filterable solids by agglomeration. Agglomeration is hastened by stirring the water to increase the collision of coagulated particles. Unlike coagulation, flocculation requires definite time intervals to be accomplished.

The more common chemical coagulants used are filter alum, ferric or ferrous sulfate, sodium aluminate, and ferric chloride. Among the coagulant aids used, the more popular ones are lime, soda ash, activated silica, and bentonite or other clays. Generally, chemical coagulants and coagulant aids are added to the waste in a separate chamber in which the waste is mixed rapidly with the chemicals. This system is followed by flocculation chambers and sedimentation tanks.

In general, coagulation reactions vary significantly with changes in $\mathrm{pH}$; therefore $\mathrm{pH}$ adjustment of the wastewater may be required to achieve 
optimum conditions. With proper design of the coagulation/flocculation system and sedimentation tank, removal efficiencies of 80-90 percent of suspended solids and $20-40$ percent of dissolved solids can be readily attained [Bond and Straub, 1973].

9,5.1.3 Filtration. Filtration is a solids-liquids separation technique to remove particulate matter from wastewater. It may be used instead of or in addition to sedimentation. In filtration, the wastewater to be treated is passed through a porous medium. Solids separation is accomplished largely by sieving action. The mechanisms involved in the removal of suspended or colloidal material from wastewater by filtration are complex and interrelated. The dominant mechanisms depend on the physical and chemical characteristics of the particulate matter and filtering medium, the rate of filtration, and the biological-chemical characteristics of the water. The mechanisms responsible for the removal of particulate matter vary with each treatment system.

Filtration can be accomplished by the use of: (1) a microstrainer, (2) diatomaceous earth filtration, (3) sand filtration, or (4) mixed-media filtration. The microstrainer is a screen in the form of a partially submerged rotating drum or cylinder. Diatomaceous earth filtration is a mechanical separation system that employs a filter aid layer of diatomaceous earth. As filtration proceeds, deposited solids build up on the precoat, resulting in an increase in pressure drop. Sand filtration is usually employed following chemical coagulation and preceding carbon adsorption or ion exchange. Generally, filtration rate is low, and backwashing is frequent because of the rapid build-up of headloss. However, removal efficiency for suspended solids is usually very good.

Mixed-media filtration was developed in an attempt to approach ideal filtration. Three to four types of media are layered into the filter, graded as to size and density, with coarse low density coal (sp. gr. about 1.0) on top, smaller regular density coal (sp. gr. about 1.6) and silica sand (sp. gr. about 2.6) in the middle two layers, and garnet sand or ilmenite (sp. gr. of 4.2 and 4.5 , respectively) in the bottom layer. These different media provide decreasing, coarse to fine, void gradation down through the filter. Large suspended solids in the wastewater are stopped near the surface with finer suspended solids being entrapped in bottom layers, thus providing full bed depth filtration. Effluent suspended solids concentrations less than $1.0 \mathrm{mg} / \mathrm{l}$ are readily achieved [Culp and Culp, 1971].

A typical granular media filter is shown in figure 9.15. The wastewater is passed through one or several layers of granular material and suspended solids are removed by physical screening, sedimentation, and interparticle action. Headloss increases until breakthrough or removal capacity is reached, and then the filter is cleaned by backwashing. 


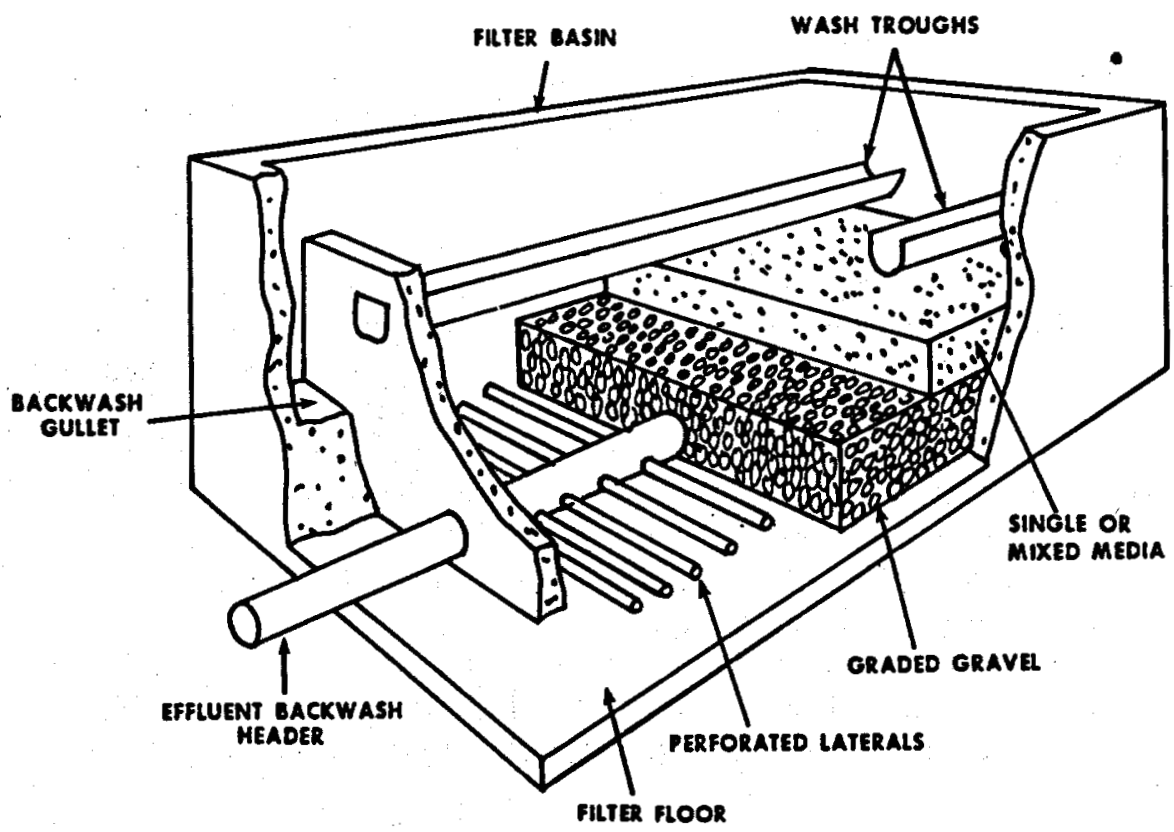

Figure 9.15-A typical granular media filter.

9.5.1.4 Reverse osmosis. In this process, a portion of the wastewater is forced through a semi-permeable membrane as depicted in figure 9.16 [Chen and Miele, 1977 (A)]. The membrane allows passage of water (permeate) while impeding passage of dissolved ions. The portion of the waste stream not forced through the membrane becomes more concentrated in dissolved solids than the original waste. This concentrated solution (retentate) must be disposed of in some manner. If it is not possible to reclaim the retentate, it must be treated to produce an effluent suitable for discharge.

The membrane is the heart of the reverse osmosis process. Most membranes in current use are cellulose aeetate. However, properties of cellulose acetate membranes vary according to the method of manufacture. Therefore, different membranes have different permeabilities for various

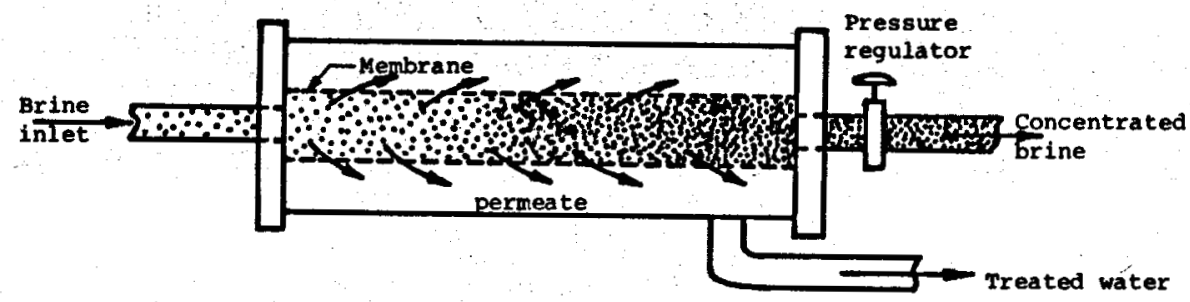

Frgukf 9.16-Reverse osmosis. In this process, a portion of the wastewater is forced through a semi-permeable membrane as depicted. 
ions. The feasibility of reverse osmosis as a treatment process is determined by the availability of a membrane which sufficiently limits passage of the ion to be removed while allowing passage of a reasonable amount of water.

9.5.1.5 Electrodialysis. This is an electrolytic process causing separation of ions in the presence of an imposed electrical field. Ions of opposite charge migrate through membranes toward their respective electrodes and the brine is separated into water and a concentrated brine [Chen et al., 1975]. The basic principles of electrodialysis are illustrated in figure 9.17.

The electrodialysis system uses a series of alternately-placed anion and cation permeable membrane, having a series of compartments. The application of an electrical potential across the system results in the migration of cations to the cathode and of anions to the anode. This creates a series of cencentrating and diluting compartments.

Electrodialysis as a wastewater treatment process is in the preliminary development stages. It has been used for the desalination of brackish water. Electrodialysis has not been used extensively in the treatment of industrial wastes.

9.5.1.6 Ion exchange. This process involves the exchange of objectionable ions in the wastewater with non-objectionable ions such as $\mathrm{H}^{+}$or $\mathrm{OH}^{-}$in the resin material [Chen and Miele, 1977 (B)]. Most ion exchange materials are synthetic polymers containing active groups such as $\mathrm{HSO}_{3}$ and $\mathrm{NH}_{4}$ to which the exchangeable ions $\left(\mathrm{H}^{+}\right.$and $\left.\mathrm{OH}^{-}\right)$are attached. The exchange reaction for removing sodium chromate from surface rinse waters by a combination of cationic and anionic exchange resins can be represented by :

$$
\begin{aligned}
& \mathrm{R}-\mathrm{H}+\mathrm{Na}^{+} \rightarrow \mathrm{R}-\mathrm{Na}^{+}+\mathrm{H}^{+} \\
& \mathrm{R}+(\mathrm{OH}-)_{2}+\mathrm{CrO}-{ }_{4} \rightarrow \mathrm{R}^{++} \mathrm{CrO}-{ }_{4}+2 \mathrm{OH}^{-}
\end{aligned}
$$

where $R^{-}$and $R^{++}$represent the cationic and anionic exchange material.

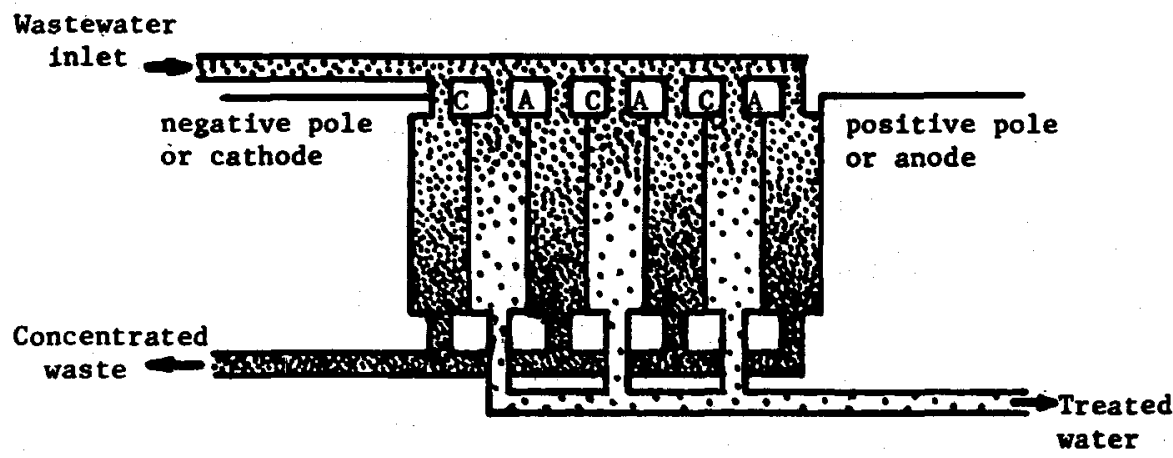

Frauke 9.17-The basic principles of electrodialysis. 
When the resins are operating on $\mathrm{H}^{+}$and $\mathrm{OH}^{-}$cycles, treatment with ion exchange also results in the production of dejonized water which can be used for process water or in other applications requiring a high quality water.

Demineralization by ion exchange is a process for removing inorganic salts and trace metals from wastewaters. In general, salts are composed of a positive ion of a base and a negative ion of an acid. These ions are removed in two stages: the positive ions by the cation exchanger and the negative ions by the anion exchanger. In the first stage the positive ions of a base such as calcium (Ca), sodium $(\mathrm{Na})$, or magnesium $(\mathrm{Mg})$ are exchanged for hydrogen ions $(\mathrm{H})$ in the cation exchange column, thereby converting these positive anions into their respective acids. In the second stage the negative ions of the acid such as silicates $\left(\mathrm{SiO}_{3}\right)$, carbonates $\left(\mathrm{CO}_{3}\right)$, chloride $(\mathrm{Cl})$, or sulfate $\left(\mathrm{SO}_{4}\right)$ are removed and exchanged for hydroxide ions $(\mathrm{OH})$ in the anion exchange column. This completes the two step removal of the salt.

9.5.1.7 Summary of process efficiencies. The wastewater control technologies presented in the previous subsections deal primarily with process effectiveness and applicability in the removal of gross constituents. A detailed assessment of the removal efficiencies for specific chemical constituents has not been made. This subsection presents a survey of control technologies for the removal of specific pollutants from wastewaters. Table 9.9 is a summary of this survey. Since most literature findings are

TABLE 9.9-Reported efficiencies of control technologies for treatment of specific constituents from wastewaters

[\% removal]

\begin{tabular}{|c|c|c|c|c|c|c|}
\hline & $\begin{array}{r}\text { Sedimen- } \\
\text { tation }\end{array}$ & $\begin{array}{c}\text { Chemical } \\
\text { precipi- } \\
\text { tation }\end{array}$ & Filtration & $\begin{array}{l}\text { Electro- } \\
\text { dialysis }\end{array}$ & $\begin{array}{r}\text { Ion } \\
\text { exchange }\end{array}$ & $\begin{array}{c}\text { Reverse } \\
\text { osmosis }\end{array}$ \\
\hline & $20-40$ & $40-60$ & $70-95$ & $30-50$ & $80-90$ & $90-99$ \\
\hline TDS & 10 & $20-40$ & 10 & 40 & $80-90$ & $85-95$ \\
\hline Fe. & $10-30$ & $60-100$ & $70-95$ & $30-40$ & $80-90$ & $95-98$ \\
\hline $\mathbf{M n}$ & $10-30$ & $65.4-99.4$ & 90-98 & $30-40$ & 80-90 & $95-98$ \\
\hline B. $\therefore$ & 10 & $20-40$ & $20-40$ & 10 & $80-90$ & $60-80$ \\
\hline $\mathbf{Z n}$. & $10-30$ & $90-95$ & $60-85$ & $30-40$ & $80-90$ & 85-95 \\
\hline $\mathrm{Ba}$. & 10 & $85-99$ & $80-98$ & 99.9 & 99 & $95-98$ \\
\hline & 10 & 99 & 10 & 10 & $80-90$ & 88-92 \\
\hline $\mathrm{Pb}$. & $10-30$ & $95-97$ & 95-98 & $30-40$ & $80-90$ & 95-98 \\
\hline $\mathrm{Cu} .$. & $10-30$ & $80-85$ & $90-95$ & $30-40$ & $80-90$ & $95-98$ \\
\hline As. & $10-30$ & $80-98$ & $75-95$ & $30-40$ & $80-90$ & $85-95$ \\
\hline $\mathrm{H}_{\mathbf{g}}$. & $10-30$ & $40-60$ & $70-80$ & $30-40$ & $80-90$ & 85-95 \\
\hline Se. . & $10-30$ & $80-90$ & $90-95$ & $30-40$ & 99.7 & $85-95$ \\
\hline Cr...... & $10-30$ & $60-99$ & $60-99$ & $30-40$ & $80-90$ & $85-95$ \\
\hline $\mathbf{A g} \ldots$ & $10-30$ & $90-99$ & 90-99 & $30-40$ & 85-95 & $85-95$ \\
\hline Cd.... & $10-30$ & $85-95$ & $90-98$ & $30-40$ & $80-90$ & 85-95 \\
\hline
\end{tabular}


limited in information and specific pollutant removal, efforts were made to contact knowledgeable persons in the field, such as equipment vendors, engineering consultants, government regulatory agencies, and academicians, to seek expert opinions on specific applications of pollutant removal from wastewater.

Wastewater treatment requirements depend upon the character of the raw wastowater compared to the quality to be maintained in the wastewater disposal area or receiving media. In order to examine the requirements, three sets of possible raw wastewater constituent characteristics and three sets of possible discharge requirements have been compiled in table 9.10. The values shown are not intended to be actual, but probably include the ranges to be considered in geothermal wastewater treatment. Possible ranges of flows for various uses are shown in table 9.11. Based on the information shown in table 9.10 the required removal efficiencies

TABLE 9.10-Assumed geothermal waste brine and surface water discharge concentrations $[\mathrm{mg} / \mathrm{l}]$

\begin{tabular}{|c|c|c|c|c|c|c|}
\hline \multirow[b]{2}{*}{ Constituent } & \multicolumn{3}{|c|}{$\begin{array}{l}\text { Geothermal waste brine } \\
\text { concentration level }\end{array}$} & \multicolumn{3}{|c|}{$\begin{array}{l}\text { Surface water discharge } \\
\text { concentration level }\end{array}$} \\
\hline & High & Mid & Low & High & Mid & Low \\
\hline Total solids.... & 100,000 & 10,000 & 2,000 & 5,000 & 1,000 & 500 \\
\hline Iron........... & 1,000 & 100 & 10 & 5. 0 & 1.0 & 0.5 \\
\hline Manganese. . . . & 1,000 & 10 & 1 & 1. 0 & 0.1 & 0.05 \\
\hline Boron. . & 500 & 10 & 1 & 5. 0 & 2.0 & 1. 0 \\
\hline Zinc. . . . . . & 500 & 10 & 1 & 10 & 5. 0 & 1. 0 \\
\hline Barium..... & 500 & 10 & 1 & 5. 0 & 2. 0 & 1.0 \\
\hline Fluoride........ & 100 & 1 & 0. 1 & 1. 0 & 0. 1 & 0.05 \\
\hline Lead........... & 100 & 1 & 0.1 & 1.0 & 0.1 & 0.05 \\
\hline Copper........ & 50 & 1 & 0. 1 & 5. 0 & 2. 0 & 1.0 \\
\hline Arsenic......... & 10 & 1 & 0.1 & 0.5 & 0.1 & 0.05 \\
\hline Mercury........ & 10 & 0.1 & 0.01 & 0.01 & 0.005 & 0.002 \\
\hline Selenium...... & 0.1 & 0.05 & 0.01 & 0.05 & 0.02 & 0.01 \\
\hline Chromium...... & 10 & 0.1 & 0.01 & 0.5 & 0.1 & 0.05 \\
\hline Silver......... & 1 & 0.1 & 0.01 & 0. 5 & 0.1 & 0.05 \\
\hline Cadmium....... & 1 & 0.1 & 0.01 & 0.05 & 0.02 & 0.01 \\
\hline
\end{tabular}

TABLE 9.11-Geothermal waste brine flow rates and levels for various uses

Conversion system

Flow rate

(liters/min.) Brine conc. levels

Direct steam power generation..... 4, 000-30, 000 Mid and low.

Flashed steam, binary, total flow, 15, 000-350, 000 High, mid and low. power generation.

Direct heating open and closed........

10-1, 000 Mid and low.

Desalination......... 1, 000-5, 000 High and mid. 
were calculated, as shown in table 9.12, for the various raw levels vs. discharge levels.

TABLE 9.12-Removal efficiencies (\%) required for treating various levels of raw geothermal fluids

\begin{tabular}{|c|c|c|c|c|c|c|c|c|c|}
\hline \multirow[b]{3}{*}{ Constituent } & \multicolumn{9}{|c|}{ Discharge concentration levels } \\
\hline & \multicolumn{3}{|c|}{ High-level waste } & \multicolumn{3}{|c|}{$\begin{array}{l}\text { Mid-level } \\
\text { waste }\end{array}$} & \multicolumn{3}{|c|}{$\begin{array}{c}\text { Low-level } \\
\text { waste }\end{array}$} \\
\hline & 1 & 2 & 3 & 1 & 2 & 3 & 1 & 2 & $\mathbf{3}$ \\
\hline Total solids (TS) & 95 & 99 & 99.5 & 50 & 90 & 95 & $\mathbf{0}$ & 50 & 75 \\
\hline Iron $(\mathrm{Fe}) \ldots$ & 99.5 & 99.9 & 99.95 & 95 & 99 & 99.5 & 50 & 90 & 95 \\
\hline Manganese (Mn). & 99.9 & 99.99 & 99.995 & 90 & 99 & 99.5 & $\mathbf{0}$ & 90 & 85 \\
\hline Boron (B) $\ldots \ldots \ldots$ & 99 & 99.6 & 99.8 & $\mathbf{5 0}$ & 80 & 90 & $\mathbf{0}$ & $\mathbf{0}$ & $\mathbf{0}$ \\
\hline Zine $\left(Z_{n}\right) \ldots$ & 98 & 99 & 99.8 & 0 & 50 & 90 & $\mathbf{0}$ & 0 & $\mathbf{0}$ \\
\hline Barium (Ba). & 99 & 99.6 & 99.8 & $\mathbf{5 0}$ & 80 & 90 & $\mathbf{0}$ & $\mathbf{0}$ & $\mathbf{0}$ \\
\hline Fluoride $(\mathbf{F})$ & 99 & 99.9 & 99. 95 & 0 & 90 & 95 & $\mathbf{0}$ & $\mathbf{0}$ & 50 \\
\hline Lead $(\mathrm{Pb}) . .$. & 99 & 99.9 & 99.95 & 0 & 90 & 95 & 0 & $\mathbf{0}$ & 50 \\
\hline Copper (Cu)... & 90 & 96 & 98 & $\mathbf{0}$ & 0 & 0 & $\mathbf{0}$ & $\mathbf{0}$ & $\mathbf{0}$ \\
\hline Arsenic (As) . . & 95 & 99 & 99.5 & 50 & 90 & 95 & $\mathbf{0}$ & $\mathbf{0}$ & 50 \\
\hline Mercury $\left(\mathrm{H}_{\mathrm{g}}\right) \ldots \ldots \ldots$ & 99. 9 & 99. 95 & 99. 98 & 90 & 95 & 98 & 0 & 50 & 80 \\
\hline Selenium (Se)... & 50 & 80 & 90 & 0 & 60 & 80 & 0 & $\mathbf{0}$ & $\mathbf{0}$ \\
\hline Chromium (Cr). & 95 & 99 & 99.5 & $\mathbf{0}$ & 0 & 50 & 0 & 0 & 0 \\
\hline Silver (Ag) . . . . . & 50 & 90 & 95 & $\mathbf{0}$ & 0 & 50 & 0 & $\mathbf{0}$ & 0 \\
\hline Cadmium (Cd) $\ldots \ldots \ldots \ldots \ldots \ldots$ & 95 & 98 & 99 & 50 & 80 & 90 & 0 & $\mathbf{0}$ & 0 \\
\hline
\end{tabular}

Cost estimates for the six processes discussed in the preceding sections have been reported elsewhere [Hartley, 1978].

\section{5.\$ Wastewater disposal technologies}

Geothermal wastewater requires disposal whether or not it requires prior treatment. In general, the cleaner the wastewater to be disposed of, the easier and less expensive the disposal method. For example, effluents that meet water quality standards can simply be discharged to surface drainage. On the other hand, it is more expensive and more difficult to dispose of wastewater that does not meet such standards; it is these disposal methods with which this discussion is most concerned. It should be borne in mind, however, that these methods may also be used for reasons other than simply disposal; for example, injection may be practiced for geothermal reservoir conservation and subsidence prevention.

9.5.2.1 Subsurface injection. Successful subsurface injection tests have been performed in a number of geothermal fields in the United States and abroad: for example, The Geysers, East Mesa, Niland, and Heber fields in California; the Valles Caldera field in New Mexico; the Matsukawa and Otake fields in Japan; the Broadlands field in New Zealand; the 
Ahuachapan field in El Salvador, etc. In The Geysers field, return of steam condensate to the geothermal reservoir by injection was started in 1969 ; about eight billion gallons of condensate have been injected to date. The current daily rate of injection is about five million gallons.

It should be realized, however, that no tests have been conducted on a scale comparable to what would be required to inject the waste liquid from a large $(>50 \mathrm{MW})$ geothermal plant situated on a liquid-dominated reservoir. If, for example, all of the waste liquid from the wellhead separators at the Ahuachapan plant (60 MW) were to be returned to the ground, this would mean over 13.5 million gallons per day would have to be reinjected. For a liquid-dominated field producing the equivalent of the current capacity of The Geysers, a total of more than 110 million gallons would have to be reinjected.

Besides geothermal, many other industries have adopted subsurface injection of liquid wastes to prevent or control water pollution. The practice is widespread in oil production fields. There are several reasons for choosing subsurface injection as a disposal method. Some of these follow:

- Alternatives to injection are isolating the waste from the environment and releasing the waste into surface water bodies. Surface isolation of large quantities of liquid waste generated by geothermal operation is difficult. In most cases, before the liquid waste can be released into surface water bodies, it will require costly treatment. Treatment will create secondary wastes, also requiring disposal.

- Failure to replace reservoir fluid may allow ground subsidence. Subsidence has been observed in the geothermal fields at Cerro Prieto, Mexico, and Wairakei, New Zealand, where fluid reinjection has not been practiced.

- If reservoir fluid is not replaced, the reservoir pressure may decline, unless there is rapid and complete natural recharge. Evidence of complete natural recharge is rare. Any decline in reservoir pressure causes a decline in the productivity of the production wells.

- Injected, cooled geothermal wastewater scavenges heat from the reservoir rock matrix and may be withdrawn again at the production wells. Injected steam condensate may be reproduced as steam. Injection of geothermal waste into the producing formation allows a higher recovery of heat stored in the reservoir.

- Injection into geothermal reservoirs is an effective means of preventing not only chemical, but also thermal, pollution of surface water bodies.

Subsurface injection, if the geothermal fluid is utilized in an open system, will generally be preceded by settling in ponds or tanks to remove suspended solids. Sometimes filters may be used for this purpose. The 
wastewater might then require chemical or physical deacration to reduce its corrosiveness. Finally, it is injected into the geothermal reservoir through tho injection well. Injection may sometimes be accomplished by gravity alone, without the need for pumping the waste down the well, because of the higher gravity head of the cooler, denser geothermal waste. Furthermore, in the case of liquid-dominated resources, the fluid may be reinjected at the separator pressure (for flash-steam systems) or at the pressure of the geothermal fluid at the primary heat exchanger (for binary systems).

Old production wells may be converted to injection wells. However, wells may be drilled solely for injection. Unless the geothermal reservoir rock is very competent (structurally self-supporting), a cased hole with slotted liner in the injection zone is used. Figure 9.18 is a schematic diagram of a typical injection well at The Geysers.

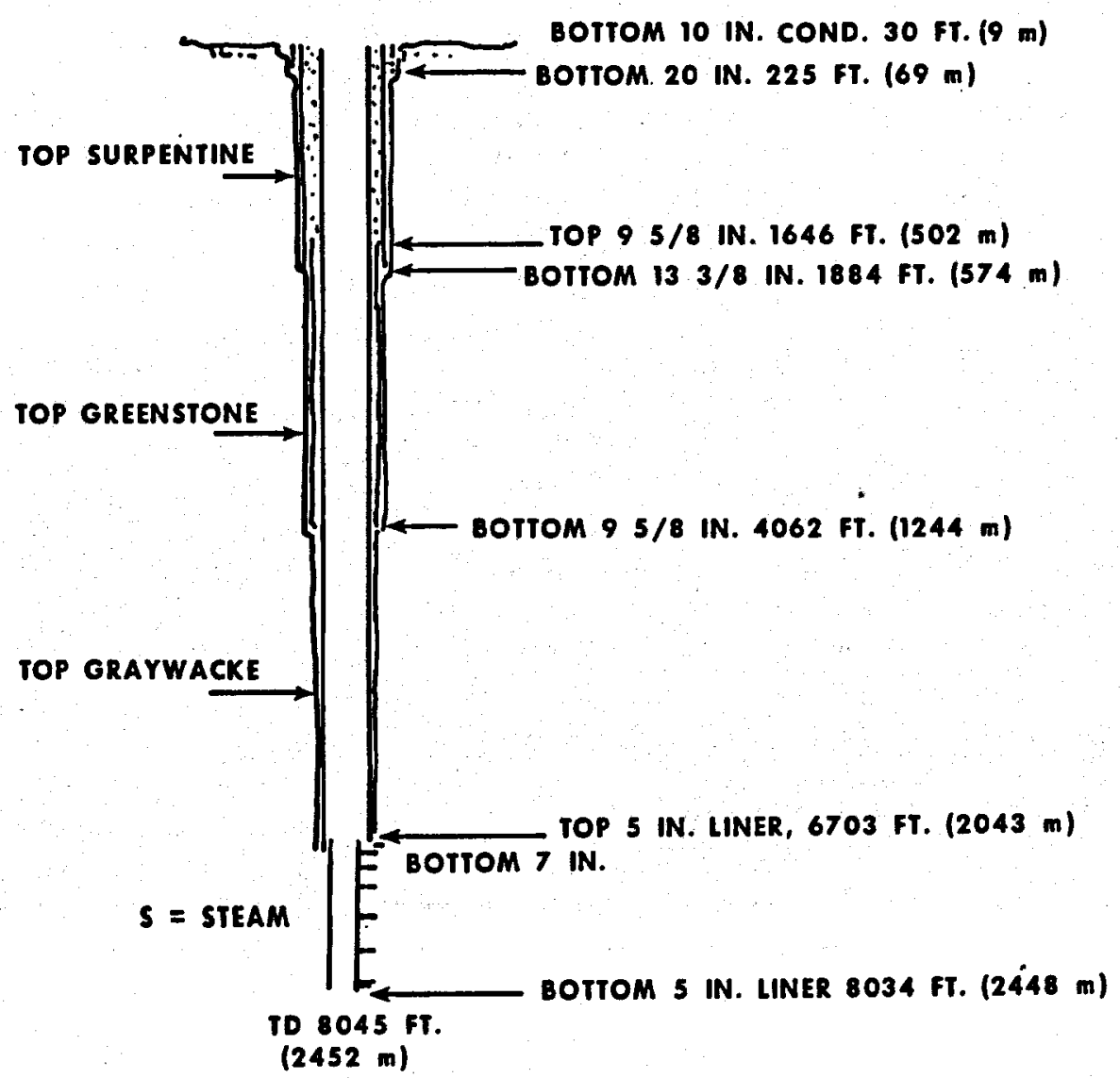

Froure 9.18-A schematic diagram of a typical injection well at The Geysers. 
The primary considerations in evaluating injection potential for a geothermal reservoir are:

- selection of optimum sites;

- cost of drilling and operating the wells compared to other methods of disposal; and

- operational aspects such as the pressure required to inject at a certain rate and the decline in injection rate with time.

The injection scheme should be designed to optimize the travel path and time of flow between injection wells and producing wells, thus preventing rapid cooling of the production water. At the same time, the water should be injected sufficiently into the producing reservoir to minimize the decline in reservoir pressure. The key factors in determining the optimum injection plan are the spatial variation of water temperature and permeability in the reservoir.

Cooling and pressure decline around the injection wellbore may cause formation plugging by the deposition of dissolved and suspended solids, and thus increase resistance to injection. In order to maintain the injection rate, pressure must then be increased. Increase in injection pressure increases operating cost and mechanical problems. If the injection system reaches its maximum pressure capacity, more injection wells may need to be drilled, or the old wells stimulated, to maintain the total injection rate, thus escalating costs. Also pretreatment strategies such as $\mathrm{pH}$ control, filtration, clarification, etc., may have to be adopted. There is no simple way yet to estimate loss of injectivity with time. The only sure means of assessing injection potential is to inject continuously for an extended period, at least a few months, and monitor wellhead injection pressure versus flow rate.

The geological suitability of the reservoir for injection has to be investigated. The reservoir must have a relatively impermeable cap rock to confine the waste from moving upward and polluting ground water aquifers. If fracture zones or faults exist, they may allow upward movement of the waste and consequent pollution [Ostroot and Ramos, 1972].

Where injection causes the pore fluid pressure to exceed the hydrostatic pressure for the area, seismic activity may be induced, if there are preexisting faults or major fracture zones near the injection zone. At Denver, Colorado, earthquakes were apparently caused by subsurface injection of waste from the Rocky Mountain Arsenal. However, the pressures required in that case far exceed those for geothermal situations, and no earthquake activity has ever been linked to injection in a geothermal field. It appears that the possibility of injection-induced earthquakes may be alleviated by minimizing the difference between the injection pressure and the original pore pressure of the reservoir fluids, particularly if there is a fault near the injection area. 
Injection wells should be completed carefully to isolate the injection horizon from shallow, fresh water aquifers. Any abandoned well near an injection well may provide a pathway for movement of the waste to shallow fresh water aquifers [Ostroot and Ramos, 1972]. Inadequate cementing behind casings and/or corrosion of liners can result in upward migration of water from' geothermal reservoirs.

The efficiency of any injection operation depends to a great extent on the physical, chemical, and thermodynamic characteristics and interrelationships of the waste fluid, the reservoir fluids, and the reservoir rock. Various types of plugging of the porespaces around the injection wellbore may occur due to the interaction between the waste and the formation, and the waste and the reservoir fluid. The problems of formation plugging, scaling in the injection lines and wellbore, and corrosion of pipes are essentially chemical in nature.

Scaling and plugging may result from one or more of the following [Sadow, 1972; Warner, 1965]: (1) precipitation and polymerization of silica and silicates; (2) precipitation of alkaline earths as insoluble carbonates, sulfates, and hydroxides; (3) precipitation of heavy metals as sulfides; and (4) precipitation of redox reaction products, e.g. iron compounds. Silica and calcium carbonate are the principal materials likely to cause pipe scaling and formation plugging.

Surface pretreatment of the wastewater from geothermal operations may be needed to ensure success of a subsurface disposal operation. Generally the pretreatment would involve one or more of the following [Sadow, 1972]:

- storage in impervious impoundments to permit, under quiescent conditions, settling and physical separation of the unwanted components;

- corrosion control by proper $\mathrm{pH}$ control, deaeration, and use of inhibitors;

- coagulation and clarification to accelerate gravity sedimentation;

- filtration and addition of bactericide to prevent plugging by bacterial growth; and

- application of electrical potential to reduce scaling.

One of the major problems in geothermal energy conversion and injection systems is silica precipitation and scale formation. Monomeric silica in solution will not precipitate nor adhere until it starts to polymerize. Polymerization reduction can be achieved in several ways [Cuéllar, 1975]:

- by maintaining a sufficiently high temperature to keep the silica solubility above saturation;

- by reducing turbulence in order to avoid fluctuations in the velocity gradients and collision of particles; and

- by lowering the $\mathrm{pH}$ of the solution : a reduction in $\mathrm{pH}$ below 6.5 causes a substantial decrease in polymerization. 
Silica-laden discharge waters have been successfully treated with slaked lime to precipitate silica and any arsenic, if present [Culp and Culp, 1971]. 'The wastewater in the Otake geothermal field in Japan is treated with slaked lime and ponded for about one hour. Colloidal silica is formed, polymerization ceases, precipitation and settling takes place, and the water can then be disposed of [Dodds et al., 1975]. Various scale inhibitors (polyelectrolytes, esters of phosphoric acid, phosphonates, etc.) have been used to slow down the precipitation rate of calcium carbonate. A glassy phosphate called Calgon has been used as a scale preventer as well as corrosion controller. Application of a negative electrical potential has been found to reduce silica scaling of the Salton Sea geothermal brines [Schock and Duba, 1975].

Although prevention of scaling can be achieved by treatment, it is also possible to remove scale. Silica scale has been successfully removed from a well-head in the Matsukawa field in Japan by allowing the scale to react with concentrated $\mathrm{NaOH}$ [Ozawa and Fuji, 1970]. The scale was completely removed in 30 minutes, although it was necessary to maintain a high temperature and pressure. Shock treatment, subjecting the formation to an almost instantaneous applied pressure differential (implosion) and sustaining the differential temporarily, has been reported to be successful in loosening the material plugging the injection formation [Van Windle and Mignotte, 1964].

Geothermal steam condensate often has a significant amount of dissolved $\mathrm{H}_{2} \mathrm{~S}$, which may create both scaling and corrosion. The $\mathrm{H}_{2} \mathrm{~S}$ may be removed by one of the technologies discussed earlier under Air Pollution Control Technology.

Generally, high salinity accelerates electrical corrosion by increasing the conductivity of the medium. Downhole corrosion rates are a function of temperature, flow rate, well depth, pressure, brine chemistry, pH, and dissolved gases (such as $\mathrm{O}_{2}, \mathrm{CO}_{2}, \mathrm{H}_{2}$ and $\mathrm{NH}_{3}$ ). The most common types of corrosion damage to metals used in geothermal environments are (1) uniform attack (ordinary rusting), (2) pitting, and (3) stress corrosion cracking [Hoffman, 1975].

Experimental tests of corrosion in the Salton Sea geothermal field have shown that corrosion is generally a problem below 300 meters and increases in severity with depth; above 300 meters, silica scale apparently protects the casing from corrosion. In several downhole tests, little corrosion was observed because of the development of a so-called "hard scale", a friable glassy (amorphous) material, formed as a thin film on the production lines. The composition of the "hard scale" was primarily silica and iron oxide, with some sulfide. Several tests also were done at The Geysers steam field. Corrosion was found to have been caused by sulfuric acid formed by sulfation of part of the $\mathrm{H}_{2} \mathrm{~S}$ in the steam by oxidation [Dodds et al., 1975].

Lowering the temperature usually decreases the corrosion rate. Increasing fluid velocity generally increases corrosion attack, with exceptions 
such as stainless steel. Very high velocities should be avoided where possible because of erosion-corrosion effects. Removing oxygen or oxidizer is an old corrosion-control technique, and may be accomplished by vacuum treatment, inert gas sparging, or oxygen scavengers. Decreasing the concentration of the corrosive and increasing $\mathrm{pH}$ (to control acidic conditions) may be effective.

Inhibitors may be used to retard corrosion. There are numerous inhibitor types which can be classified according to their mechanism and composition: (1) adsorption-type inhibitors-organic compounds which absorb on the metal surface; (2) hydrogen-evolution retardants; (3) scavengers such as sodium sulfite, sulfur dioxide, sodium thiosulfate, and hydrazine, which remove dissolved oxygen from aqueous solutions; (4) oxidizers; and (5) vapor-phase inhibitors. Inhibitors may, in themselves, be significant pollutants.

Use of alloys does not stop corrosion. It must be remembered that when an alloy or other noble metal is used, any less noble metal directly coupled to it will be sacrificed to corrosion (cathodic protection). Corrosion can be inhibited by couplings of inert materials, such as plastics. Some alloys are more corrosion-resistant than others. For example stainless steels with a chrome content higher than $10 \%$ are generally recommended [Tolivia, 1970].

Protective coatings may be used to retard corrosion. With any protective coating, however, the protection it affords is directly proportional to the continuity of the coating. The most common coatings are cement, plastic, tar, and epoxy, including Teflons. Also, controlled sodium silicate and calcium carbonate scale and glassy phosphates have been used as protective coating materials.

Capital costs for injection include the costs for drilling, casing and cementing, logging, perforation, well head equipment (including pumps and piping), control systems, and engineering supervision. Factors affecting the capital cost of an injection system include hole and pipe diameters, the pumping system required, depth of wells, number of wells, and the hydrology and geology of the site. The variation of cost per well with well diameter is shown in figure 9.19. Pump cost may vary by over $100 \%$ per well, depending on the rating and material requirements.

Froure 9.19-Variation of cost per well with well diameter.

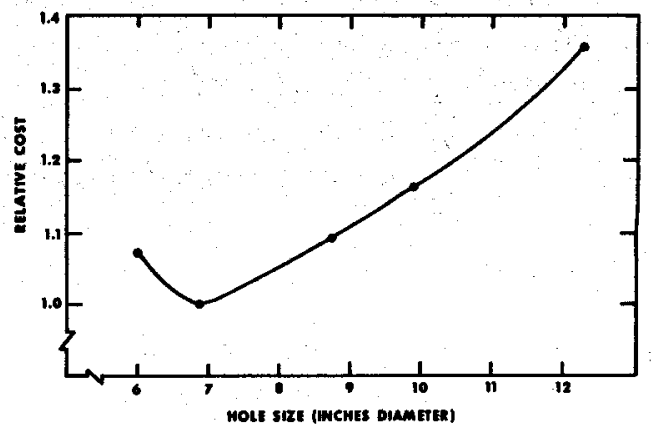


For a given geologic formation, the cost for drilling an injection well increases with depth. The relationships between drilling cost and well depth and lithology have not been clearly established for geothermal applications. Based on one study, the injection well drilling costs for sedimentary lithology vary between $\$ 150$ and $\$ 300$ per meter depth in 1976 dollars [Geonomics, 1976]. The capital cost of drilling and injection in volcanic formations may be 60 to 70 percent higher than in sedimentary. formations.

The flow capacity per well determines the number of wells that must be drilled at the site. At a given site the flow capacity depends upon àquifer formation constants that describe the permeability, thickness, and storage capacity of the aquifer. These constants vary markedly from site to site, and, thus far, have been determined at each existing site by pumping tests prior to construction of the injection system.

Because of the wide variations in site specific geology and hydrology, and a lack of complete data characterizing existing wells, injection well cost data have not been usefully parameterized. In the absence of such cost data, the capital cost of injection wells was derived by a simplistic approach involving the selection of a representative well cost using empirical cost data for actual wells. This representative cost was then used to develop total costs for multiple well systems capable of receiving various wastewater flow rates generated by the four energy conversion processes. The total cost of the well system was also estimated for four selected well capacities representative of existing wells.

Injection well cost data surveyed indicates that the capital investment for an injection well varies from $\$ 400,000$ to $\$ 1,000,000$. The individual construction costs also vary widely. The average capital cost of an injection well was taken as $\$ 500,000$. The well depth associated with the selected cost data varies from 3,000 to 10,000 feet $(914-3,048 \mathrm{~m}$ ), averaging about 6,000 feet $(1,828 \mathrm{~m})$.

The calculation of capital cost of various multiple well systems which achieve the expected geothermal wastewater generation rates (up to $350,000 \mathrm{l} / \mathrm{m}$ ) is shown in table 9.13. The total capital cost is determined from the number of wells required to achieve the required disposal flow rate. Total capital cost is then amortized over a 30 year period at an $8 \%$ interest rate. Replacement of equipment is considered negligible compared to drilling costs. The demand factor has been assumed to be $80 \%$ (i.e., the system is not operating $20 \%$ of the time).

The annualized costs for the multiple injection well systems are shown in figure 9.20 normalized to each 1000 liters of wastewater flow. Four curves are shown, each representing an injection well system utilizing one of the selected capacities. Clearly, the injection system consisting of larger wells is more economical, since fewer wells must be drilled to accomplish the required disposal rate. However, some caution should be exercised in applying the data of figure 9.20 . The plots are predicated on the assump- 
TABLE 9.13-Capital costs for injection systems at three well capacities

\begin{tabular}{|c|c|c|c|c|c|c|c|c|c|}
\hline \multirow{2}{*}{$\begin{array}{l}\text { Well capac- } \\
\text { ity-flow } \\
\text { rate (lpm) }\end{array}$} & \multicolumn{3}{|c|}{$220 \mathrm{lpm} /$ well } & \multicolumn{3}{|c|}{$1000 \mathrm{lpm} /$ well } & \multicolumn{3}{|c|}{$8000 \mathrm{lpm} /$ well } \\
\hline & No. wells & $\underset{\left(\$ 10^{\circ}\right)}{C{ }^{1}}$ & $\underset{(\$ / \mathrm{kl})}{\mathrm{AC}^{2}}$ & No. wells & $\begin{array}{r}\mathrm{CC}^{1} \\
\left(\$ 10^{0}\right)\end{array}$ & $\underset{(\$ / \mathbf{k l})}{\mathbf{A C})^{2}}$ & No. wells & $\begin{array}{l}\mathbf{C C}^{1} \\
\left(\$ 10^{\circ}\right)\end{array}$ & $\underset{(\$ / \mathbf{k l})}{\mathbf{A C} \mathbf{C}^{2}}$ \\
\hline 10 & 1 & 0.5 & 10. 60 & & & & & & \\
\hline 100 & & 0. 5 & 1. 06 & 1 & 0. 5 & 1.06 & & & \\
\hline 500 & 2 & 1.0 & 0.42 & 1 & 0. 5 & 0.212 & & & \\
\hline 1000 & 5 & 2.5 & 0. 53 & 1 & 0.5 & 0. 106 & & & \\
\hline 4000 & 20 & 10.0 & 0.53 & 4 & 2. 0 & 0. 106 & 1 & 0.5 & 0.0264 \\
\hline 5000 & 25 & 12. 5 & 0. 53 & 5 & 2.5 & 0.106 & 1 & 0.5 & 0. 0211 \\
\hline 10,000 & & & & 10 & 5. 0 & 0. 106 & 2 & 1.0 & 0.0211 \\
\hline 15,000 & & & & 15 & 7.5 & 0. 106 & 2 & 1. 0 & 0. 0141 \\
\hline 30,000 & & & & 830 & 15.0 & 0.106 & 4 & 2. 0 & 0. 0141 \\
\hline 50,000 & & & & & & & 7 & 3. 5 & 0. 0148 \\
\hline 100,000 & & & & & & & 13 & 6. 5 & 0. 0137 \\
\hline 350,000 & & & & & & & 44 & 22. 0 & 0.0133 \\
\hline
\end{tabular}

1 Initial capital cost.

2 Annualized cost per unit of flow; based on $C=P(C R F)$, where $P$ is total cost and CRF is capital recovery factor at $8 \%$ interest and 30 -year period. The demand factor for the well is assumed to be $80 \%$.

3 Arbitrary limit. 


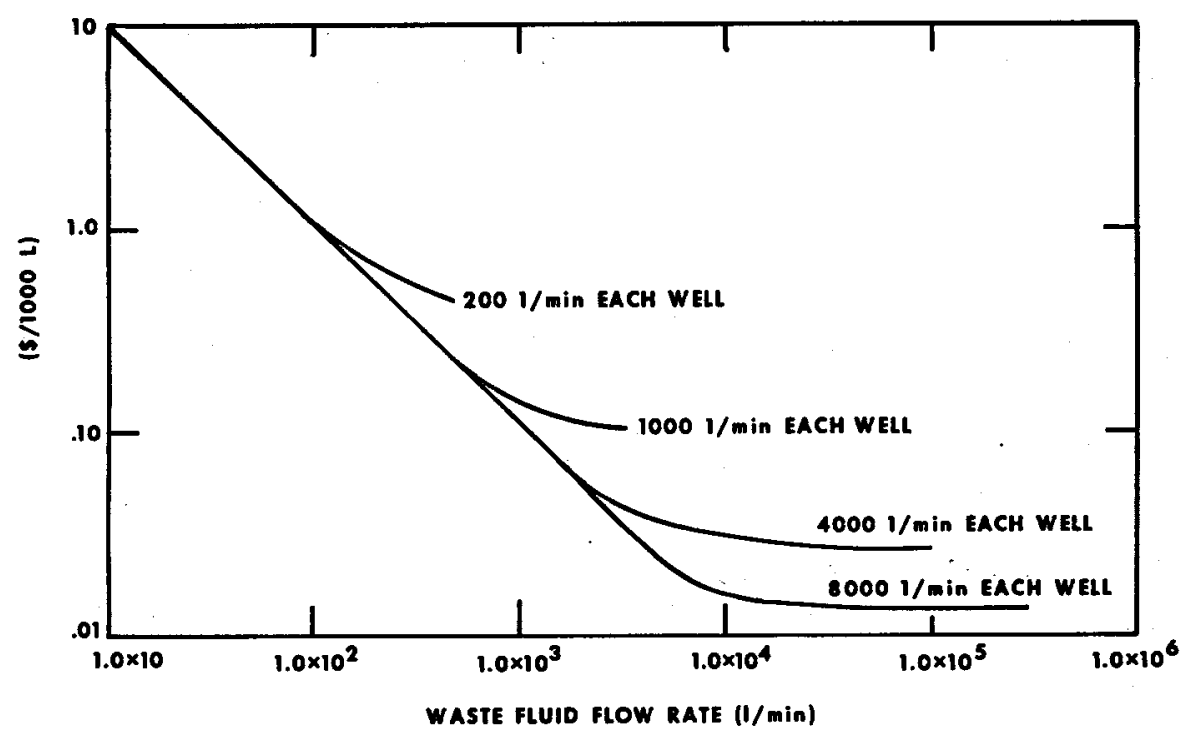

FigURE 9.20-Annualized costs for multiple injection well systems.

tion that capital cost of a well is invariant regardless of its capacity. Actually, wells of different capacities, all other site parameters being equal, may use different pumps, different pump injection pressure, or a different hole size. If a different hole size is used to accomplish additional flow capacity, such as from 4000 to $8000 \mathrm{l} / \mathrm{m}$ the relative cost of the larger diameter well would be about 1.2 times that of the smaller well. Still, the cost information developed in figure 9.20 is useful to establish preliminary cost estimates and to judge feasibility of multiple well injection systems. For example, it can be seen that the total annualized capital cost of injecting high flow levels of geothermal wastewater from flashed steam plants is relatively low compared to other environmentally acceptable disposal methods.

Operating and maintenance costs for an injection system consist of expenditures for the operation and routine maintenance of wellhead equipment, piping and pumps. The operating cost will consist mostly of the energy cost for pumping. Routine labor costs will be negligible, and maintenance costs over a thirty-year period will depend primarily on the application and service required. In many cases, repair costs will be almost zero, while in others, anticipated maintenance or repair (due to corrosion, plugging, or wear) will prohibit the use of injection entirely. For the purpose of costing, it is assumed that $0.5 \%$ of the capital investment is annual maintenance costs. This corresponds to $\$ 2,500$ per well. Depending on the flow temperature and the operating pressure of the injection well, the maintenance costs may vary somewhat.

Energy costs for pumping, in cents per thousand liters, are independent of flow rate, but are instead a function of the pressure requirement for 
the particular injection system. This pressure requirement depends on frictional losses in the tubing, elevation changes for the pumped fluid, and the hydrologic.pressure requirement (that is, the pressure required to push the waste liquid into the injection aquifer).

Frictional losses in the well tubing area are usually negligible. For a flow rate of $8000 \mathrm{l} / \mathrm{m}$ the losses are 1.3 psi per 100 feet of tubing. On the other hand, the pressure gain due to the elevation head of the waste is 42 psi per 100 feet $(9.37 \mathrm{~atm} / 100 \mathrm{~m})$ vertical depth (assuming the waste brine has the density equal to that of water at $100^{\circ} \mathrm{C}$ ). The hydrologic pressure requirement (that is, the pressure required to push the waste liquid into the injection aquifer) is considered the strongest determinant for pumping energy because of high variabilities in pressure difference.

Table 9.14 shows the expected energy cost for pumping at various values for the pressure requirement. These pressure values are representative of anticipated requirements, based on surveys of existing injection facilities. In some cases, the initial pressure requirement may be zero because of injection aquifer conditions and/or the pressure gain in the well tubing. However, a pump should still be included in the design to allow for eventual increases in pressure requirements. Pressure requirement can change because permeability of the stratum can change as solids are filtered from the injected waste.

TABLE 9.14-Operating energy cost for injection pumps

\begin{tabular}{|c|c|}
\hline Pressure requirement (psi) & $\begin{array}{l}\text { Cost (cents/ } \\
10001 \text { ) }\end{array}$ \\
\hline 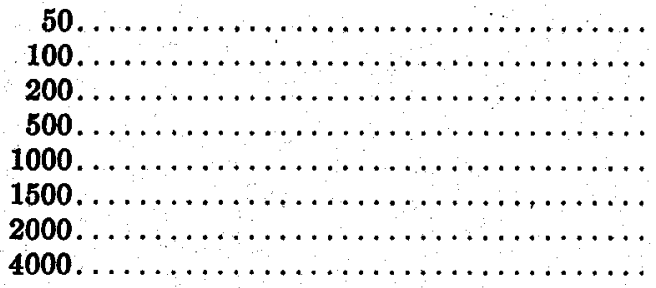 & $\begin{array}{l}0.714 \\
1.43 \\
2.86 \\
7.14 \\
14.3 \\
21.4 \\
28.6 \\
57.2\end{array}$ \\
\hline
\end{tabular}

9.5.2.2 Ocean disposal. The disposal of spent geothermal fluids to ocean waters may be an acceptable alternative in some cases since the most common constituent in geothermal brine is sodium chloride. However, if the geothermal waste significantly increases the salinity or toxicity in the area of the outfall, it will not be acceptable without appropriate prior treatment.

Ocean disposal of spent geothermal fluids would, in principle, be an uncomplicated operation. It involves the conveyance of the liquid, probably by a pipeline, from the geothermal operation to the shore and thence through a pipe laid on or in the ocean bottom to some distance offshore. At the outfall the wastewater may be released in a simple stream or jetted 
through a manifold or multiple port diffuser. The diffuser facilitates the mixing of wastewater with sea water, both upward and laterally, thus causing rapid dilution and thermal dissipation.

Because of the large volumes of geothermal waters that will generally be used per unit of energy extracted, pipelines would be large-perhaps one meter or larger in diameter.

The technical and economic advantages associated with ocean disposal of wastewaters have been diminished greatly in recent years as a result of new and more stringent pollution standards. In addition to costly pretreatment requirements, costs of conveyance and ocean disposal of geothermal plant wastewaters from sites at least 200 miles $(322 \mathrm{~km})$ from the ocean are exorbitant. An example of approximate costs for conveyance and ocean disposal of wastewaters may be obtained from compilations of existing cost data such as those prepared for the San Francisco Bay and Sacramento-San Joaquin Delta Area Wastewater Management Survey Report [USACE, 1972]. Costs are based upon open country routing, precast pipe foundations, land costs of $\$ 3000 /$ acre, and assumed life of 50 years. Further assumptions are in elevation head between 40 and 100 feet $(12-30 \mathrm{~m})$, head loss of 1.5 feet per 1000 feet $(1.5 \mathrm{~m} / 1000 \mathrm{~m})$, pump efficiency of $72 \%$, and pump life of 30 years. Costs also include ocean outfall at a depth of 200 feet $(61 \mathrm{~m})$ with a diffuser; they do not include the cost of any required wastewater pretreatment. Gross estimates are thus provided, in table 9.15 for ocean disposal at various flow rates.

TABLE 9.15-Normalized cost of ocean disposal of geothermal plant wastewaters

$[\$ / 10001 / \mathrm{min}]$

\begin{tabular}{rrrrr}
\hline $\begin{array}{c}\text { Wastewater } \\
\text { fow }(1 / \mathrm{min})\end{array}$ & $\begin{array}{c}\text { Annualized } \\
\text { cost of convey- } \\
\text { ance lines }\end{array}$ & $\begin{array}{c}\text { Annual cost of } \\
\text { pumping }\end{array}$ & $\begin{array}{c}\text { Annualized } \\
\text { outfall cost }\end{array}$ & $\begin{array}{c}\text { Annualized } \\
\text { total cost }\end{array}$ \\
\hline $1-000$ & $21-900$ & $2-660$ & $50-550$ & $75-110$ \\
$5-000$ & $6-470$ & $2-130$ & $16-200$ & $24-800$ \\
$10-000$ & $3-640$ & $1-900$ & $14-850$ & $20-390$ \\
$100-000$ & 600 & $1-330$ & $2-400$ & $4-330$ \\
$350-000$ & 110 & $1-030$ & 890 & $2-070$ \\
\hline
\end{tabular}

- The cost of conveyance is based on an assumed open country routing of 200 miles.

b It is assumed that wastewater is pumped through an elevation gain of 100 feet.

- An offshore outfall distance of 1 mile is assumed. The outfall cost is the sum of the annualized costs for the outfall line and the diffuser.

9.5.2.3 Evaporation ponds. Where large land areas are available, evaporation ponds could provide a very simple approach to geothermal wastewater disposal. Evaporation ponds are more practical in arid regions where evaporation losses may reach 60 to 100 inches per year (1500 to $2500 \mathrm{~mm} / \mathrm{yr}$ ).

Construction of evaporation ponds involves excavation and/or diking, depending upon the topography of the area. In some cases, natural depres- 
sions may be utilized. In a few instances, it may be possible to enhance natural salt marshes as a wildlife habitat, principally by providing a constant water supply. It is not expected that evaporation ponds would normally have a surface drainage outlet. Unless the soil is impermeable, evaporation ponds must be lined to prevent ground water pollution. Types of liners include clay, rubber, asphalt, concrete, and plastics.

Table 9.16 shows the expected water surface area required for evaporation ponds accepting wastewaters from the various geothermal energy conversion processes. The flow approximations represent the median of the range of wastewater production rates associated with the various processes.

TABLE 9.16-Estimated water surface area required for disposal of geothermal wastewaters

\begin{tabular}{|c|c|c|}
\hline Geothermal conversion system & $\begin{array}{l}\text { Median waste- } \\
\text { water rate, } 1 / \mathrm{min}\end{array}$ & $\begin{array}{l}\text { Water surface } \\
\text { area, acres }\end{array}$ \\
\hline $\begin{array}{l}\text { Direct steam power generation........... } \\
\text { Flashed steam, binary, total flow, power }\end{array}$ & 17,000 & 1,450 \\
\hline 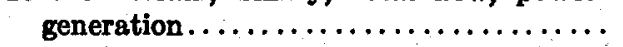 & 80,000 & 6,757 \\
\hline Direct heating open and closed systems.... & 500 & 43 \\
\hline 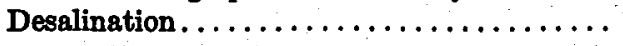 & 3,000 & 257 \\
\hline
\end{tabular}

- This is the amount of surface area required to maintain level of evaporation ponds at steady state. The required area is estimated by $A=Q / E$, where $A=$ area required, $Q=$ wastewater generation rate, and $E$-evaporation rate, $I t$ is assumed that losses through the pond liner are negligible.

The costs of evaporation ponds are related to various dependent factors in a recent study conducted for the Environmental Protection Agency [Black and Veatch, 1977]. The data apply to average situations in the United States, and have been based on actual costs of projects over a wide geographic area, including varied construction conditions. The cost estimates developed in the study are representative of national average price levels as of January, 1971.

The total capital investment cost includes the costs of construction, pond liner, embankment protection, engineering, land, and administrative requirements. The total operating and maintenance cost includes the costs of materials, supplies and labor. An estimate of total annual costs versus size of the evaporation pond is provided in figure 9.21. Variations in these costs are to be expected with variations in the controlling factors.

9.5.2.4. Land spreading. Land spreading is a treatment method that relies primarily on biodegradation of the waste constituents. Spraying on irrigable land, wooded areas, and hillsides has been used primarily for the disposal of municipal wastes. Treated effluents have been used for golf course and park watering. The amount of wastewater that can be disposed of by spraying depends largely on the climatic conditions, the infiltration capac- 


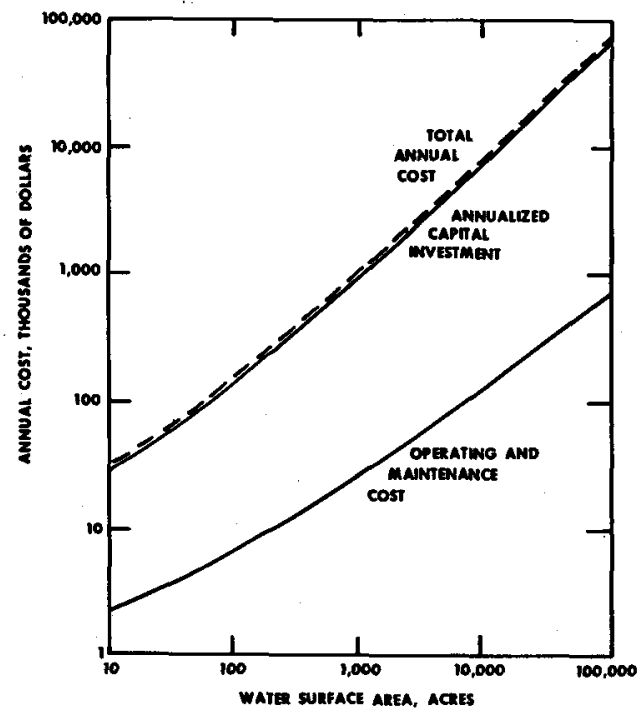

Froure 9.21-Estimate of total annual cost versus size of the evaporation pond.

ity of the soil, the types of crops of grasses grown, and the quality standards imposed where runoff is allowed.

Inorganic wastes, such as those found in geothermal wastewaters, may not be suitable for land application. Significant concentrations of heavy metals would accumulate in the soil, posing threats to plant and animal life, and surface and ground water uses. The hazards of disposing of nonbiodegradable materials on land are causing increasing concern, and regulations are becoming more restrictive.

\subsubsection{Containment of unplanned releases (spills). Geothermal energy} conversion systems will generally include the distribution of large volumes of geothermal fluids through a dispersed well and pipeline system. The possibility of system ruptures should be anticipated, and surface containment should be provided at points of high risk. Containment can include impermeable diking and/or excavation of areas large enough to contain the potential flow until the flow can be stopped.

Containment involves the routing of spills to a nearby holding basin, similar in design to an evaporation pond. Factors which will affect the design of the holding basin include: the availability of nearby land, the permeability of the soil and the ability of the environment to accept the spill without adverse effect, the presence of other lagoons or ponds already serving the plant, site topography, and geology. Generally, a holding basin will require construction to depths of 10 to 15 feet by forming an embankment with earth moving equipment.

Costs. The cost for construction of holding basins may be estimated using cost data for gerated stabilization ponds similar in design [Black and Veatch, 1977]. The costs shown in figure 9.22 are derived for these data. Costs are shown for surface containment ponds suitable to manage un- 
Frgure 9.22-Costs for construction of holding basins.

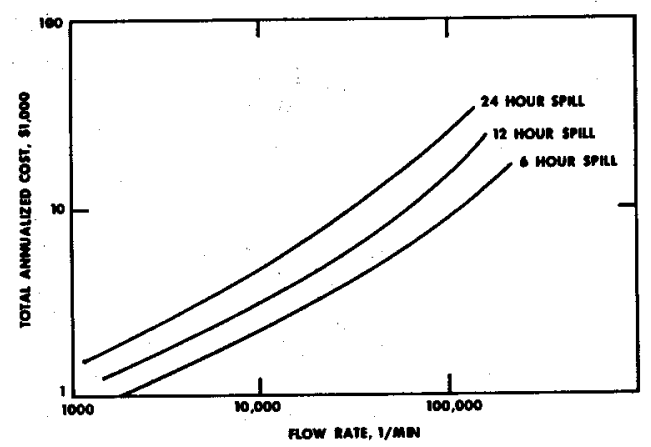

planned releases of geothermal fluids at various flows and durations. The surface area requirements for the specified flow ranges (10 to 350,000 $1 / \mathrm{min}$ ) vary from 12 square feet $\left(1.1 \mathrm{~m}^{2}\right)$ to 41 acres depending on the duration of the spill.

\subsubsection{Solid waste disposal}

In contrast to air and water treatment technologies with a diversity of options, solid waste disposal techniques are generally prescribed by regulations. The regulations usually require burial in a dry environment above, and impermeably separated from the water table. Infiltration of runoff water must be prevented or confined. Clay, shale, or other low permeability formations around the disposal site cannot always be taken as a guarantee against infiltration and consequent leaching. If any parts of the waste are soluble and leaching does occur, the leachate must be confined and treated just as a liquid waste of similar composition. Solid wastes containing significant amounts of heavy metals and other substances considered "hazardous waste" are subject to special disposal regulations that may add to the disposal cost.

Treatment of geothermal wastes, particularly for removal of waterboine constituents, can produce very large quantities of sludge, including hazardous materials, depending of course upon the original concentration and the percentage removed. Materials added to facilitate treatment, particularly if not regenerated, can add substantially to the sludge quantity. Hydrogen sulfide removal from power generating facilities may typically generate several hundred metric tons of sludge per day. Removal of dissolved solids from high-salinity fluids may produce hundreds of thousands of metric tons per day.

The cost for disposal of hazardous waste in an appropriate landfill varies from $\$ 8$ to $\$ 12$ per ton of waste. This rate is independent of quantity accepted, although reduced rates up to $25 \%$ are available when disposal can be expected on a repetitive and high volume basis [Kinna, 1977]. Normally, the greatest cost associated with waste disposal at a landfill is the hauling 
expenditure. Typical hauling rates are approximately $\$ 32$ per hour for a truck having a capacity of 20-25 metric tons. Hauling time consists of about 2 hours loading and unloading plus actual road-trip travel time.

It is estimated that the cost of sludge disposal would be $\$ 21.40$ per metric ton under the following conditions: hauling distance is 200 miles (322 $\mathrm{km}$ ) ; disposal cost is $\$ 10$ per metric ton; and the cost of hauling is $\$ 224$ per truckload of 20 metric tons. Based on these costs, waste solids disposal from a high-salinity system, in which dissolved solids must be removed, would be prohibitive in most cases, and would be a very significant cost in any case. The disposal costs assumed here do not include the costs of sludge dewatering. The degree of dewatering required would depend on the economic tradeoff between wet transportation and drying before transport.

\subsubsection{Noise control}

Noise from geothermal operations, as discussed previously, can be severe. The greatest sources of noise are the escape of air during compressed air drilling, and the direct escape of raw geothermal fluid at wellheads, separators, and vents in the fluid distribution system. Secondary sources, such as those associated with a steam turbine generation plant and cooling tower, are significant, but are of far less off-site environmental significance. Abatement technologies include prevention, shielding, and attenuation [Jhaveri, 1975].

A variety of silencers have been designed to attenuate noise from escaping air and fluid. They range from relatively crude rock-filled chambers, to baffled sound-absorbent mufflers, to large twin-cylinder centrifugal expansion towers. Two examples are shown in figures 9.23 and 9.24. The type needed will depend upon the volume and nature of the escaping medium. For example, the large centrifugal type has generally been used for flashed-separated brine, whereas the smaller sound-absorbent type has been used for steam venting. At the wellhead, air or steam venting may be into a rock and water-filled pit. Most techniques are effective, but leave much room for improvement. Noise levels as high as $140 \mathrm{~dB}$ are typically reduced to $100 \mathrm{~dB}$ or less, by methods not necessarily expensive or complex. Attenuation can often be very effectively accomplished with very simple designs.

Noise from machinery operation can be reduced by applying state-ofthe-art techniques such as shielding, baffling. vibration dampening. proper alignment, adequate lubrication, and other techniques, or by developing new technology. Noise from permanent facilities can often be dampened by judicious placement, taking advantage of the absorbent properties of topography and various types of vegetation.

The costs of reducing noise are comparatively low, and in most cases, will not be significant in total operational costs. 


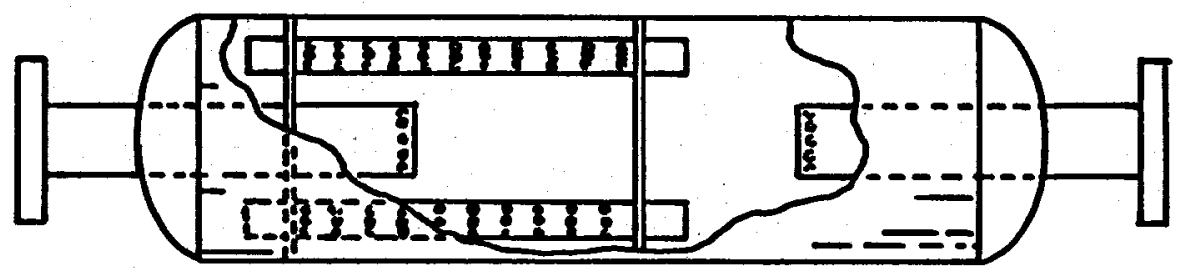

Frouke 9.23-A baffled, sound-absorbent sllencer used for geothermal operations.

\subsection{Environmental monitoring}

Monitoring as described here is primarily for the purpose of determining the quantity of pollutants discharged to the air, surface water, and ground water. As such, monitoring must include sampling and analysis for contaminants at effuent and emission points. These measurements will be required as a part of permit conditions to ensure that permitted loading limits are in fact met.

Pollutant loading limitations may be based, as discussed earlier, upon effluent and emission standards when such are developed. In the interim, those limitations will be based upon calculations and judgments, by the permitting agency, as to loadings that will allow ambient air and water standards to be met. Also as discussed earlier, ambient standards may control limitations even after the development of effuent and emission standards, where the latter would allow ambient standards to be violated.

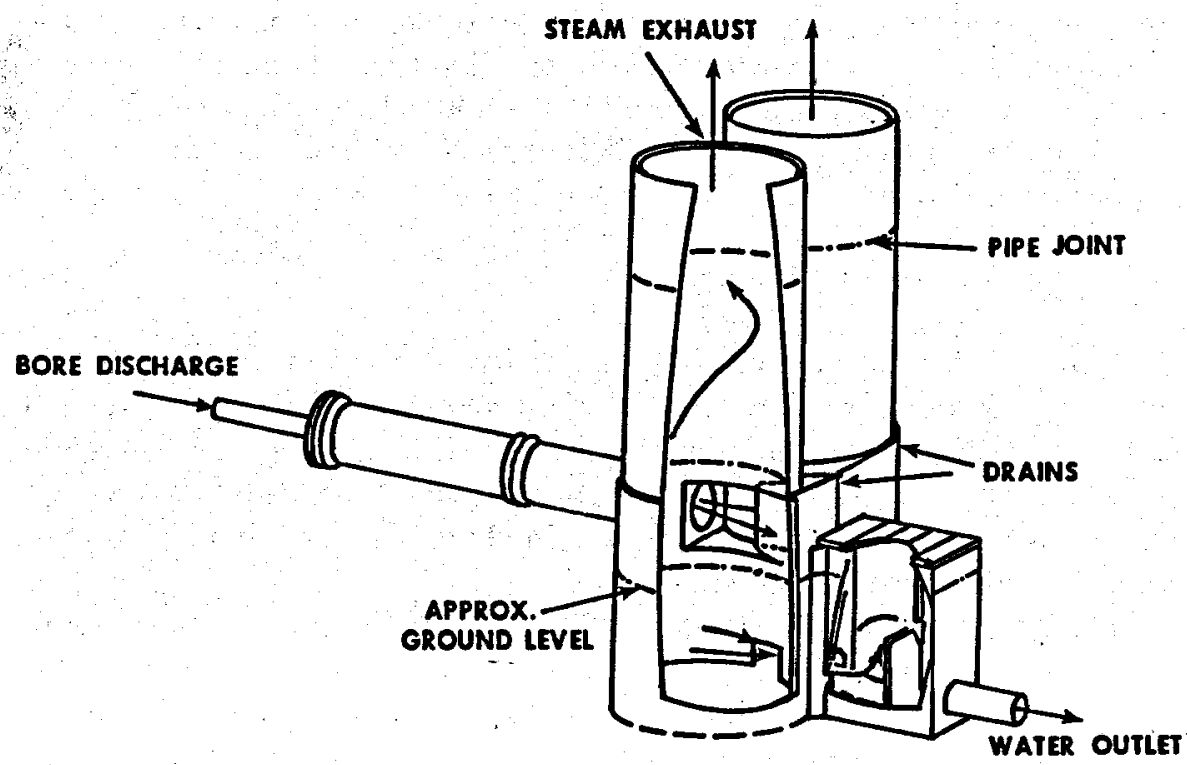

Frauke 9.24-A large twin-cylinder centrifugal expansion silencer used for geothermal operations. 
Thus, ambient monitoring at receptor points will also be required, in most cases, in addition to effluent and emission monitoring. The EPA recognizes that initial monitoring may be cumbersome until the industry and a data base have been sufficiently developed, and until monitoring methodologies specific to geothermal activities have been developed.

\subsubsection{Air and water point-source monitoring}

Any planned waste liquid discharges or gas emissions resulting from materials used in the geothermal energy conversion process must be monitored by the operator in accordance with permit requirements. For liquid discharges, the required measurements may include volume, selected chemical constituents, suspended solids, temperature, $\mathrm{pH}$, and radioactivity. Gas emission measurements will include volume and concentrations of regulated constituents such as hydrogen sulfide. Radiological analysis may be required. Any or all of the pollutants listed in section 9.2 may require measurement.

Monitoring of wastewater surface discharges and gas emissions should be conducted at each planned discharge site at a frequency commensurate with the character of discharge, e.g., less frequently for discharges of uniform character. Liquid affluents and gases often will be combined and can be sampled simultaneously. The frequency, duration, and method of sampling should be such that a calculated average constituent loading $\pm 50 \%$ will encompass the true average loading bver any period of time.

All discharge permits will require that monitoring be done by the operator, that records of measurements be maintained for inspection by the regulatory agency, that loading data for all releases be submitted periodically to the regulatory agency and that standard violations be reported. The regulatory agency may sample discharges to confirm operator monitoring results and to determine permit compliance.

\subsubsection{Ambient air monitoring}

An initial ambient air sampling and analysis program should be established by the geothermal operator for all geothermal energy conversion facilities which require emission monitoring. Such a program can be expected to last at least until data accumulation is sufficient to show that ambient air quality standards are not violated or adverse impacts do not occur as a result of the emissions.

Ambient air monitoring should be designed on a case-by-case basis to ensure receptor protection (or to detect standards violations) at the facility's boundary with other private or public property or even within its boundaries if the property is accessible for public use. Monitoring sites should be selected to conform with principal directions of pollutant transport by increased sampling frequencies at those points. 
Ambient monitoring sites should be established on the basis of a prior continuous sampling program at all compass octants from the production facilities or the geographic center of the production field. Sites should be distances from the source(s) sufficient to delineate pollutant dispersion characteristics and to encompass any area where concentrations above ambient may be caused by such source(s). The continuous sampling program should be of sufficient duration to include characteristic weather variations throughout the year. Samplings should be done within 5 meters (15 feet) of ground level, so that concentrations may be related to terrestrial receptor effects.

Any ambient air monitoring program will likely be subject to criticism, periodic reevaluation, and redesign to conform to expanded or reduced production or to natural factors not known at the time of program establishment. This may be particularly true for larger and expanding production facilities and/or those with relatively high non-condensible gas fractions in the raw geothermal field.

\subsubsection{Ambient water monitoring}

In the past, it has been common to require industries to monitor discharges, but not surface receiving water quality. The bulk of those measurements have been made by regulatory agencies. Permits may require geothermal developers to monitor ambient water quality. Even if ambient monitoring is not required, voluntary monitoring will likely be to their advantage, particularly if discharge loading limitations are based upon water quality standards. Limitations, thus developed, are intended to prevent violations of concentration limits within the receiving waters under all flow conditions.

Monitoring points should be selected to ensure, as a minimum, that the quality of surface water be monitored where it is accessible to the use of others. In many cases, this may be at the downstream point of intersection of the developer's property line and surface drainage. However if the developer's property is leased public land, water quality and thus monitoring stations may be maintained within the leasehold, since all but operationally unsafo areas may still be publicly accessible.

Surface water quality monitoring may be required even if there are no planned surface water discharges. One of the reasons for this is that air pollutants from geothermal operations may result in atmospheric "fallout" contamination. Another is that, if surface containment is employed, leakage may occur.

Water quality monitoring should include the same constituents and properties for which effluents are monitored. The locations, frequency, and duration of surface water ambient monitoring should be determined after consideration of several factors such as :

- size, flow, and flow variability of the receiving water body 
- stream mixing characteristics

- volume of the discharge

- chemical and physical characteristics of the discharge and the consistency thereof

- waste water treatment system characteristics

- air emission characteristics

- downstream water uses

- upstream pollutional discharges

- stream ecology.

Despite the apparent complexity of the monitoring selection process, the resulting monitoring scheme would be expected to be relatively simple. One extreme might be represented by a uniformly low volume, low salinity discharge into a large flowing stream. Monitoring then might be one grab sample upstream and one downstream taken monthly at points of well-mixed stream flow. The other extreme might be represented by a high volume, high salinity, relatively nonuniform discharge into a low or variably flowing stream already contaminated by upstream users. In this case, much more frequent monitoring might be required at several upstream and downstream stations. Several cross-sectional grab samples might be taken, flows measured, and data composited. In addition to determining constituent concentrations, effluent loadings may be confirmed.

Frequency of ambient water monitoring should be commensurate with variability in effluent characteristics and stream flow. However, it appears likely that in most cases, monthly sampling might be acceptable, because of the expected uniformity of discharge characteristics.

\subsubsection{Ground water monitoring}

Spent fluid is likely to be injected in many, if not most, cases to or below the geothermal reservoir to alleviate reservoir depletion and subsidence. Injection is also likely to be the most environmentally acceptable disposal method for high salinity fluids, if performed properly. Subsurface injection may be the disposal method of choice, even if spent fluid cannot be feasibly returned to the geothermal reservoir. This is the case in known geopressured areas, where injection would probably be to shallower aquifers with similar chemical characteristics.

Injection in any case will have the potential, as a result of unplanned or accidental system disruption, of contaminating aquifers usable for other purposes, such as drinking water. Such contamination could have the most serious consequences. If such contamination occurs, it may be difficult, if not impossible, to return the aquifer to its original condition. Careful monitoring may be the only way to ensure that significant contamination does not occur with injection.

Because of the serious nature of potential ground water contamination, the EPA is currently conducting a study to design an adequate ground 
water monitoring methodology for geothermal operations. Many other studies of geology, hydrology, scaling and corrosion, reservoir dynamics, etc., by other agencies will have direct bearing on injection technology and, in turn, monitoring methodology. Until monitoring methodologies are fully developed, interim requirements will necessarily be imposed, based upon state-of-the-art injection technologies.

The ground water chemical characteristics of all aquifers overlying the geothermal reservoir should be monitored. The monitored constituents should include all those that would be measured if the waste water were surface-discharged, and perhaps others, if chemicals are added to promote injection.

Methods, principally electrochemical, are being researched to monitor, by injection well instrumentation, the location and extent of migration of injected fluids. Until such methods are perfected, monitoring may require sampling from wells into each aquifer. Sampling, by fluid retrieval, of multiple aquifers from one well should not be encouraged because of potential mixing. Sampling wells should surround the geothermal operation, and all should be located within a few hundred yards of reinjection wells. The capability should exist to sample each aquifer at two or more points downgradient from principal injection wells. Existing water supply wells may be used where determined appropriate.

The frequency of ground water aquifer sampling will depend principally upon the rate of injection and the quality characteristics of the injected fluid vs, those of the aquifer. Higher injection rates of more saline brines would probably demand higher frequency sampling than lower injection rates of "cleaner" fluids. In most cases, however, it is expected that a 30-day sampling frequency will be near the optimum. Various characteristics may demand more frequent sampling. Simple grab samples should be sufficient for ground water monitoring.

\subsubsection{Land-disposed wastes}

Land-disposed wastes requiring control by isolation are determined by chemical characterization. Monitoring of storage, treatment, and disposal sites under control of the geothermal operator will be required under State and Federal regulations to determine whether any constituents escape by leaching or percolation to surface and/or ground water. Monitoring requirements will be similar to those described above for ambient surface waters and for ground water. The most significant difference is that probably only the uppermost ground water aquifer may need to be monitored.

\subsubsection{Noise monitoring}

Monitoring of noise is accomplished by noise measurements at the property line or the boundary with other use areas, at points nearest the 
noise source. It is probable that a set monitoring schedule need not be established. Rather, measurements should be made upon a change in type or mode of operation. Measurement methodologies have been developed for many specific noise sources and can be integrated to measure overall noise at the boundary site.

A noise monitoring program should be established by the operator to assure himself that violations of local, State and Federal regulations do not occur. Because noise cannot be ignored, it may be monitored frequently by regulatory agencies.

\subsubsection{Baseline air and water monitoring}

Prior to geothermal energy production, the existing state and natural variations of air and water quality should be determined in detail by the developer in accord with the needs of regulating agencies. Baseline descriptions are in fact part of the requirement for environmental impact reports and analyses, which in turn are required for all projects on Federal lands and most on State lands. Baseline asessment may require longterm, detailed measurements to establish the basis for differentiating natural and operation-caused changes.

The U.S. Department of Interior's Geothermal Environmental Advisory Panel has prepared a report entitled "Guidelines for Acquiring Environmental Baseline Data on Federal Geothermal Leases." [GEAP, 1977] The report describes procedures for gathering chemical, physical and biological data for a one-year period prior to submission of a plan for production, as required by the Geothermal Steam Act of 1970. The data are submitted to the U.S. Geological Survey Area Geothermal Supervisor, who may alter the requirements according to specific needs.

Baseline water and air quality monitoring should be viewed as setting the stage for later ambient monitoring during full-scale operations. Thus, it should include measurements of the same constituents that will be monitored later during construction and operation of the energy conversion facility. With this view in mind, it would be expected that the operational monitoring would utilize baseline stations established earlier. This of course requires coordinated planning throughout the development.

\subsection{Future development of effluent and emissions standards}

Pollution control for the geothermal industry, during its development stages and later full-scale commercialization, will be regulated by discharge and disposal permits. The permit systems will be implemented and principally administered by the States under approval by the Administrator of the U.S. Environmental Protection Agency. On Federal lands the U.S. Geological Survey supervises geothermal operations and issues operational permits. It also monitors operations for regulatory compliance, including 
pollution control. The USGS interface with other agencies in the area of pollution control has not yet been clearly defined.

During the development stages, permits are likely to be issued on a case-by-case basis, with discharge loadings based upon the maintenance of ambient standards. Later permits, during established commercialization, may restrict loadings based upon water Effluent Guidelines and air New Source Performance Standards. These guidelines and standards would, in turn, be based upon concurrent pollution control and conversion process technology development during the pre-commercial stages.

Effluent Guidelines and New Source Performance Standards must be founded upon demonstrated control technology. The geothermal industry and its regulation are unique in that the industry is just beginning, and the inertial resistance characteristic of established industries toward pollution control, created by less restrictive requirements in the past, is virtually nonexistent. The principal geothermal industrial development agency, the U.S. Department of Energy, is committed by law to concurrently develop pollution control technology. Thus, in the case of geothermal development the heretofore rare opportunity exists to create an industry with integral pollution control from the outset.

Effluent Guidelines and New Source Performance Standards are normally based upon demonstrated achievable pollutant control technology. In some cases, this may not effect the achievement of ambient standards. Thus, ambient standards in the development stage may be useful in forcing the development of improved, economically viable control technology where required.

Geothermal pollution control research, development,and demonstration costs will be largely borne by government prior to large private investment. The result should be that the geothermal industry will find itself, when it is ready to become fully operational, in the advantageous position of having pollution control limits and technology that are available and compatible. Ideally, the application of control technology then would result in no ambient standards violations in any case. This would increase industry's confidence in its ability to develop within the limits of environmental regulation.

The evolution of pollution control standards by EPA should be a cooperative process involving inputs principally from the Department of Energy, the U.S. Geological Survey, the States, and private developers. It must include a free exchange of information among all interested parties. The principal contributions of each are suggested as follows, with the most significant set in italic :

- Environmental Protection Agency

-Overview of environmental and health research and development by other agencies and the industry.

- Characterization and evaluation of pollutants.

-Evaluation of pollutant environmental and health effects. 
-Regionwide pollution monitoring.

- Guidance as to limitations based upon effects.

- Evaluation of control systems and suggestions for improvements.

- Development of new water quality criteria.

- Support of pollution control research and development.

- Development of pollution control regulations and promulgation of Effluent Guidelines, New Source Performance Standards, reinjection regulations, solid waste regulations, and guidance to states on permitting programs.

- Department of Energy

- Design, construction, and operation of pollution control systems.

- Conduct and support of control technology research, development, and demonstration.

- On-site environmental baseline characterization.

-Initial effluent characterization and evaluation of effects.

-Establishment and maintenance of liaison with all developers.

-Input to pollution control regulations development:

- U.S. Geological Survey

-Assurance of compliance with pollution limitation on Federal lands.

- Development of resource characterization data.

-Establishment of environmental regulations on federal lands where otherwise lacking.

-Input to pollution control regulations development.

- States (regulatory and development agencies)

-Implementation of interim pollution control program by permit and monitoring systems.

-Support of baseline monitoring.

$\rightarrow$ Statewide water and air quality monitoring and planning.

-Input to pollution control regulation development.

- Private developers

-Design, construction, and operation of pollution control systems to meet established and/or anticipated pollution control limits.

-Monitoring of effluents and emissions throughout development and operation.

-Evaluation of pollution control systems.

-Environmental baseline characterization.

-Input to pollution control regulations development.

\subsection{References}

Allen, G. W.; personal communication to TRW, Inc.; Pacific Gas and Electric Company; November 18, 1977.

American Conference of Governmental Industrial Hygienists; Threshold Limit Values for Chemical Substances in Workroom Air Adopted by ACGIH for 1976; ACGIH, 1976. 
Axtmann, R. C.; Environmental Impact of a Geothermal Power Plant, Science, vol. 187, No. 4179; March 1975.

Battelle Pacific Northwest Laboratories; Removal of Hydrogen Sulfide from Geothermal Steam; ERDA Contract No. E-45-1-1830; September 1976.

Black and Veatch Consulting Engineers; Wastewater Stabilization Ponds; report prepared for the U.S. Environmental Protection Agency; 1977.

Bond, R. G. and C. P. Straub; Handbook of Environmental Control-Vol. IV, Wastewater Treatment and Disposal; CRC Press, Cleveland, Ohio; 1973.

Chen, C. L., H. H. Takenaka, and R. P. Miele; Demineralization of Wastewater by Electrodialysis; EPA Report No. 600/2-75-047; October 1975.

Chen, C. L. and R. P. Miele; Demineralization of Sand-Filtered Secondary Effluent by Spiral-Wound Reverse Osmosis Process; EPA Report No. 600/2-77-169; September 1977 (A).

Chen, C. I. and R. P. Miele; Wastewater Demineralization by Two-Staged Fixed Bed Ion Exchange Process; EPA Report No. 600/2-77-146; September 1977 (B).

Cosner, S. R.; Geothermal Brine Data File; Lawrence Berkeley Laboratory. University of California; revision February 3, 1977 (available as updated via computer printout).

Cuéllar, G.; Behavior of Silica in Geothermal Waste; Proceedings of the Second U.N. Symposium on the Development and Utilization of Geothermal Resources, San Francisco; May 20-29, 1975.

Culp, R. L. and G. L. Culp; Advanced Wastewater Treatment; Litton Educational Publishing, Inc.; New York, 1971.

Dodds, F. J., A. E. Johnson, and W. C. Ham; Material and Corrosion Testing at the Geysers Geothermal Power Plant; Proceedings of the Second UN Symposium on the Development and Utilization of Geothermal Resources; San Francisco, May 2029, 1975.

Douglas, J. G., R. J. Serne, D. W. Shannon, and E. M. Woodruff; Geothermal Water and Gas-Collected Methods for Sampling and Analysis; BNWL-2094, Battelle Pacific Northwest Laboratories; August 1976.

Dow Chemical Company, Texas Division; Removal of Hydrogen Sulfide from Simulated Geothermal Brines with Oxygen; EDRA Contract No. 76-C-02-2797; April 1977.

EIC Corporation; Control of Hydrogen Sulfide Emissions from Geothermal Power Plants; Annual Status Report, ERDA Contract EY-76-C-02-2730; July 1976.

ECOVIEW; Environmental Impact Report on Borax Lake Area, Lake County, California; April 1976.

Energy Research and Development Administration; A National Plan for Energy Research, Development and Demonstration Creating Energy Choices for the Future; ERDA-76, vol. 2, 1976.

Energy Research and Development Administration; Definition Report-Geothermal Energy Research, Development and Demonstration Program; ERDA-86, October 1976.

Environmental Protection Agency; Geothermal Position Paper: EPA Regulatory Options and Research Development Information Needs; EPA report no. 600/7-77092, August 1977 (B).

Environmental Protection Agency; Information on Levels of Environmental Noise Requisite to Protect Public Health and Welfare with an Adequate Margin of Safety; Report No. 550/9-74-004, Office of Noise Abatement and Control; March 1974.

Environmental Protection Agency; National Interim Primary Drinking Water Regulations; 40 CFR Part 142; Federal Register, vol. 41, No. 3; January 20, 1976 (A).

Environmental Protection Agency; Public Health and Welfare Criteria for Noise; Report No. 550/9-73-002, Office of Noise Abatement and Control; July 1973. 
Environmental Protection Agency; Quality Criteria for Water; Office of Water and Hazardous Materials; EPA-440/9-76-023; July 1976 (B).

Environmental Protection Agency; Survey of Environmental Regulations and Assessment of Pollution Potential and Control Technology Applications for Geothermal Resources Development, Phase II Report; prepared for Office of Research and Development, Contract No. 63-03-2371, March 1977 (A) (preliminary draft).

Fairfax, J. P. and H. K. McCluer; Hydrogen Sulfide Abatement-Geysers Power Plant Progress Report 7485.3-\%1; Pacific Gas and Electric Company; January 1972.

FWPCA; Water Quality Criteria, Federal Water Pollution Control Administration, Rep. of the Nat'l. Tech. Adv. Comm. to the Sec. of the Interior, April 1, 1968.

Galeski, J.; personal communication to TRW, Inc.; Midwest Research Institute, December 7, 1977.

GEAP, Geothermal Environmental Advisory Panel; Guidelines for Acquiring Environmental Baseline Data on Federal Geothermal Leases; U.S. Geological Survey, U.S. Dept. of Interior, Menlo Park, Calif.; January 1977.

Geonomics, Inc.; A Comparison of Hydrothermal Reservoirs of the Western United States; prepared for Electric Power Research Institute; March 1976.

Gleason, M. N., R. E. Gosselin, H. C. Hodge, and R. P. Smith; Clinical Toxicology of Commercial Products; Williams and Wilkinson Co., Baltimore; 1969.

Griebe, M.; personal communication to TRW, Inc.; Ralph M. Parsons Company, December 2, 1977.

Hartley, R. P., 1978, Pollution Control Guidance for Geothermal Energy Development, EPA-600/7-78-101; Ind. Envir. Res. Lab., Cincinnati, Ohio.

Hesketh, E. H.; Understanding and Controlling Air Pollution; Ann Arbor Science Publishers, Inc., Ann Arbor, Mich., 1976.

Hoffman, M.; Jet Propulsion Laboratory, Environmental Quality Laboratory; Memoir 14; 1975.

Jhaveri, A. G.; Environmental Noise and Vibration Control at Geothermal Sites; Proceedings Second UN Symposium on Development and Use of Geothermal Resources; San Francisco; May 20-29, 1975.

Kinna, L.; personal communication; Chancellor and Ogden, Inc., Wilmington Landfill; December 1977.

Laszlo, J.; Application of the Stretford Process for $\mathrm{H}_{\mathrm{u}} \mathrm{S}$ Abatement at The Geysers Geothermal Power Plant; Proceedings of the 11th Intersociety Energy Conversion Engineering Conference, Sept. 12-17, 1976, State Line, Nev.

Matsuo, K., Drilling for Geothermal Steam and Hot Water, in Geothermal Energy, Review of Research and Development, ed. by H. C. H. Armstead; UNESCO, Paris, 1973.

National Academy of Sciences; Water Quality Criteria 1972; A Report of the Committee on Water Quality Criteria; 1973.

O'Connell, M. F. and R. F. Kaufman; Radioactivity Associated with Geothermal Waters in the Western United States; Technical Note ORP/LV-75-8A, U.S. Environmental Protection Agency; March 1976.

Ostroot, G. W. and J. Ramos; Deep-Well Acid Disposal-Planning and Completion; Underground Waste Management and Environmental Implications, Memoir 18, American Association of Petroleum Geologists; 1972.

Ozawa, T. and Y. Fuji; Phenomenon of Scaling in Production Wells and the Geothermal Power Plant in the Matsukawa Area; UN Symposium on the Development and Utilization of Geothermal Resources, Geothermics, Sp. Iss. 2, vol. 2, pt. 2, Pisa 1970.

Pacific Gas and Electric Company, Amended Environmental Data Statement, Geysers Unit 13; March 1975. 
Rascheri, R. and W. S. Cook; Exploration and Development of Geothermal Resources; U.S.G.S., Office of the Area Geothermal Supervisor, 1976 (preliminary unpublished report).

Sadow, R.; Pretreatment of Industrial Waste Water for Subsurface Injection; Underground Waste Management and Environmental Implications, Memoir 18, American Association of Petroleum Geologists; 1972.

Sanyal, S. K.; Preliminary Compilation of Chemical Composition of Geothermal Waters; Geonomics, Inc.; January 28, 1977 (personal communication).

Sax, N. I.; Dangerous Properties of Industrial Materials; Reinhold Book Corp., New York; 1968.

Schock, R., and A. Duba; Effect of Electrical Potential on Scale Formation in Salton Sea Brine; Lawrence Livermore Laboratory, Contract W-740 S-Eng-48; November 1975.

Smith, J. H.; Collection and Transmission of Geothermal Fluids, in Geothermal Energy Review of Research and Development; ed. by H. C. H. Armstead; UNESCO, Paris; 1973.

Stanford Research Institute; Environmental Analysis for Geothermal Energy Development in The Geysers Region; report for the California Energy Resources Conservation and Development Commission, volume I-Summary; May 1977.

Sung, R., G. Houser, G. Richard, J. Cotter, P. Walker, and E. Pulaski; Preliminary Cost Estimates of Pollution Control Technologies for Geothermal Development; EPA Contract No. 68-03-2560, Work Directive T-S004; review draft, January 1978.

Tolivia, M.; Corrosion Measurements in a Geothermal Environment; UN Symposium on the Development and Utilization of Geothermal Resources; vol. 2, pt. 2; Pisa; 1970.

Tolmasof; Report on H.S Air Quality and The Geysers Geothermal Development; Northern Sonoma County Air Pollution Control District; January 1976.

U.S. Army, Corps of Engineers; Cost Curves for Conveyance, Treatment and Storage of Wastewater; U.S. Army Engineer District, San Francisco; April 1972.

US. Public Health Service; Preliminary Air Pollution Survey of Hydrogen SulfideA Literature Review; Consumer Protection and Environmental Health Service; APTD 69-37; 1969.

US. Public Health Service; Public Health Service Drinking Water Standards; PHS pub. 956, U.S. Government Printing Office; 1962.

Van Windle, W. and H. Mignotte; Journal of Petroleum Technology; 161-28; 1964.

Warner, D.; Deep-Well Disposal of Industrial Wastes; Chemical Engineering, vol. 72, pp. 73-78, 1965.

White, Donald E.; Characteristics of Geothermal Resources in Geothermal Energy edited by P. Kruger and C. Otte; Stanford University Press; 1973.

Wood, B.; Geothermal Power in Geothermal Energy Review of Research and Development, ed. by H. C. H. Armstead; UNESCO, Paris, 1973. 


\section{Chapter 10}

\section{Geothermal Power Plants Around the World}

(By R. DiPippo*)

\subsection{Introduction}

\subsubsection{Historical overview}

The first commercial use of geothermal energy as a source of electric power took place in Italy in 1904. For many decades this natural resource remained untapped except at the Larderello field in Tuscany. As with all pioneering activities in a new technology, the use of geothermal energy for electric power in Italy was beset with problems. These were relatively simple to overcome in the case of the Italian geothermal resource owing to the fact that the geothermal fluid emerges from the reservoir as a superheated vapor. As such it could be employed in more or less conventional steam turbines, albeit ones built with special materials to allow for problems of corrosion and erosion.

Most geothermal reservoirs, however, are not as easy to exploit as the dry steam field at Larderello. The majority of them produce a mixture of liquid and vapor at the wellhead. Furthermore, the fluid is often burdened with significant amounts of dissolved solids and noncondensable gases, some of which may be toxic.

Exploitation of liquid-dominated hydrothermal reservoirs did not take place on a large scale until the Wairakei plant was built in New Zealand in 1958. Since that time, several other countries have begun to use their geothermal fields for electric power generation, including the United States, Mexico, the Soviet Union, Japan, El Salvador, the People's Republic of China, the Philippines, and Iceland. Furthermore, several other countries are on the verge of developing their geothermal resources. Each of these countries will be discussed in the ensuing sections of this chapter.

\subsubsection{Energy conversion systems}

There are several types of energy conversion systems currently in use for geothermal power generation throughout the world, and several new

\footnotetext{
*Southeastern Massachusetts University, N. Dartmouth, Mass.
} 
systems which are in the research and development stage. The present systems may be categorized as follows:

- Dry (or superheated) steam plants.

- Separated (or "single-flash") steam plants.

- Separated/single-flash (or "double-flash") steam plants.

- Separated/multi-flash (or "multi-flash") steam plants.

- Single-flash steam plants with pumped wells.

- Double-flash steam plants with pumped wells.

- Binary cycle plants with a secondary working fluid.

- Total flow plants.

Plants of the first four types exist and are in commercial operation; plants in the last four categories are either under construction or in the testing phase (pilot plants). The total installed geothermal power capacity in the world is currently about $1500 \mathrm{MW}$ of which about $943 \mathrm{MW}$ is from dry steam plants. A total of $2140 \mathrm{MW}$ is now under construction or planned to be online by 1982 , with an additional $1800 \mathrm{MW}$ being projected for the near-term beyond 1982. Table.10.1 lists a summary of geothermal power capacity in the world as of January 1979.

TABLE 10.1-Worldwide geothermal electric power capacity as of January 1979

\begin{tabular}{|c|c|c|c|}
\hline$\because$ & $\begin{array}{l}\text { No. of units } \\
\text { in operation }\end{array}$ & $\begin{array}{l}\text { Installed } \\
\text { capacity, } \\
\mathbf{M W}\end{array}$ & $\begin{array}{r}\text { Future } \\
\text { capacity, } \\
\text { MW }\end{array}$ \\
\hline$\ldots \ldots \ldots \ldots$ & 1 & 1 & NA \\
\hline 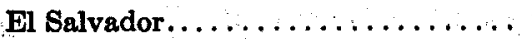 & 2 & 60 & 35 \\
\hline Iceland $\ldots \ldots \ldots \ldots \ldots \ldots \ldots \ldots$ & 4 & 64 & $\mathbf{N A}$ \\
\hline Italy $\ldots \ldots \ldots \ldots \ldots \ldots \ldots \ldots \ldots$ & 37 & 420. 6 & NA \\
\hline 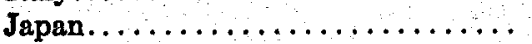 & 6 & 165 & 55 \\
\hline Mexico................... & 2 & 75 & 105 \\
\hline 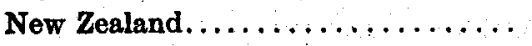 & 14 & 202. 6 & NA \\
\hline Philippines . . . . . . . . . . . . & 2 & 4. 2 & 765 \\
\hline 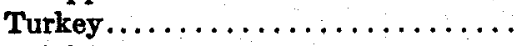 & 1 & 0.5 & NA \\
\hline U.S.S.R. . . . . . . & 1 & 5 & NA \\
\hline United States. ....... & 12 & 502 & 1180 \\
\hline Totals.............. & 82 & 1499. 9 & 2140 \\
\hline
\end{tabular}

- Under construction or in planning for 1982. Additional capacity may come from countries not presently using geothermal energy for electricity, such as Costa Rica, Kenya, Nicaragua, and others.

$\mathrm{NA}=$ Not available.

\subsubsection{Power plant performance factors}

Throughout this chapter the performance of geothermal power plants is characterized by a geothermal resource utilization efficiency, $\eta_{u}$. This factor is the proper thermodynamic measure of the energy conversion proc- 
ess which takes place in a geothermal power plant, irrespective of the details of the particular system in use. The utilization efficiency is based on the available work (or exergy) in the geothermal fluid, either as it exists in the reservoir (or at the bottom of the well), or as it is supplied to the boundary of the plant (or at the wellhead). In most cases the latter pointof-reference is chosen since more reliable properties of the fluid are available on the surface as compared with in the reservoir.

The utilization efficiency is calculated from

$$
\eta_{u}=w / w^{\circ}
$$

where $w$ is the work output of the plant (per unit mass), and $w^{\circ}$ is the exergy of the geothermal fluid (per unit mass). The exergy is obtained from

$$
w^{\circ}=h_{1}-h_{0}-T_{o}\left(s_{1}-8_{0}\right)
$$

where subscript 1 is used to denote the state of the geofluid at the inlet to the plant (or at the wellhead), and subscript $o$ denotes the ambient sink condition (i.e.; saturated liquid water at a temperature $T_{o}$ ). In those cases where the inlet state is chosen at the bottom of the well, an additional term, $-g L$, must be included in equation 10.2 to account for the potential energy of the fluid at a depth $L$ below the surface. This extra term is usually quite small except for very deep wells, i.e., $>3 \mathrm{~km}(>10,000 \mathrm{ft})$.

Another measure of plant performance that is frequently quoted is the specific geofluid consumption, or the amount of geothermal fluid that must be produced from the reservoir to generate a unit of electricity. This factor is expressed as kilograms per kilowatt hour (or $\mathrm{lbm} / \mathrm{kW} \cdot \mathrm{h}$ ).

Several factors are commonly used to describe the operations and reliability of a power plant. There are three power plant operating factors which, taken together, indicate the manner in which the plant is used to meet variations in demand. These are :

$$
\begin{gathered}
\text { Load factor, } F_{L}: F_{L}=\bar{L} / L^{*} \\
\text { Capacity factor, } F_{\sigma}: F_{\sigma}=\bar{L} / C
\end{gathered}
$$

Utilization factor, $F_{U}: F_{U}=L^{*} / C$

where the terms used in equations 10.3-5 have the following meanings:

$\bar{L}=$ average load for a given period,

$L^{*}=$ peak load for a given period,

$C=$ rated capacity of the plant or unit. 
The average load $\bar{L}$ is found from

where

$$
\bar{L}=G / h
$$
and

$G=$ total electrical generation for a given period,

$h=$ number of hours in the period (usually taken as $8760 h=1$ year). It is clear that

$$
F_{c}=F_{\mathrm{L}} \times F_{U}
$$

and that whenever the utilization factor equals unity (i.e., pure base-load operation), then the load factor becomes identical numerically to the capacity factor.

There are three commonly used power plant reliability factors:

$$
\begin{aligned}
& \text { Availability factor, } F_{A}: F_{\Lambda}=P_{S} / h \\
& \text { Forced outage factor, } F_{F o}: F_{F O}=P_{F o} / h \\
& \text { Scheduled outage factor, } F_{B O}: F_{B O}=P_{s o} / h \text {, }
\end{aligned}
$$

where

$P_{s}=$ service period, i.e., the number of hours that the unit operated with breakers closed to the station bus;

$P_{F O}=$ forced outage period, i.e., hours of down-time caused by equipment failure or malfunction;

$P_{\text {so }}=$ scheduled outage period, i.e., hours of down-time for planned maintenance.

It is clear that

$$
P_{s}=h-P_{F O}-P_{B O}
$$

It will be seen from the discussions in the following sections that geothermal power plants are capable of resource utilization efficiencies as high as $55-60 \%$, and are characterized generally by high capacity factors $(\sim 80 \%)$, and very high availability factors $(\sim 95 \%)$.

The sections which follow constitute a much-condensed summary of a thorough treatment of existing and planned geothermal power plants which will be available as a separate volume by the author.*

\subsection{China}

With the recent emphasis on education, science, and technology in the People's Republic of China, it can be expected that geothermal energy will

* Geothermal Energy as a Source of Electricity: A Worldhoide Burvey of the Desion and Operation of Geothermal Power Plants by R. DiPippo, G.P.O., 1980. 
be among those areas to be developed for practical purposes. Currently there is at least one geothermal electric power plant in operation in China. It is located on the slopes of the Himalayan mountains in Tibet. The plant is of the separated steam (or "single-flash") type with an installed capacity of $1000 \mathrm{~kW}$. Apparently the plant uses steam from a single well, obtained by means of a cyclone separator. The turbine is of the condensing type, using a barometric, direct-contact condenser. Water from a nearby river is used to supply cooling water for the condenser. Noncondensable gases are removed from the condenser by means of a water-jet ejector.

It is reasonable to assume that more details about China's geothermal energy program will become available in the near future owing to the new policy aimed at bringing China into a full partnership among the nations of the world.

\subsection{El Salvador}

\subsubsection{Overview}

El Salvador is the first of the Central American countries to construct and operate a geothermal electric generating station. Exploration began in the mid-1960's at the geothermal field near Ahuachapán in western El Salvador. The first power unit, a separated-steam (or "single-fiash") plant, was started up in June 1975, and was followed a year later by an identical unit. The $60 \mathrm{MW}$ of geothermal capacity presently constitutes $14 \%$ of the total electric generating capacity of El Salvador, but during 1977 the Ahuachapán plant produced nearly one-third of the electricity generated in the country.

The Comisión Ejecutiva Hidroeléctrica del Río Lempa (C.E.L.) is in the process of installing the third unit at Ahuachapan, a dual-pressure ("double-flash") unit which will be rated at 35 MW. In addition, C.E.L. is actively pursuing several other promising sites for additional geothermal plants. There is the possibility that eventually geothermal energy will contribute about $450 \mathrm{MW}$ of electric generating capacity. In any event it appears that by $1985 \mathrm{El}$ Salvador will be able to meet its domestic needs for electricity by means of its indigenous geothermal and hydroelectric power plants, thus eliminating any dependence on imported petroleum for power generation.

\subsubsection{Ahuachapán}

The Ahuachapán field is located in westernmost El Salvador about $18 \mathrm{~km}$ (11 mi) east of the Río Paz which forms the international boundary with Guatemala. The area consists of moderately sloping terrain on the northern side of a string of volcanic mountains. Within the $3000 \mathrm{ha}$ (7400 acre) geothermal region, there are a number of areas of active surface ther- 
mal manifestations including fumaroles, hot springs, steaming ground, and boiling mud pools. The hydrothermal reservoir consists of A huachapán andesites, the permeability of which is created by fractures in an otherwise hard formation. Young agglomerates constitute the cap rock for the reservoir. The temperature of the geofluid in the reservoir is about $230^{\circ} \mathrm{C}$ $\left(445^{\circ} \mathrm{F}\right)$. The aquifer is believed to be recharged from a volcanic lake to the south of the field.

Figure 10.1 shows the location of 27 wells that have been drilled in the vicinity of the power plant. The spacing between wells is not less than

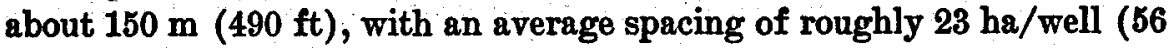
acre/well); the density in the central portion of the field is greater, being nearly $11 \mathrm{ha} /$ well (27 acre/well).

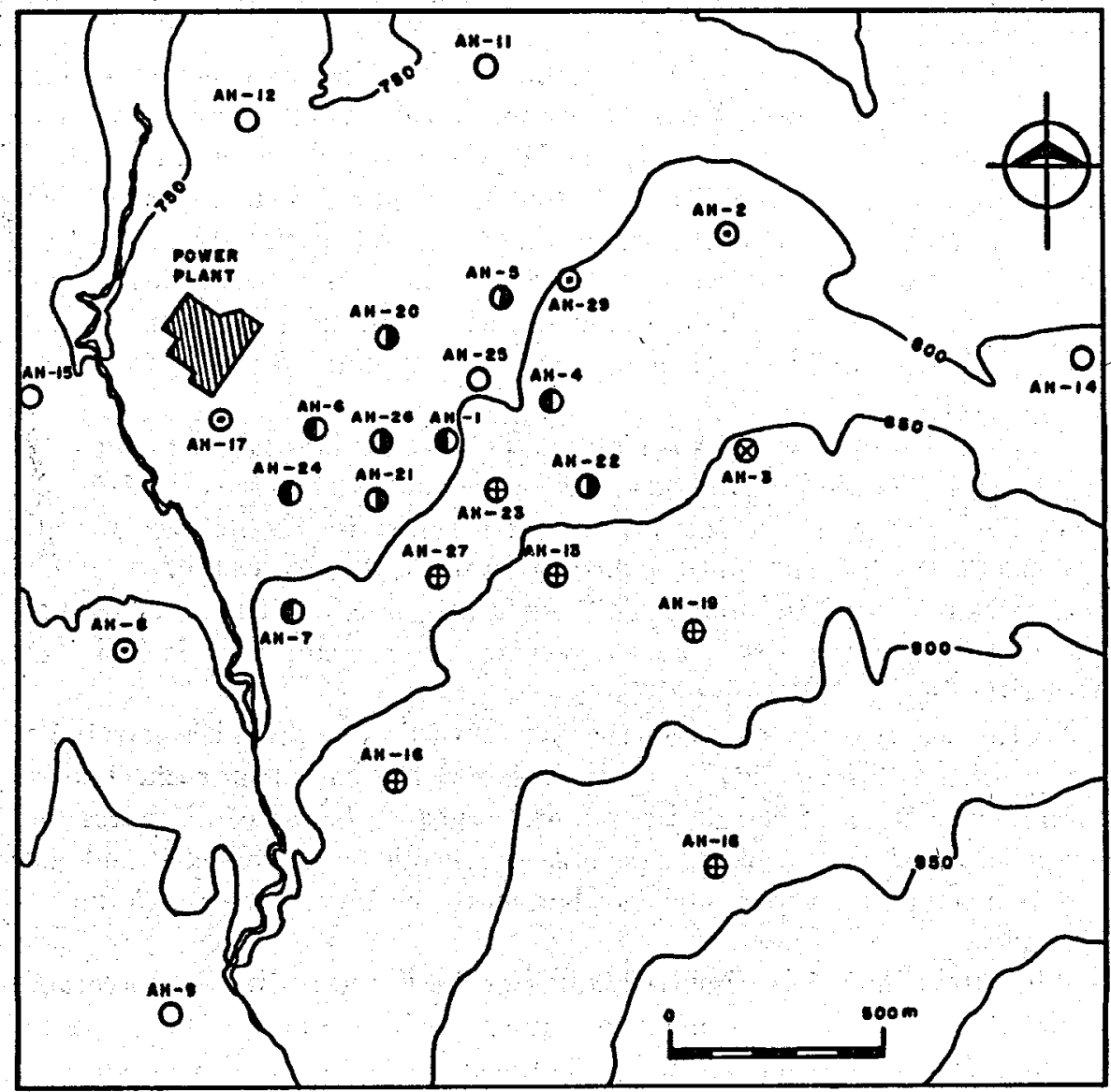

Frgure 10.1-Arrangement of wells at Ahuachapán. $O$ Wells for unit No. 1; $O$ Wells for unit No. 2; $\odot$ Reinjection wells; $\bigcirc$ Nonproductive wells; $\otimes$ Collapsed well; $\oplus$ Stand-by wells. 
A typical production well has the following configuration: $444 \mathrm{~mm}$ (171/2 in) hole with a $340 \mathrm{~mm}(133 / 8$ in) casing cemented to a depth of about $100 \mathrm{~m} ; 311 \mathrm{~mm}$ (121/4 in) hole with $244 \mathrm{~mm}$ (95/8 in) casing to $400 \mathrm{~m}$ or to the top of the reservoir; $216 \mathrm{~mm} \mathrm{(81/2}$ in) open hole through the production zone. In some cases where the formation is not sufficiently hard to prevent sluff-in, $194 \mathrm{~mm}$ ( $75 / 8$ in) slotted liner is hung from the $244 \mathrm{~mm}$ ( $95 \% 8$ in) casing.

Reinjection wells are completed in a similar way except that they are drilled deeper, into the basement rock, and fitted with a $194 \mathrm{~mm}(75 / 8$ in) casing down to the top of the basement to prevent the reinjected fluid from entering the aquifer. This casing is hung, not cemented, to allow for its easy removal in the event that the well should ever be used for production.

The well casings are J-55 API standard weight pipe. The cement is straight Portland; the drilling mud is of the Bentonitic type with coconut husks, coffee bean shells and mica being added to seal off loss-of-circulation zones.

Figure 10.2 shows a typical wellhead site. The two-phase geofluid emerges from the well and passes through a $356 \mathrm{~mm}$ (14 in) control valve before entering the $1.4 \mathrm{~m}$ (55 in) dia. Webre-type cyclone separator which has a capacity of $350 \mathrm{t} / \mathrm{h}\left(770 \times 10^{3} \mathrm{lbm} / \mathrm{h}\right)$. Separated steam leaves via a $406 \mathrm{~mm}$ (16 in) bottom outlet which leads to a ball check valve. A vertical hot water collecting tank is used to direct the liquid either to the twin vertical silencers where the liquid is flashed to atmospheric conditions and thence disposed of by means of a surface channel, or to one of four reinjection wells.

Ten wells supply units No. 1 and 2. The first unit receives steam from wells $A H-1,-4,-6,-7$, and -24 ; the second unit is fed from AH-5, -20 , $-21,-22$, and -26 . The average separator pressure for the first set of wells is $635 \mathrm{kPa}\left(92 \mathrm{lbf} / \mathrm{in}^{2}\right)$ and for the second set is $612 \mathrm{kPa}\left(89 \mathrm{lbf} / \mathrm{in}^{2}\right)$. The total steam flow to the plant is $127 \mathrm{~kg} / \mathrm{s}\left(10^{8} \mathrm{lbm} / \mathrm{h}\right)$; the total geofluid produced from the reservoir to generate this steam flow is $726 \mathrm{~kg} / \mathrm{s}$ $\left(5.8 \times 10^{6} \mathrm{lbm} / \mathrm{h}\right)$ [DiPippo, 1978f].

Of the nearly $600 \mathrm{~kg} / \mathrm{s}\left(4.8 \times 10^{8} \mathrm{lbm} / \mathrm{h}\right)$ of liquid which is separated at the wellheads, about $62 \%$ is reinjected into the basement rock. The remainder is currently being disposed of by means of surface discharge and evaporation, with the effluent from several wells being collected and conveyed through a covered concrete channel to the Pacific Ocean, $75 \mathrm{~km}$ (47 mi) away.

The total amount of dissolved solids in the liquid at the wells averages about $18,400 \mathrm{ppm}$, with the main constituents being : chloride $(10,430 \mathrm{ppm})$, sodium, $(5690 \mathrm{ppm})$, potassium $(950 \mathrm{ppm})$, silica $(537 \mathrm{ppm})$, calcium $(443$ $\mathrm{ppm}$ ), and boron (151 ppm). Noncondensable gases amount roughly to $0.05 \%$ by weight of the total well flow, or about $0.2 \%$ of the steam flow. These gases consist mainly of carbon dioxide ( $86.8 \%$ by volume) and 


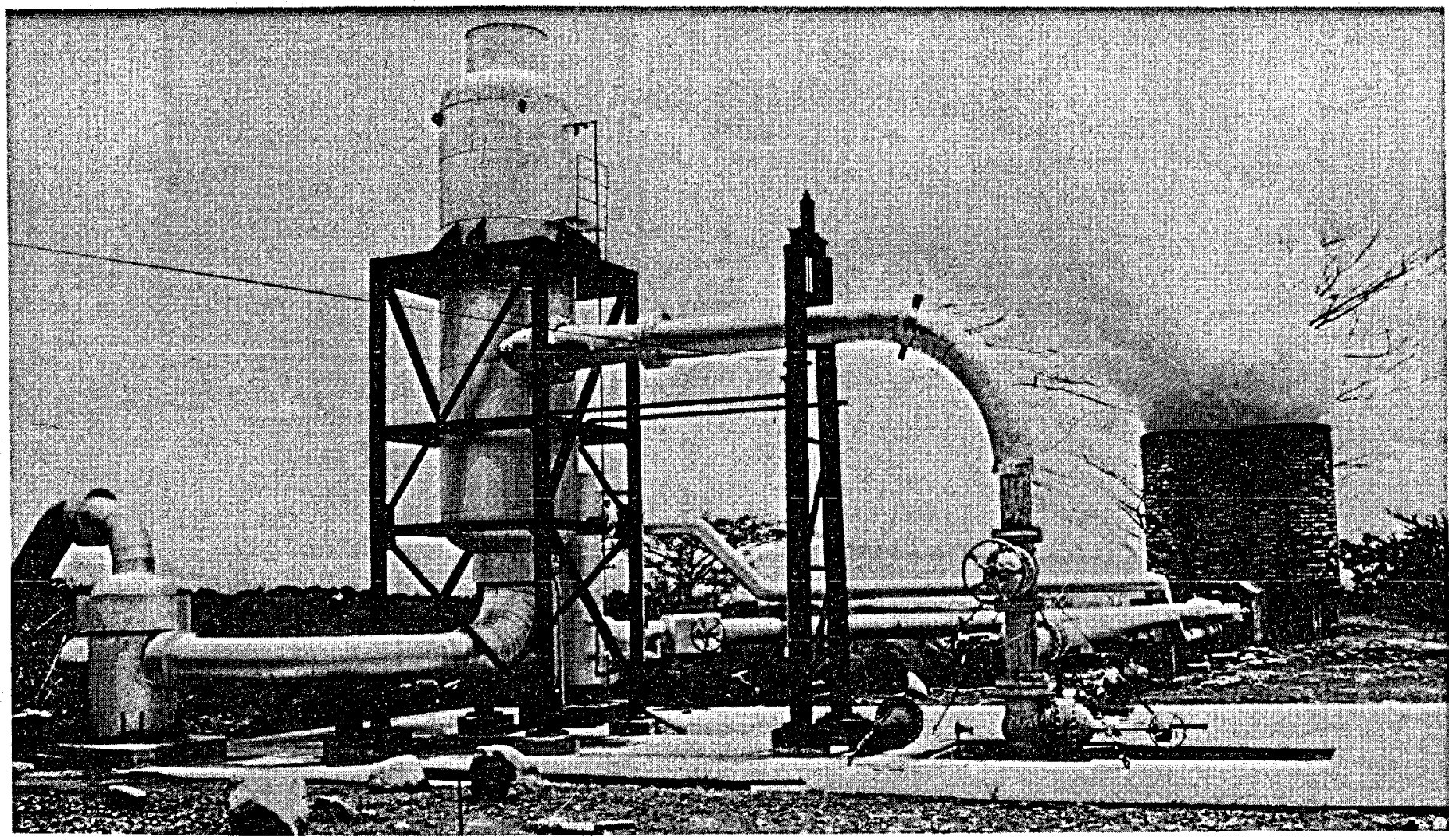

Frouge 10.2-Wellhead equipment for well AH-20. [Photo by R. DiPippo.] 
hydrogen sulfide (12.1\% by volume), with small amounts of hydrogen, nitrogen, ammonia, and methane.

There are two main power units and one auxiliary power unit presently installed at Ahuachapán, and a third unit is under construction. The technical specifications for each of these units may be found in table 10.2.

TABLE 10.2-Technical specifications for Ahuachapan geothermal power plant

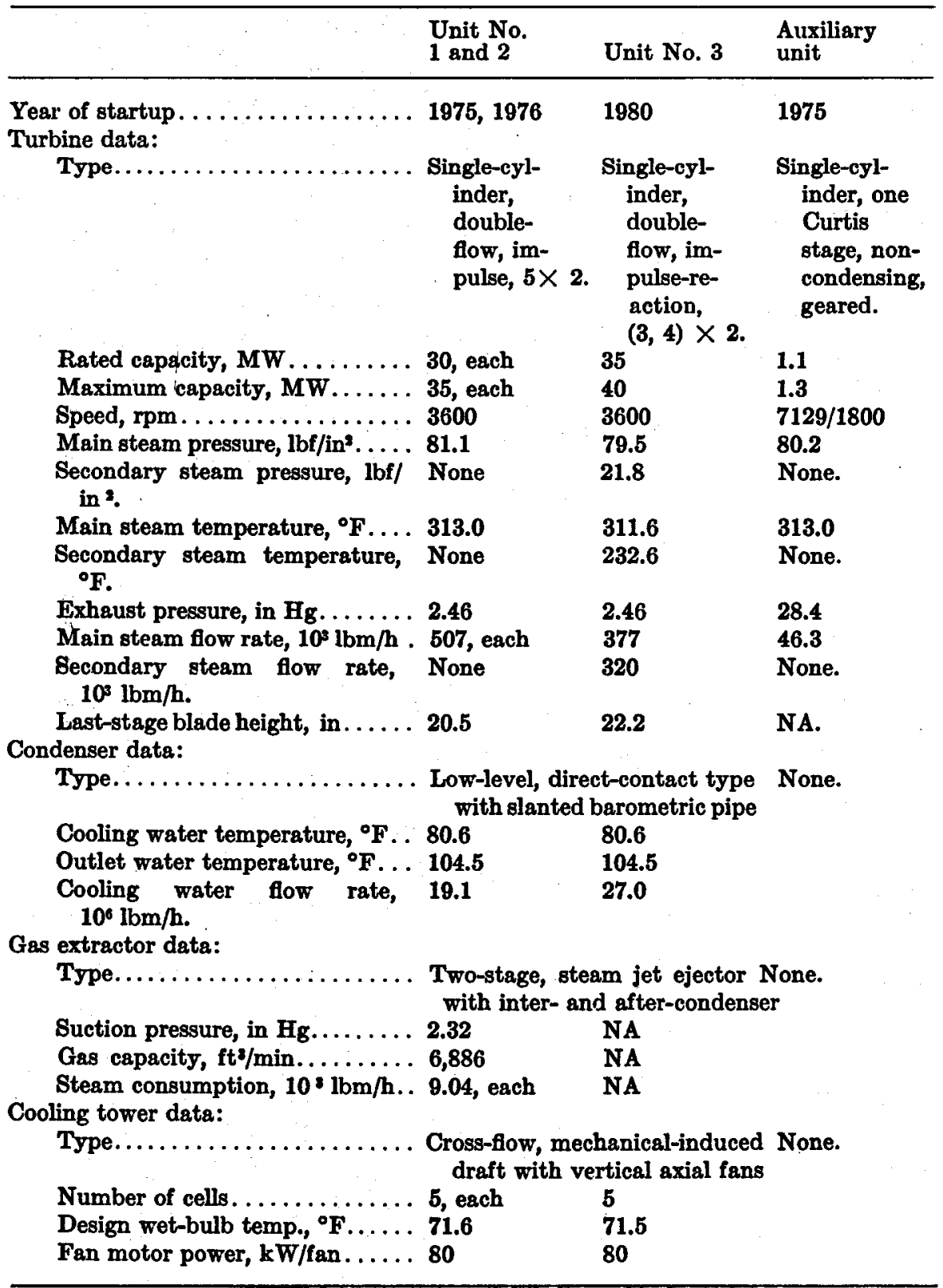


A 1.1 MW, noncondensing geothermal steam unit is used for station start-up from cold conditions. The unit is completely self-contained, requiring neither an external power source nor cooling water. Power is generated from $a$ single Curtis stage fed with separated steam; the lubricating oil is air-cooled. All mechanical, electrical, and control elements are mounted on a single platform.

The two main power units are essentially identical. They are of the separated-steam (or "single-flash") variety. A simplified flow diagram is shown in figure 10.3. Each unit develops $30 \mathrm{MW}$, and employs a 5-stage, double-flow turbine with impulse-reaction blading, mounted in a single housing. Each turbine exhausts to a low-level, direct-contact condenser equipped with a slanted barometric pipe.

The geothermal energy resource.utilization efficiency, $\eta_{u}$, may be found using the well-fiow data quoted earlier, an output of $60 \mathrm{MW}$ (both units combined), and a sink temperature of $22^{\circ} \mathrm{C}\left(71.6^{\circ} \mathrm{F}\right)$ (the design wet-bulb temperature). It turns out that $\eta_{u}=37 \%$ for units No. 1 and 2 combined. The overall steam consumption is about $7.6 \mathrm{~kg} / \mathrm{kW} \cdot \mathrm{h}(16.8 \mathrm{lbm} / \mathrm{kW} \cdot \mathrm{h})$, or $43.6 \mathrm{~kg} / \mathrm{kW} \cdot \mathrm{h}(96.1 \mathrm{lbm} / \mathrm{kW} \cdot \mathrm{h})$ in terms of the total geofluid produced from the reservoir [DiPippo, 1978f].

The third power unit originally was planned to be a $30 \mathrm{MW}$, lowpressure (LP) unit that would have used steam flashed from separated bore liquid. As the field became more developed and confidence in the steam supply grew, it was decided instead to install a dual-pressure unit of 35 MW eapacity to be supplied with medium-pressure (MP) steam from three new wells together with low-pressure (LP) steam flashed from liquid.

A highly simplified flow diagram for unit No. 3 is shown in figure 10.4. The broken lines represent hot water from eight wellhead separators. The liquid is flashed in two horizontal flash tanks, producing LP steam (solid lines) which is added to the turbine at the pass-in section. The MP steam (heavy lines) is scrubbed before entering the first stage of the turbine. Provision is made to flash a portion of the MP steam down to the LP section if necessary. Auxiliary steam (thin lines) is used for turbine gland seals, steam ejectors for gland steam, and noncondensable gas removal [Fuji, 1977].

The turbine will be of the dual-admission, double-flow type in a single housing, with an MP section consisting of three stages of essentially impulse blading followed by an LP section with four impulse-reaction stages. The generator will be air-cooled, rated at $40,000 \mathrm{kVA}, 13.6 \mathrm{kV}$ at $60 \mathrm{~Hz}$ with a 0.875 (lagging) power factor. Construction is underway and completion is expected by the end of 1979 .

The geothermal resource utilization efficiency for the third unit will be about $42 \%$, based on design specifications. Since all three units will be inter-related, the overall plant utilization efficiency, for the three units, will bo approximately $43 \%$, assuming that the thirteen wells which will supply 


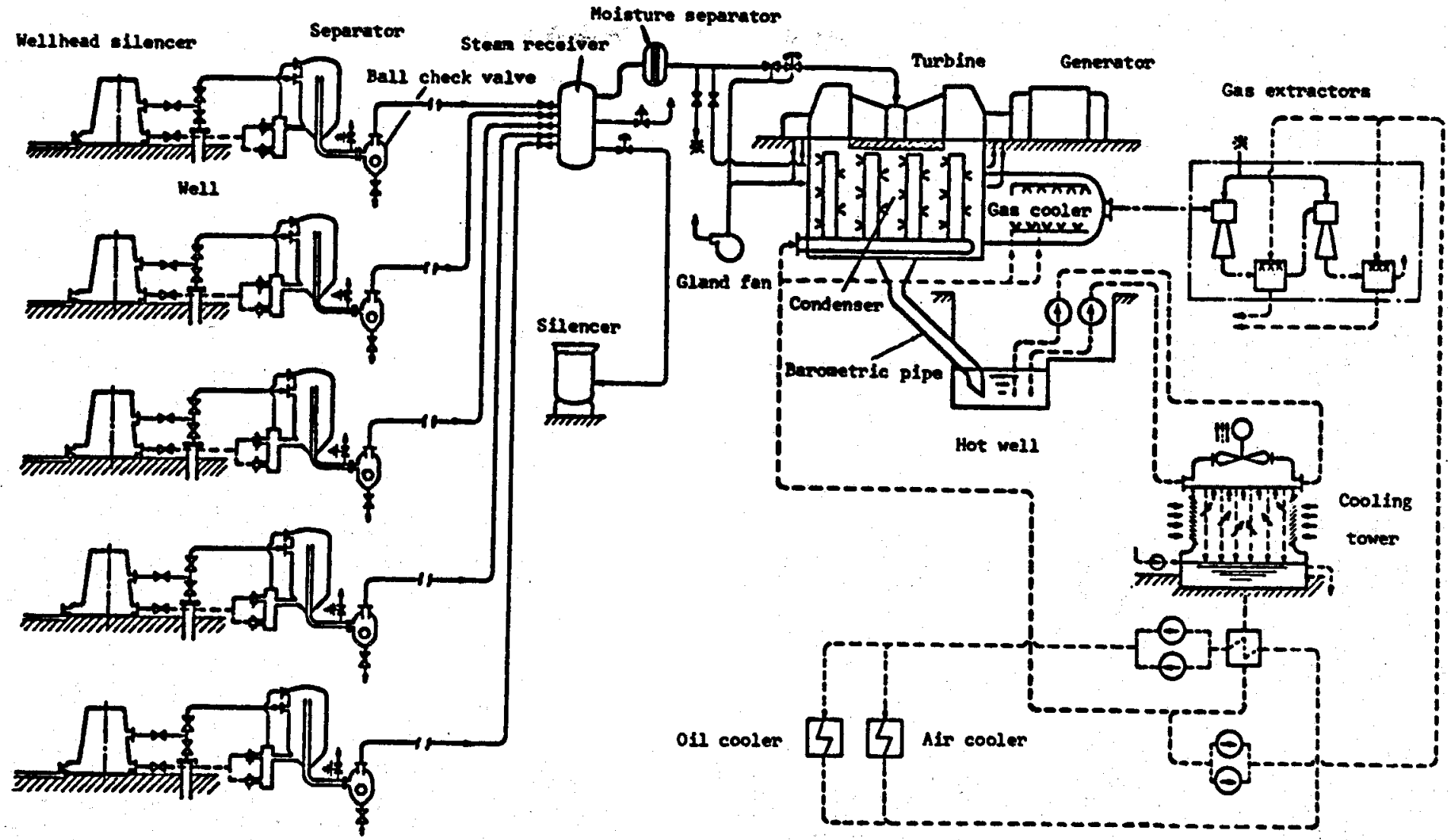

Frodre 10.3-Flow diagram for units No. 1 and 2 at Ahuachapán. 


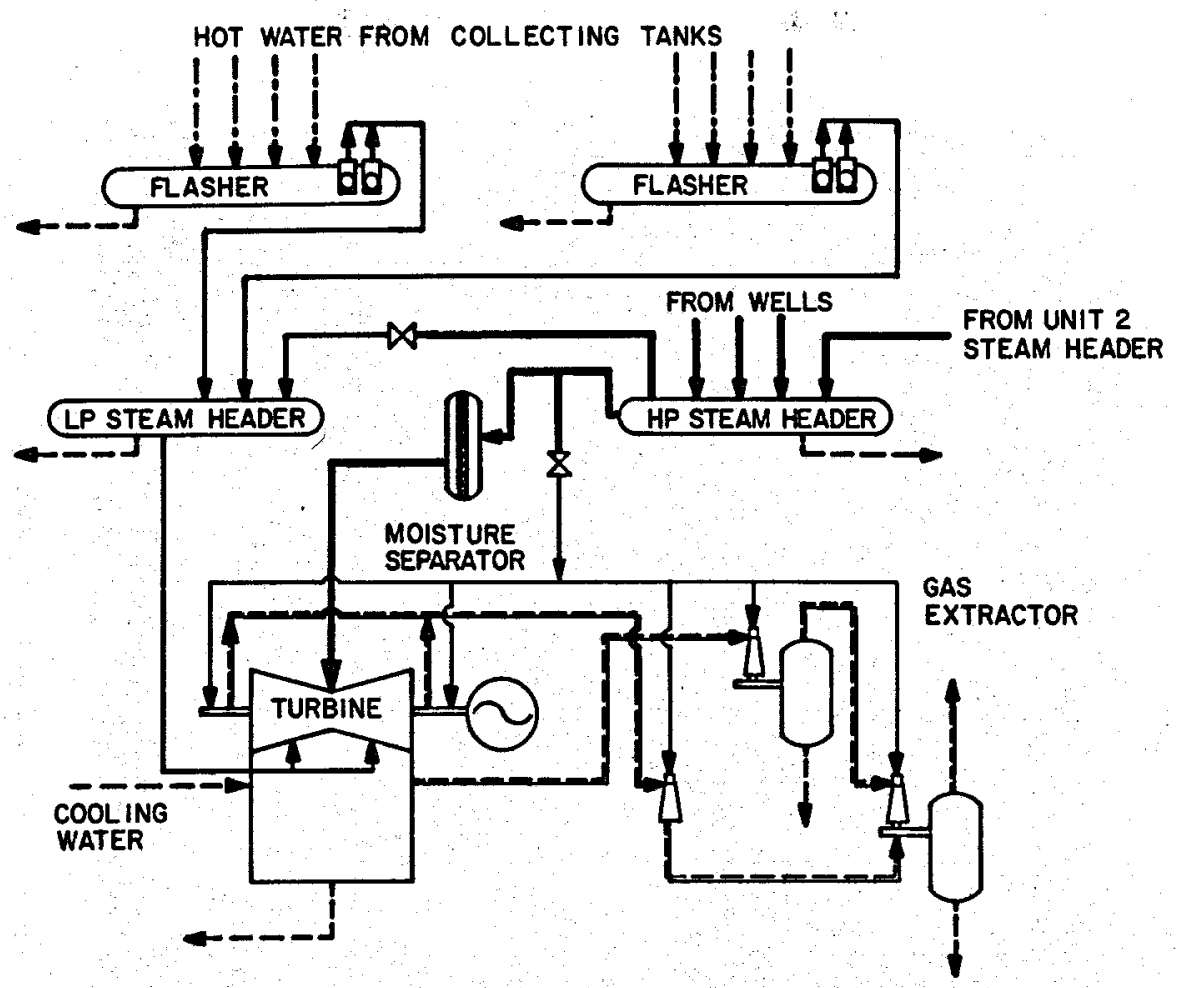

Frgure 10.4-Flow diagram for unit No. 3, under construction at Ahuachapan.

the full plant have the same average conditions of temperature, pressure, and flow rate as the ten wells now serving units No. 1 and 2.

Two methods are used for the disposal of waste liquid from the Ahuachapán plant: reinjection and surface discharge. The temperature of the reinjected liquid is not less than $150^{\circ} \mathrm{C}$, thus avoiding any problems with silica deposition that might otherwise occur at lower temperatures. Over 13 billion kilograms have been returned to the formation since reinjection was begun in 1975 . The liquid is reinjected directly from the separators, at a pressure of about $550 \mathrm{kPa}\left(80 \mathrm{lbf} / \mathrm{in}^{2}\right)$, thus eliminating the need for booster pumps. A portion of the liquid intended for surface disposal via the discharge channel passes first through one of two labyrinth retention tanks which provide 50-60 minutes of hold-up. This provides an effective means of converting monomer silica into polymer silica, thus stabilizing the silica in solution and essentially eliminating silica deposition in the long disposal channel. The photograph in figure 10.5 shows one of the open, cement retention tanks shortly after the silica deposits have been scraped from the walls of the baffles [Cuéllar, 1975; DiPippo, 1978d; Einarsson et al., 1975].

The successful operation of the Ahuachapán plant has made it a dependable link in the electricity supply system of El Salvador. Table 10.3 gives 


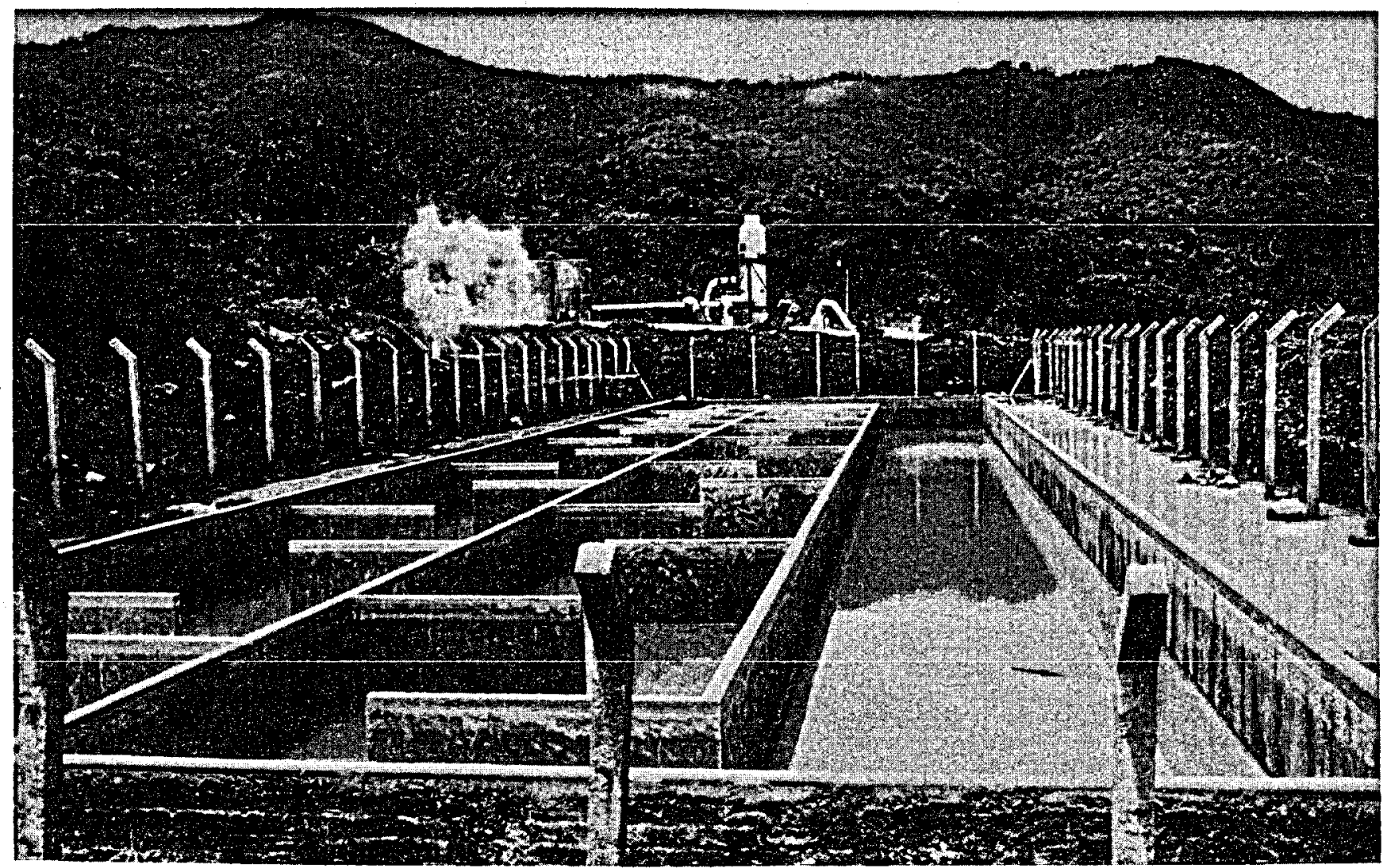

FrguRr 10.5-Baffled retention tank for waste liquid at Ahuachapan; well AH-1 in background. [Photo by R. DiPippo.] 
Table 10.3-Electricity generation at Ahuachapan

\begin{tabular}{|c|c|c|c|}
\hline Year & $\begin{array}{r}\text { Electrical } \\
\text { generation }\end{array}$ & $\begin{array}{r}\text { Capacity factor } \\
\text { (percent) }\end{array}$ & $\begin{array}{r}\text { Percent total } \\
\text { generation }\end{array}$ \\
\hline $\begin{array}{l}1975 . \\
1976 . \\
1977 .\end{array}$ & $\begin{array}{l}31 \mathrm{MW} \cdot \mathrm{h} \\
00 \mathrm{MW} \cdot \mathrm{h} \\
51 \mathrm{MW} \cdot \mathrm{h}\end{array}$ & $\begin{array}{r}47 \\
67 \\
76\end{array}$ & $\begin{array}{l}11.8 \\
25.4 \\
32.3\end{array}$ \\
\hline
\end{tabular}

the total generation, capacity factor, and percentage of total electricity in El Salvador contributed by the Ahuachapán plant since the first unit began operating in June 1975. The geothermal plant has been essentially free of major breakdowns. In 1977 the availability factor was $95 \%$ based on forced outages. This factor is reduced to $84 \%$ when scheduled outages for maintenance are included. A complete overhaul of each power unit is carried out once every two years and takes about one month.

\subsubsection{Other geothermal areas in El Salvador}

Berlin. This field is located in eastern El Salvador, about $90 \mathrm{~km}$ (56 mi) from San Salvador. Exploration took place at Berlín simultaneously with Ahuachapán in 1965 when two deep wells were drilled. The terrain is considerably more rugged than that at Ahuachapan, and this fact influenced the decision to proceed with Ahuachapán for the first geothermal power plant, although the results of the early exploratory studies at Berlín were encouraging. The first deep well was drilled to a depth of about 1800 $m(5900 \mathrm{ft})$ and encountered a temperature of $271^{\circ} \mathrm{C}\left(520^{\circ} \mathrm{F}\right)$. The geofluid at Berlín contains roughly $10,000 \mathrm{ppm}$ of total dissolved solids. Exploration is continuing at Berlin which is expected to be the site of the next (i.e., the fourth) geothermal unit in El Salvador by 1984-1985. The ultimate power capacity of this area is estimated to be $100 \mathrm{MW}$.

Chinameca. This field is about $20 \mathrm{~km}$ (12 mi) east of Berlin and $18 \mathrm{~km}$ (11 mi) west of the city of San Miguel. Exploration is presently underway. It is expected that a geothermal power unit will be operating there by 1985 . This site may eventually support $100 \mathrm{MW}$ of electrical power capacity.

Chipilapa. This area is about $5 \mathrm{~km}(3 \mathrm{mi})$ east of the Ahuachapán geothermal field and was the site of the first deep well drilled in El Salvador. Chipilapa may be part of the same geothermal field as Ahuachapán and is expected to support about 50 MW in the future.

San Vicente. The Sun Vicente geothermal field is located in east-central El Salvador, $50 \mathrm{~km}(31 \mathrm{mi})$ east of San Salvador and $40 \mathrm{~km}(25 \mathrm{mi})$ westnorthwest of Berlín. Extensive exploration activity is taking place. The potential of this site is estimated at $100 \mathrm{MW}$ (G. Cuéllar, personal communication). 


\subsection{Iceland}

\subsubsection{Geological features}

Iceland is perhaps better known for its direct use of geothermal energy in space-heating applications than for geothermal electric power generation. Roughly 65 percent of the population of this island heats its homes with geothermal hot water. Essentially all of the capital city of Reykjavik is heated by means of geothermal water at about $86^{\circ} \mathrm{C}\left(187^{\circ} \mathrm{F}\right)$. Plans call for the expanded use of geothermal hot water to provide up to $80 \%$ of the space-heating needs of the country within the next few years [Lindal, 1977].

There are only a few locations in Iceland where electric power is generated from geothermal resources. For the most part these lie inland and to the northeast, although exploration and the beginning of exploitation are now taking place on the Reykjanes peninsula in southwestern Iceland.

Iceland is situated astride the Mid-Atlantic ridge. The Icelandic graben which sweeps from the north to the southwest through the center of the island exhibits the great tension which exists in the crustal rift zone. Figure 10.6 shows this prominent geological feature along with the major cities and the existing geothermal power plants. It has been observed that the rift zone is separating at a rate of about $2 \mathrm{~cm} / \mathrm{yr}$ [Burke and Wilson, 1976]. A small geothermal plant at Svartsengi near Grindavik

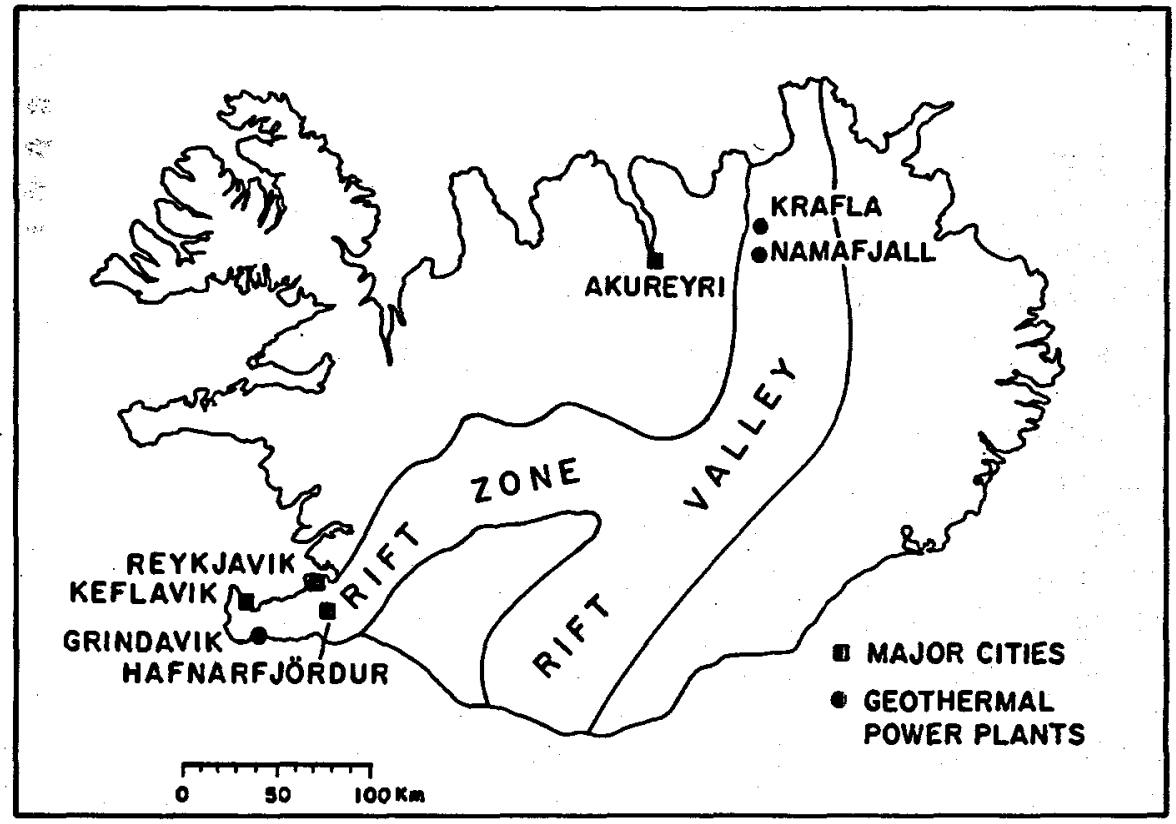

FIGURE: 10.6-Map of Iceland showing rift zones, major cities, and sites of geothermal power plants. 
is at the southwestern extremity of the west branch of the rift valley. The geothermal power plants at Námafjall and Krafla are located within the rift zone at the northern end. The geological structure of these regions is highly unstable, creating serious problems related to well completions, reservoir engineering, and geothermal power production in general.

\subsubsection{Námafjall}

The geothermal power plant at Námafjall is relatively small, having been built to supply electrical power for a diatomite plant at Kisilidjan.* This plant processes diatomaceous earth which is used as a filter aid with geothermal steam obtained from wells at the Námafjall field.

The Námafjall geothermal region has been the site of several projects making use of the thermal anomaly in the region. Wells had been drilled to permit the extraction of sulfur from the hydrogen sulfide which constitutes a portion of the geofluid. This mining operation gave rise to the name "Námafjall" which means "the mountain of the mines" [Ragnars et al., 1970].

The Námafjall thermal area covers about 400-500 ha (988-1235 acres), but is part of a much larger thermal region, including Krafla, which extends over 5000 ha $(12,350$ acres $)$. An abundance of surface thermal manifestations are found there including boiling mud pools, steaming ground, and fumaroles. The area is highly fractured with fissures and faults trending north-northeast/south-southwest. The rocks found there are of the silicic volcanic type and range in composition from basaltic andesites to rhyolites.

The arrangement of the wells relative to the power plant and the adjacent diatomite plant is shown in figure 10.7. A number of shallow wells (not shown) were drilled during 1947-1953 for sulphur mining. The present production wells were begun in 1963 , with the first of these, $\mathrm{N} 1$, having been completed in 1966, followed by $\mathrm{N} 2$ and N3 in 1968. The wells are located along two faults and are separated by about $90 \mathrm{~m}(295$ $\mathrm{ft})$. Since the uppermost $180 \mathrm{~m}(590 \mathrm{ft})$ of the formation are permeable, loss of circulation is often encountered during the shallow drilling phase. Repeated cementing is required to prevent the wells from collapsing. It was found necessary to install a U-pipe separator on each wellhead because of sand, mud, pebbles, and other solid material which is ejected occasionally from the wells. Conventional cyclone separators are used to separate the vapor and liquid phases of the geofluid.

The geothermal fluid carries with it an amount of noncondensable gases equal to about $1 \%$ (by weight) of the steam flow. The composition (by volume) of the noncondensible gases is roughly as follows: hydrogen sul-

\footnotetext{
*Power is no longer being generated at the plant. Volcanic activity has damaged the wells to the extent that sufficient steam is available only to supply the diatomite plant.
} 


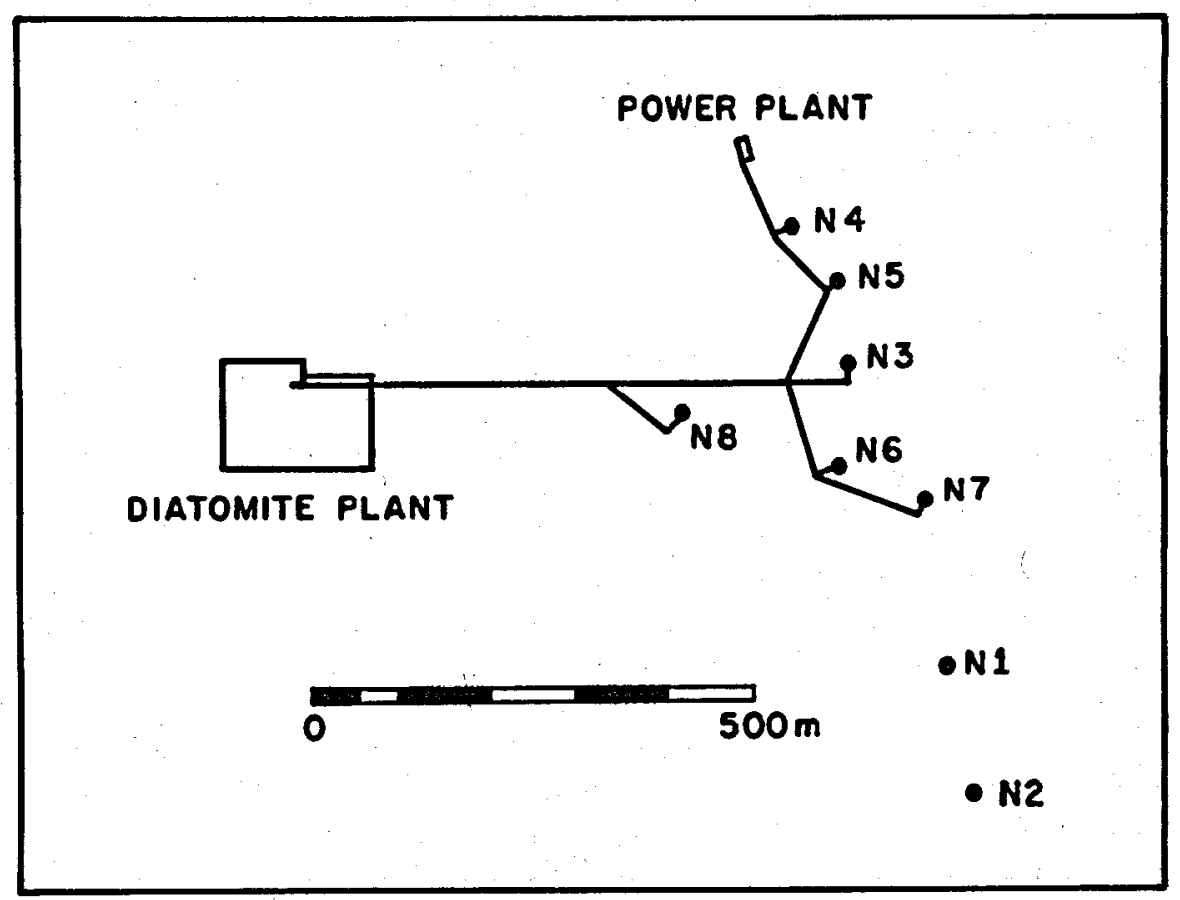

Frauke 10.7-Arrangement of wells at Námafjall to serve diatomite processing plant and 3.0 MW, noncondensing power unit [after Raguars, et al., 1970].

fide, $52 \%$; carbon dioxide, $32 \%$; hydrogen, $12 \%$; other gases such as nitrogen, methane, argon, etc., 4\% [Bjornsson, 1968]. The total dissolved solids in the liquid (down-hole) is about $1000 \mathrm{ppm}$, nearly $60 \%$ of which is silica. Down-hole temperatures of nearly $300^{\circ} \mathrm{C}\left(572^{\circ} \mathrm{F}\right)$ have been observed; normal steam delivery temperature is about $183^{\circ} \mathrm{C}\left(361^{\circ} \mathrm{F}\right)$. Each well produces about $25 \mathrm{t} / \mathrm{h}(55,000 \mathrm{lbm} / \mathrm{h})$ of separated steam at a pressure of $1078 \mathrm{kPa}\left(156 \mathrm{lbf} / \mathrm{in}^{2}\right)$.

The power plant uses a turbine of the noncondensing type with a nominal capacity of 3.0 MW. Because of the noncondensing turbine, the plant has a low resource utilization efficiency. On the assumption that $20 \%$ of the geofluid is vapor at the wellhead, and that the appropriate ambient sink temperature for the region is $11^{\circ} \mathrm{C}\left(51.8^{\circ} \mathrm{F}\right)$, then the utilization efficiency would be $14 \%$, and the plant would consume $82.5 \mathrm{~kg}$ of geofluid/ $\mathrm{kW} \cdot \mathrm{h}(182 \mathrm{lbm} / \mathrm{kW} \cdot \mathrm{h})$. The technical specifications for the Námafjall unit may be found in table 10.4 .

\subsubsection{Krafia}

The geothermal power plant at Krafla is the first major power station of its type in Iceland. The plant is a state-of-the-art design incorporating 
TABLE 10.4.-Technical specifications for Icelandic geothermal power stations

\begin{tabular}{|c|c|c|c|}
\hline & Námafjall & Krafla unit 1" & Svartsengi \\
\hline $\begin{array}{l}\text { Year of startup. } \ldots \ldots \ldots \ldots \ldots \ldots \cdots \\
\text { Turbine data: }\end{array}$ & 1969 & 1977 & 1978 \\
\hline Type.................... & $\begin{array}{l}\text { Single-cylin- } \\
\text { der, one } \\
\text { Curtis } \\
\text { strge, non- } \\
\text { condensing. }\end{array}$ & $\begin{array}{l}\text { Single-cylin- } \\
\text { der, double- } \\
\text { flow, dual- } \\
\text { admission, } \\
\text { impulse- } \\
\text { reaction. }\end{array}$ & $\begin{array}{l}\text { AEG-KANIS } \\
\text { type GT-63, } \\
\text { geared. }\end{array}$ \\
\hline Rated capacit & $\mathbf{3 . 0}$ & 30.0 & 1.0 \\
\hline Maxi & 3.4 & 35.0 & 1.0 \\
\hline$\ldots \ldots \ldots \ldots$ & 3000 & 3000 & $4479 / 1500$ \\
\hline Main steam pressure, $\mathrm{lbf} / \mathrm{in}^{2}$. . . & 142.7 & 110.0 & 78.3 \\
\hline $\begin{array}{l}\text { Main steam temperature, }{ }^{\circ} \mathrm{F} . \ldots \\
\text { Secondary steam pressure, } 1 \mathrm{bf} / \mathrm{in}^{*} \text {. } \\
\text { Secondary steam temperature, }{ }^{\circ} \mathrm{F} \text {. }\end{array}$ & 354.5 & $\begin{array}{l}334.4 \\
27.5 \\
244.4\end{array}$ & 311.0 \\
\hline Exhaust pressure, in $\mathrm{Hg} . . . \ldots$. & 31.4 & 3.5 & 50.2 \\
\hline Main steam flow rate, $10^{\circ} \mathrm{lbm} / \mathrm{h}$. . & 100 & 417 & \\
\hline $\begin{array}{l}\text { Secondary steam flow rate, } \\
10^{\circ} \mathrm{lbm} / \mathrm{h} \text {. }\end{array}$ & & 142 & \\
\hline ndenser data: & & & \\
\hline Trome & None & $\begin{array}{l}\text { Low-level, } \\
\text { direct-con- } \\
\text { tact, tray- } \\
\text { type. }\end{array}$ & None. \\
\hline $\begin{array}{l}\text { Cooling water temperature, }{ }^{\circ} \mathrm{F} . . \\
\text { Outlet water temperature, } \\
\text { Cooling water fow rate, } \\
10^{\circ} \mathrm{lbm} / \mathrm{h} .\end{array}$ & & $\begin{array}{l}71.6 \\
115.2 \\
12.4\end{array}$ & \\
\hline
\end{tabular}

- Krafla unit 2 is identical to unit 1 and is under construction.

a secondary flash process to general additional steam for power generation from liquid which would otherwise be wasted.

As can be seen from figure 10.6, Krafla lies in the same volcanic rift zone as Námafjall. The Krafla area was most recently subjected to a series of strong seismic events. In July 1975 earthquake tremors were detected. Gradually these increased in strength, and on December 20, 1975, lava burst out in Leirhnjukikur, only $3 \mathrm{~km}(2 \mathrm{mi})$ from the site of the Krafla plant. Although the lava flow lasted only a few hours, steam continued to erupt until the end of the year. During this period, 2000-4000 earth tremors were recorded each day.

During the first three months of 1976, there occurred seven earthquakes of magnitude greater than 4.0 on the Richter scale, with two of these exceeding magnitude 5.0. All of these were centered within a few kilometers of the plant site. By June 1976 most of the activity had ceased, but continuous vigilance is carried out by means of seismic monitors and field observations [Sólnes, 1976]. 


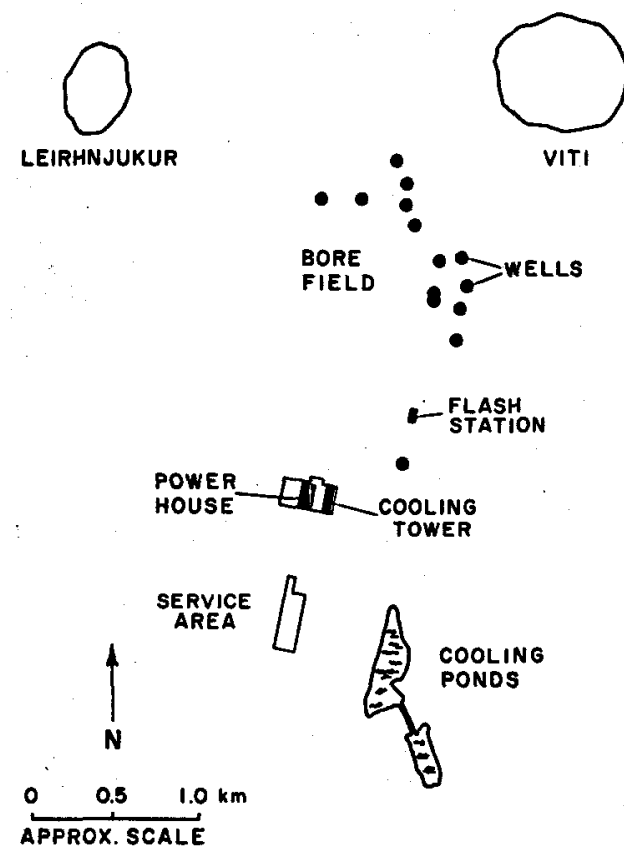

FiaURE 10.8 - Arrangement of Krafla geothermal power plant and steam wells [after Soblnes, $1976]$.

A plan view of the power station site is given in figure 10.8 which shows the locations of the power house, cooling tower, cooling pond, and proposed wells. The locations of the wells are tentative and subject to change. Also shown in the figure are the sites of recent volcanic activity, Leirhnjúkur, mentioned earlier, and Víti ("Hell") a crater which was formed at the beginning of the "Fires of Mývatn" in 1724. The proximity of these centers of volcanic action to the Krafla bore field is evident.

The plant is of the separated/single-flash (or "double-flash") steam type. A highly-simplified flow diagram for the plant is shown in figure 10.9. Only one typical wellhead is depicted; there may be five or six wells required for each turbo-generator unit. There is one $30 \mathrm{MW}$ unit currently installed at Krafla and another at the site awaiting installation although there is insufficient steam available at this time to supply even one unit fully. The technical specifications for the Krafla units are listed in table 10.4 [MHI, 1978c].

Very little information is available on the operation of the plant. It is known that trouble has been encountered with the production wells. Although the geofluid is relatively clean (TDS $1000 \mathrm{ppm}$ with about 650 ppm silica), the wells have been subject to clogging. Two plugs seem to develop: a deep plug of iron sulfide, and a shallow plug of calcium carbonate. It seems evident that the cause of the poor production from the wells is the presence of these deposits in the boreholes, rather than the collapsing of the formation from earthquake activity as was earlier thought to be the case (J.T. Kuwada, personal communication). 


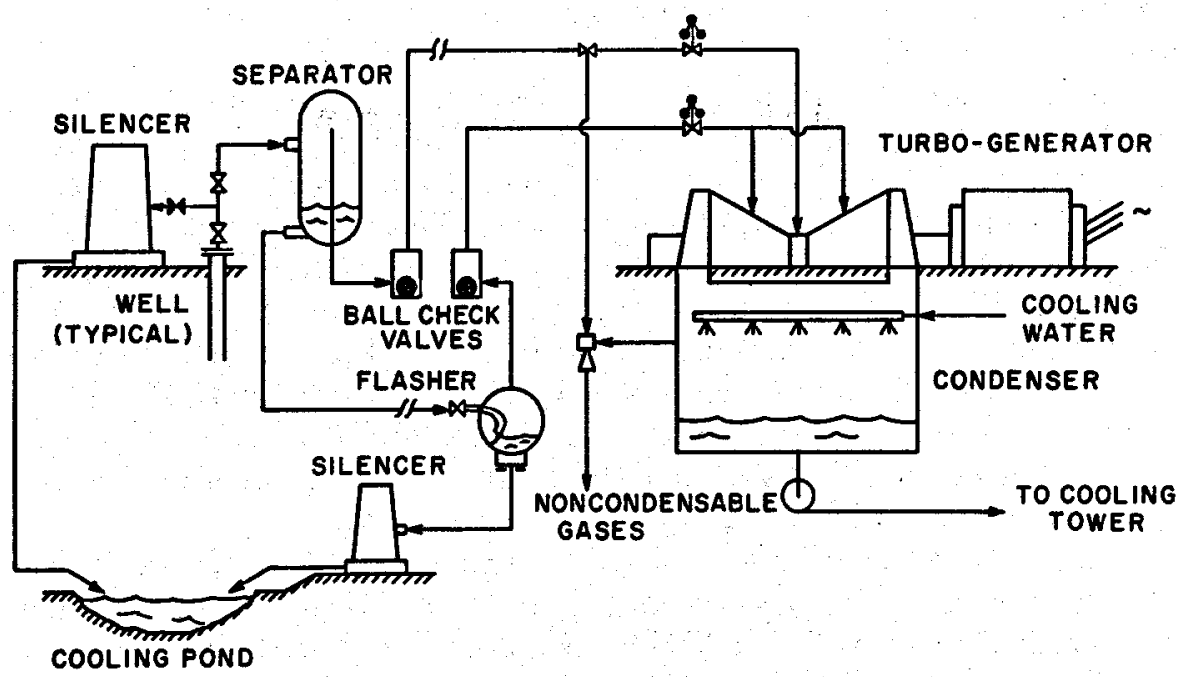

FrguRe 10.9-Simplified flow diagram for Krafla geothermal power station.

\subsubsection{Svartsengi}

The greatest success in utilizing geothermal energy in Iceland is being achieved in the form of direct heating of water for residential and commercial use. A small power plant is contributing to this use. There are two $1 \mathrm{MW}$ geothermal steam turbines installed as part of the Sudurnes District Heating Plant at Svartsengi near Grindavik on the Reykjanes peninsula in southwestern Iceland. The plant supplies hot water at $85^{\circ} \mathrm{C}$ $\left(185^{\circ} \mathrm{F}\right)$ to the 12,000 inhabitants of the area, and there are plans to supply water at $125^{\circ} \mathrm{C}\left(257^{\circ} \mathrm{F}\right)$ to more distant communities.

The bottomhole temperature is $235^{\circ} \mathrm{C}\left(455^{\circ} \mathrm{F}\right)$; the steam temperature at turbine inlet is $155^{\circ} \mathrm{C}\left(311^{\circ} \mathrm{F}\right)$. The power unit is integrated into the hot water plant: it generates power for use on the site and the exhaust steam from the back-pressure turbines is used to supply a portion of the heat needed to raise the temperature of the water prior to distribution. Table 10.4 contains some technical information about the power units [Gudmundsson, 1979].

\subsection{Italy}

\subsubsection{Overview}

Documentation exists which shows that the natural steam fields in Tuscany were recognized as early as the 3rd century, and that the commercial potential of these mineral-laden waters led to wars between the Tuscan republics during the Middle Ages [ENEL, 1970]. It was not until 1904, however, that the power of natural steam was first harnessed to pro- 
duce electricity, the accomplishment of this feat being credited to Prince Piero Ginori Conti.

Conti's original system used a reciprocating engine which recejved steam separated from the geothermal fluid. The engine was of the noncondensing type, exhausted to the atmosphere, and generated about $15 \mathrm{~kW}$ of electric power. The output from the DC generator provided lighting for the boric acid factory at Larderello in the boraciferous region of Italy. This primitive engine was replaced by a turbo-alternator of $250 \mathrm{~kW}$ capacity in 1913, thus marking the beginning of the production of electricity from geothermal sources on a commercial scale [Conti, 1924].

Since that time endogenous fluid has been tapped at two other sites, Monte Amiata and Travale, and the total installed geothermal electric generating capacity in Italy has grown to $420,000 \mathrm{~kW}$.

In the following sections we will summarize some of the geological features of the main geothermal regions currently under exploitation, Larderello, Monte Amiata and Travale, and discuss briefly the technical details related to the gathering and distribution of the geothermal fluid, the energy conversion systems, and the reliability of the plants.

\subsubsection{Larderello (Boraciferous Region)}

The Larderello region in general structural terms corresponds to a tectonic high located between the Era graben to the north and northwest and the positive feature of the crystalline basement which is evident in outcroppings to the south and southeast [ENEL, 1970]. The presence of a deep magmatic intrusion at about 6-8 $\mathrm{km} \mathrm{(4-5} \mathrm{mi)} \mathrm{is} \mathrm{inferred} \mathrm{from} \mathrm{a} \mathrm{huge}$ gravity deficit.

The high heat flow in the region is generated by the gross interaction between the African and Eurasian tectonic plates and several smaller plates which are in contact in the area. Heat flow, thermal gradients, and thermal conductivity measurements have also been employed as prospecting tools. The area is characterized by exceptionally high thermal gradients, being of the order of $30^{\circ} \mathrm{C} / 100 \mathrm{~m}\left(16^{\circ} \mathrm{F} / 100 \mathrm{ft}\right)$ and in some places, as high as $100^{\circ} \mathrm{C} / 100 \mathrm{~m}\left(55^{\circ} \mathrm{F} / 100 \mathrm{ft}\right)$. These should be compared with the accepted normal gradient of about $3^{\circ} \mathrm{C} / 100 \mathrm{~m}\left(1.6^{\circ} \mathrm{F} / 100 \mathrm{ft}\right)$. The geothermal field at Larderello is believed to cover about 25,000 ha $(62,000$ acres) [Koenig, 1973], although the drilled area extends over only about 18,500 ha (45,700 acres) [Ceron et al., 1975; Ellis and Mahon, 1977].

There are roughly 190 producing wells in the Larderello region out of a total of 511 drilled [Overton and Hanold, 1977]. The average depth of all wells is $656 \mathrm{~m}$ (2152 ft); wells drilled since 1969 average $1129 \mathrm{~m}$ (3704 $\mathrm{ft}$ ) in depth [Ceron et al., 1975]. A typical well produces natural steam through a $311 \mathrm{~mm}$ (121/4 in) open hole and a $340 \mathrm{~mm}$ (133/8 in) casing which is cemented within a $406 \mathrm{~mm}$ (16 in hole). Deeper wells typically have a $216 \mathrm{~mm}\left(8 \frac{1}{2} \mathrm{in}\right)$. open hole throughout the permeable zone with a 
$244 \mathrm{~mm}(95 / 8 \mathrm{in})$ production casing. In this case the $340 \mathrm{~mm}(133 / 8$ in) casing serves as an intermediate casing for safety purposes. The casings are J-55 API heavy wall pipe to withstand the corrosive nature of the geothermal fluid and the severe temperature cycling to which the wells may be subjected. The cement used for wells at Larderello consists of a mixture of Portland 425 cement and a fine-grained silica flour, in 60-40 proportions.

Geothermal steam is transported across the sloping landscape of Larderello in a network of over $118 \mathrm{~km}(73 \mathrm{mi})$ of weldable steel pipes from the individual wells to a number of power plants of relatively small electrical generating capacity. The pipes have wall thicknesses of 6-8 $\mathrm{mm}$ (0.24-0.31 in), have diameters of $250,350,450,650$ and $810 \mathrm{~mm}(10,14$, 18,26 and 32 in), and are insulated with asbestos fiber of thickness ranging from 30 to $120 \mathrm{~mm}(1.2-4.7$ in) [DiMario, 1961].

The steam at Larderello contains about $5 \%$ (by weight) $\mathrm{CO}_{2}$, and $0.5 \%$ $\mathrm{H}_{2} \mathrm{~S}$. It is produced at temperatures ranging from $140-220^{\circ} \mathrm{C}\left(285-430^{\circ} \mathrm{F}\right)$ and at pressures of $200-700 \mathrm{kPa}\left(29-102 \mathrm{lbf} / \mathrm{in}^{2}\right)$. Maximum flow rates vary from $50-100 \mathrm{t} / \mathrm{h}\left(110-220 \times 10^{3} \mathrm{lbm} / \mathrm{h}\right)$. Although a few wells have delivered as much as $300 \mathrm{t} / \mathrm{h}\left(660 \times 10^{3} \mathrm{lbm} / \mathrm{h}\right)$, the average flow from all wells at Larderello is about $17 \mathrm{t} / \mathrm{h}(37,500 \mathrm{lbm} / \mathrm{h})$ [Ceron et al., 1975].

There have been three types of energy conversion systems used in the Italian geothermal plants. These are referred to by the Italians as "Cycle 1, " "Cycle 2," and "Cycle 3," and are depicted schematically in figure 10.10, as (a), (b), and (c), respectively.

Cycle 1 plants are installed at locations which either have high noncondensable gas content in the geothermal steam or are not sufficiently developed to justify the construction of steam lines to join the field to the main network. Such plants are extremely simple, highly reliable, easily assembled or disassembled, and offer low costs because they may be remote controlled from a nearby power station.

Cycle 2 plants were used when it was desirable and economic to extract chemicals, such as boric acid and ammonia, from the geothermal fluid while at the same time avoiding materials corrosion problems in the turbine and taking advantage of the improved power output associated with condensing operation. However, considerable difficulty was encountered in the operation of the heat exchangers because the water tubes which formed the boiler section were subject to deposits of iron sulfide or breakage depending on whether iron or aluminum was used for the tube material. Since chemicals are no longer extracted from the fluids and the problems of corrosion of turbine blades can be avoided, this energy conversion scheme has been eliminated.

Cycle 3 plants form the mainstay of the Italian geothermal plants. The effects of impurities or corrosive substances in the steam can be reduced by scrubbers located upstream of the turbine inlet. Pure water or alkaline solutions may be injected to wash the steam; axial separators then 


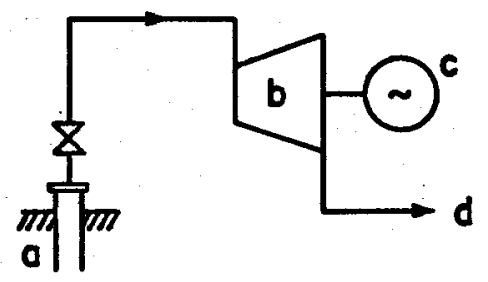

(a)

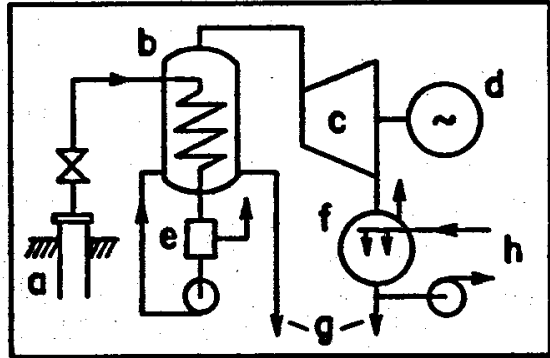

(b)

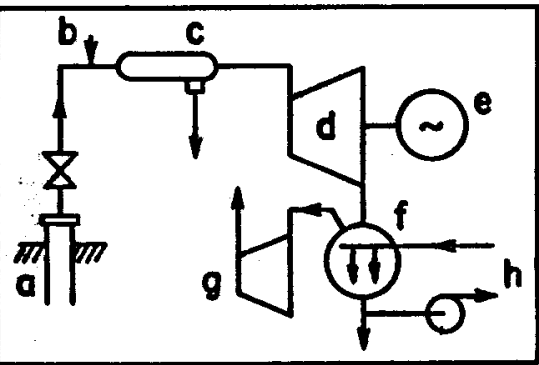

(c)
Figure 10.10-Energy conversiou schemes at Larderello. (a) Direct-intake, noncondensing, "Cycle 1" plant: $a=$ steam well, $b=$ turbine, $c=$ generator, $d=e x$ haust to atmosphere. (b) Pure-steam, condensing, "Cycle 2" plant: $a=$ steam well, $b=$ heat exchanger, $c=$ turbine, $d=$ generator, $e=$ degassing plant, $f=$ condenser, $\mathrm{g}=$ liquid discharge, $\mathrm{h}=$ to and from cooling tower. (c) Direct-intake, condensing, "Cycle 3" plant: $a=$ steam well, $b=$ water injection (scrubber), $c=$ axial separator, $d=$ turbine, $e=$ generator, $f=$ condenser, $g=$ gas compressor, $h=$ to and from cooling tower.

remove the injected liquid prior to admission into the turbine. The large amount of noncondensable gases in the steam requires the use of highcapacity turbocompressors to remove the gases from the condensers.

Power is produced at the present time in Larderello by means of energy conversion systems of the "Cycle 1 " and "Cycle 3" types. Prior to 1968, "Cycle 2" plants were also in operation. The schematic layout diagram of figure 10.11 shows a typical arrangement for a Cycle 3 power unit. Of particular interest are the three stages of intercooling used with the gas compressor, the first stage of which is integral with the condenser.

A typical flow diagram for a $14.8 \mathrm{MW}$ (gross), 13.4 MW (net) power unit is given in figure 10.12. The geothermal resource utilization efficiency, based on the available work of the geofluid relative to the design wet-bulb temperature of $19.4^{\circ} \mathrm{C}\left(67^{\circ} \mathrm{F}\right)$, is about $52 \%$. However, none of the actual 


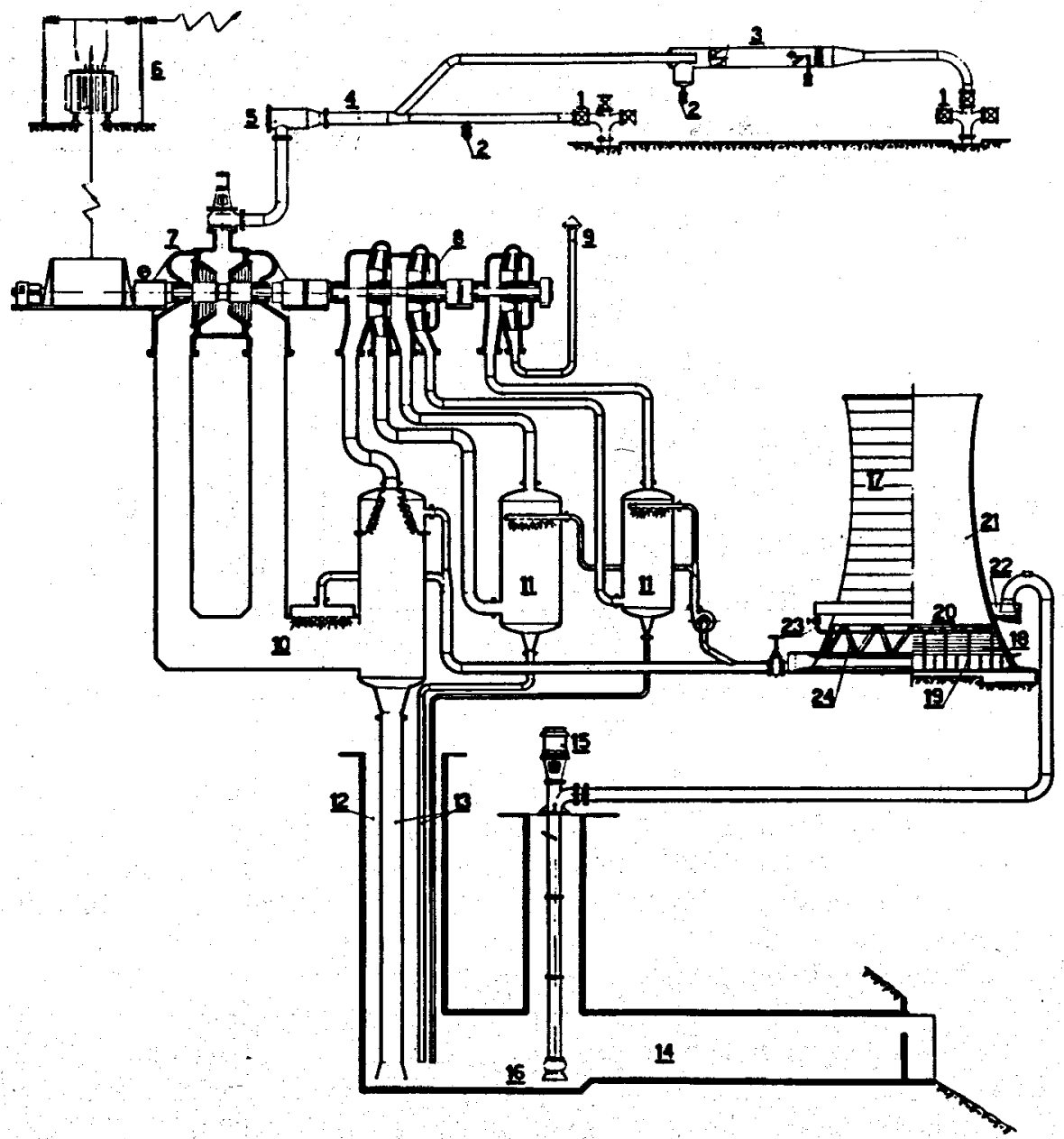

Frauke 10.11-Typical arrangement for a "Oycle 3" power unit at Larderello [Allegrini and Benvenuti, 1970].

units operating at Larderello have efficiencies as high as this; the highest actual efficiency was $47.4 \%$ for the two units located at the Sasso Pisano geothermal field [DiPippo, 1978e].

Table 10.5 gives a summary of the technical particulars for geothermal power stations in the Larderello region which are equipped with condensing steam turbines. Table 10.6 contains similar information on noncondensing units in the same region. Figure 10.13 shows the turbine hall at Castelnuovo where $26 \mathrm{MW}$ of electrical generating capacity are installed.

\subsubsection{Monte Amiata}

The Monte Amiata geothermal region is located about $70 \mathrm{~km}$ (44 mi) southeast of Larderello. Although the geology of the site is similar to that 


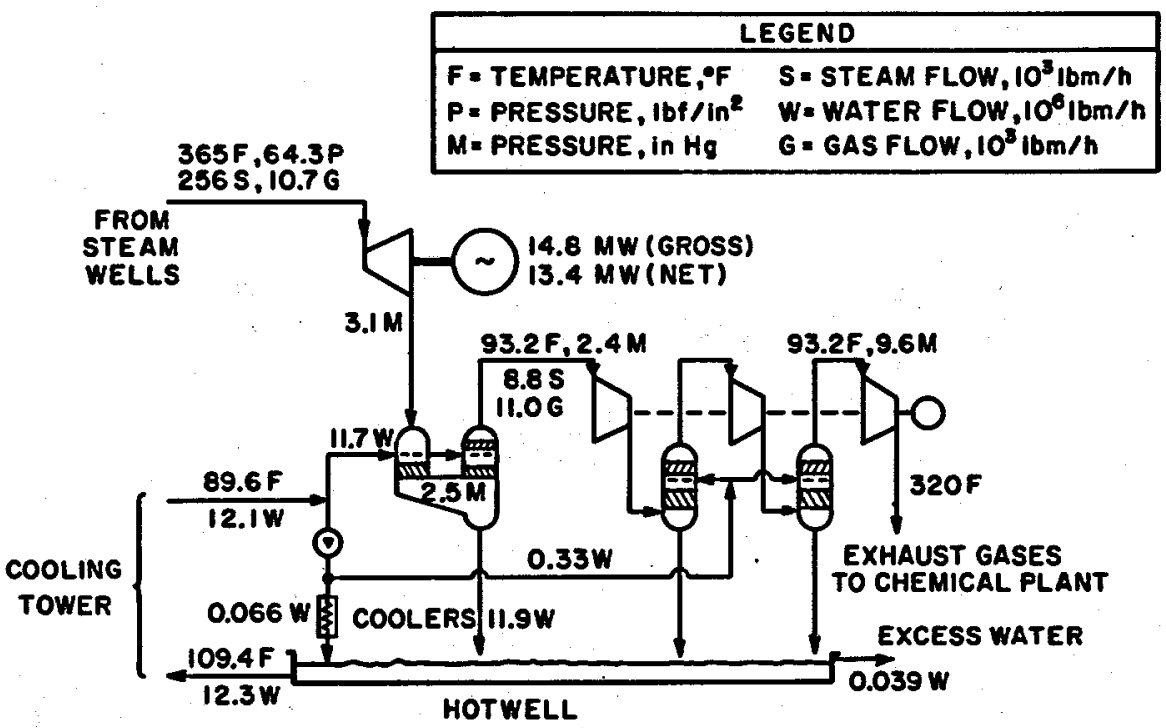

Frauke 10.12-Typical flow diagram for "Cycle 3" power unit with $14.8 \mathrm{MW}$ installed capacity [Dal Secco, 1970].

of Larderello, there are a few noteworthy differences. The Monte Amiata area is marked by magmatic extrusions, a feature absent at Larderello. Unlike the case at Larderello, there are relatively few outcroppings of the main aquifer complex. The main source of recharge fluid for the reservoir is the pervious volcanic formation which is linked to the aquifer by fractures, extrusion chimneys, and volcano-tectonic faults.

The two areas of the Monte Amiata field at which power plants are loceated, Bagnore and Piancastagnaio, are characterized by extremely high thermal gradients of about $50^{\circ} \mathrm{C} / 100 \mathrm{~m}\left(27^{\circ} \mathrm{F} / 100 \mathrm{ft}\right)$, nearly seventeen times the normal gradient. The gradient exceeds $10^{\circ} \mathrm{C} / 100 \mathrm{~m}\left(5.5^{\circ} \mathrm{F} / 100\right.$ $\mathrm{ft})$ over a wide area of $40,000 \mathrm{ha}(100,000$ acres) [ENEL, 1970].

The wells in this region produce dry, slightly superheated steam as at Larderello, but at generally lower temperatures. The steam temperature in the Bagnore area averages about $138^{\circ} \mathrm{C}\left(280^{\circ} \mathrm{F}\right)$ whereas the temperature at Piancastagnaio is $183^{\circ} \mathrm{C}\left(361^{\circ} \mathrm{F}\right)$. At the present time, closed-in wells at Bagnore and Piancastagnaio have pressures $588 \mathrm{kPa}\left(85 \mathrm{lbf} / \mathrm{in}^{2}\right)$ and $1961 \mathrm{kPa}\left(284 \mathrm{lbf} / \mathrm{in}^{2}\right)$, respectively. Wellhead operating pressures at the two sites are about $309 \mathrm{kPa}\left(45 \mathrm{lbf} / \mathrm{in}^{2}\right)$ and $804 \mathrm{kPa}\left(117 \mathrm{lbf} / \mathrm{in}^{2}\right)$.

The amount of noncondensable gas in the geothermal steam is significantly more than for the case of Larderello. At the time the field was being developed, gas content exceeded $90 \%$ (by weight) of the natural vapors. The earliest power plants encountered "steam" that contained between $30-80 \%$ (by weight) of noncondensables. This percentage has declined 


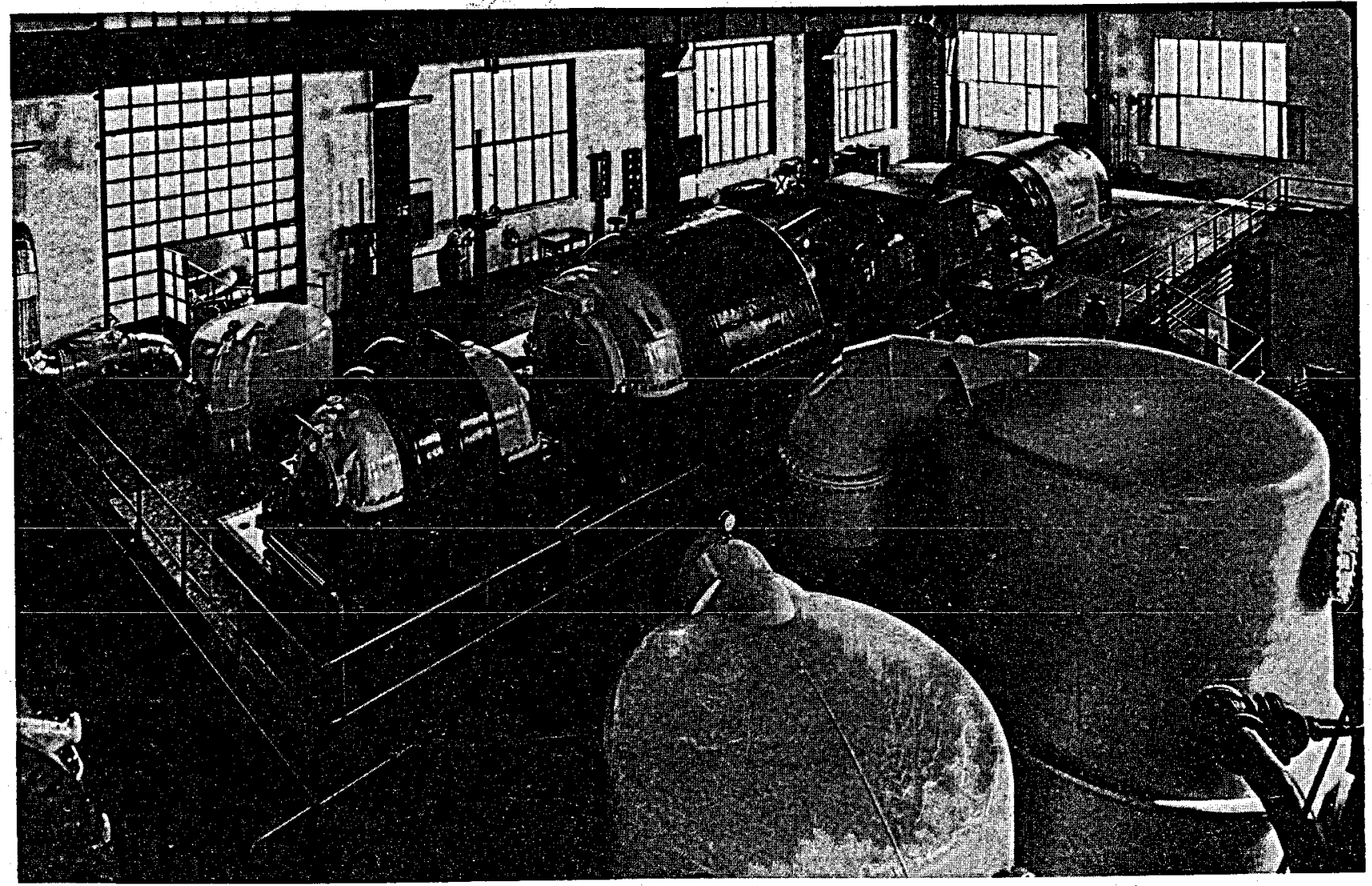


TABLE 10.5-Pover system specifications for condensing units in the Boraciferous region of Italy

\begin{tabular}{|c|c|c|c|c|c|c|c|c|c|c|c|}
\hline & (A) & (B) & (C) & (D) & (E) & (F) & (G) & $(\mathbf{H})$ & (I) & (J) & (K) \\
\hline Year of startup............... & 1938 & $1952-54$ & 1969 & 1967 & 1967 & 1967 & NA & 1960 & 1960 & NA & NA \\
\hline \multicolumn{12}{|l|}{ Turbine dats: } \\
\hline Type............. & (1) & (1) & (2) & (1) & (1) & (1) & $(2)$ & $(3)$ & $(1)$ & $\left({ }^{2}\right)$ & (1) \\
\hline Installed capacity, MW . . . . . . . . & 469 & s. 120 & 15 & 26 & 11 & 2 & 47 & 6.5 & 727 & 815.7 & 12.5 \\
\hline Speed, rev/min $\ldots \ldots \ldots \ldots \ldots$ & 3000 & 3000 & 3000 & 3000 & 3000 & 3000 & 3000 & 3000 & 3000 & 3000 & 3000 \\
\hline Steam inlet pressure, lbf/in ${ }^{2}$ & 59. 7 & 62.6 & 103.8 & 61. 1 & 27. 0 & 15. 6 & 69.7 & 29.9 & 76. 8 & 71. 1 & 64.0 \\
\hline Steam inlet temperature, ${ }^{\circ} \mathbf{F} \ldots \ldots$ & 385 & 387 & 433 & 370 & 345 & 302 & 385 & 289 & 352 & 365 & 370 \\
\hline Percent (wt.) noncondensable gases. & 7. 0 & 6. 8 & 6. 7 & 14. 3 & 3. 8 & 2. 4 & 3. 8 & 1. 8 & 2.2 & 3. 0 & 1. 7 \\
\hline Exhaust pressure, in $\mathrm{Hg}_{\mathrm{g}} \ldots \ldots \ldots \ldots$ & 3. 0 & 3. 5 & 3. 0 & 2. 6 & 2. 6 & 2. 6 & 2. 9 & 2. 0 & 2. 0 & 3. 0 & NA \\
\hline Steam flow rate, $10^{3} \mathrm{lbm} / \mathrm{h} . \ldots \ldots$ & 899 & - 1480 & 238 & 375 & 127 & 61. 7 & 9633 & 154 & 558 & - 357 & 269 \\
\hline \multicolumn{12}{|l|}{ Condenser data: } \\
\hline \multicolumn{12}{|c|}{ All units have low-level, direct-contact, barometric condensers } \\
\hline Cooling water temperature, ${ }^{\circ} \mathrm{F} \ldots$ & 87.8 & 82. 9 & 87.8 & 73. 4 & 73. 4 & 73. 4 & 84.2 & 78. 8 & 78. 8 & NA & NA \\
\hline Outlet water temperature, ${ }^{\circ} \mathrm{F} . . .$. & 105.8 & 106. 3 & 105. 8 & 98.6 & 98. 6 & 98.6 & 1040 & 95.0 & 95. 0 & NA & NA \\
\hline Cooling water flow rate, $10^{6} \mathrm{lbm} / \mathrm{h}$. & NA & NA & 17. 8 & NA & NA & NA & NA & NA & NA & NA & NA \\
\hline
\end{tabular}

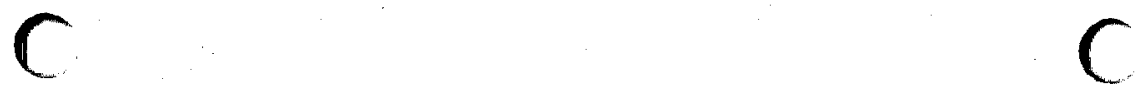


Gas extractor data:

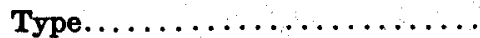

All units have multistage centrifugal turbocompressors with interstage coolers

Gas capacity, $10^{3} \mathrm{ft}^{8} / \mathrm{min} . . . \ldots \ldots .{ }^{\circ} \sim 310, \sim 330$

Power consumption, $\mathrm{kW} . . \ldots \ldots \ldots . \sim 4625 \bullet \sim 5580$

196

182

NA

NA.

134

NA

- 134

NA

Heat rejection system data:

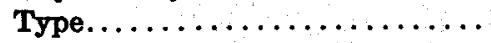

No of towers ....................

Design wet-bulb temp., of . . . . 67. 0

Water pump power, $\mathrm{kW} . \ldots \ldots \ldots$

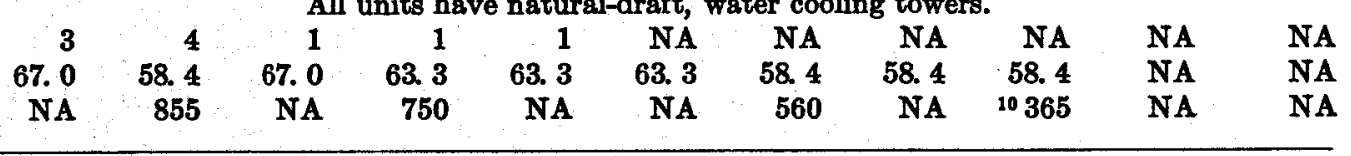

1 Single-cylinder, double-flow.

2 Tandem-compound, single-fiow (HP) and double-flow (LP).

8 Single-cylinder, single-flow.

4-14.5 MW units: 1-11 MW unit.

5 3-26 MW units; 1-24 MW unit; 2-9 MW units.

- 1-15 MW unit; 2-12.5 MW units; 2-3.5 MW units.

7 1-14.5 MW unit; 1-12.5 MW unit.

1-12.5 MW unit; 1-3.2 MW unit.

- Total for all units.

${ }^{10}$ For the $14.5 \mathrm{MW}$ unit only.

$\mathrm{NA}=$ Not available. 
TABLE 10.6-Turbine specifications for noncondensing units in the Boraciferous region of Italy

\begin{tabular}{|c|c|c|c|c|c|c|}
\hline & $\begin{array}{c}\text { Sant'Ippolito- } \\
\text { Vallonsordo }\end{array}$ & $\begin{array}{l}\text { Lagoni } \\
\text { Rossi } 1\end{array}$ & $\begin{array}{c}\text { Lagoni } \\
\text { Rossi } 2\end{array}$ & Sasso 1 & Capriola & Molinetto \\
\hline Year of startup. $\ldots \ldots \ldots \ldots \ldots \ldots \ldots$ & 1963 & 1961 & 1969 & 1969 & 1969 & NA \\
\hline 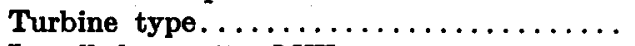 & (1) & (2) & (2) & (2) & $(2)$ & (2) \\
\hline Installed capacity, $\mathbf{M W} \ldots \ldots \ldots \ldots \ldots \ldots$ & 0.9 & 3. 5 & 3. 0 & 7.0 & 3.0 & 3. 5 \\
\hline Speed, rev/min $\ldots \ldots \ldots \ldots \ldots \ldots \ldots \ldots$ & 3000 & 3000 & 3000 & 3000 & 3000 & 3000 \\
\hline Steam inlet pressure, $1 \mathrm{bf} / \mathrm{in}^{2} \ldots \ldots \ldots \ldots$ & 109. 5 & 75. 4 & 65.4 & 71.1 & 56. 9 & 72. 5 \\
\hline Steam inlet temperature, ${ }^{\circ} \mathrm{F} \ldots \ldots \ldots \ldots \ldots$ & 419 & 313 & 356 & 369 & 379 & $\mathbf{3 7 0}$ \\
\hline Percent (wt.) noncondensable gases. . . . . . . & 3. 3 & 3. 2 & 3. 8 & 2. 7 & 4. 0 & 3. 3 \\
\hline Exhaust pressure, in $\mathrm{H}_{\mathrm{g}} \ldots \ldots \ldots \ldots \ldots \ldots$ & 30. 4 & 30.4 & 30. 4 & 30.4 & 30.4 & 30. 4 \\
\hline Steam flow rate, $10^{3} \mathrm{lbm} / \mathrm{h} \ldots \ldots \ldots \ldots$ & 52.9 & 88. 2 & 121 & 117 & 112 & 39. 7 \\
\hline
\end{tabular}

1 Single-cylinder, single-flow, impulse blading.

Single-cylinder, single-flow, impulse-reaction blading.

NA $=$ Not available. 
during exploitation and now ranges from 7-20\%. On the average, the noncondensable gas contains $95 \%$ carbon dioxide, $0.4 \%$ hydrogen sulfide, $0.4 \%$ hydrogen, $3.5 \%$ methane, and $0.7 \%$ nitrogen (by volume) [ENEL, 1970].

The only geothermal power stations in the Monte Amiata region are of the "Cycle 1" or noncondensing type. In the late 1960's there were four units in operation, two at Bagnore and one each at Piancastagnaio and Senna. The last of these was a 3.5 MW unit, very similar to the 3.5 MW unit installed at Lagoni Rossi 1 at Larderello, but has since been shut down. The technical particulars for the remaining three units are listed in table

TABLE 10.7-Turbine specifications for geothermal units in the Monte Amiata and Travale regions of Italy

\begin{tabular}{|c|c|c|c|c|}
\hline 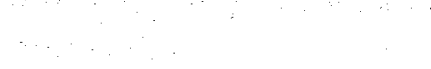 & Bagnore 1 & Bagnore 2 & $\begin{array}{l}\text { Pianca- } \\
\text { stagnaio }\end{array}$ & Travale \\
\hline Year of startup. & 1959 & 1960 & 1969 & 1973 \\
\hline Turbine type.... & (1) & (1) & (i) & (I) \\
\hline Rated capacity, MW. . & 3. 5 & 3. 5 & 15. 0 & 15. 0 \\
\hline Speed, rev/min . . . . . . . . & 3000 & 3000 & 3000 & 3000 \\
\hline Steam inlet pressure, lbf/in²... & 42. 7 & 46. 9 & 116. $6^{\circ}$ & 159. 3 \\
\hline Steam inlet temperature, ${ }^{\circ} \mathbf{F}$. . & 275 & 286 & 361 & 414 \\
\hline \multicolumn{5}{|l|}{ Percent (wt.) noncondensable } \\
\hline 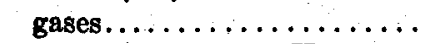 & 8. 5 & 7.2 & 21. 1 & 10.6 \\
\hline Exhaust pressure, in $\mathbf{H g}$. & 30.4 & 30.4 & 31. 3 & 31.3 \\
\hline Steam flow rate, $10^{2} \mathrm{lbm} / \mathrm{h}$. . & 97.0 & 110.0 & 483.0 & 419.0 \\
\hline
\end{tabular}

1 Single-cylinder, single-flow, impulse-type, noncondensing.

10.7. The geothermal utilization efficiency for the two units at Bagnore is only $16 \%$, whereas the $15 \mathrm{MW}$ unit at Piancastagnaio operates with a geothermal utilization efficiency of $24 \%$ and consumes $17.7 \mathrm{~kg} / \mathrm{kW} \cdot \mathrm{h}(39$ $\mathrm{lbm} / \mathrm{kW} \cdot \mathrm{h}$ ) of net electricity generated [DiPippo, 1978e].

\subsubsection{Travale}

The Travale geothermal field is located just on the southwest edge of the Era graben, a northwest-southeast trending feature. The geology of the site is similar to that of Larderello which lies $10-15 \mathrm{~km}(6-9 \mathrm{mi})$ to the west-northwest. In fact, the nature of the boundary between the hydrological systems of Larderello and Travale is not well known even though both regions have been the subject of a large number of surveys [Petracco and Squarci, 1975]. As of 1975, there had been a total of fourteen wells drilled at Travale, eight of these having been completed prior to 1969 .

There is one power plant in operation at the Travale field. It is a noncondensing unit (Cycle 1) of $15 \mathrm{MW}$ nominal capacity. The plant is essentially identical in design to the one at Piancastagnaio, $M$. Amiata. The unit, installed in 1973, utilizes the geofluid from well T22. The technical particulars are listed in table 10.7. This plant is reported to have the best 
operating efficiency of any exhausting-to-atmosphere geothermal plant in Italy. The specific steam consumption is $13.5 \mathrm{~kg} / \mathrm{kW} \cdot \mathrm{h}(29.8 \mathrm{lbm} /$ $\mathrm{kW} \cdot \mathrm{h}$ ) [Ceron et al., 1975], and the geothermal energy net utilization efficiency is $29 \%$.

\subsection{Japan}

\subsubsection{Overview}

Japan is the only country in which there have been installed geothermal plants of the dry-steam, single-flash, double-flash, and binary type. Although only $165 \mathrm{MW}$ are installed at this time, there is underway an ambitious and aggressive development program aimed at putting 48,000 $M W$ on-line by the year 2000 from all geothermal sources, including tapping volcanic magma and hot dry rocks.

The full range of geothermal activities in Japan is directed by the government's Ministry of International Trade and Industry (MITI) through the Sunshine Project. Problems relating to fundamental research and development are handled through the Geothermal Energy Research and Development Co., Ltd. (GERD), an organization which enjoys the participation of thirty institutions, mainly from industry. The Agency of Industrial Science and Technology (AIST) also oversees certain research projects, in particular those of the Geological Survey of Japan (GSJ). Projects related more to development than research are also administered by MITI, but are channeled through the Japan Geothermal Energy Development Center (JGEC) where funding is shared between government and industry on a 90/10 ratio. Thus a concerted and effective effort is underway in Japan to develop the geothermal resources of that country involving a close partnership between government and industry.

Exploitation of geothermal energy for electric power has, nevertheless, been slow in Japan because nearly all of the outstanding geothermal prospects are located in national parks which are enthusiastically protected for their natural beauty. The construction and operation of geothermal power plants thus are subject to rigid and stringent controls.

A summary of the geothermal plants in Japan is given in table 10.8 where information is provided for those plants which are in operation, in testing, under construction, and in planning. Each of these now will be described briefly; a more detailed treatment may be found in DiPippo [1978a].

\subsubsection{Matsukawa}

The geofluid at Matsukawa is dry steam which is admitted to the turbine at about $440 \mathrm{kPa}\left(63.8 \mathrm{lbf} / \mathrm{in}^{2}\right)$ and $147^{\circ} \mathrm{C}\left(296.6^{\circ} \mathrm{F}\right)$. The steam 
TABLE 10.8-Geothermal power plant development in Japan

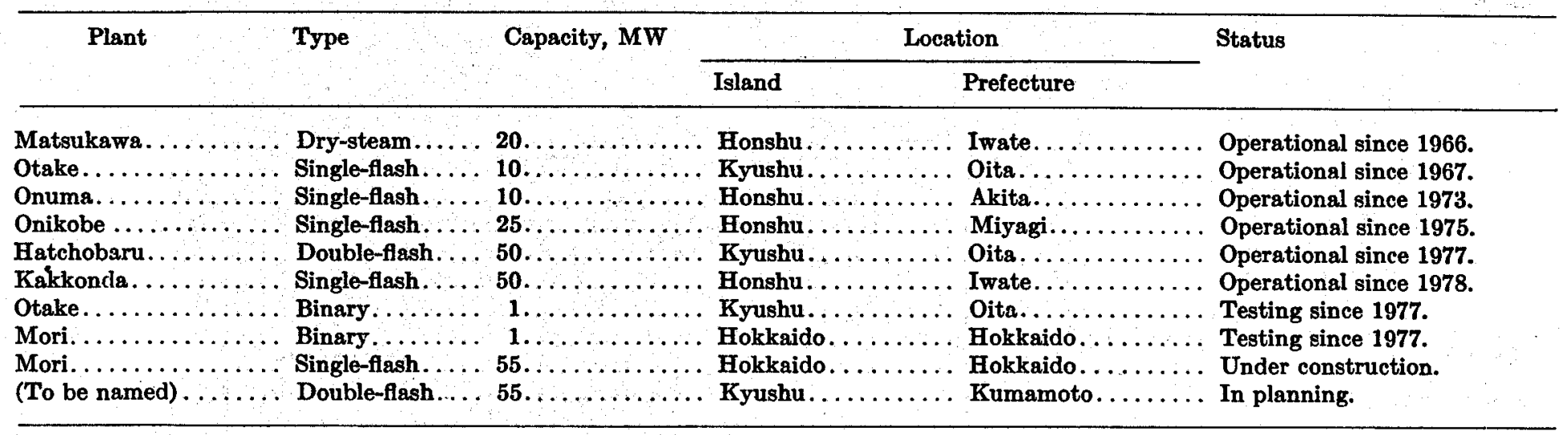




\section{Main STEAM}

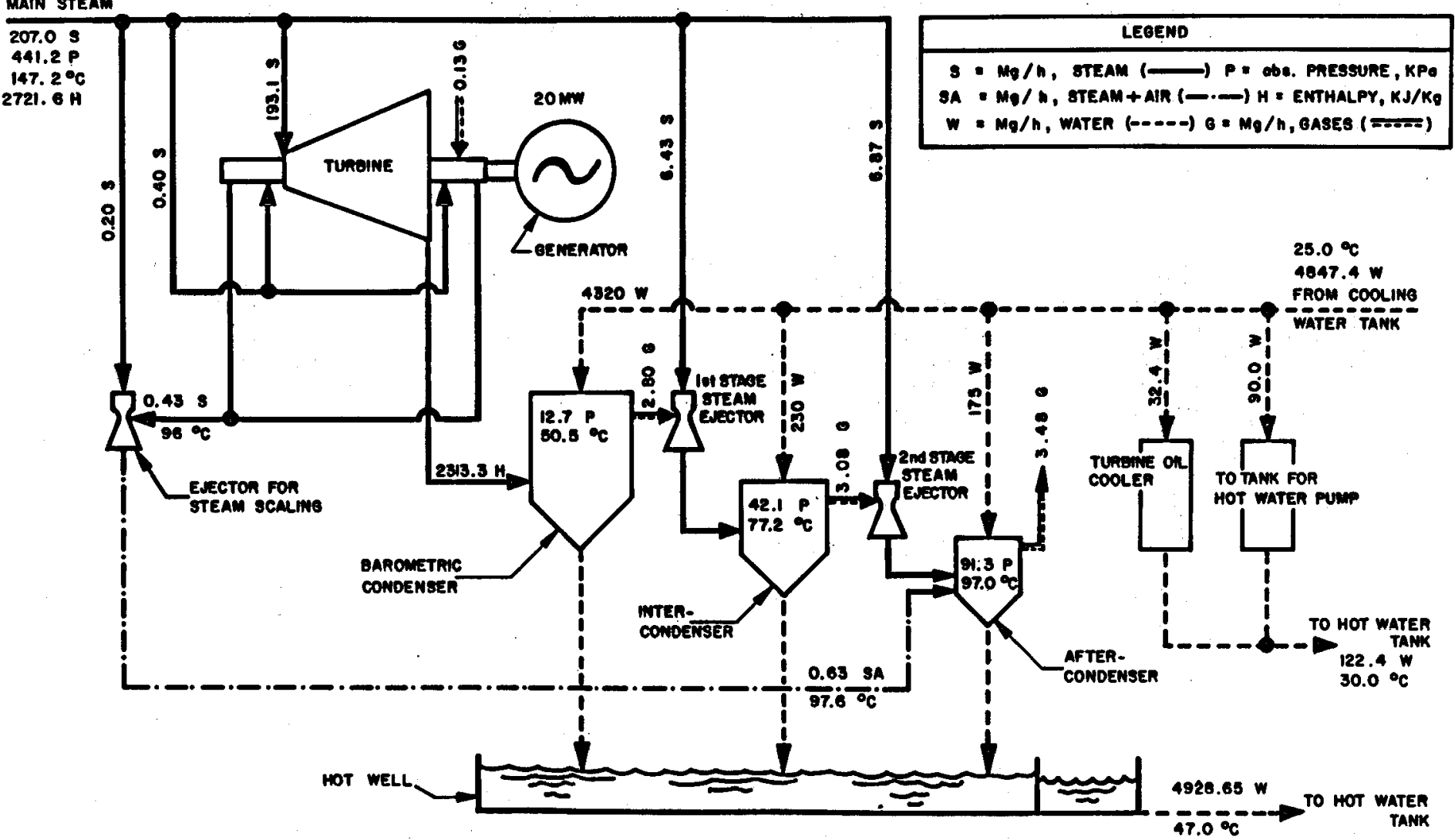

F'teuRs 10.14-Heat balance diagram of Matsukawa geothermal power plant [Akiba, 1970].

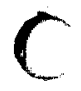


carries about $0.5 \%$ (by weight) noncondensable gases, of which about $82 \%$ (by volume) is $\mathrm{CO}_{2}$ and about $15 \%$ is $\mathrm{H}_{2} \mathrm{~S}$. The turbine is a 4-stage, impulse machine, exhausting to a barometric, direct-contact condenser at a pressure of $13.5 \mathrm{kPa}$ (4 in $\mathrm{Hg}$ ). A natural draft cooling tower reduces the temperature of the condensate from $47^{\circ} \mathrm{C}$ to $25^{\circ} \mathrm{C}\left(116.6-77^{\circ} \mathrm{F}\right)$ for recirculation and use in the spray condenser. Figure 10.14 shows the heat balance diagram for the plant at its design output of $20 \mathrm{MW}$ [Akiba, 1970].

\subsubsection{Otake}

-The separated (or "single-flash") steam plant at Otake has been in operation since 1967 . Through 1977 , the plant had logged 89,345 hours of operation out of a maximum possible 92,968 hours, for a plant availability factor of 0.961 . The full capacity of the plant was achieved, however, only in its first year of operation. Owing to the loss of several production wells and the failure to complete any successful replacement wells, the actual output of the Otake plant has fallen steadily. In 1967, the mean output was 6.4 MW compared with the original $10 \mathrm{MW}$ capacity. The geofluid is produced from a relatively shallow reservoir of depth $300-500 \mathrm{~m}$ (986$1640 \mathrm{ft})$, and is of low pressure, $245 \mathrm{kPa}\left(35.6 \mathrm{lbf} / \mathrm{in}^{2}\right)$, and temperature, $127^{\circ} \mathrm{C}\left(261^{\circ} \mathrm{F}\right)$, by the time it reaches the turbine inlet. Currently only two wells are feeding the plant, with several others serving as reinjection wells for the disposal of the waste liquid from the wellhead separators and the excess steam condensate from the cold well of the mechanicallyinduced-draft cooling tower. Reinjection is carried out under atmospheric pressure to guard against any chance of inducing earthquake activity. However, loss of reinjectivity has been severe, with a drop-off in flow rate of about 7\% per month. Alternative disposal strategies are being considered including reinjection under pressure and chemical treatment of the waste liquid to remove harmful elements and possibly eliminate the need for reinjection [DiPippo, 1978a].

\subsubsection{Onuma}

The Onuma plant is nearly identical to the Otake plant in terms of its energy conversion system. The turbine and the operating pressures and temperatures are the same. From 1973 through 1977, Onuma had operated for 36,073 hours out of a possible total of 38,424 for an availability factor of 0.939. However, unlike Otake, the Onuma plant began at about one-half capacity and has steadily increased its output, achieving a mean output of 7.7 MW in 1977. Reinjection has been going on without trouble even though the fluid is returned to the reservoir at atmospheric pressure. Figure 10.15 shows a view of the plant and one of the wellhead platforms [MHI, 1978a]. 


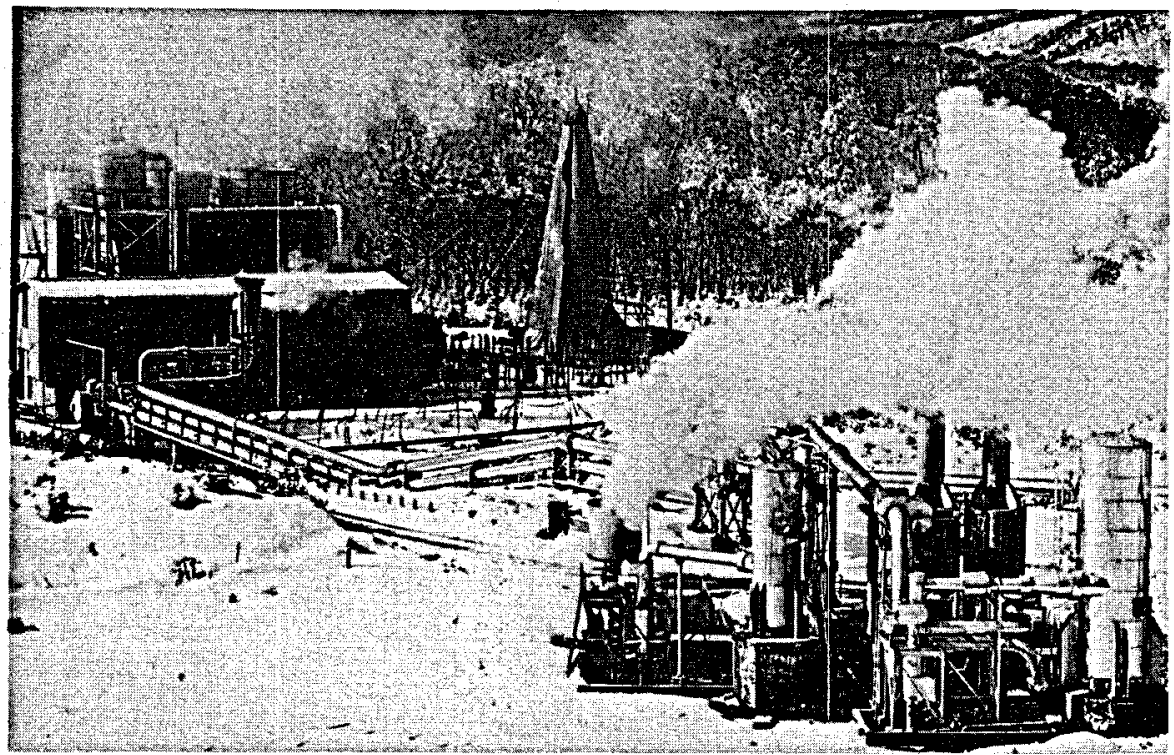

Fravae 10.15-Onuma geothermal power plant. [Photo by Mitsubishi Heavy Industries, Ittd.]

\subsubsection{Onikobe}

The plant at Onikobe is supplied with steam from a shallow reservoir which yields a 50-50 liquid-vapor mixture (by weight) at the surface. There is a large percentage of hydrogen sulfide, $\mathrm{H}_{2} \mathrm{~S}$, in the geothermal steam and the geofluid is highly acidic. The total noncondensable gas content of the steam is about $0.5 \%$, with about $36 \%$ of this being $\mathrm{H}_{2} \mathrm{~S}$. Since there are no emissions controls on the gases exhausted from the plant, a large quantity of $\mathrm{H}_{2} \mathrm{~S}$ is continuously discharged to the atmosphere. Special precautions had to be taken in the selection of materials for the plant because of the extremely corrosive nature of the geothermal fluid. Extensive corrosion fatigue tests were conducted on the materials for the turbine rotor and blades. The rotor shaft glands are especially vulnerable because of their exposure to both geothermal steam and air leakage. Because of this, titanium was selected for these elements. Over the first seventeen months of operation, the Onikobe plant had recorded an availability factor of 0.937 [Kawasaki, 1977].

\subsubsection{Hatchobare}

The Hatchobaru plant is an example of an advanced design, modern geothermal power station. It has a number of unique features: (1) 2-phase, liquid-vapor transmission of the geofluid, (2) "double-flash" operation, (3) low-level jet condenser integral with the turbine foundation, and (4) a combined steam ejector/radial blower for gas extraction. Figure 10.16 


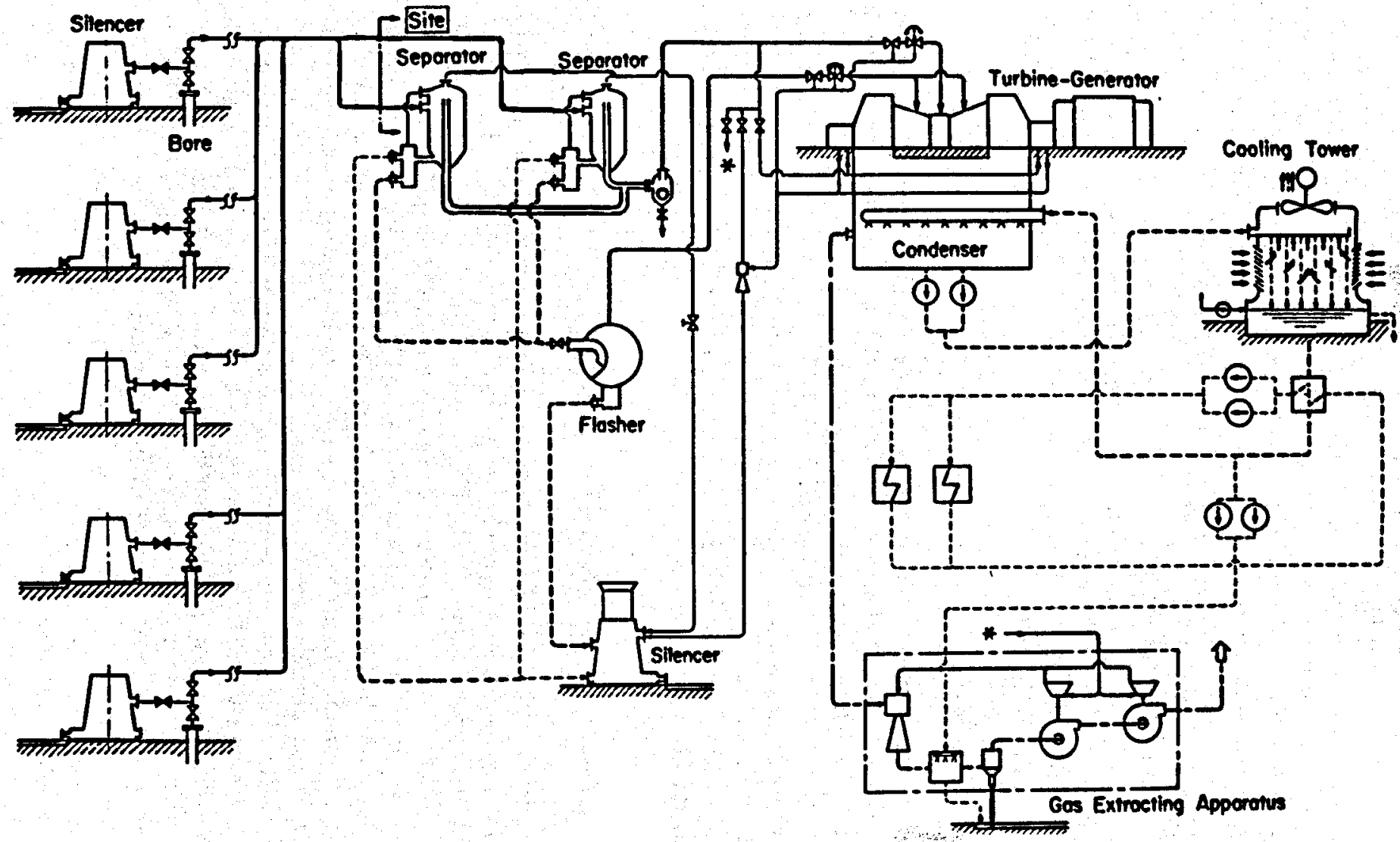

Frouke 10.16-Schematic diagram tor Hatchobaru power plant [after Aikawa and Soda, 1975; MBI, 1978b]. 
shows a schematic diagram of the plant. Each well discharges the total flow into a single pipeline which is joined to other pipelines for transmission of the geofluid to the power house. There the fluid is first separated into a vapor stream (primary steam) and a liquid stream in two vertical cyclone separators, shown in figure 10.17. The liquid fraction is flashed in a horizontal vessel to generate secondary, low-pressure steam. The turbine is a dual-admission, double-flow unit which receives primary steam at $677 \mathrm{kPa}$ $\left(98.2 \mathrm{lbf} / \mathrm{in}^{2}\right)$ and $164^{\circ} \mathrm{C}\left(329^{\circ} \mathrm{F}\right)$, and secondary steam at $99 \mathrm{kPa}(14.4$ $\left.\mathrm{lbf} / \mathrm{in}^{2}\right)$ and $102^{\circ} \mathrm{C}\left(215.6^{\circ} \mathrm{F}\right)$, and which exhausts at $9.8 \mathrm{kPa}(2.9$ in $\mathrm{Hg}$ ). The plant was commissioned in June 1977 and was delivering about $24 \mathrm{MW}$ as of October 1978. It is expected that enough wells will be drilled by the spring of 1979 to allow the plant to reach its full $50 \mathrm{MW}$ capacity [Aikawa and Soda, 1975].

\subsubsection{Kakkonda}

The newest Japanese geothermal plant is a $50 \mathrm{MW}$ single-flash plant at Kakkonda. Nearly $400 \mathrm{t} / \mathrm{h}\left(880 \times 10^{3} \mathrm{lbm} / \mathrm{h}\right)$ of separated steam pass through the 4-stage, double-flow turbine. Inlet conditions are $441 \mathrm{kPa}$ (64 $\left.\mathrm{lbf} / \mathrm{in}^{2}\right), 147^{\circ} \mathrm{C}\left(297^{\circ} \mathrm{F}\right)$; exhaust is at $13.5 \mathrm{kPa}(4 \mathrm{in} \mathrm{Hg})$. A total of eloven producing wells and fifteen reinjection wells are employed. At this plant reinjection is done at the separator pressure, i.e., at about $550 \mathrm{kPa}$. Extensive monitoring is being carried out to check for any signs of induced seismicity [DiPippo, 1979].

\subsubsection{Mori and Otake pilot binary plants}

The development of binary geothermal power cycles began in Japan in 1975 in cooperation with the Sunshine Project, promoted by the Agency of Industrial Science and Technology (AIST) of the Ministry of International Trade and Industry (MTTI). Two $1 \mathrm{MW}$ experimental pilot plants have been built and are being tested. The one at Mori on the northern island of Hokkaido uses refrigerant-114 as the secondary working fluid in conjunction with shell-and-tube heat exchangers and a surface condenser. The turbine is an axial-flow machine.

The Otake binary plant is a more ambitious design. It employs isobutane as the working fluid. Isobutane vapor is generated in a multistage flash heater from geothermal liquid from the separator of the Otake well No. 10. The geothermal liquid enters the heater at $130^{\circ} \mathrm{C}\left(266^{\circ} \mathrm{F}\right)$ with a $\mathrm{pH}$ of 8 , and carrying about $4000 \mathrm{ppm}$ of dissolved solids. A portion of the steam from the steam receiver at the nearby Otake power plant is used to provide the final heating needed to vaporize the isobutane. The turbine is a radialinflow machine, fitted with an extraction point to allow for feedheating of the isobutane liquid as it returns from the air-cooled condenser before entering the multi-stage heater. As of October 1978, three test runs had been 


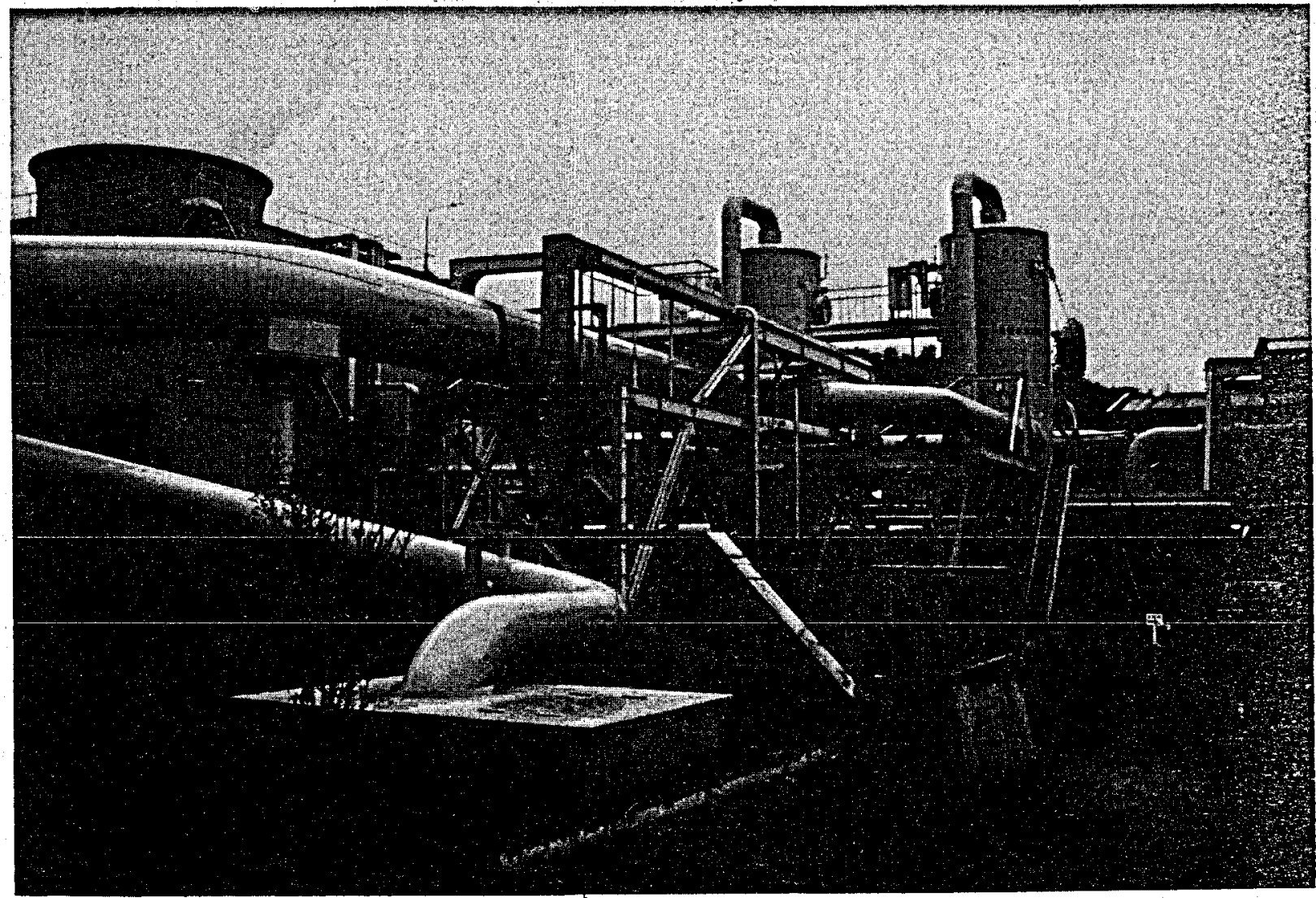

FTaurs 10.17-Main two-phase flow line and vertical cyclone separators at Hatchobaru. [Photo by R. DiPippo.] 
conducted and another was scheduled for the winter of 1978-79, during which the regenerator was to be tested for the first time.* An overall view of the Otake binary test plant is shown in figure 10.18. A much-simplified flow diagram is shown in figure 10.19. Note that the regenerator is not shown in the drawing, and that the multi-flash heater actually consists of eighteen sections. A supplementary water spray is used in the air-cooled condenser during warm weather [MHI, 1977].

\section{$10.69^{\text {Mori }}$}

A $55 \mathrm{MW}$, single-flash plant is being built at the Mori geothermal site in the southwestern part of the island of Hokkaido. The reservoir is liquiddominated and contains relatively high amounts of noncondensable gases. The production wells range in depth from $1.0-1.2 \mathrm{~km}(3280-3937 \mathrm{ft})$.

\subsubsection{Other Promising Areas in Japan}

The ultimate geothermal electric generating capacity in Japan may be as high as 100,000 MW [MITI, 1976]. A great many areas are known to be excellent sites for geothermal developments. Some of these include: Oyasu (hottest well so far in Japan), Akinomiya, Yakedake, Kirishima, Fushime, Kuzuneda, Ogachi, and Takenoyu [Mori, 1975; GERD, 1975; Iga and Baba, 1974, MITI, 1976; DiPippo, 1978a].

\subsection{Mexico}

\section{0.\%.1. General remarks}

The first exploration for sources of geothermal energy in Mexico took place in 1955 west of the city of Pachuca at Pathé. This geothermal field is situated on the Neovolcanic axis which trends east-west across the country in a region of upper Tertiary and Quaternary basaltic, andesitic, rhyolitic and pyroclastic rocks [Alonso, 1975].

As of 1975, the total installed electric capacity of Mexico was 7500 MW, with $48 \%$ being supplied by hydroelectric plants, $51 \%$ from oil and gas-fired thermal power plants, and the remaining $1 \%$ by coal and geothermal. It is unlikely that expansion in hydroelectric capacity will amount to more than about 12,000 MW. Although the discovery of extensive petroleum reserves in Mexico has allowed Mexico to become an exporter of crude oil and refined petroleum products, geothermal energy will, nevertheless, play an important role in meeting the growing demand for electricity in Mexico. There are over 130 geothermal regions in the coun-

\footnotetext{
*The test runs at both pilot binary plants are now complete, and both plants have been dismantled. The next phase will involve the design of a binary plant in the $10 \mathrm{MW}$ range. Note added in proof.
} 


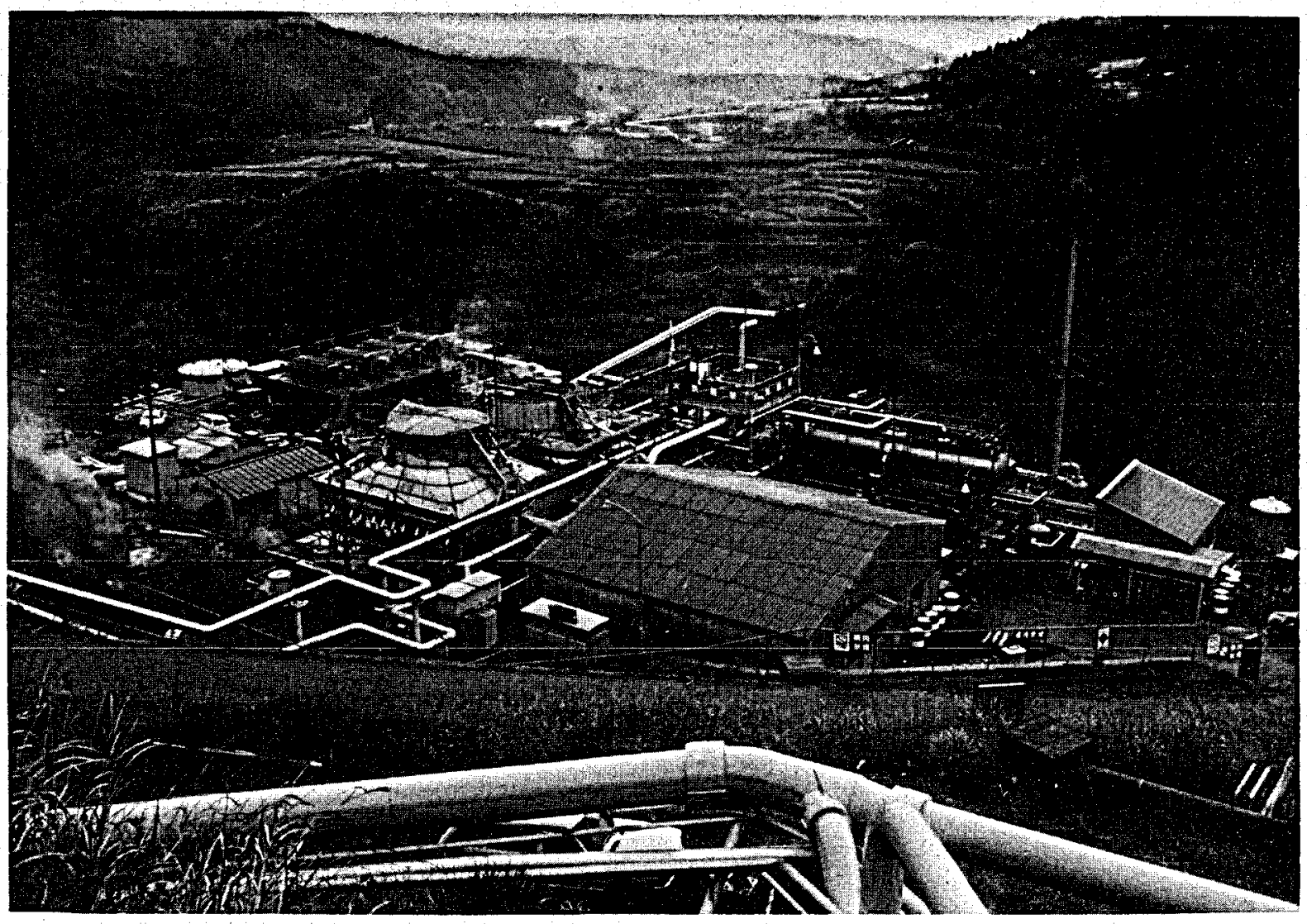




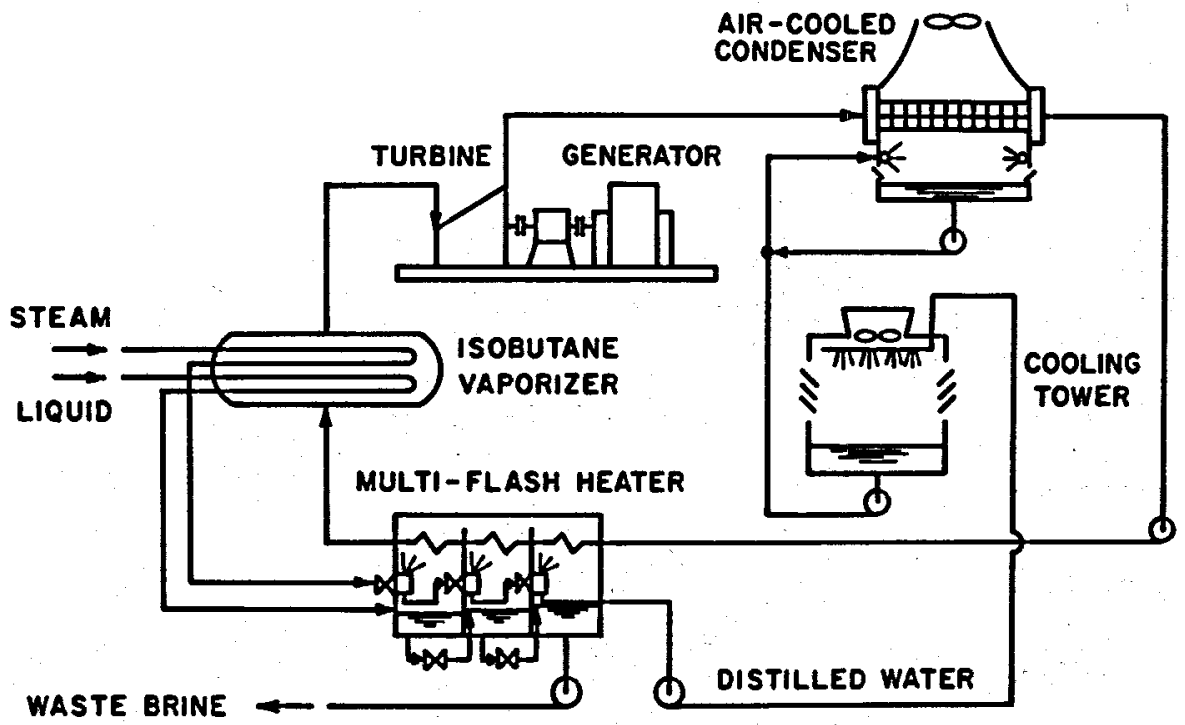

FIGURE 10.19--Schematic diagram for pilot binary plant at Otake [after MIHI, 1977].

try; these appear in 24 of the 32 states. The largest concentration of geothermal sites is in the states of Michoacán (22), Jalisco (16), Baja Califormia (15), and Guanajuato (9). Owing to their wide geographic distribution and their potential as an inexpensive source of local power, these geothermal regions will be taken seriously into account in national plans to meet the expected future demand for electricity in Mexico.

\subsubsection{Pathé}

Mexico's first geothermal power plant was installed at Pathé, a geothermal field located in the municipality of Tecozaulta, in the state of Hidalgo, about $80 \mathrm{~km}$ (50 mi) north-northeast of Mexico City. The plant began operations in 1959; it is, however, no longer operational [G. Cuéllar, personal communication].

The Pathé unit had a capacity of 3.5 MW. It employed a noncondensing turbine supplied with steam separated, most likely from one well. Very little information exists on this plant in the literature.

\subsubsection{Oerro Prieto}

Since 1973 the geothermal power plant at Cerro Prieto has been generating $75 \mathrm{MW}$ of power on a highly reliable and economic basis. The plant recently has achieved the highest capacity factor of any power plant in Mexico. So successful has been the experience that construction is underway on an extension of the plant which will duplicate the two exist- 
Fiaure 10.20-Geographical location of Cerro Prieto geothermal field [after OFE, 1971].

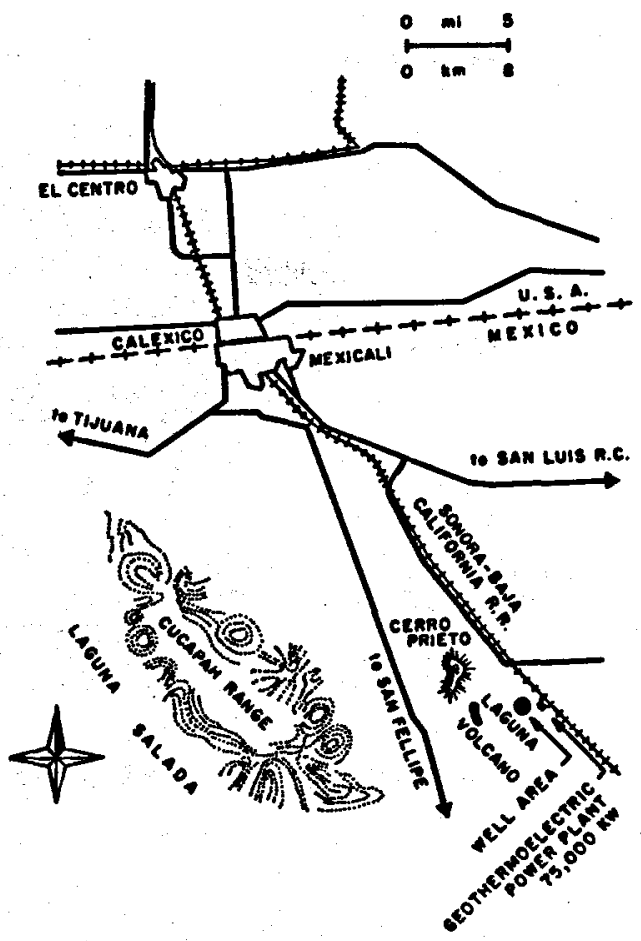

ing power units. The new units will bring the installed capacity to $150 \mathrm{MW}$ in 1979. The full potential of the field is known to be at least $400 \mathrm{MW}$.

The Cerro Prieto geothermal field is located on a plain in the MexicaliImperial rift valley in the State of Baja California, roughly $35 \mathrm{~km}(22$ $\mathrm{mi}$ ) south of the city of Mexicali and the international boundary between the United States and Mexico. The resource covers an area of about 3000 ha (7400 acres). Its general location is shown in figure 10.20. Figure 10.21 is a highly-simplified geologic cross-section of the field [after CFE, 1971]. The reservoir is capped by a layer of plastic, impermeable clays with a thickness of $600-700 \mathrm{~m}(1970-2300 \mathrm{ft})$ over the main portion of the field. Underlying the cap clays is the main reservoir which consists of shales and sandstones possessing considerable porosity and permeability. Basement faulting contributed to the permeability of the formation. The basement rock is granitic in nature and may be seen in large outcroppings in the Sierra de los Cucapahs.

Eighteen wells are connected to the first two units of the power plant, nine for each unit. Of these about 15 or 16 are needed to generate the rated $75 \mathrm{MW}$, with the others held on stand-by reserve. Figure 10.22 shows the piping lay-out for the steam gathering system. There are four main steam gathering lines which run from the wells to the steam receivers at the power house. There are over $6 \mathrm{~km}(20,000 \mathrm{ft})$ of steam pipelines of diameters greater than $406 \mathrm{~mm}$ (16 in). The mean lifetime of a well at Cerro 


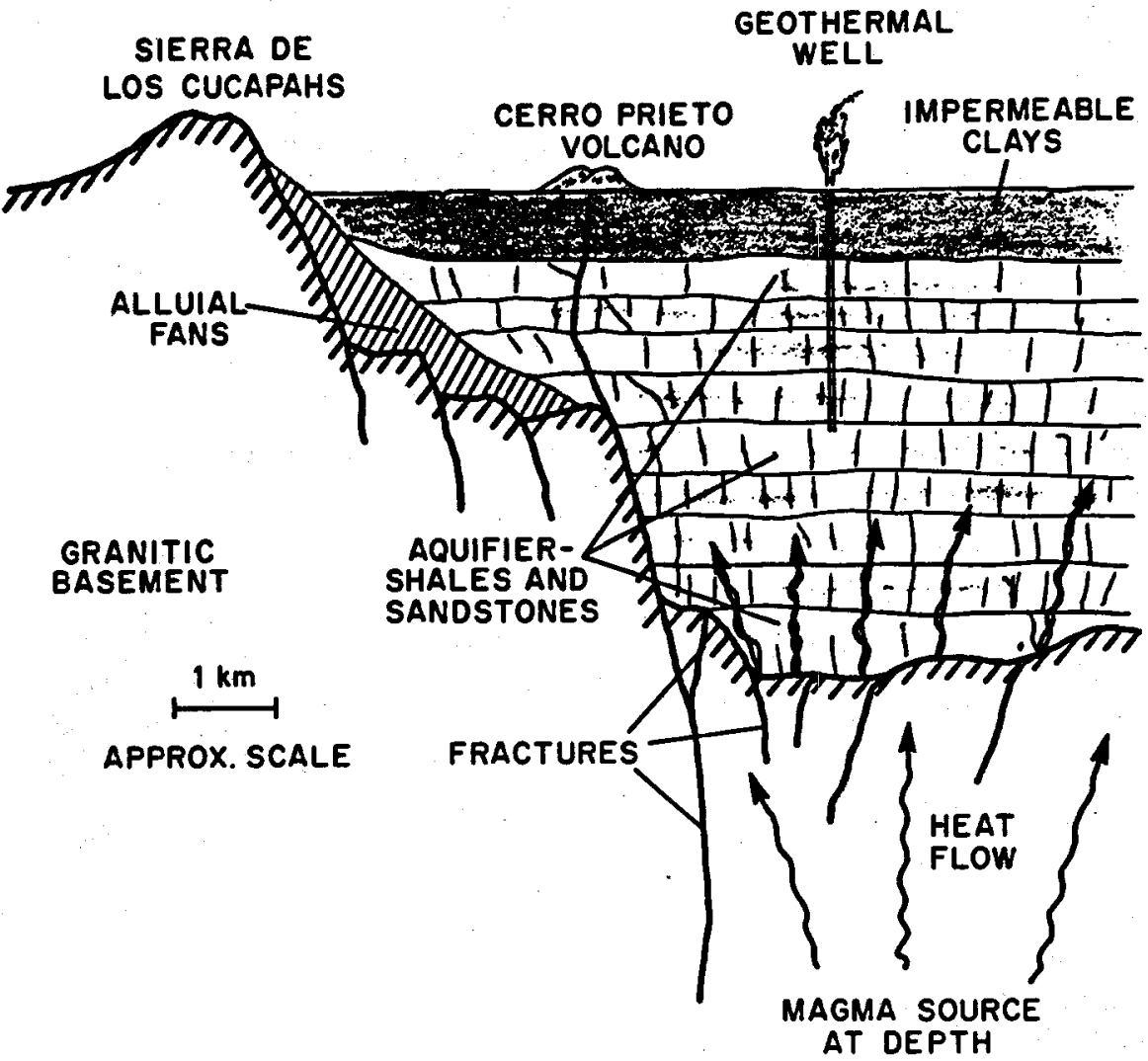

Froure 10.21-Schematic cross-section of Cerro Prieto geothermal field [after CFE, $1971]$.

Prieto is considered to be fifteen years. There are wells that are fourteen years old, still in good condition, and producing steam [Mercado, 1976]. The fluid in the reservoir is a compressed liquid which partially flashes to vapor during its ascent through the well. Under high flow rates it is observed that annular flow exists in the well bore, i.e., liquid on the walls and vapor in the core [Reed, 1975].

The two-phase geofluid is processed conventionally in Webre-type centrifugal separators, with the separated steam passing through ball check valves before entering one of the four main steam transmission lines. The main steam is collected outside the power house in a set of receivers, and passes through a final stage of moisture separation before entering the turbines. The geothermal steam contains about $1 \%$ by weight of noncondensable gases, mainly carbon dioxide and hydrogen sulfide. The separated liquid is burdened with an amount of dissolved solids which total roughly. $25,200 \mathrm{ppm}$. The main impurities are chloride, sodium and potassium, which together constitute $94 \%$ of the total. 


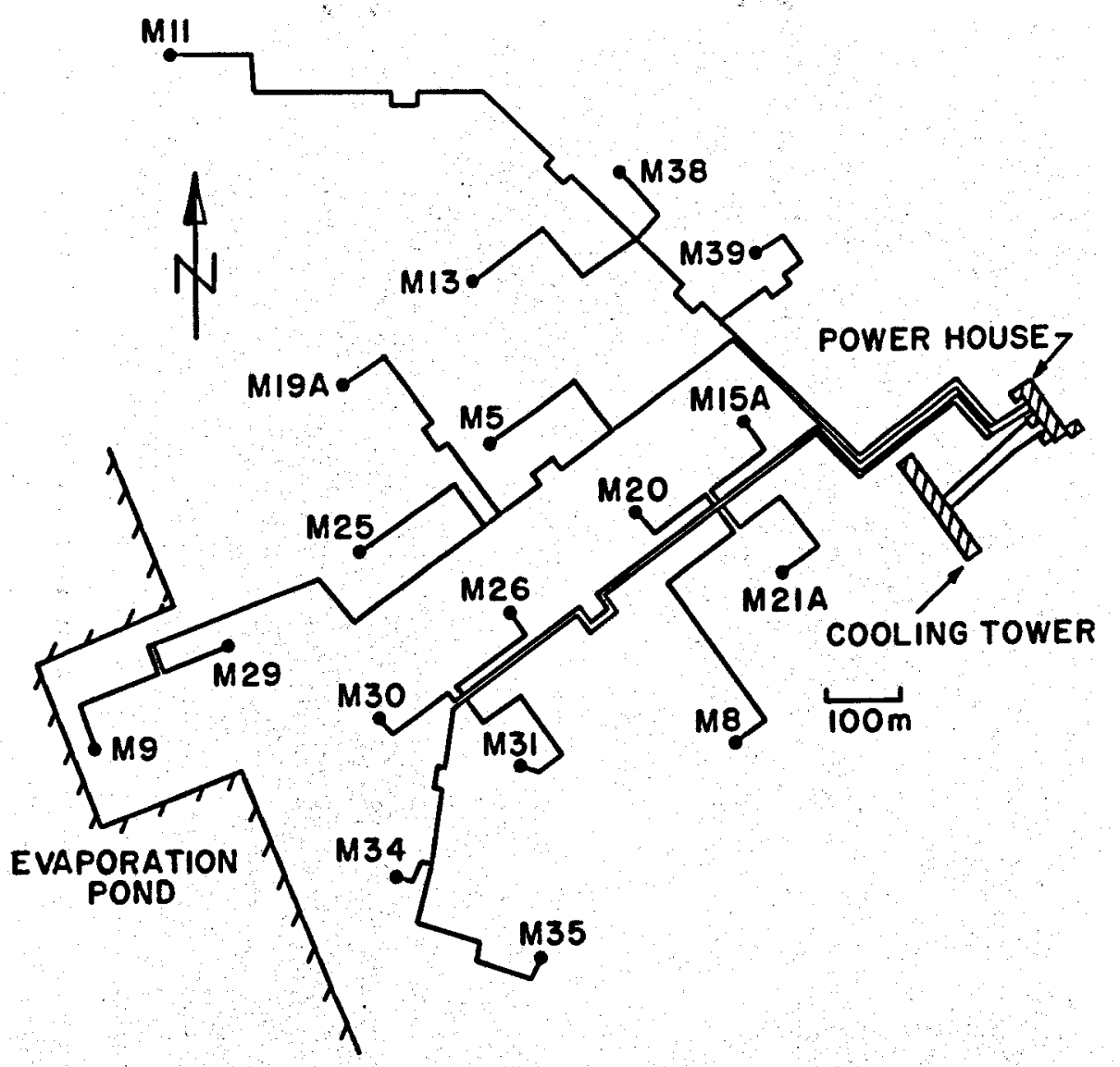

Fravae 10.22-Steam pipeline gathering system for units No. 1 and 2 at Cerro Prieto [after OFE, 1971; Mercado, 1975].

Since all of this liquid is discharged to the environment, attention must be given to the effects of the dissolved solids on the environment. Liquid which is separated from the two-phase mixture in the wellhead separators is sent either to silencers located at each wellhead site or piped directly to an evaporation and settling pond where the pressure is let down to atmospheric. Figure 10.23 shows a view of the pond and the pressure let-down process. Eventually all waste liquid (i.e., liquid from the separators or the silencers and excess steam condensate) is discharged into the pond. It is estimated that the present pond has a capacity sufficient to support 180 MW of generation. Beyond that another means must be found for the disposal of the waste liquid. The options include: (1) reinjection; (2) construction of a channel to the Laguna Salada, a dried-up lake; and (3) construction of a channel to the Sea of Cortez [Guiza, 1975; Mercado, $1975]$. 


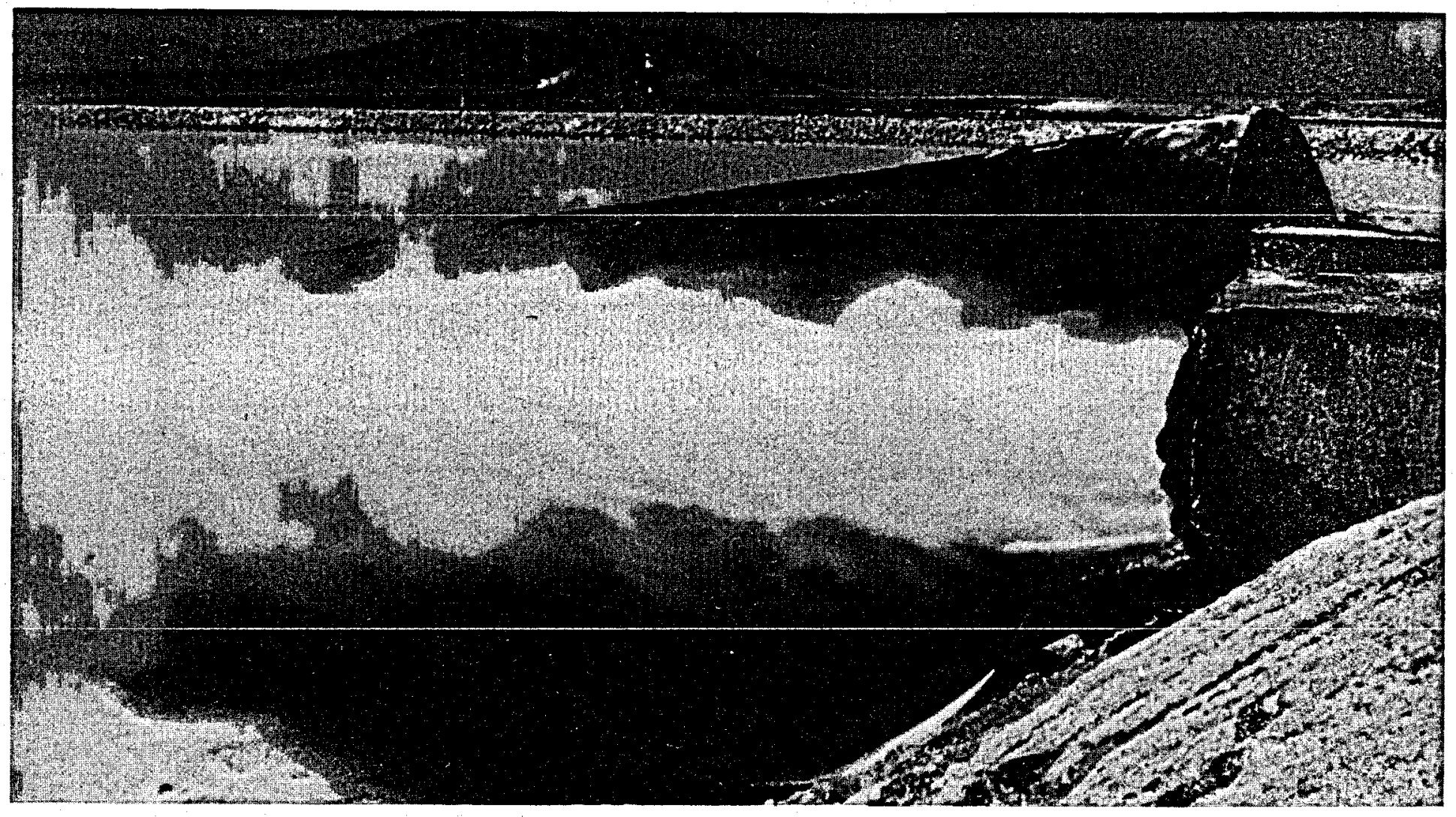

Frours 10.23-Discharge of waste liquid into evaporation pond; wellhead $M-9$ in background and volcano Cerro Prieto on the horizon. [Photo by R. DiPippo.] 
Since the evaporation pond covers a saline clayey area that originally had surface thermal manifestations, it is felt that the creation of the pond did not cause any additional environmental deterioration [Mercado, 1975].

The energy conversion system is of the separated-steam (or "singleflash") type, consisting of two units, each rated at 37.5 MW capacity. The units are of the single-cylinder, double-flow variety with six stages of impulse-reaction blades in each flow. A photograph of the turbogenerator for unit No. 2 is shown in figure 10.24. A simplified plant schematic/heat balance diagram is given in figure 10.25 [Akiba, 1970; Mercado, 1976].

The condenser is of the barometric, direct-contact type and is located next to the power house. Noncondensable gases are removed from the top of the condenser shell through a gas extraction system consisting of a 2-stage steam ejector with inter-and after-condensers. There are three firststage steam ejector nozzles operating in parallel, for redundancy. The noncondensable gases are discharged to the atmosphere through fiberglass pipes (one for each unit) which extend to a height of $40 \mathrm{~m}$ (131 ft) above the ground. Since the prevailing winds blow either from the northwest or the southeast, these gases should be swept away from the plant. However, on windless days, the concentration of hydrogen sulfide may reach dangerous levels in certain areas. An alarm system is connected to a series of $\mathrm{H}_{2} \mathrm{~S}$ detectors to protect personnel in and around the power house. Furthermore, an additional vent line was constructed from the power house at the base of the gas extraction stacks to the evaporation pond.

The geothermal resource utilization efficiency, $\eta_{u}$, of the plant is $40 \%$, based on wellhead flow conditions, assuming $24 \%$ quality, and a sink temperature of $26.7^{\circ} \mathrm{C}\left(80^{\circ} \mathrm{F}\right)$ [DiPippo, 1978d].

Owing to the corrosive nature of the geothermal liquid and vapor, special attention must be paid to the selection of materials for the plant components including the wells, silencers, piping, turbines, condensers, cooling towers, and electrical equipment.

The well casings are fabricated from J-55 API standard weight pipe with buttress couplings. Extra heavy wall thickness may be required in future wells. The cement consists of API type G with silica flour, perlite and retarders as additives [Guiza, 1975]. The silencers are made of concrete with wooden stacks in a twin-silo design [Mercado, 1975].

Carbon steel is used for pipes carrying nonaerated steam. Since the corrosion rate is three times higher when the steam is in contact with air, an allowance of extra wall thickness is provided on aerated-steam pipelines. The worst case occurs in condensate lines where the corrosion rate for carbon steel is $0.66 \mathrm{~mm} / \mathrm{yr}(0.026 \mathrm{in} / \mathrm{yr})$. Condensate lines are therefore provided with a corrosion allowance and coated with epoxy resin [Tolivia et al., 1975].

The turbine rotor is fabricated from a Cr-Mo- $\nabla$ alloy steel forging; alloy steels containing $\mathrm{Ni}$ are not used because of their poor corrosion resistance. The turbine blades are machined from $12 \mathrm{Cr}$ alloy steel bar stock. 


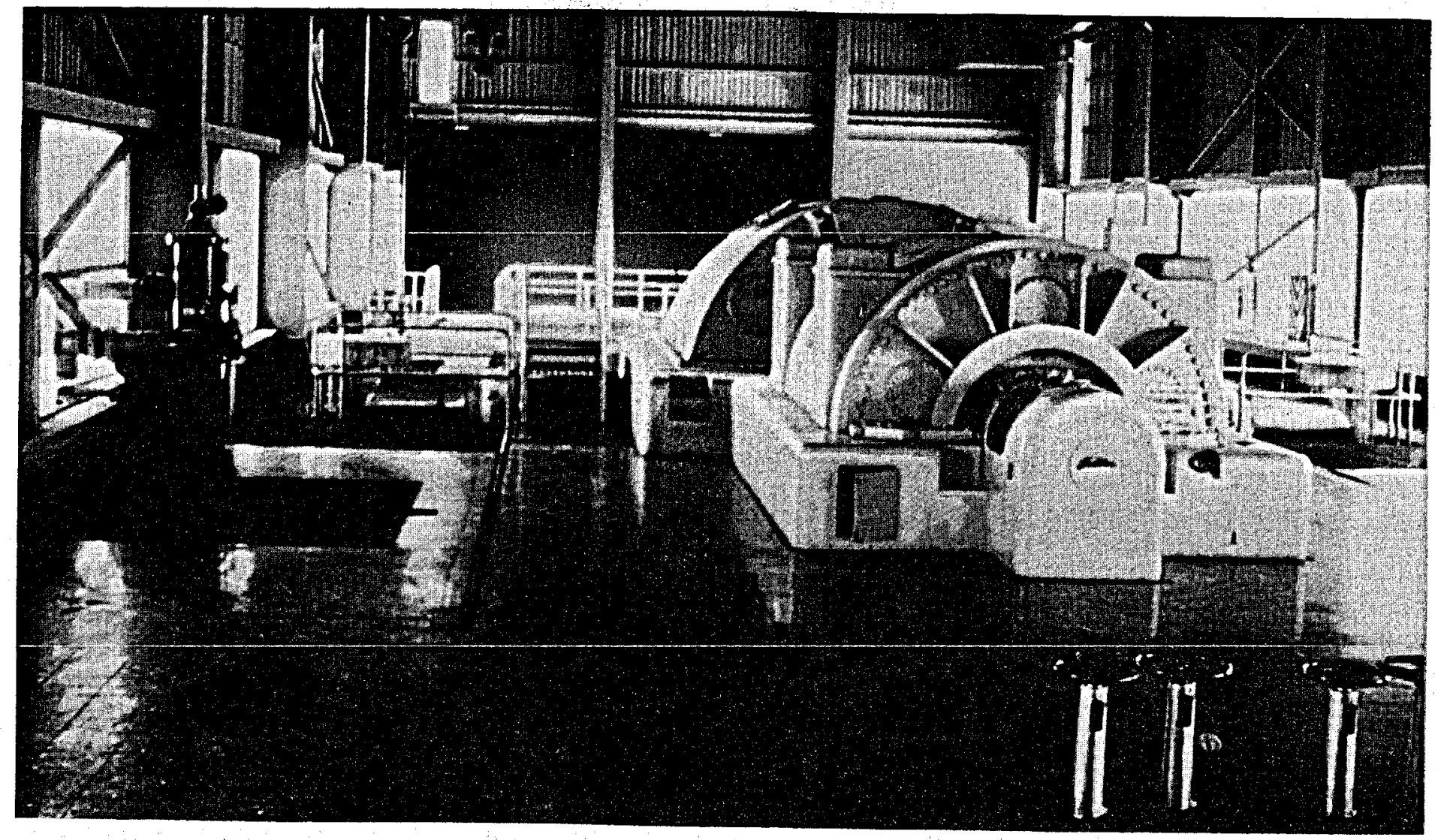

Frauke 10.24-Unit No. 2, 37.5 MW, in turbine hall at Cerro Prieto. [Photo by R. DiPippo.] 


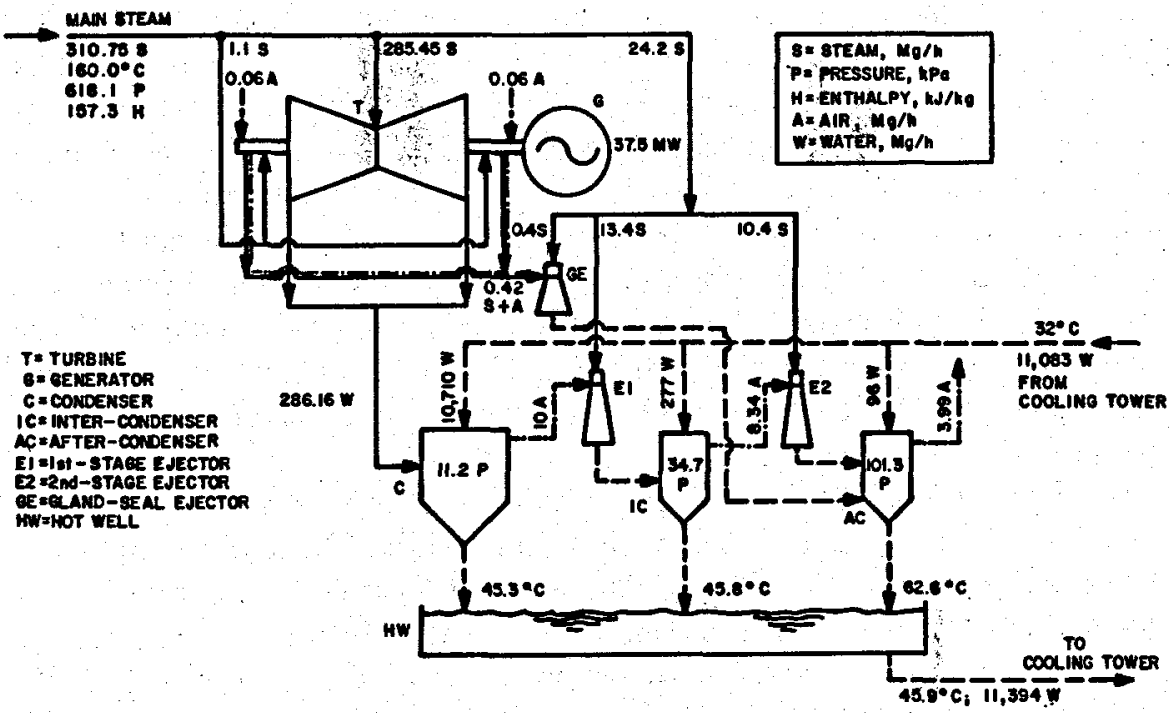

Fraure 10.25-Simplified flow diagram for energy conversion system for each unit at Cerro Prieto [after Akiba, 1970; Mercado, 1976].

The blades of the last row are fitted with stellite erosion shields and fastened together with lashing wire to minimize vibrations [Akiba, 1970].

The shell of the condenser is carbon steel with a coating of epoxy resin. The barometric pipe is made of naval brass. The structural members of the cooling tower are constructed from AISI-4140 steel; the packing is redwood and fiberglass [Mercado, 1976].

Since electrical equipment is susceptible to corrosive attack by hydrogen sulfide, special precautions are taken for the protection of this equipment. Most switch-boards, including the main switch-board, are installed in rooms which are provided with air-conditioning systems fitted with activated carbon filters filled with activated alumina beads impregnated with potassium permanganate [Mercado, 1974]. The electrical contacts on the high-voltage side at the substation are gold-plated, although the use of platinum may have been more appropriate.

The Cerro Prieto geothermoelectric power plant has operated very reliably since it was brought on-line in April 1973. For example, in 1976 a total of $570,000 \mathrm{MW} \cdot \mathrm{h}$ of electricity were generated. This corresponds to a capacity factor of $87 \%$, the highest value recorded by any Mexican power plant up to that time.

\subsubsection{Future developments of geothermal power in Mexico}

For the foreseeable future, geothermal power developments will center on the Cerro Prieto field although there are several other promising areas that someday may be exploited. 
At Cerro Prieto, units No. 3 and 4, each to be rated at $37.5 \mathrm{MW}$ and essentially duplicates of units No. 1 and 2, are under construction at this time and are expected to come on-line in 1979.* The next unit is expected to be a dual-pressure unit rated at $30 \mathrm{MW}$ which will use steam flashed from a portion of the waste liquid produced from the first four units. This unit probably will not be ready before 1982 . Additional units will most likely be $55 \mathrm{MW}$ units of standardized design, and be located in a different section of the Cerro Prieto field, necessitating the construction of a new power house and related peripheral equipment. The ultimate electric generating capacity of the Cerro Prieto field is not known with certainty; $400 \mathrm{MW}$ seems to be a conservative estimate.

A large number of other hydrothermal areas in Mexico are listed and described by Alonso in his paper at the Second United Nation's Symposium in San Francisco in 1975. Of the 130 sites that have been discovered, only nine of these have been drilled. Using conservative estimates, the ultimate geothermal power potential of the country has been placed at $4000 \mathrm{MW}$. Some include: Ixtlán de los Hervores (State of Michoacán, eight wells drilled); Los Negritos (State of Michoacán, various surveys, one well drilled) ; Los Azufres (State of Michoacán, various surveys) ; La Primavera (State of Jalisco, various surveys, a few exploratory wells drilled) ; and San Marcos (State of Jalisco, various surveys, six exploratory wells drilled).

\subsection{New Zealand}

\subsubsection{Introduction}

Now Zealand pioneered the use of liquid-dominated geothermal resources for the production of electricity on a commercial scale. Studies which were begun in the 1930's culminated in the construction of the Wairakei power station. Plant construction began in 1956; the first unit was commissioned on November 15, 1958, and was followed in short order by 12 additional units, the last of which was brought on-line in October 1963. Although the installed capacity at Wairakei is $192.6 \mathrm{MW}$, the present output is about 140-150 MW, owing to reservoir decline and planned cut-backs in draw-off to conserve the resource. It is predicted, however, that an output of $120-140$ MW will be sustainable for an indefinite period of time [Bolton, 1977].

There are currently two other geothermal areas being used or developed for electric power generation: Kawerau and Ohaki (Broadlands). At Kawerau, multiple use is being made of geothermal energy for process heating, clean steam generation, and electricity production. At Ohaki, the New Zealand Electricity Department (NZED) is in the process of installing a $150 \mathrm{MW}$ power plant in three steps of $50 \mathrm{MW}$ per unit. Concerns

*These units were commissioned in April 1979. 
about the environmental impact of geothermal power generation have contributed to the rather slow development of this natural resource in New Zealand.

\subsubsection{Wairakei}

The Wairakei geothermal field lies in an extensive thermal area on New Zealand's North Island. Wairakei is situated about $8 \mathrm{~km} \mathrm{(5} \mathrm{mi)} \mathrm{north} \mathrm{of}$ the northeast corner of Lake Taupo, roughly in the middle of the thermal belt $50 \mathrm{~km}(31 \mathrm{mi})$ wide and $250 \mathrm{~km}(155 \mathrm{mi})$ long, which trends northeastsouthwest across the North Island from a central group of volcanic mountains to the White Island volcano in the Bay of Plenty. Large, active andesitic volcanoes are located at each end of the zone, and the wider central portion is dominated by acid igneous activity. These include rhyolite domes, pyroclastic pumice deposits and ignimbrites.

The reservoir at Wairakei consists of a pumice breccia aquifer (Waiora formation) which varies in thickness from 60 to $150 \mathrm{~m}$ (200 to $500 \mathrm{ft}$ ), and which lies from 180 to $300 \mathrm{~m}$ (600 to $1000 \mathrm{ft}$ ) below the surface. The surface formations comprise mainly loosely consolidated breccias (Wairakei breccia) and a top layer of recently-deposited pumice cover. These surface layers extend to a depth of about $125 \mathrm{~m}$ (410 ft) [Bolton, 1977].

The geothermal fluid from the Wairakei field is produced as a mixture of liquid and vapor from two sets of wells, high-pressure and intermediatepressure ones. The steam is separated from the liquid by means of a complex network of cyclone separators and flash vessels. The steam gathering system is a complicated one involving three pressure levels. The complexity arose because the original plans for the development of the area included a plant to produce heavy water for the U.K. Atomic Energy Authority. This proposal was made in 1953 and the steam pressures were selected to accommodate the requirements of the distillation plant. The proposal for the heavy-water plant was withdrawn in 1956, but only after the design of the steam system had been frozen and turbines were on order.

The present gathering system is shown schematically in figure 10.26 [Bolton, 1977]. Two high-pressure wells are shown. The one on the left supplies fluid to a typical flash plant which produces steam at three pressure levels: high-pressure (H.P.), intermediate-pressure (I.P.) and intermediate-low-pressure (I.L.P.). The one at the right produces only high-pressure fluid by means of a simple cyclone separator. The figure does not show the intermediate pressure wells that also produce intermediate-pressure (I.P.) steam and additional water for the flash plant.

The wellhead separators are of two types: top-outlet cyclonic (TOC) separators and bottom-outlet cyclonic (BOC) separators. The former type incorporates a U-bend upstream of the admission point to the separator which removes about $80-90 \%$ of the liquid. A baffle arrangement 


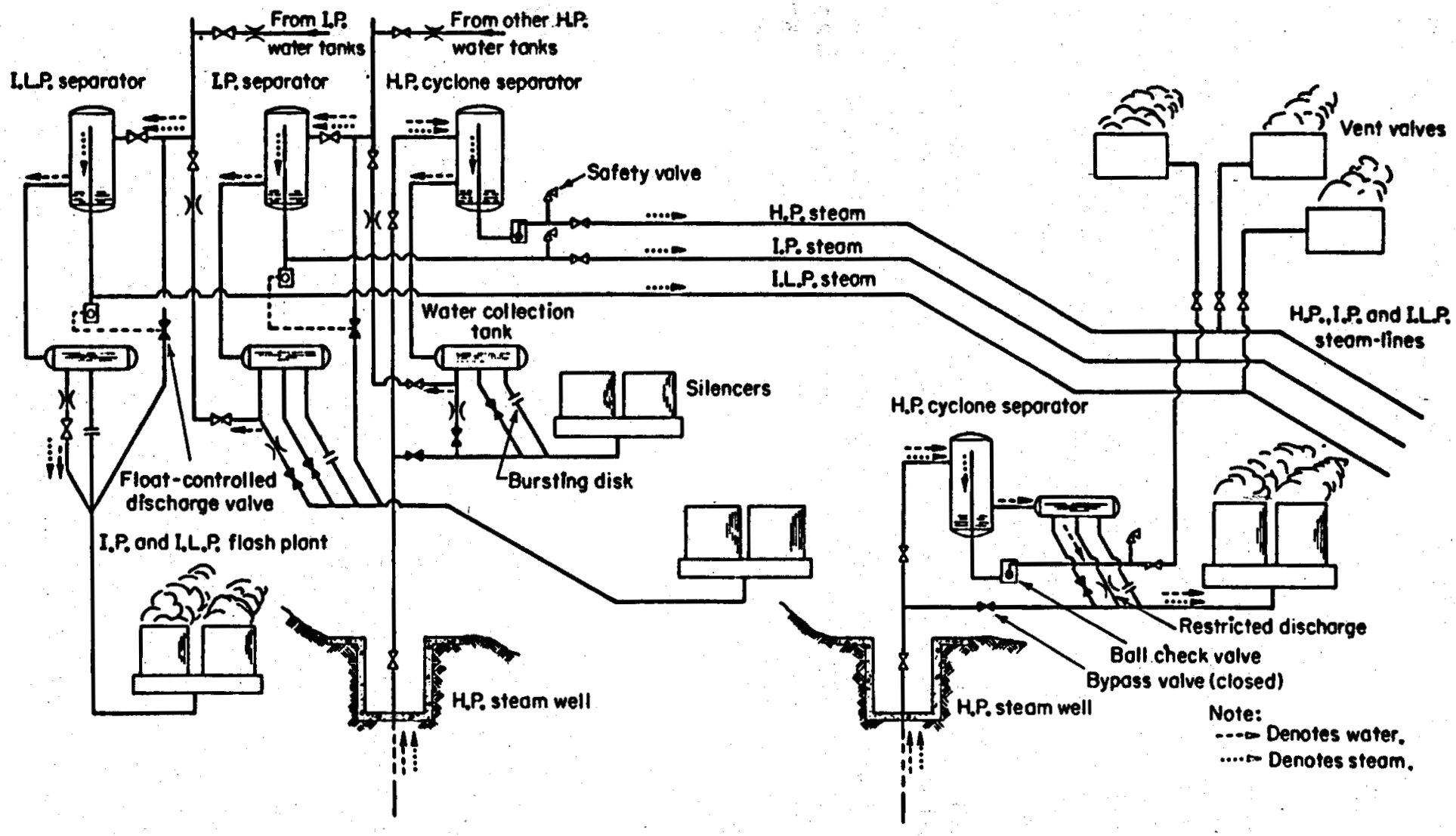

FraURE 10.26-Steam separation equipment at Wairakel [Bolton, 1977].

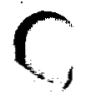


inside the separator traps the remaining liquid and allows the steam to emerge with a dryness fraction of about $99 \%$. The latter type is much simpler and has been shown to be capable of yielding steam with a dryness fraction in excess of $99.9 \%$ [Usui and Aikawa, 1970].

A simplified flow diagram for the Wairakei plant is shown in figure 10.27. As can be seen, a train of turbines is fed with steam at various pressures obtained from simple separation and successive stages of throttling of geothermal liquid, each producing dry, saturated vapor at lower and lower pressures. The main steam transmission pipelines are 508, 762, 1067 and $1219 \mathrm{~mm}(20,30,42$ and $48 \mathrm{in})$ in diameter. The largest of these carry intermediate-low pressure steam for which the specific volume is very large.

The energy conversion system consists of two $6.5 \mathrm{MW}$ and two 11.2 MW back-pressure machines supplied with separated high-pressure bore steam; two 11.2 MW back-pressure machines which receive a mixture of intermediate-pressure bore steam, intermediate-pressure flashed steam, and exhaust steam from the HP units; four 11.2 MW condensing units which run on low-pressure steam obtained from the exhaust of the IP units and let-down flashed steam from the second-stage flash vessels; and three 30 MW dual-admission condensing turbines that use the same steam which feeds the IP units and pass-in, low-pressure steam let-down from the second-stage flashers.

Of all these turbines, only the dual-admission machines may be considered as typical for a geothermal installation, the others having been installed as a consequence of the planned heavy water plant.

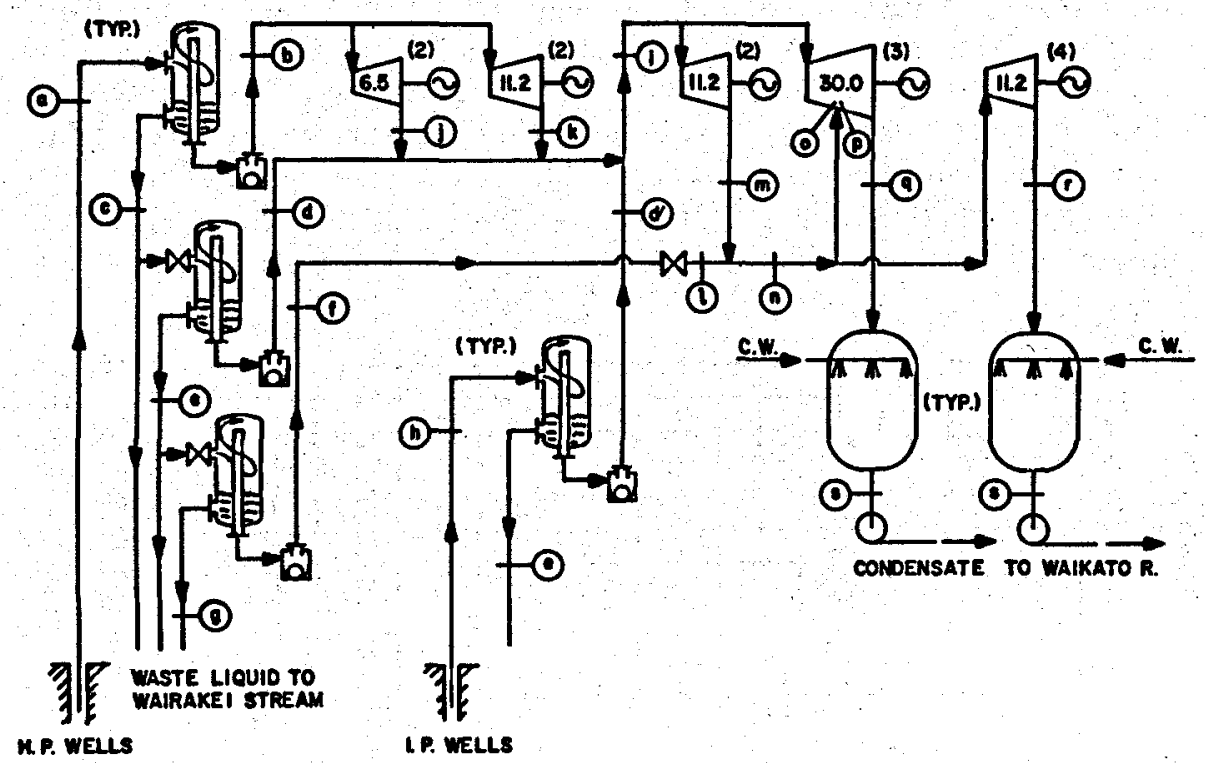

Frauke 10.27-Simplified flow diagram for Wairakei power plant [DiPjppo, 1978c]. 
The choice of materials for the plant equipment is dictated by the nature of the geothermal fluid. The Wairakei fluid is relatively clean, having no more than about $5000 \mathrm{ppm}$ of dissolved solids and less than $0.5 \%$ non-condensable gases (by weight) in the steam. Scrubbers are used to ensure that the total saline content of the steam which enters the turbine does not exceed $10 \mathrm{ppm}$ in order to avoid problems of stress-corrosion cracking in the blades. Since there are no corrosion problems with the geothermal fluid so long as contact with oxygen is avoided, the steam transmission pipes are made of seamless, mild steel, rolled and buttwelded mild steel, and spiral-welded mild steel piping. The newer, larger pipes are insulated with $38 \mathrm{~mm}$ (1.5 in) of fiberglass and covered with aluminum sheathing [NZED, 1974].

There has been a considerable reduction in field pressure during the lifetime of the project. The high-pressure wells originally produced at pressures in excess of $1400 \mathrm{kPa}\left(200 \mathrm{lbf} / \mathrm{in}^{2}\right)$ [Bolton, 1977]. The dramatic decrease in field pressure may be seen in figure 10.28 , which covers the period 1953-1975. The loss in pressure amounts to about $38 \%$ over the 23-year span, with nearly all of it having occurred since the date of the commissioning of the first machine. The pressure appears to be approaching a stable value, having lost only $6 \%$ during the last seven years.

It should be pointed out that no reinjection of the withdrawn fluid has ever taken place at Wairakei. In addition to playing a role in the pressure loss within the reservoir, this has led to significant subsidence. An area of about $6500 \mathrm{ha}(16,000$ acres $)$ shows the effects of subsidence and horizontal land movement. The maximum total drop in elevation is in excess of $4.5 \mathrm{~m}(14.8 \mathrm{ft})$ over the 10 year period from 1964 to 1974 at a spot which is removed from the borefield but within about $500 \mathrm{~m}(1640$ $\mathrm{ft}$ ) of the steam pipelines [Stilwell, et al., 1975]. Subsidence appears to be progressing at the rate of $400 \mathrm{~mm} / \mathrm{yr}(16 \mathrm{in} / \mathrm{yr})$. The subsidence volume is likely related to the volume of fluid withdrawn from the field, but a precise correlation is not available.

The geothermal resource utilization efficiency, $\eta_{u}$, has been calculated approximately. For purposes of the calculation, the power output was

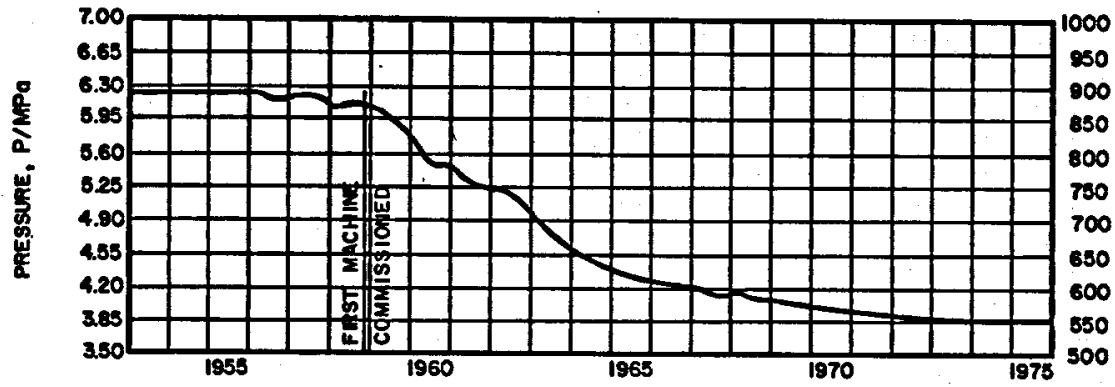

Fiquke 10.28-Reservoir pressure history at Wairakei [after Bolton, 1977; Hunt, 1977 ]. 
taken equal to the installed capacity of the plant, i.e., 182.6 MW. The actual output at the present time is considerably below this value, being about 150 MW.

With reference to figure 10.27 , the thermodynamic availability of the geofluid is composed of two contributions, one from the H.P. fluid at state $a$ and one from the I.P. fluid at state $h$. Since mass flow rates are not avail$a b l e$ in the literature at states $a$ and $h$, it was necessary to work backwards from the turbine main stop valve steam flows, and employ assumptions about the average dryness fraction at the H.P. and the I.P. wellheads. Fair approximations for these were obtained from Hunt [1961] and Wigley [1970], after making allowances for lower wellhead pressures. Thus, the resource utilization efficiency of the Wairakei plant, under conditions of maximum output (i.e., in its original design state) is about $55 \%$. It is likely that the value is somewhat, but not much, lower than this at the present time, owing to the general deterioration of the reservoir characteristics and the corresponding mismatch between the geofluid and the energy conversion equipment. However, the conversion of more and more wells to the multifiash arrangement shown in figure 10.27 will tend to maintain the level of utilization in the face of reservoir decline [DiPippo, $1978 \mathrm{c}]$.

A thorough study of the environmental impact of the Wairakei plant was conducted and reported by Axtmann [1974, 1975]. He examined all possible detrimental effects including the impact of chemical effluents in the liquids and gases which flow from the plant, physical effects such as thermal discharge and ground subsidence, general ecological effects, and esthetios or "visual pollution."

When discussing the effects of the Wairakei geothermal power plant on the environment, it is important, however, to keep in mind that the plant was designed and built at $a$ time when environmental issues were regarded as far less important than they are today. The fact that an environmental impact report was not required for the construction of the plant stands as evidence. When one considers that Wairakei was the first liquiddominated geothermal resource to be exploited for electric power, one realizes that the state of the art in geothermal technology was, in fact, in its infancy at the time it was built. Even so, the plant has operated successfully for over twenty years with a minimum of unpleasant impact on the population that lives near the plant.

The Wairakei plant has an outstanding record of reliability ; forced outages have been essentially negligible. During $1973 / 74$, the station was in service $85 \%$ of the time (availability factor) with a capacity factor of $80 \%$. This performance is unmatched by any other power station, hydro or thermal, and is significantly superior to any thermal power plant in New Zealand. In fact, the Wairakei geothermal power station has maintained this excellent record since it was fully commissioned in 1964 [Ravenholt, 1977b]. 
TABLE 10.9-Annual production of electricity at the Wairatei power plant

[After Smith and McKenzie, 1970]

\begin{tabular}{|c|c|c|c|c|}
\hline \multirow[b]{2}{*}{ Year ${ }^{2}$} & \multirow{2}{*}{$\begin{array}{c}\text { Generation, } \\
\mathbf{G W} \cdot \mathbf{h} \text { (net) }\end{array}$} & \multirow{2}{*}{$\begin{array}{r}\text { Max. load } \\
\text { MW }\end{array}$} & \multicolumn{2}{|c|}{ Capacity factors, percent } \\
\hline & & & Field-limited ${ }^{2}$ & Installed . \\
\hline 1859. & 6.4 & $(4)$ & - & - \\
\hline $1960 \ldots$ & 169 & 50.6 & 37. 9 & 27. $\theta$ \\
\hline $1961 \ldots$ & 384 & 64.0 & 68.5 & 63.5 \\
\hline $1962 \ldots \ldots \ldots \ldots \ldots$ & 491 & 65. 6 & 85. 5 & 81,3 \\
\hline $1963 \ldots \ldots \ldots \ldots \ldots$ & 761 & 131 & 66.3 & 45. 1 \\
\hline $1964 \ldots \ldots \ldots \ldots \ldots$ & 1004 & 149 & 77. 0 & 59.6 \\
\hline $1965 \ldots \ldots \ldots \ldots$ & 1194 & 175 & 78. 8 & 71.6 \\
\hline $1966 \ldots \ldots \ldots \ldots$ & 1255 & 166 & 86. 6 & 74. 6 \\
\hline $1967 \ldots \ldots \ldots \ldots \ldots$ & 1268 & 171 & 84.7 & 75.2 \\
\hline $1968 \ldots \ldots \ldots \ldots \ldots$ & 1058 & 167 & 72.2 & 78.4 \\
\hline $1969 \ldots \ldots \ldots \ldots$ & 1207 & 166 & 83. 1 & 71.6 \\
\hline
\end{tabular}

1 For the year ended March 31.

2 Based on a borefield-limited effective maximum capacity, i.e., maximum load from col. 3.

Based on an installed capacity of $69 \mathrm{MW}$ for $1960-1962$ and 192.6 MW thereafter, except for an effective installed capacity of $153.4 \mathrm{MW}$ for 1968 .

Test runs.

- Low generation caused by cutback in geofluid flow for aquifer pressure-recovery test over 4 months during which the maximum plant capacity was $75 \mathrm{MW}$.

The generating history of the Wairakei plant is given in table 10.9 . Since it has never been possible to generate sufficient geothermal steam to supply fully the installed electrical capacity of $192.6 \mathrm{MW}$, the capacity factors listed in the fourth column of the table have been adjusted accordingly. The so-called "field-limited" capacity factor is based upon the maximum load during any given year, as shown in the third column. The generation of $1207 \mathrm{GW} \cdot \mathrm{h}$ in 1969 constituted $9.9 \%$ of the entire electricity generation in New Zealand for that year. The latest figures available (1974) show that the plant is producing about $10 \%$ of the electricity requirements of North Island, although this percentage is expected to fall as the electrical generating capacity of the country as a whole increases [Bolton, 1977].

There are at present no plans to expand the installed capacity at Wairakei (N. C. McLeod, personal communication), although exploration is continuing at the nearby geothermal field of Te Mihi [Smith and McKenzie, 1970], and at other promising sites in the thermal belt. Additional geothermal power in New Zealand will likely come from new plants at such sites as Kawerau and Broadlands, which are discussed in the following sections.

\subsubsection{Kawerau}

Multiple use is being made of the geothermal resource at Kawerau, 97 $\mathrm{km}(60 \mathrm{mi})$ northeast of Wairakei. The Tasman Pulp and Paper Company, 
in fact, relocated their mills in the early 1950's specifically to take advantage of the geothermal energy available at Kawerau. Steam and hot water from a number of wells are used for the production of electricity, for the generation of clean steam by means of heat exchangers, and for a number of process applications including timber drying, liquor heaters, and log handling equipment.

The geothermal steam field layout including the pulp and paper mill is shown in figure 10.29. The most active surface manifestations of geo-

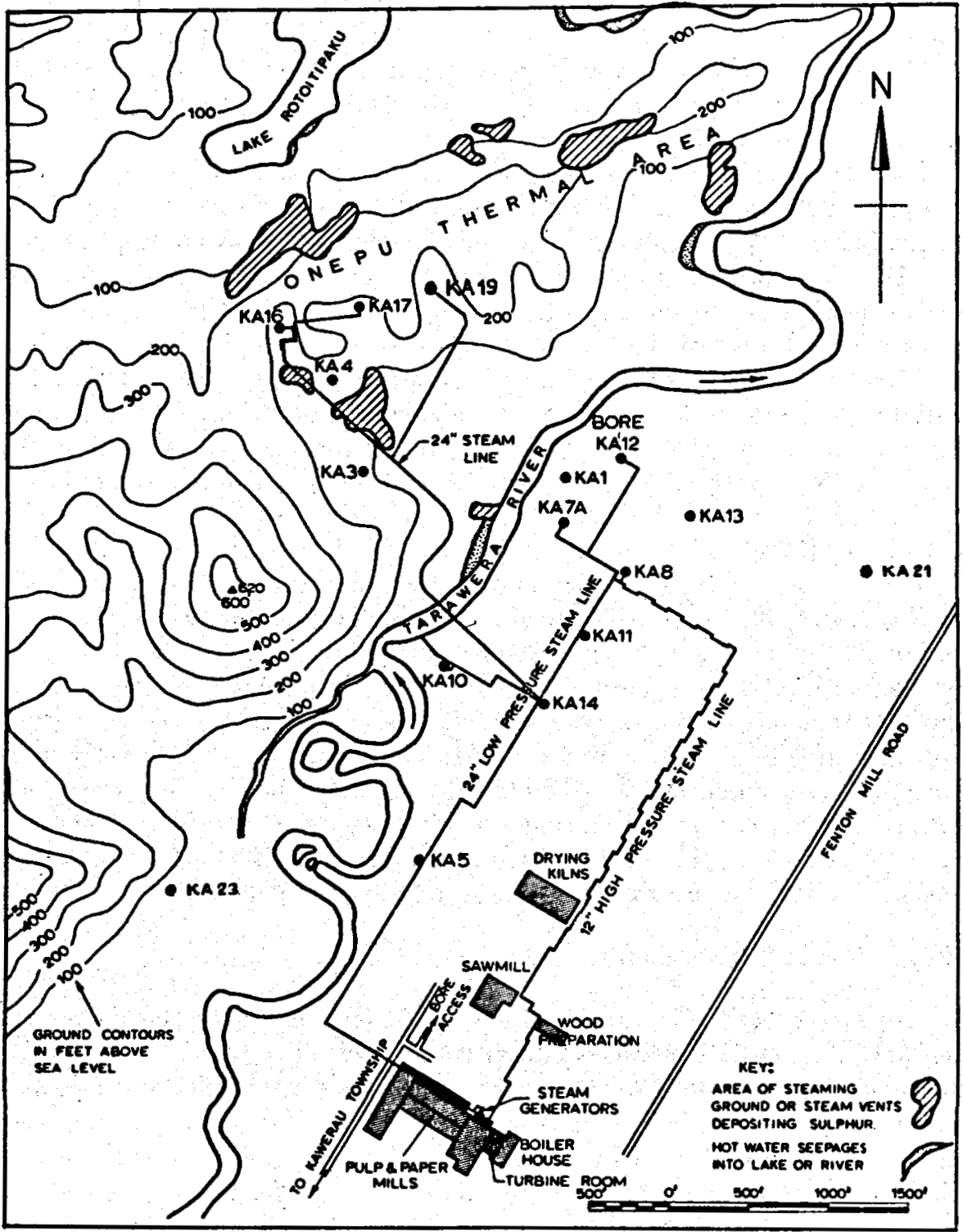

Frgube 10.29-Steam field layout at Kawerau [after Smitll, 1970; Bolton, 1977]. 
thermal energy lie to the west of the Tarawera River (cross-hatched areas), although highly productive wells have been drilled on the east bank in close proximity to the mill [Smith, 1970].

The gathering system includes branch pipes from the individual wellbeads to the main steam lines; these branch lines are 203, 305 and $406 \mathrm{~mm}$ $(8,12$, and 16 in) in diameter. The low-pressure wells feed the plant through a $610 \mathrm{~mm}$ (24 in) diameter steam main which is capable of handling $145 \mathrm{t} / \mathrm{h}(320 \mathrm{klbm} / \mathrm{m})$ of steam at $791 \mathrm{kPa}\left(114.7 \mathrm{lbf} / \mathrm{in}^{2}\right)$. The highpressure well (KA8) delivers through a $305 \mathrm{~mm}$ (12 in) supply line, at a maximum flow rate of $36 \mathrm{t} / \mathrm{h}(80 \mathrm{klbm} / \mathrm{h})$ and a pressure of $1480 \mathrm{kPa}$ (214.7 lbf/in ${ }^{2}$. Noncondensable gases constitute about $2.5 \%$ (by weight) of the geothermal steam; about $91 \%$ is carbon dioxide, with the rest being mainly hydrogen sulfide.

The plant purchases $80 \%$ of its electricity from the grid and produces the other $20 \%$ in-house. A bank of turbo-alternators operates in parallel, being fed by boiler steam and geothermal steam. The latter supplies one $10 \mathrm{MW}$, noncondensing unit. Since the steam which supplies this unit is excess geothermal steam, beyond the process needs of the plant, this unit is part-loaded most of the time. Nevertheless, it is capable of operating at full load in the event of a failure of the other turbo-alternator units. At full output, the unit has a specific steam consumption of about 14.5 $\mathrm{kg} / \mathrm{kW} \cdot \mathrm{h}(32 \mathrm{lbm} / \mathrm{kW} \cdot \mathrm{h})$. This corresponds to a geothermal utilization efficiency for electrical production of about $24 \%$, assuming a wellhead quality of $30 \%$ and taking the available sink temperature as $27^{\circ} \mathrm{C}\left(80^{\circ} \mathrm{F}\right)$ [DiPippo, 1978c].

Although the main thrust of the plan for geothermal energy utilization at Kawerau has been aimed at process heating and other industrial applications, it is likely that/serious consideration will be paid to the expansion of the facility for the generation of electricity. Encouragement comes from the fact that one of the newest wells, KA21 (see figure 10.29), by itself, appears capable of supporting a 20-30 MW generator. This is 4-6 times larger than the potential of an average geothermal well. Thus, it is expected that a separate generating station, one able to supply all of the electrical needs of the mill, will be constructed at the site as soon as present investigations justify the additional investment [Ravenholt, 1977b].

\subsubsection{Ohaki (Broadlands)}

The latest geothermal project in New Zealand concerns the proposed $150 \mathrm{MW}$ double-flash plant at Ohaki-Broadlands. The plant will be built in three stages of $50 \mathrm{MW}$ each. Steam will come from the liquid-dominated reservoirs at Ohaki and Broadlands. The plans for the station are currently being processed by the various regulatory agencies with jurisdiction in such matters. The first unit may not begin operating until 1984.

The Ohaki-Broadlands geothermal field has been intensively studied, and several reports on the geology of the site are available [Browne, 1970; 
Grindley, 1970; Grindley and Browne, 1975; Hochstein and Hunt, 1970; Macdonald, 1975]. The drilling of exploration wells began in 1965; since that time, over thirty wells have been drilled. However, only sixteen of these are considered sufficiently productive to be suitable for power production. It will take twenty producing wells to supply the required steam flow for the $150 \mathrm{MW}$ power plant.

Certain details about the design of the plant's energy conversion system are undecided at the time of writing. However, preliminary technical specifications for the proposed plant are available [Bauer et al., 1977]. On the basis of these figures, the plant would have a geothermal energy resource utilization efficiency of about $43 \%$, relative to the thermodynamic available work of the geofluid at the wellhead, with a calculated quality of $25 \%$ at the wellhead, and a sink temperature of $27^{\circ} \mathrm{C}\left(80^{\circ} \mathrm{F}\right)$.

\subsubsection{Other geothermal areas in New Zealand}

The thermal belt across North Island from Lake Taupo to White Island in the Bay of Plenty abounds with thermal areas, some of which may prove useful for the generation of electricity, district or process heating, or other commercial or industrial applications.

Some of the areas that have been investigated include:

Ngawha..... Bottom-hole temperature equals $236^{\circ} \mathrm{C}\left(457^{\circ} \mathrm{F}\right)$, but low reservoir permeability.

Orakeikorako... Few producing wells, low quality steam, infiltration of cold water.

Reporoa...... Unimpressive temperature and low reservoir permeability.

Rotokawa...., Bottom-hole temperatures approximate $306^{\circ} \mathrm{C}$ $\left(583^{\circ} \mathrm{F}\right)$, high steam quality, but high noncondensables and only moderate reservoir permeability.

Tauhara...... Adjacent to Wairakei, very similar temperatures with higher pressures, some weak linkage between Wairakei and Tauhara but not enough to influence production at either site.

Te Kopia..... Field aligned with fault scarp, steam output is moderate but of low quality, highest temperatures occur in upper formation, become indifferent at depth.

Te Mihi...... Extension of Wairakei field, at least one well has been connected to Wairakei system.

Waiotapu..... Area of considerable thermal potential, shallow wells rapidly develop calcite deposits, deep wells are more promising. 
There are other areas that hold promise, and the interested reader may consult several references for further details [Dench, 1961; Smith, 1970; Smith and McKenzie, 1970; Bolton, 1977]. Presently, however, there are no plans to install electric generating stations at any of these geothermal areas.

\subsection{Philippines}

\section{9 .1 Outlook}

Geothermal energy presently accounts for $3 \mathrm{MW}$ of electricity in the Philippines. According to optimistic projections this will rise to $1320 \mathrm{MW}$ by 1985 . By that time, geothermal energy would constitute nearly onequarter of the total electric generating capacity of the country.

\subsubsection{Tiwi}

Tiwi is the site of one of the principal geothermal fields in the Philippines. It has been one of the most popular hot springs on the island of Luzon in Albay Province. It is located at the far southeastern tip of Luzon, about $300 \mathrm{~km}$ (185 mi) from Manila [Muffler, 1975].

The Tiwi field has been investigated using a number of techniques including Wenner and dipole-dipole resistivity surveys, geological, heat flow and geochemical methods. The exploratory work began in 1964 through the Philippines Commission on Volcanology, supported with financial assistance from the National Science Development Board.

As a result of the surveys, an area of $2300 \mathrm{ha}$ (5680 acres) was outlined as a potential reservoir at drillable depths. Fourteen wells were sunk inside the resistivity low, and confirmed the indications of the surveys. The wells produced a mixture of liquid and vapor at high flow rates, and revealed the nature of the reservoir. The Tiwi system is a liquid-dominated field in a reservoir of Quaternary andesites and subsidiary dacites. It is believed that a system of microfractures lend permeability to the reservoir. A total of 20 wells have now been drilled, with 19 of these being producers; they extend to depths of between 760-2130 m (2500-7500 ft). These findings were reported by A. P. Alcaraz in 1976 and quoted by Ravenholt [1977a].

The preliminary design, equipment procurement, drafting of specifications and contract documents for the first four units at Tiwi have been completed and orders have been placed for the turbo-generators. These are identical, 55 MW single-cylinder, double-flow, $6 \times 2$ stage machines of the dual-admission type appropriate for use with separated-steam/hot-water flash (or "double-flash") systems. The technical specifications for the units are given in Table 10.10 [Toshiba, 1977]. It is anticipated that ten producing wells will be needed for each $55 \mathrm{MW}$ unit, requiring roughly $454 \mathrm{t} / \mathrm{h}$ $\left(1.0 \times 10^{6} \mathrm{lbm} / \mathrm{h}\right)$ of geothermal steam. For an average wellhead quality of 
$25 \%$, the resource utilization efficiency, $\eta_{u}$, would be approximately $41 \%$. Each unit of the power plant will produce about $1247 \mathrm{t} / \mathrm{h}\left(2.75 \times 10^{6}\right.$ $\mathrm{lbm} / \mathrm{h}$ ) of waste liquid which will be disposed of by means of reinjection wells.

\subsubsection{Makiling Banahaw (Los Baños)}

Los Baños lies about $70 \mathrm{~km}$ (43 mi) southeast of Manila on the island of Luzon. It is part of a huge area with a geothermal potential of around $720 \mathrm{MW}$; the area extends over $153,000 \mathrm{ha}$ (378,000 acres) in the MakilingBanahaw volcanic region.

At least fourteen wells have been drilled at the Los Baños thermal area. Bottom-hole temperatures are in the range $280-310^{\circ} \mathrm{C}\left(540-590^{\circ} \mathrm{F}\right)$, and geofluid qualities as high as $36 \%$ at the wellhead have been reported [Ravenholt; 1977a]. Most of the wells are located about $450 \mathrm{~m}$ (1475 ft) above sea level near Mount Bulalo.

A small, 1.2 MW, wellhead auxiliary geothermal power unit has been operating at Los Baños since early 1977; the technical particulars of this machine may be found in table 10.10. The main power units for Makiling Banahaw will consist of four identical units, each of $55 \mathrm{MW}$ capacity, of the single-cylinder, double-flow, mixed pressure, impulse-reaction design for separated-steam/hot-water flash ("double-fiash") energy conversion systems. Table 10.10 also contains the technical specifications for each of the first four units. According to these particulars, the geothermal resource utilization efficiency, $\eta_{u}$, will be $54 \%$ for a wellhead quality of $25 \%$ [DiPippo, 1878c].

\subsubsection{Leyte (Tongonan)}

A $3 \mathrm{MW}$ portable geothermal unit is operating at Tongonan on the island of Leyte. The unit consists of a noncondensing turbine, a single Curtis stage, connected to a generator through a helical reduction gear. The entire unit is mounted on a platform to facilitate its transfer from one site to another. The technical specifications are given in Table 10.10 .

\subsubsection{Other Philippine areas with geothermal potential}

The potential for geothermal development in the Philippines is significant; $1320 \mathrm{MW}$ by 1985 , as mentioned earlier. Table 10.11 gives a breakdown of the distribution of the expected generating capacity. Resistivity surveys indicate that the potential of the fields included in the table exceeds $2200 \mathrm{MW}$.

Some idea of the scope of the effort that will be needed to achieve an installed capacity of $1320 \mathrm{MW}$ in 1985 can be gotten from the fact that about 10 producing wells are needed for each $55 \mathrm{MW}$ unit. Thus, 240 producing wells must be drilled. Allowing three out of every four wells drilled 
TABLE 10.10-Technical specifications for Philippine geothermal power stations

\begin{tabular}{|c|c|c|c|c|}
\hline & $\begin{array}{l}\text { Tiwi } \\
\text { units 1-4 }\end{array}$ & $\begin{array}{l}\text { Los Baños" } \\
\text { wellhead } \\
\text { unit }\end{array}$ & $\begin{array}{l}\text { Los Bafios" } \\
\text { units } 1-4\end{array}$ & $\begin{array}{l}\text { Leyte } \\
\text { wellhead } \\
\text { unit }\end{array}$ \\
\hline $\begin{array}{l}\text { Year of startup } \\
\text { Turbine data: }\end{array}$ & 1981 & 1977 & 1981 & 1877 \\
\hline Type & $\begin{array}{l}\text { Single- } \\
\text { cylinder, } \\
\text { double-flow, } \\
\text { dual- } \\
\text { admission, } \\
6 \times 2 \text {. }\end{array}$ & $\begin{array}{l}\text { Single- } \\
\text { cylinder, } \\
\text { one Curtis } \\
\text { stage non- } \\
\text { condensing, } \\
\text { geared. }\end{array}$ & $\begin{array}{l}\text { Single- } \\
\text { cylinder, } \\
\text { double-flow, } \\
\text { dual- } \\
\text { admission, } \\
\mathbf{5 \times 2}\end{array}$ & $\begin{array}{l}\text { Single- } \\
\text { cylinder, } \\
\text { one Curtis } \\
\text { stage, non- } \\
\text { condensing, } \\
\text { geared. }\end{array}$ \\
\hline $\begin{array}{l}\text { Rated capacity, } \\
\text { MW. }\end{array}$ & 55 & 1.2 & 55 & 3.0 \\
\hline $\begin{array}{l}\text { Speed, rpm } \\
\text { Main steam pres- } \\
\text { sure, lbf/in? }\end{array}$ & $\begin{array}{l}3600 \\
101.4\end{array}$ & $\begin{array}{l}7129 / 1800 \\
95.5\end{array}$ & $\begin{array}{l}3600 \\
94.8\end{array}$ & $\begin{array}{l}7554 / 1800 \\
114.2\end{array}$ \\
\hline $\begin{array}{l}\text { Main steam } \\
\text { temperature, }{ }^{\circ} \mathrm{F} \text {. }\end{array}$ & 329.0 & 324.1 & 324.1 & 338.0 \\
\hline $\begin{array}{l}\text { Secondary steam } \\
\text { pressure, lbf/in². }\end{array}$ & 26.8 & - & 24.8 & - \\
\hline $\begin{array}{l}\text { Secondary steam } \\
\text { temperature. }\end{array}$ & 244.4 & 一 & 240.1 & - \\
\hline $\begin{array}{l}\text { Exhaust pressure, } \\
\text { in } \mathbf{H}_{\mathbf{g}} \text {. }\end{array}$ & 4.0 & 30.4 & 4.0 & 37.6 \\
\hline $\begin{array}{l}\text { Main steam flow } \\
\text { rate, } 10^{3} \mathrm{lbm} / \mathrm{h} \text {. }\end{array}$ & NA & 49.2 & 776.0 & 117.0 \\
\hline $\begin{array}{l}\text { Secondary steam } \\
\text { flow rate, } \\
10^{3} \mathrm{lbm} / \mathrm{h} . \\
\text { Condenser data: }\end{array}$ & NA & 一 & 276.0 & - \\
\hline Type & $\begin{array}{l}\text { Barometric, } \\
\text { spray jet. }\end{array}$ & None & $\begin{array}{r}\text { Barometric, } \\
\text { spray jet. }\end{array}$ & None. \\
\hline $\begin{array}{l}\text { Cooling water } \\
\text { temperature, }{ }^{\circ} \mathrm{F} \text {. }\end{array}$ & 87,1 & - & 87.1 & - \\
\hline $\begin{array}{l}\text { Outlet water } \\
\text { temperature, }{ }^{\circ} \mathrm{F} \text {. }\end{array}$ & 120.0 & - & 120.0 & - \\
\hline $\begin{array}{l}\text { Cooling water } \\
\text { flow rate, } \\
10^{\circ} \mathrm{lbm} / \mathrm{h}\end{array}$ & 27.8 & - & 29.1 & - \\
\hline $\begin{array}{l}\text { Heat rejection } \\
\text { system: Type. }\end{array}$ & $\begin{array}{l}\text { Cross-flow, } \\
\text { induced- } \\
\text { draft, } \\
\text { cooling } \\
\text { tower. }\end{array}$ & None & $\begin{array}{l}\text { Cross-fow, } \\
\text { induced- } \\
\text { draft, } \\
\text { cooling } \\
\text { tower. }\end{array}$ & None. \\
\hline
\end{tabular}

- Now called Makiling Banahaw.

- Also called Tongonan.

NA $=$ Not available.

to be producers, a total of 320 wells must be sunk. Assuming that each well costs $\$ 1,000,000$ (current costs are $\$ 750,000$ ), this will necessitate a capital investment, for wells alone, of $\$ 320,000,000$. Taking into account both the 
TaBLe 10.11-Potential geothermal power generation in the Philippines

[Ravenholt, 1977a]

\begin{tabular}{|c|c|c|c|c|c|c|c|c|c|}
\hline Geothermal field & 1978 & 1979 & 1980 & 1981 & 1982 & 1983 & 1984 & 1985 & $\begin{array}{l}\text { Est. max. } \\
\text { capacity }\end{array}$ \\
\hline Tiwi........ & 110 & 一 & 55 & 55 & - & 55 & 55 & - & 560 \\
\hline Los Bafios *. & $\mathbf{5 5}$ & $\mathbf{5 5}$ & - & $\mathbf{5 5}$ & $\mathbf{5 5}$ & - & $\mathbf{5 5}$ & 55 & 720 \\
\hline Tongonan..... & - & - & 55 & $\mathbf{5 5}$ & - & 55 & $\mathbf{5 5}$ & - & NA \\
\hline S. Negros...... & - & - & - & 55 & 55 & - & 55 & $\mathbf{5 5}$ & 425 \\
\hline Manat-Masara.... & - & - & - & $\mathbf{5 5}$ & 55 & - & $\mathbf{5 5}$ & $\mathbf{5 5}$ & $\mathbf{5 0 0}$ \\
\hline Total annual. & 165 & 55 & 110 & 275 & 165 & 110 & 275 & 165 & \\
\hline Cumulative.... & 165 & 220 & 330 & 605 & 770 & 880 & 1155 & 1320 & \\
\hline
\end{tabular}

- Now called Makiling Banahaw.

Notes.-All values in megawatts. Wellhead units not included. NA=Not available.

time required to prove a field and the construction lead time for a power plant, it is easy to see how difficult it will be to accomplish such an enormous project within seven years. Simply to drill the required wells within that time would mean that roughly four wells would have to be drilled each month.

Small, "wellhead" power units in the 1-10 MW range are expected to find application in those cases where large units are either unnecessary or impractical, particularly on the smaller islands of the Philippines such as the Visayan group of Leyte, Cebu, Bohol, Negros, and Panay. The electricity produced from them is cheaper than that generated by diesel engines, and their use provides a source of revenue and local power during the early stages of development of a geothermal field. The revenue obtained thus helps to alleviate the cash flow problem faced by field developers.

The opportunity exists for the Philippines to supply a significant percentage of its electrical needs from indigenous, geothermal energy. The high cost of imported petroleum products provides a great deal of motivation to get on with the development of the geothermal resources of the country.

\subsection{Turkey}

\subsubsection{Introduction}

The focus of geothermal energy development in Turkey is at the Kizldere field in the Menderes River Valley, western Anatolia. A small, wellhead power-generating unit is in operation at this site, and there are plans to expand the installed capacity to about $12 \mathrm{MW}$ in the near future.

Turkey is situated on an active tectonic zone and possesses great potential for geothermal energy. There are more than 600 hot springs, some with temperatures as high as $102^{\circ} \mathrm{C}\left(216^{\circ} \mathrm{F}\right)$, and numerous areas exhibit- 
ing hydrothermal alteration. Since 1962 the Mineral Research and Exploration Institute of Turkey (MTA) has been conducting surveys of the geothermal resources of the country by means of geological, geophysical, geochemical, and drilling studies. Fourteen promising areas have been thus far identified, the best of which is located at Kizuldere, near Sarayköy in the Denizli province [Alpan, 1975].

\subsubsection{Kiznldere}

The geothermal field at Kuzildere consists of two producing reservoirs, one lying between 300 and $800 \mathrm{~m}(984-2625 \mathrm{ft})$, and one between 400 and

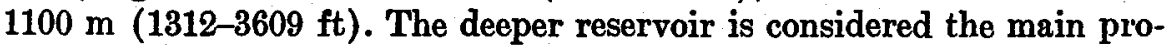
ducer and has a temperature of $200^{\circ} \mathrm{C}\left(392^{\circ} \mathrm{F}\right)$, whereas the upper zone is at $170^{\circ} \mathrm{C}\left(338^{\circ} \mathrm{F}\right)$. The chemical compositions of the fluids from the two zones are similar [Tezcan, 1975a]. Portions of the field may consist of isolated dry steam caps [Tezcan, 1975b].

From 1966 to 1975 fourteen wells were drilled in the area, with twelve of these being producers. The wells range in depth from 370-1241 m (1214-4072 ft). Half of the producing wells terminate in the upper reservoir; half reach the deep reservoir. In general, the produced fluid may be characterized as follows [Alpan, 1975]: Maximum temperature, 207.4 ${ }^{\circ}$ $\mathrm{C}\left(405.3^{\circ} \mathrm{F}\right)$; Maximum wellhead pressure, $2.16 \mathrm{MPa}\left(314 \mathrm{lbf} / \mathrm{in}^{2}\right)$; Maximum total flow rate (single well), $1003.5 \mathrm{t} / \mathrm{h}\left(2.2 \times 10^{6} \mathrm{lbm} / \mathrm{h}\right)$; Maximum vapor flow rate (single well), $67.6 \mathrm{t} / \mathrm{h}\left(149 \times 10^{3} \mathrm{lbm} / \mathrm{h}\right) ;$ Fluid dryness fraction (at wellhead) , $2-12 \%, 10 \%$ average.

A 0.5 MW power unit has been installed on well KD-XIII by MTA. The composition of the geofluid produced by this well is shown in Table 10.12 , along with the average composition for all twelve producing wells [Alpan, 1975]. Well KD-XIII is $760 \mathrm{~m}(2494 \mathrm{ft})$ deep, and produces from the lower reservoir which it enters at a depth of $590 \mathrm{~m}(1936 \mathrm{ft})$. The maximum temperature is $197^{\circ} \mathrm{C}\left(386.6^{\circ} \mathrm{F}\right)$, the production pressure is 1.08 $\mathrm{MPa}\left(157 \mathrm{lbf} / \mathrm{in}^{2}\right)$, and the flow rates of liquid and vapor are 522 and 20 $\mathrm{t} / \mathrm{h}\left(1.15 \times 10^{8}\right.$ and $\left.44 \times 10^{3} \mathrm{lbm} / \mathrm{h}\right)$, respectively [Alpan, 1975 ]. The characteristics of the wellhead turbine are given in table 10.13. The plant has a specific geofluid consumption rate of $79.8 \mathrm{~kg} / \mathrm{kW} \cdot \mathrm{h}(176 \mathrm{lbm} / \mathrm{kW} \cdot \mathrm{h})$.

A realistic appraisal of the ultimate potential of the Kuzldere field is difficult owing to serious problems of plugging of the wells. Out of a total of twelve producing wells only six have been judged to be suitable for production. However, only three of these can be relied upon at any given time because of the necessity for periodic reaming of clogged wells. With three wells in operation and $1086 \mathrm{t} / \mathrm{h}\left(2.4 \times 10^{6} \mathrm{lbm} / \mathrm{h}\right)$ of geofluid being produced, it has been estimated that $11,430 \mathrm{~kW}$ (gross) or $10,550 \mathrm{~kW}$ (net) could be generated. Under the best conditions, if six wells could be used simultaneously to produce $1640 \mathrm{t} / \mathrm{h}\left(3.6 \times 10^{\circ} \mathrm{lbm} / \mathrm{h}\right)$, then the system could support $32 \mathrm{MW}$ (gross) or $28 \mathrm{MW}$ (net). To achieve this level of 
TabLE 10.12-Geofluid characteristics at Kizzldere Field, Turkey

[After Alpan, 1975]

\begin{tabular}{|c|c|c|}
\hline \multirow[b]{2}{*}{ Substance } & \multicolumn{2}{|c|}{ Concentration, ppm } \\
\hline & Well KD-XIII & Avg. 12 wells \\
\hline Bicarbonate, $\mathrm{HCO}_{3} \ldots \ldots \ldots \ldots \ldots \ldots \ldots \ldots$ & 2116 & 2247 \\
\hline 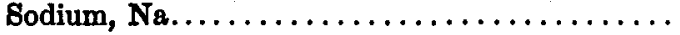 & 1174 & 1240 \\
\hline Sulfate, $\mathbf{s O}_{1} \ldots \ldots \ldots \ldots \ldots \ldots \ldots \ldots \ldots \ldots$ & 641 & 811 \\
\hline Silica, $\mathrm{SiO}_{2} \ldots \ldots \ldots \ldots \ldots \ldots \ldots \ldots \ldots \ldots \ldots \ldots \ldots \ldots \ldots$ & 327 & 288 \\
\hline Potassium, $\mathbf{K} \ldots \ldots \ldots \ldots \ldots \ldots$ & 131 & 128 \\
\hline Chloride, $\mathbf{C l} \ldots \ldots \ldots \ldots \ldots \ldots \ldots \ldots \ldots \ldots$ & 115 & 107 \\
\hline 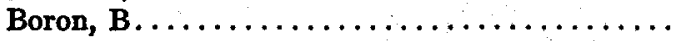 & 24. 5 & 24. 5 \\
\hline 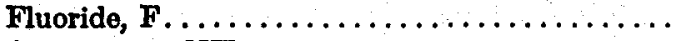 & 18. 2 & 18. 15 \\
\hline Ammonium, $\mathrm{NH}_{4} \ldots \ldots \ldots \ldots \ldots \ldots \ldots \ldots$ & 5. 8 & 3. 95 \\
\hline Calcium, Ca......... & 4. 1 & 3. 2 \\
\hline Magnesium, $\mathbf{M g}_{\mathbf{g}} \ldots \ldots \ldots \ldots \ldots \ldots \ldots$ & 1.5 & 0.95 \\
\hline Arsenic, As. $\ldots \ldots \ldots \ldots \ldots \ldots \ldots$ & 0.51 & 0. 17 \\
\hline$\ldots \ldots \ldots \ldots \ldots \ldots \ldots \ldots \ldots \ldots \ldots \ldots \ldots \ldots$ & 8. 9 & 8. 8 \\
\hline
\end{tabular}

output, a reliable and effective system of reinjection of waste water would need to be implemented [Alpan, 1975].

\subsubsection{Other areas being explored in Turkey}

Exploration has reached the drilling phase in a number of areas including: Ankara (Ayas, Cubuk, Kuzılcahamam, and Mürtet), Afyon, Izmir (Agamemnun and Seferihisar-Doğanbey), Çanakkale (Tuzla-Kestanbol), and Söke (Germencik).

Preliminary investigations are being carried out at several other sites including: Bergama-Dikili, Çan-Gönen, Eskişehir, Gediz, NevşehirKozakl, Salihli-Turgutlu, Sindırğ1-Hisaralın, and Tatvan-Nemrut.

TABLe 10.13.-Characteristics of wellhead power generator at KD-XIII, Kuzzldere, Turley

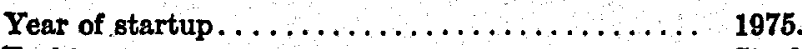

Turbine type..................... Single-cylinder, one Curtis stage, noncondensing.

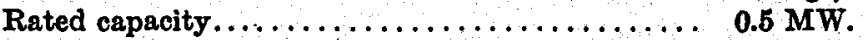

Speed........................ $4500 \mathrm{rpm}$.

Inlet steam pressure.................. $\sim 70.5 \mathrm{lbf} / \mathrm{in}^{2}$.

Inlet steam temperature................ $\sim \mathbf{3 0 2 ^ { \circ }} \mathbf{F}$.

Noncondensable gas content. ............ $17 \%$ by weight of steam.

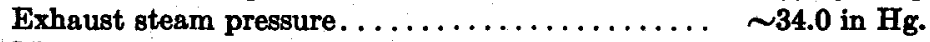

Maximum allowable pressure. . . . . . . . . . $\sim 114 \mathrm{lbf} / \mathrm{in}^{2}$.

Turbine steam flow rate $\ldots \ldots \ldots \ldots \ldots \ldots \ldots \ldots \ldots \sim \mathbf{3 2 5 5} \mathrm{lbm} / \mathrm{h}$.

Last-stage blade height............... 3 in.

a Total geofluid flow rate is $\sim 88 \times 10^{3} \mathrm{lbm} / \mathrm{h}$; dryness fraction is $3.7 \%$. 
It is hoped that the geothermal resources at these sites will be suitable to allow the generation of electricity, the heating of buildings and greenhouses, and the general improvement of hot springs for the tourist trade [Alpan, 1975].

\subsection{Union of Soviet Socialist Republics}

\subsubsection{Overview}

Although the Soviet Union has a huge potential of moderate-temperature geothermal waters which may someday be exploited for space or process heating, the only known sites at which geothermal energy is being used or contemplated for electric power production are located on the Kamchatka peninsula, well-removed from the main population centers of the country. Whereas the potential for direct heating from geothermal resources is estimated at 48,000 MW (thermal) [Tikhonov and Dvorov, 1970], the geothermal electric power capacity may only amount to a few hundreds of megawatts.

Several areas in the Kurile Islands and on the Kamchatka peninsula have been identified where electric power plants could be installed [Makarenko, et al., 1970; Tikhonov and Dvorov, 1970]. These include : Pauzhetkn, Uzono-Semyachik, Mutnovo-Zhirovo, Bolshoye-Bannoye, Goryachy Plyazh (Yuzhno-Kurilsk). All of these sites are in regions of recent volcanism which are characterized by dramatic surface thermal manifestations.

The locations of several major hydrothermal areas on the Kamchatka peninsula are shown in figure 10.30. The major population center of the area, Petropavlovsk-Kamchatskiy, is within $75 \mathrm{~km}(47 \mathrm{mi})$ of several of these geothermal prospects. By and large the resources are of low-tomoderate temperature and are situated in relatively shallow reservoirs $(<1 \mathrm{~km})$. The highest bottom-hole temperatures have been found at the Pauzhetka site, e.g., about $200^{\circ} \mathrm{C}\left(392^{\circ} \mathrm{F}\right)$ at $400 \mathrm{~m}(1312 \mathrm{ft})$.

It is known that at least two geothermal power plants have been in operation in Russia and that several others have been mentioned as either under construction or in planning. These include the flash-steam plant at Pauzhetka, the binary plant at Paratunka, the multiple-flash steam plant under construction at Bolshoye-Bannoye, and the steam plants proposed for Makhachkala and Yuzhno-Kurilsk. These will be discussed in the following sections.

\subsubsection{Pauzhetka}

Approximately 20 to 25 wells have been drilled at the Pauzhetka geothermal area. Each of these produces roughly $36 \mathrm{t} / \mathrm{h}(79,000 \mathrm{lbm} / \mathrm{h})$ of steam and liquid. The geofluid is a mixture of liquid and vapor having a dryness fraction of about $9 \%$. The wellhead pressure lies between 196-392 
FIGURE 10.30-Location of hydrothermal areas on Kamchatka Peninsula, USSR [after Vakin, et al., 1970]. Key : $1=$ Kireunsky ; $2=$ Uzon-Geyserny; $3=$ Semyachínsky; $4=$ Nalychevsky ; $5=$ Bolshoye-Bannoye ; $6=$ Paratunka ; $7=$ Zhirovsky ; $8=$ Severo, Mutnovsky ; $9=$ Khodutkinsky; $10=$ Pauzhetka ; 11=Koshelevsky ; 12= Petropavlovsk-Kamchatskiy.

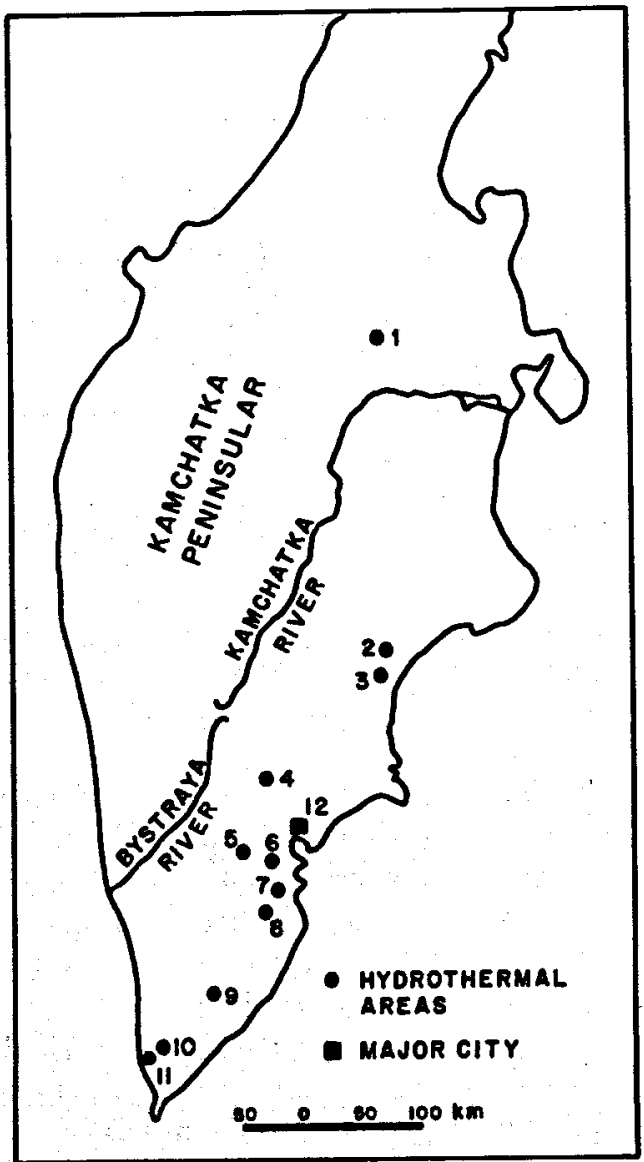

$\mathrm{kPa}\left(28-57 \mathrm{lbf} / \mathrm{in}^{2}\right)$. The fluid carries $1000-3400 \mathrm{ppm}$ of total dissolved solids, of which about $250 \mathrm{ppm}$ is silica. The noncondensable gases amount to slightly more than $0.05 \%$ (by weight) of the geofluid mixture (or $0.6 \%$ of the steam) with the bulk of the gases being $\mathrm{CO}_{2}(92 \%)$, and the rest. being mainly $\mathrm{H}_{2} \mathrm{~S}(4 \%)$ and $\mathrm{NH}_{3}(3 \%)$ [Tikhonov and Dvoror, 1970].

At present, a separated-steam plant of $5 \mathrm{MW}$ capacity is in operation at Pauzhetka. The plant is owned and operated by the Kamchatka Electricity Production and Distribution Administration. The plant began production in 1967. About nine wells are required to supply the station. The steam piping from the wells to the power house ranges in diameter from

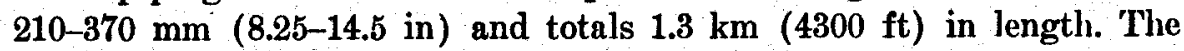
steam pipes are made of carbon steel.

The design of the plant is simple and straightforward; a flow dingram is given in figure 10.31. Cyclone separators with mist eliminators in the upper part yield steam of approximately 0.995 dryness fraction. The 5 MW output is obtained by means of two $2.5 \mathrm{MW}$ turbines arranged in 


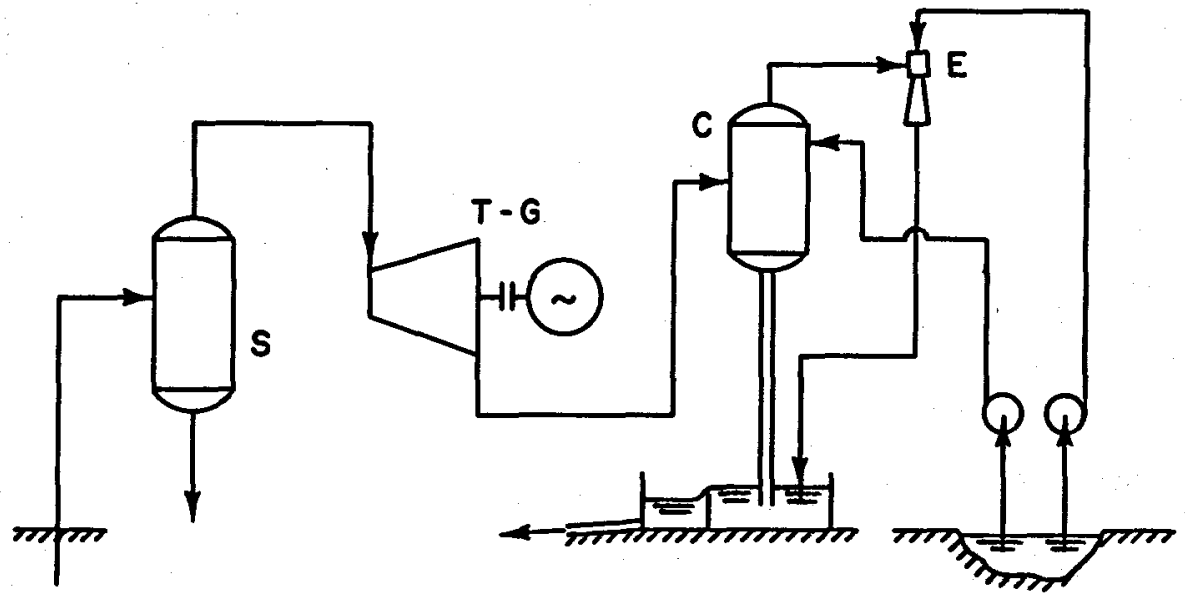

Fraure 10.31-Flow diagram for Pauzhetka flash-steam geothermal yower plant [after ARPA, 1972]. Key : $S=$ separator; $T-G=$ turbo-generntor ; $C=$ condenser; $\mathbf{E}=$ water-jet ejector.

tandem. The machines were manufactured by the 'Thermal Turbine Machine Corporation Plant at Kaluga, and are situated in a turbine room that has a floor area of $33 \mathrm{~m} \times 9 \mathrm{~m}=297 \mathrm{~m}^{2}\left(108 \mathrm{ft} \times 30 \mathrm{ft}=3200 \mathrm{ft}^{2}\right)$. The condensers are of the direct-contact type, made of stainless steel, with $11 \mathrm{~m}^{3}\left(389 \mathrm{ft}^{3}\right)$ of steam volume, and are fitted with 118 nozzles through which the cooling water is sprayed.

A summary of the technical particulars for the unit may be found in table 10.14 [Naymanov, 1970]. On the basis of the data in table 10.14 and assuming a geofluid wellhead dryness fraction of $9 \%$, the plant would have a resource utilization efficiency of $54 \%$ and would consume 56 $\mathrm{kg} / \mathrm{kW} \cdot \mathrm{h}(123 \mathrm{lbm} / \mathrm{kW} \cdot \mathrm{h})$. However, values as low as $5 \%$ have been

TABLW 10.14-Technical specifications for Pauzhetta geothermal power plant

Year of startup. . . . . $\ldots \ldots \ldots \ldots \ldots \ldots \ldots$. 1967.

Turbine data:

Type...

Tandem-compound, single-flow.

Rated capacity. $2 \times 2.5 \mathrm{MW}$.

Steam inlet pressure. . . . . . . .

Steam inlet temperature............ $260.6^{\circ} \mathrm{F}$.

Noncondensable gas content. ......... $0.6 \%$ by weight of steam.

Exhaust pressure..............

Steam flow rate. ............... $59.5 \times 10^{3} \mathrm{lbm} / \mathrm{h}$.

Condenser type................... Direct-contact, barometric.

Gas extractor data:

Type....................... Water jet ejector.

Water impeller power............. $170 \mathrm{~kW}$.

Heat rejection system: Type............. Once-through, Pauzhetka River. 
reported for the geofluid dryness fraction [Tikhonov and Dvorov, 1970], and this would reflect a much lower utilization efficiency (about 28\%). The actual value probably lies somewhere between these limits.

Power from the plant is transmitted to the town of Pauzhetka, the Ozernovsk fishing combine, and the collective farm at Krasnyy Truzhenik. The power line carries electricity at $35 \mathrm{kV}$ and is $30 \mathrm{~km}$ (19 mi) long [ARPA, 1972].

The geothermal liquid which is separated at the wellheads is discharged into the Pauzhetka River at a temperature of $110^{\circ} \mathrm{C}\left(230^{\circ} \mathrm{F}\right)$ and at a rate of $110 \mathrm{~kg} / \mathrm{s}(220 \mathrm{lbm} / \mathrm{s})$. There were plans to make use of this hot fluid for the heating of greenhouses although it is not known whether such plans have been implemented as yet [Tikhonov and Dvorov, 1970]. The same authors also reported that the cost of electricity from the Pauzhetka geothermoelectric station is less by a factor of 10 to 15 than electricity generated by diesel power plants on the Kamchatka peninsula.

Although it has been reported that there were intentions to expand the capacity of the plant to $12.5 \mathrm{MW}$, and eventually to $20 \mathrm{MW}$, these intentions remain unfulfilled at present [ARPA, 1972]. The ultimate potential of the Pauzhetka reservoir has been estimated at between 50 and 70 MW of electrical power [Tikhonov and Drorov, 1970].

\subsubsection{Paratuntea}

The Paratunka geothermal power project was an ambitious attempt at providing a form of total-energy system, albeit on a rather limited scale. The power plant was a binary-fluid cycle which employed refrigerant-12 as the working fluid in conjunction with geothermal waters at temperatures as low as $81^{\circ} \mathrm{C}\left(178^{\circ} \mathrm{F}\right)$. The power from the plant served a small village and several Soviet state farms. Furthermore, the geothermal water, after leaving the power house and having been cooled to $45^{\circ} \mathrm{C}$ $\left(113^{\circ} \mathrm{F}\right)$ in the plant's heat exchangers, was put to use to heat the soil in a series of greenhouses. Finally, the cooling water leaving the condensers of the power plant was used to water the plants in the greenhouses. It is not possible to use the waters of the Paratunka River directly for this purpose because of their low temperature of $5-7^{\circ} \mathrm{C}\left(41-45^{\circ} \mathrm{F}\right)$.

It is generally acknowledged that the Paratunka plant was the first binary geothermal pilot plant to generate electricity, having begun operations in 1967. The plant was built to test the design theories of geothermal binary plants. Although the plant apparently operated successfully for several years, it has been reported recently [Smith, 1978] that the power station has been closed and dismantled because of difficulties with leaks in the refrigerant-12 piping. Furthermore, the properties of refrigerant-12 are not ideally suited for geothermal applications [Naymanov, 1970]. Nevertheless, it is instructive to examine the details of the Paratunka plant. 


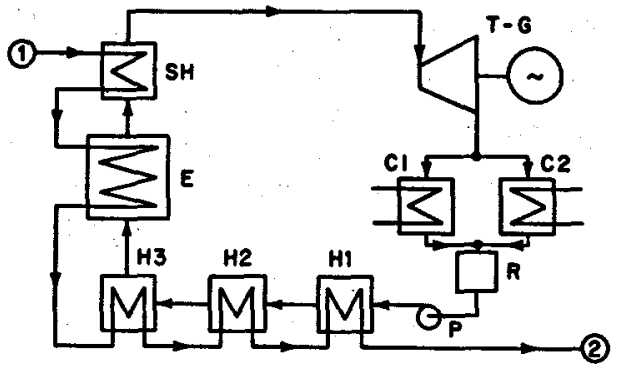

Figure 10.32-Flow diagram for Paratunka binạry geothermal power plant. Key: (1)-(2) $=$ hot water inlet-outlet; $\mathbf{H 1}, \mathbf{H 2}, \mathbf{H 3}=$ heaters; $\mathbf{E}=$ evaporatiors; $\mathbf{S H}=$ superheater; $T-G=$ turbo-generator; $\mathbf{C 1}, \mathbf{C 2}=$ condensers ; $\mathbf{R}=\mathbf{r e -}$ ceiver; $\mathbf{P}=\mathbf{p u m p}$.

The geothermal hot water is obtrined from a number of shallow wells located about $1.5 \mathrm{~km}(0.9 \mathrm{mi})$ from the plant site. The wells range in depth from 302-604 m (991-1982 ft), and in diameter from 127-200 mm (5-7.875 in) [ARPA, 1972]. Eight wells were completed in 1964 before construction got underway on the plant, six wells were used to supply the plant with about $280 \mathrm{t} / \mathrm{h}\left(617 \times 10^{3} \mathrm{lbm} / \mathrm{h}\right)$ of hot water [Moskvicheva and Popov, 1970]. One of these wells was kept on reserve.

A simplified flow diagram of the power plant is given in figure 10.32; the technical specifications are listed in table 10.15. The values given in the table are the actual values achieved during the tests reported by Moskvicheva and Popor [1970]. In certain respects, these differ from the design values. For example, the hot water inlet temperature should have been

\section{TABLE 10.15-Technical specifications for Paratunka geothermal power plant}

Year of startup. ............ 1967 (now dismantled).

Turbine data:

Type.

Rated capacity.

Radial outflow.

Maximum capacity. $680 \mathrm{~kW}$.

. $750 \mathrm{~kW}$

Secondary working fluid........ Dichlorodifluoromethane, $\mathbf{C C l}_{2} \mathrm{~F}_{3}$ (Ref-12).

Ref-12 inlet pressure......... $202.7 \mathrm{lbf} / \mathrm{in}^{2}$.

Ref-12 inlet temperature....... $149^{\circ} \mathrm{F}$.

Ref-12 exhaust pressure........ $113.8 \mathrm{lbf} / \mathrm{in}$ '.

Ref-12 exhaust temperature...... $\sim 105^{\circ} \mathrm{F}$.

Ref-12 mass flow rate......... $\sim 640 \times 10^{3} \mathrm{lbm} / \mathrm{h}$.

Geothermal fluid data:

Inlet pressure............ $42.6 \mathrm{lbf} / \mathrm{in}^{2}$.

Inlet temperature............ $178.7^{\circ} \mathrm{F}$.

Outlet temperature........... $\sim 113^{\circ} \mathrm{F}$.

Hot water flow rate......... $617 \times 10^{3} \mathrm{lbm} / \mathrm{h}$.

Condenser data:

Type................. Surface type, shell and tube.

Cooling water inlet temperature... 43-46 $6^{\circ} \mathrm{F}$.

Cooling water outlet temperature. . $55-58^{\circ} \mathbf{F}$.

Cooling water flow rate........ $3.307 \times 10^{\circ} \mathrm{lbm} / \mathrm{h}$.

Heat rejection system:

Type.................. Once-through, Paratunka River.

Water pump power.......... $110 \mathrm{~kW}$. 
$90^{\circ} \mathrm{C}\left(194^{\circ} \mathrm{F}\right)$, the cooling water from the Paratunka River should have been $5^{\circ} \mathrm{C}\left(41^{\circ} \mathrm{F}\right)$, and the condensation temperature of the refrigerant-12 should have been $15^{\circ} \mathrm{C}\left(59^{\circ} \mathrm{F}\right)$, instead of the actual values of $81.5^{\circ} \mathrm{C}$ $\left(178.7^{\circ} \mathrm{F}\right), 6^{6}-8^{\circ} \mathrm{C}\left(42.8^{-}-46.4^{\circ} \mathrm{F}\right)$, and $32^{\circ} \mathrm{C}\left(89.6^{\circ} \mathrm{F}\right)$, respectively. It should be noted, however, that the validity of the data, as reported, is doubtful since the performance data quoted in the above reference leads to a negative pinch-point temperature difference in the geofluid/refrigerant12 heat exchanger, a result which is prohibited by the laws of thermodynamics.

Nevertheless, the efficiency of the energy conversion system was determined in terms of the amount of hot water required for a given output. Figure 10.33 shows the hot water flow rate as a function of the gross power output. It may be seen that the actual fiuid consumption was roughly $65 \%$ higher than the design value at $680 \mathrm{~kW}$ because of the $8.5-9^{\circ} \mathrm{C}$ shortfall in geofluid temperature. In fact, even at the actual temperature, the actual fluid requirements exceeded the calculated values by about 9 percent. The specific hot water consumption at maximum load $(680 \mathrm{~kW})$ was about $412 \mathrm{~kg} / \mathrm{kW} \cdot \mathrm{h}(908 \mathrm{lbm} / \mathrm{kW} \cdot \mathrm{h})$. This converts to a geothermal resource utilization efficiency of $23 \%$ (gross), or $15 \%$ (net) when $110 \mathrm{~kW}$ for the cooling water pump and $130 \mathrm{~kW}$ for the two refrigerant-12 circulating pumps are subtracted from the gross output. The turbo-expander reached an isentropic efficiency of $82 \%$ at full load, two percentage points below the design value.

The turbine-generator, three preheaters, the boiler/superheater, two condensers, and the associated auxiliary equipment were located in a machine hall which was $12 \mathrm{~m}$ wide, $24 \mathrm{~m}$ long and $8 \mathrm{~m}$ high $(39 \times 79 \times 26 \mathrm{ft})$. A photograph of the turbine-generator is shown in figure 10.34 .

The specific installed cost of the plant has been reported to be four times that of the other Soviet geothermal power plant which is located at Pauzhetka. The high cost of Paratunka was attributed to the small size of the unit, the costs associated with the development of the unique halocarbon

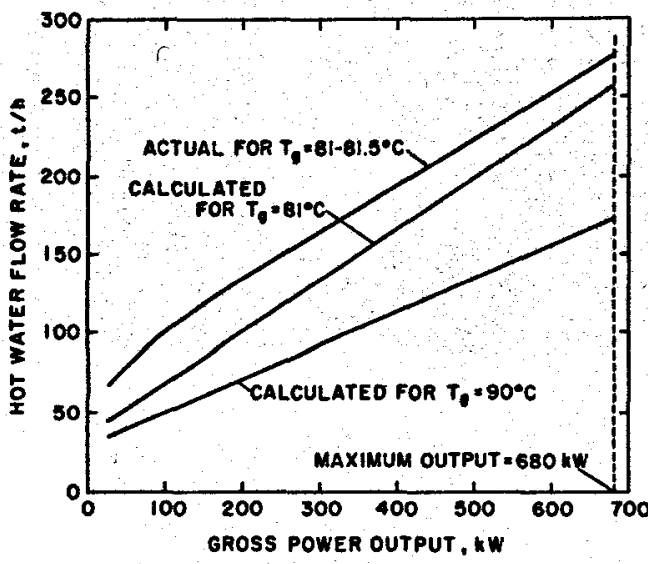

Bravae 10.33-Performance characteristics of Paratunka binary plant : bot water consumption as a function of gross power output, actual versus calculated [after Moskvicheva and Popor, 1970]. 


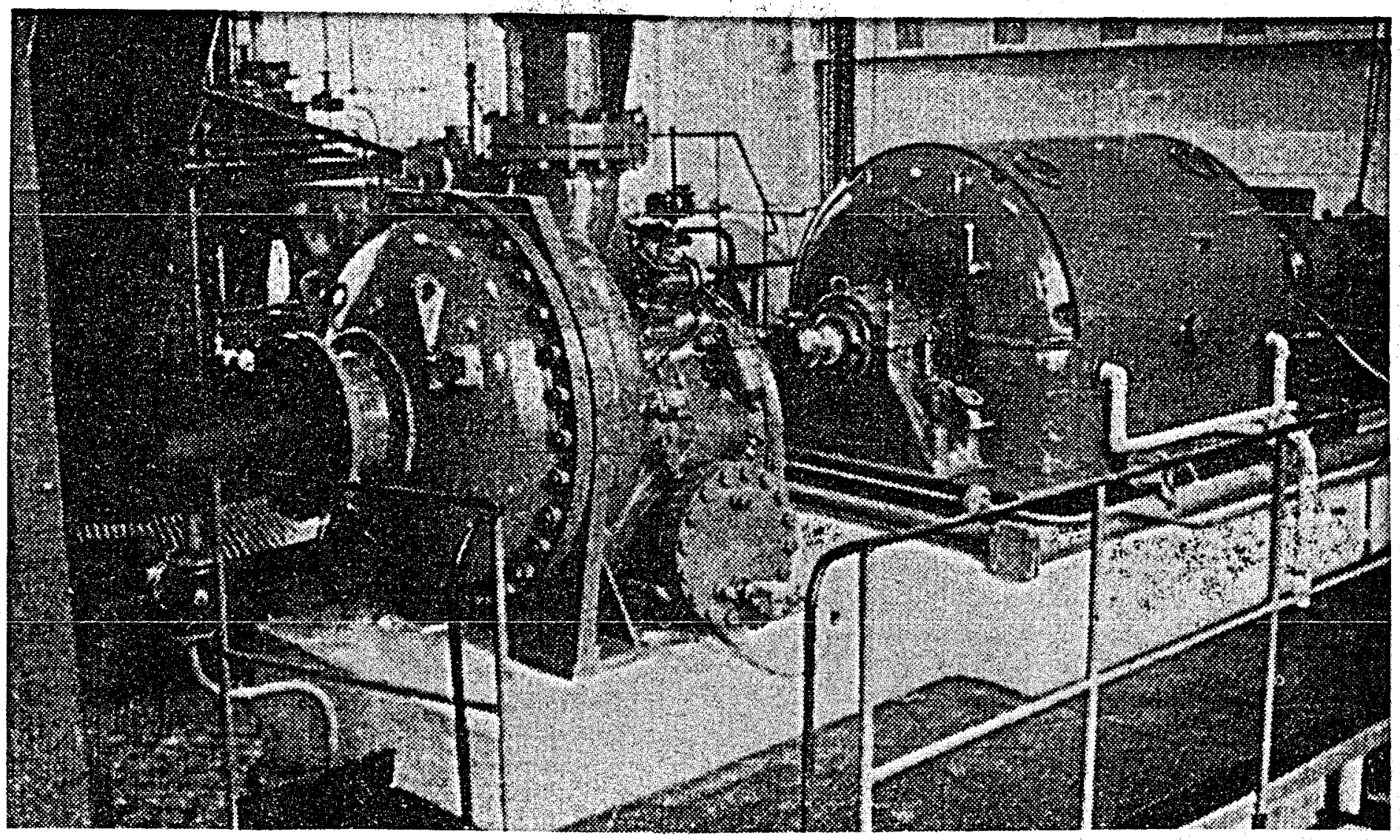

Frouke 10.34-Paratunka turbo-generator unit [Moskricheva and Popov, 1970]. 
turbo-expander, and with the installation of the piping system to supply the adjacent greenhouse facilities [ARPA, 1972].

\subsubsection{Bolshoye-Bannoye}

It was reported in 1965 [ARPA, 1972] that a sophisticnted, multipleflash geothermal power plant was under construction at Bolshoye-Bannoye. Only twenty wells had been completed and the rate of construction was slow. It is not known whether or not the plant has been completed or is in operation.

It was to have a rated output of $8 \mathrm{MW}$, and use two $2.5 \mathrm{MW}$ lowpressure turbines and four $750 \mathrm{~kW}$ very-low-pressure turbines. A flow diagram for the plant is shown in figure 10.35. A mixture of geothermal steam and hot water from a number of wells is fed to a series of separators at a pressure of $152 \mathrm{kPa}\left(22 \mathrm{lbf} / \mathrm{in}^{2}\right)$. By the time the separated steam reaches the low-pressure turbines, the pressure has fallen to $101 \mathrm{kPa}(14.7$ $\left.\mathrm{lbf} / \mathrm{in}^{2}\right)$. An intermediate flash tank generates additional steam at one atmosphere for the low-pressure turbines from the hot water which was separated at the wellheads. The remaining hot water is first collected in a receiver and then flashed successively to produce three streams of subatmospheric steam for use in a set of four multiple-admission turbines. The liquid effuent from the final flasher must be pumped back to atmospheric pressure for disposal.

Based upon the exergy of the geofluid at the wellhead and the indicated geofluid flow rate and power output, the plant would have a gross geothermal resource utilization efficiency of $35 \%$, or a specific geofluid consumption of $90 \mathrm{~kg} / \mathrm{kW} \cdot \mathrm{h}(198 \mathrm{lbm} / \mathrm{kW} \cdot \mathrm{h})$. The quality of the geofluid mixture at the wellhead would be about 7 percent. The cost of electricity from the plant was estimated to be about one-sixth the cost of electricity from conventional sources serving the city of Petropavlovsk-Kamchatskiy [ARPA, 1972].

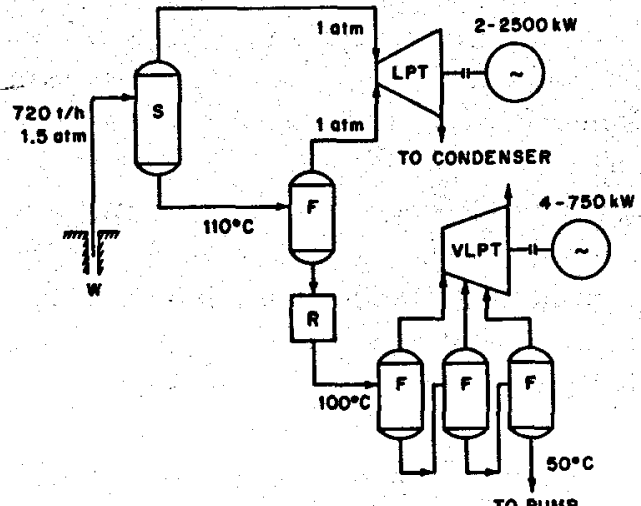

FrgURE 10.35-Flow diagram for proposed multiple-fiash plant at Bolshoye-Bannoye [after ARPA, 1972]. 


\subsubsection{Potential Soviet geothermal power stations}

Makhachkala. A $12 \mathrm{MW}$ flash-steam geothermal plant has been proposed to satisfy the electrical and heating requirements of the town of Makhachkala in the Dagestan ASSR. It is estimated that a total geofluid discharge of about $100 \mathrm{t} / \mathrm{h}\left(220 \times 10^{3} \mathrm{lbm} / \mathrm{h}\right)$ will be required to supply the plant. Very deep wells of the order of 4-4.5 km (2.5-2.8 mi) are needed in order to tap waters of $160^{\circ} \mathrm{C}\left(320^{\circ} \mathrm{F}\right)$ temperature. Water at $120^{\circ} \mathrm{C}$ $\left(248^{\circ} \mathrm{F}\right)$ may be obtained from wells $2.5-3 \mathrm{~km}(1.6-1.9 \mathrm{mi})$ in depth. No other technical details on this plant have been made available.

Yuzhno-Kurilsk. A geothermal power plant of about 5-6 MW capacity has been proposed for the Goryachy Playazh geothermal area on Kumashir Island of the Kurile Island group, about $8 \mathrm{~km}(5 \mathrm{mi})$ from the town of Yuzhno-Kurilsk. The plant will be designed to use geofluid at $130^{\circ} \mathrm{C}$ $\left(266^{\circ} \mathrm{F}\right)$. Numerous surface thermal manifestations exist in the Guryachy Playazh region, with several steam vents having temperatures of 100 $130^{\circ} \mathrm{C}\left(212-266^{\circ} \mathrm{F}\right)$.

Nizhne-Koleshevskayja. Recently, a report was issued which indicated that a plant of 50-70 MW capacity will soon be constructed at NizhneKoleshevskaya [ECPE, 1977], but no additional data were included.

Avachinski Volcano. The same source also reported that plans are underway to tap the Avachinski volcano on the Kamchatka peninsula at a depth of $3.5 \mathrm{~km}(11,500 \mathrm{ft})$ in the hope of establishing a resource which might supply a $5000 \mathrm{MW}$ geothermal plant for 500 years.

\subsection{United States}

\subsubsection{Historical background}

The history of geothermal energy in the United States dates back over one hundred and thirty years. Explorer-surveyor William Bell Elliott is credited with discovering The Geysers natural steam field in northern California while bear-hunting in April 1847 between Cloverdale and Calistoga [Tengquist and Hirschfie]d, 1976]. The awesome sight of clouds of water vapor shooting high into the air accompanied by the roar of escaping steam and the smell of odorous sulfur fumes led Elliott to believe he had discovered the very gates to the Inferno.

The region was exploited at first as a tourist attraction boasting the alleged therapeutic qualities of the hot fluids. When the popularity of the resort faded, an attempt was made in the early 1920s to develop its potential for electric power production. John D. Grant, a rock, gravel, and cement contractor, deserves the credit for initiating the development of The Geysers [Siegfried, 1925].

Large quantities of underground steam were tapped with relatively shal-

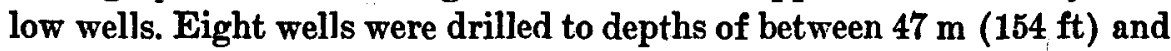


$194 \mathrm{~m}(363 \mathrm{ft})$. The steam was used to power a $250 \mathrm{~kW}$ generator driven by a reciprocating, noncondensing engine. Further power development at that time, however, was not carried out. Although the major technical obstacles to the use of geothermal energy seemed to have been overcome, geothermal electric power plants would have had to compete against hydroelectric plants that were appearing throughout the same areas where geothermal energy was present.

Thus the potential of The Geysers lay unexploited until B. C. McCabe, a Los Angeles lumber merchant with no engineering education and no prior experience in the power industry, decided to invest in the site in the early 1950's. He leased 1465 ha (3620 acres) from The Geysers Development Company, established a company called Magma Power Co., and drilled his first well in 1955 . The well was called Magma No. 1; it was $249 \mathrm{~m}$ (817 $\mathrm{ft})$ deep and produced $68 \mathrm{t} / \mathrm{h}(150,000 \mathrm{lbm} / \mathrm{h})$ of dry steam at a wellhead pressure of $790 \mathrm{kPa}\left(114 \mathrm{lbf} / \mathrm{in}^{2}\right)$.

McCabe joined forces with Dan A. McMillan, Jr. of Thermal Power Company, and together they completed six wells by 1957, ranging in depth from $161 \mathrm{~m}(527 \mathrm{ft})$ to $431 \mathrm{~m}(1414 \mathrm{ft})$. They signed a contract on October 30, 1958, with the Pacific Gas and Electric Company (PG\&E) which obligated Magma-Thermal to supply steam at a flow rate of $107 \mathrm{t} / \mathrm{h}$ $(235,000 \mathrm{lbm} / \mathrm{h})$ and at a pressure of $790 \mathrm{kPa}\left(114 \mathrm{lbf} / \mathrm{in}^{2}\right)$ to the strainer inlet of a $12,500 \mathrm{~kW}$ turbine-generator [Iengquist and Hirschfeld, 1976].

In the early days of geothermal energy discovery in the United States, several other areas besides The Geysers were explored. Most of these were areas which appeared to be promising because of surface manifestations such as steam vents, hot springs, boiling mud pots, etc. Potential sites in the Imperial Valley such as Niland and Mullet Island (Salton Sea) were studied and drilled, as early as 1927 . It is interesting to note that the wells at the Salton Sea produced gas (probably carbon dioxide), steam, water, and a large amount of "slush." The utilization of these fluids, which contain up to $800,000 \mathrm{ppm}$ of dissolved solids, remains one of the major unsolved problems in geothermal energy in the United States.

\subsubsection{The Geysers-Sonoma and Lake Counties, Calif.}

The largest geothermal electric power complex in the world is located at The Geysers in Sonoma County of northern California. The Pacific Gas and Electric Company (PG\&E) produces $663 \mathrm{MW}$ at the site with $245 \mathrm{MW}$ of additional capacity under construction as of July 1979, and intends to install an additional $220 \mathrm{MW}$ by 1982 . The present proved capacity of The Geysers exceeds $2000 \mathrm{MW}$.

The Geysers is one of several areas of hot springs and fumaroles which occur along a section of a long fault zone in the Mayacmas Mountains in northern California. The geothermal reservoir is of the vapor-dominated type and extends over an area $21.5 \mathrm{~km} \times 8.6 \mathrm{~km}(13.3 \mathrm{mi} \times 5.3 \mathrm{mi})$, bounded 
by the Mercuryville fault zone on the southwest and the Collayomi fault zone on the northeast [I Donnelly et al., 1976]. The drilled area covers over 5000 ha $(12,350$ acres $)$ in an $11.2 \mathrm{~km} \times 4.5 \mathrm{~km}$ (7 mi $\times 2.5 \mathrm{mi})$ strip lying roughly between the Big Sulphur Creek in Sonoma County and the border between Sonoma and Lake Counties.

The source of the thermal energy is believed to be a magmatic intrusion which lies at about $10 \mathrm{~km}(32,800 \mathrm{ft})$. The steam-producing areas are highly fractured regions with near-vertical orientation. The fractures occur in hard, dense graywacke (a sandstone), and steam is found in two depth ranges: a shallow zone at 300-600 $\mathrm{m}$ (984-1968 ft) and a deep zone at 1.5-3.0 km (4920-9840 ft) [Reed and Campbell, 1975]. It is known, furthermore, that the vapor-dominated reservoir is characterized by a pressure that is far less than the hydrostatic pressure and which extends to depths of at least $3 \mathrm{~km}(9840 \mathrm{ft})$.

Approximately 175 wells have been drilled at The Geysers, with 75 of these actively delivering steam to the first eleven units having a total installed capacity of $502 \mathrm{MW}$. Approximately 15 wells are needed to support a typical $110 \mathrm{MW}$ unit. A steam well will produce $34-159 \mathrm{t} / \mathrm{h}(75,000$ $350,000 \mathrm{lbm} / \mathrm{h})$ at a wellhead pressure of $960 \mathrm{kPa}\left(140 \mathrm{lbf} / \mathrm{in}^{2}\right)$. A steam flow rate of $91 \mathrm{t} / \mathrm{h}(200,000 \mathrm{lbm} / \mathrm{h})$ may be taken as typical. The closed-in pressure is about $3.4 \mathrm{MPa}\left(490 \mathrm{Jbf} / \mathrm{in}^{2}\right)$ and the corresponding temperature is $240^{\circ} \mathrm{C}\left(465^{\circ} \mathrm{F}\right)$, with a specific enthalpy of $280 \mathrm{~kJ} / \mathrm{kg}(1204 \mathrm{Btu} / \mathrm{lbm})$. A combination of mud and air drilling is used, with mud being used for the larger portions of the wells (dia. $>317.5 \mathrm{~mm}$ (>12.5 in)). Although aiv drilling is faster since the cuttings are removed more quickly from beneath the drill bit, it can only be used in the smaller diameter sections where the seepage of liquid into the hole is not a serious problem.

A typical gathering system for a $55 \mathrm{MW}$ unit consists of a network of carbon steel pipes, starting with $254 \mathrm{~mm}$ (10 in) O.D. pipes at the wellheads and ending with $914 \mathrm{~mm}$ (36 in) O.D. pipes of $9.5 \mathrm{~mm}$ (0.375 in) wall thickness at the power house. Usually seven wells must be connected to the system to supply the required $450 \mathrm{t} / \mathrm{h}\left(10^{8} \mathrm{lbm} / \mathrm{h}\right)$ of steam. A centrifugal axial separator is situated on the steam line at each well to remove particulate matter that can cause erosion of the steam pipes and turbine blades [Matthew, 1975].

$\Lambda$ map of The Geysers area is shown in figure 10.36 [Jan et al., 1975] from which the locations of the first fifteen units may be seen. The steam pipelines are not longer than about $2 \mathrm{~km}(6560 \mathrm{ft})$ so as to control the loss of available energy of the steam from the wellhead to the turbine.

The power units at The Geysers have evolved from relatively small units with barometric, external condensers and no emissions controls to units of $110 \mathrm{MW}$ capacity with low-level, surface-type condensers and Stretfordtype $\mathrm{H}_{2} \mathrm{~S}$ removal systems. Table 10.16 contains a list of the geothermal units at The Geysers together with some technical information on each of them. Table 10.17 contains a summary of the technical specifications for 


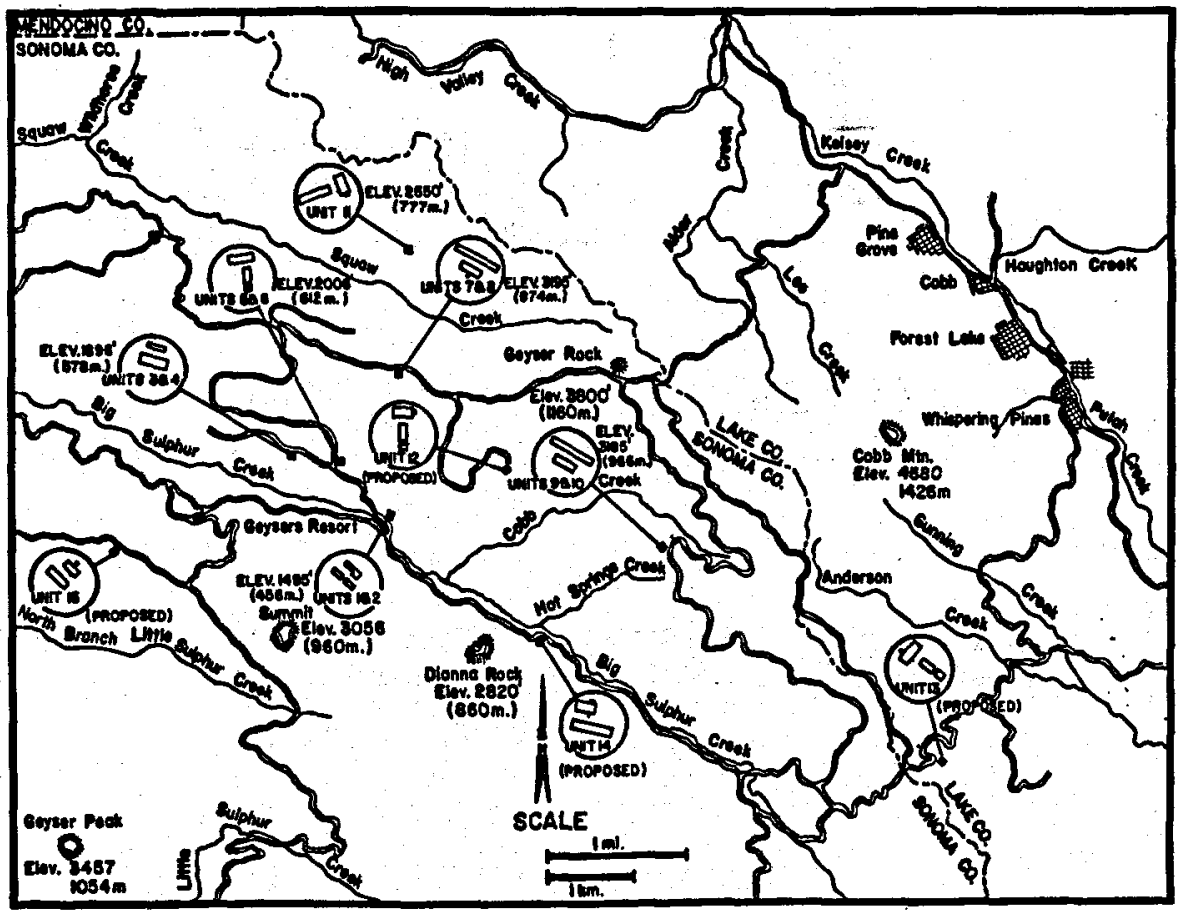

Froure 10.36-May of The Geysers area showing location of Units 1-15 (1)an, et al., 1975].

those power units in operation at The Geysers as of early 1979. A flow diagram/heat balance schematic for Units 5-10 is shown in figure 10.37, and the photograph in figure 10.38 shows the cooling tower and power house for Units 5 and 6.

One of the two units under construction at this time, Unit No. 13, which is expected on-line in February 1980, is unique in several respects. It is the first unit to be built in Lake County rather than Sonoma County, and the first to be supplied with steam from a producer other than Union-MagmaThermal; in this case, the supplier is Aminoil (formerly the Signal Oil and Gas Company). It will be the largest single geothermal unit in the world with a rated capacity of $135 \mathrm{MW}$. Furthermore, the unit will be fitted with a turbine manufactured in the United States, this being the first turbine from an American manufacturer to be installed at The Geysers in over a decade.

The unit was initially designed with a direct-contact condenser of the low-level jet type; however, it will be built with a surface condenser of the shell-and-tube type in order to assist the hydrogen sulfide abatement system which will also be installed on the unit. This will be the first unit to have a surface condenser at The Geysers, and the first unit of any dry steam geothermal plant in the world to be so equipped. Furthermore, this unit, and all succeeding units, will be fitted with a means of controlling the 
Table 10.16-Geothermal power plant development at The Geysers natural steam field, California

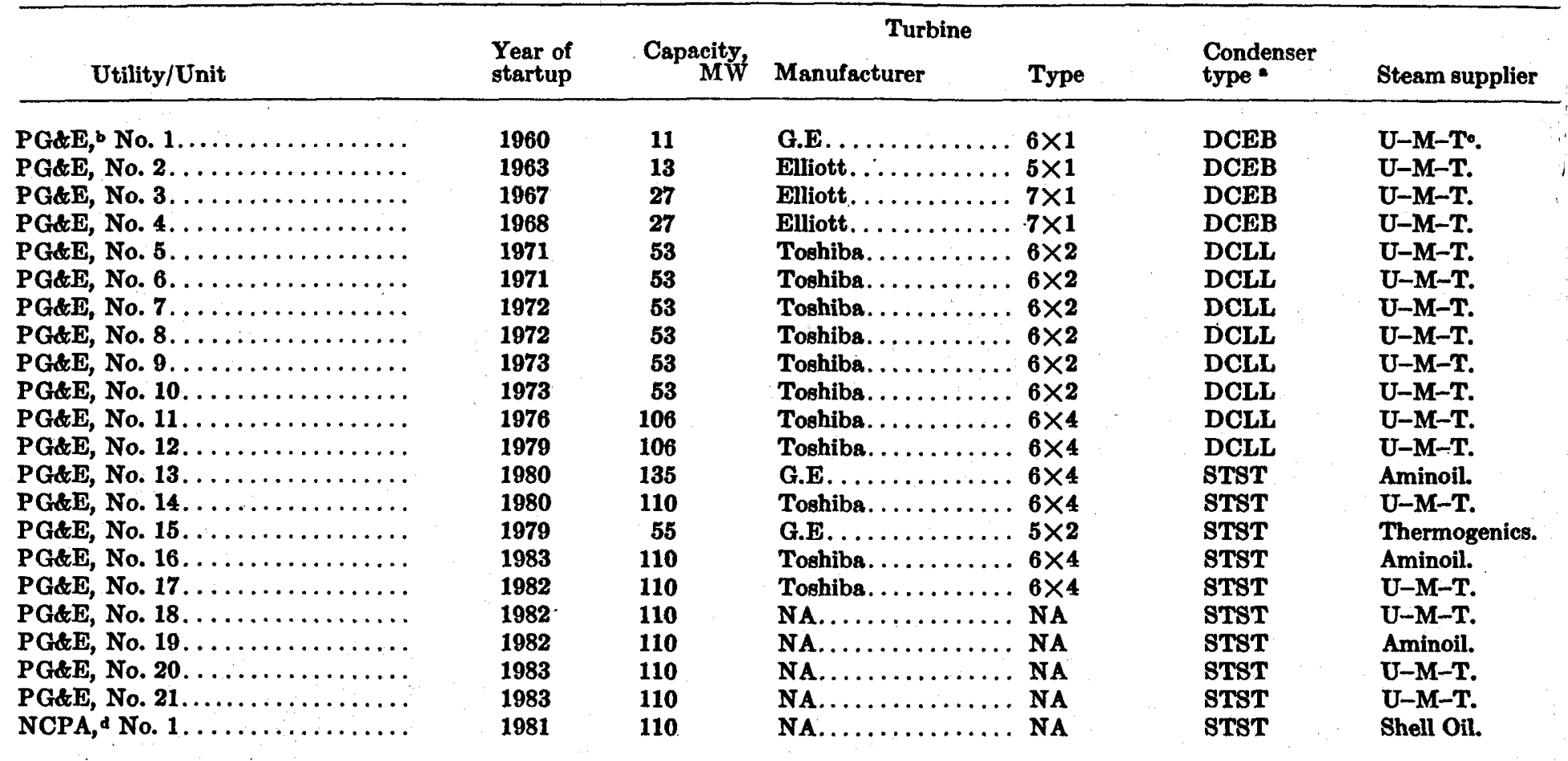

- DCEB = Direct-contact external, barometric type; DCLL=Direct-contact, low-level type; STST=Shell-and-tube, surface type.

- PG\&E = Pacific Gas \& Electric Co.

- U-M-T = Union Oil-Magma Power-Thermal Power.

d NCPA $=$ Northern California Power Agency.

NA $=$ Not available.

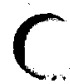


TABLE 10.17-Technical specifications for geothermal units in operation at The Geysers

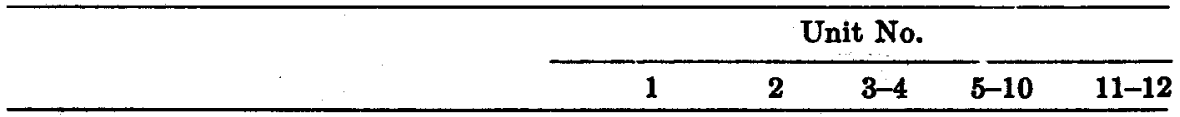

Turbine data:

Type *...............

Rated capacity, MW ..........

Speed, rpm..................

Steam pressure, $\mathrm{lbf} / \mathrm{in}^{2}$. . . . . . .

Steam temperature, ${ }^{\circ} \mathrm{F} . \ldots \ldots \ldots$. . .

Noncondensable gas, $\%$ wt. .....

Exhaust pressure, in $\mathrm{Hg}_{\mathrm{g}} . . . \ldots \ldots$.

Steam flow rate, $10^{s} \mathrm{lbm} / \mathrm{h} . . \ldots \ldots$

Condenser data:

Cooling water temperature, ${ }^{\circ} \mathrm{F}$... .

Outlet water temperature, ${ }^{\circ} \mathbf{F}$.....

Water flow rate, $10^{\circ} \mathrm{lbm} / \mathrm{h} . . . \ldots$.

Gas extractor data:

Type...................

Gas capacity, $\mathrm{ft}^{\mathrm{s}} / \mathrm{min} \ldots \ldots \ldots \ldots$.

Steam consumption, $10^{3} \mathrm{lbm} / \mathrm{h}$. ...

Heat rejection system data:

Type.

$\begin{array}{rrrrr}\text { SCSF } & \text { SCSF } & \text { SCSF } & \text { SCDF } & \text { TCFF } \\ 11 & 13 & 27 & 53 & 106 \\ 1800 & 3600 & \mathbf{3 6 0 0} & \mathbf{3 6 0 0} & \mathbf{3 6 0 0} \\ \mathbf{9 3 . 9} & \mathbf{7 9 . 7} & \mathbf{7 8 . 9} & \mathbf{1 1 3 . 0} & \mathbf{1 1 3 . 3} \\ \mathbf{3 4 8} & \mathbf{3 4 8} & \mathbf{3 4 1 . 8} & \mathbf{3 5 5} & \mathbf{3 5 5} \\ <0.3 & <\mathbf{0 . 3} & <0.5 & <0.5 & <1.0 \\ 4.0 & \mathbf{4 . 0} & 4.0 & 4.0 & 4.0 \\ 240 & \mathbf{2 5 5} & . \mathbf{5 1 0} & \mathbf{9 0 7 . 5} & 1808\end{array}$

$\begin{array}{rrrrr}80.6 & 80.6 & 80.6 & 80.0 & 80.0 \\ 120.8 & 120.0 & 119.8 & 118.4 & 118.4 \\ 5.5 & \sim 6.0 & 6.41 & 21.3 & \sim 62.8\end{array}$

Number of cells. .............

Design wet-bulh temperature, ${ }^{\circ} \mathrm{F}$. .

Water pump power, $\mathbf{k W} . \ldots \ldots \ldots$

Fan motor power, kW...........

All units have steam jet ejectors

$\sim \mathbf{3 5 0} \sim \mathbf{3 5 0} \sim 1000 \sim 1830 \sim \mathbf{3 6 6 0}$

$\sim 10 \sim \sim 10 \quad \sim 23 \quad 58.4 \quad \sim 120$

All units have cross-fiow, mechanicalinduced draft, water-cooling towers.

- SCSF = Single-cylinder, single-flow; SCDF = Single-cylinder, double-flow; TCFF = Tandem-compound, four-flow.

113.7 for units 5 and 6 .

- $\mathbf{5 1 6}$ for unit 4.

NA $=$ Not available.

hydrogen sulfide emissions from the plant. A Stretford system will be employed on those units which are expected on-line in the near future.

The choice of materials used in the manufacture of the various components of a geothermal power plant is determined in large measure by the composition of the geothermal fluid. The steam from The Geysers field is relatively noncorrosive as it comes from the wells in a slightly superheated state. Thus, carbon steel (ASTM A106 Gr. B or equivalent) may be used in the gathering system, including main steam pipelines, valves and strainers. The turbines are made from manufacturer's standard materials for the most part, with items of cast, forged or fabricated steel. The casing is carbon steel. The blading, however, is of $13 \%$ chrome steel. Moisture removal provisions exist in the lower pressure stages where the expansion leads to higher moisture content. Such moisture traps are of standard design and are used as well in conventional steam turbines [Finney, 1972]. The quality of the steam at the turbine exhaust hood is typically about $90 \%$. 


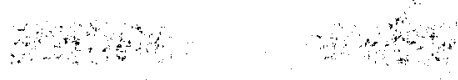

LEGeav

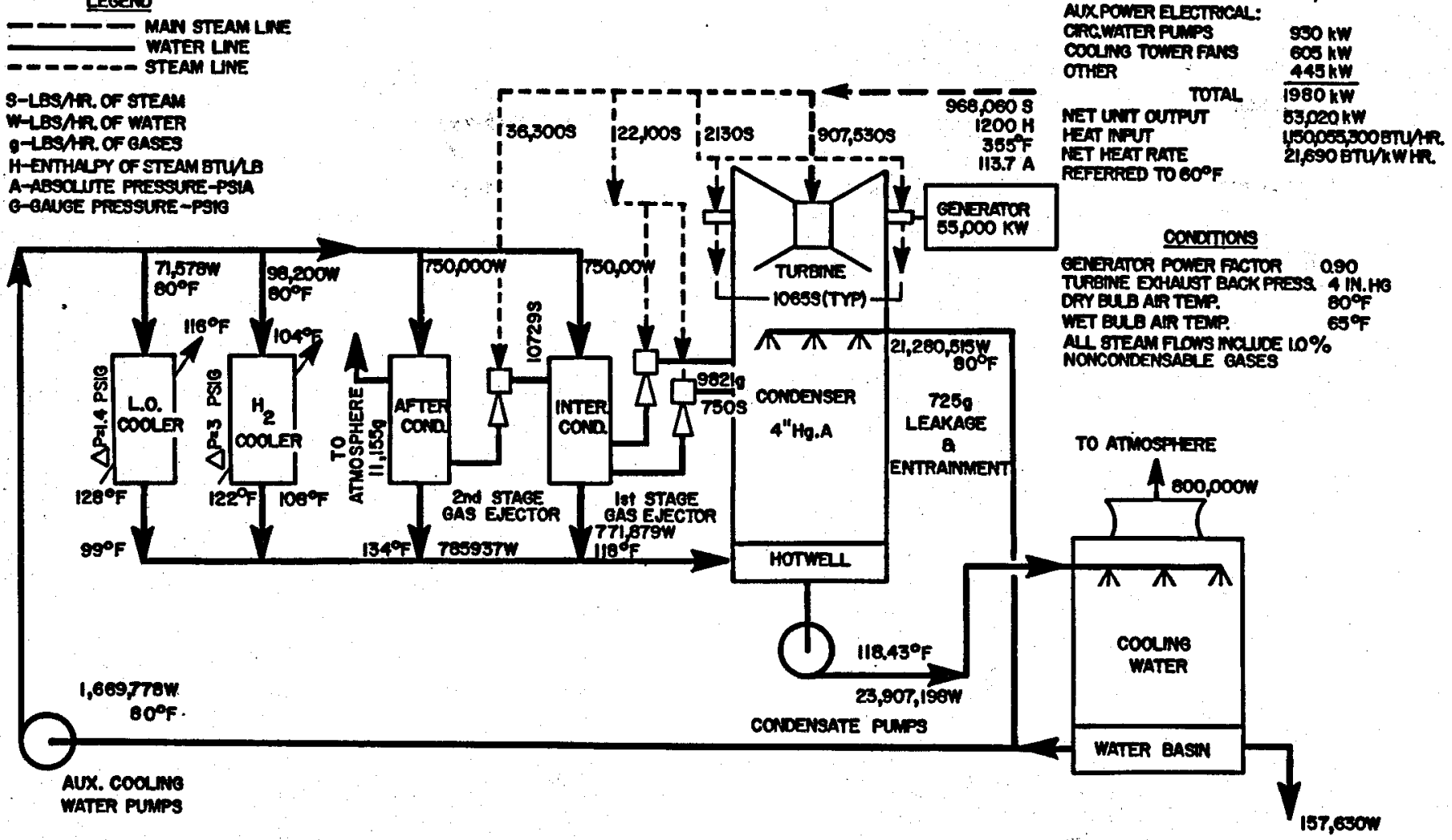

FiquRe 10.37-Heat balance diagram units 5-10-The Geysers [Matthew, 1975]. 


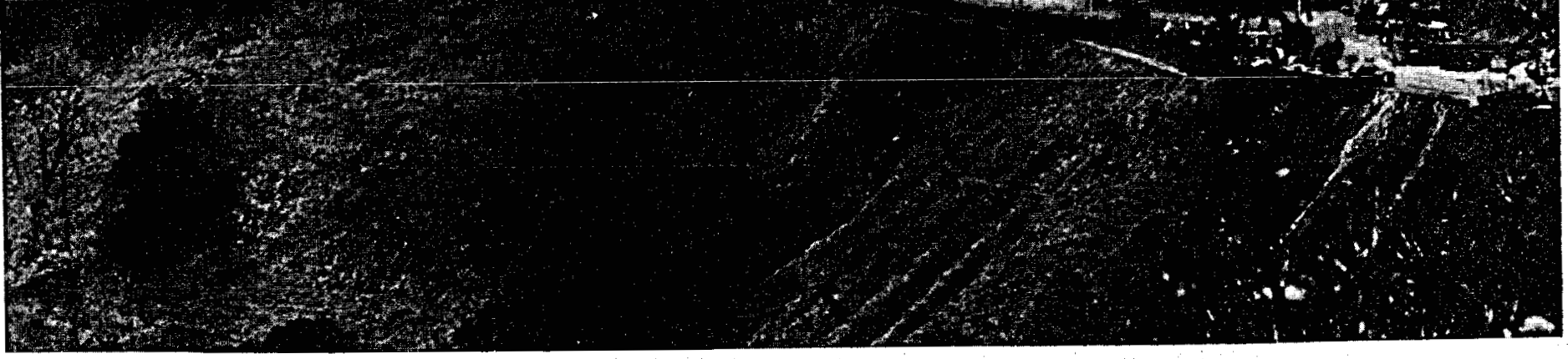

Froure 10.38-Units 5 and 6-The Geysers. [Photo by PG\&E News Bureau.] 
The corrosive nature of the geofluid becomes manifest when the steam condenses, especially in the presence of air. As with all turbines which operate under vacuum conditions, some infiltration of air into the turbine through the seals is unavoidable. Under condensation, the noncondensable gases become more concentrated, the hydrogen sulfide in the presence of air oxidizes to weak sulfuric acid, and the fluid becomes highly corrosive to such materials as carbon steel, cast iron, copper-based alloys, zinc, cadmium, silver, wood and concrete.

The condenser is comprised of a shell of carbon steel plate overlaid with $1.6 \mathrm{~mm}(1 / 16 \mathrm{in})$ thick Type $304(19 \% \mathrm{Cr}, 9 \% \mathrm{Ni})$ stainless steel and internals made of solid stainless steel. The condensate lines are fabricated from Type 304 stainless steel pipe. The condensate pumps are of conventional canned, vertical design, but with all wetted parts, including impellers and bowls or volutes, made of austenitic Type 304 stainless steel. The circulating water lines above ground are made of aluminum pipe of Type 3003, 3053, or 6061. Aluminum alloys with no copper content are used.

Since copper alloys and silver are susceptible to corrosive attack by hydrogen sulfide, electrical equipment should not be made of these materials. Experience shows that tin alloy coatings are effective in resisting corrosion, but they are unsatisfactory on current-carrying contact surfaces. Aluminum, stainless steel and some precious metals are particularly effective. Platinum inserts or plating have been used on these contacts.

Approximately $20 \%$ of the mass of geothermal steam produced from the wells must be disposed of as excess liquid from the cooling tower basin. From 1960 to 1970 the problem was solved by allowing the liquid to run into the nearby Big Sulfur Creek. Beginning with Units 5 and 6, however, the excess water has been reinjected into the producing reservoir. For each $55 \mathrm{MW}$ unit, $1700 \mathrm{~m}^{3} /$ day ( $312 \mathrm{gal} / \mathrm{min}$ ) must be reinjected. In 1974, four wells were employed for the reinjection of approximately $14000 \mathrm{~m}^{3} /$ day (2570 $\mathrm{gal} / \mathrm{min})$ of excess water [Reed and Campbell, 1975]. Since the steam producing reservoir is of anomalously low pressure relative to hydrostatic conditions, it is not necessary to pump the liquid down the well; pumping is required only to move the liquid from the cooling tower sites to tne reinjection wells.

The noncondensable gases are vented to the atmosphere at two places in the plant: the gas ejector and the cooling tower. The most objectionable of the gases discharged is hydrogen sulfide, $\mathrm{H}_{2} \mathrm{~S}$, owing in part to its unpleasant small and to the very low level of detection by the human olfactory sense. The California ambient air quality standard for $\mathrm{H}_{2} \mathrm{~S}$ is 30 parts per billion ( $\mathrm{ppb}$ ), based on an assumed odor detection threshold [Semrau, 1976]. Although no Federal standards exist for $\mathrm{H}_{2} \mathrm{~S}$, the U.S. Environmental Protection Agency (EPA) has suggested a maximum of 200 $\mathrm{g} / \mathrm{MW} \cdot \mathrm{h}$ of electrical production or its equivalent [Hartley, 1978]. 
The first ten units at The Geysers were provided with no means of control of $\mathrm{H}_{2} \mathrm{~S}$ emissions. The daily operation of these ten uncontrolled units produced $22 \mathrm{t} /$ day or $2300 \mathrm{~g} / \mathrm{MW} \cdot \mathrm{h}$ of $\mathrm{H}_{2} \mathrm{~S}$ [Weres; 1976]. All new units will be fitted with some type of $\mathrm{H}_{2} \mathrm{~S}$ abatement system. An iron hydroxide system of about 70\% efficiency was tested on Unit 11. It discharges on the a verage $2 \mathrm{t} /$ day or $800 \mathrm{~g} / \mathrm{MW} \cdot \mathrm{h}$ into the atmosphere, including pre-plant emissions and vent emissions which occur during plant shutdown and are uncontrolled at this time [Weres, 1976]. Units 13, 14, 15, and future units will have surface condensers instead of jet condensers. Separate chemical processing plants operating on the Stretford process will remove the hydrogen sulfide on Units 13-15 [Semrau, 1876]. The product of the Stretford process is pure, marketable sulfur.

The price which PG\&E must pay for steam for its Geysers units is determined from the following formula [Dutcher and Moir, 1976]:

where

$$
C_{s}=\left[2.11 E_{F}\left(\bar{C}_{R} / \bar{C}_{F}^{\circ}\right)\left(M H R / M H R^{\circ}\right)+E_{N} \bar{C}_{N}\right] /\left(E_{F}+E_{N}\right)
$$

$C_{s}=$ cost of steam (mill $/ \mathrm{kW} \cdot \mathrm{h}$ ) for the year $n$,

$E_{\mathrm{r}}=$ electricity produced from fossil fuel during year $n-1$,

$E_{N}=$ electricity produced from nuclear fuel during year $n-1$,

$\bar{C}_{r}=$ average cost of fossil fuel for year $n-1$,

$\bar{C}_{N}=$ average cost of nuclear fuel for year $n-1$,

$\bar{C}$; $=$ average cost of fossil fuel in 1968 ,

$M H R=$ minimum heat rate for fossil plants during year $n-1$,

$M H R^{\circ}=$ minimum heat rate for fossil plants during 1968 ,

$2.11=$ negotiable constant.

Thus, the cost of geothermal steam for any year is determined by the amount and cost of electrical production by fossil and nuclear means during the previous year. Base figures are taken for the cost of fossil fuel and fossil plant heat rate during 1968. In addition, there is a surcharge of 0.5 mill/kW $\cdot h$ for reinjection of the spent geofluid. The historical price of steam at The Geysers since 1969 is given below:

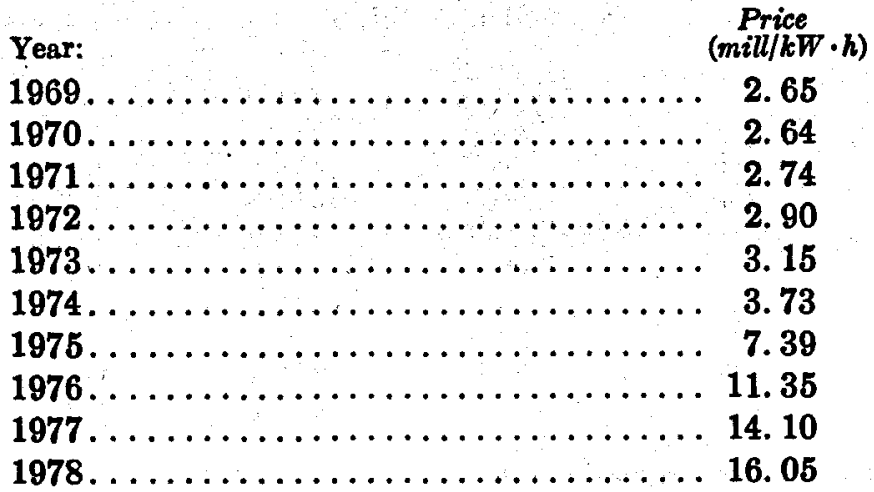


The only other geothermal steam contract at The Geysers is the one signed on June 27, 1977, between Shell Oil Company and the Northern California Power Agency (NCPA). The contract calls for NCPA to pay Shell according to the amount of steam delivered. The initial price, at the time of the contract, was $\$ 0.6917 / 1000 \mathrm{lbm}$ of steam. Beginning on July 1, 1977, the price will be adjusted semi-annually by the GNP Implicit Price Deflator Index (IPD) published by the U.S. Department of Commerce for the preceding calendar quarter [Lindsay, 1977]. The IPD is the ratio of the GNP (in current dollars) to the GNP (in constant 1972 dollars) for the current period. The geothermal steam supplied by Shell must be dry and at a pressure no lower than $799.8 \mathrm{kPa}\left(116.0 \mathrm{lbf} / \mathrm{in}^{2}\right)$; when the amount of noncondensable gases exceeds $0.5 \%$ (weight), the flow rate of steam will be corrected accordingly. Uncontaminated waste liquid will be returned to Shell for disposal at a temperature not greater than $79.4^{\circ} \mathrm{C}$ $\left(175^{\circ} \mathrm{F}\right)$ and at a pressure not less than $262 \mathrm{kPa}\left(38 \mathrm{lbf} / \mathrm{in}^{2}\right)$.

For the operating year 1976, PG\&E reported [Mahoney and Bangert, 1977] that their geothermal power plants produced electricity at the lowest cost of any type steam plant in its system. The figures (in 1977 dollars) are as follows:

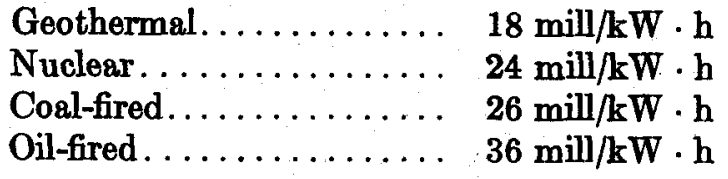

In addition, geothermal plants were the least expensive to construct, being $26 \%$ cheaper than oil-fired plants, about half as expensive as coal-fired plants, and costing only $38 \%$ of a typical nuclear plant. All comparisons are on a dollars-per-kilowatt basis.

Table 10.18 contains a summary of the calculations of the geothermal resource utilization efficiency, $\eta_{u}$, for the thirteen operating units together with estimates for the two units which are under construction. It may be

TABLE 10.18-Resource utilization efficiency of The Geysers units *

\begin{tabular}{rlrrrr}
\hline Unit No. & $T,{ }^{\circ} F$ & $h$, Btu/lbm & $w^{\circ}$, Btu/lbm & $w$, Btu/lbm & $\eta_{u}, \%$ \\
\hline 1 & 348 & 1200.5 & 324.9 & 164.6 & 51 \\
2 & 348 & 1203.2 & 316.2 & 166.9 & 53 \\
3 & 341.8 & 1200.2 & 314.8 & 169.7 & 54 \\
4 & 341.8 & 1200.2 & 314.8 & 167.7 & 53 \\
$5-6$ & 355 & 1200.4 & 335.6 & 187.0 & 56 \\
$7-10$ & 355 & 1200.6 & 335.3 & 187.0 & 56 \\
$11-12$ & 355 & 1200.5 & 335.5 & 187.6 & 56 \\
13 & 338 & 1190.3 & 332.8 & 165.3 & 50 \\
14 & 355 & 1200.4 & 335.8 & 187.7 & 56 \\
15 & 338 & 1190.6 & 332.4 & 164.8 & 50 \\
\hline
\end{tabular}

- Based on a sink temperature of $80^{\circ} \mathrm{F}$. 
seen that $\eta_{\mu}$ ranges from $50-56 \%$. Units 13 and 15 are expected to operate with steam at the lowest temperature of any unit $\left(170^{\circ} \mathrm{C}\left(338^{\circ} \mathrm{F}\right)\right)$ and may have the lowest efficiency of all the units at The Geysers. Although they are not included in the table, Units 16 and 17 will be similar to Unit 14 in design and performance; i.e., they may be expected to operate at a $56 \%$ resource utilization efficiency.

\subsubsection{Magmamax Dual Binary Plant-East Mesa, Calif.}

The geothermal power plant being constructed at East Mesa, Calif., by the Magma companies is of the binary type in which the hot geofluid is used as the heating medium for a secondary working fluid of a suitably low boiling point which is in turn used in a more or less conventional Rankine cycle. When completed in 1979, the Magmamax * Dual Binary plant will be the first geothermal power plant of this type in commercial operation in the United States. The plant will have a rated capacity of 11.2 MW.

The power plant incorporates pumped wells, total reinjection of spent geofluid, two parallel power cycles, one using isobutane and one using propane, an isobutane recuperator-propane preheater, and a cooling water system with combined spray cooling and phased storage ponds. If the plant lives up to its design specifications, it should operate with a specific brine consumption of about $58.5 \mathrm{~kg} / \mathrm{kW} \cdot \mathrm{h}(129 \mathrm{lbm} / \mathrm{kW} \cdot \mathrm{h})$ for brine at $182^{\circ} \mathrm{C}$ $\left(360^{\circ} \mathrm{F}\right)$ [Hinrichs and Falk, 1978]. The reinjection temperature will be about $82^{\circ} \mathrm{C}\left(180^{\circ} \mathrm{F}\right)$. Roughly 11 ha (27 acres) will be dedicated to the storage ponds for the phased cooling system. The plant is located in the desert portion of the Imperial Valley where land usage is less critical than in the intensively-farmed areas of the valley. $A$ simplified flow diagram of the patented Magmamax process is shown in figure 10.39, in which the cooling water lines have been omitted for the sake of clarity.

The isobutane turbine was built by the York Division of Borg-Warner Corporation to the specifications of $J$. Hilbert Anderson [Anderson, 1973]. The machine is of the double-flow type with each side being a 3-stage radial-inflow turbine. The unit used to be a compressor, but has been redesigned for turbine duty. The turbine is expected to operate at an isentropic efficiency of about $77 \%$.

The propane turbine was built by Mafi-Trench Corporation and is typical of machines of the type used for low-temperature applications. It is of the radial-inflow type; the preliminary design specifications indicated an expected isentropic efficiency of about $86 \%$ [Mafi, 1978].

Preliminary design specifications for the Magmamax plant are given in table 10.19. On the basis of the preliminary specifications, the system should be capable of a resource utilization efficiency of about $52 \%$, assuming a sink temperature of $27^{\circ} \mathrm{C}\left(80^{\circ} \mathrm{F}\right)$.

*U.S. Patent No. 3757516. 


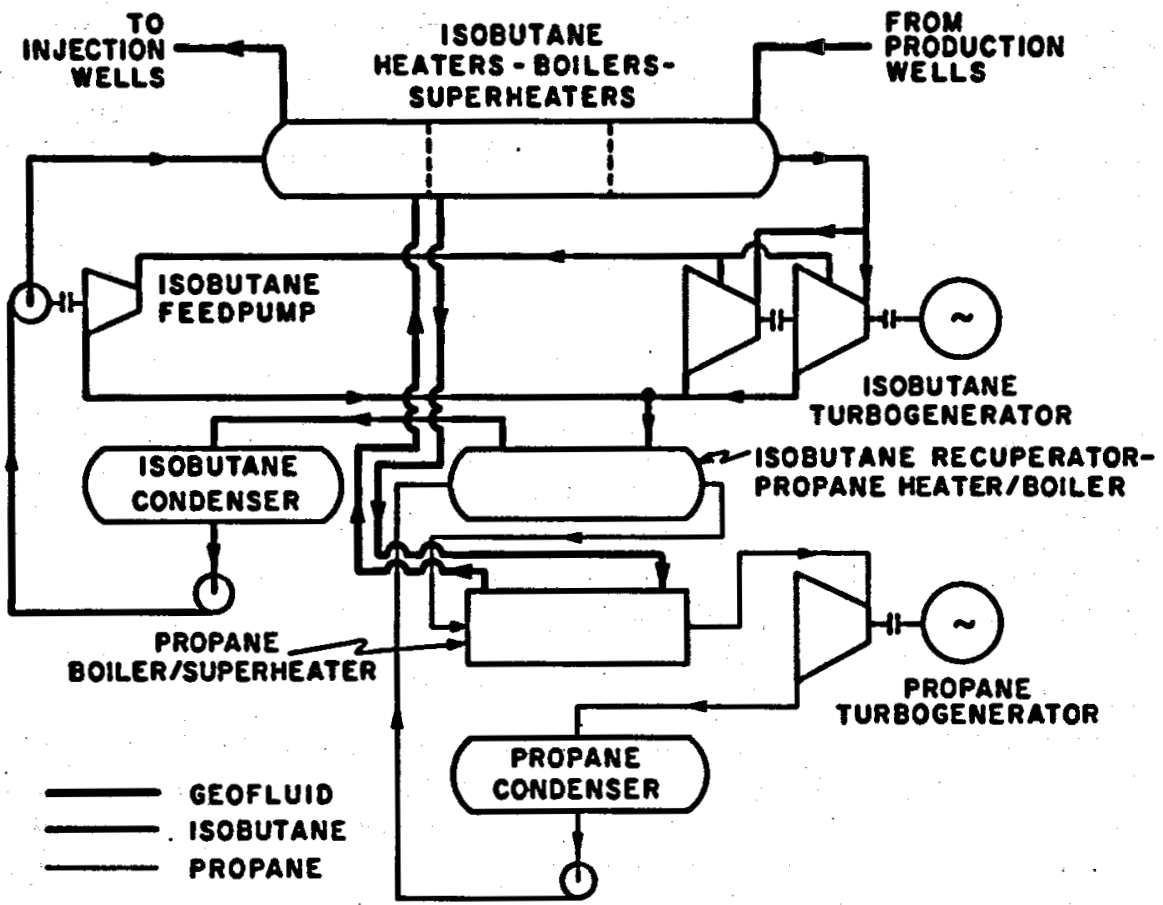

Frauke 10.39-Simplified flow diagram for the Magmamax process (U.S. l'at. No. 3757516) of the dual binary plant at East Mesa.

\subsubsection{Republic Geothermal-East Mesa, Calif.}

Republic Geothermal, Inc. is currently developing a portion of the East Mesa geothermal field with the intention of building a $48 \mathrm{MW}$ double-flash power plant which should be operating by 1980 . The Republic plant will be located about $5 \mathrm{~km}(3 \mathrm{mi})$ north of the Magmamax Dual Binary plant. The wells will be operated in a pumped mode using down-hole, electricpowered, submersible pumps. It is expected that each well should deliver about $85 \mathrm{~kg} / \mathrm{s}(675,000 \mathrm{lbm} / \mathrm{h})$ of fluid under pumped conditions.

Republic was the recipient of the first award made by the government under the Geothermal Loan Guaranty Program (GLGP). The guaranty was issued in May 1977 for $\$ 9$ million to drill a number of additional production and reinjection wells at the East Mesa site. Each well is expected to be capable of producing at least $2 \mathrm{MW}$ of electric power [Silverman, 1977; ERDA News, 1977].

A single-flash plant of $10 \mathrm{MW}$ output is planned to be one of the first of its type in the United States. This pilot plant should be built in 1980 [Holt, 1977]. The main plant will be a $48 \mathrm{MW}$ (net) double-flash system which is presently being designed. An artist's impression of the proposed plant is shown in figure 10.40 . 
TaBle 10.19-Preliminary design specifications for the Magmamax dual binary plant, East Mesa, Calif.

\begin{tabular}{lll}
\hline & $\begin{array}{l}\text { Isobutane } \\
\text { expander }\end{array}$ & $\begin{array}{l}\text { Propane } \\
\text { expander }\end{array}$ \\
\hline
\end{tabular}

Turbine data:

Type.

Tandem-com-
pound, double-
flow, radial-
inflow.

Rated capcity

0.0 MW.......2.2 MW.

Speed (turbine/generator)

$7000 / 3600$ rpm... NA.

Inlet pressure. ................ 500

$500 \mathrm{lbf} / \mathrm{in}^{2} . \ldots \ldots .474 \mathrm{lb} / \mathrm{in}^{2}$.

Inlet temperature.

$345^{\circ} \mathrm{F} . \ldots \ldots 205^{\circ} \mathrm{F}$.

Exhaust pressure...............66 60

Exhaust temperature..............230

$60 \mathrm{lbf} / \mathrm{in}^{2} \ldots \ldots \ldots 142 \mathrm{lbf} / \mathrm{in}^{2}$.

Flow rate................... $1.031 \times 10^{6} \mathrm{lbm} / \mathrm{h} \ldots 274 \times 10^{3} \mathrm{lbm} / \mathrm{h}$.

Geofluid data:

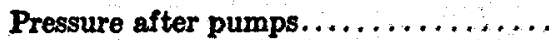

Inlet temperature................

Pressure after heat exchangers........

Outlet temperature................

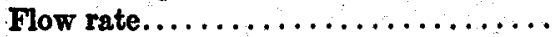

Condenser data:

Type......................

Pressure......................

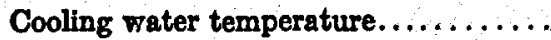

Outlet water temperature.............

Water flow rate. ..................

Heat rejection system data:

Type.

Number of ponds...............

Design wet-bulb temperature........

$$
\begin{gathered}
270 \mathrm{lbf} / \mathrm{in}^{2} \\
360^{\circ} \mathrm{F} \\
117 \mathrm{bf} / \mathrm{in}^{2} \\
180^{\circ} \mathrm{F} \\
1.444 \times 10^{\circ} \mathrm{lbm} / \mathrm{h}
\end{gathered}
$$

Surface type, shell-and-tube

$$
\begin{gathered}
59 \mathrm{lbf} / \text { in }^{2} \\
62^{\circ} \mathrm{F} \\
79.5^{\circ} \mathrm{F}
\end{gathered}
$$

NA

Phased cooling, storage ponds with sprays

$$
2
$$

$58^{\circ} \mathrm{F}$

NA = Not available.

\subsubsection{Southern Oalifornia Edison-Brawiey, Oalif.}

A separated steam (or single-flash) plant is being constructed at the Brawley geothermal field which lies about $38 \mathrm{~km}(24 \mathrm{mi})$ northwest of East Mesa in the Imperial Valley. The plant will be operated by Southern California Edison using steam supplied by Union Oil. The unit will be rated at $10 \mathrm{MW}$ and will require $32 \mathrm{t} / \mathrm{h}(70,000 \mathrm{lbm} / \mathrm{h})$ of steam. The reservoir temperature is about $260^{\circ} \mathrm{C}\left(500^{\circ} \mathrm{F}\right)$ and the fluid carries about $100,000 \mathrm{ppm}$ of dissolved solids.

\subsubsection{Planned geothermal plants in the Imperial Valley, Oalif.}

The Imperial Valley of southern California holds a huge reserve of geothermal energy. A recent conservative estimate of the potential of this area 


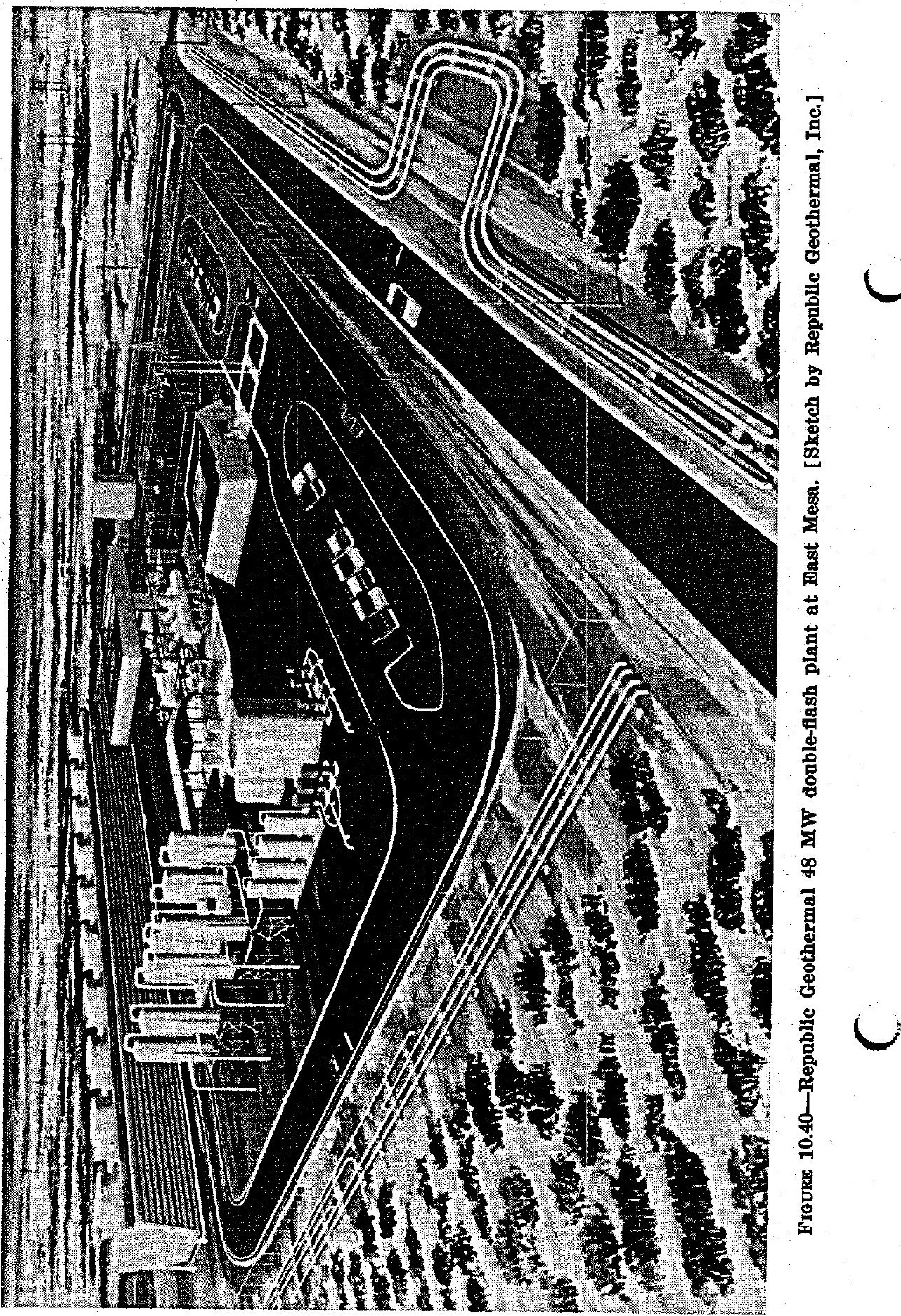


suggests that $8700 \mathrm{MW}$ of geothermal electrical capacity may be possible assuming 20-30 year plant lifetimes [Younker and Kasameyer, 1978]. A number of power plants of various designs are either under construction or in the advanced stages of planning. Table 10.20 contains a list of particulars on these plants.

\subsubsection{Double-boiling binary plant_Raft River, Idaho}

A $5 \mathrm{MW}$ (gross) binary plant is being designed by the Idaho National Engineering Laboratory for operation at the Raft River KGRA in Idaho [Ingvarsson and Madsen, 1976]. The plant will use geothermal fluid at the relatively low temperature of $143^{\circ} \mathrm{C}\left(290^{\circ} \mathrm{F}\right)$, and will employ isobutane as the cycle working fluid. A simplified process flow diagram is shown in figure 10.41. Optimization studies show that the system should be designed to use isobutane and two boilers, one at $116^{\circ} \mathrm{C}\left(240^{\circ} \mathrm{F}\right)$ or $2.63 \mathrm{kPa}(382$ $\left.\mathrm{lbf} / \mathrm{in}^{2}\right)$, and one at $82^{\circ} \mathrm{C}\left(180^{\circ} \mathrm{F}\right)$ or $1.40 \mathrm{MPa}\left(203 \mathrm{lbf} / \mathrm{in}^{2}\right)$. The net output of the plant will be 3.35 MW (e). The cycle conditions and state properties for the nominal design case may be found in Ingvarsson and Madsen [1976]. The plant will require about $141 \mathrm{~kg} / \mathrm{kW} \cdot \mathrm{h}(310 \mathrm{lbm} / \mathrm{kW} \cdot \mathrm{h})$, and have a resource utilization efficiency $\eta_{u} \approx 32 \%$ [DiPippo, 1978b].

Although the plant will serve primarily as a test-bed for low-temperature geothermal power plants, the electricity produced will be fed into the grid of the Raft River Electrical Cooperative. The cost of electricity is estimated to be $31.15 \mathrm{mill} / \mathrm{kW} \cdot \mathrm{h}$ [Ingvarsson and Madsen, 1976]. It is expected that the plant will begin operating in January 1980.

\subsubsection{Hawaii geothermal project-Puna, Hawaii}

A separated steam (or single-flash) plant of $5 \mathrm{MW}$ capacity will be installed near Cape Kumukahi in the Puna region of the Big Island of Hawaii in 1980. The geothermal area lies in the east rift zone at the easternmost tip of the island [Furumoto, 1978].

Six wells have been drilled in the area, but only one of these was successful, well HGP-A. Reservoir temperature is $358^{\circ} \mathrm{C}\left(676^{\circ} \mathrm{F}\right)$, and the dryness fraction of the two-phase geothermal mixture ranges from 52$64 \%$ [Chen et a]., 1978]. The well was drilled to a depth of $1871 \mathrm{~m}$ $(6140 \mathrm{ft})$. The results of flow tests on this well have been highly encouraging, and it has been estimated that the Kapoho geothermal reservoir at which well HGP-A is located may be capable of supporting 50,000 MW - years [Chen and Grabbe, 1978]. Unfortunately, the greatest demand for electricity is on the island of Oahu, whereas the greatest potential for geothermal power production is on the Big Island of Hawaii. Nevertheless, a geothermal development group has been formed in 1977 to promote this resource in an attempt to reduce the State of Hawaii's dependence on imported fuel oil. The group consists of the State Department of 
TABLE 10.20-Geothermal power plants in the Imperial Valley, Calif.

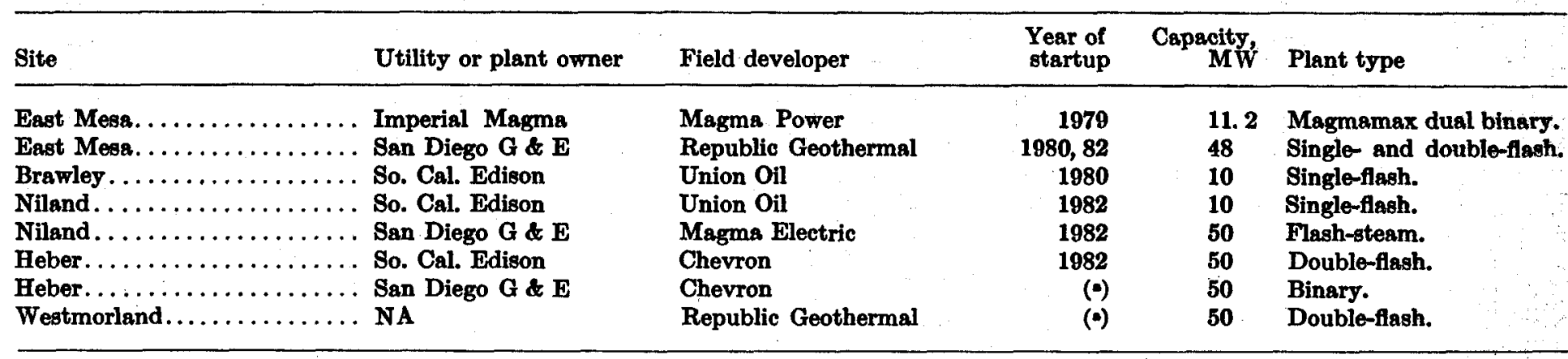

- In planning. 


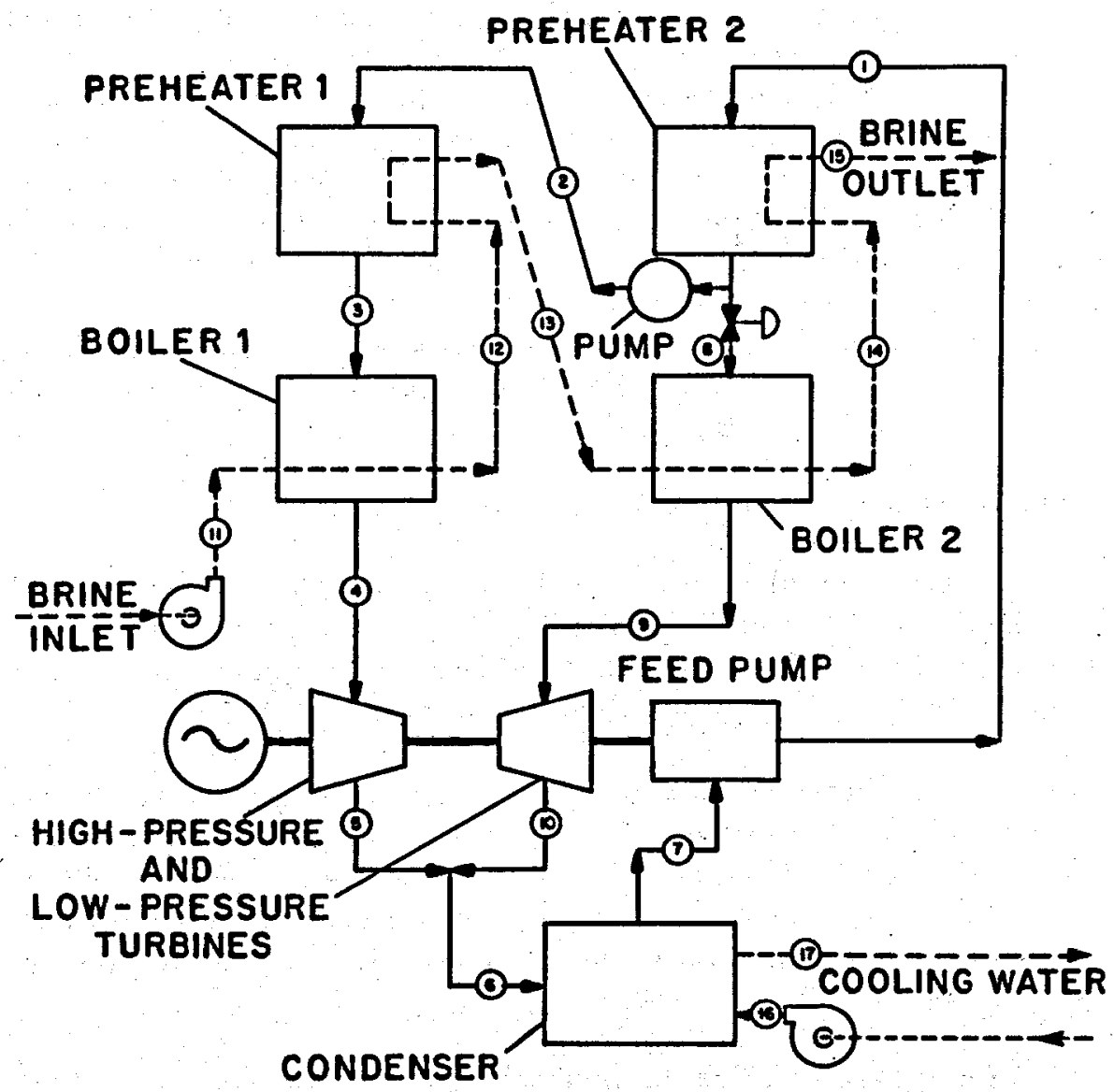

Fraure 10.41-Process flow diagram for Raft River double-bolling isobutane hinary cycle power plant [Ingvarsson and Madsen, 1976].

Planning and Economic Development (DPED), the University of Hawaii's Hawaii Geothermal Project (HGP), and the County of Hawaii. In addition the Hawaiian Electric Company (Honolulu) and the Hawaii Electric Light Company (Hilo) are participating as consultants [Chen and Grabbe, 1978].

\subsubsection{Flash-steam demonstration plant-Valles Caldera, N. Mex.}

The U.S. Department of Energy, through its Division of Geothermal Energy, is contributing to the support of the design and construction of a $50 \mathrm{MW}$ flash-steam plant to be located about $56 \mathrm{~km}(35 \mathrm{mi})$ west of Los Alamos at an area known as Baca. No. 1 within the Valles Caldera of the Jemez Mountains in north-central New Mexico. The plant is scheduled to go on-line in 1982 [GEM, 1878]. The intent is to show that geothermal 
power plants using liquid-dominated resources can be built and operated in the United States on an economically competitive basis.

The geothermal field has been developed by the Union Oil Company which will supply steam to the Public Service Company of New Mexico. It is believed that each production well will be capable of providing 91 $\mathrm{t} / \mathrm{h}(200,000 \mathrm{lbm} / \mathrm{h})$ of geothermal fluid with a quality of $35 \%$ at a wellhead pressure of $965 \mathrm{kPa}\left(140 \mathrm{lbf} / \mathrm{in}^{2}\right)$. Roughly fifteen wells will be needed to supply the $50 \mathrm{MW}$ plant.

The U.S. Geological Survey reported that the Valles Caldera KGRA has the potential to support $1870 \mathrm{MW}$ of electrical power production for 30 years [White and Williams, 1975].

\subsubsection{Other potential geothermal plants in the U.S.}

Table 10.21 lists the proposed geothermal power plants for the United States outside California. The plants shown for Roosevelt Hot Springs, Utah, Desert Peak, Nevada, and the hybrid coal-geothermal plant proposed by the City of Burbank, California, are not definite, but are in advanced planning stages.

Table 10.22 shows the projected growth in installed geothermal electric generating capacity through 1983. By that time, the United States should have over $1800 \mathrm{MW}$ on-line. Furthermore, geothermal energy will be contributing about $3 \%$ of the electric power needs of the states in which geothermal plants will be operating, namely, California, Hawaii, Nevada, New Mexico, and Utah.

\subsection{Countries planning geothermal power plants}

\subsubsection{Overall survey}

The number of countries engaged in geothermal exploration, development, or exploitation for all purposes or which have an interest in putting their geothermal resources to use is estimated to be at least sixty-five [GEM, 1977]. These include: Australia, Austria, Bahamas, Barbados, Belgium, Bhutan, Bolivia, Brazil, Canada, Chile, China, Colombia, Congo, Costa Rica, Dominican Republic, Ecuador, Egypt, El Salvador, Ethiopia, Fiji, France, Germany, Ghana, Greece, Guatemala, Guinea, Guyana, Haiti, Honduras, Hungary, Iceland, India, Indonesia, Iran, Israel, Italy, Jamaica, Japan, Kenya, Kuwait, Malaysia, Mexico, New Zealand, Nicaragua, Panama, Philippines, Portugal (Azores), Saudi Arabia, Spain (Canary Islands), Sri Lanka, Switzerland, Taiwan, Tanzania, Trinidad and Tobago, Turkey, Uganda, Union of Soviet Socialist Republics, United Arab Emirates, United Kingdom, United States, Venezuela, Yugoslavia, Zaire, and Zambia. 
TABLE 10.21-Proposed U.S. geothermal power plants outside California

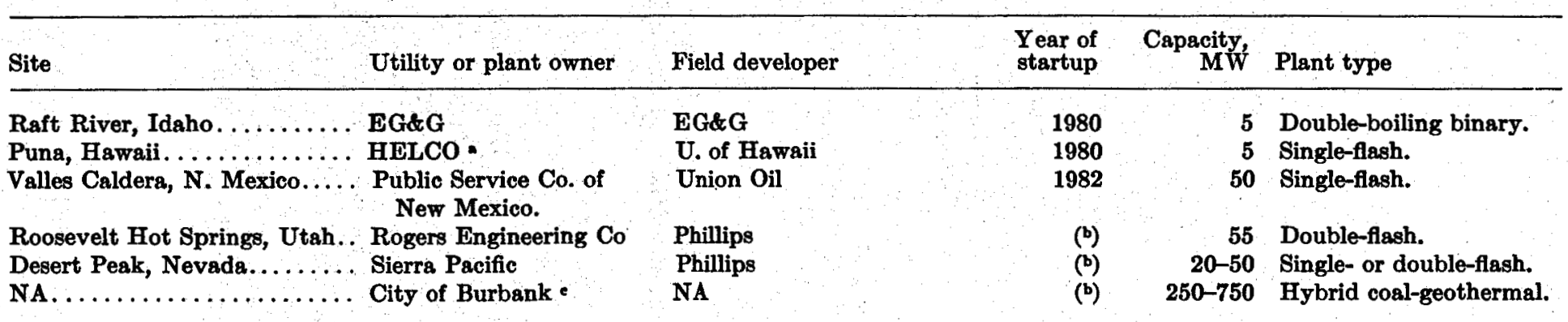

- Hawaii Electric Light Co.

b In planning.

- In conjunction with a consortium of neighboring cities in the Los Angeles area. 
TABLE 10.22-U.S. geothermal electric power development projected through 1988, as of July 1979

\begin{tabular}{|c|c|c|}
\hline Year & Cumulative MW & New Geothermal Power Plants \\
\hline 1978 & 502.0 & $\begin{array}{l}\text { None. } \\
\text { (106 MW (PG\&E No. 12). }\end{array}$ \\
\hline 1979 & 674.2 & $\begin{array}{l}55 \mathrm{MW} \text { (PG\&E No. 15). } \\
\text { 11. } 2 \mathrm{MW} \text { (Magmamax Dual Binary). } \\
\text { 135 MW (PG\&E No. 13). } \\
110 \mathrm{MW} \text { (PG\&E No. 14). }\end{array}$ \\
\hline 1980 & 947.55 & $\begin{array}{l}10 \mathrm{MW} \text { (Republic Geothermal). } \\
10 \mathrm{MW} \text { (So. Cal. Edison-Brawley). } \\
\text { 3.35 MW (Raft River). } \\
\text { 5 MW (Hawaii Geothermal). }\end{array}$ \\
\hline 1981 & 1057.55 & $\begin{array}{l}110 \mathrm{MW} \text { (NCPA No. 1). } \\
(110 \mathrm{MW} \text { (PG\&E No. 17). } \\
110 \mathrm{MW} \text { (PG\&E No. 18). } \\
110 \mathrm{MW} \text { (PG\&E No. 19). }\end{array}$ \\
\hline 1982 & $* 1585.55$ & $\begin{array}{l}50 \mathrm{MW} \text { (Valles Caldera). } \\
48 \mathrm{MW} \text { (Republic Geothermal). } \\
50 \mathrm{MW} \text { (So. Cal. Edison-Heber). } \\
10 \mathrm{MW} \text { (So. Cal. Edison-Niland). } \\
50 \mathrm{MW} \text { (San Diego G\&E-Niland). } \\
\text { (110 MW (PG\&E No. 16). }\end{array}$ \\
\hline 1983 & 1915. 55 & $\left\{\begin{array}{l}110 \mathrm{MW} \text { (PG\&E No. 20). } \\
110 \mathrm{MW} \text { (PG\&E No. 21). }\end{array}\right.$ \\
\hline
\end{tabular}

*48 MW (Republic Geothermal) includes 10-MW pilot plant of 1980.

In the rest of this section we shall discuss those countries which are on the threshold of exploiting their geothermal resources for the generation of electricity.

\subsubsection{Azores (Portugal)}

The islands of the Azores lie on the Mid-Atlantic Ridge, a spreading tectonic plate boundary. Of the nine islands which comprise the group, the largest and most heavily populated is São Miguel.

In 1970 a well was drilled on the northern flank of the Agua de Pau volcano and encountered fluids in excess of $200^{\circ} \mathrm{C}\left(392^{\circ} \mathrm{F}\right)$ at depths greater than $550 \mathrm{~m}$ (1805 ft). The full depth of the well was $981 \mathrm{~m}$ (3219 ft) [Meucke et al., 1974].

A 3 MW wellhead power unit is being designed for São Miguel, and could be in operation as soon as 1979 [K. Aikawa, personal communication].

\subsection{Chile}

The El Tatio geothermal field has been the subject of considerable exploration and drilling. The site is located in northern Chile, an Anto- 
fagasta province, in a region consisting of a volcanic desert plateau at an elevation of over $4000 \mathrm{~m}(13,100 \mathrm{ft})$ with Quaternary volcanic mountains rising to nearly $6000 \mathrm{~m}(19,700 \mathrm{ft})$. Owing to the extreme remoteness and near-inaccessibility of the field, exploration is proceeding slowly. Furthermore, because the region is essentially arid, any geothermal development is likely to include the production of fresh water [Koenig, 1973].

It has been estimated that about $18 \mathrm{MW}$ of electricity could be generated from the existing thirteen wells [Lahsen and Trujillo, 1975]. The wells range in depth from 600 to $1820 \mathrm{~m}(1970-5970 \mathrm{ft})$ and have encountered geofluids at temperatures from 180 to $265^{\circ} \mathrm{C}\left(356-509^{\circ} \mathrm{F}\right)$. A small pilot plant is in operation and plans are underway to construct a $15 \mathrm{MW}$ plant in the near future [Ellis and Mahon, 1977].

\subsubsection{Costa Rica}

The geothermal development program in Costa Rica is directed by the Instituto Costarricense de Electricidad (I.C.E.) and has concentrated on the Guanacaste province in the northwestern part of the country. The geothermal area extends for $30 \mathrm{~km}(19 \mathrm{mi})$ along the flank of a chain of active volcanoes [Furgerson and Afonso L., 1977]. An integrated program involving heat flow, temperature gradient, geochemical, electrical and hydrological investigations is being carried out in the southwestern portion of the Cordillera de Guanacaste.

Particular attention is being given to the areas of Las Hornillas de Miravalles, Las Pailas, and Borinquen, where some drilling has been conducted [Blackwell et al., 1977]. A total of 35 exploratory wells have been sunk in the area; twenty-four have been to depths of $50 \mathrm{~m}$ (164 ft) or less and nine have exceeded $90 \mathrm{~m}(295 \mathrm{ft})$. Active development is underway and a $40 \mathrm{MW}$ geothermal power plant is scheduled by I.C.E. to be installed by 1984-1985.

At Las Hornillas de Miravalles geochemical studies have revealed the possibility of a deep, chlorinated aquifer with reservoir base temperatures as high as $240^{\circ} \mathrm{C}\left(464^{\circ} \mathrm{F}\right)$ [Gardner and Corrales, 1977]. A program of deep drilling is underway with the objective of achieving a total depth of $4000 \mathrm{~m}(13,000 \mathrm{ft})$, which should allow for the completion of four wells since the aquifer is estimated to lie at a depth of between $800-1200 \mathrm{~m}$ (2625-3937 ft) (J. T. Kuwada, personal communication).

\subsubsection{Guatemala}

The national electric company of Guatemala, I.N.D.E., is aiming at a goal of $100 \mathrm{MW}$ of installed geothermal capacity by the early 1980's [Meidav et al., 1977]. Three areas, Moyuta, Amatitlán and Zunil, have been under exploration with technical assistance from Japan. 
There were high hopes for the field at Moyuta which is about $25 \mathrm{~km}$ (16 mi) northwest of the successful project at Ahuachapan across the border in El Salvador. Shallow wells revealed temperature gradients of about $0.25^{\circ} \mathrm{C} / \mathrm{m}\left(0.14^{\circ} \mathrm{F} / \mathrm{ft}\right)$. Unfortunately, two wells produced low temperatures, and the site has been abandoned [Dominco, 1977; J. T. Kuwada, personal communication].

Attention is still being given to the other two sites; Amatitlán may someday support 50-100 MW, whereas Zunil appears to be a rather small area with limited prospects.

\subsubsection{Honduras}

In 1977 the national electric authority of Honduras, E.N.E.E., began a program of geothermal exploration that focused on two areas: Pavana, in the southernmost part of the country near Choluteca, and San Ignacio, which is located northwest of the capital city of Tegucigalpa [Meidav et al., 1977]. At the present time the exploration program is temporarily in abeyance [J. T. Kuwada, personal communication]. By 1982, E.N.E.E. hopes to have $50 \mathrm{MW}$ of geothermal power on-line, with an additional 50 MW by 1984-1985 [Meidav et al., 1977].

\subsubsection{Indonesia}

Indonesia's locution at the junction of three tectonic plates with the associated volcanism and earthquake activity together with its average annual rainfall of $2000 \mathrm{~mm}$ (79 in) create a potentially valuable source of geothermal (hydrothermal) power. Exploration for geothermal energy began in 1926; extensive geophysical, geological and geochemical surveys have been conducted by various teams of scientists from France, Japan, New Zealand, the United States, and the United Nations (UNESCO). A summary of these studies has recently been published [Radja, 1975].

Among the many promising thermal areas, the one at which a geothermal power plant is likely to appear first is Kawah Kamojang. Fumaroles abound at this thermal site, the oldest to be discovered and explored in the Indonesian archipelago. A $250 \mathrm{~kW}$ wellhead power generating unit has been purchased and is now operational, and a $3 \mathrm{MW}$ unit has been designed and will soon be under construction at Kawah Kamojang.

Power production at Kamojang will begin with the $250 \mathrm{~kW}$, noncondensing, wellhead turbo-generator under the direction of PERTAMINA, the State Oil and Natural Gas Mining Company [GR, 1978]. The unit is selfcontained and consists of a turbine, generator, controls, gearbox and exhaust silencer diffuser mounted on a platform. The package cost just over $\$ 400 / \mathrm{kW}$ in 1978 . The power generated will be used during the development phase of the project. After the $3 \mathrm{MW}$ unit is installed in the second 
phase, the plan is to build a $30 \mathrm{MW}$, condensing unit [Basoeki and Radja, 1978].

A large number of other thermal areas are evident throughout the Indonesian archipelago. Surface manifestations such as hot springs, boiling mud pools, solfataras, and/or fumaroles are present at the sites listed below. Some surveys have been conducted at a few of these, and the reader is referred to other sources of information for more details [Akil, 1975; Muffler, 1975; Radja, 1975].

- On the island of Java: Danau (Banten), Dieng, Ijen, Kawah Derajat, Kromong-Careme.

- On the island of Sumatra : Toba, Padang Highlands, Pasumah.

- On the island of Borneo: Kalimantan.

- On the island of Halmahera: North Halmahera.

- On the island of Sulawesi : Minahasa, Gorontalo, Central Sulawesi, South Sulawesi.

- On the islands of Nusa Tenggara : Waikokor, Wai Pesih, Magekoba.

Although there are large supplies of petroleum within Indonesia, it is often difficult to transport it to the places where power is needed. Furthermore, petroleum is a very valuable export commod:ty. The demand for electric power is expected to reach $5100 \mathrm{MW}$ in 1990; it was less than 1000 $M W$ in 1975. Thus, geothermal energy, with its low cost and indigenous advantages, figures to play an important role in meeting the growing demand for electrical power in Indonesia.

\subsubsection{Kenya}

Six wells have been drilled in the Olkaria geothermal region in the Rift Valley province of Kenya in east Africa. Although the majority of the wells encountered conditions of low permeability, the two best wells yielded roughly $30-40 \mathrm{t} / \mathrm{h}\left(66-88 \times 10^{8} \mathrm{lbm} / \mathrm{h}\right)$ of liquid-vapor mixture. The reservoir lies at 700-800 $\mathrm{m}(2297-2625 \mathrm{ft})$, and the fluid temperature is $245^{\circ} \mathrm{C}\left(473^{\circ} \mathrm{F}\right)$. Temperatures as high as $300^{\circ} \mathrm{C}\left(572^{\circ} \mathrm{F}\right)$ have been reported at a depth of $1650 \mathrm{~m}$ (5414 ft) [Ellis and Mahon, 1977]. A $15 \mathrm{MW}$ geothermal power unit is being designed for this resource [K. Aikawa, personal communication].

\subsubsection{Nicaragua}

The national electric authority of Nicaragua, E.N.A.L.U.F., is predicting that $100 \mathrm{MW}$ of geothermal power will be installed in Nicaragua by the early 1980's, with about 150-220 MW installed by 1985, 300-400 MW by 2000 , and as much as $800 \mathrm{MW}$ by the year 2020 [Meidav et al., 1977]. The most likely candidate site for the first geothermal power plant is the Momotombo field which was investigated from 1969 to 1971 , along with 
the San Jacinto-Tisate area. These two promising areas were explored under a program sponsored by the U.S. Agency for International Development. Work at the sites was delayed several years on account of the Managua earthquake of December 23, 1972 [Muffler, 1975], and has suffered another setback because of political problems in Nicaragua in 1978.

The geothermal field at Momotombo is located on the lower slopes of the Momotombo Volcano, on the edge of Lake Managua. A total of 25 wells have been drilled in the field. Some of these wells show drastic temperature inversions, as much as $-1.5^{\circ} \mathrm{C} / \mathrm{m}\left(-0.8^{\circ} \mathrm{F} / \mathrm{ft}\right)$, indicating the presence of colder fluid at depth. Some flow rates from a few of the wells have been reported [Girelli, 1977]:

Momotombo well No. $3 \ldots \ldots \ldots \ldots \ldots .85 \mathrm{t} / \mathrm{h}\left(187 \times 10^{3} \mathrm{lbm} / \mathrm{h}\right)$

Momotombo well No. $9 \ldots \ldots \ldots \ldots \ldots .56 \mathrm{t} / \mathrm{h}\left(123 \times 10^{3} \mathrm{lbm} / \mathrm{h}\right)$

Momotombo well No. 12......... $40 \mathrm{t} / \mathrm{h}\left(88 \times 10^{3} \mathrm{lbm} / \mathrm{h}\right)$

Construction was scheduled to begin in 1979 on a geothermal power plant at Momotombo but the size of the unit has not been decided. The site is believed capable of supporting $100 \mathrm{MW}$, but a smaller, $30 \mathrm{MW}$ unit may be installed initially until confidence in the field is thoroughly established [Girelli, 1977].

\subsubsection{Panama}

Panama presently has a total installed electric capacity of 237 MW with projections of $534 \mathrm{MW}$ by 1984 . Although hydroelectric plants constitute a significant fraction of Panama's generating capacity, it is believed that a $75 \mathrm{MW}$ power plant, either conventional thermal or geothermal, will be needed by 1985 .

The most promising geothermal site in Panama is at Cerro Pando. It is too carly, however, to assess the quality and the potential of this area in the light of the minimal amount of exploratory work completed at this time [Ho, 1977; Meidav et al., 1977].

\subsection{References}

The following references are cited several times:

Proceedings of the United Nations Conference on New Sources of Energy: Solar Energy, Wind Power and Geothermal Energy, Rome, Italy, Aug. 21-31, 1961, vols. 2 and 3, "Geothermal Energy," United Nations, New York, 1964. (Referred to as Rome-1961, hereafter.)

Proceedings of the United Nations Symposium on the Development and Utilization of Geothermal Resources, Pisa, Italy, Sept. 22-Oct. 1, 1970; Geothermics, Spec. Issue 2, vols. 1 and 2, 1970, Pergamon Press, Inc., New York, 1970. (Referred to as Pisa1970 , hereafter.)

Proceedings of the Second United Nations Symposium on the Development and Use of Geothermal Resources, San Francisco, California, May 22-29, 1975, vols. 1-3, " 
U.S. Government Printing Office, Washington, D.C., 1976. (Referred to as San Francisco-1975, hereafter.)

Aikawa, K. and Soda, M., 1975. "Advanced Design in Hatchobaru Geothermal Power Station," San Francisco-1975, vol. 3, pp. 1881-1888.

Akiba, M., 1970. "Mechanical Features of a Geothermal Plant," Pisa-1970, vol. 2, pp. 1521-1529.

Akil, I., 1975. "Development of Geothermal Resources in Indonesia," San Francisco1975 , vol. 1, pp. 11-15.

Allegrini, G. and Benvenuti, G. "Corrosion Characteristics and Geothermal Power Plant Protection (Collateral Processes of Abrasion, Erosion and Scaling)," Pisa1970, vol. 2, pp. 865-881.

Alonso, H., 1975. "Geothermal Potential of Mexico," San Francisco-1975, vol. 1, pp. $21-24$.

Alpan, S., 1975. "Geothermal Energy Exploration in Turkey," San Francisco-1975, vol. 1, pp. 25-28.

Anderson, J. H., 1973. "The Vapor-Turbine Cycle for Geothermal Power Generation," in Geothermal Energy-Resources, Production, Stimulation, P. Kruger and C. Otte, eds., Stanford Univ. Press, Stanford, Calif., pp. 163-175.

ARPA, 1972. "Soviet Geothermal Electric Power Engineering," Report 2, ARPA Order No. 1622-3, Informatics, Inc., Rockville, Md.

Axtmann, R. C., 1974. "An Environmental Study of the Wairakei Power Plant," N.Z. Dept. Sci. Ind. Res., Phys. Eng. Lab. Rept. No. 445.

Axtmann, R. C., 1975. "Environmental Impact of a Geothermal Power Plant," Science, vol. 187, pp. 795-803.

Basoeki, M. and Radja, V. T., 1978. "Recent Development of 30 MW Kamojang Geothermal Power Project, West Java, Indonesia," Geothermal Resources Council Trans., vol. 2, sec. 1, pp. 35-38.

Bauer, H. E., Jones, E. M. E., Stirling, J. J., Willis, D. J., and Wu, P., 1977. "Environmental Impact Report for the Broadlands Geothermal Power Development," New Zealand Electricity Department, Power Development Section, Wellington, N.Z.

Björnsson, \$., 1968. "Aflmaeling â N-3 Námafjalli," Geothermal Division, National Energy Authority, Reykjavik, Iceland (in Icelandic).

Blackwell, D. D., Granados, G. E., and Koenig, J. B., 1977. "Heat Flow and Geothermal Gradient Exploration of Geothermal Areas in the Cordillera de Guanacaste of Costa Rica," Geothermal Resources Council Trans., vol. 1, pp. 17-18.

Bolton, R. S., 1977. "Geothermal Energy in New Zealand," in Energy Technology Handbook, D. M. Considine, Ed.-in-Chief, McGraw-Hill, New York, pp. 7.14-7.33.

Browne, P. R. L., 1970. "Hydrothermal Alteration as an Aid in Investigating Geothermal Fields," Pisa-1970, vol. 2, pp. 564-570.

Burke, K. C. and Wilson, J. T., 1976. "Hot Spots on the Earth's Surface," in Continents Adrift and Continents Aground, W H. Freeman and Co., San Francisco, pp. 58-69.

Ceron, P., DiMario, P., and Leardini, T., 1975. "Progress Report on Geothermal Development in Italy from 1969 to 1974 and Future Prospects," San Francisco-1975, vol. 1, pp. 59-66.

CFE, 1971. "Cerro Prieto: Underground Power," Comisión Federal de Electricidad, G. V. Caravantes, Dir. Gen., Ródano 14, México 5, DF., México.

Chen, B. H. and Grabbe, E. M., 1978. "Planning for Geothermal Development in Hawaii," Geothermal Resources Council Trans., vol. 2, sec. 1, pp. 95-98.

Chen, B. H., Kihara, D. H., Yuen, P. C., and Takahashi, P. K., 1978. "Well Test Results from HGP-A," Geothermal Resources Council Trans., vol. 2, sec. 1, pp. 99-102.

Conti, Prince P. G., 1924. "The Larderello Natural Steam Power Plant," Proc. First World Power Conf., June 30-July 12, London. 
Cuéllar, G., 1975. "Behavior of Silica in Geothermal Waste Waters," San Francisco1975, vol. 2, pp. 1337-1347.

Dal Secco, A., 1970. "Turbocompressors for Geothermal Plants," Pisa-1970, vol. 2, pp. 819-833.

Dan, F. J., Hersam, D. E., Kho, S. K., and Krumland, L. R., 1975. "Development of a Typical Generating Unit at The Geysers Geothermal Project-A Case Study," San Francisco-1975, vol. 3, pp. 1949-1958.

Dench, N. D., 1961. "Investigations for Geothermal Power at Waiotapu, New Zealand," Rome-1961, vol. 2, pp. 179-191.

DiMario, P., 1961. "Remarks on the Operation of the Geothermal Power Stations at Larderello and on the Transportation of Geothermal Fluid," Rome-1961, vol. 3, pp. 334-353.

DiPippo, R., 1978a. "Geothermal Power Plants of Japan: A Technical Survey of Existing and Planned Installations," Brown Univ. Rept. No. CATMEC/9, D.0.E. No. COO/4051-16, Providence, R.I.

DiPippo, R., 1978b. "Geothermal Power Plants of the United States: A Technical Survey of Existing and Planned Installations," Brown Univ. Rept. No. CATMEC/ 14, D.O.E. No. COO/4051-20, Providence, R.I.

DiPippo, R., 1978c. "Geothermal Power Plants of New Zealand, Philippines and Indonesia: A Technical Survey of Existing and Planned Installations," Brown Univ. Rept. No. CATMEC/17, D.0.E. No. COO/4051-23, Providence, R.I.

DiPippo, R., 1978d. "Geothermal Power Plants of Mexico and Central America: A Technical Survey of Existing and Planned Installations," Brown Univ. Rept. No. CATMEC/18, D.0.E. No. COO/4051-26, Providence, R.I.

DiPippo, R., 1978e. "Geothermal Power Plants of Italy: A Technical Survey of Existing and Planned Installations," Brown Univ. Rept. No. CATMEC/26, D.O.E. No. COO/4051-34, Providence, R.I.

DiPippo, R., 1978f. "The Geothermal Power Station at Ahuachapán, El Salvador," Geothermal Energy Magazine, vol. 6, No. 10, pp. 11-22.

DiPippo, R., 1979, "Kakkonda Geothermal Power Plant," Dept. of Energy, Div. of Geothermal Energy Rept. No. COO/4051-40, Brown University, Providence, R.I. Dominco, E., 1977. "Guatemala," Geothermal Resources: Survey of an Emerging Industry, Geothermal Resources Council Spec. Short Course No. 6, Houston, Tex.

Donnelly, J. M., Goff, F. E., Thompson, J. M., and Hearn, B. C., Jr., 1976. "Implications of Thermal Water Chemistry in The Geysers-Clear Lake Area," Proc. Geothermal Environ. Sem.-'76, Lake County, Calif., pp. 99-103.

Dutcher, J. L. and Moir, L. H., 1976. "Geothermal Steam Pricing at The Geysers, Lake and Sonoma Counties, California," Proc. 11th IECEC, Sept. 12-17, Lake Tahoe, Nev., vol. I, pp. 786-789.

ECPE, 1977. " 5000 MW Geothermal Power Plant?" Energy in Counties with Planned Economies, vol. 1, No. 4, Dec. 14.

Einarsson, S. S., Vides R., A., and Cuéllar, G., 1975. "Disposal of Geothermal Waste Water by Reinjection," San Francisco-1975, vol. 2, pp. 1349-1363.

Ellis, A. J., and Mahon, W. A. J., 1977. Chemistry and Geothermal Systems, Academic Press, New York, N.Y.

ENEL, 1970. Larderello and Monte Amiata: Electric Power by Endogenous Steam, Ente Nazionale per L'Energia Elettrica, Compartimento di Firenze, Direzione Studi e Richerche, Rome (in English).

ERDA News, 1977. "ERDA Okays Geothermal Loan for Republic Geothermal," Geothermal Energy Magazine, vol. 5, No. 6, p. 21.

Finney, J. P., 1972. "The Geysers Geothermal Power Plant," Chem. Eng. Prog., vol. 68 , pp. 83-86.

Fuji Electric Company, Ltd., 1977. "Ahuachapán Unit No. 3, C.E.L., El Salvador," Tokyo, Japan. 
Furgerson, R. B. and Afonso L., P. S., 1977. "Electrical Investigations in the Guanacaste Geothermal Area (Costa Rica)," Geothermal Resources Council Trans., vol. 1, pp. 99-100.

Furumoto, A. S., 1978. "The Relationship of a Geothermal Reservoir to the Geological Structure of the East Rift of Kilauea Volcano, Hawaii," Geothermal Resources Council Trans., vol. 2, sec. 1, pp. 199-201.

Gardner, M. C. and Corrales, R., 1977. "Geochemical and Hydrological Investigations of the Guanacaste Geothermal Project, Costa Rica," Geothermal Resources Council Trans., vol. 1, pp. 101-102.

GEM, 1977. "Countries in Geothermal," Geothermal Energy Magazine, vol. 5, No. 5, May.

GEM, 1978. "Geothermal Plant Proposed in N.M.," Geothermal Energy Magazine, vol. 6, No. 2, p. 49.

GERD, 1975. "Harnessing the Earth's Thermal Energy," Geothermal Energy Research and Development Co., Ltd., Tokyo, Japan.

Girelli, M., 1977. "Nicaragua," Geothermal Resources: Survey of an Emerging Industry, Geothermal Resources Council Spec. Short Course No. 6, Houston, Tex.

GR, 1978. Geothermal Report, vol. VII, No. 11, June 1, p. 4 .

Grindley, G. W., 1970, "Subsurface Structures and Relation to Steam Production in the Broadlands Geothermal Field, New Zealand," Pisa-1970, vol. 2, pp. 248-261.

Grindley, G. W. and Browne, P. R. L., 1975. "Structural and Hydrological Factors

Guiza L., J., 1975. "Power Generation at Cerro Prieto Geothermal Field," San Francisco-1975, vol. 1, pp. 377-386.

Gudmundsson, J. S., 1979. Geothermal Division, National Energy Authority of Iceland, Reykjavik, Iceland, personal communication to J. Kestin.

Guiza L., J., 1975. "Power Generation at Cerro Prieto Geothermal Field," San Francisco-1975, vol. 3, pp. 1976-1978.

Hartley, R. P., 1978. "Pollution Control Guidance for Geothermal Energy Development," EPA-600/7-78-101, Ind. Envir. Res. Lab., Cincinnati, Ohio.

Hinrichs, T. C. and Falk, W. H., Jr., 1978. "The East Mesa 'Magmamax Process' Power Generation Plant," Geothermal Energy Magazine, vol. 6, No. 1, pp. 44-46.

Ho, A., 1977. "Panama," Geothermal Resources: Survey of an Emerging Industry, Geothermal Resources Council Spec. Short Course No. 6, Houston, Tex.

Hochstein, M. P. and Hunt, T. M., 1970, "Seismic, Gravity and Magnetic Btudies, Broadlands Geothermal Field, New Zealand," Pisa-1970, vol. 2, pp. 333-346.

Holt, B., 1977. "Geothermal Utilization Projects in the Western United States," Geothermal Resources Council Spec. Short Course No. 6, Houston, Tex.

Hunt, A. M., 1961. "The Measurement of Borehole Discharges, Downhole Temperatures and Pressures, and Surface Heat Flows at Wairakei," Rome-1961, vol. 3, pp. 196-207.

Hunt, T. M., 1977. "Recharge of Water in Wairakei Geothermal Field Determined from Repeat Gravity Measurements," N.Z.J. Geol Geophys., vol. 20, No. 2, pp. 303317.

Iga, H. and Baba, K., 1974. "Annual Information on Development and Utilization for Geothermal Energy in Japan-1973," Japan Geothermal Energy Association, Geothermics, vol. 3 , No. 3, pp. 122-124.

Ingvarsson, I. J. and Madsen, W. W., 1976. "Determination of the 5 MW Gross Nominal Design Case Binary Cycle for Power Generation at Raft River, Idaho," INEL, EG\&G Idaho, Inc., Rept. No. TREE-1039, Idaho Falls, Idaho.

Kawasaki, 1977. "Outline of Onikobe Geothermal Power Plant," Kawasaki Heavy Industries, Ltd., Kobe, Japan, Dwg. No. 83GZ1-GT99-02.

Koenig, J. B., 1973. "Worldwide Status of Geothermal Resources Development," in Geothermal Energy-Resources, Production, Stimulation, P. Kruger and C. Otte, eds., Stanford Univ. Press, Stanford, Calif., pp. 15-58. 
Lahsen, A. and Trujillo, P., 1975. "The Geothermal Field of El Tatio, Chile," San Francisco-1975, vol. 1, pp. 157-177.

Lengquist, R. and Hirschfeld, F., 1976. "Geothermal Power: The Sleeper in the Energy Race," Mech. Eng., vol. 98, No. 12, pp. 25-31.

Lindal, B., 1977. "Geothermal Energy for Space and Process Heating," in Energy Technology Handbook, D. M. Considine, Ed.-in-Chief, McGraw-Hill, New York, pp. 7.43-7.58.

Lindsay, D. R., 1977. "A New Steam Sales Contract at The Geysers," Geothermal Resources Council Spec. Short Course No. 6, Houston, Tex.

Macdonald, W. J. P., 1975. "The Useful Heat Contained in the Broadlands Geothermal Field," San Francisco-1975, vol. 2, pp. 1113-1119.

Mafi, S., 1978. "Turboexpanders in a Geothermal Power Recovery Cycle," Turbomachinery Int., vol. 19, No. 3, pp. 41-42.

Mahoney, D. J. and Bangert, A. C., 1977. "Economic Impact of Geothermal Development, Sonoma and Lake Counties, California," Pacific Gas and Electric Co., San Francisco, Calif.

Makarenko, F. A., Mavritsky, B. F., Lokshin, B. A., and Konov, V. I., 1970. "Geothermal Resources on the USSR and Prospects for Their Practical Use," Pisa1970, vol. 2, pp. 1086-1091.

Matthew; P., 1975. "Geothermal Operating Experience, Geysers Power Plant," San Francisco-1975, vol. 3, pp. 2049-2054.

Meidav, T., Sanyal, S., and Facca, G., 1977. "An Update of World Geothermal Energy Development," Geothermal Energy Magazine, vol. 5, No. 5, pp. 30-34.

Mercado G., S., 1974. "The Geothermal Plant of Cerro Prieto, B.C., Mexico, and Problems Encountered During Its Development," Geothermics, vol. 3, No. 3, pp. 125126.

Mercado G., S., 1975. "Cerro Prieto Geothermoelectric Project: Pollution and Basic Protection," San Francisco-1975, vol. 2, pp. 1385-1398.

Mercado G., S., 1976. "Cerro Prieto Geothermal Field, Mexico-Wells and Plant Operation," Proc. Int. Cong. on Thermal Waters, Geothermal Energy and Vulcanism of the Mediterranean Area: Geothermal Energy, Athens, Greece, vol. 1, pp. 394408.

Meucke, G. K., Ade-Hall, J. M., Aumento, F., MacDonald, A., Reynolds, P. H., Hyndman, R. D., Quintino, J., Opdyke, N., and Lowrie, W., 1974. "Deep Drilling in an Active Geothermal Area in the Azores," Nature, vol. 252, pp. 281-285.

MHI, 1977. "Binary Cycle Geothermal Power Generation Systems with Multistage Flash-Heating," Mitsubishi Heavy Industries, Ltd., Tokyo, Japan.

MHI, 1978a. "Geothermal Power Generation by Mitsubishi," Mitsubishi Heavy Industries, Ltd., Tokyo, Japan, Brochure JA-309, (1.0) 78-3.

MHI, 1978b. "Hatchobaru Geothermal Power Plant: Mitsubishi 50,000 kW Double Flash Cycle Plant," Mitsubishi Heavy Industries, Ltd., Tokyo, Japan, Brochure JA-327, (1.0) 78-6.

MHI, 1978c. "List of Geothermal Power Plant," Mitsubishi Heavy Industries, Ltd., Tokyo, Japan.

MITI, 1976. "Present Status and Future Prospect of Developing Geothermal Resources in Japan," Ministry of International Trade and Industry, Agency of Natural Resources and Energy, Tokyo, Japan.

Mori, Y., 1975. "Geothermal Resource Development Program in Northeastern Japan and Hokkaido," San Francisco-1975, vol. 1, pp. 183-187.

Moskvicheva, V. N. and Popov, A. E., 1970. "Geothermal Power Plant on the Paratunka River," Pisa-1970, vol. 2, pp. 1567-1571.

Muffler, L. J. P., 1975. "Summary of Section I-Present Status of Resources Development," San Francisco-1975, vol. 1, pp. xxxii-xliv. 
Naymanov, O. S., 1970. "A Pilot Geothermoelectric Power Station in Pauzhetka, Kamchatka," Pisa-1970, vol. 2, pp. 1560-1566.

NZED, 1974. "Wairakei-Power from the Earth," New Zealand Electricity Department, Pamphlet No. 50392H, A. R. Shearer, Gov. Printer, Wellington, N.Z.

Overton, H. L. and Hanold, R. J., 1977. "Geothermal Reservoir Categorization and Stimulation Study," Los Alamos Scientific Laboratory, Int. Rept. LA-6889-MS, Los Alamos, N. Mex.

Petracco, C. and Squarci, P., 1975. "Hydrological Balance of Larderello Geothermal Region," San Francisco-1975, vol. 1, pp. 521-530.

Radja, V. T. 1975. "Overview of Geothermal Energy Studies in Indonesia," San Francisco-1975, vol. 1, pp. 233-240.

Ragnars, K., Saemundsson, K., Benediktsson, S., and Einarsson, S. S., 1970. "Development of the Namafjall Area-Northern Iceland," Pisa-1970, vol. 2, pp. 925-935.

Ravenholt, A., 1977a. "Energy from Heat in the Earth-Philippines Taps Immense Resources of Pacific Fire Belt," Fieldstaff Reports, Southeast Asia Series, vol. XXV, No. 5.

Ravenholt, A., 1977b. "Wairakei and New Zealand's Geothermal Power," Fieldstaff Reports, Southeast Asia Series, vol. XXV, No. 6.

Reed, M. J., 1975. "Geology and Hydrothermal Metamorphism in the Cerro Prieto Geothermal Field, Mexico," San Francisco-1975, vol. 1, pp. 539-547.

Reed, M. J., and Campbell, G. E., 1975. "Environmental Impact of Development in The Geysers Geothermal Field, U.S.A.," San Francisco-1975, vol. 2, pp. 1399-1410.

Semrau, K. T, 1976. "Control of Hydrogen Sulfide from Geothermal Power Production," Proc. Geothermal Environ. Sem.-'76, Lake County, Calif., pp. 185-189.

Siegfried, H. N., 1925. "The Geysers," Geothermal Exploration in the First Quarter Century, D. N. Anderson and B. A. Hall, eds., Geothermal Resources Council Spec. Rept. No. 3, Davis, Calif., 1973, pp. 59-88.

Silverman, M., 1977. "Geothermal Loan Guarantee Program," oral presentation at Geothermal: State of the Art, 1977 Annual Meeting Geothermal Resources Council, May 9-11, San Diego, Calif.

Sólnes, J., 1976. "Kröfluvirkjun-Krafla Geothermal Power Plant," The Krafla Geothermal Project Executive Committee, Akureyri, Iceland.

Smith, J. H., 1970. "Geothermal Development in New Zealand," Pisa-1970, vol. 2, pp. 232-247.

Smith, J. H. and McKenzie, G. R., 1970. "Wairakei Power Station New ZealandEconomic Factors of Development and Operation," Pisa-1970, vol. 2, pp. 17171723.

Smith, R. A., 1978. "Soviet Failure," Geothermal Report, vol. VII, No. 24, Dec. 15, p. 3.

Stilwell, W. B., Hall, W. K., and Tawhai, J., 1975. "Ground Movement in New Zealand Geothermal Fields," San Francisco-1975, vol. 2, pp. 1427-1434.

Tezcan, A. K., 1975a. "Geophysical Studies in Sarayköy-Kızildere Geothermal Field, Turkey," San Francisco-1975, vol. 2, pp. 1231-1240.

Tezcan, A. K., 1975b. "Dry Steam Possibilities in Sarayköy-Kizldere Geothermal Field, Turkey," San Francisco-1975, vol. 3, pp. 1805-1813.

Tikhonov, A. N. and Drorov, I. M., 1970. "Development of Research and Utilization of Geothermal Resources in the USSR," Pisa-1970, vol. 2, pp. 1072-1078.

Tolivia M., E., Hoashi, J., and Miyazaki, M., 1975. "Corrosion of Turbine Materials in Geothermal Steam Environment in Cerro Prieto, Mexico," San Francisco-1975, vol. 3, pp. 1815-1820.

Toshiba, 1977. "Toshiba Experience List on Geothermal Power Plant," Tokyo Shibaura Electric Company, Ltd., Heavy Apparatus Division, Tokyo, Japan.

Usui, T. and Aikawa, K., 1970. "Engineering and Design Features of the Otake Geothermal Power Plant," Pisa-1970, vol. 2, pp. 1533-1545. 
Vakin, E. A., Polak, B. G., Sugrobov, V. M., Erlikh, E. N., Belousov, V. I., and Pilipenko, G. F., 1970. "Recent Hydrothermal Systems of Kamchatka," Pisa-1970, vol. 2, pp. 1116-1133.

Villa, F. P., 1975. "Geothermal Plants in Italy: Their Evolution and Problems," San Francisco-1975, vol. 3, pp. 2055-2064.

Weres, O., 1976. "Environmental Implications of the Exploitation of Geothermal Brines," Proc. Geothermal Environ. Sem.-'76, Lake County, Calif., pp. 115-123.

White, D. E. and Williams, D. L., eds., 1975. "Assessment of Geothermal Resources in the United States-1975," USGS Circular 726, U.S. Department of the Interior, Washington, D.C.

Wigley, D. M., 1970. "Recovery of Flash Steam from Hot Bore Water," Pisa-1970, vol. 2, pp. 1588-1591.

Younker, L. and Kasameyer, P., 1978. "A Revised Estimate of Recoverable Thermal Energy in the Salton Sea Geothermal Resource Area," Lawrence Livermore Laboratory Rept. No. UCRI -52450 , Livermore, Calif. 


\section{index}

Abraham, G., 604

Abrams, M. J., 14

Ackerman, H. D., 52, 57

Acoustic logs, 168

Acoustic velocity, and porosity of rocks, 157-158, 159

Aerial photography, 14

Afleck, J., 34

Afonso L., P. S., 963

Agriculture

air pollution, $814-816$

waste heat utilization, 650

water pollution, 812,813

Agua de Pau voleano, Azores, 962

Ahuachapán field, El Salvador

annual electricity generation, 883

arrangement of wells, 875-876

flashed steam cycle, 276, 277

flow diagrams, $878,880,881$

geothermal power plants, $874-883$

life cycle cash flow, 684

technical specifications, 879

wastewater disposal, 844, 881, 882

wellhead equipment, 276, 278, 876, 877

Aikawa, K., 212, 214, 560, 905, 906, 921, 962, 965

Air drilling, 137

Air pollution

baseline measurements in monitoring, 864

burner-scrubber process, 836

catalyst-scrubber process, 836

Claus process, 833,834

catalyst-scrubber process, 836

Claus process, 833,834

control technology, 820-836

Deuterium process, 836

Dow oxjgenation process, 831

effects on plants and crops, $814-816$

EIC process, 826-931

emission and ambient concentration standards, 790-791, 818

environmental monitoring, 860-861

DPA suggested discharge limits, 817818 hydrogen peroxide process, $834-835$

hydrogen sulfide limits, 817-818

Iron catalyst process, 823-826

ozone process, 835

solid sorbent process, 831-833

Stretford process, 821-823

toxlcological effects on humans, 814, 815

Akil, I., 965

Aladier, I. T., 117

Albarede, F., 24

Alcarez, A. P., 928

Alger, T., 515, 517

Algorithms, in design optimization, 749750

Allegrini, G., 893

Alleman, R. T., 628, 629

Allen, G. W., 825

Allis-Chalmers, 627

Alonso, H., 908, 918

Alpan, S., 932, 933, 934

Alseimer, J. H., 139, 140, 151

Aluminum

condenser tubes, 593

performance of alloys, 674,677

Aives, G. E., 216, 217

Amatitlán fleld, Guatemala, 963-964

American Association of Petroleum Geologists, 9,73

American Conference of Governmental Industrial Hygienists (ACGIH), 814 American Oil Shale Corporation, 117 American Petroleum Institute, $\mathbf{4 0 0}$

American Society of Heating, RefrigeratIng and Air-Conditioning Engineers (ASHRAE), 353, 553, 574, 614, 617

American Society of Mechanical Engineers Boiler and Pressure Vessel Code, 400, 404, 406

American Society of Photogrammetry, 14

Ammonia

cooling towers, 628-629

corrosion from, 667

surface condensers, 569 
Anderson, D. L., 51

Anderson, J. H., 953

Anderson, O. L., 12

Anderson, W. L., 44

Angevine, J. M., 729-772

Anisotropy

electrical resistivity measurements, 38 seismic measurements, 47

Anno, G. H., 750

Annular flow

friction factors, 210

in pipeline, 215

in vertical flow, 201-202

A. P. I. Research Project No. 44, 352, 353

Aqueous solutions, 269-270

Archambeau, C. B., 51

Archle, G. E., 37

Arizona, 34

Armstead, H. C. H., 212

Armstrong, R. L., 16

Arsenic, 791

Artesian flow in wells, 174-176

ASME Boiler and Pressure Vessel Oode, $400,404,406$

Assessment of Geothermal Resources of the United States, 113, 115

Atkinson, P. C., 129

Atlantic Coastal Plain, 73

Atwater, T., 12, 57, 66

Austin, A. L., 177, 504-538, 505

Austin, C. F., 56, 117

Australia, 9

Arachinski volcano, U.S.S.R., 942

Availability, thermodynamic, 208-210

dead state, 209

defined, 203

equation, 243

friction factors in two-phase flow, 209210

graphical representation, 257-267

in hybrid energy conversion system, 473-475

utilization factor, 208-209

of well pipe-power plant system, 203207

Avè Lallemant, H. G., 47

Awerbuck, I., $\mathbf{3 0 0}$

Axtmann, R. C., 812, 923

Aziz, K., 129

Azores, 982

Baba, K., 908

Babcock and Wilcox, 633

Baehr, H. D., 257
Baffied towers, 441-442

Bagnore plant, Italy, 894,899

Balley, R. A., 19, 57, 62, 63

Bainbridge, A. E., 199, 208

Baker, F., 613

Baker, O., 216, 217, 218

Balje, D., 47

Bancroft, D., 47

Bandy, O. L., 66

Bangert, A. C., 952

Banwell, C. J., 156, 199, 203

Baranov, V., 19, 62, 63

Barber, R. C., 706

Baroczy, C. J., 210

Barometric condensers, 55\&-559

Barrett, D. L., 47

Basin and Range province, U.S.A.

conductive environments, $9-10,12,70-$ 72

magnetic data, 34, 35

magnetotelluric methods of resistivity measurement, 42

Roosevelt Hot Springs area, 59

young igneous intrusions, 12

Basoeki, M., 965

Battelle Pacific Northwest Laboratories (BPNL), 831-833

Bauer, H. E., 927

Baumann, K., 487, 488

Beall, S. E., Jr., 549

Bear, J., 107

Beaumont, O., 30

Beaver, R. J., 593

Bechtel Corporation, 544, 560, 580, 588, $589,590,648,649,650,651,653,739$, 772

Bechtel steam cycle, 300-303

Beck, A. E., 21, 156

Beck and Associates, 626, 627

Belin, R. E., 199, 203

Bell, P. M., 24

Ben Holt Co., 442, 443

Benediet, M., 352

Beneft-cost analysis, 697-699

Benson, S. M., 743, 772

Bentall, R., 19

Benvenuti, G., 893

Beoware, Nevada, 497, 499, 500

Berg, A., 440

Berlín fleld, El Salvador, 883

Berman, E. R., 118

Bermejo de la Mora, F. J., 342

Best, M. G., 60

Bhattacharyya, B. K., 16, 34 
Bialy, S. C., 305-310

Biehler, S., 32, 66, 69

Billhartz, H. L., Jr., 127

Binary cycles, 350-464

axial flow organic fluid turbines, 370379

brine/binary cycle, 360-363

brine heat exchange, $379-383$

cycle thermodynamics, $360-370$

flash/binary cycle, 363-368

salinity and noncondensible gas and performance, 368-370

schematic, 235, 236

thermophysical properties of working fluids, 351-359

working finid selection, 741-742

see also Direct contact binary cycles

Bioconversion facilities, 549

Birch, F., 8, 10, 14, 21, 22, 23, 24, 46, 47, $48,49,50$

Bird D. K., 66

Bischoff, J. L., 66

Bishnol, P. R., 358

Bits, drill, 187-140

tri-cone roller, 138

in well logging records, 166

Bjornsson, S., 63, 886

Jlack and Vetch Consulting Engineers, 855,856

Blackwell, D. D., 8, 10, 11, 16, 22, 34, 43, 71,063

Blair, C. K., 445, 446

Blake, G. I., 71

Blank, H. R., Jr., 18

Blankenship, R. L., 19

Bliss, R. W., 416, 430, 432

Blistering, hydrogen, 666

Bloomster, C. H., 682-713, 702, 717, 736

Blowouts, 139

advanced drilling methods, 150-151

pollution effects from, 797

Bodvarsson, G., 13, 109, 129, 156, 198, 199, 203,207

Body wares, in selsmic measurements, $45-46$

Boehm, R. F., 413-464, 416, 420, 428, 436, $450,451,661$

Bollers

heat exchangers, 894-897, 405, 445-453

surface-type, 446-447

volume-type direct, $445-446$

Boldizar, T., 78, 74

Bolshoye-Bannoye plant, U.S.S.R., 941

Bolt, B. A., 63
Bolton, R. S., 918, 919, 920, 922, 924, 925, 928

Bond, R. G., 837, 838

Boraciferous Region, Italy. See Larderello region, Italy

Borg-Warner Corporation, 953

Bories, S., 129

Boron, 814, 816

Bosnjakovic, F., 257

Bostick, F. X., Jr., 41

Bouche, R. E., 152

Bouger gravity anomaly, 30-31, 58

Bowman, O., 608

Boyd, W. K., 676, 677

Boyko, L. D., 389

Brace, W. F., 38, 47

Brady-Hazen, Nevada, 497, 499, 500

Brandvold, G. E., 56

Brawley field, Californila, 66, 497, 499, 500, 955, 958

Brederhoft, J. D., 22

Brewer, M. C., 21

Brigham, W. E., 131, 216

Brine beat exchangers. See Heat exchangers

Bringer, R. P., 398

Brittle fracture susceptibility, 345, 676

Broadlands, New Zealand, 40, 843

Brook, C. A., 18, 57

Brooks, R. H., 127

Brott, C. A., 22, 71

Brown, D. L., 74

Browne, P. R. L., 66, 926, 927

Brunot, A. W., 281-305

Bubble flow

iriction factors, 210

in pipelines, 215

in vertical flow, 201

Buckets

intermediate height, 326

last stage, $325-326$

leading edges, 300

materials selection, 345, 348, 349

Budd, O. F., Jr., 149

Budiansky, B., 47

Buffe, C. G., 64

Bulldup in reservolrs, 109-113

Bullard, E. O., 21

Burbank, California, 473, 492, 493, 494, 496,960

Bureau of Reclamation (USBR), 67, 68, 70

Burke, D. B., 22, 70

Burke, K. O., 884

Burner-scrubber process, 836 
Burnham, J. B., 56

Busser, J., 353

Butane, 434

Butterfly valves, 338-339

Byerly, P. E., 16, 34

Cadmium, 791

Cady, G. V., 127, 131

Cagniard, L., 41

Galder, C. A., 218

Calderas, and gravity measurements, 31

Calhoun, J. C., 127

Oalifornia

hybrid energy conversion systems stud. les, 496-498

hydrogen sulfide regulation, 790,817

Caliper logs, 166

Cameron, Joseph A., 343-350

Campbell, G. E., 94, 950

Campbell Diagram, 325

Cann, J. R., 47

Cantwell, T., 45

Capillary pressure, 126-127

Carbon dioxide

concentrations of, in geothermal steam, 578

condenser choice, 279-281

corrosion from, 667

downhole concentration, 282-285

equilibrium partial pressure, 284

flashing steam mixture, 285-287

In geothermal brines, 282-287

Indirect steam cycle, $296-300$

primary flash temperature and release, 293-294

steam turbine performance, 281-305

variation of exergy for vapor-dominated well, 248

Carlson, J. E., 12, 15, 16

Oarnot cycle, 254

Carnot engine, 254-255

Carryunder, in bollers, 445

Carslaw, H. S., 16, 17, 22, 114

Carson, O. C., 747, 772

Carter, N. L., 47

Carter, W. D., 14

Casa Diablo wells, Long Valley caldera, California, 62

Cascade Range, 22

Cash flow, 728

Casings, drilling, 140-141, 346

Castelnuovo plant, Italy, 893, 895

Catalki, R., 7

Catalyst-scrubber process, 836

Cates, R. E., 622

\author{
Caufourier, P., 473 \\ Cavitation, 667 \\ Cements \\ as construction materials, 680 \\ In drilling, 140-141 \\ Ceron, P., 890, 891, 900 \\ Cerro Pando fleld, Panama, 966 \\ Cerro Prieto plant, Mexico, 66, 910-917 \\ barometric condensers, 279, 280 \\ concentration of gasses in geothermal \\ steam, 578 \\ ejector steam consumption, 586 \\ exploration, 13 \\ future developments, 917-918
}

geologic cross-section of field, 911, 912

helical rotor expander, 512

as hot water-dominated convection system, 115

operational stages in drilling, 142

plant schematic/heat balance diagram, 915, 917

steam pipeline gathering system, 911, 913

turbogenerator for unit No. 2, 915, 916 waste heat rejection, 544

waste liquid disposal, 913-015

Chaipayungpun, W., 41

Chalk Point, Maryland, 641

Chao, J., 353

Chapman, R. E., 31,76

Chapman, R. H., 58

Chaturvedi, S. K., 609, 610

Check valves, 335-337

Chemical explosives, in rock fracturing, 116, 117

Chemical geothermometers, 19-20

Chemical precipitation, in wastewater treatment, 837-838

Chemical reactions, in heat generation, 25

Chemical substances

concentrations in geothermal fluids, 800,801

Toxic Substances Control Act regulation, 792

Chen, B. H., 106, 131, 957,959

Chen, C. L., 839, 840

Chen, K. H., 609

Chen, N. C. J., 641

Chen, S. S., 353

Chenoweth, J. M., 590

Chile, 962-963

Chiltón, C. H., 394

Chimney, in nuclear explasion, 118

China, 871, 873-874

Chinameca field, fil Salvador, 883 
Chipilapa field, El Salvador, 883

Chisholm, D., 199

Chloride corrosion, 667,675

Christensen, N. I., 47

Christiansen, R. L., 7, 12, 15, 16, 18, 19, 71

Churn flow, 201

Ciechittl, A., 209

Cigni, U., 140, 141, 142

Clacy, G. R. T., 55

Claerbout, J. F., 52

Clark, H., 23, 24

Clark, S. P., Jr., 14, 25, 77

Claus process, for alr pollution, 833,834

Clean Air Act Amendments, 788, 790-791, 814

Cleaning methods

condenser tube, 688

heat exchanger, 408-409

Clifton, R. J., 116

Clot, A., 73

Coagulation, in wastewater treatment, 837-838

Coal-fired steam plants, 472 hybrid plants compared with, 498-500 see also Fossll fuel systems

Coats, K. H., 132

Cobalt alloys, 674, 677

Codes

design optimization with, 732-733

materials selection, 779,785

Cohen, L. H., 66

Colt, R. L., 576

Colburn, A. P., 388

Collayomi fault, California, 58, 944

Collier, J. G., 389

Colorado, 15

Colp, J. L., 56

Columbia plateau, 22

Combarnous, M., 129

Combs, J., 13, 29, 32, 50, 51, 54, 66, 69

Combs, S. K., 270, 271, 358, 553, 593, 594, 596,597

Comfort, W. J., 517, 522, 527, 529

Comisión Ejecutiva Hidroeléctrica del R1o Lempa (C.E.L.), 874

Compressed air, in drilling, 141

Compressed gas, in well pumping, 182183

Computer programs

design optimization with, 494-495, 733734

for direct contact binary cycles, 416420

Concrete polymer composition, $679-680$
Condensers, 552-600

barometric, 279, 281, 558-559

bubble type direct contact, $461-463$

carbon dioxide abatement, 279-281 .

direct-contact, 453-464, 557-562

drop-type direct-contact, $457-461$

enhanced-surface tubes, 593-598

film type direct-contact, $450-457$

hydrogen sulfide abatement, 279

low-level direct-contact, 559-560

mixing, 558-560

multipressure, 576-578

single-fluid direct-contact, 557-561

saturation pressure of common work-

ing fluids, $\mathbf{5 5 3}$

station performance and temperatures, 555-557

surface, 562-598

titanium for tubes, $590-593$

tube failure, 589-590

tube fouling, 586-589, 597

two-fluid direct-contact, 557, 561-562

Conductive systems, 8-12

drili hole measurements supporting, 8-9

extrapolation of shallow temperatures

to depth, 9-10, 25-26

ground water flow and disturbances, 22

models for calculation of temperature

at specifle depths, 10-12

Conductivity, heat and thermal

materials selection, 345

thermal properties of rocks, 22-24

Conover, M. F., 664-681

Consolidated Edison, 473

Consortium for Continental Refiection

Profiling (COCORP), 52

Conti, Prince P. G., 890

Controls, steam turbine, 329-343

check valves, $335-337$

inlet steam strainers, 331

load limiters, 343

main stop valves, $\mathbf{3 3 1 - 3 3 5}$

on plpes, 211-212

protective and auxiliary controls, 342343

speed, 342-343

steam throttling control valves, 337 339

valves, 331-342

Convective hydrothermal systems, 7

conditions for onset, 105

East Mesa area, California, 66-70 
Convective hydrothermal systems-Con. examples, 57-70

fluid flow physics and heat transport, 121-135

The Geysers-Clear Lake region, 57-69 heat content, 114-116

heat transfer, 103-107

hot water-dominated, 109, 114, 115

Long Valley caldera, Callfornia, 62-65

Nusselt number, 106

Rayleigh number formulations, 105106

Roosevelt Hot Springs area, 59-62

vapor-dominated, 109, 115

Cook, D. S., 416, 458, 461

Cook, N. G. W., 116

Cook, W. S., 796

Cooling systems. See Heat dissipation systems

Cooling towers, 611-641

alternatives, 550

circular mechanical-draft, 619-620

concentration relationships, 636-641

definition of terms, 614-615

deluge cooling for dry towers, 632-634

direct dry, 624-626

drift eliminators, 617

drift from wet cooling systems, 637-641

dry, 612-613, 624-629

evaporative or adiabatic, 634-635

heat dissipation, 611-641

indirect dry, 626-629

natural-draft, 611-612

parallel-path, 629

variable plume control, 630-631

waste heat pollution, 803

waste heat rejection, 544

wet/dry, 629-636, 654-655

wet mechanical-draft, 615-619

wet natural-draft, 620-624

Copper-based alloys, 674, 677 .

Corey, A. T., 127

Corrales, R., 963

Correia, R. J., 486, 488, 490

Corrosion

condenser tube, 588-689

crevice, 675,676

geothermal fluids, 667-668, 670-671

heat exchanger, 408

intergranular, 675

Iron catalyst process for air pollution, 825

materials selection, 328, 344

performance of metals, 668-679

stand-by, $\mathbf{3 4 7}$ wastewater injection, 849

Corwin, R. F., 44

Cosner, S. R., 800

Coso geothermal area, Callfornia, 50, 497, 499,500

Cost accounting, 688

Cost effectiveness, 697-699

Costa Rica, 693

Costain, J. K., 12, 20, 73

Costs

air pollution control technology, 822$823,825-826,830-831,832$

design optimization, 740-741

drilling operations, 142-149

evaporation ponds, 855

The Geysers project, Calltornia, 951

heat exchanger materials, 401, 402

noise control, 858

ocean disposal of wastewater, 854

operational, 724-725

power production, 699-710

solid waste disposal, 857-858

waste heat rejection systems, 543

wastewater spill containment, 856-857

Council on Environmental Quality, 795

Coutant, O. C., 601

Covington, Loren O., 676

Crevice corrosion, 675, 676

Cromling, T., 137

Cross, J. H., 47

Cruver, J. E., 198

Cuéllar, G., 847, 881, 883, 910

Culp, G. L., 838, 848

Culp, R. L., 838, 848

Cumberlidge, J. T., 25

Curzon, A. M., 664-681

Dakin, R., 766

Dal Secco, A., 894

Daly, R. A., 30

Dambly, B. W., 477

Damping, material, 345

Dan, F. J., 044, 045

Darcy, H., 107

Darrieus, G., 257

Das, T. R., 270, 271, 852, 356, 358

Dead state, and availability, 209, 243

Dealloying, 667

DeBarry, D. W., 664

Decker, E. R., 9, 47

Decompression devices, in drilling, 142

Deeds, R. S., 446

Defense Mapping Agency, 32

DeJong, V. J., 199

Demand, and selection criteria, 717-719 
Demineralization by ion exchange, 841

Dench, N. D., 140, 928

Density of rocks

gravity methods, 80-31

heat transfer, 116

log of, for subsurface roeks, 165-168

Denver, Colorado, 846

Department of Defense, 82

Department of Energy (DOE), 787

cooling tower specifications, 624

Division of Geothermal Energy, 959

environmental impact statement gulde-

lines, 795

EPA regulatory approach, 788

Federal Non-Nuclear Energy Research

and Development Act of 1974, 794

geothermal energy projects, 67,78

Geothermal Fnergy Research and Development Act of 1974, 723

pollution control contributions, 865,866

Department of Interior

Bureau of Land Management, 793

Geothermal Environmental Advisory Panel, 864

Desert Peak, Nevada, 960, 961

Design optimization, 729-772

algorithms, 749-750

brine production and disposal, 742

complexity of geothermal power plants, 729

design objective, 735

economic analysis tools, 732

inconsistencles in previous work, 729 732

Injection pumplng, 743

selection criteria, 784-735

software limitations, 733-734

state-of-art codes, 782-783

synthesis of plant/field alternatives, $785-742$

systems analysis, 748-750

transposed critical temperature (TPCT), 754-755

well design Influences, 746-748

working fluld selection for binary cycles, 741-742

Deuterium Corporation, 836

Deuterium process, in air pollution, 896

Diadkin, Y. D., 116

Diaphragm blades, 846

Diekey, J. B., 610, 621, 622

Dickinson, D. J., 15

Dlekinson, G., 76

Dickinson, N. L., 398

Differential analysis, 694
DiMario, P., 891

Diment, W. H., 8, 11, 20, 21, 22, 23, 24, 28 , $29,51,56,57,69,72,73,114$

Din, F., 248

DiPippo, Ronald, 1-6, 136-155, 230, 246, $351,473,476,477,480,481,486,488$,

578, 731, 771, 785-972, 876, 877, 878,

$881,882,894,899,900,903,906,907$,

908, 909, 914, 915, 916, 921, 923, 926, 029, 957

Direct contact binary cycles, 413-464

baffled towers, 441-442

bollers, $445-453$

condensers, 453-464, 657-662

heat exchangers, 436-464

preheaters, 436-437

recovery of working fluids from spent brine, $428-430$

sleve plate towers, $442-445$

spray towers, 437-441

superheated vapor, 463-464

Thermodynamic Figure of Merit (TFM), 420-423

thermodynamics of, $413-420$

turbine considerations, $430-435$

typical performance, $420-423$

working fluid losses, 423-428

DIRGEO (computer program), 416-420

Dix, O. H., 46

Dobrin, M. B., 80, 46, 49, 61

Dodd, H. M., 142, 143

Dodds, F. J., 848

DOE. See Department of Fnergy (DOE)

Doell, R. R., 19, 57

Doll, H. G., 159

Domenico, E., 964

Domenico, S. N., 50

Dominguez A., B., 140, 141, 142, 151

Donaldson, I. G., 129, 130

Dondanville, R. F., 57, 59, 65

Donnelly, J. M., 57, 944

Dorfman, J. R., 238, 352

Dorsey; N. F., 36

Double-flash systems, 234, 235

Double-flow turblne, 305-807

Douglas, J. G., 800

Douze, E. J., 55

Dow Chemical Company, 181

Dow oxygenation process, 831

Doyle, P. A., 663, 738, 739, 740, 750, 754, 755,756

Drains, in heat exchangers, 404

Draney, C. T., 300

Drawdown in reservoirs, 109-113

Drift, In cooling towers, 637-641 
Drill hole measurements

of conductive environments, 8-9

equipment, 20-21

extrapolation of shallow temperature

to depth, 9-10, 25-26

Drilling, 136-155

advanced methods, 149-153

blowout prevention problems, 139, 150151

casing and cementing, 140-141

compressed air use, 141

costs, 142-149

decompression devices, 142

depth and penetration rates for wells

in Imperial Valley and The Geysers, 138,139

drill bits and drilling fluids, 137-140

drilling and completion costs at The

Geysers, 145, 147

foaming agents used, 141-142

geothermal well site, 136-137

liquid nitrogen for well flow, 141

noise, 803-805

perforation of casing, 130-140

pollution effects, 796, 797

rig designs, 159

rock-melting penetrators (Subter-

renes), 151-152

rotary drilling, 186

rotating costs, 142-145

stimulating well flow, 141-142

swabbing, 141

tri-cone roller bit, 138

well completion techniques, 163

well costs at selected 0.8. sites, 145, 146,147

Drilling charts, Onuma fleld, Japan, 168, 169

Drinking water, and pollution regulation, 789, 791, 807-810

Dropek, R. K., 108

DSS Engineering, 561-662

Duba, A., 24, 848

Dukler, A. E., 203, 209, 210, 219, 772

Dump valies, 333

Dundas, H. J., 675

Dunn, F. D., 714-729, 744

Duprat, A., 13

Dutcher, J. L., 951

Earlougher, R. C., 743, 772

Earnest, G., 853

Earth filtration, 838

Earthquakes, 53-65
East Mesa field, Imperial Valley, Calr fornia, $477,953,954,955,956$

condensers, 561, 597

convective hydrothermal fleld, 66-70

distributed-parameter model for flow, 132

helical rotor expander, 512

hybrid plant studies, $497,499,500$

interference between adjacent wells, 113

geothermal well characteristics, 67,68 microearthquake studies, 54

rift system, 66

seismic measurements, 51

seismic noise studies, 55

temperature profiles, 29-30, 67

volcanism, 66

wastewater injection, 843

Eastern United States

conductive environments, $2-10,12$

teleseismic P-wave delay methods, 53

Eaton, G. P., 16, 32, 60

Economic considerations, 682-713

analytical methods, 692-699

basic concepts and terminology, 683-687

cost accounting, 688

definition of terms, 688-690

income statement, 691-692

inflation, 710-712

power costs, technical and financial tactors, 699-710

cee also Costs

ECOVIEW, 835

Edinger, J. R., 603, 604

Effiuent guidelines

under Federal Water Pollution Control Act Amendments, 789-780

future development, 864-865

Eggers, D. E., 207

EIC process, 826-831

Einarsson, S. S., 73, 881

Einarsson, T., 129

El Salvador, 871, 874-883

Elastic wave propagation, in well logging, 157-158

Elasticity, in materials selection, 344

Elastomers, 189, 680

Elder, J. W., 106, 129

Elders, W. A., 66

Electric Power Research Institute

(EPRI), 560,600, 641, 646

Electrical logs, 169, 170

Electrical loss, in turbines, 321 
Flectrical methods of exploration, 35-45 anisotropy, 38

effects of composition, 35-37

galvanic resistivity methods, 38-41

induction (electromagnetic) methods, 43-44

interpretation of, 35

in Long Valley caldera, Callfornia, 6465

magnetotelluric methods, $41-43$

over-voltage method, 45

pressure effects, 38

properties measured, 36-38

Schlumberger array, 39-40,43

self-potential methods, 44

telluric methods, 43

temperature effects, 38

Electrodialysis, in wastewater treatment, 840

Electrolytes, In electrical resistivity measurements, 36-37, 38

Electromagnetic methods of resistivity measurement, $43-44$

Schlumberger soundings, 43

time-domain sounding method (TMS), 44

Flectromagnetic radiation, and heat transport, 24

Electron beams, in drilling, 152

Elgawhary, A. M., 609

Elliott, D. G., 177, 183, 192, 195, 513, 748, $745,746,747,758,767,769,770$

Ellott, Wllliam Bell, 942

Ellis, A. J., 19, 25, 283, 285, 890, 863, 965

Dils, P. F., II, 664-681

Ellis, R. M., 41

El-Sawy, A., 142, 144, 145, 146

El-Wakll, M. M., 473

Emission standards

Clean Air Act Amendments, 790-791

EPA suggested limits, 817-818

future developments, 864-865

Endangered Species Act, 793, 795

England, A. W., 15

Environmental considerations, 785-868

federal laws, 788-795

geothermal pollutants, $805-817$

pollution control monitoring, 859-864

regulatory approach and applicable laws, 786-795

Wairakei plant, New Zealand, 923

water rights, 551-552

Environmental Protection Agency (EPA)

air pollution limits suggested by, 817818
Clean Air Act Amendments, 790

effluent guidelines under F'ederal Water

Pollution Control Act Amendments, 789-790

environmental monitoring, 860

evaporation ponds, 855

future development of effiuent and emissions standards, 864, 865

ground water monitoring, 862

hydrogen sulfide emissions, 850

noise pollution regulation, 793,816

once-through cooling system, 602

pollution control contributions, 865-866

regulatory approach, 788

Safe Drinking Water Act, 791

solld waste disposal under Resource

Conservation and Recovery Act of 1976, 791-792

state and local pollution regulation, 795

suggested pollution discharge limits, 817-820

water pollution regulations, 810,813 , 818-819

Environmental Research Institute of Michigan, 14

Environmental Systems Corporation, 611

Environmental test programs, in materials selection, $\mathbf{3 2 7}$

EPA. See Environmental Protection Agency (EPA)

Erdman, W., 622

Erosion resistance, and materials selection, 328, 344, 667

Eskesen, J. H., 281-343, 350-351, 356, 358, $360-379,862$

Eubank, P. T., 352, 356, 358

Evans, D. M., 54

Evaporation ponds, $854-856$

Exergy, 244-245

Exfoliation, 679

Exhaust loss, from turbine, 319-321

Exploration of geothermal systems, 18-55 data sources, 14

electrical methods, $35-45$

equipment for temperature measurement, 20-21

hot springs and geochemical thermometry, $10-20$

late Cenozolc sllicic rocks, 15-19

magnetic methods, 32-36

pollution effects, 796-797

remote sensing, 14-15

seismic methods, 45-55

subsurface temperatures and heat flow, $20-80$ 
Exploration of geothermal systems-Con. strategies, 13

target area, 13-14

temperature logs, 26-30

thermal properties of rocks, 22-24

Explosives, in rock fracturing, 116, 117

Facca, G., 54, 228, 505

Fair, J. R., 437, 441, 455, 464

Fairfax, J. P., 824

Faletti, D. W., 633

Falk, W. H., Jr., 953

Fan, L-N, 601

Fannar, H., 561

Faroug Ali, S. M., 131

Fassbender, L. L., 702

Fatigue

materials selection, $345,666-667,678-$ 678

rotating buckets, 348

Fauske, H. K., 198, 199

Faust, C. R., 121-135, 181, 182

Faust, L. Y., 158, 168

Feder, W. A., 611

Federal lands

Geological Survey supervision of geothermal operations, 864-865

Geothermal Steam Act regulation, 793 noise regulation, $793,795,816,820$

Federal Non-Nuclear Energy Research and Development Act of 1974, 793, 794

Federal pollution laws, 788-795

Federal Water Pollution Control Act Amendments (FWPCA) of 1972, 550, $788,789-790$

Fehlberg, E. L., 26

Fergerson, R. B., 36, 37

Ferrifloc system, 823-826

Ferris, J. G., 110

Feues, M., 47

Fiber reinforced laminates, 680

Fick, T. R., 772

Filtration treatment of wastewater, 838 , 839,844

Financing, and selection decisions, 728

Finney, J. P., 579, 947

Firey, J. O., 199

First-law analysis, 227, 239-241

Fish, L. W., 358

Fish and Wildlife Coordination Act, 793, 795

Fixed charge rate, $695-696$
Flashed steam systems, 276-350, 507-508

cycle thermodynamics, 281-305

noncondensable gas, 281-305

total flow systems compared with, 508509

Flash temperatures

in binary cycle, $363-368$

carbon dioxide release, 293-294

Fletcher, J. B., 53

Fletcher, R., 750

Floating ring seals, 376-379

Flocculation, in wastewater treatment, 837-838

Flow. See Fluid flow physics

Flow rate, and power production costs, 703-704

Floyd, A. L., 714-729, 778-785

Fluid flow physics

analysis of flow in reservoir-well system, 172-226

annular fiow, 201-202

artesian flow in wells, 174-176

Benedict-Webb-Rubin (BWR) equation, 353-356, 358

bolling point/depth curve, 177-180

bubble flow, 201

captllary pressure, 126-127

choked flow, 197-199

churn flow, 201

combined well-reservoir system characteristics, 183-200

continuity equations for vertical flow in pipe, 172-174

distributed-parameter models, 131-132 energy balance, 125

factors affecting flow, 107-108

flow patterns in vertical flow, 201-203

free convection models, 129-130

general model, 124-129

heat transport, 121-135

ideal gas properties, $\mathbf{3 5 3}$

initial and boundary conditions, 128129

lumped-parameter models, 130-131

Martin-Hou equation, 356-358

mass balance, 125

mass flowrate estimation, 199-200

momentum balance, 125

non-adiabatic well, 176-177

patterns of two-phase association in

vertical two-phase flow, 200-203

phase change within well, 176

pipe models, 129-130

pumped well, 180-183 
Fluid flow physics-Continued

single-phase (liquid) pumped system, 186-187

slug flow, 201

stepped-diameter well, 194-196

surface transmission of geofluids, 210 222

thermodynamic avallability in geothermal Bystems, 203-210

thermodynamic properties of mixtures, 358

thermodynamics of working fluids, 351-359

transition of flow pattern, 203

transport properties of fluids, 358-359

two-phase self-flowing, 187-191

variations in. depth to flash level in self-flowing wells, 195-197

well pipe, 172-183

wellhead characteristics for self-flowIng flashing well, 191-194

wellhead pressure-flow rate characterIstic, for self-flowing well, 185-186

Fluorocarbons

formulations of fundamental equation, 270-271

working fluids, 362

FMO Corporation, 835

Foaming agents, in drilling, 141-142

Fontana, Mars G., 675, 677

Ford, J. D., 458

Fossil fuel systems

geothermal systems combined with. See

Hybrid energy conversion systems

Ideal a vallable work, $253-254$

state of the art, $476-478$

use of term, 472-473

Fouling

condenser tube, 586-589, 597, 601

design specifications, 349

heat exchanger, 407-411

Fournier, R. O., 19, 20, 50, 62, 156

Fracturing of rocks

geothermal energy in hot dry rock, b657

methods for, 116-118

Francis, T. J. G., 47

Freeston, D. H., 220

Freon

In direct contact systems, $433,449-450$, 458, 460

surface condensers, 569

\section{Friction factors}

availability in two-phase flow, 209-210

pipeline flow, 216, 219-220

Friedman, E. J., 142, 144, 145, 146

Frischknecht, F. C., 35, 36, 38, 39, 41, 43, 45

Frostline, 15

Fuji, Y., 848

Fuji Electric Company, Ltd., 878

Fukuda, M., 173

Full-Are start, 333

Fulton, R. L., 663, 729-772, 738, 740, 750, 754

Furgerson, R. B., 903

Furumoto, A. C., 957

Galeski, J., 825, 826

Galvanic coupling, 666, 676

Galvanic resistivity measurements, 38-41. bipole-dipole methods, $40-41$

Schlumberger array, 39-40

Gamma-ray log, 165

Gardner, G. H. F., 48, 49

Gardner, M. C., 963

Garg, S. K., 182

Garnish, J. D., 114, 147

Garnish, J. F., 73

Garvey, M. J., 12

Garwin, L., 441

Gary, Margaret, 14

Gaskell, T. F., 161

Gat, Y., 445, 446

General Electric Co., 307, 627

Geoflulds. See Fluid flow physies

Geological Survey (U.S.G.S.), 4, 9, 73

basellne air and water quality monitorIng, 864

geothermal operations on federal lands supervised by, 791, 864-865

magnetic maps, 85

noise regulation on federal lands, 783, 795,820

pollution control contributions, 866

Geological Survey of Japan (GSJ), 900

Geology of geothermal a reas, 7-103

Geonomies, Inc., 850

Geophysics of geothermal areas, 7-103

Geopressured systems, 8, 74-77

definition of, 74

dissolved minerals and gases, 230

northern Gulf of Mexico basin, 75

rock type and location, 76

salt dome intrusions, 76-77

United States basins, 74-75 
George, P. F., 676

Geothermal Energy Research and Development Act of 1974, 793, 794

Geothermal Energy Research and Development Co., Ltd., (GERD), 900

Geothermal Environmental Advisory Panel, 864

Geothermal fluids characteristics of, 505-506 chemical constituent concentrations, 800,801

noncondensible gases, 802

pH values effected by, 800

pollution effects from, 796, 797-803

radioactive elements, 802

range of impurities in, and materials selection, 346, 347

surface transmission, 210-222

waste heat, 802-803

see also Fiuid flow physics

Geothermal Loan Guaranty Program (GLGP), 954

Geothermal Reservoir Engineering Management Program Plan (GREMP), 168

Geothermal Resources Operational orders, 791

Geothermal Steam Act of 1970, 791, 793794, 864

Geothermal systems

avallable work in thermodynamic considerations, 227-275

classification of, 7-8

examples of kinds of, $56-77$

geolosy and geophysics, 7-109

ceopressured systems, 74-77

high-porosity conductive environments, 72-74

low-porosity conductive environments, 70-72

minerals dissolved in, 229-230

schematic diagram of convective cells, 228-229

systems related to young intrusions in upper crust, 56-70

thermodynamic state at inlet and exit, 230-232

typical installations, 232-237

Geothermometers, 156

GEOTHM (computer program), 494, 495, 646, 750-755, 757-770

Geyer, J. C., 603, 604

Geysers, The, California

air pollution control technology, 820836 burner-scrubber process, 836

butterfly valves, 339

casing wear in wells, 140

catalyst-scrubber process, 836

choice of materials for plant components, 947-950

concentration of gases in geothermal steam, 578, 579

construction stages for steam turbine, 307-308, 309, 310, 311, 312

cooling tower and power house for units 5 and 6, 945, 949

cost of geothermal steam, 951

depth and penetration rate for wells, 139

development of units, 944, 946

discovery, 942

drilling site problems, 137

EIC process, 827, 829

exploration, 13

factors affecting seismic measurements, 47, 50, 51

flow diagram/heat balance schematle, 945, 948

geothermal electric power complex, 943-953

gravity measurements of pluton beneath, 31

historical background to energy use, 942-943

hydrogen peroxide process, 835

hydrogen sulfide emissions, 817, 818, 950-951

iron catalyst process, 824,825

map of, 944, 945

microearthquakes near, 623

noise measurements, $804-805$

resource utilization efficiency, 952-953

Stretford process costs, 822-823

temperature/depth curves, $179,-180$

temperature logs, 26-27, 59

technical specifications, 944,947

rapor-dominated system, 114

waste heat rejection, 544

wastewater injection, $843,844,845$

water pollution, $81 \theta$

Y-type strainer used, 331

Geysers-Clear Lake area, California

convective hydrothermal system, 57-69

microearthquake studies, 54

teleseismic P-wave delay methods, 53

Gibbons, J. H., 604, 605

Gibbs, J. W., 257

Gllbert, P. T., 679

Gilluly, J., 70 
Gindler, B. J., 552

Girelli, M., 866

Glass, W. A., 145, 147

Gleason, M. N., 810

Gof, F. E., 57, 58

Goforth, T. T., 55

Goguel, J., 16

Golding, R. M., 283, 285

Goldman, K., 398

Goldstein, N. E., 82

Goodling, J. S., 644

Goodyear, C. P., 601

Goodwin, L. H., 71

Goranson, C. G., 743, 772

Gough, D. I., 16

Gould, T. L., 172, 177, 505

Gouy, M., 257

Grabbe, E. M., 957, 859

Graham, D. J., 549, 650

Grant, F. S., 30, 32, 33, 34, 35, 37, 46

Grant, John D., 942

Granular media flters, 888, 839

Grass Valley, Nevada, 52

Gravity

density and porosity of rocks and measurements of, 30-32

magnetle maps differentlated from, $33-$ 84.

maps of, 32

Gravity separation, in wastewater treatment, 837

Gray, D. D., 641

Great Lakes Chemlcal Company, 562

Green, D. H., 12

Green, J. B., 675

Green, M. A., 494, 663, 788, 739, 741, 750, 752,767

Green, 8. J., 149

Greene, Norbert D., 675, 677

Gregory, R. G., 12

Grens, J. Z., 505

Gretener, P., 21

Griebe, M., 822, 823

Grieder, R., 145

Griggs, D. T., 56

Grim, P. J., 8, 69

Grimble, R. E., 641

Grindley, G. W., 123, 927

Griscom, A., 66

Grossman, F., 158

Ground water

environmental monitoring, 862-863

temperature disturbances, 22

Guatemala, 863-864

GuffantI, M., 7
Guild, D. A., 641

Guiza L., J., 813, 815

Gulf of Mexico, 74, 75, 230

Haas, J. L., Jr., 77, 269, 270

Hadley, D., 64

Haldane, T. G. N., 212

Hales, A. L., 21, 53

Hall-Taylor, N. S., 198, 215

Hamblin, W. K., 60

Hamilton, R. M., 10, 64

Hankins, B. E., 77

Hanold, R. J., 890

Hansen, A. C., 413, 420, 428, 436, 450, 451, 561

Hardenability, in materials selection, $\mathbf{3 4 5}$

Harleman, D. R. F., 603, 604

Harlow, F. H., 56, 117, 131

Harriott, P., 456, 457

Harris, B. R., 461

Harris, J. S., 413

Hart, G. K., 413, 439, 441, 446, 448, 450, 451, 453

Hart, R. 8., 51

Hartley, R. P., 785-869, 843, 950

Hartnett, J. P., 389

Hatchobaru plant, Japan, 904-906

condensers, 560

pipeline transmission, 214

Haum, J. D., 163, 166

Hawali, 957-959, 061

Hawkins, M. F., Jr., 74

Haywood, R. W., 472, 481

Heacock, J. G., 16

Healey, J. H., 63, 54

Healey, R. N., 757, 759, 760

Heard, D. G., 57

Hearn, B. C., Jr., 58

Heat conductivity, in materials selection, 345

Heat dissipation systems

amblent temperature fluctuation, 650663

amount of heat rejected per megawatt of capacity, 547,548

atmospheric absorption of heat, 542543

condensers, 652-600

cooling lakes and ponds, 602-605

cooling towers, 611-614

design considerations, 544-547

Heber and Nlland plants, California, $648-655$

Heller-type cycle, 544, 546

legal aspects, 550-552

nozzles, 606-607 
Heat dissipation systems-Continued once-through cooling systems, $600-602$ phased cooling, 644-645

spray ponds and canals, 605-011 utilization, 548-550

variable or floating cooling concept, 645-647

Heat Exchange Institute, $560,567,575$

Heat exchangers, 379-413

area requirement calculations, 384-387 baffled towers, 441-442

boilers, 394-397, 445-453

cleaning methods, 408-409

condensation coefficient, 388-389

cost impact of design pressure, 402-403

cost impact of materials, 401-402

design principles, $383-390$

direct contact binary cycles, $436-464$

distribution and magnitude of thermal resistance, 404-407

flow path options, 395

fouling factors, 407-411

geothermal fluid cycles, 379-383

impingement protection, 403

loading, 404

mechanical and system design considerations, 400-404

nomenclature, 391

optimization and trade-off studies, 400

ordering information, 398-400

preheaters, 391-394, 436-437

resistances, $387-388$

sieve plate towers, 442-445

size, 382-383, 400-401

specification sheet and applicable codes and standards, 398-400

spray towers, 437-441

standard shell-and-tube type, $390-400$

subcooling at preheat outlet, 411-413

supercritical primary heaters, 398

superheaters, 397-398

thermal expansion, 403

types of, 383

vent and drains, 404

vibration, 403

Heat flow

correction of temperature data, 21-22

subsurface temperatures, 20-30

Heat generation

chemical reactions, 25

decay of radioactive minerals, 24-25

thermal properties of rocks, 22-24

Heat transfer, 103-121 drawdown and buildup in reservoirs, 109-113

flow of geotluids, 107-108

hot water-dominated systems, 115

hydrothermal convection systems, 114116

hydrothermal How, 108-109

Igneous-related geothermal systems, 113-114

Interference between adjacent wells, 112-113

mechanical properties of rocks, 116

physics of fluid flow, 121-135

rock fracture methods, 116-118

surface condensers, 568-577

thermal convection, 108-107

vapor-dominated system, 115

Heavy metal ions, and corrosion, 668

Hebden, W. E., 607

Heber plant, California

condensers, 560

heat rejection equipment, $544,646,648$ 652

wet/dry cooling towers, $654-055$

Heler, K. S., 24

Helland, C. A., 35

Helgeson, H. C., 66, 758

Heller-type cycle, 544, 546, 561

Hellstrom, G. W., 424

Hemley, J. J., 25

Hemp, W. S., 623

Henderson, C. L., 580

Henry, R. E., 198, 215

Hentinger, R., 73

Henjey, T. L., 66

Hermance, J. F., 56

Herrin, E., 52, 53

Hesketh, E. H., 830

Hess, H. H., 47

Hill, D. P., 16, 49, 52, 54, 62, 63, 64

Hill, J. H., 57

Hill, P. G., 352

Himmelblau, D. M., 749

Hinricks, T. C., 953

Hinze, W. J., 34, 35

Hirschfeld, F., 942, 943

Hitchcock, Tim, 51, 55

Hite, J. R., 26

Ho, A., 966

Hoagland, J. R., 66

Hochstein, M. P., 166, 927

Hoffman, D. P., 609, 610

Hofiman, M., 848

Holburt, M. B., 552 
Holding basins, for wastewater spills, 856 Holland, D. S., 74, 76

Holmberg, J. D., 616, 621, 629, 640

Holst, P. H., 129

Holt, B., 735, 772

Honduras, 964

Hoover, D. B., 41, 42, 44, 64, 65

Horal, $\mathbf{K} ., 23,24$

Horne, R. N., 129

Las Hornillas de Miravalles fleld, Costa Rica, 063

Hot dry rock, 7

fracturing methods, 56-57

geothermal systems related, $56-57,70$ meteoric water modification, 70-72

Hot spots, 12

Hot springs, 19-20

HÖTERV Institute, Budapest, 633

Hougen, 0. A., 388

House, P. A., 613, 684

Houx, J. R., Jr., 631

Hu, S. O., 456

Hughes, D. \$., 47, 60

Hughes, R. R., 216-217

Humbolt Plate, 67

Hungarian Basin, 73-74

Hunt, A. M., 923

Hunt, T. M., $30,166,922,927$

Hybrid energy conversion systems, 471501

all-coal power plant compared with, $498-600$

avallable work and entropy production, $473-475$

design and economlc criteria, 491-500

fossil-superheat systems, 846-491

geothermal-preheat system, $479-486$

one-stage systems, $488-490$

plant siting, 492-493

thermodynamics, $478-47 \theta$

two-stage systems, 490

Hydrocarbons, 270-271

Hydrogen blistering, 666,669

Hydrogen embrittlement, 676

Hydrogen Ion corrosion, 667

Hydrogen peroxide process, in air pollut1on, 834-835

Hydrogen sulfide

air pollution control technology, 820836

air quality legislation, 780,814

burner-scrubber process, 836

cholce of condensing system, 279

Claus process, 833-834 concentrations, 678-579.

corrosion from, 667

Deuterium process, 836

Dow oxygenation process, 881

effects of, 814-816

EIO process, 826-831

EPA suggested limits, 817-818

fracturing of casing steel, 140

at The Geysers, Callfornia, 950-961

hydrogen peroxide process, $823-826$

Iron catalyst process, $834-835$

plants and crops affected by, 814

pollution effects, 802

solld sorbent process, 831-833

stress cracking, $349,666,669,676$

Stretford process, 821-822

waste heat rejection, $\mathbf{6 4 7}$

wastewater injection, 848

Hydrothermal convection systems. See

Convective hydrothermal systems

Iceland

geological features, 884-885

geothermal power plants, 885-880

Idaho National Engineering Laboratory, 648,957

Iga, H., 908

Impact statements, environmental, $\mathbf{3 2 8}$

Impact tests, $\mathbf{3 2 8}$

Imperial Valley, California

cooling towers, 620

depth and penetration rates for wells, 139

dissolved solids in geothermal fluids, 124

microearthquakes, 54, 623

planned geothermal plants, 955-957

pollution problems with salinity, 787, 800,801

potential for geothermal energy, 543

total flow systems, 617

waste heat rejection, 650

See also East Mesa feld, Imperial Valley, California

Impulse devices; in total flow systems; 613-615, 633-634

Impulse/reaction machines, in total flow systems, 511-612.

Income statements, 691-692

Indian Point plant, New York, 473

Indonesia, 964-065

Induction $\mathrm{log}$, in resistivity measurement, 163

Induction methods, in resistivity measurements, 43-44 
Industrial water supply, 813

Inflation, 710-712

Infrared (IR) imagery, 14-15

Ingersoll, $\mathbf{L} . \mathbf{R} ., 22$

Ingvarason, I. J., 957, 959

Injection of wastewater, 843-853

capital costs, 849-852

corrosion control, 849

- design optimization, 743

evaluation site potential, 846

flow capacity per well, 850

fluid velocity, 848-849

geological suitabillty of site, 846

ground water monitoring, 862

old production wells, 845

operating and maintenance costs, 852853

reasons for choosing, 844

Safe Drinking Water Act, 791

scaling and plugging of operation, 847

silica precipitation and scale formation, 487-848

surface pretreatment of wastewater, 847

water pollution control, 819

Intercomp, 132

Intermountain Power Project (IPP), 493-494

Internal rate of return, 693-694

International Association for the Properties of Steam, 269

International Formulating Committee, International Association for the Properties of Steam, 269

Ion exchange, in wastewater treatment, 840-841

Iregui, R., 714-729

Iron, and magnetle properties of rocks, 32-35

Iron catalyst process for air pollution, $823-826$

Irvine, M. D., 766

Isachenko, V. P., 460, 461

Isbin, H. S., 198, 209

Isherwood, W. F., 30, 31, 58

Isobutane

brine/binary cycle, $362-363,364$

characteristic design parameters for heat exchanger, 271

direct contact system, 424-428,434, $449-450,451,460$

formulations of fundamental equation 270-271

surface condensers, 560
Isopentane

brine/binary cycle, 362-363, 364

direct contact system, 451

Israel, G. W., 641

Italy, 890-800

Iyer, H. M., 47, 51, $63,65,58,63$

Jacobs, H. R., 413-464, 416, 420, 428, 436, $446,447,448,450,451,458,460,464$, 561

Jackson, E. D., 12

Jaeger, J. C., 9, 10, 16, 17, 21, 22, 114, 116

Jakosky, J. J., 35

Jallonk, P. A., 641

James, C. R., 473, 486

James, F., 749, 750, 751, 752, 756

James, Russell, 59, 112, 180, 195, 199, 200, $212,216,217,219,505$

Japan, 800-908

Jarzabek, D., 51

Jemez Platean, New Mexico, 57

Jessop, A. M., 9

Jet plercing drills, 152

Jhaveria, A. G., 858

Jirka, G. H., 604

Joesting, H. R., 32

Johnson, G. R., 15

Johnson, P., 505

Johnson, R. W., 436

Jolivet, J., 73

Jones, P. H., 75, 76

Jouget, M. E., 257

Journal bearings, $\mathbf{8 4 2}$

Journal of Geophysical Research, 27, 62

Kamatchatka peninsula, U.S.S.R., 234, 935, 942

Kane, M. F., 31, 64

Karkalits, O. C., 77

Kasameyer, P. W., 66, 957

Kassay, D. R., 106

Katto, P., 199

Kaufman, R. F., 802

Kawah Kamojang, Indonesia, 59, $964^{\circ}$

Kawasaki Heavy Industries, Ltd., 904

Kawerau plant, New Zealand, 40, 918, 924-926

Keenan, J. H., 126, 248, 248, 257, 269, 352 , $482,553,569,583$

Keer, L. M., 118

Kehat, E., 438, 439, 440, 441, 442, 443

Keller, G. V., 35, 36, 37, 38, 39, 43, 45, 49

Kelley, G. F., 310-329, 370-879

Kelley, V. C., 66

Kennedy, G. C., 56 
Kenya, 965

Kern, D. K., 383, 388

Kern, D. Q., 398, 406, 562, 565

Kestin J., 1-6, 227-275, 238, 253, 269, 270, $351-359$, 352, 358, 359, 393, 473, 474, $476,480,731,732,738,764,772$

Kettenacker, W. C., 132

Kettle rebollers, 395

Keyes, F. G., 260, 352, 482, 653, 569

Keys, S. W., 28

Khalifa, H. E., 1, 351-359, 358, 471-501, $473,476,477,478,480,482,486,491$, $500,501,555,656-663,660,662,731$, 736, 738

Kharaka, Y. K., 76

Kldd, G. J., 641

Kilauea Iki lava lake, 56

Kinna, L., 857

Kinney, O. L., 616, 621, 629, 640

Kirilin, V. A., 257

Kittel, C., 24

Kizldere field, Turkey, 831, 932-933

Knight, J., 17

Knock-out plate, 395

Knopoff, L., 51

Knox, F. B., 199

Knutsen, C. A., 736

Koenig, J. B., 66, 890, 963

Koh, R. C. Y., 601

Kolfat, T. D., 614, 619

Koppel, L. B., 398

Korim, K., 73, 74

Kosterin, S. I., 216

Kovach, R. L., 66

Kracek, F. C., 25

Krafla plant, Iceland, 885, 886-888

Kraus, A. D., 398

Kreld, D. R., 633

Kremnjov, O. A., 149

Krige, L. J., 21

Kruger, Paul, 579

Krumbein, W. C., 389

Kumar, B., 358

Kumar, K. H., 270, 271

Kunetz, G., 40

Kunze, J. F., 71

Kurile Islands, U.S.S.R., 934, 942

Kushnyrev, V. I., 460, 461

Kuwada, J. T., 888, 963, 964

Kyser, J. M., 604

Lachenbruch, A. H., $8,9,10,11,12,16$, $17,21,22,24,28,58,62,65,71$

Lahsen, A., 963

Lambert, I. B., 24, 30
Land spreading of wastewater, 855-856, 863

Landisman, M., 41

Landon, R. D., 631

Lange, A. L., 54

Lapwood, E. R., 106

Larderello (Boraciferous) region, Italy, 59,248

condensing unit speciflcations, 896-897 exploration of, 13

power plant, 870, 890-893

turbine specifications, 898

types of energy conversion systems, 891-893

vapor-dominated system, 114

Large Aperture Seismle Array, Montana, 53

Larinoff, M. W., 635, 636

Larson, R. L., 66

Lasers drift in cooling towers, $640-641$ drilling with, 152

Laskowski, S. M., 641

Lasseter, T. J., 132

Laszlo, J., 821, 825, 836

Latanision, R. M., 675

Laterolog, in resistivity measurement, 163

LaVerne, M. E., 641

Lawrence Berkeley Laboratory (LBL), $67,168,772$

Lawver, L. A., 66

Leach Hot Springs, Grass Valley, Nevada, 52

Leaching, In solid waste disposal, 857

Leakage losses, in steam turbines, $\mathbf{8 1 0}$

Leang, J. T., 199

Lee, T. C., 66

Lee, W. H. K., 8

Lelgh, J., 760

Leighton, F., 766

Lelrhnjúkur, Iceland, 887, 888

Lekic, A., 458

Lengquist, R., 942, 943

Leonard, G. W., 56, 117

LeRoy, L. W., 163, 166

Letan, $R ., 438,439,440,441$

Leu, Lel-Kuang, 16, 34

Levelt Sengers, J. M. H., 267, 352

Leyte, Phllippines, 829, 930, 931

Liebowitz, H., 116

Llen au, P. J., 548

Limestone, 159

Lindal, B., 884 
Lindh, A. G.; 63

Lindsay, D. R., 952

Lindsley, D. H., 32

Lipman, P. W., 12, 15, 18

Lippman, M. J., 132

Liquid-dominated systems, 122-123

Lithology logs, 166-167

Lizlovs, E. A., 675

Load factor, and power production costs, 707

Load Limiters, 343

Loading, in heat exchangers, 404

Local government, and pollution control, 795

Lockhart, R. W., 209, 210

Loeltz, O. J., 67, 69

Loginow, A. W., 675

Logs, See Well logging

Long, C. L., 41

Long Valley caldera, California analysis of cooling of intrusions, 17 blpole-dipole methods of resistivity measurement, 40

convective hydrothermal system, 62-65

distributed-parameter model for flow, 132

duration of volcanic system, 19

electrical prospecting, 64-65

exploration of, 13

gravity measurements for sedimentary fill, 31

hybrid plant studies, 497, 499, 500

microearthquake studies, 54

recent seismicity, 62-63

refraction profles of seismic stratigraphy, 62, 64

Schlumberger soundings for resistivity with depth, 40

seismic noise studies, 55

teleseismic P-wave delay methods, 53 temperature logs, 27-29, 65

time-domain electromagnetic sounding method (TMS), 44

Los Alamos Scientific Laboratory (LASL), 57

Los Baños field, Philippines, 829, 830, 931

I.oscutoff, W. V., 631, 633

Losses, steam turbine, $319-822$

direct contact system, $\mathbf{4 2 3 - 4 2 8}$

exhaust, 319-321

leakage and seal, $\mathbf{s 1 0}$

radiation, electrical, and hectanical. 821-822

turn-up, $\mathbf{3 2 0}$
Lovering, T. S., 16

Luedke, R. G., 15

Luenberger, D. G., 748, 749

Lund, J. W., 548

Lyons, P. L., 32

Mabey, D. R., 31, 35, 40, 60, 71, 72

Macdonald, W. J .P., 40, 927

MacFarlane, J. A, 644

Madden, T. R., 41, 45

Madsen, W. W., 957, 959

Maeder, P. F., 682-713

Maf, S., 953

Mafi-Trench Corporation, 953

Magma, 7

geothermal systems related to, 56

heat transfer to adjacent rock, 113-114

hydrothermal cooling efficiencles, 17

young igneous intrusions, 12-13

Magmamax plant, East Mesa, California. 053, 954, 955

Magnetization of rocks

exploration of geothermal systems with, 32-35

frozen-in (thermoremanent) compo. nent, 33

gravity maps differential from, 33-34

intensity of, 32-33

satellite measurement, 34

well logging records, 166

Magnetotelluric methods of resistivity measurement, 41-43

Mah, Clifford, 583, 584, 586, 587

Mahon, W. A. J., 19, 890, 963, 965

Mahoney, D. J., 952

Main stop valve, 331-335

Majer, E. L., 50, 51, 52, 54, 59

Makarenko, F. A., 934

Makhachkala, U.S.S.R., 942

Makiling Banahaw plant, Philippines, 929

Mao, H. K., 24

Maples, G., 644

Marchello, J. M., 580

Marine Protection, Research, and Sanctuaries Act, 793, 795

Mariner, R. H., 62

Marks, L. S., 661

Maron, \$. H., 38

Marshall, W. L., 88

Marshall, T., 669

Martin, J. C., 181

Irartin, J. J., 352

Martinetli, R:C., 209, 210 
Materials selection, 343-350, 664-680 bucket design, 325-326 coefficient of thermal expansion, 345 component parts, 328-329

composition of materials, $345-346$ corrosion resistance, 344, 666-667 erosion resistance, $\mathbf{8 4 4}$

fatigue strength, 345

geothermal fluids and corrosion, 667688, 670-671

geothermal power cycles, 664-666

guidelines for, select, $327-329$

hardenabllity, 345

location and procurement of components, 778-785

material damping, 345

modulus of elasticity, 844

nonmetallic materials, $670-680$

performance of metals, $668-67 \theta$

range of impurities in geothermal waters, 346, 347

specific heat and thermal conductirity, 345

strength considerations, 324-327

susceptibllity to brittle fracture (toughness), 345

tensile properties, 344

weldabllity, $\mathbf{3 4 5}$

Mathias, K. E., 21, 29, 156, 109

Matsukawa plant, Japan, 59, 843, 848. 900-903

Matsuo, K., 137, 140, 168, 169, 797

Matthew, $P, 044,048$

Maurer, W. C., 139, 162

Maurette, C., 50

Masacmas Mountains fault zone, Callfornia, 943

Máyher, M. A., 16, 34

McAdams, T. H., 568, 574, 581

McBimes, A. R., $\mathbf{5 0}$

MeCabe, B. C., 943

McCluer, H. K., 824

MeDonald, C. L., 702

McDougall, I., 12

McEdwards, D. G., 113, 743, 772

MeEvilly, T. V, $50,51,52,64,69$

Mefarland, O. B., xvil, 1, 2

McKay, R. A., 512

McKee, E. H., 15, 16, 18, 71

McKee, R. W., 696

McKenzie, G. R., 924, 928

McKenrie, W: F., 10

McLaughlin, R. J., 58

McLeod, N. C., 924
McMillan, Dan A., Jr., 943

McNitt, J. R., 13

Mead, $R$., 750

Mehdizadeh, Parvis, 679

Meldav, T., 13, 963, 964, 965, 966

Mellilt, A. S., 310-329

Melting pentrators, in arilling, 151-132

Menard, $\mathbf{H} . \mathbf{W}, \mathbf{1 2}$

Mercado, S., 66, 012, 913, 915, 917

Mercer, J. W., 121-135, 128, 131, 132

Mercury, 579-580

Mercuryville fault zone, Callfornia, 58, 944

Merkel, F., 613

Merriam, R., 66

Messmer, J. H., 24

Jethane, 230

Meucke, G. K., 962

Mexicali-Imperial rift ralley, 911

Mexico

future derelopment of geothermal power, 917-918

geothermal electric power capacity, 871 power plants, 908-918

Meyer, C. A., 126, 247, 269

Michel, J. W., 595, 597

Michaelldes, E., 736, 738

Microearthquake studies, 53-55, 623

Mllerolaterolog, in resistirity measurement, 163

Microlog, in resistivity measurement, 163

Microcracks, and seismic measurements, $46-47$

Microstrainer, in filtration, 838

Microware exploration of soll moisture, 15

Mid-Atlantic Ridge, 962

IIiele, R. P., 839, 840

Mignotte, H., 848

Milford Valley, Utah, 60

Millaris, E. S., 624, 625

Miller, E. H., 476, 477

Miller, L. G., 71

Miller, R. E.; 69

Miller, R. L., 677

Miloza, S. L., 270, 271, 352, 853, 356, 85T, 356, 362, 471, 475, 478, 758, 741, 764. 766,770

Mineral Mountains, Utah, 60

MINUITS (computer program), 749-750

Misener, A. D., 20, 21, 156

Mississippi Power Company, 610

Mitchell, B. J., 58

Mitchell, J. C., 71 
Mizen, L. B., 329-343

Yoalem, D., 461

Moench, A. F., 129

Molr, L. H., 951

Mollier diagram, 263-266

Molybdenum

rock-melting penerators, 152

stress corrosion cracking, 675,679

Momotombo field, Nicaragua, 965-966

Monitoring pollution control programs, 850-864

Monroe-Joseph, Utah, 497, 499, 500

Montana, 53

Monte Amiata region, Italy, 893-899

Moore, D. G., 66

Moore, F. K., 531, 628

Moore, J. G., 352

Moore, M. J., 487

Moore, W. D., III, 153

Morgan, W. J., 12

Mori, Y., 908

Mori plant, Japan, 906, 908

Morris, G. B., 47

Morris, W. B., 131

Hoses, R. J., 551

Moskvichera, V. N.. 938, 939, 940

Mossop, S. C., 156

Mostinskii, I. L., 396

Moulton, R. W., 198

Moyuta field, Guatemala, 963, 964

Mueller, A. C., 410

Muffer, L. J. P., 7, 12, 13, 32, 40, 54, 56,

$57,59,62,64,66,67,70.71,116,505$. 928. 965,966

Iuffiers, for noise control. 804, 858, 859

Munroe, R. J., 8

Murase, T., 50

Murty; N. S., 456

Muscovite, in heat exchangers. 408

Mrers, D. M.. 607, 609, 610, 611

Nagata, T., 32

Nakajima, Y., 140

Nakamura, H., 59

Námafjall plant. Iceland. 885-886, 887

Narasimhan. T. N.. 110, 111. 112, 113, 128, 743. 772

Nashner, R., 47

Nathenson, M.. 28, 176. 177

National Engineering Laborators, scotland, 199

National Environmental Policy Act of 1969, 794-795

National Park Srstem. 552
National Pollution Discharge Elimination System (NPDES), 790

Naymanov, O. S., 508, 936, 937

Neill, D. T., 397, 404, 410

Nelll, J. S., 604, 605

Nelder, J. A., 750

Nelson, D. B., 210

Net present ralue method, 692-693

Nettleton, L. L., 30, 31, 33

Neuronen, K. J., 25

Nevada, 16, 496-498

New Madrid region, Missouri, 53

New Mexico, 15

New Zealand, ప̄5, 871, 918-828

Newsom, M. M., 142

Newton-Raphson iteration, 131, 132

Nicaragua, 965-966

Nicolas, A., 47

Nichols, D. G., 748, 749

Nickel-based alloys, 674, 677

Niland geothermal station, California, 270,830

heat rejection equipment, $544,648,652-$ 654

hybrid plant studies, 497, 499, 500

wastewater injection, 843

Nizhne-Koleshevskaya, U.S.S.R., 942

Noise regulations, $795,858,859$

EPA suggested limits, 820

geothermal operations, 803-805

at The Geysers, 804-805

monitoring of control programs, 863864

Noise Control Act of 1972, 793

Noise, seismic, $\mathbf{5 5}$

Northern California Power Agency (NCPA), 952

Norton, D., 17

Norwood, E. J., Jr., 74, 76

Nozzles

outer sidewall assembly, 308-309, 313. 314

spray ponds, 606-607

total flow systems, 515-517

Nuclear power plants, 249-250

Nur, A., 47, 50

Nurminen, J. I., 675

Nuttli. O. W.. 53

Oak Ridge Tational Laboratory (ORNL), 593, 641

Occupational Safety and Health Administration (OSHA), 814. 816, 817. 820 
Ocean disposal of wastewater, 853-854

O'Connell, M. F., 802

O'Connell, R. J., 47

Ohaki (Broadlands) plant, New Zealand, 918, 926-927

Okamura, R. T., 56

O'Keefe, William, 583

Oliver, H. W., 30

Oliver, J., 52

Olkaria region, Kenya, 965

Olsen, E. R., 66

Omnes, G., 13

Onikobe plant, Japan, 904

Onuma plant, Japan, 903, 904

Opal Mound fault, 61

Orange, A. S., 38, 47

Oregon Institute of Technology, 548

Ostroot, G. W., 846, 847

O'Sullivan, M. J., 129

Otake plant, Japan, 477, 843, 848, 803, 906-908, 910

Othmer, D. F., 580

Otte, Carel, 578

Orer-voltage methods, 45

Overcamp, T. J., 641

Overton, H. L., 890

Ozawa, T., 848

Ozone process, for air pollution, 835

Pacific Gas and Electric Company, 823, 043, 051, 952

Pacific Northwest Laboratory, 633, 634

Packed bed type condensers, 456-457

Paddison, F. C., 64, 73

Paddock, R. A., 604

Padgett, L. R., 748, 749

Palen, J. W., 396

Pálmason, G., 13, 156

Palmer, W. F., 576, 577

Panama, 966

Papadopulos, I. S., 22

Papadopulos, S. S., 74, 77

Parasnis, D. C., 35

Paratunka power project, U.S.S.R., 281, 937-931

Parisky, Y. H., 116

Parr, P. D., 641

Pathé plant, Mexlco, 808,910

Paulson, B., 32

Pauzhetka field, U.S.S.R., 934-937

Payback period, 694-695

Peck, D. L., 17, 56

Perkins, P. C., 12

Permits, pollution control, 864-865
Perry, R. H., 383, 389, 394

PERTAMINA, 964

Peselnick, L., 47, 50, 51

Pessall, N., 675

Peterson, D. E., 550

Petracco, C., 899

Phased cooling, 644-645

Philipplnes, 871, 828-931

Piancastagaino, plant, Italy, 894, 899

Plckett, G. R., 158

Plerson, R., 132

Pike, F. P., 604

Pines, H. S., 494, 646, 647, 663, 729-772, $738,739,740,750,754,757,759,760$

Pirson, S. J., 36, 157, 158, 162, 165

Pitt, A. M., 54, 63

Pitting, in metal surfaces, 666, 675, 676

Pitzer, K. S., 248, 269, 270, 287, 757

Plass, S. B., 441

Plug flow, 215

Plasmas, in drilling, 152

Polak, R., 269

Policastro, A. J., 604

Polito, J., 145, 148, 149, 153

Pollastri, G., 211, 222

Pollution

dissolved gases, 787-788

environmental effects, 805-817

environmental monitoring, 859-864

EPA suggested discharge limits, 817820

federal laws relating to, 788-795

geothermal energy operations, 796-817

geothermal fulds, $800-803$

land-disposed wastes, 816

radiation, 817

see also Air pollution; Nolse regulatlons; Water pollution

Polymer cements, 680

Polymer concrete, 140, 679-680

Ponds, evaporation, 854-855

heat dissipation, 602-611

phased cooling, 644-645

Pope, W. L., 729-772, 738, 739, 740, 741, $750,752,754,757,759,760$

Popov, A. E., 938, 939, 940

Porter, R. W., 609, 610

Portugal, 962

Possell, C. R., 512

Poston, S. W., 127

Potter, K. W., II, 74

Powell, M. J. D., 750

Prache, P., 20

Pracht, W. E., 56, 117, 131

Pratt, H. R., 116 
Prausnitz, J. M., 352, 358

Precipitation processes, in wastewater treatment, $837-838,847-848$

Preheaters

In heat exchangers, 391-394, 405, 436437

in hybrid systems, $479-486$

PREHET (computer program), 416

Press, F., 47, 48, 49

Pritchett, J. W., 132

Prutton, C. F., 38

Public Health Service, 814

Puna, Hawail, 957-959, 061

Quist, A. S., 38

Rachmilev, I., 456

Radiation

electromagnetic, and heat transport, 24 heat generation from decay of minerals, 24-25

loss, in turbines, 821-322

pollution effects, 802,817

well logging, 165-166

Radja, V. T., 904,965

Raft River, Idaho, plant, 957, 959, 961 drawdown and bulldup, 110, 111, 113 geophysical exploration, 72

interference between adjacent wells, 113

distributed-parameter model for flow, 132

Schlumberger soundings for resistivity measurements, 40

tectonic environment, 71

Ragnars, K., 885, 886

Raitt, R. W., 47

Raleigh, C. B., 54

Ramey, H. J., 107, 112, 122, 123, 126, 127, 131

Ramos, J., 846, 847

Randall, W., 69

Randolph, P. L., 77

Rant, Z., 247, 266, 267

Rao, R. U. M., 9

Rascheri, R., 796

Ravenholt, A., 923, 826, 928, 929, 931

Ray, M., 247

Ray, R. G., 14

Rayleigh, Lord, 105

Raymond, L. S. 168

Reed, C. O., 352, 356, 358

Reed, M. J., 66, 912, 944, 950

Reeves, R. G., 14

Reflection seismology, 51-52
Refraction surveys, 52, 64

Reid, R. O., 352, 358

Reinjection wells, 791, 903

Remote sensing, 14-15

Rendine, A. P., 310-329

Renner, J. L., 19, 115

Republic Geothermal, Inc., 27, 28, 954, 956

Resistivity, electrical

bipole-bipole methods for measurement of, 40-41

effects of composition, 36-37

galvanic resistivity methods, $88-41$

interpretation of logs, 163-165

magnetotelluric methods, 41-43

Schlumberger array, 39-40, 43

well logging measurements, 158-165

Resource Conservation and Recovery Act of $1976,789,791-792,795,820$

Reverse osmosis, 839-840

Rex, R. W., 27, 28, 29, 62, 64, 65, 66

ReykJavik, Iceland, 884

Ribando, R. J., 106

Rice, J. K., 593

Rice, W., 512

Richter, C. F., 53

Richter, D., $\mathbf{4 7}$

Rlemer, D. H., 416

Rift Valley province, Kenya, 965

Risk, G. F., 38, 40

Rivkin, S. L., 269

Roberts, V. W., 646, 735, 740, 748, 759, $760,763,772$

Robertson, R. C., 552-647

Roble, R. A., 14, 23, 30

Robinson, D. B., 858

Roblnson, P. T., 66

Roffman, Amiram, 641

Rogers, V. C., 413

Rogers Engineering Co., Inc., 210

Rohsenow, W. M., 389

Roos, M., 749, 750, 751, 752, 756

Roosevelt Hot Springs, Utah, 960, 961 convective hydrothermal system, 59-62 hybrid plant studies for, 497, 499, 500 magnetotelluric methods applied to, 4243

microearthquake studies, 54

Ross, L. W., 168

Rossie, J. P., 625, 626, 627

Rotary drilling, 136

Rotstein, Y., 50

Rowan, L. C., 14

Rowe, J. J., 19 
Roy, R. F., 8, 9, 10, 11, 20, 21, 22, 24, 25, 53

Rubin, L. C., 852

Rubow, I. H., 152

Rundle, J. B., 30

Russia. See Union of Soviet Socialist Republles (U.S.S.R.)

Ryan, P. J., 608, 607, 608, 609, 610, 611

Ryley, D. J., 103-121, 136-226, 173, 192, $197,198,199,203,216,217,504-538$

Sadow, R., 847

Safe Drinking Water Act, 789, 791

Salisbury, J. K., 481

Sammel, E. A., 19, 21

Samurin, N. A., 772

San Jacinto-Tisate area, Nicaragua, 966

San Vicento field, El Salvador, 883

Sanford, S. K., 800, 802

Sanyal, S. K., 800, 802

Săo Miguel, Azores, 902

Sass, J. H., 8, 9, 11, 12, 16, 20, 22, 24, 58,71

Sastri, V. M. K., 456

Satellite magnetometry, 34

Saull, V. A., 25

Sax, N. I., 810, 814, 815

Sbar, M., 60

Schatz, J. F., 24

Schechter, B., 61, 54

Schlumberger array, 39-40, 43

Schroeder, R., 743, 747, 758, 772

Schumacher, B. W, 162

Scott, D. S., 203

Scrubber processes, for alr pollution, $\mathbf{8 3 6}$

Second-law analysis, 227, 238, 241-243

Sedimentation wastewater treatment, 837

Selder, E. N., 389

Selsmic methods in exploration, 45-65

Selsmic wave logs, 166

Seki, A. S., 181

Selection criteria, 714-785

conceptual design optimization, 729-772

market factors, 717-722

operating factors, $723-728$

see also Materials selection

Self-potential (SP) methods, 44

Semran, K. T., 850, 951

Sengers, J. V., 267, 852

Shaffer, C. J., 428, 798

Shah, A. M., 607

Shapiro, T., 641

Shaw, H. R., 12, 17, 18, 56, 68, 118, 114

Sheinbaum, I., 413, 442

Sheldon, R. C., 472

Sideman, S., 461, 464
Siegfried, N. H., 942

Silvester, L. F., 248, 269, 270, 287, 663, $729-772,738,741,750,757$

Simay, G. L., 473, 398, 501, 714-729, 778785

Simmons, G., 16, 20, 24, 47, 50

Simmons, M. G., 23, 24

Sims, A. F., 442, 443, 445, 448, 451

Sinha, A. K., 73

Slug flow, 201, 210, 216

Small, W. M., 396

Smith, A. R., 25

Smith, B. D., 441

Smith, D. L., 12, 24

Smith, E. C., 635, 636

Smith, H. W., 41

Smith, J. H., 151, 157, 167, 168, 924, 925, 926, 928, 937

Smith, J. L., 27, 28, 29, 62, 64, 65

Smith, R. B., 16, 34, 60, 62, 63

Smith, R. L., 12, 15, 17, 18, 19, 56, 57, 58, 113,114

Smith, R. V., 199

Snake River Plain, 18-19, 22, 71

Soda, M., 203, 212, 214, 216, 217, 560, 905, 906

Solid-waste disposal

effects of pollution, 816

geothermal fluid pollution, 803

hazardous waste definition, 792

Resource Conservation and Recovery Act of 1976 on, 791-792

state regulation, 795

Sólnes, J., 887, 888

Somerton, W. H., 128

Sorrells, G. G., 66

Soske, J. I., 66

South Sister, Oregon, 114

Southern California Edison plant, Brawley, California, 955,958

Soviet Union. See Union of Soviet Soclalist Republics (U.S.S.R.)

Spray towers, $437-441$

Squarel, P., 899

Staehle, R. W., 675

Starling, K. F., 270, 271, 352, 338, 356, $358,554,754,764,766$

State government

hydrogen sulfide emission regulation, 814

pollution control laws and regulations,

$790,793,794,795,866$

toxic substances regulation, 792

water quality standards, 806-807

water rights issues, 551-552 
Steeples, D. W., 53, 54, 63

Steinmeyer, D. E., 440

Stewart, J. H., 12, 15, 16, 60

Stewart, R. M., 50, 51

Strangway, D. W., 41

Stratified flow, 215

Stresses

corrosion, 666, 676

drilling, 152

Stretford process, 821-823

Sulfur dioxide

air pollution regulation, 814

Claus process, 833, 834

plants and crops effected, 814

Sung, R., 821

Sunshine Project, Japan, 900, 906

Superheaters

In heat exchangers, 397-398

In hybrid energy conversion systems, $486-491$

Suratt, W. B., 413, 539, 441, 446, 448, 450, 451, 453

Surface, M. O., 550, 624, 628

Surface condensers, 562-598

Svartsengi plant, Iceland, 884-885, 887, 889

Swanberg, C. A., 24, 29, 66, 67, 69

Szewalski, R., 477, 482

Taborek, J., 406

Taitel, $\mathbf{Y}, 210$

Taggart, J., $\mathbf{5 3}$

Takahashi, P., 212, 216, 217, 219

Tantalum, 674, 677

Tardiff, G. E., 772

Tasman Pulp and Paper Company, 024925

Tauhara field, New Zealand, 15

Taupo voleanic zone, 25

Tax policies, 709-710

Telford, W. M., 35, 42, 44, 52

Telluric methods of resistivity messurement, 43

Temperature logs, $26-30$

Teng, T. L., 51

Tennessee Valley Authority (TVA), 549, 608

Tester, J. W., 270, 352, 353, 356, 357, 362, $471,475,478,741,764,766,770$

Thermal infrared (IR) imagery, 14-15

Thermistors, 20, 156

Thermocouples, 156

Thermometers, 19, 20, 21, 156

Thomas, C. K., 182
Thomas, K. D., 456, 457

Thompson, G. A., 12, 70

Tikhonov, A. N., 934, 935, 937

Time-domain electromagnetic sounding method (TMS), 44

Titanium

condenser tubes, $590-593$

performance, $674,670-677$

Tiwi fleld, Philippines, 928-929, 930, 931

To, J. K. W., 623

Tonanl, F, 13, 54

Tongonan plant, Leyte, Philippines, 929, 030, 931

Toronyi, R. M., 131

Torrance, K. E., 628

Total flow system, 504-538

Toulmin, P.; III, 25

Toxic Substances Control Act, 789, 792

Trabalka, J. R., 601

Travale field, Italy, 899-900

Travernier, P., 20

Tri-cone roller bits, 138

Tripp, A. C., 43, 61

Truesdell, A. H., 19, 20, 115

Trufillo, P., 863

TRW Systems Group, 69

Tubular Exchange Manufacturers A8soclation (TEMA), 398, 400

Turkey, 871, 931-934

Union Oil Company, 836, 955, 960

United Engineers, 648, 654

Union of Soviet Socialist Republics (U.S.S.R.)

drilling costs in, 149

geothermal electric power capacity, 871 power plants, 934-942

proposed plants, 942

United States (U.S.)

geothermal electric power capacity, 871 gravity map, $\mathbf{3 2}$

historical background to geothermal energy use, 942-943

magnetic maps, 34-35

power plants, 942-960

proposed geothermal plants, 960,961

Uranium, 24, 165

Urban, T. C., 21, 26, 27, 28, 29, 58, 59, 67, 72

Utah, 15, 496-498

Uyeda, S., 8

Vacquier, V., 34

Vakin, E. A.. 180, 935 
Valles Caldera, New Mexico, plant, 950 960,961

Value analysis, in economics, 697-699

Valves, turbine, 331-339

Vargaftik, N. B., 359

Varnado, S. G., 145, 148, 149, 151, 152, 153

Visual Search Microfilm Files (VSMF), 780-782, 785

Vital, B. F., 140, 141, 151

Wairakei field, New Zealand, 870, 918, 919-824

environmental impact of, 923

reservolr pressure history, 922

simplified flow diagram, 921, 923

steam separation equipment, 179, 180

Wallace, R. H., Jr., 74, 75, 76, 77

Walsh, J. B., 13, 35, 42, 43, 53, 54, 59, 60, 61

Waste heat. See Heat dissipation systems

Water pollution, $807-813$

agricultural use, 812,813

aquatic life, $810-813$

baseline measurements in monitoring, 864

EPA suggested guidelines, 818-819

monitoring programs, 861-862

public drinking water supplies, $807-810$

state regulation of pollutants, $806-807$

Water rights issues, $651-652$

Waters, K. H., 62
Weiss, H., 512, 515

Well logging, 155-172

Wescott, Blaine B., 667, 679

West, G. F., 30, 32, 33, 34, 35, 37, 46

White, D. E., 7, 12, 15, 21, 26, 54, 56, 57, $59,61,66,67,115,122,123,129,229$, $505,786,860$

Whiting, R. L., 122, 123, 131

Wiegandt, $\mathrm{H}$., 456, 457

Wigley, D. M., 212, 216, 923

Wilderness Act, 793, 795

Willey, L. M., 62

Willams, J. D., 7, 56, 62, 64, 960

Willams, P. L., 40, 41, 71, 72

Wilson, J. T., 12, 884

Witherspoon, P. A., 129, 131, 743, 772

Woodward, T., 438, 439, 440, 441, 442 , 443

Wyodak plant, Wyoming, 624, 627

Y-type strainer, 331, 332

Yamagata, K., 754

Yao, S. C., 640

Young, H. W., 71

Yuhara, K., 176

Zablocki, C. J., 44

Zebib, A., 106

Zirconium, 674, 677

Zunil field, Guatemala, 964

Zwolinski, B. J., 853 